
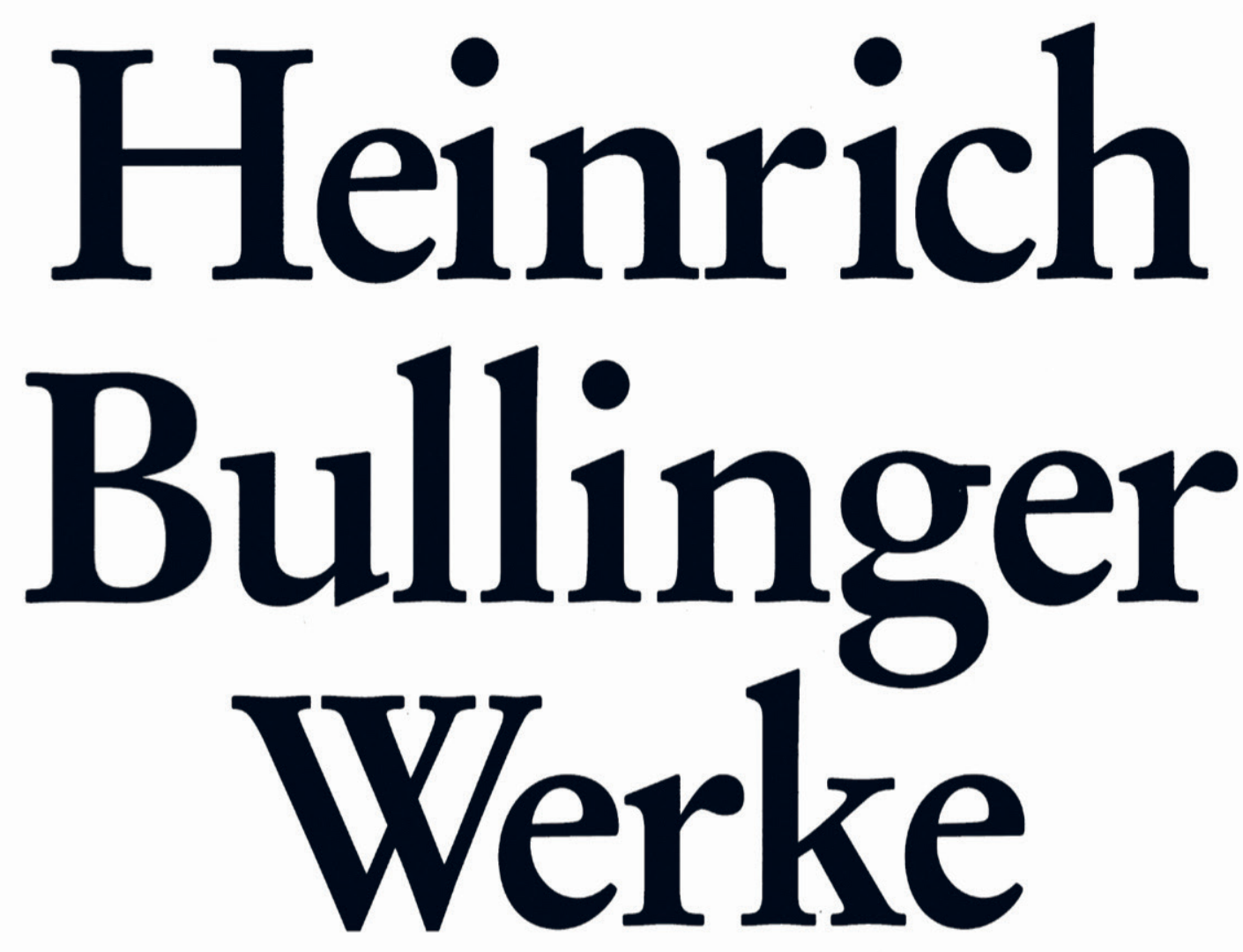

Dritte Abteilung: Theologische Schriften

\title{
Band 9:
}

Kommentare zu den neutestamentlichen Briefen

Hebräerbrief - Katholische Briefe

\section{$\mathbf{T} \mathbf{V} \mathbf{Z}$}

Theologischer Verlag Zürich 

Heinrich Bullinger Werke

III/9 


\title{
HEINRICH BULLINGER WERKE
}

\author{
Dritte Abteilung \\ Theologische Schriften
}

herausgegeben von

Peter Opitz

Band 9

T V Z

Theologischer Verlag Zürich 


\section{HEINRICH BULLINGER KOMMENTARE ZU DEN NEUTESTAMENTLICHEN BRIEFEN}

Hebräerbrief - Katholische Briefe

herausgegeben von

Luca Baschera

T V Z

Theologischer Verlag Zürich 
Die Druckvorstufe dieser Publikation wurde vom Schweizerischen Nationalfonds zur Förderung der wissenschaftlichen Forschung unterstützt.

Der Theologische Verlag Zürich wird vom Bundesamt für Kultur mit einem Strukturbeitrag für die Jahre 2019-2020 unterstützt.

Bibliografische Informationen der Deutschen Nationalbibliothek

Die Deutsche Bibliothek verzeichnet diese Publikation in der Deutschen Nationalbibliografie;

detaillierte bibliografische Daten sind im Internet über 〈http://dnb.dnb.de〉 abrufbar. ISBN (Print): 978-3-290-18198-7 ISBN (PDF): 978-3-290-18275-5

DOI: https://doi.org/10.34313/978-3-290-18275-5

Satz: Christian Moser, Zürich

Druck: AZ Druck und Datentechnik GmbH, Kempten

(C) 2019 Theologischer Verlag Zürich www.tvz-verlag.ch

\section{(c) $(1) \Theta \Theta$}

Creative Commons 4.0 International 
INHALT

Einleitung . . . . . . . . . . . . . . . . . . . . . . . . . IX IX

1. Die Übersetzung der biblischen Texte . . . . . . . . . . . X X

2. Der Kommentar zu 1Joh (1532) . . . . . . . . . . . . . . XI

3. Der Kommentar zu Hebr (1532) . . . . . . . . . . . . . . XIV

3.1 Präfatorische Stücke . . . . . . . . . . . . . . . . XIV

3.2 Entstehung und Struktur . . . . . . . . . . . . . XVI

3.3 Quellen . . . . . . . . . . . . . . . . . . XVIII

4. Der Kommentar zu 1-2Petr (1534) . . . . . . . . . . . . XXX XX

4.1 Entstehung und Widmung . . . . . . . . . . . . . . . $\mathrm{XX}$

4.2 Autorschaft der Briefe und Struktur des Kommentars . . . XXII

4.3 Quellen . . . . . . . . . . . . . . . . . . . XXIII

5. Der Kommentar zu Jak (1537) . . . . . . . . . . . . . . XXIV

5.1 Entstehung und Struktur . . . . . . . . . . . . . . XXIV

5.2 Quellen . . . . . . . . . . . . . . . . . . XXVI

6. Die Kommentare zu 2-3Joh und Jud (1537) . . . . . . . . . XXVII

7. Editionsrichtlinien und Benutzungshinweise . . . . . . . . . XXVII

Kommentar zum Hebräerbrief . . . . . . . . . . . . . . . . . . 1

Widmungsbrief . . . . . . . . . . . . . . . . . . . 3

Lectori . . . . . . . . . . . . . . . . . . . . . . . 9

Catalogus . . . . . . . . . . . . . . . . . . . . . . . 9

Praefatio . . . . . . . . . . . . . . . . . . . . . . 10

De authore huius epistolae . . . . . . . . . . . . . . . . . . 10

Argumentum epistolae . . . . . . . . . . . . . . . . . . . . 17

Prima epistolae pars . . . . . . . . . . . . . . . . . . . . . 18

Kap. 1 . . . . . . . . . . . . . . . . . . . . . . . . . 19

Kap. 2 . . . . . . . . . . . . . . . . . . . . . . . . . 37

Kap. 3 . . . . . . . . . . . . . . . . . . . . . . . . . 50

Kap. 4 . . . . . . . . . . . . . . . . . . . . . . . . . 57

Secunda epistolae pars . . . . . . . . . . . . . . . . . . . . 64

Kap. 5 . . . . . . . . . . . . . . . . . . . . . . . . 67

Kap. 6 . . . . . . . . . . . . . . . . . . . . . . . . . 77

Kap. 7 . . . . . . . . . . . . . . . . . . . . . . . . . 89

Kap. 8 . . . . . . . . . . . . . . . . . . . . . 103

Kap. 9 . . . . . . . . . . . . . . . . . . . . . . . . . 110

Kap. 10 . . . . . . . . . . . . . . . . . . . . . . . 126

Tertia epistolae pars . . . . . . . . . . . . . . . . . . . . . 136

Kap. 11 . . . . . . . . . . . . . . . . . . . . . . . . . 143 
Kap. 12 . . . . . . . . . . . . . . . . . . . . . . . . . 157

Kap. 13 . . . . . . . . . . . . . . . . . . . . . . . 166

Vorrede zu den Katholischen Briefen . . . . . . . . . . . . . . . 173

Kommentar zum ersten Petrusbrief . . . . . . . . . . . . . . . . 177

Praefatio . . . . . . . . . . . . . . . . . . . . . . . 179

Argumentum epistolae . . . . . . . . . . . . . . . . . . . . 180

Kap. 1 . . . . . . . . . . . . . . . . . . . . . . . . . . 181

Kap. 2 . . . . . . . . . . . . . . . . . . . . . . 216

Kap. 3 . . . . . . . . . . . . . . . . . . . . . . . . . . 234

Kap. 4 . . . . . . . . . . . . . . . . . . . . . . . . . . 247

Kap. 5 . . . . . . . . . . . . . . . . . . . . . . . . . . 260

Kommentar zum zweiten Petrusbrief . . . . . . . . . . . . . . . 273

Praefatio . . . . . . . . . . . . . . . . . . . . . . . 275

Argumentum epistolae . . . . . . . . . . . . . . . . . . . . 276

Kap. 1 . . . . . . . . . . . . . . . . . . . . . . . . . . 277

Kap. 2 . . . . . . . . . . . . . . . . . . . . . . . . . . 287

Kap. 3 . . . . . . . . . . . . . . . . . . . . . . . . . . 300

Kommentar zum ersten Johannesbrief . . . . . . . . . . . . . . 307

Praefatio . . . . . . . . . . . . . . . . . . . . . . . . . 309

Argumentum epistolae . . . . . . . . . . . . . . . . . . . . 309

Kap. 1 . . . . . . . . . . . . . . . . . . . . . . . . . . 311

Kap. 2 . . . . . . . . . . . . . . . . . . . . . . . . . . 320

Kap. 3 . . . . . . . . . . . . . . . . . . . . . . . . . 338

Kap. 4 . . . . . . . . . . . . . . . . . . . . . . . . . . 350

Kap. 5 . . . . . . . . . . . . . . . . . . . . . . . 360

Epilogus . . . . . . . . . . . . . . . . . . . 370

Kommentar zum Jakobusbrief . . . . . . . . . . . . . . . . . . 371

De autore epistolae . . . . . . . . . . . . . . . . . . . . . 373

Argumentum epistolae . . . . . . . . . . . . . . . . . . . . 374

Kap. 1 . . . . . . . . . . . . . . . . . . . . . . . . 375

Kap. 2 . . . . . . . . . . . . . . . . . . . . . . . . . . 389

Kap. 3 . . . . . . . . . . . . . . . . . . . . . . . . . . 409

Kap. 4 . . . . . . . . . . . . . . . . . . . . . . . . . . 415

Kap. 5 . . . . . . . . . . . . . . . . . . . . . . . . . . 420 
Kommentar zum zweiten und dritten Johannesbrief sowie zum Judasbrief 431

Commentarius in secundam epistolam Ioannis . . . . . . . . . . 433

Commentarius in tertiam epistolam Ioannis . . . . . . . . . . . 437

Commentarius in epistolam Iudae . . . . . . . . . . . . . . . 441

Bibliographie . . . . . . . . . . . . . . . . . . . . . . . . 453

1. Quellen . . . . . . . . . . . . . . . . . . . . . . . . 453

2. Reihen, Quellensammlungen, Bibliographien, Lexika und weitere Nachschlagewerke . . . . . . . . . . . . . . . . . 464

3. Literatur . . . . . . . . . . . . . . . . . . . . . . . . 465

Bibelstellenregister . . . . . . . . . . . . . . . . . . . . . . 467

Quellenregister . . . . . . . . . . . . . . . . . . . 483

Personenregister . . . . . . . . . . . . . . . . . . . . . . . 487

Ortsregister . . . . . . . . . . . . . . . . . . . . . . . . 493 



\section{EINLEITUNG}

Der vorliegende Band enthält eine historisch-kritische Ausgabe von Heinrich Bullingers Kommentaren zu Hebr sowie zu den Katholischen Briefen des Neuen Testaments. Bullinger kommentierte das gesamte Corpus der neutestamentlichen Briefe innerhalb von fünf Jahren: von März 1532, als er den Kommentar zu 1Joh veröffentlichte, ${ }^{1}$ bis März 1537, als die Gesamtausgabe der Kommentare erschien, welche zusätzlich zu den bereits davor einzeln gedruckten Kommentaren auch noch Auslegungen von Jak, 2-3Joh sowie Jud enthält. ${ }^{2}$ Bullinger beschäftigte sich also von Anfang bis Schluss seiner exegetischen Arbeit an den neutestamentlichen Briefen mit den Katholischen Briefen, was wiederum zur Folge hat, dass der vorliegende Band Texte unterschiedliche Phasen seines Schaffens umfasst. So ist es auch kaum überraschend, dass sich in ihnen Veränderungen im Kommentarstil Bullingers beobachten lassen.

Die Reihenfolge der Kommentare in der vorliegenden Ausgabe entspricht jener, die Bullinger für die Gesamtausgabe von 1537 festlegte. Dabei wich er bezüglich der Anordnung der Katholischen Briefe bewusst von der damals bereits traditionell gewordenen $\mathrm{ab}$, indem er die beiden Petrusbriefe an den Anfang stellte, darauf den ersten Johannesbrief folgen ließ und schließlich den Jakobus-, den zweiten und dritten Johannes- sowie den Judasbrief aneinanderfügte. Wie Bullinger in einem kurzen Vorwort »an den Leser « darlegt, bewog ihn die herausragende Bedeutung, die 1-2Petr und 1Joh im Vergleich zu den übrigen Katholischen Briefen zukomme, zu dieser Veränderung: »In ihnen werden die Hauptartikel unserer Religion auf reinste Weise behandelt, nämlich der rettende Glaube an Christus, die Liebe als einziges Gebot Christi, die heilige Unschuld und die Geduld, die alles Böse überwindet. Überall in ihnen strahlt apostolische Autorität und Würde auf. [...] Die Kirche Christi hielt sie immer für unvergleichliche Juwele, weshalb sie auch eine Vorrangstellung verdienen. $\ll^{3}$

Im Folgenden wird auf die einzelnen Kommentare allerdings weder entsprechend der traditionellen Anordnung noch entsprechend derjenigen Bullingers eingegangen, sondern in der Reihenfolge ihrer Drucklegung: 1Joh (Kap. 2), Hebr (Kap. 3), 1-2Petr (Kap. 4), Jak (Kap. 5), 2-3Joh und Jud (Kap. 6). Der Betrachtung der einzelnen Kommentare gehen einige Anmerkungen zur Übersetzung der biblischen Texte voraus (Kap. 1). Die Einleitung wird schließlich durch eine Erläuterung der Editionsrichtlinien abgerundet (Kap. 7).

Moser 2012, XIV.

Moser 2012, XXX.

Siehe unten S. 175,8-13: »Purissime tractantur in ipsis praecipua religionis nostrae capita: fides in Christum purificans, charitas praeceptum Christi unicum, innocentia sancta et pa- tientia malorum victrix. Ubique in his relucet authoritas et reverenda maiestas apostolica. [...] Habitae sunt in ecclesia Christi pro gemmis incomparabilibus semper, unde primas tenent merito.« 


\section{Die Übersetzung der biblischen Texte}

Vergleicht man Bullingers Übersetzung des jeweils ersten Kapitels von 1Joh, Hebr, 1-2Petr und Jak sowie die Übersetzungen von 2-3Joh und Jud mit dem »Novum Instrumentum « (1516: A) bzw. mit den verschiedenen Auflagen des »Novum Testamentum« (1519: B; 1522: C; 1527: D; 1535: E) des Erasmus, so wird dadurch die Aussage Bullingers bestätigt, er sei bei der Wiedergabe der biblischen Texte »meist der Edition von Herrn Erasmus von Rotterdam seligen Angedenkens gefolgt $\kappa^{4}{ }^{4}$ Allerdings lässt sich nicht eindeutig feststellen, ob eine bestimmte Auflage der Übersetzung des Erasmus und wenn ja, welche Bullinger als Grundlage gedient hat.

Ein Indiz dafür, dass die erste Auflage diesbezüglich nicht in Frage kommt, stellt die Tatsache dar, dass Bullinger in den allermeisten Fällen, bei denen die verschiedenen Auflagen des »Novum Testamentum « vom »Instrumentum« abweichen, die spätere Fassung übernahm:

IJoh 1,1: ... de sermone [wie B-E; A/Vulgata: verbo] vitae ...

2 Joh 4: ... sicut praeceptum [wie B-E; A: mandatum] accepimus ...

2Joh 6: ... praeceptum ... praeceptum [wie B-E; A: mandatum ... mandatum] ...

2Joh 12: ... spero me venturum [wie B-E; A: futurum] ...

3Joh 5: ... in hospites [wie B-E; A: peregrinos] ...

3Joh 10: ... indicabo facta illius [wie B-E; A: commonefaciam illum operum] ...

Jud 2: misericordia [wie B-E; A: gratia] vobis ...

Jud 8: ... dominos vero ... potestate praeditos [wie B-E; A: dominationem vero ... glorias autem] ...

Jud 10: ... animantia rationis expertia [wie B-E; A: muta animantia] ...

Jud 12: ... a ventis circumaguntur [wie B-E; A: circumferuntur] ...

Jud 15: ... de factis omnibus, quae impie patrarunt [wie B-E; A: de omnibus operibus impietatis illorum] ...

Jud 16: ... loquitur tumida [wie B-E; A: superba] ...

Jud 18: ... quod [wie B-E; A: quia] dixerunt ... qui iuxta suas impias cupiditates ambularent [wie B-E; A: iuxta proprias impietatum concupiscentias ambulantes] ...

Dies bedeutet allerdings nicht, dass Bullinger das »Novum Instrumentum « gänzlich außer Acht ließ. Vielmehr zog er alle Auflagen der Übersetzung des Erasmus heran und entschied sich dort, wo diese voneinander abwichen, mal für die eine mal für die andere Variante. Außerdem wird an manchen Stellen die VulgataÜbersetzung gegenüber derjenigen des Erasmus bevorzugt:

4 Bull. lect. (Baschera 7,10-12): »[...] curavi, ut bona fide recitarem tibi apostolorum verba, qua quidem parte potissimum sequutus sum beatae memoriae d[omini] Erasmi Roterodami aeditionem.« 
Hebr 1,3: ... expressa imago substantiae eius [wie Vulgata; A-E: illius] agatque [wie B; A: portetque; C-E: modereturque; Vulgata: portansque] omnia verbo potentiae suae ... 1Petr 1,8: Quem, cum non videritis [wie A/E; B-D: videatis; Vulgata: videntes], diligitis ...

2 Petr 1,1: Symeon Petrus servus et apostolus Iesu Christi his [wie Vulgata; A-E: iis], qui aeque pretiosam nobiscum sortiti sunt fidem in iustitia [wie A/Vulgata; B-E: per iustitiam] dei nostri et servatoris Iesu Christi ...

Jak 1,25: ... cum non sit auditor obliviosus [wie E; A: non auditor obliuiosus cum sit; B-D: cum sit non auditor obliuiosus; Vulgata: non auditor obliviosus factus] ...

Schließlich bietet Bullinger in den Kommentaren zu 1Joh, Hebr und 1-2Petr auch eigene Übersetzungen bestimmter Passagen an: ${ }^{5}$

IJoh 1,2: ... vidimus, ideo [A/Vulgata: et; B-E: etiam; Griechisch: $x \alpha i ́$ ] testamus ... Hebr 1,1-2: Deus olim saepenumero diversimodeque [A-E: multiphariam multisque modis; Vulgata: multifarie multisque modis] patribus loquutus est [A-E: loquutus patribus; Vulgata: loquens patribus] per prophetas, in postremis vero hisce diebus [A-E: extremis diebus hisce; Vulgata: novissime diebus istis] loquutus est ...

Hebr 1,4: ... prae ipsis nomen haereditate conquisivit [A-E: prae illis sortitus est nomen; Vulgata: prae illis nomen haereditavit].

Hebr 1,14: ... eorum, qui futuram salutem haereditabunt [A-E: propter eos, qui haeredes erunt salutis; Vulgata: propter eos, qui haereditatem capiunt salutis]?

1Petr 1,24f: ... postquam [A-E: propterea quod; Vulgata: quia] omnis caro quasi gramen est $^{6}$ [A-E: omnis caro gramen sit; Vulgata: omnis caro ut foenum] ... Hoc autem est verbum, quod praedicatum est vobis [A-E: quod per evangelium delatum est ad vos; Vulgata: quod evangelizatum est in vos].

2 Petr 1,5: Toto itaque studio huc incumbite, ut in fide vestra subministretis virtutem ${ }^{7}$ [A-E: sed et in hoc ipsum omni adhibito studio, subministrate in fide vestra virtutem; Vulgata: vos autem curam omnem subinferentes ministrate in fide vestra virtutem] ...

\section{Der Kommentar zu 1Joh (1532)}

Hatte sich Bullingers Lehrtätigkeit in Kappel auf das Corpus der paulinischen Briefe konzentriert, so widmete er sich später in Bremgarten auch den Katholischen Briefen und anderen Teilen des Neuen Testaments: Zwischen 1529 und 1530 legte er »an den Festtagen « den ersten Johannesbrief, die beiden Petrusbriefe, die Apostelgeschichte sowie die ersten neun Kapitel des Evangeliums

5 An manchen Stellen der beiden Petrusbriefe macht sich der Einfluss der Übersetzung bemerkbar, die in Martin Luthers Kommentar zu diesen beiden Schriften (1524) enthalten ist, vgl. dazu auch unten Kap. 4.3.
6 Vgl. Luth. 1Petr. 34r: »Postquam omnis caro ut gramen est $[. .$.$] .«$

7 Vgl. Luth. 2Petr. 117r: »Toto itaque studio huc incumbite, ut in fide vestra exhibeatis virtutem.« 
nach Johannes aus, während er an Wochentagen über die paulinischen Briefe sowie über die ersten vier Kapitel des Jakobusbriefes predigte. ${ }^{8}$

Die Veröffentlichung des Kommentars zu 1Joh im März 1532 steht somit einerseits im Zusammenhang mit seiner Predigttätigkeit in Bremgarten und kann als deren Ausfluss betrachtet werden. Andererseits stellt sich jedoch die Frage, weshalb Bullinger seine Karriere als Exeget des Neuen Testaments mit einer Auslegung ausgerechnet dieses Briefes zu beginnen beschloss. Im Vorwort »an den Leser«, das den Kommentar eröffnet, beantwortet Bullinger diese Frage, indem er zum einen auf die Vorzüge dieser kleinen neutestamentlichen Schrift verweist. Denn sie stamme aus der Feder des »Lieblingsjüngers « Jesu, der beim Letzten Mahl auf dem Schoß seines Meisters lag und »die göttlichen Geheimnisse aufs Genaueste und restlos in sich aufnahm «. ${ }^{9}$ Insofern sei es auch nicht verwunderlich, dass in ihr - der »Hauptzierde des Neuen Testaments « (praecipuum novi testamenti decus) - »die christliche Frömmigkeit deutlicher und scharfsinniger « erörtert werde, als dies in verschiedenen viel ausführlicheren Abhandlungen der weisesten Autoren der Fall sei. Das sei der Hauptgrund, weshalb sich Bullinger der Aufgabe angenommen habe, einen Kommentar darüber zu schreiben, und zwar mit dem zweifachen Ziel, »die Gelehrten dazu zu bewegen, Besseres hervorzubringen, und den Studenten sowie den weniger Erfahrenen zu helfen, in der Erkenntnis der heiligen Dinge möglichst ungehindert voranzuschreiten $\ll .{ }^{10}$

Bullingers Entscheidung, sich zunächst mit einem eher kurzen Brief zu beschäftigen, hatte allerdings offenbar auch einen weiteren, pragmatischeren Grund. Er betrachtete nämlich die kurze Auslegung von 1Joh - er bezeichnet sie explizit als commentariolus - als eine Art Probestück und Muster, das er in die Hände seiner Leser legte, um dann anhand ihrer Reaktionen zu entscheiden, ob er sich umfangreicheren biblischen Schriften zuwenden sollte: »Im Übrigen, wenn ich festellen werde, dass diese meine Vorübungen [praeexercitamenta] bei den frommen Lesern auf Gefallen stoßen, werde ich auch eine Auslegung des Briefes an die Hebräer herausgeben. $\ll{ }^{11}$ Da sein umfangreicher Kommentar zu Hebr bereits im August desselben Jahres erschien, ${ }^{12}$ kann man jedoch wohl annehmen, dass er die Arbeit daran nicht erst nach der Drucklegung des Kommentars zu 1Joh in Angriff nahm.

8 HBD, 19,5-9: « Pro publica concione diebus festis exposui Ioannis canonicam, utramque Petri, acta Apostolorum et evangelium Ioannis usque in 9. cap[ut]. Prophanis diebus explicabam epistolas Pauli ordine omnes, et absolvi omnes, exposui item 4 capita in epistola d[ivi] Iacobi.«
Siehe unten S. 309,6f. Vgl. Joh 13,23.

Siehe unten S. 309,8-12.

Siehe unten S. 309,16-18.

Vgl. HBBibl I, Nr. 38. 
Wie in den anderen Kommentaren zu den neutestamentlichen Briefen wird der Text von 1Joh in lateinischer Übersetzung vers- oder abschnittsweise wiedergegeben und fortlaufend ausgelegt. Hinsichtlich der Struktur besteht somit kein bedeutender Unterschied zwischen diesem frühen Kommentar und den späteren. Die einzige kleine Abweichung ist, dass Bullinger hier zusätzlich zum »Argumentum« des gesamten Briefes jedem Kapitel eine kurze Zusammenfassung vorausschickt.

Im Kommentarstil sind hingegen deutlichere Unterschiede zu erkennen. Allgemein bleibt Bullinger in diesem seinem ersten Kommentar sehr nah am biblischen Text und vermeidet es, einzelne theologische Fragen im Rahmen von Exkursen zu behandeln, was später hingegen häufig geschehen sollte. Darüber hinaus zieht er kaum außerbiblische - sei es patristische, mittelalterliche oder frühneuzeitliche - theologische Quellen heran. So verweist Bullinger je einmal auf Werke des Irenäus von Lyon, ${ }^{13}$ Didymus des Blinden, ${ }^{14}$ Eusebius von Cäsarea $^{15}$ und Ambrosius von Mailand, ${ }^{16}$ während Tertullian insgesamt viermal erwähnt wird. ${ }^{17}$

Auch auf exegetische Werke zu 1Joh nimmt Bullinger kaum Bezug. Es fehlen etwa gänzlich Hinweise auf die Homilien des Augustinus zu 1Joh, auf die Kommentare Bedas und von Didymus dem Blinden, wie auch auf die 1524 veröffentlichten »In epistolam Ioannis apostoli catholicam primam [...] demegoriae « des Johannes Oekolampad. ${ }^{18}$ Allerdings dürfte dieses Werk, welches Bullinger mit größter Wahrscheinlichkeit kannte, an mindestens einer der Stellen gemeint sein, bei denen Bullinger allgemein auf »andere« (alii) Exegeten verweist. ${ }^{19}$ Selbst auf die in späteren Kommentaren eifrig benutzten »Annotationes « des Erasmus wird nur an einer einzigen Stelle verwiesen, ${ }^{20}$ auf dessen $\gg$ Paraphrasis « von 1Joh kein einziges Mal. Dafür zieht Bullinger je einmal die »Copia« sowie die »Adagia « heran. ${ }^{21}$ Auch die »Commentaria linguae Graecae« des Guillaume Budé werden nur ein einziges Mal erwähnt. ${ }^{22}$ Ebenso spärlich sind schließlich die Zitate aus klassischen Quellen.

Bullinger eröffnete also seine publizistische Tätigkeit als Exeget des Neuen Testaments mit einem verhältnismäßig kurzen Kommentar, den er bewusst als möglichst einfache und in strikter Anwendung des Prinzips »scriptura sui ipsius interpres« entfaltete Auslegung konzipierte.

Siehe unten S. 332.

Siehe unten S. 333.

Siehe unten S. 332.

Siehe unten S. 356.

Siehe unten S. 332f.; 337; 356.
VD16 O 345; vgl. Staehelin 1939, 221-232.

Siehe unten S. 315,26.

Siehe unten S. 365.

Siehe unten S. 331; 343

Siehe unten S. 321. 


\section{Der Kommentar zu Hebr (1532)}

\subsection{Präfatorische Stücke}

Das kirchenpolitische Handeln Philipps »des Großmütigen«, Landgraf von Hessen (1504-1567), war von Anfang an von der Vision eines Zusammenschlusses aller evangelischen Kräfte im Reich geleitet worden. ${ }^{23}$ Darauf ist nicht nur sein gescheiterter - Versuch zurückzuführen, mit dem Marburger Religionsgespräch (1529) die Streitfragen zwischen Zwingli und Luther aus dem Weg zu räumen, sondern auch die Tatsache, dass er selbst nach der Niederlage von Kappel (1531) nicht aufhörte, die Zürcher zu unterstützen. So war es vor allem dem Einsatz Philipps und der oberdeutschen Städte zu verdanken, dass die Anhänger der Schweizer Reformation vom 1532 auf dem Nürnberger Tag beschlossenen Frieden zwischen katholischen und protestierenden Ständen nicht offiziell ausgeschlossen wurden. ${ }^{24}$

Es ist insofern alles andere als Zufall, dass Bullinger seinen ersten umfangreichen Bibelkommentar Philipp von Hessen zueignete. Im Widmungsbrief verleiht er zum einen seiner und der Zürcher Dankbarkeit Ausdruck, und zwar sowohl Philipp selbst als auch Gott gegenüber, der Philipp zu solch einem »ausgewogen urteilenden Verteidiger « ihrer Sache gemacht hatte. ${ }^{25}$ Zum anderen ermahnt er den Landgrafen aber auch, sich nicht von den Häresievorwürfen beirren zu lassen, die gegen die Zürcher von ihren Feinden ausgesprochen werden. Denn, wie Bullingers Auslegung von Hebr klar beweise, weiche ihre Lehre in allen Hauptpunkten christlichen Glaubens keineswegs davon ab, was immer schon als »gesunde, katholische und orthodoxe« Doktrin gegolten habe. ${ }^{26}$ Ebenso wenig solle Philipp ferner denjenigen Gehör schenken, die im gewaltsamen Tod Zwinglis und in der militärischen Niederlage der Zürcher einen Beweis für die Verwerflichkeit ihrer Positionen sehen. Denn Zwingli sei vielmehr mit den Propheten, den Aposteln und all denjenigen zu vergleichen, die ihr Leben um der göttlichen Wahrheit willen geopfert haben. ${ }^{27}$ Deren Verteidigung sei auch Philipp von Gott aufgetragen worden, weshalb Bullinger seine Widmung mit dem Appell abschließt: »Übergebe dich also auch ganz dem mächtigen und gütigen Vater,

Mühling 2001, 76.

HBBW II 161, Anm. 4.

5 Siehe unten S. 3,12-15: »Gratulamur hic quoque tibi, princeps piissime, de illa praeclara, quae in te est, prudentia et constantia et deo nostro patri benignissimo gratias agimus, quod te nostrae caussae dederit aequum et iudicem et tutorem.«

26 Siehe unten S. 5,5-10: »[...] nos de scriptura, testamento et lege dei, de deo, unitate et tri- nitate dei, de Christo deo et homine, mediatore, sacerdote et sacrificio, de vera saluta et iustificatione, de ecclesia, de vocatione ad munus docendi, de vera fide, de sacramentis et vero dei cultu, primariis nostrae religionis capitibus, nihil novum, factiosum aut haereticum, sed prorsus sana, catholica et orthodoxa credere et praedicare.«

27 Siehe unten S. 6. 
diene seiner Wahrheit, halte fest an ihr, bleibe in ihr. Wenn du dies tun wirst, wirst $\mathrm{du}$ das vollziehen, wonach Paulus in diesem ganzen Brief an die Hebräer strebt. $\ll^{28}$

Neben der Widmung und einem Verzeichnis der im Kommentar behandelten Loci $^{29}$ gehört zu den präfatorischen Stücken auch eine detaillierte Erörterung der Frage nach der Autorschaft von Hebr. Dazu wird Bullinger wohl durch die zum Teil bereits in der Antike erhobenen, aber besonders durch Erasmus von Rotterdam bekräftigten Einwände gegen die Zuschreibung dieses Briefes an Paulus bewogen. ${ }^{30}$ In der Tat kann der kleine Traktat »De authore huius epistolae « als eine genaue Widerlegung der Argumentation des Erasmus gelesen werden, nimmt Bullinger doch auf alle Themen Bezug, die Erasmus auch anspricht, kommt aber dabei zu diametral entgegengesetzten Schlüssen. So entkräftigt Bullinger etwa das Argument, der Stil von Hebr unterscheide sich zu sehr von jenem anderer paulinischen Briefe, durch den Hinweis, er sei von Paulus vermutlich zunächst auf Hebräisch geschrieben und erst später ins Griechische übersetzt worden. ${ }^{31}$ Bullinger sieht zudem in der Erwähnung einer Gefangenschaft in Hebr 10,34 eine indirekte Bestätigung der Echtheit dieses Briefes. ${ }^{32}$ Beide Argumentationslinien lehnt Erasmus jedoch unmissverständlich $\mathrm{ab}^{33}$ und relativiert darüber hinaus die Bedeutung genau jener patristischen Quellen, die Bullinger als Zeugen der Echtheit von Hebr anführt.

Dieser Diskrepanz zwischen seiner Position und derjenigen des niederländischen Humanisten war sich Bullinger als aufmerksamer Leser von Erasmus' exegetischen Schriften mit Sicherheit bewusst. Umso interessanter ist es also zu bemerken, dass der Zürcher an keiner Stelle Erasmus explizit kritisiert. Die einzige Passage aus dessen Kommentar zu Hebr, die Bullinger in diesem Zusammenhang zitiert, ist sogar eine, bei der Erasmus den paulinischen Charakter der Theologie von Hebr doch betont und die Bullinger also zur Bestätigung seiner eigenen Position anführen kann. ${ }^{34}$ Bullingers Entscheidung, keine explizite Kritik an Erasmus zu üben, obwohl er sich in der Sache von ihm deutlich und unmissverständlich abgrenzte, mag auf den ersten Blick verwundern. Sie dürfte aber im tiefen Respekt begründet sein, den Bullinger vor Erasmus als Ausleger des Neuen Testaments hegte, was wiederum den Zürcher an diesem wie auch an anderen

28 Siehe unten S. 9,3-5: »Patri itaque tam potenti et benigno te quoque totum trade, veritatem eius cole, in hac persta, huic immorere. Id si feceris, illud sane praestiteris, quod Paulus tota hac ad Hebraeos epistola ambit.«

29 Siehe unten S. 9f.

30 Siehe Erasm. Hebr. (ASD VI/10 378-384). Eine zwar weniger ausführliche, aber in der Sache deckungsgleiche Behandlung dieses
Fragekomplexes findet sich bereits in Bullingers Kappeler Vorlesungen zum Hebräerbrief, vgl. Bull. vorl. Hebr. (Berg/Hausammann 138140); Backus 2004, 110-113.

Siehe unten S. 15.

Siehe unten S. 16.

Erasm. Hebr. (ASD VI/10 384,372-374); ebd. (ASD VI/10 338,315-318).

34 Siehe unten S. 15,27-29. 
Stellen seiner exegetischen Werke davon abhielt, gegen den großen Humanisten zu polemisieren. ${ }^{35}$

\subsection{Entstehung und Struktur}

Stand die Abfassung des Kommentars zu Hebr im Zusammenhang mit Bullingers Predigttätigkeit im Jahr 1532, ${ }^{36}$ so hatte die intensive Beschäftigung mit dieser biblischen Schrift bereits während seiner Kappeler Zeit begonnen. Wie sich aus der Datierung der handschriftlich überlieferten »Kurtzen usslegung ettlicher epistlen S. Pauli« erschließen lässt, hielt Bullinger in der Klosterschule von Kappel am Albis zwischen Oktober bzw. November 1526 und Anfang Januar 1527 Vorlesungen über Hebr, die er sogleich in die besagte, dem Prior von Kappel, Peter Simler (1486-1557), gewidmete Sammlung von kurzen Kommentaren einbettete. ${ }^{37}$

Zwischen den Kappeler Vorlesungen und dem lateinischen Kommentar von 1532 bestehen stellenweise zwar inhaltliche Ähnlichkeiten, aber die Differenzen überwiegen sowohl hinsichtlich der allgemeinen Struktur wie auch des Stils und der thematischen Akzentsetzung. Die »Usslegung « zu Hebr wird zwar auch wie der spätere Kommentar durch eine Behandlung der Frage nach der Autorschaft des Briefes, eine Skizzierung des Inhalts und eine Auflistung von theologischen Loci eröffnet. Allerdings stellt die »Usslegung « keinen fortlaufenden Kommentar dar, sondern nimmt sich als Reihe von »annotationes « zu besonders wichtigen Passagen oder Begriffen aus, wobei der Text von Hebr nicht vollständig wiedergegeben wird. Stattdessen folgt auf die Anmerkungen eine deutsche Paraphrase des jeweiligen Kapitels und eine Zusammenfassung der wichtigsten darin behandelten Themen. ${ }^{38}$ Eine weitere Differenz betrifft die allgemeine Struktur der beiden Schriften: Die »Usslegung « ist in fünf »Bücher« gegliedert, während der Kommentar in nur drei Teile zerfällt. Wenn man aber berücksichtigt, dass Teil zwei und drei im Kommentar weiter unterteilt werden, und genauer betrachtet, welche Textabschnitte in den jeweiligen Büchern bzw. Teilen behandelt werden, so lässt sich doch eine größere Ähnlichkeit zwischen den beiden Schriften als zunächst angenommen feststellen:

Vgl. Baschera 2017, 259.

HBD 21,22f.

7 Zentralbibliothek Zürich, Ms D 4, 231v-316r. Die Kappeler Vorlesungen zu Hebr liegen in historisch-kritischer Edition vor, vgl. Bull. vorl. Hebr. Zur Datierung der Vorlesungen siehe ebd. (Berg/Hausammann 268, Anm. 480). Zu Peter Simler vgl. HBBW I 53f.

38 Vgl. Bull. vorl. Hebr. [Kap. 1] (Berg/Hausammann 143-148 [Anmerkungen]; 148-150 [»Paraphrasis«]; 150 [»Loci insignes «]). 
»Usslegung «

\begin{tabular}{|c|c|c|}
\hline Buch & Inhalt & Umfang \\
\hline I & $\begin{array}{l}\text { »Daß man Christum nitt hinwärffe, sunder hörre und imm } \\
\text { ghorsam sye }{ }^{39}\end{array}$ & $1,1-4,13$ \\
\hline II & $»$ Christus $\ldots$ der einig, hoch, ware priester $«^{40}$ & $4,14-8,13$ \\
\hline III & $\ll\left[\right.$ Christus] das einig oppffer für die sünd $\aleph^{41}$ & $9,1-10,18$ \\
\hline IV & $»$ Gedult imm lyden $\ll^{42}$ & $10,19-12,29$ \\
\hline $\mathrm{V}$ & $»$ Exemplen, sprüchen, glichnussen $\ll{ }^{43}$ & $13,1-25$ \\
\hline
\end{tabular}

\section{Kommentar}

Teil

I

II

III
Inhalt / Titel

[Ermahnung an die Juden, damit sie an Christus glauben]

[Über das Priesteramt und das Opfer Christi]

Digressio

Reditus

Sacrificium

[Allgemeine Ermahnungen]

Peroratio

Aphorismi
Umfang

$1,1-4,13$

$4,14-10,18$

5,11-6,20

7,1-8,13

$9,1-10,18$

$10,19-13,25$

$12,18-29$

13,1-25

»Usslegung « und Kommentar unterscheiden sich schließlich voneinander in Bezug auf Anzahl und Inhalt der Exkurse, in denen Bullinger bei bestimmten, in seinen Augen besonders wichtigen theologischen Fragen verweilt. Die »Usslegung « enthält nur drei solche Exkurse: über den Eid, ${ }^{44}$ den Tabernakel ${ }^{45}$ sowie über die Ehe, wobei Letzterer der umfangreichste ist und auch die Themen »Hurerei und Ehebruch « behandelt. ${ }^{46}$ Über den Eid und den Tabernakel finden sich auch im lateinischen Kommentar an den entsprechenden Stellen thematische Exkurse, ${ }^{47}$ die Abhandlung über Ehe und Ehebruch wird hingegen ausgelassen. Dafür fügte Bullinger nun elf weitere Exkurse unterschiedlichen Umfangs über folgende Themen hinzu: die Trinität; ${ }^{48}$ Christi $»$ Sitzen zur Rechten des Vaters $« ;{ }^{49}$

\footnotetext{
Bull. vorl. Hebr. (Berg/Hausammann 141).

Bull. vorl. Hebr. (Berg/Hausammann 141).

Bull. vorl. Hebr. (Berg/Hausammann 141).

Bull. vorl. Hebr. (Berg/Hausammann 142).

Bull. vorl. Hebr. (Berg/Hausammann 142).

44 Bull. vorl. Hebr. (Berg/Hausammann 175f.), mit Bezug auf Hebr 6,16-20.

45 Bull. vorl. Hebr. (Berg/Hausammann 195-

198), mit Bezug auf Hebr 9,1-5.
}

46 Bull. vorl. hebr. (Berg/Hausammann 246-260), mit Bezug auf Hebr 13,4.

47 Siehe unten S. 87f. [Eid]; 111-115 [Tabernakel].

48 Siehe unten S. 25-27, mit Bezug auf Hebr 1,3.

49 Siehe unten S. 28f., mit Bezug auf Hebr 1,3. 
die Engel $;{ }^{50}$ den Leib Christi $;{ }^{51}$ die kirchlichen Ämter und das Priestertum $;{ }^{52}$ die Lehre der Apostel $;{ }^{53}$ die Aufhebung des Gesetzes $;{ }^{54}$ den Bund $;{ }^{55}$ die Sakramente ${ }^{56}$ die $\gg$ Opferhandlungen $«$ der Christen und das Heilige Abendmahl $;{ }^{57}$ den Glauben.$^{58}$ In dieser Fülle an kleinen theologischen Abhandlungen, die den Fluss der Auslegung unterbrechen, schlägt sich wohl die Intention Bullingers nieder, aus seinem Kommentar zu Hebr eine möglichst ausführliche Darstellung reformierter Theologie und ihrer Kongruenz mit der »gesunden, katholischen und orthodoxen $\ll$ Lehre zu machen. ${ }^{59}$

\subsection{Quellen}

\section{Kommentarliteratur}

Anders als bei 1 Joh entfaltet Bullinger seine Exegese von Hebr in stetem Gespräch mit verschiedenen ihm zur Verfügung stehenden Kommentaren. Explizit bezieht er sich allerdings nur auf zwei Ausleger, nämlich Johannes Chrysostomos und Erasmus von Rotterdam. Auf Chrysostomos, dessen Kommentar er in der lateinischen Übersetzung von Mucianus (6. Jh.) las, ${ }^{60}$ weist Bullinger an insgesamt vierzehn Stellen hin. ${ }^{61}$ Weit weniger zahlreich sind die expliziten Hinweise auf die »Annotationes« des Erasmus (insgesamt sechs), ${ }^{62}$ wobei eine vergleichende Lektüre der »Annotationes « und des Kommentars Bullingers ergibt, dass Letzterer an mindestens fünfunddreißig weiteren Stellen verschiedene Begriffserklärungen und Gedankengänge von Erasmus übernahm. ${ }^{63} \mathrm{Im}$ Vergleich dazu sind die Bezüge auf Erasmus' »Paraphrasis« zu Hebr spärlich, mit nurmehr drei expliziten Verweisen. ${ }^{64}$

Im ganzen Kommentar finden sich zwar keine Erwähnungen der Auslegungen von Theophylakt (der in später erschienenen Kommentaren eine wichtige Referenz Bullingers darstellt ${ }^{65}$ ), Jacques Lefèvre d'Étaples oder Johannes Bugenhagen. Allerdings lässt sich aufgrund von inhaltlichen Übereinstimmungen vermuten, dass Bullinger an einigen Stellen, an denen er pauschal auf die Ansichten

50 Siehe unten S. 34-37, mit Bezug auf Hebr 1,14 .

51 Siehe unten S. 47f., mit Bezug auf Hebr 2,17.

52 Siehe unten S. 68-72, mit Bezug auf Hebr 5,5-6.

53 Siehe unten S. 77-81, mit Bezug auf Hebr $6,1-2$.

54 Siehe unten S. 96f., mit Bezug auf Hebr 7,1314.

55 Siehe unten S. 106-108, mit Bezug auf Hebr $8,8-9$.

56 Siehe unten S. 117, mit Bezug auf Hebr 9,810.

57 Siehe unten S. 131-135, mit Bezug auf Hebr
10,15-18. Vgl. auch S. 170f., mit Bezug auf Hebr 13,15-16.

58 Siehe unten S. 144-147, mit Bezug auf Hebr 11,1 .

59 Siehe oben Kap. 3.1.

60 VD16 J 397, 55-173.

$61 \quad$ Siehe unten S. 59; 67; 77; 91; 100; 111; 119; 126f.; 140; 145; 153.

62 Siehe unten S. 23f.; 82; 103f.; 114.

63 Siehe unten S. 24; 28; 30; 56-58; 63; 65; 67f.; 70; 73; 76; 78f.; 83; 90; 93; 96; 101; 103; 112; $128 ; 144 ; 146 ; 157 f$.; 161; 167.

64 Siehe unten S. $100 ; 124 ; 153$.

65 Vgl. etwa Baschera 2012, LXXIII; LXXVI. 
»anderer« Ausleger hinweist, wohl den Kommentar Bugenhagens (vier Fälle ${ }^{66}$ ) bzw. denjenigen Theophylakts (drei Fälle ${ }^{67}$ ) im Sinn gehabt haben dürfte.

\section{Sonstige Quellen}

$\mathrm{Zu}$ den nichtexegetischen Quellen, auf die Bullinger Bezug nimmt, zählen zum einen Schriften von Autoren der klassischen Antike wie Homer, Aristoteles, Plutarch (dem Bullinger auch die später als unecht erkannte Schrift »De placitis philosophorum« zuschreibt), Cicero, Ovid, Quintilian, Plinius d. Ä., Aulus Gellius, Nonius Marcellus, Macrobius und Vergil. Die Funktion von Zitaten aus Werken solcher Autoren besteht jedoch vor allem darin, der Auslegung Bullingers eine gewisse Eleganz zu verleihen.

Anders verhält es sich freilich mit den Kirchenvätern, die Bullinger als theologische Gesprächspartner betrachtet und besonders im Rahmen der Exkurse intensiv heranzieht. Meist zitiert werden Tertullian (neun Zitate ${ }^{68}$ zwei davon ohne explizite Angabe der Quelle) und Augustinus (sieben Zitate ${ }^{69}$ ). Weitere Kirchenväter, auf die Bullinger verweist, sind: Hieronymus, Cyprian von Karthago, Laktanz, Rufinus von Aquileia, Eusebius von Cäsarea, Epiphanios von Salamis, Irenäus von Lyon sowie der christliche Dichter Aurelius Prudentius Clemens. Darüber hinaus zitiert Bullinger an zwei Stellen ausführlich aus dem »Liber de ecclesiasticis dogmatibus« des Gennadius von Marseille (gest. zwischen 492 und 505), allerdings ohne diese Quelle anzugeben. ${ }^{70}$ Bullinger verweist schließlich auf verschiedene Schriften des Athanasios von Alexandria, bei denen es sich jedoch immer um mittlerweile als unecht betrachtete Werke handelt. So stellen etwa im Rahmen des Exkurses über die Engel die pseudo-athanasischen »Quaestiones ad Antiochum principem « eine wichtige Referenz dar. ${ }^{71}$ Diese Schrift lag Bullinger in der annotierten lateinischen Übersetzung vor, welche Johann Reuchlin (1455-1522) 1519 besorgt hatte. ${ }^{72}$

Auf mittelalterliche Quellen nimmt Bullinger im Kommentar zu Hebr kaum Bezug - die einzige Ausnahme bilden zwei Zitaten aus dem »Officium de festo corporis Christi « des Thomas von Aquin. ${ }^{73}$ Humanistische »Nachschlagewerke« wie die »Commentaria linguae Graecae« des Guillaume Budé (1468-1540), die »Lectionum antiquarum libri XVI« des Ludovico Ricchieri (Rhodiginus, 1469 1525) und die »Adagia « des Erasmus von Rotterdam, werden dagegen immer wieder herangezogen. Im gesamten Kommentar verweist Bullinger schließlich nur an einer einzigen Stelle auf eine theologische Schrift seiner Zeit. Im Zusammenhang mit der Erörterung der Frage nach dem Verhältnis von Altem und

\footnotetext{
Siehe unten S. 80; 83; $113 f$.

Siehe unten S. 80; 114; 172.

Siehe unten S. 21f.; 26; 45f.; 66; 73; 133.

Siehe unten S. 26; 40; 48; 65; 117; 132; 169.

Siehe unten S. 27; 46.

Siehe unten S. 34-36.

VD16 A 3996.

Siehe unten S. 113; 133.
} 
Neuem Bund gibt er zwar nur eine kurze Passage aus Zwinglis Kommentar zu Jesaja wieder, nutzt aber gleich die Gelegenheit, um den Zürcher Reformator in den höchsten Tönen zu loben: Zwingli »seligsten Angedenkens« sei ein Mann »unvergleichlicher Gelehrsamkeit, Beständigkeit und Frömmigkeit« gewesen, der aufgrund seiner Verdienste gar als »Apostel Helvetiens« zu bezeichnen sei. ${ }^{74}$

\section{Der Kommentar zu 1-2Petr (1534)}

\subsection{Entstehung und Widmung}

Der Kommentar zu 1-2Petr war das fünfte exegetische Werk Bullingers, das innerhalb von zwei Jahren auf den Büchermarkt kam. Nach der Veröffentlichung der Kommentare zu 1Joh und Hebr (1532, siehe oben) waren 1533 auch seine Auslegungen von Röm (Februar) und Apg (August) erschienen. ${ }^{75}$ Später sollte Bullinger seine Beschäftigung mit dem paulinischen Corpus fortsetzen, aus der in rascher Folge die Kommentare zu 1Kor (Juni 1534) und 2Kor (März 1535) hervorgingen. ${ }^{76}$

Dass Bullinger mitten in einer Phase intensiver Beschäftigung mit den Paulusbriefen sich erneut zwei Katholischen Briefen zuwandte, ist nicht ohne Weiteres selbstverständlich ${ }^{77}$ und wirkte offenbar auch auf manche seiner Zeitgenossen überraschend. In zwei Briefen des Berchtold Haller an Bullinger etwa, die kurz vor bzw. unmittelbar nach der Veröffentlichung des Kommentars zu 1-2Petr verfasst wurden, verlieh der Schreiber behutsam und doch unmissverständlich seiner Verwunderung Ausdruck: »Der Verleger [sc. Christoph Froschauer d.Ä.] schreibt uns von deiner Auslegung der Petrusbriefe, du aber [sagst] nichts [davon]; vielmehr [erwähntest du] einmal die der Korintherbriefe. ${ }^{18}$ Und einen knappen Monat später: »Ich vernehme, dass deine Kommentare zu den Petrusbriefen gedruckt worden sind, ich aber erwartete welche zu den Korintherbriefen. $\ll^{79}$

Die Erwartung, Bullinger würde nach Röm nun 1Kor und 2Kor kommentieren, dürfte darin begründet gewesen sein, dass man wusste, er beschäftige sich bereits seit einiger Zeit mit diesen beiden Schriften ${ }^{80}$ Zudem finden sich bei Bullinger

Siehe unten S. 109,15-22.
HBBibl I, Nr. 42; 43 .
HBBibl I, Nr. 53; 71.
Einen umittelbaren Zusammenhang mit seiner
Predigttätigkeit ist in diesem Fall nicht gege-
ben, hatte Bullinger bereits zwei Jahre davor
über die Petrusbriefe gepredigt, vgl. HBD
21,23 .
Berchtold Haller an Bullinger, 26. Februar
1534 (HBBW IV 72,50f.): »Typographus scribit ad nos de tuis in Petri epistolas annotationibus; tu vero nihil, sed de Corinthiis olim.« 79 Berchtold Haller an Bullinger, 14. März 1534 (HBBW IV 91,70f.): »Audio in Petri epistolas tuas commentationes esse impressas, ego vero in Corinthios expectabam.«

80 Vgl. Dionysius Melander an Bullinger, 3. April 1534 (HBBW IV 109,14f.): »Expec- 
selbst Hinweise darauf, dass der Kommentar zu 1-2Petr in Eile niedergeschrieben wurde, ${ }^{81}$ als hätte er eigentlich gar nicht geplant, zu diesem Zeitpunkt daran $\mathrm{zu}$ arbeiten, und es dennoch für nötig hielt, dieses Projekt genau jetzt in Angriff zu nehmen. Was hatte ihn nun aber dazu bewogen? Obwohl sich diese Frage nicht vollständig klären lässt, liefert gerade die Widmung im Kommentar zu 1-2Petr wichtige Hinweise zu deren zumindest tentativer Beantwortung.

Anders als bei den meisten Bibelkommentaren Bullingers, die überhaupt eine Widmung enthalten, ist diese an keine bestimmte Person oder politische Instanz gerichtet, sondern allgemein an »alle Brüder, die in den deutschen Landen um Christi und des Evangeliums willen unterdrückt und vertrieben sind «. ${ }^{82}$ Sie alle, die schweren Verfolgungen ausgesetzt sind, würden stets von der Versuchung heimgesucht, die Wahrheit zu leugnen, um ihrem Leiden ein Ende zu setzen. Deshalb bedürften sie auch der wiederholten Ermahnung, sich in Geduld zu üben und auszuharren, damit sie letztlich den Lohn bekommen, der alle, die so handeln, bei Gott im Überfluss erwarte. ${ }^{83}$ Genau das sei aber das zentrale Thema der Petrusbriefe: die Ermahnung zu Unschuld und Geduld ${ }^{84}$ deshalb habe Bullinger entschieden, diese beiden Briefe auszulegen und die Frucht seiner Arbeit allen verfolgten Protestanten zu widmen. ${ }^{85}$

Es bleibt jedoch unklar, welche Ereignisse genau Bullinger vor Augen hatte, als er sich an die Verfolgten evangelii causa im Reich wandte. Nicht unwahrscheinlich ist, dass der Zürcher Antistes dabei an die schwierige Lage der Protestanten in Frankfurt a.M. dachte, mit denen er bereits im vorhergehenden Jahr in Kontakt getreten war. Er hatte nämlich im August 1533 dem Frankfurter Rat, der zuvor am 23. April 1533 offiziell die Reformation eingeführt hatte, seinen Kommentar zur Apostelgeschichte gewidmet ${ }^{86}$ und sollte auch später vor allem

tamus pii omnes ardentissimis votis, quae nunc meditaris in Corinthios.«

81 Bullinger an Joachim Vadian, 17. März 1534 (HBBW IV 92,12f.): »Mitto tibi commentarios nostros in epistolam Petri utramque effusos verius quam scriptos in hisce negotiorum turbis« (Hervorhebung, LB). Siehe auch unten S. 306,12-14: »Dandum est etiam brevitati temporis nonnihil, qua oppressus vix relegere, non iam dicam revidere et expolire licebat, quod iamiam effuderam. «

82 Siehe unten S. 179,1f.: »Omnibus per Germaniam fratribus nomine Christi evangeliique afflictis et exulibus [...].«

83 Siehe unten S. 179,16: »[...] perseverantibus copiosissima est apud deum merces reposita.«

84 Bereits 1526/27 hatte Bullinger festgehalten, dass die »gedult« der besondere »locus« des Petrus, d.h. der theologische Brennpunkt sei- ner beiden Briefe, sei, vgl. Bull. vorl. Hebr. (Berg/Hausammann 137): »Yeder [Apostel] hat sin eigne locos communes, darin er gern ussbricht, dass man inn kent. Also hat Ioannes die liebe, also Petrus die gedult, also Paulus den glouben und den geist wider den bůchstaben und gsatzt als der heyden Apostel wyder die Juden.«

85 Siehe unten S. 179,16-19: »De qua cum multis hac epistola agat Petrus suaeque aetatis homines mira evidentia ad tolerantiam exhortetur, visum est ipsam, uti nostris illustrata est commentariis, dicare imo commendare vobis omnibus.«

86 Vgl. Bullinger an Rat und Bürger von Frankfurt am Main, 25. August 1533 (HBBW III 173-177) sowie die Antwort des Frankfurter Rates an Bullinger, 19. September 1533 (HBBW III 184f.). 
durch Dionysius Melander über die dortige Lage informiert bleiben. ${ }^{87}$ Besonders beunruhigend dürfte deshalb die Nachricht gewesen sein, dass auf Antrieb der kurmainzischen Regierung der dritte Reformationsprozess gegen Frankfurt eröffnet worden war ${ }^{88}$ was aus allen dort lebenden Protestanten eben Verfolgte »um Christi und des Evangeliums willen« machte.

\subsection{Autorschaft der Briefe und Struktur des Kommentars}

Bestand zu Bullingers Zeiten kein Zweifel bezüglich der Echtheit von 1Petr, so war bereits in der Antike in Frage gestellt worden, dass der zweite Petrusbrief vom gleichnamigen Apostel stamme. So führt Erasmus am Schluss seiner Auslegung von 2 Petr die entsprechenden patristischen Belege an, die zeigen, wie selbst ein und derselbe Autor (etwa Hieronymus) an verschiedenen Stellen seines Schrifttums die Echtheit von 2Petr mal bekräftigen, mal anzweifeln konnte. ${ }^{89}$ Anders als bei Hebr möchte Erasmus zwar nicht gänzlich ausschließen, dass es sich bei 2 Petr um einen echten Brief handeln könnte, er spricht sich jedoch auch nicht deutlich zugunsten dieser These aus. ${ }^{90}$

Ganz andere Töne schlägt indessen Bullinger an, der in einem kurzen Vorwort zu seinem Kommentar die traditionelle Zuschreibung an Petrus dezidiert verteidigt. Dabei macht Bullinger zunächst auf die inhaltliche Übereinstimmung von 2Petr mit den übrigen kanonischen Schriften aufmerksam, ein Argument, das er aber gleich als unzureichend erkennt. ${ }^{91}$ So weist er zusätzlich auf die Eröffnung des Briefes (2Petr 1,1), auf die darin enthaltene Erwähnung des Verklärung (2Petr 1,16-18) sowie allgemein auf die Beschaffenheit der Argumentation und die Anordnung des Stoffes hin. Den Einwand, es bestünden doch große stilistische Unterschiede zwischen 1Petr und 2Petr, lehnt Bullinger kurzerhand als »kindisch « (puerilis) ab. ${ }^{92}$ Sein Fazit lautet, 2Petr sei »voller äußerst gesunde Lehre und Ermahnungen « und somit von großem Nutzen für die Kirche. Genau dies erkenne allerdings auch der Teufel und versuche deshalb, Zweifel an dessen Echtheit zu streuen. ${ }^{93}$ Seinerseits halte Bullinger daran fest, Petrus sei der Autor,

87 Siehe Baschera 2012, LXIf.

88 Vgl. Jahns 1976, 249-302.

89 Erasm. 2Petr. (ASD VI/10 518,398-404): »De hac quoque secunda Petri epistola, cuius esset, controuersia erat. Id testatur Hieronymus in Catalogo scriptorum illustrium his quidem verbis: >Scripsit duas epistolas, quae canonicae nominantur, quarum secunda a plerisque eius negatur propter stili cum priore dissonantiam.< [Hier. vir. ill. 1 (PL XXIII 638B-C)] At idem alias variat nunc volens eam esse Petri et stili dissonantiam reiiciens in interpretem, quo tum Petrus sit vsus, nunc negans illius esse, quod reclamet stilus [Hier. epist. 120,11,5 (CSEL LV 508,1-4)].«

90 Erasm. 2Petr. (ASD VI/10 518,410).

91 Siehe unten S. 275,11-20.

92 Siehe unten S. 275,22-26.

93 Siehe unten S. 275,31-276,2: »Breviter: plena est saluberrimae doctrinae et admonitionis, ut mihi persuaserim prorsus istud dubii, quodcunque apud quoscunque de hac epistola fuit, ex diaboli enatum esse versutia.« 
und nehme sich somit vor, diesen Brief als »Werk des Heiligen Geistes« (spiritus sancti opus) auszulegen. ${ }^{94}$

Die Struktur des Kommentars zu 1-2Petr entspricht derjenigen der übrigen Kommentare zu den neutestamentlichen Briefen: Auf ein »Argumentum epistolae«, in dem die Hauptthemen und der Duktus der Argumentation skizziert werden, folgt jeweils die fortlaufende Auslegung ohne zusätzliche Gliederung des Stoffes in thematische Abschnitte. An manchen Stellen bettet Bullinger allerdings Exkurse unterschiedlicher Länge zu bestimmten Themenkomplexen in die Exegese ein: der Kontinuität zwischen Altem und Neuem Testament; ${ }^{95}$ dem christlichen Priestertum, dem kirchlichen Amt und den Opfern der Christen; ${ }^{96}$ der Würde und den Pflichten der kirchlichen Amtsträgern $;{ }^{97}$ der Verklärung Christi; ${ }^{98}$ den Merkmalen der Häretiker und der falschen Propheten. ${ }^{99}$

\subsection{Quellen}

Im Kommentar zu 1-2Petr finden sich keine Hinweise darauf, dass Bullinger altkirchliche oder mittelalterliche Auslegungen dieser beiden Briefe, wie etwa jene von Didymus dem Blinden oder Beda Venerabilis, benutzte, obgleich diese ihm bekannt gewesen sein dürften. Als wichtigste exegetische Referenz Bullingers erweist sich eindeutig Erasmus von Rotterdam. Dabei überwiegen die expliziten Bezüge auf die »Paraphrases « $\left(\right.$ vierzehn $^{100}$ ) gegenüber denjenigen auf die »Annotationes « $\left(\right.$ sieben $\left.^{101}\right)$. Allerdings lässt sich auch in diesem Kommentar an vielen Stellen, an denen Erasmus nicht explizit genannt wird, einen Einfluss der »Annotationes« auf Bullingers Auslegung vermuten. Darüber hinaus konsultierte Bullinger - obwohl er nur ein einziges Mal explizit darauf verweist ${ }^{102}$ - den Kommentar Martin Luthers, den er nach der von Martin Bucer 1524 besorgten lateinischen Übersetzung zitiert. ${ }^{103}$ Dieser wird jedoch fast ausschließlich im Zusammenhang mit Fragen der Übersetzung des biblischen Textes herangezogen. ${ }^{104}$

Auch im Kommentar zu 1-2Petr finden sich zahlreiche Hinweise und Zitate aus weiteren Quellen, auf die sich Bullinger bezieht, um Textstellen zu erläutern, Gedankengänge zu entfalten oder seine Position zu bekräftigen. Dazu gehören neben einigen lateinischen und griechischen klassischen Autoren (wie etwa Ver-

94 Siehe unten S. 276,7f.

95 Siehe unten S. 192-206, mit Bezug auf 1Petr $1,10 \mathrm{f}$.

96 Siehe unten S. 218f. sowie 222-225, mit Bezug auf 1Petr 2,5.9.

97 Siehe unten S. 260-266, mit Bezug auf 1Petr 5,1-3.

98 Siehe unten S. 284-286, mit Bezug auf 2Petr 1,17 .
99 Siehe unten S. 288-292, mit Bezug auf 2Petr 2,1-3.

100 Siehe unten S. 187f.; 192; 218; 226; 235; 238; 241; 254; 258; 267.

101 Siehe unten S. 206; 228; 235; 253; 265; 293.

102 Siehe unten S. 227.

103 VD16 L 4599.

104 Siehe unten S. 212; 239; 262; 270; 291. 
gil, Plinius d.Ä. und Strabo) vor allem abendländische Kirchenväter, wobei die drei am Häufigsten herangezogenen Augustinus (zehn Mal ${ }^{105}$ ), Tertullian (acht $\mathrm{Mal}^{106}$ ) und Cyprian von Karthago (fünf $\mathrm{Mal}^{107}$ ) sind. Weit geringerer Anzahl sind die Bezüge auf frühneuzeitliche Werke. Zu dieser Gruppe gehört neben den üblichen Verweisen auf enzyklopädische Werke (Budé, Ricchieri, Erasmus) ${ }^{108}$ auch ein explizites Zitat aus der 1532 erschienenen Genesis-Auslegung des groBen Hebraisten und Lehrers an der »Schola Tigurina«, Konrad Pellikan (14781556), ${ }^{109}$ auf die Bullinger im Rahmen des Exkurses über das Verhältnis von Altem und Neuem Testament verweist. ${ }^{110}$ Noch interessanter, weil auf den ersten Blick in keiner Weise als solches erkennbar, ist schließlich ein mittellanges Zitat aus Huldrych Zwinglis »Christianae fidei brevis et clara expositio ad regem Christianum « (1531). Dabei handelt es sich um eine Passage aus dem Abschnitt über das ewige Leben, in der Zwingli die »selige Schau Gottes « (visio beatifica) beschreibt und die Bullinger nahtlos in seine Auslegung von 1Petr 1,4 einflicht. ${ }^{111}$

\section{Der Kommentar zu Jak (1537)}

\subsection{Entstehung und Struktur}

Mit den ersten vier Kapiteln von Jak hatte sich Bullinger nach eigener Aussage bereits im Rahmen seiner Predigttätigkeit in Bremgarten (1529) auseinandergesetzt. ${ }^{12}$ Die Arbeit an einer vollständigen lateinischen Auslegung dieses Briefes nahm er allerdings erst im Zuge der Vorbereitung der Gesamtausgabe seiner Kommentare zu den Briefen des Neuen Testaments in Angriff. ${ }^{13}$

Der Kommentar zu Jak enthält zwar keine Widmung, dafür aber ein Vorwort, in dem Bullinger auf die Autorschaftsfrage eingeht. ${ }^{14}$ Diese Frage - die zur Reformationszeit aufgrund von Luthers Infragestellung der Kanonizität von Jak an Brisanz gewann - war bereits in der Antike unterschiedlich beantwortet worden. Anders als bei Hebr und 2Petr stand allerdings nicht so sehr zur Debatte, ob der Brief echt sei. Vielmehr blieb es unklar, mit welcher biblischen Gestalt denn der als Autor des Briefes angegebene »Jakobus « zu identifizieren sei. Darüber hinaus wird Letzterer in manchen Handschriften auch als »Apostel« bezeichnet, was wiederum die Frage aufwarf, ob überhaupt und wenn ja, um welchen der zwölf Apostel es sich bei diesem Jakobus handle.

\footnotetext{
105 Siehe unten S. 195; 231; 257-259; 281; 304.

106 Siehe unten S. 182f.; 192; 195; 208; 226; 245.

107 Siehe unten S. 181f.; 226; 255; 259.

108 Siehe oben S. XIX.

109 BZD C 217.
}

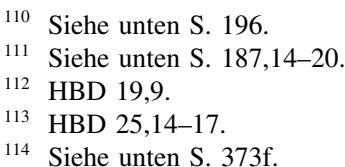

110 Siehe unten S. 196.

112 HBD 19,9.

114 Siehe unten S. $373 f$. 
Bullinger referiert in diesem Zusammenhang zwei Meinungen, die er gleichermaßen verwirft. Einige hätten den Autor von Jak mit dem sogenannten »Herrenbruder « identifiziert, welcher wiederum von Jakobus, »dem Sohn des Alphäus « (Mt 10,3), zu unterscheiden und als dreizehnter Apostel zu betrachten sei. Andere lehnten dies ab und favorisierten vielmehr die These, der Autor von Jak sei der Sohn von Maria, der Schwester der Mutter Jesu, gewesen. Bullinger schließt sich seinerseits lieber der Position des Hieronymus an, der den »Herrenbruder«, Jakobus (Sohn des Alphäus) und den Sohn der Maria, »[Tochter] von Kleopas «, als ein und dieselbe Person betrachtet. Letztlich sei allerdings - so Bullinger - die genaue Identifizierung des Autors dieses Briefes zweitranging gegenüber der Beachtung des Inhalts, wie Erasmus selbst in seinen »Annotationes « bereits treffend betont habe: »Es ist überflüssig, über den Autor kümmerlich zu streiten; lasst uns vielmehr uns der Sache annehmen und dem Heiligen Geist als Autor unseren Lob erteilen. ${ }^{115}$

Bullinger zufolge unterscheide sich Jak von anderen neutestamentlichen Briefen dadurch, dass in ihm nicht so sehr die Grundsätze des christlichen Glaubens erörtert, sondern vielmehr einzelne Formen von Fehlverhalten getadelt und korrigiert werden. Dies sei ferner als Hinweis darauf zu betrachten, dass die Adressaten von Jak »Bekehrte« waren, die der elementaren Unterweisung nicht mehr bedurften. ${ }^{116}$

Der Stoff des Briefes lasse sich in sechs Teile gliedern, wobei die ersten fünf bestimmte Themen bzw. »loci ${ }^{117}$ behandelten: Geduld und Ungeduld (1,2-12); Gebrauch und Missbrauch der Sprache (1,13-21); das Verhältnis von Glaube und Lebenswandel (1,22-2,26); den Zusammenhang von äußerer Berufung und Ausübung des Lehramtes (3,1-18); das rechte Maß in der Verfolgung eigener Interessen $(4,1-5,6)$. Darauf folge schließlich ein sechster, allgemeiner gehaltener Abschnitt, der vor allem Trostworte an geplagte Glaubensgeschwister enthalte (5,7-20). ${ }^{118}$ Die fünf erwähnten Themen werden nacheinander im Rahmen der Auslegung der jeweiligen Textstellen entfaltet. Angesichts der nicht zuletzt kontroverstheologischen Relevanz des dritten locus ist es kaum überraschend, dass Bullinger besonders ausführlich darauf eingeht. ${ }^{119}$

115 Siehe unten S. 374,26-28. Vgl. Erasm. Iac. (ASD VI/10 388,20f.).

116 Siehe unten S. 374,31-375,4: »Scribit s[anctus] Iacobus conversis ad Christum dominum, ideoque nihil agit in hac epistola de primis fidei rudimentis et dogmatis nostrae religionis: de poenitentia, de abrogata lege, de fide sola iustificante, hoc est de salute per unicum Christum parta totique mundo oblata, aut de peccato et libertate christiana idque genus locis aliis, in quibus proculdubio satis erant instituti; sed corrigit quaedam, quae in populo dei exoriebantur peccata.«

117 Siehe unten S. 375,22; 380,18; 409,30.

118 Siehe unten S. 374f.; 423.

119 Siehe unten S. 395-404 (zu Jak 2,14-17) sowie 406-408 (zu Jak 2,20-24). 


\subsection{Quellen}

Wie dies bereits bei 1-2Petr der Fall war, nimmt Bullinger im Kommentar zu Jak nie Bezug auf patristische oder mittelalterliche exegetische Werke. ${ }^{120}$ Allgemein finden sich darin recht wenige explizite Verweise auf die bestehende Kommentarliteratur: Auf die »Annotationes« des Erasmus verweist Bullinger nur an zwei Stellen (wobei die eine sich nicht im Kommentar selbst, sondern im eröffnenden Traktat $»$ De autore epistolae « befindet),${ }^{121}$ auf dessen $»$ Paraphrasis $«$ an vier; ${ }^{122}$ auf die 1533 durch Leo Jud herausgegebene »Brevis et luculenta expositio « Zwinglis wird lediglich drei Mal Bezug genommen. ${ }^{123}$ So könnte der Eindruck entstehen, dass Bullinger bei der Verfassung seines Kommentars nur gelegentlich auf Zwingli oder Erasmus zurückgegriffen habe. Eine komparative Lektüre der vier Werke ergibt jedoch ein ganz anderes Bild: Inhaltliche Übereinstimmungen lassen sich zwischen Bullingers Auslegung und den »Annotationes « des Erasmus in weiteren vier Fällen, zwischen Bullinger und Zwingli in siebzehn Fällen feststellen. Die größte Diskrepanz zwischen expliziter Bezugnahme und effektiver Verwendung ist jedoch bei Erasmus' »Paraphrasis « vorhanden, auf die Bullinger zwar nur viermal explizit verweist, aus der er aber an weiteren zwanzig Stellen ganze Passagen übernimmt und nahtlos in seinen Text einfließen lässt. ${ }^{124}$

Die wenigen Hinweise auf klassische Autoren, die überhaupt im Kommentar zu Jak zu finden sind, entnimmt Bullinger sehr wahrscheinlich den »Adagia « des Erasmus. ${ }^{125}$ An einer Stelle verweist Bullinger ferner auf ein weiteres Werk des niederländischen Humanisten, die Schrift »Lingua $\ll .{ }^{126}$ Aus den $\gg$ Commentarii linguae Graecae« des Guillaume Budé, die in anderen Kommentaren eine stete Referenz bilden, zitiert er nur zweimal, allerdings ohne Angabe der Quelle. ${ }^{127}$ Viel zahlreicher sind hingegen die Verweise auf patristische Autoren (vornehmlich Augustinus), wobei die meisten von ihnen im Exkurs zur Frage nach dem Verhältnis von Glaube und Werken begegnen: Fast vier Folio-Seiten füllt Bullinger dort mit ausführlichen Zitaten aus insgesamt sechs verschiedenen Schriften des Bischofs von Hippo, um zu belegen, dass die reformierte Rechtfertigungsund Heiligungslehre in Übereinstimmung mit dem altkirchlichen, »katholischen« Konsens stehe. ${ }^{128}$ Weitere Kirchenväter, aus dessen Schriften Bullinger gelegentlich zitiert, sind schließlich Cyprian von Karthago und Hieronymus.

120 Siehe oben Kap. 4.3. Die einzige Erwähnung des Beda Venerabilis als Ausleger von Jak findet sich innerhalb eines Zitats aus den $» \mathrm{An}$ notationes« des Erasmus, s. unten S. 427,36.

121 Siehe unten S. 374f.; 427f.

122 Siehe unten 382f.; 414; 425; 429.

123 Siehe unten S. 390f.; 408; 411.
124 Siehe unten S. 379f.; 382f.; 387; 411-417; 419; 424f.; 429.

125 Siehe unten S. 378; $419 f$.

126 Siehe unten S. 413.

127 Siehe unten S. 407.

128 Siehe unten S. 397-403. 
6. Die Kommentare zu 2-3Joh und Jud (1537)

Auch 2-3Joh und Jud legte Bullinger erst im Hinblick auf die Veröffentlichung der Geamtausgabe seiner Kommentare zu den neutestamentlichen Briefen aus. Dass er 2-3Joh und Jud gleichsam in einem Kapitel zusammenfasste und dieses an den Schluss der Reihe der Katholischen Briefe setzte, deutet darauf hin, dass Bullinger diese drei kurzen Texten eher als zweitrangig betrachtete. Gleichwohl fällt die Auslegung im Verhältnis zum Umfang der Briefe selbst nicht weniger ausführlich aus.

Bullinger hält entgegen der Meinung von Hieronymus und Erasmus ${ }^{129}$ an der traditionellen Zuschreibung von 2-3Joh an den »Lieblingsjünger « fest, und zwar vorwiegend aufgrund der ihm zufolge auffallenden inhaltlichen Kontinuität zu 1Joh. ${ }^{130}$ Wie Origenes und Beda identifiziert ferner auch Bullinger den Autor von Jud mit dem »Judas Sohn des Jakobus«, der in Lk 6,16 erwähnt wird, welcher wiederum derselbe Mann sei, den Mt 10,3f. und Mk 3,18 »Thaddäus « nennen. ${ }^{131}$

Bullingers Auslegung bleibt nahe am Text und enthält wenige Zitate oder Hinweise auf außerbiblische Quellen. Im Kommentar zu 2Joh finden sich etwa lediglich zwei Zitate aus der »Paraphrasis« des Erasmus, ${ }^{132}$ während der Kommentar zu Jud zwei explizite Hinweise auf die »Annotationes ${ }^{133}$ sowie fünf Zitate ohne Quellenangabe aus der »Paraphrasis ${ }^{134}$ enthält. An keiner Stelle wird auf Luthers Kommentar zu Jud verwiesen, welcher zusammen mit den Auslegungen von 1-2Petr erschienen und somit Bullinger wohl bekannt war. Dafür zitiert er ziemlich ausführlich aus einer anderen, »edlen « Schrift (liber nobilis) dieses »sehr berühmten Mannes« (clarissimus vir) - der »Responsio ad librum Ambrosii Catharini« (1521) - und stimmt der dort zu findenden Anwendung von Jud 12 auf die Missstände in der Kirche Roms zu. ${ }^{135}$

\section{Editionsrichtlinien und Benutzungshinweise}

Der nachfolgenden Edition von Bullingers Kommentaren zu Hebr, 1-2Petr und 1Joh werden die jeweiligen Erstauflagen sowie die erste Gesamtausgabe von 1537 zugrunde gelegt. Die Erstauflagen werden mit den Siglen F, G und H bezeichnet, die entsprechenden Teile der Gesamtausgabe mit ZF, ZG und ZH. Die Edition der Vorrede zu den Katholischen Briefen in der Gesamtausgabe

129 Siehe unten S. 440,33-441,1. Vgl. Erasm. 3Joh. (ASD VI/10 564,23-25).

130 Siehe unten S. 437,3-5.

131 Siehe unten S. 441,6-9.

133 Siehe unten S. 442f.; 447.

134 Siehe unten S. 445; 448; 451.

135 Siehe unten S. 448,1-22.

132 Siehe unten S. 435 (implizit) sowie 436 (explizit). 
sowie der Kommentare zu Jak, 2-3Joh und Jud hat ebenso die Erstausgabe von 1537 zur Grundlage.

\begin{tabular}{|c|c|c|c|}
\hline Edition & Textgrundlage & $\mathrm{Nr} .{ }^{136}$ & Sigle \\
\hline \multirow[t]{2}{*}{ Hebr } & $\begin{array}{l}\text { In Pauli ad Hebraeos epistolam commentarius, Zürich: } \\
\text { Christoph Froschauer d.Ä., } 1532\end{array}$ & 2 & $\mathrm{~F}$ \\
\hline & $\begin{array}{l}\text { In omnes apostolicas epistolas commentarii, Zürich: } \\
\text { Christoph Froschauer d.Ä., 1537, 639-731 }\end{array}$ & 9 & $\mathrm{ZF}$ \\
\hline VKathB $^{137}$ & $\begin{array}{l}\text { In omnes apostolicas epistolas commentarii, Zürich: } \\
\text { Christoph Froschauer d.Ä., } 1537,2^{138}\end{array}$ & 9 & $\mathrm{Z}$ \\
\hline \multirow[t]{2}{*}{ 1Petr } & $\begin{array}{l}\text { In Petri epistolam utranque commentarius, Zürich: } \\
\text { Christoph Froschauer d. Ä., 1534, 1r-84r }\end{array}$ & 4 & G \\
\hline & $\begin{array}{l}\text { In omnes apostolicas epistolas commentarii, Zürich: } \\
\text { Christoph Froschauer d.Ä., 1537, 3-54 }\end{array}$ & 9 & ZG \\
\hline \multirow[t]{2}{*}{ 2Petr } & $\begin{array}{l}\text { In Petri epistolam utranque commentarius, Zürich: } \\
\text { Christoph Froschauer d. Ä., } 1534,84 \mathrm{v}-114 \mathrm{r}\end{array}$ & 4 & G \\
\hline & $\begin{array}{l}\text { In omnes apostolicas epistolas commentarii, Zürich: } \\
\text { Christoph Froschauer d.Ä., 1537, 55-73 }\end{array}$ & 9 & $\mathrm{ZG}$ \\
\hline \multirow[t]{2}{*}{ 1Joh } & $\begin{array}{l}\text { In epistolam Ioannis expositio, Zürich: Christoph } \\
\text { Froschauer d.Ä., } 1532\end{array}$ & 1 & $\mathrm{H}$ \\
\hline & $\begin{array}{l}\text { In omnes apostolicas epistolas commentarii, Zürich: } \\
\text { Christoph Froschauer d.Ä., 1537, 74-107 }\end{array}$ & 9 & $\mathrm{ZH}$ \\
\hline Jak & $\begin{array}{l}\text { In omnes apostolicas epistolas commentarii, Zürich: } \\
\text { Christoph Froschauer d.Ä., 1537, 108-141 }\end{array}$ & 9 & $\mathrm{Z}$ \\
\hline 2Joh & $\begin{array}{l}\text { In omnes apostolicas epistolas commentarii, Zürich: } \\
\text { Christoph Froschauer d.Ä., 1537, 142-144 }\end{array}$ & 9 & $\mathrm{Z}$ \\
\hline 3Joh & $\begin{array}{l}\text { In omnes apostolicas epistolas commentarii, Zürich: } \\
\text { Christoph Froschauer d.Ä., 1537, 145-147 }\end{array}$ & 9 & $\mathrm{Z}$ \\
\hline Jud & $\begin{array}{l}\text { In omnes apostolicas epistolas commentarii, Zürich: } \\
\text { Christoph Froschauer d.Ä., } 1537,147-153\end{array}$ & 9 & $\mathrm{Z}$ \\
\hline
\end{tabular}

Als Grundtexte fungieren F, G, H sowie Z für die Vorrede zu den Katholischen Briefen und die Kommentare zu Jak, 2-3Joh und Jud. Etwaige Abweichungen in ZF, ZG und ZH oder Emendationen werden im textkritischen Apparat wiedergegeben.

Die Seitenwechsel der Vorlagen werden im Text durch einen senkrechten Strich kenntlich gemacht, jeweils mit Angabe der Paginierung der Vorlagen an der Blattinnenseite. Fehlpaginierungen der Vorlagen werden korrigiert und durchgestrichen in Klammern vermerkt.

136 Bibliographienummer, vgl. Moser 2012, XIV; XVI; XX; XXXf.

137 Vorrede zu den Katholischen Briefen.
138 Mit Beginn der Kommentare zu den Katholischen Briefen fängt in $\mathrm{Z}$ die Paginierung neu an, vgl. Moser 2012, XXXI. 
Die Absatzgestaltung entspricht den Erstauflagen; abweichende Absatzgestaltungen in der Gesamtausgabe werden nicht dokumentiert. In F, G und $\mathrm{H}$ ist der Fließtext kursiv und der Bibeltext recte gesetzt; in der Gesamtausgabe (ZF-ZH sowie Z) wird zwischen dem (recte gesetzten) Fließ- und Bibeltext mittels verschiedener Schriftgrößen unterschieden. In dieser Edition erscheint der Bibeltext als textgliederndes Element kursiv und der daran anschließende Kommentar in Normalschrift. Die dem Bibeltext zur besseren Orientierung in kleinerer Schriftgröße beigegebenen Versnummern sind in den Vorlagen nicht enthalten.

Konsequente Normalisierungen werden im Bereich der Interpunktion und der Groß- und Kleinschreibung vorgenommen: Die Interpunktion folgt den heute üblichen Gepflogenheiten und der Text wird mit Ausnahmen in Kleinschreibung wiedergegeben. Groß geschrieben werden Satzanfänge, Personen- und Ortsnamen, Bezeichnungen von Sprachen und Personengruppen sowie Werktitel. Wörter, die in den Vorlagen in Versalien erscheinen, werden hier in Kapitälchen wiedergegeben, außer es handelt sich um Überschriften oder Zeichenfolgen zu Beginn eines Kapitels oder Abschnitts. Die Gestaltung der Buch-, Teil- und Kapitelüberschriften sowie die dazugehörigen Schlussbemerkungen erfolgt in der Edition unabhängig von den Vorlagen; das Vorkommen von Initialen oder Zierinitialen wird nicht vermerkt. Trennung und Zusammenschreibung folgen der Erstauflage, Abweichungen werden im textkritischen Apparat vermerkt. Die Kolumnentitel werden unabhängig von den Vorlagen gestaltet; sie weisen stets auf die gerade behandelte Bibelstelle hin bzw. halten den jeweiligen Buchteil (z.B. »Praefatio«) fest.

Die Buchstaben $\mathrm{u} / \mathrm{v}$ werden nach ihrem Lautwert normalisiert und $\mathrm{j}$ stets mit $\mathrm{i}$ wiedergegeben. Das lange s wird als s, $B$ als ss, e-caudata als »ae« und \& als »et« aufgelöst. Stillschweigend aufgelöst werden auch Ligaturen (z.B. æ/ae, oe/oe etc.), Abbreviaturen (z.B. q ${ }_{3}$ que) und Nasalstriche. Nicht wiedergegeben werden auch die Akzente über den Vokalen (à, â, etc.). Die Akzentsetzung bei griechischen Wörtern erfolgt nach den heute üblichen Regeln. Abkürzungen werden in eckigen Klammern aufgelöst; syntaktisch nicht eingebundene Bibelstellenangaben hingegen bleiben unaufgelöst. Die Zahlzeichen folgen ebenfalls den Erstauflagen, der Punkt nach dem Zahlzeichen wird aber nur bei Ordinalzahlen wiedergegeben.

Deutsche Wörter und Textpassagen erscheinen in den Vorlagen in Fraktur (Erstauflagen) bzw. Kursivschrift (Gesamtausgabe), hier werden sie gesperrt gesetzt. In Abweichung zum Umgang mit dem lateinischen Text wird $\beta$ beibehalten, Vokale mit übergesetzten Vokalen (z.B. ů ù ů ò etc.) erscheinen unverändert. Abweichende Schreibweisen in der Erstauflage und der Gesamtausgabe werden im textkritischen Apparat dokumentiert. Auch bei den deutschen Texten wird die Interpunktion normalisiert. 
Der Text wird durch zwei Apparate erschlossen. Im textkritischen Apparat werden die Varianten in den verschiedenen Vorlagen festgehalten, außer es handelt sich um Abweichungen, bei denen - wie oben beschrieben - Normalisierungen vorgenommen werden. Die Referenzierung erfolgt durch Zeilenzahlen; die einzelnen textkritischen Anmerkungen sind durch einen Halbgeviertstrich voneinander getrennt.

Der sachkritische Apparat weist die von Bullinger explizit zitierten oder implizit verwendeten Quellen nach. Zudem gibt er Rechenschaft über biblische, patristische, mittelalterliche oder zeitgenössische philologische und theologische Traditionen, die Bullingers Argumentation zugrunde liegen. Zusätzlich werden im sachkritischen Apparat Erklärungen zu Personen (biblische und allgemein bekannte Personen wie etwa Cicero, Augustin oder Zwingli ausgenommen) und Begriffen geliefert. Im Normalfall wird eine Personenerklärung bei der ersten Erwähnung der Person angebracht und die entsprechende Seite im Personenregister durch einen Asterisk * gekennzeichnet. Erklärungen zu Begriffen (z.B. zu rhetorischen Figuren) erfolgen beim ersten Vorkommen. Bei weiteren Vorkommen wird auf diese Erklärung verwiesen. Etwaige Zitationen von Bibelstellen im sachkritischen Apparat erfolgen nach der Vulgata. ${ }^{139}$ Ergänzungen zu von Bullinger angebrachten Bibelstellenangaben bzw. Angaben zu von ihm zitierten Bibelstellen erscheinen in eckigen Klammern direkt im Fließtext und nicht im sachkritischen Apparat. Alle verwendeten Siglen von Autoren und deren Werken werden in der Bibliographie aufgelöst. Zitate aus alten Drucken folgen den hier dargelegten Editionsrichtlinien. Zitate aus modernen Editionen werden unverändert nach der Vorlage wiedergegeben, was aufgrund von unterschiedlichen Editionsgrundsätzen zu verschiedenen Schriftbildern führt, die hier aber in Kauf genommen werden.

Die Edition wird durch insgesamt vier Register (Bibelstellen, Quellen, Personen und Orte) erschlossen. Für nähere Angaben zur Benutzung dieser Register siehe die jeweiligen einleitenden Hinweise.

139 Biblia sacra iuxta vulgatam versionem, hg. von Robert Weber und Roger Gryson, Stuttgart ${ }^{5} 2007$. 
KOMMENTAR ZUM HEBRÄERBRIEF 

Ago tibi gratias, illustrissime princeps, communi omnium piorum nomine, quod caussam nostram, imo non nostram, sed Christi domini, multis iam annis, ma5 xime vero proximis diebus Schuinfordiae primum, deinde Norinbergae adversus eos strenue defenderis, qui nos et nostram, quam »Zuinglianam« vocant, doctrinam voluere proscriptam. ${ }^{2}$ Vidisti enim acri illa, qua a summo principe deo donatus es, prudentia non hominis proscribi doctrinam, sed dei veritatem, quam Zuinglius non minus pie quam cordate toti orbi praedicavit. Memor itaque ver10 borum apostoli, quibus Timotheum suum contestatur et dicit: »Ne pudeat te testimonii domini nostri neque te pudeat mei, qui sum vinctus illius « [2Tim 1,8], noluisti veritatem ullo humani nominis praetextu proscribi. Quapropter gratulamur hic quoque tibi, princeps piissime, de illa praeclara, quae in te est, prudentia et constantia et deo nostro patri benignissimo gratias agimus, quod te nostrae caussae dederit aequum et iudicem et tutorem. Illum porro indefessis ora|mus precibus, ut, quod coepit, confirmet ${ }^{3}$ et dona sua in te augeat, imperium quoque securum, domum tutam, exercitus fortes, senatum fidelem, populum probum et obedientem, prophetas quoque sanctos et veraces tribuat, et te nobis diu incolumem et in via veritatis conservet. Scimus enim absque singulari numinis afflatu 20 tenuem esse principum pietatem, ut nunc id totum, quod per te nobis confertur, divinae bonitati feramus acceptum, quae te et tuo ministerio ceu honorifico vase ${ }^{4}$ ad gloriam nominis sui utitur in domo sua. Neque enim ista in hoc scribimus, quod veritatis negotium sine tuo aut aliorum principum consensu interiisse aut constare non posse censeamus; qui iam olim didicimus ipsam veritatem per se quidem esse invincibilem et immortalem, qua non principes solum, sed omnia regna mundi conserventur et, quicquid laudis vel vituperii, commodi vel incommodi principes habeant, id omne aut ex veritatis cultu aut neglectu oriri. Quid enim apertius, quam quod Christus dixit: »Ego vero ab homine testimonium non accipio« [Joh 5,34]? Quid evidentius, quam quod propheta scripsit: »Nolite fidere

Z. (1) Illustrissimo] In ZF darüber die Überschrift In piam et eruditam Pauli ad Hebraeos epistolam commentarius

1 Philipp, Landgraf von Hessen (1504-1567), stand in engem Kontakt zu Bullinger, wovon der rege Briefwechsel zwischen den beiden zeugt. Vgl. HBBW II 181.

2 Gemeint sind die Verhandlungen, die im Vorfeld des Regensburger Reichstages (1532) zwischen dem 30. März und dem 9. Mai in Schweinfurt sowie vom 3. Juni bis zum 24 . Juli in Nürnberg geführt wurden. Philipp von Hessen war zu verdanken, dass die »Zwing- lianer« aus dem in Nürnberg abgeschlossenen Friedensvertrag (»Nürnberger Anstand «) nicht ausgeschlossen wurden, wie der Kaiser hingegen anfänglich gefordert hatte. Vgl. RTAJ X/1 129-146; Martin Bucer an Joachim Vadian, 21. Mai 1532 (MBBW VIII 62-68); Martin Bucer an Bullinger, 12. Juli 1532 (HBBW II 161).

Vgl. Phil 1,6.

Vgl. 2Tim 2,21. 
principibus aut quoquam hominum, in quibus non est salus. Ab homine enim cum abit spiritus eius, redit ad terram suam, tunc pereunt universae cogitationes eius; foelicem autem eum, cuius robur est deus Iacob, cuius spes est ad dominum deum suum, qui coelos, terram ac mare / condidit, et quicquid in eis est, qui FIDEM IN PERPETUUM SERVAT « [Ps 146,3-6]? In historiis quoque sacris videmus Saulem, ${ }^{5}$ Achab, ${ }^{6}$ Ioas $^{7}$ et Zedechiam, ${ }^{8}$ praecipuos veritatis hostes, per omnem vitam periclitari, tumultuari, nihil satis tuti aut firmi habere et tandem foeda etiam suorum strage et vita et regno exui; interim vero veritatem, quam illi extinctam volebant, nihilominus perennem manere. Contra vero Davidem, Iosaphat, ${ }^{9}$ Ezechiam ${ }^{10}$ et Iosiam, ${ }^{11}$ fidelissimos veritatis cultores, veritatis beneficio etiam in mediis peri- 10 culis impavidos obdurare, in ipsis quoque tumultibus tranquillos perstare, foeliciter et summa cum laude res gerere, et aeterna demum immortalitatis gloria a deo fidelissimo agonotheta munerari. ${ }^{12}$ Ex quibus constat veritatem per se quidem esse foelicem et immortalem. Qui enim veritatem propugnant, ab ipsa quidem defenduntur et eius beneficio multis perfruuntur bonis. Qui vero impugnant eam, 15 ii foelicitate non modo destituuntur, sed ne illud quidem, quod voluerunt, assequuntur. Siquidem veritas ab ipso mundi exordio immota adversus omnium tyrannorum insultus perstitit. Benigne itaque tecum egit pater coelestis, princeps illustrissime, qui tibi veritatis studium insevit et te honorifico vase in ecclesia sua uti voluit; unde nunc pietas tua prudenter fecerit, si illius vocationi non desit et in 20 timore domini veritatem impense coluerit.

Neque vero ignoramus, quid hostes nostri tibi hic obiiciant: nostram doctrinam inconstantem esse, factiosam et haereticam; nos vero ut schismaticos et seditiosos homines vitandos. Scimus, quanta linguae virulentia, quantis calumniis nos deferant atque proscindant. Verum, cum aequum te nobis hactenus praesti- 25 teris spectatorem, futurum speramus, ut ne nunc quidem talibus convitiis nobis iniquus reddaris. Nam doctrinam nostram sanctam esse et veram evicit compluribus scriptis ille sanctae memoriae antecessor noster H[uldrychus] Zuinglius; evicit et inculpatae vitae et incomparabilis eruditio|nis vir Ioan[nes] Oecolam-

Z. (3) foelicem] felicem $Z F-(11-12)$ foeliciter] feliciter $Z F-(14)$ foelicem] felicem $Z F$ - (16) foelicitate] felicitate $Z F-(28) \mathrm{H}[$ uldrychus]] Huldrychus $Z F$ - (29) Ioan[nes]] Ioannes $Z F$

1Sam 9,1-31,5.

1 Kön 16,28-22,40.

Der Grund, weshalb Bullinger Joasch, der ansonsten als »guter« König von Juda gilt (vgl. 2Kön 12,3), doch zu den »Feinden der Wahrheit « rechnet, liegt vermutlich in der durch ihn befohlenen Steinigung des Propheten Secharja, vgl. 2Chr 24,20-22.

2Kön 24,17-20; Jer 52,1-11.

1 Kön 22,41-51.

2Kön 18,1-20,21.
2Kön 22,1-23,29.

12 Vgl. Tert. mart. 3,3 (CCSL I 5,23-26): »Bonum agonem subituri estis in quo agonothetes Deus uiuus est, xystarches Spiritus sanctus, corona aeternitatis, brabium angelicae substantiae, politia in caelis, gloria in saecula saecu-

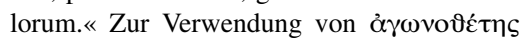
als Bezeichnung Gottes bzw. Christi in der patristischen Literatur der ersten vier Jahrhunderte vgl. Leemans 2005. 
padius. ${ }^{13}$ Eandem illam doctrinam, quam illorum ministerio ex sacris a deo accepimus, utpote non hominum, sed dei discipuli, cuius illi erant servi, adhuc illibatam custodimus. Id quod hoc meo in Hebraeos Pauli commentario, imo et ipsa Paulina epistola comprobamus. Ex qua, si per occupationes legere liceret, 5 intelligeres nos de scriptura, testamento et lege dei, de deo, unitate et trinitate dei, de Christo deo et homine, mediatore, sacerdote et sacrificio, de vera saluta et iustificatione, de ecclesia, de vocatione ad munus docendi, de vera fide, de sacramentis et vero dei cultu, primariis nostrae religionis capitibus, nihil novum, factiosum aut haereticum, sed prorsus sana, catholica et orthodoxa credere et 10 praedicare.

Igitur cum ipsa res clamitet sanctam et veram esse do|ctrinam, quam sequimur, tuarum partium erit, princeps clarissime, veritatem non deserere et ipsa re, quod diceris, esse: princeps veritati et iusticiae consecratus, qui non modo calumniis iniquorum adversus innocentes non irritetur, sed ne periculis quidem a vero et iusto absterreatur. Vere enim Cicero omnem laudem facti esse putavit, quod prudentia sine constantia nihil sit. ${ }^{14}$ Et Plato in eo opusculo, cui titulus »Laches«, putavit scientiam sine iusticia caeterisque virtutibus calliditatem potius esse quam sapientiam. ${ }^{15}$ Et sane non dubitamus isti tuo tam generoso animo tantum a numine roboris esse inditum, ut is neque Cappellana nostra clade neque Zuinglii 20 nostri insperato interitu ${ }^{16}$ concutiatur. Scimus enim, quanto dicendi imo nugandi apparatu adversarii, quo magis caussae nostrae incommodent, hostium iactitent victoriam. Scimus, inquam, quod alii quidem clamitant, factiosum hominem iusto dei iudicio per tumultum esse oppressum. Alii vero contendunt huius interitum haereticae doctrinae certissimum esse argumentum. Sed audi, clementiss[ime] princeps: non potuit propter tumultum occubuisse, qui verae pacis, aequitatis, iusticiae et patriae amantissimus fuit. Bello quidem et tumultu non pessimi, sed optimi quique plerunque oppressi sunt. Plura autem pro hoc viro hac in re nunc non dicam, qui eatenus hominem defendo, quatenus illi veritatis caussa coniuncta est, et ita coniuncta est, ut veritati aut commodet aut incommodet. | Alias agnoscimus illud Paulinum: »Quis est Cephas, Paulus aut Apollos, nisi ministri, per quos credidistis? « [1Kor 3,4f.] Neque vero plura de caussa aut iure belli, bellum

Z. (13) iusticiae] iustitiae $Z F$ - (17) iusticia] iustitia $Z F$ - (19) Cappellana] Capellana $Z F$ - (25) non ... occubuisse] non propter tumultum occubuit $Z F$

13 Johannes Oekolampad (1482-1531), Basler Reformator, vgl. TRE XXV 29-36.

14 Vgl. Cic. off. 2,9,34 (Miller 202): »[...] prudentia sine iustitia nihil ualet.«

15 Die Passage, auf die Bullinger hinweist, findet sich vielmehr in Plat. Menex. 246e-247a

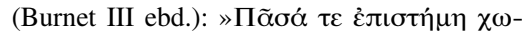


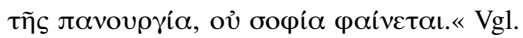
Cic. off. 1,19,63 (Miller 64): »Praeclarum igitur illud Platonis: >[...] scientia, quae est remota ab iustitia, calliditas potius quam sapientia est appellanda<.«

16 Bullinger spielt auf den Tod Zwinglis am 11. Oktober 1531, während der Schlacht bei Kappel am Albis, an. 
ne an tumultus fuerit, scribam, cum quod nihil istius ignores, tum quod praelo potissima eius generis ante acceptam cladem a clarissimo nostro senatu Tigurino in lucem aedita sunt. ${ }^{17}$ Hoc adiiciam: interitum qualemcunque tandem vel fidem vel doctrinam neque probare neque improbare posse. Videas enim homines impiissimos faustissimis excedere fatis; rursus videas optimos quosque viros a pessimis mortalium inhonestissimo fere mortis genere extingui. Isaias enim, omnium prophetarum princeps, serra dissectus sub prophetarum latrone Manasse occubuit. ${ }^{18}$ Ieremias ${ }^{19}$ prophetarum constantissimus et Zacharias ${ }^{20}$ longe fidelissimus a sceleratissimis mortalium lapidati sunt. Quid praeterea commemorem Ioannem Zachariae filium, quo sanctior alius a mulieribus nemo prognatus est? Quid vas electionis Paulum nostrum? Quorum ille consilio turpissimi scorti ab omnium impurissimo Herode etiam in carcere caesus, ${ }^{21}$ hic vero, ceu publicae pacis interturbator ab omnium, qui sunt et fuerunt, crudelissimo latrone Domitio Nerone $^{22}$ truncatus est capite. ${ }^{23}$ Interim vero nemo nisi impiissimus quisque doctrinam et vitam istorum propter supplicia posuit in dubium. Cur ergo isti 15 Zuinglii nostri interitum trahunt ad damnationem fidei eius $\mid$ et doctrinae? Cum satis constet in iis a piis desiderari nihil. An vero obliti sunt verborum domini? »Si me persecuti sunt, et vos persequentur« [Joh 15,20]. Item: »Veniet tempus, ut quisquis interficiat vos, videatur cultum praestare deo« [Joh 16,2]. An ignorant, quod »per multas afflictiones oporteat nos intrare in regnum dei« [Apg 14,22]? 20 An vero evangelium ita orbi praedicabunt, ut nihil patiantur, semper placeant, neminem offendant, delitiis fruantur et securi sequacibus securitatem polliceantur? Novus sane praedicandi modus, prophetis et apostolis incognitus; illi enim omnium hominum odia in se suscipientes clamabant: »Si hominibus placuissemus, servi dei nequaquam essemus « [Gal 1,10], et: »Qui iuxta faciem volunt 25 placere in carne, cogunt vos circuncidi, tantum ne ob crucem Christi persecutionem patiantur « [Gal 6,12]. Quod si aliud sentiunt isti, cur, obsecro, nos adeo vilipendimur, idque eo potissimum nomine, quod ab hostibus veritatis affligimur, contumeliis afficimur, substantia nostra exuimur, caedimur et quotidie mortis expectatione angimur? Cur indies minantur interituros etiam superstites eius (ut 30 aiunt) sectae viros? Quasi vero ipsi doctrinae genus invenerint, cui qui adhaereat, extra omnem teli iactum ${ }^{24}$ constiterit. At mihi crede, illustrissime princeps, non ea

Z. (22) delitiis] deliciis $Z F-(26)$ circuncidi] circumcidi $Z F$

17 Vgl. Kurtz. Ber.

18 Der Überlieferung nach ließ König Manasse den Propheten Jesaja zersägen, vgl. Hier. in Is. 15,57,1-2 (CCSL LXXIIIA 641,52-54): »[...] Esaiam de sua prophetare morte, quod serrandus sit a Manasse serra lignea, quae apud eos certissima traditio est.«

19 Vgl. Hier. adv. Iovin. 2,37 (PL XXIII 350C):
»Jeremias captivitatem nuntians, lapidatus a populo. «

20 2Chr 24,20f.

Mt 14,3-10.

22 Nero, römischer Kaiser 54-68 n. Chr., vgl. NP VIII 851-855.

23 Hier. vir. ill. 5 (PL XXIII 647B).

24 Erasm. adag. 293 (ASD II/1 398,330f.): » 
sunt nostra tempora, quae lenitatem et securitatem mereantur, neque tales hodie sumus, qui liberam veritatem ferre aut possimus aut velimus. Cum itaque nobis, | qui verbo praesumus, cum mundo (nemo enim piis probari vetat) tam bene conveniat, verendum est plurima a nobis per adulationem fieri et multo plura per 5 ignavum timorem omitti. Et ut libere tecum loquar, princeps clementissime, id non minus timendum est, eo res nostras brevi deventuras, ut communibus votis optemus nos una cum iis, quos nunc diris devovemus illa clade Capellana interceptos, dicamusque eos esse foelicissimos, quibus pro veritate et patria fortiter oppetere contigit, quod miseri longe crudeliora tandem per universam Germaniam experiri cogemur. Atque utinam vanus sim vates! Atqui scriptura prodit Iosiae quoque temporibus legis librum esse repertum, ${ }^{25}$ prophetiam quoque / una cum vero dei cultu restitutam, ${ }^{26}$ at nihilominus paucis post annis sanctissimum regem Iosiam impiissimi idololatrae Nechaonis ${ }^{27}$ manu esse interfectum, ${ }^{28}$ adeoque eum esse interfectum, qui oraculo a domino acceperat: »Quoniam audisti 15 legem et humiliatus es in conspectu dei, ego quoque exaudivi te et colligam te ad patres tuos, nec videbunt oculi tui malum, quod ego inducturus sum super locum istum « [2Kön 22,19f.]. Siquidem non multis post annis maxima et principum et populi strage Hierusalem urbium laudatissima ab impiis direpta, incensa et funditus excisa est. Caussam istis reddidit Ieremias in 16.: »Eo, quod patres vestri 20 dereliquerunt me, ait dominus, et secuti sunt deos alienos, quos et coluerunt et ado|raverunt, me autem deseruerunt et legem meam non custodierunt; vos quoque sceleribus vestris malitiam patrum vestrorum superavistis. Quisque enim vestrum sequitur pravas cogitationes cordis sui mali, quo minus mihi pareat « [Jer 16,11f.]. Quibus si nostra conferamus tempora, quid, oro, similius? Restituta enim est lex domini, sed pereunt protinus optimi viri. Et quid postea? Praedicatur equidem alicubi veritas, sed ea nihilosetius una cum deo floccipenditur. Nam ex prophetis alii quidem in papa mendacium prophetant, alii vero, qui a veritate stare videntur, ea parte plus, quam decet, muti sunt, qua tamen maxime vocales esse oportebat. Siquidem de charitate, lenitate et divina miseratione suaviter et maximo vulgi plausu commentantur, ubi de iusticia disserendum erat eaque severiter protrahenda scelera, quibus totus orbis hodie scatet. Ipse enim magistratus, cuius erat aequitatem et iusticiam colere, partim innocentes veritatis nomine in exilium pellit et iugulat, veritatem ipsam proscribit et sanguine civium vivit, partim religionem simulat, ideoque et iudicium et iusticiam negligit, imo et ipse vim 35 facit, personas suscipit, perpotat, scortatur, luxu vestium, alea, immoderatis ve-

Z. (8) foelicissimos] felicissimos $Z F-(34)$ iusticiam] iustitiam $Z F$

tra telorum iactum< pro eo, quod est: in tuto citraque periculum. $«$

25 2Kön $22,8$.

26 2Kön 23,2f.21-23.
27 Necho II., ägyptischer König (Pharao) der 26. Dynastie (610-595 v. Chr.), vgl. NP VIII $781 f$. 28 2Kön 23,29. 
nationibus, fastu et pompa concoquit, quicquid in publico erat aerario, deinde vero novis exactionibus, alienis bellis et malis artibus totas populi enervat cum vires tum opes. Populus quoque ipse frau|dat, mentitur, iurat et peiurat, potat et nihilo segnius luxu dissipat, quod malis artibus collegerat. Interea vero omnes suaviter commentamur de evangelio, sed nemo vitam mutat in melius, nemo ita, ut decebat, accusat scelera, nemo protrahit et conficit. Quid autem dicam de monopolis, crematistis, publicanis et usurariis, qui omnes suas illas iniquitatis radices tam alte egerunt, ut annosam quercum minori negotio evellas, ${ }^{29}$ quam istos redigas in ordinem? Hi impune totum orbem expilant; in horum manibus sunt totius orbis negotiationes et thesauri cumque eo per furtum, fraudem et rapinam evecti sint, nemo tamen ex illis, qui christianae religionis columina videri volunt, se illis vel mediocriter opponit. Ita fit, ut vi quadam res nostrae agantur, pauperes opprimantur »ipseque iudex«, ut propheta ait, »in reddendo« [Mi 7,3] sit. Quid ergo nobis nisi communis aliqua pestis, vel Nabuchodonosor ${ }^{30}$ vel Sanherib ${ }^{31}$ vel Antiochus ${ }^{32}$ vel alia generis humani lues, expectanda, quae 15 semel ferro et flamma, fame et peste execrabilem hanc terram lustret? Quod ergo Zuinglium sustulit dominus, quod cum eo tot sanctos, tot probos, tot doctos, tot patritios et senatores, tot denique innocentes cives et colonos una hora sustulit, nimirum omine et divino quodam consilio factum est, proculdubio quod graviora, ni prorsus convertamur, miseros nos maneant. Ut nunc ea clades te malgis ani- 20 A7r $F$ mare, quam a sancto instituto debeat retrahere.

Neglecta itaque quorundam dicacitate memineris, inclyte princeps, verborum domini tui, quibus cultores suos affatur et ait: »Venite ad me omnes, qui laboratis et onerati estis, et ego reficiam vos. Tollite iugum meum super vos et discite a me, quod mitis sim et humilis corde, et invenietis requiem animabus vestris. Iugum 25 enim meum commodum est et onus meum leve est « [Mt 11,28-30]. Equidem, quod nos attinet, libere hoc de veritate et benignitate domini cum gratiarumactione referre possumus, quod ecclesiae nostrae in mediis afflictionum procellis nunquam defuit, sed perinde suos animavit, imo ne nunc quidem deserit. Siqui-

\section{Z. (2) alienis] exteris $Z F$}

29 Vgl. Erasm. adag. 343 (ASD II/1 444,893897): »Annosam arborem transplantare. [...] In eos dicitur, qui sera atque exacta iam aetate conantur dediscere, quibus diu iuuenes assueuerint. Aut simpliciter de iis, quae frustra molimur, neque enim loco mouenda arbor, vbi iam alte fixerit radices, sed cum plantula adhuc est.«

30 Nebukadnezar (Nabû-kudurri-usur) II., neubabylonischer König von 605 bis 562 v. Chr. Unter seiner Herrschaft wurde 597 und 587/86 Jerusalem erobert. Vgl. NP VIII 780.
31 Sanherib (Sin-ahhe-eriba), assyrischer König von 705 bis 681 v. Chr. 701 unternahm er einen Feldzug gegen Phönizien und Palästina, der in einer Belagerung Jerusalems kulminierte, vgl. NP XI 39.

32 Antiochos IV. Epiphanes (gest. 164 v. Chr.), König des Seleukidenreiches. Seine Bemühungen um eine Hellenisierung Jerusalems führten 166 v.Chr. zum Makkabäeraufstand, vgl. NP I 769.

\section{5}


dem senatus noster perstat, perstat et prophetia, perstant leges quoque adversus papismum et luxum aeditae. Perstat et populus atque utinam sic benefacere pergat dominus. Patri itaque tam potenti et benigno te quoque totum trade, veritatem eius cole, in hac persta, huic immorere. Id si feceris, illud sane praestiteris, quod

5 Paulus tota hac ad Hebraeos epistola ambit, quam ita, ut nostris illustrata est commentariis, tuo nomini voluimus dicatam. Dominus Iesus confirmet te spiritu suo sancto. Amen.

Tiguri, 17. Augusti 1532.

10 Heinrychus Utingerus ${ }^{33}$ et Werdherus Steinerius, ${ }^{34}$ viri pietate clari et ad promovenda honesta studia promptissimi, non modo ad hoc laboris capescendum fortiter animarunt, sed et hoc a me impetrarunt, ut Paulinis locos nonnullos communes inseruerim, quorum pariter omnium indicem sive catalogum subiicere volui et te impense obtestari, ut omnia legas cum iudicio et, sicubi a catholica veritate aberravero, discendas, si vero mentem Pauli assecutus fuero, mecum deo gratias agas. Vale.

\section{Catalogus.}

De foedere seu testamento veteri et novo [Hebr 8,8-12].

Quomodo ad nos perlatum evangelium et quae eius authoritas [Hebr 2,3f.].

20 Catechismus apostolorum [Hebr 6,1f.].

Quae evidentissima scripturae expositio [Hebr 4,11].

Contemptus verbi dei [Hebr 3,7-4,13].

De exemplo patrum [Hebr 3,7-11; 11,4-32].

De usu legis et eius abrogatione [Hebr 7,13-19].

25 De unitate et trinitate dei [Hebr 1,3].

De dextera dei [Hebr 1,3].

A8r $F \quad$ De iureiurando et veritate dei [Hebr 6,16-18].

Z. (9-S. 10.14) Lectori ... patientia] om. ZF

33 Heinrich Utinger (ca. 1470-1536), enger Mitarbeiter Zwinglis und Schlüsselfigur der Zürcher Reformation, war u.a. Kustos des Großmünsterstiftes, vgl. HBBW II 98.

34 Werner Steiner (1492-1542), Chorherr in Be- romünster und Prediger in Luzern und Zug, siedelte 1529 infolge seines offenen Bekenntnisses zur Reformation nach Zürich über, vgl. HBBW I 45; HLS XI 878. 
Cui debeatur oratio [Hebr 5,7].

De angelis [Hebr 1,14].

Christus verus deus et homo [Hebr 1-2].

Christus mediator et intercessor [Hebr 4,14-16].

Christus sacerdos [Hebr 5,1-10; 7f.].

Christus sacrificium [Hebr 9f.].

Remissio et expiatio peccatorum [Hebr 1,3].

De vera fide [Hebr 10f.].

De ecclesia Christi [Hebr 3,6].

De tabernaculo Mosi [Hebr 9,2-5].

De iis, quae erant in tabernaculo [Hebr 9,2-5].

De vocatione ad sacerdotium [Hebr 5,1-6].

De sacramentis, usu et abusu eorum [Hebr 9,8-10; 10,15-18].

De constantia et patientia [Hebr 12,1-17].

Qui authores sibi sumunt exponendos, multa praefari solent de laudibus eius, quem quisque sibi enarrandum delegit, item de consilio autoris, phrasi et dicendi genere. Aggressurus ergo expositionem epistolae Pauli ad Hebraeos, lectores remitto ad Lucae libellum »de actibus apostolicis « praetitulatum et ad Chrysos- 20 tomi ${ }^{35}$ homelias de laudibus Pauli erudite ac copiose conscriptas. ${ }^{36}$ Ego enim in praesentiarum de authore huius epistolae dicam, quandoquidem de eo dubitari video. Deinde vero paucula per argumentum de consilio Pauli deque scripti genere adiitiam. Et de authore quidem huius epistolae haec habemus.

| De authore huius epistolae.

Qui hanc epistolam Paulo adimunt, istis niti videntur. ${ }^{37}$ Principio sunt in hac (inquiunt) nonnulla veterum haeresum patrocinia, maxime in sexto ${ }^{38}$ ubi Novatianicam ${ }^{39}$ caussam plurimum iuvisse creditur. $^{40}$ Deinde quod multo tempore a

35 Johannes Chrysostomos (ca. 349-407), ab 397 Erzbischof von Konstantinopel, gilt als der hervorragendste Prediger in der Geschichte der Ostkirche, vgl. TRE XVII 118-127; NP V $1059 \mathrm{f}$.

36 Chrys. laud. Vgl. Chrys. laud. transl.

37 Die folgenden Einwände gegen die Zuschreibung des Hebräerbriefes an Paulus werden auch - allerdings in knapperer Form und in anderer Anordnung - in Bull. vorl. Hebr. (Berg/Hausammann 138-140) besprochen.

38 Hebr 6,6.

39 Novatianus (um 250 n. Chr.), römischer christlicher Theologe und Initiator einer rigoristischen Bewegung, die später als häretisch verurteilt wurde, vgl. NP VIII 1021. 
Latinis non est recepta, utpote quae et veteribus semper fuerit suspecta. ${ }^{41}$ Rursus quod nomen Pauli pro more omnium epistolarum non praemittat. ${ }^{42}$ Neque stilum neque orationis Paulinae refereat characterem. ${ }^{43}$ Maxime vero quod hic author in secundo testatur capite evangelium sese ab apostolis didicisse, ${ }^{44}$ cum interim 5 Paulus in Galatis id neget ac perneget. ${ }^{45}$ Haec, inquam, illorum fulcra sunt. Nam quod alii hoc obiiciunt epicherematis, ${ }^{46}$ Ambrosium $^{47}$ in omnes scripsisse Pauli epistolas, in hanc unam non scripsisse, unde consentaneum sit eam non esse Pauli, facile ipsa Ambrosii authoritate diluitur. Is enim huius epistolae testimoniis passim citatis utitur in reb[us] quoque ad religionem spectantibus non postremis, quin et ipse eam Paulo videtur adscribere. ${ }^{48}$ Nos ad caetera properabimus, ut ea paulo diligentius excutiamus.

Et initio si libris sacris ideo sua est infirmata authoritas, quod eorum abutuntur An Novati testimoniis haeretici, quis non videat novi testamenti primarium codicem, Ioannis videlicet evangelion, prorsus obsolevisse? Hinc enim arma sibi tota Arrianorum ${ }^{49}$ phalanx acce|pit. Atqui sanis abusi sunt testimoniis, itaque immota manet sua sacris authoritas. Videtur autem (id quod ex hac mihi subolet obiectione) eo tempore id accidisse Hebraeorum epistolae, quod nostris temporibus ${ }^{50}$ Iacobinae, quam multi nostrorum Iacobo ademerunt apostolo nulla alia caussa, nisi quod Nazaraeis, quos et Minaeos vocavit Hieronymus, ${ }^{51}$ favere videretur, qui iusticiam

Z. (3) refereat] referat $Z F$ - (3) characterem] charactarem $F$ - (9) reb[us]] rebus $Z F$ - (19) iusticiam] iustitiam $Z F$

Erasm. Hebr. (ASD VI/10 298-300,894-897): »Hic quoque locus [sc. Hebr 6,6] in causa fuit, quo minus haec epistola Pauli putaretur nonnullis, quod id videatur asserere, quod a nonnullis haereticis defensum est, si quis a baptismo relapsus esset in peccatum letale, hoc est in homicidium aut adulterium aut simile, non posse poenitentia restitui.«

41 Erasm. Hebr. (ASD VI/10 380,822f.; 382,869f.).

42 Erasm. Hebr. (ASD VI/10 380,815f.).

43 Erasm. Hebr. (ASD VI/10 378,811f.; 382,866868).

44 Hebr 2,3.

45 Gal 1,12 .

46 Mit »epicherema« (Epicheirem) wird eine Expansionsform des klassischen Syllogismus bezeichnet. Dabei können die Ober-, die Unterprämisse oder beide durch ein oder mehrere Stützargumente erweitert werden, vgl. Isid. orig. 2,9,16-18 (Lindsay I [G5]v-[G6]r); HWR II 1251-1258. An dieser Stelle scheint Bullinger diesen Begriff allerdings etwa in der Bedeutung von »Argumentationszusatz« zu verwenden.
47 Ambrosius (ca. 340-397), ab 374 Bischof von Mailand, Autor zahlreicher exegetischer, theologischer und ethischer Schriften. Vgl. TRE II 362-386; NP I 582-584.

48 Erasm. Hebr. (ASD VI/10 382,864f.): »Ambrosius licet in hanc vnam non aediderit commentarios, tamen eius testimoniis non infrequenter vtitur et videtur eam Paulo tribuere.«

49 Arius (ca. 280-336), Presbyter in Alexandria. Seiner Leugnung der Göttlichkeit Jesu Christi wegen wurde er vom Konzil von Nizäa (325) verurteilt. Vgl. TRE III 692-719.

50 Bullinger spielt hier auf die Infragestellung der Kanonizität des Jakobusbriefes durch Martin Luther an, vgl. Luth. vorr. 384,7-18.

51 Hieronymus Stridonensis (gest. 419/420), Kirchenvater, Bibelübersetzer und Exeget, vgl. TRE XV 304-315; NP V 548-551. Vgl. Hier. epist. 112,13 (CSEL LV 381,24-382,2): »Usque hodie per totas orientis synagogas inter Iudaeos heresis est, quae dicitur Minaeorum et a phariseis huc usque damnatur, quos uulgo Nazaraeos nuncupant, qui credunt in Christum, filium dei natum de Maria uirgine, et eum dicunt esse, qui sub Pontio Pilato et pas- partes hac epistola defendantur. 
non fidei, sed hominum tribuunt operibus. ${ }^{52}$ Cum tamen in hoc prorsus non sit apostolus. Neque enim sibi probandum sumpsit opera iustificare, sed fidem sine operibus non esse fidem quin magis vanam opinionem. Unde mira gratia operibus tribuit per alloeosim, ${ }^{53}$ quod fidei revera tribuendum erat. Aut certe per fidem $\varkappa \alpha \tau \alpha \chi \rho \iota \sigma \tau \varkappa \tilde{\omega} \varsigma^{54}$ intellexit non fidem veram, sed opinionem falsam, sicut per opera fidem operantem. Id quod illi non viderunt, ut ne nostri quidem intelligunt, apostolum in huius epistolae 6. cap[ite] Novati partes nihil iuvisse, sed longe aliud spectasse, sicuti palam eo loci demonstrabimus. ${ }^{55}$ Ideoque nihil in hac re probabunt, qui sectam obiecere Novatianicam. Adde, quod temeritaris notam effugere non potest, qui propter unum aut alterum locum minus intellectum, 10 prorsus negligit et abiicit optimum authorem.

Veterum de hac epistola iudicium. Latini.

Et de Latinis, qui hanc non receperint epistolam, quid dicam aliud, quam quod apud Latinos Novati secta primum et coeperit et efferbuerit? Quemadmo|dum videre est apud d[ivum] Cecilium Cyprianum. ${ }^{56}$ Itaque cum Novatiani non parum niterentur huius epistolae cap[iti] 6. idque plaerisque catholicis facesseret nego- 15 tium totaque ista tragoedia mox inter prima oriretur ecclesiae initia, factum est, ut etiam inter initia Latinae ecclesiae haec epistola ab aliis male audierit, ab aliis vero prorsus contempta sit, nempe ne eius patrocinio impia evinceret Catharorum

Graeci. secta. Deinde constat Graecorum ecclesiam semper fuisse florentiorem, utpote ex qua in nostros defluxerit, quicquid apud nos solidae invenias eruditio|nis. Quis 20 enim nescit d[ivos] Ambrosium et Hieronymum, duo Latinae ecclesiae lumina, ex Graecis, Origene ${ }^{57}$ potissimum, omnem pene sacrarum accepisse cognitionem? Si itaque Graeci de hac bene senserint epistola, minus urgebit nos Latinorum iudicium, quod interim d[ivi] Hieronymi testimonio, non omni prorsus parte nobis adversum esse comprobabimus. Prius tamen videbimus, quidnam scripse- 25 rint Graeci, quo simul et hoc elucescat, veterum primarios quosque de hac epistola ut Pauli semper pronunciasse, etiam si quorundam Latinorum non nescierint nec dissimularint contrarium iudicium. Eusebius ergo Caesariensis, ${ }^{58}$

Z. (14) Cecilium] Caecilium $Z F$ - (15) cap[iti]] capiti $Z F$ - (15) plaerisque] plerisque $Z F$ - (20) solidae] solide $F$

sus est et resurrexit, in quem et nos credimus, sed, dum uolunt et Iudaei esse et Christiani, nec Iudaei sunt nec Christiani.«

52 Vgl. Hier. in Ezech. 4,16,16 (CCSL LXXV 182,1473f.).

53 Unter »Alloiosis« versteht man die »Umbildung einer gebräuchlichen sprachlichen Struktur durch Einsetzung ähnlicher, aber von der syntaktischen oder semantischen Norm abweichender Formen und Ausdrücke « (HWR I 415-417).

54 Vgl. Quint. inst. 8,6,34 (Winterbottom II 469): $»[\ldots]$ catachresis, quam recte dicimus abusi- onem, quae non habentibus nomen suum accomodat quod in proximo est «; Erasm. cop. 1,19 (ASD I/6 66).

55 Siehe unten S. 81-83.

56 Cypr. epist. 52,2,1-3 (CCSL IIIB 245-247). Zu Cyprian (ca 200-258), ab 248 Bischof von Karthago, vgl. TRE VIII 246-254; RGG $^{4}$ II 508f.

57 Origenes (185/6-254), christlicher Theologe, Autor zahlreicher exegetischer Schriften sowie von »De principiis«, der ersten systematischen Gesamtdarstellung christlicher Lehre, vgl. TRE XXV 397-420; Quasten II 37-101. 
eruditissimus idemque diligentissimus vetustatis indagator, hoc negotium sic collegit et absolvit, ut Minervam sus erudierit, ${ }^{59}$ si post virum tantum quisquam idem tentarit. Is, inquam, de Clemente ${ }^{60}$ Pauli discipulo scri|bens Ecclesiast[icae] Clemens. histo[riae] lib[ro] 3., cap[ite] 38.: »Clemens«, inquit, »in epistola, quam Corin5 thiis scribit, meminit epistolae Pauli ad Hebraeos et utitur eius testimoniis. $\ll^{61}$ Rursus in 6., cap[ite] 11. Alexandrini Clementis ${ }^{62}$ mentionem faciens: »De epistola vero ad Hebraeos«, inquit, »ita disserit, quod manifeste Pauli sit apostoli, scripta sit autem Hebraeo sermone tanquam Hebraeis, a Luca vero, qui erat Pauli discipulus, interpretata in Graecum; unde et stilus eius magis similis videatur libello illi, quem Lucas de apostolorum actibus scripsit. « ${ }^{63}$ Item in eodem, cap[ite] 18. canonem edisserens, quem in sacris libris posuerit Origenes, quatu- Origenes. ordecim numerat canonicas Pauli epistolas, mox adiiciens: »Quamvis et nonnulli de ea, quae ad Hebraeos scripta est, dubitaverint pro eo, quod non videatur in ea servari eius illa sententia, quam de se ipse pronunciat, dicens se imperitum esse 15 sermone. Sed ego dico, sicut mihi a maioribus traditum est, quia manifestissime Pauli est, et semper omnes antiqui maiores nostri ita eam ut Pauli epistolam susceperunt. « ${ }^{64}$ Meminit idem Eusebius Irenaei ${ }^{65}$ Lugdunensis Galliarum epi- Irenaeus. scopi (de quo multi dubitant Graece scripserit, an Latine), qui plurima de epistola ad Hebraeos in suis dialogis »De diversis « conscriptos ponat testimonia. ${ }^{66}$ Ipse Eusebius.

20 denique author noster Eusebius non uno loco tribuit hanc epistolam Paulo. Nam in 3., cap[ite] 25. recensens libros novi testamenti, quorum aliquando suspecta fue |rit authoritas, huius ad Hebraeos epistolae plane non meminit. ${ }^{67}$ Et in capite 3 . veluti contemnens Latinorum iudicium: »Pauli quoque«, inquit, »manifeste quatuordecim sunt epistolae, quae in authoritate habentur, licet sciam apud Latinos de epistola, quae ad Hebraeos scribitur, haberi dubitationem. ${ }^{68}$ His iam accedit Hieronymus.

\section{Z. (4) histo[riae]] hist[oriae] $Z F-(22)$ capite] cap[ite] $Z F$}

58 Eusebius (ca. 260-340), ab 313 Bischof von Cäsarea, Theologe und Kirchenhistoriker, vgl. TRE X 537-543; NP IV 309f.

59 Erasm. adag. 4 (ASD II/1 154,215-217): »Sus Mineruam, subaudiendum $>$ docet $<$ aut $>$ monet $<$, dici solitum, quoties indoctus quispiam atque insulsus eum docere conatur, a quo sit ipse magis docendus. $\ll$

60 Clemens (2. Jh. n. Chr. [?]), traditionell als der dritte Bischof von Rom betrachtet. Ihm werden verschiedene Schriften zugeschrieben, u.a. der bei Eusebius erwähnte »Brief an die Korinther « (Quasten I 43-51). Vgl. NP III $28 \mathrm{f}$.

61 Euseb. hist. eccl. 3,38,1 (GCS IX/1 285,3-5).

62 Titus Flavius Clemens von Alexandria (gest. vor 215/221 n. Chr.), christlicher Philosoph, Lehrer an der alexandrinischen Katechume- nenschule und Begründer der auf griechischer Bildung beruhenden theologischen Literatur. Vgl. NP III 30f.; Quasten II 5-35.

63 Euseb. hist. eccl. 6,14,2 (GCS IX/2 551,1-5).

64 Euseb. hist. eccl. 6,25,11-13 (GCS IX/2 579,1-6).

65 Irenäus (2. Jh.), Theologe und Bischof von Lyon, Autor des antignostischen Traktats »Adversus haereses «, vgl. TRE XVI 258-268; NP III 919-921. Die von Eusebius erwähnte Schrift, bei der es sich vermutlich um eine Sammlung von Predigten hendelte (vgl. Quasten I 293), ist verschollen.

66 Euseb. hist. eccl. 5,26 (GCS IX/1 499,11f.).

67 Euseb. hist. eccl. 3,25,3-5 (GCS IX/1 251,20253,7)

68 Euseb. hist. eccl. 3,3,5 (GCS IX/1 191,9-12). 
et Hieronymi, in Latinorum ecclesia non postremi doctoris, quam supra polliciti sumus, sententia, qui ad Dardanum ${ }^{69}$ de terra promissionis disserens: »Illud nostris dicendum est «, inquit, »hanc epistolam, quae inscribitur ad Hebraeos, non solum ab ecclesiis orientis, sed ab omnibus retro ecclesiis Graeci sermonis scriptoribus quasi Pauli apostoli suscipi, licet plerique eam vel Barnabae vel Clementis arbitrentur, et nihil interesse, cuius sit, cum ecclesiastici viri sit et quotidie ecclesiarum lectione celebretur. Quod si eam Latinorum consuetudo non recipit inter scripturas canonicas, nec Graecorum quidem ecclesiae Apocalypsim Ioannis eadem libertate suscipiunt, et tamen nos utraque suscipimus nequaquam huius temporis consuetudinem, sed veterum scriptorum authoritatem sequentes, 10 qui plerunque utriusque utuntur testimoniis, non ut interdum de apocryphis facere solent, quippe qui et gentilium literarum non raro utantur exemplis, sed quasi canonicis et ecclesiasticis. ${ }^{70}$ Et hoc quidem d[ivi] Hieronymi de hac epistola ad Hebraeos iudicium est. Quod, ut Latinorum, qui hanc | epistolam Paulo adimebant, non accedit, ita eandem vehementer probavit et tanquam canonicam ec- 15 clesiae commendavit. Et hactenus veterum sententias retulimus, ex quibus satis elucere putamus veterum primarios quosque optime de epistola Pauli ad Hebraeos sensisse eamque Paulo adscripsisse apostolo. Ut illi nunc satis imprudenter pronunciarint, qui dixere veteres semper de hac dubitasse maleque pronunciasse epistola.

De nomine autem Pauli omisso, quod illi in abdicationis traxere argumentum, disseruit et Eusebius ex sententia Alexandrini Clementis dicens: »Quod autem superscriptionem solitam inibi non habet, id est Paulus apostolus, hoc esse rationis ostendit, quia praeiudicatum Hebraeis erat de Pauli nomine, ne eius dicta susciperent, et iccirco prudenter declinasse, ne statim in principio Pauli nomine inspecto lectio eius repudiaretur. $«^{71} \mid$ Haec Clemens apud Eusebium. Et sane scimus Paulum omnibus factum omnia et omnium in se mores suscepisse, ut omnes Christo lucrifaceret. ${ }^{72}$ Athenis enim longe alio modo aliaque ratione de pietate disserit quam apud Antiochenos. Nam ibi agit pro more gentilitio, gentilem allegans Aratum ${ }^{73}$ et a gentilium ordiens sacris. ${ }^{74}$ Hic vero, tanquam apud 30 Iudaeos rem acturus, a deo et patribus, Iudaeorum delitiis, auspicatur dicens: »Deus populi huius « [Apg 13,17] etc. Sed et totam orationem propheticis firmat oraculis. Sic et hanc | epistolam pro sancta sua vafricie a deo orditur et patribus sanctisque scripturis totam confirmat. Quo fit, ut omissus titulus magis iuvet caussam nostram, quam infirmet. 5 
Iam vero de stilo huius epistolae disputatum est apud veteres quoque. Audiv- De stilo Pauli. imus enim Clementis Alexandrini super hac re sententiam. Origenes vero: »Si vero«, inquit, »requiras a me, per quem sit epistolae sermo compositus, opinio ad nos usque pervenit eiusmodi: a quibusdam dicebatur, quod Clemens, apostolorum 5 discipulus et episcopus urbis Romae, Graeco eam sermone, non tamen sensibus expoliverit; alii, quod Lucas, qui evangelium scripserit et Actus apostolorum. ${ }^{75}$ Cui non dissimile est Eusebii iudicium in hunc modum perscriptum: »Constat sane, quod apostolus tanquam Hebraeis mittendam patrio eam sermone conscripserit et (ut quidam tradunt) Lucam evangelistam, alii autem Clementem 10 interpretatum esse, quod et magis verum est, quia et stilus epistolae, quae ad Corinthios extat huius Clementis, cum hac concordat et sensus nimirum utriusque scripturae plurimam similitudinem ferunt. $\ll^{76}$ Huius sententiae est Hieronymus quoque in opusculo de viris illustribus. ${ }^{77}$ Quod, si exactius negotium hoc perpendas, videbis istos non prorsus vanos fuisse vates. Nescio enim, si post unam notarios scripsit, id quod clarissime liquet ex Romanorum epistola, quam ex sententia Pauli scripsit Tertius. ${ }^{78}$ Hic autem fieri solet, ut materia et inventio authoris sit veri, eloqutio autem aut character notarii vel librarii. ${ }^{79} \mathrm{Cum}$ igitur verisimile sit Paulum nec notariis semper dictavisse nec uno semper usum esse 20 notario, sed pluribus, ut sese et comitum et regionum offerebat occasio, certe nemini novum videri debet amplius, si non sit unus omnium epistolarum Pauli stilus. Proinde stili dissimilitudo ad abdicationis argumentum trahi non potest, nisi et eam, quae ad Ephesios scripta est epistolam, ob stili dissimilitudinem Paulino nomini subtrahere velis. Nam de ea sic censuit Erasmus ille Roterodamus: »Certe stilus huius epistolae tantum dissonat a caeteris Pauli epistolis, ut alterius videri possit, nisi pectus atque indoles Paulinae mentis hanc prorsus illi vindicaret. $\ll^{80}$ At de hac nostra ad Hebraeos epistola idem sic scripsit: »Et ut a stilo Pauli, quod ad phrasim attinet, longe lateque discrepat, ita ad spiritum ac pectus Paulinum vehementer accedit. $\ll^{81}$ Sed haec hactenus.

Illi porro nulla prorsus videntur venia digni, qui sic colligunt: authorem huius Nodus 2. epistolae testari se ab apostolis didicisse evangelium; sed Paulum apostolum id in $\begin{aligned} & \text { cap[itis] } \\ & \text { dissolvitur. }\end{aligned}$

Z. (18) eloqutio] eloquutio $Z F$

75 Euseb. hist. eccl. 6,25,14 (GCS IX/2 579,611).

76 Euseb. hist. eccl. 3,38,2f. (GCS IX/1 285,5$10)$.

77 Hier. vir. ill. 5 (PL XXIII 647C-650A).

78 Röm 16,22.

79 Vgl. Bull. vorl. Hebr. (Berg/Hausammann 140): »Inventio authoris est, at eloquutio et dispositio scribae.« Zur Unterscheidung zwi- schen »inventio« und »elocutio« vgl. Cic. inv. 1,9 (Hubbell 18-20): »Inventio est excogitatio rerum verarum aut veri similium, quae causam probabilem reddant; [...] elocutio est idoneorum verborum ad inventionem accommodatio.«

80 Erasm. Eph. (ASD VI/9 162,7-9).

81 Erasm. Hebr. (ASD VI/10 378,811-813). 
Galatis negare; ${ }^{82}$ unde consequatur hanc epistolam non esse ullius apostoli, nedum Pauli, sed alicu|ius apostolici. ${ }^{83}$ Sed nos scire cupimus, ubi nam istud testetur epistolae author? Respondent: in 2. cap[ite], cum dicit: »Quae cum primum enarrari coeperint per ipsum dominum, ab iis, qui audierant, in nos confirmata sunt « [Hebr 2,3]. »Audis«, inquiunt, »ab iis, qui audierant.« Sed non vident miseri particulam »ab iis «, cui stolidissime innituntur, non esse consequentiae ex alio notam, sed ordinis potius. Ut sit sensus: »Initio quidem evangelii negotium ab ipso domino praedicatum est, deinde ab iis, qui cum eo conversati erant, apostolis; ${ }^{84}$ postremo autem et post istos evangelii functio ad me quoque delata est.« Ut, inquam, hic idem ille ordo servetur, qui et in Corinthiis, cap[ite] 15. 10 servatus est, ubi legimus primum quidem apparuisse dominum Petro, deinde vero 12 apostolis, ab iis plusquam 500 fratribus, ${ }^{85} \gg$ postremo autem omnium «, inquit Paulus, »velut abortivo visus est et mihi« [1Kor 15,8]. Huc accedit, quod Gra-

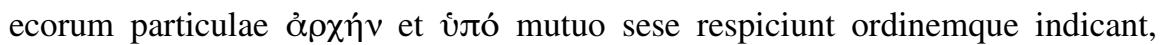
quemadmodum et apud Latinos »primum« et »secundum«. Quid quod illi non 15 vident $»$ ab iis « particulam idem pollere Latinis, quod particula »post hos «? Nam Latinus dicit: »Primo loco est Mauritania, ab hac Numidia, deinde vero Carthago.«Et Plinius: ${ }^{86} »$ Praecipuum «, inquit, »est stercus columbarum, proximum caprarum, ab hoc ovium. ${ }^{87}$ Quid quod etiam haec particula $\mid »$ in nos « non tam ad Pauli quam totius ecclesiae referri poterat personam?

Sed hactenus ad istorum obiectiones, quibus omnibus declarare voluimus istos

suis obiectionibus epistolam hanc Paulo non ademisse, quin potius veteres a nostris stare partibus, qui potamus verisimilius esse hanc epistolam a Paulo quam alio quoquam conscriptam. Et hanc sententiam iuvant ea quoque, quae scripsit in fine cap[itis] 10, ubi meminit persequutionis et vinculorum prorsus in eum 25 modum, quem cernimus in 1. ad Philip[penses] cap[ite] et in 1. ad Thess[alonicenses] 2. capite servatum. ${ }^{88}$ Non enim referam in praesentiarum Timothei men-

Z. (25) cap[itis]] capitis $Z F-(25)$ persequutionis] persecutionis $Z F-(27)$ capite] cap[ite] $Z F$

82 Gal 1,12.

83 Vgl. Bug. Hebr. 116v: »Paulum non scripsisse hanc epistolam vel ex secundo capite palam est, ubi dicit se didicisse ex praedicatione aliorum et ex ostensione miraculorum evangelium Christi, id quod fortiter Paulus de se negat ad Gal[atas] 1.«

84 Vgl. Erasm. par. Hebr. (ASD VII/6 46,86-89).

851 Kor $15,5 f$.

86 Caius Plinius Secundus (der Ältere, 1. Jh. n. Chr.), römischer Historiker und Rhetor, vgl. NP IX 1135-1141.

87 Zit. nach Erasm. cop. 1,52 (ASD I/6 117,226f.); vgl. Plin. nat. 17,52 (Ianus/Mayhoff III $79,11 \mathrm{f}$.).
88 In Erasmus' Ausgabe des Neuen Testaments lautet Hebr 10,34 (ASD VI/4 304): »Tois

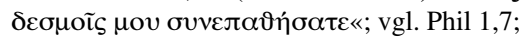
1Thess 2,2. Das hier von Bullinger zur Bestätigung der Echtheit des Hebräerbriefes vorgetragene Argument wird durch Erasmus scharf zurückgewiesen, vgl. Erasm. Hebr. (ASD VI/10 338,315-318): »Porro quod Laurentius [sc. Valla] arbitratur ex hoc potissimum verbulo doceri posse hanc epistolam esse Pauli, quod de vinculis suis meminerit, friuolum est, ne dicam ridiculum, quasi non omnes ferme apostolorum successores et adiutores in vinculis fuerint.«

\section{5}


tionem $^{89}$ et capitis ultimi rationem, quo apprime sese Pauli exerit genius. Et haec quidem copiosius disputavi propter eos, quibus curiositas magis cordi est quam pietas. Pii enim de hisce rebus non digladiantur. Maxime cum vident totam epistolam scriptura sacra firmari, Christum purius et melius doceri quam ulla alia, 5 denique totum christianismum hoc pulchrius ornari, quo firmius impugnatur Iudaica perfidia. Nolumus autem magnis pollicitationibus rem alias summam exaggerare. Confidimus enim ipsum epistolae genium et tractatum sic sese omnibus probaturum lectoribus, ut perlecta hac quisque per sese dicat nihil se legisse Paulo dignius conformiusve, nihil pulchrius, nihil pientius et canonicum magis.

10 Nunc ad argumentum accingimur epistolae.

Tria sunt, quae hac tractantur epistola. Principio enim monet, ne reiiciant Christum Iudaei neque aspernentur evangelii negotium per incredulitatem, quando- Evangelion. quidem angelis potentior sit et Mose maior, angelorum etiam dominus et deus 15 conditor, nihil interim elevante eius maiestatem humana natura, quam sibi ex Abrahae traxerit prosapia. Consyderent autem miserum maiorum suorum exemplum, quorum murmur, perfidia et incredulitas misere sit mulctata in deserto; ${ }^{90}$ unde consentaneum sit ipsos pessime nunc quoque habituros, si ipsum verbum dei vivum ipsumque dei filium perrexerint contemnere. Et haec agit per integra 20 prima quatuor capita, nimirum adversus eos sic perorans, qui Christum aspernantes obiiciebant: »Nos Mosi discipuli sumus, cui per angelos loquutus est deus; hunc vero Iesum, unde sit aut quis sit, nescimus, pergemus ergo in viis patrum nostrorum« [vgl. Joh 9,28f.]. Quo simul et infirmos primumque Christo ex Iudaismo initiatos et rudes a veritate avertebant evangelica; quos interim Paulus istis suis et firmare et in vera religione officioque retinere contendit. Deinde vero sacerdotium. velut hypotyposi quadam ob oculos ponit sacerdotium Aharonicum prorsus fuisse umbram, Christum autem verum esse sacerdotem, ab ipso deo iureiurando creatum, neque secundum ordinem Aharon, sed se|cundum ordinem Melchizedeck ordinatum, Levitis maiorem et meliorem, utpote cuius sacerdotium sit et ỏं $\alpha-$

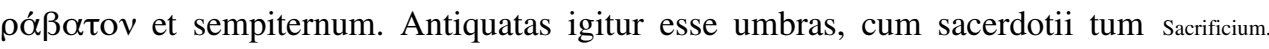
sacrificii. Quippe cum veterum sacrificia non minus quam sacerdotia fuerint inefficatia et typi Christi, qui sit vera hostia unica et sempiterna pro peccatis totius mundi. Haec autem doctissime simul et copiosissime tractat per initium cap[itis] 5. (nam in fine, et per integrum cap[ut] 6. digreditur) item per integrum

Z. (16) Consyderent] Considerent $Z F$ - (31) sacerdotia] sacerdotium $Z F$ - (32) inefficatia] inefficacia $Z F$ - (34) cap[itis]] capitis $Z F$ - (34) 6.] sextum $Z F$

89 Hebr 13,23 .

$90 \quad$ Num 14. 
cap[ut] 7., 8., 9. et decimi mediam partem. Plane adversus eos, qui nitebantur caeremoniis, sacerdotio et sacrificiis, qui clamitabant christiana religione omnem semel tolli divinum cultum, omnem vetustatem et gentis gloriam. His igitur commonstrat in Christo omnem esse plenitudinem et legis perfectionem, ut, qui Christum per fidem possideat, is dei gloriam et sacerdotem et hostiam absolutissime possideat.

Fides. Postremo adhibitis calcaribus ${ }^{91}$ urget eos ad fidendum Christo sacerdoti unico et hostiae perpetuae. Esse enim fidem illam omnium ab exordio mundi iustorum veterum veram religionem, qua illi deo servierint et in qua multa perstiterint patientia. Patientia ergo hic quoque opus esse et constantia, ad quam deinde multis hortatur exemplis, iudiciis, similibus. Nam mire torquebantur, qui a Mose desciverant ad Christum. Ad finem autem epistolae, | per integrum videlicet cap[ut] 13., appendicis loco subdit breves quosdam veluti aphorismos, sententias et institutiones. Hoc vero totius epistolae argumentum est.

Phrasis. Dictio vero pura est, gravis, dilucida, evidens et propria. Genus autem orationis 15 mixtum est. Nam epistolae medium genus agnoscit didacticum. Docet enim apostolus veluti demonstrativa contentione veterum umbras, quoad sacerdotium et sacrificium, prorsus abolitas, Christum vero esse verum sacerdotem et aeternam hostiam. At initium epistolae et finis sub genus referuntur deliberativum. Nam utraque parte hortatur: illic ne Christum reiiciant, hic autem in Christo 20 fidant et per patientiam in veritate persistant. $^{92}$

\section{| Prima epistolae pars.}

Ordinis ratio. Placuit autem, amice lector, epistolam hanc in tres partiri partes, idque perspicuitatis gratia et quod iam nunc diximus tria in universum hac pertractari epistola. Prima vero exhibebimus tibi praeclaram istam exhortationem, qua monet Iudaeos, 25 ut Christum per evangelii suscipiant praedicationem neque avita aspernentur incredulitate. Caeterum, cum nonnulla essent, quae auditores remorarentur $\mathrm{He}$ braeos, maxime quod angelorum et Moseos verba Christi praeferenda putarent

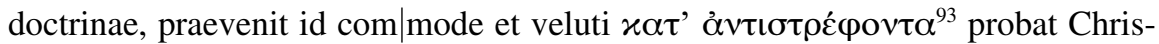
tum angelis esse maiorem. Demonstrationem porro istam expositione sive nar- 30

Z. (1) cap[ut]] caput $Z F$ - (2) caeremoniis] ceremoniis $Z F$

91 Vgl. Erasm. adag. 147 (ASD II/1 264,185191): »Calcar addere currenti. [...] Ita nobis calcar addit, qui extimulat languente.«

92 Zu den Redegattungen in der klassischen Rhetorik (judizial, deliberativ und epideiktisch bzw. demonstrativ) vgl. Quint. inst. 2,21,23 (Winterbottom I 128,6-9).
93 Vgl. Bud. comm. 694,5-10; Gell. 5,10 (Rolfe I

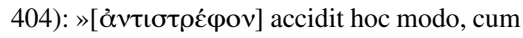
argumentum propositum referri contra convertique in eum potest a quo dictum est, et utrimque pariter valet.« 
ratione argumentosa init, ostendens evangelium multo nobiliore allatum esse nuntio, quam veterum praedicata sit religio. Totumque hoc negotium brevissima hac comprehendit ratiocinatione: nemo unquam ab ipso mundi exordio impune contempsit sermonem dei per angelos nuntiatum; unde consentaneum est vel illos 5 maxime puniendos, qui contempserint sermonem dei per angelorum dominum praedicatum. ${ }^{94}$ Et haec subiunguntur in capite 2. Praeit autem Christum Iesum angelorum esse dominum, utpote dei filium. Hinc commode et necessario infertur: »Proinde oportet nos vehementius attendere« [Hebr 2,1], quod initium est capitis 2. Ideoque genuinus sensus non nisi per initium capitis secundi absolvitur.

Quocirca videri poterat naturalis propositionum ordo esse inversus, ${ }^{95}$ id quod Hyperbaton. alias apud oratores quoque frequentissimum est, ut vel illa Ciceronis praeclara oratione pro Milone ${ }^{96}$ apparet. $^{97}$ Media enim interponitur illatio et rei summa, sequitur maior, praeit minor, quanquam et in alium possit cogi ordinem; sed ego hunc sequi malui utpote simpliciorem et dilucidiorem. Iam vero toto capite primo

15 copiose exponit et astruit id, quod dubium apud eos erat, Christum scilicet angelis esse maiorem, dei fillium. Nam posterius illud ve|luti indubitatum nulla assertione egebat. In hoc enim tota scriptura versatur, ut doceat contemptum sermonis angelici semper fuisse contemptoribus exitialem. Proinde ad id accingitur, quod apud illos minus probabile erat, nempe Christum angelis esse maiorem, poten20 tiorem dignioremque, dei videlicet filium, angelorum dominum, ac dicit:

\section{Deus olim saepenumero diversimodeque patribus loquutus est per pro- phetas, 2 in postremis vero hisce diebus loquutus est nobis per filium,}

Summam totius negotii paucis perstrinxit: veteribus quidem missos esse prophetas, nobis autem filium dei. Iucundum autem erat Hebraeis dei, patrum et prophetarum nomen; consulte ergo istis auspicatur apud Hebraeos dicturus, certe ut auditorum duros alias et iniquos Christi negotio animos demulceret sibique astringeret arctius, interim filii nomen ingereret eiusque negotium collatione

Z. (2) nuntio] nuncio $Z F$ - (4) nuntiatum] nunciatum $Z F$ - (6) 2.] secundo $Z F$ - (9) 2.] secundi $Z F$

94 Vgl. Bull. vorl. Hebr. [1,1] (Berg/Hausammann 143).

95 Marg. »Hyperbaton«: Das »Hyperbaton« ist die Trennung zweier syntaktisch eng zusammenhängender Wörter durch ein nicht an diese Stelle gehöriges Satzglied, vgl. Quint. inst. 8,6,62-67 (Winterbottom II 475,22-476,22).

96 Titus Annius Milo, Praetor 55 v.Chr. und Freund Ciceros. Die Verteidigungsrede »Pro Milone« verfasste Cicero anlässlich des Prozesses gegen Annius Milo, der 52 v.Chr. sei- nen langjährigen Feind Publius Clodius Pulcher (NP III 37-39) ermordert hatte, vgl. NP I $712 \mathrm{f}$.

97 Entgegen dem Usus, eine Rede in »prooemium «, »narratio«, »probatio $\ll / »$ refutatio $\ll$ und »peroratio« zu gliedern (vgl. Quint. inst. 3,9,1 [Winterbottom I 177,12-14]), lässt Cicero in »Pro Milone « die »refutatio « der »narratio vorausgehen, vgl. Cic. Mil. 3,7-8,22 (Watts 12-30) (»refutatio $\ll$ ); 9,23-11,31 (Watts 3040) (»narratio $\ll$ ). 
occulta angelicae, Mosaicae atque proheticae legationi longe anteferret. Siquidem hoc erat genuinum apostoli Christi officium: Christi nomen orbi proponere solum.

»Saepenumero autem loquutum «, ait, »deum patribus«, eo quod diversis temporibus alios subinde atque alios mi|serit prophetas. Nulla enim gens est, quae plures Iudaeis habuerit veros ac divinitus inspiratos vates. Hinc et propheta: »Annunciat verba sua Iacob «, inquit, »statuta et iudicia sua Israel. Non fecit similiter omni genti et iudicia non cognoverunt « [Ps 147,19f.]. Unde et consequens est nullam extare religionem, quae firmioribus nitatur fundamentis quaeque certioribus possit probari testibus quam christiana. Et frequentia testium dei erga nos probat studium diligentiamve, sed diversitas facilitatem et benignitatem. 10 Pulchre enim divina bonitas sese ad nostrum attemperavit captum. Hinc apostolus

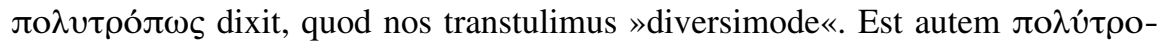
$\pi$ лo homo versatili, dextro facilique ingenio, quod cum quovis hominum genere

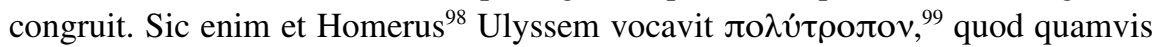
personam apte gereret: mendici, patrisfamilias et ducis. Ita videmus etiam deum 15 variam induisse faciem, item variis modis atque revelationibus voluntatem suam revelasse, ac humani generis quaesisse salutem. Caeterum »postremos« dies dixit proximos. Nam particulae »olim« et »postremis hisce diebus« mutuo sese respectant relativa quadam ratione, ut non sit necesse disputare de extrema iudicii die. Idem enim pollet, ac si dixisset: »Equidem deus olim se orbi aperuit per 20 prophetas, nunc vero hisce proximis diebus loquutus est nobis per filium.«

\section{| 2 quem constituit haeredem omnium, per quem et saecula fecit;}

Iam brevibus, sed iisdem gravissimis enarrat gloriam Christi, nempe, quod omnium sit dominus et universae molis (id enim per »saecula« intelligit) machinaeque mundi ${ }^{100}$ conditor. Id quod alias copiosius exponitur in epistola Pauli 25 Christus ad Col[ossenses] 1., item in evangelio Ioan[nis], cap[ite] 1. et 5. ${ }^{101}$ Allusit autem shaeres巛
quomodo referre possint; sed attemperatur ita sermo humana similitudine, ut ineffabilia illa dei mysteria aliquo modo intelligamus. Nam qui haereditate succedunt in paternas opes, omnium prorsus domini sunt, quorum dominus fuerat pater, adeoque in 30 possessione et dominio patri aequales sunt. Sic etiam filius dei haeres paternarum rerum dicitur, eo quod filio subdita sunt a patre omnia. ${ }^{102}$ Idem itaque possent hae orationes duae: Christus est haeres omnium, et: filio subdita sunt omnia. Nam et

Z. (21) loquutus] loqutus $F$ - (26) Col[ossenses]] Coloss[enses] ZF

98 Homer (wohl um 700 v.Chr.), traditioneller Verfasser der Epen »Ilias« und »Odyssee«, vgl. NP V 686-699.

99 Hom. Od. 1,1 (Ludwich I 1).
100 Vgl. Lucr. 5,96 (Bailey ibid.): »[...] ruet moles et machina mundi.«

101 Kol 1,16f.; Joh 1,3; 5,17.

102 Vgl. 1Kor 15,28. 
in evangelio dicit: »Omnia quaecunque habet pater, mea sunt « [Joh 16,15]. At apud homines filii possessio parentis est decessio. Apud hos est prius ac posterius. Sed nihil tale invenias apud deum patrem et filium. Quanquam enim distinctae sunt personae, una tamen est monarchia, aequale regnum, aequalis potes5 tas et gloria. Nihil in patre et filio prius, nihil posterius, nihil maius, nihil minus: »Nam sicut pater vivificat, quos vult, sic eti|am filius vivificat, quos vult « [Joh $5,21]$. Nec patri propterea aliquid decedit nec filio magis accedit, ut in humana haereditate fit, sed coaequalitas est utrobique. Iam, etsi filius vel dono vel haereditate aliquid dicitur accepisse a patre, tamen iterum ad humana allusio facta est 10 notataque divina dispositio. Rectissime enim Tertullianus ${ }^{103}$ adversum Praxeam ${ }^{104}$ illud allegat patris de filio testimonium: »Hic est filius meus dilectus, in quo bene sensi; ipsum audite« [Mt 17,5], cui mox infert: »Habes filium in terris, habes patrem in coelis. Non est separatio ista, sed dispositio divina. Caeterum scimus deum etiam intra abyssos esse et ubique consistere, sed vi et potestate; filium 15 quoque ut individuum cum ipso ubique. Tamen in ipsa oixovo $\mu i \alpha$ pater voluit filium in terris haberi, se vero in coelis $\aleph^{105}$ etc. Haec enim Tertull[ianus]. D[ivus] item Athanasius ${ }^{106}$ de Arriana et catholica confessione ad Theophil[actum] ${ }^{107}$ lib[ro] 8.: »Et ideo«, inquit, »sicut unam substantiam, ita unam potestatem patris et filii et spiritus sancti credo. Quod autem accepit filius, secundum hominem 20 accepit, id est secundum servilem formam, secundum nostrae conditionis naturam, ipso domino in evangelio dicente: >Et iudicium dedit ei facere, quia filius hominis est $<$ [Joh 5,27]. « ${ }^{108}$ Haec Athan[asius]. Denique pari ratione legimus per filium omnia esse condita. Nam eo ipso iterum notatur essentiae unitas et personarum discrimen. Alius enim est, qui facit, et alius, per quem aliquid fit, ${ }^{109}$ etsi non sit aliud. ${ }^{110}$ Unus enim, qui condidit omnia, deus est. Et Christus: »Ego«,

Z. (4) aequale] indivisum $Z F$ - (16) Tertull[ianus]] Tertullianus $Z F$ - (17) Theophil[actum]] Theophylactum $Z F$

103 Tertullian (Quintus Septimius Florens Tertullianus, geb. ca. 160/70 n. Chr.), frühchristlicher lateinischer Theologe, Verfasser von apologetischen, katechetischen und antihäretischen Werken. Nach 200 wandte er sich dem Montanismus zu. Vgl. TRE XXXIII 93-17; NP III 253-255.

104 Praxeas (um 200), christlicher Lehrer kleinasiatischer Herkunft, der in Rom wirkte; Vertreter des modalistischen Monarchianismus (auch als »Identifikationstheologie« bezeichnet: Jede Unterscheidung zwischen Gott Vater und Jesus Christus wird aufgelöst), vgl. NP X 278.

105 Tert. adv. Prax. 23,4 (CCSL II 1192,16-21).

106 Athanasius (ca. 295-373), ab 328 Bischof von Alexandria, Kirchenvater und vehementer
Verfechter der nizänischen Orthodoxie. Vgl. TRE IV 333-349; NP II 157f.

107 Die »Professio Ariana et confessio catholica « macht das elfte Buch der Schrift »De trinitate libri duodecim« aus, welche traditionell Athanasius von Alexandria, später auch Vigilius von Thapsus (gest. um 490, vgl. LThK $^{3}$ $\mathrm{X}$ 788) und Eusebius von Vercelli (gest. um 370, vgl. LMA IV 108) zugeschrieben wurde. Mittlerweile werden alle genannten Zuschreibungen angezweifelt, vgl. Quasten III 33f.; AtH 353.

108 Ps.-Vigil. Thaps. trin. 11 (PL LXII 299A-B).

109 Vgl. Tert. adv. Prax. 9,2 (CCSL II 1168,1518): »Sic et Pater alius a Filio [...] dum alius qui facit, alius per quem fit.«

110 Vgl. Aug. civ. 11,10 (CCSL XLVIII 330,9-12):
Quomodo filius accepisse aliud dicatur. 
inquit, »et pater $\mid$ unum sumus« [Joh 10,30]. Non ait: »Unus sum«, sed: »Ego et pater unum sumus.« Ideoque iterum allusit ad eorum hominum morem, qui maximas quasque res administrant per homines sibi coniunctissimos, prudentia quoque et rerum peritia summos et sibi aut aequales aut aliquanto superiores. Sic, inquam, deus per fililum condidit omnia. Has allusiones multi non vident, imo intelligere nolunt, quod ineffabilia alias mysteria humanis vestiuntur similibus, certe ut fidelis mens per ista evehatur ad altiora. Id cum isti non recipiant, fit, ut imprudenter, imo impie omnia in sacrosancta triade misceant, cum haec interim dei dispositio et divinitati Christi prorsus nihil deroget et personas non conturbet, neque unitatem in trinitate dividat.

\section{3 qui cum sit splendor gloriae et expressa imago substantiae eius}

Alia, sed illustriori, metaphora pingit gloriam Christi apostolus, demonstrans eum esse filium dei deo aequalem. Nam, sicut splendor (ỏ $\alpha u ́ \gamma \alpha \sigma \mu \alpha$ ) refulgentia, fulgor sive radius ex sole emicat, sic etiam filius ex seipso non existit, sed ex patre genitus est. Et sicut radius a sole non separatur, sic neque a patre filius 15 dividitur. Interim sphaera sive globus solis non est radius, neque radius globus et neutrum horum calor, neque calor globus aut radius; sunt tamen haec tria non tres soles, sed unus sol. Sic utique et una est magnifica gloria (hoc enim nomine decorat apostolus deum), non duo vel tres; substantiae tamen vel personae ex illa duae, verum ab ea prorsus non sunt separatae. Hinc doctissimus Tertullianus, 20 cuius testimoniis ob vetustatem, sanctimoniam vitae et erunditionem libenter utimur, adversus Praxeam: »Nec dubitaverim«, inquit, »filium dicere et radicis fruticem $\mid$ et fontis fluvium et solis radium, quia omnis origo parens est et omne, quod ex origine profertur, progenies est, multo magis sermo dei, qui etiam proprie nomen filii accepit. Nec frutex tamen a radice nec fluvius a fonte nec 25 radius a sole discernitur, sicut neque a deo sermo. Igitur secundum horum exemplorum formam profiteor me duos dicere: deum et sermonem eius, patrem et filium ipsius. Nam et radix et frutex duae res sunt, sed coniunctae; et fons et flumen duae species sunt, sed indivisae; et sol et radius duae formae sunt, sed cohaerentes. Omne, quod prodit ex aliquo, secundum sit eius necesse est, de quo 30 prodit, non ideo tamen est separatum. Secundus autem ubi est, duo sunt, et tertius ubi est, treis sunt. Tertius enim est spiritus a deo et filio, sicut tertius a radice fructus ex frutice et tertius a fonte rivus ex flumine et tertius a sole apex ex radio. Nihil tamen a matrice alienatur, a qua proprietates suas ducit. Ita trinitas per

Z. (2) allusit] allussit $F$ - (31) Secundus] Sequundus $F$

»Alius est autem quam pater et filius, quia nec pater est nec filius; sed >alius $<$ dixi, non >ali- ud<, quia et hoc pariter simplex pariter que incommutabile bonum est et coaeternum.« 
consertos et connexos gradus a patre decurrens et monarchiae nihil obstrepit et oixovouías sta|tum protegit ${ }^{111}$ etc. Haec Tertullianus.

Ad lucem prioris facit et expositio membri posterioris. Nunc enim Christum Quomodo vocat »characterem « substantiae paternae. Est autem hoc loco $\chi \alpha \rho \alpha \varkappa \tau \eta ́ \rho$ forma christus 5 expressa ex alio, ${ }^{112}$ a $\chi \alpha \rho \alpha ́ \tau \tau \omega$, ut Erasmus monet, »quod est >insculpo< sive $>$ notam imprimo $\ll,{ }^{113}$ veluti si caerae nota imprimatur sigilli. Pater itaque typus est, sed filius character, imago et forma sive figura typo expressa. Mira autem est similitudo, imo aequalitas typi et figurae typo expressae, ut et eadem est divinitas, gloria et maiestas patris et filii. Philippo enim dicit apud Ioannem: »Philippe, qui vidit me, vidit patrem. Quomodo itaque tu dicis: >Ostende nobis patrem?< Non credis, quod ego in patre sim et pater in me? « [Joh 14,9f.] Ideoque, quemadmodum in caera propriissime exprimitur sigillum, ita in Christo propriissime

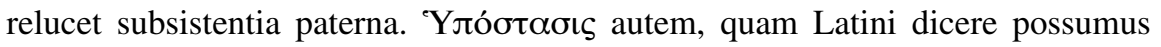
»subsistentiam «, a subsistendo dicta est ${ }^{114}$ unde claret apostolum allusisse ad 15 illud nomen dei ineffabile, quod tetragrammaton vocant, quod et ipsum ab essendo nomen habet. ${ }^{115}$ Quasi dixerit apostolus filium esse de paterna substantia,

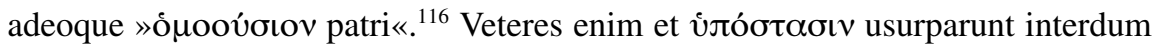

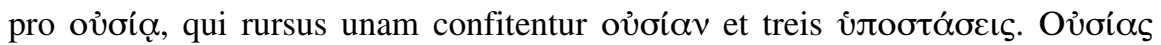
igitur vocem immerito (ut vides) proscripsit Ariminensis synodus, ${ }^{117}$ quam in-

terim vocem Eusebius $\mid$ Caesariensis homo Graecus dilucide et vere sic exposuit: »Praedicandum est filium patri esse consubstantialem, eo quod nullam aequalitatem ad creaturas factas dei filius habeat, sed soli patri genitori per omnem modum sit similis et non sit ex alia qualibet substantia vel essentia, sed ex patris ${ }^{118}$ etc. Sed haec hactenus. Ex quibus omnibus illud liquido constare con25 fidimus, Iesum Christum non modo angelis maiorem, sed ne deo quidem patre esse minorem, quippe cum sit angelorum dominus patri coaequalis, vita et subsistentia omnium. Iam enim clarius sequitur:

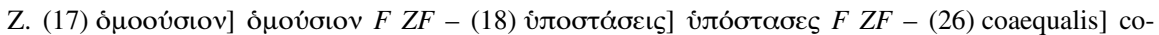
aequalis et consubstantialis $Z F$

111 Tert. adv. Prax. 8,5-7 (CCSL II 1168,29-47).

112 Erasm. Hebr. (ASD VI/10 230,17).

113 Erasm. Hebr. (ASD VI/10 230,18f.).

114 Erasm. Hebr. (ASD VI/10 230,23f.): »Yлó-

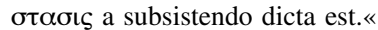

115 Vgl. Zw. Isa.1,24 (Z XIV 125,3f.): »Tetragrammaton יהוה Hebr. ab essendo sumptum est.«

116 Symb. Nic. (DH 125).

117 Die Synode von Rimini (359) wurde durch Kaiser Constantius II. einberufen, mit dem Ziel, eine Sanktionierung der »homoiischen« Christologie herbeizuführen, vgl. Dobner 2004, 239. Vertreter des Arianismus versuch- ten während der Verhandlungen jedoch, die Synode zu einer grundsätzlichen Ablehnung des des Begriffs oủoía im Zusammenhang mit christologischen Fragen zu bewegen, vgl Cassiod. hist. 5,20,14 (CSEL LXXI 246,7176): »Dicebant enim Ariani convenientes Arimino volentes Hesperiis suadere simplicibus, quia non oporteret propter duo verba, quae nec invenirentur scripta, separari corpus ecclesiae, sed similem per omnia profiteri filium genitori, substantiae vero tacere nomen. Sed fallaciam sentientes horum homousiani pontifices eos abdicaverunt.

118 Cassiod. hist. 2,11,8 (CSEL LXXI 101,59-63). 
3 agatque omnia verbo potentiae suae;

Omnia in Dicit Paulus, quod omnia consistant robore, vi et potentia Christi. Nam et IoChristo annes: »In ipso«, inquit, »vita erat« [Joh 1,4]. Alibi vero: »In deo vivimus, movemur et sumus « [Apg 17,28] et in Christo vivimus, ${ }^{119}$ ergo Christus verus est deus. Omnia enim ex illo et per illum sunt, ${ }^{120}$ et sine eo factum est nihil, quod modo factum est. Mira autem est in Paulinis verbis evidentia. Recte enim monet Erasmus $\varphi \varepsilon ́ \rho \omega \nu$ hoc loco non significare »baiulare« ac »portare«, sed »agere« potius sive »movere « et »moderare « omnia, ut nunc apostolus senserit mundum non modo per Christum esse conditum, sed eum etiamnum illius administratione regi. ${ }^{121}$ Nisi malis portandi verbum metaphoric $\tilde{\omega} \varsigma$ usurpari et verborum magni- 10 ficentia unius Christi humeris veluti veri Herculis totam coeli im/ponere machinam. ${ }^{122}$ Verum si consequentia spectes, iam prior sensus magis quadrabit. Sentit enim apostolus potenti administratione per Christum in orbe geri et conservari, quicquid tandem geritur et conservatur. Nam verbum hoc in loco administrationem significat, ut sit sensus: »Agit omnia verbo potentiae suae«, id est, 15 »agit omnia sua administratione potenti.«

Haec vero ideo tot inculcamus et verbis et testimoniis, quod infoelicia nostra tempora subinde novas verae religionis pestes, impios, hypocritas et extreme blasphemos homines (an daemones dicam, nescio) progerminent, qui non modo veram Christi divini|tatem in dubium vertunt, sed et sacrosanctam trinitatem $20 \quad 649 \mathrm{ZF}$ hydrae Gerioni, ${ }^{123}$ Briareo $^{124}$ et infero pene Cerbero ${ }^{125}$ ceu fabulosissimum nugamentum conferunt, ${ }^{126}$ digni prorsus, qui furiis infernalibus laniandi ac Cerbero trifauci proiiciantur devorandi. Nam ut Davidis, ${ }^{127}$ Hieremiae $^{128}$ et Danielis ${ }^{129}$

\section{Z. (17) infoelicia] infelicia $Z F$}

119 Vgl. 1Kor 1,30.

120 Vgl. Röm 11,36.

121 Erasm. Hebr. (ASD VI/10 232,27-33): »Meo quidem iudicio $\varphi \varepsilon ́ \rho \omega \nu$ hoc loco non significat idem quod >portans< siue >baiulans<, sed $>$ agens $<$ potius siue $>$ mouens $<$ ac $>$ moderans $<$. [...] Sentit enim Paulus aut quisquis fuit autor epistolae, non solum mundum hunc conditum per Filium, quemadmodum modo dixerat sper quem fecit et secula<, verum conditum regi et administrari.«

122 Vgl. Theophyl. Hebr. transl. 143v: »Ferens tanquam digitis tantam hanc mundi molem haud secus deportet, ac si nihil esse constaret. «

123 Geryoneus, mythischer Riese mit drei Köpfen bzw. drei Leibern und Widersacher des Herkules in der zehnten Tat des Dodekathlon, vgl. NP IV 981f.

124 Briareos, einer der »Hundert-Händer ( $\left({ }^{\mathrm{E}} \mathrm{E} \varkappa \alpha-\right.$

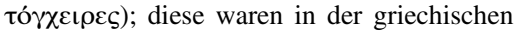
Mythologie kräftige Monsterwesen, die entsprechend einem Überlieferungsstrang die durch Zeus besiegten Titanen im Tartaros zu bewachen hatten. Vgl. NP V 271.

125 Kerberos, dreiköpfiger Wachhund der griechisch-römischen Unterwelt, vgl. NP VI $439 f$.

126 Der spottende Vergleich des Trinitätsdogmas mit dreigliedrigen oder dreiköpfigen Monstergestalten aus der antiken Mythologie wurde später zum Gemeinplatz in der antitrinitarischen Literatur und ist etwa in Michael Servets »Christianismi restitutio « (1553) belegt, vgl. Serv. rest. 119; 700. Wer oder welche Schrift in der vorliegenden Passage gemeint gewesen sei, bleibt allerdings unklar.

127 Ps $110 ; 132,11$.

128 Jer 23,5f.

129 Dan $7,13 \mathrm{f}$. 
transeam testimonia, certe Isaias ${ }^{130}$ prophetarum princeps de utraque in Christo Clara de indole, cum humana tum divina, tam aperte tam copiose tam etiam vere disseruit, $\begin{aligned} & \text { divinitate } \\ & \text { Christi }\end{aligned}$ ut planiora et meliora non nisi desperati, vesani et diabolo dedicati homines testimonia. postulare possint. Et quid, obsecro, clarius dici potest, quam quod Ioannes dixit: Ioan. 1[,1f.]. $5 \gg$ In principio erat verbum et verbum erat apud deum, ergo verbum erat deus; illud sane, quod in principio apud deum erat «? Et paulo post: $\mid \gg$ Et verbum caro factum est et habitavit in nobis « [Joh 1,14] etc. Item ipse dominus Iesus testatur in eodem evangelio ac dicit: »Amen amen dico vobis: antequam Abraham esset, ego sum.« Ioan. 8[,58]. Item: »Amen amen dico vobis: qui confidit mihi, habet vitam aeternam.« »Ego Ioan. 6[,47]. 10 sum panis vivus, qui de coelo descendi. Si quis ederit ex hoc pane, vivet in aeternum « [Joh 6,51]. Et iterum: oves meas »nemo rapiet de manu mea. Pater Ioan. meus, qui dedit mihi, maior omnibus est, et nemo potest rapere de manu patris 10[,28-30]. mei. Ego et pater unum sumus. « Rursus dicit Iesus discipulis suis: »Ne turbetur Ioan. 14[,1]. cor vestrum! Creditis in deum et in me credite! « Et Thomas redivivo acclamat: Ioan. 20[,28]. 15 »Dominus meus et deus meus!« Testatur etiam Paulus in Roma[nis], cap[ite] 9., ac dicit Israelitarum esse promissiones ac patres, ex quibus, quod scilicet carnem attinet, Christus sit: ${ }^{131} »$ Qui est«, inquit, »in omnibus deus laudandus in saecula « [Röm 9,5]. Et in 1. ad Corinth[ios], 8. cap[ite]: »Etiamsi sunt«, ait, »qui dicantur dii, sive in coelo sive in terra, quemadmodum sunt dii multi et domini multi, 20 nobis tamen est unus deus, qui est pater ille, ex quo omnia et nos in illum, et unus dominus Iesus Christus, per quem omnia et nos per illum« [1Kor 8,5f.]. Item ad Titum: »Expectantes beatam illam spem et apparitionem gloriae magni dei et servatoris nostri Iesu Christi« [Tit 2,13]. Sed quorsum opus tot sanctorum testimoniis, cum unus Ioannes omnium dilucidissime de Iesu Christo testetur et dicat: professo tradit Iesum Christum verum esse deum?

Verum mirantur illi, cum pater non sit filius et tamen deus verus, neque filius sit pater, interim tamen deus verus, quomodo unus possit esse deus verus. Au- De unitate et diant ergo Mosen dicentem: »Audi Israel: dominus deus tuus, deus unus est « [Dtn 30 6,4]. Quae sententia si vera est, quaestio ista finita est. Consequitur enim patrem et filium et spiritum sanctum unum esse deum verum. Si enim non est unus deus, duo vel tres sunt. Si autem duo vel tres sunt, mentitur, qui dicit: »Dominus deus tuus deus unus est « [Dtn 6,4]. Mentitur, qui dicit: »Videte, quoniam ego sum deus et non est alius praeter me« [Dtn 32,39]. Sed quia mentiri non potest veritas, constat patrem, filium et spiritum sanctum non treis dominos aut deos esse, sed unum dominum deum. Dicite enim nobis, an haec prophetarum verba de Christo domino intelligenda sint, an non sint. Si sunt, confiteamini oportet filium cum patre et spiritu sancto unum esse deum verum. Si vero non sunt, iam dabitis duos esse deos ac dominos. Nam et filius, ut iam multis ostensum est, et deus est et

130 Jes 9,5; 43,11.13.

131 Röm 9,4f. 
dominus dicitur. Aut itaque confitemini patrem et filium unum esse dominum deum, aut negate Iesum dominum et deum esse dictum. Cum vero postremum hoc nulla ratione facere possitis, consequitur prius esse verum et hanc|vocem: »Ego sum deus et non est alius praeter me« [Jes 45,5.18] non unius tantum personae, sed sacrosanctae triadis esse vocem. Trinitas quippe secundum veram fidem, pater, filius et spiritus sanctus, in cuius nomine baptizamur, ${ }^{132}$ et unus dominus deus noster est et praeter ipsum alius non est. »In trinitate ergo«, ut et Augustinus ait, »quae deus est, et pater deus est et filius deus est et spiritus sanctus deus est, et hi treis unum sunt. ${ }^{133}$ Haec vero hactenus. Quibus Tertulliani quoque sententiam propter eos adscribere visum est, qui laborant librorum inopia. 10 Is enim hoc negotii adversus Praxeam et brevibus et dilucidis sic absolvit, ubi prius personarum probasset ostendissetque discrimen:

Tertul[liani] sententia de trinitate et unitate dei.
»>Ergo<, inquis, >provocabo te, ut hodie quoque ex authoritate istarum scripturarum constanter duos deos et duos dominos praedices $<$. Absit. Nos enim, qui et tempora et caussas scripturarum per dei gratiam inspicimus, maxime paracleti, 15 non hominum discipuli, duos quidem definimus, patrem et filium, et iam treis cum spiritu sancto secundum | rationem oeconomiae, quae facit numerum, ne, ut vestra perversitas infert, pater ipse credatur natus et passus, quod non licet credi, quia non ita traditum est. Duos tamen deos et duos dominos nunquam ex ore nostro proferimus, non quasi non et pater deus et filius deus et spiritus deus, et 20 deus unusquisque, sed quoniam retro et duo dii et duo domini prae/dicabantur, ut, ubi venisset Christus, et deus agnosceretur et dominus vocaretur, quia filius dei et domini. Si enim una persona et dei et domini in scripturis inveniretur, merito Christus non esset admissus ad nomen dei et ad domini (nemo enim alius praeter unus deus et unus dominus praedicabatur) et futurum erat, ut ipse pater descen- 25 disse videretur, quia unus deus et unus dominus legebatur et tota oeconomia eius obumbraretur, quae in materiam fidei prospecta atque dispensata est. At ubi venit Christus et cognitus est a nobis, quod ipse, qui numerum retro fecerat, factus secundus a patre et cum spiritu tertius, etiam pater per eum plenius manifestatus, redactum est iam nomen dei et domini in unione ${ }^{134}$ et quae sequuntur.

»Nihil igitur creatum aut serviens in trinitate credamus, ut vult Dionysius ${ }^{135}$ Arrii fons. Nihil inaequale, ut vult Eunomius. ${ }^{136}$ Nihil inaequale gratiae, ut vult

Mt 28,19.

Aug. c. Maximin. 2,10,2 (PL XLII 765).

134 Tert. adv. Prax. 13,5-7 (CCSL II 1174f.,3256).

135 Dionysios (3. Jh.), 247/48-264/5 Bischof von Alexandria. Von seinen zahlreichen Schriften sind nur Fragmente in Werken anderer Autoren wie Eusebius von Cäsarea oder Athanasius von Alexandria erhalten. Dionysios wurde mitunter als Inspirator des Arius betrachtet. Vgl. NP III 646; Quasten III 61f.

136 Eunomios (gest. 394 n. Chr.), Bischof von Kyzikos und Anführer der »Anhomöer «, die jegliche Gleichheit des Sohnes mit dem Vater bestritten, vgl. NP IV 255. 
Aetius. ${ }^{137}$ Nihil anterius posteriusve, maius vel minus, ut Arrius. ${ }^{138}$ Nihil extraneum aut officiale alteri, ut Macedonius. ${ }^{139}$ Nihil persuasione aut surreptione insertum, ut Manichaeus. ${ }^{140}$ Nihil corporeum, ut Melito. ${ }^{141}$ Nihil corporaliter effigiatum, ut anthropomorphitae. Nihil creaturis visibile, ut Fortunatus. ${ }^{142}$ Nihil 5 moribus vel voluntate diversum, ut Martion. ${ }^{143}$ Nihil confusum, ut Sabellius. ${ }^{144}$ Sed totum perfectum, quia totum ex uno et unum ex toto, non tamen solitarium, ut praesumunt Praxeas et Sylvanus, ${ }^{145}$ stolida hominum capita. ${ }^{146}$

|Caeterum haec paucis annotare libuit, ut futuros praeveniremus errores. His si quis Athanasii iunxerit symbolum, ${ }^{147}$ summam rerum paucis verbis iisdemque

10 perspicuis habebit comprehensam. Nos redimus ad Paulum.

3 per semetipsum purgatione facta peccatorum nostrorum, consedit in dextera maiestatis in excelsis;

Sunt autem haec utraque divinitatis Christi argumenta. Nam in evangelio vel pharisaei dicunt: »Quis potest remittere peccata nisi solus deus?« Rursus in Mar. 2[,7].

15 Matthaeo interrogat Christus pharisaeos ac dicit: »>Quid vobis videtur de Chris- Math. to? Cuius filius est? $<$ Dicunt ei: >David<. Ait illis: >Quomodo ergo David in spiritu vocat eum dominum dicens: dixit dominus domino meo: sede a dextris meis, donec ponam inimicos tuos scabellum pedum tuorum [Ps 110,1]. Si ergo David

137 Aetius (gest. 367 n.Chr.), Diakon und Vertreter einer anhomöischen Christologie. Eunomios (s. oben) gilt als dessen Schüler. Vgl. BBKL I 49f.

138 Arius (ca. 280-336), Presbyter in Alexandria. Seiner Leugnung der Göttlichkeit Jesu Christi wegen wurde er vom Konzil von Nizäa (325) verurteilt. Vgl. NP I 1043.1077-1079; TRE III 692-719.

139 Makedonios (gest. vor 364 n.Chr.), Bischof von Konstantinopel und Unterstürtzer der Homöusianer, die die Wesensgleichheit von Vater und Sohn zwar bestritten, aber deren »Wesensähnlichkeit« zuzugestehen bereit waren. Später wurden als »Makedonier « all jene bezeichnet, die die Göttlichkeit des Heiligen Geistes

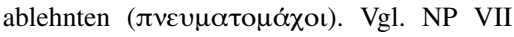
$748 f$.

140 Mani (geb. 216 n.Chr.), Gründer einer gnostischen Sekte, die sich bald im gesamten römischen Reich verbreiten konnte. Zur Lehre der Manichäer gehörte u.a. die Leugnung der Göttlichkeit Jesu Christi. Vgl. TRE XXII 2545; NP VII 811-813.

141 Meletios (gest. 381 n.Chr.), Bischof von Antiochia. Meletios vertrat die homöische Got- teslehre, nach der eine nicht näher spezifizierte Ähnlichkeit von Vater und Sohn postuliert wurde, galt aber im Westen als Arianer. Vgl. NP VII 1181f.

142 Fortunatus (4./5. Jh. n.Chr.), Manichäischer Priester, mit dem Augustinus in seiner Schrift »Contra Fortunatum« polemisierte. Vgl. AugL III 58-60.

143 Markion (ca. 85-160), christlicher Häretiker und Gründer einer eigenen Kirche, vgl. TRE XXII 89-101; NP VII 918f.

144 Sabellius, über dessen Leben wenig bekannt ist, wurde wegen seiner modalistischen Gotteslehre von Papst Callixtus I. (217-222) exkommuniziert, vgl. NP X 1184.

145 Silvanos (4. Jh. n.Chr.), Bischof von Tarsus und prominenter Vertreter des Homöusianismus, vgl. LThK $^{3}$ IX 585.

146 Gennad. dogm. 4 (PL LVIII 982A-B). Im vierten Kapitel von Gennad. dogm. werden auch Tertullian und Origenes als Vertreter heterodoxer trinitätstheologischer Ansichten genannt. Bullinger lässt die entsprechenden Passagen jedoch aus.

147 Symb. Quic. (DH 75f.). 
vocat eum dominum, quomodo filius eius est? « etc. Proinde: cum solius dei sit peccata remittere, dominum esse et ad dexteram dei sedere; Christus vero peccata remittat, dominus sit et ad dexteram sedeat; necesse est Iesum Christum verum esse deum. Haec ad statum rei.

Peccatorum

Videtur autem studio industriaque Paulus peccatorum remissionem post aliremissio. quot posuisse membra, in hoc nimirum, ne quis ambigeret de criminum expurgatione; qui audissemus illum ipsum, qui expurget, filium esse dei, haeredem et conditorem omnium, ${ }^{148}$ praeterea $\mid$ et splendorem paternae gloriae characteremque ipsissimae dei subsistentiae, ${ }^{149}$ motorem, vitam, conservationem, adeoque et per-

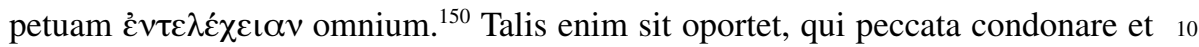

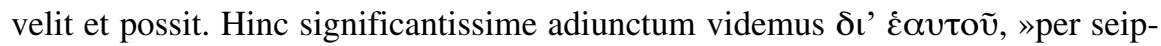
sum «. ${ }^{151}$ Neque enim per alium quenquam purgatio fieri potuit. Sic enim et Isaias in 43. cap[ite] praedixit ${ }^{152}$ et Paulus in Hebr[aeis], cap[ite] 9. asseveravit absque sanguinis effusione remissionem non fieri; ${ }^{153}$ sed non sanguinis cuiusvis, verum filii dei duntaxat. Unde etiam d[ivus] Petrus dicit nos redemptos esse »precioso 15 sanguine agni immaculati et incontaminati Christi « [1Petr 1,19]. Tantum abest, christiane lector, ut impius ille Romanorum pontifex una cum coniuratorum suorum manipulo peccata condonare possit miseris nobis mortalibus.

Caeterum »sedere ad dexteram patris «, ut Cyprianus ait, sive is Ruffinus ${ }^{154}$ sit, ${ }^{155} »$ carnis assumptae mysterium est. Neque enim incorporeae illi naturae 20 convenienter ista absque assumptione carnis adduntur; neque sedis coelestis perfectum divina natura, sed humana conquirit. $\ll^{156} »$ Ascendit ergo ad coelos, non ubi verbum deus ante non fuerat, quippe qui erat semper $\mid$ in coelis et manebat in patre, sed ubi verbum caro factum ante non sedebat. $\ll^{157}$ Haec ille. Rursus sedere in dextera maiestatis $\tau \rho 0 \pi \iota x \tilde{\omega} \varsigma$ dixit pro eo, quod est divina virtute et adminis- 25 tratione coelitus regnare. Nam sedere et habitare $\mid$ est et regnare, et nequaquam loco (ut quidam nugantur) adfixum esse. Siquidem Lucae 24. dicit Christus: »Vos autem sedete in civitate Hierusalem «, id est, Hierosolymis praestolamini, quiescite et habitate, »donec induamini virtute ex alto« [Lk 24,49]. Et 3. Reg[um] 1. dicit David de filio Solomone: »Sedebit super solium meum et ipse regnabit pro

\section{Z. (27) Lucae] Luce $F$ - (28) Hierusalem] Ierusalem $Z F$}

148 Hebr 1,2.

149 Hebr 1,3.

150 Vgl. Bull. vorl. Hebr. [1,3] (Berg/Hausammann 145): »Deus perpetua entelechia est.«

151 Erasm. Hebr. (ASD VI/10 232,40f.): »Graeci addunt $\delta \iota^{\prime} \varepsilon \alpha v \tau o \tilde{v}$, id est >per seipsum purgationem peccatorum faciens $<$.«

152 Jes 43,10-13.

153 Hebr 9,22.

154 Tyrannius Rufinus von Aquileia (gest. 410), Mönch, wirkte vor allem als Übersetzer von
Werken des Eusebius, Origenes, Basilius von Cäsarea und Gregor von Nazianz ins Lateinische. Vgl. NP X 1154.

155 Erasmus hatte bereits 1519 in der Widmung seiner Cyprian-Ausgabe an Kardinal Lorenzo Pucci angemerkt, dass die traditionell Cyprian zugeschriebene »Expositio fidei « von Rufinus stammen könnte, vgl. Erasm. epist. 1000 (Allen IV 25,35-37). Vgl. Sider 1998, 243.

156 Rufin. symb. 30 (CCSL XX 165,1-4).

157 Rufin. symb. 29 (CCSL XX 164f.,17-20). 
me« [1Kön 1,30]. Hinc et solium et sedes in scripturis accipiuntur pro imperio. Sed et Latini dicimus hominem, qui Tigurum inhabitat, Tiguri sedere; rursus Iulium Caesarem ${ }^{158}$ annis sedisse, id est, regnasse, quinque. Et dextera in principum consessu locus est primus, summus et dignissimus. Et qui ad dexteram sive

5 ad latus sedere dicuntur, summae rerum praeesse intelliguntur. Hinc mater filiorum Zebedaei: »Dic«, inquit, »ut hi filii mei duo sedeant, unus a dextris et alius a sinistris in regno tuo « [Mt 20,21 par.], id est: concede, ut in regno tuo constituantur primi. Proinde ad dexteram dei sedere dicitur nunc filius, allusione

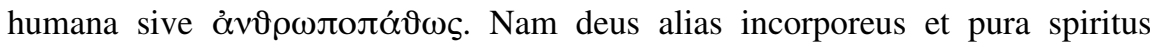
substantia, manibus ut non indiget, sic etiam caret, nisi crassum placeat anthropomorphitarum placitum. Necessitate itaque quadam consequitur hanc locutionem, »sedere Christum ad dexteram patris«, prorsus et revera esse tropicam. Addidit item apostolus »maiestatis «, »sedere «, inquam, »filium in dextera maiestatis«, quod locutionis genus augustius est, quam si dixisset: »Sedet ad dexteram dei.«Plus enim | et augustius aliquid dixisti: »Caesarea maiestas imperavit«, quam si dicas: »Caesar imperavit.« Nec hoc contentus apostolus subiunxit et aliud evidentius: sedere illum »in excelsis «, certe ut clare videremus, quid esset sedere in dextera maiestatis, nempe hisce ereptum esse terris, in aethera subvectum, terrenis quoque solutum esse cupiditatibus et adfectibus, agere nunc eum in coelestibus divinaque coelitus potentia administrare agereque omnia. Ad hunc enim modum id negotii absolvit clarius idem in Ephe[siis], cap[ite] 1., quae, si requiras, haec sunt: »Deus suscitavit Iesum ex mortuis et sedere fecit ad dexteram suam in coelestibus, supra omnem principatum ac potestatem et virtutem et dominium et omne nomen, quod nominatur, non solum in saeculo hoc, verum etiam in futuro. Et omnia subiecit sub pedes eius et eum dedit caput super omnia ipsi ecclesiae, quae est corpus illius, complementum eius, qui omnia in omnibus adimplet« [Eph 1,20-23]. Hucusque verba apostoli recensuimus.

Ista vero eos dextre impugnant, qui sacramentorum ratione neglecta nescio quid carnalis praesentiae in eucharistia imaginantur. Interim non negamus Christum adesse; imo scimus et credimus Christum in coena suo modo vere adesse, hoc est non carnaliter, sed sacramentaliter. Vere enim adsunt, quae vera fides coram iis oculis cernit, quibus Galatae viderant | Iesum Christum inter sese esse crucifixum. ${ }^{159}$ Sed haec obiter; ${ }^{160}$ nunc sequitur:

\section{Z. (13) Addidit] Addit $Z F$ - (21) Ephe[siis]] Ephes[iis] $Z F$ \\ 158 Caius Iulius Caesar (100-44 v.Chr.), römi- scher Konsul, Diktator, Feldherr und Autor. \\ 159 Gal 3,1. \\ 160 Siehe unten S. $145 \mathrm{f}$.} Seine Ermordung steht am Übergang von der römischen Republik zur Kaiserzeit, vgl. NP II 908-923. 
4 tanto praestantior factus angelis, quanto excellentius prae ipsis nomen haereditate conquisivit.

Propius nunc accedit ad rem et id colligit, quod voluit, nempe Iesum Christum angelis esse maiorem, filium videlicet dei. Nam »nomen« posuit pro gloria, maiestate et magnifico titulo, adeoque pro omni eo, quod hactenus de Christo audivimus. Id vero nominis dicit Christum haereditate conquisivisse, nimirum in coepta perseverans allusione, de qua satis dictum in superioribus. Certe si legas pro »haereditavit « »sortitus est «, ${ }^{161}$ iam periit apud nos allusionis gratia. Refert enim haereditatis vocabulum nescio quid dominii et unionis utriusque et patris et filii substantiae. Nam et homines parentum filii et haeredes sumus non merito aut 10 gratia, sed ipsa natura, quemadmodum et filius dei »haereditate«, id est natura, filius dei est, non gratia aut adoptione. Verissime enim definivit Nicena synodus filium ex patre genitum esse ante saecula, lumen ex lumine, deum verum ex deo vero $^{162}$ etc.

5 Nam cui dixit unquam angelorum: filius meus es tu, ego hodie genui te? Ac rursum: ego ero ei pater et ille erit mihi filius? 6 Rursum au|tem, cum inducit pri|mogenitum in orbem terrarum, dicit: et adorent eum omnes angeli dei.

Quod paucis dixerat, id nunc copiosissimis diducit ac firmat testimoniis ex adytis scripturarum petitis. Principio quod apud eos ageret negotium, apud quos ea 20 nullius prorsus authoritatis erant, quaecunque tandem non firmarentur scripturae testimoniis. Unde etiam nobis discendum, ne quasvis res hominum quorumlibet suaviter et composite fabulantium temere recipiamus; sed probemus »spiritus, an ex deo sint « [1Joh 4,1]. Qui autem verba dei loquitur, ex deo est. Qui vero sua quaerit et ex seipso loquitur, ex deo non est. Nisi ergo in rebus dubiis et ad 25 religionem spectantibus accedat scripturarum authoritas, nihili putetur, quantumvis recepta et laudata vetustas. Deinde voluit apostolus istis tam firmis istorum profligare errorem, qui putarunt Christum fuisse vel angelum vel etiam prophetam eximium a deo in hunc orbem missum. Prius autem testimonium sumpsit ex Psal[mo] 2., ${ }^{163}$ qui de Davide scriptus Christo per typum et allegoriam recte 30 accommodatur. De eo enim coelitus audita est patris vox dicens: »Hic est filius meus dilectus, in quo animus meus placatus est; ipsum audite« [Mt 3,17]. Pos-

\section{Z. (30) Psal[mo] 2.] Psalmo secundo $Z F$}

161 Erasm. Hebr. (ASD VI/10 234,61f.).

162 Symb. Const. (DH 150). Das Nizänum enthält

163 Ps 2,7. die Worte »ante omnia saecula« nicht, vgl. Symb. Nic. (DH 125). 
terius vero ex 2. Reg[um], 7. cap[ite ${ }^{164}$ petitum et de Solomone dictum, pulchre et proprie competit in Christum, de quo in evangelio dixit baptista: »Pater diligit filium et omnia dedit illi in manum « [Joh 3,35]. Porro | ultimum testimonium, quod non absque praefatiuncula inducit, accepit ex Psal[mo] 69., ${ }^{165}$ in quo prae5 dicitur fore, ut omnes angeli dei illum sint adoraturi primogenitum dei. Nemo autem nisi deus adoratur, ${ }^{166}$ quocirca necesse est primogenitum illum verum esse deum. Praeterea in confesso est, id esse minus, quod adorat, maius vero, quod adoratur; caeterum adorant angeli, Christus vero adoratur; unde consequens est Christum maiorem esse angelis. Praefatiuncula autem hoc dicit: »Cum meminit eius primogeniti vates, qui in orbe regnaturus erat, sic dicit: >Et adorent eum $\ll$ etc. Denique Christus iterum dicitur per humanam allusionem »primogenitus «. Primogenitus Erant enim apud Hebraeos primogeniti haeredes et omnium rerum domini. Unde et d[ivus] Hieronymus adversus Helvidium ${ }^{167}$ recte dixit primogenitum non tam eum esse, post quem et alii, quam eum, ante quem nullus. ${ }^{168}$ Dicitur et $\gg$ unige15 nitus «, fortassis quod solus filius non sit factus, sed genitus. ${ }^{169}$ Itaque prius quidem dominii est et regni, posterius vero divinitatis aeternitatisque argumentum. In hanc sententiam scripsit et magnus ille Alexandriae Athanasius de assumptione hominis adversus Marcellinum: ${ }^{170} \gg$ Quamobrem «, inquiens, »>unigenitum < dum scriptura refert, secundum divinitatem indicat, quia in deitate uni20 genitus a deo patre omnino fratres non habet; et dum >primogenitum < nominat, naturam hominis ostendit $\ll^{171}$ etc.

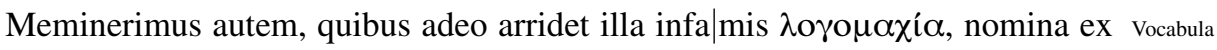
rebus existere et non ipsas res esse ex nominibus, iccirco accomodemus nomina rerum naturae, quarum sunt nomina, et non aestimemus res ad vivum, quod dici 25 solet, ${ }^{172}$ ex nominibus. ${ }^{173}$ Sunt enim arcana ista dei nobis ineffabilia, interim tamen aliquo modo et, quantum satis et possibile est, humanis allusionibus effigiata.

\section{Z. (4) Psal[mo]] Psalmo ZF}

1642 Sam 7,14.

165 Gemeint ist Ps 97,7 (Vulg. 96,7)

166 Mt 4,10; Offb 22,8.

167 Helvidius (4. Jh.), römischer Christ, der die in Hier. virg. Mar. verworfene Meinung vertrat, Maria habe nach der Geburt Jesu mit Joseph Kinder gezeugt, vgl. Quasten IV 239.

168 Hier. virg. Mar. 10 (PL XXIII 203A): »Colligitur eum primogenitum vocari, qui vulvam aperiat et ante quem nullus sit, non eum quem frater post genitus subsequatur.«

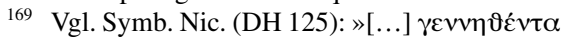

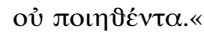

170 Es handelt sich dabei um das dritte Buch der Schrift »De trinitate libri duodecim«. Zur Frage nach der Autorschaft dieser Schrift siehe oben S. 21, Anm. 107.

171 Ps.-Vigil. Thaps. trin. 3 (PL LXII 263A-B).

172 Vgl. Erasm. adag. 1313 (ASD II/3 328,201f.): »)Ad viuum resecare< [...] est >rem exactius, quam sat est, ac morosius excutere <.«

173 Vgl. Agric. inv. 1,22 (Mundt 134,19-21): »Quod autem locum nomini inter ea, quae sunt in substantia, fecerint, non video, quam ratione sint secuti, cum rerum apud omnes gentes eadem sit substantia, nomina diversa.« 
7 Et ad angelos quidem dicit: qui creat angelos suos spiritus et ministros suos ignis flammam.

Hactenus testimonia de filio posuit, nunc de angelis per collationem locorum contrarium ex Psal[mo] 103. subiungit. ${ }^{174}$ Superioribus autem probatum est Christum Iesum esse dei filium genitum, non factum. Hic vero audimus angelos esse factos creatosque. Item superius testatum est filium adorari ut dominum; sed hic legimus angelos esse ministros, prorsus ergo Christo minores sint oportet. Sed de angelis paulo post plura.

8 Ad filium autem: thronus tuus deus in saeculum saeculi, virga rectitudinis, virga regni tui. 9 Dilexisti iustitiam et odisti iniquitatem, propterea unxit te deus, deus tuus oleo exultationis ultra consortes tuos.

Aliud est de filio testimonium sumptum ex Psal[mo] 44., ${ }^{175}$ cuius vis in hoc consistit, quod eum $\mid$ nunc aperte $\mid$ deum vocat, quem paulo ante filium appellarat. Thronus autem sive sedes, ut et supra indicavi, ${ }^{176}$ imperium sive regnum est. Regnum Christi. Regnum autem Christi aeternum est, Luce 1[,33]. »Sceptrum vero a virgarum 15
ratione«, ut Coelius ${ }^{177}$ dicit in Antiquis lectionibus, »haud ita dissitum est. Id signum veteribus censebatur imperii sive regni, nec non orationis et iusticiae quoque. ${ }^{178}$ Proinde Agamemnoni late imperitanti ${ }^{179}$ et Telemacho apud Homerum concionanti ${ }^{180}$ datur, adeoque et pro ipsa regni administratione iusta et sancta usurpatur. Nam et Achilles ${ }^{181}$ per sceptrum ceu iusticiae symbolum iurat. ${ }^{182}$ Imo 20 in mystico hoc carmine, quod Solomonis alias videri poterat epithalamium esse, protinus sequitur: »Dilexisti iusticiam et odisti iniquitatem « [Ps 45,8], quibus verbis idem prorsus tradidit propheta, quod Isaias de regno Christi per 11. ac 16. cap[ut] prodidit. ${ }^{183}$ Verum in hoc unxit, instruxit et misit filium suum in mundum, ut aequitate regnaret et iusticia, qui ipsus vera est iusticia et iustificans omnes, 25 quotquot sunt fideles in eum. ${ }^{184}$ Unctio igitur haec humanae peculiariter naturae Oleum. est. Oleum vero per metaphoram spiritus sancti vires significat, ut claret Isaiae

Z. (4) Psal[mo]] Psalmo $Z F$ - (17) iusticiae] iustitiae $Z F$ - (20) iusticiae] iustitiae $Z F$ - (22) iusticiam] iustitiam $Z F$ - (25) iusticia] iustitia $Z F-(25)$ iusticia] iustitia $Z F$

174 Ps 104,4 (Vulg. 103,4).

175 Ps 45,7f. (Vulg. 44,7f.).

176 Siehe oben S. 28f.

177 Ludovico Ricchieri (Coelius Rhodiginus, 1469-1525), italienischer Humanist und Lexikograph, Autor der »Lectionum antiquarum libri XVI «, vgl. CoE III 155.

178 Rhod. lect. 194.

179 Hom. Il. 9,96-99 (Ludwich I 352f.).
180 Hom. Od. 2,37-39 (Ludwich I 23).

181 Hom. Il. 1,234-245 (Ludwich I 18f.).

182 Vgl. Rhod. lect. 194: »Proinde Agamemnoni late imperitanti datur, sed et concionanti Telemacho, verum etiam Achilli. Qui iniuria item affectus per sceptrum velut iustitiae iurat symbolum.«

183 Jes 11,1-5; 61[!].

184 Vgl. Apg 13,39; Röm 3,22. 
61. ${ }^{185}$ Sed fructus spiritus sancti sunt iusticia, fortitudo, alacritas, agendi ardor, constantia, veritas, gaudium et exultatio. ${ }^{186}$ At non dedit pater (ut baptista ait) filio spiritum secundum mensuram, ${ }^{187}$ proinde ultra consortes, reges et sacerdotes, qui Christum retro fi|gurabant, unxit deus filium; cuius rei gratia a Daniele »sanctus 5 sanctorum « appellatur. ${ }^{188}$ Observabis denique iterato iam asseri personarum discrimen et dei unitatem. Nam audivimus iamiam regem hunc nostrum unctum deum esse vocatum, sed et in calce testimonii videmus etiam eum dici deum, qui unxerit deum. Pater igitur deus est et filius deus est, et hi duo unum sunt, unus scilicet deus vivus, verus et aeternus.

10 Et: tu initio, domine, terrae fundamenta iecisti et opera manuum tuarum sunt coeli. 11 Ipsi peribunt, tu autem permanes; et omnes ut vestimentum veterascent 12 ac velut amictum circumvolves eos et mutabuntur, tu autem idem es et anni tui non deficient.

Testimonium vero hoc ex Psal[mo] $101 .{ }^{189}$ sumptum magis sensu ex antecedentibus petito quam ipsis praesentibus verbis refertur ad rei probationem. Supra enim audivimus per filium saecula esse condita, ${ }^{190}$ sed ex hoc testimonio praesenti discimus saecula esse a domino condita. Iam igitur si unus tantum est conditor, et filius fundavit et dominus fundavit, consequens est filium esse dominum; dominum, inquam, illum deum incommutabilem. Nam collatione cor-

20 ruptibilis mundi ostendit et auget incorruptibilitatem dei. Non quod sen|tiamus mundum aliquando prorsus fore abolendum, quem scimus esse renovandum; sed 2. Pet. 3[,13]. quod omnia, quae in mundo sunt, ut Ioannes ait, tempore senescant et intereant. ${ }^{191}$ Alibi enim legimus omnem gloriam carnis flori deciduo esse similem. ${ }^{192}$ Ut nunc quivis facile possit hunc locum, qui varie a multis tractatus est, per tropum expedire, metonymiam ${ }^{193}$ vel synecdocham. ${ }^{194}$ Videas autem multos se aut inani labore macerare aut nodum in scyrpo quaerere, ${ }^{195}$ quod vel tropos non observant, vel eos data opera et invidia quadam negligunt.

\section{Z. (1) iusticia] iustitia $Z F$}

185 Jes 61,1.

186 Vgl. Gal 5,22.

187 Joh 3,34

188 Dan 9,24 .

189 Ps 102,26-28 (Vulg. 101,26-28).

190 Hebr 1,2.

191 Vgl. 1Joh 2,17.

192 Jes 28,1.4.

193 Verwendung eines Wortes in der Bedeutung eines anderen, das semantisch mit dem verwendeten Wort in einer realen Beziehung steht, vgl. HLR 292.
194 Tropus, bei dem eine quantitative Verschiebung zwischen dem gemeinten und dem tatsächlich ausgedrückten Begriff vorliegt, vgl. Quint. inst. 8,6,19-22 (Winterbottom II 465f.); HWR IX 356-366.

195 Erasm. adag. 1376 (ASD II/3 382,305f.): " Nodum in scyrpo quaeris< in anxium dicebatur nimisque diligentem aut meticulosum, qui illic scrupulum moueret, vbi nihil esset addubitandum.« 
13 Ad quem autem angelorum dixit unquam: sede a dextris meis, donec posuero inimicos tuos scabellum pedum tuorum?

Hoc testimonium ex Psal[mo] 109. ${ }^{196}$ citavit etiam Christus pro assertione divinitatis suae. ${ }^{197}$ De qua re satis in superioribus. ${ }^{198}$ Hoc unum hic videbatur monendum: sedere ad dexteram, donec omnes hostes scabellum subiiciantur pedibus, 5 proverbiali locutione dictum esse pro eo, quod est: regnare, quoadusque omnes illi subdantur hostes. Quos enim prorsus vincimus nostroque subiicimus imperio, eos scabelli in morem pedibus subdidisse videmur. Inde vero nata nobis locutio, qua discimus Christum aliquando hostibus devictis triumphaturum, imo Christum orbis iudicem esse constitutum. ${ }^{199}$ Nemo igitur seducatur foelici tyrannorum suc- 10 cessu. Aderit enim $\mid$ dies, qua vos, impii, iusto iudici et ultori dignas iniuriarum dependetis poenas!

14 Nonne omnes sunt administratorii spiritus, qui in ministerium emittuntur eorum, qui futuram salutem haereditabunt?

Iterum per collationem ex conditione et officio probat angelos Christo esse $15 \quad 654 \mathrm{ZF}$ minores. »Nam Christus«, inquit, »sedet ad dexteram patris, inde venturus iudex universorum; ${ }^{200}$ sed angeli nihil aliud quam ministri sunt, non modo Christi, sed etiam omnium electorum dei; multo igitur minores sunt Christo domino.« Caeterum hanc orationem figurat interrogatione, ut hoc sit et vividior et vehementior.

Vide autem, christiane lector, quanta simplicitate, luce et puritate de angelis 20 disputet scriptura, profecto longe foelicius, quam hactenus fecerint sophistarum scholae, quae, cum dubia protulerint de angelis, multa etiam vana et superstitiosa commentati sunt innumera. Quid vero multis opus? Angeli creaturae sunt, spirituales substantiae, ministri et, ut propheta ait, flamma ignis. ${ }^{201}$ Sive ut Graeci

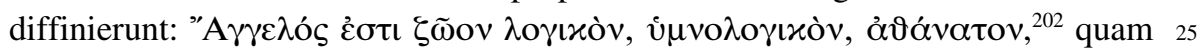
finitionem sic reddidit incomparabilis eruditionis vir Capnion: ${ }^{203} »$ Angelus est suppositum vivum, rationale, hymnisonum, immortale. ${ }^{204}$

\section{Z. (10) foelici] felici $Z F-(21)$ foelicius] felicius $Z F$}

96 Ps 110,1 (Vulg. 109,1).

97 Mt 22,44.

198 Siehe oben S. 24f.

199 Vgl. Mt 25,31f.; Phil 2,10.

200 Vgl. Symb. apost. (DH 30).

201 Ps 104,4.

202 Ps.-Athan. quaest. 30 (PG XXVIII 616B).

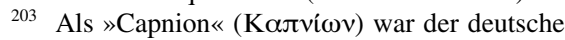
Humanist Johannes Reuchlin (1455-1522) bekannt, vgl. CoE III 145-150.
204 Reuch. quaest. Athan. E4v. Reuchlin gibt in seiner Anmerkung zum soeben zitierten Text (Antwort 30) auch den griechischen Originaltext wieder, vgl. ebd. O1r-v. Reuchlins annotierte Übersetzung von Ps.-Athan. quaest. stellt wahrscheinlich Bullingers Hauptinformationsquelle für den folgenden Exkurs über die Engel dar. Zu Entstehung und Bedeutung von Reuch. quaest. Athan. vgl. Posset 2015, 739-745. 
Quando autem conditi sint, ante hominem an post ho|minem, nihil certi prodidit scriptura, diversa vero inter se senserunt veteres Epiphanius, ${ }^{205}$ Hieronymus, Damascenus $^{206}$ et reliqui. ${ }^{207}$ Sed quid haec ad religionem veram? Certe conditos esse constat. Constat item eos nullo certo constringi numero. Nam in Daniele 5 legimus: »Millia millium ministrabant ei et decies centena millia millium assistebant ei« [Dan 7,10]. »Quae verba prophetae Ioan[nes] Chrysostomus in Panegyrico de angelis 3. dicit esse scripta de supernis virtutibus et potestatibus, quas numerans innumerabiles ostendit et indeterminata mensura non mensurabiles repraesentavit. ${ }^{208}$ Ad essentiam fortassis eorum dilucidius exponendam, faciunt prophetae verba, quibus et spiritus vocat angelos et flammam ignis. ${ }^{209}$ Opponitur Angeli spiritus. autem vocabulum »spiritus « corpori corruptibili et gravi, ut intelligamus angelos esse spirituales substantias, incorruptibiles, sui generis et corporis, absque impedimentis, onere et adfectibus humanis. Unde in evangelio disserens dominus de animabus corpore solutis et perpetuis, adeoque de statu animarum post hanc 15 vitam dicit: »Et erunt sicut angeli dei« [Mt 22,30]. Et Chrysostomus in Pan-

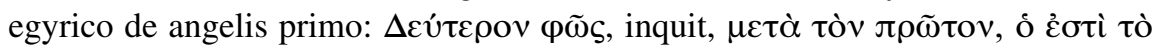

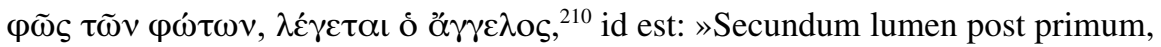
quod est lumen luminum, dicitur angelus. ${ }^{211}$ Item Dionysius ${ }^{212}$ in Divinis nominibus, cap[ite] 4.: »Angelus est«, inquit, »imago dei, ostensio $\mid$ occultae lucis, 20 speculum purum, nitidissimum, incoinquinatum, immaculatum, incontaminatum,

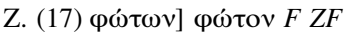

205 Reuch. quaest. Athan. C4r: »Epiphanius Cypri archiepiscopus in libro contra Paulum Samosatensem, cui titulus extat Panaria, latius exposuit asserens una cum caelo et terra illos [sc. angelos] esse creatos. « Vgl. Epiph. haer. 65,4f. (PG XLII 17C-20B). Epiphanios (ca. 310 402), Asket und Bischof von Constantia/Salamis (Zypern), besonders bekannt für sein

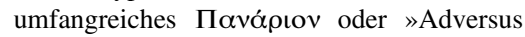
haereses «, vgl. NP III $1152 \mathrm{f}$.

206 Johannes von Damaskos (7./8. Jh. n. Chr.), christlicher Theologe, besonders bekannt für seine systematische Darstellung »Expositio fidei «, vgl. NP V $1069 f$.

207 Reuch. quaest. Athan. I3r: »Constat autem aliquos decrevisse ante primum diem mundi constituti angelos esse creatos, ut docet sanctus Hieronymus in epistola Pauli ad Titum capite primo. Et Damascenus libro secundo cum similibus.« Vgl. Hier. in Tit. 1,2-4 (PL XXVI 594B); Ioh. Dam. exp. fid. 17 (Kotter 48,7581).

208 Reuch. quaest. Athan. K1v. Bei den hier erwähnten »Panegyrici de angelis« handelt es sich vermutlich um Homilien, die Johannes Reuchlin handschriftlich vorlagen und die er als ein Werk des Johannes Chrysostomos betrachtete. Keine frühneuzeitliche Ausgabe der Werke des Chrysostomos enthält allerdings eine Schrift mit diesem Titel. In der PG findet sich der Text, den Reuchlin als »ersten Panegyricus « bezeichnet, unter den Schriften des Theodoros Studites (759-826, vgl. Pratsch 1998), Abt des Studiosklosters in Konstantinopel, vgl. Theod. Stud. coel. (PG XCIX 729748); Adalma 1965, Nr. 44.

209 Ps $104,4$.

210 Theod. Stud. coel. 12 (PG XCIX 745A).

211 Reuch. quaest. Athan. I4v.

212 »Dionysios Areopagites«, Pseudonym eines Autors, der sich als Paulus-Schüler (vgl. Apg 17,34) und »Bischof von Athen« ausgab, aber wohl in der Zeit der Wende vom 5. zum 6. Jh. $\mathrm{zu}$ datieren ist. Dem »Corpus Dionysiacum « war eine beachtliche Wirkungsgeschichte beschieden, welche bis heute andauert, vgl. NP III 647f.; Suchla 2008. 
suscipiens totam (si phas est dicere) pulchritudinem boniformis divinae speciei et syncere resplendens seu repraesentans in seipso, quantum possibile est, eam, quae in adytis et secretis habitat bonitatem. ${ }^{213}$ Haec Dionysius. Sic, inquam, erimus sicut angeli dei, ${ }^{214}$ sic, inquam, sunt illi spiritus quoque. Quo plurimum facit etiam alia prophetae similitudo a flamma ignis ducta. ${ }^{215}$ Nam angeli revera non sunt flammae corporeae et visibiles, sed diaphonia, pulchritudine, puritate, vi, agilitate et celeritate flammam referunt. Hinc et »seraphim « nomen proculdubio $\mathrm{ab}$ ardore indepti sunt, ut et alia multa ex ipsa re nomina. ${ }^{216}$ Unde fortassis non fuerit operaepretium pluribus de angelorum inter se substantia disserere. Verisimile enim est, ut »omnes homines unius esse speciei humanae, sic omnes angelos unius esse speciei angelicae $\ll{ }^{217} \mathrm{Et}$ ut diversa sunt hominum munia, sic alia atque alia angelorum esse officia, ex quibus et deinde diversa existant nomina. Cui concordat etiam Chrysostomus in Panegy[rico] de ange[lis] 1., cum de universis et singulis angelis ita quaerit: »Quomodo unius substantiae existentes, non unam ac similem formam et visionem in terra versantes ostendunt hominibus? ${ }^{218} 15$ »Damascenus (fortasse melius) arbitratur nescire nos, an sint aequales angeli, an distent inter se. $\ll^{219}$ Hoc autem satis | certum est: varias de iis texi in sacris expositiones, quae partim ex ea ductae sunt forma, qua se ostenderunt hominibus, partim vero a rebus humanis per allusionem transumptae sunt. Sic enim legimus angelos veluti satellites domini stipare latera, applaudere, succinere, volare, ${ }^{220}{ }_{20}$ denique talariis instructos nunciare et renunciare, aliam subinde atque aliam speciem induere, ${ }^{221}$ salva tamen intus substantia propria, eam item defuncto munere rursus exuere et ad genium redire, monere, custodire, deducere et in omnibus humano generi inservire. ${ }^{222}$ Iccirco enim a deo sunt conditi, ut et cum deo gaudeant, et humano generi inserviant. Plura hic inseri possent, sed cessemus 25 de hisce rebus, quae revera supra nos sunt, cu|riosius disputare; satis sit ista delibasse. Quin potius miretur quisque apud se et dei ineffabilem in condenda angelica substantia cum sapientiam tum potentiam et nunquam satis laudatam bonitatem, qua factum est, ut miseris nobis mortalibus tam dignos et speciosos

\footnotetext{
Z. (1) phas] fas $Z F$

213 Zit. nach Reuch. quaest. Athan. I4v. Vgl. Ps.Dion. Ar. div. nom. 4,22 (Suchla 169,22170,5).

214 Mt 22,30.

215 Ps $104,4$.

216 Vgl. Isid. orig. 7,5,24 (Lindsay I T2v,28-30): »Seraphin quoque similiter multitudo est angelorum, qui ex Hebraeo in Latinum ardentes vel incendentes interpretantur.«

217 Reuch. quaest. Athan. K2v.

218 Zit. nach Reuch. quaest. Athan. K3r. Vgl.

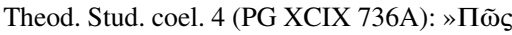

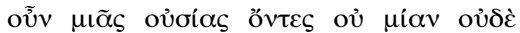

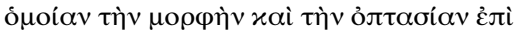

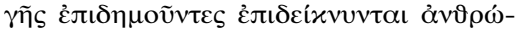

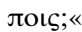

219 Reuch. quaest. Athan. K3r. Vgl. Ioh. Dam.

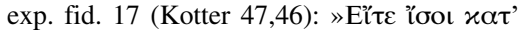

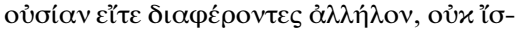
$\mu \varepsilon v . \ll$

220 Jes 6,2f.; Lk 2,13f.

221 Vgl. Num 22,22-35; Mt 28,2f.; Lk 1,11-20.

222 Jos 5,13-15; Dan 10,13.21; 12,1. 
dederit ministros. Non enim satis fuit deo vere opt[imo] max[imo], ut conderet hominem et in hunc mundum ceu paradysum induceret, aleret, conservaret ac ornaret, nisi et angelos nobis adderet et ministros et custodes, imo et filium pro nobis traderet in mortem. Haec, inquam, miremur, istis gratias agamus, denique 5 et vitam nostram sic instituamus, ut dignitatis et vocationis nostrae memores cogitemus et angelos et deum $\mid$ ipsum omnium operum nostrorum astare testes et spectatores. Et haec per necessariam digressionem hactenus, nunc ad ipsam rem redimus.

1 Propterea oportet nos vehementius attendere his, quae dicta sunt nobis, ne quando perfluamus.

Hisce tandem absolvitur sensus, qui ab initio 1. cap[itis] hactenus fuit suspensus. Nunc enim palam, quod voluit, infert, quasi dicat: »Cum ergo filium nobis miserit deus, angelorum imo universae creaturae dominum, aequum est, ut maximo animi fervore ea amplectamur, quae tantus nobis tradidit legatus, videlicet ne 15 aliquando id nobis excidat, quod docuit, vel perfluat, quod animis insidere voluit.«Videtur autem apostolus metaphoram a fluida sumpsisse papyro, quae literarum characteres obscurius recipit vel receptas protinus diffundit transmittitque, ut et animo minus attento accidit, cui, nisi firmus sit et solidus, ea excidunt, quae negligentius audierat. Ioannes Chrysostomus exponit: »Ne quando pereamus « et allusum putat ad illud Solomonis: »Fili mi, ne effluas « [Spr 3,21]. Quae autem dilabuntur, ea prorsus pereunt. ${ }^{223}$

\section{Etenim si is, qui per angelos dictus fuerat sermo, fuit firmus et omnis} transgressio et inobedientia iustam praemii repensationem accepit, 3 quomodo nos effugie|mus, si tantam neglexerimus salutem?

25 Caussa est superioris et, ut supra indicavimus, ${ }^{224}$ huius argumentationis veluti maior propositio. » $\mathrm{Si} \ll$, inquit, »maiestatem et authoritatem quandam, sed et certitudinem et robur habuit, quod per angelorum legationem docuit deus; certe maiorem authoritatem et gravius pondus habeat necesse est, quod per filium, angelorum dominum, deus orbi nunciavit. Et si dignas dederunt poenas, qui vel 30 angelicam vel propheticam legationem aut aspernati sunt, aut ei non obedierunt;

Z. (1) opt[imo] $\max [\mathrm{imo}]]$ optimo maximo $Z F$ - (2) paradysum] paradisum $Z F$ - (11) 1. cap[itis]] primi capitis $Z F$

223 Erasm. Hebr. (ASD VI/10 238,92-94): »Chrysostomus interpretatur >pereamus< sumptumque putat ex prouerbiis Salomonis: >Fili mi, ne effluas<, vić, $\mu \grave{\eta} \pi \alpha \rho \alpha \rho \rho v \tilde{n} s$. Prorsus enim irreparabiliter perit quod dilabitur.« Vgl. Chrys. Hebr. 3,3 (PG LXIII 31).

224 Siehe oben S. 19. 
quanto dignioribus gravioribusque mulctabuntur poenis, qui tantam contempserint salutem? Nam Christus Iesus dei filius illa ipsa salus est et negotium Christi, quod negotium evangelii est, illud salutare et vivificum negotium est, ideoque quisquis illud contempserit graviter puniendus erit. ${ }^{225}$ Hic vero non erat opus copiosioribus exemplis. Nam satis constabat omnibusque Hebraeis notus erat ille maiorum miserabilis in deserto interitus. ${ }^{226}$ De quo et ipse apostolus satis prolixe disputabit in sequentibus, maxime in cap[ite] $3 .^{227}$

3 Quae cum initio quidem coepit enarrari per ipsum dominum, ab iis, qui audierant, in nos confirmata fuit 4 contestante simul deo signis et prodigiis et virtutibus variis et spiritus sancti donis, secundum suam voluntatem distributis.

Quia vero tantam dixerat salutem, obiter nunc per amplificationem (quod haec res maxime faceret ad praesens institutum) ostendit, quanta nam sit illa salus,

Quomodo ad nos perlatum evangelium. denique et quam rata, certa et firma. Principio autem id demonstrat per authorem et professores, deinde vero et a signis et miraculis; argumentis, inquam, a pro- 15 nunciatorum loco $^{228}$ ductis. Dicit autem hanc evangelii lucem salutemque ab ipso rerum domino fuisse praedicatam, qua re nihil potest augustius nedum dici, sed ne cogitari quidem. Maximum enim est, quod ipse dei filius in persona (ut dici solet) propria evangelium mundo praedicavit. Marcus enim: »Venit«, inquit, »Iesus in Galilaeam praedicans evangelium regni dei, dicens: >Impletum est 20 tempus instatque regnum dei; resipiscite ergo et credite evangelio « [Mk 1,14f.]. Deinde vero $\mid$ illud ipsum evangelium, sicuti prophetae praedixerant et Christus Apostoli. tradiderat, ita ab ipsis quoque praedicatum est apostolis, quos delegerat Christus auditores, testes et spectatores cum operum omnium tum doctrinae universae. Illi enim, posteaquam Christus defuncto munere suo coelos conscendisset, ${ }^{229}$ in or- 25 bem diffusi totum mundum praedicatione evangelii replevere. Sed ne istis quidem contentus deus, vocavit et post istos omnes et post coeptam etiam ac firmatam evangelii praedicationem apostolum Paulum virum primarium, ${ }^{230}$ qui evangelium suum non didicit neque ab ho|mine neque per hominem, ${ }^{231}$ sed ab ipso coelitus deo. Coelestis enim scholae discipulus recte meritoque dixit: »In nos

225 Vgl. Bull. vorl. Hebr. [2,1] (Berg/Hausammann 150): »So die nie ungestrafft blibend sind, die der englen wort verachtet habend, so werdent one zwifel ouch die tüwr gestraafft, welche des herren der englen wort verachtend. Christus aber ist der herr der englen, Gottes sun. Dorumb soll niemands sin wort verschmahen, will er anders ungeplaget sin.«

226 Num 14

227 Hebr 3,16-19.
228 Vgl. Agric. inv. 1,23 (Mundt 138,1-10): »Locum, qui sumitur ex eis, quae quisquam de re proposita vel dixit, vel (quod perinde est) sensit, $[. .$.$] pronunciata appellare maluimus [. .$.$] .$ Pronunciata autem dicimus, quae quisquam ulla de re, ut affirmaret aut negaret, est elocutus.«

229 Lk 24,51; Apg 1,9.

230 Apg 9,15.

231 Gal 1,15f. 
confirmata fuit «, sentiens evangelium et ad se et ad ecclesias indubitata fide perlatum. Haec vero de evangelii authoritate primisque professoribus. Iam vero, ne quid a quoquam desyderari posset, ipse deus praedicationem hanc multis ornavit signis firmioremque reddidit prodigiis, virtutibus et donis spiritus sancti Miracula.

5 variis orbi coelitus distributis. Notissima enim sunt, quae prodidere de Christi atque apostolorum miraculis, et evangelistarum et Actuum apostolorum monumenta. Tam firma, tam, inquam, certa est evangelii doctrina, ut nunc maxime peccarit, qui tantam neglexerit salutem. Ita singula probe referuntur ad statum.

Caeterum per signum intellexit apostolus (ni fallor) experientiam, quemad- signum.

10 modum eius quoque usus est apud dialecticos et rhetores, qui pallorem, trepidationem, vestes sanguine conspersas signa caedis appellitant. ${ }^{232}$ Ita usurparunt et angeli apud Lucam cum dicunt: »Et hoc vobis signum: invenietis infantem « [Lk 2,12] etc. Helvetii propriissime vocamus signum ein wortzeychen, quod verbis additur, vel ein w arzey chen, quod res, quibus additur, firmet. Iam vero 15 Non[ius] Marcellus ${ }^{233}$ prodigia ait esse deorum iras vel minas, ${ }^{234}$ sed et Latini omnes prodigium »dictum volunt quasi porro agendum $\ll^{235}$ vel praedicidium, quod semper aliquid mali $\mid$ praesagiat. Hic tamen satis constat prodigium accipi pro miraculo et re, quae fit praeter expectationem et rerum pene naturam, quale illud est, quod mortui ad vivos redeunt, caeci visum recipiunt, claudi saliunt et 20 leprosi mundantur, ${ }^{236}$ non herbis aut aliquo adiuti medicamine, sed solo verbo curati. Imo ne quid obmitteret apostolus, subdidit »varias virtutes« quoque. Est

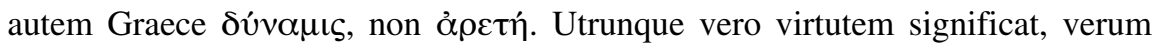
hoc, ut opponitur vitio, illud autem, ut opponitur imbecillitati. Virtus igitur hoc loco potentia est, sed et maiestas, authoritas et dicendi libertas. Dona autem Dona spiritus. spiritus sancti varia sunt, ut copiosioribus indicavit apostolus in 1. ad Cor[inthios] cap[ite] 12. ${ }^{237}$ eaque dividit deus sicuti vult, huic liberalius illi vero partius. Nec est, qui deum huius rei caussa in ius vocare possit.

Haec vero omnia evangelio adiuncta sunt testimonia, ne quis vel fidem vel Authoritas maiestatem vel authoritatem in eo desyderaret. Si enim propterea alicui religioni evangelii

30 fides habenda est, quod docto orta sit authore, vel magnis et laudatis propagata sit professoribus, vel admirandis roborata sit prodigiis, certe christiana doctrina

Z. (3) desyderari] desiderari $Z F$ - (26) partius] parcius $Z F$ - (29) desyderaret] desideraret $Z F$

232 Cic. inv. 1,48 (Hubbell 86-88): »Signum est quod sub sensum aliquem cadit et quiddam significat quod ex ipso profectum videtur, quod aut ante fuerit aut in ipso negotio aut post sit consecutum, et tamen indiget testimonii et gravioris confirmationis, ut cruor, fuga, pallor, pulvis, et quae his sunt similia «; Sen. Ag. 947f. (Miller 78): »Adest cruenta coniugis victrix sui / et signa caedis veste maculata gerit.«
233 Nonius Marcellus (4./5. Jh. n.Chr.), Grammatiker und Schriftsteller, Autor von »De compendiosa doctrina ad filium «, vgl. NP VIII 994f.

234 Non. 5 (Lindsay III 701,2).

235 Mirab. pol. 146r.

236 Mt 11,5.

237 Kor 12,4-11. 
imprimis amplectenda erit; utpote quae authorem habeat non angelum, philosophum, divinum aut magnum alias hominem, sed ipsum dei filium. Professores autem non prophanos, inconstantes, contentiosos aut iactabundos sophi|stas, sed divinitus inspiratos prophetas et spiritu dei plenos apostolos, qui non modo innocentia vitae, sed et sanguine comprobarunt, quod docuerunt; nec hoc modo, sed et talia doctrinae coelesti addidere et signa et prodigia (operante per eos deo), qualia non habuit vel vidit in orbe religio ulla. Pessime igitur cesserit nobis, si adeo sanctam, eximiam, certam, ratam, adeoque indubitatam incredulitate neglexerimus cum salutem tum doctrinam.

Disce item ex hoc apostoli loco signa addi doctrinae et non doctrinam signis attemperari. Signa enim per se nihil probant, maxime si scripturis contraria sint. signorum. Sic enim dicit in Deuteronomio dominus: »Si surrexerit propheta et praedixerit signum atque portentum, et evenerit quod locutus est, dixerit autem tibi: >Eamus et sequamur deos alienos<, non audies prophetam, quia tentat vos dominus deus vester«, Deut. 13[,2-4]. Plura huius generis invenias et apud Augustinum, contra 15 Petiliani ${ }^{238}$ Donatistae epistolam, cap[ite] $16 .^{239}$

\section{Non enim angelis subiecit orbem terrae futurum, de quo loquimur.}

Hactenus absolvit argumentum huius negotii potissimum: Christum angelis esse maiorem; sed angelorum sermonem nunquam impune fuisse contemptum; unde consequens sit $\mid$ et evangelium, Christi sermonem, non posse citra maximam 20 aspernantium contemni iacturam; | consulto igitur facturos Iudaeos, si evangelii praedicationem neque oderint neque tantum legatum contempserint. Quae vero sequuntur, potissimum etiam pertinent ad superiorem probationem, quod Christus angelis maior sit. Fit tamen iisdem etiam transitus ad caussam consequentem de vera Christi carne, quae caussa re ipsa naturaque pendet ex rerum statu. Occa- 25 sione enim ex praecedentibus accepta, veluti digrediens, dissolvit, quod ex Psal[mo] 8. poterat obiici, Christum prophetae testimonio infra angelos (ut sic dicam) esse minoratum; ${ }^{240}$ proinde ostendit apostolus, quomodo dixerit propheta filium angelis aliquanto esse minorem. Qua expositione adactus mox etiam copiosius disserit de caussis humanae naturae a Christo assumptae quodque veram 30 assumpserit carnem. Hic vero omnium consequentium status est, hic ordo. Annotandum porro et illud, enallagen ${ }^{241}$ temporis inesse huic locutioni: »De quo

\section{Z. (27) Psal[mo]] Psalmo $Z F$}

238 Petilianus (gest. ca. 420), Donatistischer Bischof von Cirta, vgl. NP IX 662.

239 Aug. un. eccl. 19,49 (CSEL LII 295f.). Augustins Schrift »De unitate ecclesiae« zirkulierte auch unter dem Titel »Liber contra Pe- tiliani Donatistae epistolam«, vgl. Aug. op. VII 343-376.

240 Ps 8,6; Hebr 2,7.

241 Vgl. Erasm. cop. 1,13 (ASD I/6 54,547f.): »[Enallage] est, cum eadem voce modice de- 
loquimur«. Id enim posuit pro eo, quod est: »De quo sequenti testimonio loquemur $\ll$.

6 Testatus est autem alicubi quidam dicens: quid est homo, quod memor es eius, aut filius hominis, quod invisis illum? 7 Fecisti eum paulo inferiorem angelis, gloria et honore coronasti eum et constituisti eum super opera manuum tuarum. 8 Omnia subiecisti sub pedes eius. revera gratiarumactio, laus et admiratio est potentiae bonitatisque dei, quod tam accurate miserum curet genus mortalium. Quae itaque sunt omnium revera ho10 minum, ea apostolus per catagogam ${ }^{243}$ peculiariter Christo tribuit, ut et alia hominis ornamenta decoraque per allegoriam de resurrectione et regno Christi exponit. Sed audiamus ipsum apostolum sancte de prophetae verbis disserentem:

8 In hoc enim, quod et subiecit omnia, nihil omisit illi non subiectum. At nondum videmus illi omnia esse subiecta.

15 Initio $x \alpha \tau^{\prime} \alpha^{\prime} v \tau \iota \sigma \tau \rho \varepsilon ́ \varphi o v \tau \alpha^{244}$ iisdem prophetae verbis, quae obiiciebant adversarii, probat Christum rerum esse dominum, quod de angelis (ut et supra audivimus) dici non possit, utpote quibus orbis terrae non sit subiectus. ${ }^{245}$ Argumentatur autem »ex toto ${ }^{246}$ et dicit: qui dicit se omnia alicui subiecisse, is ne angelos quidem imo nihil prorsus excepit, quod non subiecerit; deus autem subiecit

20 Christo omnia, ut ait propheta; itaque nihil est, quod Christo non sit subditum. Caeterum cum in praesentiarum nonnulla sint, quae ei non subiecta sint, praevenit obiectionem et ait: etiamsi in praesentiarum omnia Christo nondum sint subiecta, subiiciet tamen is in futuro, qui dixit: »Sede a dextris meis, donec ponam inimicos tuos scabellum pedum tuorum « [Ps 110,1]. | De qua subiectione scripsit et 25 in 1 . ad Cor[inthios], 15. cap[ite], apostolus. ${ }^{247}$ Sic autem vides authorem etiam adversariorum uti argumento pro re sua atque ista omnia etiamnum referri ad superiorem probationem, Christum angelis esse maiorem. Sequentibus vero deflectit ad aliud et obiectionem tandem diluit.

Z. (25) Cor[inthios]] Corinth[ios] ZF

flexa varietatis nonnihil conciliatur.« Bullinger scheint hier den Begriff »Enallage « allerdings bloß als Synonym für »Veränderung « zu verwenden.

242 Ps 8,6.

243 Die »catagoga « definiert Bullinger als Anwendung eines allgemeinen Sachverhaltes auf et- was Spezielles, vgl. Bull. stud. rat. 26 (Stotz I 10,30f.; II 250).

244 Siehe oben S. 18, Anm. 93.

245 Hebr 2,5.

246 Zum »locus de toto et partibus« vgl. Agric. inv. 1,9 (Mundt 58-64).

247 Kor $15,24-28$. 
9 Eum vero, qui pusillum quiddam diminutus fuerat infra angelos, cernimus Iesum propter cruciatum mortis gloria et honore coronatum, ut per gratiam dei pro omni gustaret mortem.

Quomodo Christus angelis minor sit.

Demonstrat enim nunc eodem prophetae testimonio Christum sane angelis aliquanto esse minorem, sed addit, quomodo aut quare sit minor quodque id gloriae Christi nihil deroget. Minorem enim esse, si quis spectet crucem et mortem, quae in angelos prorsus non incidant. ${ }^{248}$ Hic tamen velut per parenthesim intercludit nihilo minus ipsum »gloria et honore coronatum«, id est, mox ab ipsa morte per resurrectionem declaratum esse filium dei; adeoque et ipsam mortem Christi non poenam mulctamve fuisse delicti, sed divinae gratiae argumentum. Id enim sentit 10 cum dicit: »Ut per gratiam dei pro omni gustaret mortem. « Unde iam claret gloriam Christi nihil obscuratam esse cruce et interitu, ut etiamsi hac parte minor videatur, maior tamen sit passi gloria, quam si passus non fuisset. ${ }^{249}$ Neque vero nescio apud | Hebraeos legi: »Minuisti eum paulo minus a deo $\ll .{ }^{250}$ Verum haec lectio sensu nihil discrepat $\mid$ a Paulina, siquidem et ipse Christus testatus est patrem se maiorem esse ${ }^{251}$ quam rem ne ipse quidem dissimulavit maximus divinitatis Christi assertor Athanasius, qui dixit: »Aequalis patri filius per divinitatem, minor patre secundum humanitatem. $\ll^{252}$

10 Decebat enim eum, propter quem sunt omnia et per quem sunt omnia, $u t$, multis filiis in gloriam adductis, principem salutis illorum per afflictiones perfectum redderet.

Ansa igitur accepta ex professo nunc asserit veram Christi carnem et disserit de caussis incarnationis eius. Primo, ut videremus incarnatione adeo non obscurari

248 Erasm. Hebr. (ASD VI/10 242,125-131): »Proinde mihi videtur illud >paulominus $<$ [...] non ad dignitatis imminutae modum esse referendum, sed ad temporis modum quo versatus est Christus in terris, [...] ad Iesu vitam actam in terris et passionem.«

249 Vgl. Erasm. par. Hebr. (ASD VII/6 48,109115): »Videbatur esse factus inferior angelis qui nec morti nec vlli dolori sunt obnoxii, nunc tanta gloria et honore coronatus est vt mundus intelligat ipsum, immunem ab omni culpa, iuxta voluntatem Dei volentis humanae saluti consulere, subisse mortis supplicium. Siquidem mors illius non erat poena commissi per illum, sed erat fauor diuinus erga genus humanum, quod sua gratuita beneficentia redimi voluit per mortem innocentissimi Filii sui, Iesu Christi.«
250 Vgl. Fab. Stap. Hebr. 233v [vgl. ASD IX/3 201,4-9]: »Vulgata aeditio: minuisti eum paulominus ab angelis. Sic habet interpres Pauli. Verum id ex Septuaginta desumpsit et non interpretatus est, quod dicebat Paulus. Nam certum est Paulum hanc epistolam Hebraice scripsisse et in forma verbum hymnologiae Davidicae adduxisse, ubi >deus $<$ habetur [...]. Ergo, quod dicitur $>$ ab angelis $<$, interpretis est, non Pauli, sed Pauli >a deo<.« Aufgrund ihrer unterschiedlichen Interpretation von Hebr 2,7 entflammte zwischen Erasmus von Rotterdam und Jacques Lefèvre d'Étaples eine heftige Kontroverse; vgl. dazu Steenbek 1996, 7-16.

251 Joh 14,28.

252 Symb. Quic. (DH 76). 
gloriam Christi, ut ea mundo magis innotuerit. Secundo, ut nunc ostendat Christum verum esse hominem, quem superiore cap[ite] verum demonstravit esse deum. ${ }^{253}$ Prior autem incarnationis et mortis Christi caussa est ordinatio, consi- 1. caussa lium et iusticia dei, quem hic propter maiestatem ineffabilem periphrasi circum- ${ }^{\text {assumpti }}$ hominis.

5 scribit: illum, inquam, eum esse, »propter quem et per quem sint omnia«, id est, qui sit omnium vita et essentia. Dicit ergo: »Sic statutum erat apud deum, imo id dei exigebat iusticia et sic decebat, ut deus miserum genus mortalium non alia via quam per mortem $\mid$ Christi reduceret ab exilio in aeternas sedes.« Oportuit enim immundos ac imperfectos prius mundari et perfici per eum, qui mundus erat et perficere sive expiare poterat. Caro, imo totus homo, perierat; carne igitur et homine restituendus erat. Mortem meruerat homo, morte ergo redimendus erat. Denique corrupta erat omnis caro, ${ }^{254}$ proinde oportuit dei descendere filium et ex virgine per sanctum incarnari spiritum. Quomodo enim moreretur, qui carnem non haberet? Atque haec potissima est incarnationis dominicae caussa, de qua 15 pluribus ipse disseret in sequentibus apostolus.

11 Quandoquidem et qui sanctificat et qui sanctificantur ex uno sunt omnes.

Christus sanctificat, id est, purgat, abluit, lustrat et emundat nos. Homines vero tanquam immundi sanctificamur. Iam ergo, ne quis miraretur, quod dixerat adflictione sive cruce nos per authorem salutis Christum vere absolutos esse et perfectos, subiicit caussam: »Nam ex uno«, inquit, »patre Adam sive homine sumus omnes, tam nos, qui sanctificamur, quam ille, qui sanctificat, Christus; hinc enim vere pati et adfligi potuit, quod verus nobiscum ex homine homo fuit.« Hac caussa deducit Lucas genealogiam Christi ad Adae usque generationem, ${ }^{255}$ ne unquam de vera ambigerimus Christi humana carne.

11 Quam ob caussam non erubescit fratres illos vocare, 12 dicens: annunciabo nomen tuum fratribus meis, in medio ecclesiae laudabo te. 13 Et rursum: et ero fidens in illo. Et iterum: ecce ego et pueri, quos mihi dedit deus.

30 Quam ob caussam? Quod ex uno nobiscum sit patre genitus, »non erubescit nos fratres appellare«. Id vero clarissimis scripturae locis confirmat, ut ipsa Christi humanitas non minoribus infirmioribusve nitatur scripturae testimoniis quam ipsa

Z. (2) cap[ite]] capite $Z F$ - (3) Marg. 1.] Prima $Z F$ - (4) iusticia] iustitia $Z F$ - (7) iusticia] iustitia $Z F$

\footnotetext{
253 Hebr 1,2-4.

255 Lk 3,23-38.

254 Vgl. Gen 8,21; Eph 2,3.
} 
eius divinitas, quam 1. cap[ite] satis valide confirmavit. ${ }^{256}$ Primum vero testimonium sumpsit ex Psal[mo] 22., ${ }^{257}$ qui de Davide scriptus est, sed is typum gessit Christi, qui nos mortales nominat fratres et gloriam dei splendide in mundo per evangelii praedicationem annunciavit. Secundum autem accepit ex Psal[mo] 17., ${ }^{258}$ qui pari ratione Christo aptatur per allegoriam, praesenti autem negotio sic accomodatur: si Christus purus duntaxat fuisset deus, non homo etiam verus, non dixisset: »Ego ero fidens in illo.« Quis enim sanae mentis dixerit deum deo fidere? Sed Christus deo fidit, proinde secundum hominem fidat oportet, verum itaque hominem esse Christum necesse est. Sed tertium testimonium mutuatus est ex Isaiae cap[ite] $8 .^{259}$ eadem denuo catachresi ${ }^{260}$ usus.

14 Posteaquam igitur pueri commertium| habent cum carne et sanguine et ipse similiter particeps factus est eorundem, ut per mortem aboleret eum, qui mortis habebat imperium, hoc est diabolum, 15 et libe|ros redderet eos, quicunque metu mortis per omnem vitam obnoxii erant servituti.

Applicat nunc negotio et instituto suo testimonia praecitata, maxime vero ulti- 15 mum. Istis autem exegetica epanaphora ${ }^{261}$ clarius repetit et exponit priorem illam Idiotismus. dominicae incarnationis caussam. Et per »pueros« quidem intelligit homines mortales, qui »commertium« habemus »cum carne et sanguine«, id est, qui revera caro et sanguis sumus, veri homines, qui carne et sanguine corpore et anima constamus. Eorundem autem ipse Christus »particeps factus est «, hoc est, prorsus 20 nobis similis factus est. Id enim pollent isti in sacris usitati Hebraismi. Nam ad Philippenses absque omni huius rei involucro dicit apostolus: »Christus exinanivit se ipsum, forma servi assumpta, in similitudine hominum constitutus et figura repertus, ut homo« [Phil 2,7]. Et haec quidem veri hominis probatio est, sequitur nunc assumpti hominis caussa, sive superius indicatae caussae expositio. 25 Assumpsit autem hominem, ut per mortem (quae non poterat fieri, nisi in vero homine) solveret, evacuaret et aboleret $\mid$ mortis et authorem et principem diabolum; hoc est (adduntur enim sequentia expositive), ut absolveret et liberaret omnes eos, qui peccatorum iugo oppressi nihil aliud quam peccati authoramentum, ipsam videlicet aeternam expectabant mortem. Nam aeterna illa mors pec- 30 catorum nostrorum mulcta, corporali et innocenti morte Christi devicta est, eaque nobis per Christum spes data est, ut etiamsi semel corpore migrandum et moriendum sit, aeterna tamen morte simus liberati. Atque hic est fructus carnis

\section{Z. (18) commertium] commercium $Z F$}

256 Hebr 1,5-13.

257 Ps 22,23.

258 Vgl. Ps 18,3 (Vulg. 17,3).

259 Jes 8,18 .
260 Siehe oben S. 12, Anm. 54.

261 Isid. orig. 1,36,9 (Lindsay I F1v): »Epanaphora est in uno versu per principia sensuum eiusdem verbi repetitio.« 
dominicae, de quo copiosius in Roma[nis] apostolus cap[ite] 5., 6. et 8.;62 item Ioan[nes] 6., 8., 11. et $12 .{ }^{263}$ Summa: oportebat incarnari Christum, ut haberet, quod pro nobis offerret et holocausto proprii corporis mortales vitae restitueret etc.

16 Nuspiam enim angelos assumit, sed semen Abrahae assumit.

Epanaphora ${ }^{264}$ est et asseveratio vehementissima, quam extulit sententia ex con- Christus trariis composita, ne cuiuspiam animus vel suspicari posset hominis vel huma- ${ }_{\text {assumpsit }}$ nitatis in Christo defuisse quicquam. »Nuspiam«, inquit, »legas in divinis literis, quod deus assumpserit angelicam naturam vel spiritum vel corpus aereum. «Nam 10 per angelum intellexit omnem invisibilem, subtilem aut spiritualem substantiam. Assumpsit autem hominem verum, certe ex semine (ut omnis testatur scriptura) Abrahae, verus homo existens, natus ex vero homi|ne virgine Maria. Caussam eius istis verbis reddidit Tertullianus in libro de carne Christi: »Christus«, inquit, »salus hominis fuit caussa, scilicet ad restituendum, quod perierat. Homo perierat, 15 hominem restitui oportuerat. Ut angelum gestaret Christus, nihil tale de caussa est. Nam etsi angelis perditio reputatur in ignem praeparatum diabolo et angelis eius, ${ }^{265}$ nunquam tamen illis restitutio promissa est. Nullum mandatum de salute angelorum suscepit Christus a patre. Quod pater neque repromisit neque mandavit, Christus administrare non potuit. ${ }^{266}$ Haec Tertullianus. Sed quomodo assumpserit semen Abrahae Christus, docuere copiosioribus Matthaeus atque Lucas. $^{267}$

Nos autem cum ex hoc Pauli loco tum ex aliis scripturae testimoniis, denique ex ipsis definitionibus ecclesiasticis credimus et confitemur, quod tantum filius humanam assumpserit naturam, non pater, non spiritus sanctus. Quia non conveniebat, ut ad alium transiret filii nomen, qui non esset aeterna nativitate filius. Sed et unum confitemur filium, non duos. Ideo qui erat in divinitate dei patris filius, eum oportebat fieri in homine hominis matris filium. ${ }^{268} \gg$ Dei ergo filius factus est hominis filius, natus secundum veritatem naturae, ex deo dei filius, verus deus et secundum veritatem naturae ex homine hominis filius, homo verus; 29v $F \quad 30$ ut veritas geniti non adoptione, non gratia, non appellatio|ne, sed in utraque nativitate filii nomen nascendo habere essetque verus deus et verus homo unus ille filius. Non enim duo dii sunt, non duo filii, non duo Christi, sed deus et homo unus filius, qui propterea unigenitus appellatur. Manet enim in duabus substantiis

262 Röm 5,6-11; 6,1-11; 8,2-4.

263 Joh 6,53-63; 8,21-30; 11,25f.; 12,24-28.

264 Siehe oben S. 44, Anm. 261.

265 Vgl. Mt 25,41.

266 Tert. carn. 14,1f. (CCSL II 899,3-11).

267 Mt 1,18-23; Lk 1,26-38.

268 Vgl. Gennad. dogm. 2 (PL LVIII 981A-B):
»Non pater carnem assumpsit, neque Spiritus sanctus, sed Filius tantum: ut qui erat in divinitate Dei Patris Filius, ipse fieret in homine hominis matris filius; ne filii nomen ad alterum transiret, qui non esset aeterna nativitate filius. «
Confessio de dominicae incarnationis sacramento. 
sive naturis, sicut ei contulit veritas naturae, non confusis naturis neque immixtis, sicut Timothiani ${ }^{269}$ volunt, sed societate unitis. Proinde deus hominem assumpsit, homo in deum transivit, non versibilitate naturae, sicut Apollinaristae ${ }^{270}$ dicunt, sed dei dignatione, qua factum est, ut $\mid$ nec deus assumendo hominem mutatus sit in humanam substantiam nec homo in divinam glorificatus fit in deum. Quandoquidem mutatio et versibilitas naturae et diminutionem et abolitionem substantiae facit. ${ }^{271} »$ Ita quoque dei filius ex homine natus est, non per homine, id est ex viri coitu, quemadmodum opinabatur impiissimus Hebion, ${ }^{272}$ sed carnem secum traxit ab illibata virgine Maria. Neque enim e coelo secum illam tulit, ut nugatur cum Euthyche ${ }^{273}$ Martion. Neque phantasma fuit, ut Valentinus ${ }^{274}$ men- 10 dacissime dixit. $\ll^{275} »$ Neque sic natus est ex virgine ut et divinitatis initium homo nascendo acceperit, quasi, antequam nasceretur ex virgine, deus non fuerit, sicut Arthemon $^{276}$ et Berillus ${ }^{277}$ et Marcellius ${ }^{278}$ tradiderunt; sed aeternus deus et homo ex virgine natus est $\ll,{ }^{279}$ qui verum et solidum et humanum corpus gessit, ve|rus homo ex vero natus homine, sicut et verus deus ex vero genitus est deo. Quia 15 scriptum est: »Verbum caro factum est « [Joh 1,14].

269 Timotheos II. Ailuros (gest. 477), Patriarch von Alexandria und strenger Monophysit, vgl. NP XII/1 600f. Siehe auch Aug. haer. app. 1 (CCSL XLVI 349,1-7): »Timotheani dicunt filium dei uerum quidem hominem ex uirgine Maria natum, sed non ita unam reddidisse personam, ut non in unam sit redactus naturam; conflatorium quoddam uolentes fuisse interiora uirginis, per quod duae naturae, id est deus et homo, in unam resolutae et compactae massam, unam dei et hominis exhibuerint formam, immutata uidelicet naturarum proprietate efficientium coitionem«; Gennad. vir. ill. 83 (Richardson 90,4-6).

270 Apollinarios von Laodikeia (ca. 315-392), Verfechter der nizänischen Orthodoxie, später als Monophysit verurteilt, vgl. NP I 855f; Quasten III 377-383.

271 Gennad. dogm. 2 (PL LVIII 981B-C).

272 Die Ebionäer (gelegentlich auch »Minäer« oder »Nazoräer« genannt, vgl. Hier. epist. 112,13 [CSEL LV 381,24-382,2]) waren eine judenchristliche Sekte ohne eindeutiges theologisches Profil, welche heterodoxe christologische Ansichten vertrat, vgl. TRE XVII 310-325; NP III 860f

273 Eutyches (gest. nach 454), Mönch und Vorsteher des Hiobsklosters in Konstantinopel, wurde vom Konzil von Chalkedon (451) we- gen seiner monophysitischen Christologie verurteilt, vgl. NP IV $323 f$.

274 Valentinus (2. Jh. n. Chr.), Theologe und Dichter; auf der Basis seiner Lehren entwickelte sich die Sekte der Valentinianer, die wohl wichtigste christlich-häretische Strömung des 2. und 3. Jh. n. Chr., vgl. NP XII/1 1082; 1087.

275 Gennad. dogm. 2 (PL LVIII 981C).

276 Artemon (3. Jh. n.Chr.), Anführer einer häretischen Sekte, gegen die Hippolyt von Rom in einem verschollenen Traktat polemisierte, vgl. Quasten II 196. Artemon leugnete - ähnlich wie Paul von Samosata - die Göttlichkeit Jesu Christi, vgl. Euseb. hist. eccl. 5,28,1f. (GCS IX/1 500,3-11).

277 Beryllus (3. Jh. n. Chr.), Bischof von Bosra (Syrien), Vertreter monarchianistischer Ansichten, die er später unter dem Einfluss des Origenes widerrief, vgl. Euseb. hist. eccl. 6,33,1-3 (GCS IX/2 588,4-18); Hier. vir. ill. 60 (PL XXIII 706B-C); Quasten II 40; $\mathrm{RGG}^{4}$ I 1353.

278 Markellos (gest. 374 n.Chr.), Bischof von Ankyra. Markellos wurde wegen seiner monarchianisch-modalistischen Christologie als Häretiker verurteilt, vgl. Cassiod. hist. 3,9 (CSEL LXXI 148f.); Quasten III 197-201; NP III 915f.

279 Gennad. dogm. 3 (PL LVIII 982A). 


\section{Unde debuit per omnia fratribus similis reddi,}

Qua concomitantia adhuc evidentius demonstrat Christum induisse verum ho- De vero Christi minem, utpote qui per omnia excepto peccato nobis sit similis factus. Ideoque, ut carnem habuit sensibilem, sic animam rationalem; animam, inquam, non absque 5 sensu et ratione, ut Apollinaris aiebat, neque carnem absque anima, cuius loco fuerit divinitas, ut sentiebat Eunomius, sed animam tanquam verus homo cum ratione sua habuit et carnem cum sensibus suis, per quos sensus veros in passione et ante passionem carnis suae dolores, secundum Isaiae vaticinium, ${ }^{280}$ sustinuit. ${ }^{281}$ Ideo et corpus Christi finitum et circumscriptum et in loco constitutum sit oportet.

10 Sumus enim etiam nos in loco. Ideo indoluisse, sitisse, esurisse, flesse, lassatum esse, gaudio suffusum, ira et indignatione turbatum, infirmitate (quam pro miseria semper et non pro peccato accipimus) debilitatum, denique et tentatum esse et mortalem factum legimus. Ideo etiam videmus, quod hunc hominem, quem semel induit, nunquam amisit, nunquam exuit, ne per resurrectionem quidem.

15 Corpus sane clarificatum est, sed non ideo annihilatum est; mutata sunt accidentia, sed $\mid$ ipsa mansit substantia. ${ }^{282}$ Nam corruptibile incorruptibilitatem induit, ${ }^{283}$ unde et ipsum quoque clarificatum corpus circumscriptum mansit. Solus enim deus infinitus est. At caro Christi in deum conversa non est, quod converti in aliud, finis sit pristini; ${ }^{284}$ finita igitur et loco conclusa est. Si enim a resurrectione

20 corpus gessisset infinitum, iam ne corpus quidem fuisset, sed ne ipsa quidem nostrae carnis resurrectio aliquid esset.

Videant ergo, quid nugentur, qui sua illa in pane corporali praesentia et veram Christi carnem negant et resurrectionem carnis nostrae labefactant. Etenim si corpus Christi verum et naturale vere et naturaliter ubique est, ut incircumscrip25 tum esse oportet; si simul et semel in omnibus per orbem hostiis corporaliter sive substantialiter est, iam verum Christi corpus amplius verum corpus non est. ${ }^{285}$

280 Jes 52,$14 ; 53,3$.

281 Vgl. Gennad. dogm. 2 (PL LVIII 981D-982A): »Anima non absque sensu et ratione, ut Apollinaris, neque caro absque anima, ut Eunomius; sed anima cum ratione sua, et caro cum sensibus suis: per quos sensus veros in passione, et ante passionem suae carnis dolores sustinuit.«

282 Vgl. Zw. antw. Luth. (Z VI/2 56,11-16): »Unnd nenn glych die tödemliche unnd erklärung accidentia, wiechtigkeiten [...]. Und blybt dennocht die substantz eadem numero eine, aber einer nüwen gstallt.«

2831 Kor $15,53$.

284 Tert. carn. 3,4 (CCSL II 876,26): »Conuerti enim in aliud finis est pristini.«

285 Damit wendet sich Bullinger gegen einen
Grundsatz lutherischer Christologie, der gemäß Christi Leib aufgrund der Übertragung der Attribute seiner göttlichen Natur auf die menschliche allenthalben präsent sein kann (Ubiquitätslehre). Vgl. Luth. wort (WA XXIII 145,13-16): »Wenn Christus ym abendmal diese wort $>$ Das ist mein leib $<$ gleich nie hette gesagt noch gesetzt, so erzwingens doch diese wort >Christus sitzt zur rechten Gotts $<$, das sein leib und blut da müge sein wie an allen anderen o̊rtern. « Brenz Ioh. 354: »Nam Christus, postea a mortuis resurrexit, non solum ut Deus, verum etiam ut homo ibi regnat, ubi Pater regnat, hoc est ubique, sive in caelo sive in terra sive in mari sive in morte sive in inferno."Siehe auch TRE XXXIV 227-239.
Corpus Christi circumscriptum 
Tolle enim (ut Augustini verbis ad Dardanum utar) locorum spatia in corporibus et $\gg$ nusquam erunt et, quia nusquam erunt, nec erunt. Tolle ipsa corpora qualitatibus corporum, non erit, ubi sint, et ideo necesse est, ut non sint. $\ll^{286}$ Est autem corpus Christi corpus verum, unde et loco circumscriptum, quocirca neque per omnes singulasque hostias naturaliter diffusum. Rursus si corpus Christi clarificatum nullo concluditur loco, sed per omnia se dei in morem diffundit, iam et corpora nostra ubique erunt, quandoquidem talis esse debet corporum nostro|rum resurrectio, qualis erat Christi resurrectio. Porro si corpora nostra ubique erunt, ne corpora quidem erunt, sic neque ipsum Christi corpus corpus fuerit. Si vero id verum est, iam concidit fidei nostrae articulus, quo credimus carnis resurrectio- 10 nem. Resurget autem caro nostra, sicut Christi resurrexit. Verum de illa dicunt angeli: »Surrexit, non est hic; ecce locus, ubi posuerunt eum« [Mt 28,6]. De hac dixit ipse etiam Christus ad discipulos: »Videte manus meas et pedes meos, quia ego ipse sum. Contrectate me et videte, quia spiritus carnem et ossa non habet, sicut me videtis habere « [Lk 24,39]. Proinde certum est corpus Christi etiam 15 clarificatum in loco esse et proinde verum corpus esse; veram igitur fore et resurrectionem carnis nostrae et ideo falsissimam istorum opinionem esse, qui aiunt clarificatum corpus Christi contineri in sacramento altaris. Cum revera illa, quae est in coena Christi praesentia, non sit $\mid$ substantialis, naturalis vel localis, sed potius spiritualis ac sacramentalis. ${ }^{287}$ Fides enim absentia loco praesentia 20 videt intellectu. Sed haec obiter. ${ }^{288}$

17 ut misericors esset et fidelis pontifex in iis, quae apud deum forent agenda, ad expiandum inquam populi peccata.

Posterior hic assignatur incarnationis caussa. Prior fuit, ut haberet, quod pro nobis offerret et mortem morte perimeret. Posterior autem, ut in omnibus iis | negotiis, 25 31v $F$ quae mortalium generi coram deo agenda sunt per omnem vitam, fidelem et misericordem agere posset pontificem ac intercessorem, nempe ut condonentur nobis nostra delicta. Hinc apostolus Paulus ad Rom[anos] 5.: »Christus«, inquit, »pro nobis mortuus fuit. Multo igitur magis iustificati nunc sanguine eius servabimur per eum ab ira. Nam, si cum inimici essemus, reconciliati fuimus deo per 30 mortem filii eius, multo magis reconciliati servabimur per vitam ipsius « [Röm 5,8-10]. Et iterum: »Deus est, qui iustificat; quis ille, qui condemnet? Christus est, qui mortuus est, imo qui et suscitatus est, qui etiam est ad dexteram dei, qui et

Z. (22) Marg. 2.] Secunda ZF

286 Aug. epist. 187,6,18 (CSEL LVII 96,9-11).

287 Vgl. Zw. fid. exp. (Z VI/5 145,5-7): »Non editur itaque a nobis naturaliter aut per essentiam corpus Christi, quanto magis non men- suraliter, sed solum sacramentaliter et spiritualiter."

288 Siehe unten S. 145 f. 
intercedit pro nobis« [Röm 8,33f.]. Ioannes item apostolus: »Si quis«, inquit, »peccaverit, advocatum habemus apud patrem, Iesum Christum iustum. Et ipse est propitiatio pro peccatis nostris, non pro nostris autem tantum, sed etiam pro totius mundi« [1Joh 2,1f.]. Breviter: oportuit incarnari Christum, carnem in 5 coelos rapi, sedere ad dexteram patris, ut non modo intercederet, sed et talis esset, a quo caro nostra non abhorreret. Est enim caro Christi soror carnis nostrae. Confidenter itaque eum accederemus, qui nostri similis frater fratrum misereretur.

18 Nam in hoc, quod accidit illi tentatio, potest tentatis quoque ferre suppetias.

10 Non modo superiorum caussa est et expositio, sed et epicherema ${ }^{289}$ evidens, quo infirmiores maxima vi $\mid$ conatur attrahere ad Christum, ut illi fidant, illum invocent, illi uni haereant. Esse enim illum, qui per omnia tentatus ${ }^{290}$ miseris succurrere didicerit; esse praeterea illum, de quo Isaias praedixerit: »Despectus et contemptissimus erit omnium, qui tamen dolorum et aegritudinum peritus est «

15 [Jes 53,3]. Solent autem, qui malis exercitati sunt, promptius et citius afflictis eodemque morbo laborantibus succurrere, quam qui, quid afflictio sit, nunquam didicerunt. Proinde non abs re assumpsit carnem et tentatus est Christus. Non abs re ipse in evangelio dixit: »Venite ad me, qui laboratis et onerati estis, et ego reficiam vos« [Mt 11,28]. Et paulo post apostolus: »Non habemus«, ait, »talem

20 pontificem, qui non possit compati infirmitatibus nostris, sed tentatum per omnia $\ll[$ Hebr 4,15].

Haec diligentius perpendant, qui contra incarnationis dominicae mysterium et Divorum virtutem divorum iactitiant intercessionem. ${ }^{291}$ Quid enim caussae est, quod divos invoces? »Peccator sum«, inquis, »Christum accedere non ausim, quin hoc magis nunc adeundus erat.« Verum tu cum accedere non ausis, fidem non habes neque intelligis, cur deus hominem assumpserit. In hoc autem assumpsit, ut misericors in peccatorum negotiis esset intercessor. Cum itaque tu misericordem adire nolis, creaturas autem adeas, claret, quod tu huic divinae misericordiae non fidas et proinde incarnatio Christi tibi nihil prosit. Prodest enim iis duntaxat, qui vere 30 credunt. $^{292}$

|Et hucusque disseruit de vera humanitate Christi idque miro et foelici ingenio. Epilogus. In primis enim admirabile est illud, quod caput verae religionis, Christum videlicet verum esse deum et hominem, obiter et aliud interim agens, adeo solide, adeo et absolute tractarit, ut nihilominus extra oleas, ${ }^{293}$ quod dici solet, non

Z. (31) foelici] felici $Z F-(32)$ In primis] Imprimis $F$

289 Siehe oben S. 11, Anm. 46.

290 Hebr 4,15.

291 Vgl. Eck ench. 15 (Fraenkel 173).
Vgl. Joh 6,47.

293 Erasm. adag. 1110 (ASD II/3 136,187f.): »Extra oleas fertur. Vbi quis terminos praescriptos 
cucurrerit. Institutum enim Pauli erat hortari Hebraeos, ut Christum per evangelii suscipiant praedicationem. Praestat autem eum agnoscere, quem amplectaris; proinde suo loco et necessario tantis de Christo disseruit, ne illi incognitum per imprudentiam inscitiamve aspernarentur. Quid quod ista eorum quoque firma sunt fundamenta, quae mox de sacerdotio et sacrificio Christi sequentur? Nemo enim alius coram deo fungi potuit sacerdotio quam ipse dei filius, sed et nullum aliud sacrificium deo placere potuit quam assumptae de illibata virgine carnis holocaustum. Oportuit itaque mediatorem hunc verum esse deum et hominem, quo fit, ut propriissime et commodissime tantis de utraque in Christo natura disseruerit.

Proferant autem vel unum ex Cicerone, omnium oratorum principe, locum, qui sic prophanis addicti sunt, ut a sacris tanquam barbaris abhorreant; proferant, inquam, unum locum, qui huic Paulino possit eruditione, vi, elegantia, proprietate, perspicuitate et maiestate cum rerum tum verborum conferri! Quod si ne queunt, ut sane non poterunt, discant etiam sacris suum deferre honorem.

CAP. III. 1 Unde, fratres sancti, vocationis coelestis participes, consyderate apostolum et pontificem confessionis nostrae Christum Iesum,

Pulchre redit ad exhortationis caput illationemque iterato ingerit, adhortans, ut Christum agnoscant et evangelium non respuant. Caeterum, quo magis gratiae et favoris et sibi et caussae accederet, auditores appellitat »fratres « eosque »sanc- 20 tos « etiam vocat, quos alibi nominat »credentes «; 294 sanctos quidem, quod (ut in Corinthiis ait) sanguine Christi et sancto dei spiritu sint sanctificati. ${ }^{295}$ Idem dicuntur participes vocationis coelestis eo, quod ab ipso deo per unicum filium coelitus vocati sint ad haereditatem vitae aeternae. Porro filius dei ob salutiferam evangelii functionem, »apostolus « sive »legatus «296 cognominatur. Nam et in 25 Romanis: »Illud«, inquit, »dico, Iesum Christum ministrum fuisse circumcisionis pro veritate dei ad confirmandas promissiones patrum et ut gentes pro misericordia glorificent deum « [Röm 15,8f.]. »Pontifex « enim vocatur, quod intercessor et mediator sit dei et hominum, ut in 5. cap[ite] dilucidius patebit. ${ }^{297}$ Quod autem filius orbi et doctor et redemptor missus sit, confessionis, hoc est fidei et 30 religionis, nostrae summa, caput et fundamentum est. | Breviter, hic est illationis huius sensus: »Cum ergo filium coelitus miserit deus, filius vero legationem susceperit, hominem induerit, doctorem egerit et redemptorem, itaque ad aeterna vocarit gaudia; age, praeeuntem sequamur vocantemque non contemnamus, imo

transgreditur aut aliena nec ad rem pertinentia facit dicitue.

294 Vgl. Röm 10,4; Gal 3,22.

295 Vgl. 1Kor 6,11.
296 Erasm. Hebr. (ASD VI/10 274,581): »Caeterum >apostolum < vertere poterat >legatum $<$.«

297 Hebr 5,1-10. 
agnoscamus hunc esse verum populi dei apostolum, ducem et pontificem. Id enim fidei religionisque nostrae professionem decebit.«

2 quod fidelis sit ei, qui ipsum constituit, quemadmodum et Moses in tota domo ipsius.

5 Auget dignitatem Christi et urget negotium praesens collatione sive exemplo. Fidelitas Christi Nam Mosi confert Christum, qua collatione pulchre (ut audiemus) ad id proin agendo. greditur, quo probat Christum Mose maiorem esse. »Hic vero si«, ait, »Mosis administrationem commendavit fidelitas, diligentia et sedulitas, cur non et Christi administratio sive praedicatio nobis esset commendatissima? Utpote quae non minorem in agendo ardorem et diligentiam fidelitatemque habuerit, quam Mosis.« Est autem fidelitas potissimum et maxime necessarium in docentibus ac proceribus populi donum. Nam in Corinthiis: »Sic nos aestimet homo«, inquit, 1. Cor. 4[,1f.]. »ut ministros Christi et dispensatores mysteriorum dei. Quod superest autem, illud requiritur in dispensatoribus, ut fidus aliquis reperiatur. «Summum itaque or 15 namentum et quod functionem nostram maxime commendet, est fidelitas.

\section{Tanto enim maiore gloria hic prae Mose dignus est, quanto maiorem} honorem habet is, qui domum construxit, quam ipsa domus. 4 Omnis enim domus construitur ab aliquo; qui autem omnia condidit, deus est.

Neque vero hoc contentus apostolus, quod Christum aequasset Mosi, quin istis nunc Mosi Christum quam longissime praefert, ita aliud quoque impedimentum, quod Hebraeos remorari poterat, removens. Quemadmodum enim superiori tractatione Hebraeis extorsit illam de angelorum legatione iactantiam, ${ }^{298}$ ita nunc quoque eripit illis, quam falso in Mosen habebant, confidentiam. Iactitabant enim et hic (ut etiam in argumento monuimus) ${ }^{299}$ se Moseos esse discipulos, cui locutus 25 sit deus, Iesum vero istum se prorsus ignorare. ${ }^{300} \mathrm{Cum}$ revera sic essent Moseos discipuli, ut erant Christi discipuli. Vere etenim in evangelio dixit dominus: »Est, qui accuset vos, Moses, in quo speratis. Si enim credidissetis Mosi, credidissetis utique mihi; de me enim ille scripsit. Si autem illius scriptis non creditis, quomodo verbis meis credetis?«, Ioannis 5[,45-47]. Ideoque ut insolentibus cristas 30 convelleret $^{301} \mid$ apostolus, probat Christum ut angelis, sic Mose etiam esse

Z. (15) fidelitas] in ZF folgt Locus de fidelitate Mosis, unde haec sumpsit apostolus, extat Num. 12[,7]. Ex eodem texuntur et consequentia. - (19) vero] enim $Z F$

298 Hebr 2,2f.

299 Siehe oben S. 17.

300 Joh 9,28 f.

301 Vgl. Erasm. adag. 769 (ASD II/2 294,210-
213): »Tollere cristas. [...] Translatum ab auibus cristatis, in quibus cristae erectiores alacritatis atque animorum indicia sunt.« 
maiorem; idque allegorico quodam aenigmate, quo et divinitatem Christi obiter subindicat. Nam per domum intelligit mundum, per fabricam creationem, et per aedificantem deum conditorem. Iam ergo sic colligit: aedificans maior est ipsa domo; Christus autem aedificans est; ergo Christus ipsa domo maior est. Verum nullius pensi hoc fortassis argumentum fuerit, nisi intelligas aedificantem (ut monuimus) hic appellari deum conditorem. Nam Paulus: »Omnis enim domus «, inquit, »construitur ab aliquo; sed qui omnia condidit, deus est.« Per Christum vero condita sunt omnia, ergo Christus deus est, et proinde etiam Mose maior est.

5 Et Moses quidem fidelis fuit in tota domo illius veluti minister in testimonium eorum, quae post dicenda erant. 6 At Christus tanquam filius administravit domum ipsius,

Argumentum hoc a comparatis ${ }^{302}$ ductum ad evidentiam facit superioris. Comparat enim nunc Mosen et Christum inter se, sed ita, ut Christum denuo Mosi longe praeferat. Nam Mosen vocat servum, Christum autem filium. Maxima autem est inter servum et filium distantia. Maximum igitur inter Mosen et Chris- 15 tum, si dignitatem spectes et conditionem (doctrina enim eadem) discrimen est. Nam quo dignior est filius ser|vo, hoc maior Mose Christus. Poterat sane tota haec Pauli argumentatio in hanc formam colligi: domus minor est aedificante; minister domus minor est ipsa domo; ergo minister minor est aedificante. Et per expositionem: Moses minister est; Christus aedificans est; ergo Christus Mose 20 maior est. Quid quod ipse Moses non modo de iis, quae paulo post evangelio tradebantur testimonium tulit, sed et palam toti orbi Christum proposuit velut sydus unicum, potissimum cum post multa dixit: »Futurum est, ut omnis anima, quae non audierit prophetam illum, exterminetur a populo«, Deuter. 18.? $?^{303}$

6 cuius domus sumus nos, si fiduciam et gloriationem spei ad finem usque firmam tenuerimus.

Clavis est, quo superior allegoria reseratur: »Nos«, inquit, »si modo vere credamus, illa domus dei, de qua diximus, sumus.« Nam in 1. ad Corinth[ios] 3. cap[ite] dicit apostolus: »Templum dei sanctum est, quod estis vos « [1Kor 3,17], sed si in vera fide ad finem usque perseveraverimus. »Qui enim perseveraverit«, 30 ut dicit in evangelio Christus, »usque in finem, hic salvus erit« [Mt 24,13 par.]. Idem asseverat Ezechiel cap[ite] $18 .{ }^{304}$ Et apostolus multo magis dixit: Koì đò

Z. (1) aenigmate] in ZF folgt ducto ex 12. cap[ite] Numeri [vgl. Num 12,8]-(25) fiduciam] fidutiam ZF

302 Zum »locus a comparatis« vgl. Agric. inv. ${ }^{303}$ Apg 3,23; vgl. Dtn 18,19. 1,24 (Mundt 144-152).

304 Ez 18,5-9. 


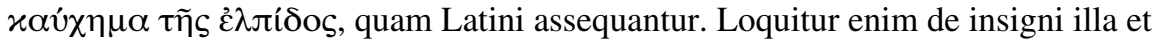
infallibili spe fidelium, qua certo norunt se dei esse filios. De qua spe et in Rom[anis] apostolus: »Non solum autem hoc«, inquit, »verum etiam gloriamur in deo per dominum nostrum Iesum Christum, per quem nunc gloriationem asse5 quuti sumus«, Rom. 5[,11].

Hinc vero discimus ecclesiam, quae domus dei est, sanctorum, hoc est fide- De ecclesia lium, collectio et coetus, quod, inquam, ea, ut solida in deum fide nititur, sic eadem ex fide per verbum veritatis nascatur. Fide item consistat et mundum vincat, ut non frustra dixerit apostolus: haec scripsi, »ut noris quomodo oporteat $\quad$ 1. Tim. 3[,15]. te versari in domo dei, quae est ecclesia dei viventis, columna et basis veritatis «, quam dilexit Christus »et exposuit se pro ea, ut illam sanctificaret, mundatam Ephe. 5[,25-27]. lavacro aquae per verbum, ut adiungeret sibi ipsi gloriosam ecclesiam, non habentem maculam aut rugam aut quicquam eiusmodi, sed ut esset sancta et irreprehensibilis.« Huius domus et ecclesiae caput, pastor, sponsus, vita, vis et Ephe. 2[19-22]. salus est Christus Iesus. In hac Moses, prophetae et apostoli ministri sunt. Verbum dei vitae regula, lumen, lex et studiorum institutio. Haec domus illud ipsum ovium Christi ovile est unicum, cuius ostium Christus est, qui dicit: »Per me si Ioan. 10[,9]. quis introierit, servabitur, et ingredietur et egredietur, et pascua inveniet.« Iccirco extra hanc veram Christi ecclesiam nulla salus est, ${ }^{305}$ nulla fides, nulla veritas, 20 nulla religio vera. Pontificia enim ecclesia, in qua ipse pontifex caput, legislator, iudex, prora et puppis, ${ }^{306}$ denique omnia unus est, cacodaemo|nis et schismatica ecclesia est, a vero capite Christo, a veritate scripturarum et fidei unitate avulsa, suis fundata legibus, decretis, ceremoniis et humanis stultitiis, ut ab aliis copiosius disputatum est. ${ }^{307}$

7 Quapropter, sicut dicit spiritus ille sanctus: hodie si vocem eius audieritis, 8 ne obduretis corda vestra, sicut in exacerbatione in die tentationis in deserto, 9 ubi tentaverunt me patres vestri; probaverunt me et viderunt opera mea 10 quadraginta annis. Quapropter offensus eram generationi huic et dicebam: semper errant corde, ipsi vero non cognoverunt vias meas, 11 sicut iuravi in ira mea, si ingressuri sunt in requiem meam.

Z. (3) Rom[anis]] Roma[nis] $Z F$ - (21) puppis] pupis $F$

305 Vgl. Cypr. epist. 73,21,2 (CCSL IIIC $555,380): »[\ldots]$ quia salus extra ecclesiam non est.«

${ }^{306}$ Erasm. adag. 8 (ASD II/1 120,415-420): $»$ Prora et puppis. [...] Prora itaque et puppi summam consilii nostri significamus, prapterea quod a prora et puppi, tanquam a capite et calce, pendeat tota nauis.«

307 Vgl. Zw. ußleg. 8 (Z II 59-64); Zw. epich. (Z II 570,24-572,10). 
»Quapropter « sive סıó particula nihil peculiariter infert, sed connectendi nota est. Hactenus enim demonstravit Christum etiam Mose esse maiorem; ne quid superesset, quo Hebraei vel gloriari possent vel a cognitione Christi impediri, iam vero producit prophetica ex Psal[mo] 94. verba ${ }^{308}$ eaque tractat dignissime, et ita praesenti suo accommodat instituto, ut te singula non audire, sed coram contueri putes. Monet autem Hebraeos istis veluti vivo exemplo Christum suscipiant et evangelium non contemnant, quippe qui videant patres suos tanta seve/ritate esse punitos, quod videlicet Mosis tantum legationem contempserint; siquidem verisimile esse et se multo inclementius fore puniendos, si eum aspernari perrexerint, qui etiam Mosis dominus sit.

Vides autem, quid possit maiorum exemplum vel factum, si non sit cum maiorum. honesto, iusto et vero coniunctum. Si itaque falsa vel scripturis adversa sit patrum religio, ne imitemur, ne iactitemus. Nulla etenim valet patrum contra veritatem authoritas, veritati nulla praeiudicat consuetudo, nulla vetustas. Quod et Lactantius $^{309}$ diserte persecutus est Instit[utionum] divina[rum] lib[ro] 2. »de 15 error[is] orig[ine]«, cap[ite] $7 .^{310}$ Itaque istis illam quoque subruit Hebraeis gloriationem, qua, ut patres subinde iactitabant, ita sancte asseverabant se, quod religionem attineret, in viis patrum ambulaturos. Quod si facere perrexerint, indicat hoc loco apostolus, quid ipsis certo sit eventurum: idem prorsus, quod obstinatis maioribus, miserabilis videlicet interitus. Non enim Abrahae et sanc- 20 torum imitabantur (ut et Christus indicat) vestigia, ${ }^{311}$ sed eorum patrum, qui et deo recalcitrarunt et prophetas persecuti sunt.

Neque vero dubitarim Paulum ista non citra epanaphoram ${ }^{312}$ inseruisse ac resumpsisse. Audivimus enim in 2. cap[itis] initio inobedientiam patrum olim a deo horribiliter esse punitam. ${ }^{313}$ Parce vero id tunc perstrinxit, idem ergo nunc 25 praesenti prophetae testimonio copio|sius retractat et exponit. Ipseque quantum praesenti satis est negotio, prophetae verba enarrat, ut nostris non sit opus interpretamentis. Sic enim subiungit:

12 Videte fratres, ne fortasse sit in ullo vestrum cor depravatum incredulitate, ut desciscat a deo vivente, 13 sed exhortemini vos invicem quotidie, quoad appellatur dies hodiernus, ne quis ex vobis induretur seductione peccati.

Z. (15) Instit[utionum]] Institut[ionum] $Z F$ - (16) error[is]] erro[ris] $Z F$

308 Ps 95,7-11 (Vulg. 94,7-11).

309 Lucius Caelius Firmianus Lactantius (ca. 250325), christlicher Theologe und Apologet, Autor der »Divinae institutiones«, vgl. TRE XX 370-374; NP VI $1043 f$.
310 Lact. inst. 2,7,1-6 (CSEL XIX/1 124,17$125,12)$.

311 Joh 8,39f.

312 Siehe oben S. 44, Anm. 261.

313 Hebr 2,2f. 
Haec omnium summa est, hic scopus, quem ad morem Hebraicum praemittit, et Incredulitas. consequentia omnia ad eum dirigit. »Propterea «, inquit, »adduxi hoc ex propheta miserabile maiorum exemplum, ut quisque apud se probe curet, ne incredulus sit dei negotio. « Incredulitas enim efficit, ut a vero, vivo et aeterno deo turpiter 5 deficiamus. Id quod non tam ex hoc patrum liquet exemplo, quam ex Adae, protoplasti nostri, lapsu. Is enim, cum plus crederet serpentinis lenociniis quam verbis dei, ${ }^{314}$ a deo et promissione eius excidit, calamitatis nostrae author factus; qui proculdubio ipsi etiam peribimus, si evangelio per Christum annunciato repugnaverimus. Quid igitur fiet? »Sed exhortemini«, ait, »vos invicem quotidie. «Idem autem dicit, quod supra, sed variata oratione per oppositum membrum sentiens conferre plurimum, si per hanc brevem et inbecillem, quae adhuc supersit, vitam omni studio nos in|vicem ad fidendum deo et verbis eius cohortemur, ne quis tandem incredulitatis scelere (id quod fieri solet) induretur, ut deinceps per omnem vitam nihil aliud, quam desperate vivere, possit.

14 Christi participes facti sumus, si sane initium substantiae usque ad finem firmum tenuerimus.

| Quando vero ex piis multi essent (videtur enim haec ad pientiores fieri apostrophe), qui Christi iactabant cognitionem, interim tamen parum aut prorsus nihil in coepto pergerent itinere et nonnunquam etiam in media conciderent via, »non satis est«, inquit, »bene coepisse, nisi et bene coepta perficiamus vita illibata et firma constantia «. Perseverantia enim in fide in primis est necessaria et sine qua Perseverantia. fides non est fides, sed magis opinio vana. Paulus enim sanctum fidei initium propterea vocavit »initium substantiae«, quod fides vera subsistentia, certa expectatio, ipsa certitudo et $\pi \lambda \eta \rho о \varphi о \rho i ́ \alpha$ quaedam sit, ut audiemus in cap[ite] $2511 .{ }^{315}$ Porro de fidei augmento, cuius hic fit mentio, disseruit dilucide admodum apud Marcum dominus similitudine inducta seminis, quod initio herbam, mox spicam, postremo autem frumentum in spica progerminat. ${ }^{316}$ Discamus igitur et nos in fide constantes esse, et non modo verbum dei audire, sed etiam custodire illud. Tum enim sapienti viro similes in petram aedificavimus aedificium adversus $\mid$ omnes tempestatum procellas duraturum, Matth[aei] 7[,24f.].

15 In hoc dicitur: hodie, si vocem eius audieritis, ne obduretis corda vestra, sicut in exacerbatione. 16 Nam quidam, cum audissent, exacerbaverunt, at non omnes, qui profecti fuerant ex Aegypto per Mosen.

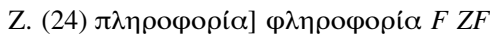

314 Gen 3,17.

316 Mk 4,28.

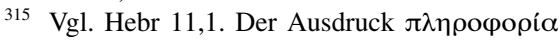

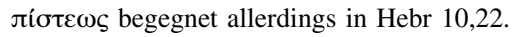


Alii legunt: »In hoc, quod dicitur. $\ll^{317}$ Sed abundat »quod« et obscurat sensum. Paulus enim scripsit $\dot{\varepsilon} v \tau \widetilde{\omega} \lambda \varepsilon \dot{\varepsilon} \gamma \sigma \vartheta \alpha$, id est, »in hoc dicitur«, hoc est, »huc iam pertinet illud, quod ex propheta citavimus: $>$ Hodie si vocem eius audieritis $<$ [Ps 95,7].« Sentit enim eo spectare propheticam cohortationem, ne animum ad evangelii praedicationem obduremus, sed ut initium substantiae ad finem usque firmum teneamus. Nunc enim exponit verba prophetae eaque suo accommodat instituto, demonstrans incredulitatem patribus in deserto cladis et interitus fuisse caussam; praestare itaque, ne obduremus corda ad praedicationem evangelii, »sicut in exacerbatione «, id est, sicut eo accidit tempore, quo et ipsi Iudaei amaro praediti animo erga deum ingrato murmure provocarunt benefactorem, et ipse deus eorum murmure et ingratitudine exasperatus obstinatis vehementer succenseret. Nam erant tunc quoque (ait apost[olus]) qui animis admodum infestis intellectae resistebant veritati, quanquam suo maximo malo. Erant et alii, qui solida fide perstiterunt, qui et in terram promissam introducti sunt, quorum exemplum imitari praestat.

17 Quibus autem infensus fuit quadraginta annis? Nonne his, qui peccaverant, quorum membra conciderunt in deserto? 18 Quibus autem iuravit non ingressuros in requiem suam, nisi his, qui non obedierant?

Idem dicit, quod iam dixerat: propter incredulitatem patres eorum esse peremptos. Sed orationis habitum interrogatione figurat et vehementiorem efficit, ut nunc 20 singula miram spirent vehementiam. Primo etenim dicit deum illis non modo iratum fuisse, sed etiam infensum, hoc est, incredulitatem patrum deo concivisse

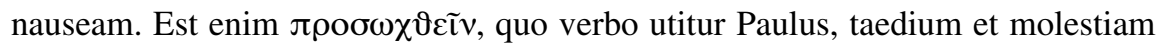
capere ex re aliqua. Secundo autem loco et aliud subiicitur ardentius, in hac vehementi indignatione deum etiam iurasse: »Si introibunt in requiem meam.« 25 Quod locutionis genus et ipsum stomachum et aposiopesin ${ }^{318}$ habet patheticam, cui nostra respondet lingua, cum dicimus: Ja schenck ich dir das, intelligimus enim aliquid vel iam male disperam, vel aliud eiusmodi quiddam. Ita hic Macrobius quoque per indignationem iurat dominus incredulos nunquam ingressuros esse in Satur[nalium] requiem. Hanc rem satis alias ardentem magis adhuc incendit tempus, quod 30 cap[ite] 3., 4. videlicet quadraginta annis in deserto oberrarunt; item modus et locus, ${ }^{319}$ quod et

Z. (10) benefactorem] befactorem $F-(23) \pi \rho \circ \sigma \omega \chi \vartheta \varepsilon \tilde{\imath} v] \pi \rho \circ \sigma o \chi \vartheta \varepsilon \tilde{\imath} v F F$

317 Erasm. Hebr. (ASD VI/10 280,626): »Indicat Chrysostomus hic hyperbaton esse, >in hoc quod dicitur vocem eius etc.« Vgl. Chrys. Hebr. 6,2 (PG LXIII 56; 279f.).

318 Unter óлобı́́лєбıৎ versteht man die Auslassung der Äußerung eines Gedankens, vgl. Quint. inst. 9,2,54 (Winterbottom II 500f.).
319 Marg. »Macrobius ... 4.«: Bullinger wollte vermutlich auf Macrobius' Ausführungen anspielen, wie Gefühle durch bestimmte Orte und andere Ursachen erregt werden, vgl. Macr. Sat. 4,3f. (Willis 221-230). Von Ambrosius Theodosius Macrobius (um 400 n. Chr.), über dessen Herkunft und Werdegang nichts be- 
in deserto hoc misere tandem conciderunt vel peste ${ }^{320}$ vel gladio ${ }^{321}$ absumpti et nonnunquam $\mid$ terra absorpti, ${ }^{322}$ nonnunquam vero et fulmine attacti atque extincti; tandem vero, quod omnium erat miserrimum, ipsa etiam requie frustrati. Haec, inquam, omnia deplorata certe et supra modum misera iis obvenere, qui pecca5 verant, hoc est, verbo dei per Mosen praedicato non crediderant; unde liquet, quantum malum sit nuncio dei repugnare. Incredulitas enim omnis mali vis, seminarium et robur est. Unde et Samuel ad Saulem tanta constantia dicebat: | »Nunquid vult dominus holocausta et victimas et non potius, ut obediatur voci domini? Melior est enim obedientiae quam victimae et auscultare magis quam offerre adipem arietum. Quoniam quasi peccatum hariolandi est repugnare, et quasi scelus idololatriae nolle acquiescere«, 1. Sam. 15[,22f.].

\section{Et videmus, quod non potuerint ingredi propter incredulitatem.}

Kaí accipitur pro »ergo« vel pro »sic«, ut sit vel inferentis nota vel repetentis, in hunc sensum: »Sic, inquam, videmus, quod illi per incredulitatem non potuerint 15 ingredi in requiem. « Sic etenim ad finem expositionis pulchre appendit, quid nam istis prophetae verbis effectum voluerit, adeo ut clausulae et epiphonematis ${ }^{323}$ speciem habeat sententia. Sed ipsam rerum summam illatione consequenti dilucidissime sic infert: quiem eius videatur aliquis ex nobis fuisse frustratus.

Cum igitur (inquit) patres vestri propter incredulitatem requie pollicita sint exclusi, cavendum est vobis, ne etiam vos ab ea per inobedientiam exludamini.

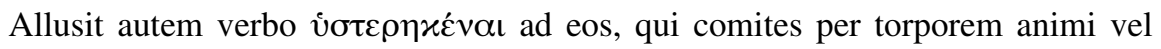
inertiam corporis in coepto itinere assequi non possunt. ${ }^{324}$

\section{Etenim nobis id quoque nunciatum est, quemadmodum et illis.}

Ne quis obiiceret: »Quid vero mea retulerit, vel maiorum incredulitas vel illis Promissiones pollicita requies?«, praevenit id et sibi hunc prophetae locum contra Iudaicam veterum vendicat proterviam, et ait: »Quod autem hortamur, ut ad promissam properetis

kannt ist, wurden drei lateinische Schriften überliefert: »Saturnalia«, »Commentarii in somnium Scipionis« und »De differentiis et societatibus Graeci Latinique verbi«. Vgl. NP VII 627-630.

320 Num 17,14; 25,9.

321 Num 14,45.
Num 16,31f.

323 Vgl. Quint. inst. 8,5,11 (Winterbottom II 457,25f.): »Est enim epiphonema rei narratae uel probatae summa acclamatio.«

324 Vgl. Erasm. Hebr. (ASD VI/10 280,644): »Yo$\tau \varepsilon \rho \eta x \varepsilon ́ v \alpha$, id est >non assequutus fuisse «.« 
requiem, inde est, quod illa requies non minus nobis quam patribus nostris proposita est.« Hinc enim Paulus significantissime evangelii voce usus est, scri-

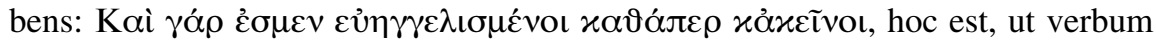
verbo reddam: »Etenim sumus evangelisati, sicut et illi «; ${ }^{325}$ id est: »Id beneficii de requie, non minus nobis quam illis nunciatum est«; vel: »Hoc beneficio non minus nos donavit deus quam illos. «Valeant itaque, qui veteris instrumenti scripta non nobis etiam, sed veteribus duntaxat scripta esse produnt. Nam vel hic locus satis coarguit ea, quae $\mid$ spiritus fidei et charitatis sunt, prorsus non esse abrogata. Non enim nunc dicam, quid aliis in locis, nempe ad Rom[anos] 4., 15., 2. Timoth. 3., de hac re scribat idem apostolus Paulus, ${ }^{326}$ siquidem ad expositi- 10 onem redeundum est.

2 At non profuit illis audisse sermonem, quod is non esset cum fide coniunctus iis, qui audierant.

Alium hic tollit errorem: »Sed istis«, ait, »non profuit promissio propterea, quod promittenti deo nunciisque eius non crederent, imo ipsum Mosen aspernarentur et 15 contra deum ipsum murmurarent. Sic ne vobis quidem profuerit audivisse evangelium, nisi etiam fideli cordi inscribatis, quod audistis.« Nam et d[ivus] Iacobus: $»$ Sitis effectores«, inquit, »sermonis et non auditores tantum « [Jak 1,22]. Docuit et in Corinthiis apostolus veteres quidem baptizatos esse et sacris cibatos mysteriis, sed ideo non absolutos fuisse: plurimos enim ira dei concidisse in deser- 20 to. ${ }^{327}$ Nihil igitur et nobis profuturum sacris initiatos esse mysteriis, nisi etiam vera fide deo totis adhaereamus viribus. Annotavit hoc loco et illud Erasmus, $\mu \grave{\eta}$

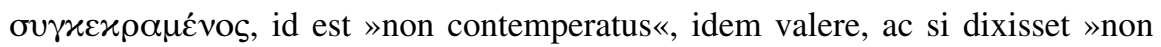
Iacobi 2[,26]. apte coniunctus «, veluti anima corpori coniungitur temperatura quadam. Esse enim fidem veluti auditus vitam. ${ }^{328}$

3 Introimus enim in requiem nos, qui|credidimus, quemadmodum dixit: sicut iuravi in ira mea, si ingressuri sint in requem meam,

Quasi dicat: »Iccirco fidem verbis dei habendam doceo, quod ii duntaxat, qui credunt, veram requiem introeunt. Nam qui non credunt, a requie exclusi sunt.« Quod argumentum duxit a contrariis. ${ }^{329}$ Iam enim, quod superius coeperat, pergit 30

\footnotetext{
Z. (4) evangelisati] evangelizati $Z F$ - (9) Rom[anos]] Roma[nos] $Z F$ - (29) veram] in veram $Z F$

325 Vgl. Erasm. Hebr. (ASD VI/10 282,645f.):

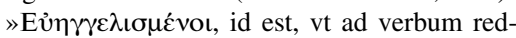
dam >euangelizati sumus $<$.«

326 Röm 4,13-17; 15,1f.; 2Tim 3,1-5.

327 Kor $10,1-5$.
} , 
ostendere apostolus, prophetae $\operatorname{locum}^{330}$ non modo intelligendum esse de requie externa terrae Chanaan, sed magis de aeterna quiete per Iesum, non equidem Nave filium, ${ }^{331}$ sed dei filium, paratam. Quo simul haec duo perstringit: quae sit vera requies et qui nam huius sint participes. |Atque hic consequentium scopus est. Instituit autem hanc disputationem propterea, quod apud Hebraeos prophetae verbis nihil videbatur egisse, nisi simul et illud probasset, quod ea, quae de requie a propheta erant scripta, ad nos quoque, non ad veteres duntaxat pertinerent.

\section{3 et sane operibus ab ipso mundi exordio factis. 4 Dixit enim in quodam} loco de die septimo sic: et requievit deus die septimo ab omnibus operibus suis. ${ }^{332}$

Ioan[nes] Chysostomus hom[elia] in Hebraeos Pauli 6.: »Tres«, inquit, »requies esse dicit: unam sabbathi, qua deus requievit ab operibus suis. Secundam in Palaestina, in quam ingressi Iudaei requieturi erant ex miseria multa et la|boribus. Tertiam, quae revera est requies, hoc est regnum coelorum, ad quam quos pervenire contigerit, revera requiescunt a laboribus et difficultatibus suis. Harum trium igitur mentionem facit, ut ostendat prophetam de hac dicere. De prima enim non dixit, utpote quae olim facta sit. Sed neque de ea, quae in Palaestina fuit. Nam dixit: >Non introibunt in requiem meam< [Ps 95,11]. Restat igitur tertiam hanc esse reliquam. Nam et David post generationem eorum, qui terram Chanaan 20 ingressi sunt, dixit: >Hodie si vocem eius audieritis, ne obduretis corda vestra $<$ [Ps 95,7f.]. Hinc enim clarum est, quia est quaedam requies. Si enim iam acceperant requiem, quae erat in Palaestina, quare eis iterum dicit >hodie $<$ ? Quae est ergo alia requies nisi regnum coelorum, cuius imago et umbra est sabbathum? ${ }^{333} \mathrm{Haec}$ omnia Chrysostomi sunt. Poterant autem haec Pauli verba simplicius etiam tractari hoc, ni fallor, quem indicabimus, modo.

Z. (11) Ioan[nes]] Ioannes $Z F$ - (11) hom[elia]] homelia $Z F$ - (12) sabbathi] sabbati $Z F$ - (23) sabbathum] sabbatum $Z F$

329 Zum »locus a contrariis« bzw. »ex oppositis« vgl. Agric. inv. 1,26 (Mundt 164-170).

330 Ps 95,11.

331 Gemeint ist Hoschea, Sohn Nuns und Haupt des Stamms Efraim, welcher zusammen mit den Häuptern der anderen Stämme Israels durch Mose ausgesandt wurde, um das Land Kanaan zu erkunden, vgl. Num 13,2-15. Von Hoschea wird berichtet, dass Mose ihn »Josua« nannte (Num 13,16), weshalb in der Spätantike und dem Mittelalter üblich wurde, ihn als »Iesus Nave« zu bezeichnen, vgl.
HISMA IV 114. In Chrys. Hebr. 6,2 (PG LXIII 56) wird Hebr 4,2f. auf Hoschea (Josua) und Kaleb bezogen, die sich nach Num 14,6-10 als einzige dem Aufruhr des Volkes nicht anschlossen ( $\mu$ ๆ̀ $\sigma v \gamma \varkappa \varepsilon \varkappa \rho \alpha \mu \varepsilon ́ v o v \zeta$ ), vgl. Erasm. Hebr. (ASD VI/10 282,666f.; 284,686).

332 Vers 5 lässt Bullinger kommentarlos aus, vgl. Erasm. Hebr. transl. (ASD VI/4 240): »Et in hoc rursum: si introibunt in requiem meam.«

333 Zit. mit Auslassungen aus: Chrys. Hebr. transl. $77 \mathrm{f}$. 
G[ulielmus] Budaeus ${ }^{334}$ in doctissimis illis suis de linguae Graecae commentariis copiose tradidit varium apud authores huius dictionis xoítoı usum. ${ }^{335}$ Hinc transtulere quidam »licet«, alii »quanquam«, alii »vero« et »sane«. Certe expositiva videtur esse particula; videtur et orationi inesse quaedam $\dot{x} x \lambda \varepsilon i ́ \psi \iota \varsigma$, hoc est defectus. Nam hic est apostoli sensus: »Introimus in requiem nos, qui credimus, et sane in eam, quam deus iactis mundi fundamentis $\mid$ ingressus est. Nam scriptura manifeste testatur deum septima tandem die requievisse.« Et si hic verus et genuinus sensus est, ut sane contextui non inepte innectitur, iam testimonium illud: »Sicut iuravi in ira mea « [Ps 95,11; Hebr 4,3] etc. per parenthesim videbitur insertum. Sed videamus, quomodo cohaereant cum consequentibus. Et in hoc iterum, id est ad hanc quietem dei aeternam (nam et ipsa terra Chanaan istius quoque typum gessit), vocavit eos, qui duce Mose ex Aegypto sunt egressi; verum apernantibus iis oblatam quietem, iuravit istos nequaquam ad se in aeterna gaudia perventuros. Interim tamen deus verax est et quietem humano generi promisit. Sequitur itaque:

6 Posteaquam igitur illud reliquum est, aliquos introire in eam, et quibus prius annunciatum fuit, non introierunt propter incredulitatem; 7 rursum quendam praefinit diem, hodie, inquit David dicens, post tantum temporis, quemadmodum dictum est: hodie si vocem eius audieritis, ne obduretis corda vestra. 8 Nam si eis Iesus requiem praestitisset, nequaquam de alio post hac die locutus fuisset.

Id est, ut paucis multa complectar: ergo aliud praefiniit tempus, quo velit denuo alios etiam vocare ad requiem aeternam. Elegit enim tempora Christi, | quae praesentia sunt. Nunc enim omnes vocamur ad poenitentiam et regnum coelorum. Sed ipse apostolus omnia fusius tractat: »Et certum est«, inquit, »ex verbis dei 25 aliquos introituros in requiem. Illi autem, quibus primo nunciatum est, non introierunt. Restat ergo, quod aliqui sint ingressuri, ii nimirum, quibus alia per Davidem praescripta est dies. « David autem longo post Mosen intervallo haec, quae audimus, ${ }^{336}$ scripsit et in ea terra scripsit, quam deus promisit, ut iam nemini dubium esse possit, quin de alia locutus sit et requie et terra, quam ea fuerit, in 30 qua haec scripsit. Nam si quis obiiciat requiem eam, cuius propheta meminit, per Iosue $^{337}$ esse praestitam, fallitur. Nam si illa, in quam induxit Iosue, vera fuit

\section{Z. (1) G[ulielmus]] Gulielmus $Z F-(30)$ locutus] loquutus $Z F$}

334 Guillaume Budé (1468-1540), französischer Humanist und Diplomat, Bibliothekar am Hof des französischen Königs Franz I., vgl. CoE I 212-217.
335 Bud. comm. 1288,13-1289,34.

336 Ps 95,7f.

337 Jos 3. Siehe aber auch oben S. 59, Anm. 331. 
$668 Z F$ quies, quid opus erat alterius quietis mentionem facere eum, qui in illa terra, $\mid$ in quam induxerat Iosue, erat? Quid ergo? Quorsum haec omnia?

\section{Relinquitur itaque requies populo dei.}

Ex istis itaque constat (nam praedisputatorum conclusio est), quod vera illa, cuius 5 meminit propheta, requies non sit per Iosue praestita neque ea requies patribus duntaxat sit pollicita, sed quod per Christum Iesum, cuius typum gessit Iosue, sit praestita et omni populo dei parata. Intelligimus autem nomine populi dei omnes eos, qui deo ex Iudaeis et gentibus | nomina dederunt, imo ei sese totos dediderunt; illi, inquam, ingredientur in requiem promissam.

10 Nam qui ingreditur in requiem eius, etiam ipse quiescit ab operibus suis, quemadmodum a suis deus.

Hanc sententiam lucis gratia postliminio et per epanaphoram ${ }^{338}$ adiecit. Respicit enim ad illud, quod modo audivimus in istis: »Et sane operib[us] ab ipso « [Hebr $4,3]$ etc. Atque ita clarius exponit, quae nam sit illa populi dei requies, nempe vitae aeternae requies, in qua cessabit (ut prophetae aiunt) omnis labor et dolor. ${ }^{339}$ »Oportet enim corruptibile induere incorruptibilitatem et mortale hoc induere immortalitatem « [1Kor 15,53]; ita enim quiescemus ab operibus nostris, sicuti

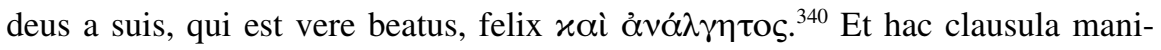
festum fit superiorem, quem annotavimus, sensum genuinum esse cassoque labore istos se conficere, imo aliena a Pauli mente inducere, qui hoc loco multis de sabbatho disputant. Nihil enim hic disputat de feriis, nihil de otio festivo, sed peculiariter de aeterna requie et vita per Christum nobis parta, cuius haeredes sint fideles. ${ }^{341}$ Nunc enim capulum rei repetit et infert:

11 Studeamus igitur ingredi in illam requiem, ne quis eodem concidat incredulitatis exemplo.

43r $F$ Quasi diceret: »Ista vero omnia in hoc adduximus, | ut ad fidendum Christo et evangelio eius invitaremus. Huius enim auspiciis, vi et beneficiis consequimur vitam aeternam, denique et miserabilem effugimus interitum, quo maiores vestri propter incredulitatem interempti sunt.«

Z. (13) operib[us]] operibus $Z F$ - (21) sabbatho] sabbato $Z F$

338 Siehe oben S. 44, Anm. 261.

339 Vgl. Jes 35,10; 51,11.

340 Vgl. Zw. fid. exp. (Z VI/5 69,7-10): »[...] deus, qui [...] est et óvó $\lambda \gamma \eta \tau o s$, hoc est nulli passioni aut adfectioni obnoxius.«
341 Vgl. Fab. Stap. Hebr. 235v: »Neque hic pro sabbato Iudaeorum sumitur neque pro sabbato christianorum [...]. Ergo sabbatum aeternum est (ut praecedente capite dictum est), quod in futura celebrabitur vita.« 
Scripturas interpretari.

Vides autem, amice lector, quam proprie, quam etiam anxie omnia retulerit ad scopum apostolus. Nam quemadmodum prophetae pulchro dicendi ordine omnia sua perorarunt, sic etiam apostoli exactissima (quam spiritus suppeditabat) dicendi ratione sua proposuerunt, utpote venusti et perspicacis ingenii homines. Errant enim toto coelo, qui phanaticum spiritum et inconstans in prophetis ingenium taxant. Errant, qui apostolis rusticitatem tribuunt et obscurum in eis ac desultorium criminantur ingenium. Nam qui vel mediocriter in eorum scriptis versati sunt, norunt neque ipsos prophetas neque Christi apostolos temere rerum permiscuisse argumenta, sed omnia ad certum retulisse scopum iusta et dilucida, attamen illaborata inadfectataque dicendi ratione adhibita. Nam ut fucum oderunt 10 superstitiosum, ita perspicuitati et rei studuerunt. Id cum multi non observemus, fit, ut, dum commentarios in sacra polliceamur, nihil aliud quam rapsodias concinnemus aut locos communes coacervemus, ipso interim orationis instituto et contextu, hoc est ipsa orationis medulla prorsus neglecta. Cum tamen | praecipua interpretis functio sit potissimum authoris annotare scopum; deinde vero, quo- 15 modo ad statum hunc referantur singula, ubi ab instituto diverterit, quae neglecta, quae observanda, quis verborum usus, quis rerum sensus sit, indicare, adeoque et superstitiose etiam indicare; quae sane fieri non poterunt, nisi oratio dispersa colligatur, institutum indicetur sententiarumque componatur contextus sive cohaesio. ${ }^{342}$ Cohaesio porro ista firmissimum est et in iudicando et in disputando 20 munimentum, lumen in tenebris, veritatis regula infallibilis et haeresum praesentaneum venenum. Surripiat enim e contextu sententiam haereticus, adulteret et ad suum dogma roborandum detorqueat; adhibeatur autem iudex et vindex veritatis cohaesio, iam abreptum locum pristino cum ordini tum nitori restituet. Eo quod introducta sententia neque authoris instituto conveniat neque consequentia et 25 praecedentia quadrent etc. Sed redimus.

| 12 Vivus est enim sermo dei et efficax et penetrantior quovis gladio utrinque incidente, et pertingens usque ad divisionem animae simul et spiritus compagumque et medullarum, et discretor cogitationum et intentionum cordis. 13 Nec est ulla creatura, quae non manifesta sit in conspectu illius, sed omnia nuda et resupi|nata oculis eius, ad quem nobis est sermo.

Virtus verbi dei. Subiiciuntur haec ab apostolo confirmationis vice. Sentit enim verbum dei nunc quidem non minoris esse virtutis quam olim, adeo ut, quemadmodum olim peste et gladio $^{343}$ inobedientes perdiderit deus, sic etiam nunc idem expectandum sit a 35 verbo, dei filio orbi per praedicationem evangelii patefacto. Quippe quod vivum

$342 \mathrm{Zu}$ den Grundsätzen von Bullingers Schrift-

343 Siehe oben S. 57. hermeneutik vgl. Bull. lect. (Baschera 7f.); Baschera 2012, LXVIIIf. 
sit, hoc est efficax. Subiicitur enim posterius ad explanationem superioris. 'Evé $\rho-$ $\gamma \varepsilon \iota \alpha$ enim efficatia est, quae non tam dicere videtur, quam ostendere. Hinc in Galatis apostolus: »In Christo Iesu«, inquit, »neque circumcisio quicquam valet

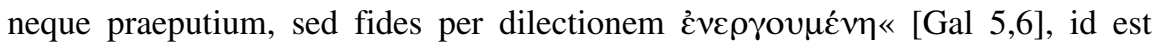
5 »efficax «. Significat enim evidentem vim exerentem se in nobis, quod spiritus proprium est. Sic, inquam, verbum dei vivum est et efficax, agens et operationis vivae. Idem verbum gladio comparat, quod ex Isaiae 49. cap[ite] desumpsisse videtur; ibi enim Messias dicit: »Dominus ab utero vocavit me, de ventre matris meae recordatus est nominis mei; et posuit os meum quasi gladium acutum « [Jes 49,1f.]. Et mox ipse apostolus allegoriam aperit et subdit: »Pertingens usque ad divisionem animae simul et spiritus compagumque et medullarum«; indicans filium et vim verbi dei (utraque enim mira commiscet crasi) intima penetrare

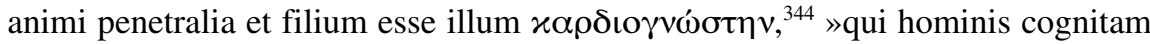
habeat mentem «; nec mentem solam, sed totum $\mid$ in universum hominem. Nam a 15 partibus totum colligit et per spiritum intima et subtilissima quaeque intelligit Non enim de corpore ista carnaliter exponenda sunt, quasi hic gladius visibilis sit gladius; sed allegoria et hyperocha ${ }^{345}$ quadam adumbrare voluit, quod clarioribus ipse mox exponit: »Verbum iudicare cogitationes et intentiones cordis. « Unde facile nunc liquet nullius posse perfidiam latere, nullius hypocrisin nec istam Koıtıxóc est sermo dei, quia unquam fore inultam. Quo fortassis et illud prophetae videbitur spectare: »Vae, qui profundi estis corde, et dicitis: >Quis videt nos? Et quis novit nos?< Perversa est haec nostra cogitatio, quasi si lutum contra figulum cogitet et dicat opus Ioan 9[,39].: »In iudicium ego in mundum veni« factori suo: >Non fecisti me<, et figmentum dicat fictori suo: >Non intelligis « «, Isaiae 29[,15f.]. Item illud Pauli in 1. ad Corinth[ios] cap[ite] 14.: »Quod si omnes prophetetis, ingrediatur autem in coetum vestrum indoctus et coarguitur ab omnibus, diiudicatur ab omnibus, et sic occulta cordis eius manifesta fiunt « [1Kor 14,24f.] etc. Nunc enim palam sequitur: »Nec est ulla creatura, quae non manifesta sit in conspectu illius «; quae sane verba absque omni involucro idem nobis referunt, imo clarius exponunt, quod iamiam per figuram obscurius est

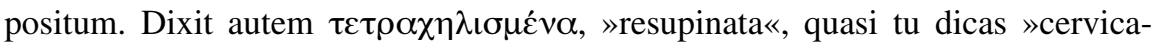
ta ${ }^{346}$ hoc est intus et in cute, tanquam in speculo. Graeci volunt »metaphoram sumptam ab ovibus, quibus pellis a cervice detrahi|tur, cum excoriantur «. ${ }^{347}$ Detracta autem pelle et resupinato corpore nudantur omnia. Deinde vero dixit »nec est ulla creatura« pro eo, quod est: »Nihil uspiam in ullis rebus creatis est «,

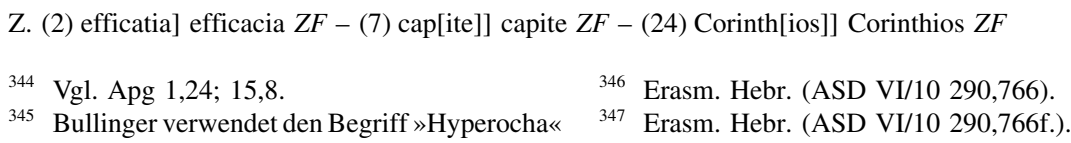

$\begin{array}{ll}346 & \text { Erasm. Hebr. (ASD VI/10 290,766). } \\ 347 & \text { Erasm. Hebr. (ASD VI/10 290,766f.). }\end{array}$

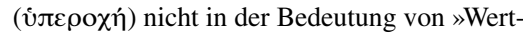
überschuss « (vgl. NP V 807), sondern als Synonym von »Hyperbel«, vgl. HWR IV 117. 
vel: »Nihil prorsus est, quod filium lateat.« Ad finem autem affigit: »Ad quem nobis sermo«, quod bifariam exponi potest. Vel quod deo, quem nihil lateat, reddenda sit ratio. ${ }^{348}$ Varia enim significat $\lambda$ ó $\gamma$ os. Vel quod transitum faciat ad consequentia et dicat se nunc copiosioribus de verbo dei, hoc est filio dei, disputaturum.

Epilogus. HISCE VERO absolvimus primam epistolae huius partem, qua Hebraeos hortatus est Paulus, Christum suscipiant, qui angelis et Mose maior, utpote dei filius, sit; unde negotium suum tuto contemni non possit, quando contemptus verbi dei per Mosen praedicati in patribus per desertum misere et palantibus et expirantibus punitus sit. Verbum etenim dei vivum esse et penetrantius gladio ancipiti, unde et 10 hostes nihilo segnius punire possit, atque illa punierit Israelitis immissa lues.

| Secunda epistolae pars.

Indicavimus in argumento ${ }^{349}$ sacerdotium et sacrificium Christi altera epistolae huius parte tractari idque per collationem quandam ad sacerdotium $\mid$ et sacrificium Aaronicum; id quod nunc quidem auspicabitur et ita, ut et consequentia nectat 15 superioribus et summam consequentium brevibus praemittat. Initio enim ea per epilogum repetere et colligere videtur, quae disputavit de divina et humana Christi natura in cap[ite] 1. et 2. Deinde vero iisdem illis et hunc consequentium constituit statum, Christum Iesum verum esse sacerdotem; utpote qui deo iunxerit hominem, ut verum coram deo pontificem agere posset. Sic enim delecto et 20 eximio quodam ordine nunc exponit, quis sit ille Christus, ad quem Hebraeos hactenus tanto invitavit ardore. His iam adde ea quoque, quae in argumento diximus, nempe quo consilio haec faciat apostolus. Nunc enim ipsa Pauli verba tractabimus:

14 Habentes igitur pontificem magnum, qui penetravit coelos, Iesum filium dei, teneamus confessionem. 15 Non enim habemus pontificem, qui non possit affici sensu infirmitatum nostrarum, sed tentatum per omnia, iuxta similitudinem, absque peccato.

Hoc autem dicit: »Cum igitur satis constet ex praecedentibus Iesum Christum verum esse deum et hominem, liquido etiam illud constat, quod idem apud deum 30

Z. (6) VERo] nicht in Versalien in $Z F$ - (18) cap[ite] ... 2.] capite primo et secundo $Z F$ - (25) Habentes] Marg. CAP. V. F ZF

348 Vgl. Theophyl. Hebr. transl. 148v: »Illi, inquit, 349 Siehe oben S. $17 \mathrm{f}$. et gestorum per nos reddenda ratio est et pro commissis danda supplicia.« 
verus mediator sit ac pontifex generis humani, qui | proprii corporis hostia lus- Pontifex et trarit omnia mundi peccata.«Et sane pontificem esse et mediatorem esse prorsus mediator idem. in idem, quod scilicet ipsam rem attinet, incidit. Oportuit autem mediatorem dei et hominum utriusque naturae participem esse; hinc est, quod tanta diligentia 5 repetiit apostolus pontificem nostrum dei esse filium, deum verum, et per omnia homini assimilatum, hominem verum. Nam et d[ivus] Ioan[nes] Chrysostomus in epistolam Pauli ad Timotheum priorem home[lia] 7.: »Enimvero mediator «, inquit, »utrisque eis debet societate coniungi, quorum mediator est. Id quippe mediatoris est proprium, utrorumque participem fieri, quorum fuerit mediator. «350

10 »Quemadmodum enim loci cuiuslibet medium utranque partem contingat necesse est, ita et naturarum ambarum medium oportuit utrasque naturas contingere atque connectere. Quemadmodum igitur homo factus est ita etiam deus erat. Homo quippe purus mediator nunquam penitus fieret; oportebat enim huiusmodi mediatorem cum deo colloqui. Deus item solus mediator esse non posset, neque 15 enim eum suscepissent hi, quorum mediator accederet. $\ll^{351}$ Hactenus Chrysostomi verba retulimus, quibus in omnem modum ea consonant, quae et Augustinus de mediatore scripsit lib[ro] de civit[ate] dei 9., cap[ite] $15 .{ }^{352}$ Pontifex igitur noster verus deus et homo fuit, et coelos penetravit; quo ad officium sacerdotum et tabernaculum allusit. Christus enim non ingressus est in tabernaculum ab hominibus constructum, | sed in ipsum coelum, ut nunc pro nobis in conspectu dei compareat. Idem etsi filius esset, omnem tamen nobis exhibuit mansuetudinem, etiam nunc benignus et minime severus, rigidus et inexorabilis, sed fidelis et

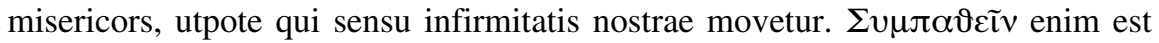
»affici et moveri sensu alieni mali $\ll{ }^{353} » N a m$ et tentatus «, id est malis exercitatus, »est; exercitatus, inquam, per omnia«, hoc est omni modo, »sicut nos exerceri solemus, hoc uno dempto, quod peccatum neque fecit neque facere potuit.« Dixit autem »iuxta similitudinem « idiotismo Hebraico pro eo, quod est: »Prorsus eo

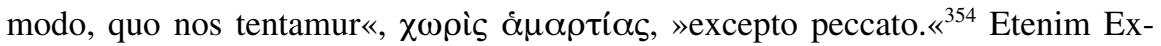
od[i] 25. eodem schemate scriptum legimus: »Facientque mihi sanctuarium iuxta omnem similitudinem, quam ostendam tibi« [Ex 25,8f.], id est, prorsus tale, quale illud est, quod ostendo. Item ad Rom[anos] 5.: »Regnavit«, inquit apostolus, »mors ab Adam usque ad Mosen in eos quoque, qui non peccaverant in simili-

Z. (6) Ioan[nes]] Ioannes $Z F$ - (7) home[lia]] homelia $Z F$ - (17) lib[ro]] libro $Z F$ - (17) civit[ate]] civitate $Z F$ - (28-29) Exod[i]] Exodi $Z F$ - (31) Rom[anos]] Roma[nos] $Z F$

350 Chrys. 1Tim. transl. 193. Vgl. Chrys. 1Tim. 7,2 (PG LXII 536).

351 Chrys. 1Tim. transl. 194. Vgl. Chrys. 1Tim. 7,2 (PG LXII 537).

352 Aug. civ. 9,15 (CCSL XLVII 262f.).

353 Erasm. Hebr. (ASD VI/10 290,779).

354 Vgl. Erasm. Hebr. (ASD VI/10 290,781-784):

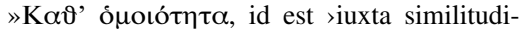
nem<. Quod non ita accipiendum est, quasi Christus aut non fuerit vere homo aut non fuerit vere passus, sed quod ipse immunis a peccato, carnis naturae peccatricis mala assumpsisset et perinde poenas dederit, quasi ipse peccasset.« 
tudinem transgressionis Adam « [Röm 5,14], id est, regnavit in eos etiam, qui non illud ipsum peccatum peccarant, quod peccavit Adam. Ita ad Philip[penses] 2. legimus Christum in similitudine hominum fuisse constitutum, id est vere incarnatum, ut verum gesserit hominem, sicut nos gerimus. ${ }^{355}$ Ideoque pari schemate hoc quoque loco dixit Christum tentatum esse per omnia iuxta similitudinem, id est, ita tentatum et malis exercitatum esse, sicuti ho|mines exerceri solemus. Id quod tot inculcamus verbis, ne quis imaginariam | Christi carnem arbitretur. Haeretici enim schematum et locutionum ignari in hunc locum impegerunt atque putativum corpus Christo affinxerunt. ${ }^{356}$ Videant igitur, quo spiritu nonnulli ab idiomatum et schematum cognitione, studio et usu adeo abhorreant. Cum interim haec figurata locutio multo sit vividior et vehementior, quam Latini assequamur. Germani fortassis exactius referimus, cum dicimus: In glycher g stalt, wy $\beta$ und maaß. Illo enim locutionis genere nihil omittimus, quod non comprehendamus; totidem videlicet et tanta in hoc esse, quanta in illo sunt, cui hoc conferimus atque assimilamus.

16 Accedamus igitur cum fiducia ad thronum gratiae, ut consequamur misericordiam et gratiam inveniamus in opportunum auxilium.

Fides in Dixerat: »Teneamus confessionem « [Hebr 4,14]; eo iam redit per epanaphoram, ${ }^{357}$ Christum. ut nihil sit obscurum, simul et illud indicans, quis sit finis eorum, quae de sacerdotio Christi disputare instituerit. Nempe ut fidamus Iesu Christo dei filio et 20 agnoscamus hunc illum esse verum a deo ordinatum sacerdotem, intercessorem et redemptorem, proinde talem solida fide et nihil haesitantes accedamus. Pedibus enim ad eum non pervenimus, sed fide. | Nam accedentem oportet credere. Ut autem hoc liberius et audentius accedamus, illud in primis movere debet, quod, cum ad Christum supplicaturi venimus, non severi iudicis tribunal accedimus, sed 25 ad clementissimi patroni thronum; qui iccirco »thronus gratiae« appellatur, quod Christus petentibus sese comem paratum et misericordem exhibet, quippe qui ad se omnes eos vocat, quotquot laborant et onerati sunt, ${ }^{358}$ se enim adflictis omnibus requiem praestiturum. Falluntur igitur, qui aiunt sese suis impediri peccatis, sed et illius terreri maiestate, quo minus ipsum adeant Christum. Nam hic au- 30

\section{Z. (2) Philip[penses]] Philippenses $Z F$ - (29) praestiturum] praestiturum pollicens $Z F$}

355 Phil 2,7.

356 Vgl. Tert. carn. 16,3f. (CCSL II 902f.,16-24): »Nam et si alibi in similitudine inquit carnis peccati fuisse Christum, non quod similitudinem carnis acceperit quasi imaginem corporis et non ueritatem, sed similitudinem peccatricis carnis uult intellegi, quod ipsa non peccatrix caro Christi eius fuerit par, cuius erat pecca- tum, genere, non uitio adaequanda. Hinc etiam confirmamus eam fuisse carnem in Christo, cuius natura est in homine peccatrix, et sic in illa peccatum euacuatum, dum in Christo sine peccato habetur quae in homine sine peccato non habebatur.«

357 Siehe oben S. 44, Anm. 261.

358 Vgl. Mt 11,28. 
dimus maiestati iunctam esse misericordiam, imo et humanum adfectum. Rursus ipsum dominum non modo dominum et dei filium, sed et gratiae esse thronum. Confiteamur igitur peccata nostra deo et adeamus eum, qui, ut omniscius est et omnipotens, ita et nobis compati potest et misericors est. Nam et Ioannes: »Si 5 confiteamur «, inquit, »peccata nostra, fidelis est et iustus, ut remittat nobis peccata nostra et emundet nos ab omni iniquitate « [1Joh 1,9]. Accedamus igitur ad Christum; accedamus, inquam, ut gratiam et peccatorum remissam, denique et

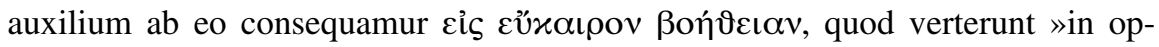
portunum auxilium «, ${ }^{359}$ id est, ut tunc illius sentiamus auxilium, cum ipsa pos-

10 tularit res. Nota enim est opportunitas vel ex ipsis Erasmi Chi|liadibus. ${ }^{360}$ Ioannes

Chrysostomus sic exposuit: »Bene dixit >in opportuno auxilio<. Si enim nunc accedas, accipies et gratiam et misericordiam, opportune quippe accedes. Si autem non accesseris, nequaquam, inanis quippe erit accessio tunc (cum venerit finis). Non enim erit tunc sedes gratiae (sed iudicii). ${ }^{361}$ Et huic sensui magis 15 quadrat occasio sive xaıрós. Et hactenus praefatus, propositionem et rei summam praemisit:

1 Omnis enim pontifex ex hominibus assumptus pro hominibus constituitur in his, quae erga deum aguntur, ut offerat dona et victimas pro peccatis 2 et qui condolere possit ignorantibus et errantibus, quandoquidem et ipse circundatus est infirmitate 3 et propter hanc debet, quemadmodum pro populo, ita et pro seipso immolare pro peccatis. 4 Neque quisquam hoc honoris sibiipsi usurpat, sed qui vocatur a deo, quemadmodum et Aaron.

Nunc vero summae rei tanquam scopo et propositioni suam adhibet probationem, quam duxit a comparatis sive similibus. ${ }^{362}$ Probat enim vel ipsa lege Mosaica Christum esse sacerdotem, ipsum demonstrativa quadam contentione conferens Mosaicis. Neque vero hic aliud probat, quam Christum esse sacerdotem. Nam in 7. demum cap[ite] probabit Christum unicum esse sacerdotem $\mid$ et aeternum, per quem etiam Leviticum abrogatum sit sacerdotium. Caeterum ista, quae ascrip30 simus verba, sensum non absolvunt. Sunt enim altera tantum collationis pars, quae non intelligetur citra posteriorem, quam protinus | subiungemus, si illud prius monuerimus in Levitico ea maxime contineri, quae hic a Paulo citata sunt. Item Paulum in hac epistola pontificis vocabulo plerunque complecti totum

Z. (17) Marg. CAP. V.] om. $F Z F-(20)$ circundatus] circumdatus $Z F-(21)$ immolare] imolare $F$ (28) cap[ite]] capite $Z F$

359 Erasm. Hebr. (ASD VI/10 290,787f.).

360 Vgl. Erasm. adag. 670 (ASD II/2 196f.,497502 app. crit.).
361 Chrys. Hebr. transl. 82. Vgl. Chrys. Hebr. 7,2 (PL LXIII 64).

362 Siehe oben 52, Anm. 302. 
sacerdotii genus et ordinem, quanquam et suo in loco pro summo duntaxat usurpet. Denique $\mu \varepsilon \tau \rho เ о л \alpha \vartheta \varepsilon \tau$ v Graecam vocem »a moderandis affectibus $\ll^{363}$ esse dictam idemque pollere, quod nos dicimus modice affici vel »moderate ferre $\ll$, nec $»$ graviter succensere $\ll .{ }^{364}$ Tali mente Christum videmus esse praeditum, qui ovem errantem non laniat aut nimia concitus ira lacerat, sed in caulam reducit. ${ }^{365}$ Iam vero cum haec altera tantum pars sit collationis, supra modum hallucinantur, qui nunc huius loci robore sacerdotium statuunt papisticum. At hoc ipso magis produnt, quales sint; nihilo videlicet meliores sacerdotibus Iudaicis. Quid enim interest inter Iudaeum, qui subinde easdem offert hostias, et pseudochristianum, qui idem imitatur? Si enim christianus est, fidat hostiae semel duntaxat 10 immolatae et in sempiternum duraturae. Sed nunc subiungemus contrarium similitudinis sive collationis membrum:

5 Ita et Christus non semetipsum glorilficavit, ut fieret pontifex, sed is, qui dixerat illi: filius meus es tu, ego hodie genui te. 6 Sicut et alibi dicit: tu es sacerdos in aeternum secundum ordinem Melchisedech.

Agnoscis nimirum similitudinis notam »ita«, ut hisce tandem absolvatur sensus. Nunc enim posteriorem collationis partem primo loco resumit et ex vocatione sic argumentatur: queadmodum apud veteres nemo sacerdotii dignitatem et officium privata sibi authoritate vindicabat, ita ne Christus quidem sacerdotium sibi propria voluntate usurpavit, sed a deo vocatus et constitutus est sacerdos secundum 20 ordinem Melchisedech. Prior pars confirmatur et sacra lege et exemplo Aaronis et Eleazari, ${ }^{366}$ denique clarissimis hisce, quae extant Numeri 16. et 20. cap[ite], ${ }^{367}$ pronunciatis. Posterior vero pars probatur duplici testimonio. Alterum enim sumptum est ex Psal[mo] 2., ${ }^{368}$ ut indicavi in cap[ite] $1 .{ }^{369}$ Alterum vero ex Psal[mo] 109., ${ }^{370}$ de quo plura in consequentibus. Quod si infirmior videatur 25 argumentatio, ita disponas licebit: omnes sacerdotes, qui vere sacerdotes sunt, non ipsos sese ingerunt sacerdotio, sed vocantur a deo; et Christus sese non ingessit sacerdotio, sed vocatus est a deo; Christus itaque verus sacerdos est. Habes mentem Pauli.

Nemo igitur posthac vel artibus malis vel muneri|bus vel alio quopiam malo $30 \quad 49 \mathrm{v} F$ episcopatum. imbutus adfectu ad docendi et episcopatus penetret functionem, ne Simonis magi consors maledictionem pro benedictione reportet. ${ }^{371}$ Quod si quis vocatus sit,

Z. (11) immolatae] imolatae $F$ - (24) Psal[mo]] Psalmo $Z F$ - (25) Psal[mo]] Psalmo ZF

363 Erasm. Hebr. (ASD VI/10 292,800f.).

364 Erasm. Hebr. (ASD VI/10 292,796).

365 Vgl. Mt 18,12-14 par.

366 Lev 8.

367 Num 16,8-35; 20,23-29.
368 Ps 2,7 .

369 Siehe oben S. 30.

370 Ps 110,4 (Vulg. 109,4).

371 Apg 8,18-23. 
vocationis sanctae memor gregi dominicae invigilet, ${ }^{372}$ lectioni, exhortationi et doctrinae attendat, ${ }^{373}$ ut sese probatum deo statuat, operarium non erubescendum, qui negotium veritatis recte secet $^{374}$ et summo studio in via dei ambulet. Iam etsi Paulus ad Timotheum dicat: »Si quis episcopi munus appetit, honestum opus 1. Tim. 3[,1]. 5 appetit«, ambitum tamen non probavit, sed proculdubio ex praesupposito scripsit. Erant enim indigni (ut fit) plurimi, qui honoris et quaestus gratia episcopi functionem ambirent idque hoc velarent praetextu: institutum esse honestum. Illis

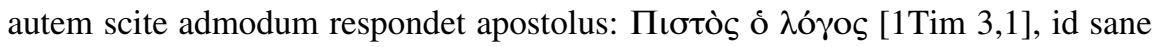
citra omnem controversiam verum est, quod, qui munus appetit episcopi, pulch10 rum et honestum opus appetit, si scilicet ipsam spectes functionem; sed hanc Corinthum (ut proverbio aiunt) non licet adire quibuslibet. ${ }^{375}$ Siquidem »oportet episcopum irreprehensibilem esse « [1Tim 3,2] et quae sequuntur. Nisi malis appetendi verbo honeste uti, quemadmodum eius quoque usus in scripturis non infrequens est, nempe non pro ambiendi impudentia, sed pro illo animi ardore, 15 quo ecclesiae dei cupimus prodesse. ${ }^{376}$ Item pro sedula in rebus sacris diligentia, qua fit, ut ecclesia dei nos, qui erudi|tioni, innocentiae et pietati verae invigilamus, ultro ad ecclesiastica vocet officia; quae sane apostolus et in 1. ad Co- Ecclesiastici rinth[ios] 12. et ad Ephes[ios] 4. cap[ite] recensuit omnia, ${ }^{377}$ et ita recensuit, ut nihil eorum, quae necessaria sunt, intermiserit et tamem nullibi sacrificorum 20 meminit, quales Romani pontificis episcopi ordinaverunt. Nullus igitur nobis sermo de ea hominum fece, quoties loquimur sive de sacerdotibus sive de episcopis ecclesiae. Nam ecclesia non est episcoporum vel cardinalium et praelatorum collectio, sed sanctorum, hoc est fidelium, coetus. ${ }^{378}$ Huic autem ecclesiae prae|fecit deus »alios quidem«, ut Paulinis utar verbis, »apostolos, alios vero 25 prophetas, alios autem evangelistas, alios autem pastores et doctores « [Eph 4,11] etc. Iam etsi sacerdotis nomen nullibi, quod equidem ego sciam, legatur apostolis Sacerdotes. et verbi ministris palam datum, est tamen sancte apud veteres usurpatum et e veteri (ut apparet) synagoga desumptum, quanquam longe alio respectu. Docet enim hac epist[ola] apostolus ibi nullam pro peccato restare hostiam, ubi plenaria (ut aiunt) sit peccatorum remissio; $;{ }^{379}$ talem autem esse in novo test[amento]; unde consequens est nec ullos in novo test[amento] esse sacerdotes, quales constituit

Z. (4) Timotheum] Timothaeum $F$ - (17-18) Corinth[ios]] Corin[thios] $Z F$ - (18) Ephes[ios] Ephesios $Z F$ - (29) epist[ola]] epistola $Z F$ - (30) test[amento]] testamento $Z F$ - (31) test[amento]] testamento $Z F$

372 Vgl. Apg 20,28.

373 1Tim 4,13.

3742 Tim 2,15.

375 Erasm. adag. 301 (ASD II/1 407,1-8): »Non est cuiuslibet Corinthum appellere. [...] Vetustum iuxta ac venustum adagium de rebus arduis et aditu periculosis quasque non sit cuiuslibet hominis affectare. Inde natum, quod (vt refertur apud Suidam) nec facilis nec satis tutus sit nautis in Corinthiacum portum appulsus.«

376 Vgl. Hebr 6,11.

377 1Kor 12,27-30; Eph 4,11-13.

378 Vgl. Symb. apost. (DH 30).

379 Zur Verwendung dieser Terminologie (»plenaria peccatorum remissio«) vgl. Decr. Grat. C. 33 q. 3 c. 87 (Friedberg 1185). 
Rom[anus] pontifex. Quid quod sacerdotis vocabulum non tantum eum, ut plerique falso opinantur, significat, qui hostias caedit et imolat, sed eum etiam, qui rebus sacris servit? Nam »sacrificare « apud Latinos est rem sacram facere.|Hinc sacerdos is dicitur, qui deo dicatus est et res sacras facit. Et »sacerdotium « sacerdotis est officium. Iam vero Paulus in 1. ad Corinth[ios] 4. cap[ite]: »Sic nos aestimet homo«, ait, »ut ministros Christi et dispensatores mysteriorum dei« [1Kor 4,1]. Mysteria porro illa (ne quis vel miretur vel aberret) sunt mysteria Christi, evangelii scilicet praedicatio, id quod probamus ex ult[imo] cap[ite] ad Rom[anos] et ex epist[ola] Pauli ad Ephesios. ${ }^{380}$ Vetusti itaque episcopos hoc significatu et ad hunc modum dixere »sacerdotes«, nempe, quod evangelio et 10 sacris praeessent precibus, non quod hostias offerrent, quales intelligit pontifex. Huc enim plurimum facit illud Pauli ad Rom[anos] 15. cap[ite]: »Data est mihi

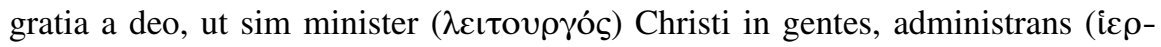

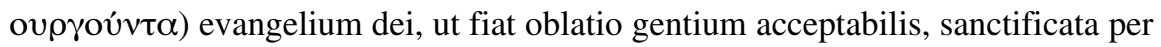
spiritum sanctum « [Röm 15,15f.]. En tibi: habes in hoc testimonio sacrificum 15

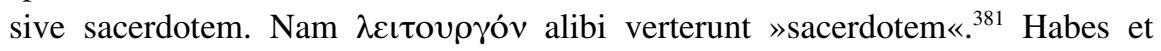
oblationem. Sacrificarunt autem apostoli, quoties evangelium dei praedicarunt.

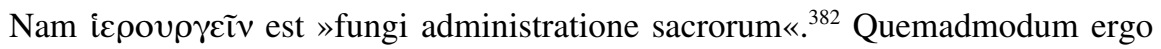
sacerdotes Mosaici pecudes caedebant ac immolabant in odorem suavitatis deo, ita apostoli et ministri verbi beluinos hominum affectus evangelii praedicatione caedunt et immolant in odorem suavitatis, ut nunc ipsi homines illa sint, quae offertur, oblatio, quemadmodum / Paulus apertis verbis in hoc explicat testimonio.

Petrus et Iacobus primi celebrarunt liturgiam. Atque hoc sensu facile concedimus apostolum Petrum primam celebrasse liturgiam, id est, primo praedicasse evangelii mysterium; id enim indicavit et Lucas Act. 2[,14]. At nostri, non expendentes »liturgiae« vocem, missam interpreta- 25 runt. ${ }^{383}$ Quemadmodum et illud de Iacobo fratre domini adulterarunt, quod Graeci

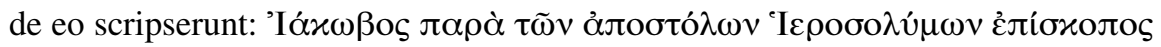

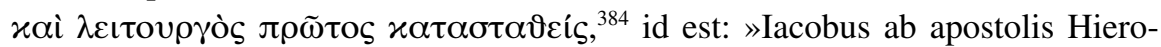
solymorum episcopus et minister sacrorum primus est ordinatus. « Hinc enim nugandi ansam sumpserunt Iacobum fratrem domini primitus apud Hierosoly- 30 mitas invenisse instituisseque missandi ritum. ${ }^{385} \mathrm{Id}$ enim crassuli isti $\lambda \varepsilon \varepsilon$ เ

Z. (1) Rom[anus]] Romanus $Z F$ - (8-9) ult[imo] ... epist[ola]] ultimo capite ad Romanos et ex epistola $Z F$ - (12) Rom[anos]] Romanos $Z F$

380 Röm 16,25f.; Eph 1,9.

381 Vgl. Erasm. Hebr. (ASD VI/10 316,67-69):

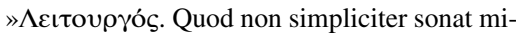
nistrum, sed plerunque ministrum sacrorum et qui fungatur officio sacerdotii pro aliis.«

382 Erasm. Rom. (ASD VI/7 348,648).

383 Vgl. Eck ench. 17 (Fraenkel 202f.): »Ordo missae vel orationum, quibus Deo oblata sa-

50 v $F$ 5 10

(


voce intelligunt, cum interim et ex Egesippo ${ }^{386}$ et ex Eusebio satis constet Iacobum primum ab apostolis Hierosolymitis datum esse episcopum, ut sacras res apud eos administraret. ${ }^{387}$ Quid quod missa post aliquot annorum a Iacobi interitu centurias, per multorum suffragia episcoporum, successu etiam temporis con5 stituta est? Quomodo itaque illud agere potuit, quod nondum, cum ipse viveret, erat? Et si Petrus primam celebravit missam, quomodo Iacobus primo etiam celebravit eandem $?^{388}$ Videtis iam istos mendatiorum magistros veteris proverbii esse oblitos: mendaces memores esse oportere. ${ }^{389}$ Et haec de sacerdotis nomenclatu|ra. Episcopi vero vox officii, non dominii vox est, vigilem significans et Episcop[us]. pastorem gregis dominici, qualem describit Paulus in epistolis ad Timoth[eum] et $\begin{aligned} & \text { Pastor. } \\ & \text { Doctor. }\end{aligned}$ Titum scriptis ${ }^{390}$ et in Actis apud Ephesios et Melitonenses presbyteros, cap[ite] Evangelista.

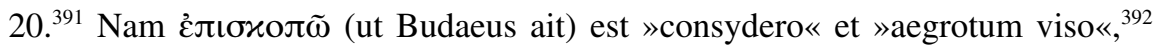

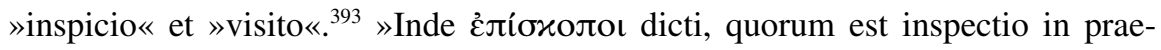
sidiis Christi et summa cura. $\ll^{394} \mathrm{Hi}$ dicuntur et pastores per allusionem, Ezech. 34[,1]., et doctores a docendo et evangelistae a praedicando evangelio. Presbyteri Presbyter. vero primates, legati ac seniores dicuntur; quod nomen inde tractum videtur, quod senioribus olim, utpote prudentioribus, commiteretur magistratus, cura et administratio plebis. Nobis vero evangelium comissum est, non dominium; plebi itaque verbo veritatis consulamus, sicut et Petrus docuit in priore epist[ola], cap[ite] 5[,1-4]. Porro apostoli legati erant a $\mid$ Christo in universum mundum Apostolus. emissi, quorum officium erat incertis vagare sedibus atque evangelii gloriam per universam spargere terram. De quibus alibi. ${ }^{395}$ Sed qui prophetat hominibus (ut 1 . Propheta. Cor. 14[,3]. extat), loquitur aedificationem et exhortationem et consolationem. Nihil igitur prophetis commune cum sacrificiis papisticis, quin hoc iam constat ex 25 iis, quae hactenus disputavimus, sacerdotes, presbyteros, prophetas, pastores, evangelistas, doctores, episcopos et seniores aliud non esse quam divini verbi ministros, non sacrificos, sed ad dispartien|da mysteria dei ordinatos; vocationem autem istis in primis esse necessariam. De qua et Cyprianus nonnulla scripsit in 1 .

Z. (7) mendatiorum] mendaciorum $Z F$ - (10) Timoth[eum]] Timotheum $Z F$ - (19) epist[ola]] epistola $Z F$

nem, cui primum credita est Iherosolimitana ecclesia, et Basilius, episcopus Caesariensis, [...] addiderunt nobis missae celebrationem.«

386 Hegesippos (2. Jh.), christlicher Schriftsteller. Von seinen 'Үло $\mu v \eta \dot{\mu} \alpha \alpha$ in fünf Büchern sind nur Fragmente überliefert, vgl. NP V $239 f$.

387 Euseb. hist. eccl. 2,23,4-18 (GCS IX/1 166170). Eusebius zitiert an dieser Stelle aus den Үло $v^{\prime} \mu \alpha \tau \alpha$ des Hegesippos, vgl. Quasten I 285.

388 Vgl. Bull. orig. euch. b2r.
389 Erasm. adag. 1274 (ASD II/3 292,703-708): »Mendacem memorem esse oportet. [...] Satis liquet adagii sensus, nempe perdifficile esse, vt, qui mentitur, semper sibi constet, nisi sit summa memoria.«

390 1Tim 3,1-7; Tit 1,7-9.

391 Apg 20,28.

392 Bud. comm. 464,13f.

393 Bud. comm. 464,26f.

394 Bud. comm. 464,38f.

395 Siehe oben S. 38. 
epistolarum lib[ro], epist[ola] $4 .{ }^{396}$ Haec vero per digressionem tempori nostro prorsus necessariam.

7 Qui in diebus carnis suae preces et supplicationes apud eum, qui poterat ipsum a morte servare, cum clamore valido et lachrymis obtulit et exauditus est pro reverentia,

Hoc membrum posterius superioribus ad hunc modum respondet: sacerdotes ex hominibus eligebantur, ut homines compati possent hominibus. Sed et in hoc eligebantur, ut ea agerent negotia, quae hominibus propter transgressiones erant agenda, id est, ut pro populi intercederent ignorantiis et pro hominum sacrificarent delictis. Huic autem membro iungitur hoc praesens sic: et Christus Iesus ex 10 hominibus natus, infirmitatem nostram assumpsit, ut homo hominibus compati Dissimile. posset. ${ }^{397}$ Quanquam in eo, quod pro propriis (quae non habebat) peccatis non obtulit, ${ }^{398}$ Mosaicis sacerdotibus dissimilis, imo maior sit. Intercessit tamen pro populo Christus et sui corporis hostiam pro nobis immolavit. Ex quibus sequitur, quod Christus verus sit sacerdos. Vel brevius ad hunc modum dispone: sacerdotis est intercedere et offerre; Christus intercedit et offert; ergo sacerdos est. Argumentum vero ex officio petitum est. | Nunc caetera perstringemus. Principio verborum ordo nonnihil obscuritatis in se habet. Poterit itaque lectio ad hunc redigi modum: »Qui cum in humanis et hisce ageret in terris «, id enim schematismo quodam per »dies carnis« intellexit, »ei, qui a morte poterat servare, 20 obtulit cum lachrymis et clamore valido preces et supplicationes, unde etiam pro reverentia exauditus est. «In istis autem videas miram verborum emphasim et

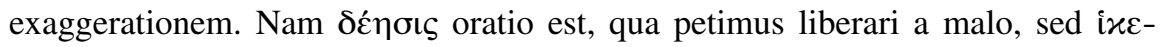

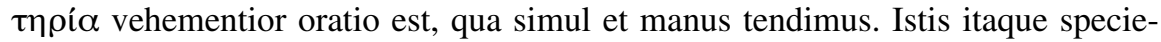
bus indicare voluit ingentem Christi adfectum et ardentissimas fuisse pro nobis 25 preces. Quo et illud referri debet, quod dicit illum cum lachrymis et clamore valido obtulisse, hoc est maximis cruciatibus corporis, et summo cum affectu, modo item omnibus modis fidelissimo et summo sacrificium peregisse. Nam si interroges ubinam talia de Christo tradiderint apostoli, nihil aliud quam 17. cap[ut] Ioan[nis] ostendere possum ${ }^{399}$ et illud, quod in crucem adactus clamavit: 30 »Pater ignosce illis, quia nesciunt, quid faciunt!« [Lk 23,34] Quod etiamsi peculiariter de iis dicatur, qui Christum crucifixerant, generaliter tamen toti humano generi aptari potest. Quia ea, quae in cruce egit, generalia erant. Sed missis istis teneamus apostolum vehementissimis quidem illis indicare voluisse Christum sacerdotii functio|nem summo cum affectu et absolutissime subiisse et peregisse. $35 \quad 53 \mathrm{r} F$ Porro illud in primis videtur nobis observandum, quod dicit supplicasse Christum

\footnotetext{
396 Cypr. epist. 67,1-5 (CCSL IIIC 447-456). 398 Vgl. Hebr 4,15.

397 Hebr 4,15. 399 Joh 17,9-23.
} 
(nam secundum hominem loquitur) et ei supplicasse, qui potuerit a morte servare. Hinc enim discemus, cui nos quoque vota, orationes et preces nostras imolare debeamus, uni videlicet sapienti, potenti, vero et aeterno deo. Solus enim est omniscius, solus omnipotens, solus omnis boni fons, solus immortalis et vitam 5 halitumque praestans omnibus et hanc suam solius gloriam alteri non communicat. ${ }^{400}$ Insaniunt igitur, qui praeces suas, vota et animi consilia vel creaturis vel animabus etiam beatis offerunt; quae et ipsae nihil habent (si quid habent), quam quod per gratiam ab hoc summo bono adepti sunt. ${ }^{401}$ Neque vero id a deo adepti sunt, ut dii sint, omniscii, omnipotentes, incircumscripti, qui et videant et audiant

10 nos, imo ubique nobis adsint; id quod interim is habeat et eum praestare necesse est, cui oratio nostra offerenda est. ${ }^{402}$ Hinc cum emphasi quadam dixit in evangelio dominus: »Si quid petieritis patrem IN NOMINE MEO, dabit vobis« [Joh 15,16]. Sequitur: »Et exauditus | est pro reverentia.«Ubi $x \alpha$, »et«, iterum est

Cui offerri debeat oratio. inferentis sive collectionis nota; ut sit sensus: »Proinde exauditus est pro reve-

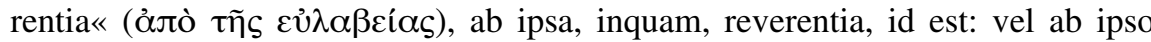
exauditus est deo reverendo; vel exauditus est propter singularem sanctiomoniam

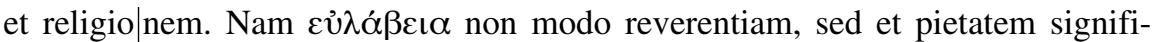
cat. ${ }^{403}$ Caeterum si exauditus est, iam redempti et servati sumus, iam interiit mundus, peccatum, daemon et quicquid nos perdere poterat. Id quod clarius 20 subiecta docebit sententia: »Itaque perfectio factus est « [Hebr 5,9] etc.

8 et quanquam filius esset, attamen didicit ex iis, quae passus est, obedientiam.

Obscura oratio est propter idiotismum Hebraicum. Id enim dixit apost[olus]: »Et Obedientia. quanquam filius esset, tamen ipsam crucem subiit, passus et mortuus est; itaque patri se subiecit, ut inobedientiam obedientia rependeret atque lustraret et ut mortem morte perimeret.« Idem enim hoc loco sentit, quod in Phil[ippensium] epist[ola] iisdem pene, sed clarioribus interim verbis dixit: »Tametsi esset in forma dei, tamen humiliavit seipsum factus obediens usque ad mortem, mortem autem crucis« [vgl. Phil 2,6-8]. His adde, quae idem scripsit ad Rom[anos], cap[ite] $5 .{ }^{404}$ Videtur autem in hoc istam subiecisse sententiam, ut clare intelligeremus Christum non modo preces, sed et semetipsum sese pro nobis obtulisse,

Z. (23) apost[olus]] apostolus $Z F-(26-27)$ Phil[ippensium] epist[ola]] Philippensium epistola $Z F$ (29) Rom[anos]] Romanos $Z F$

400 Vgl. Jes $42,8$.

401 Vgl. 1 Kor 4,7 .

402 Tert. apol. 30,5 (CCSL I 141,23-25): »Haec ab alio orare non possum, quam a quo me scio consecuturum, quoniam et ipse est, qui solus praestat.«
403 Erasm. Hebr. (ASD VI/10 292,813f.): »Illud item admonendum $\varepsilon u ̉ \lambda \alpha ́ \beta \varepsilon \iota \alpha v$ non modo significare reuerentiam, verumetiam pietatem.« 404 Röm 5,6-10.
Tertull[ianus] in apolog[etico] adver[sus] gen[tes], cap[ite] 30 .

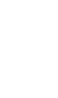


itaque eum et dona habuisse et victimas; dona quippe, preces et victimas proprii corporis holocaustum. Ea nimirum, quae sacerdotem habere decebat, sicut in priori membro audivimus. ${ }^{405}$

9 Itaque perfectio factus est omnibus sibi obedientibus, caussa item salutis aeternae, 10 cognominatus a deo pontifex secundum ordinem Melchisedech.

| Haec illa epanaphora ${ }^{406}$ est, qua redit et docet, quomodo exauditus sit, id est, quis 54r $F$ sit finis et fructus sacrificii et sacerdotii Christi, vita aeterna, peccatorum remissio et perfectio. Id vero subinde ingerit. Nam parum est, si duntaxat credamus Iesum esse sacerdotem; oportet enim, ut etiam credamus Iesum nobis esse sacerdotem. 10 Recte itaque hoc loco iterum repetit, quod prius non semel monuit, fructum sacerdotii, imo totius negotii Christi, esse vitam aeternam. ${ }^{407}$ Nam sacrificium ita absolutum est, ut nihil in eo desyderes, ita amplum et opulentum, ut nullum hominum genus non absolvat et redimat, modo credat. Nam »qui credit in filium«, inquit baptista, »habet vitam aeternam; qui autem incredulus est filio, non 15 videbit vitam, sed ira dei manet super eum« [Joh 3,36]. Christus enim $\tau \varepsilon \lambda \varepsilon \varepsilon-$

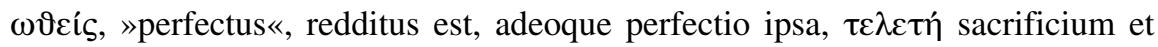
expiatio nostra, sed et $\alpha i \iota \iota s$, , »caussa «, vis et author aeternae salutis est. Ipse enim factus est nobis a deo sapientia, iusticia, sanctificatio et redemptio. Neque ulla alia salus in quoquam alio est, sed ipse omnium fidelium omniumque tem- 20 porum sacerdos est, constitutus a deo secundum ordinem Melchisedech. De quo copiosius disputabitur in cap[ite] $7 .{ }^{408}$ Hactenus enim ex vocatione et officio probavit Iesum Christum verum esse sacerdotem.

\section{Digressio.}

11 De quo nobis multa forent dicenda | eaque difficilia explicatu, quandoquidem segnes facti estis auribus. 12 Etenim cum debebatis pro temporis ratione doctores esse, rursum opus habetis, ut doceamus vos, quae sint elementa initii eloquiorum dei,

Digressio. Hic vero paululum deflectit ab instituto apostolus et caussa de sacerdotio Christi suspensa ad aliud digreditur. Est autem digressio »alicuius rei, sed ad utilitatem 30 caussae pertinentis, extra ordinem excurrens tractatio $\ll .{ }^{409}$ Et tunc maxime locum

Z. (19) iusticia] iustitia $Z F$

405 Hebr 5,1.

408 Hebr 7,1-17.

406 Siehe oben 44, Anm. 261.

409 Quint. inst. 4,3,14 (Winterbottom I 228,5f.).

407 Vgl. Hebr 2,11; 3,6. 
habet, cum generale aliquid invenerimus, in quod parata est via ex re proposita et ex quo rursus, in quod digredi volumus, facilis est accessus. Sed et utilis et propemodum necessaria est, potissimum si de tali re dicendum sit, a cuius mentione auditorum abhorreant aures, ut interposita $\mid$ aliqua, quae illos movere 5 possit, re sensim et plumbeo, quod aiunt, pede ${ }^{410}$ ad id, quod institueramus, deducamur. Id quod hoc loco a Paulo observari videmus. Nam de sacerdotio Christi dicere coeperat; $a b$ ea autem tractatione multorum abhorrebant aures, quod vel Mosaicis nimium tribuerent vel segnius divina scrutarentur mysteria; hinc maxime necessarium erat, ut aliqua interfatione, qua illi poterant moveri excitarique praemissa, commodius de sacerdotio continuare valeret. Ideoque ex- Summa. postulat nunc cum Hebraeis horumque $\mid$ increpat segnitiem ac tarditatem, poenas item, ni pergant in veritate, intentat: neque enim frustra praedicari verbum dei, sed ut fructum feramus per fidem et constantiam; neque vero ipsum dei verbum esse incertum vel promissiones dubias, sed longe certissimas et iuramento dei

15 firmatas. Quae etsi omnia dicantur per digressionem, tamen ad ipsam rem maxime pertinent, id cum primis, quod de veritate dei disseritur. Haec enim caput et firmamentum est sacerdotii Christi. Dixit enim propheta: »Iuravit dominus et non poenitebit eum: tu es sacerdos secundum ordinem Melchisedech« [Ps 110,4]. Itaque priusquam de illo novo sacerdotali dissereret ordine, voluit ea praemittere, 20 quae in ipso prophetae praeibant testimonio, et per hoc ipsum pulchre ad 7. cap[itis] initium, eo videlicet, unde digressus erat, reverti. Ita vides omnia probe connecti et nihil prorsus temere. Istud autem huius digressionis caput et summa est. Caeterum ipsa apostoli verba satis sunt exposita. Negotium etenim de sacerdotio Christi non ipsa re difficile esse dixit, sed quod parum alacri susciperetur mente. Omnem itaque difficultatem non ex ipsis oriri scripturis, sed nostra socordia. Quod in 2. ad Corinth[ios] epistola 4. cap[ite] planioribus edisserit verbis. ${ }^{411}$ Segnitiem igitur istorum increpat eamque temporis accessu exaggerat, quasi diceret: »Si quis tempus, quo sacra audistis, spectet, iam alios docere debebatis, tam illi|berale est, ut tot annorum discipuli nihil aliud didiceritis, quam aliorum esse discipuli adeoque pueri elementarii.« Sic enim allusionis ornatu excrevit oratio. Allusit enim ad alphabetarios vel elementarios infantulos, quibus Elementa.

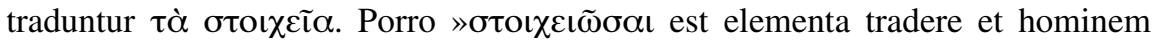
rudimentis « imbuere. ${ }^{412}$ Hinc $\sigma \tau o \iota \chi \varepsilon \tau \tilde{\tau} \alpha$ rudimenta sunt et primordia, qualia sunt apud dialecticos et grammaticos Porphyrii ${ }^{413} »$ Isagoge « et Donati ${ }^{414} »$ Rudimen- $^{2}$ 35 ta«. Hoc consilio vocavit etiam Paulus alibi Iudaicas ceremonias »elementa

410 Vgl. TPMA IV 144, Nr. 117.

411 Vgl. 2Kor 4,6f.

412 Bud. comm. 1526,18-20.

413 Porphyrios (ca. 234-305/310 n. Chr.), neuplatonischer Philosoph und Gelehrter aus Tyros, bekannt vor allem wegen seiner sehr einfluss- reichen »Einführung in die Kategorien des

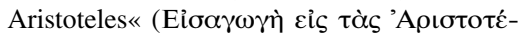

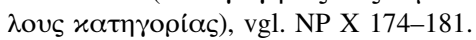

414 Aelius Donatus (4. Jh. n. Chr.), lateinischer Grammatiker und Lehrer des Kirchenvaters Hieronymus. Donatus verfasste eine »Ars 

mundi« [Kol 2,8], id est externas quasdam institutiones et manuductiones. Elementa, inquam, non terram utique aut aerem, ignem aut aquam, sed ipsam institutionem primariam, quae rudes adhuc rerum divinarum paulatim provehat ad altiora, proniores vero ad peregrinos cultus veluti cancellis sepiat atque constringat. Mundana autem dicuntur, id est externa, quod externis gaudeat mundus, 5 externis ducatur et moveatur. Concessit ergo infirmioribus quendam ritum externum, sed ut ab hac transvehatur mens ad veram spiritus religionem. Siquidem indecorum est, si grandiusculus adhuc agat in scholis alphabetariorum. Pudendum itaque, si quis perpetuo ceremoniis addictus esse velit. Verum nullus hic nobis privatus de ceremoniis sermo; loquimur enim de rudimentis doctrinae 10 christianae. De quibus copiosius in $6{ }^{415}$ Haec autem per insertionem et occasionem dixi.

| 12 factique estis hi, quibus lacte sit opus et non solido cibo. 13 Nam quisquis lactis est particeps, is rudis est sermonis iusticiae, infans enim est. 14 Porro perfectorum est solidus cibus, nempe horum, qui propter assuetudinem sensus habent exercitatos ad discretionem boni pariter et mali.

Exercitatio. Idem dicit, quod supra, sed copiosius et mutato sermonis habitu. Nam aliud simile adducit ab infantibus, quo et in Corinthiis usus est, 1. Cor. 3[,1]. Et quod prius vocavit elementa, nunc lactis nomine vestit. Abstrusiora vero, spiritualiora 20 et altiora scripturarum mysteria, iustam, inquam, divinarum rerum cognitionem solidiorem dixit cibum. At qui lacte alitur, is est, cui adhuc traduntur rudimenta

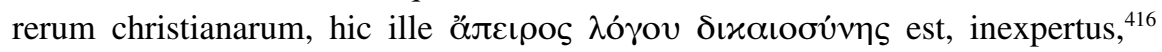

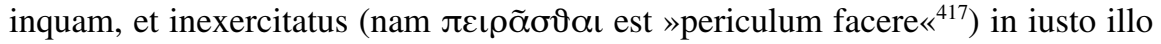
dei negotio, id est in absoluta illa Christi philosophia. Nam et Latini dicimus 25 iustam vel libri vel hominis vel alterius rei magnitudinem, cui nihil desit, quod | ad decus et necessitatem pertineat. Ad expositionem horum facit etiam alia pars similitudinis, quae est: et ut adultiores solidi duntaxat capaces sunt cibi, ita pro exercitatis tantum est penitior sacrarum scripturarum enarratio. Discamus $\mid$ itaque et nos »adolescere $«^{418} \gg$ in virum«, ut Paulus ait in Ephesiis, »perfectum, in 30 mensuram aetatis plene adultae Christi, ut non amplius simus pueri, qui fluctuemus et circumferamur quovis vento doctrinae $[$ Eph 4,13f.] etc. Annotandum et illud: $\check{\xi} \xi\left\llcorner\right.$, quam Latinus vertit $»$ assuetudinem $\ll,{ }^{419}$ proprie significare habitum,

grammatica«, deren erster einleitender Teil auch als eigenständiges Werk unter dem Titel »Ars minor « bzw. »Grammaticae Latinae rudimenta« handschriftlich überliefert und später gedruckt wurde. Vgl. NP III 775.

415 Siehe unten S. 77-81.
416 Erasm. Hebr. (ASD VI/10 296,852).

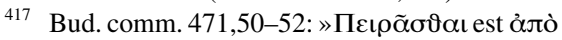

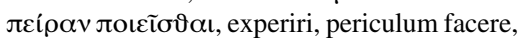
et experiri, id est adispisci.«

418 Eph 4,15.

419 Vgl. Erasm. Hebr. (ASD VI/10 296,860). 
qui opponitur ruditati. »Habitum enim«, inquit Cicero in 1. de inven[tione] lib[ro], »appellamus animi aut corporis constantem et absolutam aliqua in re perfectionem, ut virtutis aut artis alicuius perceptionem. ${ }^{420}$ Sive ut philosophi finierunt: »Habitus est alicuius rei sive in animo sive in corpore a natura concepta, 5 sed usu corroborata et plena perfectio. $\aleph^{421}$ Quae sane finitio probe nostris congruit, ut et illud, quod in istum locum Ioan[nes] Chrysostomus annotavit. ${ }^{422} \mathrm{Haec}$ vero omnia in hoc dixit apostolus, ut segniores excitaret auditores et humi repentes ad altiora sustolleret mysteria, nempe ut purgatioribus auribus et cordibus ea perciperent, quae mox de sacerdotio Christi ex scripturarum arcanis disputaturus erat. Nunc enim sequitur collectio, cur ista hactenus dixerit.

1 Iccirco omisso illo initiali rerum christianarum sermone feramur ad ea, quae perfectiora sunt,

»Non haec refero«, inquit, »quod istis immorari velim, sed quod omissis istis, quae iam olim didicisse oportuit, animos vestros ad absolutiora pararem. « Et ne

15 quid ob|scuritatis aut ambigui quicquam lectorem remoraretur et suspenderet, adhuc illud quoque subiicit:

1 non rursum fundamentum iacientes poenitentiae ab operibus mortuis et fidei in deum, 2 baptismatum doctrinae ac manuum impositionis et resurrectionis mortuorum et iudicii aeterni.

20 Ex quibus iam claret, quid in 5. cap[ite] intellexerit per elementa et alimentum lactis, ${ }^{423}$ nempe locos istos communes rerum christianarum, quos hic maxima parte recenset fundamentaque vocat, hoc est primordia. ${ }^{424}$ Nam fundamenta priCatechismus mo in omnibus collocantur aedificiis. Discimus autem ex iis, quae sit isagoge in fidem, hoc est in religionem Christi, et quomodo apud nos etiam christiana religio commode initiari possit ac debeat; nimirum, si generaliora et maxime necessaria primum doceamus, nempe: quid sit scriptura, quae eius authoritas, quid veritas, religio, deus, fides, Christus, peccatum, gratia et iusticia. Sed quid ista recensemus, cum ipse apostolus potissima numerarit? Quae alii in hunc ordinem redegerunt, quod candidati nominis christiani primo instituti sint de poenitentia et fide 30 in deum, deinde vero (de adultis loquor) baptisati, post baptismum vero de

Z. (18) baptismatum] baptizmatum $F-(27)$ iusticia] iustitia $Z F-(30)$ baptisati] baptizati $Z F$

${ }^{420}$ Cic. inv. 1,36 (Hubbell 72).

421 Mar. Victorin. rhet. 1,25 (CCSL CXXXII 114,64-66).

422 Vgl. Chrys. Hebr. transl. 87; Chrys. Hebr. 8,3 (PG LXIII 73).

423 Hebr 5,12.
424 Vgl. Erasm. Hebr. (ASD VI/10 296,866-868): »Melius vertisset >primordii< siue >principii<, quemadmodum paulo ante vertit exordii, $\dot{\alpha} \rho \chi \tilde{\eta} \varsigma$. Sentit autem verba, quibus rudes adhuc in Christo initiantur et instituuntur, nempe catechumeni.« 
spiritus sancti acceptione, item de resurrectione et iudicio edocti. ${ }^{425}$ Nos autem singula expendemus.

Poenitentia. $\quad \mid$ Primo autem loco posuit »poenitentiam «, hoc est resipiscentiam ${ }^{426}$ et vitae mutationem, id est conversionem »a mortuis operibus «, hoc est a peccatis. Nam »stipendium peccati mors est« [Röm 6,23]. Ideoque plura in recessu habet poenitentia quam fronte promittat. Habet enim errorum ac scelerum agnitionem et vitae immutationem. Et proinde qui poenitentiam praedicat, non istam duntaxat vocem ingeminat: »Poenitentiam agite!«, sed omnem protrahit impietatem, superstitionem et errorem, scelera item atque peccata nudat, accusat et obiurgat; contra vero religionem suadet et ad sanctimoniam vitae et iusticiam veram hor- 10 tatur. Sic Ioan[nes] Baptista, ${ }^{427}$ sic ipse dominus Iesus, ${ }^{428}$ sic apostoli ${ }^{429}$ Christi omnes poenitentiam praedicarunt et ab hac praedicationem suam orsi sunt. In primis enim scire refert, quid nam illud sit, a quo averti, et quale illud sit, ad quod converti debeamus; item qualis sis, qualia etiam studia tua. Nam ab ipsa hominis

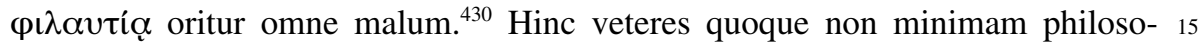
phiae partem esse crediderunt, si quisque se, qualis sit, agnoscat. Hinc illud nobis

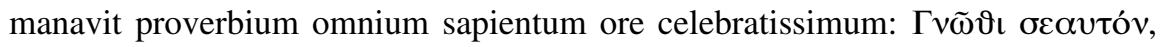
»nosce te ipsum«, quod (ut in Char|mide testatur Plato) pro foribus templi Delphici ab amphictyonibus ${ }^{431}$ inscriptum, veluti deo dignum viseretur. ${ }^{432}$ Et huc fortassis merito quis retulerit legem, per quam (ut Paulus ait) existit cognitio 20 peccati. $^{433}$

Z. (6) agnitionem] agnitionem, confessionem, quae deo fit, reconciliationem $Z F-(10)$ iusticiam] iustitiam $Z F$

425 Erasm. Hebr. (ASD VI/10 298,871-877): »At Graecanica scholia sic interpretantur, vt separatim sit legendum >omittentes sermonem illum, quibus primum instituuntur rudes in Christo<, nempe eum qui est de poenitentia, hoc est: primum admonentur, vt relinquant vitam pristinam renascituri in Christo, deinde de fide in Christum condiscunt, quid sit credendum, deinde his traditis succedit baptisma, cuius mysteria tum demum aperiuntur. Post haec docentur de sacramentis fidei nostrae et parantur ad accipiendum Spiritum sanctum.«

426 Vgl. Lact. inst. 6,24,6 (CSEL XIX/2 572,912): »Quem enim facti sui paenitet, errorem suum pristinum intellegit, ideoque Graeci me-

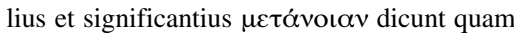
nos Latine possumus resipiscentiam dicere.«

427 Mt 3,2; Mk 1,4; Lk 3,3.

428 Mt 4,17; Mk 1,15.

429 Apg 2,38; 8,22; 17,30.

430 Vgl. Erasm. adag. 292 (ASD II/1 398,311-
315): »Qui sibi vehementer placent quique suis ipsorum commodis impense student aliorum rebus vel neglectis vel etiam afflictis, a Graecis eleganter $\varphi$ í $\lambda \alpha v \tau o \iota$ vocantur. Vitium ipsum $\varphi \iota \lambda \alpha v \tau i ́ \alpha$ dicitur. [...] Id vitii Plato malorum omnium fontem autumat.« Vgl. Plat. leg. V 731e (Burnet V ebd.).

431 Als ỏ $\mu \varphi \iota \varkappa \tau v o v i ́ \alpha \iota$ wurden Bünde bezeichnet, die sich um ein Heiligtum gruppierten und dessen Kult pflegten, vgl. NP I 611-613.

432 Erasm. adag. 595 (ASD II/2 117,35-38): »Ad eandem sententiam pertinent tria illa inter omnia sapientum apophthegmata vel maxime celebrata, adeo vt, quemadmodum in Charmide testatur Plato, pro foribus templi Delphici ab Amphictyonibus inscripta veluti digna deo viserentur. Quorum primum est $\gamma \gamma \tilde{\omega} \vartheta \mathrm{\iota} \sigma \varepsilon \alpha v-$

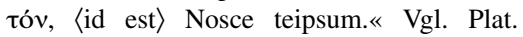
Charm. 164d (Burnet III ebd.).

433 Röm 7,7. 57v $F$ 
| Secundus locus est fides in deum, hoc est cognitio dei et fidutia in illum. Fides. Proximum enim est, ut, postquam me, qualis sim, cognorim, protinus et deum cognoscam, ne superstitionis et scelerum conscientia desperem, quin potius norim deum esse benignum et misericordem, cui fidere et eius auxilium implorare 5 eiusque debeam veritate frui. Atque hic comprehenderit quis non immerito iusticiam et misericordiam dei, veritatem et omnipotentiam, breviter, quid deus sit, quid fides.

Tertio loco numerat baptismata doctrinae. Id quod alii de doctrina initiali Baptismata. intelligunt, quod baptismus sit initiatio vitae christianae; ut sit sensus se loqui de

10 ea in deum fide, quae candidatos initiet, non de ea, quae incrementis ad iustam pervenit magnitudinem. ${ }^{434}$ Alii separatim legunt et partim iungunt doctrinam sequentibus et legunt: »doctrinae manuum impositionis «; ${ }^{435}$ partim nectunt praecedentibus et legunt: »baptismatum doctrinae«, quasi fidem sequatur baptismus aquae, baptismum vero amplior doctrina de perfectione. ${ }^{436}$ Id quod alias in adultis 15 verum esse nemo ierit infitias, sed num ea suo dicantur in loco iudicent lectores. Certe cum in ecclesia dei non sit nisi unicum baptisma, apostolus autem coniunctim et plurativo numero dixit $\beta \alpha \pi \tau \iota \sigma \mu \tilde{\omega} \nu \delta เ \delta \alpha \chi \tilde{\eta} \varsigma$, »baptismatum doctrinae«, apparet eum locutum esse non de baptismi sacramento aut catechi|smo, sed de traditione baptismatum, id est generibus lustrationum. B $\alpha \pi \tau i \xi \omega$ enim »mergo« et »tingo« est; quia vero ea mundantur, quae lavantur sive tinguntur, fit, ut baptismus accipiatur pro emundatione, per metalepsim. ${ }^{437}$ Doctrinam igitur de purgandi generibus ideo subiunxit fidei, quod ipsa fides in deum, huc unice spectet, ut credamus sanguine Christi non modo peccata nostra esse expurgata, sed et omnia alia lustrandi genera per hanc unam Christi purgationem esse abolita. Nam in 9. cap[ite] palam audiemus apostolum baptismata prorsus in hanc accepisse partem dixisseque ista velut iustificationem carnis, »usque ad tempus correctionis imposita « [Hebr 9,10]. Ibi tamen significantius »ablutiones« transtulit interpres. ${ }^{438}$ Huc autem referri debet peccatorum remissio, redemptio et quicquid per Christum consecuti sumus.

Quartus locus est impositio manuum, quae semel in se complectitur totum Impositio prophetiae munus, quo non aliud in ecclesia magnificentius: complectitur vocationem, missionem docendique authoritatem. Illis enim imponebantur seniorum manus, quorum fidei committebatur ecclesiarum cura et divini verbi ministerium. Nam ad Timotheum scribit apostolus: »Ne neglexeris, quod in te est, donum

\footnotetext{
Z. (5-6) iusticiam] iustitiam $Z F$ - (22) huc] hunc $Z F$ - (25) 9. cap[ite]] nono capite $Z F$

434 Erasm. Hebr. (ASD VI/10 298,877-879): »Si mauis coniunctim legere, nihil vetat quo minus intelligat de instituto et doctrina prima, quae baptizandis, hoc est catechumenis, solet tradi.«

435 Erasm. Hebr. (ASD VI/10 298,880).

436 Theophyl. Hebr. transl. 150v.

437 Vgl. Quint. inst. 8,6,37 (Winterbottom II 470): »[...] metalempsis, id est transumptio, quae ex alio tropo in alium uelut uiam praestat.«

438 Erasm. Hebr. transl. (ASD VI/4 284).
} 
delegatum tibi ad prophetandum idque roboratum est manuum impositione a senioribus «, 1. Timoth. 4[,14]. Atque utinam haec postliminio ad nos redeat manuum impositio, ritus sanctissimus iuxta et utilissimus! Quo proculdubio multa tollerentur schismata offendiculaque, quo et istorum proterva refrenaretur impudentia, qui non vocati sua sponte et malitia ad docendi irruunt officia, homines audacissimi et Chore Abironisque factiosissimi filii, ${ }^{439}$ qui arrogantia eo deveniunt, ut, quicquid libet, mox licere etiam credant. At hinc nobis in ecclesia omnis oritur rixandi, haeresum et factionum materia. Neque vero dubitarim apostolum sub hac manuum impositione semel comprehendisse alios quoque necessarios in ecclesia Christi ritus, coetus, orationes, ferias, ieiunia, imo ipsa ecclesiae sacra- 10 menta, quae sunt significatione et mysteriis saluberrima, augusta ac sacrosancta, baptismus scilicet et eucharistia. Nam aequum est, ut christianae ecclesiae ritus et sacra intelligamus, postquam conversi ad deum didicimus omnem in Christo esse gratiam et plenitudinem, conciliationem, veritatem et iusticiam, decus et munditiam, quam suae largiatur ecclesiae, quam regat verbo, conservet spiritu, con- 15 stringat baptismo et excitet sancto eucharistiae monimento. Alii per impositionem manuum hysterologia ${ }^{440}$ quadam intelligunt spiritus sancti dona, ${ }^{441} 1$. Corinth. 12[,4-11]. ${ }^{442}$ Quibus non adeo reclamarim.

Resurrectio. Quintus vero locus est resurrectio mortuorum, spes nostra, finis et fructus evangelii | amoenus et suavis. | De quo copiosissime disseruit Paulus in 1. ad 20 Corinth[ios] 15[,12-58]. Observabis autem mortuorum resurrectionem esse corporum resurrectionem. Nam anima non moritur, corpus tantum moritur. Proinde mortuorum resurrectio est corporum resurrectio; quae nisi certissima esset, quis, oro, iusticiae fructus? Quis esset probitatis et honestatis cultus? An non illud Epicureum $^{443}$ rite celebraretur ab omnibus: $»$ Edamus et bibamus, cras enim mo- 25 rimur « [1Kor 15,32]? Rursus si vere credamus resurrectionem, quis, oro, ex nobis temere polluerit corpus suum, quod certo novit immortalitati esse dicatum? Necessaria itaque est mortuorum resurrectio et maxime hominibus inculcanda.

\section{Z. (24) iusticiae] iustitiae $Z F$}

439 Bullinger spielt hier auf den Aufstand Korachs, Datans und Abirams gegen Mose an, Num 16,1-3.

440 Als »Hysterologia « wird die dem natürlichen Geschehenablauf entgegengesetzte Anordnung zweier Satzinhalte bezeichnet, vgl. HLR $440 \mathrm{f}$.

441 Vgl. Bug. Hebr. 125v. Dieser Interpretation, von der hier teilweise Abstand genommen wird, hatte sich Bullinger früher selbst angeschlossen, vgl. Bull. vorl. Hebr. [6,2] (Berg/Hausammann 173).
442 Theophyl. Hebr. transl. 150v: »[Impositio manuum,] qua [...] spiritum sanctum accipiebant, cuius gratia et futura praedicerent et miracula ederent. Ait enim alibi Paulus[!]: >Cum manus eis imposuisset, acceperunt spiritum sanctum< [Apg 19,6].«

443 Epikuros (ca. 342-271 v.Chr.), Philosoph und Gründer der epikureischen Schule. Epikuros vetrat in der Ethik eine hedonistische Position, auf die hier Bullinger anspielt. Vgl. NP III $1130-1140$. 
Ultimo loco statuitur iudicium aeternum, hoc est ultimum illud iustissimi dei Iudicium. decretum, quo alios quidem aeternis addicet cruciatibus, alios vero nunquam finiendis gaudiis, unde consequitur aeternam esse et vitam et mortem. Vitam, inquam, iustorum et mortem, hoc est condemnationem, iniustorum perpetuam, 5 Ioann. 5[,21-30]., Matth. 25[,31-46]., Isaiae 66[,14-16]., et Marci 9[,42-48]. Et haec quidem communia sunt capita introductionis in religionem christianam, verus et genuinus apostolorum catechismus.

\section{Atque id faciemus, siquidem permiserit deus.}

Istis iam removet a se communium locorum tractationem elementariamve institutionem ac redit ad ob/iurgationem, exitium minitans, ni pergant in re coepta et persistant. »Atque de iis«, inquit, »satis iam olim disputatum, ut nunc nihil supersit aliud, quam ut indies Spartam, quam nacti sumus, adornemus etiam. ${ }^{444}$ Ad quam rem perficiendam opus erit dei consilio auxilioque. « Nam deus is est, qui agit in nobis, et ut velimus et ut efficiamus pro bono animi proposito « [Phil 15 2,13]. Siquidem ipsi non idonei sumus ex nobis ipsis cogitare quicquam, sed omnis idoneitas nostra ex deo est, qui et in evangelio dixit: »Sine me nihil potestis facere « [Joh 15,5]. Prudentissime itaque adiecit apostolus: »Siquidem permiserit deus.«

\section{Nam impossibile est, ut qui semel fuerint illuminati gustaverintque} donum coeleste et participes facti fuerint spiritus sancti 5 gustaverintque bonum dei verbum ac virtutes futuri saeculi, 6 si excidant, denuo renoventur per poenitentiam, ab integro crucifigentes sibimetipsis filium dei et ludibrio exponentes.

Nunc admovet currentibus calcaria, ${ }^{445}$ poenas intentans et indignitatem rei proponens, si in ipso cursu aut constiterint segnes aut prorsus exciderint. Atque hic ille in speciem difficilis locus est, revera facilimus, quo nonnulli arbitrantur Novatianicum ${ }^{46}$ dogma asseri, quod lapsis a baptismi lavacro poenitentiam negat. At Paulus neque hic neque alibi negavit lapsis poe|nitentiam et proinde catha- Oppositi loci. rorum $^{447}$ sectam non iuvit. Id si a me clarius dici velis, exhiheo tibi huius 30 epistolae caput 7., 8., 9., 10., in quibus ipse Paulus probat Christum unica

444 Erasm. adag. 1401 (ASD II/3 397,2-5): »Spartam nactus es, hanc orna. [...] Admonet adagium, vt quamcunque prouinciam erimus forte nacti, ei nos accommodemus proque huius dignitate nos geramus. «

445 Siehe oben S. 18, Anm. 91.

446 Siehe oben S. 10, Anm. 39.

447 »Cathari« (die »Reinen«) war ursprünglich eine Alternative Bezeichnung der Novatianer, vgl. Rufin. hist. 10,6 (GCS IX/2 967,9): »Et Catharos, qui apud nos Novatiani sunt [...].« Im Mittelalter wurden auch die Anhänger der als häretisch verfolgten Bewegung der »Guten Christen « »Katharer « genannt, vgl. LMA V 1064-1068. 
oblatione non unicum tantum aut certa quaedam abstulisse peccata, sed omnia. Sed et in 2. cap[ite] clarissime dicit Christum per omnia fratribus similem esse factum, ut misericordem et fidelem agere posset pontificem in iis, quae apud deum forent agenda, ad expianda, inquam, populi peccata. ${ }^{448}$ Et in 5.: $\gg$ Accedamus igitur «, inquit, »cum fiducia ad thronum gratiae, ut consequamur misericordiam et gratiam inveniamus in opportunum auxilium « [Hebr 4(!),16]. Ideo lapsis poenitentiam non negavit, qui Christum intercessorem nobis proposuit, et ad hunc omni tempore et quoties auxilio opus fuerit invitavit. Quid igitur hoc loco phrasis. sibi voluit? Verborum et rerum amplificatione Hebraeos deterrere ab inconstantia, segnitie et tarditate et hortari, ut constanter in veritatis pergant tramite. Habet 10 autem hoc dicendi genus omnia ea schemata, quae reddunt acrem et ardentem orationem, adeo ut nonnunquam ipsa sese amplior sit et sese vincat oratio. Quis enim nescit, quid vel una possit amplificatio, quid hyperbole? Sub quas proculdubio hic Pauli locus referri debet maxime, quod tanto verborum incremento, congerie et delectu omnia agit, quod Christum a desertoribus iterato crucifigi, 15 eundem et infamari asseverat. Quis | enim tam stupidus, qui hic non videat et amplificationem et hyperocham? ${ }^{449}$ Qui igitur fit, ut non obser|vemus et authoris consilium et dicendi genus? Quid, obsecro, nodum quaerimus in scyrpo $?^{450}$ Quin ipse protinus subiungit: »Caeterum meliora de vobis pollicemur nobis, tametsi sic loquamur « [Hebr 6,9]. Cum enim exhortatio nescio quid monentis praecipientis- 20 que aut etiam desperantis habeat et quorundam ingeniorum tanta sit pertinatia, ut non nisi asperis moveantur, fit, ut post acerbitatem cupiamus importunitati nostrae dari veniam. Id quod hoc etiam loco a Paulo observari videmus, ut nunc nemini dubium esse possit, quin in deterrendo exaggerationibus usus sit, inde vero dixerit »impossibile« esse. Nam et Erasmus dicit hanc difficultatem expli- 25 cari posse, si accipiamus »impossibile« dictum esse pro eo, quod admodum sit rarum et difficile. ${ }^{451}$

Contextus. Quod, si etiamdum contendas et simplicitatem orationis vel dictionem amplecti nolis, iam illud te amplecti oportebit, apostolum a necessitate et impossibili ${ }^{452}$ argumentari ad hunc modum: »Dixi ista nos facturos, nec temere dixi. Necessario enim, qui vere credunt, sancte perstant in veritate et subinde pergunt in synceritate. Si enim non pergant vel prorsus excidant, proculdubio credentes non erant, sed hypocritae. Nam Ioannes: >Exierunt $<$, inquit, >ex nobis, sed non erant ex

\section{Z. (21) pertinatia] pertinacia $Z F$}

448 Hebr 2,17.

449 Siehe oben S. 63, Anm. 345.

${ }^{450}$ Erasm. adag. 1376 (ASD II/3 382,305f.): ") Nodum in scyrpo quaeris batur nimisque diligentem aut meticulosum, qui illic scrupulum moueret, vbi nihil esset

451 Erasm. Hebr. (ASD VI/10 300,897-899): »Verum hanc difficultatem duobus explicant modis. Primum vt accipiamus impossibile dictum quod admodum difficile voulit intelligi.«

452 Vgl. Agric. inv. 2,10 (Mundt 268,118-129). 
nobis; nam si fuissent ex nobis, permansissent $\mid$ utique nobiscum< [1Joh 2,19]. Cum ergo fides vera sit constantissimum dei donum, necessario sequitur, quod ista facturi sitis.« Vel ad hunc modum: »Si possibile esset, ut quis a cognito deficeret deo, nulla illi restaret salus; verum id impossibile est; ergo salus, si vere credatis, certissima est, si, inquam, credatis et persistatis in vero. Ideoque si salus vobis cordi est, pergite in veritate. Nam a vero excidere est sese in ipsum averni barathrum praecipitare. « Haec de sensu et consilio apostoli; nunc caetera perstringemus.

Copia autem et incremento verborum utitur, cum dicere vult: qui vere credunt, Qui vere

10 non excidunt, sed perstant. Id enim pluribus verbis, sed in idem recidentibus, exponit, veluti endiadi utens, qua de una re loquimur, ac si plures sint. ${ }^{453} \mathrm{Nam}$ quid aliud est illuminatum esse, quam donum coeleste gustasse? Et quodnam illud donum coeleste, nisi spiritus sancti dotes? Et quaenam illae dotes, nisi illae, quas per salutiferum dei verbum percipimus, quod, inquam, aeternae gloriae 15 haeredes sumus? Istud, inquam, qui perceperit et arrha sancti spiritus fuerit obsignatus, excidere non potest (id enim est $\pi \alpha \rho \alpha \pi i \tau \tau \omega)$. Quod si exciderit, hypocrita fuit, homo reprobus, cui non restat ulla alia hostia, quando ab ea sua sponte excidit, quae sola purificat. Itaque non est, ut in eo renovationem expectemus per resipiscentiam. Ea enim in eo mens non est, quae resipiscere velit, quando ab eo $\mid$ abhorret, per quem restituendus erat. Atque hoc ipsum in caussa fuit, cur nonnulli hunc locum exposuerint de peccato in spiritum sanctum, ${ }^{454}$ de quo et 1. Ioan. 5[,16f.]. Porro qui nomen Christi sicut Demas, ${ }^{455}$ Hymeneus et Philetus ${ }^{456}$ professi recidunt et, ut Petrus ait, canis in morem ad vomitum redeunt, ${ }^{457}$ ii Christum denuo crucifigunt eumque summa afficiunt ignominia. Nam apostolus posuit $\pi \alpha \rho \alpha \delta \varepsilon \imath \gamma \mu \alpha \tau i ́ \zeta o v \tau \alpha \varsigma$ pro infamantes ${ }^{458}$ et exemplificantes. Solent autem malefici, qui ob malefacta puniuntur, fieri exemplum, quae extrema inter homines ignominia est. Latinus ergo sensum reddere volens dixit »ludibrio exponentes $\ll .{ }^{459}$ Alii aliud hoc loco sequuntur, sed magis quadrat hyperocha ${ }^{460}$ deterrenti. In hyperochis autem nemo putat omnia revera fieri.

7 Siquidem terra, quae imbrem saepius in se venientem conbiberit et progenuerit herbam accomodam eis, quorum opera colitur, recipit benedictionem a deo. 8 At quae produxerit spinas et tribulos, reproba est et maledictioni confinis, cuius exitus huc tendit, ut exuratur.

\footnotetext{
453 Zur rhetorischen Figur »Hendiadyoin « ( $\tilde{v} v \delta ı \grave{\alpha}$ Svoĩv) vgl. HWR III 1344-1350.

454 Vgl. Bug. Hebr. 126r-v.

4552 Tim 4,10 .

$4562 \operatorname{Tim} 2,17 \mathrm{f}$.
}

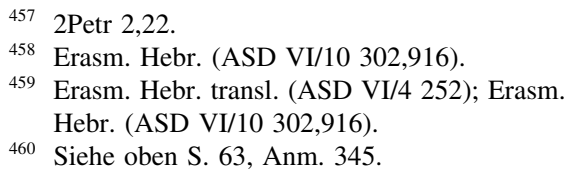

credunt, peccant
quidem, sed non excidunt. 
Simile est, quo idem dicit, quod dixerat superius, sed clarius et apertius. Adhibentur enim similia lucis et perspicuitatis gratia. Per terram autem intellexit Fructus homines. Per imbrem foecundans dei verbum. Per fructus vero opera iusticiae. iusticiae. Per tribulos autem perfidiam | et iniquitatem. Qui ergo operantur iusticiam, benedictionem a deo consequuntur; qui vero sectantur malitiam, maledictionem accipiunt a deo. Paria pene istis legimus apud Matth[aeum] in 13. et Lucam in 13., Ioan[nem] quoque in 15., ${ }^{461}$ unde haec fortassis desumpta vi|deri poterant. Hactenus autem omni studio torporem ex Hebraeorum excussit animis, cohortans ad constantiam et piam sedulitatem.

9 Caeterum persuasimus nobis meliora et quae sint salubria de vobis, dilecti, tametsi sic loquamur.

Mitigat superiora, quod ea satis fuerint aspera et importuna, quemadmodum superius annotavimus. Huic vero praemollitioni non prorsus absimilis ea est, qua apud Iudaeos usus est Petrus dicens: »Et nunc scio, fratres, quod per ignorantiam fecistis « [Apg 3,17] etc., Actor[um] 3. c[apite].

10 Non enim iniustus est deus, ut obliviscatur operis vestri et laboris ex charitate suscepti, quam exhibuistis erga nomen illius, qui ministrastis sanctis et ministratis.

Caussa est, cur speret salutem eorum, sensus autem planus est, nisi quod iusticia dei hoc loco accipitur pro veritate dei. Veritate itaque dei hortatur, ut pergant. 20 Certam enim fore salutem, si pergant. Sed et laudis nonnihil miscet. Porro laus in persuadendo plu|rimum potest. Nam »ita mortalium animos natura finxit, ut vix quisquam adeo demisso sit pectore, quin laudibus erigatur $«{ }^{462}$ Laudat itaque bona opera. eorum opera, charitatem in primis, quod deus misericordiam velit, non sacrifi-

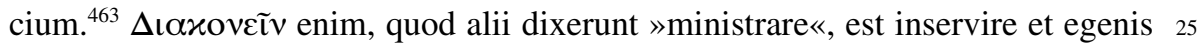
suppeditare de facultatibus. Caeterum, quod egeno in nomine domini impartimur, id ipsi deo impartimur, qui in evangelio dicit: »Quod uni ex istis minimis meis fecistis, mihi fecistis « [Mt 25,40]. Studeamus itaque et nos similibus deo placere charitatis operibus, stultulas vero, non ceremonias, sed gentiles ineptias aspernari et omne animi studium ac promptitudinem convertere in egenos. Nam de mise- 30 ricordia habebit sermonem, cum venerit iudicare vivos et mortuos, Matth. 25[,31-

Z. (3) iusticiae] iustitiae $Z F-(4)$ iusticiam] iustitiam $Z F-(6)$ Matth[aeum]] Matthaeum $Z F$ (15) Actor[um]] Actorum $Z F$ - (19) iusticia] iustitia $Z F$

\footnotetext{
461 Mt 13,3-23; Lk 13,6-9; Joh 15,1-8.16. $\quad 463$ Hos 6,6.

462 Erasm. conscr. (ASD I/2 324,22-24).
} 
46]. Misericordiam exigebat et a patribus nostris apud Isaiam in $58 .{ }^{464}$ Misericordiae igitur studeamus.

11 Cupimus autem, ut unusquisque vestrum idem praestet studium ad certificationem spei usque ad finem, 12 ne sitis imbecilles, sed imitatores eorum, qui per fidem et longanimitatem haereditatem accipiunt promissionis.

Catastrophe ${ }^{465}$ est et collectio. Quasi dicat: »Quae vero diximus, non eo pertinent, ut censeam vos esse spinas igni deditas, sed huc magis spectant, ut constantiam | in vero apud vos obtineam, segnitiem porro et inconstantiam pectoribus vestris 10 excutiam. « Et quo certius hoc apud eos obtineret, mox aliud quoque argumentum ab exemplo maiorum deductum affigit in hunc modum: »Atque ad talem con- Constantia. stantiam in primis pertrahere debet gratissimum illud et pulcherrimum patrum vestrorum exemplum, qui constantia et longanimitate maximas res consecuti sunt. Sitis igitur et vos robusti mente, non imbecilles, pavidi, segnes, trepidi et incon15 stantes, sed quisque vestrum idem praestet studium ad certificationem spei usque in finem; id est, ut ipsa spes vestra persuasa, certa et indubitata sit in finem usque.« Non enim qui bene coeperint servabuntur, sed qui in vero et bono perseveraverint usque in finem. ${ }^{466}$

\section{Deus enim pollicitus Abrahae, cum non posset per quenquam maiorem} iurare, iuravit per seipsum 14 dicens: nisi benedicens benedixero tibi et multiplicans multiplicavero te. 15 Atque ita cum patienter expectasset, consecutus est promissum.

Dixerat quosdam fide et constantia haereditasse promissionem, hoc est res promissas. Est enim synecdoche. ${ }^{467}$ Istius itaque rei nunc singulare exemplum de Abraham producit, quo simul et ad veritatem dei asserendam transit. Quod ad exemplum attinet, nihil obscurum est. Abraham enim patienter et cum insi|gni quadam infractaque expectavit constantia | ac fide, iccirco id, quod expectavit, assecutus est. Expectemus igitur et nos, fidamus verbis eius, scrutemur veterno excusso mysteria eius, perseveremus, inquam, in via eius et proculdubio promis-

\section{Z. (5) imitatores] immitatores $F$}

464 Jes $58,5-7$.

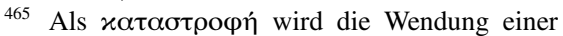
Handlung zur Ruhelage bezeichnet, vgl. HLR

466 Mt 10,22; 24,13

467 Siehe oben S. 33, Anm. 194. 
siones, id est res promissas, nos quoque haereditabimus. Quod autem veritatem et certitudinem promissionum dei attinet, ipse deus per semetipsum iuravit dicens:

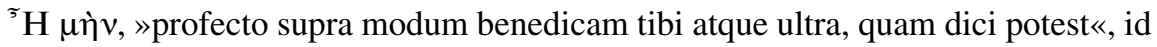

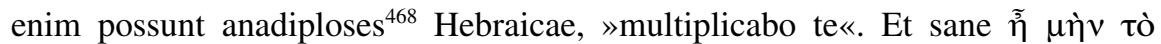

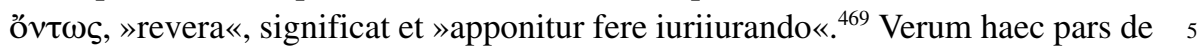
veritate dei et de iuramento plenius intelligitur ex consequentibus.

16 Nam homines quidem per eum iurant, qui sit maior, atque iisdem omnis controversiae finis est, si accedat iurisiurandi confirmatio. $17 \mathrm{Hui-}$ us rei gratia, cum deus eximie vellet haredibus promissionis ostendere firmitatem consilii sui, interposuit iusiurandum, 18 uti per duas res immutabiles, in quibus fieri non posset, ut mentiretur deus, validam consolationem haberemus,

Deus cur Humano more, $\varkappa \alpha \tau^{\prime} \grave{\varepsilon} \xi \eta ́ \gamma \eta \emptyset \sigma v$ de iurandi ritu inducto, demonstrat, cur deus iuraverit. iuraverit et quam certa sit veritas eius. Humanus vero iurandi ritus hisce ver|bis describitur apud Mosen, Exodi 22.: »Si quis dederit proximo suo asinum vel 15 bovem et omne iumentum ad custodiam, et mortuum fuerit aut confractum vel captum nullusque hoc viderit; iusiurandum domini erit inter ambos, quod non extenderit manum ad rem proximi sui, suscipietque dominus rei iuramentum et ille reddere non cogetur « [Ex 22,10f.]. Ex quibus verbis liquido constat, quomodo iuramentum dirimat litem omnisque controversiae finis sit. Nam reus iuramento 20 dato absolvitur et accusator iuramento accepto ita astringitur, ut accusationem ponere cogatur illiusque accedere iuramento. Ad hunc itaque modum, cum deus humano generi certitudinem earum rerum, de quibus nonnunquam humana ambigere solet imbecillitas, demonstrare vellet, iusiurandum interposuit, ut vel sic infirmitati nostrae succurreret, qui iuramento astricti palam videmus immutabilia 25 esse consilia dei, utpote iuramento et promissione firmata; nihil igitur haesitaremus, sed firmam consolationem haberemus fore, ut ea certo assequeremur, quae ille promisit et iuramento firmavit. Iuravit autem fore, ut ingrediamur in requiem eius, modo credamus et benignas aures verbo eius praebeamus; ${ }^{470}$ iuravit item fore, ut Christus sit fidelium sacerdos in aeternum secundum ordinem Melchi- 30 sedech ${ }^{471}$ et proinde certo consequemur salutem, et Christo fruemur unico et aeterno sacerdote. Iam enim commodissimo et $\mid$ nativo transitu ad id redit, unde paulo ante digressus erat, quod equidem sequentibus ostendemus, si illud prius monuerimus.

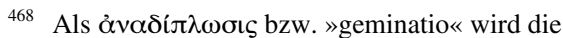
Wiederholung eines Wortes oder einer Wortgruppe an einer Stelle im Satz bezeichnet, vgl. HLR 312-314; Quint. inst. 9,3,29 (Winterbottom II 518f.).

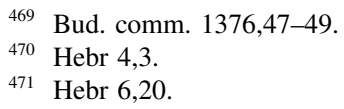


Hinc constare, quod christiano iuramentum dare et magistratui liceat accipere. De iureiurando. Siquidem apost[olus] hoc in loco palam dicit deum ad morem iurasse humanum. Non est igitur, quod nobis male sani baptistae obiiciant, apostolum loqui de prophanis. ${ }^{472}$ Non enim prophanis rebus adaptat se deus sanctus, sed puris, sanctis 5 et bonis. Sanctum itaque et bonum est iuramentum. De honesto enim vero et sancto loquimur, non de periurio, blasphemia et execrabili execratione. Nam ut haec cupimus e christianorum consortio sublata, ita istud in summa aestimatione et reverentia volumus haberi, nisi nobis sordeat gloria dei, qui praecepit et dixit: »Dominum deum tuum timebis et illi soli servies, ac per nomen illius iurabis«

10 [Dtn 6,13]. Unde et propheta desumpsit, quod in Psalmis postea scripsit: ille habitabit cum deo, »qui iurat proximo suo et non mutat «, Psal. $14 .{ }^{473}$ Et iterum: »Et laudabitur omnis, qui iurat per deum«, Psal. $62 .{ }^{474}$ Nam iusiurandum est contestatio dei, quod ea, quae adserimus vel negamus, prorsus ita habeant, sicut asserimus vel negamus, et adeo certa et firma sint, ut omni nos penitus dei 15 subduxerimus auxilio, ni ita habeant. ${ }^{475}$ Illa itaque vera et iusta est iurisiurandi formula, qua ad exemplum dei, Abrahae et sanctorum omnium, item ad $\mid$ praescriptum verborum dei apud Isaiam in 45 . et $65 .{ }^{476}$ non per alium iuramus quam per summum et aeternum; solus autem deus summus est; ergo per solius dei nomen iurandum est, non per creaturas, nisi eas creatori aequare velimus. Qui enim | iurant, summum et charissimum sibi et optimum bonum contestantur, quod aliud esse non potest quam ipse deus. Proinde perfidiam a se depellere nullo iure possunt, qui iuramenta vel dant vel accipiunt divorum nomine firmata. Neque vero exemplum pro se habent in sacris ullum. Nam ut veteres iurabant: »Vivit dominus «, ita vetus dei ecclesia aliud non praescripsit iuramenti genus quam:

25 »Ita, me deus adiuvet.« Maxima autem semper fuit apud omnes gentes iurisiurandi religio. ${ }^{477}$ Sanctissima quoque est eius in sacris scripturis mentio, gravissima item poena periurio et perfidiae statuta; quid quod in plerisque legibus perfidia capitalis est? Hoc itaque impudentius et calamitosius est praesens nostrum saeculum, quo adeo vilipenditur iuramenti sacramentum, ut non alio aeque. Nam et ipsi principes iuramenta pro libito et commodo figunt et refigunt. Populus autem nihilo impudentius eadem pro utilitate aestimat. Siquidem ipse deus nobis sordet, sordet omnis religio ipsaque fides, ipsa item veritas »superas« concessit »ad auras $«,{ }^{478} \gg$ in quorum subiere locum fraudesque dolique, insidiaeque et vis et

Z. (2) apost[olus]] apostolus $Z F$

472 Vgl. Zw. elench. (Z VI/1 145,28f.): »Catabaptistę [iusiurandum] solum decisionem vocant et dei contestationem obmittunt«; Bull. adv. cat. 121r.

473 Ps 15,4 (Vulg. 14,4).

474 Ps 63,12 (Vulg. 62,12).

475 Vgl. Zw. elench. (Z VI/1 145,6): »Est iusiu- randum dei contestatio ad aliquid decidendum aut pręstandum. «

476 Vgl. Jes 45,23; 65,16.

477 Vgl. Gell. 6[!],18 (Rolfe II 74-76). Aulus Gellius (2. Jh. n.Chr.), Verfasser des Miszellanwerks »Noctes Atticae«, vgl. NP IV 896f.

478 Vgl. Verg. Aen. 6,128 (Mynors 231). 
amor sceleratus habendi $\ll{ }^{479}$ At in hoc institutum erat iusiu|randum, ut veritatem assereret, insidias prohiberet et sanctimoniam, iusticiam et iudicium conservaret. Ideo merito coleretur sanctius neque ob quasvis res ridiculas et leviculas exigeretur. Nam frequens illius et prophanus usus contemptum parit, contemptum sequitur poena et excidium. Ubi vero de gloria dei et de salute reipublicae ac proximi agitur, tum citra offensionem dei et accipi et dari potest iuramentum. Sed redimus ad Paulum; »ne quid nimis $\ll .{ }^{480}$

18 qui huc confugimus, ut potiamur proposita spe, 19 quam velut ancoram tenemus animae tum tutam tum firmam et introeuntem usque ad ea, quae sunt intra velum, 20 ubi praecursor pro nobis ingressus est, iuxta ordinem Melchisedech pontifex factus in aeternum.

Hic ille ad consequentia transitus est, cuius sensus est: »Ista vero omnia in hoc dicta sunt, ut promissionibus dei credatis utpote firmis et salutaribus. Id enim si feceritis, Christum suscipietis sacerdotem, quippe qui iureiurando ordinatus est sacerdos a deo secundum ordinem Melchisedech, ideoque et purgatis etiam ac benignis auribus de hoc Christi sacerdotio audietis disserentem. «Istis vero iterum Spes. ad id redit, unde in 5. cap[ite] fuerat digressus. ${ }^{481}$ Hic tamen notandum, quod per spem intellexit ipsam rem, quae speratur. Spei vero obiectum est ipse deus, veritas eius, Iesus Christus, quem et venustissima allusione vocavit ancoram animae et tutam et firmam. Nam sub eius praesidio tuti degimus et solido innixi 20 fundamento firmiter adversus omnia mala stamus. Erasmus enim in Chiliad[ibus]: ancoram, inquit, Graeci proverbialiter usurpant pro refugio et pro omni eo, »cui innitimur cuique fulcimur fidutia, sumpta a navibus metaphora, quae, cum ancoris fultae sunt, veluti defensae a fluctibus quiescunt $\ll .{ }^{482}$ Praeterea fingit Paulus ancoram istam in coelos etiam (quos per interiora figuravit) pertingere et 25 infixam esse, hoc est, spem nostram in coelestia fixam esse. In coelos enim susceptum esse Christum, qui sit via, veritas, vita ${ }^{483}$ et sacerdos, per quem et serventur, quotquot confitentur eum esse illum a deo ordinatum sacerdotem secundum ordinem Melchisedech. De qua re prolixe satis disseret in consequentibus hucusque enim pertingit digressio. Tu interim committe haec Pauli verba 30 ultima iis, quae dixerat in medio cap[itis] 5., ${ }^{484}$ dum iam digredi vellet, et videbis venustum ingenium.

\section{Z. (2) iusticiam] iustitiam $Z F$ \\ 479 Ov. met. 1,130f. (Anderson 5). \\ 480 Ter. Andr. 61 (Prete 59). \\ 481 Hebr 5,9f.}

482 Erasm. adag. 243 (ASD II/1 358,344-346).

483 Joh $14,6$.

484 Hebr 5,9f. 
Reditus.

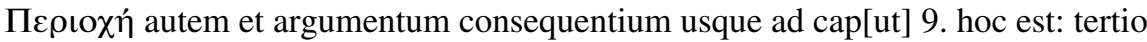
iam dixerat Christum prophetae vaticinio sacerdotem ${ }^{485}$ esse cognominatum secundum ordinem Melchisedech, semel itaque expli|candum erat, quis ille Mel5 chisedech et quis ordo (ut sic dicam) Melchisedechicus. Porro ea expositione docemur solum Christum verum et aeternum esse sacerdotem unice venerandum, quod equidem huius disputationis caput est. Docemur eundem Levitis quoque maiorem et meliorem esse, utpote per quem abolita sit lex ipsumque cessaverit Leviticum sacerdotium, cui interim pulchre confertur sacerdotium Christi, ut 10 huius videatur perfectio, illius vero imbecillitas. At in 8. cap[ite] eadem | illa omnia brevi quodam colligit repetitque epilogo, quae hactenus disputarat de sacerdotio, eademque adhuc evidentiora facit ascripto Ieremiae testimonio. Caeterum, in quem finem haec omnia de Christi sacerdotio disputentur, annotavimus in argumento epistolae. ${ }^{486}$ Ipsius autem Pauli verba haec sunt:

1 Hic enim Melchisedech erat rex Salem, sacerdos dei altissimi, qui occurrit Abrahae revertenti a caede regum et benedixit illi, 2 cui et decimas ex omnibus impertitus est.

Et hactenus quidem pura solaque recensuit historiae verba, quae in Genesi totidem pene verbis extant cap[ite] $14 .^{487}$ et a d[ivo] Hieronymo in epistola ad 20 Evagrium $^{488}$ ex Hebraeo sic translata sunt: »Et Melchisedech rex Salem protulit panem et vinum, erat autem sacerdos dei excelsi, benedixitque illi et ait: >Benedictus Abram deo excelso, qui creavit coelum et terram, et bene/dictus deus altissimus, qui tradidit inimicos tuos in manu tua<; et dedit ei decimas ex omnibus. $\ll^{489}$ Porro Iosephus ${ }^{490}$ Antiq[uitatum] lib[ro] 1., cap[ite] 18.: »Ministravit autem«, inquit, »iste Melchisedech Abraham exercitui xenia et multam abundantiam rerum opportunarum simul exhibuit; et super epulas eum collaudare coepit et benedicere deum, qui ei subdiderat inimicos. Abraham vero dante ei etiam

Z. (10) cap[ite]] capite $Z F$ - (22) terram] terrram $F$ - (24) Antiq[uitatum] lib[ro]] Antiquitatum libro $Z F$

485 Hebr 3,1.

486 Siehe oben S. $17 \mathrm{f}$.

487 Gen 14,18-20.

488 Evagrius (ca. 320-394), ab 388 Bischof von Antiochia, vgl. NP IV 202f. Frühneuzeitliche Ausgaben der Werke des Hieronymus geben Evagrius als Adressaten des hier zitierten gegen in modernen Ausgaben der Name des Empfängers zu »Evangelus« korrigiert wird.

489 Hier. epist. 73,5 (CSEL LV 18,11-16).

490 Flavius Josephus (1. Jh. n. Chr.), jüdisch-hellenistischer Historiker, Autor der hier von Bullinger erwähnten »Antiquitates Iudaicae «, vgl. TRE XVII 258-264; NP V 1089-1091. 
decimas spoliorum munus accepit $\ll^{491}$ etc. Porro, ne quis miretur, sciendum est

Reges etiam pontifices. apud gentes et maiores nostros reges semper fuisse sacerdotes pontificesque, idque ob singularem probitatem, integritatem et pietatem, qua praecellere debent, qui rerum gubernaculis praefecti sunt. Sic apud Maronem ${ }^{492}$ legimus: »Rex Anius, rex idem hominum Phoebique sacerdos. ${ }^{493}$ Et alibi: »Iura magistratusque 5 legunt sanctumque senatum. ${ }^{494}$ At in Paulo sequitur:

\section{Qui primum quidem ex interpretatione dicitur rex iusticiae, deinde vero etiam rex Salem, quod est rex pacis, 3 sine patre, sine matre, sine ge- nealogia, nec initium dierum neque vitae finem habens, sed assimilatus filio dei manet sacerdos in perpetuum.}

Quomodo Iam ipse, quantum praesenti servit negotio, singula exponit; in primis vero excutit circumstantias, ${ }^{495}$ nomen videlicet rei, genus, locum et conditionem, quae sigillatim expendemus. ${ }^{496}$ Primum quidem Melchisedech per $\mid$ etymologiam dicitur rex iusticiae. Nam מלך significat regem, צדק autem iusticiam. ${ }^{497}$ Porro de Christo tradit sanctum evangelium, quod rex sit mansuetus ${ }^{498}$ et iustus sancti populi dei, 15 »iustificans eos, qui sint fidei in eum« [Röm 3,26]. Hunc enim Iesum illum a deo nobis factum esse sapientiam, sanctificationem, iusticiam et redemptionem. ${ }^{499}$ Christus itaque verus est Melchisedech, unica totius orbis iusticia, quem retro per typum figuravit Chananaicus rex Melchisedech. Deinde vero audimus Melchisedech regem fuisse Salem, hoc est pacificum regem. שלום enim significat 20 pacem. ${ }^{500}$ At de Christo scripsit apostolus ad Ephes[ios] 2.: »Christus est pax nostra, qui fecit ex utrisque unum « [Eph 2,14], ut reconciliaret Iudaeos et gentes in uno corpore deo per crucem. ${ }^{501}$ Et ad Col[ossenses] 1.: »In Christo placuit patri

Z. (7) iusticiae] iustitiae $Z F$ - (14) iusticiae] iustitiae $Z F$ - (14) iusticiam] iustitiam $Z F$ - (17) iusticiam] iustitiam $Z F$ - (18) iusticia] iustitia $Z F$

491 Flav. Ios. ant. transl. 7r. Vgl. Flav. Ios. ant. 1,181 (Niese I 44,15-20).

492 Vergil (Publius Vergilius Maro, 70-19 v.Chr.), römischer Dichter, Verfasser der »Aeneis«, »Bucolica « und »Georgica «, vgl. NP XII/2 4260.

493 Verg. Aen. 3,80 (Mynors 155).

494 Verg. Aen. 1,426 (Mynors 116).

495 In der klassischen Rhetorik wurden sieben »circumstantiae« aufgezählt, vgl. Aug. rhet. 4 (PL XXXII 1442f.): »Est igitur circumstantia

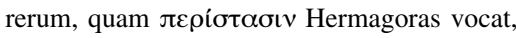
sine qua ulla omnino controversia non potest esse. Quid sit autem peristasis, facilius partitione quam definitione eius deprehendi potest. Sunt igitur partes circumstantiae, id est peristaseos, septem [...]. Sunt igitur haec: quis, quid, quando, ubi, cur, quem ad modum, quibus adminiculis.« Zur Herkunft der sieben »circumstantiae« vgl. Sloan 2010.

496 Vgl. die Behandlung dieser vier Aspekte in Bull. vorl. Hebr. [7,1-3] (Berg/Hausammann 180).

497 Erasm. Hebr. (ASD VI/10 308,971-974): »Nam Melchisedech apud Hebraeos sonat regem iustitiae. Quandoquidem illis מַלְִי, Malci, >rex meus $<$ dicitur. In compositione autem iod litera euphoniae gratia assumitur, צֶד, zedec, >iustitia<.«

498 Mt 21,5.

4991 Kor 1,30 .

500 Erasm. Hebr. (ASD VI/10 308,974): »Solom, שָׁלוֹ, autem pacem sonat.«

501 Eph 2,16. 
universam plenitudinem inhabitare et per eum reconciliare cuncta erga se, pacificatis per sanguinem crucis eius per eundem, sive quae in terra sunt sive quae in coelis« [Kol 1,19f.]. Christus itaque verus est Melchisedech rex Salem, vera animae pax verumque conscientiae gaudium. Quae autem Hieronymus ad salem.

5 Evagrium de Salem contra Iosephum disputat, non est huius nostri instituti recensere. Multis enim probat Salem hanc non fuisse Hierusalem, sed oppidum quoddam iuxta Scythopolim, ${ }^{502}$ cuius mentio et in Genesi fiat, cap[ite] 33., et in evangelio Ioan[nis] 3. ${ }^{503}$ Siquidem parum referre, Salim legas an Salem. ${ }^{504}$ Qui ergo plura velit, in ea, quam citavimus, | epistola legat. Tertio, quod ipsum genus

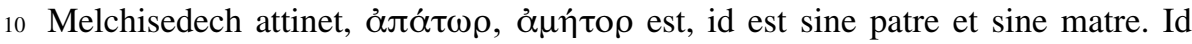
vero quomodo intelligi debeat, exponit ipse Paulus hac subiecta voce: ỏ $\gamma \varepsilon v \varepsilon \alpha-$ $\lambda$ ó $\eta \tau$ Tos, id est sine genere, sentiens Melchisedechi genus vel prosapiam in scripturis non esse relatam atque hoc quidem modo Melchisedechum esse sine patre et sine matre. Etenim divino consilio factum | esse, ut Melchisedechi 15 progenies a Mose non sit recensita, propter Christum. Hinc et Erasmus transtulit »ignoti patris «, »ignotae matris« et »generis ignoti ${ }^{505}$ quod equidem minus habet quaestionis, quam si dicamus »sine patre et sine matre«. Et d[ivus] Chrysostomus: »Intuere«, inquit, »quali contemplatione istud exposuit. Et quis hoc unquam de homine dixerit? Non re ipsa, inquit, dico; hoc est: nescimus, 20 quem patrem habuit vel quam matrem, neque quando natus est et quando mortuus est. $\ll^{506}$ Haec ille. De industria ergo subticuit scriptura genus Melchisedech; non quod homo verus non fuerit, sed ut typum Christi referret. Alias non ignoramus Hebraeorum commentum, quod et d[ivus] annotavit Hieron[ymus], Melchisedechum ex Sem primo Noe filio esse genitum. ${ }^{507}$ Sed valeant haec. Hic enim 25 legimus: »Neque initium dierum, neque vitae finem habens.« Cuius quidem expositio mox sequitur: »Assimilatus est filio dei«, quasi diceret: non ipsa re sic fuit, sed ita de eo loquitur scriptura, ut $\mid$ typum gereret Christi. De quo revera scripserunt prophetae: »Generationem eius quis enarrabit?« [Jes 53,8] Et iterum: $»$ Et egressus eius ab initio a diebus aeternitatis « [Mi 5,1]. Ideoque si divinitatem 30 in Christo spectes, matre caret. Nam ex patre genitus est ante saecula. Porro si humanitatem Christi spectes, sine patre est. Non enim ex virili semine conceptus

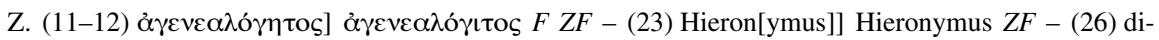
ceret] dicat $Z F$

502 Hier. epist. 73,7 (CSEL LV 20,13-16): »Salem autem non, ut Iosephus et nostrorum omnes arbitrantur, esse Hierusalem, nomen ex Graeco Hebraeoque conpositum, quod absurdum esse peregrinae linguae mixtura demonstrat, sed oppidum iuxta Scythopolim, quod usque hodie appellatur Salem.«

503 Gen 33,18; Joh 3,23.
504 Hier. epist. 73,8 (CSEL LV 21,8): »Nec refert, utrum Salem an Salim nominetur.«

505 Erasm. Hebr. transl. (ASD VI/4 260).

506 Chrys. Hebr. transl. 99. Vgl. Chrys. Hebr. 12,1 (PG LXIII 97).

507 Hier. epist. 73,9 (CSEL LV 22,3f.): »[...] nitantur Hebraei Melchisedech, regem Salem, filium Noe Sem ostendere.« 
et aeditus est, sed cooperante sancto dei spiritu ex intemerata virgine Maria. D[ivus] Augustinus de haeresibus ad Quodvultdeum ostendit ex hoc loco exortam esse Melchisedechianorum haeresim, qui senserint Melchisedechum hunc nostrum non verum fuisse hominem, sed angelum sive virtutem dei magnam. ${ }^{508} \mathrm{De}$ qua re disputavit etiam Hieronymus ad Evagr[ium]. ${ }^{509}$

Ordo Melchisedechicus.

Sed quorsum haec omnia? Ut intelligamus, quis sit ordo Melchisedechicus, nempe is, quo unus et solus et semper est sacerdos. Nunc enim palam sequitur: »MANET sacerdos in PERPETUUM. «Christus itaque, qui est iusticia et pax nostra, verus deus et homo, ille in prophetis et lege promissus sacerdos est perpetuus, post quem credentes alium sacerdotem non quaerunt, quod hic perpetuus sit et 10

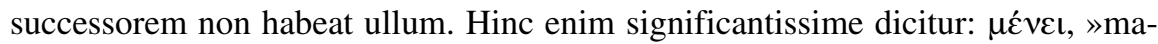
net sacerdos «, et non: »est sacerdos«; illud enim evidentius est. Nam si manet neque vicario neque successore opus habet. De quo plura in sequentibus. Ex istis vero facile liquet, quis sit ordo $(\tau \alpha \dot{\xi} \xi \varsigma),{ }^{510}$ modus, ratio, | constitutio et dispositio sacerdotii Melchisedechici, iuxta quam credimus Christum esse sacerdotem. Et 15 cum haec tam sint clara et firma et ecclesia dei non agnoscat alium ordinem quam Melchisedechicum, non immerito miretur quis, quonam ordine constituantur in papistica ecclesia sacerdotes, qui quotidie sacrum Christi pro peccatis corpus immolent. Fortassis secundum ordinem Bel, Achab et Iezabel. ${ }^{511}$

4 Consyderate vero, quantus hic fuerit, cui etiam decimas dederit Abraham patriarcha de spoliis.

Pergit apostolus et ex eodem Mosis loco $^{512}$ ostendit Christum ut sacerdotem perpetuum, ita multis modis Levitis quoque esse maiorem et digniorem; ${ }^{513}$ quibus pulchre delabitur ad confutationem Mosaici sive Aaronici sacerdotii, certe ut solius Christi statuat sacerdotium. Haec autem veluti summa proponitur conse- 25 quentium, Christum videlicet praecellentiorem esse Levitis, quanquam haec praesentia magis pertineant ad illud, quod primo sequetur argumentum. Caeterum per

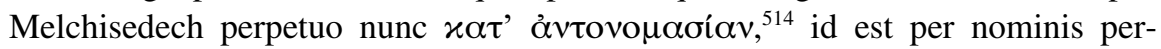
mutationem, Christum intelligit idque propter typum. Decimas autem vocavit

Z. (5) Evagr[ium]] Evagrium $Z F$ - (8) iusticia] iustitia $Z F$ - (19) immolent] imolent $F$ - (20) Consyderate] Considerate ZF

508 Aug. haer. 34 (CCSL XLVI 305): »Melchisedechiani Melchisedech, sacerdotem dei excelsi, non hominem fuisse, sed uirtutem dei esse arbitrantur.«

509 Hier. epist. 73,9 (CSEL LV 21,12-22,3).

510 Hebr 6,20.

511 Kön 16,29-32.

512 Gen 14,20.

513 Vgl. Bull. vorl. Hebr. [7,4-10] (Berg/Hausam- mann 180): »Hie hept er an zuo bewysen, das Christus ein höherer priester und wirdiger sye dann die levitischen priester.«

514 Die Antonomasie ist die Setzung eines Appellativs oder einer Periphrase an die Stelle eines Eigennamens, vgl. Quint. inst. 8,6,29 (Winterbottom II 468): »Antonomasia, quae aliquid pro nomine ponit [...]«; HLR 300f. 
xenia sive munera, propterea quod honorifica apud veteres munera decimae dicerentur. 'A $x \rho o \vartheta i v ı \alpha$ vero, quae interpres dixit »spolia ${ }^{515}$ revera frugum primitiae sunt; sed $\mid$ apostolus ea per catachresim ${ }^{516}$ posuit pro manubiis et opimis spoliis, ${ }^{517}$ etsi non dubitem eum ad primitias et decimationes frugum allusisse, eo 5 quod paulo post earum quoque decimarum meminit. ${ }^{518}$ Praemissis autem istis iam ipsa subiicit epicheremata ${ }^{519}$ omniaque per collationem quandam coniungit sic:

\section{Equidem filii Levi, qui sacerdotio erant praefecti, mandatum ex lege} habent, ut decimas accipiant a populo, hoc est a fratribus suis, tametsi $\mid$ et ipsi ex lumbis egressi sint Abrahae. 6 At is, qui genus suum ab illis non ducit, decimas accepit ab Abraham

Ex ratione dantis et accipientis, hoc est ex relativis, quae Aristotiles vocavit $\pi \rho o ́ \varsigma$ $\tau \iota x \alpha i ̀ ~ \pi \rho o ̀ \varsigma ~ \alpha ̈ \lambda \lambda \eta \eta \lambda \alpha,{ }^{520}$ nostri vero »ad aliquid «, ${ }^{521}$ probat Christum Levitis esse maiorem, ad hunc modum: Levitae non nisi a suis fratribus, qui et ipsi erant de prosapia Abrahae, veluti aequales ab aequalibus, accepere decimas; sed Melchisedech non a fratribus et contribulibus suis, sed ab ipso Abrahamo xenia accepit; hoc ergo maior Levitis est Melch[isedech], quo dignior est filiis pater. Alii hunc locum, per soriten, ${ }^{522}$ quae $x \lambda i$ í $\alpha$, hoc est gradationi, ${ }^{523}$ confinis est, sic fere expedierunt: Christus est sacerdos secundum ordinem Melchisedech; Melchisedech vero, quia xenia accepit, maior est Abrahamo dante; porro Abraham, quia patriarcha est, maior Levitis est; ergo Christus maior Levitis est. ${ }^{24}$ Porro minutius est illud, quam quod sit annotandum »sacerdotium accepisse «, quod habet vulgata aeditio, idem esse, quod »sacerdotio praefectum esse «, quod ego propter perspicuitatem sequi malui. Item fratres Hebraeis dici contribules, qui sunt de eadem familia. Et »ex lumbis egredi« idem esse, quod nasci aut genus ab

515 Erasm. Hebr. transl. (ASD VI/4 260).

516 Siehe oben S. 12, Anm. 54.

517 Erasm. Hebr. (ASD VI/10 308-310,989-992):

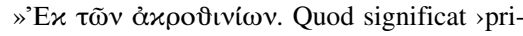
mitias frugum $<$. [...] Verum hoc loco ỏ $x \rho o-$ Өivı $\alpha$ dixit pro spoliis siue exuuiis ab hoste detractis.«

518 Hebr 7,5.

519 Mit »epicherema« (Epicheirem) wird eine Expansionsform des klassischen Syllogismus bezeichnet. Dabei können die Ober-, die Unterprämisse oder beide durch ein oder mehrere Stützargumente erweitert werden, vgl. Isid. orig. 2,9,16-18 (Lindsay I [G5]v-[G6]r); HWR II 1251-1258. Bullinger scheint diesen Begriff allerdings in der allgemeineren Bedeutung von »Argumentationszusatz « zu verwenden.
520 Arist. cat. 10, 11b 31f. (Minio-Paluello 34):

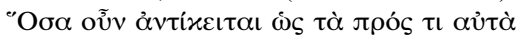

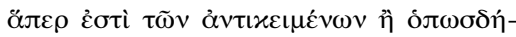
$\pi о \tau \varepsilon \pi \rho \grave{\varsigma} \varsigma$ ö $\lambda \lambda \eta \lambda \alpha \lambda \dot{\varepsilon} \gamma \varepsilon \tau \alpha$.

521 Agric. inv. 1,26 (Mundt 166,48f.): »Ad aliquid (quae et relata dicuntur) sunt ea, quae secundum hoc ipsum, quod sunt, aliorum dicuntur.«

522 Mit »Sorites« wurde in der Antike eine Art von Fangschlüssen bezeichnet, die auf der Vagheit alltagsprachlicher Begriffe beruhten. Später - wie bei Bullinger auch - bekam der Begriff die allgemeinere Bedeutung von »Kettenschluss «, vgl. HWR VIII 1027-1031.

523 Vgl. Quint. inst. 9,3,54f. (Winterbottom II 524,10-13): »Gradatio, quae dicitur $x \lambda \tau \mu \alpha \xi$, [...] repetit enim quae dicta sunt, et priusquam ad aliud descendat in prioribus resistit.«

524 Vgl. Chrys. Hebr. transl. 99. 
aliquo ducere. Christus autem genus a Levitis non ducit et tamen accipit decimas in Melchisedech. De decimis lege Numeri 18. et 2. Paral[ipomenorum] 31. cap[ut]. ${ }^{525}$

6 et ei benedixit, qui promissiones habuit. 7 Illud vero citra controversiam est, quod illud, quod minus est, a praestantiore benedicitur.

Haec ratiocinatio plana est. Nam talis est: nemo nescit id minus esse, quod benedictionem accipit, maius vero, quod benedicit; accepit autem benedictionem Abraham, benedixit Melchisedech; minor ergo est Abraham, maior Melchisedech. Et per consequens si minor est patriarcha, qui promissiones habuit et magnus coram deo fuit, certe minores sunt etiam filii Levitae. Verisimile autem 10 non est Melchisedechum virum sanctum et prudentem aniles praestigias super caput immurmurasse Abraham, sed apostolum magis allusisse ad promissionem Benedictio. Abrahae dictam et semini eius: »In semine tuo benedicentur omnes gentes « [Gen 22,18; 26,4; Apg 3,25]. Et quod clarius | de hac benedictione scripsit apostolus in Ephe[siorum] cap[ite] 1.: »Benedictus deus et pater domini nostri Iesu Christi, 15 qui benedixit nos omni benedictione spirituali in coelestibus Christo « [Eph 1,3], hoc est: »Laudatus sit deus, qui est pater domini nostri Iesu Christi, qui abunde ditavit nos omnigenis dotibus coelestibus et spiritualibus tum, cum Christum nobis exhiberet.«Varius enim in sacris huius verbi »benedicere« usus est.

8 Atque hic quidem homines, qui moriuntur, decimas accipiunt, illic autem is, de quo testatum est, quod vivat.

Tertia probatio et collatio et ipsa plana est, deducta ab oppositis, quae Graeci vocarunt $\tau \grave{\alpha} \dot{\varepsilon} v \alpha v \tau i ́ \alpha,{ }^{526}$ quanquam vita et mors revera sint privantia. Porro sensus est: »In lege mortales homines accipiunt decimas, at in typo evangelii vivens accipit xenia. Quo itaque morte praestantior vita et quo immortalis mortali 25 melior, hoc Christus Levitis maior est.« Et quidem observandum est quod perpetua quadam antonomasia ${ }^{527}$ usurpat Melchisedechum pro Christo. De eo enim scriptum est: »In ipso vita erat $\ll[$ Joh 1,4$]$.

Z. (2) Numeri] Num[eri] $Z F$ - (3) cap[ut].] In $Z F$ folgt Summi dei sacerdoti decimas dat Abraham in testimonium, quod omnia deo debeantur.

525 Num 18,21-28; 2Chr 31,4-7.

527 Siehe oben S. 92, Anm. 514.

526 Agric. inv. 1,26 (Mundt 166,33-36). Vgl.

Arist. cat. 10, 11 b 18 (Minio-Paluello 33). 


\section{Et, ut ita loquar, in Abraham decimatus est etiam ipse Levi, qui decimas solet accipere. $10 \mathrm{Nam}$ is adhuc in lumbis patris erat, cum Abraham occurreret ipsi Melchisedech.}

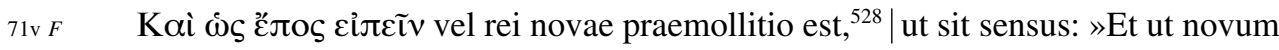
5 et mirabilius quiddam dicam«; vel correctio est, quasi dicat: »Et ut augustius quippiam dicam«, ipsi Levitae addecimati sunt Melchisedecho. Probatio: erat enim tunc, cum Abrahae occurreret Melchisedech, Levi in lumbis patris sui; maior itaque Christus Levitis. Nam Levi per metonymiam ${ }^{529}$ pro omnibus ponitur Levitis. Et hactenus locum Mosis Gen. 14[,18-20]. illustravit eoque illud pro10 phetae exposuit: »Tu es sacerdos in aeternum secundum ordinem Melchisedech « [Ps 110,4]. Ex istis enim didicimus, quis ille Melchisedech, quis ordo, quodnam sacerdotium et quam excellens. Iam sequitur: (populus enim ab hoc legem accepit), quid, obsecro, opus erat alium exoriri sacerdotem, qui secundum ordinem Melchisedech et non secundum ordinem Aaron diceretur?

Propius ad institutum suum accedit et omnia clarius dicit. Principio tamen observandum est Levitici sacerdotii nomine, id quod vel illa satis coarguit parenthesis, Paulum intelligere, quicquid ceremoniarum et rituum comprehenditur in sacerdotio illo externo. Ideo, posteaquam in praecedentibus antithesi ob oculos adumbrasset Christum Levitis esse maiorem, idem illud nunc clarioribus facit argumentis in hoc, ut videremus et sacerdotium et legem quoad ritus veluti infirma ces|sasse per Christum. ${ }^{530}$ Nam sic argumentatur: si Aaronicum sacerdotium eo consilio a deo ordinatum erat, ut in hoc immutaretur nihil, sed unica et sola satis esset ad salutem, id quod Hebraei contendebant, iam non opus fuisset ullum alium polliceri sacerdotem quam Aaronicum. Atqui alius per prophetam promissus est, qui secundum ordinem non Aaron, sed Melchisedech ${ }^{531}$ sit constituendus. Proinde Aaronicum sacerdotium tale non est, quale Hebraei videri vultis, sed imperfectum et una cum lege sua abolendum. Istis vero ancillantur et consequentia.

528 Vgl. Erasm. Hebr. (ASD VI/10 312,19): »[...] praemolliit sermonem dicens $>$ vt ita loquar< $[\ldots] . \ll$

529 Siehe oben S. 33, Anm. 193.

530 Vgl. Bull. vorl. Hebr. [7,11-21] (Berg/Hausammann 182): »Nach dem und er erwysen hat, daß Christus Jesus ein >priester $<$ ist >nach der ordnung Melchizedec $<$, vil grösser dann die levitischen, damit er inen das priesterthůmb genommen, so houwt er ouch an das gsatzt hin, daß ouch das selbig nitt volckomne und nit geben sye, daß es ewig blibe, sunder, wann das priesterthůmb verenderet, daß ouch dann das gsatzt werde verenderet.«

531 Ps $110,4$. 
12 Translato autem sacerdotio necesse est, ut legis quoque translatio fiat.

Quod ex Malach[iae] 2. cap[ite] desumptum videtur. Ibi enim propheta: »Labia«, inquit, »sacerdotis custodiunt scientiam et legem requirent ex ore eius, quia nuncius domini exercituum est« [Mal 2,7]. Huic autem maximae ista subiunge: translatum est autem sacerdotium, ergo translata etiam lex. Quod autem translatum sit sacerdotium, probatur non modo iis, quae iamiam praecesserunt, sed iis quoque, quae sequuntur.

13 Nam is, de quo dicuntur haec, ad aliam tribum pertinet, de qua nullus altari astitit. 14 Palam est enim, quod e tribu Iuda exortus sit dominus noster. At nihil locutus est Moses de sacerdotio, quod ad hanc tribum pertineat.

Lex (inquit) Levitica a deo per Mosen Hebraeis data eos duntaxat constituit sacerdotes, qui sunt ex tribu Levi, Numeri 16. et 17. Christus autem non est ex tribu Levi, sed ex tribu Iuda, utpote Davidis filius, ex quibus nemo unquam praeter infoelicem Osiam ${ }^{532}$ altari astitit, id est, sacerdotali functione usus est. 15 Nequaquam itaque secundum legem Christus ordinatus est. Interim vero sacerdos est, quia de eo scriptum est: »Tu es sacerdos in aeternum secundum ordinem Melchisedech « [Ps 110,4]. Ergo sacerdotium translatum est, translata itaque et lex. Haec autem omnia disseruit adversus Hebraeos, qui adeo nitebantur Levitico sacerdotio et ceremoniis, ut ea deseruisse scelus esse crederent ineluibile. Hinc 20 etiam Christum aspernarentur et haec Mosaica adversus christianismum ceu blasphemam sectam allegarent, impios se fore existimantes, si descederent a legalibus. Proinde non temere haec hactenus tanta $a b$ apostolo diligentia sunt disputata.

Exigit autem hic locus, ut paucis de abrogatione legis dicamus. Quod ergo alii 25 usus legis. perplexis tradunt disputationibus, id figurarum et schematum beneficio lucidissime et brevissime exponemus, nempe synecdocha ${ }^{533}$ quadam dici legem esse abrogatam. Si enim per legem intelligas voluntatem dei, ut sane lex aliud non est quam perpetua dei voluntas, quis, obsecro, dicet voluntatem dei, ne fiat aut praedicetur, esse abrogatam? |At cum lege dei quaedam pro tempore et personis $30 \quad 73 \mathrm{r} F$ externa et typica praecepta sint, fit, ut lex abrogata dicatur, cum revera ea duntaxat pars sit abrogata, qua traduntur typica. Nam aequum est, ut corpori cedat umbra et perfectiori imbecillius. Qua ratione ea legis pars verius translata dicetur a nobis quam abolita. Imo cum de ipsa mandatorum lege dicimus eam quoque

\section{Z. (15) infoelicem] infelicem $Z F$ \\ 532 2Chr 26,16-21.}

533 Siehe oben S. 33, Anm. 194. 
esse abolitam, non id, quod plerique autumant, dicimus, mandata de pietate et innocentia esse deleta, sed odium legis in cordibus nostris dicimus esse ablatum. Cum enim Christi beneficio spiritu libertatis donamur, fit, ut nunc volentes et cum gaudio aga|mus, quod prius per carnis imbecillitatem summo etiam odio

5 insectati sumus. Abolita itaque dicitur lex, id est legis odium, quod in carne, priusquam spiritum imbiberet, erat. At quis hic tam stupidus, ut metonymiam ${ }^{534}$ non sentiat? Sed et eadem illa lex per metalepsim ${ }^{535}$ accipitur pro eo, quod lege fit et manifestatur. Per legem autem manifestatur peccatum et damnatio, ${ }^{536}$ itaque pro peccato et damnatione usurpatur. Hac autem significatione tunc dicimur liberati a lege, cum per crucem Christi ea nobis peccata credimus esse abolita, quae inditio legis cognovimus esse peccata. Sic Paulus: »Etenim quod lex«, ait, »praestare non poterat, eo quod imbecillis erat per carnem, hoc deus proprio filio in carnem misso praestitit« [Röm 8,3] et quae sequuntur. Notus est enim lo|cus Pauli ad Rom[anos] 8. Rursus cum lex alibi pro vindicta ponatur, quam de 15 maleficis sumere iubet deus, christiani a lege liberati dicuntur, quod alias per fidem iusti sint, nemini noceant et in leges istas non incidant. Sic Paulus dixit iusto legem non esse positam. ${ }^{537}$ Item fit, ut lex pro ipsa ponatur scriptura. Quis vero hic dixerit omnem scripturam esse abolitam? Rursus quis nesciat plurima veteris scripturae, maxime promissiones de Christo, per Christum esse comple20 tas? Et proinde legem ea duntaxat parte abrogatam aut verius translatam, qua traduntur promissiones. Quae cum multi non videant aut videre nolint, fit, ut alii quidem impia quaedam tradant, alii vero tam intricate de plano alias negotio disserant, ut ipsis pene aliis opus sit interpretibus, qui, quid disputarint, exponant. Sed redimus.

15 Idque totum inde clarius liquet, siquidem ad similitudinem Melchisedech exoritur sacerdos alius, 16 qui non creatur secundum praescriptum mandati carnalis, sed secundum potentiam vitae indissolubilis, 17 cum testificetur: tu es sacerdos in aeternum secundum ordinem Melchisedech; 18 sane abrogatio fit prioris praescripti sive legis, idque propter ipsius imbecillitatem et inutilitatem.

Idem tradit, quod superius, nempe sacerdotium $\mid$ Leviticum una cum lege quadam necessitate esse mutatum, sed subinde clarius loquitur. Nunc enim per opposita ad hunc modum argumentatur: lex Levitica carnalis est et carnem variis lustrat ceremoniis; porro sacerdos ille, cuius propheta ${ }^{538}$ meminit, carnalis non est, quia

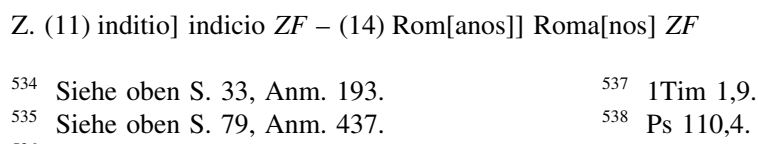


Hypotheticis maxime delectatus est Paulus. ceremoniis dicatus non est; oportuit ergo mutari carnalem legem. Nam si carnalis lex non erat immutanda aliquando, sane nullus alius sacerdos nisi ad praescriptum carnalis legis fuerat etiam constituendus; est autem alius constitutus; non equidem ad praescriptum legis carnalis, sed secundum potentiam vitae indissolubilis, nempe ne aliquando moreretur aut non esset aut crassis illis ac pecuinis victimis egeret; prorsus itaque ipsa lex mutanda erat per sese alias infirma et inutilis. Quod si haec ita se habent, ut sane aliter habere nequeunt, quem, oro, posthac pigeat animum a sacerdotio subducere Levitico? Quis vero non gestiat etiam sese totum Christi dedicare iugi sacerdotio? »Nam Christus perfectio legis est ad salutem omni credenti « [Röm 10,4]. »In eo enim complacuit patri omnem inhabitare plenitudinem « [Kol 1,19] et perfectionem. Proinde si sponte temetipsum semel tradideris Christo sacerdoti, figuras autem deserueris Mosaicas, nihil prorsus amisisti, o Hebraee, nisi quod amisisse, quam servasse, praestat. Legalia enim imbecillia sunt et inutilia. At quis non malit | sibi firmissima pro infirmis et utilissima dari pro inutilibus rebus? Stupidissimi itaque mortalium sumus et nos, 15 qui hodie quoque stultum et elumbe pontificis Romani sacerdotium, sed et humanas traditiones defendimus, de quibus tamen scriptum est: »Frustra me colunt docentes doctrinas hominum« [Mt 15,9; Jes 29,13].

19 Nam nihil ad perfectionem adduxit lex, verum erat introductio ad spem potiorem, per quam appropinquamus deo,

Occupatio est, quia enim dixerat legem propterea esse abolitam, quod imbecillis esset et inutilis, poterat quis non immerito obiicere: »Ergon[e] legem contemnis, an inutile illud esse censes, quod tradidit deus?« Respondet: »Inutilis sane et infirma est lex. Nam ad perfectionem nihil conducit.« Hoc est, ceremoniae legis, ipsum sacerdotium et sacrificium $\mid$ Leviticum peccata non tollunt, itaque infirma 25 et inutilia sunt. Cur itaque instituta? Ut introducerent ad spem potiorem, id est, ut Christi essent figura, per quem ad deum accedimus. Nam cum is sit via, veritas et vita, nemo venit ad patrem nisi per Christum. ${ }^{539}$ Monebant ergo ceremoniae nihil elementis esse tribuendum, sed omnia futuro Messiae. Nam de lege etiam mandatorum sic scripsit idem ille ad Galatas apostolus: »Etenim si data fuisset lex, 30 quae possit vivificare, vere ex lege esset iusticia. Sed lex omnia sub peccatum conclusit, ut promissio ex | fide Iesu Christi daretur credentibus. Porro antequam venisset fides, sub lege custodiebamur, conclusi in eam fidem, quae erat revelanda. Itaque lex paedagogus noster fuit ad Christum, ut ex fide iustificaremur «, Gal. 3[,21-24].

\section{Z. (31) iusticia] iustitia $Z F$ \\ 539 Joh 14,6 .}


20 atque hoc potiorem, quod non absque iureiurando res acta sit.

Haec praecedentia et consequentia connectunt et summam consequentium proponunt. Dixerat enim Leviticum sacerdotium ideo esse abrogatum, quod infirmum sit et inutile, ${ }^{540}$ Christi vero sacerdotium substitutum, eo quod iuge sit et 5 sempiternum. At cum ista non ab omnibus probaretur sententia, idem dilucidius et copiosius per antitheses illustrat, docens Leviticum sacerdotium Christi ad- Conten[tio] ventu cessasse propter imbecillitatem et inutilitatem, Christi vero fidelibus utpote demonstrativa. perfectum et sempiternum unice esse propositum. Caeterum ea, quae coepimus, sequentibus absolvuntur.

20 Nam illi quidem citra iusiurandum sacerdotes facti sunt, 21 hic vero cum iureiurando per eum, qui dixit ad illum: iuravit dominus et non poenitebit eum; tu es sacerdos in aeternum secundum ordinem Melchisedech. 22 Tanto potioris testamenti sponsor factus est Iesus.

Prima antithesis est, cuius sensus est: Christus iureiurando ut immutabili inau- Confertur guratus est sacerdotio. Id | vero probatur prophetico testimonio: »Tu es sacerdos « sacerdotium [Ps 110,4] etc. At Levitae veluti propediem immutandi citra iusiurandum sacer- et Christi. dotes sunt constituti. Ex illis vero iam sequitur mutabile, infirmum, adeoque inutile esse Leviticum sacerdotium; perpetuum vero perfectum et orbi unice necessarium Christi sacerdotium. Hanc autem argumentationem ingenti prosequitur spiritu et per exclamationem quandam hoc subiicit epiphonematis: ${ }^{541} \gg$ Tanto, inquam, potioris testamenti sponsor factus est Iesus. «Quo significavit nunc multo certissimam illam salutem esse, quae Christi, non Levitarum, nitatur sacerdotio, quippe quod certiore et firmiore constitutum sit ordinatione. Nam testamentum pro ordinatione posuit, sponsorem pro sacerdote, quanquam non dubitem allusum esse ad testamenta humana. Illud porro augustum est, quod propheta dixit: »Iuravit dominus et non poenitebit eum « [Ps 110,4]. Nam poenitere dei est institutum mutare. Ideoque iureiurando se astrinxit deus sacerdotium filii sui sese nullatenus mutaturum. ${ }^{542}$

23 Et illi quidem plures facti sunt sacerdotes, propterea quod per mortem non sinerentur permanere. 24 At hic, quod idem maneat in aeternum, perpetuum habet sacerdotium, 25 eo quod absolute et sine defectu salvare

540 Hebr 7,18.

541 Siehe oben S. 57, Anm. 323.

542 Vgl. Aug. quaest. hept. 2,124 (CCSL XXXIII 128,2020-2023): »Et ideo dictum est in illo sacerdotio secundum ordinem Melchisedec: $>$ non paenitebit eum $<$, ut significaretur, quia de sacerdotio Aaron paenituit eum, id est mutauit illud.« 
potest, qui per ipsum adeunt deum, semper vivens ad hoc, ut interpellet pro illis.

Christus successores non habet.

Secunda antithesis est: plures (inquit) apud maiores erant sacerdotes. Caussa: Caussa: Aeternus enim et immortalis cum sit, successoribus minime opus habet. Ex quibus sequitur Leviticum sacerdotium infirmum esse et inutile, sed Christi sacerdotium unicum et perpetuum. Haec expendant Romani pontificis sacerdotes, qui multitudine non modo Iudaicos superant sacerdotes, sed ipsas etiam Libycas harenas. ${ }^{543}$ Expendant et illud, quid sequitur: »Hic, quod idem maneat in aeternum « etc. Nam si idem perpetuo manet sacerdos, vicarios vel successores non 10 habet. Vicarii enim absentum sunt vicarii et successores discedentium sunt successores. Christus autem idem perpetuo manet sacerdos, non discessit neque sacerdotium nobis resignavit. Cuius itaque vices agitis, o vanissimi homines?

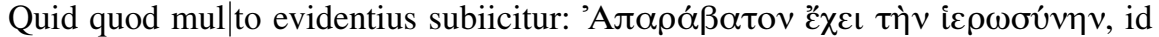
est: »Immigrabile«, ut sic dicam, »habet sacerdotium. « Sive, ut alii transtulerunt: $»$ Perpetuum habet sacerdotium. $\aleph^{544}$ Perpetuum autem dicimus integrum, solidum

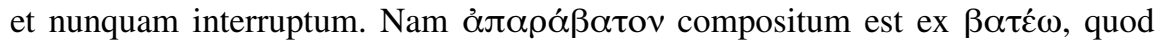
est »vado«, $\pi \alpha \rho \alpha ́$ praepositione et privativa particula $\dot{\alpha}$. Tale enim sacerdotium intellexit, quod successione prosus non possit transire ad alium quempiam. Hinc et Erasmus in Paraph[rasibus]: »At hic noster«, inquit, »unus est pro omnibus nec eget successore, sed, quia $\mid$ manet in aeternum, perpetuum habet sacerdotium. $\aleph^{545}$ Et Ioan[nes] Chrysostomus: »Ergo qui salvat«, ait, »non moritur, quia semper vivit et non habet successorem $\ll^{546}$ etc. Cur autem successorem non habet? »Quia ipse«, inquit Paulus, »ad plenum omnes credentes servare potest. « Eỉ tò $\pi \alpha v-$

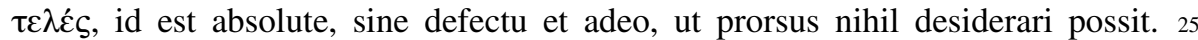
Semper enim vivit et in hoc vivit (en ut »perpetuo « subiiciatur, quod clarius sit et

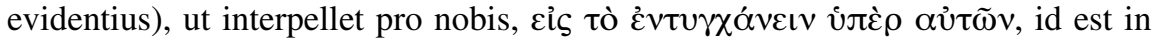
hoc, ut conciliet, intercedat et nostram in se caussam recipiat. Quibus quid, oro, dici posset clarius, laetius et sanctius? Quid itaque vestra sacerdotali functionem opus, o impudentissimi Romanistae? Cuius, quaeso, successores estis? An non- 30 dum intellexistis Christum successorem habere nullum, sacerdotium vero perpetuum, adeo ut unus pro omnibus, unus, inquam, et solus ipse pro nobis, ipse, inquam, nunc et semper intercedat? Unicus enim est ecclesiae suae pontifex.

\footnotetext{
Z. (20) Paraph[rasibus]] Paraphr[asibus] $Z F-(22)$ Chrysostomus] Chrysosto[mus] ZF

${ }^{543}$ Die »libyschen Sandkörner « galten als Sinnbild für eine unzählbare Menge, vgl. Erasm. conscr. (ASD I/2 309,12-14): »In praesentia ne consilii quidem est omnes epistolarum formas recensere, id quod non minus infiniti neg-

ocii puto, quam Libycas harenas pernumerare.«

544 Erasm. Hebr. transl. (ASD VI/4 270).

${ }_{545}$ Erasm. par. Hebr. (ASD VII/6 66,539-541).

${ }^{546}$ Chrys. Hebr. transl. 103.
} 
Unicus mediator et intercessor, non in uno aliquo peccato, sed in tota peccatorum multitudine, neque vero unius saeculi et aliquorum hominum duntaxat, sed omnium hominum et totius mundi. Nam semper vivit, semper, inquam, vivit, et

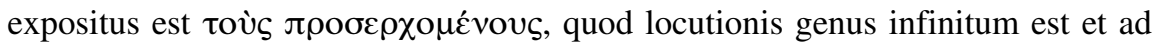
5 omnes singulosque pertinet, qui fide accedunt. Ad deum autem, non ad divos accedunt, | et per Christi intercessionem, non divorum accedunt. »Tu enim«, Isaiae 63[,16]. inquit ad deum Isaias, »es pater noster; Abraham vero nescivit nos et Israel ignoravit nos. Tu autem, domine, pater noster es, redemptor noster et nomen tuum ab aeterno est. « Ubi ergo nunc divorum intercessio? Ubi sacerdotium papisticum? Ubi vero illud impiissimum dogma est, quo sophistae nobis tradebant, Christum pro aliquibus tantum et peccatis et hominibus perlitasse? Hic enim didicimus Christum perpetuum sacerdotium habere, ad plenum salvare et semper vivere. Quod si ad plenum salvat, quid ergo remanet in purgatorio igne lustrandum? Viden[e] imposturas? Venustus sane et foecundus locus est, quem diligentius 15 scrutandum diligenti relinquo lectori; ego enim ad textum redeo.

26 Talis enim decebat, ut esset nobis pontifex sanctus, innocens, impollutus, a peccatoribus segregatus et sublimior coelis factus,

Huc iam ipso orationis cursu delatus est, ut paucis summum illum ecclesiae christianae pontificem describat, simul et ipsa necessitate demonstret neminem in hisce terris ex omnibus, qui vivunt, hominibus sacerdotem coram deo agere potuisse praeter unicum dei filium Iesum Christum. Siquidem deus purus est, sanctus et innocens, proinde oportuit eum quoque purum $\mid$ et sanctum esse, qui coram hoc deo sacerdotali fungeretur munere. Caeterum omnes homines humano concepti semine peccatores sunt. Unus Christus purus et sanctus est, utpote qui per spiritum sanctum conceptus et ex intemerata virgine natus est. ${ }^{547}$ Solus itaque Christus verus et sanctus coram deo vero et sancto sacerdos est. Hic autem una cum Aaronicis penitus corruunt etiam Romani praesulis sacrifici. Nam quis nostrum quicquam vel impurius vel impudentius vidit papisticis sacerdotibus? Ut enim fastum, luxum, pocula, avaritiam, invidiam, iners otium et caetera transeam flagitia, certe scortationi, stupris et adulterio sic polluti et addicti sunt, ut castum etiam execrentur coniugium, imo ad sacrum hunc suum ordinem probos et coniugatos non admittant. Verum hic noster (ut redeamus) pontifex, őoıos, id est sanctus et integer, est; öxaxos, innocens et doli expers $;{ }^{548}$ impollutus quoque, nulla, inquam, vitiorum aut immunditiei labe aspersus, sed omni parte beatus 35 omnique modo purus, nitidus et a peccatoribus segregatus. Nam etiamsi assumpserit speciem hominis et carnis peccatricis, »peccatum tamen non fecit, nec inventus est dolus in ore eius « [1Petr 2,22]; hinc verum coram deo sacer|dotem

547 Mt 1,18.

548 Erasm. Hebr. (ASD VI/10 314,51). 
agere potuit, ipsis etiam »coelis sublimior factus «, id est, in coelum super omnia exaltatus, ut ibi velut in vero dei templo pro nobis semper appareat in conspectu dei.

27 cui non sit quotidie necesse, quemad| modum illis pontificibus, prius pro propriis peccatis victimas offerre, deinde pro peccatis populi. Nam id fecit semel, cum semetipsum obtulit.

Pertinent haec quoque ad superiorem descriptionem et antithesim. Nam Levitae (inquit) immolabant quotidie, Christus non quotidie, sed semel tantum. Levitae item primum pro suis propriis, deinde vero pro alienis populique offerebant peccatis. ${ }^{549}$ At Christus cum peccatum non haberet, pro suis non obtulit, sed 10 duntaxat pro nostris peccatis; obtulit autem non pecudes aut sanguinem beluinum, sed sui proprii et purissimi corporis holocaustum. Ex quibus iterum apparet legem Leviticam non aliam ob caussam quam ob infirmitatem et inutilitatem esse abolitam, Christi vero sacerdotium unicum esse et perpetuum. Cum ergo tam clare audiamus ab apostolo quotidianum reprobari sacrificium taleque sacerdo- 15 tium, quod et pro suis et pro populi immolat peccatis, hoc est, quale opus habet lustratione aliena; papisticum vero prorsus tale sit; consequitur pari ratione Christi unico sacerdotio papisticum sicuti et Iudaicum aboleri sacerdotium. Sed quid, oro, habetis, o pontificii, quod vel ad haec brevissima Pauli respondeatis? »Nam $\mathrm{id} \ll$, inquit Paulus, »fecit SEMEL, cum SEMETipsum obtulit.« Auditis enim Chris- 20 tum semel, semel, inquam, semel tantum oblatum esse. Auditis, quod non per alium quam per semetipsum sit $\mid$ immolatus. Qua itaque fronte vobisipsis propria arrogatis authoritate, quod ne angelorum quidem est? Nam in evangelio adhuc clarius ipse dominus ait: »Ego pono animam meam, ut iterum sumam eam. Nemo tollit eam a me, sed ego ponam eam a me ipso. Potestatem habeo ponendi eam et 25 resumendi. Hoc mandatum accepi a patre meo « [Joh 10,17f.]. Quid itaque iteratis, o miseri, quod iterari non potest, imo non necesse est? Quid vobis vendicatis, quod in mortalem incidere non potest?

28 Lex enim homines constituit sacerdotes infirmitatem habentes; sermo autem iurisiurandi, qui post legem est, filium constituit in aeternum consummatum.

Est et haec privata quaedam antithesis, qua et hoc clarius exponitur, quod audivimus sacerdotes Mosaicos pro suis propriis immolasse peccatis. In hoc autem

Z. (3) dei.] in $Z F$ zusätzlich De quo sequentur quaedam in cap[ite] 8. - (14) et] et et $F$

549 Lev 16,11.17. 
consistit antithesis: lex infirmos neque semper aptos sacrificiis ordinavit sacrificos; sed is, qui novum iureiurando constituit sacerdotium, filium constituit, qui, cum absque peccati infirmitate sit, semper ad obeunda sacerdotis munera aptus est; hinc etiam verus, sempiternus et unicus sacerdos est, per quem cessavit 5 imbecillius legis sacerdotium. Recte autem monet Erasmus $\tau \varepsilon \tau \varepsilon \lambda \varepsilon \iota \omega \mu \varepsilon ́ v o v$, quod legimus »consummatum «, perinde dictum esse, atque si tu »dicas >factum semper idoneum et legitimum $<$. Neque enim sacerdos semper et ubique ido|neus est ad peragendum sacrum. $\ll^{550}$ Quod cum et in nostros competat, vides non citra insignem caussam a nobis tantopere culpari sacerdotium papisticum. De sacerdotio

10 autem evangelico quoad docendi rationem dixi in cap[ite] 5. ${ }^{551}$ Annotandum et

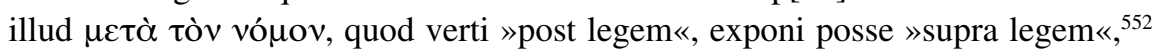
quasi dixerit pluris esse aestimandam ordinationem iureiurando firmatam quam legalem, vel »ante legem «. Nam etiamsi David id verbi post legem datam scripserit, ipsum tamen Melchisedechi negotium longo temporis intervallo praecessit. Quod, si legas »post legem«, sane et haec lectio plurimum derogabit legi. Si enim perfecta fuit lex, quid, obsecro, opus erat alterius miminisse sacerdotis? Hactenus autem de abrogato sacerdotio Levitico.

1 Summarium autem eorum, quae disputavimus, hoc est, quod talem habemus pontificem, qui consedit ad dexteram throni maiestatis in coelis, 2 sanctorum administrator ac veri tabernaculi, quod fixit deus et non homo.

| Nunc colligit ea, quae a 5. cap[ite] hucusque de sacerdotio Christi adversus caput rei. sacerdotium Aaronicum disseruit. Eam collectionem vocavit $\varkappa \varepsilon \varphi \alpha ́ \lambda \alpha \iota v$, nos »summarium« vertimus, alii ỏv $\alpha \varkappa \varepsilon \varphi \alpha \lambda \alpha i \omega \sigma \iota v$ dixere. De priore scribit

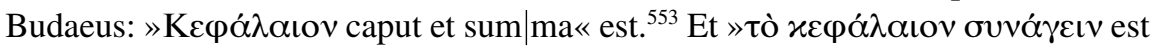
summam colligere $\ll .{ }^{54}$ De posteriore sic scribit Fabius ${ }^{555}$ in 6.: $\gg$ Rerum repetitio, quae Graece dicitur ỏv $\alpha x \varepsilon \varphi \alpha \lambda \alpha i \omega \sigma \iota \varsigma$, a quibusdam Latinorum enumeratio, memoriam auditoris reficit et totam simul caussam ponit ante oculos. $\aleph^{556}$ In hac, quae repetemus, quam brevissime dicenda sunt et, quod Graeco verbo patet, decurrendum per capita. Id quod hoc loco praestitit eruditissimus author noster Paulus. Nam quae fusius hucusque de sacerdotio (ut iam dixi) disputata sunt, ea mira brevitate hoc capite 8 . repetiit, quorum caput et summam praemittit istam: habere nos pontificem vere summum, quippe qui in coelis ad dexteram sedeat patris; maiore itaque et nobiliore utatur templo, ipso videlicet coelo, quam Le-

550 Erasm. Hebr. (ASD VI/10 314,59-61).

551 Siehe oben S. 69-71.

552 Erasm. Hebr. (ASD VI/10 314,55).

553 Bud. comm. 177,5f.

554 Bud. comm. 176,33f.
555 Marcus Fabius Quintilianus (ca. 35-100), berühmter römischer Rhetoriklehrer, Verfasser des rhetorischen Lehrbuchs »Institutio oratoria«, vgl. NP X 716-721.

556 Quint. inst. 6,1,1 (Winterbottom I 318,15-18). 
vitae, qui in hoc corruptibili et manibus constructo servierint tabernaculo. Sed de his omnibus plura in 1. et 5. cap[ite]. ${ }^{557}$ Illud vero haudquaquam videtur esse

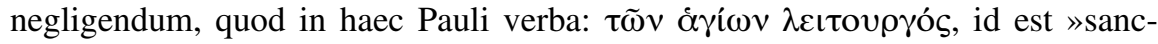

Vide, quid sit liturgia. torum administrator «, annotavit Erasmus: »Quod nos vulgo vocamus officium, Graeci $\lambda \varepsilon \iota \tau o v \rho \gamma i \alpha v$ appellant. Vocem putant hinc dictam, $\lambda$ njïtov olim dicebant >prytanaeum<, hoc est locum publicum, in quo versabantur magistratus, et $\tilde{\varepsilon} \rho \gamma o v$

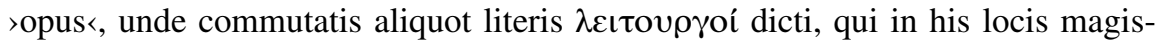
tratibus inserviebant. Porro genitivus >sanctorum< potest vel ad homines referri vel $\mid$ ad ipsa sancta, ut dicatur administrare sancta pro nobis veluti sacerdos $\aleph^{558}$ etc.

3 Omnis enim pontifex ad offerendum donaria et victimas constituitur, unde necesse est, ut hic etiam habeat aliquid, quod offerat.

Sacerdos est

Summam totius negotii, quam de sacerdotio Christi praemisit, eandem nunc diducit. Et quia duas quaestiones proposuit tractavitque, quarum prior Christum esse sacerdotem, posterior vero Christum esse unicum et aeternum sacerdotem, per quem etiam ipsa lex abolita ac impleta sit, ea nunc hisce colligit ascriptis verbis, quae de prima quaestione disputavit. Porro haec est collectio: sacerdotes pro more veteri in hoc constituebantur, ut donaria offerrent et victimas; et Christus propterea assumpsit carnem, ut offerret donaria et victimas, id est preces et proprii corporis holocaustum; ergo sacerdos est.

4 Porro si in terra esset, iam ne sacerdos quidem esset. Cum hi, qui offerunt secundum legem munera, 5 exemplari et umbrae deserviunt coelestium, quemadmodum oraculo responsum est Mosi, cum esset absoluturus tabernaculum: nam vide (ait), ut facias omnia secundum exemplar, quod ostensum est tibi in monte.

Istis autem colligit, quod de posteriore quaestione $\mid$ disputavit, Christum non esse 25 80v $F$ sacerdotem creatum secundum ordinem Aaron, sed secundum ordinem Melchisedech, non lege carnali, sed ordinatione perpetua et coelesti. ${ }^{559}$ Carnali enim ordinari Levitas, sed coelesti eum, qui est ex tribu Iuda, qui semper vivat, iccirco etiam unicum et incommutabile habeat sacerdotium. Haec omnia fusius in capit[e] 7. ${ }^{560}$ Istis porro veluti postliminio annectit testimonium Mosis, desumptum 30

557 Hebr 1,8f.; 5,5-10.

558 Erasm. Hebr. (ASD VI/10 316,69-74).

559 Vgl. Bull. vorl. Hebr. [8,4-5] (Berg/Hausammann 191): »Diß ist die summ deß, das er nitt ein fleischlicher priester sye nach der ordnung Aarons, sunder der recht, der durch das fleichslich priesterthümb vorgebildet ist.« Hebr 7,11-17. 
ex 2. Mos[is], cap[ite] 25. ${ }^{561}$ quo certius etiam evinceret priora ista et Levitica

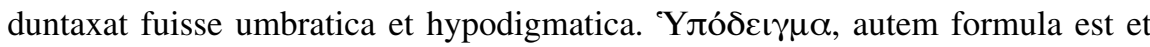
exemplar, ad cuius praescriptum aliquid fit, quod Helvetii vocamus ein muster, vorbild, formular und visierung. Iam ergo observa mihi orationis ac 5 testimonii huius vim et evidentiam: »Exemplar«, inquit, »verum, ad cuius similitudinem haec in terris Levitica deformata sunt, in coelis est.« Ipsa itaque coeleste veritas in coelis est, umbra in terris. Antiquius ergo illud, quod est in coelis, nuperum vero, quod est in terris. Proinde qui hic egere sacerdotes, non veri fuerunt sacerdotes, sed umbra tantum coelestis sacerdotii. Christus igitur tanquam verus et aeternus sacerdos coelos ascendit, ${ }^{562}$ ut verum et unicum et perpetuum vere ageret sacerdotem. Ex quibus liquido liquet universum pro peccatis offerendi sacerdotium in coelos esse translatum. Hic enim in conspectu dei is semper apparet, qui semel | oblatus | amplius non offertur, sed »unica hostia absolvit lustravitque omnes, qui sanctificantur, in perpetuum « [Hebr 10,14]. Quid itaque vos, o surdissimi Romani praesulis sacrifici, vestrum in terris pro delictis offerendi ordinem propugnatis $?^{563}$ An non videtis vestro dogmate imo vanissimis naeniis, totum in ecclesiam Christi Aaronicum sive Iudaicum introduci sacerdotium? Quin deo datis gloriam et a vestro prophano et Iudaico terrenoque deficitis sacerdotio, ei adhaerentes, cui, qui crediderint, non pudefient!

6 Nunc vero hoc excellentius sortitus est sacerdotium, quo praestantioris testamenti mediator est, quod et in praestantioribus promissis sancitum est.

Etiam legem Leviticam audivimus esse abrogatam, id quod hic paucis repetitur. Lex abolita. Per mediatorem autem, ut in 5. etiam cap[ite] ostendimus, sacerdotem intelligit. ${ }^{564}$ Sed testamentum opponit umbrae legis ordinationemque firmam esse putat, quod cum iureiurando confirmata sit; id quod in Levitica non item factum sit; infirmiorem ergo Leviticam, aeternam vero christianam. Huc iam facit et illud, quod sequitur:

7 Etenim si prius illud tale fuisset, ut nihil in eo potuisset reprehendi, neutiquam fuisset secundo quaesitus locus.

\section{Z. (1) Mos[is]] Mosis ZF}

561 Ex 25,40.

562 Lk 24,51; Apg 1,9.

563 Herb. ench. 16 (Schlager 68,16f.): »Hic observa hoc sacrificium offerendum pro peccatis

proque delictis populi.« Vgl. Eck ench. 17 (Fraenkel 205-207); Eck sacr. 3,1 (Iserloh et al. 124).

564 Siehe oben S. $64 \mathrm{f}$. 
Quodnam prius illud testamentum? Utique illud, quo leges latae sunt de sacerdotio, ciborum delectu, genere / vestium, purgatione et si qui sunt alii ritus ad sacerdotium Leviticum pertinentes. Si, inquit, illa, quae praecessit constitutio, ita a deo lata est, ut vel cultores purgaret, absolveret perficeretque, vel ita lata esset, ut nihil non modo mutari, sed ne desiderari quidem potuisset; iam aliud non promisisset, quo perficeremur. Promisit autem aliud. Ergo prius illud perficere non potuit. Propter imbecillitatem itaque et inutilitatem merito abolitum est.

8 Nam incusans eos loquitur illis: ecce dies venient, dicit dominus, et feriam cum domo Israel et cum domo Iuda testamentum novum, 9 non iuxta testamentum, quod feci patribus illorum in die, cum apprehenderem manum illorum, ut educerem eos ex Aegypto; quoniam non perstiterunt in testamento meo, et ego neglectui eos habui, dicit dominus.

Probatio est, quod aliud testamentum promiserit, simul et vehemens authoris spiritus, quo iam disputatam veluti triumpho prosequitur caussam, adscribens longe pulcherrimum ex Ieremiae 31. cap[ite] locum, ${ }^{565}$ quo nobis deus certam in 15 Christo pollicitus est peccatorum remissionem, non utique per sacrificia et ceremonias, sed per gratiam in Christo. Sic autem Ieremiae ver|ba adduxit, ut appareat secutum per omnia aeditionem LXx. Sufficit autem interpreti reddidisse sensum, etsi verba non appenderit omnia. De qua re multis agit d[ivus] Hieronymus de optim[o] interp[retandi] gen[ere] ad Pamachium. ${ }^{566}$ Quod vero ipsum 20 attinet Pauli scopum, ipse ad finem testimonii, quantum suo satis est negotio, colliget et applicabit. ${ }^{567}$

Iam vero, quod testamentum attinet, de quo varia est apud theologos conceraliqua, metaphora sumpta a morientibus, qui testamenta condunt, id est, ita res 25 suas disponunt ordinantque, ut volunt. Aliquando pro certa ponitur promissione et per metalepsim ${ }^{568}$ nonnunquam pro ipsa etiam re promissa. Sic enim solemus ipsam peccatorum remissionem testamentum vocare. Quod vero hunc attinet locum, testamentum hoc foedus et illud dei pactum est, quo deus voluntatem suam erga nos testatus est, prorsusque nobiscum certis convenit conditionibus. 30 Caeterum eas conditiones patribus nostris, Abrahae in primis, sic praescripsit: »Ero deus tuus, illa rerum omni sufficientia « [Gen 17,1], ero, inquam, »deus tuus et seminis tui post te in sempiternum « [Gen 17,7]. »Tu vero ambula coram me et

565 Jer 31,31-34.

566 Hier. epist. 57,9 (CSEL LIV 520,19-22): »Perspicuum est apostolos et euangelistas in interpretatione ueterum scripturarum sensum quaesisse, non uerba, nec magnopere de ordinatione sermonibusque curasse, cum intel- lectui res paterent.«Pammachius (4./5. Jh.), Senator, Mitschüler und Freund des Hieronymus, vgl. PRE XVIII/3 296-298.

567 Hebr 8,13.

568 Siehe oben S. 79, Anm. 437. 
esto integer « [Gen 17,1]. »Et haec foederis sive pacti conditiones sunt « [Gen 17,10]. Ad expositionem porro istarum pertinent iam consequentia: »Semen

82 v $F$ mulieris conculcabit caput ser|pentis « [Gen 3,15]. Et: »In semine tuo benedicentur omnes cognationes terrae « [Gen 22,18]. Item: »Dabo tibi terram melle et lacte 5 fluentem« [Ex 3,8]. Rursus: »Vindicabo te de hostibus tuis« [vgl. 2Sam 7,11]. Et mille alia. Istis enim exponit, quomodo illorum deus futurus sit. Et iterum: »Non habebis deos alienos « [Ex 20,3]; ne pollueris te immunditia gentium; ${ }^{569}$ innocentiam, iusticiam | et aequitatem colito. ${ }^{570}$ Qui enim haec faciunt, integre coram deo ambulant, deum et proximum diligunt. Haec autem de testamento et foederis substantia dicta sint.

Illud vero testamentum incommutabile est, unicum et sempiternum. ${ }^{571}$ Una Unicum enim sanctorum et veterum et nostrorum, unica, inquam, ecclesia est; unus deus, $\begin{aligned} & \text { duntaxat } \\ & \text { testamentum. }\end{aligned}$ una tantum omnium saeculorum religio vera. Unde igitur nobis veteris et novi testamenti nomina? Nonne duo dicit, qui vetus et novum dicit? Quod si duo sunt, 15 quomodo unum esse potest? Ipsa nimirum substantia unum est, sed modo tradendi duo sunt. Expende enim, quid ipsa re veteribus sit traditum, et idem invenies, quod nobis. Nempe unum esse deum, hunc solum esse colendum, colendum autem spiritu, innocentia et fide. Idem unicam esse orbis iusticiam et redemptionem, unicum sacerdotem et sacrificium verum, Iesum Christum dei et

20 hominis filium. Sperandam quoque a deo animarum perpetuitatem et corporum resurrectionem. Et haec quidem est illa praeclara Adae, Noe, Abrahae, | Mosis, Samuelis, Davidis, prophetarum omnium, Stephani quoque, Ioan[nis] Baptistae, Petri, Iacobi, Pauli, Athanasii et Augustini religio ac fides, eritque usque ad consumationem saeculi omnium electorum dei fides. Quod ergo fidei ac testamenti substantiam attinet, idem prorsus utriusque traditum, unde consequens est unicum tantum esse testamentum.

Iam vero expende modum, quo illud nobis idemque istis traditum sit. Hic Paulus: »Veteribus«, inquit, »omnia contingebant in figura. At nobis non item. Nam Christum, qui legis est perfectio, dedit nobis deus, ut nunc veluti praesens praeteritumque, adeo et completum veneremur, quod illi futurum, complendum et in typo velatum habebant, imo verius expectabant.« Proinde modus tradendi diversus est, sed res utrisque eadem. Illi figuras habebant, nos ipsam rem. Illi externis gaudebant, nos spiritualibus. Nam Christus omnia direxit in spiritum. Eo iam pertinet sacerdotium et sacrificium Aaronicum, sacerdotii et sacrificii Christi figura. Huc pertinent varia baptismata, verae expurgationis per Christum exhi-

Z. (8) iusticiam] iustitiam $Z F$ - (18) iusticiam] iustitiam $Z F$ - (22) Ioan[nis]] Ioannis $Z F$ - (24) consumationem] consummationem $Z F-(27)$ Marg. test[amentum]] testamentum $Z F$

569 Vgl. Esr 6,21.

570 Vgl. Ps 37,37.

571 Zur folgenden Abhandlung über die Einheit und die verschiedenen Aspekte von Gottes Gnadenbund vgl. Zw. elench. (Z VI/1 163,8165,2).
Vetus et novum test[amentum]. 
bitae typi. Atque ex hac diversa traditione existunt iam veteris et novi testamenti voces, quae quid significent, ex iis, quae diximus, liquet. Siquidem ea traditio, qua per typos et figuras veteribus tradita est religio, dicitur »testamentum vetus«. Sed ea, qua sine figuris atque ipsa re nobis traditur Chri|stus, qui omnia legis et prophetarum implerit, iam omnia solus, »novum« dicitur »testamentum«. Non ideo novum, quasi veteres Christum, gratiam et peccatorum remissionem non habuerint; sed novum collatione veteris et quod ipsum corpus accessu suo aboleverit umbram.

Ex iis etiam rectius intelliges, quomodo Biblia nominemus vetus et novum testamentum. Neque enim ipsi Bibliorum scripti libri magis sunt ipsum testa- 10 mentum, quam tabulae sive literae testamentales testamentum ipsum sunt et tamen testamentum dicuntur. Verum id nominis ex eo sortiuntur, quod describunt. Quia ergo prioribus Bibliorum libris describuntur ritus, traditiones ac modi varii, quibus deus veteres in testamento suo et vera religione deduxit, $\gg$ vetus testamentum « dici coeperunt. Sic etiam illi libri, qui post exhibitum Christum de eo 15 scripti sunt, quomodo in Christo omnia completa et innovata, novus item populus ex Iudaeis et gentibus collectus sit et in testamento et voluntate dei ductus sit, »novum testamentum « appellati sunt. Sed et ipsa sacramenta pari prorsus schemate testamentum dicuntur. Nam circumcisio vocatur testamentum, Gen. 17[,13]. Et poculum domini apud Matthaeum etiam in 26. cap[ite] dicitur testamentum. ${ }^{572} 20$ Quae omnia fusius fortassis quam pro re annotavimus; nunc caetera perstringemus.

Quod deus in hoc praesenti prophetae testimonio dicit se Israelitarum apprehendisse manum, diligentiae est et insignis curae nota. Notat enim insignia illa beneficia, quae illis exhibuerit, dum ipsos ex Aegypto eduxerit. Adiicit tum 25 quidem se illis tradidisse legem, iniisse foedus, quod tamen illi violarint. Praeceperat enim unum deum colerent, alienos deos non adorarent. Addiderat sacra et sacrificia, ut proclivem alias ad peregrinos cultus gentem, in officio et lege sua contineret. Sed frustra. Illi enim contempta dei lege (id quod et Stephanus eis impingit ${ }^{573}$ ) pactis non steterunt, sed, quod deo debebatur, idolis impendebant, 30 quocirca deus istos veluti perduelles et perfidos neglexit. Nam ipsos ultra Damascum (ut Amos inquit ${ }^{574}$ ) transtulit.

| 10 Nam hoc est testamentum, quod disponam domui Israel post dies illos, dicit dominus, dans leges meas in mentem illorum et in corde illorum inscripsi illas, et ero illis deus et ipsi erunt mihi populus. 11 Et non docebit quisque proximum suum et unusquisque fratrem suum dicentes:

Z. (10) Bibliorum] Bibliarum $F$ - (13) Bibliorum] Bibliarum $F$

572 Mt 26,28.

574 Am 5,27.

573 Apg 7,39-43. 
cognosce dominum; quod omnes cognituri sint me ab eo, qui pusillus fuerit inter eos, usque ad eum, qui magnus est inter eos, 12 quoniam placatus ero super iniustitiis eorum et peccatis illo|rum et iniquitatum eorum non recordabor amplius.

5 Ista adiiciuntur expositive. Exponit enim sese, quid per novum testamentum Novum intellexerit. Utique gratuitam peccatorum remissionem, quae toti generi humano testamentum. (id enim voluit per »maiores « et »minores « propheta) contingat, non opera legis sacrificiorum aut ceremoniarum, sed merito Christi. Nam ubicunque est plenaria peccatorum remissio (ut audiemus in 10.), ibi nulla superest oblatio pro pecca10 to. ${ }^{575}$ Contigit autem nobis per Christum absoluta peccatorum remissio, ergo nullum restat sacrificium pro peccato. Proinde novum testamentum aliud non est, quam quod in filio suo deus humano generi omnem dedit perfectionem. De qua re satis superius disputatum. Porro hoc dei beneficium a deo nobis per Christum exhibitum multis quidem verbis magnifice describit, quibus tamen docendi praedicandique officium non tollitur. Docte enim et pie sanctissimae memoriae H[ULDRYCHUS] ZUINGLIUS, incomparabilis eruditionis, constantiae et pietatis vir, praeceptor noster fidelissimus et omnium mortalium charissimus, in hunc prophetae locum: »Hic non tollitur «, inquit, »doctrinae beneficium, quomodo catabaptistae ganniunt, sed hyperocha ${ }^{576}$ est: cognitionem dei vulgarem fore; deum enim docturum et illustraturum mentes, ut sciant dei filium in hoc descendisse, ut nobis sociaretur, | et nobis comitatus aeternam haereditatem adiret. ${ }^{577}$ Haec ille Helvetiae nostrae apostolus.

13 Per hoc, quod dicit novum, antiquavit prius. Porro quod antiquatur et senescit, in propinquo est, ut evanescat.

25 Redit ad statum et edisserit, in quem finem hunc prophetae locum adduxerit, nempe ut Ieremiae etiam testimonio evinceret legem quoad sacerdotium, ritus et ceremonias prorsus esse abolitam.

Subiungerem nunc epilogum eorum, quae de sacerdotio Christi disputavimus, nisi ipse Paulus hoc me labore levasset. Ipse enim epilogum contexuit. Itaque ad sacrificium Christi tractandum transimus.

Z. (15) H[ULDRYCHUS]] HULDRYCHUS $Z F$ - (17) omnium] om. $Z F$ - (26) testimonio] testimomio $F$ (28-30) Subiungerem ... transimus] Hactenus epilogum contexuit Paulus, nunc ad sacrificium Christi tractandum transimus $Z F$

575 Hebr 10,18.

577 Zw. Ier. 31,34 (Z XIV 612,5-9).

576 Siehe oben S. 63, Anm. 345. 


\section{Sacrificium.}

Simili pene dicendi ordine disputat de sacrificio, quo disputarat de sacerdotio Scopus Christi. Primo enim docet Christum esse illam unicam et veram pro peccatis sequentium. totius mundi hostiam, multo maiorem et praestantiorem victimis Aaronicis. Deinde vero probat Aaronicas inefficaces fuisse et umbram tantum et proinde victima Christi abolitas, qui sit unica et aeterna omnium credentium hostia. Haec summa est omnium eorum, quae sequuntur usque in mediam partem cap[itis] 10. Istis autem vis et scopus evangelii tam plane, tam etiam proprie attingitur et tractatur, ut nihil planius et magis evangelicum dici possit. Neque aliud est, quod christia|no homini perinde sit cognitu necessarium vel quod prophetae et apostoli diligentius, 10 crebrius, maiorique gravitate tradiderunt, quam dei filium hostiam factam esse pro peccatis nostris. Quid enim Moses tam copiose descripsit atque immolandi et Sacrificium. victimarum rationem? Quid vero istis aliud quam hostiam Christi praefiguravit? Isaias quidem clamavit: »Nos omnes velut oves erravimus; dominus autem imposuit ei omnes iniquitates nostras ad propitiandum« [Jes 53,6]. Ioan[nes] 15 Bap[tista] vero dixit: »Hic est agnus dei, qui tollit peccatum mundi« [Joh 1,29]. Imo et ipse Christus: »Et sicut Moses«, inquit, »serpentem exaltavit in deserto, ita oportet exaltari filium hominis, ut omnis, qui credit in eum, non pereat, sed habeat vitam aeternam « [Joh 3,14]. Paulus quoque dixit: »Christus dilexit nos et tradidit semetipsum pro nobis oblationem ac victimam deo in odorem bonae 20 fragrantiae« [Eph 5,2]. Iam vero si operibus nostris, si sacrificiis cultui et ritibus debetur iusticia, sane Christus frustra oblatus est ${ }^{578}$ frustraneum autem esse non potest, | quod a dei filio factum est; icciro unicum filii dei sacrificium omnium credentium omniumque saeculorum salus est. Et haec quidem est illa sacrosancta evangelii summa ac vis, quae hic dignissime et copiosissime tractatur a Paulo, 25 certe ut Hebraeos ab umbraticis abstraheret sacrificiis et unicae Christi iungeret hostiae. De eo autem Pauli consilio dixi in argumento epistolae. ${ }^{579}$ Priusquam

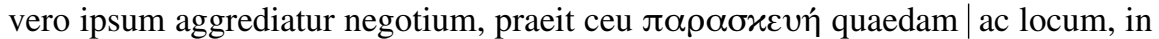
quo veteres suas immolabant hostias, obiter et aliud interim agens describit, fere ad morem historicorum, qui insignem aliquam pugnam descripturi prius locum, 30 in quo facta est pugna veluti pictura ob oculos ponunt. Sed audiamus ipsa Pauli verba:

CAP. IX. 1 Habuit quidem et prius illud iustificationes, cultus ac sanctimoniam mundanam.

Z. (8) attingitur et] om. $Z F-(22)$ iusticia] iustitia $Z F-(28)$ quaedam] quadam $F Z F$

578 Vgl. Gal 2,21.

579 Siehe oben S. $17 \mathrm{f}$. 
Quae sane transitionis formula est. Maximum enim orationis ornamentum est, si velut ansulis cohaereat et non sit, quod de Senecae ${ }^{580}$ scriptis dicebat Caligula, ${ }^{581}$ »harena sine calce ${ }^{582}$ Connectit itaque orationem Paulus, ac si dicat: »Et hactenus quidem de testamento novo; nunc redibimus ad vetus, indicaturi, quid ceremoniarum habuerit. «Quas equidem non ipsa re dixit esse iustificationes, sed

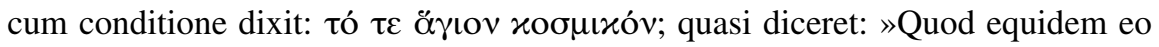
modo dico, quo externa sunt munditia.« Ritus enim Iudaici ipsa re iustificabant neminem, sed mundana erant omnia. Mundanum autem vocamus, quod externum et elementale est, ut in 5. huius epistolae cap[ite] indicatum est. ${ }^{583}$ Ioan[nes]

10 Chrysostomus aliud sentit et ait: »Sanctum saeculare dicit, quoniam omnibus licebat intrare et manifestus erat ille locus in illo tabernaculo, ubi sacerdotes stabant, ubi Iudaei, ubi proselyti et gentiles et Nazaraei. Quoniam ergo et gentibus accessibile erat, saeculare illud appellat $\aleph^{584}$ etc. lucernae, mensa et propositio panum; id autem vocant sancta. 3 Post secundum autem velum erat tabernaculum, quod vocatur sanctum sanctorum, 4 aureum habens thuribulum et arcam testamenti undique circuntectam auro, in qua urna aurea habens manna et virga Aaron, quae germinaverat, et tabulae testamenti. 5 Supra hanc autem Cherubim gloriae obumbrantia propitiatorium, de quibus non est nunc dicendum sigillatim.

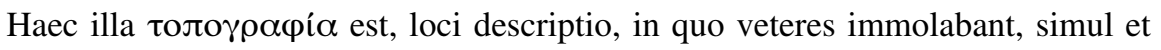
expositio, quisnam ille prioris testamenti cultus fuerit. Quae omnia propterea praemittit, quod in cursu orationis saepe dicetur de tabernaculo, de sacerdotibus ingredientibus sancta et de summo pontifice introeunte sanctum sanctorum; ne igitur tunc remoraretur lector, paucis sacrorum locum adumbrare voluit. Porro Tabernaculum. non dixit duo veteribus (quod tamen parum attentis videri poterat) fuisse tabernacula. Unicum enim fuit, sed per velum in duas partes divisum, ${ }^{585}$ tali propemodum modo, quo apud nos templa dividuntur in chorum et ecclesiam sive

Z. (9) Ioan[nes]] Ioannes $Z F$

580 Lucius Annaeus Seneca (gest. 65 n. Chr.), spätstoischer Philosoph, Lehrer des jungen Nero. Zu seinen Werken zählen zahlreiche Tragödien, philosophische Dialoge sowie die »Epistulae morales ad Lucilium«. Vgl. NP XI 411-419.

581 Caligula (Caius Iulius Caesar Augustus Germanicus), römischer Kaiser 37-41, vgl. NP II 937-939.
582 Erasm. adag. 1257 (ASD II/3 276,356f.): »[...] Senecae orationem sine calce arenam sit $[\mathrm{Ca}-$ ligula Caesar] solitus appellare tanquam dissolutam ac neruis carentem et ordine. « Vgl. Suet. Cal. 53,2 (Ihm 185,3-7).

583 Siehe oben S. $75 \mathrm{f}$.

584 Chrys. Hebr. transl. 109. Vgl. Chrys. Hebr. 15,1 (PG LXIII 117).

585 Ex 26,33. 
populi stationem. Hic itaque finge chorum esse sancta sanctorum, sed ecclesiam esse sancta. Proinde neces|sum est istis Pauli verbis, »post secundum autem

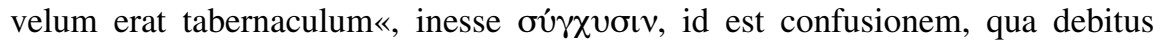
verborum ordo turbatur, qui tamen sic possit restitui: »Post velum autem erat secundum tabernaculum«, id est secunda pars tabernaculi. Nam si secundum referas ad velum, non ad tabernaculum, iam consequetur duo fuisse vela et tria tabernacula, id quod falsum est; ${ }^{586}$ etsi non ignorem paria pene apud Iosephum reperiri. ${ }^{587}$ Nisi fortassis ad illud velum respexerit apostolus, quod in introitu pendebat tabernaculi, sancta dividens ab atrio tabernaculi. De quo legis in fine cap[itis] 26. in Exodo: »Facies et aulaeum in introitu tabernaculi« $[$ Ex 26,36] etc. 10 Et ipsa $\mid$ quidem loca per se neque sancta sunt neque prophana. Usus autem eorum vel sacra facit vel prophana. Sanctum fuit typicum sacerdotium et sacrificium, hinc sanctum dicebatur locus, in quo res agebatur sancta. Sed multo sanctior est intercessio et victima Christi, hinc sancta sanctorum is locus dici coepit, in quo peragebatur figura sacrosancti sacrificii Christi. Nam Christus est ille, ut Daniel 15 ait, »sanctus sanctorum « [Dan 9,24], id est omnium sacratissimus. Nam notissimae nunc sunt illae crebrae anadiploses Hebraicae. ${ }^{588}$

Unum vero fuit tabernaculum, quia una tantum est ecclesia veterum et nostra, interim tamen in duas partes, hoc est, in duplicem populum et ritum divisa. Veteris ecclesiae formam refert ea pars, quae dicitur $» \operatorname{san} \mid$ cta $«$, in qua offerebatur $20 \quad 87 \mathrm{v} F$ quotidie. Novae autem faciem refert interior pars, quae sine ara et in qua arca tantum erat, et »sancta sanctorum « dicebatur. Iam vero, quod quaelibet partium sua habuit ornamenta, non citra insigne factum est mysterium. Nos pro viriculis nostris singula in transcursu $\varkappa \alpha \tau^{\prime} \alpha \partial \lambda \lambda \eta \gamma o \rho i ́ \alpha v$ exponemus. ${ }^{589}$

De candelabro vide Exodi $25 .{ }^{590}$ et observa, quod propheta dixit: »Lucerna 25 pedibus meis verbum tuum et lumen semitis meis« [Ps 119,105]. Constabat autem candelabrum ex auro mundissimo, ${ }^{591}$ quia pura et mera debet esse veritatis doctrina, lucere etiam, ut omnes errorum discutiat tenebras. Calamos vero sive lucernas habuit septem. ${ }^{592}$ Porro septenarius numerus, ut apud Macrobium in

Z. (1) stationem] stationem. Ad haec accessit atrium sancto direptum alio quodam velo. Quemadmodum et nostris templis quibusdam atrium videmus additum. $Z F-(7-8)$ etsi ... reperiri] unum enim erat tabernaculum in duas partes divisum $Z F-(9)$ dividens] dividens non a tabernaculo tertio, sed $Z F$ (25) Exodi] Exo[di] $Z F$ - (29) Macrobium] Macrob[ium] $Z F$

586 Vgl. Erasm. Hebr. (ASD VI/10 322-324,142146): » Secundum< referendum est ad >velamentum $<$, non ad >tabernaculum $<$. Apud nos enim anceps est sermo, apud Graecos nequaquam. Licet ipsa res atque etiam sermonis tenor reclamet Graecorum lectioni. Paulus enim distinguit duo tabernacula, non duo velamenta. $\mathrm{Nec}$ enim erant duo velamenta.«

587 Flav. Ios. ant. 3,122-133 (Niese I 182-185).
588 Siehe oben S. 86, Anm. 468. Vgl. Erasm. Hebr. (VI/10 322,139-141).

589 Vgl. Bull. vorl. Hebr. [9,1-5] (Berg/Hausamman 198): »Dieses wil ich also in kürtze nach der allegory geredt haben [...].«

590 Ex 25,31-40.

591 Ex 25,31.

592 Ex 25,37. 
som[nium] Scip[ionis] ${ }^{593}$ extat, perfectionis est numerus. ${ }^{594}$ Perfectissima itaque et absolutissima est veritatis doctrina, ut nullis prorsus egeat legibus et scriptis subsidiariis.

De mensa lege Exodi 25. ${ }^{595}$ Porro ea videri poterat esse typus ministrorum Mensa. 5 verbi, qui integri esse debent, sana fide imbuti et portatiles, hoc est comes, qui se ad captum auditorum attemperent, non adulando, sed sancta vafricie, ut plurimos Christo lucrifaciant. ${ }^{596}$ Alii per mensam intellexere scripturam. ${ }^{597}$

Mensae imponebantur panes propositionis, Levitici 24[,5-9]., quos alii voca- Panes runt »panes facierum «, ${ }^{598}$ nimirum quod subinde in conspectu facieque hominum super hac re commentum ex egregio illo Hebraeorum nugatore R[abbi] Solomone ${ }^{599}$ producit, quod iudicio diligentis relinquo lectoris. ${ }^{600}$ Certe panes illi verbum dei praefigurarunt homini, qui »non modo pane vivit, sed de omni verbo, quod egreditur ex ore dei« [Mt 4,4]. Hi panes infermentati sunt, unde postea

15 Christus monuit discipulos, caverent sibi a fermento pharisaico, quod erat hypocrisis et humana traditio. ${ }^{601}$ Itaque verbum dei purum est et sanctum et affectibus nostris neutiquam vitiandum. Illis imponebatur thus lucidissimum, in odorem deo bonae fragrantiae. Verbum autem dei, si sit cum fide in pio pectore coniunctum, synceram efficit conscientiam; porro ex syncera conscientia effun20 duntur ad deum preces purae et deo gratissimae. Caeterum, quod mensae imponebantur mundissimae et a solis edebantur sacerdotibus, figurabatur, quinam participes futuri essent coelestis sapientiae, purae videlicet et sanctae mentes. Noluit enim dominus, ut sanctum proiiceremus canibus. ${ }^{602}$ Erravit ergo Aquinas,${ }^{603}$ qui perversa huius loci allegoria lapsus non vere cecinit: »Solis presbyteris, quibus hoc convenit, ut ipsi sumant et dent caeteris. $\ll^{604}$ Siquidem analogiam cum

Z. (10) ant[iquarum]] antiq[uarum] $Z F$

593 Publius Cornelius Scipio Aemilianus Africanus (185/84-129 v.Chr.), römischer Feldherr und Staatsmann, vgl. NP III 178-182.

594 Macr. somn. 1,6,75f. (Willis 32,19-33,2).

595 Ex 25,23-28.

596 1Kor 9,19-22. Vgl. Erasm. adag. 93 (ASD II/1 201,342-344): »Quin et diuus Paulus apostolus sancta quadam iactantia gloriatur hac pia vafricie sese vsum esse, atque omnia factum omnibus, vt omnes Christo lucrifaceret.«

597 Bug. Hebr. 133r: »Lucernae sunt lumen verbi dei, mensa sacra scriptura.«

598 Vgl. Pagn. thes. 1918.

599 Raschi (Schlomo Jizchaki, 1040-1105), berühmter jüdischer Gelehrter und Kommentator des babylonischen Talmud, vgl. LMA VII $445 f$.
600 Rhod. lect. 240: »In Hebraeo panes vocantur facierum, ut sic dicam, quia, ut Rabi Salomon autor est, figura erant quadrata, altera tamen parte longiore, cuius extremitates in surrectum replicarentur.«

601 Mt 16,6-12.

602 Mt 7,6.

603 Thomas von Aquin (1225-1274, gen. »doctor angelicus «), Dominikanermönch, Schüler des Albertus Magnus und Professor der Theologie in Paris, vgl. TRE XXXIII 433-458; LMA VIII 706-711.

604 Thom. Aqu. off. corp. 2,2 (STO VI 580): »Sic sacrificium istud [Christus] instituit, / cuius officium committi voluit / solis presbyteris, quibus sic congruit, / ut sumant et dent ceteris.« 
fidei tum rei ad typum non observavit. Aliud enim censuit apostolus in 1. Corinth. $11 .^{605}$

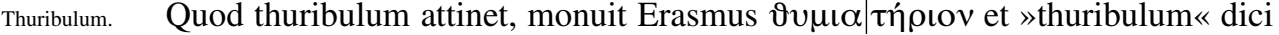
et $\gg$ aram, in qua suffitus fiat $«{ }^{606}$ quare nonnulli permoti transtulerunt $\gg$ altare aureum $«,{ }^{607}$ sed minus proprie. Nam Exodi 30. legimus: »Facies quoque altare ad adolendum thymiamata de lignis Setim vestiesque illud auro purissimo, et pones illud ante velum, quod ante arcam pendet« [Ex 30,1.3.6]. At Paulus nunc eorum

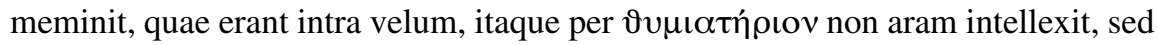
thuribulum, quo orationes et desyderia sanctorum significantur, dicente propheta: »Sit oratio mea incensum coram te, elevatio manuum mearum sacrificium ves- 10 pertinum « [Ps 141,2]. Plura Levit[ici] $16 .{ }^{608}$

De arca lege Exod[i] 25. ${ }^{609}$ Haec dicitur $\gg$ arca testamenti« propter testamenti tabulas impositas, quanquam et ipse tabulae sic dicantur testamentum, ut supra de Bibliis in 8. c[apite] annotavimus. ${ }^{610}$ Et primae quidem tabulae fractae sunt, ${ }^{611}$ secundae vero servatae. ${ }^{612}$ Nam lex spiritualis, quae posterior est, immutabilis et 15 sempiterna est. Haec in arcam, hoc est in fidelium corda, imo in universam dei ecclesiam posita est. Nam arca sacramentum fuit praesentiae | divinae, typus ecclesiae dei, quae, etsi lignea sit, nihilominus deaurata est. Ecclesia enim nun-

Manna. quam a peccatis, quoad vivit, libera, ab iisdem tamen purgata est. In hac arca post tabulas impositum erat manna, quod deus Exodi 16. eis $\mu \nu \eta \mu o ́ \sigma u v o v$ iusserat 20 asservari. ${ }^{613}$ Paulus ergo hoc in loco ait id in urna aurea fuisse repositum, quod Virga Aaron. coelestis et veritatis dei cibus in corde $\mid$ pio et bono custodiatur. In eadem illa arca erat et virga Aaron, de qua Numeri 17. ${ }^{614}$ Qua significabatur docendi officium, sceptrum veritatis insuperabile, vocatio et electio, quam sequitur mentis viriditas tam in docente quam auditore, folia et fructus iusticiae amoenissimi suavissi- 25 mique. ${ }^{615}$

Quid autem dicemus ad id, quod 2. Paralip[omenorum] 5. scriprum est: »Nihil aliud in arca erat nisi duae testamenti tabulae« $[2 \mathrm{Chr} 5,10]$ ? Alii ergo respondent regum temporibus nihil in arca fuisse nisi tabulas tantum, reliqua vero succedentibus imposita esse temporibus. ${ }^{616}$ Alii dicunt exclusivam $\pi \lambda \eta \dot{\nu}$, quae legatur 30

\section{Z. (11) Levit[ici]] Levitici $Z F$ - (25) iusticiae] iustitiae $Z F$}

6051 Kor $11,27-29$.

606 Erasm. Hebr. (ASD VI/10 324,150f.).

607 Orig. in Exod. 9,1 (GCS XXIX 235,12).

608 Lev 16,12f.

609 Ex 25,10-22.

610 Siehe oben S. 108.

611 Ex 32,19.

612 Ex 34,27f.

613 Ex 16,32-34.

614 Num 17,23-25.
88 v $F$ 5

${ }^{615}$ Vgl. Bug. Hebr. 133r: »Virga Aaron electio a deo ad docendi officium, quam sequuntur viriditas mentis, folia eloquentiae et fructus suavissimi in doctore et audientibus."

616 Theophyl. Hebr. transl. 156r: »Nec tamen in ipsis primordiis, sed longo post tempore, cum esset necesse, ut Hieremiae temporibus arca occultaretur, in ea et urnam dicunt fuisse et virgam reconditas.« 
in aeditione LXx, apud Hebraeos non haberi. ${ }^{617}$ Poterat tamen videri synecdocha, ${ }^{618}$ qua potissima recensemus, alia subintelligimus. Arca enim testamenti a tabulis testamenti nomen habet, itaque recensitae sunt potissimum.

Supra arcam erant Cherubim gloriae. Cherubim autem, si Iosepho credimus, Cherubim.

5 erant $\gg$ animalia volatilem habentia figuram, quae a nullo hominum est inspecta, quae Moses dixit se in sede dei conspexisse figurata $\ll .{ }^{619}$ Certe si etymon spectes, »cherubim « significat scientiae multitudinem. ${ }^{620} \mathrm{Si}$ vero consyderes scripturae rationem, iam plerunque eorum fit mentio in sacris, cum deus praesens esse videtur. ${ }^{621}$ Ex quibus colligimus Cherubim veluti ministros dei et divinae prae10 sentiae nuncios ac indices esse. Unde etiam a Paulo non Cherubim / tantum, sed

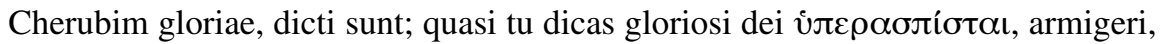
satellites et praenuntii. Hi obumbrant propitiatorium, i[d est], divina maiestas Propitiatorium. assumptam Christi conservat humanitatem. Nam humanitas Christi, quae per propitiatorium authore ad Rom[anos] Paulo figurata est, ${ }^{622}$ pura ex illibata virgine gratiae pignus et redemptionis praetium est, illudque דביר, hoc est »oraculum«, sive $\lambda \alpha \lambda \eta \tau$ ๆ́ เov, id est »locutorium «, ${ }^{623}$ fuit, per quod locutus est orbi deus. Porro hoc propitiatorium, ut erat Cherubim subiectum, contegebat arcam. Nam Christus eatenus est caput et protector ecclesiae suae, quatenus deus et homo est. Sed haec de istis omnibus annotasse sufficiat, cum ipse apostolus longiorem de 20 his disputationem a se commode averterit. Ad aliud enim accelerat; nunc enim sequitur:

6 His autem ad hunc ordinatis modum in prius quidem tabernaculum semper ingrediuntur sacerdotes, qui sacrorum ritus peragant. 7 In secundum autem semel quotannis solus pontifex non sine sanguine, quem offert pro seipso et pro populi ignorantiis.

Iam vero ipsam aggreditur rem et figurae adhibens veritatem demonstrat solum Christi sacrificium verum esse et efficax ad expiandum mundi peccata, veterum vero non item. Praesentibus autem verbis typum | tantummodo proposuit alteram duntaxat demonstrationis partem, quae interim duobus constat membris. Primum:

Z. (3) potissimum] potissimmu $F-(10)$ nuncios $]$ nuntios $Z F-(12)$ i[d est]] id est $Z F-$ (14) Rom[anos]] Romanos $Z F-(16) \lambda \alpha \lambda \eta \tau \dot{\rho} \rho ı v] ~ \lambda \alpha \lambda \eta ́ \rho ı v ~ F ~ Z F$

617 Auf welchen Exegeten Bullinger an dieser Stelle anspielt, konnte nicht eruiert werden.

618 Siehe oben S. 33, Anm. 194.

619 Flav. Ios. ant. transl. 29r.

620 Hier. in Ezech. 12,41 (CCSL LXXV 599f.,1511f.): »>Cherubim< interpretatur >scientiae multitudor.«

621 Vgl. Ez 10.
622 Röm 3,25.

${ }^{623}$ Hier. in Eph. 1,2,19-22 (PL XXVI 507A): »Condaturque in nobis arca testamenti custos legis Domini [...]; dicamurque >dabir< (דביר), quod nos >oraculum $<$ sive >responsum $<$ possumus appellare, et ut contentiosius verbum exprimamus, e verbo, $\lambda \alpha \lambda \eta \tau \eta ́ \rho ı ⿻$, id est >locutorium $<$, dicere. $\ll$ 
in anteriori tabernaculo, quod »sancta « dicebatur, quotidie sacrificabant sacerdotes, Numeri 28[,3-8]. Secundum: in posterius autem, hoc est in »sancta sanctorum«, non nisi semel in anno solus ingrediebatur summus sacerdos offerens pecuinum sanguinem pro se et pro populi ignorantiis, Levit. 16[,11.15]. His iam ordine suam cuique subiungit expositionem vel sua contraria membra sic:

8 Isto autem significavit spiritus sanctus nondum patefactam esse sanctorum viam adhuc priore tabernaculo consistente, 9 quae erat similitudo temporis tunc praesentis, in quo dona sacrificiaque offerebantur, quae non poterant iuxta conscientiam perfectum reddere cultorem, 10 in cibis duntaxat et potionibus et diversis ablutionibus ac iustificationibus carnis usque ad tempus correctionis imposita. anteriori tabernaculo praefiguratum sit, nempe Leviticum sacrificium, quod prorsus vanum sit et inutile. Id quod tot pene argumentis firmat, quot verbis hanc rem elocutus est. Nam si aditus ad sancta sanctorum, hoc est ad ipsum coe|lum, etiam 15 tum non aperiebatur, cum illi strenue admodum immolarent, certe consequens est Leviticis victimis aditum ad coelos non parari et proinde inutiles esse. Id quod minime obscuris verbis mox subiungit: »Ea non potuerunt iuxta conscientiam perfectum reddere cultorem.« Quae locutio hoc valet: Levitica sacrificia conscientiam eorum pacare non potuerunt, pro quibus offerebantur. Caussa: nam ut 20 omnia alia Levitica externis tantum nituntur et constant, ita victimae in primis carnales sunt; sed peccatum non corporis labes est, sed animi; proinde Levitica, hoc est carnalia, sacrificia conscientiam a peccatis non purgant; itaque inutilia sunt, quinimo externa duntaxat iusticia sunt. Nam Paulus ad Rom[anos] 4. »carnis« vocabulum etiam usurpat pro re externa et ait: »Quid ergo dicemus Abraham 25 patrem nostrum meruisse ( $\dot{v} \rho \eta x \varepsilon ́ v \alpha$ enim non modo invenisse est, sed et impetrasse et meruisse ${ }^{624}$ ) secundum carnem? « [Röm 4,1], id est meritis et opere sive iusticia externa. At de varietate ciborum, potus et ablutionum sive baptismatum, lege Leviticum in 11., item Numeri 19. Rursus, cum dicit ista omnia ad tempus correctionis imposita, quis tam stupidus, ut non animadvertat infirma et 30 inutiliora fuisse, quae erant corrigenda, perfectiora autem, quae correctionis gratia erant substituenda? Porro Christus legis correctio et perfectio est. Christus itaque verum et aeternum fidelium holo|caustum est, qui et fideli animae satis est, 
cum unus et solus omnia ea habeat perfectissime, quae anima desiderare potest. De qua re dicetur in secundo membro.

Haec propius et iusta expendant trutina, qui sacramentis tribuunt iustificationem. Nam si in sacramentis res et signum consideranda sunt, quaero, cuius An sacramenta 5 respectu sacramenta conferant gratiam? Signine an rei? Si enim respectu rei conferunt gratiam, iam solius fidei beneficio iustificamur. Planius itaque de sacramentis disserendum erat, ne quis falsa opinione imbutus visibilibus tribuat rebus, quod alias erat invisibilium. Nam si pergamus sacramentis respectu signi tribuere gratiam, iam sequetur mentitum esse Paulum, qui hoc loco longe aliud de veterum tradidit sacramentis. Quos autem aequat fides, eos neque inferiores neque superiores faciunt sacramenta. Sequetur et illud, Iudam iustificatum esse protinus atque sacramentum accepit. Id cum omni modo falsissimum sit, sequitur multo rectius sensisse Augustinum, qui in lib[ro] quaest[ionum] 3., quaest[ione] 84. de hac re sic disseruit. De latrone non legimus, quod alicubi visibiliter sit 15 sanctificatus, nihilominus dixit ei dominus: »Hodie mecum eris in paradyso « [Lk 23,43]. »Neque tamen sine sanctificatione invisibili tanta foelicitate donatus est. Proinde colligitur invisibilem sanctificationem quibusdam adfuisse atque profuisse sine visibilibus sacramentis, quae pro temporum diversitate mutata sunt, | ut alia tunc fuerint, alia vero modo sint. Visibilem vero sanctificationem, quae fieret 20 per visibilia sacramenta, sine ista invisibili posse adesse, non posse prodesse. Nec tamen ideo sacramentum visibile contemnendum est. Nam contemptor eius invisibiliter sanctificari nullo modo potest. Hinc est, quod Cornelius et qui cum eo erant, cum iam invisibiliter infuso sancto spiritu sanctificati apparerent, baptisati sunt tamen; ${ }^{625}$ nec superflua iudicata est visibilis sanctificatio, quam invisibilis iam praecesserat. « ${ }^{626}$ Haec Augustinus, cuius sententiam illis optarem esse cognitissimam, qui hactenus magna gloria, invitis etiam omnibus veritatis hostibus evicere nulla merita, opera sive res externas, sed solam fidem iustificare; nunc vero contentione abducti maximis etiam convitiis a nobis postulare audent, sacramentis tribuamus gratiam et iustificandi beneficium, quod quam alienum a veritate sit, nemo est, qui nunc non videat. Illud etiam videtur annotandum, nonnullos ita distinguere inter donum et sacrificium, ut donum sit frugum, sacrificium vero sanguinis et victimarum. ${ }^{627}$ Verum confunduntur utraque et alterum pro altero ponitur in sacris.

\section{Z. (16) foelicitate] felicitate $Z F-(23)$ baptisati] baptizati $Z F$}

625 Apg 10,44.48.

626 Aug. quaest. hept. 3,84 (CCSL XXXIII 228,1907-1919).

627 Vgl. Petr. Lomb. in Hebr. 9,9-14 (PL CXCII
470A): »Distingue inter hostias et munera. Hostiae sunt de animalibus, munera de aliis, scilicet de thure, de simila, de panibus.« 
11 At Christus accedens pontifex futurorum bonorum per maius et perfectius tabernaculum non manufactum, hoc est non huius structurae, | 12 neque per sanguinem | hircorum et vitulorum, sed per proprium sanguinem ingressus est semel in sancta, aeterna redemptione reperta.

Unicum Christi perpetuum.

Haec posteriori membro respondent. Istis autem exponit, quid per sancta sanc- 5 torum praefiguratum sit, novi videlicet testamenti populus et sacrosanctum Christi sacrificium, quod unicum et solum satis sit ad expianda omnia mundi peccata. Quae omnia planiora fient per subiectam antithesim, qua Christum sic confert summo pontifici, ut longe praecellere videamus. Nam summus (inquit) pontifex ad sacra peragenda ingrediebatur manibus humanis constructum tabernaculum. 10 Oportebat igitur et Christum, quandoquidem pontifex erat, ingredi tabernaculum. Ideoque ingressus est tabernaculum Christus, sed quod praestantius erat. Ille enim in terrenum duntaxat ingrediebatur immolaturus. Hic vero ipsum coelum ascendit. Quod futurorum bonorum esset pontifex, hoc est, quod revera esset pontifex, per quem illam assequimur benedictionem, quam expectarunt omnes sancti patres, 15 non temporale aliquod bonum, sed aeternum et immarcessibile, ${ }^{628}$ quod in futura gloria nobis continget omnibus. Rursus: cum summus pontifex interius ingrediebatur tabernaculum, non sine sanguine ingrediebatur; oportuit ergo Christum etiam cum sanguine ingredi in suum illud tabernaculum; hinc sanguinem fudit Christus, | sed longe meliorem. Nam ille inferebat sanguinem beluinum. Hic vero $20 \quad 92 \mathrm{v} F$ proprium, humanum et sanctum sanguinem. Et pontifex quidem solus et semel in sancta sanctorum ingrediebatur, offerens pro suis et populi peccatis. ${ }^{629}$ Necesse itaque erat, ut solus etiam Christus pro peccatis immolaret. Et immolavit quidem, sed multo perfectius. Ille enim unicam offerendi vicem quotannis semel repetebat et pro suis et populi peccatis offerebat. Hic vero semel duntaxat citra omnem 25 repetitionem, semel, inquam, non pro suis peccatis, quae nulla erant, ${ }^{630}$ sed pro mundi peccatis sanguinem suum deo fudit. Quod autem semel tantum sanguinem Vide. fudit, in caussa fuit, quod unica oblatione coram deo invenit SEMPER DURATURAM expiationem pro omnibus iis, qui crediderunt, credunt et credituri sunt. Ideoque per unicam corporis Christi hostiam cessarunt non modo Iudaica, sed omnia alia 30 in orbe pro peccatis sacrificia. Nam unicum Christi sacrificium toti mundo satis est. Unice ergo toti orbi proponitur vera fide venerandum. Anathema ergo sit, qui aliud statuerit sacrificium vel unicum multiplicarit, vel dixerit Christum non omnia mundi peccata delevisse. Anathema sit, qui aliam expiationem pro peccatis praeter eam quaesierit, quae unico Christi sanguine semel fuso parta est.

Z. (5) sancta] sanctum $Z F$ - (22) sancta] sanctum $Z F$ - (28) caussa] causa $Z F$

628 Vgl. 1Kor 9,25.

630 Hebr 4,15 .

629 Hebr 9,7. 
13 Nam si sanguis taurorum et hircorum | et cinis iuvencae aspersus inquinatos sanctificat ad carnis purificationem, 14 quanto magis sanguis Christi, qui per spiritum aeternum seipsum obtulit immaculatum deo, purgabit conscientiam vestram ab operibus mortuis ad serviendum deo viventi?

Confirmat superiora argumento ducto a comparatis. ${ }^{631} » \mathrm{Si}$ incredibilis «, inquit, »res apud vos fuit credibilis, nempe quod beluino sanguine purgata sint peccata vestra, quanquam ego ablutionem istam aliud nihil fuisse credam « (vide, ut omnia praeveniat apostolus) »quam externum purgandi ritum et veritatis typum; 10 quanto verisimilius est illud, quod admodum credibile est, innocenti Christi morte et sacro eius cruore deleri peccata credentium, cum is verus fuerit deus et immaculatum sese deo obtulerit? «D[ivus] Chrysostomus: »Si carnem«, ait, »potest mundare sanguis beluinus, multo amplius animae sordem diluet sanguis Christi. Ne enim audiens >sanctificat<, magnum aliquid putes, mox ostendit utriusque mundationis differentiam. $\ll{ }^{632}$ Haec ille. At de sanguine taurorum et hircorum lege Levit[icum], 9. et 16. cap[ite]. ${ }^{633}$ De cinere autem vaccae lege Numeri 19. ${ }^{634}$ Et quod dicit Christum per spiritum aeternum immolatum esse, non ita intelligendum est, quasi spiritualiter tantum, non etiam vere passus sit. Petrus enim: »Christus«, inquit, »in carne passus, mortuus est secundum | carnem, 20 vivificatus autem spiritu « [1Petr 3,18]. Itaque per spiritum aeternum veram in Christo divinitatem notatione quadam periphrastica voluit notare et $\mid$ negotium hoc synchysi ${ }^{635}$ efferre, quae tamen sic poterit explanari: Christus obtulit sese immaculatum deo, idque per spiritum aeternum. Hoc est, quod immaculatum sese deo obtulit, id quidem per spiritum aeternum, hoc est per deitatem, stetit, qua 25 factum est, ut nullis sordibus coinquinari potuerit Christi humanitas. Hinc ad virginem diserte dicebat angelus: »Quod ex te nascetur sanctum, filius dei vocabitur « [Lk 1,35]. Ioan[nes] Chrysost[omus] aliud videtur sensisse. Dicit enim Christum sese non per ignem aut aliena quaedam, sed per spiritum aeternum immolasse. ${ }^{636}$ Et sanguis per se quidem, ut res externa et humana est, non lavisset animi maculas, nisi is, qui lavit sanguinemque fudit, etiam dei fuisset filius. Hinc Ioannes: »Et sanguis«, inquit, »Iesu Christi filii dei emundat nos ab omni peccato« [1Joh 1,7]. Sic hoc loco Paulus dicit: »Sanguis Christi, qui per spiritum aeternum se immaculatum deo obtulit, purgabit conscientiam nostram.« Quod in

\footnotetext{
Z. (12) D[ivus]] Divus $Z F$ - (16) cap[ite]] capite $Z F$ - (27) Chrysost[omus]] Chryso[stomus] $Z F$

631 Siehe oben 52, Anm. 302.

632 Chrys. Hebr. transl. 110.

633 Lev 9,1-4; 16,5-10.

634 Num 19,2-9.

635 Eine oú $\gamma \chi v \sigma ı \varsigma$, auch »mixtura verborum« genannt, stellt ein mögliches Resultat der Ver-
}

Obtulit se per spiritum aeternum. 
primis venustum est. Nam haec opponit praecedentibus, in quibus audivimus in veteri testamento indesinenter esse sacrificatum, sacrificia vero ista quotidiana non potuisse cultorum perficere conscientiam. ${ }^{637}$ Hic vero audimus: sanguis Christi, qui semel fusus est, abluit peccata et purgat conscientiam fidelium a mortuariis operibus, hoc est ab iis peccatis, quae $\mid$ extra fidem occidunt ac damnant animam, ut audivimus cap[ite] $6 .{ }^{638}$ »Sed quomodo abluit peccata «, inquis, »itane, ut posthac libere peccemus, utpote qui didicimus sanguine Christi omnia peccata mundi esse deleta?« Respondet apostolus: »Minime. Sic enim purgavit, ut, quod superest, brevissimum vitae spacium innocentiae impendamus. « De qua re copiosius disseruit ad Rom[anos] 6., 13., ${ }^{639}$ et Petrus 1. Pet[ri] 10 4. ${ }^{640}$ Ergo omnis sanctificatio hominis universaque criminum expurgandi lustrandique ratio non in indulgentiis, absolutionibus, satisfactionibus nostris sive in igne purgatorio consistit, sed in unico Christi sanguine. Sanguis Christi est mors et redemptio Christi; at ignis purgatorius, indulgentiae et Romani praesulis diplomata non sunt sanguis Christi; ergo non purificant, sed artes tantum sunt, 15 quibus opes imprudentum imo et superstitiose prudentum emungunt suasque faciunt.

15 Et ideo novi testamenti mediator est, ut morte intercedente ad redemptionem earum praevaricationum, quae erant sub priori testamento, hi, qui vocati sunt, promissionem accipiant aeternae haereditatis.

Oportuit Legimus in evangelio Ioan[nis] cap[ite] 12. Christum aliquando dixisse se brevi

pro totius mundi salute immolandum fore ${ }^{641}$ Cui talia opposuerunt Iudaei: »Nos didicimus ex lege, quod Christus manet in aeternum. Quomodo ergo tu dicis: $>$ Oportet exaltari filium hominis $<$ ? [ Joh 12,34] Ad $\mid$ quem modum et hoc loco Paulus, posteaquam ostendisset Christum Iesum dei filium verum Messiam im- 25 molatum esse pro peccatis nostris, ne Hebraei id, quod apud evangelistam obiecere, hi quoque Paulo opponerent, praevenit et digressiuncula quadam ex ratione testamenti probat mediatorem novi testamenti mori oportuisse. »Et ob id«, inquit, »quod sanguinem fudit et oblatus est, novi testamenti mediator est.« Oportuit enim mortem mediatoris intercedere, ut ea peccata, quae erant sub priori testa- 30 mento, hoc est, quae adhuc supererant Leviticisque sacrificiis expiari non potuerant, nunc quidem morte Christi lustrarentur itaque non modo ii, qui fuerant sub veteri testamento, sed et omnes, qui vocati sunt, id est, qui electi sunt et credunt,

Z. (6) cap[ite]] ca[pite] $Z F$

${ }^{637}$ Hebr 9,6-9.
${ }^{638}$ Hebr 6,1.
${ }_{639}$ Röm 6,1-18; 13,12-14.

640 1Petr 4,12-19.

641 Joh 12,32. 
per Christum aeternae efficerentur consortes vitae. Sed omnia firmiora et clariora fient consequentibus.

16 Siquidem ubi testamentum est, mors testatoris intercedat necesse est. 17 Nam testamentum in mortuis ratum est; quandoquidem nondum valet, cum vivit testator.

A communi hominum more veluti »ex pronunciatis $\aleph^{642}$ clariorem superiorum subiungit caussam, sic argumentans: ubicunque testamentum est, ibi testatoris mors intercedat necesse est; sed iusticia et peccatorum remissio testamentum est; ergo testatorem mori necesse est. Propositio probatur: »Nam testamentum «, in-

10 qu (ut aiunt) non habet. Quae probatio et ipsa a communi hominum more, velut a pronunciatis desumpta est. Assumptio autem $\mid$ confirmatur Ieremiae testimonio. ${ }^{643}$ Proinde necessitate quadam sequitur mediatorem novi testamenti, verum Messiam, mori oportuisse. Deus enim testator est; at is immortalis est, interim testator assumpsit, ut in carne moreretur utque a morte testatoris remissio peccatorum omnibus daretur credentibus. Sic, inquam, testatoris mors omnino et ex necessitate quadam necessaria fuit. Mors autem non cuiusvis hominis, sed filii dei. Nam deus erat testator et testatorem mori oportet. Mediator itaque novi testamenti a Paulo dictus est Christus, quod utriusque naturae eum oportebat esse participem.

18 Unde ne prius quidem illud absque sanguine dedicatum fuit. 19 Cum enim Moses omne praeceptum iuxta legem exposuisset omni populo, sumpto sanguine vitulorum et hircorum cum aqua et lana coccina et hysopo simul et ipsum librum et totum populum aspersit, 20 dicens: hic est sanguis testamenti, quod mandavit vobis deus. 21 Insuper autem et tabernaculum et omnia $\mid$ vasa ministerii sanguine consimiliter aspergebat. 22 Et omnia fere secundum legem sanguine purificantur et absque sanguinis effusione non fit remissio.

30

Quod iam monstrarat humana similitudine, id nunc firmat scripturarum robore ipsa etiam figura probans, quod Messiam mori et offerri oportuerit quodque testamentum citra sanguinem absolvi non potuerit. Verba autem transcripsit ex Exodi cap[ite] $24 .{ }^{644}$ et adeo aperta sunt, si conferantur superioribus, ut nostra non

Z. (8) iusticia] iustitia $Z F$

642 Zum Locus »ex pronunciatis« vgl. Agric. inv. $\quad{ }_{643}^{643}$ Vgl. Hebr 8,8-12; 9,15; Jer 31,31-34. 1,23 (Mundt 138-144).
Christus testator et mediator. 
egeant expositione. Nisi illud monendum sit, in eo, quem iam citavimus Exodi loco, nullam fieri mentionem aquae, hysopi et lanae coccinae, et tamen eadem in sacris creberrime sacrae adhiberi lustrationi. Cuius rei testimonia extant Numeri 19. et Levit[ici] $14 .{ }^{645}$ Certe id, in quo rei cardo vertitur, ipse apostolus in hanc brevem collegit sententiam: »Et omnia fere secundum legem sanguine purificanAnimadverte. tur et ABSQUE SANGUINIS effusione NON fit REMISSIO." Post haec enim redit et planissimis verbis, attamen ad typum aptatis, exponit mysterium Christi, ut coeperat, docens unicum Christi sacrificium verum et perpetuum esse sacrificium. Infert autem ad hunc modum:

23 Itaque necesse est exemplar ipsum coeleste hisce rebus purificari, ipsa autem coelestia potioribus, quam hae sint, victimis mundentur.

| Exemplar vocat rem ipsam, non typum vel umbram. Nam in 8. cap[ite] audivimus Mosaica sacra a coelesti exemplare et visione esse deformata. ${ }^{646}$ Veriora ergo esse coelestia. Mutabilia vero et umbratica tantum Mosaica. Iam ergo apostolus sic colligit: cum typica omnia fuerint sanguine purificata, non potuit 15 iste ritus aliunde quam a coelesti petitus esse exemplari; quocirca necesse est, ut ipsa etiam veritas sanguinis effusione mundetur. Est tamen hic differentia quaedam. Nam quo augustiora et praestantiora sunt umbraticis vera, hoc oportebat praestantioribus victimis et puriore et nobiliore sanguine vera mundari. Atque hinc iam ducit expositionem de Christo unico et aeterno sacrificio. Sequitur enim: 20

24 Non enim in manu facta sancta ingressus est Christus, deformatio verorum, sed in ipsum coelum, ut appareat nunc in conspectu dei pro nobis.

Quod ante digressiunculam coeperat, id nunc repetendo plenius absolvit: Christum coelos ingressum esse, verum templum, utpote verum sacerdotem in hoc, ut 25 appareat nunc in conspectu dei, id est, sacerdotis munere fungatur coram deo, non ut toties offeratur, quoties peccamus, cum idem semper maneat et caussam nostram coram deo agat, ut clarius exponetur in consequentibus. Observabis hoc

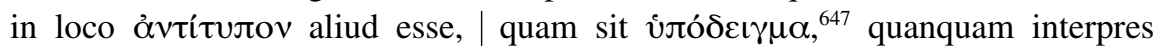

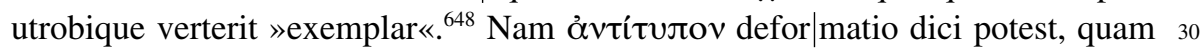

Z. (4) Levit[ici]] Levitici $Z F$ - (15) typica] in typo $Z F$ - (17) ipsa ... veritas] in ipsa etiam veritate $Z F$ (17) mundetur] mundentur omnia $Z F$

645 Num 19,6; Lev 14,4f.

${ }^{646}$ Hebr 8,5.

647 Hebr 9,23.

648 Erasm. Hebr. transl. (ASD VI/4 290). Vgl.
Erasm. Hebr. (ASD VI/10 328,209): »Qui scripsit hanc epistolam nihil interesse putauit

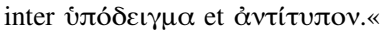


Helvetii vocamus ein contrafactur oder abmachen, quae figuram et habitudinem alterius rei ac corporis exprimit, ut panis et vinum in coena domini, veri corporis et sanguinis representant veritatem. Cuius rei gratia ipsa eucharistia

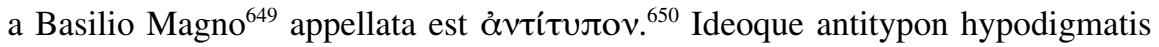
5 est antitypon, ut similitudo aut simulachrum eius rei est simulachrum, a qua deformatum est et cuius similitudinem refert.

\section{Non ut saepius offerat semetipsum, quemadmodum pontifex ingreditur in sancta singulis annis per sanguinem alienum; 26 alioqui oportuisset illum saepius passum fuisse a condito mundo.}

10 Expositio est superiorum, ne quis putet iccirco Christum immolari quotidie, quod ad morem summi sacerdotis, qui quotannis in sancta oblaturus ingrediebatur, ${ }^{651}$ ipse etiam Christus ideo coelum ingressus putetur, ut quotannis vel quotidie

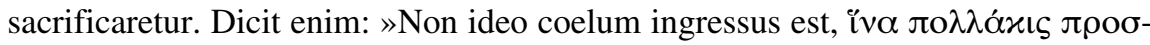

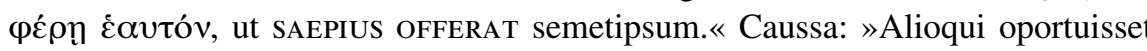
Vide miram

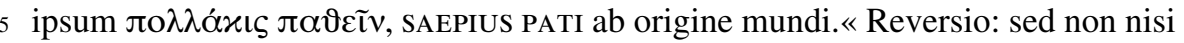
semel mortuus est; ergo non ni|si semel oblatus est. Sequitur enim: »Nunc autem semel sub consumationem saeculorum ad profliganda peccata « [Hebr 9,26] etc. Ex istis vero liquet idem in hoc negotio pollere mori et immolari. Clarissime enim Mori et offerri dicit: »Alioqui oportuisset illum saepius passum esse a condito orbe.« Nam nota est particula »alioqui«, notum est et Pauli consilium. Hisce enim vult reddere caussam, cur dominus non potuerit saepius offerri: quia non potuerit nisi semel mori. Sed et superius audivimus: »Ubicunque testamentum est, ibi etiam testatoris mors intercedat necesse est « [Hebr 9,16]. Item: sacrificia celebrari ad delictorum expiationem. ${ }^{652}$ Rursus: $\gg$ Absque sanguinis effusione non fieri ullam remissionem« [Hebr 9,22]. Ex quibus nunc sponte sequitur illud sacrificium, quod pro expiatione peccatorum sit immolandum, sine morte et sanguine esse non posse; commode itaque et Paulum moriendi et sacrificandi verbo pro eodem usum esse. Huc facit et illud, quod prioris saeculi mentionem facit. Nam si unicum Christi sacrificium vel unica Christi mors non omnia omnium electorum

Z. (10-13) superiorum ... enim] superiorum: »Ingrediebatur in sancta pontifex ideo, ut sacrificaret non semel quidem, sed quotannis « [ $\mathrm{vgl}$. Hebr 9,7]. Iam ne quis crederet Christum quoque coelos ingressum esse, ut immolaret quotannis, subiungit apostolus $Z F-(17)$ consumationem] consummationem $Z F$

649 Basilius »der Große« von Cäsarea (ca. 329379), Kirchenvater, Bischof und Metropolit von Kappadokien. Auf ihn dürfte dürfte die Anaphora der »Basiliusliturgie - neben der Chrysostomosliturgie die vorherrschende Form des byzantinischen Ritus - zurückgehen, vgl. NP II 459-461; LMA I $1532 \mathrm{f}$.

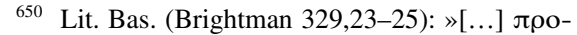

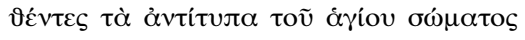

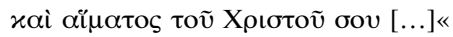

651 Hebr 9,7.

652 Vgl. Hebr 5,3. 
expiasset scelera, iam oportuisset Christum saepius passum esse a condito orbe. Propterea quod ab electis dei ab exordio mundi saepissime peccatum sit. Peccata autem non nisi morte et effuso sanguine expiari potuerint. Hinc enim nunc sequeretur Christum saepius mori et sanguinem fundere oportuisse.

\section{| 26 Nunc autem semel sub consumationem saeculorum ad profligationem} peccati per immolationem sui ipsius apparuit.

Solum Christi satis est.

Reditus est. Sic enim coeptam argumentationem continuat: sed Christus non nisi semel mortuus est; ergo non nisi semel oblatus est; ergo et unica oblatione omnia totius mundi peccata expiavit, et proinde unicum tantum et perpetuum sacrificium est Christi sacrificium. Mirum vero est, quanta emphasi singula dicantur. 10 Primo enim dicit: »Nunc autem «, nempe non ab exordio mundi, sed in fine mundi, »semel oblatus est «. Deinde vero non dicit »ad profligenda peccata «, sed »ad profligationem peccati«, id est ad evacuationem non unius peccati, sed quicquid peccati nomine censeri potest. Tertio autem dicit istam immolationem non per alium esse factam, sed per ipsum dei filium. Nemo enim mortalium 15 immolare potest dei filium. Nam in 7. audivimus: »Talis decebat, ut esset nobis pontifex « [Hebr 7,26] etc. Quae ergo Erasmus in hunc praesentem Pauli scripsit locum, adeo sunt propria et elegantia, ut necessitate quadam ascripserim: talis, inquit, fuit Christus, »ut satis fuerit semel immolare semetipsum ac semel aspersione proprii sanguinis abolere peccata omnium saeculorum usque ad finem 20 mundi. Idque factum est non ab initio mundi, sed instante fine, cum omnibus constaret omnia vitiata peccatis nec ullum esse remedium nisi a deo, ut palam esset, quam $\mid$ esset efficax sacerdos, qui unica victima tam immensum acervum peccatorum expiaret relicto parato facilique remedio, ut eadem hostia in annos innumeros satisfaceret omnibus, qui sese non preberent indignos. Transtulit enim 25 in se non solum eorum peccata, qui ante multos annos spem salutis in eo posuerant, verumetiam eorum, qui multis post saeculis credituri essent eius evangelio. ${ }^{653}$ Haec Erasmus.

Missa. $\quad$ Miror autem si quid habeant infoelices missastae, quod hisce Pauli tam claris pro sacrificio missae opponant. Nam quod Ioannes Apocalyp[seos] 13. Christum 30 vocat agnum ab origine mundi occisum, ${ }^{654}$ his Paulinis adeo non reclamat, ut magis succinat. Voluit enim Ioannes indicare unica Christi morte et victima omnium sanctorum peccata ab exordio mundi esse purgata. Quod vero aiunt se

Z. (5) consumationem] consummationem ZF - (24) relicto] relictio $F$ - (29) infoelices] infelices $Z F$ (30) Apocalyp[seos]] Apocal[ypseos] $Z F$

653 Erasm. par. Hebr. (ASD VII/6 74,724-733).

654 Offb 13,8 stellte eine wichtige Referenz in der römisch-katholischen Kontroversliteratur über das Messopfer, vgl. Eck sacr. 10 (Iserloh et al. $63)$. 
mystice et spiritualiter Christum offerre ${ }^{655}$ nemo est, qui nunc non intelligat istud commentum verborum duntaxat niti praestigiis. Nos vero ex hoc Pauli loco haec duo missatico opponimus sacrificio. Primum: Christus »amplius non moritur, mors illi ultra non dominabitur«, Rom. 6[,9].; ergo a nemine amplius sacrificatur.

5 Consequentia praesentibus probatur Pauli verbis. Secundum: in omni eo sacrificio, quod peccata expiare debet, necesse est sanguinem fundi et mortem intercedere. Probatur Pauli verbis: »Sine sanguinis effusione non fit remissio « [Hebr 9,22] et: »Ubicunque testamentum est, ibi | mors testatoris intercedat necesse est « [Hebr 9,16] etc. Sed in missa neque Christi sanguis funditur neque ipse Christus moritur. Probatur authoritate Pauli ad Rom[anos] 6., Hebr[aeos] 9. et quod sanguis semel effusus, amplius non effunditur, sed satis est ad delenda omnia mundi peccata. Itaque missa non est sacrificium pro peccato.

\section{Et quatenus illud manet omnes homines, ut semel moriantur, post hoc} autem iudicium, 28 ita et Christus semel oblatus est, ut multitudinis tolleret peccata. Secundo autem absque peccato apparebit omnibus expectantibus se ad salutem.

Similitudine docet Christi sacrificium unicum esse et perpetuum, ut posthac non sit ulli ulla alia expectanda victima. Homo enim non nisi semel moritur; et Christus homo fuit; ergo non nisi semel mortuus est. Proinde et semel duntaxat immolatus est. Semel, inquam; observabis autem, quoties iam illud SEMEL ingeminarit. Homines non morimur quotidie, itaque et Christus non immolatur quotidie. Et quemadmodum post mortem nobis nihil aliud restat nisi iudicium, ita post unicam Christi mortem non restabit ullum aliud sacrificium ad iudicium

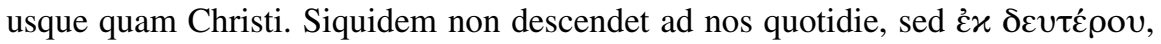
id est secundario, altera duntaxat vice, dum venerit »iudicare vivos et mortuos «. ${ }^{656}$ Aderunt quidem in postremis | temporibus pseudoprophetae, qui iuxta vaticinium Christi dicent: »Ecce hic, ecce illic est Christus« [Mt 24,23], sed Matth. 24. subdit: »Ecce praedixi vobis. Si ergo dixerint vobis: >Ecce in deserto est $<$, nolite exire; >ecce in penetralibus $<$, nolite credere. Sicut enim fulgur exit ab oriente et apparet usque in occidentem, ita erit adventus filii hominis « [Mt 24,25-27]. Quasi diceret: »Iccirco nolim istis fidem a vobis dari, quod praesentia Christi non erit ita, ut aiunt, invisibilis et obscura. Cum enim redierit, celer et clarus, fulguris in morem emicabit « etc. Duo enim sunt adventus Christi secundum carnem. Prior in carnem, quo peccata nostra in se transtulit et expiavit; postea vero coelos

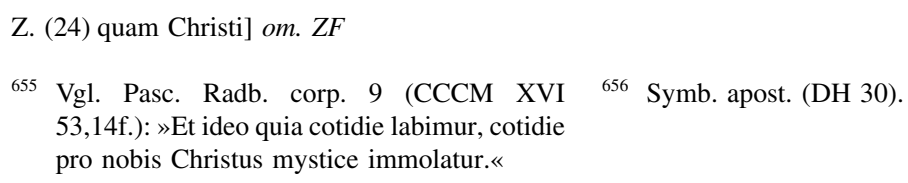


ascendit et carnem huic mundo subtraxit. Posterior in iudicium, quo iam non expiabit peccata (quod Paulus schemate quodam dixit »sine peccato apparere «), sed iustus iudex puniet omnem iniquitatem; salutaris nihilominus futurus omnibus iis, qui sibi vera fide crediderunt. Recte ergo quaerit d[ivus] Chrysostomus: »Quare multitudinis sive multorum et non omnium sustulit peccata? Quia non omnes crediderunt. Pro omnibus quidem mortuus est, quantum in ipso est. Non autem omnium peccata abstulit, propterea quod noluerunt. $« 557$

CAP. X. 1 Nam lex umbra existens futurorum bonorum, non ipsa rerum imago, iis hostiis, quas singulis annis easdem continenter offerunt, nunquam potest accedentes perfectos reddere. 2 Alioqui nonne desiissent offerri? Propterea quod ii, qui sacrificassent et semel purgati essent, nullam iam habuissent conscientiam peccatorum.

Adver[sus] Posteaquam ostendisset unicum Christi sacrificium verum esse et perpetuum, veterum
acr[ificia]. nunc illud etiam multis iisdemque clarissimis argumentis demonstrat, quod et supra attigerat, ${ }^{658}$ veterum sacrificia prorsus fuisse inutilia. Nimirum ut inenar- 15 rabili illa sedulitate sua sacrificia, baptismata et alia id genus typica sacra tam altis fixa in Hebraeorum corda | radicibus evelleret, contra vero Christum penitus insereret piis pectoribus. Idem ergo subinde inculcat. Nam copiosa tractatione eademque perspicaci et firma adeoque et superstitiosa apud Hebraeos pertinacissimum genus mortalium ${ }^{659}$ opus erat. Sensus autem eorum, quae dicit, hic est: 20 »Porro quod legali fiditis sacrificio, stulte facitis. Nam lex umbra tantum fuit

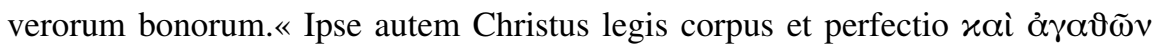

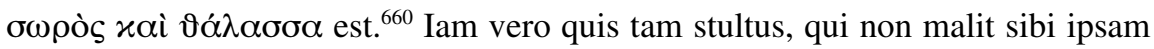

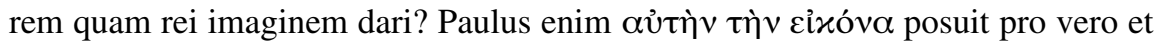
expresso, quod ipsum per sese sit et in se rem ipsam exhibeat, non specie aliqua 25 sive typo representet. ${ }^{661}$ Caeterum quod umbra fuerit lex quodque inutilia legis sacrificia, hinc patet, quod ibi sa|crificia prorsus cessant, ubi perficiunt et peccata expiant. Nam in quem finem victimam iteret, qui victimam habeat, quae semel oblata, semper satis sit ad expianda omnia peccata? Levitica autem sacrificia non cessabant. Nam eadem quotannis et continenter sineque omni intermissione of- 30 ferebantur; itaque peccata non expiabant et proinde non modo inefficacia, sed et inutilia fuerunt. D[ivus] Chrysostomus haec omnia pulchra similitudine exponit

Z. (13) Marg. Adver[sus]] Adversus ZF - (14) argumentis] argunentis $F$

657 Chrys. Hebr. transl. 115.

658 Vgl. Hebr 8,4f.

659 Vgl. Ex 33,3.

660 Erasm. adag. 229 (ASD II/1 341,922f.): »'A $\gamma \alpha \vartheta \tilde{\omega} v \vartheta \alpha ́ \lambda \alpha \sigma \sigma \alpha$, id est >Bonorum mare<, de magnis et vehementer cumulatis commo- ditatibus.« Ebd. 231 (ASD II/1 342,942f.): »'A $\gamma \alpha \vartheta \tilde{\omega} v \sigma \omega \rho o ́ s$, id est >Bonorum aceruus $<$. De opibus ingentibus.«

661 Erasm. Hebr. (ASD VI/10 330,214f.): »>Ipsam< posuit pro > veram< et >expressam<, quae rem totam vt est, repraesentet.«
99 v $F$ 
et ait: »Quid autem opus erat multis, dic mihi, una sufficiente? Proinde quod multae et semper offerebantur, ostendit eos nunquam purgari. Sicut enim medicamentum, quando fuerit forte et salutis efficax et valens cunctam valetudinem repellere, semel impositum totum operatur. Si ergo semel impositum totum ope5 ratum fuerit, ostendit suam virtutem, ut non ulterius apponatur; et hoc est eius opus, ut iam non apponatur. Si vero semper apponitur, manifestum indicium est nihil illud praevaluisse. Medicamenti quippe illa virtus est, ut semel imponatur et non frequenter. Sic etiam hic. ${ }^{662}$ Haec Chrysostomus.

Vos autem hic appello »missastas«, vos, inquam, qui missam venditatis pro

10 sacrificio abluente peccata vivorum et mortuorum; vos, inquam, appello: dicite nobis, an missa peracta purgaveritis eius peccata, pro quo obtulistis, an non purgaveritis. Si non purgastis, inefficax ${ }^{663}$ et inutilis est missa vestra et impostura| est hostia vestra. Si vero purgastis, quid, obsecro, non iam altera vice, sed quotannis ut Iudaei, imo centies iterumque centies offertis pro mortuis? Quid 15 depositionis diem, septimam, trigesimam et continenter deinceps anniversariam multiplici celebratis victima? »Sed quotidie «, inquiunt, »peccamus, quotidie ergo sacrificamus. $\ll^{664}$ Id quod pro vivis obiiciunt; nam pro mortuis nihil prorsus habent, quod dicant. Atqui ad istud etiam commentum, quod pro vivis obiiciunt, hoc respondit apostolus: unicum esse Christi sacrificium et ita unicum, ut semel 20 duntaxat immolatum iterari non possit neque necessum sit. Unicum enim et solum semper satis esse ad omnia ea peccata condonanda, quae in hac vita a nobis committantur.

\section{Atqui in istis commemoratio fit peccatorum quotannis.}

Occupatio est. Nam, ne quis obiiceret: »Si inutilia sunt sacrificia, cur, oro, cur

instituta?«, respondet: »In hoc instituta sunt, non ut peccata abluant, sed ut sacrificatum peccata refricent eosque peccati convincant, qui sacrificant.« Id quod et superius in 7. de institutione legis annotavimus. ${ }^{665}$ Chrysostomus: proinde, inquit, constitutio sacrificiorum »accusatio peccatorum fuit, non solutio. Quia fiebat accusatio infirmitatis, non virtutis ostensio. In eo enim, quod offerebantur, redargutio 30 peccatorum; in eo autem, quod semper, redargutio fit infirmitatis $\ll^{666}$ etc.

Z. (8) Chrysostomus] Chrysosto[mus] ZF - (15) anniversariam] aniversariam $F$ - (22) committantur] commitantur $F$

662 Chrys. Hebr. transl. 115f.

663 Marg. »Brendly Murer«: Bezeichnung für jemanden, der sich vergeblich abmüht, vgl. SI XVI 1232.
664 Siehe oben S. 125, Anm. 655.

665 Siehe oben S. 98.

666 Chrys. Hebr. transl. 116. 
Brevibus haec abrumpit, quasi diceret: quid vero multis? Peccatum animi, non corporis vitium est, ergo peccatum corporea re non tollitur; corporea autem fuere veterum sacrificia; itaque ea non purgarunt animi peccata.

5 Ideo, cum ingressurus esset mundum, dixit: sacrificium et oblationem noluisti, corpus autem aptasti mihi. 6 Holocaustomata et pro peccato non comprobasti. 7 Tunc dixi: ecce, adsum, in capite libri scriptum est de me, ut faciam, deus, voluntatem tuam.

Scriptura. Prophetico testimonio nunc confirmat, quod hactenus disputavit, sacrificio Christi omnes veterum victimas esse abolitas. Christi autem hostiam unicam esse et 10 perpetuam.|Testimonium autem sumpsit ex Psal[mo] 39. ${ }^{667}$ finxitque haec Christum iam mundum ingredientem loqui. Sciendum vero in Hebraica veritate non legi: »Corpus aptasti mihi«, sed: »Aures perforasti mihi«. Et quamvis verba sic dissonent, sensus tamen idem est. Apostolus enim voce corporis ita utitur, ut umbrae opponitur, nempe pro ipsa re, quae adumbratur typo. Iam vero propheta 15 »aures« sic usurpat, ut fidei et obedientiae instrumentum sunt, adeoque et per Rom. 5[,6]. metalepsim ${ }^{668}$ aures pro ipsa posuit obedientia. ${ }^{669}$ At obedientia Chri|sti illud ipsum corpus, id est, illa ipsa res est, quam typi figurarunt. Noluit ergo Christus umbrae servire, sed ipsum corpus suum per obedientiam in mortem crucis tradere ${ }^{670}$ Deinde vero sciendum $»$ caput libri« positum esse pro summa et scopo 20 legis. Est autem scopus et summa legis, deo subiici et voluntati eius obtemperare.

\section{Superius cum dicit: sacrificium et oblationem et holocaustomata et pro peccato noluisti neque comprobasti, quae iuxta legem offeruntur, 9 tunc dixit: ecce, adsum, ut faciam, deus, voluntatem tuam; tollit prius, ut posterius statuat. 10 Per quam voluntatem sanctificati sumus, per obla- tionem corporis Iesu Christi semel peractam.}

Nunc adaptat instituto suo, quod citarat testimonium. Et de industria quidem omnis generis sacrificia veluti sufficienti enumeratione recenset: oblationes, hos-

Z. (17) obedientia] obedientia. Et aures servorum in lege perforabantur terebello affigebanturque superliminari in argumentum, quod dominis obedientiam deberent servi, Exod. 21[,6]. ZF

667 Ps 40,7-9 (Vulg. 39,7-9).

668 Siehe oben S. 79, Anm. 437.

669 Erasm. Hebr. (ASD VI/10 330,233-238): »Diuus Hieronymus iuxta veritatem Hebraicam transtulit hoc modo: >Victima et oblatione non indiges, aures autem fodisti mihi. [...]
Caeterum quod dicit >aures autem perfodisti mihi $<$ indicat obedientiam fidei, quam Deus iam requirebat a suis cultoribus fastiditis victimis.«

670 Vgl. Phil 2,8. 
tias, holocaustomata et victimas, quae interim omnia nolit deus. Unde necessario Differentiam sequitur omnia veterum sacrificia prorsus esse abolita, sola autem innocenti horum legere hostia filii sui delectari deum. Et sane Paulus voluntatem posuit pro beneplacito. est apud Etenim in Christo placatus est orbi pater, qui supra caput filii testificans ista

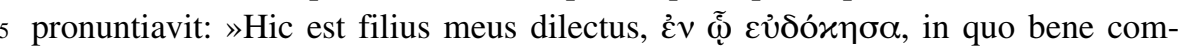
placitum est « [Mt 3,17]. Placatus est itaque nobis pater per oblationem corporis Christi, ut nunc sanctifi|cati, unica Christi contenti simus hostia. Vera itaque sanctificatio non constat rebus humanis et externis, sed sola dei gratia, Ephes. $2[, 8]$. Et hactenus quidem de inefficacia victimarum veterum. saepius offerens hostias, quae nunquam possunt auferre peccata. $12 \mathrm{Hic}$ vero una pro peccatis oblata victima perpetuo sedet ad dexteram dei, 13 id quod superest expectans, donec ponantur inimici eius scabellum pedum ipsius. 14 Unica enim oblatione perfectos effecit in perpetuum eos, qui sanctificantur.

Iam vero epilogum sive anacephalaeosim ${ }^{671}$ omnium eorum contexit, quae hu- Quod Christus cusque a 9. cap[itis] initio de sacrificio disputavit. Contexit autem eo prorsus aeterna victima dicendi modo et consilio, quo in 8 . cap[ite] caussam sacerdotii collegit. ${ }^{672}$ Epilogus vero ipse constat, ut superiora pleraque, contentione demonstrativa. Totum enim negotium summi pontificis et Christi quoad sacrificium veluti de novo ob oculos revocat et Christum sacerdotib[us] sic committit. Levitici sacerdotes nedum ipse summus pont[ifex] easdem quotidie immolabant hostias. Christus vero unicam semel duntaxat obtulit victimam. Porro illi easdem saepius obtulere hostias, quod inefficaces subinde iterarentur et tamen peccata non abluerent. Sed cum Christi victima semel tantum | oblata omnium omnia expurgarit peccata, perpetua facta est, ipseque Christus, veluti de peccato, daemone et inferno devicto omnique re foeliciter gesta, triumphans coelos ascendit, subiugaturus hostes et poenas posthac de omnibus iis sumpturus, qui eius sacrificio absolutissimo non obedierunt. His subiicitur elegans et firma admodum $\pi \rho 0 \sigma \alpha \pi \delta ́ \delta \omega \sigma \iota \varsigma .{ }^{673} \gg$ UNICA ENIM OBLATIONE PERFECTOS EFFECIT IN PERPETUUM EOS, QUI SANCTIFICANTUR.« Proinde omnes, qui sanctificantur, sanctificati sunt et in futuro usque ad iudicii diem sanctificabuntur, unica illa (observa: UNICA) Christi hostia sanctificabuntur. Quid | ergo alia opus hostia? Quis Levitica post hac curaverit sacrificia? Aut quis

Z. (17) cap[itis]] capitis $Z F$ - (21) sacerdotib[us]] sacerdotibus $Z F-(22)$ pont[ifex]] pontifex $Z F$ (27) foeliciter] feliciter $Z F$

671 Siehe oben S. 103, Anm. 556.

672 Hebr 8,1f.

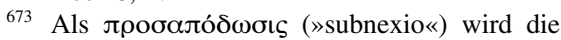

Epilogus.

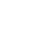

$-$

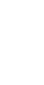

西


iteret victimam, quae iterari nequeat, sed et sola et semel caesa sufficiat ad expianda peccata, imo et amplius offerri caedique non possit? Istis autem prorsus conculcantur omnia merita, sacrificia, missae et placita hominum universa. Contra vero solius statuitur Christi gloria, redemptio, iusticia et sacrificium perpetuum. Verum ipse Paulus, postquam repetiit solum Christi sacrificium esse perpetuum, etiam illud, quod sacrificiorum abrogationem attinet, sequentibus sic colligit:

Nemo autem existimet apostolum Paulum esse unum ac primum huius dogmatis authorem, quod Christus semel duntaxat mortuus unica hostia omnia mundi peccata sustulerit. Tradidit hoc ipse apud Zachariam in 3. cap[ite] dominus, priusquam nasceretur Paulus, aut in mundum ipse venisset Christus. Verba domini, si quis requirat, haec sunt: »Audi nunc, Iehosua, sacerdos magne, tu et socii tui, qui sedent ante te, quia viri portenti sunt. Quoniam ecce, ego adduco servum meum Germen«; »super lapidem unum oculi septem. Ecce, ego aperio apertionem eius, dicit dominus exercituum, et auferam iniquitatem terrae illius IN DIE UNA « [Sach 3,8.9] etc. Ex quibus proculdubio sumpsit Apostolus, quae in praesenti de unico Christi tradidit sacrificio. Appellat in vaticinio dominus summum praecipue pontificem, deinde vero sacerdotes caeteros, quos nuncupat »viros portenti $\ll$, id est »portendentes«. Nam sacerdotes Levitici omnes typum praetulere Christi. His nunciat dominus consilium suum, nempe quod statuerit orbi dare Iesum sacerdotem verum, quem protinus triplici insignit nomine. Servum enim vocat, id quod Isaias ante ipsum factitavit cap[ite] 42. 20 et Matth[aeus] in $12 .{ }^{674} \gg$ Exinanivit enim semetipsum forma servi assumpta« [Phil 2,7] venitque in mundum, »non ut sibi ministraretur, sed ut ipse ministraret« [Mt 20,28]. Germen vero appellavit et Ieremias in cap[ite] 23. et Isaias in 11. cap[ite]. ${ }^{675}$ Idem in cap[ite] 28. nominavit lapidem. ${ }^{676}$ Id quod David, Daniel, Petrus atque Paulus fecere. ${ }^{677}$ Senserunt enim omnes Christi robur et firmitatem inexplicabilem. »Super lapidem vero hunc«, ait, »unum oculi septem« [Sach 3,9]. Et septenarius numerus perfectionis numerus est. Unus item, hoc est solus, praeponitur omnibus. Dicit ergo omnium cum hominum tum aetatum oculos in solum Christum ut unicum totius mundi salvatorem intentos esse. Caeterum ista salus per mortem et sanguinis parta est effusionem. ${ }^{678}$ Hinc dominus: »Ego«, inquit, »aperio apertionem eius«, id est: »Lapidi huic infligo plagas.« Nam et Zacharias hic 30 idem: »Percutio«, ait, »pastorem « [Sach 13,7]. Et Isaias: »Dominus«, ait, »fecit concurrere in eo omnium nostrum iniquitates« [Jes 53,6]. »Ipse vulneratus est propter iniquitates nostras et contritus est propter scelera nostra « [Jes 53,5]. Refert item Ioannes e suspenso in crucem exanimato corpore lanceaque aperto promanasse sanguinem et aquam. ${ }^{679} \mathrm{Nam}$ morte Christi vivificati et sanguine eius a peccatis sumus mundati. Unde et apud Zachariam dominus: »Et auferam «, inquit, »iniquitatem terrae illius in die una « [Sach 3,9]. Non utique terrae Chananaicae tantum, sed totius etiam mundi, dicente Baptista: »Ecce agnus dei, qui

Z. (4) iusticia] iustitia $Z F$ - (5-7) Verum ... colligit] ZF mit anderer Fassung, siehe Einschub unten (8) Nemo] Der Einschub ersetzt in ZF oben Verum ... colligit

674 Jes 42,1; Mt 20[!],27f.

675 Jer 23,5; Jes 11,1 .

676 Jes 28,16 .
677 Ps 118,22; Dan 2,34f.; Apg 4,11; Röm 9,32f.

678 Vgl. Hebr 9,22.

679 Joh 19,34 .

i


tollit peccatum mundi « [Joh 1,29$]$. Illud autem peccatum sublatum est uno die et unica hostia, quam et ipse dominus pronunciavit per omnia esse absolutam. Notissima est enim illa vox domini: »Consummatum est« [Joh 19,30]. Habes, quid spectarit Paulus et unde petierit voculam UNICA hostia, sed et suum SEMEL. ${ }^{600}$ Aequipollent enim haec duo: »semel

5 oblatus est et peccata expiavit« et: »in uno die« vel »unica hostia expiavit peccata«. Huc nimirum pertinet, quod Petrus quoque in priore 3. cap[ite]: »Christus«, inquit, »semel pro peccatis passus est, iustus pro iniustis, ut nos adduceret deo« [1Petr 3,18]. Iam vero ipse Paulus, postquam repetiit solum Christi sacrificium esse perpetuum, etiam illud, quod sacrificiorum abrogationem attinet, sequentibus sic colligit:

15 Hoc firmat nobis etiam spiritus sanctus, nimirum cum praedixit: 16 hoc est testamentum, quod feriam cum illis post dies illos, | dicit dominus, dans leges in corde illorum et in mentibus illorum inscribam eas, 17 et peccatorum atque iniquitatum illorum non recordabor amplius. 18 Porro ubi horum est remissio, ibi non est amplius oblatio pro peccato.

15 Qu

Quemadmodum caussam de sacerdotio Christi collegit Ieremiae testimonio, ut audivimus in $8 .{ }^{681}$ ita caussam sacrificii Christi eodem concludit testimonio ${ }^{682}$ et nunc quidem comprobat ac colligit, quae de abrogato Levitico sacrificio dispu- Quod per tavit. Sed dispositio ver/borum Pauli haec est: ubi est plenaria peccatorum re- Christum missio, ibi nulla superest oblatio pro peccato; sed in novo testamento est plenaria antiquatae.

20 peccatorum remissio; ergo in novo testamento nulla restat oblatio pro peccato. Maior clarissima est. Quorsum enim opus est sacrificia adhibere pro diluendis peccatis, quae iamiam unica Christi morte condonata sunt? Minor probatur testimonio Ieremiae. Quid ergo restat? Unicum et solum Christi sacrificium satis esse ad diluenda omnia delicta mundi. Cessasse itaque omnia in orbe sacrificia, contra vero unicam Christi victimam fide venerandam omnium proponi fidelium mentibus.

$»$ Ergone«, inquis, »ita abolita sunt omnia sacrificia, ut nihil habeat christia- De sacrificiis norum ecclesia, quod deo offerat? « Respondeo duo quidem esse sacrificiorum ge| christianorum. nera: alterum expiationis pro peccato, alterum vero laudis, iusticiae et gratiarumactionis. Iam vero nullum prorsus restat expiationis et pro peccato sacrificium, quod amplius offeratur in ecclesia. Nam unica Christi hostia una pro omnibus peccatis est et semel oblata semper satis est, et de hac hostia hactenus disputavit apostolus. At in 13. cap[ite] ${ }^{683}$ audiemus de spiritualibus quibusdam christianorum hostiis, quae gratitudinis, iustitiae et laudis hostiae sunt, nempe quod benefecerit deus, quod peccata nostra per cruorem filii sui deleverit, non quod per nostras

\section{Z. (29) iusticiae] iustitiae $Z F$}

680 Hebr 10,10.14.

681 Hebr 8,8-12.
682 Jer 31,33f.

683 Hebr 13,15f. 
oblationes nunc primum deleat. Sed de iis dicemus in cap[ite] $13 .{ }^{684}$ Hinc vero

Quomodo dicatur eucharistia sacrificium. liquet, quid etiam de coena domini sentiendum sit. Non quod pontificii sentiunt: in ea a sacerdote offerri reale et naturale corpus Christi ad expianda vivorum et mortuorum peccata; id enim veritati et virtuti mortis et hostiae Christi plus quam

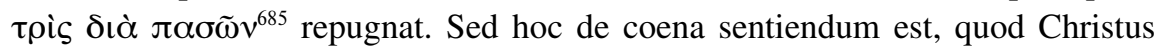
sentire iussit, qui dixit: »Hoc facite in mei commemorationem « [Lk 22,19]. Est itaque coena sancta et fidelis commemoratio mortis et sacrificii Christi semel in cruce pro nobis oblati, qua et ea symbola sumimus, quae sumere iussit, et gratias agimus, quod sub peccatum venditos redemit. Caeterum, cum commemorationi id quoque nominis communicetur, quod illud revera habet, cuius est commemoratio, 10 coena autem commemoratio sit sa|crificii Christi in cruce semel peracti, fit, ut apud veteres pene omnes sacrificii nomen tribuatur coenae, ipsa itaque coena dicatur esse christianorum sacrificium, non ipsa re, sed nominis communicatione. Est et alia caussa, cur coena sive eucharistia veteribus dicta sit sacrificium: cum enim gratiarumactio et laus sit christianorum sacrificium, eucharistia autem nihil 15 aliud sit, etiam si etymon spectes, quam gratiarumactio, fit, ut eucharistia a veteribus dicatur sacrificium, non eo nomine, quod caro et sanguis (ut pontificii volunt) offeratur, sed quod coetus, concordia, charitas, unio, oratio, laus et gratiarumactio verum sint christianorum sacrificium. Atque huius rei testes vocamus vetustos omnes: Irenaeum in primis lib[ri] adver[sus] haere[ses] 4. cap[ite] 32., 20 33. et 34. ${ }^{686}$ deinde vero Tertullianum adver[sus] Iudaeos ${ }^{687}$ et adver[sus] Martion[em] lib[ro] 3. et 4., ubi in illud Malachiae: $\gg \mathrm{Ab}$ ortu solis usque ad occasum offeretur sacrificium nomini meo mundum « [Mal 1,11] clarissime dicit: »Gloriae scilicet relatio et benedictio et laus et hymni $\ll{ }^{688} »$ simplex oratio de conscientia pura $\ll{ }^{689}$ Testem advoco et d[ivum] Caecil[ium] Cyprianum epistol[arum] lib[ro] 25 2., epist[ola] 3. ${ }^{600}$ Idem author 4. epist[olarum] lib[ro], epist[ola] 5. sacrificii pro mortuis sic meminit, ut palam constet sacrificia illa aliud nihil fuisse quam laudes mortuorum et gratiarumactiones deo pro beneficiis exhibitis. ${ }^{691}$ Testamur et $\mathrm{Au}-$ gustinum ad Bonifacium ${ }^{692}$ epist[ola] $23 .{ }^{693}$ et in lib[ro] de civit[ate] dei $\mid 10$., cap[ite] 4., 5. et $6 .{ }^{694} \mathrm{Nec}$ est, ut hic cristas erigant pontificii. Non enim paucorum 3

Z. (20) adver[sus]] adversus $Z F-(21)$ adver[sus]] adversus $Z F-(21)$ adver[sus]] adversus $Z F-$ (25) Caecil[ium]] Caecilium $Z F$ - (25) epistol[arum]] epist[olarum] $Z F$ - (29) civit[ate]] civitate $Z F$

684 Siehe unten 170f.

685 Vgl. Erasm. adag. 163 (ASD II/1 276,495497): »Quae pugnantissima inter sese videren-

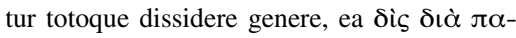
$\sigma \tilde{\omega} v$ inter se discrepare dicebant.«

686 Iren. haer. 4,29-31 (Harvey II 193-210).

687 Tert. adv. Iud. 5,4f. (CCSL II 1350f.,28-45).

688 Tert. adv. Marc. 3,22,6 (CCSL I 539f.,17f.).

689 Tert. adv. Marc. 4,1,8 (CCSL I 546,8).

${ }^{690}$ Cypr. epist. 63 (CCSL IIIC 389-417).
691 Cypr. epist. 39,3,1 (CCSL IIIB 189,49-51): »Sacrificia pro eis semper, ut meministis, offerimus, quotiens martyrum passiones et dies anniuersaria commemoratione celebramus.«

692 Bonifacius (gest. nach 432), ab 423 »comes Africae«, stand in brieflichem Kontakt mit Augustinus, vgl. AugL I 653-655.

693 Aug. epist. 98,9 (CSEL XXXIV/2 530f.).

694 Aug. civ. 10,4-6 (CCSL XLVII 276-279). 
est haec oblatio, sed omnium in Christum credentium, Iudaeorum et gentium, virorum et mulierum, iuvenum atque senum. Siquidem non succinemus vobis: Missa »Solis presbyteris, quibus hoc convenit, ut ipsi sumant et dent caeteris. ${ }^{695}$ Quin potius Paulo succinemus, qui universae Corinthiorum ecclesiae sic scripsit: 5 »Quotiescunque comederitis panem hunc et de poculo hoc biberitis, mortem domini annunciabitis, donec venerit« [1Kor 11,26]. Non quod ordinem et honestatem interturbari velimus in ecclesia. Nam ipsum decorum et exemplum Christi postulat iubetque, non modo ne pueri aut mulieres sacris ministrent, sed ut aliquis praesit actioni coenae et symbola distribuat; quod equidem nemo iustius

10 faciet quam minister verbi una cum diaconis et senioribus ecclesiae viris. Sed tot tantaque omnibus ex aequo viris et mulieribus | impertiat, quantum ipse sumit. Nam quod sacerdos pontificius duntaxat sacrificet et pro aliis sacrificet omnibus, caeteri vero non sacrificent participando sacramentis, imo ne illa contingere quidem ausint, ea demum summa est impietas, impostura, temeritas atque schisma ecclesiae Christi indignissimum. Istud nos omnibus modis damnamus. Istud demum inter nos fieri nolumus. Item quod sacrificus pecunias de oblatione suscipit et pro mortuis sacrificat, caeteri vero pecunias conferunt et | participando sacramentis pro mortuis non immolant. Rursus quod sacrificus privata sacrataque veste ornatus veluti Leviticus aliquis pontifex in coetum prodit, pro se quaedam 20 eaque peregrina lingua immurmurat, gesticulationibus veluti ad chorum saltitat, ${ }^{696}$ denique et characteribus omnia incantatoris in morem circumscribit, ipse quoque utraque communicat specie, caeteri vero non item; id sane stolidum, puerile, ludicrum et impium est, nulla parte rei tam gravi respondens. Nihil enim tale videas in coena domini, nihil tale cernas ab apostolis esse traditum.

25 Nos ergo, qui apud Helvetios papisticae valediximus missae, melius et divinius quippiam et quod institutioni Christi propius et traditioni apostolicae conformius, imo ipsam domini institutionem in abrogatae missae locum substituimus. Nam initio quidem non quotidie, sed certis statutisque diebus eucharistiae sacra celebramus. ${ }^{697}$ Quotidie autem in coetum ad preces et audiendum verbum dei convenimus. ${ }^{698}$ Caeterum $^{699}$ cum denunciatis diebus ad illa eucharistiae sacra congregamur, de quibus Christus cum libertate quadam pronunciavit: »Quotiescunque feceritis, in mei memoriam facietis « [1Kor 11,25], ante omnia factis ad deum communibus votis et precibus ea, qua quisque a deo donatus est, gratia tradimus Christum pro nobis mortuum et oblatum esse. Eam oblationem unicam solam ad

695 Thom. Aqu. off. corp. 2,2 (STO VI 580): »Sic sacrificium istud [Christus] instituit, / cuius officium committi voluit / solis presbyteris, quibus sic congruit, / ut sumant et dent ceteris. $\ll$

696 Vgl. Erasm. adag. 1567 (ASD II/4 67,163f.): ») Extra chorum saltare<, dicitur qui dicit aut facit a re, quam proposuit, alienum aliquid.«
697 Zw. act. (Z IV 17,3-5): »Und dise ordnung werdend wir, so veer es unseren kilchen gefallen wirdt, vier mal im jar bruchen: zů ostren, pfingsten, herbst, wienacht.«

698 Vgl. AGZR, Nr. 866 [November 1525].

699 Zur folgenden Beschreibung der Zürcher Abendmahlsliturgie vgl. Zw. fid. exp. (Z VI/5 94-104). 
omnia mun|di peccata expianda satis esse. Hic itaque plebem in templo publico summa cum humilitate et attentione circumstantem provocamus ad sui et peccatorum agnitionem, provocamus ad fidendum deo tam benigno, provocamus item ad laudandum deum et gratias agendum liberationi per Christum. Addimus sacra symbola a Christo hoc nomine esse instituta. Ea non esse prophana signa, sed sacrosancta. Istis enim repraesentari verum corpus et sanguinem Christi, adeoque ipsa fidei conspectu coram cerni. Explicamus mortis et sacrificii Christi virtutem et modum, quomodo pro nobis fractus sit et sanguinem pro nobis fuderit, quomodo item haec praesentibus exprimantur symbolis et postremo quomodo Christus sese nobis totum impenderit. Hortamur ergo accedant, accedant autem fide purgati et charitate innocentiaque ornati, condonet itaque quisque proximo suo delictum in se atque sic coeant in unum corpus, spiritum et populum. Neminem enim separamus, neminem reiicimus nisi eum, quem sua in deum perfidia et incredulitas recedere et sacra nostra contemnere iussit. Istis vero ad hunc modum pro publica contione peroratis accedit minister verbi primus, qui eccle- 15 siae pastor est, diaconis concomitatus, honesta, sed vulgari veste indutus ad mensam, quae mundissimo lino tecta, canistris pane infermentato refertis et poculis vino plenis instructa adstat. Porro nullus hic auri splendor aut eboris lu|xus irradiat, omnia tenuia, sed tamen munda. Fidem, innocentiam et charitatem docemus esse vera religionis ornamenta. Auro autem non deum ornandum, sed 20 pauperibus subveniendum esse. Posteaquam vero communicaturi omnes sese in sua prope domini mensam receperint loca, mox praemissa ad deum oratione ea, quae nobis Germana lingua est, subiungit diaconus caput Ioan[nis] 6., quod clara voce praelegit ecclesiae, ut ex ipsis domini verbis discant, quid sit carnem Christi vere edere et sanguinem eius vere bibere. Deinde vero interiecta communi laude 25 dei praelegit alius diaconus cap[ut] 11. prioris ad Corin[thios], ut ex ipsa domini institutione populus intelligit, quid a domino institutum sit in coena et quare

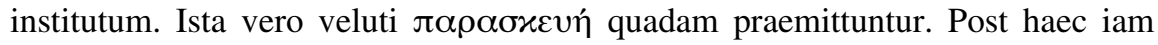
propius aggredimur rem. Nam et articulos fidei nostrae profitemur et peccata nostra deo confitemur, ipsum oramus, ut nostri misertus nos nostrasque preces 30 suscipiat, sibi uniat, fidem augeat, innocentiam tribuat et in vitae sanctimonia conservet. Hinc vero monet primus ille verbi minister, ut quisque apud se hoc negotii probe expendat, nihil ex hypocrisi faciat aut indigne, hoc est, sine fide Haec illa accedat, ne corporis et sanguinis domini reus fiat. Hic ergo omnes procumbunt in coena nostra. genua et ora|tionem dominicam quisque apud se tacite pastore praeeunte maxima animi devotione dicunt. Hac absoluta accipit pastor panem $\mid$ azymum in manus et spectante coramque audiente ecclesia, maxima gravitate et religione ac voce quam potest clarissima et distinctissima recitat verba coenae domini. Deinde vero panem iis, qui circum mensam astant ministris distribuit, qui cum summa suscipiunt reverentia et mox in calathis per totam circumferunt ecclesiam subse- 40 
quentibus aliis cum poculis, quae simili ut panem modo tradidit primus verbi minister diaconis et senioribus ad hoc in ecclesia destinatis viris. At ipse populus cibum potumque sacrosanctum expectans ipse in manus sumit, quod traditur a ministris, editque et proxime assidenti offert quisque partem eius, quod accepit; 5 itaque omnes de uno pane et uno poculo participant. Interim vero dum sic sacra sumunt mysteria, praelegit lector scripturae colloquium coenae, quod Ioannes aliquot absolvit capitibus, ordiens a pedum ablutione. ${ }^{700}$ Aliquousque autem legit, donec calathi crateresque redierint omnes. Tum enim tota in genua iterum procumbit ecclesia et agit gratias deo pro morte filii et peccatorum remissione; deinde vero se totam commendat deo. Sic, inquam, sanctum domini sacrificium in ecclesiis nostris, qui sumus Tiguri, Bernae, Basileae, Sanctogalli, Schaffhusii Sacrificium non Bielae, Mylhusii et multis aliis in locis nunquam cessat; sacrificium, inquam, Christi perpetuum, huius commemoratio, laus et gratiarumactio. Mentiuntur enim impudentissime, qui nos $\mid$ impietatis et prophanationis sacramentorum omnium15 que aliarum rerum sacrarum accusant. Nam prophanationem sanctarum rerum, missam, abrogavimus, sed in locum eius substituimus sacrosanctam domini coenam. Quod firmiter credamus neminem posse meliorem vel deo gratiorem ritum instituere, quam quem Christus dei filius instituit, apostoli vero eccelesiae dei ceu per manus tradiderunt, ecclesia autem ab apostolorum tempore plus quam quin20 gentis annis syncerum servavit. Quid autem nostra retulerit, quid visum sit Scholastico, ${ }^{701}$ Gregorio Magno, ${ }^{702}$ Adriano ${ }^{703}$ aliisque Romanae ecclesiae praesulibus? Non enim hominum discipuli sumus, sed Iesu Christi filii dei, a quo et »christiani« cognominamur. Sed haec per digressionem.

Porro cum ipse Paulus caussam sacrificii in brevem, ut vidimus, collegerit epilogum, non est ut actum agamus.

HiSCE VERO absolvimus et alteram huius epistolae partem, in qua opes et Epilogus. thesaurum religionis christianae aperuit Paulus, sacerdotium videlicet et sacrificium Christi. Unde iam didicimus in Christo omnem esse plenitudinem, sapien-

\section{Z. (11) Sanctogalli] Sangalli $Z F$}

700 Joh 13,1ff. Vgl. Zw. fid. exp. (Z VI/5 102,16$18)$.

701 Gemeint ist jener »Scholasticus«, den Gregor I. in einem seiner Briefe als Autor eines Gabengebets erwähnt, vgl. Greg. M. epist. 9,26 (CCSL CXLA 587,32): »[...] precem quam scolasticus composuerat $[\ldots] \ll$. Siehe auch Durant. rat. 4,47,3 (CCCM CXL 506,64).

702 Gregor I. der Große, Papst 590-604. Ihm zuzuschreiben sind zahlreiche Orationen, die im nach ihm benannten Sakramentar »Gregorianum « (ca. 630) enthalten sind, vgl. LThK ${ }^{3}$ VI 981; Stählin 1955, 43 f.
703 Hadrian I., Papst 772-795. Er ließ auf Bitten Karls des Großen ein Sakramentar (genannt »Gregorianum-Hadrianum «) anfertigen, das den römischen Ritus dokumentierte und $\mathrm{zu}$ dessen Verbreitung im Frankenreich beitrug, vgl. LThK ${ }^{3}$ IV 1133f.; VI 981. Vgl. auch Durant. rat. 5,2,5 (CCCM CXLA 15,213f.): »Adrianus papa concilium conuocauit ubi statutum est quod gregorianum deberet uniuersaliter obseruari.« 
tiam, iusticiam, redemptionem, resurrectionem et vitam, imo quicquid homini ad vitam vere beatam necesse est; ut nunc nihil amiserit, qui externum illum cultum in mundo dimisit, omnia vero possideat, qui Christum fide possideat, qui et in Ioan. 6[35]. evangelio dixit: »Ego sum panis vitae. Qui|venit ad me, non esuriet, et qui credit in me, non sitiet unquam.«Prudentissime itaque feceris, christiane lector, si evangelicum imitatus mercatorem omnem tuam vendideris substantiam atque hunc thesaurum emeris ${ }^{704}$, quo solo foelix esse possis. Verum audi, obsecro, ipsum quoque Paulum te huc maximo orationis robore trahentem. Huc enim pertinent sequentia.

Tertia epistolae pars.

Scopus. Quae enim superest pars tertia et ultima, in hoc tota est, ut Hebraeis primum, deinde toti orbi persuadeat Christum verum deum et hominem, sacerdotem et victimam suscipiant, huic se uni totos dedicent, ab hoc non deficiant, sed per fidem in patientia omnia adversa vincant. Neque enim satis est cognovisse Iesum esse Messiam, nisi uni solique omnibus neglectis adhaereamus. Nam $\gg$ sine tali 15 fide impossibile est quenquam placere deo« [Hebr 11,6]. Fides vero, nisi patientiam et constantiam habeat, opinio est. Hinc fit, ut apostolus de his quoque disserat, qui superioribus sic infert.

19 Cum itaque, fratres, habeamus libertatem introeundi in sancta per sanguinem Iesu 20 ea via, quam dedicavit nobis recentem ac viventem per velamentum, hoc est per carnem suam, 21 cumque habeamus sacerdotem | magnum, praefectum domui dei,

Longum est hyperbaton, ${ }^{705}$ vix enim post adscripta verba sequenti absolvitur sententia. Sensus tamen expositus est. Id enim voluit Paulus: »Cum ergo per Christum, qui factus est nobis a deo mediator, sacerdos et sacrificium, via ad 25 coelos aperta sit, age, Christo fidamus, ut per eum coelos ingredi liceat.« Haec omnium summa est, sed Paulus mira copia et per enumerationem quandam singula diducit expolitque. Porro cum dicit nos habere libertatem, copiam et facultatem ingrediendi ad sancta, nimirum ad illud, quod in 9. cap[ite] audivimus, ${ }^{706}$ respexit priore adhuc consistente tabernaculo nondum patefactam esse 30 sanctorum viam. Praesentia itaque illis opponere voluit. Nam morte, sacrificio et sanguine Christi prius illud tabernaculum dirutum est, ergo et via ad sancta aperta

Z. (1) iusticiam] iustitiam $Z F-(7)$ foelix] felix $Z F$

704 Mt 13,44.
705 Siehe oben S. 19, Anm. 95.

706 Hebr 9,2. 
est. »Recens« itaque dicitur ac »vivens«. »Recens« quidem respectu illius, quod plerique hactenus putarunt sacrificiis, ceremoniis et externis ritibus patere ad coelos viam. »Vivens « vero, quod nunc per Christum filium dei vivi aditum ad vitam vere apertum esse credamus. Nam et in evangelio ipse dixit dominus: »Ego

5 sum via, veritas et vita; nemo venit ad patrem nisi per me « [Joh 14,6]. Si vero haec est illa recta, vera et certa ad coelos via, iam sponte sequitur neque per monastica vota neque per sacrificia neque per ulla alia media perveniri ad regnum dei. Nam si | alia patet aditus, sane Christus vel frustra mortuus est vel non solus via est. Caeterum ipsam carnem Christi merito vocavit velamentum. Suscepta enim in coelos carne Christi mox apparuerunt coelestia. Unde ipse etiam in evangelio dixerat: »Expedit vobis, ut ego vadam « [Joh 16,7]. Et Paulus: »Etiamsi cognovimus Christum secundum carnem, nunc tamen non amplius novimus« [2Kor 5,16]. Sed de sacerdotio Christi et domo dei, quae hic per repetitionem innovantur, satis dictum in superioribus.

22 accedamus cum vero corde in certitudine fidei cordibus a mala conscientia purgatis, abluti item corpore aqua munda. 23 Teneamus confessionem spei non vacillantem,

Hisce iam absolvitur hyperbaton, ${ }^{707}$ sed ipsa oratio prorsus est metaphorica. Nam Fides. animo accedimus deum, non pedibus. Animus autem debet esse syncerus et minime fucatus. Nihil enim perinde odit deus atque hypocrisim. ${ }^{708} \mathrm{Nam}$ ut deus verus est, ita veritatem amat. Certitudinem autem fidei posuit pro certa et persuasa fide, qua purgantur corda et conscientiae hominum. Non equidem baptis- Ioan. 4[,42]. matis variis, quibus se indies abluebant Hebraei, sed fide, quod et Petrus censuit in Act[is], cap[ite] $15 .^{709}$ Interim Paulus orationem sic vestivit figuris, ut externis Ephe. 5[,25f.] purificationem tribuisse videatur, quibus tamen nihil tribuit. Externis enim peTitum 3[,7]. netrare voluit ad interiora et endiadi ${ }^{710}$ quadam de una fide lo|qui, quasi de variis lustrandi disserat generibus. Interim nihil aliud dicere voluit quam hoc: si quis magnifecerit Iudaicos purgandi ritus eosque minime putarit deserendos, is sciat non elementis, sed fide purgari corda hominum. Fidem ergo si quis habeat, veram 30 purgationem habeat necesse est. Ideoque teneamus posthac confessionem spei non vacillantem, id est firmam, immobilem et non »huc atque illuc nutantem «; ${ }^{711}$ confessionem, inquam, spei, hoc est veram illam religionem de Christo, qui est spes nostra, baptismus fidelium et expiatio, 1. Petri 3[,15.18.21].

Z. (31) vacillantem] facillantem $F$

707 Siehe oben S. 19, Anm. 95.

708 Mt 15,7-11 par.

710 Siehe oben S. 83, Anm. 453.

709 Apg 15,9.

711 Erasm. Hebr. (ASD VI/10 334,277). 
23 fidelis enim est, qui promisit.

Veritate dei, argumento ab authoritate ducto monet, ut deo per Christum fidant. Promptius autem ad ea rapimur, quae certa et indubitata esse scimus. Sed de veritate dei dixi in $6 .{ }^{712}$

24 Et consyderemus nos invicem in hoc, ut provocemus ad charitatem et

bona opera, 25 non deserentes congregationem nostri mutuam, sicuti mos est nonnullis, sed adhortantes invicem

Concordia. Iam veluti ex obliquo agit argumenta. Nihil enim est, quod fidei perinde adversum sit atque discordia et contentio. Ut ergo fidei robur adderet, ad charitatem etiam vocat. »Charitas enim longanimis et benigna est, charitas non est praefracta, 10 inflata vel fastidiosa « [1Kor 13,4]. Ubi ergo charitas, ibi spes est fore, ut fides subinde gli|scat, quisque item monentem audiat, ab errore resiliat melioraque tradenti obediat. Ubi vero charitas non est, ibi fastus, pro|tervia et pertinatia est. Ubi vero pertinatia, ibi dissidiorum materia inexhausta, sectae, defectio et odium veritatis, quibus omnibus illi maxime apud Hebraeos flagrabant, qui patriis ad- 15 dicti ceremoniis, ecclesiam una cum evangelica veritate malebant deserere, quam quicquam a concepta opinione cedere. Talia prorsus hominum capita, qualia plurima habent infoelicia nostra tempora, quibus adeo sordet vera pietas et germana simplicitas, ut centies malint omnia in ecclesia misceri, quam purae veritati gloriam dare. Porro de charitatis operibus, quae vere bona opera sunt, qui plura 20 velit, legat priorem Pauli ad Corinth[ios] et illam praeclaram Ioannis apostoli epistolam. ${ }^{713}$ Nos quaedam in 6 . annotavimus. ${ }^{714}$

25 idque hoc magis, quod videtis appropinquantem diem.

Argumentatur a tempore, sicut ad Rom[anos] 13.: »Tempestivum est nos a somno expergisci. Nunc enim propius est nobis salus« [Röm 13,11] etc. Ita hoc loco: 25 »Quo propius«, inquit, »cernitis approperare fatalem horam, hoc promptius debebatis fide amplecti Christum.«Usurpat enim scriptura diem illum non modo pro extremo iudicio, sed pro fatali cuiusvis hominis hora. ${ }^{715}$ Haec vero hactenus ad omnes initiatos fide, fideles, firmiores et infirmiores.

Z. (4) 6.] sexto $Z F$ - (5) consyderemus] consideremus $Z F$ - (13) pertinatia] pertinacia $Z F$ - (14) pertinatia] pertinacia $Z F$ - (18) infoelicia] infelicia $Z F$ - (21) Corinth[ios]] Corinthios $Z F$ - (22) 6.] sexto $Z F$ - (24) Rom[anos]] Roma[nos] $Z F$

712 Siehe oben S. 86.

713 1Kor 13; 1Joh 2,7-11.
714 Siehe oben S. 84f.

715 Vgl. 2Tim 4,8; Bull. adv. cat. 41v-42r. 
| 26 Nam si volentes peccaverimus post acceptam cognitionem veritatis, nulla alia pro peccatis restat hostia, 27 sed formidabilis quaedam expectatio iudicii et zelus ignis, qui devorabit adversarios.

Nunc vero illis, de quibus modo coeperat, desertoribus et transfugis ecclesiae 5 minatur, ut et hos revocet et in fide officioque contineat. Ducit autem argumentum a suppliciis eaque omnibus amplificat modis. Interea vero sciendum eos voluntarie peccare, qui non ex infirmitate quadam peccant carnisve succumbunt Voluntarie cupiditatibus, sed qui destinata malitia veritatem in mendacio detinent: nempe qui probe norunt, quod nulla alia in orbe possit esse hostia pro peccatis quam unica 10 Christi, interim vero se isti unicae adeo non committunt, ut magis aspernentur, itaque in contemptu dei impie vivendo pergunt. Iam vero cum non sit alia, nisi una pro peccatis hostia, illi autem hanc unicam contemnant, certe aliam non invenient ullam. Petrus enim roganti domino, an et ipse una cum caeteris a se deficere velit, respondit: »Domine, ad quem ibimus? Verba vitae aeternae habes Ioan. 6[,68f.]. et nos credimus et cognovimus, quod tu es Christus filius dei vivi.« Talibus ergo contemptoribus nihil aliud restat quam formidabilis expectatio iudicii, id est vindictae et damnationis, quae est ignis et vehemens et perpetua in impios saevitia. De qua et in proph[etis] $]^{716}$ et in Paulo, 2. Thes. 1[,7-9].| Hic sane igni per prosopopoeiam tribuit zelum. ${ }^{717}$ Prosopopoeia autem inanimatae rei tribuit, quod 20 revera sensatae erat. ${ }^{718}$

28 Qui violarit legem Mosi, absque misericordia sub duobus aut tribus moritur testibus. 29 Quanto putatis peioribus afficietur suppliciis, qui filium dei conculcarit et sanguinem testamenti ceu prophanum habuerit, per quem fuerat sanctificatus, et spiritum gratiae contumelia affecerit?

25 Comparatione, quae amplificandi ratio est, effert mulctam contemptorum Christi, hoc est voluntarie peccantium, ac dicit: »Si absque ulla miseratione plectitur is, qui violatae legis iusto statutoque convincitur testimonio, quibus, oro, suppliciis Deut. 17[,6]. dignus is esse censebitur, qui non Mosen aliquem, sed ipsum dei filium conculcarit? « Atque hic denuo utitur ea hyperocha, ${ }^{719}$ qua usus est etiam in cap[ite] $6 .{ }^{720}$ 30 Quae enim conculcamus, ea nullius momenti esse ducimus. Conculcant itaque

Z. (7) succumbunt] succunbunt $Z F-(18) \operatorname{proph}[$ etis]] prophetis $Z F$

716 Jes 66,15 .

717 Vgl. Bull. vorl. Hebr. [10,27] (Berg/Hausammann 212): »Und das die sach an ir selbs wurde dister grusammer, gipt er per exaggerationem dem füw yfer zů, wie wol es ouch ist prosopopoeia.«
718 Vgl. Quint. inst. 9,2,29-37 (Winterbottom II 494-496).

719 Siehe oben S. 63, Anm. 345.

${ }^{720}$ Hebr 6,4-6. Siehe oben S. 81-83. 
Christum, qui non in delitiis et inter suprema bona precium redemptionis habent, qui sanguinem Christi effusum non secus aestimant, quam si prophanus sit, hoc est, nullius privatae et singularis potentiae sit nihilque distet a communi victimarum sanguine, qui saepius effusus ne tum quidem efficit quicquam. Aliud enim sacratiusque de morte Christi sentiendum, nempe quod semel facta, | semper satis sit ad diluenda omnia hominum peccata. »Sanctificatus « autem dixit pro »sanctifi|candus « $\varkappa \alpha \tau$ ' $\dot{\tau} \tau \dot{\varepsilon} \rho \omega \sigma \iota$. Porro spiritus gratiae est vis divinae bonitatis, quae se in Christo, fidelium maximo bono, infidelium autem maximo detrimento, exeruit. Est enim illis in resurrectionem, his vero in ruinam. Quo enim strenuius omnis gloria uni Christo tribuenda praedicatione evangelica traditur, hoc impu- 10 dentius irritatiorique mente illi redemptionis vim convitiis incessunt suasque ceremonias statuunt.

30 Novimus enim eum, qui dixit: meum est ulcisci, ego rependam, dicit dominus. Et iterum: dominus iudicabit populum suum. 31 Horrendum est incidere in manus dei viventis.

Vindicta. Duplici sententia ex scripturis petita ostendit, quanta istos maneant supplicia, qui et ipsum Christum contemnunt et Christi studiosos veritatis gratia persequuntur. Producit autem istas terrifica praemunitione ac dicit: »Novimus eum, qui dixit«, quod locutionus genus id prorsus pollet, quod Germanis: Wir sôltend dennocht nun dalyme den kennen, cum de eo loquuntur, qui aliquot vindictis 20 ac facinoribus nomen suum orbi terrificum fecit. Utraque autem petita est ex Deut[eronomii] 32. cap[ite]. ${ }^{721}$ Sed in posteriore posuit »iudicare« pro »vindicare «. Et utranque pulcherrimo absolvit epiphone|mate, ${ }^{722}$ horrendum videlicet esse incidere in manus ac vindictam dei. Nam vere admodum dicit Chrysostomus, etiamsi hostes dei nunc quidem non recipiant poenam, postea tamen recepturos, 25 cum deus semper vivat. Pios ergo in manus duntaxat hominum incidere, impios vero in manus dei. ${ }^{723}$ Vide Matth[aeum] in $10 .{ }^{724}$

32 Hic vero memores estote superiorum dierum, in quibus illuminati ingens certamen sustinuistis afflictionum: 33 partim quidem dum et probris et pressuris affecti spectaculo fuistis omnibus, partim dum consortes ita conversantium facti estis.

Z. (1) delitiis] deliciis $Z F$ - (1) precium] pretium $Z F$ - (27) Matth[aeum]] Matthaeum $Z F$

721 Dtn 32,35f.

722 Siehe oben S. 57, Anm. 323.

723 Chrys. Hebr. transl. 123: "proinde at si nunc non recipiunt, postea recepturi sunt; illos opor- tere congemiscere, non nos. Non enim in illorum incidimus manus, illi autem in manus dei.«

724 Mt 10,17-22. 
Hactenus contemptores a perfidia, poenis et suppliciis deterruit, sed et eos ad Afflictio. fidem vocavit, qui in bivio constituti, deliberabant Christine an Mosis sequerentur castra, hoc est, Christumne unicam reciperent hostiam, an Leviticis haerere pergerent. Nunc vero apostropha quadam convertitur ad fideles, qui sese totos 5 Christo dedicarant domino reliquis omnibus longo intervallo post tergum relictis, cuius rei gratia mire tum quidem ab impiis torquebantur. Hos autem hortatur, ut in fide persistant per patientiam. Et ita $a b$ anteactis hortatur, ut Vergilianus Aeneas adflictos alloquebatur socios:

$\mathrm{O}$ socii (neque enim ignari sumus ante malorum),

o passi graviora, dabit deus his quoque finem. ${ }^{725}$

Ita Paulus quoque censet eam, quae brevis supersit, mo|lestiam nunc quoque esse vorandam, cum tot tantaque hactenus superarint pericula. Ea autem in genere primo proponit et macrologia quadam Hebraica dicit: »Ingens certamen sustinuistis afflictionum «, id est: »Multa perpessi estis mala.« Deinde vero ea mala partitione quadam recenset: »Siquidem partim gravia quaedam in proprio«, inquit, »perpessi estis corpore, nempe maledictis et convitiis adobruti et variis pressuris adflicti, adeo ut et spectaculo fueritis omnibus.« Fiunt autem spectaculum, qui in theatrum forumque ceu facinorosi capiteque plectendi producuntur; itaque ludibrium et fabula vulgi fiunt. »Partim vero sensu alieni mali afflicti estis.

20 Nam consortes facti estis eorum, qui propter Christum affliguntur.« Solet autem sensus alieni mali nonnunquam pios vehementius excruciare quam domestici infortunii dolor. Iam sequitur praecedentium expositio sive expolitio:

\section{Siquidem et afflictionum, quae ex vinculis meis contigerunt, participes fuistis}

25 Hoc enim exponit posterius proximiusve partitionis membrum. Et de vinculis quidem Pauli plura in postremis Actuum capitibus, in epist[olis] item ad Ephe[sios], Philip[penses] et post[eriore] ad Tim[otheum]. ${ }^{726}$ Non poterant autem inter Hebraeos compati Paulo, nisi religiosissimi quique. vos habere in vobis potiorem substantiam in coelis ac manentem. probris, sed pressuris etiam esse affectos; ${ }^{727}$ nunc enim exponit, quae nam illae fuerint pressurae, nempe direptio facultatum. Quibus et illud consolationis gratia 
adiecit: »Scientes vos habere meliorem et permanentiorem in coelestibus thesaurum.« De quo etiam Christus, Matth. 6[,19-21]. Nullam ergo iacturam fecit, qui amissione temporalium aeterna acquisivit. Ad lucem horum plurimum ea faciunt, quae idem apostolus de hac eadem persecutione ad Thessal[onicenses] hisce verbis scripsit: »Vos, fratres, imitatores facti estis ecclesiarum dei, quae sunt in Iudaea in Christo Iesu, quod eadem passi sitis et vos a propriis contribulibus, quemadmodum et ipsi nos a Iudaeis. Qui, ut et dominum occiderunt Iesum et proprios prophetas, ita et nos persecuti sunt et deo non placent et omnibus hominibus adversantur« etc., 1. Thes. 2[,14f.]. Haec autem omnia studiosissime vobis commendo, fratres charissimi, qui per Germaniam et Gallias impiorum tyrannide oppressi, convitiis adobruti et patriis tandem sedibus pulsi, hoc tantum nomine patimini, quod unico Christi sacerdotio et sacrificio nitimini, missam vero, idola, divorum cultum et papisticam religionem abnegastis. Vobis, inquam, volo haec Paulina esse commendatissima. Vobis illud idem ingemino, quod Paulus Hebraeis suis:

| 35 Ne abieceritis igitur fiduciam vestram, quae magnam habet praemii retributionem.

Istis enim nunc absolvitur sensus, et explicatur, quorsum haec pertineant, quae de afflictione dixit, nempe ut in fide perstent et omnia reliqua adversa fide frangere pergant, quandoquidem tantum malorum agmen irruperint. Pergant autem 20 $\pi \alpha \rho \rho \eta \sigma i \alpha$, hoc est libertate credendi, dicendi et agendi. Est enim fides christiana $\pi \alpha \rho \rho \eta \sigma i \alpha$ quaedam admodum laeta, alacris et libera. Addit calcar: ${ }^{728} \gg$ Nam haec habet magnam praemii recompensationem.« Nam et ipse Christus Matth[aei] 5.: »Beati estis«, inquit, »cum insectati vos fuerint homines et dixerint omne malum adversus vos mentientes, propter me. Gaudete et exultate, quoniam merces vestra 25 multa est in coelis « [Mt 5,11f.]. Et apud Marcum in 8.: »Quisquis perdiderit animam suam«, ait, »caussa mea et evangelii, hic servabit eam« [Mk 8,35]. Similia invenias et in 10 . cap[ite] et apud Ioan[nem] in 12 . et $16 .^{729}$

36 Nam patientia vobis est opus, ut, ubi voluntatem dei peregeritis, reportetis promissionem.

Subsidium fidei est patientia, de qua apud Lucam dominus: »Per patientiam vestram possidete animas vestras « [Lk 21,19]. Et alibi legimus: »Nemini confertur corona, nisi legitime certaverit« [2Tim 2,5]. Sed de his copiosius in 12. cap[ite]. ${ }^{730}$

Z. (5) imitatores] immitatores $F$ - (9) 1.] 2. ZF-(16) fiduciam] fidutiam ZF

728 Siehe oben S. 18, Anm. 91.

729 Mk 10,29f.; Joh 12,24-26; 16,33. 
37 Adhuc enim perpusillum temporis et, | qui venturus est, veniet et non tardabit. 38 Iustus autem fide vivet et, si se subduxerit, non probabitur animo meo.

Quae dixerat de fide et patientia, nunc confirmat prophetico testimonio, quod 5 sumpsit ex Abacuk, cap[ite] 2. ${ }^{731}$ Est autem sensus: aliquousque durandum esse in adversitatibus. Brevi enim certoque affuturum redemptorem, interea vero fide praestolandum esse. Fidem enim vitam esse fidelium, victoriam mundi et unicum animae in adversis remedium. A qua si qui per desperationem in cruce defecerint, eos demum prorsus displicere deo. Nam »sine fide impossibile est quenquam 10 placere deo $\ll$ [Hebr 11,6].

39 At nos non sumus, qui subducamus nos in perditionem, sed ad fidem pertinemus in acquisitionem animae.

Mitigatio est superiorum. Verum absit, ait, ut nos ab ea fide deficiamus, quam didicimus veram esse et salutiferam. Atque hinc iam progreditur ad fidei prae15 conium.

1 Est autem fides sperandarum rerum substantia, argumentum eorum, CAP. XI. quae non videntur. exordio mundi sancti patres deum coluerint eaque deo placuerint, mundum item

20 fide vicerint, fide quoque iustificati sint. Fidem er|go verum esse cultum, veram religionem et iusticiam. Id quod infinitis demonstrat exemplis, a primo homine iusto usque ad ipsa pene tempora Christi repetitis. Quibus interim omnibus haec duo maxime videtur spectasse. Primum: quandoquidem summa religionis christianae in unicam (ut audivimus) fidem innitebatur, istis nimirum voluit virtutem fidei commendatiorem facere eosque ad fidem maiorum exemplis trahere, quos hactenus rationibus evincere non potuit. Secundum: cum christiani fidei nomine multis afficerentur malis, ipsos haud dubie praesentibus confirmare voluit, ut intrepide in eo pergerent itinere per fidem et patientiam, quo videant omnes ab exordio mundi sanctos ad coelestia contendisse. Huc enim post multam tandem expositionem defertur, ut in 12. cap[ite] inferat: »Proinde nos quoque cum tanta « [Hebr 12,1] etc. Potuit et illud spectasse Paulus, quod Hebraei pro ceremoniis suis (ut et nostri) subinde allegabant patres et fidem veterem, quorum opinionem stultam et falsam hisce voluerit confutare, e diverso autem evangelicam fidem, 
quam illi ceu novam aspernabantur, exemplis fideque patrum propugnare. Ut Oratio Stephani, idem pene argumenti hic tractarit Paulus, quod Stephanus in Actis, qui satis Acto. 7. prolixa oratione Iudaeis exempla cum fidei tum ceremoniarum proponit, quibus probat, quod fides ante latam legem et a lege promulgata, non ceremoniae, a deo praecepta quaesitaque sit. Est autem ea oratio Stephani admodum elegans, ardens prorsusque absoluta. Id quod satis subiuncta convincit catastrophe: ${ }^{732} \gg$ Duri cervice et incircum[cisi] « [Apg 7,51] etc. Haec autem hactenus per exemplum de consilio apostoli; nunc de eo commentabimur, quid sit fides.

»Fides«, inquit, »est substantia rerum sperandarum.« Quo quid poterat dici brevius? Quid argutius et exactius? Essentialis enim finitio est constans (si illud forsan quis requirat) genere et differentia. ${ }^{733}$ »Substantia« enim genus est, »res sperandae« differentia. Quod autem protinus sequitur, »argumentum eorum, quae non videntur«, per interpretationem subiicitur; substantia videlicet significari argumentum et sperandas res res esse invisibiles. De quibus nos sigillatim ista

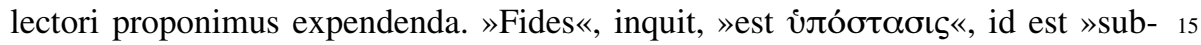

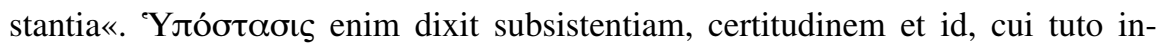
nitimur et infallibiliter fulcimur. ${ }^{734}$ Sunt qui expectationem exposuerunt. ${ }^{735} \mathrm{Hel}-$ vetii certe diceremus: Der gloub ist ein sicher, gw üß, bestăndig unnd wåsenlich vertruwen. Nunc enim per interpretationem sequitur: »Fides est argumentum «, है $\lambda \varepsilon \gamma \chi 0 \varsigma$ enim »argumentum« est. Non equidem tale, quale finivit 20 Fabius, argumentum esse $»$ rem, quae alterius probationi adhibeatur $«{ }^{736}$ sed argumentum certum inditium est, experimentum et cognitio $\mid$ certa, et adeo certa, ut de cogniti natura nihil prorsus dubitemus, quippe ipsa veritate sic convicti, ut nihil supersit, quod impediat, ein eygenlichs wüssen und gruntlichs ergryffen. 'E $\lambda \varepsilon \dot{\gamma} \chi \varepsilon\llcorner\nu$ enim est convincere et caussam aliquam sic protrahere, ut 25 reo nihil supersit, quo se tueatur. Sic enim ipse Christus hoc verbo usus est de

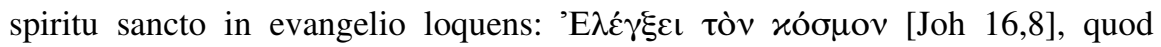
Latinus vertit: »Arguet mundum $«{ }^{737}$ hoc est, protrahet in lucem et evincet. Et in

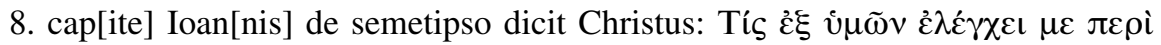

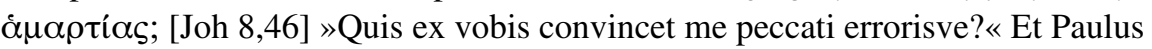

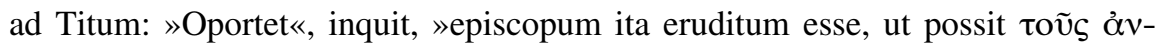
$\tau \iota \lambda \dot{\varepsilon} \gamma o v \tau \alpha \varsigma \dot{\varepsilon} \lambda \dot{\varepsilon} \gamma \chi \varepsilon \iota{ } \ll$ [Tit 1,9], id est, contradicentes convincere. Rectissime

Z. (22) inditium] indicium $Z F$ - (30) Marg. vberzügen] überzügen $Z F$

732 Siehe oben S. 85, Anm. 465.

733 Petr. Hisp. tract. 2,13 (De Rijk 21,23f.): »Diffinitio enim debet esse ex genere et differentiis.« Vgl. Arist. top. 6,4, 141b 25-28 (Ross 122).

734 Erasm. Hebr. (ASD VI/10 342,361f.): »'Yлó-

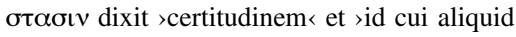
innititur et fulcitur $\ltimes$ «
735 Vgl. Mel. loc. (Engelland/Stupperich 116,2022): »Principio fidem sic definit: >Fides est sperandarum rerum hypostasis $<$, id est, exspectatio, certitudo non apparentium. «

736 Quint. inst. 5,14,1 (Winterbottom I 306,16f.).

737 Erasm. Joh. transl. (ASD VI/2 168). 
ergo Chrysostomi interpres, ${ }^{738}$ quod nos argumentum, ipse convictionem vertit. ${ }^{739}$ Ipseque Chrysostomus commode: »O quam mirabili«, inquit, »verbo usus est, dicens: >Convictio eorum, quae non videntur<. Convictio enim est in rebus admodum manifestis; fides igitur visio est non apparentium. Caeterum ad eam 5 satisfactionem ducit, ad quam inducunt ea, quae coram videntur. ${ }^{740}$ Haec ille. Est itaque fides non vulgaris quaedam cognitio, qua expositioni aut argumentationi alicui fidem damus credimusque, sed substantialis quaedam fiducia et cognitio est, hoc est firma, certa, persuasa et indubitata, cui innitimur et tu|to fulcimur, quae et vitalis et salutaris est. Istis autem excludimus omnem credulitatem et opinionem, ut hic non nisi constantissima et compertissima divinaque sint omnia, quorum vi etiam vivemus et conservabimur. Huc enim pertinent iam ea, quae diximus de ancora in cap[ite] $6 .{ }^{741}$ et quae audivimus in 10 . de confessione spei non vacillante, ${ }^{742}$ et quod ibidem dixit: | Accedamus $\dot{\varepsilon} v \pi \lambda \eta \rho \circ \varphi \circ \rho i \alpha$ $\pi i \sigma \tau \varepsilon \omega \omega_{\varsigma}$ « [Hebr 10,22], id est in certitudine fidei, hoc est per indubitatam fidem. 15 Nam $\pi \lambda \eta \rho о ф о \rho о \tilde{u} \mu \alpha$ est plenissime et compertissime rem scire; ${ }^{743}$ unde

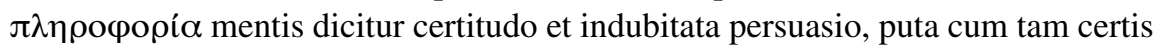
argumentis fides facta est, ut nihil amplius desideremus. ${ }^{744}$ Verum in ipso nunc Paulo audiemus, qualis sit ea animi certitudo et cui innitatur. Sequitur enim: »Fides est substantia rerum sperandarum. «Igitur fides non est quarumvis rerum, sed sperandarum. Videndum ergo, quid intellexerit per res sperandas. Utique invisibiles. Nam posteriori membro mox per interpretationem sequitur: »Fides est argumentum eorum, quae non videntur. «Sed hoc aeque obscurum est atque illud. Nam si fides omnium earum rerum est, quae non videntur, iam ex quolibet fiet quodlibet $^{745}$ ipseque lapidem praebebo et aurum me praebuisse asseram. Id si negaveris probabo: »Credas oportet et aurum erit! Nam etsi coram lapidis cernas speciem, fidei tamen virtute aurum latitat, ut nunc lapis aurum sit; fides enim est rerum invisibilium.« At $\mid$ quis tam stupidus, qui stropham non sentiat? Aliud itaque intellexit Paulus, nimirum per invisibilia periphrasi quadam significans aeterna et divina, adeoque ipsum deum, qui est invisibilis, verus, bonus, sapiens, omnipotens et $»$ Schaddai $\ll,{ }^{746}$ in quo res nostrae consistunt et in quo omnis fortuna, expectatio et spes nostra sita est. Nam in hoc ipso cap[ite] mox sequetur:

\section{Z. (7) fiducia] fidutia $Z F$}

738 Mucianus (6. Jh.), genannt »Scholasticus«, Freund des Cassiodor (vgl. NP II 1004-1007) und in dessen Auftrag Übersetzer der Kommentare Chrysostomos' zum Hebräerbrief sowie zur Apostelgeschichte ins Lateinische, vgl. PRE XVI/1 411.

739 Chrys. Hebr. transl. 126; 128.

740 Chrys. Hebr. transl. 126.

741 Hebr 6,19.

742 Hebr 10,23.

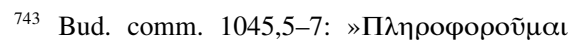
etiam dicitur pro eo, quod est >compertum habeo $<$ et >certissime novi<.«

744 Erasm. Hebr. (ASD VI/10 304,933f.): »Nam $\pi \lambda \eta \rho о \varphi о \rho i ́ \alpha$ dicitur, cum certissimis argumentis rei cuiuspiam fit fides. «

745 Vgl. Arist. phys. 1,5, 188a 33f. (Ross ebd.):

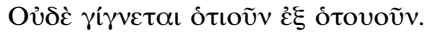

746 Gen 17,1 .
Fides est rerum sperandarum et
invisibilium. 
»Per fidem reliquit Moses Aegyptum, nihil veritus ferotiam regis, perinde enim, quasi vidisset eum, qui est invisibilis, ita obduravit« [Hebr 11,27]. En, habes in hoc clarissimum exemplum, quid sit fides et quae illa invisibilia. Item ad Romanos 1.: »Illud«, inquit, »quod de deo cognosci potest, gentibus manifestavit deus. Siquidem invisibilia illius, IPSA, inquam, aeterna eius potentia et divinitas, 5 cum ex creatione mundi tum ex actis operibusve eius intelliguntur « [Röm 1,19f.]. Proinde illa invisibilia, in quae innititur fides, aeterna sunt, adeoque ipse deus est, qui fidei obiectum est. Nam fides vera in nullam rem visibilem et corpoream innititur, sed in unicum deum, qui est spes nostra (1. Tim. 1[,1]., Hebr. 6[,1719].), qui bonorum copiae cornu est, salus et vita fidelium. Rectissime ergo dixit Paulus fidem non esse assensum aut credulitatem quarumvis rerum, sed substantiam rerum sperandarum et invisibilium. Nam ad Rom[anos] 8. adhuc clarius dicit apostolus: »Spe servati sumus; porro si spes videatur, non est spes. Quod enim quis cernit, cur idem speret? « [Röm 8,24] Quae ergo sperantur, non sunt praesen|tia, sed futura et aeterna. Apostolus enim »videre« pro ipso sensu posuit, quo sen- 15 sibus corporeis corporaliter rem experimur, et »spem « in secundo membro pro ipsa re posuit, quae speratur. Ut sit sensus: »Certa quidem salus est, quae per Christum parta est, sed spe nobis in hac vita expectanda. Si enim id iam adesset, quod speramus, quomodo rem praesentem sperare expectareve possemus? Spes itaque est expectatio vitae melioris et futurae. Et proinde res sperandae hoc quoque loco spirituales sunt, aeternae et futurae. Ut nunc ipsa fides non nitatur rebus visibilibus et corporeis, sed invisibilibus et futuris, aeternis ac divinis, hoc est ipsi deo omnium bonorum thesauro absolutissimo, qui nullis corporalibus percipitur sensibus, sed solo spiritu solaque mente et anima.« Ex quibus etiam discimus, cur Christus subinde dixerit apud Ioannem: »Qui credit in me, non 25 Christum. credit in me, sed in eum, qui misit me« [Joh 12,44]. Nam pura caro Christi non est obiectum fidei nostrae, sed gratiae pignus et declaratio divinae bonitatis et iusticiae. Ipse vero Christus, quatenus unus est cum patre, deus verus, salus nostra et fidei nostrae obiectum est. Ut nunc in Iesum Christum non ut hominem purum, sed etiam deum verum credamus, qui carnem humanam sibi propter redemptionis expiationisque dispensationem inseparabiliter copulavit, adeo ut, nisi verus deus et homo esset, salus et redemptio nostra esse non posset. | Nisi enim deus fuisset, neque salvare neque fidei obiectum esse potuisset. Nisi vero homo fuisset, nihil habuisset, quod pro satisfactione peccatorum nostrorum offerre potuisset. Istis denique illorum dogma dissolvitur, qui huius fidei finitionis falsa intelligentia 35 delusi docent verum et naturale corpus Christi fidei virtute carnaliter et corporaliter et tamen ineffabiliter in pane manducari. ${ }^{747} \mathrm{Sed}$ haec obiter.

Z. (1) ferotiam] ferociam $Z F$ - (3-4) Romanos] Rom[anos] $Z F$ - (28) iusticiae] iustitiae $Z F$ - (31) inseparabiliter] inseperabiliter $F$

747 Vgl. Petr. Lomb. sent. 4,10,4f. (Grottaferrata II 291f.). 
Caeterum cum ista sic habeant, consequitur hunc esse huius finitionis genuinum sensum: fides est constantissima mentis certitudo, quae in eas res innititur, vide. in quas omnis spes nostra dirigitur, nempe certissima cognitio rerum invisibilium et aeternarum, id est salutaris expectatio deprehensioque salutis et vere beati dei, 5 qui omnis boni fons inexhaustus est. | Talis autem fides non est ex carne et sanguine, sed ex solo deo, ${ }^{748}$ qui spiritu suo sancto et verbo scripturae divinae, nostras transformat et illuminat mentes, ut prorsus divina quadam metamorphosi transformati, ${ }^{749}$ alii prorsus homines simus, toti nunc ab hoc uno deo pendeamus, omnia ab hoc uno petamus, unicum colamus, omnia prae eo contemnamus. Breviter: haec fides facit, ut totos nos ad dei tam sancti, iusti et boni voluntatem componamus, nuspiam ab eo deficiamus. Nam Paulus: »In omnibus«, inquit, »superamus per eum, qui dilexit nos. Certus enim sum, quod neque mors, neque vita, neque principa|tus, neque potestates, neque instantia, neque futura, neque ulla creatura alia poterit nos separare a dilectione dei, quae est in Christo Iesu 15 domino nostro« [Röm 8,37-39]. Haec ergo illa vera sanctorum hominum dei fides est, de qua plurima nunc producet exempla, quibus tamen duo quaedam praemittit. Primum:

\section{Per hanc enim testimonium meruerunt veteres.}

Haec veluti summa omnium est. »Hac fide«, ait, »placuerunt veteres sancti deo.« Fides vera

20 Nam testimonium mereri posuit pro placere et probari deo. Fide ergo servierunt religio. deo, fide coram deo iustificati sunt et proinde in fide consistit vera religio. Secundum:

\section{Fide intelligimus condita esse saecula verbo dei et quod ex non ap- parentibus ea facta sint, quae nunc videmus.}

25 Multo quidem labore (ut in Placitis Plutarchi, ${ }^{750}$ Aristotile De coelo et mundo, Plinio quoque et Coelio videre est $)^{751}$ indagarunt philosophi rerum principia et an Fides vera mundus finitus sit an infinitus, pluresne an unus sit mundus. At tanta est fidei vis et dignitas, ut una perfectissime tradat, quod illi omni alias instructi sapientia assequi non potuerunt, unum videlicet deum authorem esse istorum omnium, qui

748 Vgl. Mt 16,17.

749 Vgl. Röm 12,2.

750 Plutarch von Chaironeia (ca. 45 v.-125 n.Chr.), Vertreter des Mittelplatonismus und Verfasser zahlreicher philosophischer (»Moralia $)$ sowie historisch-biographischer Werke (»Vitae parallelae«), vgl. NP IX 1159-1175. Bullinger weist an dieser Stelle auf das unechte doxographische Werk »Placita philosopho-

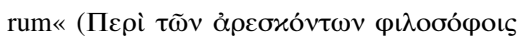

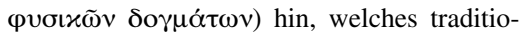
nell als Teil der »Moralia « überliefert wurde (874A-911C), vgl. NP I 208f.; IX 1169f.

751 Vgl. Ps.-Plut. placit. 1,4f. (Lachenaud 78-81); Arist. cael. 1,9, 277b 27-279b 4 (Guthrie 8294); Plin. nat. 2,1-13 (Ianus/Mayhoff I 128132); Rhod. lect. 8. 
ineffabili suo verbo, virtute et potentia ex nihilo condiderit universa, quae nunc quidem videmus, invisibilia etiam, angelos et $\mid$ spiritus. Fides enim tam magnifice de deo sentit, ut haec parva illi sint, quae Moses tradidit de creatione mundi. Ex quibus liquet fidem veram esse sapientiam. Iam sequuntur exempla, quae perstringemus tantum.

4 Per fidem uberiorem hostiam Abel obtulit deo quam Caim; per quam testimonium meruit, quod esset iustus, testimonium perhibente de donariis illius deo, et per hanc mortuus adhuc loquitur.

Hoc exemplo discimus verum dei cultum non constare externis, hostiis, donariis et ceremoniis, sed solida et syncera fide. Nam, si externa respicias, Caim non 10 minus obtulit hostiam deo quam Abel. Sed Caim fidem non habebat, itaque illud, quod offerebat, ingratum erat deo. Nam »quicquid non est ex fide, peccatum est « [Röm 14,23]. Fide ergo constat vera religio, fide iustificatus est Abel et non sacrificio. »Per fidem enim«, ait apost[olus], »testimonium meruit, quod esset iustus. « Siquidem opera non iustificant, fides tantum iustificat. Operibus tamen 15 per communicationem nonnunquam tribuitur, quod re vera fidei erat; nihilominus sola fides est iusticia, quanquam fides sine operibus mortua sit. ${ }^{752} \mathrm{Nam}$ et hic videmus deum testimonium perhibere de donariis Abel. Quod autem sequitur: »Et per hanc mortuus adhuc loquitur«, iis insignem fidei vim descripsit: fide videlicet | parari immortalitatem. Dixit enim »adhuc loquitur« pro eo, quod est »adhuc vivit«, secundum animam proculdubio. Nam corpus iam olim computruerat. Etenim omnes sancti dei martyres, qui veritatis nomine caesi sunt, apud deum vivunt. Moriuntur quidem carne, sed vivunt apud deum spiritu. Huc vero pertinet illud Christi: »Qui perdiderit animam suam, in aeterna vita inveniet eam « [Mt 16,25 parr.; Joh 12,25]. Et illud: »Amen amen dico vobis: qui sermonem 25 meum audit et credit in eum, qui misit me, habet vitam aeternam et in iudicium non veniet, sed transivit de morte ad vitam« [Joh 5,24]. Historiam Abel lege Genes[eos] $4 .^{753}$

Enoch. 5 Per fidem Enoch fuit translatus, ne videret mortem, nec fuit inventus, propterea quod transtulerat eum deus.

Superiori exemplo docuit fide parari animae immortalitatem, hoc autem demonstrat fide constare etiam corporum resurrectionem. Totus enim Enoch anima et corpore $\mid$ sublatus est, totus itaque servatus est. Historiam lege Gen[eseos] $5 .^{754}$

Z. (14) apost[olus]] apostolus $Z F-(17)$ iusticia] iustitia $Z F$

$\begin{array}{ll}752 & \text { Jak } 2,17 . \\ 753 & \text { Gen } 4,1-8 .\end{array}$ 
5 Priusquam enim transferretur, testimonium meruerat, quod placuisset deo. 6 Atqui sine fide fieri non potest, ut quisquam illi placeat.

Ne quis putaret tanta aliunde contigisse Enoch quam per fidem, probat fide sublatum esse Enoch. Probatio | autem constat hoc syllogismo: quicunque deo 5 placent, fide placent; sine fide enim impossibile est quenquam placere deo. Enoch autem placuit deo; priusquam enim transferretur, testimonium habuit, quod placuisset deo. Enoch itaque credidit fideque immortalitatem consequutus est. Tu interim, amice lector, hanc sententiam: SINE FIDE IMPOSSIBILE EST QUENQUAM PLACERE DEO, imis reconde sensibus ${ }^{755}$ et confer ei historias evangelicas.

\section{Nam qui accedit ad deum, hunc credere oportet esse deum et esse} remuneratorem quaerentibus se.

Alia probatio est, quod Enoch nulla alia re praeterquam fide sublatus sit. Est autem sensus expositus: accedentem ad deum oportet credere; accessit autem Enoch ad deum; igitur Enoch credidit. Obiter autem perstringit summa fidei Capita fidei. capita, quibus pia mens nititur, nempe: esse deum et remuneratorem esse. Prima enim in re quavis quaestio est »an sit«, proxima vero »quid « vel »quale sit «. ${ }^{756}$ Hic vero »Diagoras Milesius, ${ }^{757}$ Theodorus Cyrenensis, ${ }^{758}$ Eumerus Tegeates ${ }^{759}$ deos prorsus nullos esse censuerunt $\ll ;{ }^{760}$ sed et propheta: »Dixit insipiens «, inquit, »in corde suo: non est deus « [Ps 14,1]. Contra vero ipsa veritas et fides suadet, imo certo novit esse deum neque esse solum, sed et remuneratorem esse, quaerentibus sc[ilicet]. Remuneratorem autem dixit apostolus benignum, | omniscium, bonum, omnipotentem et supremum bonum. Talis enim sit necesse est, qui velit omnium quaerentium esse remunerator. Itaque vera fides non tantum credit esse deum, sed illum deum suum esse deum credit, qui credenti bene velit illudque sit copiae cornu, in quo affatim habeat, quicquid desideret. Et haec fuit praeclara illa non modo Enoch, sed omnium verterum fides religioque.

755 Vgl. Verg. ecl. 3,54 (Mynors 7): »Sensibus haec imis (res est non parua) reponas."

756 Cic. top. 82 (Hubbell 444): »Cognitionis quaestiones tripertitae sunt; aut sitne aut quid sit aut quale sit quaeritur.« Vgl. Quint. inst. 3,5,6 (Winterbottom I 140,1-6); Agric. inv. 2,8 (Mundt 246,46f.).

757 Diagoras (5. Jh. v. Chr.), lyrischer Dichter aus Melos, wurde angeblich wegen Gottlosigkeit und Entweihung der Mysterien zum Tode verurteilt, vgl. NP III 509f.

758 Theodoros (um 300 v.Chr.), genannt »der
Gottlose«, Philosoph aus der Schule der Kyrenaiker, vgl. NP XII/1 326f.

759 Euhemeros (um 300 v.Chr.), Philosoph und Mythograph. In seiner Schrift 'I $\varepsilon \rho \alpha \grave{\alpha} \alpha \alpha-$ $\gamma \rho \alpha \varphi \eta ́$ werden die olympischen Gottheiten als vergöttlichte Menschen dargestellt, vgl. NP IV $235 \mathrm{f}$

760 Ps.-Plut. placit. 1,7 (Lachenaud 84). Bullinger zitiert hier aus Ps.-Plut. placit. nach der Übersetzung von Guillaume Budé, vgl. Ps.-Plut. placit. transl. 515. 
7 Per fidem admonitus oraculo Noe, ea, quae nondum videbantur, veritus, apparavit arcam ad salutem domus suae, per quam arcam condemnavit mundum, et eius, quae ex fide est, iusticiae factus est haeres.

Impii contemnunt cum admonitiones tum minas dei, quia potentiam, iusticiam et veritatem eius nesciunt. Fides autem, quae vera est cognitio dei, expectatio et deprehensio certa, verbis dei credit et res suas ad verbi dei regulam componit. Hinc Noe, cum vere deo fideret, oraculo dei admonitus arcam apparavit. Nam etiamsi nihil tale tum quidem experiretur, quale futurum dixerat deus, ipse tamen iustum et veracem sciens deum futura ceu praesentia extimuit et res suas ad praescriptum verbi dei composuit. Hac itaque fide sua servatus est. Est ergo fidei servare in adversis, ipsa item adversa praevidere, imo ipsa etiam praevenire. Illud vero in primis observandum, quod dixit Noe eius iusticiae factum esse haeredem, quae ex fide sit. Isto enim | palam significavit fidem veram esse coram deo iusticiam. »Iudicare « autem, quod Latinus vertit »condemnare $\ll,{ }^{761}$ posuit Paulus pro testificari et convincere sive arguere. Cum enim periret mundus, Noe autem 15 servaretur arca, impii fide et arca Noe ceu certissimis testibus convicti, videbant se dignas incredulitatis et contemptus luere poenas. Hoc sensu dicit etiam Christus futurum, ut Ninivitae iudicaturi sint populum Israel. Alias enim satis constat solum dei filium constitutum esse universorum iudicem. ${ }^{762}$ De Noe lege Gen[eseos] $6 .^{763}$ cepturus erat in haereditatem, et exivit nesciens, quo esset venturus.

Plura nunc sequentur elegantia exempla de clara fide patris nostri Abrahae. Primum autem sumpsit ex Gen[eseos] cap[ite] $12 .{ }^{764}$ Nihil autem dulcius homini patria, domo, cognatis et amicis. Nihil contra erumnosius, quam exulem esse 25 incertisque vagare sedibus. At tanta est fidei virtus, ut fidelis Abraham protinus atque a deo patriis evocaretur sedibus, incontanter et alacri animo exiliret vocantemque sequeretur, iuxta carnem nesciens, quo duce|retur. Pluris enim aestimabat illius promissionem et amicitiam quam universam suam substantiam omnesque in orbe delicias. Omnia enim prae hoc deo contemnebat. Porro hoc 30 exemplum probe quadrabat $\mid$ temporibus Pauli, quibus plurimi (ut in 10. audivimus) $)^{765}$ fidei nomine patria pellebantur in exilium. Sed augustiora sunt, quae sequuntur.

Z. (3) iusticiae] iustitiae $Z F$ - (4) iusticiam] iustitiam $Z F$ - (12) iusticiae] iustitiae $Z F$ - (14) iusticiam] iustitiam $Z F$

761 Erasm. Hebr. transl. (ASD VI/4 310).

762 Mt 25,31-46.

763 Gen 6,5-22. 
9 Fide commoratus est in terra promissa tanquam in aliena et habitabat in tentoriis cum Isaac et Iacob cohaeredibus eiusdem promissionis. 10 Expectabat enim habentem fundamenta civitatem, cuius opifex et conditor deus est.

5 Istis enim vere tandem et proprie ob oculos ponit, quid fides, quam constans subsistentia et patiens expectatio sit. Haud enim adeo magni pendendum erat, quod Abraham splendidis evocatus dei pollicitationibus patrias deseruerat sedes. Illud vero arduum et rarum, quod in eum, quem expectaverat locum deveniens, nihil solidi certive comperit, unde indignatio quaedam suppullulascere potuerat.

10 At nihil eiusmodi in sancto dei viro Abraham comperias. Non enim responsat deo, non murmurat, non contemnit promissionem, eo quod in pollicita terra sub tentoriis agere, cum incolis Philistaeis subinde conflictari et nullis non adversis exerceri cogeretur, sed a terrenis avertit animum pium et omnem spem suam in aeterna et invisibilia figit, expectans coelestia; qui ipsa re didicerat, terrena ceu

15 fluida et mutabilia prorsus esse viro forti aspernenda. De qua re paulo post plura. $^{766}$ accepit et praeter aetatis rationem peperit, quod fidelem iudicaret eum, qui promiserat. 12 Quapropter et ex uno prognati sunt posteri eoque iam annis effoeto, tanto numero, quanto sunt stellae coeli, et velut arena, quae est in littore maris innumerabilis.

Haec legere est Gen[eseos] 21. ${ }^{767}$ Maxima autem fidei vis et laus est, quod ibi tandem fidei virtus nullo operatur negotio, ubi semel cessavit omnis naturae operatio. Quanquam omnis virtus proprie sit operantis dei, ut clare liquet in exemplo Elizabeth, de quo Luce $1{ }^{768}$ Quod hic subiecit: »Quapropter et ex uno etc., ad amplificationem pertinet. Voluit enim eximias fidei opes ostentare, ut ipsa fidei gloria et nobilitate auditorum mentes ad fidem pelliceret. Plura lege ad Rom[anos] $4 .{ }^{769}$

13 Iuxta fidem mortui sunt hi omnes, cum non accepissent promissiones, sed procul eas vidissent et credidissent salutassentque et confessi fuissent se hospites atque advenas esse in terra. 14 Nam haec qui dicunt, declarant se patriam inquirere. 15 Et si illius quidem memores fuissent, unde

766 Hebr 11,16.

767 Gen 21,1-8.

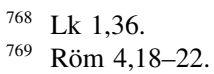


fuerant profecti, habebant opportunitatem revertendi. 16 Nunc autem meliorem expetunt, hoc est coelestem. Qua|propter non erubescit ipse deus vocari deus illorum, paraverat enim illis civitatem.

Veluti summa colligit omnium patriarcharum fidem. »Patres«, inquit, »terram promissam vere nunquam possederunt, sed quemadmodum ii, qui eminus rem vident, gustum tantum rei visae habent, et qui hominem salutant, tantummodo nosce coeperunt, ita illi in terra promissa veluti hospites et peregrini fuerunt. Nihilominus non murmurarunt adversus dominum, sed in fide perstiterunt et in fide certaque expectatione defuncti sunt, meliorem credentes ipsis terram esse a deo paratam. « Hic enim a carnalibus ad spiritualia deflectit apostolus et quan- 10 doquidem paulo ante ${ }^{770}$ coeperat demonstrare Abrahae adeoque omnium veterum fidem non in visibilia et terrena, sed in invisibilia et coelestia fuisse fixam, aliam enim eos terram aliamque civitatem expectasse, nunc quidem id copiosius et planius exponit et ad hunc modum ratiocinatur: »Qui fatentur se hospites esse, ii fatentur se aliam habere patriam, quam ea sit, in qua versantur. Patriarchae autem 15 confessi sunt se esse hospites, ergo aliam sperarunt patriam, quam ea fuerit, in qua agebant.« Iam se|quitur confirmatio: »Nam eam terram, in qua erant, quomodo, obsecro, patriam credere poterant, cum dicerent se esse hospites? An vero quisquam in aedibus suis et patrio solo agens dicit se hospitem esse? Sed $/$ et eam terram, unde digressi erant, si patriam suam putassent, sane non deerat redeundi 20 opportunitas. Cum ergo neque Chaldaea, e qua egressi erant, neque Chananaea, in qua agebant, illa patriarcharum fuerit patria, consequens est patriarchas nullam expectasse terrenam patriam, sed coelestem; atque ita deum coluisse patris loco coelumque expectasse patriam. Unde ipse etiam deus illos in filios et cives susceperit, et illorum deus vocatus sit.« Ex quibus iam constat sola fide coli deum 25 fideque iustificari orbem.

17 Per fidem obtulit Abraham Isaac, cum tentaretur, et unigenitum obtulit, in quo promissiones acceperat, 18 ad quem dictum fuerat: in Isaac vocabitur tibi semen; 19 cum illud secum perpendisset deum vel a mortuis excitare posse, unde illum etiam resurrectionis typo reduxit.

Admirabilem et raram Abrahae fidem mire exaggerat. Siquidem cum illud secum Gen. 22[,2]. expendere potuisset: »Unigenitus est, quem si mactaveris, mendacem feceris deum, qui in hoc tibi posteritatem pollicitus est «; sed nihil tale admittebat fides, quin potius illud ingerebat, deum, qui caedem filii praeceperat, vivum esse et

\footnotetext{
Z. (1) opportunitatem] oportunitatem $F-(21)$ opportunitas] oportunitas $F$

${ }^{770}$ Hebr 11,10.
} 
omnipotentem, mortuum itaque vitae restituere posse. Quo loco iterum videre est, quanta sit virtus fidei et quomodo invisibilibus nitatur. Quod autem Latinus interpres vertit: |»Unde illum etiam resurrectionis typo reduxit «, ${ }^{771}$ perspicuitatis gratia sic vertit. Nam in Graeca veritate non est nisi: »Unde illum et in simili5 tudine reduxit.« Sentit autem Isaac typum gessisse Christi, qui oblatus pro peccatis nostris tertia die revixit. ${ }^{772}$

20 Per fidem de futuris benedixit Isaac filio Iacob et Esau. 21 Per fidem Iacob moriens singulis filiis Ioseph benedixit et adoravit fastigium virgae illius. 22 Per fidem Ioseph moriens de egressione filiorum Israel meminit deque ossibus suis mandavit.

De his omnibus copiosissime scripsit Moses Gen[eseos] 27., 48. et 50. cap[ite]. ${ }^{773}$ Benedictio autem de futuris insigne argumentum fidei fuit. Nisi enim credidissent deum esse adeoque et omnis boni inexhaustum fontem esse benignum et munificum, certe nunquam prospera posteris imprecati fuissent, quae non ipsis con15 ferebantur praescriptis verbis, sed a divina tandem miseratione expectanda erant. Ita praeceptum Ioseph de transferendis ossibus certissimum argumentum fuit, quod deo promittenti liberationem ex Aegypto indubitata fide adhaeserit. Nemo autem miretur, quod in secundo exemplo secus legit apostolus, quam in Hebraeo habeatur. Hic enim legit: »Adoravit ad fastigium virgae illius« [Gen 47,31], Hebraeus autem habet: »Adoravit ad lectuli caput.« Nam מטה ambiguum est, et »lectum« et »virgam« significans. ${ }^{774} \mid$ Maluit autem Paulus posteriore uti, ut suo adaptaret negotio. Voluit enim adumbrare, quod fides Iacob etiam ad regnum Christi penetrarit. Id quod et Erasmus istis expressit verbis: »Sed longius etiam prospiciebat senis fides, cum exosculans summam virgam filii Ioseph veneraretur Christum omnibus imperaturum, cuius ille delatus ac proditus a fratribus imaginem gesserat. ${ }^{775}$ Quod vero superstitiosum tumulandi ritum attinet, quem multi sepultura. exemplo Iosephi confirmant, istis diluit Chrysostomus: »Quid autem dic mihi? Num ipsius Mosis ossa, Aaron, Danielis et Ieremiae, nonne in peregrinis iacent? Apostolorum autem plurimorum ossa nescimus, vel ubi iaceant. Petri et Pauli quidem et Ioannis et Thomae manifesta sunt sepulchra, aliorum vero, cum tanti sint, minime cognitum est, ubi sint. Nihil igitur pro hac re lugeamus. Ubicunque enim sepelimur, domini est terra et plenitudo eius, scilicet, quod oportet fieri, efficitur $\ll^{776}$ etc.

771 Erasm. Hebr. transl. (ASD VI/4 316).

772 Vgl. Symb. Nic. (DH 125).

773 Gen 27,27-29.39f.; 48,8-16; 50,24f.

774 Hier. quaest. hebr. in Gen. 48,2 (CCSL LXXII 5,13-16): »LXX interpretes [...] ipsum uerbum metta, quod hic in lectulum transtulerunt, supra, ubi diximus adorasse Iacob, uirgam potius quam lectulum nominauerunt.« Vgl. Erasm. Hebr. (ASD VI/10 352,469-477).

775 Erasm. par. Hebr. (ASD VII/6 88,1033-1036).

776 Chrys. Hebr. transl. 142. 
23 Per fidem, cum natus esset Moses, occultatus est menses tres a parentibus suis, propterea quod viderent elegantem puellum, nec veriti sunt edictum regis.

Fide parentum bono publico servatus est Moses. Nisi autem parentes eius divinae providentiae confisi augustius quippiam de deo invisibili sensissent quam de Aegyptii regis potentia, certe infantem neque ab|scondissent neque aquae commisissent. Historiam lege Exodi 2. ${ }^{777}$

24 Per fidem Moses iam grandis renuit vocari filius filiae pharaonis, 25 potius eligens simul malis affici cum populo dei, quam temporariis peccati commodis frui, 26 maiores arbitratus divitias probrum Christi quam Aegyptiorum thesauros. Respectum enim habebat remunerationis.

Quadrabat hoc quoque exemplum prae caeteris Pauli temporibus, quibus magna fidelium pars malebat cum Christo exulari, quam in errore et impietate frui delitiis. Significanter ergo dixit Mosen maiores arbitratum divitias probrum Christi, quam Aegyptiorum thesauros. Nam probrum Christi vocavit vitam erum- 15 nis plenam convitiisque pessimorum hominum obiectam, qualem in hisce terris (quem spiritu vidit Moses) egit Christus, specimen exhibens omnibus cultoribus suis. De quibus et Paulus ad Timotheum: »Omnes«, inquit, »qui pie volunt vivere in Christo, persecutionem patiantur oportet « [2Tim 3,12]. Temporaria autem peccati commoda brevem illam voluptatem dixit, quae impios concomitari solet. 20 Ea brevissima cum sit, temporariam vocavit. Nam et ipse Christus: »Hac nocte «, inquit, »animam tuam abs te repetent; haec autem cui parasti?«, Luc. 12[,20]. Et Matt[haei] 16.: »Quid profuerit homini, si totum mundum lucratus | fuerit, animae vero iacturam fecerit?« [Mt 16,26] Prudenter itaque Moses respectum habuit remunerationis, id est, oculos in remuneratorem fixit deum. De quo paulo ante. ${ }^{778} 25$

27 Per fidem reliquit Aegyptum, haud veritus ferotiam regis. Perinde enim quasi vidisset eum, qui est invisibilis, ita obduravit. 28 Per fidem fecit pascha et effusionem sanguinis, ne is, qui perimebat primogenita, tangeret ipsos. 29 Per fidem transierunt rubrum mare veluti per siccam terram, quod cum tentassent Aegyptii, absorpti sunt.

Supra modum viva et elegantia exempla fidei sunt, hoc etiam evidentiora, quo sunt clariora. Nam si haec superioribus conferas ipsaque Mosis verba Exodi 12.

\footnotetext{
Z. (14) delitiis] deliciis $Z F$ - (23) Matt[haei]] Matthaei $Z F$ - (26) ferotiam] ferociam $Z F$

777 Ex 2,2. ${ }^{778}$ Hebr 11,6.
} 
13. et $14 .{ }^{779}$ adhibeas, sed et statum, in quem finem omnia dicantur, observes, iam nulla supererit difficultas. In hoc autem dicuntur omnia, ut intelligamus, quae sit fidei virtus etc.

30 Per fidem conciderunt moenia Iericho circundata ad dies septem. 31

$5 \quad$ Per fidem Raab meretrix non periit una cum iis, qui non obedierant, cum excepisset hospitio exploratores pacifice.

Ea citra controversiam admirabilis virtus est, quae munitissima quaeque diruit. Non est autem sapientia, nullum consilium aut ulla fortitudo contra dominum. | Vide Iosue $6{ }^{780}$ et de Raab Iosue $2 .{ }^{781}$ et comperies non aequandam mulieris 10 fidem.

\section{Et quid praeterea loquor? Deficiet enim me tempus commemorantem de Gedeone, de Barac et Sansone et Hiephtae, nec non Davide et Sa- muele ac prophetis.}

Hactenus pulchra et digesta enumeratione potissima summorum virorum recen15 suil suit exempla, nunc in genere plurimorum commiscet. De Gedeone autem lege Iud[icum] 7., de Barac Iud[icum] 4., de Sansone Iud[icum] 14., de Hiephtae Iud[icum] 11., de Davide 1. Sam[uelis] 17., de Samuele 1. Sam[uelis] 12. ${ }^{782}$ Caeterum ipse apostolus nunc plura alia subiicit.

33 Qui per fidem expugnaverunt regna, operati sunt iusticiam, adepti sunt promissiones, occluserunt ora leonum, 34 extinxerunt vim ignis, effugerunt acies gladii, convaluerunt de infirmitate, effecti sunt robusti in praelio, impressiones averterunt exterorum.

| Quid, obsecro, maius, dignius, admirabilius de fide dici poterat? Regna autem Virtus fidei. praeter caeteros expugnarunt Iosue et David, belli duces fortissimi, Iosue 12., 2.

25 Reg. ${ }^{783}$ 8., 1. Paralip. 20. Iusticiam autem et iudicium operati sunt Samuel cum omni Israel et David cum rege Saul. ${ }^{784}$ Promissam terram assecuti sunt Iosue et David, | ut supra est annotatum. Sanson porro, David et Daniel occluserunt ora leonum, Iud. 14[,5f.]., 1. Reg. ${ }^{785}$ 17[,34f.]., Danielis 6[,23]. Sed Aaron et tres illi

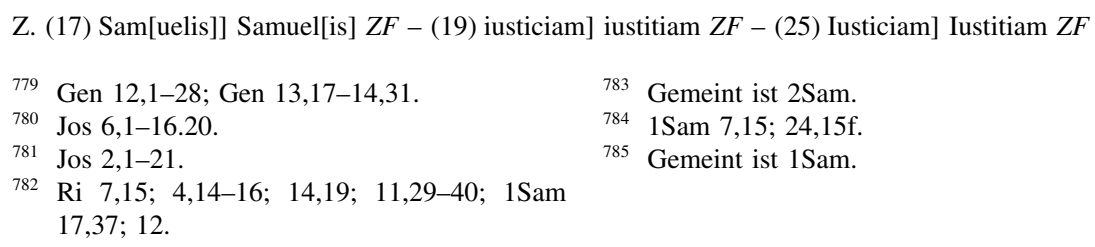

${ }^{783}$ Gemeint ist 2Sam.

784 1Sam 7,15; 24,15f.

785 Gemeint ist 1 Sam. 
apud Danielem pueri extinxerunt vim ignis, Numeri 16[,35]. et Danielis 3[,25]. Et Helias quidem una cum aliis nonnullis prophetis effugit aciem gladii, hoc est acutum gladium, ne capite plecteretur sub Iezabel, 3. Reg. ${ }^{786}$ 19[,10]. Ezechias autem Davidque de infirmitate maxima convaluerunt, Isaiae 38. et Psal. 6[,5.10]. Item Sangar, Sanson et fortes David in praelio robusti effecti sunt, Iudicum 3[,31]., 15[,8].; 1. Paral. 11. Caeterum Ionathas, Asa et Iosaphat impressiones hostium avertere a civibus, 1 . Reg. ${ }^{787} 14[, 1-15] .$, 2. Paral. 14. et 20. cap[ite].

35 Mulieres acceperunt ex resurrectione mortuos suos.

Schema loquendi hoc potest: »Mulieribus iterum ad vivos redierunt, qui fuerant mortui.« Tale enim legimus de filio Sunamitidis, quem fide in deum Elizeus ad 10 superos revocavit, 4. Reg. ${ }^{788} 4[, 34 \mathrm{f}$.$] .$

35 Alii vero distenti sunt, aspernati redemptionem, ut meliorem resurrectionem sortirentur.

Resurrectio. Ieremias enim tympani in morem distentus est, Ierem. 20[,2]., sed spe melioris vitae praesentem contempsit. Usurpavit enim Paulus resurrectionem pro vita 15 semper consistente, sicut et Christus Ioan[nis] 5.: »Resurgent«, inquit, »in resurrectionem vitae« [Joh 5,20], id est, ut semper vivant.

| 36 Alii rursus ludibriis et flagris explorati sunt, insuper et vinculis et carcere. 37 Lapidati sunt, dissecti sunt, tentati sunt, occisione gladii occubuerunt,

Ludibriis et flagris vexati sunt complures prophetae, vinculis quoque et carceribus puniti Helias, ${ }^{789}$ Micheas ${ }^{790}$ et caeteri. Lapidabatur Zacharias ${ }^{791}$ filius Ioiade et Naboth $^{792}$ virorum innocentissimus. De Isaia referunt veteres, quod serra sub Manasse sectus occubuerit. ${ }^{793}$ Multos item sacerdotes et prophetas et Saul et Iezabel gladio occidit. ${ }^{794}$

37 oberrarunt in ovillis et caprinis pellibus, destituti, pressi, afflicti, 38 quibus indignus erat mundus, in desertis errantes et montibus ac speluncis et cavernis terrae.

786 Gemeint ist 1 Kön.

787 Gemeint ist 1 Sam.

788 Gemeint ist 2Kön.

789 Gemeint ist wohl Jeremia, vgl. Jer 20,2; 32,2; 37,15 .

790 1Kön 22,26f.
791 2Chr 24,20f.

792 Kön 21,13f.

793 Zur »Zersägung Jesajas« durch König Manasse vgl. oben S. 6, Anm. 18.

794 1Sam 22,16-19; 1Kön 18,13. 
Per ovillas et caprinas pelles vestes intellexit laceras, reiectitias et usibus humanis

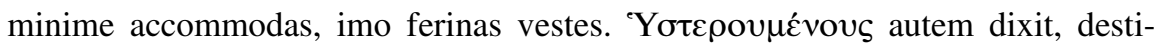
tutos omni re necessaria, ${ }^{795}$ cibo et potu, pressos propter undique imminentem tyrannorum saevitiam. Afflictos autem propter excruciantes curas, animi pertur5 bationes et terrores. Addit ipsos in desertis oberrasse, hoc est, exules patria et vide. aedibus in morem ferarum in sylvis ferarumque lustris latitasse. Mira ergo brevitate omnia pene humani generis incommoda recensuit iisdemque ostendit fideles a deo non modo morte non potuisse avelli, | sed ne exilio quidem et miseria, quae morte durior est; maximam itaque fidei esse virtutem.

39 Atque omnes hi testimonium promeriti per fidem non acceperunt promissionem, 40 quod deus de nobis melius quiddam providerat, ne sine nobis consummarentur.

Clausula est superiorum, quasi diceret: »Et hactenus quidem exempla adduximus, Illatio. quibus instructi videmus veteres omnes fide esse probatos. «Nam istis hoc negotium coeperat: »Per fidem testimonium meruerunt seniores« [Hebr 11,2], ideoque idem repetendo disputationem de fide concludit. Quod autem addit, veteres promissionem non esse assecutos, sciendum omnium promissionum unicum esse colophonem Iesum Christum et corporum resurrectionem, ut nunc apostolus per promissionem non intellexerit quietem, sed magis Christi adventum et corporum resurrectionem. Illis enim absolute perficitur universa san|ctorum ecclesia. Cui sententiae adminiculantur ea quoque, quae Petrus scripsit 1. Pet[ri] 4.: »In hoc mortuis quoque annunciatum est evangelium, ut iudicentur quidem secundum homines carne, vivant autem iuxta deum spiritu« [1Petr 4,6]. Et hactenus de fide vera. omni et tenaciter haerente peccato per tolerantiam curramus in proposito nobis certamine, Nunc tandem deflectit ad patientiam, a qua in fine $\mid$ cap[itis] $10 .^{796}$ erat digressus. Ad hanc autem hortatur exemplis, similibus, praemiis et poenis. Quod sine pa30 tientia, quae non est sine animi constantia, fides prorsus nihil sit. Istis vero rei summam proponit et consequentia superioribus nectit. Et fideles quidem ceu in stadio et certamine quodam sudantes alloquitur, cum revera hominis vita super terram nihil aliud sit (teste Iob) quam militia. ${ }^{797}$ Solent autem, qui in stadio

Z. (21) Pet[ri]] Petri $Z F-(28) 10$.$] decimi Z F$

795 Erasm. Hebr. (ASD VI/10 360,580f.): » ${ }^{\top}$ Yo$\tau \varepsilon \rho o u ́ \mu \varepsilon v o t$, id est >destituti rebus necessari- 
currunt, omnia impedimenta oneraque abiicere, ut hoc expeditius currant. Eo ergo allusit Paulus, qui hortatur fideles, ut socordia et curis huius mundi reliquisque id genus cupiditatibus natura nobis insitis, et quae a sancto retrahunt instituto, abiectis in veritate evangelica per patientiam currant; cum videant tot sanctorum myriades (»nubem « enim vocavit ingentem vim et copiam) ${ }^{798}$ constanti patientia 5 in fide ad finem usque perseverasse. ${ }^{799}$

2 respicientes ad fidei ducem et consummatorem Iesum, qui proposito sibi gaudio pertulit crucem, ignominia contempta et ad dexteram throni dei considet.

Christus Non modo a sanctorum patrum hortatur exemplis, sed et a Christi exemplo, qui 10

exemplum. fidei, hoc est religionis nostrae, principium et finis, prora et puppis, ${ }^{800}$ id est, solus

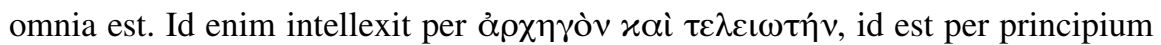
et finem, ducem et consummatorem. ${ }^{801}$ Potuisset et ille se immunem ab omni|bus adversis praeservasse, sed maluit nostri gratia pati mortem; quem igitur posthac pigeret veritatis et Christi nomine extrema quaeque experiri? Non retrahebat 15 Christum ab instituto ignominia et maledicorum hominum calumnia, iccirco etiam susceptus est in gloria. Proinde si obfirmato vultu in coepto pergamus itinere, ut ut mundus insaniat et nobis maledicat, perveniemus tandem cum Christo ad gloriam.

3 Id, inquam, reputate vobiscum, quod is talem sustinuerit a peccatoribus adversus se contradictionem, ne defatigemini animis defecti.

Per repetitionem amplificat Christi exemplum et ait: »Exemplum autem Christi sic velim a vobis expendi, ut simul observetis, quanta in dei filium probra et crimina iecerint impii, quae ille evicit patientia, ut iis et vos instructi, convitiis impiorum non defatigemini et propter iniurias istorum a veritate non deficiatis. « 25

\section{Nondum usque ad sanguinem restitistis adversus peccatum repugnantes}

Extenuat incommoda praeterita, ut ad maiora animet, ac dicit: »Hactenus quidem probris duntaxat estis affecti, substantia vestra exuti sedibusque pulsi; aliud porro expectandum erat, capitis etiam supplicium; tantum abest, ut in minutulis quidem illis non omnem praestetis patientiam, cum ne sanguini quidem parcendum sit $\mid \begin{array}{lll}30 & 127 \mathrm{v} F\end{array}$

798 Erasm. Hebr. (ASD VI/10 362,592f.).

799 Vgl. Mt 10,22; 24,13.

800 Siehe oben S. 53, Anm. 306.

801 Erasm. Hebr. (ASD VI/10 362,598-602):

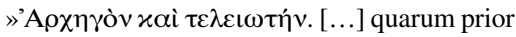

composita est ex principio, posterior deducta a fine. Perinde quasi dicas >inceptorem $<$ et $>$ finitorem $<$, vt idem Christus sit autor initii simul ac finis.«

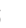

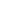


propter Christum.« His vero per amicam obiurgationem (quae hortationi familiaris est) subiungit:

5 et obliti estis consolationis, quae vobis tanquam filiis loquitur: fili mi, ne neglexeris correptionem domini neque deficias, cum ab eo argueris. 6 Quem enim diligit dominus, corripit, flagellat autem omnem filium, quem recipit.

Sententiam sumpsit ex sententiis sive proverbiis Solomonis, quae cum plana et dilucida sit, non est, ut ei immoremur. Extat in cap[ite] $3{ }^{802}$ Hoc interim in hac re in primis videtur monendum, nos hoc loco nihil loqui de sontium et impiorum suppliciis, sed de eorum | cruce tantum, qui veritatis nomine affliguntur. Nam et d[ivus] Petrus: »Ne quis vestrum«, inquit, »affligatur ut homicida aut fur« [1Petr $4,15]$ etc. Caeterum ex praesenti prophetae loco nunc multa educit argumenta satis quidem perspicua.

\section{Si castigationem sustinetis, veluti filiis vobis offert se deus. Quis enim} est filius, quem non castigat pater?

Ab utili sumptum est argumentum. Cui generalem subiungit sententiam: »Quis enim est filius « etc. Caeterum externis exemplis penetrat ad interiora. Nam fide efficimur filii dei, Ioan. 1[,12]. spurii estis, non filii.

A contrario ducitur argumentum. Sensus autem est: »Omnes filii castigationis sunt participes; vos non vultis castigationis esse participes; ergo filii esse non vultis. Interim christiano nomine gaudetis; nothi itaque et supposititii estis, qui patris genium nulla parte referunt.« Nam etsi deus cultoribus suis pacem non25 nunquam concedat, eandem tamen subinde conturbat cruce. Exemplo est vita Abrahae, Isaaci, Iacobi et Iosephi, sed et omnium sanctorum.

9 Itaque, cum carnis nostrae patres habuerimus castigatores et reveriti sumus illos, an non multo magis subiiciemur patri spirituum et vivemus?

Istis vero copiosius expolitione propositum diducit illustratque sententiam. Porro patrem spirituum schematismo quodam dixit pro patre spirituali, qui sit spiritus,

\section{Z. (1) His] Hic $Z F$ \\ ${ }^{802}$ Spr 3,11f.}


hoc est deus, Ioan. 4[,24]. Nemo autem in malam partem interpretatur, si a patre carnali corripiatur. Non enim in hoc corripit, ut noceat, sed ut prosit. Ita, cum pater coelestis corripit, in hoc corripit, ut nostrae saluti consulat. Quis ergo murmuret ad tam sanctam et utilem castigationem? Sed haec apertius proponuntur consequentibus.

10 Atque illi quidem ad paucos dies pro ar|bitratu suo nos erudierunt; hic autem ad commodum nostrum in hoc, ut impartiat nobis sanctimoniam suam.

A comparatis ${ }^{803}$ et ab utili haec duxit, iis superiora expolit. Patres terreni, etsi filios severe castigent, amplam tamen haereditatem relinquunt. Sed ampliorem 10 deus, sanctimoniam videlicet, patientibus communicat, quae quidem sanctimonia et praesentis vitae, sed magis futurae est. Nam et d[ivus] Petrus: »Nunc quidem ad breve«, inquit, »tempus affligimini, ut exploratio fidei vestrae (quae multo preciosior est auro, quod perit et tamen per ignem probatur) reperiatur in laudem et gloriam et honorem tum, cum revelabitur Iesus Christus, reportantes finem 15 fidei vestrae, animarum salutem«, 1. Petri 1[,6-9].

11 Omnis autem castigatio in praesens quidem non videtur esse gaudii, sed molestiae. At postea fructum tranquillum iusticiae reddit iis, qui per illam fuerint exercitati.

$\Gamma \nu \omega ́ \mu \eta$ est speciem referens antypophorae. ${ }^{804}$ Verum sane (inquit), quod quis 20 dicere poterat, facilem esse de hisce rebus disputationem, sed graviorem actionem. Nam sicut potiones salutiferae aegrotis videntur amarissimae, vulnerum quoque cura doloris sentiatur esse plenissima; sic castigatio quoque primo aggressu minimum gaudii, plurimum autem videtur habere mole|stiae. Verum non id solum, quod ob oculos versatur, spectandum, sed illud magis, quod futurum est 25 et quid boni ex hoc malo existat. Nam sicut amara potione pellitur aegritudo vulnerumque saeva adustio et contrectatio integritatis sanitatisque caussa est, ita variis malis exercitato fideli contingit tandem non fluidum aut marcessibile aliquod praemium, ${ }^{805}$ sed fructus suavis et pacatus, qui iustis debetur, flos scilicet immortalitatis. Nam ad Rom[anos] 5.: »Gloriamur etiam«, inquit apostolus, »su- 30 per afflictionibus, scientes, quod afflictio« [Röm 5,3] etc.

Z. (14) preciosior] pretiosior $Z F$ - (18) iusticiae] iustitiae $Z F$ - (20) antypophorae] antipophorae $Z F$ (30) Rom[anos]] Roma[nos] $Z F$

803 Siehe oben 52, Anm. 302.

804 Unter »Anthypophora « versteht man eine Fragefigur, bei der der Redner eine von ihm gestellte Frage selbst beantwortet, vgl. Quint.

inst. 9,3,87 (Winterbottom II 532); HWR I $685 f$.

805 Vgl. 1Kor 9,25. 
12 Quapropter manus remissas et genua soluta surrigite 13 et curate, | ut gressus pedibus vestris recti sint, ne claudicatio aberret a via, imo sanetur potius.

Capulum rei petit et infert id, cuius caussa hucusque tanta produxit in medium. 5 »Itaque patientes «, inquit »et constantes in fide perseveremus. « Id vero meta- Constantia. phora quadam, in qua perstat quaque in initio etiam cap[itis] usus erat, ${ }^{806}$ copiosius effert, alludens ad certandi rationem. Vult enim pios imitari strenuos cursores et fortes pugiles, qui collectis et resumptis viribus, recto item firmatoque cursu vel colluctatorem premunt vel recta metam properant, certe ut vincant. 10 Quod si quid cessatum vel erratum sit a piis, id monet nova alacritate sartiant. Fit enim nonnunquam, ut currentibus labascant nutentque genua et luctantibus manus et bra|chia lassescant. Quibus metaphoris Paulus iam non modo animi sui consilium dicit, sed et ea, quae dicere voluit, ob oculos ponit. Neque enim sine caussa metaphoram adeoque et allegoriam vocavit Tullius »stellam orationis «. ${ }^{807}$

14 Pacem sectemini cum omnibus et sanctimoniam, sine qua nemo videbit deum,

Nunc ea etiam prodit, quae patientiam et constantiam maxime interturbabant et a vera fide retrahebant. Non enim satis est nosce, quid facias; praestat etiam scire, quid caveas et quid maxime nocere possit. Maxima autem pietatis pestis est Pestes pietatis. contentio, amaritudo animi et immunditia, a quibus caveri vult, si modo velint verae pietatis esse cultores. De pace sive concordia nonnulla diximus in cap[ite] 10. ${ }^{808}$ Copiosiora vide ad Rom[anos] $12 .{ }^{809}$ De sanctimonia vero dixit Christus: »Beati mundi corde, quoniam ipsi deum videbunt « [Mt 5,8]. Porro munditia sive integritas ista animi est incorruptae fidei beneficium, quae omnem excludit hy25 pocrisim.

15 curam agentes, ne quis sit, qui deficiat a gratia dei, ne qua radix amarulentiae suppullulans obturbet et per hanc inquinentur multi,

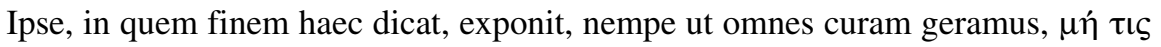

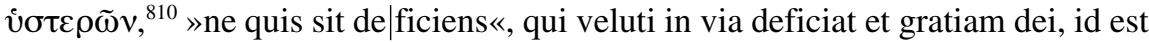
evangelii negotium (evangelium enim gratiae divinae testimonium est), assequi De hoc verbo nequeat. ${ }^{811}$ Atque hic protinus aliud subiungit malum, »amaritudinem animi

806 Hebr 12,1f.

807 Cic. orat. 92 (Hubbell 372): »Cuius [sc. Phalerei Demetrii] oratio cum sedate placideque liquitur tum illustrant eam quasi stellae quaedam tralata verba atque mutata.«
808 Siehe oben S. 138.

809 Röm 12,9-21.

810 Marg. »De hoc ... 4. cap[ite]《: Siehe oben S. 57.

811 Vgl. Erasm. Hebr. (ASD VI/10 366,646f.): 
quam metaphora quadam radicem appellitat suppullulantem, idque propter malorum feracitatem et materiam, quam hoc malum suppeditat. Ea enim ut haedera multa implicat totamque ecclesiam conturbat. De hac Iacobus: »Si aemulationem amaram habetis et contentionem in corde vestro, nolite gloriari« [Jak 3,14] etc. Notissimus enim est Iacobi locus in cap[ite] 3. Sequitur aliud malum:

16 ne quis scortator aut prophanus velut Esau, qui unico edulio permutavit ius primogeniti. 17 Scitis enim, quod et postea, cum vellet haereditario iure benedictionem assequi, reprobatus sit. Non enim reperit poenitentiae locum, tametsi cum lachrymis quaesivisset eam.

Immundicia cognatum sibi habet contemptum rerum sacrarum. Quis enim apud 10 eum sacri respectus sit, qui sibi persuasum habeat voluptatem rerum esse summam? Hic proculdubio totam evangelii praedicationem minoris vendiderit, quam Esau primogeniti iura. Invenias enim, qui dicant se malle vini sextarium quam | brevi voluptatula aeternam emit poenitudinem. Siquidem cum vellet haereditario 15 iure benedictionem assequi, reiectus est, adeo ut nulla illi restitutionis spes fuerit reliqua. Quod equidem nemo intelligit de peccatorum resipiscentia, sed de immutatione fortunae. Nam liberum non erat Esau resumendi ius primogeniti, posteaquam levitate quadam semel vendiderat. Frustra ergo torquentur, qui hoc loco

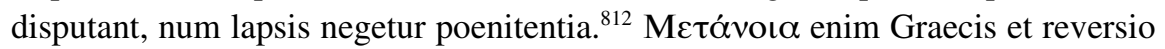
et correctio est, imo et immutatio rei cuiusvis, non tantum ea poenitentia, quae theologis in usu est. Sed et nulla nobis mentio de remissione peccatorum, sed de iure primogeniturae loquimur quantumve mali sit sacra contemnere. Equidem exemplo Esau indica|re voluit optima quaeque ammitti immunditia et contemptu rerum sacrarum. Et haec quidem de constanti in fide patientia.

\section{Peroratio.}

18 Non enim accessistis ad contactum montem et incensum, ignem ac turbinem et caliginem et procellam 19 tubaeque sonitum et vocem verborum, quam qui audierant, deprecati sunt, ne iis adiungeretur oratio. 20 Non enim ferebant, quod edicebatur: si bestia tetigerit montem, lapida-

Z. (2) feracitatem] copiam $Z F-(10)$ Immundicia] Immunditia $Z F$

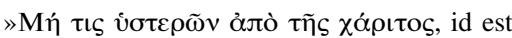
$>$ ne quis sit deficiens< aut >destitutus a gratia Dei<, hoc est qui non possit assequi velut in via sunt qui deficiant.«
812 Siehe oben S. 81-83. 
bitur aut iaculo con|figetur; 21 et adeo terribile erat visum, quod apparebat, ut Moses dixerit: expavefactus sum et tremebundus.

Post multam et variam disputationem colligit tandem, quod per universam trac- Ita nihilominus tavit epistolam idque imagine quadam statuit ob oculos contemplandum. Prin- ${ }^{\text {vocat ad }}$ sanctimoniam. 5 cipio autem colligit ea, quae disputarat de legis infirmitate et inefficatia. Deinde ea, quae de evangelii dignitate et Christi redemptione absoluta. Postremo ea, quibus ad fidendum Christo suscipiendamque evangelii praedicationem in prima atque secunda parte epistolae cohortatus erat. Est autem haec illius imago, qua secundam epistolae partem revocat ob oculos: fingite duos astare montes: alterum

10 Sinai, alterum Sion; priori representari legem, posteriori Christum et evangelium. Hic vero copiose describit eum montem, in quo data est lex, idque ex 19. Mosis secundi libri. ${ }^{813}$ At cum ibi omnia sint terrifica et tristia, significatum est lege adeo non perfici et absolvi cultores, ut magis terreantur et accusentur. Non enim lege, sed evangelio confertur conscientiae pax. Hinc dixit: »Non accessistis ad 15 contactum montem «, sed ad montem Sion. Contactum autem dixit per antiphrasim; ${ }^{814}$ nemo enim montem audebat contingere. Iam quod scribit Mosen dixisse, »expavefactus sum«, nullibi sane comperias in sacris, ${ }^{815}$ sed eiusmodi locutionis genus est quale illud: tam for|midabilis erat hostium incursus, ut vel ipsi duces terreri potuissent. Et sane non infrequens est, ut »dixerit« ponatur pro »dicere potuerit«. Sunt autem haec sub amplificationem referenda.

22 Sed accessistis ad montem Sion et ad civitatem dei viventis, Hierusalem coelestem, et ad innumerabilium angelorum coetum 23 et ecclesiam primogenitorum, qui conscripti sunt in coelis, et ad iudicem universorum deum et ad spiritus iustorum perfectorum, 24 et ad novi testamenti mediatorem Iesum et ad sanguinem aspersionis meliora loquentem, quam loquebatur sanguis Abel.

Istis colligit, quod secunda parte fusius docuit, Christi sacrificio nos absolutos esse, huius morte et sacerdotio patere ad coelos viam. Atqui omnia haec etiam in peroratione copiosius tractat et figuris vestit. Et montem quidem Sion vocat Christum et gratiam evangelicam. Nam ut de Sinai lex progressa est, ita de Sion vita et salus. Allusit autem ad Isaiae 2. et Micheae 4. cap[ut]. ${ }^{816}$ Civitas autem dei

Z. (5) inefficatia] inefficacia $Z F-(21-22)$ Hierusalem] Ierusalem $Z F$

813 Ex 19,16-19.

814 Bei der Antiphrasis oder Litotes wird der superlativische Grad der Bedeutung durch die Negierung des Gegenteils umschrieben, vgl. HLR 304.
${ }^{815}$ Vgl. aber Dtn 9,19.

816 Jes 2,1-5; Mi 4,1-8. 
est coelestis Hierusalem, id est vita aeterna. In hac perpetuum gaudent angelorum chori. In hac videre est primogenitos, hoc est electos dei, omnes sanctos patres, quos »primogenitos « appellavit allusione ad primogenitos patrum, qui dilecti et 1. Ioan. 2[1f.]. domini rerum erant. In hac item videre est ipsum deum / omnium iudicem, id est omnium potentem, sed et omnium iustorum animas. Quae res minime vulgaris est. Nam et ipse Socrates moriturus: » $\mathrm{Si} \ll$, inquit, »mors emigratio est in eas oras, quas qui e vita excesserint incolunt, quis me beatior? ${ }^{817}$ Cui dabitur convenire eos, qui iuste cum fide vixerint. »Quanti enim aestimatis colloqui cum Orpheo, ${ }^{818}$ Musaeo, ${ }^{819}$ Homero et Hesiodo ${ }^{820}$ Equidem saepe mori, si fieri posset, vellem, ut ea, quae dico, mihi liceret invenire. ${ }^{821}$ Haec de Socrate Plato apud Tullium, 10 Tusc[ulana] quaest[ione] 1. Iam vero sequitur per interpretationem: »Accessistis ad montem Sion«, id est ad mediatorem Iesum, etc. His enim exponuntur superiora, quod sanguine Christi pateat ad coelos via. Aspersionis interim meminit alludens ad typum, de quo in cap[ite] $9 .{ }^{822}$ Meliora autem loquitur sanguis Christi quam Abel. Huius enim | vindictam, illius autem loquitur expiationem; quae $15 \quad 727 \mathrm{ZF}$ dicuntur per prosopopoeiam. ${ }^{823}$

25 Videte, ne aspernemini eum, qui loquitur. Nam si illi non effugerunt, qui aversabantur eum, qui loquebatur in terra, multo magis nos, si eum, qui de coelis est, aversemur.

Cohortatio. Colligit ea, quae prima parte huius epistolae tractarat. De coelis autem locutus est 20 nobis Christus doctor coelestis annuncians sanguine suo mundari orbem. Iam a comparatis argumentatur. ${ }^{824} \mathrm{Si}$ gravissime puniti sunt, qui contemnebant Mosen terrenum hominem, sed dei $\mid$ interpretem, certe nos multo minus effugiemus, si filii dei salutarem contempserimus praedicationem. semel ego concutio non modo terram, verumetiam coelum.

Z. (1) Hierusalem] Ierusalem $Z F$

817 Cic. tusc. 1,41,98 (King 116): »Sin vera sunt quae dicuntur, migrationem esse mortem in eas oras, quas qui e vita excesserunt incolunt, id multo iam beatus est.«

${ }^{818}$ Orpheus, berühmtester Sänger in der griechischen Mythologie, vgl. NP IX 54-57.

819 Musaios, Mythischer Musenbegleiter und Archeget der Dichtung, vgl. NP VIII 501-503.

${ }^{820}$ Hesiod (um 700 v. Chr.), griechischer Dichter, Acker und Viehbauer, Verfasser des didakti- schen Epos »Werke und Tage « und der »Theogonie «, vgl. NP V 506-510.

821 Cic. tusc. 1,41,98 (King 116): »Ut vero colloqui cum Orpheo, Musaeo, Homero, Hesiodo liceat, quanti tandem aestimatis? Equidem saepe emori, si fieri posset, vellem, ut ea, quae dico, mihi liceret invenire.«

822 Hebr 9,13.

823 Siehe oben S. 139, Anm. 718.

824 Siehe oben S. 52, Anm. 302. 
Obiter interserit anacephalaeosim ${ }^{825}$ abrogatae legis istamque firmat Aggei prophetae testimonio, quod ipse in hunc modum suo applicat instituto.

27 Porro quod dicit: adhuc semel, significat eorum, quae concutiuntur, translationem, eorum videlicet, quae facta sunt, ut maneant ea, quae non concutiuntur.

Facta appellat ea, quae manibus erant facta, cuiusmodi erat tabernaculum et universum Leviticum ministerium, quod per Christi perpetuum sacerdotium sublatum est, Heb. 7[,18f.]. Hic cum aeternus sit et incommutabile sacerdotium habeat, recte Paulus: »Ut maneant«, ait, »ea, quae non concutiuntur.«

28 Quapropter regnum assumentes, quod concuti non possit, habemus gratiam, per quam ita colamus deum et illi placeamus cum reverentia et religione. 29 Etenim deus noster ignis consumens est.

Generalis illatio est totius negotii, quasi diceret: »Cum ergo expectetis, o Hebraei, Hisce et 3. regnum Messiae, interim videatis Christum Iesum verum esse deum et hominem, $\mid \begin{aligned} & \text { epist[olae] par } \\ & \text { colligitur. }\end{aligned}$ qui habeat sacerdotium perpetuum. Age, cum talem habeamus gratiam, ipsum, inquam, Christum, qui gratiae pignus est, age, inquam, suscipiamus Christum fide! Agnoscamus hunc esse illum regem et sacerdotem nostrum; istius regnum illud sempiternum esse regnum. Serviamus huic cum reverentia et religione, id est vera fide et constanti patientia.« His subnectit speciosum epiphonema: ${ }^{826}$ Isaiae 33. Isaiae 33. cap[ite] ${ }^{827}$ Haec autem, quae dicuntur de regno Christi et cultu dei, diligenter piis lectoribus observanda sunt.

\section{Aphorismi.}

Istis autem, quae praecesserunt, ordine totam absolvit epistolam; quae nunc 25 sequuntur, appendicis loco adfixa sunt. Agit autem in hac varie de rebus variis, eo propemodum orationis genere, quo solent tractari sententiae. Unde nos $»$ aphorismos « libertate quadam nuncupavimus. Sunt enim aphorismi sententiae separatae, absolutae et breves, ut sunt sapientum apophthegmata. 'A $»$ separare et secernere ${ }^{828}$ Nos paucis singula perstringemus.

Z. (13) Marg. epist[olae]] epistolae $Z F-(20)$ Deut[eronomii]] Deute[ronomii] $Z F$

825 Siehe oben S. 103, Anm. 556.

826 Siehe oben S. 57, Anm. 323.
827 Dtn 4,24; Jes 33,11f.14.

828 Bud. comm. 988,42f. 
CAP. XIII. 1 Fraterna charitas maneat. 2 Hospitalitatis ne sitis immemores. Per hanc enim quidam inscientes exceperunt angelos hospitio. 3 Memores estote vinctorum, tanquam una cum illis vincti; eorum, qui affliguntur, velut ipsi | quoque versantes in corpore.

Charitas. Charitas primum locum obtinet, quod (teste apostolo) consummatio legis sit. ${ }^{829} 5$ Huic hoc loco addit epitheton »fraterna«. At cum veteres christianos appellarint »fratres «, fit, ut charitas fraterna dicatur charitas christiana, ${ }^{830}$ nempe quae ad Christi charitatem formata $\mid$ est, qua opere et veritate diligimus. Hinc subiunxit: »Hospitalitatis ne sitis immemores. «Hospitalitate autem synecdocha ${ }^{831}$ quadam omnia misericordiae opera, quorum meminit Christus Matth[aei] $25 .^{832}$ comple- 10 xus est. Et ut persuaderet, exemplum una cum utilitate quadam addidit, nempe sanctos olim hospitalitate angelos suscepisse, id quod de Abrahamo et Loth legimus Gen[eseos] 18. et $19 .{ }^{833}$ Quod si cui desit facultas, tamen, si syncere diligat, non deerit voluntas. Hinc subiungit: »Memores estote vinctorum« etc. Nam et apostolus alibi: »Quis«, ait, »infirmatur et ego non infirmor? Quis 15 offenditur et ego non uror? « [2Kor 11,29] Plura lege in 1. Corinth[iorum] 12. et cap[ite] 10. huius epistolae. ${ }^{834}$

4 Honorabile est inter omnes coniugium et cubile impollutum. Scortatores autem et adulteros indicabit deus.

Castitas. De castimonia disserit adversus incontinentiam. Illius autem dignitatem laudibus 20 effert. Huius vero foeditatem et indignitatem indicat. Coniugium, quale sit, docent divinae literae, Gen. 3., Matth. 19., Ioan. 2. et Paulus 1. Corinth. 7. ac Ephes. $5{ }^{835}$ Honorem autem matrimoniis et apud gentes habitum esse, liquet ex histori is, poetis et legibus, maxime ex illa egregia Metelli Numidici ${ }^{836}$ sententia, qui: $» \mathrm{Si}$, inquit, »sine uxore possemus esse, omnes ea molestia careremus; sed 25 quoniam ita natura tradidit, ut nec cum illis satis commode nec sine illis ullo modo vivi possit, saluti perpetuae potius quam brevi voluptati consulendum est. ${ }^{837}$ Author A[ulus] Gellius in 1., cap[ite] 6. Quod autem sequitur, thorum coniugalem esse impollutum, id est, moderatum in connubio coitum non reputari

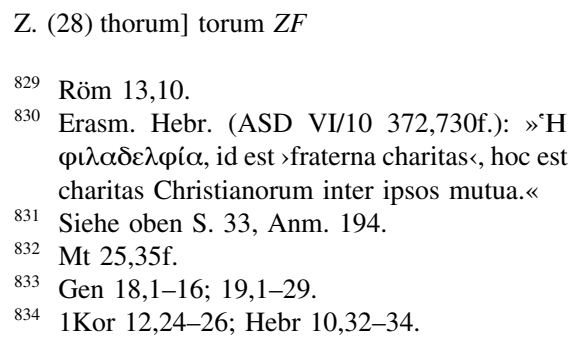

835 Gen 2[!],24; Mt 19,4-6; Joh 2,1-10; 1Kor 7,27f.; Eph 5,21-33.

836 Quintus Caecilius Metellus Numidicus (2./1. Jh. v.Chr.), römischer Konsul, führte die römischen Truppen im Krieg gegen Jugurtha, vgl. NP II 890.

837 Gell. 1,6,2 (Rolfe I 30). 
pro peccato, id Paulus clarioribus ad Corinthios dixit: »Propter stupra vitanda suam quisque uxorem habeat « [1Kor 7,2] etc. Et Paphnutius ${ }^{838}$ in Consilio Niceno, qui clericis connubium prohibere volentibus restitit, honorabiles confessus nuptias et castitatem esse dicens concubitum cum propria coniuge. Quae quidem 5 extant in Socrate ${ }^{839}$ Constantinopolitano apud Epiphanium lib[ro] 2., cap[ite] 14. ${ }^{840}$ Quocirca iniquum atque impium est pontificis Rom[ani] decretum, ${ }^{841}$ quo 1. Tim. 4[,1-3]. connubia sacerdotibus inhibuit et scortationem admisit. Caeterum de scortatione et adulterio lege Exod[i] 20., 1. Corinth[iorum] $6 .{ }^{842}$ et Plutarchum in vita Lycurgi ${ }^{843}$ item Gen[eseos] 20. et Iudicum 19., et senties Paulum non frustra dixisse 10 deum iudicare, id est, punire et damnare scortatores et adulteros.

5 Sint mores alieni ab avaritia, contenti his, quae adsunt, siquidem ipse dixit: non te desero neque derelinquo, 6 ut fidentes dicamus: |dominus mihi auxiliator nec timebo, quid faciat mihi homo.

Adversus avaritiam duo producit testimonia, alterum extat Iosue 1., sed clarius Avaritia. 15 Matthaei 6.; ${ }^{844}$ alterum Psal[mo] 117. et 55. ${ }^{845}$ Plura qui velit, legat Paulum in 1. ad Timotheum 6. aut, si malit, Salustium ${ }^{846}$ in Con[iuratione] Catil[inae]. ${ }^{847}$

\section{Mementote eorum, qui praefuerunt vobis, qui et sermonem dei locuti sunt vobis, quorum imitemini fidem consyderantes, qui fuerit exitus con- versationis illorum.}

20 Hic monet, ut in doctrina apostolorum, a quibus Hebraei primum didicerant Doctrina. evangelium, perseverent, et illorum imitentur in fide constantiam et sanctimoni-

Z. (6) Rom[ani]] Romani $Z F$ - (8) Exod[i]] Exodi $Z F$ - (16) Timotheum] Timoth[eum] $Z F$ (16) Con[iuratione]] Coniurat[ione] $Z F$ - (18) imitemini] immitemini F - (18) consyderantes] considerantes ZF - (21) imitentur] immitentur $F$

838 Paphnutios (gest. 360), Wüstenmönch, Bischof der Thebais und Teilnehmer am Konzil von Nizäa (325), vgl. LThK ${ }^{3}$ VII 1325.

839 Sokrates Scholastikos (ca. 380-439), griechischer Kirchenhistoriker, vgl. NP XI 687f.

840 Epiph. haer. 68,5 (PG XLII 192B-C); Soz.[!] hist. 1,23 (GCS L 44f.); Decr. Grat. D. 31 c. 12 (Friedberg 114): »Surgens autem Pahfnucius confessor contradixit, honorabiles confessus nuptias, et castitatem dicens esse cum propria coniuge concubitum [...].«

841 Vgl. Decr. Grat. D. 31 c. 14 (Friedberg 115): »Occidentalium nullus sacerdotum a subdiacono usque ad episcopum licentiam habet coniugium sortiendi.«
${ }^{842}$ Ex 20,14.17; 1Kor 6,12-20.

843 Plut. vit. Lyc. 15,1-10 (Flacelière et al. 140f.). Lykurgos, legendärer Gesetzgeber Spartas, vgl. NP VII 579f.

844 Jos 1,5; vgl. Mt 6,32.

845 Ps 118,6 (Vulg. 117,6); 55,5.10.

846 Caius Sallustius Crispus (86-34 v.Chr.), römischer Politiker und Historiker, vgl. NP X 1254-1258.

847 Vgl. Sall. Catil. 11 (Kurfess 10f.). Lucius Sergius Catilina (gest. 62 v. Chr.), römischer Politiker, vgl. NP II 1029f. 
am. Ex quibus claret, quis sit verus divorum cultus, nempe imitatio fidei et innocentiae sanctorum. De qua re alibi satis copiose. ${ }^{848}$ Quod autem haec sic intelligenda sint, convincunt consequentia.

8 Iesus Christus heri et hodie, idem est etiam in saecula. 9 Doctrinis variis et peregrinis ne circumferamini.

Videtur autem verbis inesse enallage ${ }^{849}$ quaedam, nempe quod persona pro re ponatur: Iesus Christus pro salute, veritate, redemptione et religione christiana. Sic enim sensus erit apertissimus: eandem apud omnes semper esse religionem Christi, eandem vim sacerdo|tii et sacrificii Christi. Huic enim commode iam additur: »Doctrinis variis et peregrinis, ne circumferamini«, quippe cum eadem 10 semper et constantissima sit veritatis do/ctrina, idem Christus eademque omnibus saeculis virtus Christi. »Varium« itaque dixit, quod aliis atque aliis rebus fidere docet. »Peregrinum « autem, quod ex alio quam unico Christi et veritatis fonte haustum, vel e carne vel philosophia petitum est. Sed vide Paulum ad Ephes[ios] 4. et Coloss[enses] 2. ${ }^{850}$

9 Bonum est enim gratia constabiliri cor, non escis, quae non profuerunt iis, qui versati sunt in illis.

Iam exhibet Hebraeis suis exemplum sanae et non sanae sive peregrinae doctrinae. Sana doctrina perhibet sola gratia stabiliri cor. Peregrina escis ac sacrificiis externis emundationem tribuit. Sed falso. Nam iis nihil profuerunt sacrificia et 20 delectus ciborum, qui etiam superstitiosissimi Leviticae legis cultores fuerunt, id quod in 10. cap[ite] audivimus. ${ }^{851}$ Cor itaque posuit pro mente sive interiore homine, qui non purgatur vel saturatur nisi spirituali manducatione, Ioan. 6[,63].

10 Habemus altare, de quo non est fas edere iis, qui tabernaculo deserviunt.

Et superiorum expositio est, quod nulla re externa, sed gratia confirmetur conscientia et quaedam occupatio. Poterat enim quis dicere: $\gg$ Ergon[e] nullum nos Altare. sacrifi|cium habemus? « Respondet: »Habemus equidem altare, hoc est sacrificium, sed non tale, quale veteres. Illi enim de altari, hoc est de sacrificiis, epulabantur splendide carnaliterque. Nos vero Christum manducamus spiritualiter, hoc 30

Z. (1) imitatio] immitatio $F$ - (14) Ephes[ios]] Ephesios $Z F$ - (15) Coloss[enses]] Collos[senses] $F$

848 Vgl. Bull. orig. div.

${ }^{849}$ Siehe oben S. 40, Anm. 241.
850 Eph 4,14f.; Kol 2,8.

851 Vgl. Hebr 10,1-4. 
est fide.« Hinc et August[inus]: »Quid «, ait, »dentem et ventrem paras? Crede et manducasti. ${ }^{852}$ Altare ergo per metonymiam ${ }^{853}$ posuit pro eo, quod altari imponitur. Neque enim sacerdotes lapidibus vescebantur, aere aut ligno, quibus constabant arae, sed sacrificiis.

11 Animalium enim, quorum sanguis infertur pro peccato in sancta per pontificem, horum corpora cremantur extra castra. 12 Quapropter et Iesus, ut sanctificaret per proprium sanguinem populum, extra portam passus est.

Etiam typo ostendit Christi sacrificium non esse eiusmodi, de quo possit carna- Altare unicum. 10 liter manducari. Fuisse enim et veteribus sacrificium, de quo non ederint sacrorum ministri. »Erat«, inquit, »apud veteres victima«, ut in Numeris extat, cap[ite] $19 .{ }^{854} \gg$ quae pro peccato expiando offerebatur. Ea vero tota concremabatur extra castra, ut nihil reliquum fuerit sacerdotibus comedendum.« Huic autem typo probe respondit Christus, qui peccata nostra expiaturus extra portam passus et 15 oblatus est. Unde nunc consequitur Christum non esse talem aram sive oblationem, de qua possit participari carnaliter, sed spiritualiter tantum. Istis autem confutantur omnia $\mid$ ea, quae pontificii de aris iisdemque consecrandis, de oblationibus et carnali manducatione Christi nugantur. ${ }^{85}$ Quod autem haec denuo repetiit per exemplum, quae alias tota epistola diligentissime tractavit, propter 20 duritiam Iudaicae gentis factum est, quibus nulla pene diligentia superstitio Levitica poterat extorqueri.

13 Exeamus igitur ad eum extra castra opprobrium eius portantes. 14 Non enim habemus hic manentem civitatem, sed futuram inquirimus.

Ab exemplo Christi obiter hortatur ad patientiam et sequelam Christi, de qua ipse sequela Christi. etiam Christus copiosiora apud Mat[thaeum] in 16. Interim ipse apostolus sententiam, qua persuadeat, addit: »Non enim habemus« etc. Siquidem peregrini sumus, quorum »conversatio in coelis est « [Phil 3,20], Heb. 11[,10]., 2. Corinth. 5[,1-4]., Philip. 3. cap[ite].

15 Per ipsum igitur offerimus hostiam laudis semper deo, hoc est fructum labiorum confitentium nomini eius. 16 Beneficentiae autem et communicationis nolite oblivisci. Talibus enim hostiis delectatur deus.

Z. (1) August[inus]] Augustinus $Z F-(25)$ Mat[thaeum]] Matth[aeum] $Z F$

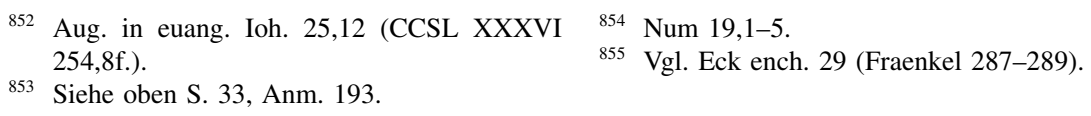


Redit ad id, quod supra coeperat: ${ }^{856}$ numquid superesset, quod nos offerremus? Sane nullum pro peccatis sacrificium. Una enim Christi hostia perpetua est. Quid ergo? »Per ipsum«, inquit, »offerimus hostiam laudis.« Per ipsum, inquam, id est per Christum aut per fidem in |Christum, qua credimus nobis Christi hostia nostra ablata esse pec/ cata, offerimus hostiam laudis. Quae vero haec? Fructus utique non agri, sed »labiorum confitentium nomini eius«. Confiteri autem in sacris nonnunquam est laudare et gratias agere sicut hoc loco et in Psal[mis]: »Confitemini domino, quoniam bonus, quoniam in aeternum misericordia eius « $[\mathrm{Ps}$ 106,1]. De hoc laudis et gratiarumactionis, quae ex fide est, sacrificio lege Oseam in 14., Psal[mum] 49. et $115 .{ }^{857}$ Est et aliud sacrificii genus beneficentia et 10 misericordia. De hac Oseas: »Misericordiam volo et non sacrificium« $[$ Hos 6,6], Micheas quoque in $6{ }^{858}$ Et Paulus ad Romanos 12. alterius quoque generis meminit, quo corpora nostra offerimus sanctam hostiam deo. ${ }^{859}$ Haec enim hostiarum genera deo placent. Omnium meminere vetusti, in primis Lactantius Instit[utionum] lib[ro] 7. de vero cultu, ${ }^{860}$ cap[ite] 24. et $25 .{ }^{861}$ Aurel[ius] quoque 15 Prudentius ${ }^{862}$ qui in vita Romani ${ }^{863}$ martyris scribit fidelium corda vera esse dei templa: in hisce astare fidem sacerdotis loco, quae iubeat offerre

victimas Christo et patri, quas scit placere candidatas, simplices:

frontis pudorem, cordis innocentiam,

pacis quietem, castitatem corporis,

dei timorem, regulam scientiae,

ieiuniorum parcitatem sobriam,

spem non iacentem, semper et largam manum.

Ex his amoenus hostiis surgit vapor

vincens odorem balsami, thuris, croci,

| sublatus inde coelum adusque tollitur

et prosperatum dulce delectat deum. ${ }^{864}$

Z. (10) Psal[mum]] Psalm[um] $Z F$ - (14-15) Instit[utionum]] Institut[ionum] $Z F$ - (15) Aurel[ius]] Aurelius $Z F$

856 Hebr 13,10.

857 Vgl. Hos 14,3; Ps 50,14 (Vulg. 49,14); 116,17 (Vulg. 115,8).

858 Mi 6,8.

859 Röm 12,1.

860 Der Erörterung des »wahren Gottesdienstes « widmete Laktanz allerdings nicht das siebte, sondern das sechste Buch seiner »Divinae Institutiones $\ll$.

${ }^{861}$ Lact. inst. 6,24 (CSEL XIX/2 576,15f.): »Hic cultor est uerus dei, cuius sacrificia sunt man- suetudo animi et uita innocens et actus boni «; ebd. 6,25 (CSEL XIX/2 578,19-21): »Nulla igitur alia religio uera est nisi quae uirtute et iustitia constat.«

862 Aurelius Prudentius Clemens (um 348-405), kaiserlicher Beamter und lateinischer christlicher Dichter, vgl. NP X 488f.

863 Romanos (gest. 303), christlicher Märtyrer, vgl. LThK $^{3}$ VIII $1276 f$.

864 Prud. perist. 10,354-362.364f. (CCSL CXXVI 342). 
His iunge, quae scripsi in cap[ite] 10. de Christ[i] sacrif[icio]. ${ }^{865}$

17 Parete iis, qui praesunt vobis, et concedite. Nam illi vigilant pro animabus vestris tanquam rationem reddituri, ut cum gaudio hoc faciant, et non gementes; nam id inutile est vobis.

5 Obedientiam docet et addit quaedam, quae ad obedientiam permoveant. Ea sump- obedientia. ta sunt ab eorum persona, qui praesunt. Eorum enim officium est vigilare et reipublicae inservire, iusticiam et iudicium exercere. Nam haec tam ad ipsum magistratum quam ad ministros verbi referenda sunt. Vide Exodi 18., Ezech[ielis] 3. ${ }^{866}$ Maximum autem flagitium et extrema ingratitudo est, si plebs non agnoscat beneficium procerum etc.

18 Orate pro nobis. Confidimus enim, quod omnes ii, qui honeste conversari cupiunt, bene de nobis sentiant. 19 Magis autem obsecro vos, ut id faciatis, quo celerius restituar vobis.

Orandum esse pro ministris verbi non modo hic locus docet, sed alii innumeri, Oratio. maxime Act. 4[,29]., 12[,5]., Mat. 9[,38]., Eph. 6[,18f.]. Et pro restitutione sua saepe multisque in locis preces fieri iussit. Ad Philemonem: »Spero«, ait, »quod auxilio precum vestrarum donabor vobis« [Phlm 22]. Disce item ex hoc loco neminem posse placere omnibus; sufficere autem, si quis placeat piis.

| 20 Deus autem pacis, qui reduxit a mortuis pastorem ovium illum magnum, per sanguinem testamenti aeterni dominum nostrum Iesum, 21 perficiat vos in omni bono opere ad faciendum voluntatem ipsius, efficiens, ut, quod agitis, acceptum sit in conspectu suo per Iesum Christum, cui gloria in saecula saeculorum. Amen.

Valedictionis formula est vere apostolica et mysteriis Christi plena, sicuti ea Opera bona. quoque est, qua ad Rom[anos] 16. usus est. ${ }^{867}$ Summa: imprecatur integritatem et constantiam et ut omnia illorum deo per Christum placeant. Sunt enim ea tantum deo grata, quae per Christum fiunt et non per nostram opinionem, sed in dei voluntate fiunt; ea demum vere bona opera sunt, quae utique a deo sunt. Nam deus is est, »qui«, ut Paulus ad Phil[ippenses] ait, »agit in $\mid$ nobis, et ut velimus et ut efficiamus pro bono animi proposito « [Phil 2,13]. Porro deus pacis dicitur sicut

Z. (1) sacrif[icio]] sacrificio $Z F-(7)$ iusticiam] iustitiam $Z F-(25)$ Rom[anos]] Romanos $Z F-$ (29) Phil[ippenses]] Philip[penses] $Z F$

865 Siehe oben S. $131 \mathrm{f}$.

867 Röm 16,25-27.

866 Ex 18,13-27; Ez 3,16-21. 
deus misericordiae, hoc est deus misericors et pacificus, qui nobiscum rediit in concordiam, nobis placatus est et conscientias serenat. Hic constituit Christum pastorem ecclesiae, de qua re plura Ioan. 10[,1-18]. At Christus sanguine suo aeternam redemptionem invenit. Hinc sanguis eius dicitur sanguis AETERNI TESTAMENTI.

22 Obsecro vos, fratres, sufferte sermonem exhortationis; etenim paucis scripsi vobis. 23 Agnoscite fratrem nostrum Timotheum ad|vos delegatum, cum quo, si celerius redierit, visam vos. 24 Salutate omnes, qui praesunt vobis, et omnes sanctos. Salutant vos Itali. 25 Gratia cum omnibus vobis. Amen.

Civiliter declinat a se omnem invidiam et arrogantiae suspicionem, ac christiana modestia lenit omnia. Commendat item Hebraeis suum illum Timoth[eum], quo nimirum usus est tabellione. De hoc plura Phil. 2[,19-24]. Debent autem fratres christiani nobis esse commendatissimi, maxime ii, quorum opera utimur in sacris.

2. Thes. 3[,17]. Tandem vero salutationibus suo more concludit epistolam, quam aiunt scriptam 15 esse ab Italia. ${ }^{868}$

Haec sunt, amice lector, quae in illam sanctam et eruditam Pauli ad Hebraeos epistolam habuimus. Ea tibi pro christiana charitate communicamus obsecrantes, ut syncero animi iudicio quaeque expendas. Non enim hac opella spectavi aliud, quam ut gustum aliquem disputationis Paulinae tibi exhiberem, quo delibato 20 expeditius versari posses in reliquis etiam Pauli epistolis. Deinde vero volui tibi hisce universam Christi gloriam ob oculos statuere, ut palam cerneres Iesum Christum verum esse deum et hominem, orbis doctorem unicum, sacerdotem, mediatorem, hostiam, redemptionem et vitam unicam veram et perpetuam; ut vel tantis rebus persuasus soli, omnibus aliis relictis, te totum stabili fide commit- 25 teres. Id si a te impetravi, assecutus sum, quod volui, et deo gratias ago.

Finis.

Z. (12) Timoth[eum]] Timotheum $Z F$

868 Vgl. Theophyl. Hebr. transl. 143r. 
VORREDE ZU DEN KATHOLISCHEN BRIEFEN 

Epistolis d[ivi] apostoli Pauli XIIII addo nunc VII epistolas apostolorum canonicas nostris illustratas commentariis, si hac opella nostra ecclesiae Christi prodesse tibique, lector pie, inservire possim. Verum haud abs re consuetum harum epis5 tolarum ordinem mutavi. Licet enim quatuor postremae et ipsae canonicae, sanctae et utiles sint, multis tamen nominibus praestant priores Petri et Ioannis. Nam totidem propemodum habent sententias et mysteria, quot verba. Ardent et vivunt in his omnia. Purissime tractantur in ipsis praecipua religionis nostrae capita: fides in Christum purificans, charitas praeceptum Christi unicum, innocentia 10 sancta et patientia malorum victrix. Ubique in his relucet authoritas et reverenda maiestas apostolica. Praeterea de prioribus nemo bonus vel doctus dubitavit unquam. Habitae sunt in ecclesia Christi pro gemmis incomparabilibus semper, unde primas tenent merito. Tuum erit, pie lector, labore nostro bene uti et gratum esse benefactori Christo, cui soli gloria semper.

$15 \quad \mathrm{H}$ [einrychus] $\mathrm{B}$ [ullingerus]. 

KOMMENTAR ZUM ERSTEN PETRUSBRIEF 

Omnibus per Germaniam fratribus nomine Christi evangeliique afflictis et exulibus Heinrychus

Bullingerus gratiam, vitae innocentiam et patientiam a deo patre optat per Iesum Christum.

5 Nisi sancti, quotquot ab exordio mundi vixere, variis afflictionibus exerciti, innumeris obiecti fuissent periculis, merito quidem vices nostras, o fratres, nunc lugeremus temporaque nostra sane quam exulcerata turbidaque accusaremus, quibus praeter meritum solo veritatis et Christi nomine persequtionem et dira odia sustinemus, affligimur, in exilium pellimur et, qui optime habemus, nullo mo10 mento tuti tanquam oves occisionis reputamur. ${ }^{1}$ Verum id illud ipsum est, quod praedixit dominus, venturum tempus, quo, quisquis interficiat nos, videatur cul- Ioan. 16[,2]. tum praestare deo. Quo et apostolus Paulus alludens: »Omnes«, inquit, »qui pie 2. Tim. 3[,12f.]. volunt vivere in Christo Iesu, persequtionem patientur. Porro mali homines et impostores proficient in peius, dum et in errorem abducunt et errant ipsi.«

15 Proinde non infoelices admodum in veritate, licet in mundo infoelicissimi, sumus. Siquidem perseverantibus copiosissima est apud deum merces reposita. ${ }^{2}$ De qua| cum multis hac epistola agat Petrus suaeque aetatis homines mira evidentia ad tolerantiam exhortetur, visum est ipsam, uti nostris illustrata est commentariis, dicare imo commendare vobis omnibus. Scio enim, quam graviter tententur multi.

20 Nam veterum exemplorum immemores vel in lege dei non probe docti veritatem religionis vel multitudine vel foelicitate saeculari metiuntur, ut ab eorum parte veritatem stare autument, apud quos est victoria, securitas atque voluptas, quin et hominum applausus celebritasque; apud eos autem mendacium, qui, ut variis affliguntur malis, ita paucitate quoque sunt contemptibiles. Sed ea sunt iudicia 25 dei, ut et prophetae nonnunquam super hac re cum deo contenderint. Abakuk enim: »Usque quo«, ait, »domine, clamabo et non exaudies? Quare reservasti me Abakuk 1[,1-4]. in ista iniusta tempora? Quare respicis contemptores et taces conculcante impio iustiorem se? Propterea laceratur lex, cumque impius sic praevalet, egreditur iudicium perversum. « Caeterum ista quidem iudicio dei iusto relinquamus; no- Psal. 36.

30 strum est accurate veritatem spectare, in hac perseverare, eventum deo committere. ${ }^{3}$ Huc vocat hac epistola Petrus, qua interim veram religionem ita propugnat, ut quisque vel mediocriter animatus vel non prorsus stupidi ingenii pro ista quidvis cupiat et ferre et facere. Nos iam istius subiiciemus hypothesin. Vobis

Z. (1) Omnibus] In ZG darüber die Überschrift In d[ivi] Petri apostoli epistolam utranque commentarius - (8) persequtionem] persecutionem $Z G$ - (8-9) odia sustinemus] sustinemus odia $Z G$ (13) persequtionem] persecutionem $Z G-(15)$ infoelices] infelices $Z G$ - (15) infoelicissimi] infelicissimi $Z G-(21)$ foelicitate] felicitate $Z G-(25)$ Abakuk] Abacuc $Z G$

Vgl. Ps 44,22; Röm 8,36.

Vgl. Mt 5,12.
Vgl. Ps 37,1-4 (Vulg. 36,1-4). 
autem omnibus imprecor firmam in pietate constantiam et patientiam per Christum, cui soli gloria et honor. Tiguri, mense Mar[tio], anno 1534.

| Argumentum epistolae.

Obscurior paulo est prior Petri epistola, non modo propter sententias reconditiores, sed et propter ordinem perturbatiorem asperioremque, quem nos in prae- 5 sentiarum vel complanare, vel certe aliis occasionem subministrare istud dexte-

Status. rius absolvendi conabimur. Consilium certum nemo (opinor) praefixisset, nisi ipse Petrus adiecisset ad finem epistolae: »Per Sylvanum vobis fidelem fratrem, ut arbitror, paucis scripsi, adhortans ac testificans hanc esse veram gratiam dei, in qua statis « [1Petr 5,12]. Hinc enim colligimus hanc esse epistolam hortatoriam simul et expositoriam. Ita enim fideles hortatur in ea fide, quam acceperant, neglectis afflictionibus perseverent, ut interim summarium religions et fidei fundamenta ubique ponat, denique et christiana perstringat officia. Desultoria enim

Patientia. est. Persequtio a fide vel absterrebat vel prorsus avocabat (ut fit) plurimos, potissimum ergo hortatur ad patientiam, qui huius epistolae veluti primarius 15 scopus est; cui protinus attexitur alius non minus infrequens, ad confirmationem Fides vera. tamen superioris pertinens, verissimam esse praedicationem, quae de fide christiana ipsis sit praedicata. Id etenim hoc attexitur consilio, ne isti se frustra in caussa non bona pati ti|merent. Veritati huic adiungit pietatis synceritatem integritatemque, deflectens ad innocentiae studium, quo in loco non minore dili- 20 gentia frequentiave laborat quam in superioribus. Maximas enim partes et primi et secundi capitis huic impendit, adhortans, ut vitam vivant sanctam et sua vocatione dignam. Haec autem omnia generatim prosequitur. Absoluta vero fide et vitae innocentia, quae verae pietatis summa est, specia|tim pertractat christiana

Officia. quaedam eaque apprime necessaria officia, docens, quid debeamus magistratui, 25 legibus, quid deceat servos, quid coniugatos; breviter Christi exemplo ad maximas quasque virtutes, potissimum vero ad patientiam et innocentiam vitae animat, ubique amoliens, quod impedire, et admovens, quod promovere ad haec poterat, Crux et idque agit a fine secundi cap[itis], per tertium et initia quarti. Nam sub finem afflictio. huius miro ardore miraque evidentia tolerantiam suadens afflictiones attenuat. In 30 5. autem ad officiorum institutionem rediens, instituit episcopos hortaturque ad humilitatem animi et accuratam vigiliam. In summa: varia est epistola et veluti locis luxurians communibus, in quibus tamen primas tenent fidei in Christum veritas, vitae innocentia (sub qua recensentur varia officia) sanctaque tolerantia. Maxima ergo ex hac expectes licebit, quae fidei christianae vis et veritas, quae 35 
vera religio, quae verae fidei opera, quae chri|stianorum officia, quae patientiae dignitas etc.

Erudita vero est et profecto digna (ut Eras[mus] ait) apostolorum principe, Dictio. plena authoritatis ac maiestatis apostolicae, verbis quidem parca, sententiis vero 5 differta. $^{4}$ Scriptam aiunt e Babylone per Sylvanum. ${ }^{5}$

\section{Inscriptio.}

1 Petrus apostolus Iesu Christi advenis sparsim incolentibus Pontum, Galatiam, Capadotiam, Asiam et Bithyniam, delectis 2 iuxta praefinitionem dei patris per sanctificationem spiritus in obedientiam et aspersionem sanguinis Iesu Christi. Gratia vobis et pax multiplicetur.

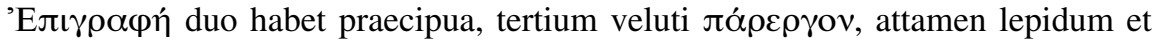
saluberrimum est. Primo enim proditur epistolae author PETRUs ille quondam Christo dilectus vir, de quo plurima scripserunt evangelistae. Hunc veteres »principem apostolorum « dixere,${ }^{6}$ non quod primatum apud apostolos fuisse putarent, ${ }^{7}$ qualem neoterici contra scripturas tuentur, sed quod caeteris ardentior, primas fere in agendo dicendoque apud dominum in ordine apostolorum teneret et quod ipsi gratia prae multis copiosior a deo data esset, ${ }^{8}$ unde et caeteris nonnunquam | constantior et audentior fuit, quanquam eundem oportuerit non citra mysterium maximum fieri infirmitatis humanae veraeque poenitentiae exemplum. D[ivus] $22[, 31-34.56-62]$

20 Caecilius Cyprianus hunc ipsum facit typum unitatis ecclesiae, De simplicitate praelatorum in haec verba scribens: »Loquitur dominus ad Petrum: >Ego tibi dico, quia tu es Petrus et super istam petram aedificabo ecclesiam meam, et portae inferorum non vincent eam. Et tibi dabo claves regni coelorum, et quae ligaveris super terram, erunt ligata et in coelis, et quaecunque solveris super terram, erunt »Tibi dabo soluta et in coelis < [Mt 16,18f.]. Et eidem post resurrectionem suam dicit: >Pasce oves meas< [Joh 21,17]. $\ll^{9}$ Et $\gg$ quamvis apostolis omnibus post resurrectionem SUAM PAREM POTESTATEM tribuat et dicat: >Si cui remiseritis peccata, remitentur

Z. (3) Eras[mus]] Erasmus $Z G$ - (8) Capadotiam] Cappadotiam $Z G$ - (12) saluberrimum] saluberrimmum $G$
4 Erasm. par. 1Petr. (ASD VII/6 184,3-5): »Petrus [...] Iudaeis scribit sparsim incolentibus gentium regiones epistolam profecto dignam apostolorum principe, plenam autoritatis ac maiestatis apostolicae, verbis parcam, sententiis differtam.«

5 Erasm. par. 1Petr. (ASD VII/6 184,23-25).

6 Vgl. Rufin. hist. 2,14,6 (GCS IX/1 139,21f.); Hier. vir. ill. 1 (PL XXIII 638B).

7 Vgl. Eck ench. 3 (Fraenkel 48).
Vgl. Rufin. hist. 2,14,6 (GCS IX/1 139,20-22): »[...] probatissimum omnium apostolorum et maximum fidei magnificentia et virtutis merito primorum principem Petrum.«

9 Cypr. unit. eccl. 4 (CCSL III 251,73-81). Cyprians Schrift »De catholicae ecclesiae unitate « trägt in Erasmus' Ausgabe von Cyprians Werken den Titel »De simplicitate praelatorum«, vgl. Cypr. op. 162.
Petrus

apostolorum princeps. 
ei; si cui tenueritis, tenebuntur< [Joh 20,23], tamen, ut unitatem manifestaret, unitatis eiusdem originem ab uno incipientem sua authoritate disposuit. Hoc erant utique et caeteri apostoli, quod fuit Petrus, PARI consortio praediti et HONORIS ET POTESTATIS, sed exordium ab unitate proficiscitur, ut ecclesia una monstretur. ${ }^{10}$ Tantum sanctissimus ille martyr. Porro Petrum perhibent veterum monumenta a 5 Nerone crucis patibulo damnatum ita migrasse, ut ipsi praedixerat in evangelio Petrus an dominus. ${ }^{11}$ Nec me latet, quid multi de eo disputarint, quod Petrus Romam Romam venerit. nunquam venerit. ${ }^{12}$ Ego vero vetustis $\mid$ hac in re diversum testantibus plus fidei tribuerim. ${ }^{13}$ Habeo autem testes locupletissimos: Irenaeum adver[sus] Valentin[ianos], lib[ri] 3. cap[ite] 1., ${ }^{14}$ Tertullia[num] in Praescriptionib[us] haeret[ico- 10 rum], ${ }^{15}$ proximos apostolorum temporib[us]; Lactantium Firmia[num] in 4. cap[ite] 21., ${ }^{16}$ Caium quoque scriptorem vetustiss[imum] ${ }^{17}$ et Dionysium Corinthiorum episcopum ${ }^{18}$ apud Eusebium, ${ }^{19}$ quem interim in opere Chronico falsum esse temporum computatione non ambigo. Ibi enim refert Petrum Romam venisse anno Claudii ${ }^{20}$ Caes[aris] secundo rexisseque Romanam ecclesiam annis $25 .{ }^{21} 15$ Occubuisse enim ultimo Neronis anno, qui imperavit annis 14. Atque hanc quidem sententiam imitatus est et d[ivus] Hieronymus in opere De viris illustrib[us]. ${ }^{22}$ Caeterum si accurate ista conferamus ad ea, quae Paulus scripsit in 2 . cap[ite] ad Galat[as], prorsus illam Eusebii computationem falsam esse depraehendemus. Id quod et ante $\mid$ nos clarissimus vir et Helvetiae nostrae decus $20 \quad 5 \mathrm{zG}$ immortale d[ominus] Ioachimus Vadianus ${ }^{23}$ observavit. $^{24}$ In Galatis enim refert

Z. (9) adver[sus]] adversus $Z G$ - (10) Tertullia[num]] Tertullianum $Z G$ - (11) temporib[us]] temporibus $Z G$ - (11) Firmia[num]] Firmianum $Z G$ - (12) vetustiss[imum]] vetustissimum $Z G$ - (15) Caes[aris]] Caesaris $Z G$ - (17) Hieronymus] Hierony[mus] $Z G$ - (17-18) illustrib[us]] illustribus $Z G$ - (19) Galat[as]] Galatas $Z G$

10 Cypr. unit. eccl. 4 (CCSL III 251f.,80-98).

11 Hier. vir. ill. 1 (PL XXIII 638B). Vgl. Joh 21,18f.

12 Vgl. Vel. Petr.

13 Vgl. Bullinger an Oswald Myconius, 31. März 1534 (HBBW IV 100,18-21): »Negotium de eo, quod Petrus Romam vel viderit vel non viderit, in nullius tractavi praeiudicium, sed ut rem dubiam et in qua parum utilitatis est, si pietatis summam spectemus, dubiam reliqui, ut quisque suo sensu abundet.«

14 Iren. haer. 3,1,2 (Harvey II 3): »[...] cum Petrus et Paulus Romae evangelizarent [...].«

15 Tert. praescr. 32,1f. (CCSL I 212f.).

16 Lact. inst. 4,21 (CSEL XIX/2 367,17-19): »Quae Petrus et Paulus Romae praedicauerunt et ea praedicatio in memoriam scripta permansit.«

17 Gaius (2 Jh.), griechisch schreibender Theologe aus Rom, vgl. NP IV $738 f$.
18 Dionysios, um 170 Bischof von Korinth, vgl. NP III 646.

19 Euseb. hist. eccl. 2,25,6-8 (GCS IX/1 176,21178,15).

20 Claudius, römischer Kaiser 41-51, vgl. NP III 22-26.

21 Euseb. chron. 2 (PL XXVII 449f.): »Petrus apostolus [...] Romam mittitur ibique evangelium praedicans XXV annis eiusdem uribis episcopus perseverat.«

22 Hier. vir. ill. 1 (PL XXIII 638B): »Simon Petrus [...] secundo Claudii anno ad expugnandum Simonem magum Romam pergit ibique viginti quinque annis cathedram sacerdotalem tenuit usque ad ultimum annum Neronis, id est quartum decimum.«

23 Joachim Vadian (von Watt, 1484-1551), Reformator und seit 1526 Bürgermeister der Stadt St. Gallen, vgl. HBBW II 38.

24 Dazu und zu den folgenden Berechungen vgl. 
Paulus se post annos quatuordecim (nimirum a conversione sua) ascendisse Hierosolymam ibique invenisse Petrum, Ioannem et Iacobum. ${ }^{25}$ Is autem sextus erat Claudii annus. Si enim Tiberius ${ }^{26} 23$ annis regnavit, ut de eo scripsit Suetonius, ${ }^{27}$ et in 18. anno passus est Christus, ut testatur Tertullianus, ${ }^{28}$ supersunt de 5 regno eius anni 5. His unum adime. Altero enim a morte Christi anno ad fidem Christi conversus est Paulus. Remanent ergo $\mid$ anni 4, quibus si addas ex Caligulae regno annos 4 et ex Claudii 6, invenies annos, de quibus Paulus in Galatis loquitur, 14. Non iam referam tres illos annos, quorum in 1. cap[ite] meminit. ${ }^{29}$ Ita enim nono Claudii anno Petrus etiamdum Hierosolymis fuisset. Nec vero simile est Petrum Claudio vivente Romam venisse, utpote cuius nulla fit a Paulo in Roma[nis] mentio neque a Luca in postremo Actuum capite, interim cum in epistola Rom[anis] scripta multo inferiorum nomina cum reverentia recenseat, ${ }^{30}$ praeterea in hoc historia in quartum usque Neronis annum deducatur. ${ }^{31}$ Proinde si vera scripsere veteres, verisimile est Petrum post Paulum, cum iam Nero annis 15 aliquot imperitasset et Paulus fortassis Hispaniam adiisset, ${ }^{32}$ appulisse Romam confirmandi evangelii fratrumque gratia. Sed nos de hac re ut dubia ita non magnae frugi prolixius disseruimus, quam institueramus. Secundo docet غ̇лı$\gamma \rho \alpha \varphi \eta ́$, quibus scripta dicatave sit epistola: $\pi \alpha \rho \varepsilon \pi ı \delta \eta ́ \mu o เ s, ~ q u o s$ alii proselitos, alii advenas exponunt, ${ }^{33}$ cum Graecis $\dot{\varepsilon} \pi \iota \emptyset n \mu o$ et populares dicantur. ${ }^{34}$ Populares 20 vero dixere Latini de uno populo amicos. ${ }^{35}$ Proinde non absurdum fuerit, si intelligamus hanc epistolam Iudaeis Petri popularibus esse scriptam. Quo et illud

\section{Z. (11) capite] cap[ite] $Z G$ - (13) in hoc] Actorum $Z G$ - (18) proselitos] proselytos $Z G$}

Vad. epit. 122-125. Da Vad. epit. allerdings erst im September 1534 erschienen ist, bezieht sich Bullinger hier vermutlich auf die Vorträge über Apg, die Vadian 1523 vor einem kleinen Kreis von Gelehrten in St. Gallen gehalten hatte und welche die Vorlage für Vad. epit. bildeten, vgl. Bonorand 1962. Diese zirkulierten zunächst als Manuskript und waren Bullinger in dieser Form auch bekannt (vgl. Bull. act. $* 3 \mathrm{v})$. Bullinger bedauerte später gegenüber Vadian, dass er sich während der Arbeit am Kommentar zu den Petrusbriefen nicht auf Vad. epit. stützen konnte, vgl. Bullinger an Joachim Vadian, 17. März 1534 (HBBW IV 92,12-15): »Mitto tibi commentarios nostros in epistolam Petri utramque effusos verius quam scriptos in hisce negotiorum turbis. Quam vero optarem Epitomen illam tuam hodie esse aeditam! Sed et nunc quoque oro, aeditionem matures.« Gal 2,1.9.

26 Tiberius Caesar Augustus, römischer Kaiser 14-37, vgl. NP XII/1 532-535.
27 Suet. Tib. 73,2 (Ihm 151,3f.): »[...] obiit in uilla Lucullana octauo et septuagesimo aetatis anno, tertio et uicesimo imperii. «Sueton (Gaius Suetonius Tranquillus, 1./2. Jh. n. Chr.), römischer Biograph und Antiquar, Autor der »De Caesarum vita libri octo«, vgl. NP XI 1084-1088.

28 Tert. adv. Iud. 8,16 (CCSL II 1362,120f.): »Huius [sc. Tiberii] quintodecimo [!] anno imperii patitur Christus [...].«

29 Gal 1,18 .

30 Röm 16,3-15.

31 Hier. vir. ill. 7 (PL XXIII 650C-651A): »[...] cuius [sc. libri Apostolicorum actuum] historia usque ad biennium Romae commorantis Pauli pervenit, id est usque ad quartum Neronis annum.«

32 Vgl. Röm 15,24; Bull. Rom. 15,23-24 (Baschera 215,11-29).

33 Erasm. 1Petr. (ASD VI/10 429,5-10): »Non est Graece $\pi \rho \circ\rceil \eta \lambda u ́ \tau o เ \varsigma$, quo verbo significare solent eos, qui ex paganismo sese contulissent ad legem Mosaicam, sed $\pi \alpha \rho \varepsilon \pi เ \delta \eta ́-$ 
pertinet, quod dispersionis meminit. Iudaeos enim bellorum procellae olim sub Assyriorum, Babyloniorum, Persarum et Macedonum regibus ortae alios alio di| spulerunt, ut abunde satis sacra testatur historia. ${ }^{36}$ Neque vero consequens est istis regionibus a Petro praedicatum fuisse evangelium propterea, quod hanc ipsis adscribit. ${ }^{37}$ Romanis enim adscripsit Paulus Romanos, quos Iunius et Andronicus primi in religione instituerant. ${ }^{38}$ Leguntur et Galatae et Asiani Paulo preceptore in fide primo esse imbuti. ${ }^{39}$ De Bithynis et Capadocibus nihil prodit sacra historia. Certe Petrus istis omnibus hac epistola attestari voluit eam fidem, quam acceperant sive a Paulo sive ab ipso Petro sive alio quopiam apostolorum, veram esse. De Ponto multa Strabo ${ }^{40}$ Geog[raphiae] 12. lib[ro] et Plinius in $6 .{ }^{41}$ Tertium iam 10 sequitur. Nam, cum paucis potuisset dicere: »Petrus apostolus gratiam et pacem precor omnibus Ponticis et Asianis Christo dicatis«, maluit hoc postremum copiosius persequi et christianae religionis maxima commemorare mysteria, ade-

Electio dei ordinaria et

iusta. oque et salutis et verae pietatis modum rationemque perstringere. Prima in hac

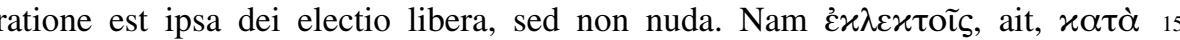

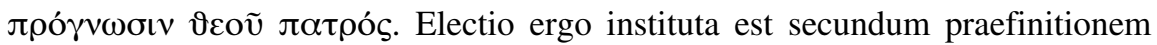
sive praescientiam. Hac vero et misericordiam suam et iusticiam prodit deus. Misericordiam quidem, quod citra meritum nostrum sola et nativa bonitate nos vocat et beat, id quod Paulus ad Ephe[sios] 1. latius persequitur, ${ }^{42}$ iusticiam vero, quod electio non est $\mid$ temeraria, sed secundum praescientiam. Haec enim redemp- 20 5v $G$ tionis expiationisque trahit mysterium. Quos ergo delegit, in sanctificationem delegit, hoc est, quos beat deus, eos non temere beat, sed per sanctificationem spiritus. At voce »spiritus « omnem externum exclusit purificandi ritum, fidem in Christum unicam extulit. ${ }^{43}$ Clarius enim sequitur: »In obedientiam et aspersionem sanguinis Iesu Christi.«Ecce, haec est vera spiritus sanctificatio: obedire evan- 25 gelio, fidere Christo, qui sanguine suo effuso dignos nos fecit aeterna vita. Neque

Z. (7) Capadocibus] Cappadocibus $Z G$ - (17) iusticiam] iustitiam $Z G$ - (19) iusticiam] iustitiam $Z G$ (22) sed] se $G$

$\mu$ oıs, vt nihil dicat Lyranus, qui putat haec proselytis potissimum scribi. Etiamsi is Bedam videtur sequutus, qui admonet in commentariis aduenas Latine dici qui Graecis dicuntur proselyti subindicans hanc epistolam illis scribi.« Der traditionellen, durch Erasmus abgelehnten Auslegung von »advenae« schließt sich hingegen Luth. 1Petr. 4r-v an.

34 Fab. Stap. 1Petr. 18v: ">Advenis <: peregrinis, incolis, $\pi \alpha \rho \grave{\alpha} \dot{\varepsilon} \pi \mathrm{\delta} \hat{\mu} \mu \mathrm{ols.}$ «

35 Non. 1 (Lindsay I 57,31f.): »Populare significat populi amorem conciliare: unde populares dicti de uno populo amici.«

36 Vgl. 2Kön 17,6; 25,11. Vgl. Vad. epit. 264 271.
37 So hingegen Hier. vir. ill. 1 (PL XXIII 638B). 38 Röm 16,7.

39 Gal 1,11; Apg 19,10.

40 Strabon (1. Jh. v./1. Jh. n.Chr.), griechischer Geograph und Historiker, vgl. NP XI 10211025.

41 Strab. geog. 12,3,1-7 (Jones V 370-380); Plin. nat. 6,1-7 (Ianus/Mayhoff I 428-431).

42 Eph 1,3-12.

43 Erasm. 1Petr. (ASD VI/10 430,32f.): »Sanctificationem Spiritus opposuit operibus legis Mosaicae, a quorum fiducia vult eos abducere.« 
vero dubitandum est Petrum »aspersionis« vocabulo allusisse ad legalia, quasi dixerit: salus dilectis dei non contingit »ex asperso vituli sanguine $\ll{ }^{44}$ sed ex redemptione Christi. De qua re copiosius disputavit Paulus ad Hebrae[os] 9.45 Ratio igitur verae salutis haec est: eligimur ad salutem a deo. Ista vero non temere 5 confertur, sed per redemptionem Christi, in qua oportuit declarari cum misericordia tum iusticia dei. Huic autem Christo unice fidendum eiusque doctrinae obediendum. Itaque errant qui solam electionem vel praedicant vel iactitant, fidem vero, iustitiae fructus et preces ardentes ceu inutiles contemnunt. Quasi vero electio dei iniusta aut temeraria esse possit. »Quos«, ait Paulus, »praescivit, eosdem et praefinivit conformes imaginis filii sui« [Röm 8,29] etc. De salutatione apostolica in $\mid$ Paulinis epistolis alias copiosius. ${ }^{46} \mid$ In hac praeter communem morem: »Pax «, ait, »multiplicetur «, nimirum quod ibi animi pace securitateque Pax. opus est, ubi mala praeter solitum affligunt hominem. Huc pertinet illud salvatoris dictum: »In mundo afflictionem habebitis, in me vero pacem« [vgl. Joh 6,33].

3 Laudandus est deus et pater domini nostri Iesu Christi, qui iuxta suam copiosam misericordiam regenuit nos in spem vivam per hoc, quod resurrexit Iesus Christus ex mortuis 4 in haereditatem immortalem et incontaminabilem atque immarcessibilem, conservatam in coelis erga vos, 5 qui virtute dei custodimini per fidem ad salutem, quae in hoc parata est, ut patefiat in tempore supremo,

Expositione init negotium gratulationeque in animos sese insinuat auditorum. Summa omnium istorum in hoc est: »Laudandus est deus, qui misericordia sua per Christum redemit nos a morte vitamque nobis donavit aeternam.« Copiosius autem persequitur membra singula, partim ut ipsum dei beneficium commendaret, partim ut consequenti argumentationi viam sterneret commodam. Principio laudandus est deus, inquit; laudis enim sacrificium novi populi, gratissimum deo | Sacrificium sacrificium est, ${ }^{47}$ quo si quis non litarit, nequaquam nomine Christi accensendus erit. Deinde per expositionem subiungit, quis sit ille deus, nimirum pater domini Dei nomina. nostri Iesu Christi. Qua sententia divinitatem Christi et personarum demonstrat subsistentiam. Et nomina sive appellationes dei essentiam dei non circumscribunt pleneque nobis referunt, sed aliquo modo et formula quadam captui humano commoda efferunt. ${ }^{48}$ Iam et deum esse aliud non est quam beneficum, benignum,

Z. (6) iusticia] iustitia $Z G$

44 Erasm. par. 1Petr. (ASD VII/6 188,32).

45 Hebr 9,11-28.

46 Siehe Bull. Rom. 1,1-7 (Baschera 20-25).
47 Siehe oben S. 170f.

48 Vgl. Biel sent. I d. 2 q.2 C 16-19 (Werbeck/Hofmann I 149): »Perfectiones attribu- 
bonum, auxiliarem, denique et vitam et conservatorem esse omnium. Cum ergo istam suam beneficentiam et opes ineffabiles tum maxime mundo prodidit, cum filium unicum in mundum misit, non abs re dicitur pater domini nostri Iesu Christi, utpote qui se in Christo maxime deum, id est benignum et servatorem, ostenderit. Sed ipse Petrus dilucide iam addit caussas, cur sit laudandus, in quibus simul et divinae naturae declaratur indoles. Dicit enim: »Qui iuxta copiosam suam misericordiam regenuit nos in spem vivam.« Propterea, inquit, laudandus est deus, quod nullis nostris provocatus meritis, mera et nativa bonitate sua ductus nos a morte aeterna revocavit ad spem vitae immortalis. Haec vero evangelii summa et scopus est. Vide autem, quam gravibus verbis efferat singula. Mise- 10 ricordiae appositum addit epitheton, »copiosam《 aut »multam《 aut »divitem « appellitans. Pro|pheta enim: »Miserator«, inquit, »et misericors dominus, longanimis et multum misericors. Non in perpetuum irascetur « etc., Psal. 102. ${ }^{49}$ Deinde multo vividius est: »Regenuit nos in spem vivam«, quam si dixisset:

Renascentia. »Restituit nobis vitam. « Principio enim regenerandi verbum commonet nos no- 15 strae infirmitatis et miseriae. Genuerat nos Adam, sed ad mortem, ${ }^{50}$ natura enim filii irae sumus. ${ }^{51}$ Regeneratione ergo opus iis, qui filii haeredesque dei esse debebant. Hanc vero renascendi potestatem fecit deus omnibus in Christum credentibus, ut diligentius excutitur apud Ioannem in capite primo et tertio. ${ }^{52}$ Deinde plus dixit: »Regenuit nos in spem vivam«, quam si dixisset: »Vivificavit«; non 20 tam quod orationis genus dicendique figura augustior est, quam quod ipsa res sic enunciata nescio quid magni spirare videtur. Iam et modum et rationem ostendit, per quam simus renati in spem vivam, nimirum per id, quod deus filium excitavit

Resurrectio. a mortuis. Resurrectio sane comprehendit totum Christi mysterium. Resurrectione enim declaratur orbi, quod peccatum sit expiatum. Nisi enim peccatum ex- 25 piasset dominus, praevaluisset mors peccati poena. ${ }^{53}$ Revixit autem dominus, proinde et mortem et peccatum abolevit; non quod non sint, sed ne fidelibus noceant, qui iam per vivificam Christi resurrectionem discunt vitam parem ipsis esse paratam. De qua multis in $\mid 1$. ad Corinth[ios], cap[ite] $15 .{ }^{54}$ Porro hic mi|ra verborum turba miro incremento loquitur de aeterna vita per Christum nobis parta, quam iam ante vocarat $»$ spem vivam $\ll$. Nunc haereditatem vocat immorImmortalitas. talem, Graece ö $\varphi \vartheta \alpha \rho \tau o v, »$ incorruptibilem $\ll,{ }^{55}$ tacita collatione hanc haereditatem cunctis in orbe praemiis praeferens. In hoc saeculo nihil tam firmum, pulchrum et desiderabile est, quod incorruptionis sit expers, haec sola spes vivifica et

Z. (29) Corinth[ios], cap[ite]] Corinthios, capite ZG

tales $[. .$.$] neque sunt Deus neque in divina$ essentia. Patet, quia sunt conceptus vel signa divinam essentiam significantia. Illa autem non sunt Deus.«

49 Ps 103,8f. (Vulg. 102,8f.).

50 Röm 5,17; 1 Kor 15,22.
Eph 2,3.

Joh 1,$13 ; 3,3.5 f$.

Röm 6,23.

1Kor 15,20-28.

Vgl. Fab. Stap. 1Petr. 20r. 
immortalis est. Reliqua duo paraphrastes sic interpretatus est: »Manet illa nos foelix haereditas, quae neque taedio molestiave contaminari neque senio situve marcessere possit. $\aleph^{56}$ Apparet autem postremam metaphoram sumptam esse a floribus. Ad superiorem amplificationem pertinet et sequens: »Conservatam in 5 coelis erga vos.«Hoc autem et excellentiam et certitudinem salutis declarat. Quasi dicat: »Nec est, quod metuamus, ne quis hanc intervertat $\ll^{57}$ aut eam nobis praeripiat haereditatem aut humanis aestimet sensibus; coelestis et divina est. Paulus in Colossen[ses] hanc eandam rem aliis verbis ita eloquutus est: »Emortui estis et vita vestra abscondita est cum Christo in deo« [Kol 3,3]. Et ad Philip- Hebraeis

0 pen[ses]: »Nostra «, ait, »conversatio in coelis est, ex quo et servatorem expectamus dominum Iesum Christum, qui transfigurabit corpus nostrum humile, ut conforme reddat corpori suo glorioso « [Phil 3,20f.] etc. Proinde spes nostra, hoc est haereditas nostra, coelestis est, aeterna. Exuti enim mortali hoc corpore »ipsum numen in sua substantia videbimus, in sua specie cumque universis 15 dotibus opibusque suis fruemurque his omnibus non parce, sed ad sacietatem, non ad fastidium, quod fere comitatur saturitatem, sed ad iucundam impletionem, quae quidem minus afficitur taedio, quam flumina, dum perpetuo in mare influunt et per terrae abyssum refluunt, nullum adferunt hominibus taedium, sed commodum potius et gaudium, semper rigando, laetificando ac nova germina foven20 do. $\ll^{58}$ Et Seneca de hac alibi multo foelicius theologastris quibusdam disseruit. ${ }^{59}$ Sequitur nunc occupatio: si enim bravium foelicitas et beata vita in coelis conservata est, quid interim nos in terris? Quae hic nobis spes habenda? »Custodimur«, inquit, »virtute dei per fidem ad salutem.« Multa hic nobis mala perferenda pietatis nomine, sed vincunt sancti fide, quae virtus dei est. Nam et Ioannes: Sic delabitur ad patientiam. »Haec est victoria«, ait, »quae vicit mundum, fides vestra« [1Joh 5,4]. Fides in adversis animat, confirmat, consolatur, erigit et ducit, ne uspiam impingamus aut, si ruere coeperimus, non corruamus saluteque excidentes collidamur. Proinde, dum in humanis agimus, nullae induciae, nulla pax speranda est. Caeterum, ubi foeliciter hanc absolverimus militiam, tum corona ista immarcessibilis in coelis reposita imponitur vincentibus. Id quod Petrus sic extulit: »Quae in hoc parata est, Corona immarcessibilis. ut | patefiat tempore extremo.« Extremum autem tempus animae respectu est, quum ex humanis excedimus, at respectu finis rerum omnium, quum corpora resuscitantur ad iudicium; tum enim aeternum et animo et corpore vivent sancti, impii perpetua morte peribunt. Non potui hic non annotare paraphrastis vere

Z. (2) foelix] felix ZG - (8) Colossen[ses]] Collossen[ses] $G$ - (9-10) Philippen[ses]] Philippenses $Z G$ (15) sacietatem] satietatem $Z G$ - (17) influunt] influnt $G$ - (20) foelicius] felicius $Z G$ - (21) foelicitas] felicitas $Z G-(29)$ foeliciter] feliciter $Z G$

56 Erasm. par. 1Petr. (ASD VII/6 188,69-71).

57 Erasm. par. 1Petr. (ASD VII/6 188,71f.)

58 Zw. fid. exp. (Z VI/5 131,1-8).
59 Vgl. Sen. dial. 11,9,5-9 (Hermes 322,26$324,4)$.

"abscondere « est »servare«, ergo »abscon»servata $\ll$. De aeterna vita.

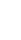


aurea verba ista: »Nunc latent praemia et saepe iuxta vulgarem aestimationem peius habent, qui meliores sunt, et perire videntur, qui maxime sunt incolumes, et florere videntur, qui maxime pereunt. Hic exercendae pietatis tempus est; praemio suum praescriptum est tempus, quod non oportet antevertere. Nobis interim sit satis, quod aeterna foelicitas nobis est in tuto, quam nullus hominum aut daemonum possit intercipere, modo ne nos deficiat fides, qua neglectis rebus mortalium, toti pendeamus a coelo. Sint interim feroces, qui deo rebelles fidunt mundi praesidiis. Insultent interim; caeterum, ubi venerit illa dies versis in diversum rerum vicibus affligentur illi, vos exultabitis victores. $\ll^{60}$

6 in quo exultatis, nunc ad breve tempus, si necesse sit, afflicti in variis experimentis, 7 quo exploratio fidei vestrae multo preciosior auro, quod perit et tamen per ignem probatur, reperiatur in laudem et gloriam et honorem tum, cum revelabitur Iesus Christus.

Patientia. $\mid$ Fundamentis per superiora iactis captisque beatitudinis aeternae desyderio lectoribus, superstruit nunc patientiae praeclarum aedificium, per praemia et coe- 15 lestia bona ad ipsam adhortans. Diximus autem in argumento patientiam frequentem et celebrem esse huius epistolae locum. ${ }^{61}$ Ad hunc porro modum cohaerent singula. Dixit immarcessibilem $\mid$ coronam nobis esse in coelis repositam. Huic iam subiungit: »In quo ( $\dot{\alpha} \gamma \alpha \lambda \lambda \iota \tilde{\alpha} \sigma \vartheta \varepsilon)$ exultatis« vel (imperandi modo) »exultate «, ${ }^{62}$ deß jr üch fròuwen und trồsten sòllend, »qui nunc adversam 20 fortunam experimini «. Caeterum, ut brevitas docta argumentatione est referta, ita hic aliud quoque a temporis brevitate intertexitur argumentum. Habent mala singula, quantumvis magna sint, finem suum et totum hoc, quod vivimus, tempus quam brevissimum est. Mala itaque minus diuturna sunt. Pulcherrime enim Seneca: »Propone«, ait, »profundi temporis vastitatem et universum complectere, 25 deinde hoc, quod aetatem vocamus humanam, compara immenso: videbis, quam exiguum sit, quod optamus, quod extendimus. Ex hoc quantum lachrymae, quantum solicitudines occupant? Quantum mors, antequam veniat, optata, quantum valetudo, quantum timor? Quantum teneri aut rudes aut inutiles anni? Dimidium ex hoc edormitur. Adiice labores, luctus, pericula, et intelliges etiam in longis- 30 sima vita minimum esse, quod vi|vitur. $\ll^{63}$ Adiicitur et aliud non minus iucundum et consolatione plenum: »Si necesse sit.«Quasi dicat: si exigat negotium ipsaque

Z. (5) foelicitas] felicitas $Z G-(11)$ preciosior] pretiosior $Z G-(14)$ desyderio] desiderio $Z G$ (23) quantumvis] quantumis $G$

62 Erasm. 1Petr. (ASD VI/10 432,44): »Legi potest et >exultate< imperandi modo.«

63 Sen. epist. 99,10f. (Hense 471,18-472,4).

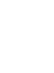


salus nostra, brevi finiet afflictiones dominus. »Fidelis enim deus, qui non sinit nos tentari supra id, quod possumus« [1Kor 10,13]. Vel: »Afflicti, si opus sit«, id est: non afflixerit dominus, nisi prosit vobis afflictio. A caussa ergo ductum argumentum. Declaratur autem isto eos errare plurimum, qui crucem sive afflic-

5 tionem inter summa infortunia primam numerant vel non expectata dei sententia Afflictio sancta. sibiipsis imponunt crucem. ${ }^{64}$ Hoc enim crede: si necesse sit, dominum non obdormiturum res tuas; tu magis curaveris, ut ad afflictionem tuam patienter feras manum eius, sive ipsa crux multo sive pauco sit ferenda tempore. Ad $\dot{\xi} \xi o v \vartheta-$ $\varepsilon v ı \sigma \mu o ́ v^{65}$ illud pertinet, quod afflictiones iam »experimenta« vocat, ab utilitate 10 argumentans. Locus autem praesens a Paulo elucidatus legitur ad Roma[nos] 5.: »Gloriamur super afflictionibus scientes, quod afflictio« [Röm 5,3] etc. Nam notissimus alias locus. Quin et consequens ómoíwoıৎ de auro et igne facit ad expositionem loci praesentis. Quod enim ignis est auro, id afflictio est fideli: aurum igne non deperditur, sed probatur purgaturque; proinde afflictionibus non 15 perduntur fideles, sed excoquuntur in hoc, ut synceri sint in fide. ${ }^{66}$ Recte ergo afflictiones vocavit »experimenta . Ductum est et hoc argumentum ab utilitate, sed exornatum collatione et allusione. | Confertur enim auro fides, quae et ipsa ut aurum probatur; atque hac re auro similis est, sed auro nobilior fides. Aurum sane preciosissimum est in rebus mortalium, sed longe excellit fides, quae rerum 20 aeternarum est, cum illud caducum sit, $\gg$ res alioqui perdita et peritura $\ll{ }^{67}$ Eras-

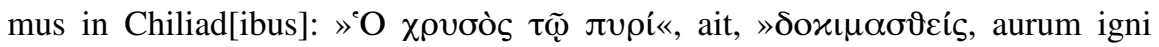
probatum dicitur is, cuius fides rebus adversis explorata spectataque est. $\ll^{68}$

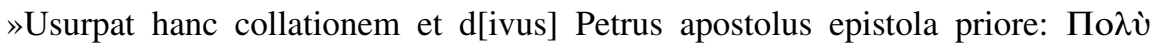

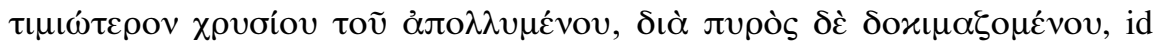
est: >Multo preciosius auro, quod perditur $<$, sive >auro pestifero, quod tamen per ignem probatur. $<$ Est autem hoc auro non citra miraculum peculiare, ut igni non solum non fiat deterius, sed magis ac magis enitescat. Itidem is, qui vere bonus est, obiectis malorum procellis illustrat animi virtutem, non amittit « ${ }^{69}$ et quae sequuntur. Hactenus enim Eras[mi] verba retulimus. Allusum quoque ad literas 30 sanctas. Nam Psal[mo] 65.: »Quoniam probasti nos deus«, inquit David, »igne nos examinasti, sicut examinatur argentum. Induxisti nos in laqueum, posuisti

Z. (10) Roma[nos]] Rom[anos] $Z G$ - (19) preciosissimum] pretiosissimum $Z G$ - (29) Eras[mi]] Erasmi $Z G$ - (30) Psal[mo]] Psalmo $Z G$

64 Vgl. Luth. 1Petr. 12v: »Multi namque homines sunt, qui velut impetu quodam coelum invadere conantur et ilico irrumpere atque ideo sibi ipsis crucem pro suo arbitrio imponunt [...]. At Deus ista damnat.«

65 Eine von mehreren Unterarten der Ironie, vgl. HLR 303.

66 Vgl. Luth. 1Petr. 13r: »Ignis aurum non im- minuit, sed mundat et reddit pururm, ut inde, quicquid admixtum fuerit, evaporet. Eadem ratione deus omnibus christianis crucem imposuit, per quam purgentur.«

67 Erasm. par. 1Petr. (ASD VII/6 190,99f.).

68 Erasm. adag. 3058 (ASD II/7 74,681f.).

69 Erasm. adag. 3058 (ASD II/7 76,698-703). 
tribulationes in dorso nostro, imposuisti homines super capita nostra. Transivimus per ignem et aquam, et eduxisti nos in refrigerium « [Ps 66,10-12 (Vulg. 65,1012)]. Item Zachar[iae] 13., qui locus maxime huc pertinere videtur, legimus dixisse dominum: »Et covertam manum meam | ad parvulos, et erunt in omni terra, dicit dominus. In duas partes dividentur et deficient, et tertia pars relinquetur in ea, et hanc ducam per ignem et excoquam eos, sicut excoquitur argentum, et probabo eam, sicut probatur aurum « [Sach 13,7-9]. Porro id totum (iam iterum deflectit ad utile) in hoc fit, »ut, quod hic videbatur illatum ad dedecus, cedat in laudem ${ }^{70}{ }^{70}$ gloriam et honorem. Habet autem virtutem verborum congeries, eximiam significans fore sanctorum gloriam non in hoc mundo, sed tum, 10 cum apparuerit salvator Christus. Ioannes enim: »Scimus«, ait, »quoniam, si apparuerit, similes ei erimus, quoniam videbimus eum, sicuti est« [1 Joh 3,2]. Et Paulus: »Transfigurabit corpus nostrum humile, ut conforme reddat corpori suo glorioso« [Phil 3,21]. Item: »Iustum est apud deum reddere iis, qui affligunt vos, afflictionem et vobis | relaxationem« etc., 2. Thessalonicen. 1[,6f.]. Hactenus 15 9 zG animavit afflictos nomine fidei ad patientiam; potissimum autem spem futurorum bonorum proposuit, quae ut sola fide percipiuntur, ita patientia sola fide animatur.

8 Quem, cum non videritis, diligitis; in quem in praesentia, cum non videatis, credentes tamen, exultatis gaudio ineffabili et glorificato, 9 reportantes finem fidei vestrae, salutem animarum;

Nunc ergo de ingenio fidei paucula haec obiter inserit, ut aditum simul ad approbationem certitudinis fidei paret. Caro experimenta poscit et visibilibus De natura fidei. haeret; fidei autem natura est rebus invisibilibus, hoc est aeternis et divinis, haerere. Paulus enim ad Hebraeos undecimo: »Fides«, inquit, »est substantia rerum sperandarum, argumentum eorum, quae non videntur « [Hebr 11,1]. Ubi 25 plura de natura fidei annotavimus. ${ }^{71}$ Certe Petrus paucis fidei vim et effectum compraehendit. Principio enim adimit illi sensum animalem et obiectum visibile, substituens spiritualem et internum adeoque coelestem sensum, qui nititur rebus et verbis dei aeternis. »Christum «, inquit, »non vidistis, sed in presentiarum «, hoc est, »in mundo oculis carnalibus.« Alias enim nemo nescit et fidei suos esse 30 oculos. Nam in Galatis dicit Paulus: »O stulti Galatae, quis vos fascinavit, ut non

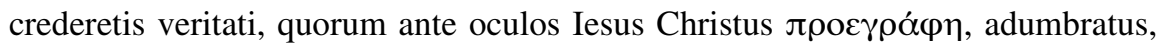
Christus in inter quos et crucifixus? « [Gal 3,1] Hac ratione adest et videtur Christus in coena

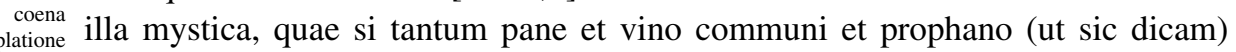

fidei. instructa esset, iam neque »coena mystica neque »coena domini dici posset. 35

\section{Z. (3) Zachar[iae]] Zachariae ZG}

70 Erasm. par. 1Petr. (ASD VII/6 190,105f.). $\quad{ }^{71} \quad$ Siehe oben S. 143-157. 
Iam quae fides comprehendit, vere comprehendit; vera enim, non falsa comprehendit. Proinde cum in coena dominum fidei oculis contemplamur, vere utique adest in coena dominus, vere, inquam, | ut fidei poscit natura. Quod ergo alii sub voce »vere«, »corporaliter« aut »carnaliter« subingerunt, de suo contra fidei 5 naturam adiiciunt. ${ }^{72}$ Fides sane orthodoxa credit Christum dominum incarnatum, in carne mortuum et resuscitatum, ascendisse coelos, sedere ad dexteram patris, inde venturum iudicare vivos et mortuos. ${ }^{73}$ Igitur, quoad in hoc mundo agit fidelis, non videt aut attingit aut manducat Christum corporaliter, id est carnaliter, sed magis spiritualiter. Siquidem ipse Christus apud Ioannem de vera iusticia et fide disserens ait: spiritus sanctus autem arguet mundum »de iusticia, quia ad patrem vado et posthac non $\vartheta \varepsilon \omega \rho \varepsilon \tau \tau \varepsilon$, videtis«, id est videbitis, »me« [Joh Tempus pro $16,10]$. Sed de hac re alias. Deinde fides vera efficit in cordibus fidelium dilectionem cum dei tum proximi. Hinc enim Petrus: »Quem cum non videatis«, ait, Dilectio. »diligitis.« Et Paulus ad Galatas 5.: »In Christo Iesu neque circumcisio neque

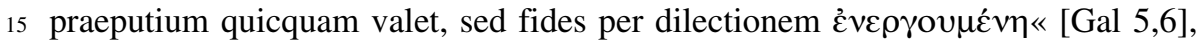
efficax aut agens. Ioannes quoque dilectionem proximi ex dilectione dei aestimans dicit: »Si quis dicit: >Diligo deum<, et fratrem suum odit, mendax est. Qui enim non diligit fratrem suum, quem vidit, deum, quem non vidit, quomodo potest diligere? « [1Joh 4,20] Praeterea pacem et gaudium parit fides in pectoribus Gaudium.

20 fidelium. Nam Petrus: »Credentes tamen, exultatis gaudio«, nec vulgari, sed »ineffabili et glorificato«, | id est defecato. Gaudia enim mundi varia disturbant infortunia, at gaudium fidei nemo hic interturbat. In hoc gaudio omnia pericula contemnentes sancti per patientiae et virtutum tramitatem constanter pergunt ad vitam. Nam fidei finis est aeterna vita. Petrus enim: »Reportantes«, ait, »finem fidei vestrae, salutem animarum.« Ita oportuit et Christum pati et ingredi in gloriam suam. Et in Actis legimus Paulum exhortatum fuisse Antiochenos et Lystranos Iconiensesque, ut perseverarent in fide, et quod per multas afflictiones oporteat intrare in regnum dei, Acto. 14[,22]. Iam ut fide nil verius, certius et constantius est, ita fine eius, aeterna videlicet vita, nil certius, verius praesenti30 usque.

10 de qua salute exquisierunt et scrutati sunt prophetae, qui de ventura in vos gratia vaticinati sunt, 11 scrutantes, ad quem aut cuiusmodi temporis articulum significaret, qui in illis erat spiritus Christi. Qui, priusquam

Z. (9) iusticia] iustitia $Z G$ - (10) iusticia] iustitia $Z G$ - (14) Galatas] Galat[as] $Z G$

72 Vgl. Brenz syngr. (Brecht et al. 272,25-28): »Maria tangens Ihesu pedes, retigit pedes filii dei, qui est intangibilis carnaliter. Quid igitur absurdum erit, si fateamur corpus Christi in- comestibile carnaliter nos edere, dum panem coenae edimus? «

73 Vgl. Symb. apost. (DH 30). 
acciderent, testabatur venturas in Christum afflictiones, et quae essent consequturae glorias;

| Duo simul hisce absolvit. Disserit enim de fidei nostrae veritate ac certitudine, ne afflicti timerent se pati propter caussam sive doctrinam pravam. Sed et prophetiis et Christi exemplo docet non nisi per $\mid$ adversa patere aditum ad foelices beatasque sedes. Paraphrastes ista paucis quidem, sed dilucidissime (ut alias fere omnia) exponit hisce verbis: »Ingens lucrum est, cum iactura caduci corporis servatur immortalis anima. Sic visum est aeterno consilio dei, ut hic rationibus salutem consequerentur homines, quibus et Christus ipse pervenit ad aeternam beatitudinem. Neque enim haec fortuito geruntur, sed, quod nos factum vidimus, id prophetae veteres, qui multo ante nos vaticinati sunt fore, ut per fidem et evangelicam gratiam absque legis Mosaicae praesidio servaremini, diligenter exquisierunt et scrutati sunt, non contenti tanquam per nebulam videre, quod esset futurum, sed illud quoque pia curiositate sciscitati sunt a spiritu Christi, qui iam tum illis arcano afflatu significabat, quid esset passurus Christus ac mox ad quantam gloriam evehendus, quo vel quali tempore id esset futurum. Siquidem ingenti desyderio salutis huius tenebantur illorum animi. $\ll^{74}$ Tantum paraphrastes. Sunt autem nobis singula exactius et diligentius excutienda. Nam hic locus

Unus est spiritus veteris et novi testamenti. maxima firmamenta et mysteria fidei nostrae continet. Principio, quod attinet prophetarum dignitatem et authoritatem, non possum satis mirari quorundam 20 crassam inscitiam et temeritatem blasphemam, qui, cum in prophetis sint inexercitatissimi nec in literis apostolorum magis docti, audent tamen sibi $\mid$ censoriam virgulam in pietatis negocio sumere, pronunciantes duos esse spiritus, duo testamenta et duplicem populum; fortassis addent aliquando ex Cerdone ${ }^{75}$ haereticissimo monstro duos etiam deos, alterum quidem cum priore saeculo cru- 25 delius, alterum vero cum posteriore mitius agentem. ${ }^{76}$ Quam sententiam opinionemve impiissimam plane multis in Marcione persecutus est eruditissimus Tertull[ianus] doctis in illum libris aeditis. ${ }^{77}$ Equidem fateor diversorum spirituum, testamentorum duplicisque populi mentionem fieri in sacris, sed longe alio

Z. (2) consequturae] consequuturae $Z G$ - (5) foelices] felices $Z G$ - (17) desyderio] desiderio $Z G$ (23) negocio] negotio $Z G$ - (27) Marcione persecutus] Martione persequutus $Z G$ - (28) Tertull[ianus]] Tertullianus $Z G$

74 Erasm. par. 1Petr. (ASD VII/6 190,122-133).

75 Kerdon (Cerdo), syrischer Gnostiker, aktiv in Rom um 140, vgl. RGG ${ }^{4}$ II 88. Siehe auch Aug. haer. 21 (CCSL XLVI 299,6-8): »Quidam uero in duobus principiis suis duos deos ita eum [Cerdonem] dixisse perhibent, ut unus eorum esset bonus, alter autem malus.«

76 Vgl. die ähnliche Argumentationsweise bei Zw. elench. (Z VI/1 164,2-7): »Duo vero testa- menta dicuntur, non quod duo diversa testamenta sint; nam sic oporteret non tantum duos diversos esse populos, sed duorum diversorum populorum duos quoque deos. Quod dum non viderent quidam apud veteres, diversos docebant esse deos, alterum veteris, alterum novi testamenti, istum crudelem, hunc civilem et humanum.

Tert. adv. Marc. (CCSL I 441-726). 
sensu, quam isti intelligant. Isti protinus clamitant veterem ecclesiam prorsus fuisse carnalem, Christi ecclesiam novum esse populum, nempe spiritualem. Vetus ergo testamentum carnale esse, novum autem spirituale. Proinde et spiritum novum esse datum nobis, de quo scriptum sit: »Spiritus nondum erat datus, quia 5 Iesus nondum erat glorificatus « [Joh 7,39]. Item: »Nescitis, cuius spiritus sitis « [Lk 9,55]. Caeterum non expendunt isti populi Iudaici testamenti et legis datae rationem, vim et institutum. Ab initio nullus vel Adae, Enoch, Noe vel ipsi Religio Abrahae praescriptus ceremoniarum ordo. Primi saeculi homines nitebantur pol- ${ }_{\text {patrum. }}^{\text {antiquorum }}$ licitationi primis factae parentibus: »Semen mulieris calcabit caput serpentis«

10 [Gen 3,15]. Abrahae vero et posteris in pauca quaedam capita tota religionis summa est coniecta, in hanc nempe:|»Ero deus tuus et seminis tui post te« [Gen 17,7], deus, inquam, omnisufficientia sive copiaecornu $;{ }^{78} \gg$ dabo tibi semen «, illud videlicet, quod caput serpentis calcabit, in quo omnes gentes servabuntur; »tu vero ambula coram me et sis integer « [Gen 17,1]. Id vero totum, quid erat aliud, quam quod nobis in christianae fidei summa dicitur: deus nostri misertus filium suum in mortem pro nobis dedit, ut eius morte servati et docti posthac vivamus in novitate vitae $?^{79}$ Hactenus ergo unus est spiritus et unum testamentum utriusque populi. Porro ubi vetus illa Adae, Abrahae et omnium ab ortu mundi sanctorum fides et religio in posteris convictu Aegyptiaco obliterari incoepisset, idololatria 20 et corruptis gentium moribus ceu contagione vitiatis Iudaeis, per Mosen educti in desertum ibique ad montem Sinai intra veteris religionis metas ac carceres inclusi sunt lege scripta. Haec tabularum erat, ipso dei digito inscripta, quae et authore Christo et apostolis aliud nihil quam amorem dei et proximi, ${ }^{80}$ hoc est ea ipsa religionis capita, quae supra Abrahae diximus esse data, comprehendit, quae et 25 ipse dominus Iesus et apostoli eius praedicatione et scriptis docuerunt. Hactenus ergo spiritus iterum unus, testamentum quoque idem utriusque populi. Iam vero, cum ne lege quidem scripta et absolute omnia, quae ad beatam et honestam vitam sufficere videbantur, compraehendente tradenteque $\mid$ intra verae et avitae religionis limites continerentur, ipsis subinde tumultuantibus et ad Aegyptiacos mores deficientibus, circumscripti sunt et statutis ritibusque quibusdam sacrorum, quos generali vocabulo nominamus »ceremonias «. | Hae ritu quidem et agendi modo carnales sunt, significatione autem spirituales. Porro ipsa lex, quae voluntas dei est, spiritualis est; quatenus ergo carnalis, respectu hominum, non dei, carnalis est et iccirco ea parte, qua carnalis, non est de substantia (ut aiunt) legis. Neque vero

35 et sancti ceremoniis quicquam tribuerunt. Id cum multis astrui possit prophetarum et historiarum testimoniis, unico tamen, sed eo per quam claro et efficaci, Ieremiae comprobabimus testimonio. In 7. ergo cap[ite] dicit: »Haec dicit do-

Z. (19) obliterari] oblitterari $G$ - (37) cap[ite]] capite $Z G$

78 Gen $17,1$.

80 Mt 22,37-40 par.

79 Vgl. Joh 3,16. 
Und frăssend üwer fleysch selbs, non esurio.$$
\text { Ps. }
$$
mihi populus; et ambulate in omni via, quam mandavi vobis, ut bene sit vobis [Jer 7,21-23]. Quid vero his super hac re dici potuit planius? Videmus ergo deo tum quoque, cum ceremoniae summo essent in precio et usu, spiritualem fuisse ecclesiam, carnalem vero non minus tunc quoque quam nunc exosam. Vetus igi|tur populus propter figuras et res istas significativas non a substantia, sed magis accidente legis dictus est carnalis aut vetus populus. Quis autem tam vaecors, ut nunc colligat: »ergo tota lex carnalis«, »ergo populus vetus carnalis «? Tunc enim non minus quam nunc spiritualis et carnalis erat populus. At turbatores nostri neutrum admittunt. Nam ut veterem ecclesiam prorsus carnalem faciunt, ita contra Paulum, 1. Corinth. 10[,16f.]., nostram ecclesiam carne exemptam prorsus spiritum esse volunt. ${ }^{82}$ Sed redimus. Unus fuit spiritus sanctorum in lege et ante 15 legem. Caeterum in lege multi erant, qui neglecto legis spiritu literam sequerentur occidentem, ${ }^{83}$ ii autem dignas luebant poenas. Horum ergo respectu, quin et Confer haec figurarum caussa pollicebatur dominus spiritum et cor novum, ${ }^{84}$ legem et testacum 31 . Ieremiae. mentum novum; non utique novum et alienum a primario Abrahae testamento aut diversum a sanctorum spiritu, sed eundem et hoc uno abundantiorem, quo prae- 20 sentiora nobis sunt ea, quae sancti veteres expectabant. Eundem ergo spiritum nobis dedit et alium sive novum: eundem, quia eadem religionis summa; et alium sive novum, quia alio modo et palam se iam aperit divina bonitas, adimplens ipsa re per filium incarnatum omnia, quae abavis nostris avisque promissa. Vides iam, unde enatae sint appellationes veteris et novi testamenti et populi, et, quod attinet 25 ipsam testamenti | et legis substantiam, idem sit utriusque populi spiritus. Si enim omnino diversus esset, iam Christus et apostoli perperam nobis Abrahae et veterum exempla, imo ipsam fidem proposuissent imitandam. Petrus certe spiritum prophetarum palam hoc in loco spiritum Christi nominat. Apud Lucam durius excipiens intempestivam discipulorum vindicandi cupiditatem dominus, 30 non damnat Heliae factum aut spiritum, cum et baptista dicatur spiritu Heliae imbuendus, sed zelum nimis praecocem in discipulis culpavit idque communi Lucae 9[55]. schemate dicens: »Nescitis, cuius spiritus sitis « pro eo, quod est: »Nescitis« aut »certe non expenditis, quo animo ista loquamini.« Iam quod apud Ioannem

Z. (7) precio] pretio $Z G-$ (9) propter] popter $G$

81 Marg. »Psal. 49.«: Vgl. Ps 50,12f. (Vulg. 49,12f.).

82 Bullinger wendet sich hier gegen die spiritualistischen Tendenzen der Täufer, vgl. Bull. adv. cat. $105 \mathrm{r}-\mathrm{v} ; 137 \mathrm{v}-142 \mathrm{v}$.
14 v $G$ 
legitur: »Nondum erat spiritus sanctus, quia Iesus nondum erat glorificatus « [Joh 7,39], loqutionis genus est dependens ex consequenti. Hactenus enim spiritus quidem in fidelibus fuerat, sed copiosius et pluribus ab ascensione dabatur credentibus. Unde et Augustinus quaestionem super hac re movens, quomodo ne5 getur fuisse spiritus in sanctis, cum post multos alios legamus Simeonem et Zachariam repletos spiritu sancto prophetasse, et respondet eundem quidem fuisse spiritum sanctum, sed modum donationis fuisse diversum. ${ }^{85}$ Sed haec paucis; plura in Actorum capite secundo ${ }^{86}$ et Hebraeorum capite octavo. ${ }^{87}$ Plura scripsit Tertullianus adver[sus] Martionem in quarto libro et contra Iudaeos; | Irenaeus

10 quoque adver[sus] Valent[inianos]; Euseb[ius] item in praefat[ione] Eccle[siasticae] histo[riae] et Lactant[ius] lib[ri] 4. cap[ite] $20{ }^{88}$ Symbolum secundo con-

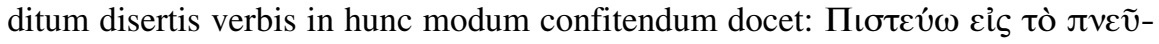

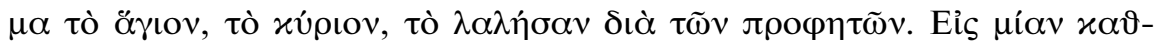

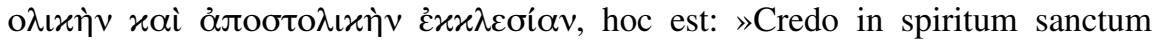
15 dominum, qui loqutus est per prophetas, in unam catholicam et apostolicam ecclesiam. $\ll^{89}$ Audis unum atque eundem esse spiritum, qui per prophetas loquatur in unam generalem ecclesiam, olim quidem a prophetis, nunc ab apostolis, verbo veritatis, qui sancti spiritus instinctus est, collectam. Caeterum qui lepidum istud de duplici spiritu | commentum obtrudunt simplicioribus, aliud volunt, quam 20 quod suavia alias et hypocritica verba prima fronte ${ }^{90}$ pollicentur. Res enim moliuntur novas, novam ecclesiam colligere cogitant, e qua magistratum expellant et se rerum dominos in ea constituant; ideo enim ministerium verbi nostri, quod tamen non nostrum, sed dei est, omnemque sancti magistratus administrationem in unitate et disciplina ecclesiastica conservanda et instituenda condemnant. ${ }^{91}$ Sed

25 pereat maligni spiritus consilium! Nos iam ad nostra redimus. Quae prophetae nobis protulere, ex spiritu dei, non animi sui libidine prodiderunt. Prodiderunt Evangelium autem totam hanc evangelii de salute aeterna per Christum consequenda ratioex prophetis. nem, | quam Petrus hic »salutem«, mox »gratiam« (ein früntlichen handel

Z. (2) loqutionis] loquutionis $Z G-(8)$ Hebraeorum] Hebr[aeorum] $Z G-(8)$ octavo] 8. $Z G$ - (9) adver[sus]] adversus $Z G$ - (9) quarto] 4. $Z G$ - (10) adver[sus]] adversus $Z G$ - (10) Euseb[ius]] Eusebius $Z G$ - (10-11) praefat[ione] ... histo[riae]] praefatione Ecclesiasticae historiae $Z G$ - (11) Lactant[ius]] Lactantius $Z G$ - (15) loqutus] loquutus $Z G$

85 Aug. in euang. Ioh. 32,6 (CCSL XXXVI 303,21-24): »Non enim alium spiritum etiam prophetae habuerunt, qui Christum uenturum praenuntiauerunt. Sed modus quidam futurus erat dationis huius, qui omnino antea non apparuerat: de ipso hic dicitur.«

86 Bull. act. 19r-20r.

87 Siehe oben S. 107f.

88 Vgl. Tert. adv. Marc. 4,1,6-11 (CCSL I 546f.); Tert. adv. Iud. 9-14 (CCSL II 1364-1396);
Iren. haer. 4,18 (Harvey II 168f.); Euseb. hist. eccl. 1,2,6 (GCS IX/1 12-14); ebd. 1,4,10-12 (GCS IX/1 42-44); Lact. inst. 4,20,4f. (CSEL XIX/2 364,14-365,5).

89 Vgl. Symb. Const. (DH 150).

90 Erasm. adag. 888 (ASD II/2 398,510f.): »>Prima facie $<$, >prima fronte $<$, pro eo, quod est primo obtutu et priusquam pressius ac diligentius consideres.«

91 Vgl. Bull. adv. cat. 98r-99v; 104v-107r. 
Gottes ) apellitat. Salus enim gratuito nobis per redemptionem Christi contingit. Nec vulgariter aut per transennam ${ }^{92}$ salutis mysteria nobis contemplanda proposuerunt, sed exactissime. Rerum etenim divinarum sitientissimi salutis mysteria exquirebant et scrutabantur. Siquidem Daniel non postremus inter prophetas primarios illa de re $»$ vir desyderiorum $«$ a domino appellatus est,${ }^{93}$ certe quod nihil magis desyderaret quam rerum divinarum et salutis verae cognitionem, quae et illi pro voto prae caeteris contigit. Caeterum tria subiicit per consequentia rerum capita, sed ea, in quibus fidei christianae comprehenditur summa, quae prophetae studiose a numine exquisierint orbique scripto ceu per manus tradiderint. Primum: ad quem aut cuiusmodi temporis articulum salus per Christum esset per- 10 agenda; quando aut quibus temporibus esset venturus. Secundum: quas afflictiones esset subiturus. Tertium: quomodo glorificandus. De singulis sigillatim dicemus. Principio, quod tempora Christi attinet, clarissima extant prophetarum testimonia. Iacob enim patriarcha apud Mosen, Gen. 49.: »Non auferetur«, inquit, »sceptrum de Iuda et legislator de medio pedum eius, donec veniat, qui mittendus 15 est; et ad eum erit expectatio gentium « [Gen 49,10]. Eam prophetiam Onkelus ${ }^{94}$ Syrus interpres ad hunc | modum, interprete Pellicano ${ }^{95}$ nostro, exposuit: »Non recedet potestas regia de domo David et scriba de filiis filiorum eius quousque in saeculum, quousque veniat Messias, cuius est regnum, et ad eum obedientiam praestabunt gentes. $\ll{ }^{96}$ Eusebius vero Ecclesiast[icae] histo[riae] lib[ri] 1. cap[ite] 20 4. prophetiam istam de temporibus Herodis ${ }^{97}$ Antipatri, ${ }^{98}$ qui $\gg$ primus ex alienigenarum genere ortus regnum obtinuerit gentis Iudaicae «, exponit. ${ }^{99}$ Sed et plerique ecclesiasticorum scriptorum ad eum modum interpretarunt. Caeterum huic expositioni adversatur, quod apud Ieremiam in cap[ite] 22. divina sententia in Iechoniam ita pronunciatur: $\gg$ Sic dixit dominus: >Scribite virum istum orbatum 25 sine haerede, virum, qui non prosperabitur in diebus suis, quia non prosperabitur a semine eius vir sedens super solium David et dominans adhuc in Iuda « [Jer 22,30]. At Christus dominus intra 670 plus minusve annos nondum adveniebat et intra hos nullus legitur dignitate potestateque regia regnasse in solio David super

Z. (5) desyderiorum] desideriorum $Z G$ - (6) desyderaret] desideraret $Z G$ - (14) auferetur] aufferetur $G$

92 Erasm. adag. 2049 (ASD II/5 65,91f.): »PPer transennam aspicere< prouerbiali nimirum figura dictum est pro eo, quod est non propius neque singillatim, sed procul et summatim inspicere.«

93 Dan 10,11.

94 Aquila (Onqelos [?], 2. Jh. n.Chr.), Proselyt aus Sinope und Bibelübersetzer, vgl. NP I 932.

95 Konrad Pellikan (1478-1556), ab 1525 Professor der griechischen und hebräischen Sprache in Zürich, vgl. Zürcher 1975.
96 Pell. Gen. 64.

97 Herodes I., der Große (gest. 4 v.Chr.), römischer Klientelkönig in Judäa, Galiläa, Samaria und angrenzenden Gebieten, vgl. NP V 458460.

98 Antipatros, Kanzler des jüdischen Reiches 47-43 v.Chr. und Vater des Herodes I., vgl. NP I 777.

99 Rufin. hist. 1,6,1 (GCS IX/1 49,2-6). 
Iuda. Quod enim de Machabaeorum dominio multa leguntur, ad rem praesentem Alii, licet nihil pertinent. Machabaei enim de stirpe Levitica prognati erant. Proinde claret Levitae essent, iam, quod in fine regni Babylonici prophetia Iacob de sceptro auferendo expleta tamen stirps sit. Nam in Iechonia abrogata est dignitas regia domui Iuda, sed nondum interim nascebatur »Schilo«, ${ }^{100}$ Messias Christus dominus. Quid ergo | dicemus, cum videamus Eusebianam expositionem parum habere firmamenti? Certe expendenti ista diligentius duo occurrerunt, quae hic opponi posse videbantur. Prius prophetiam Iacob non modo de sceptro, sed lege quoque sive legislatore auferendo disserere. Porro legislatorem, quem Iacob vocavit מחקק, etiam doctum in lege,

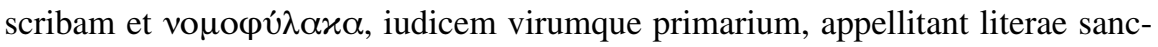
tae. Tales vero nunquam defuerunt tribui Iuda a reaedificata urbe usque ad Herodem illum magnum, qui primus ex alienigenis sibi in populo Iudaico paravit monarchiam. ${ }^{101}$ Pessundata enim a Babyloniis dignitate regia, emerserunt e tribu Iuda duces, quorum primus Zorobabel apud Haggeum et Zachariam fuisse re15 fertur cretus sanguine regio. ${ }^{102}$ Nam Matthaeo iudice filius fuit Salathiel, qui rege Iechonia erat natus. ${ }^{103}$ Proinde non frustra crediderim pedum et מחקק in vaticinio Pedes in Iacob fieri mentionem. ${ }^{104}$ Voluit enim significare primo quidem regiam dignita- $\begin{gathered}\text { Daniele } \\ \text { significant }\end{gathered}$ tem fore conculcandam, deinde vero e conculcatis reliquiis exorituros duces et postremas 13 ZG viros in sanctitate primarios, e qui|bus deinde nasciturus sit »Schilo«; tum quidem, cum turbatis rebus mortalium rerum summa totiusque Iudaicae gentis imperium ad alienigenam fuerit devolutum. Quod a Babylonica captivitate ad 17v $G$ Herodis usque tempora completum esse comprobabimus, ubi prius istud anno taverimus istis palam probari regnum Christi non fore carnale. Videmus enim carnalia in regno Iudae omnia esse abrogata, priusquam adveniret rex verus et aeternus. Iam vero ad superiorum confirmationem expositionemque faciunt ea, quae dicuntur alibi a prophetis aliis. Haggei ult[imo] legimus: »In die illo, dixit Haggeus. dominus exercituum, accipiam te Zorobabel filium Salathiel, servum meum, dixit dominus, et ponam te sicut annulum, quia te elegi« [Hag 2,23]. In die, inquam, illo, quo commovebo coelum et terram et omnes gentes, ${ }^{105}$ hoc est, quo primaria regna mundi inter se committam, Persico Macedonicum, Macedonico Romanum; in istis, inquam, turbis te et posteritatem tuam servabo. Te enim elegi, ut sis annulus signatorius, hoc est ille, per quem veritatem promissionis meae obsignem. Id est: te elegi, ut ex te nascatur Christus secundum carnem, qui omnibus satisfaciat, quae in lege et prophetis promisi. Daniel autem clarius in 2. cap[ite]: »In diebus Daniel. autem regnorum illorum «, inquit, »suscitabit deus coeli regnum, quod in aeter-

Z. (14) apud] appud $G$ - (15) iudice] indice $G Z G$ - (22) prius] prus $G$ - (26) ult[imo]] ultimo $Z G$ (30) Persico] Perico $G$

100 Gen 49,10 .

101 Vgl. Flav. Ios. ant. 14,490f. (Niese III 330).

102 Hag 1,1; 2,21; Sach 4,6.
103 Mt 1,12 .

104 Gen 49,10 .

105 Hag 2,21f. 
num non dissipabitur, et regnum eius alteri populo non tradetur. Comminuet autem et consumet universa regna haec et ipsum stabit in aeternum « [Dan 2,44].

Sub Romano imperio natus

Christus.

Isaiae 28[,16].

Psal. 117.

Matth. 21[,42].

Lucae 2[,34].

Zacharias.

Christus a

temporibus

Adae dictus זרע,

semen [Gen

3,15]; a

temporib[us]

David צמח,

germen, propter

promissiones. Vide, obsecro, consonantiam prophetalem: etiam Daniel »in diebus« ait »regnorum «, videlicet Macedonici et Romani, quae paulo ante postremo loco recensuerat, »suscitabit deus regnum Christi aeternum, quod | omnia alia comminuet «. 5 18r $G$ Superius enim mentionem fecit cuiusdam lapidis sine manibus abscissi de monte, qui immissus regnis omnia comminuerit. ${ }^{106}$ Quis vero hic lapis? Respondeant prophetae ${ }^{107}$ alii, respondeant evangelistae: Christus dominus est lapis iste coelo descendens, ex virgine natus, qui coelesti virtute citra humanam opem sibi totum subdidit orbem. Similia his invenies et apud Zachariam in 6. cap[ite]. Posteaquam 10 enim monarchiarum conflictum exactius et copiosius quam Haggeus pinxisset, tandem ad Iesum sacerdotem ac Zorobabelem perveniens, ita ad hunc dei iussu loquitur: »Sic dicit dominus exercituum, dicens: >Ecce vir, צמח, Germen (alii Oriens) nomen eius, et sub eo germen erit et aedificabit templum domini. Et ipse aedificabit templum domini, et ipse portabit decorem et sedebit et dominabitur 15 super solio suo. Et erit sacerdos super solium suum et consilium pacis erit inter ambos « [Sach 6,12f.]. Quibus nihil potuit ad rem praesentem dici quadrantius. Videmus coram, quomodo subverso Iudae solio subrepserit e reliquiis iste Zorobabel, e quo tandem commissis inter se regnis et se mutuo lacerantibus Romanisque superantibus nascitur Christus verus rex et sacerdos. Zorobabel dicitur 20 צמח, germen, quia de stirpe David. Ex hoc germine orietur (ait) aliud germen, illud videlicet, de quo Ieremias in 23.: »Ecce dies venient, et suscitabo Davidi צמה צדיק, germen iustum, et regnabit rex et sapiens erit«[Jer 23,5]. Et Zorobabel quidem aedificavit templum domini. Sed propter Christum eadem sententia repetitur: »Et ipse aedificabit templum domini« [Sach 6,13], illud nimirum de quo 25 Haggeus: »Et venient cum desyderabilibus omnes gentes et implebo domum istam gloria, dixit dominus exercituum « [Hag 2,8]. »Maior erit gloria domus istius posterioris quam prioris, dixit dominus exercituum; et in loco isto dabo pacem, dixit dominus exercituum « [Hag 2,10]. Id quod Iudaei nunquam possunt ostendere impletum esse carnaliter. In ecclesia autem nostra abunde praestitit 30 omnia deus, in qua simul et rex et sacerdos est Iesus Christus dominus noster, qui sibi ex Iudaeis et gentibus ecclesiam delegit macula et ruga carentem. ${ }^{108}$ Et ut nulla erat inter Iesum et Zorobabelem aemulatio, ita nulla cogitanda est inter patrem et filium. Ex his (opinor) intelligere licet, quod, tametsi sceptrum a Iuda sub monarchia Babylonica ablatum, attamen מחקק e medio pedum Iudae non sit 35 sublatus, donec rerum summa ad Herodem Ascolonitam devoluta, e tribu Iuda

Z. (26) desyderabilibus] desiderabilibus $Z G$

106 Dan 2,34.

108 Eph 5,27.

107 Marg. »Psal. 117.«: Ps 118,22f. (Vulg. $117,22 \mathrm{f}$.). . 
nasceretur Christus dominus, qui et rex et sacerdos regnavit in solio David patris sui. Atque hanc quidem priorem arbitratus sum esse rationem, qua difficultas vaticinii Iacob et contraria Ieremiae sententia superari atque explicari possit.

| Sequitur iam ratio posterior. Daniel, qui merito desideriorum vir cognomi- Danielis

5 natur, ${ }^{109}$ scrutans res populi dei futuras et praeterita expendens, animo consternatus, quod videret $\mid$ omnes fere prophetias veteres impletas, in summum venit discrimen. Legens enim Ieremiae vaticinia consideransque, quod sceptrum a Iuda esset ablatum et quod Lxx anni captivitatis iam essent exacti, interim vero populus Iudae nihilominus oppressus ageret inter idololatras, Hierusalem iaceret 10 vastata, regni et gentis suae gloria interisset prorsus, ad deum conversus et in orationem ardentissimam profusus, quae 9. cap[ite] Danielis continetur, orat dominum, ut secundum promissiones suas populum reducat, Hierusalem restituat, idque למען אדני, id est »propter dominum « [Dan 9,17], Christum intelligens, quem David in Psal[mo] 109. dominum* suum appellitat. ${ }^{110} »$ Non «, ait Daniel, »propter nos ipsos restitue nos, sed propter Christum dominum, nempe ut per hunc toti orbi exhibeas, quod pollicitus es. Nisi enim populum tuum reducas, nisi urbem restituas, quomodo exibit lex de Zion et verbum domini de Hierusalem? Quomodo implebuntur ea, quae promisisti per prophetas? «111 Iam ergo exaudiri a deo meretur, qui ardentissimis votis non suam, sed dei quaerebat gloriam. Itaque protinus ipsi astat angelus Gabriel expositurus fata populi Iudaici, nempe quod reducendus, quod Hierusalem aedi|ficanda, deinde quod destinato tempore adducenda sit צדק עלמים, »iusticia saeculorum « [Dan 9,24], id est Christus, qui est omnium saeculorum et sanctorum ab exordio mundi ad finem usque iusticia et sanctificatio, »per quem visio et prophetia a deo obsignatur « [Dan 9,24], id est, per quem rata effecit deus, quaecunque praedixit per os omnium sanctorum suorum prophetarum. Praesuposito itaque eo, quod populus reducendus et urbs restituenda, adeoque iam iam restituta sit, consequentibus disserit de temporibus Christi. Prius in genere proposuerat hebdomades LXx, hoc est, dixerat Iudaico populo totidem restare hebdomades ab urbe restituta ad excidium usque cum gentis tum urbis, intra quas tamen omnia essent adimplenda, quae de Christo praedixerant prophetae; nunc ergo speciatim disserit de singulis et principio de temporibus Messiae, quando sit venturus, dicens: »Scito ergo et animadverte, quod ab exitu verbi, ut redeatur et aedificetur Hierusalem, usque ad משיח נגיד,, CHRISTUM principem, »hebdomades septem et hebdomades sexaginta duae « [Dan Levit. 25[,8].

35 9,25]. Caeterum propheta hebdomades annorum intelligit. ${ }^{12}$ Septuaginta autem hebdomades efficiunt annos 490. Hic vero ab urbe reaedificata ad Christum

\section{Z. (7) vaticinia consideransque] vaticinium consyderansque $Z G-(23)$ iusticia] iustitia $Z G$}

109 Dan $10,11$.

110 Ps 110,1 (Vulg. 109,1).

111 Vgl. Dan 9,18f.
Quia de lumbis eius natus verus homo, et tamen dominus verus, Matth. 22[,43-45]. 
usque non 70, sed 69 numerantur hebdomades. Nam 7 et 62 confitiunt 69 . Remanet ergo ad alia tempora ultima illa et unica nempe septuagesima hebdomas. At intra 32. Darii ${ }^{113}$ annum et 42 . Augusti, ${ }^{114}$ veluti limites et septa, currit praesens 69 hebdomadum computatio. Daniel enim ab exitu (ait) verbi, ut aedificetur Hierusalem usque ad Christum hebdomades 69. ${ }^{115}$ Est autem notandum loqutionis genus: »Ab exitu verbi, ut restituatur Hierusalem « id enim pollet, quasi dicas Germanice: wenn sich verloffen, das Hierusalem gebuwen. Hoc autem factum legimus 32. Darii Histaspis ${ }^{116}$ anno, Nehem. 5[,14]. Quibus et Iosephus consentiens dicit Nehemiam opus sustinuisse per annos duodecim. ${ }^{117}$ Cum ergo 20. Darii ${ }^{118}$ Artaxerxis ${ }^{119}$ (quod omnium Persicorum regum, ut Ae- 10 gyptiorum »Ptolemaeus« ac »Pharao«, Romanorum »Caesar«, Palaestinorum vero »Abimelech«, cognomen erat) anno Nehemias manumissus sit, ut extat Nehe. 2[,1]., duodecim autem annos impenderit urbi restituendae, certe 32. Darii Histaspis aut Artaxerxis anno opus absolvit. Nunc ergo Daniel hoc dicit: numerabis a 32. Darii anno hebdomades 69, id est annos 483 (totidem enim annos 15 efficiunt 69 per septenarium numerum multiplicata), et habebis annos nativitatis Christi certos. Videamus iam temporum ex chronicis rationem, quomodo isti concinant vaticinio. 32. annus Darii incidit in 3. annum olympiadis 72., olympias autem habet annos 4. Porro 42. Augusti annus, quo natus est Christus, incidit in 3. annum olympiadis $194 .{ }^{120}$ Tolle iam ab his 194 | olympiades 72 superiores, et 20 20v $G$ remanebunt olympiades 122 . Porro 122 per quaternarium numerum multiplicata constituunt annos 488, certe 69 hebdomadum annos, 5 duntaxat annis superantibus. Nam 69 hebdomades efficiunt tantum 483 annos. Verum exiguus hic 5 annorum numerus superans nihil potest expositioni huic alias sibi probe constanti, simplici, clarae ac verae dubii ingerere. Scripsimus ante annos aliquot de heb- 25 domadis hisce opusculum, ${ }^{121}$ sed interim varia experientia, in primis autem $\mathrm{d}$ [omini] Theodori Bibliandri ${ }^{122}$ praeceptoris nostri fidelissimi doctissimique institutione et opera, didici nullam supputationem certiorem esse, quam quae fiat per olympiades. Illa ergo, quae tum scribebam, ad ista nunc exigi et con|ferri

Z. (6) loqutionis] loquutionis $Z G-(28)$ supputationem] suputationem $G$

113 Dareios I., Sohn des Hystaspes und persischer König 522-493 v. Chr., vgl. NP III 322f.

114 Augustus (63 v.-14 n.Chr.), ab 31 v. Chr. Alleinherrscher im römischen Reich, vgl. NP II 302-314.

115 Dan 9,25.

116 Hystaspes (6. Jh. v.Chr.), Sohn des Arsames und Vater des Dareios I., vgl. NP V 829.

117 Flav. Ios. ant. transl. 122r: »Quos labores sustinuit Neemia per annos duodecim et menses quatuor.«

118 Dareios II., Sohn des Artaxerxes I. und per- 
adeoque ex hisce sarciri et emendari volo. Quod attinet ad rem praesentem, abunde praestitum sartumque opinor per Danielis diligentiam, quod quisquam desyderare poterat in subobscuro Iacobi apud Mosen aenigmate. Opinor et illud luce clarius esse expositum, quod Petrus dixit prophetas scrutatos esse, ad quem 5 aut cuiusmodi temporis articulum venturus esset Christus. Hactenus enim audivimus, quanta sedulitate, certitudine et diligentia in hac re indaganda laborarint Moses, Daniel, Haggeus et Zacharias, qui et ipsum punctum adventus Christi acu (ut dicitur) attigerunt. ${ }^{123}$

| Sed quia semel coepimus hebdomadas Danielis obiter enarrare, addamus et etiam hic propheta venturas (ut Petrus ait) in Christum afflictiones admiranda claritate praedixerit. Sequitur igitur: »Et post hebdomades sexaginta duas«, iam omittit minorem numerum, qui tamen subintelligendus est, »occidetur Christus [Dan 9,26], et nihil ei, intellige: habebunt, quod impingant meriti. Hactenus 15 de temporis articulo, quo Christus erat venturus, scripsit, nunc de Chrito ipso, de populi peccato et excidio dicet. Hoc autem de Christo dicit: exactis hebdomadis istis 69 in postrema ista et ultima hebdomada occidetur Christus. Nam in posteriori versu clarius subditur: »Confirmabit autem pactum multis hebdomada una « [Dan 9,27], ubi maxime loqutionis genus observandum est. Hebdomadi 20 enim videtur tribuere, quod revera Christi est, qui morte sua (ut in Hebraeis disputat Paulus) testamentum confirmavit. ${ }^{124}$ Sed et nobis in usu est loqui: »Hic annus foelix erit« aut »abundantem dabit frugum copiam. «Porro haec septimana De passione et gloria Christi ex prophetis. pertingit a nativitate ad excidium usque urbis et gentis. Aliam enim rationem a superioribus habere videtur. Nec enim integra nec dimidia tantum annos 5 habet, quae si ducatur per denarium fient anni 70, intra quos Christus absolvit tempus dispensationis et Iu|daei mensuram peccatorum, ut post dirutum templum et urbem solo aequatam obtingeret ab Isaia et aliis intentata repudiatio. ${ }^{125}$ Iam si per olympiades 70 annorum inquiras numerum, dices omnia sibi pulchre constare. Diximus enim Christum natum esse 3. anno olympiadis 194.; caeterum constat 30 templum et urbem Hierosolymorum diruta esse 2. Vespasiani Caes[aris] ${ }^{126}$ anno, qui 2. annus erat olympiadis 212.; numerantur ergo a nato Christo ad urbis

Z. (3) desyderare] desiderare $Z G$ - (9) enarrare] ennarrare $G$ - (19) loqutionis] loquutionis $Z G$ (22) foelix] felix $Z G$ - (24) 5] quinque $Z G$ - (29) 3.] tertio $Z G$ - (30) 2.] secundo $Z G$ - (30) Caes[aris]] Caesaris $Z G-(31) 2$.] secundus $Z G$

1534, vgl. Pell. chron. (Riggenbach 126f.). Zu Bullingers Mitschrift dieser Vorlesungen vgl. Zentralbibliothek Zürich, Ms Car I 147 (freundlicher Hinweis von Dr. Christian Moser).

123 Erasm. adag. 1393 (ASD II/3 392,508-511): » $>$ Rem acu tetigisti<, pro eo, quod est >rem ipsam diuinasti, nihil aberrans $<$. Metaphora sumpta videri potest a lusu quopiam, in quo diuinator id, quod alius notasset, summa acu tangebat: aut lineam, aut calculum, aut aliud quiddam simile.«

124 Hebr 9,11-22.

125 Jes 50,1; Jer 3,8.

126 Titus Flavius Vespasianus, römischer Kaiser 69-79 n. Chr., vgl. NP XII/2 125-130.
»Multis «, quia gentibus quoque et omnibus credentibus, Matthaei 26[,28]., increduli se excludunt. 
excidium olympiades 18 , quae efficiunt annos 72 , hoc est, ultimam istam hebdomadam uno atque altero duntaxat anno superante. Totidem ferme colliguntur anni, si per Caesarum quoque annos supputationem instituas. Tam probe sibi constant et certa sunt dei oracula. Illud vero in primis lepidum est, quod hanc ipsam septimanam dividit, ita ut dimidiata Christo et dimidiata populo et urbi Cursus et serviat. Intra triginta tres annos absolvit Christus cursum suum. In mortem enim a mors Christi. popularibus suis traditus praeter meritum vel ipso iudice Pilato attestante: »Nihil criminis invenio in hoc homine « [Joh 18,38; 19,6], dei tamen dispensatione propter peccata mundi expianda in crucem adactus clamavit: »>Consummatum est! Inclinatoque capite emisit spiritum « [Joh 19,30]. Protinus autem atque haec facta, »scissum est velum templi a summo usque deorsum « [Mt 27,51 parr.], ut vel hisce signis prodigiisque deus attestaretur duricervicibus Iudaeis per hostiam filii abrogata iam esse omnia ty|pica sacrificia. ${ }^{127}$ Recte ergo Daniel: »In dimidio«, inquit, »hebdomadis cessabit hostia et sacrificium« [Dan 9,27]. Sed dum illi constanter pergerent sancta quidem olim, at nunc nephanda et abominanda 15 offerre sacrificia, praeterea et sanctos Christi persequerentur, in exilium pellerent et multos interimerent, longanimitate sua ad poenitentiam vocavit eos dominus, per residuos huius hebdomadis triginta septem annos, imo et minis ab concepta absterruit pertinacia. Siquidem שקוּצים משמם (ait propheta) ועל כנף, id est: »Et super alam, pinnam sive portam abominationum vastator «, intellige, »erit« [Dan 20 9,27]. Vocat autem templum ipsum, quod hactenus sanctum dicebatur, »abominationes«. Abominabatur enim ea dominus, quae a morte Christi secundum legem in templo fiebant. Ergo prodigio quodam super pinnam sive portam templi per procuratorem Iudaeae Pilatum curavit statui vastatorem, id est signum vastationis. Legimus enim in historiis Pilatum portae templi dominici auream im- 25 posuisse aquilam. ${ }^{128}$ Porro aquila Romanorum intersigne signum erat furoris divini, portendens Romanos et templum et urbem occupaturos, ni coeptis desisterent Chri|stumque domini susciperent. Sed nequicquam moniti perrexere patrum mensuram implere; proinde deus iusta ira commotus et templum et urbem et gentem funditus excidit, veluti immisso diluvio. Idque to|tum fecit per prin- 30 22 v $G$ cipalem populum venientem (iuxta Balaam vaticinium) ex Italia. ${ }^{129} \mathrm{Nec}$ primo protinus aggressu istos unica strage extinxit, sed per varias calamitates, turbarum, seditionis, coniurationis, famis et pestilentiae per annos 35 vexatos, ad finem demum belli excidit; ${ }^{130}$ nimirum in vindictam omnis effusi sanguinis iusti, pro-

\section{Z. (3) supputationem] suputationem $G$ - כנת [כנף (19 Z Z}

127 Hebr 8,5f.

128 Es war allerdings nicht Pilatus, sondern Herodes I., der einen Adler am Tempeleingang anbringen ließ, vgl. Flav. Ios. ant. transl. 188r: »Construxerat [Herodes] supra portam templi munus quasi deo propositum, aquilam auream immanem, et qualitate et quantitate opulentam «; NP V 459.

129 Num 24,24.

130 Gemeint ist die Zerstörung des Jerusalemer 
phetarum, apostolorum ac Christi domini, potissimum et ut reliquiis Iudaeorum palam declararet, quod Messiam miserit pollicitum, qui legem adimplens summam religionis intra fidei et charitatis limites constituerit, abrogatis simul cere- Abrogatio legis. moniis sive sacris carnalibus templi omnibus. Iccirco enim oportuit post con5 culcatum sacerdotium et regnum ne templi quidem ruinas posteris superstites remanere. Et haec quidem copiosius, sed non abs re et citra lectorum (ni fallar) insignem utilitatem huiusque loci luculentam explanationem. Audivimus enim, quae hic propheta Christo praescripserit tempora et quod passibilem fore praedixerit.

10 Addamus iam ex eodem hoc propheta, quas ille praedixerit consecuturas Christi mortem glorias. In 7. cap[ite].: »Aspiciebam«, inquit, »in visione noctis, et ecce cum nubibus coeli quasi filius hominis veniebat et usque ad antiquum dierum pervenit, et adductus est in conspectum eius. Et dedit ei potestatem et honorem et regnum et omnes populi, tribus et linguae $\mid$ servient ei. Potestas eius potestas 15 aeterna, quae non auferetur, et regnum eius non corrumpetur « [Dan 7,13f.]. Testimonium hoc foecundum est et praeter id, quod diserte loquitur de consecutura gloria Christi, totum pene Christi mysterium perstringit. Initio enim pulchre notatur utraque Christi indoles divina et humana. Secundum divinam venit »ad antiquum dierum «, id est, similis sive coaequalis est patri. Neque enim ea locutio 20 localiter est exponenda. Consequens sententia: »Et adductus est in conspectum

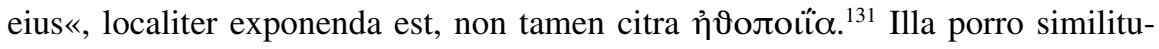
dinem habet, ut cum Latinus dicit: »Accedit ad hoc«, hoc est, »huic non dissimile est.« Itaque Christus secundum divinam naturam patri coaequalis est. Unde a Ioan. [,1]. Ioanne »verbum dei «, a Paulo vero »character« et »imago substantiae dei«, item 25 »in forma dei« et »deo aequalis« esse dicitur. Secundum humanam naturam verus Hebrae. 1[,3]. Coloss. $1[, 15]$ et perfectus homo est. Hinc enim non dicitur homo, sed »filius hominis«. Ut enim apud Gellium Fronto ${ }^{132}$ censet eum plus dixisse, qui ait »multi mortales«, quam qui dicit $»$ multi homines $«{ }^{133}$ ita plus dixit, qui ait $»$ filius hominis «, quam qui dicit »homo«. Illud enim comprehendit tacitum quendam genium omnibus insitum indolemque humanae naturae et miseriae. Verum igitur et perfectum hominem fatetur Christum Daniel, cum filium hominis appellitat. Id quod Paulus diluc-

\section{Z. (11) cap[ite]] capite $Z G$ - (19) locutio] loquutio $Z G$}

Tempels im Jahre 70 n. Chr. durch Titus, der spätere Kaiser Titus Vespasianus Augustus (römischer Kaiser 79-81 n. Chr., vgl. NP XII/1 633f.).

131 Als ท७ษัภо terische Gestaltung des Charakters einer Person durch einen fingierten Auspruch bezeichnet, vgl. HLR 408. Hier weist Bullinger mit diesem Terminus darauf hin, dass Dan 7,13 etwas Wesentliches zur Person Christi aussagt.
132 Marcus Cornelius Fronto (2. Jh. n.Chr.), römischer Rhetor, vgl. NP IV 679f.

133 Gell. 13,29,4 (Rolfe II 508): »Namque >multorum hominum< appellatio intra modicum quoque numerum cohiberi atque includi potest, $>$ multi< autem $>$ mortales $<$ nescio quo pacto et quodam sensu inenarrabili omne fere genus quod in civitate est et ordinum et aetatum et sexus comprehendunt.«
Gloria Christi victoria et regnum.
Quare Christus in evangelio dicatur filius hominis. 
idiori|bus verbis ita extulit: »Exinanivit seipsum forma servi sumpta in similitudine hominum constitutus, et figura repertus ut homo« [Phil 2,7]. Caeterum homo factus est, ut haberet, quod pro homine offerret. Id ubi explesset et unica hostia aeternam redemptionem invenisset, consedit ad dexteram patris, inde venturus iudicare et approbare omnibus impiis iusticiam et innocentiam et gloriam suam. ${ }^{134}$ Unde coram Caiapha consistens et varias ab impiis contumelias perpetiens, tandem ad praesens testimonium prophetae allusit et dixit: »Ammodo videbitis filium hominis sedentem a dextris virtutis et venientem in nubibus coeli.« Crucem ergo Christi illa in primis gloria est consequta, quod redivivus coelos ascendit, quod in coelis sedet ad dexteram patris. Porro iudicio futuro maxime declarabit gloriam suam, quod patri coaequalis, ${ }^{135}$ quod unus solus et aeternus deus sit cum patre et spiritu sancto, quin et ipsi, ubi finis appetierit omnium, subdentur omnia, hoc est, ipsi subiicietur potestas adversaria eaque tormentis excruciabitur perpetuis, ipse vero una cum sanctis suis aeternum regnabit. Haec ex Daniele.

Subiiciemus iam et alia prophetarum de passione et gloria Christi testimonia, gloria Christi. nec quaelibet nec vulgaria, sed dilucida, praeclara et certissima quidem illa. Apud Zachariam in cap[ite] 3. ita de Iesu sacerdote magno disseritur, ut pleraque et Christo domino compe|tant, quaedam vero prorsus sibi habeat peculiaria Iesus sacerdos. In his vero hic illius gessit typum. Intentatur Iesu a Satana crimen. ${ }^{136} 20$ Tentatum et salvatorem nostrum a Satana re/fert historia evangelica. ${ }^{137}$ Crimen intentatum erat sordida vestis. ${ }^{138}$ Hac significabatur incarnatio Christi. Speciem enim servi suscepit dominus et caro eius, cum revera purissima et sanctissima esset, peccati caro visa, Satanae spem iniecit fore, ut nonnihil sibi iuris in ipsum esset reliquum. Sed nihil invenit in eo. Etsi enim torris et nostri similis factus sit, 25 concupiscentia tamen non ambustus, sed in ara crucis crematus morte sua nos ab aeterna morte redemit. ${ }^{139} \mathrm{Haec}$ de incarnatione et passione domini; nunc de glorificatione: »Auferte«, inquit dominus, »vestimenta sordida ab eo. Ecce abstuli a te iniquitatem tuam et indui te מחלצות, puris vestimentis « [Sach 3,4]. Christus dominus de spiritu sancto conceptus, peccatum non habuit, »nec dolus inventus 30 est in ore eius « [1Petr 2,22]. Dominus autem imposuit ei omnia delicta nostra. Oblatus est ergo, ut peccata mundi expiaret. Qua re absoluta tertia die redivivus apparuit discipulis, non iam mortalem, sed clarificatam carnem habens. ${ }^{140}$ Praeterea et cidaris munda et corona aurea imposita est capiti eius. ${ }^{141}{ }$ Deus enim

Z. (5) iusticiam] iustitiam $Z G$ - (9) consequta] consequuta $Z G-(10)$ Marg. Ioan[nis]] Ioannis $Z G-$ (11) coaequalis] coequalis $G$

134 Vgl. Symb. Nic. (DH 125); Symb. Const. (DH 150).

135 Vgl. Joh 5,22f.

136 Sach 3,1.

137 Mt 4,1-11 par.

138 Sach 3,3.

139 Vgl. Sach 3,2.

140 Vgl. Joh 20,19.

141 Sach 3,5. 
dedit illi nomen, quod est supra omne nomen« etc., Philip. 2[,9]. Quod autem hic sit post historiam sensus genuinus, comprobabunt verba con|sequentia. Sequitur enim: »Audi, quaeso, Iesu sacerdos magne, tu et amici tui sedentes coram te, quia viri portendentes sunt: ecce, enim ego adducam servum meum Germen. Quia 5 ecce lapis, quem dedi coram Iesu: super lapidem unum septem oculi. Ecce, ego caelabo sculpturam eius, dixit dominus exercituum, et delebo iniquitatem terrae in die uno « [Sach 3,8f.]. Iesum et amicos, id est consacerdotes, palam nominat »viros portenti «. Omnes enim sacerdotes Aaharonici typi fuerunt sacerdotii Chris- Isaiae 8[,18]. ti. Quin et planius sese exponens addit: »Ecce adducam eum, in quem omnium

10 oculi sunt intenti, qui in crucem adactus uno die et una hostia omnium peccata auferet « [vgl. Sach 3,8f.], Christum significans dominum, quem primo »servum« vocat, sicut Isaias in cap[ite] 42., quem locum citavit et Matth[aeus] in cap[ite] 12. ${ }^{142}$ Secundo appellat ipsum $»$ germen $\ll$, de quo paulo ante diximus. ${ }^{143}$ Tertio »lapidem «, propter firmitatem, sicut et Isaias et Daniel. ${ }^{144}$ Super hunc lapidem 5 unum, id est primarium, dicit fuisse oculos septem, id est, in Christum esse omnium prophetarum et sanctorum oculos intentos. Omnium enim saeculorum firmitas et salus est Christus. Et R[abbi] David Kymhi ${ }^{145}$ recte divinat septenarium numerum perfectionis esse. ${ }^{146}$ Porro hunc lapidem sculpsit deus, quando clavis cruci suffixus est Christus. Tunc vero uno die et $\gg$ unica hostia perfectos effecit in perpetuum eos, qui sanctificantur « [Hebr 10,14]. De qua re copio|sissime disputavit ad Hebraeos apostolus. In 13. huius prophetae capite pater per prosopopoeiam ${ }^{147}$ ad gladium: »Gladie«, inquit, »excitare super pastorem meum« [Sach 13,7], Christum significans, qui ex hoc loco apud Ioannem in 10. pastorem se ovium dicit ${ }^{148}$ propter assumptam naturam humanam et dispensationis mysterium. Sed aliud quoque in Christo excellentius est; sequitur enim: גבד עמיתי ועל »coaequalem meum «. Christus enim secundum divinam naturam patri coaequalis Expressum divinitatis Christi est, aeternus, immortalis, sed secundum naturam humanam passibilis. Proinde additur: »Percute pastorem et dispergentur oves« [Sach 13,7]. Passionem enim et

142 Jes 42,1 ; Mt 12,18.

143 Siehe oben S. 198.

144 Jes 8,14; 28,16; Dan 2,34.45.

145 David Kimchi (ca. 1160-1235), Rabbi sowie Grammatiker und Exeget in Narbonne, vgl. LMA V 1142.

146 Im Kommentar des David Kimchi zu Sach 3,9 findet sich tatsächlich diese Interpretation (vgl. Kim. Zech. 3,9 [McCaul 39f.]). Ob Bullinger diese Information einer gedruckten Ausgabe der »Mikraot Gedolot« (auch »Rabbinische Bibel« genannt; zu den frühneuzeitlichen Drucken vgl. Heller 2005) oder einer anderen Quelle entnahm, bleibt allerdings unklar. Dass die Zahl Sieben in den biblischen Schriften auf Ganzheit bzw. Vollkommenheit hindeute, war jedenfalls seit der Antike christlichen Exegeten allgemein bekannt, vgl. Aug. epist. 55,3,5 (CSEL XXXIV/2 175,3f.): »Septenarius numerus solet in scripturis ad quandam perfectionem mysticus apparere.«

147 Als лообшлолоӥ $\alpha$ bzw. fictio personae wird die Einführung nichtpersonhafter Dinge als zu personhaftem Verhalten befähigter Personen, vgl. Quint. inst. 9,2,29-37 (Winterbottom II 494-496); HLR 411.

148 Joh $10,11$. 
crucem eius significavit gladius, qui ubi providentia dei filio esset immissus, dispersi discipuli, solum in afflictione reliquerunt dominum. De qua re apud Matth[aeum] in 26. cap[ite] plura. ${ }^{149}$ Adderem his 53. Isaiae caput clarissime de passione et gloria Christi conscriptum, nisi non multis ante diebus in 8. cap[ite] Act[orum] aposto[lorum] conscribens commentarium paraphrasi exposuissem. ${ }^{150}$ Ex psalmis, si post tot clara testimonia requiris plura, extat inter alios de Christi dispensatione et mysterio testificans 2., 15., 22. et 109. ${ }^{151}$ Haec autem in hoc exposui verbosius, ut videres, quomodo spiritus Christi ipsum adventus Christi articulum, passionem et gloriam per prophetas orbi explanarit. Unde iam colligimus religionem christia|nam longe certissimam et verissimam esse, utpote quae tantis, tam doctis, tam sanctis tamque vetustis nitatur testibus. Caetera vero, quae ad Petri pertinent consilium exposuimus in capite huius disputationis, iam ad verba Petri redimus.

12 quibus et illud revelatum est, quod haud sibiipsis, imo nobis ministrarent haec, quae nunc annunciata sunt vobis per eos, qui vobis praedicaverunt evangelium per spiritum sanctum emissum e coelo, in quae | desiderant angeli prospicere.

Plures expositiones in Annotationibus suis recensuit Erasmus, ${ }^{152}$ sed occupatio est. Respondet enim illis, qui prophetarum scripta nihil ad se pertinere et veteri duntaxat populo data credunt: »Imo«, ait, »non ideo docti inspiratique a deo 20 prophetarunt, ut sibiipsis aut sui duntaxat temporis hominibus consulerent, sed ut omnem posteritatem erudirent.« Sic et Paulus: »Quaecunque«, ait, »scripta sunt, in nostram doctrinam scripta sunt, ut per consolationem scripturarum spem habeamus « [Röm 15,4]. Et in Actis causam agens coram rege Agrippa: ${ }^{153} »$ Nihil «, inquit, »extra id doceo, quod prius docuerunt prophetae et Moses«, Act. 26[,22]. 25 Eodem ergo spiritu profecta sunt, quae scripsere et egere post prophetas apostoli. De prophetis enim audivimus, quod spiritus Christi fuerit in eis. ${ }^{154}$ De apostolis nunc audimus, quod $\mid$ ea annunciarint, quae prius revelata sint prophetis. Nam quae illi dixerunt ventura, hi venisse et expleta testantur, ${ }^{155}$ idque spiritus sancti

Z. (24) causam] caussam ZG

149 Mt 26,40-45.69-75.

150 Siehe Bull. act. 105r-107r. Bullingers Kommentar zur Apostelgeschichte war im August 1533 erschienen, vgl. HBBibl I, Nr. 43.

151 Ps 2,2.7; 16,2-6 (Vulg. 15,2-6); 22,1-32; 110, 1-7 (Vulg. 109,1-7).

152 Erasm. 1Petr. (ASD VI/10 434-436,81-92). Erasmus zählt vier verschiedene mögliche Auslegungen auf.

153 Marcus Iulius Agrippa II. (geb. 28 n.Chr.), Sohn des Herodes Iulius Agrippa, vgl. NP VI 24.

154 Petr 1,11

155 Vgl. Erasm. 1Petr. (ASD VI/10 436,103f.): »[...] ea quae de Christo sunt praenunciata per prophetas ac deinde praedicata per apostolos.« 
opera, qui iuxta evangelicam historiam non multis ab ascensione Christi diebus Acto. 2[,1-4]. apostolis datus est, nimirum ut coelesti virtute roborati evangelium hoc praedi- Ioan. 16[,13]., carent toti orbi. Iam quae ad finem adiecta est sententia: »In quae desiderant angeli prospicere «, hyperocham ${ }^{156}$ et tacitam quandam collationem habet, sed ad 5 maximam evangelii, hoc est negocii Christi, commendationem facit. Egregie enim paraphrastes: »Haec tam «, ait, »ineffabili dei consilio gesta, non mirum, si Evangelium prophetae concupiscebant cernere, cum etiam ipsis angelis sit admodum iucun- $\begin{aligned} & \text { sanctorum } \\ & \text { delitiae. }\end{aligned}$ dum gratumque spectaculum, cuius contemplatione non queunt expleri. $«{ }^{157}$ Certe invenias non raro in sacris veteres patriarchas et prophetas maximo animi desiderio Christi exoptasse adventum. Et Christus hoc nomine beatos dixit apostolos, quorum oculi viderint, quae multi reges et prophetae, viri utique primarii et eruditi, cupierint videre, sed non viderunt. ${ }^{158}$ Simeon ille pius et iustus senex pusionem suscipiens Iesum in ulnas sibi totique mundo congratulans clamat: »Nunc dimittis servum tuum, domine, secundum verbum tuum in pace. Quia viderunt oculi mei salutare tuum, quod parasti ante faciem omnium populorum « [Lk 2,29-31] etc.

13 Quapropter succincti lumbis mentis |vestrae, sobrii perfecte sperate in eam, quae ad vos defertur gratiam, dum vobis patefit Iesus Christus, 14 tanquam filii obedientes, ut non accommodetis vos pristinis concupiscentiis, quibus, dum adhuc ignoraretis Christum, agebamini, 15 sed quemadmodum is, qui vos vocavit, sanctus est, ita ipsi quoque sancti in omni conversatione reddamini, 16 propterea quod scriptum est: sancti estote, nam ego sanctus sum.

Demonstrata ex prophetarum testimonio religionis christianae fideique certitudine et quod fatali quadam necessitate, imo paterno dei consilio, ad exemplum capitis Christi omnia eius membra sint affligenda, iam infert: »Contempta igitur afflictione in veritate firmi persistite. « Huic tamen illationi aliud iam institutum appendit. Deflectit enim ad innocentiam vitae, ad quam miris modis incitat credentes, quod sine hac fides esse nequeat, sed et patientia nulla esse possit. Oratio autem mira copia miraque exornatione est variegata, praeterea et occulto spiritus afflatu vegeta floridaque. Cum enim paucis potuisset sic collegisse: »Igitur, cum haec ita habeant et videatis, quid frugis ferat patientia et quam certa sit ea spes, cuius gratia affligimini, immobiles in veritate perstate«, ma|luit tamen

\footnotetext{
Z. (1) ascensione] ascentione $G$ - (5) negocii] negotii $Z G$ - (6) Marg. delitiae] deliciae $Z G$

156 Bullinger verwendet den Begriff »Hyperocha« (
} überschuss « (vgl. NP V 807), sondern als Synonym von »Hyperbel«, vgl. HWR IV 117. $14[, 16 \mathrm{f}$.$] .$ 
Vera et hoc posterius omni diligentia per figuras orationis exornatum proferre. Principio syncera fides. enim utitur metaphora transumpta ab iis, qui impedimentis omnibus positis expediti accinguntur itineri. Aperitur autem metaphora per unicam voculam adiectam: lumbos enim non corporis, sed mentis dixit, a corpore ad animum transiens. Tertullianus 4. adversus Martionem libro: »Succingere«, inquit, »debemus lumbos, id est, expediti esse ab impedimentis laciniosae vitae et implicitae, item lucernas ardentes habere, ${ }^{159}$ id est mentis a fide accensas et operibus veritatis relucentes, atque ita expectare dominum, id est Christum. ${ }^{160}$ Breviter: succincti lumbis sunt, qui omnia animo impedimenta veritatis deposuere to|tumque deo

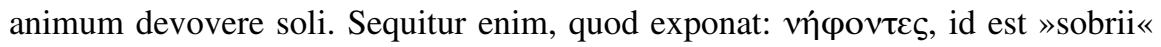
sive »vigiles«; hoc est: succincti lumbis sunt, qui vigiles sive sobrii, veternum carnis excusserunt et humanae sapientiae crapulam edormierunt. Porro id tum fit, cum $\tau \varepsilon \lambda \varepsilon i \omega \varsigma$, id est $»$ perfecte « ${ }_{161}^{161}$ fidimus evangelio, quod gratiam dei nobis nunciat, ex qua nobis donatus est filius dei. Iterum enim sequitur expositio: $\dot{\varepsilon} v$

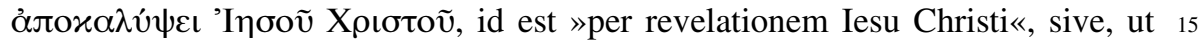
Erasmus vertit significantius: »dum nobis patefit Iesus Christus« ${ }^{162}$ Hoc est: »Illam intelligo gratiam, qua nobis Iesus Christus manifestatus est.« Iam vero hisce omnibus verbis nihil | aliud dixit, quam: $\gg$ Proinde expunctis omnibus e pectore humanis carnalibusve affectibus, toto corde credite Christo domino, qui vobis praedicatus est per evangelium. « Non ergo operaepretium fuerit multis hic 20 agere de sobrietate, castitate aut temperantia, de quibus nihil dicitur, sed de vera et syncera constantique fide in Christum, quae excoquit et absumit carnis affectiones, pavorem, inconstantiam et impatientiam, aspernatur autem mundi voluptates et gaudia, uni sese deo totam dedicans. Quod vero sequitur ad verbum hoc sonat: »ut filii obedientiae, nequaquam conformes prioribus ignorantiae vestrae 25 cupiditatibus. « Erasmus perspicuitati studens sensum probe reddidit. ${ }^{163}$ Deflectit autem Petrus ad innocentiam, ad quam argumento a natura filiorum ducto hortatur. Filiorum est genio et actis referre parentem, huius obedire praeceptis. Porro fides efficit nos filios dei, qui nos e mundo evocatos sibi vult in innocentia vitae servire. Proinde nos quidem, qui deo credidimus, non in pristinae nativitatis, sed novae vitae moribus ambulare debemus. Voluptatibus, luxui, crapulae, ambitioni, irae, avariciae, superbiae sese dedunt, qui hunc tantum mundum norunt, Christum et vitam beatam in futuro saeculo nesciunt. Nos autem, qui vocatione evangelii de mundo avocati sumus, ut illa non expectemus, quae suis ille impartitur cultoribus, sed maiora et perma|nentiora et amoeniora, animum quoque et mores carnis $3528 \mathrm{r} G$

\section{Z. (32) avariciae] avaritiae $Z G$}

159 Lk 12,35.

160 Tert. adv. Marc. 4,29,6 (CCSL I 625,6-10).

161 Erasm. 1Petr. (ASD VI/10 438,112).

162 Erasm. 1Petr. transl. [1,13] (ASD VI/4 392).

163 Erasm. 1Petr. transl. [1,14] (ASD VI/4 392): »Tanquam filii obedientes, vt non accomodetis vor pristinis concupiscentiis, quibus dum adhuc ignoraretis Christum, agebamini.« 
avitos debemus mutare. De qua transformatione scripsit et Paulus, Roman. 12[,2]. Quin ipse Petrus hisce protinus adiungit patris coelestis exemplum invitans ad innocentiam et synceritatem, dicens: »Sed quemadmodum is, qui vos vocavit, sanctimonia. sanctus est, ita ipsi quoque sancti estote in omni vestra conversatione.« Idque iam 5 denuo confirmat et explanat eleganti a pronunciatis ${ }^{164}$ petita sententia: »Iuxta illud, quod scriptum est: >Sancti estote, quia et ego sanctus sum<.« Locus autem extat Levit[ici] 19. ${ }^{165}$ Caeterum sanctimonia illa, de qua loquitur Petrus, non contingit nobis ex nostris meritis, sed ex fide Christi, qui nos lavit a peccatis nostris et nos sibi sanctificavit in peculium per fidem, cuius virtute custodimur ab 1. Cor. 6[,11]. illecebris mundi, ${ }^{166}$ quae custodia hic dicitur sanctimonia. Alias nemo nescit mortalem non posse aequari integritate et sanctimonia deo. Proinde nobis, dum in humanis agimus, nostra est sanctimonia, quae gratia magis quam merito sanctimonia est. Plura de hac re in Psal[mo] 14., Ezech[ielis] 36. et paulo post in cap[ite] $4 .{ }^{167}$ Hinc vero intelligimus errare illos, qui praeceptis externis, cere15 moniis rebusque nihili, sanctimoniam instituunt. Qualis est superstitiosa et propudiosa monachorum colluvies, una cum reliqua superstitiosorum doctorculorum

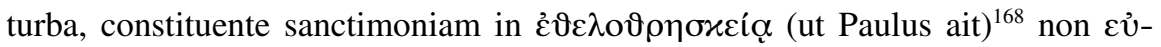

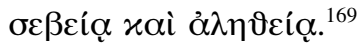

\section{Et si patrem invocatis (citra personarum respectum iudicantem iuxta} cuiusque opus) videte, ut in timore conversantes incolatus vestri tempus transigatis. 18 Cum sciatis vos non caducis rebus velut argento aut auro fuisse redemptos a vana vestra conversatione, quam ex patrum acceperatis traditione, 19 sed precioso sanguine, velut agni immaculati et incontaminati, Christi.

25 Eodem haec pertinent, quo et superiora. Iterum enim adhortatur ad innocentiam vitae argumento ducto a natura fidei et cognitionis dei. Invocandi enim verbum Fides vera posuit pro vera et solida religione seu fide. Ut sit sensus: »Si vere credidistis deo, ${ }_{\text {habet. }}^{\text {timore }}$ si item cognovistis deum esse patrem vestrum, ita tamen, ut simul malum puniat citra ullius personae respectum «|(alibi enim ad Cornelium idem Petrus dicit: »In Acto. 10[,34f.]. veritate comperio, quod non sit personarum respectus apud deum, sed in quacunque gente, qui timet deum et operatur iusticiam, acceptus est illi«), »iam ipsa haec dei agnitio efficiet, ut hoc temporis, quantulumcunque sit, quo a patriis«,

Z. (7) Levit[ici]] Levitici $Z G$ - (13) Psal[mo]] Psalmo $Z G$ - (13) Ezech[ielis]] Ezechielis ZG -

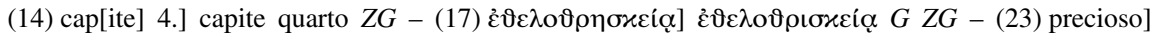
pretioso $Z G-(31)$ iusticiam] iustitiam $Z G$

164 Zum Locus »de pronunciatis« vgl. Agric. inv. 1,23 (Mundt 138-144).

165 Lev 19,2.

166 Vgl. 1Petr 1,5.

167 Ps 15,1-5 (Vulg. 14,1-5); Ez 36,24-32; 1Petr $4,7-10$.

$168 \mathrm{Kol} 2,23$.

169 Vgl. 1Tim 4,7. 
hoc est coelestibus sedibus, ${ }^{170}$ »exules, in hisce reptamus atque peregrinamur terris, transigamus in timore dei.« At timor ab immunditia omni abstrahit, sanctimoniam custodit et gignit. Hic ego reliqua dili|genti lectori expendenda relinquo, nempe quod praecipuo huic argumento, cuius summam iamiam exposuimus, alia duo intertexuit: prius, quod vera sanctimonia non consistat in circumcisione, non in ritu legis externo, sed in vera animi pietate. Hinc enim dixit: »Iudicat iuxta cuiusque opus.« Posterius, quod brevitate et miseria huius vitae, item conditione et $13[, 14]$. cap[ite]. nostra, quod hic non habemus manentem locum, voluptates mundi spernendas, coelestia autem et vere permanentia bona ambienda suasit. Iam et a redemptionis precio, quod per collationem egregie amplificat, innocentiam suadet: »Liberati $\ll, 10$ ait, »estis adeoque et redempti, non auro aut argento, sed sanguine Christi; redempti, inquam, a vana conversatione, quam ceu per manus acceperatis a patribus.«Quo vero maius est precium, quo redempti sumus, quo maius periculum, e quo liberati sumus, hoc magis cavendum, ne iisdem involvamur sordibus. Porro vanas patrum traditiones de gentium et Iudaeorum potes intelligere 15 institutis. Gentes enim a maioribus idololatriam acceperant, quam facile sequitur omnium scelerum lerna. ${ }^{171}$ Iudaei vero sacra et ceremonias colebant et venerabantur, quae dispendii multum, utilitatis autem parum habuere. »Ad tempus etenim correctionis«, ut apud Paulum est, »imposita « [Hebr 9,10] erant. Ab iis ergo, hoc est superstitionibus, erroribus et peccatis, liberavit nos Christus. A lege 20 vero, quae | dei voluntas perpetua est (loquimur autem de decalogo, de fide et charitate), neminem liberavit, qui venit, ut legem adimpleret. ${ }^{172}$ Quod precium redemptionis attinet, aperta satis est collatio. ${ }^{173} \mathrm{Ad}$ amplificationem pertinet, quod sanguinem »preciosum « vocat, quod ipsum Christum »agnum immaculatum et incontaminatum « appellitat. Nihil enim in orbe preciosius est Christo et 25 redemptione eius. Nihil habet anima nobilius, nihil charius aut desyderabilius. Hic ex spiritu sancto conceptus et virgine natus macula caret, purus et illibatus est ab omni immunditiae inquinamento, unde et pro peccatis nostris hostia pura, sancta et illibata solus esse potuit. ${ }^{174}$ Id quod lege quoque apud Mosen in 12. cap[ite] Exodi praefiguratum erat. ${ }^{175}$ Ad quem locum alludens etiam Baptista de 30 Christo domino testificans dicit: »Ecce agnus dei, qui tollit peccatum mundi« [Joh 1,29]. Et Paulus: »Pascha nostrum immolatus est Christus« [1Kor 5,7] etc. De redemptione autem per Christum praestita pluribus disputatum est apud Pau-

Z. (10) precio] pretio $Z G$ - (13) precium] pretium $Z G$ - (22) precium] pretium $Z G$ - (24) preciosum] pretiosum $Z G$ - (25) preciosius] pretiosius $Z G$ - (26) desyderabilius] desiderabilius $Z G$

170 Vgl. Erasm. par. 1Petr. (ASD VII/6 192,185).

171 Vgl. Erasm. adag. 227 (ASD II/1 338f.,879f.): » $\Lambda \dot{\varepsilon} \rho \vee \eta \varkappa \alpha x \tilde{\omega} v$, id est >lerna malorum<, de malis item plurimis simul in vnum congestis et accumulatis.« $\begin{array}{ll}172 & \text { Mt 5,17. } \\ 173 & \text { Hebr 9,12. } \\ 174 & \text { Hebr 10,14. } \\ 175 & \text { Ex 12,3-14. }\end{array}$ 
lum ad Hebraeos 7., 8., 9. et 10., item ad Roma[nos] 3. capite. ${ }^{176}$ Recte vero ex hoc loco aestimamus perperam colligere eos, qui ex patrum maiorumve consuetudine aut traditionibus veritatem religionis alicuius approbare volunt. De eorum stultitia alibi in Act[a] apostolorum diximus. ${ }^{177}$

20 Qui praeordinatus quidem fuerat, antequam conditus esset mundus, sed ma|nifestatus fuit extremis temporibus propter vos, qui per illum creditis in deum, 21 qui illum excitavit e mortuis et gloriam ei dedit, ut vos fidem et spem haberetis erga deum,

Occasione arrepta de Christo domino pro more apostolico disserit obiter. Quoties 10 enim per occasionem licet, excurrunt apostoli in mysterium Christi. Quod autem hic dicit huiusmodi est: »Quae de agno hoc immaculato, pura, inquam, Christi hostia dicimus, non nupera sunt aut hominum arte inventa vel composita, sed aeterna et aeterni dei consilio profecta. Deus enim ab aeterno filium suum sacrificio destinavit, ut per hoc emundarentur sancti.« Unde alibi Christum Ioannes agnum vocat ab origine mundi occisum, id est eum, qui ab aeterno hostiae sit destinatus, per quam mundentur omnes ab origine mundi electi. Paulus enim in 9. cap[ite] ad Hebrae[os] Christum non nisi semel oblatum esse sub finem mundi Christus agnus ab origine mundi occisus, testatur. ${ }^{178}$ Est et illud in verbis Petri considerandum, quod redemptio nostra gratuita est. Si enim in uno Christo salus est et is nobis, antequam iacerentur fundamenta mundi, | destinatus est, profecto salus non ex merito nostro, qui nondum eramus, sed ex nativa bonitate prorsus gratuita est. De qua re copiosius scripsit Paulus ad Eph[esios] 1. ${ }^{179}$ Dicet iam aliquis: »Si ab aeterno destinavit nobis filium deus, qui factum $\mid$ est, ut serius hunc miserit in mundum? « Respondet Petrus: »Sed manifestatus fuit extremis temporibus propter vos, qui per illum creditis in deum. « Ubi duo nobis consideranda sunt. Prius, quod ipsum dei consilium statuit non quibusvis, sed postremis tandem temporibus sanctos per filium redimere. Id enim per prophetas orbi nunciavit, qui haec sub postrema tempora praedixerunt futura. Proinde apostoli non temere postremorum meminere temporum, quae et postrema non ideo dicuntur, quod finis immineat protinus toti mundo, sed quod postrema sint respectu visionum et prophetiae, quae per Christum implendae erant. ${ }^{180}$ Posterius, quod consilium et factum dei a nobis non est culpandum calumniandumve, quod hoc sic fecerit aut illud tardius fecerit, sed in quovis opere dei, quid aut quare fecerit cogitandum. In praesentiarum cum

Z. (1) Roma[nos]] Romanos $Z G$ - (1) capite] cap[ite] $Z G$ - (4) Act[a]] Acta $Z G$ - (17) Hebrae[os]] Hebr[aeos] $Z G-(22)$ Eph[esios]] Ephesios $Z G$

176 Hebr 7-10; Röm 3,23f.

177 Bull. act. 172v.

179 Eph 1,5-12.

178 Hebr 9,28. 
gratiarumactione expendendum, quod, quaecunque deus per Christum fecit, propter nos fecit, nimirum in hunc finem, ut per Christum cognoscamus deum cognitoque fidamus toto pectore. Nam in Christo declaratur nobis veritas, iusticia atque bonitas dei, quibus recte perceptis deo quam firmissime adhaereamus. Quaecunque ergo deus cum Christo egit, in hoc egit, ut nos sibi familiares faceret et aeternum bearet. Atque illud in negocio Christi expendendum est, non cur tardius miserit aut quare sanctis patribus non praestiterit, ut et $\mid$ ipsi coram aspicerent eum, quem salutis suae credebant esse authorem. Praeterea expendendum, quid fecerit, nempe excitarit illum a mortuis, ut nobis (sicut et supra annotatum est) ${ }^{181}$ certam faceret immortalitatis spem, et hanc ipsi contulit glo- 10

Gloria Christi. riam, ut propter ipsum haberemus spem in deum. Id est: eum nobis dedit mediatorem, ut liberum ad deum haberemus accessum. Nam et Paulus ad Roma[nos] 5. dicit: »Per Christum nacti sumus aditum fide in gratiam istam, in qua stamus et gloriamur sub spe gloriae dei« [Röm 5,2]. Porro si in eo vera et unica filii dei gloria est, ut illum credamus et confiteamur eum esse, per quem nobis iratum 15 numen placatum et aditus ad aeternas sedes paratus sit, item cuius nomine in conspectum dei prodire audemus, quoties vel peccati onus vel periculorum procellae opprimunt et in profundum demergunt; certe planum est illos gloriae dei derogare, qui praeterito Christo divos contendunt esse peccatorum patronos et hominum merita, hoc est humana commenta parare aditum ad aedes beatas. 20 Responsum est superioribus ad calumnias nostri quoque saeculi rixatorum, quibus hoc potissimum nomine damnatur evangelium, quod iam primum sit restitutum. Sed de his alias.

22 qui animas vestras purificastis obediendo veritati per spiritum cum charitate fraterna ab omni simulatione alie|na, ex puro corde vos invicem diligite impense, 23 renati non ex semine mortali, sed immortali, per sermonem viventis dei et manentis in aeternum, 24 postquam omnis caro quasi gramen est et omnis gloria hominis quasi flos graminis. Exaruit gramen et decidit flos, 25 verbum autem domini manet in aeternum.

Verba Petri ad veritatem Graecanicam ad hunc propemodum modum habent: 30 $»$ Castificantes animas vestras $\aleph^{182} \gg$ in obedientia veritatis $\ll^{183} \gg$ per spiritum ad fraternam dilectionem, quae sine fuco sit, ex puro corde invicem diligentes vehementer «. ${ }^{184}$ Caeterum cuivis expositum puto, quo haec verba pertineant et quomodo cum praecedentibus cohaereant. Dixerat de fide et spe in dominum,

Z. (3) iusticia] iustitia $Z G$ - (6) negocio] negotio $Z G$ - (12) Roma[nos]] Romanos $Z G$

181 Siehe oben S. $186 f$.

183 Erasm. 1Petr. (ASD VI/10 440,145f.).

182 Luth. 1Petr. 30v. Vgl. Fab. Stap. 1Petr. 19v: $»$ Animas vestras castificantes $[\ldots] . \ll$

184 Vgl. Erasm. 1Petr. (ASD VI/10 440,147.149): $»[\ldots]$ per spiritum $[\ldots]$ in fraternum amorem 
idque obiter, cum alias instituerat dicere de innocentia et sanctimonia vitae. Verum cum illa non nisi ex fide nascatur, subinde de fide, aliud tamen agens, disserit, interim vero ad institutum rediens vicissim ad sanctimoniam transilit. Eo iam pertinet, quod de castificatione (ut sic dicam) animarum profert. Castificatio 5 animorum nihil aliud est quam vera sanctificatio, quae quidem hypocritica est, si ex animo non est. Animum ergo addidit Petrus, sed et caussam: »In obedientia veritatis per spiritum.«Author enim verae innocentiae et sanctificationis est spiritus | dei, qui ex eo nomen | adeptus est. Nam scriptura spiritum dei ab effectu spiritum sanctificationis vel spiritum sanctum vocat. ${ }^{185}$ Qui non quovis modo aut 10 ritu sanctificat, sed $\gg$ in obedientia veritatis «, id est per fidem veram. Illa enim veritati obedit. Atqui haec post se trahit dilectionem; nec quamvis, sed fraternam, hoc est christianam, »quae fucum nescit«. Porro illa fucum nescit, quae ex puro corde et $\dot{x} x \tau \varepsilon v \widetilde{\omega} \varsigma$, id est intense, vehementer sive impense, ${ }^{186}$ diligit proximum. De qua multis egit Ioannes apostolus in sua Canonica. ${ }^{187}$ Hactenus vero descripsit 15 per gradus sive species quasdam veram sanctimoniam, quae consistit in fide, animi pietate, moribus puris et charitate christiana; nunc ad hanc iterum animat rapitque argumento ducto a renascentia et indole filiorum. Quasi dicat: »Renatos Renascentia. nova vita decet, nempe ut moribus parentem referant, e quo nati sunt.« Porro renati sumus non utique carnaliter, hoc enim intellexit per semen corruptibile, sed 20 spiritualiter, nempe per sermonem viventis dei. ${ }^{188}$ Convenit igitur, ut novam vivamus vitam, id est sanctam, spiritus sancti virtute et opera institutam. Sermo autem sive verbum dei, vis dei et potentia coelestis est, quam apud Ioannem in cap[ite] 3. dominus cum Nicodemo de hac ipsa renascentia disputans aquam et ventum appellitat. ${ }^{189}$ Non quod renascentia virtute elementorum fiat, sed ideo isto dicendi genere usus est, | ut collatione et similitudine rerum terrestrium facilius coelestia intelligeremus. Renascimur ergo coelitus spiritu sancto convertente et instituente corda nostra virtute sua atque opera verbi veritatis, quod ab ipso servatore nostro apud Matthaeum semini confertur fructificanti. ${ }^{190} \mathrm{Nec}$ caret mysterio et emphasi, quod non dixit »per verbum dei«, sed »per verbum viventis

$30 \mathrm{dei} \ll$. Significavit enim efficacem et viventem vim verbi agentem in cordibus fidelium. Audiunt quidem et impii verbum dei, sed nulla interim vivifica vis in cordibus eorum. E diverso per semen corruptibile et primam nativitatem intelligit vim, hoc est impotentiam, carnis, denique totam corruptionem generis humani, quam sane variae calamitates variaque scelera, ut renascentiam omnis generis

non simulatum, ex puro corde «; Fab. Stap. 1Petr. 19v: »[...] simplici ex corde invicem diligite attentius.

185 Vgl. Röm 1,4; Joh 14,26.

186 Erasm. 1Petr. (ASD VI/10 440,152f.): »'Ex$\tau \varepsilon v \widetilde{\omega} \varsigma$, id est > vehementer< siue >impense< aut si magis ad verbum cupias reddi >intense $<$.«
187 1Joh 2,7-11; 4,7-21.

188 Vgl. Erasm. par. 1Petr. (ASD VII/6 194,219221): »[...] renati, non ex semine mortali terrenoque iuxta corpus sed ex semine immortali coelestique per sermonem Dei viventis.«

189 Joh 3,5.8.

190 Mt 13,24.

\section{Verae \\ sanctimoniae notatio per \\ species et affinia.}


comitantur virtutes. Atque hic iterum invenit, quo a terrestribus abstrahat ad foenum. Verbum dei aeternum.
Omnis caro

coelestia. Nam verbum dei aeternum, contra vero omnia terrena marcida esse dicit, adducens elegantissimam ex 40. Isaiae cap[ite] sententiam. ${ }^{191}$ Qua divinus vates Iudaeos in Babylonica captivitate oppressos solatur pollicens futurum, ut convulso regno Babylonico ipsi domum redeant. Istud autem praesenti confirmat sententia, qua totum mortalium genus comparat gramini, in primis vero Babylonem flori, qui tamen emarcuerit. Omnia enim mortalium flaccida, solum domini consilium perpetuum et immutabile esse. D[ivus] Pe|trus hac sententia

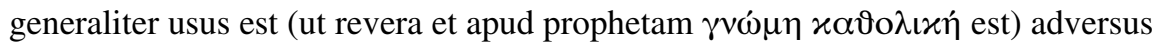
omnem carnis gloriam, opes videlicet, voluptates, prudentiam et quicquid prae- 10 cipuum est in rebus mortalium. Caeterum elegans illud miseriae humanae simulachrum per gramen sive flores et folia adumbratum etiam ethnicorum scriptis celebratum extat. Glaucus enim apud Home[rum], Iliad[os] 6. ad hunc modum interprete Eras[mo] loquitur:

Tale quidem genus est hominum quale est foliorum,

quorum haec ventus humi fundit, rursum illa virescens

profert sylva, simul veris iam afflaverit aura. ${ }^{192}$

Loci communes. Iam et multa egregia ex hoc loco dogmata discere vel locos communes licebit annotare: quae vel qualis vera castitas; qualis esse debeat fraterna charitas; quod prima nativitas omnesque vires carnis nostrae nullae sunt, quandoquidem ad 20 salutem renascentia opus est; quid vel qualis sit renascentia; quod omnia mundana fluida et peritura sint, solum verbum domini aeternum. Quae si quis per singulas persequi velit partes, iustum pene volumen conscribet. Ego mei officii esse puto ista paucis annotare, consilium vero authoris et orationis contextum superstitiosius etiam observare et ceu digito demonstrare studioso lectori, qui 25 deinde singula diligentius excutiet atque perrimabit, nisi commentariis abuti velit.

| 25 Hoc autem est verbum, quod praedicatum est vobis.

Alii verbum interpretantur Christum, qui aeterni patris verbum et, in prophetis promissus, in fine temporum sit exhibitus. ${ }^{193}$ Alii referunt ad verbum proxime praecedens, nec male; ut sit sensus: »Illud, quod vobis evangelica praedicatione 30

Z. (3) cap[ite]] capite $Z G$ - (8) D[ivus]] Divus $Z G$ - (13) Home[rum], Iliad[os]] Homerum, Iliados $Z G$ (14) Eras[mo]] Erasmo $Z G$ - (15) foliorum] filiorum $G$

191 Jes 40,6-8.

192 Zit. nach Erasm. adag. 1248 (ASD II/3 258,925-927). Vgl. Hom. Il. 6,146-148 (Ludwich I 254f.).

193 Vgl. Fab. Stap. 1Petr. 21v: »[...] verbum dei, quod manet in aeternum; quod est nobis an- nunciatum per prophetas, per apostolos, per evangelistas, quod, ut diviniloquus Ioannes testatur, >in principio erat apud deum et deus erat verbum < [Joh 1,1], quod superadmirabili dei consilio >caro factum est et habitavit in nobis< [Joh 1,14].« 33r $G$ 10 
annunciatum est, illud ipsum domini verbum est, quod invito mundo, invitis Animant infernalibus furiis in aeternum manebit. ${ }^{194} \mathrm{Et}$ sane ut ut mille quingentis hac- $\begin{aligned} & \text { haec ad } \\ & \text { perseverantiam. }\end{aligned}$ tenus annis saevierint tyranni et male genii adversus veritatem evangelicam, victrix tamen perstitit semper perstabitque adversus omnes insultus Antichristi in 5 finem usque. Interim vero peribit impiorum mundi et carnis gloria, maiestas, iactantia et superbia; nec peribit modo in hoc saeculo ipsa impiorum caro floris in morem sensim marcescens, sed in futuras reservata poenas fine rerum omnium appetiente resuscitabitur, ut aeterna, hoc est condigna aeternum, luat supplicia. Caeterum videri poterat haec sententia Petri et docta esse clausula, qua totam summa huius 1. cap[itis] disputationem clauserit, veluti cum Cicero post copiosam arevangelii. gumentationem, qua probavit, quod bellum contra Mithridatem ${ }^{195}$ sit suscipiendum, tandem: »Quare videte«, ait, »num dubitandum vobis sit omni studio ad id bellum incumbere, in quo agitur gloria nominis vestri ${ }^{196}$ etc. Sic enim et Petrus post copiosam disputa|tionem de fide, patientia et sanctimonia, clausulam subi-

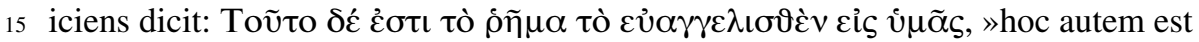
illud verbum, quod evangelizatum est vobis«. Verbum autem summam rei et negotium ipsum dixit, quemadmodum et apud prophetas legimus: »Verbum domini, quod factum est ad Osee« [Hos 1,1] etc. Sensus enim est: »Hactenus vero summam eorum contexui, quae olim vobis per evangelii praedicationem copi20 osius sunt exposita. Sunt tamen haec nostra illa ipsa.« Si enim diligentius omnia colligas, quae hactenus audivimus in hoc cap[ite] 1., ipsam habebis evangelii substantiam; nempe quod deus nativa bonitate ductus filium suum ad hostiam pro peccatis mundi destinarit, priusquam mundus conditus sit, quodque hanc suam ineffabilem gratiam prophetis revelarit, significans, quando haec essent futura, quando venturus Christus, quid passurus, quomodo glorificandus, quae omnia temporum plenitudine revoluta prorsus eo modo completa sint, quo complenda praedixerat per prophetas. Praescripto enim tempore incarnatum et passum asserit Christum, qui sanguine suo a peccatis nos laverit spiritumque filiorum dederit, qui ad honesta impellat, nempe ut in hac fide constantes per patientiam vincamus

30 adversa et per veram sanctimoniam vitaeque innocentiam, sed et in charitate 34v $G \quad$ fraterna colamus deum, qui morti genitos regenuit nos in vitae $\mid$ novae institutum et spem vitae posthac nunquam terminandae. Ita vides, quae fuerit apostolis ratio praedicandi evangelii peculiaris et quam longe lateque $a b$ hac absint istorum decreta, qui apostolico nomine gaudent, apostolicam autem doctrinam proscribunt et persequuntur.

194 Vgl. Erasm. par. 1Petr. (ASD VII/6 194,226228): »Hic est sermo Dei Patris aeternus aeterni quem olim legis prioris vmbrae vobis deliniarunt, caeterum nunc per Euangelii praecones aperte praedicatur.«
195 Mithridates VI. Eupator Dionysos, König von Pontos 120-163 v. Chr., vgl. NP VIII 278-280. 196 Cic. Manil. 19 (Hodge 30). 
CAP. II. 1 Proinde deposita omni malitia et omni dolo et simulationibus et invidentiis et omnibus obtrectationibus, 2 ut modo nati infantes lac illud rationale ac doli expers appetite, ut per illud subolescatis. 3 Siquidem gustastis, quod benignus sit dominus, 4 ad quem accedentes, qui lapis est vivus, ab hominibus quidem reprobatus, apud deum vero electus et preciosus, 5 ipsi quoque velut vivi lapides aedificemini, domus spiritualis, sacerdotium sanctum, ad offerendum spirituales hostias acceptabiles deo per Iesum Christum.

Eodem et haec pertinent, quo superiora, sed et eandem rem dicit, sed mutata orationis figura. Perstat enim in coepta metaphora sive allegoria, docens, quid 10 renatos deceat. Illud porro aliud non est quam institutio in sanctimonia et innocentia vitae. Ad hanc vero institutionem illatione defertur. Quasi dicat: |»Proinde cum per doctrinam evangelicam nuper generatione coelesti estis renati, adeoque pueri et infantuli dei effecti, aequum est, ut pueros imitati sanctos scelera quaevis De his ad deponatis, in primis autem malitiam, dolum, hypocrisim, invidiam et obtrectatiRoma[nos]
$1[$.29f.]. affectus. Unde in evangelio legimus dominum adducto in medium discipulorum infantulo humilitatem animi eius docuisse exemplo. Matthaeus enim / in capite 18.: contendentibus, ait, discipulis, quis maximus esset in regno coelorum, »statuit Iesus puellum in medio illorum et dixit: Amen dico vobis, nisi conversi tuit Iesus puellum in medio illorum et dixit: >Amen dico vobis, nisi conversi 20 fueritis et efficiamini sicut parvuli, non ingrediemini in regnum coelorum « $[\mathrm{Mt}$ 18,2] etc. Huc nimirum allusit apostolus Petrus, qui et allegoriam de lacte ex 66. Isaiae transumpsit. Ibi enim legimus: »Laetamini cum Hierusalem et cum ea exultate omnes, qui diligitis eam. Sugetis enim et saturabimini de mamma consolationis eius; sugetis et delectabimini ab ubertate gloriae eius « [Jes 66,10f.]. 25 Consolans enim ecclesiam propheta de restitutione eius verba facit, inter quae lactis meminit, hoc est donorum spiritus sancti, coelestis sapientiae, evangelii et genii divini. Inest enim lacti quidam veluti genius, qui in pueros per ubera fere transfunditur. Petrus ergo a corpore ad animum transiens notas quasdam addidit, per quas intelligeremus, de quo | lacte loqueretur, nimirum illo, quo de Isaias. $30 \quad 35 \mathrm{v} G$

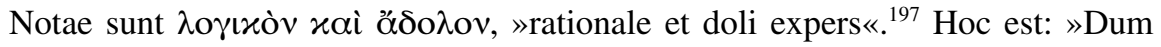
iubeo lac appetatis, non corporis aut humanum inserens genium intelligo, sed rationale, id est spirituale, et doli expers, id est syncerum; ipsam, inquam, intelligo synceritatem, spiritum et animi integritatem. Et quemadmodum pueri non semper sunt pueri, neque semper lacte vivunt materna, sed adolescunt aliquando, 35 ita nolim vos semper esse pueros, sed grandescere, donec perveniatis ad men-

Z. (14) imitati] immitati $G$ - (15) Marg. Roma[nos]] Romanos $Z G$ - (19) 18.] 8. G ZG - (23) Hierusalem] Ierusalem $Z G$

197 Erasm. 1Petr. (ASD VI/10 442,159f.). 
suram aetatis plene adultae Christi«, ut Paulus dicit ad Ephesios 4. ${ }^{198}$ Atque his ad hunc modum absolutis, calcar admovet currentibus. ${ }^{199}$ Addit enim: »Atque hoc

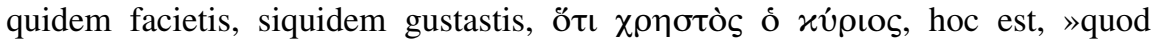
benignus « sive »comis « et »humanus sit dominus $«{ }^{200}$ Tantae enim virtutis est 5 illud coeleste nectar, cognitio videlicet dei et evangelii eius, ut, qui de eo semel gustarint, eius desiderio sic capiantur, ut prorsus in alios mutati subinde sese in fide et rerum divinarum studio superare contendant atque indies magis magisque ardeant amore et studio rerum coelestium. Mutuavit autem et hanc sententiam ex Psal[mo] 33. ${ }^{201}$ Haec de priore allegoria, cui protinus posteriorem de spirituali 10 associat aedificio, nec aliud hac ipsa docens, quam quod superiori docuerat: christianos decere sanctimoniam. Caeterum maxima brevissimis verbis immiscuit mysteria, sen|sus tamen planus est hic: iubet credentes Christum accedant, hoc est, Christo fidant, sese per fidem sanctificent, ut templum ac sacerdotes dei esse possint, qui spirituales deo offerant hostias, id est, cui sanctimonia et puris litent 15 precibus. Principio autem utitur accedendi verbo, sed per metaphoram sicut et Paulus ad Hebrae[os] 11.: oportet accedentem ad deum credere. ${ }^{202}$ Neque enim pedibus accedimus ad deum, sed animo. Proinde »accedere « significat credere et sese deo dedicare. Deinde per eandem metaphoram appellat Christum lapidem, Christus lapis sed tropum exponens ipse $»$ vivum $\ll$ addit. Lapis enim dicitur propter soliditatem 20 ac veritatem fidemque infallibilem, sed vivus additur, ne quis tropum nesciret. Hic autem de reprobatione et precio lapidis huius quaedam inserit, de quibus paulo post clarius ac copiosius dicet. ${ }^{203}$ In praesentiarum ad institutum suum properans subiungit: »Ita porro ad hunc lapidem vivum debetis accedere, ut ipsi quoque veluti lapides vivi superaedificemini.«Et ne quis nesciret, de quo loqueretur aedificio, sese exponens dicit: »Sic autem volo ista intelligi, ut ipsimet illud Ephes. sitis aedificium, verum dei templum, domus spiritualis adeoque et sacerdotium $2[, 20-22]$ sanctum, id est sacerdotes sancti, qui in spirituali templo spirituales offeratis hostias, hoc est vosipsos fide Christi sanctificatos. Haec enim hostia per fidem Christi sic oblata deo placet.«Videntur autem haec decerpta | esse ex 66. cap[ite] 30 Isaiae. In eo enim cap[ite] docet propheta deum et templum et sacrificia et sacerdotes repudiaturum, delecturum vero templum, sacrificium et sacerdotium novum. ${ }^{204}$ Templum dei nos sumus, qui deo fidimus, 1. Cor. 3[,16f.]. et 2. Cor. Templum dei.

\section{Z. (9) Psal[mo]] Psalmo $Z G$ - (21) precio] pretio $Z G$ - (30) cap[ite]] capite $Z G$}

198 Eph 4,13.

199 Erasm. adag. 147 (ASD II/1 264,185-192): »Calcar addere currentibus. [...] Translatione sumpta ab equitibus, qui nonnunquam etiam sponte currentibus equis, quo currant celerius, calcar addunt. Ita nobis calcar addit, qui extimulat languentes; addit currentibus, qui cupiditatem ac studium nostrum auget acuitque.«
200 Vgl. Erasm. 1Petr. (ASD VI/10 442,180f.): »[...] quod benignus sit Dominus.«

201 Ps 34,9 (Vulg. 33,9).

202 Hebr 11,6.

2031 Petr 2,6-8.

204 Jes 66,3f.21. 
6[,16]. Quin et Isaias dei verba recensens dicit: »Ad quem autem respiciam, nisi ad afflictum spiritu et trementem sermones meos?« [Jes 66,2] Quasi dicat: »Ego vero aliud templum mihi elegi: corda sanctorum. « Sacerdotes porro in hoc templo sunt, quotquot Christo fidunt. Isaias enim in eo, quem iam citavimus loco: $\gg$ Et assumam«, ait, »ex eis (intelligit gentibus) in sacerdotes et Levitas « [Jes 66,21]. Sacrificium. Sacrificium autem, quod hoc offeret deo sacerdotium, spirituales sunt hostiae, non corporeae aut visibiles, beluinae aut materia constantes terrena, sed coelestes spiritualesque. Egregie enim paraphrastes: ut, inquit, deus »spiritus est, non corpus, ita spiritualibus hostiis delectatur. Ne quid desideretis Mosi ritus per evangelium | Christi iam antiquatos, pro variis animantium generibus mactatis affectus mundanos brutosque (libidinem, superbiam, iram, invidiam, vindictae cupiditatem, luxum, avaritiam) pro thymiamate puras preces e synceri pectoris ara subvolantes in coelum. ${ }^{205} \mathrm{Haec}$ paraph[rastes]. Recte ergo collegerunt ex hoc loco nostri saeculi theologi omnes christianos esse sacerdotes; sed sinistrius intellexere tumultuosuli quidam, qui non vocati, non $\mid$ electi nec in scripturis docti versatique ad fastigium ascenderunt evangelisticum, sumentes sibi docendi authoritatem in ecclesia, quam tamen in populo Christi nemo sibi privata authoritate arrogaret, nisi is (ut Paulus dicit), »qui a deo vocatur quemadmodum Aaron« [Hebr 5,4]. Et sane aliud est esse sacerdotem dei, aliud esse ministrum ecclesiae dei. Loquimur autem de officio. Sed de his copiosius disputatum in epistola ad 20 Hebraeos, ubi et de sacrificio christianorum, maxime in cap[ite] 13. ${ }^{206}$ sicut et ad Romanos, cap[ite] 12. et $15 .{ }^{207}$ disseritur. Hic vero mihi temperare non potui, quin elegantissimos Aur[elii] Prudentii versus de sacerdotio et sacrificio christianorum, piissime conscriptos hisce insererem commentariis. Verba autem sunt Romani martyris, qui post longam de deo disputationem in hunc modum subdit:

Cognostis ipsum; nunc colendi agnoscite ritum modumque, quale sit templi genus, quae dicari sanxerit donaria, quae vota poscat, quos sacerdotes velit, quod mandet illic nectar immolarier.

Aedem sibi ipse mente in hominis condidit vivam, serenam, sensualem, flabilem, solvi incapacem posse nec destructilem, pulchram, venustam, praeminentem culmine, discriminatis illitam coloribus. (Baschera 181f.); 15,14-16 (Baschera 212). 69-71. 
| Illic sacerdos stat sacrato in limine foresque primas virgo custodit fides, innexa crines vinculis regalibus poscit litari victimas Christo et patri, quas scit placere candidatas, simplices: frontis pudorem, cordis innocentiam, pacis quietem, castitatem corporis, dei timorem, regulam scientiae, ieiuniorum parcitatem sobriam, spem non iacentem, semper et largam manum.

Ex his amoenus hostiis surgit vapor vincens odorem balsami, thuris, croci, auras madentes Persicorum aromatum; sublatus inde coelum adusque tollitur et prosperatum dulce delectat deum. ${ }^{208}$

His, obsecro, quid poterat vel excogitari quadrantius? Videtur omnino sanctus dei martyr data opera praesentem Petri locum exposuisse, sed pergimus ad caetera.

\section{Propterea continet scriptura: ecce pono in Zion lapidem summum} angularem, electum, preciosum; qui credet in eum, non pudefiet. 7 Vobis igitur preciosus est, qui creditis. Caeterum iis, qui non credunt: lapis, quem reprobaverunt aedificantes, hic coepit esse caput anguli 8 et lapis, in quem impingitur, et petra, ad quam offendant, | nempe his, qui impingunt in sermonem neque credunt in id, ad quod et instituti fuerant. 9 Vos autem genus electum, regale sacerdotium, gens sancta, populus peculiaris, ut vires annuncietis eius, qui e tenebris vos vocavit in admirabilem lucem suam. 10 Qui quondam eratis non populus, nunc populus dei; qui quondam | non consequti misericordiam, nunc estis misericordiam consequti.

Scripturis declarat atque confirmat, quod hactenus de lapide Christo et sacerdotio christianorum dixit, ut simul et Christum pro more apostolico conversis nuper ad fidem Iudaeis gentibusque commodius praedicaret commendaretque et sua contra calumniatores solidaret. Dixerat Christum lapidem esse vivum quidem, sed reprobatum ab hominibus et tamen a deo electum; ${ }^{209}$ id iam comprobat Isaiae

Z. (19) preciosum] pretiosum $Z G$ - (20) preciosus] pretiosus $Z G-(27)$ consequti] consequuti $Z G$ (27-28) consequti] consequuti $Z G$

208 Prud. perist. 10,341-365 (CCSL CXXVI 209 1Petr 2,4. 341f.). 
Unica salus in Christo.

testimonio transcripto ex 28. cap[ite]. Verba Isaiae haec sunt: »Audite verbum domini, o illusores, qui consultum vobis putatis (sensum reddo) ceremoniis et rebus externis: fallimini prorsus et frustra vobis salutem ex mendatio pollicemini. Nemo enim nisi per Messiam sanabitur. Sic enim dicit dominus: ecce ego mittam in Zion lapidem, lapidem probatum, angularem, preciosum, firmissime fundatum; qui crediderit, non festinet « [Jes 28,14-16]. Deus ergo unicam | duntaxat in orbe firmitatem constituit, cui qui innituntur, non cadunt. Id quod festinandi verbo per metalepsim ${ }^{210}$ significavit. Qui enim festinant, plerunque impingunt et cadunt, ${ }^{211}$ qui vero cunctantius atque circumspectius incedunt, rarius offendunt et cadunt. Apostoli ergo non verba, sed sensum reddiderunt: »Qui crediderit in illo, non pudefiet.«Sed quid nobis frustra facimus negotium, cum ipse Petrus locum Isaiae luculenter exponat? Iucunda enim distributione subdit: »Vobis quidem preciosus est, qui creditis; caeterum incredulis lapis reprobatus.« Hic nos de singulis agemus plusculis. Petrus enim in scripturarum abdita relegans, occasionem ampliora cogitandi sedulis suppeditavit lectoribus. Primo lapis dicitur Christus proptes 15 firmitatem, ut supra quoque annotavimus, ${ }^{212}$ et veritatem. David enim in Psalmis Psal. 17. dicit: $\gg$ Diligam te, domine, fortitudo mea. Dominus rupes mea et propugnaculum meum et eripiens me, lapis meus, confidam in ipso, scutum meum et cornu salutis Lapis in meae, protectio mea « [Ps 18,2f. (Vulg. 17,2f.)]. Deinde lapis dicitur fundatus fundamento fundatus. firmissime sive in fundamento fundatus, vel propter fidem dei immobilem vel propter contemptum et humilitatem incarnationis vel propter aedificium impositum. Christus enim fundamentum et petra ecclesiae est. Et Paulus eo alludens ait: $\gg$ Fundamentum nemo potest ponere aliud, quam quod positum est: Iesus Christus.« Sed et non ipsum|nos, sed ipse nos portat, qui dixit: »Non vos me elegistis, Lapis angularis. sed ego vos elegi«, Ioan. 15[,16]. Praeterea »angularis« dicitur lapis. Petrus in

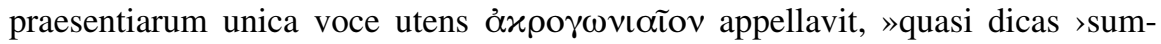
mangularem $\ll: 213$ idque duplici nomine, tum propter glorificationem, quae reprobationem consequta est, tum propter hostes, qui ipsum reprobarunt, quibus factus est lapis angularis, in quem, licet convitiis impingant impii, sibi tamen suisque capitibus magis quam angulari lapidi nocent. ${ }^{214}$ Angularis quoque dictus, 30 quod iuxta Pauli verba ex duabus gentibus unam fecit, ${ }^{215}$ veluti in aedificiis Lapis preciosus. publicis angularis solet duos sibi nectere parietes. ${ }^{216}$ Iam et preciosus dicitur

Z. (5) preciosum] pretiosum $Z G$ - (12) preciosus] pretiosus $Z G-(28)$ consequta] consequuta $Z G$ (32) Marg. preciosus] pretiosus $Z G-(32)$ preciosus] pretiosus $Z G$

210 Vgl. Quint. inst. 8,6,37 (Winterbottom II 470): »[...] metalempsis, id est transumptio, quae ex alio tropo in alium uelut uiam praestat.«

211 Vgl. Zw. Isa. [28,16] (Z XIV 285,37-286,2): »Frequens enim est eis, ut festinandi verbo utantur virtute metalepseos pro errandi aut cadendi verbo. Qui enim festinant, ferme praecipites concidunt aut imprudentes errant.«
212 Siehe oben S. 205.

213 Erasm. 1Petr. (ASD VI/10 446,215).

214 Vgl. Erasm. par. 1Petr. (ASD VII/6 196,278f.): »[...] in quem suo malo impingerent et incurrerent quicunque aduersarentur huic nouo aedificio.

215 Eph 2,14.

216 Vgl. Hier. in Eph. 1,2 (PL XXVI 476C-D): 
propter pios, quibus in hoc mundo nihil est preciosius Christo precioque redemptionis eius. Sentiunt enim in hoc uno satis esse firmamenti, gaudii et vitae, in nulla autem creatura istius quicquam. Unde d[ivus] Petrus apud Ioannem: »Quo Ioan. 6[,68f.]. iremus domine? «, ait, »tu verba vitae habes et nos credimus et cognovimus, quod 5 tu es Christus filius dei vivi.« Norunt pii lapidem quidem istum reprobatum esse a sapientibus mundi, sed huic id opponunt, quod revera preciosus est. Impiis enim Lapis (descendimus iam ad alterum distributionis membrum) lapis reprobationis et petra scandali est. Quae sane verba d[ivus] Petrus partim ex Isaiae 8. cap[ite], partim ex Psal[mo] 117. transcripsit. Isaias populum Iuda consolans, ne sibi ab

\section{doct, qui sit petra firmissima sibi fidentibus et sese ad ipsum in spe recipientibus,} petra autem offensionis diffidentibus. ${ }^{217} \mathrm{Ut}$ enim fidelium pater, ita infidelium praetor et iudex est deus. Pari ratione Christus dominus piis author est salutis, impiis argumentum damnationis. Nam qui in eum non credit, iam iam condem- Ioan. 3[,36].

15 natus est. Porro locus Psalmi 117. hic est ad verbum: »Lapidem, quem reprobaverunt aedificantes, factus est in caput anguli. A domino factum est istud, et est mirabile in oculis nostris « [Ps 118,22f. (Vulg. 117,22f.)]. Continent autem haec prophetae verba et gloriam et contumeliam sive mortem Christi, praeterea et frustratam impiorum spem. Caeterum collationem habent tacitam. Quemadmo20 dum enim aedificantes lapidem aliquem insignem reiiciunt ab aedificio, ne locum in eo habeat ullum, qui tamen vel invitis vel nesciis aedificii magistris tandem in summum | elatus angularis fit lapis; ita Christus dominus a scribis ac legis doctoribus, qui populi dei videbantur magistri, reprobatus et veluti impostor et seditiosus minimeque aedificio dei aptus primum quidem e synagoga eiectus, deinde vero in crucem adactus, tandem invitis hostibus suis tertia die a mortuis resurrexit coelosque conscendit, factus iam angularis lapis, qui ex utrisque unum fecit, ${ }^{218}$ et piis author salutis, impiis argumentum aeternae damnationis existit; in quem, si qui impingunt doctrinae evangelicae vel infensi vel in Christum crucifixum iniurii et blasphemi, suopte vitio corruunt et in pulverem atteruntur. Simeon enim apud Lucam in 2. dixit: »Hic positus est in ruinam et in resurrec- Petra scandali. tionem multorum in Israel, et in signum, cui contradicitur « [Lk 2,34]. Quin et ipse Petrus Israelitas maxime impegisse dicit: »Hi enim impegerunt«, ait, »in sermonem nec crediderunt, ad quod instituti fuerant.« Impingunt enim in evangelium Iudaei, dum eius praedicatione offenduntur non credentes eum esse Mes-

\section{Z. (1) preciosius] pretiosius $Z G-(1)$ precioque] pretioque $Z G-(6)$ preciosus] pretiosus $Z G$}

«[Christus] assumptus a Deo in angularem lapidem, ut duos parietes ipse medius contineret; et per illum uterque populus ad Deum haberet accessum «; Isid. orig. 7,2,39 (Lindsay I [S5]v): »Lapis angularis, [...] quia duos pa- rietes e diuerso, id est de circumcisione et praeputio, uenientes in unam fabricam Ecclesiae iungit.«

217 Jes 8,14f.

218 Eph 2,14. 
siam, quem tamen fides veritasque evangelica Christum esse testatur et cuius Act. 3[24-26]. nomine tot patribus factae sunt promissiones, quarum cum ipsi haeredes sint, eas tamen opes repellunt, quas ipsis ante caeteras offert deus. Id quod et Christus in ipsis accusat apud Matthaeum in 21., ubi et pluribus de occaecatione eorum disserit. ${ }^{219}$ Hisce vero omnibus sustulit Petrus etiam crucis scandalum atque istorum docuit contemnendas esse calumnias, qui evangelium indignis conspurcant ludibriis. Nunc per apostrophen ad gentes, imo ad omnes christianos conversus dicit: »Vos autem genus electum, regale sacerdotium« etc. Quibus verbis superiora illa, quae de sacerdotio omnium christianorum proposuerat, ${ }^{220}$ ita confirmat, ut tamen filum orationis non interrumpens novam ordiatur telam. Adhuc enim cohaerent haec cum iis, quae proxime praecesserunt. Hoc enim dicit: »Iudaei, qui christianam religionem et doctrinam evangelicam convitiis proscindunt lapidemque Christum reprobant, putant nos esse prophanos, se vero populum electum, qui templum, sacrificia et sacerdotium habeat; sed longe falluntur. Nam ipsos non probat deus, qui carne rebusque externis repudiatis spiritum et 15 spiritualia poscit. Quod ergo coeperam dicere, vos, qui Christo fiditis, esse domum spiritualem sacerdotiumque sanctum, id nunc absolvam et scripturis muniam, nempe quod vos, qui Christo creditis, elegerit Iudaeorum infidelium Iudaeorum
populus dei. loco, ut vos posthac gens electa et sancta ipsi spirituales offeratis hostias, sacrificium videlicet laudis et gratiarum actionis. «Transumpsit autem testimonia ex 20 Exodi cap[ite] 19., Isaiae 43. vel 66. et Oseae 1. Verum retractabimus singula; est enim locus insignis et foecundus. Dominus apud Mosen non citra conditionem elegit in peculium gentem Iudaeorum. Dixit enim: »Si audiendo audieritis vocem meam et custodieritis pactum meum, eritis mihi in peculium de cunctis populis. Mea est enim omnis terra, sed vos eritis mihi in regnum sacerdotale et gens 25 sancta « [Ex 19,5f.]. Istis vero testatur dominus suam esse totam terram, adeoque ad se omnium gentium pertinere curam. Non enim putandum est, quod deus verax, iustus, clemens et omnipotens solos curarit Iudaeos, alias vero gentes neglexerit omnes, sed illud potius credendum est, quod, dum $\mid$ curam gereret omnium, ex omnibus tamen delegerit sibi gentem Iudaicam in peculium, ita ut in 30 hac maxima potentiae, bonitatis et iusticiae suae aederet argumenta; in primis vero per hanc toti orbi exhiberet Christum, adeoque et hanc faceret toti mundo exemplum. Interim vero, dum illam sibi delegerit, non citra conditionem delegit, utique liberum sibi permittens illam, si videretur, si pactis non staret, repudiare et aliam in locum istius substituere. » $\mathrm{Si} \ll$, ait, »audiendo audieritis vocem meam et 35 custodieritis pactum meum, eritis mihi in peculium« [Ex 19,5]; proinde: »Si non audieritis vocem meam, non eritis peculium mihi.« Iam Petrus dixit, quod Iudaei

Z. (4) Matthaeum] Mattthaeum $G$ - (31) iusticiae] iustitiae $Z G$

219 Mt 21,42-44.

2201 Petr 2,5 . 
non crediderint in id, ad quod instituti fuerant; unde iam planum relinquitur, quod Iudaei posthac non sint peculium dei, sed illi potius, qui audiunt verbum dei, credunt et pactum custodiunt. Id quod gentes fecere; unde et gentes posthac sunt gens vere sancta, id est munda et separata a prophanis, verum utique peculium

5 ein sundertrut Gottes. Impii sane et prophani, iniurii et blasphemi in filium et evangelium dei non possunt esse peculium dei. Regale sacerdotium vocavit praecipuum et nobile sive selectum, ut cum nos delicias nostras vel epulas vel vestes vel liberos appellamus regium cibum, vestem, puerum, ein künigliche spyß oder ein fürstlich mensch. Iam vero, quo illud | pertineat sacerdo10 tium, explanant | consequentia: »Ut vires praedicetis illius, qui e tenebris vos vocavit in admirabilem lucem suam. « Id quod ex Isaiae 43. cap[ite] desumptum videtur, ubi ad hunc modum legimus: »Populum istum formavi mihi, ut laudem meam annunciet« [Jes 43,21]. Quibus non absimilia legis in 66. eiusdem cap[ite]. ${ }^{221}$ Certe annunciandi verbo et prophetae et apostoli utuntur pro laudandi 15 et gratias agendi affectu. Id frequentissimum est in Psalmis ${ }^{222}$ et Paulus, 1. Cor. 11.: »Mortem domini«, ait, »annunciate, donec veniat« [1Kor 11,26], id est, »mortem domini gratiarum actionibus et laudibus celebrate $«{ }^{223}$ Quin et hoc loco Sacrificium caussam obiter recensuit, ob quam deus sit a novo hoc concelebrandus sacerdotio, nimirum quod ab errorum et peccatorum tenebris liberatos illuminarit nos gratia 20 sua et evangelica veritate; quae multis nominibus luci passim in scripturis confertur, ${ }^{224}$ id quod notius est, quam multis iam exponendum sit. De hoc ipso sacerdotio et sacrificandi modo Oseas propheta disertissimis verbis ita disseruit: Oseae. 14[,2]. »Convertere, Israel, ad dominum deum tuum.« Unica enim via ad salutem est conversio ad deum. Ad hanc porro in primis monere debet peccatorum calamitas.

25 Addit ergo: »Quoniam impegisti in peccatis tuis « [Hos 14,2]. Sed et copiosius exponit, quid deo offerendum sit, ubi ad eum converti statueris: »Tantum verba«, ait, »portate vobiscum « [Hos 14,3], id est sacrificium confessionis et laudis, bringend nun gùte wort mit üch.|Iam et illa bona verba, id est formulam huius sacrificii, praescribit: »Dicite: $>$ Omnem aufer iniquitatem et accipe bonum 30 et reddemus vitulos labiorum nostrorum« « [Hos 14,3]. »Grave«, inquam, »scelerum onus animis incumbit nostris, tu solus id auferre potes; miserere ergo nostri domine et aufer a nobis peccata nostra, und nimm răcht für gů t von uns, boni consule tenuitatem nostram et offeremus tibi vitulos labiorum, id est laudes et gratiarum actionem, pro eo, quod nos a peccatis mundaveris. « Hoc vero quid 35 aliud est, quam quod Petrus dixit »annunciare virtutem eius, qui nos e tenebris in admirabilem lucem vocavit«? Admirabilem, inquam, quia et Isaias dixit: »Domine, quis credet auditui nostro? « [Jes 53,1] $]^{225}$ et David: »A domino factum est

221 Jes $66,19$.

222 Vgl. Ps 50,17; 96,3.

223 Vgl. Bull. 1Cor. 11,23-26 (Baschera 381,36382,1): ">Annuntiare mortem domini< dixit pro eo, quod est recolere et laudare passionem domini, cuius repraesentatio est fractio panis.«

224 Vgl. Jes 60,1; Joh 1,5.9.

225 Vgl. Joh 12,38.
»Annunciare« pro »celebrare $\ll$

.


hoc et est mirabile in oculis nostris « [Ps 118,23]. Istis omnibus per se alias satis firmis adiicit clariss[imam] de vocatione gentium sententiam ex 1. cap[ite] Oseae sumptam, ne quid dubii in cuiusquam pectore remaneret: in ea gentes vocavit, non populum, id est impios, quorum non miserabatur deus. ${ }^{226}$ Verum hunc locum explanat Paulus ad Ephesios 2. ${ }^{227}$ Illud obiter annotandum, Petrum dixisse $\lambda \alpha$ òs

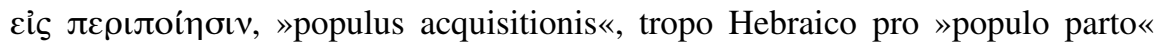
sive »acquisito ${ }^{228}$ nimirum sanguine Christi, ein erarnet volck. Attamen ego subinde verti »populum peculii«, qui proprius, $\pi \varepsilon \rho \iota$ ov $^{\prime} \operatorname{lo}^{229}$ et acquisitus dicitur. Plura de significatione huius verbi $\mid$ Erasmus in Annotat[ionibus], 2. cap[ite] ad Titum. ${ }^{230}$ Ista vero de Christo hactenus peroravit Petrus, quod solus Christus sit firmitas et fundamentum fidelium, quem cum Iudaica gens recipere noluerit, repudiata sit et in locum eius gentes surrogatae, quae posthac sanctus dei populus deo spirituales, hoc est laudis et gratiarum actionis, offerant hostias. Ex quibus nos illud primo colligimus: unam esse ecclesiam, unum populum veterem et nostrum, sive nos in locum repudiatorum successisse Iudaeorum. Id quod 15 Paulus clarius declaravit per similitudinem arboris, e qua naturales rami defracti, et in defractorum locum sylvestres insiti sint. ${ }^{231}$ Quo et illae domini in evangelio similitudines pertinent, quibus regnum dei vineae comparat et nuptiis. ${ }^{232}$ Non enim aliam sibi comparat vineam, non novas componit nuptias, sed alios conducit colonos, atqui in eandem vineam, et neglectis iis, quos primo invitarat, alios ad 20 nuptias, sed easdem, invitat. Ut vinea semper eadem, eaedem permaneant nuptiae, coloni et invitati tantum mutentur. Porro quantum aut qua in re a nobis distent veteres illi ante adventum Christi patres, alibi satis est expositum. ${ }^{233}$ Secundo colligimus pont[ificem] Romanum prorsus esse impium, utpote qui sibi tribuit, quod nulli hominum citra maximam potest tribui blasphemiam. Hic enim ver- 25 borum Petri, cuius se falso iactitat vicarium, oblitus, sese ecclesiae caput, pe|tram et fundamentum esse ait. Idem ille verum Christi sacerdotium suo illo Chananaico, hoc est mercatorio, sacerdotum ordine obscuravit adeoque et conculcavit, sed et carnalibus suis sacrificiis spirituales et veras christianorum oblationes in neglectum et contemptum abduxit. Id cum hodie plerique feramus indignius, ille nos haereticos esse clamitat. Caeterum nos $\mid$ nihil aliud quam Christi gloriam assertam et verum sacerdotium veraque sacrificia cupimus restituta. Nec diffi-

Z. (2) clariss[imam]] clarissimam $Z G$ - (2) cap[ite]] capite $Z G$ - (9) Annotat[ionibus]] Annotationibus $Z G$ - (24) pont[ificem]] pontificem $Z G$

226 Hos 1,6.

227 Eph 2,11-13.

228 Vgl. Erasm. 1Petr. (ASD VI/10 448,236-238):

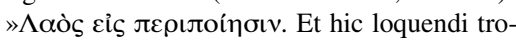
pus Hebraicus sit oportet. Sentit enim populum, qui lucro accessit adoptatus et insitus in populum Dei.«
229 Tit 2,14.

230 Erasm. Tit. (ASD VI/10 204-206,371-393).

231 Röm 11,17.

232 Mt 21,33-41 parr.; 22,2-14 par.

233 Vgl. Zw. elench. (Z VI/1 169,17-170,16). 
dimus deo, certi, quod spiritu oris sui indies magis magisque interficiet impium, interim et petra futurus sit credentibus et lapis offensionis omnibus adversus veritatem convitiantibus. Erudite enim Zacharias in cap[ite] 12. ecclesiam et semper veritatem christianam comparat lapidi oneris sive exercitationis, ad quem fortitudinem suam explorent adolescentes, attamen non sine insigni suo periculo. Dicit autem: »In die illo ponam Hierusalem lapidem oneris omnibus populis. Qui tollent illum, lacerando lacerabuntur, et congregabuntur contra eam omnes gentes terrae « [Sach 12,3]. Pugnabitur quidem adversus veritatem dabiturque quibusdam victoria et successus tam foelix, ut prorsus vicisse videantur et lapidem istum 10 super verticem capitis levasse; sed vincet tandem pondere illisque ipsis illidet cerebrum victoribus. Quod et Christus hisce verbis significavit: »Qui ceciderit super lapidem | illum, confringetur; super quem vero ceciderit, conteret eum « [Mt 21,44]. Nemo igitur prosperitate impiorum seducatur. Aderit aliquando deus ultor. Nihil in hoc mundo stabile. »Omnis caro foenum et omnis gloria ceu flos graminis; exaruit gramen et decidit flos, at verbum domini manet in aeternum « [Jes 40,6-8; 1Petr 1,24f.]. Proinde quisque curet, ut omnibus divenditis margaritam emat evangelicam, ${ }^{234}$ atque omni huius mundi securitate contempta conferat se in petram Christum lapidem vivum, preciosum et in fundamentis Zion firmissime fundatum, cui qui nituntur, aeternum non cadent.

\begin{abstract}
11 Dilecti, obsecro tanquam advenas et peregrinos: abstinete a carnalibus concupiscentiis, quae pugnant adversus animam, 12 et conversationem vestram habete honestam inter gentes, ut in hoc, quod obtrectant vobis quasi maleficis, ex bonis operibus aestimantes vos glorificent deum in die visitationis.
\end{abstract}

25 Quae hactenus ex prophetarum testimoniis de Christo lapide et populo sancto dicta sunt, aliena cuipiam ab instituto Petri poterant videri, set propriissima sunt.

Contextus et status orationis. Institutum Petri est innocentiam sanctorum pectoribus inserere. Huc iam probe quadrabant testimonia de sancto populo super Christum fundato. Hos enim in primis decebat innocentiam vitae colere, ne $\mid$ impii et prophani sic aliquando abiicerentur, ut Iudaei, in quorum locum subiere, erant abiecti. Verum istud iam clarissimis verbis ingerit, cum dicit: »Obsecro, ut abstineatis a carnalibus desideriis «, nimirum ut verum dei templum, gens sancta et sacerdotium sanctum esse possitis. ${ }^{235}$ Pro more autem pristino passim non vulgaria miscet argumenta, quibus auditores ad sanctimoniam trahat. Principio blandis eos verbis compellans, monet meminerint sortis suae, nempe quod in hisce terris non habeant manentem
Z. (18) preciosum] pretiosum $Z G$ - (31-32) desideriis] desyderiis $Z G$
234 Mt 13,46.
235 Vgl. 1Petr 2,5.9. 
Christiani peregrini sumus. locum, sed velut advenae sint et peregrini. »Nostra enim conversatio«, ut Paulus ait, »in coelis est« [Phil 3,20]. Coelestia ergo nobis cogitanda animique ad aeternam patriam allevandi sunt. Si quid interim, dum hic in exilio agimus, sinistrior abstulerit fortuna, si raptores huius mundi nos spoliarint facultatibus terrenis, aut si dexterior aspirans fortuna mollius hic vivere contingat, meminerimus semper nos peregrinos esse, qui, etsi lautius vivant in diversoriis, desertis tamen deliciis iis pergunt ad veras patriae delicias; etsi spolientur, aequi bonique consulunt, modo ad patrias aedes aliquando perveniant. Nobis itaque pari ratione spernenda voluptas, contemnendae adversariorum minae, constanter per patientiae campum tendendum ad patriam coelestem, »sedes, ubi fata quietas osten- 10 dunt $\ll,{ }^{236}$ ubi et illorum (ut poeta dicit) $»$ meminisse iuvabit $\ll .{ }^{237}$ Per carnales vero concupiscentias | intellexit totam scelerum et peccatorum universitatem, quae ex concupiscentia animi, malorum omnium et fonte et fomite, existit. De ea ad Roma[nos] $7 .^{238}$ Additur caussa, cur carnalibus sit reluctandum affectibus: militant enim adversus animam. Anima vero accipitur hic pro mente religiosa et 15 illuminata a deo. Illam oppugnant concupiscentiae carnales, ut vincant, occidant, in suas partes pertrahant et in sempiternum demergant interitum. Tracta est metaphora a militia. Usus est eadem Paulus ad Galat[as] 5. et Romanos 7. atque 8. cap[ite], ${ }^{239}$ ubi de his plura annotata sunt. His iunguntur iam argumenta ab honesto et utili ducta. Pulchrum enim est, ut coram iis vivamus sancte, qui vel 20 odio vel ignorantia, maleficii nos insimulant. | Utile quoque, quod inde glorificatur deus et reluctantes pertrahuntur ad agnitionem veritatis. Semper quidem male audiit christiana religio, id quod videre est in Apologetico Tertulliani et in operibus Cypriani et Eusebii ${ }^{240}$ nil ergo mirum si vel hodie male audiat. Verum innocentia vitae et morum probitate semper superati sunt a christianis adversarii. 25 Eadem ratione et hodie nobis vincendi sunt hostes evangelii, qui religionem nostram haereseos, turbarum et proditionis insimulant. Sancta et vera est doctrina

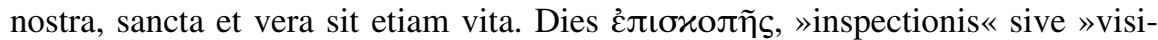
tationis $\ll,{ }^{241}$ hoc in loco in bonam par|tem usurpavit. Paraphrastes sensum sic reddidit: integritate morum et in omnes beneficentia comperta, »resipiscent et illi agnoscentes errorem suum, afflati misericordia dei, cum illi visum fuerit et illos attrahere, qui vos delegit, iamque glorificent eum ex piis vestris operibus, quem ante ignotum detestabantur $\ll .{ }^{242}$

\section{Z. (7) deliciis] delitiis $Z G$ - (7) delicias] delitias $Z G$}

236 Verg. Aen. 1,205f. (Mynors 109).

237 Verg. Aen. 1,203 (Mynors 109).

238 Röm 7,7f

239 Gal 5,17; Röm 7,14-23; 8,6-8.

240 Vgl. Tert. apol. 1-4 (CCSL I 85-94); Cypr.

Demetr. 3-5 (CCSL IIIA 36f.); Euseb. hist. eccl. 5,1,15 (GCS IX/1 406-408).

241 Erasm. 1Petr. (ASD VI/10 448,249f.).

242 Erasm. par. 1Petr. (ASD VII/6 198,313-315). 
13 Proinde subditi estote cuivis humanae creaturae propter dominum, 14 sive regi tanquam praecellenti sive praesidibus, ut qui per eum mittantur ad vindictam quidem nocentium, laudem vero recte agentium. 15 Quoniam sic est voluntas dei, ut benefaciendo obturetis os hominibus stultis et ignorantibus: 16 tanquam liberi et non veluti praetextum habentes malitiae libertatem, sed tanquam servi dei.

Hactenus in genere de vera disseruit religione, certitudinem fidei nostrae ostendens et summa quidem eius fundamenta iaciens, praeterea monens, ut in hac per patientiam vitaeque sanctimoniam constanter perseveremus in finem usque; post10 hac speciatim ad praecipua christianorum officia descendens, ea, ut in patientia et vera sanctimonia praestanda sint, praescribit. Primo autem disserit de obedientia magistratui et legibus civilibus praestanda. In genere vero: »Subiecti «, ait, »estote Obedire dictis principum. cuivis humanae creaturae.« Id quod Lutherus | vertit: »Subiecti estote omni

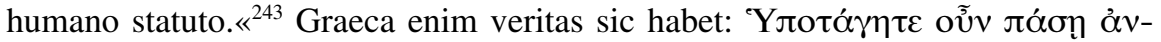

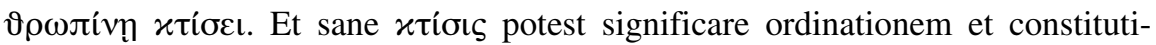
onem civilem, quam forsan dixit humanam, id est ad res hominum conservandas institutam. ${ }^{244}$ Caeterum videri poterat Petrus suo quodam dicendi genere usus, nihil tamen dixisse aliud, quam quod Paulus praecepit: potestatibus supereminentibus obediendum esse. ${ }^{245}$ Nam statim subiungitur $\gg$ sive regi sive praesidibus«, quibus exposuit, quid per humanam intellexerit creaturam, ordinationem videlicet magistratus, quae ad res humanas conservandas sit instituta. Quod si priorem sententiam fueris sequtus, observabis duplices esse constitutiones humanas: aut enim versantur circa religionem, aut circa res civiles. Quae circa Humanae religionem versantur, praescribunt cultum dei, ceremonias instituunt et extra verbi dei regulam varia superstitionis instituta tradunt. Cuius generis sunt pleraeque patrum traditiones et constitutiones pontificiae. De quibus in evangelio dominus dixit: »Frustra me colunt docentes doctrinas, praecepta hominum « [Mk 7,7]. Porro quae circa res civiles versantur, aequitatem, pacem publicamque honestatem instituunt. Cuiusmodi sunt leges Caesareae et civiles de emendo, 30 vendendo, locando, mutuo, haereditatibus, idque genus aliis ad religionem nihil pertinentibus innumeris. Qui|bus si quis non obediat, nisi cum pietate et charitate prorsus pugnent, non video, quomodo christiano nomine dignus esse possit. Nihil enim firmamenti habet, quod tumultuosuli quidam subinde obiiciunt: »Frustra me colunt praeceptis hominum « $[\mathrm{Mk} 7,7]$. Neque enim haec a nobis in cultum dei

Z. (4) obturetis] obduretis $G Z G$ - (22) sequtus] sequutus $Z G$

243 Luth. 1Petr. 56v.

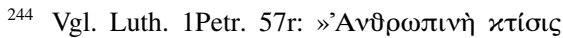
hic humanum statutum, legem aut mandatum significat.« 
fiunt, sed in emolumentum nostrum, nempe ut salva republica, nos quoque salvi esse possimus. ${ }^{246}$ Neque vero dominus istud verbi (ut audivimus) dixit de civilibus, sed spiritualibus (ut vocant) constitutionibus, quae ad cultum dei instituuntur. Quod si posteriorem amplectaris sententiam, iam sub regis et praesidum nominibus omnis generis magistratum intellige. De quo ad Roma[nos] 13. copiosiora dedi. ${ }^{247}$ Iam vero, quare obediendum sit, adiungit: »Propter dominum.« Non (inquit) hoc tantum nomine obediendum, quo supplicium devitemus, quod sumit de inobedientibus magistratus, sed quod ipse quoque dominus obedientiam praecipit. Paulus enim dicit: »Quisquis resistit potestati, dei ordinationi resistit. Qui autem | restiterint, sibiipsis iudicium accipient« [Röm 13,2]. Appenditur et aliud, cur obediendum sit: missi sunt $\gg$ ad vindictam nocentium, laudem vero recte agentium «. Finis, in quem (ait) institutus est magistratus, bonus est; ergo omni modo obediendum est. Hic autem est finis, ut suppliciorum metu coerceantur

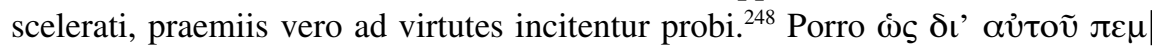
$\pi о \mu \varepsilon ́ v o ı \varsigma$, id est: »tanquam iis, qui per eum mittuntur«, anceps et dubia est oratio. 15 Ad regem enim et ad deum referri potest, ${ }^{249}$ melius tamen ad deum. ${ }^{250}$ Non est enim potestas nisi a deo, qui in Psalmo 81. dicit: »Iudicate pauperem et orphanum, inopem et egenum iustificate. Eripite pauperem et inopem de manu impiorum liberate « [Ps 82,3f. (Vulg. 81,3f.)]. Id demum est »ad vindictam nocentium, laudem vero bonorum « esse missum. Neque novum est, quod laus ponitur pro 20 assertione defensioneque. Veterum enim »leges«, id quod et Eras[mus] ex Platone annotavit, »non solum minabantur poenam male agentibus, verum etiam praemiis invitabant ad officia ${ }^{251}$ Et dominus apud Lucam in 22. ait: »Reges gentibus

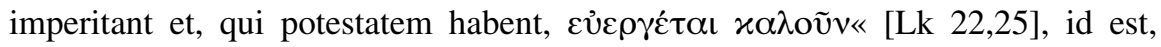
»benefactores vocantur«. »Vocantur« autem dixit ad morem Hebraicum pro 25 »sunt«. Id est, in hoc instituti sunt reges, ut benefici sint. Plura de his ad Roma[nos] 13. ${ }^{252}$ Praeterea adiungitur aliud, quod moveat ad obedientiam: »Haec enim est voluntas dei, ut benefaciendo calumnias ethnicorum eludatis, qui, si aequum iugum detrectaretis legum, probabiliter dogma damnarent christianum quasi omni parte aequo et iusto repugnans, cum alias mysteriorum dei ignari 30 temerius et sinistrius iudicent de religione christiana: nolim ergo commodiorem ipsis praeberi nostra inobedientia ansam damnandi sanctum et verum dogmatis genus.« D[ivus] Pau|lus alibi eandem hanc rationem clarioribus verbis sic extulit:

\section{Z. (17) Psalmo] Psal[mo] ZG - (21) Eras[mus]] Erasmus $Z G$}

246 Vgl. 1Tim 2,2.

247 Bull. Rom. 13,1-7 (Baschera 190-197).

248 Vgl. Erasm. par. 1Petr. (ASD VII/6 198,325f.): »[...] vt nocentes ac scelerosos suppliciorum metu coerceant ac probos praemiis inuitent ad officium.«

249 Erasm. 1Petr. (ASD VI/10 450,264f.): " $\Omega \varsigma$ $\delta$ '’ $\alpha$ ชỡ id est >tanquam per eum<, nempe regem, siue >per eum<, videlicet Deum.«

250 So auch Luth. 1Petr. 57r-v.

251 Erasm. 1Petr. (ASD VI/10 450,267f.). Vgl. Diog. Laert. vit. 3,79 (Hicks I 346).

252 Röm 13,4. 
»Subditi estote, ne nomen dei et doctrina male audiat « [1Tim 6,1]. Iam vero, quod multi tum essent, ut et nostris fuere saeculis, qui libertatis christianae praesidio se a magistratus et omnium legum iugo arbitrarentur liberatos, non intelligentes verae christianorum libertatis naturam et genium, non citra increpationem tacitam dicit: »Nec est, quod quisquam vestrum se libertatis christianae titulo obedientia magistratus iusta subducat. Liberi sane estis, sed a peccatis, ne illa vobis dominentur, a lege, id est umbra et maledictione legis. Nemo igitur maliciae suae aut instituto perverso debet praetexere libertatem, quasi vero christiana libertas licentia peccandi sit, quam mox titulo libertatis defendere liceat. Servi dei sumus, liberati a servitute daemonis, mundi et carnis. Deo ergo posthac serviamus. Deus praecepit magistratui obediamus. Proinde serviamus deo obedientia.« Copiosius de libertate christiana disputatum est in Romanis. ${ }^{253}$

\section{Omnes honorate, fraternitatem diligite, deum timete, regem honorate.}

Rem copiosissimam uno iam verbo brevique sententia comprehendit, quid chris- Scopus tiani debeamus non modo magistratui, sed omnibus pene hominibus; id quod multi copiosissimis libris aeditis nondum assequti sunt. Sententia Petri tripertita est. Primam sententiae | partem sic exponit Paulus: »Reddite omnibus, quod debetur: cui tributum tributum, cui vectigal vectigal, cui timorem timorem, cui honorem honorem« [Röm 13,7]. Germanice diceremus: Thůnd yederman, was jr schuldig sind. Secundam partem idem Paulus hisce verbis explanavit: »Nemini quicquam debeatis nisi hoc, ut invicem diligatis« [Röm 13,8]. Tertiam vero paribus pene verbis annumeravit Christus: »Reddite, quae sunt Caesaris, Caesari, et quae sunt dei, deo« [Mt 22,21 parr.]. Illud tamen observandum in primis, quod deo timorem, regi vult impendi honorem. ${ }^{254}$

18 Famuli subditi sint cum omni timore dominis, non solum bonis ac humanis, verum etiam pravis. 19 Nam haec est gratia, si quis propter conscientiam dei suffert molestias praeter meritum affectus malis. 20 Quae enim est laus, si, cum peccantes alapis caedimini, sufferetis? At si, cum benefacitis et tamen malis afficimini, suffertis. Haec enim est gratia apud deum.

Instituit famulos. Graeca veritas oixécas dixit. At Caelius Lectio[num] Servi.

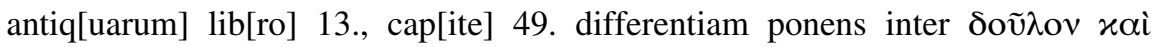

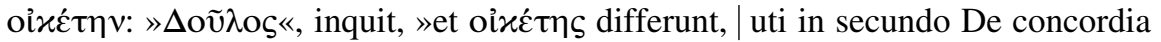

Z. (8) maliciae] malitiae $Z G-(16)$ assequti] assequuti $Z G$

253 Röm 7,5-13.

254 Bull. Rom. 13,7 (Baschera 197,3f.): »Timo- rem habemus dominis. Honorem vero aliis dignitatem gerentibus«; vgl. Oecol. Rom. 97r. 


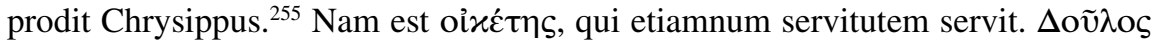
autem ỏ $\alpha \varepsilon \lambda \varepsilon v ́ v \varepsilon \rho o v$ in|dicat, id est libertum et universim ministrum quemlibet. ${ }^{256}$ Instituit ergo Petrus servos, qui servitutem serviebant et sub infidelium

1. Tim 6[,1]. dominorum iugo gementes indignum putabant, ut liber populus, christianorum videlicet, tam indignis modis opprimeretur ab impiorum dominio. Habuere et vetera saecula Iudam Galilaeum, ${ }^{257}$ Saduchum, ${ }^{258}$ Spartacum $^{259}$ et nostra tempora turbarum per universam fere Germaniam authores, ${ }^{260}$ qui eiusdem sententiae cum his libertatem christianorum non intellexere. In 1. ad Corinth[ios], 7. cap[ite] dicit Paulus: »Qui in domino vocatus est servus, libertus domini est « [1Kor 7,22]. »Ne ergo tibi sit curae; attamen, si potes liber fieri, magis utere « [1Kor 7,21]. Ita et Petrus, ut fervorem et impatientiae aestum restingueret, ait: »Nolo, ut servi ora sua herili subducant capistro, sed potius volo, ut subsint dominis suis, adeoque et cum timore ac reverentia subsint.« Timor supercilium, contemptum et fastum deprimit. Eadem verba legere est et apud Paulum in 6. cap[ite] ad Ephesios. ${ }^{261}$ Iam ne responsarent: »Obediremus, si essent viri boni et christiani, at durum est 15 tam misere excarnificari innoxios ab impiis«, praevenit et ait: »Non solum bonis

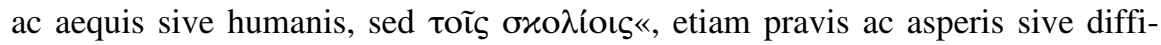
cilibus. ${ }^{262}$ Rationem addit, quam per antistrephon ${ }^{263}$ quodpiam ipsorum opponit obiectioni: »Haec«, ait, »est gratia, si quis praeter meritum tantum propter conscien|tiam dei affligitur.« Obscurior autem paulo est haec sententia propter ser- 20 48v $G$ monem insolentiorem. Nam »haec est gratia « dixit pro eo, quod est »illud demum meretur laudem«. Germani contrarium foelicius enunciaverimus: Du wirst

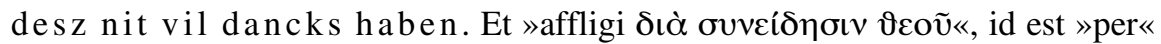
sive »propter conscientiam dei«, dixit pro eo, quod est »propter caussam iustam pati «, nempe cum afflictus sibi de innocentia sua coram deo probe conscius 25 patienter fert iniuriam. Eam dixit Petrus »conscientiam dei«. Sensus itaque est: illud demum deo gratum est et summis vehendum laudibus, si quis iustus sit

Z. (8) Corinth[ios]] Corinthios $Z G$ - (14) cap[ite]] capite $Z G-(22)$ foelicius] felicius $Z G$

255 Chrysippos (3. Jh. v.Chr.), stoischer Philosoph und drittes Schuloberhaupt, vgl. NP II 1178-1183.

256 Rhod. lect. 707.

257 Judas der Galiläer, jüdischer Rebell gegen die römische Herrschaft zur Zeit Jesu, vgl. Flav. Ios. ant. 18,1-10 (Niese IV 140f.); Hengel 1976, 79-150.

258 Gemeint sind die »Sadduzäer«, die in der Zeit vom 2. Jh. v.Chr. bis zur Zerstörung des Jerusalemer Tempels 70 n.Chr. neben Phasisäern und Essenern eine einflussreiche innerjüdische Gruppierung darstellten, vgl. NP X 1204-1206.

259 Spartacus, 73-71 v.Chr. Anführer des wohl bedeutendsten Sklavenaufstands in der römischen Geschichte, vgl. NP XI 795f..

260 Bullinger deutet hier vermutlich auf den »Bauernkrieg « und auf den Anführer der aufständischen Bauern in Thüringen, Thomas Müntzer (1489-1525), an. Vgl. RGG ${ }^{4}$ V 15851587; TRE XXIII 404-436.

261 Eph 6,5-8.

262 Erasm. 1Petr. (ASD VI/10 452,285f.).

263 Vgl. Bud. comm. 694,5-10; Gell. 5,10 (Rolfe I

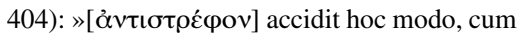
argumentum propositum referri contra convertique in eum potest a quo dictum est, et utrimque pariter valet.« 
iustamque caussam habeat, interim tamen afflictionem perpetiatur atque in hac patiens sit. Huic sententiae addit contrariam, quam per interrogationem figurat, dicens: »Quid autem laudis fuerit, si quis vestrum, cum ob malefacta vapulat, suffert? Merito enim vapulant mali. Caeterum si quis, cum benefecerit, illatas 5 iniurias constanti toleret animo, id demum laudem et apud deum et apud homines non prorsus stupidos meretur. « Additur enim per pleonasmon ${ }^{264}$ fere aut repetitionem: »Haec enim est gratia apud deum.« Ex istis omnibus colligimus eos, qui Martyres. ob malefacta caeduntur aut puniuntur, nequaquam martyrum nobili dignos esse nomine. Exempla verius sunt, quam martyres. Nam qui meritas luunt poenas, exemplum fiunt aliorum, ut hi illorum calamitate territi minus $\mid$ peccent. Martyres vero in caussa vera, iusta et bona afflicti caesique testimonium ferunt veritati. Sed de hac re copiosissime simul et doctissime scripsit d[ivus] Aur[elius] Augustinus adversus Donatianos Petilium ${ }^{265}$ et Gaudentium ${ }^{266} \cdot{ }^{267}$ Plura dicet Petrus in cap[ite] $4 .{ }^{268}$

21 Siquidem in hoc vocati estis, quoniam et Christus afflictus est pro nobis, relinquens nobis exemplum, ut insequeremini vestigia ipsius. 22 Qui peccatum non fecerat nec inventus est dolus in ore eius; 23 qui, cum maledictis incesseretur, non regessit maledicta, cum malis afficeretur, non minabatur, sed tradidit vindictam ei, qui iudicat iuste;

20 A vocatione sive professione et exemplo Christi trahens argumenta, evidentius rapit ad patientiam, ita tamen loquens servis, ut nemini nostrum non competant Primo dicit: religio christiana non promittit in hoc saeculo cultoribus suis opes Christiani ad crucem amplas, voluptates varias honoresque splendidos, sed crucem et afflictionem, contemptum et facultatum direptionem. Hac ergo lege in hoc vitae institutum a baptismate suscepti estis, ut patiamini. Proinde nemo caussari potest se sua spe frustratum esse. Secundo absolutum Christi exemplum proponit, qui, cum innocentissimus esset, afflictionem tamen sustinuit, nimirum ut eius exemplo | moniti nil aliud quam afflictiones assiduas nobis polliceremur atque in his exerciti ad quaevis mala faciem obfirmaremus. Caeterum verbis Petri mira inest copia, vis et maiestas, quam si quis pro dignitate persequi incipiat, vix multis absolvere queat; nos summas | rerum duntaxat perstringemus. Principio in genere dicit:

\section{Z. (12) Aur[elius]] Aurelius ZG}

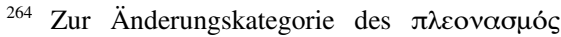
bzw. der adiectio vgl. HLR 251; HWR VI 1286.

265 Petilianus (gest. nach 419/422), donatistischer Bischof von Cirta (heute Algerien), vgl. NP IX 662.

${ }^{266}$ Gaudentius (4./5. Jh.), donatistischer Bischof von Thamugadi (heute Algerien), vgl. AugL III 95f.

267 Vgl. Aug. c. Petil. 2,83,184-88,195 (CSEL LII 112-121); Aug. c. Gaud. 2,12,13 (CSEL LIII 270,27-30).

268 1Petr 4,12-19. 
»Etiam Christus afflictus est pro nobis. «Deinde, ne quis hoc verbi tantum ad redemptionis precium traheret, addit: »Relinquens nobis exemplum, certe ut Christus insequeremini vestigia ipsius. « Unde nos colligimus Christum non tam ad saluexemplum vitae. tem et propitiationem quam ad lucem et exemplum mundi missum esse mortalibus. In evangelio secundum Matthaeum legimus dixisse dominum: »Si quis vult me sequi, abneget semetipsum, tollat crucem suam quotidie ${ }^{269}$ et sequatur me.« Illo autem videtur allusisse Petrus, qui et metaphoram transumpsit ab iis, qui vestigiis quibusdam imprudentioribus viam veluti delineant. Hinc succisis membris, quid aut qualia qualive animo passus sit Christus, enarrat, ut tacita quadam antithesi intelligamus, quid nos quoque deceat: »Christus«, ait, »peccatum non 10 fecit nec inventus est dolus in ore eius, attamen afflictus est.« Ea autem sunt Isaiae verba ex cap[ite] 53. ${ }^{270}$ His iam oppone: nos vero peccatores sumus, adeoque non nisi ex dolis, mendatio et hypocrisi consuti; minus igitur mirandum, si et nos affligimur, multo minus etiam deo respon|sandum est, quoties patimur.

Convitiari. Item, cum dira in Christum congererent convitia Iudaei et horum primores pha- 15 rizaei et scribae, ut extat apud Matth[aeum] in 27. cap[ite] ex Psal[mo] 22., ${ }^{271}$ cumque domino non deessent gravissima scelera, quae in adversarios vere potuisset eiaculari, obticuit tamen, imo et pro hostibus suis patrem obsecravit caecitatis eorum misertus. ${ }^{272}$ Hinc iam disce id, quod Paulus ad Roma[nos] 12. docuit: »Bene loquamini de iis, qui vos insectantur; bene loquamini, inquam, et 20

Vindicta. ne male precemini« [Röm 12,14]. Rursum: cum indigna pateretur dominus, cum pro omnipotentia et divina sua virtute illos vel fulmine coelitus vocato vel tellure iussa dehiscere semel potuisset omnes extinguere, deglutire et in aeternum demergere interitum, nil tamen vel minabatur istorum, sed omnem vindictam patri reliquit, ${ }^{273}$ quem et iustum iudicem esse novit, qui, ut nemini irrogat iniuriam, ita 25 nullam illatam iniuriam sinit impunitam. Discamus ergo et nos vindictam eidem tradere deo iusto, aequo, vero et ultori; id quod etiam Paulus in eodem cap[ite] docuit, quod iam iam citavimus.

24 qui peccata nostra ipse pertulit in corpore suo super lignum, quo peccatis mortui, iusticiae viveremus, cuius eiusdem vibice sanati fuistis. 25 Nam eratis velut oves errantes, sed conversi estis nunc ad pastorem et curatorem animarum vestrarum.

Christus Occasione accepta ex Isaiae cap[ite] 53. ${ }^{274}$ modice ab instituto suo deflectens pro more apostolico scribit de gratia et redemptionis precio deque iustificatione per

Z. (16) Matth[aeum]] Matthaeum ZG - (19) Roma[nos]] Rom[anos] ZG
269 Lk 9,23.
270 Jes 53,9.
271 Mt 27,42f.; vgl. Ps 22,9.
272 Lk 23,34.
273 Vgl. Dtn 32,35; Röm 12,19.
274 Jes 53,4 f. 
Christum. Pleraque vero transcripsit ex Isaia. Breviter: cum nos onere peccatorum gravati succubuissemus turpiter et iam iam aeternum expectaremus supplicium, deus nostri misertus filium suum in mundum misit, ${ }^{275}$ qui ferendo oneri idoneus esset. Veniens ergo in mundum filius dei, hominis factus est filius

5 suscepta carne peccati, id est suscepta natura humana in qua in crucem adactus peccata nostra munda sua carne, sancto, inquam, holocausto expiatur, ${ }^{276}$ quod quidem holocaustum divinae literae »peccatum « appellitant, propterea quod pro peccatis sit oblatum. ${ }^{277}$ Alias fidei syncerae et orthodoxae mysteriis docti, credimus Christi carnem de spiritu sancto conceptam et ex intemerata virgine natam carere peccato, labe seu macula. ${ }^{278}$ In crucem ergo suspensus est Christus, ut peccata nostra portaret, id est, expiaret hostia corporis sui itaque nos mundaret a peccatis ${ }^{279}$ deinde ut innocentiam vitae commendaret nobis. ${ }^{280}$ Debemus enim nos, qui credimus Christum pro nobis passum esse, mortuum et resuscitatum, carnem nostram una cum concupiscentiis crucifigere, ut in novam vitam spiritu Galat. 5[,24]. dei resuscitati deum colamus non mortuis operibus, sed vivis fidei sanctae fructibus. De qua re egregie disputavit Paulus ad Rom[anos] 6. ${ }^{281}$ Caeterum operibus hisce sancto|rum vivis, iusticiae inquam, non tribuenda peccatorum expiatio, sed sanguini Christi. Petrus enim dicit: »Cuius eiusdem vibice sanati sumus.« Ambrosius alibi legit: »Cuius vulnere plagarum sanati sumus. ${ }^{282}$ Alii legunt: »Cuius 20 livore sanati sumus. ${ }^{283}$ Est autem livor $»$ vestigium plagae in cute $«,{ }^{284}$ vel tumor »ex plaga concretus ${ }^{285}$ ein blütmaaß. Intellexit autem propheta crucem et verbera, vulnera, sanguinis effusionem et ipsam mortem, quae vita et emundatio nostra est. ${ }^{286}$ Ex eiusdem prophetae authoritate comparat genus mortalium ovibus palantibus, ${ }^{287}$ ut apta $\mid$ collatione et miseriam notet mortalium et gratiae divinae 25 erga nos magnitudinem. Eadem allegoria usus est etiam Christus apud Lucam in

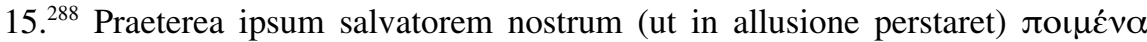

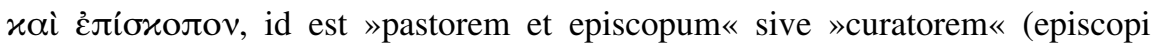
enim de rebus necessariis prospiciunt ${ }^{289}$ vocavit, id quod apud Ioan[nem] in cap[ite] 10., Lucam in 15. et Ezech[ielem] 34. cap[ite] exponitur. ${ }^{290}$ Paraphrastes: 30 Christi, ait, vinculis, plagis, vulneribus, cruci et morti debetis, quod pristinae vitae peccata non imputat deus. ${ }^{291}{ }$ Nam ante $\ll$, nempe ante cognitum Christum,

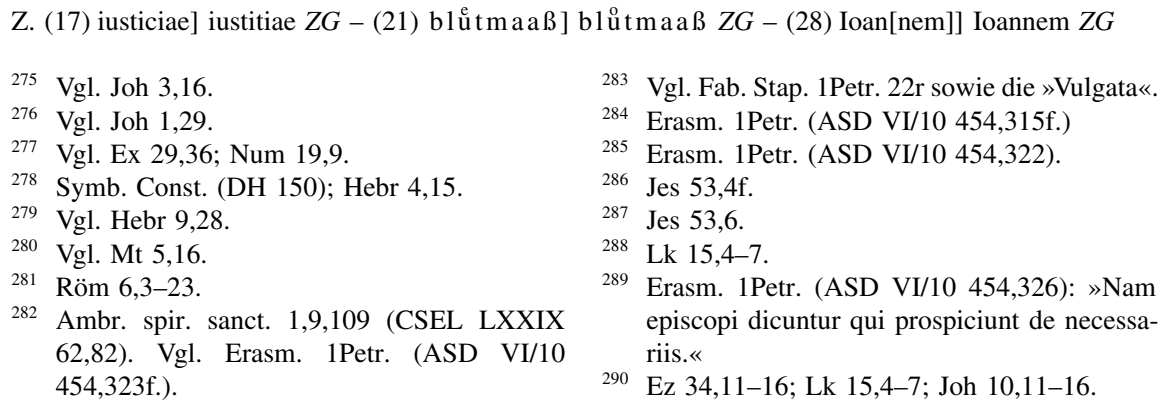
episcopi dicuntur qui prospiciunt de necessariis.«

290 Ez 34,11-16; Lk 15,4-7; Joh 10,11-16. 
»velut oves palantes absque duce, alii alio aberrabatis, quo quemque sua ducebat cupiditas, existimantes licere, quicquid liberet; sed ab errore pristino nunc conversi estis ad Christum Iesum, pastorem et curatorem animarum vestrarum. Hunc si sequamini ferendis praeter $\mid$ meritum afflictionibus malorum, illo duce pervenietis ad immortalitatis gloriam. $\ll^{292}$

CAP. III. 1 Similiter, uxores, subditae sitis vestris viris, ut etiam qui verbo non obtemperant, per uxorum conversationem absque verbo lucrifiant, 2 dum consyderant cum reverentia coniunctam, castam conversationem vestram, Redit nunc in viam, et officia christiana describere pergit. Multum autem bonae frugis in matrimonio est, si recte institutum sit in timore dei. Nam et calamitates variae et scelera innumera oriuntur ex coniugio malo. Qui hactenus de operibus bonis ex pontificiorum parte scripserunt, vere bona opera neglexerunt, fictitia quaedam laudibus extulere. Nam monachismum, ceremoniarum studium, ieiunia stolida et preculas superstitiosas laudavere, interim vera christianorum officia 15 neglexere prorsus. Neque putaverunt eos labores, quos perferunt servi vel coniugati ullum inter opera bona habere locum. At d[ivus] Petrus his primum assignat. In praesentiarum eas primum uxores instituit, quae incredulis iugatae maritis imperium eorum hoc ferebant impatientius. ${ }^{293}$ Petrus autem nihilo minus obediendum esse docet, nimirum in iis, quae religioni christianae prorsum ad- 20 versa non sunt. Paulus enim in 1. ad Corinth[ios] cap[ite] 7. loquens de im/pari connubio: »Si quae mulier«, inquit, »maritum habet infidelem et is assentitur, ut habitet cum ea, ne dimittat illum « [1Kor 7,13]; item: »Si quis frater uxorem habet infidelem et haec assentitur, ut habitet cum illo, ne dimittat eam « [1Kor 7,12]. Interim pulchre monet Petrus incredulos viros non uxorum rixis, sed conversa- 25 tione sancta in consensum religionis pertrahi. Hortatur ergo castae, integrae atque modestae sint, ut integritate, quae nascitur ex fide, permoti mariti istam quoque fidem et doctrinam amplectantur, quam vident tantarum virtutum esse altricem. Et sane $»$ per quam acres stimulos habet syncera probitas $«,{ }^{294}$ quae plus fere potest apud adversarios non omnino perversos quam docta disputatio. Sed et vita im- 30 proba plus nonnunquam diruit, quam sana doctrina aedificari possit.

291 Vgl. Erasm. par. 1Petr. (ASD VII/6 200,382384): »Quod pristinae vitae peccata non imputat Deus, huius vinculis, huius plagis, huius vulneribus, huius cruci, huius morti debetis.«

292 Erasm. par. 1Petr. (ASD VII/6 200,384-388).
293 Vgl. Luth. 1Petr. 66v-67r: »Hic d[ivus] Petrus potiss[imum] de uxoribus loquitur, qui [!] eo tempore adhuc infideles habebant maritos.«

294 Erasm. par. 1Petr. (ASD VII/6 200,400f.). 
3 quarum ornatus sit non externus, qui situs est in plicatura capillorum et additione auri aut in palliorum amictu, 4 verum occultus, qui est in corde homo, si is careat omni corruptela, ita ut spiritus placidus sit ac quietus, qui spiritus in oculis dei magnifica ac sumptuosa res est. 5 Nam hoc modo ornabant quondam se sanctae illae mulieres, quae spem suam in deum collocabant et subditae erant viris suis, 6 quemadmodum Sara obedi|vit Abrahae, dominum illum appellans, cuius factae estis filiae, dum benefacitis et non terremini ullo pavore.

Interpres Erasmus ipse fatetur se hisce verbis sensum magis quam verba superstitiosius reddidisse. ${ }^{295}$ Porro plurimum momenti habet, qua quis sit veste amictus. Habitus et Neque enim temere apud veteres et nostri aevi homines adagium increbuit: »Ex $\begin{aligned} & \text { vestitus } \\ & \text { corporis. }\end{aligned}$ veste aestimari hominem. ${ }^{296}$ Credimus enim plaerique varii et inconstantioris animi indicium esse vestem varicolorem, corrupti aut lacerandi cupidi laceratam sive conscissam, arrogantis et impudentis plus nimio exquisitam et procacem.

Proinde Petrus adversus muliebrem luxum, quem sibi | velut cognatum habent, disserit, modestiam et vitae sanctimoniam commendat. Praecipuus autem foeminarum cultus consistit $\dot{\varepsilon} v \pi \lambda \mathrm{o} \kappa \tilde{\eta} \varsigma \tau \rho \iota \tilde{\omega} \nu$, id est in contextu, plicatura sive »crispatura capillorum $\ll,{ }^{297}$ cui addunt mitras tiarasve e bisso contextas et acu varie pictas, insertis passim auri et argenti gemmarumque pigmentis. Deinde $\gg$ in amictu palliorum«; at sub palliorum vocabulo complexus est Petrus omnis generis, omnium nationum aetatumque preciosas et exquisitas vestes, quas aetates varie mutant et regiones pro varietate morum diversissimas habent. Hic vero: »Non externo cultu«, ait Petrus, »exornatur christiana mulier, sed animi bonis.« Unde iam externum cultum asper|nandum, internum vero consectandum docuit. Animus et mens Internum vero cultum dicit in homine interiore esse, nempe si foemina sit animo hominis pia menteque incorrupta, nil agat ex affectibus muliebribus, nil intemperantiae, iracundiae, rixis, ambitioni, arrogantiae vel procacitati tribuat, sed mitis, placida, tractabilis et mansueta sit. Id demum deo probari. Hic »spiritus«, hic ornatus »magnifica«, inquit, et preciosa res est »in oculis dei«. Prophani homines precio 30 et sumptu aestimant ornatum corporis et hoc meliorem et speciosiorem credunt, quo pararint emerintve carius, sed deus fidem miratur, ex fide aestimat omnia.

Z. (9-10) verba superstitiosius] superstitiose verba $Z G$ - (12) plaerique] plerique $Z G$ - (21) preciosas] pretiosas $Z G$ - (29) preciosa] pretiosa $Z G-(29)$ precio] pretio $Z G$

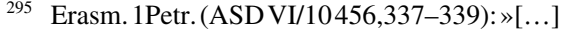
vt sententiam magis reddamus quam verba, $>$ quarum sit ornatus non externus qui situs est in crispatura siue >contextu capillorum aut appositione auri aut amictu vestium $<$ aut $>$ palliorum<.《

296 Vgl. Sen. epist. 47,16 (Hense 141,18-22):
»Quemadmodum stultus est, qui equum empturus non ipsum inspicit, sed stratum eius ac frenos, sic stultissimus est, qui hominem aut ex veste aut ex condicione, quae vestis modo nobis circumdata est, aestimat.«

297 Erasm. 1Petr. (ASD VI/10 456,338f.). 
Caeterum ex hoc loco colligimus duplicem esse hominem: externum et internum; magis tamen probari internum, qui, si incorruptus sit, sanctiorem esse externum quoque. Paulus in 2. ad Corinth[ios] 4. cap[ite] utriusque mentionem faciens dicit externum corrumpi quidem, sed internum renovari indies. ${ }^{298}$ Proinde qui sapiunt, momentanea relinquunt, permanentia et aeterna requirunt. Nec Petrus haec primum de vero corporis cultu protulit, sed et Solomon Proverb[iorum] 11. ait: »Mulier, quae honorem tuetur, gratiosa est« [Spr 11,16]. Item: »Mulier, quae formosa est, sed immodesta, non dissimilis est porco naribus aureum torquem gerenti« [Spr 11,22]. Et iterum in cap[ite] ult[imo]: »Fallax venustas est et vana est forma, mulier timens deum laudanda est « [Spr 31,30]. Et Propertius: ${ }^{299} » A m-10$ pla satis forma pudicitia. ${ }^{300}$ Paulus quoque $\mid$ apostolus 1. [ad] Timoth[eum] 2. cap[ite] velut Petri verba exponens dicit: »Volo mulieres in amictu esse honesto«, sive modesto, »cum verecundia et castitate ornare seipsas, non tortis crinibus aut auro aut margaritis aut vestitu sumptuoso, sed quod decet mulieres profitentes pietatem per opera bona « [1Tim 2,9f.]. Fortassis haec ipsa Pauli verba mutuavit 15 Petrus et, quod sanctos dei viros nunquam puduit, inter sua retulit. Accusanda igitur hoc in loco arrogans illa nostri saeculi superbia, invehendum oratori divino in nimium istum et fatuum corporis cultum, quem et a prophetis videmus accerrime fuisse increpitum. Certe ne in hac re quicquam negligeret, Petrus exemplum, at exemplis ad permovendum auditoris animum nihil evidentius, proponit: »Sic enim egere «, ait, »sanctae quondam foeminae, quae erant fideles. Nam viris erant subditae, deinde variis virtutibus sese exornabant, externum et nimium corporis cultum negligebant. Idem itaque et vos factitare decet, modo fideles estis.« Atque hic ex omni sanctarum mulierum turba protrahit Saram. Hanc matrem facit omnium fidelium foeminarum, sicut ex scripturis constat Abraham patrem esse 25 omnium credentium virorum, eorum, inquam, qui exemplum imitantur patris et Gen. 18[,12]. genium referunt paternum. Sara porro Abrahae fuit subdita et »dominum « appellavit illum. Qua appellatione summus notatur honor, summa obedientia. Neque | enim verbis et blanda duntaxat appellatione exhibetur obedientia, sed magis ipsa re. Igitur si quae gaudent »Sarae« dici »filiae«, Sarae quoque imitentur exemplum. Sunt stolidi quidam, qui loqutionis genus non intelligunt et dominos se ab uxoribus salutari poscunt, abutentes authoritate sua. Sunt alii, qui sorditiem hic commendari credunt, ut illam putent mulierem esse integerrimam, quae immunda veste cincta, tetrica sordidaque simulat sanctimoniam. Sed modus est in re qualibet. ${ }^{301}$ At nil aliud quam modum docuit Petrus. Iam cum superstitiosulum 35 quoque sit genus muliebre et iccirco in rebus nihili frequenter exanimetur, timens

Z. (6) Proverb[iorum]] Prover[biorum] $Z G$ - (9) ult[imo]] ultimo $Z G$ - (31) loqutionis] locutionis $Z G$

298 2Kor 4,16.

299 Sextus Propertius (1. Jh. v.Chr.), römischer Elegiendichter, vgl. NP X 415-418.
300 Prop. 1,2,24 (Barber 4).

301 Vgl. Hor. sat. 1,1,106 (Klingner 165): »Est modus in rebus."

\section{.}


sibi, ubi nihil periculi, et credens, quae sunt superstitiosa minimeque credenda, iubet, ut posito illo inani pavore totas sese deo dent. Hic locus est agendi contra inanes anilesque fabulas, contra benedictiones stultas, superstitionem foemineam et si quid aliud est huius generis. Haec demum vera sunt christianarum mulierum 5 officia, quae et a Paulo in hunc prorsus modum exposita sunt in 2. cap[ite] ad Titum et 1. [ad] Timoth[eum] 5. ${ }^{302}$ Qui loci sic repugnant vitae nonnaticae, ut nostro tempore scripta credere possis.

7 Viri similiter cohabitent secundum scientiam velut infirmiori vasi, muliebri impartientes honorem tanquam etiam cohaeredibus vitae, ne interrumpantur preces vestrae.

| Viris quoque, quid facto opus sit, praescribit. Sunt enim, qui, ut iam iam dicere coeperam, abutuntur authoritate sua, putantes viri in uxorem imperium esse Maritorum tyrannidem. Hi clamitant: »Scriptum est: >Uxoris caput est maritus $<$ Eph 5,23].« Equidem; sed nunquid caput in reliquum tumultuatur corpus? An non magis 15 caeteris membris servit omnibus? An non regit et consulit omnibus? Ita et maritus uxoris caput esse debet, id est iucundus convictor, consultor et vitae dux commodus. Id si negligat, non magis titulo capitis dignus est quam caput illud, quod, ut in fabulis est, vulpes inventum isto notavit dicterio: »O quale sine cerebro caput! ${ }^{303}$ Petrus itaque importunam quorundam refrenans audaciam et intemperiem, unico verbo istud negocium totum complectitur et dicit: »Viri, cohabitate uxoribus cum scientia. «Id quod Germanice foelicius exponere possumus: sind vernunft. vernünfftig und verståndig gàgen jnen. Scientiam opposuit affectibus, tyrannidi, irae, morositati. Scientia solida et iusta facile restinguit intemperiem animi. Contra vero tyrannidis, arrogantiae et iniuriarum caussa est barbaries illa, quae nihil recte sinit sapere, imprudentia adeoque stulticia et stupiditas, quae facit, ne ulla quidem beneficia agnoscamus, imo ne nos quidem noverimus amplius. Hisce addit argumenta quam elegantia, certe ut persuadeat. Primum ductum est ab imbecillitate muliebri: »Hoc«, | ait, »maiorem illis honorum deferte et hoc promptius inservite, quo imbecilliores esse videtis.« Qua parte allusit ad illud 30 domini dictum: in adiutorium viri condita est mulier. ${ }^{304}$ Meminerimus ergo uxores nostras nobis in solatium esse conditas: robur, sapientiam et affectuum moderationem virorum esse; imbecillitatem vero mulieribus quasi congenitam, ut posthac feramus aequius, si paulo sint imprudentiores, ut melius consulamus, si

Z. (14) tumultuatur] tumultatur $G-(20)$ negocium] negotium $Z G-(21)$ foelicius] felicius $Z G$ (22) gågen] gegen $Z G-(25)$ stulticia] stultitia $Z G$

302 1Tim 5,10; Tit 2,3-5.

304 Vgl. Gen 2,18.

303 Aesop. fab. 27,2 (Hausrath I 40,4): " $\Omega$ oil $\alpha$

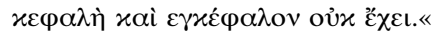


affectibus deditiores. De qua re copiosissime disseruit Erasmus in libello De instit[utione] matrimo[nii] inscripto. ${ }^{305}$ Disputatum est, fateor, hic a multis, quis honor uxoribus sit exhibendus, cur »infirmitatis« dixerit »vasa« Petrus. Sed paucis: honoris vocabulo usus est ut in cap[ite] 2.: »Omnes honorate « [1Petr $2,17]$ et ut nos dicimus: er hat sy in eeren. Deinde vasculum dixit mulierem, ut apta similitudine imbecillitatem adumbraret muliebrem. At plerumque usu venit, ut tenerrima quaeque et infirmissima vascula omnium sint utilissima magisque necessaria caeteris. Secundum argumentum duxit a dignitate mulierum: sunt etiam cohaeredes gratiae; proinde familiarius tractandae. Huius generis sunt quaedam et apud Paulum in 1. ad Timoth[eum] 2. cap[ite]: peccavit quidem 10 mulier, et peccatum in mundum induxit, interim tamen sanguine Christi mundata est. $^{306}$ Non ergo est, quod ob sexum contemnat uxorem aut lapsum imputet maritus. Tertium ab utili traxit: »Ne interrumpan|tur preces vestrae.« Ubi enim iurgia, lites, verbera, ibi nullae preces purae. Erasmus prope aliud videtur sequtus. Sic enim scribit: »Neque enim christiani mariti sunt, qui uxores tantum habent ad 15 usum coitus; imo magis annitendum est, ut sociae fiant ieiuniorum, eleemosynarum, vigiliarum, precationum, quo, quae vocatae sunt ad commune praemium aeternae vitae, communibus etiam studiis huc contendant. $\ll^{307}$

8 Postremo sitis omnes unanimes, similiter affecti, fraterna praediti charitate, misericordes, affabiles, 9 non retaliantes malum malo aut convitium convitio, sed contra benedicentes, scientes vos in hoc vocatos esse, ut benedictionem haereditate possideatis.

Veluti pertesus singulis ordinibus singula ac propria scribere officia, in fasciculum colligit generalia et summa quaedam, quae, si observentur accuratius, nullum non ordinem rite instituant atque conservent. Tò $\delta \dot{\varepsilon} \tau \varepsilon ́ \lambda o \zeta$, id est »in summa 25 vero ${ }^{308}$ sive $»$ postremo«, quae nota est isthaec generalem esse omnium officiorum institutionem. Primas hic obtinet concordia sive unanimitas. De hac et Paulus copiosius in 1 . ad Cor[inthios] cap[ite] 1 et Philip[pensium] 2. ${ }^{309}$ Sequitur:

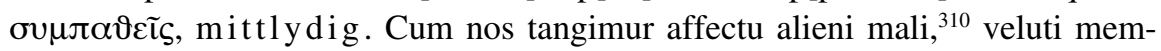
brorum mos est: patiente enim uno, compatiuntur reliqua. Et $\mid$ Paulus: »Memores $30 \quad 56 \mathrm{r} G$ estote vinctorum «, | ait, »tanquam una cum illis vincti; eorum, qui affliguntur, $37 Z G$ veluti ipsi quoque versantes in corpore« [Hebr 13,3]. Additur: $\varphi \iota \lambda \alpha ́ \delta \varepsilon \lambda \varphi$,

Z. (6) plerumque] plerunque $Z G$ - (10) Timoth[eum]] Timotheum $Z G-(14)$ sequtus] secutus $Z G-$ (28) Cor[inthios]] Corinth[ios] $Z G$

305 Vgl. Erasm. matr. inst. (ASD V/6 221f.,703734).

3061 Tim 2,14f.

307 Erasm. par. 1Petr. (ASD VII/6 202,434-437).
308 Erasm. 1Petr. (ASD VI/10 460,384).

309 1Kor 1,10; Phil 2,1-4.

310 Vgl. Erasm. 1Petr. (ASD VI/10 460,387): »Qui mutuo tangantur affectu.« 
»fraterna praediti charitate «; intelligit autem christianam. De qua dominus: »Maiorem hac dilectionem nemo habet, ut quis animam suam ponat pro amicis suis« [Joh 15,13]. Accedit aliud: عű $\pi \lambda \alpha \gamma \chi v o l$, »misericordes« vel »ex visceribus propensi ad benefaciendum«. Hebraeus רחמים viscera sive miserationes vocat. ${ }^{311}$

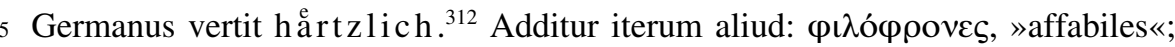
refertur ad vitae consuetudinem, faciles commodosque significans, ${ }^{313}$ fründtlich. Alii verterunt: »studiosi accomodatique amicitiae $\ll .{ }^{314}$ Quae hisce praeterea membris iunguntur, de eo, quod etiam Christus dominus docuit, malum malo vel Iterum deflectit convitium convitio non esse repulsandum, exposita sunt in cap[ite] 2. ${ }^{315}$ Porro

10 epicheremate, ${ }^{316}$ quod ad finem adiecit, afflictos consolatur. Id tale est: »Scientes in hoc vos vocatos, ut benedictionem haereditate consequamini.« Quasi dicat: »Ut benedicatis iis, qui vobis maledicunt, in primis illud movere debet, quod nemo hic veram assequi potest benedictionem. Quoad in hisce terris reptaverimus, subinde bella et malorum expectanda nobis convitia. Ubi vero hisce fue15 rimus exuti miseriis, tum veram benedictionem, id est vitam sempiternam, aeterna haereditate possidebimus, modo filii benedictionis esse perrexerimus.« Fortassis allu|sit Petrus ad illam Abrahae factam pollicitationem: »In semine tuo benedicentur omnes cognationes terrae $\ll\left[\right.$ Gen 12,3]. ${ }^{317}$

10 Nam qui vult vitam diligere et videre dies bonos, coerceat linguam suam a malo et labia sua, ne loquantur dolum. 11 Declinet a malo et faciat bonum, quaerat pacem et persequatur eam. 12 Quoniam oculi domini super iustos et aures eius ad deprecationem illorum. Rursus aspectus domini super eos, qui faciunt mala.

Eandem fere rem dicit, sed aliis verbis. Adducit enim verba Psalmi 33., ${ }^{318}$ ut simul illa quoque, quae dixerat, plus authoritatis haberent. Caeterum clariora sunt illa, quam quod multa egeant expositione. Illud quoque constat vel prophanarum vide Iacobum literarum testimonio plerasque hominum pestes ex vitio oriri linguae. ${ }^{319}$ Unde $^{\text {in } 3 . \text { cap[ite]. }}$

Z. (6-7) fründtlich] früntlich $Z G$

311 Vgl. Pagn. thes. 2350-2353.

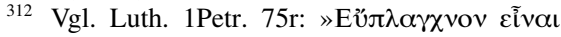
idem esse atque ex toto corde affectum, quod Germanice dicimus: hertzlich sein.«

313 Erasm. 1Petr. (ASD VI/10 460,391f.): » $\Phi_{\mathbf{l}}$

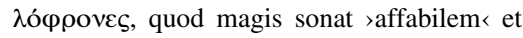
$>$ humanum< et >ad vitae consuetudinem facilem commodumque $<$.

314 Luth. 1Petr. 75v.

315 1Petr 2,20-23.

316 Mit »epicherema« (Epicheirem) wird eine Expansionsform des klassischen Syllogismus be- zeichnet. Dabei können die Ober-, die Unterprämisse oder beide durch ein oder mehrere Stützargumente erweitert werden, vgl. Isid. orig. 2,9,16-18 (Lindsay I [G5]v-[G6]r); HWR II 1251-1258. An dieser Stelle scheint Bullinger diesen Begriff allerdings etwa in der Bedeutung von »Argumentationszusatz« zu verwenden.

317 1Petr 3,9 wird auch bei Luth. 1Petr. 77v-78r in Zusammenhang mit Gen 12,3 gebracht.

318 Ps 34,13-17 (Vulg. 33,13-17).

319 Jak 3,1-12. 
propheta prudenter ait: »Qui vult vitam diligere et videre dies bonos«, id quod in utramque partem, et de foeliciore in terris et beata vita in coelis interpretari potes, »coerceat linguam suam«; ita autem coerceat, »ne vel dolum concinnet vel mendacia, convicia et calumnias effutiat « [Ps 34,13f. (Vulg. 33,13f.)]. Caeterum, ut hoc praestare queat, declinet quisque a malo et faciat bonum, deserat lites et quaerat pacem, nec quaerat modo, sed et persequatur. ${ }^{320}$ Atqui ut hoc quoque gnaviter perficiat, illud maxime movere debet, quod dominus iis benignus est, qui iusti sunt, eosque in suam $\mid$ curam recipit et clementer audit, qui iusticiae et paci ex animo bene volunt; rursus illis iratus et praesentissimus ultor est, qui faciunt mala. ${ }^{321}$ Itaque si quis velit sibi deum propitium, si quis illius cupiat ultionem 10 effugere, ipse quoque sit beneficus, neminem laedat, malum malo non repellat.

13 Iam quis est, qui sit afflicturus vos, si, quod bonum est, aemulemini? 14 Imo si quid etiam acciderit incommodi propter iusticiam, beati tamen estis.

Patientia. Pulchre ab innocentia delabitur ad patientiam. Docuit hactenus, quam sanctam 15 esse deceat christianorum conversationem; iam infert: »Quod si tales esse pergitis, quales esse debetis, christiani (nempe qui omnibus etiam hostibus benefaciunt, neminem laedunt), quis, obsecro, invadet atque affliget bene meritos?« Hic adiiciendum propter eclipsim: ${ }^{322} \gg$ Nemo. «st enim tacita subiectio, cui protinus adiungitur correctio: »Porro, si qui sint tanta caecitate attacti, ut immeritos, imo 20 bene meritos persequantur, memineritis verborum domini apud Matth[aeum] in cap[ite] 5.: »Beati, qui persequtionem patiuntur propter iusticiam, quoniam illorum est regnum coelorum « $[\mathrm{Mt} 5,10] .{ }^{323}$ Quae consolatio desumpta est a caussa et praemio, et commode et summa cum dignitate ad institutum praesens inserta.

14 Caeterum terrore illorum ne terrea|mini neque turbemini, 15 sed dominum deum sanctificate in cordibus vestris. Sitis autem parati semper ad respondendum cuilibet petenti, ut loquamini de ea, quae in vobis $\mid$ est, spe 16 cum mansuetudine et reverentia.

Constantia. Confirmat afflictos verbo dei, ne uspiam in veri confessione tyrannorum minis territi labascant aut nutent. Formidulosi, ait, sunt isti fidelibus, qui ut placidi et 30 modesti sunt, ita isti saevi et truculenti nil aliud quam minantur et affligunt. Sed ipse dominus in evangelio dixit: »Nolite timere eos, qui corpus tantum occidunt;

Z. (2) foeliciore] feliciore $Z G-$ (4) convicia] convitia $Z G$

320 Ps 34,15 .

321 Ps $34,16 \mathrm{f}$.

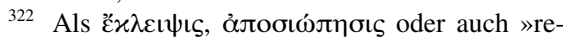

ticentia « wird die Auslassung eines Gedankens oder Satzgliedes, vgl. HLR 438.

323 Vgl. Luth. 1Petr. 80r. 
animam occidere non possunt. Sed illum magis timete, qui animam et corpus una potest in inferos demergere « [Mt 10,28]. Et Isaias in 8., unde hic locus Petri videtur desumptus, dicit: »Ne timeatis neque paveatis. Dominum exercituum ipsum sanctificate: ipse pavor vester et ipse terror vester « [Jes 8,12f.]. Unde iam

5 claret, quod tum sanctificamus dominum, cum ipsum super omnia observamus, ipsi adhaeremus et ipsum confitemur, spretis mundi convitiis, minis et suppliciis. Proinde, quoties ingruit persequtionis procella, semper horum meminerimus. Huc refer Isaiae cap[ut] 49. et 51. ${ }^{324}$ Caeterum quod haec istum, quem retulimus, sensum habeant, convincunt consequentia verba de apologia christianorum. Ea ad

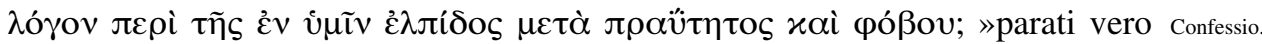
semper ad responsionem « sive »satisfactionem omni caussanti vos sermonem de spe illa, quae in vobis, cum mansuetudine et timore«. Id est: »Tum vere sanctificaveritis dominum in cordibus vestris, cum parati fueritis placide de religione christiana quaerentibus veritatem confiteri et exponere.«Potest tamen non tam ad confessionem Christi quam ad institutionem in religione referri. Erudite enim paraphrastes: Christi »hostes«, inquit, »non sunt exacerbandi convitiis, verum, ubicunque offeret se spes aliqua posse illos ad Christum pertrahi, sitis faciles Respondendum promptique ad respondendum quibuslibet cupientibus cognoscere, qua fiducia cuilibet. quave spe contemnatis huius vitae commoda et incommoda toleretis. Idque facite non indignabundi, non contumeliose velut illis infensi, sed cum omni mansuetudine et reverentia. $\ll^{325}$ Observanda autem synecdoche ${ }^{326}$ in vocabulo »cuilibet $\ll$. Non enim iubet, id quod vel Christus vel Paulus vetant, sanctum proiicere canibus et verborum pugnis cum adversariis contendere; sed, si quae spes est de illo, qui interrogat, vel ipsa dei gloria asserenda vel nomen Christi iustas ob caussas confitendum est. Nam neque ipse dominus neque prophetae apostolive semper responderunt adversariis. Iudicium ergo et delectus $\mid$ in responsione requiritur. Nihil interim hic spectandum est aliud, quam ut gloria Christi et utilitas proximi propagetur latissime. Damnatur hisce istorum vaesania, qui nuspiam suavius de 30 Christo et religione vera disserunt, quam ubi in tabernis sese vino prorsus ingurgitarunt; aut ita de Christo disputant, ut tandem a verbis ad verbera deveniatur; aut qui plus nimio amari nihil de religione vel scripto vel verbo proferunt, quod non spinis et aculeis ita sit intricatum ac hispidum, ut nulla ex parte citra periculum hauriri contrectarive queat. Id quod de importunis et intempestivis

Z. (6) suppliciis] supplitiis $Z G$ - (7) persequtionis] persequutionis $Z G$ - (29) vaesania] vesania $Z G$

324 Vgl. Jes 49,14-21; 51,6-11.

325 Erasm. par. 1Petr. (ASD VII/6 204,505-510).

326 Tropus, bei dem eine quantitative Verschiebung zwischen dem gemeinten und dem tat- sächlich ausgedrückten Begriff vorliegt, vgl. Quint. inst. 8,6,19-22 (Winterbottom II 465f.); HWR IX 356-366. 
quorundam convitiis, non autem de iustis in impios et impietatem invectivis intelligi velim: nota satis severitas prophetica, nota est et maiestas apostolica. Colligimus praeterea ex hoc loco cognitionem atque scientiam Christi et evangelii eius olim christiano populo perspectiorem fuisse, quam sit hodie. Id quod debemus pontificiis indignum, imo impium, vel nunc quoque post tot tantasque admonitiones putantibus, si lectione biblica exerceatur laicus. Verum nos apostolica authoritate aliud docti, scimus aequum et christiana religione dignum esse, ut, quotquot Christi nomen profitentur, rationem quoque nominis christiani teneant, quae non nisi ex literis petitur sacris. Indignissimum enim est, si eius nesciamus leges ac placita, cuius tamen nomine et professione censemur. Nemo se | Platonis censet esse discipulum, nemo Stoicorum aut Epicureorum agnoscit titulum, nisi prius placita et disciplinam istius professionis teneat, adeoque ad unguem $^{327}$ teneat omnem. Solis christianis licet esse ignaris legum et professionis suae. ${ }^{328}$ Atqui ista lege istaque ratione lupi isti rapaces ecclesiasticum ovile minore negotio potuerunt irrumpere. Caesis enim paucis quibusdam pastoribus in 15 lege dei doctis relinquam simplicis plebeculae turbam ad votum, ad libidinem, ad rapinam et caedem habuere expositissimam. Nec hodie alia caussa ita furiunt et in pastores, quos ipsi dicunt haereticos, et in artem impressoriam inque vulgatas bibliorum interpretationes, quam quod oves sapere incipiunt $\mid$ et illi pro sua libidine misera plebe ad quaestum nunc ut quondam abuti non possunt. Verum 20 dominus, qui potens est, verus, iustus et deus ultor, conterat Sathanam istum sub pedes nostros brevi! Fiat.

16 Et bonam habete conscientiam, ut in hoc, quod vobis detrahunt tanquam scelerosis, pudefiant hi, qui incessunt vestram bonam in Christo conversationem. 17 Praestat enim, ut bene agentes, si ita velit dei voluntas, malis afficiamini, quam male facientes.

Repetitur illud ipsum, quod expositum est superius in cap[ite] 2. ${ }^{329} \mathrm{Nec}$ mirum nec inutile, maxime si res tam $\mid$ honesta tamque necessaria saepe repetatur totiesque inculcetur. Meminerimus nos istud in primis observandum esse nobis, quod toties ingeritur. Equidem in rebus mortalium nihil melius, nihil suavius aut 30 iucundius illibata atque integra conscientia. Sola mens sibi bene conscia totaque pendens a deo potest alacriter ferre omnia. Illud quoque egregium est, si quis hoc sibi persuadeat. Nemo in hoc mundo vivit, qui non suo prematur infortunio.

327 Erasm. adag. 491 (ASD II/1 562,1000f.): »Ad unguem [...]. A marmorariis sumpta metaphora, qui superinducto vngui commissuras explorant marmorum.«

328 Vgl. Erasm. paracl. (Holborn 140,19-25): »Platonici, Pythagorici, Stoici, Cynici, Peripatetici, Epicurei suae quisque sectae dogmata tum penitus habent cognita, tum memoriter tenent, pro his digladiantur illi vel emorituri citius quam auctoris sui patrocinium deserant. At cur non multo magis tales animos praestamus auctori nostro principique Christo? « 29 Vgl. 1Petr 2,12.15.19f. 
Quandoquidem ergo hic patiendum est, satius est, ut in caussa iusta et bona adeoque propter deum patiamur quam in negotio iniusto, quod, ut laboris ac doloris multum, ita nihil utilitatis habet. Qui patiuntur propter iusticiam, praemium sibi habent propositum vitam aeternam, ad quam devicta morte et tem5 porariis quibusdam cruciatibus modico momento exantlatis eluctamur.

18 Quandoquidem et Christus semel pro peccatis passus est, iustus pro iniustis, ut nos adduceret deo, mortificatus quidem carne, sed vivificatus spiritu,

Quemadmodum in fine cap[itis] 2., ${ }^{330}$ ita et in huius calce exemplo Christi 10 adhortatur ad patientiam, a qua item eidem haerens exemplo et ad innocentiam vitae transit commendandam fidelibus. Caeterum id in praesentiarum non absolvit. Digreditur enim in locum quempiam communem, redit autem ad initium capitis $4 .{ }^{331}$ Quod attinet exemplum Christi, quo commendatur patientia, planum quidem hic, sed et 2. cap[ite] expositum est. ${ }^{332}$ Ad digressionem explanandam 15 accingimur, quae, ut plurimum difficultatis, ita frugis vicissim multum habet. Magno enim et excellenti ingenio viri admodum sese in hoc loco explicando torsere ${ }^{333}$ nos pro ingenii nostri exilitate citra aliorum praeiudicium exhibebimus lectori aequo, quod dominus nobiscum communicavit. Duo in Christo nobis a patri coelesti data esse nemo nescit. Habemus enim et redemptionem et exem- Christus

20 plum vitae in ipso. Itaque Petrus producens exemplum Christi, quo inhortaretur ad patientiam, per occasionem iam defertur ad redemptionem. Nam hic est scopus omnium saeculorum et huius digressionis: ostendit unica Christi morte non tantum suo tempore superstitum aut mortem Christi consequentium hominum duntaxat, sed et omnium a condito orbe defunctorum peccata expiari. Principio autem dicit: »Christus semel pro peccatis passus est «, in quibus verbis duo observanda censeo: quod semel passus est et quod pro peccatis passus est. Peccatum expiari non potest nisi hostia munda et sancta, adeoque et effusionem sanguinis; sed passio Christi, quae vera Hebrae. 9[,22]. est pro peccatis hostia, non nisi unica est; sola ergo omnium saeculorum peccata expurgat. Sed de hac re copiosius scripsit in Hebraeis apostolus Paulus. ${ }^{334}$ Deinde 60v $G 30$ addit: »Iustus pro iniustis. « Iam vero sic | colligere licet: iniusti sese iustificare non possunt; omnes autem homines iniusti sunt; proinde nullus hominum sese iustificare potest. Unus Christus iustus est; solus itaque Christus iniustos iustificat. Porro »iniustorum« voce non tantum intelligo certae aetatis, sed omnium aetatum iniustos. Recesserat totum mortalium genus a deo, totum ergo ad deum

\section{Z. (3) iusticiam] iustitiam $Z G$ - (13) capitis] cap[itis] $Z G$}

330 1Petr 2,21-24.

331 1Petr 4,1.

332 Siehe oben S. 232.
333 Vgl. Erasm. 1Petr. (ASD VI/10 462f.,418436).

334 Hebr 7,27; 9,12.26-28. 
erat reducendum. Omnes enim tanquam oves erravimus, at dominus Christo imposuit omnia peccata nostra. ${ }^{335}$ Atque hic est fructus passionis dominicae, quod fugitivos reduxit ad patrem et perditos in aedes beatas, id quod Lucas per 15 . cap[ut] pulchris persequitur parabolis. ${ }^{336}$ Additur et modus et ratio redemptionis: »Mortuus quidem carne, sed iustificatus spiritu.«Quam sententiam plerique sic exposuerunt: »Mortuus est Christus secundum corporis imbecillitatem, sed resurrexit virtute spiritus. ${ }^{337}$ Caeterum videtur lo|qutio resipere Hebraismum, ut sit sensus: Christus secundum assumptam naturam humanam, secundum carnem videlicet veram, declaratus est esse mortalis, adeoque et hominibus visus est omnino esse extinctus; at secundum spiritum declaratus est esse vita mortalium, 10 quod videlicet vivificus sit omnibus credentibus. Proinde per spiritum intellexit vim et potentiam Christi divinam atque vitalem, puchre asserens in morte Christi spiritum, id est vitam, consistere mortalium. Poterat igitur videri haec $\mid$ esse tacita quaedam praesumptio, quasi dixerit: »Scio equidem, quod impii nobis Christi nostri obiiciunt mortem, sed illud expendant velim, quod secundum carnem 15 mortuus est. Sic enim visum est deo, ut per filii immaculatam hostiam purgaret peccata fidelium. Unde illum quoque corpus mortale oportuit suscipere, ut haberet, quod pro nobis offerret.« Caeterum illud interim addendum erat, quod haec ipsa mors vitam reparavit fidelibus. Tametsi enim carne mortalis fuit, spiritu tamen est vivificus.

19 in quo etiam abiit et spiritibus, qui erant in carcere, praedicavit, 20 qui inobedientes fuerant quondam. Cum semel expectabatur dei lenitas in diebus Noe, cum apparabatur arca, in qua paucae, hoc est octo, animae servatae fuerunt per aquam.

Christus Nunc vero palam edicit Christi mortem profuisse iis quoque, qui iam olim descendit ad inferos. excesserant e vivis: »In quo«, ait, »abiit et spiritibus, qui erant in carcere, praedicavit.« Diximus autem spiritum hoc in loco esse vivificam illam vim Christi. ${ }^{338}$ Proinde sensus est: »Vita quoque et redemptio illa per mortem Christi parta, defunctis sive inferis nunciata est, id est, mortuis quondam sanctis patribus profuit.«Videntur enim haec per ethiologiam sive prosopopoeiam ${ }^{339}$ esse suffi- 30 gurata, maxime cum in cap[ite] 4. multo clarissima sequatur expositio. Nam in
$40 Z G$

\section{Z. (7) loqutio] loquutio $Z G$}

335 Vgl. Jes 53,6.

336 Lk15,3-7.8-10.11-32.

337 Erasm. 1Petr. (ASD VI/10 462,423f.): »Christum mortuum iuxta corporis imbecillitatem, caeterum resurrexisse virtute spiritus «; Erasm. par. 1Petr. (ASD VII/6 204,533-535): »Expiauit autem nos Christus morti traditus ob im- becillitatem humani corporis quod assurnpserat, sed reuocatus ad vitam virtute spiritus qui nullis afflictionibus vinci poterat.« Vgl. auch Luth. 1Petr. 87r.

338 Siehe oben S. 244.

339 Siehe oben S. 205, Anm. 147. 
hoc ait: »Mortuis annunciatum est evangelium« [1Petr 4,6]. Atqui evangelium annunciari nil aliud est, quam redemptionem nunciari. Proinde etsi Petrus in praesentiarum de persona Christi videatur loqutus, quae descenderit ad inferos, certo tamen de vita et redemptione Christi loqutus est, quae defunctis quoque 5 profuit, id quod per abeundi praedicandique verba extulit. Sed plura de his annotavimus in 2. cap[ite] Act[orum]. ${ }^{340}$ Pluscula forsan dabimus in cap[ite] huius epistolae $4 .{ }^{341}$ Porro, ubi nam locorum hic fuerit carcer, nobis ignotum est. Nihil enim de hoc prodidere literae sanctae. Hoc certum est, quod nil in eo fuit squaloris, nil tenebrarum aut cruciatuum: refrigerii locum ${ }^{342}$ nominat evangelica Lucae.

10 veritas, denique et »sinum Abrahae«. Interim vero carceris nomen obtinuit, quod $16[, 22.24]$ eo in loco detinerentur beatorum animae. Tertullianus 4. lib[ro] adversus Martionem putavit locum fuisse paulo aeditiorem inferis. ${ }^{343}$ Sed nescio, num ita in rebus dubiis, quae sibi reservavit deus, ita liceat coniectari. Satis sit fideli animae id novisse, quod sanguine Christi omnes ab exordio mundi animae sanctorum a 15 peccatis sunt expurgatae. Fortassis huc pertinuerit illud Zachariae dictum: »Etiam Zach. 9[,11]. tu in sanguine testamenti tui dimisisti vinctos tuos ex puteo, in quo non est aqua.« Iam vero diverso quodam modo nunciatum est inferis evangelium. Credulis enim sanctisque patribus salus, incredulis porro merita innotuit damnatio. ${ }^{344} \mid$ Atqui hic locus anantapodoto ${ }^{345}$ inabsolutus est. Desideratur enim ex membris alterum, id 20 quod ex ipso sensu orationis ad fidei regulam atque modum putavi restituendum sarciendumve. Sanctorum enim partes iam negligit, impiorum tantum perstringit, simul et iustum dei iudicium indicat. Longanimis enim deus diu dissimularat olim prioris saeculi impietatem, si forte converterentur ad ipsum; ${ }^{346}$ verum, dum pertinaciter in impietate procaci pede pergerent, diluvio impoenitentes iuste extinxit.

25 Atque hic per speciem genus intellexit. Unius enim saeculi homines nominavit, reliquos vero in his omnes inclusit impios. Iis vero omnibus nunciatus est Christus, non equidem in vitam, sed in argumentum damnationis commeritae, ut et piis omnibus in argumentum vitae aeternae. Quin et isthaec omnia etiam in arca Noe et in diluvio significata sunt. Nam ut arca fideli Noe occasio fuit salutis, utpote per quam ex undarum vi ereptus est, incredulis vero argumentum commeriti

\section{Z. (3) loqutus] locutus $Z G$ - (4) loqutus] loquutus $Z G$ - (27) equidem] aequidem $G$}

340 Bull. act. 28r-29v.

341 Siehe unten S. 251.

342 Zum Ausdruck »locus refrigerii « vgl. Hier. epist. 60,3 (CSEL LIV 551,15): »Lazarus uidetur in sinu Abraham locoque refrigerii $[\ldots] . \ll$

343 Tert. adv. Marc. 4,34,13 (CCSL I 638,10-12): »Eam itaque regionem, sinum dice Abrahae, etsi non caelestem, sublimiorem tamen inferis, interim refrigerium praebere animabus iustorum.«
344 Vgl. Erasm. par. 1Petr. (ASD VII/6 205,538f.): »[...] cui [evangelicae doctrinae] qui crediderunt salutem sunt assequuti, qui credere recusarunt damnationis aeternae cumulum sibi accersierunt.«

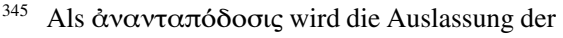

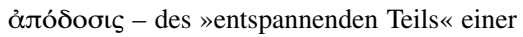
Periode - bezeichnet, vgl. HLR 459. An dieser Stelle verwendet Bullinger den Begriff als Synonym für »Auslassung « im Allgemeinen. 346 Vgl. Jer 26,3. 
supplicii. Nam Paulus ad Hebraeos 11.: »Per arcam«, ait, »condemnavit Noe mundum « [Hebr 11,7]. Item: quemadmodum diluvium sive aqua credulos servavit arcam in foelicitatis portum ferendo, incredulos autem extinxit, | ita Christus dominus, qui lapis est positus in ruinam et resurrectionem multorum, ${ }^{347}$ inferis quoque diversa ratione praedicatus est, aliis ad vitam aliis vero ad interitum. Praeterea: ut paucae | tum servabantur animae, id est homines certi et destinati, sic nunc quoque servantur credentes duntaxat et ordinati ad vitam, qui contempto mundo per patientiam expectant bona sempiterna.

21 Cuius figurae nunc respondens baptismus nos quoque salvos reddit; non is quidem, quo carnis sordes deponuntur, sed conscientiae bonae interrogatio in deum per resurrectionem Iesu Christi, 22 qui est ad dexteram dei, profectus in coelum, subiectis sibi angelis et potestatibus ac virtutibus.

Christus Expositio est superiorum et comprobatio, quod Christus ut veterum, ita subse-

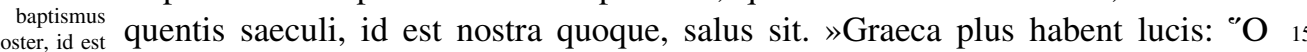

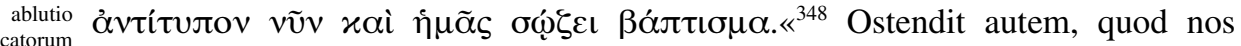
peccatorum eadem virtute servemur, qua patres vetustos constat esse servatos, nempe vi redemptionis Christi sive per spiritum vivificum Christi, quem nunc propter typum (perstat enim in allegoria coepta) vocat »baptismum«. Per Christum enim abluimur a peccato. Nam ne quis de baptismo aquae exponeret, ipse praevenit et 20 ait: »Non is quidem baptismus nos salvat, quo abluimus sordes externas humani corporis; sed per baptismum intelligo illam vim fidei, illum spiritum et virtutem Christi adeoque ipsum Christum, quo fit, ut conscientia nostra pacata, secure agat coram oculis dei.« Nam idiotismum linguae sanctae clarius exponens pro eo, quod Petrus dixit: »Conscientiae bonae interrogatio in deum«, Erasmus vertit: 25 »Quo fit, ut bona conscientia bene respondeat apud deum. $\ll^{349}$ Ad expositionem et sensum hunc nostrum faciunt iam ea quoque, quae sequuntur de resurrectione Christi. Nam nemini obscurum est resurrectionem apostolis, Petro in primis, usurpari pro vivifica illa vi Christi et toto redemptionis negotio. Iam vero dicit Petrus, quod conscientia per resurrectionem Christi bene sibi apud deum respon- 30 deat. Dixerat praeterea, quod per baptismum aliud non intellexerit quam illud, per quod conscientia conciliatur deo. Cum itaque per resurrectionem Christi conciliatur sive pacificatur, certe nihil vetat, quo minus baptismum exponamus pro ipso Christo, vivifica vi eius et aqua vitae, qua nos lavit a peccatis. Alii de baptismi sacramento exponunt, ${ }^{350}$ quibus, ut non admodum reclamo, ita illos 35

Z. (3) foelicitatis] felicitatis $Z G$

347 1Petr 2,4-8.

348 Erasm. 1Petr. (ASD VI/10 466,452). 
vicissim moneo, ne plus nimium rebus tribuant creatis. Quae ad finem de gloria Gloria Christi. Christi appenduntur, quod coelos ascenderit, ad dexteram patris consideat, quin et angelos et omnes virtutes sibi subdiderit, excitant fidem nostram in eum, quem credimus totius mundi esse salutem, scandalum crucis extenuant et potentiam

$63 \mathrm{v} G$ 5 Viv propter haec Petri verba credas quicquam dissidii inter deum et angelos esse obortum, cuius gratia illi per Christum sint sub iugum missi; sed isto loqutionis genere magis adumbratur gloria Christi, qui super omnes coelos elevatus, regnum accepit aeternum, in quo omnibus imperitans creaturis angelis utitur ut creaturis. Unde consequens est ipsum angelis esse maiorem, id quod copiosius exponitur in epistola Pauli ad Hebrae[os]. ${ }^{351}$ Breviter: hisce notatur illa filii dei insignis gloria, de qua Paulus dixit: »Deus filium in summam extulit sublimitatem ac donavit illi Philip. 2[,9-11]. nomen, quod est supra omne nomen, ut in nomine Iesu omne genu se flectat coelestium, terrestrium ac infernorum omnisque lingua confiteatur, quod dominus sit Iesus Christus ad gloriam dei patris.« Errant itaque turpissime, qui Christum vel angelis aequant vel minorem esse censent. Nam dominus angelorum et universae creaturae est. Haec vero habuimus in illam Petri brevem quidem, sed utilissimam digressionem, qua didicimus Christum dominum omnium saeculorum certissimam esse salutem. Id quod cum illorum sacrilego dogmate vehe20 menter pugnat, qui docent Christum pro originali peccato duntaxat vel pro veterum, qui ante Christi natalem vixere, non pro omnium fidelium ad finem usque mundi peccatis perlitasse. ${ }^{352}$ Atqui nostrum erit istorum nugas execrari $\mid$ et fideli mente mysterium fidei nostrae te|nere, ne sacrilega ingratitudine vel redemptionis gloriam tribuamus rebus aliis vel istam rapiamus in peccandi licentiam et omnium scelerum praetextum.

1 Cum igitur Christus passus sit pro nobis carne, vos quoque iuxta eandem cogitationem armemini; qui enim patiebatur in carne, destitit a

Z. (1) creatis] in ZG folgt zusätzlich Exponant sese et suas loquutiones symbolicas, quemadmodum vident apostolum Petrum fecisse. Recte einm et verissime hic etiam des sacramento baptismi dixit: »Salvos nos facit baptismus«, sed statim addit: »Non aquae«, ne quis elemento nimium tribueret, rursus cogitaret in sacramentis non spectanda duntaxat visibilia, sed magis interna. - (7) loqutionis] loquutionis $Z G$ - (11) Hebrae[os]] Heb[raeos] $Z G$

»Iam quod fuit illis arca Noe, hoc vobis est baptismus [...]. Baptismus rite acceptus seruat $\mathrm{ab}$ exitio ac diluit sordes non corporum sed animorum«; Erasm. 1Petr. (ASD VI/10 466,453): »Baptisma nos quoque saluos facit«; Fab. Stap. 1Petr. 30r: »[Baptismus], qui nos salvos facit.«

351 Hebr 1,4-14.
352 Vgl. Biel sent. II d. 32 q. un. (Werbeck/Hofmann II 580-584); Bull. adv. cat. 26v-28r. Auch Zwingli lehnt diese Auffassung ab, Zw. rel. (Z III 722,26f.): »[...] dicunt Christum pro originali modo culpa perlitasse, aut pro eorum tantummodo peccatis, qui ante ipsum fuerunt.« 
peccato 2 in hoc, ut iam non concupiscentiis hominum, sed voluntati dei, quod superest in carne tempus, vivat.

Hic demum absolvit, quod in 3. coeperat cap[ite]. Quod autem dicit, tale est: cum dux et author vitae nostrae Christus per varias afflictiones in regnum patris introierit »cumque tolerantiae armis devicerit adversarios, aequum est «, ${ }^{353}$ ut paribus ad hanc pugnam armis cingamini. Frequens autem est allusio in sacris ad militiam armaque militaria: vita enim hominis aliud non est quam militia super terram. ${ }^{354}$ Quod vero dicit Christum carne passum, mysterio et ratione non caret. Constat enim unica Christi persona natura duplici, divina et humana, quarum quaeque suum retinet ingenium. Iuxta divinitatem aeternus et immortalis est. 10 Iuxta humanitatem passibilis et mortalis est. Petrus ergo: »Christus «, ait, »carne passus est. «Sed ea de re exactius disseruere veteres, qui Nestorii ${ }^{355}$ et Eutychis ${ }^{356}$ blasphemiis responderunt. Cum vero in Christo omnes thesauros nobis dederit pater $\mid$ coelestis, ${ }^{357}$ non tantum ad patientiam hortatur Christi exemplo, sed et ad vitae innocentiam, quo iam sequentia pertinere videntur. Quod »qui patiebatur in 15 carne, destitit a peccato in hoc, ut iam non concupiscent « etc. Quae sententia ab aliis sic est exposita: »Qui in carne affligitur, cessat a peccato $\ll,{ }^{358}$ ut Petrus hac exposuerit afflictionis et patientiae fructum. Caeterum ipse crediderim primum membrum adhuc referri ad Christum. Graece sic legitur: "O

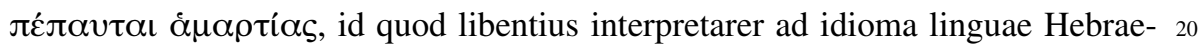
ae: »Quoniam, qui patiebatur in carne, quiescere aut cessare fecit peccatum«, ut intelligamus morte Christi deletum esse peccatum; non ut non sit in carne nostra, sed ne reliquum gratiae tempus, in quo nobis in hoc mortali vivendum corpusculo, carni et affectibus impenderemus, sed voluntati dei. Opposuit itaque pulchra antithesi concupiscentiis hominum voluntatem dei. Concupiscentiam vero hanc 25 paulo post »ethnicam voluntatem« vocat et per partes sive officia ac fructus subiectos, qualis sit, exponit. ${ }^{359}$ Et Paulus in 1. ad Thessal[onicenses] 4. cap[ite]: »Haec«, ait, »est voluntas dei, sanctificatio vestra, ut abstineatis a scortatione et sciat unusquisque vestrum vas suum possidere cum sanctificatione et honore, non

Z. (8) terram] terra $G Z G-(19) \pi \alpha \vartheta \omega ̀ v] ~ \pi \alpha \vartheta \tilde{\omega} v G Z G-(20)$ idioma] idoma $G$ - (27) Thessal[onicenses]] Thess[alonicenses] $Z G$

353 Erasm. par. 1Petr. (ASD VII/6 207,588).

354 Vgl. Hiob 7,1.

355 Nestorius (nach 381-um 451), Bischof von Konstantinopel 428-431, lehnte die Bezeich-

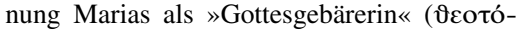
$\varkappa o \varsigma)$ ab und plädierte für die Bezeichnung

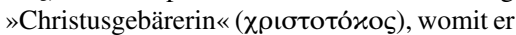
zum Begründer des sog. Nestorianismus wurde. Seine Lehre wurde auf dem Konzil von Ephesus 431 verurteilt, vgl. NP VIII 864-866.
356 Eutyches (gest. nach 454), Mönch und Vorsteher des Hiobsklosters in Konstantinopel, wurde vom Konzil von Chalkedon (451) wegen seiner monophysitischen Christologie verurteilt, vgl. NP IV $323 f$.

357 Vgl. 2Kor 4,7; Kol 2,3.

358 Luth. 1Petr. 91v.

359 1Petr 4,3. 
cum affectu concupiscentiae, quemadmodum et gentes, quae non noverunt deum« [1Thess 4,3-5] etc. Plura ad Roma[nos] 6. et $8 .^{360}$

65 r $G$

3 Sat enim est nobis, quod anteacto vi|tae tempore voluntatem gentium patraverimus, cum versaremur in lasciviis, concupiscentiis, vinolentiis, comessationibus, compotationibus et abominandis simulachrorum cultibus.

A tempore et anteactis argumentans adhortatur ad vitae novitatem. »Satis alias«, ait, »superque satis flagitiorum designatum iam olim, cum Christi synceram doctrinam nesciremus; at posteaquam docti sumus ita nos per Christum a peccatis esse lotos, ut posthac studeamus innocentiae, aequum est, ut voluntatem ethnicam, id est mores vitae pristinae, hoc est impiae, abnegemus.«Simul autem per partes et synatrismon ${ }^{361}$ exponit, quae sit voluntas ethnica, quam nimirum antithesi quadam opposuit voluntati dei, de qua supra mentionem fecit. ${ }^{362}$ Reliqua omnia satis sunt exposita, nisi illud forsan videatur annotandum ỏ $\sigma \varepsilon ́ \lambda \gamma \varepsilon \iota \alpha \nu$ alibi

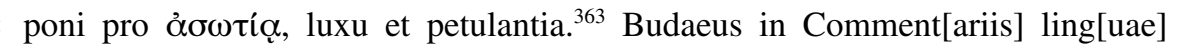
Graec[ae] ex Cyrilli ${ }^{364}$ et Aeschinis ${ }^{365}$ authoritate pro libidine et obscenitate stuprorumque flagitiosa consuetudine exposuit. ${ }^{366}$ Breviter per lasciviam omnem intellexit Petrus luxum, obscenitatem et libidinem procacem. Subiunguntur et alia

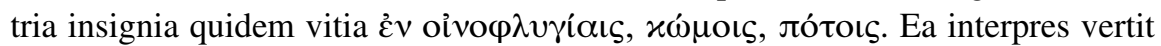
$\gg$ in vinolentiis, comessationibus, compotationibus «. ${ }^{367}$ Primum significat morbum quendam et animum dedi|tum vino, nugis et petulantiae, quae comitantur vini studium, ut est apud Plinium in 14. cap[ite] 22. ${ }^{368}$ Secundum significat vinolentiam et commessationem quidem, sed multum quidem levitatis habentem. Comus enim noctur|narum saltationum habetur deus, cuius mystae probe poti et coronati noctu cum facibus et instrumentis musicis ad amicarum fores prodibant

Z. (2) Roma[nos]] Rom[anos] $Z G$ - (15-16) ling[uae] Graec[ae]] linguae Graecae $Z G$

360 Röm 6,12; 7[!],7.

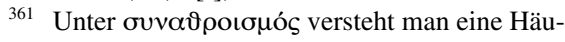
fung von Satzgliedern, die einem bereits vorhandenen Satzglied semantisch und syntaktisch koordiniert sind (koordinierende Häufung). Vgl. Quint. inst. 8,4,27 (Winterbottom II 454,25f.); HLR 336.

362 1Petr 4,2.

363 Vgl. 1Petr 4,4.

364 Kyrillos (5. Jh.), Bischof von Alexandria, war am Nestorianischen Streit maßgeblich beteiligt und übte großen Einfluss auf die Entwick- lung der altkirchlichen Christologie aus, vgl. NP VI 1007-1009.

365 Aischines (4. Jh. v. Chr.), attischer Redner und Politiker, vgl. NP I 347-349.

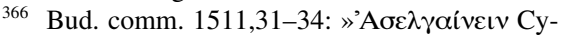

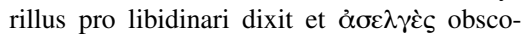

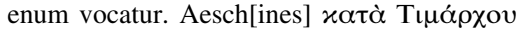
pro obscoenitate et stuprorum flagitiosa consuetudine accepit.«

367 Erasm. 1Petr. transl. [4,3] (ASD VI/4 420).

368 Plin. nat. 14,140f. (Ianus/Mayhoff II 507,17$508,10)$.
Ezech.

$16[, 10-13]$. et

22[,10f.].

Isaiae. 5[,8-24].

Ephes. 5[,18]. 
saltatum. ${ }^{369}$ Tertium inexhaustam illam notat ingluviem eorum, qui ad numerum bibunt. Foedum illud omnibus quidem saeculis et apud omnes vitium, hodie apud Idololatria. Germanos miseros summo in pretio haberi coepit. Porro idololatriae epitheton addidit haud suave, nephariam enim illam sive abominabilem cognominavit. Rationem ostendimus in Act[is] apost[olorum] et 1. cap[ite] ad Rom[anos] adeoque et in locis aliis multis. ${ }^{370}$ Lex ipsa Deuter[onomii] 7. idola omnis generis, quae videlicet prostituuntur ad cultum, execrans habet: »De idolo nil inferes in domum tuam, ne fias anathema, sicut et illud est. Quasi spurcitiam detestaberis et velut inquinamentum ac sordes abominationi habebis, quia anathema est « [Dtn 7,26]. Multo igitur minus convenit, ut, qui nomina Christo dedimus, idololatriam 10 defendamus. Idololatriam voco idolorum sive simulachrorum cultum. Iam vero nemo nescit, quid ad cultum pertineat et quanto studio, quantis impensis a nobis colantur idola; sed de his alibi. ${ }^{371}$

4 Atque id absurdum illis videtur, quod $\mid$ non accurratis una cum ipsis in eandem luxus refusionem, qui de vobis male loquntur; 5 sed reddent rationem ei, qui paratus est iudicare vivos et mortuos.

Poenitentem vitam irrident impii.

Occupatio est. »Scio«, ait, »quid odii morum dissimilitudo vobis sit conflatura apud gentes, quibus cum hactenus convenit vobis, dum socii essetis turpitudinis suae, at nunc, cum frugalitate et sanctimonia temperantiaque vitae illorum videmini damnare luxum, prodigalitatem et intemperantiam immundam, nil mirum, 20 si obtrectant vobis, turpiora impingentes scelera.« Videas enim vel hodie helluones quosdam poenitentibus nunc quidem et evangelicam synceritatem profitentibus, olim vero crapulae illorum sociis, impingere haeresim, blasphemiam, dei et fidei sanctae odium atque abnegationem, hoc duntaxat nomine, quod pro more nolint posthac scortari, alea ludere, commessari, compotare, stipendia ambitio- 25 sorum regum sequi. Notum enim est istorum dicterium: Er was ouch etwan ein gůt gsell, jetz hatt in ds nüw kătzerisch ding ouch verfürt. $»$ Sed non est«, inquit Petrus, »ut horum convitiis aut odiis commoveamini $\ll^{372}$ aut mutuis convitiis calumniam a vobis repellatis. Habebunt enim iudicem suum, nempe eum, qui aliquando iudicaturus est vivos et mortuos, ${ }^{373}$ qui $\gg$ redditurus est 30 unicuique secundum opera sua « [Röm 2,6]. Consolatur itaque Petrus poenitentes a poena et $\mid$ praemio. De iudicio futuro non est hic dicendi locus. Plura in

Z. (4) nephariam] nefariam $Z G$ - (6) Deuter[onomii]] Deute[ronomii] $Z G$ - (25) commessari] comessari $Z G-(27)$ jetz] yetz $Z G-(27)$ in ds] jn das $Z G$

369 Vgl. Philostr. imag. 1,2 (Fairbanks 8-12).

370 Bull. act. 219v-220v; Bull. Rom. 1,22-23 (Baschera 35,3-42,2); Bull. orig. div. [E7]rG5v.
371 Siehe oben Anm. 370.

372 Erasm. par. 1Petr. (ASD VII/6 208,612f.).

373 Symb. apost. (DH 30). 
prophetis, Daniele ${ }^{374}$ in primis et in Paulo, 2. Thess. 1[,5-10]. et 1. Thess. 4[,16f.]., item 1. Corinth. 15[,23-26]. Quod ad locum attinet praesentem, illud dicit: »Impii iudicabuntur«, id est, aeternis mancipabuntur suppliciis, »vos autem, Poena si ita in fide coepta et integritate ac temperantia vitae perrexeritis ad finem usque, impiorum.

5 a morte quidem corporea vivent animae vestrae in deo, at ad iudicium futurum resurgent simul et corpora vestra, ut deinceps anima et corpore aeternum vivatis; illi porro anima et corpore aeternum ardeant.«

Daniel. 12[,2] Matth.

\section{Nam in hoc mortuis quoque praedicatum est evangelium, ut iudicentur quidem secundum homines carne, vivant autem iuxta deum spiritu.}

10

Christum tam vivos quam mortuos iudicaturum: »Ad hoc enim mortuis quoque

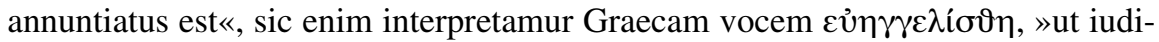
centur, quod ad carnem attinet, vulgari more, quo iudicabuntur omnes homines, spiritu vero per deum vivant. « Hic initio audimus Christum mortuis nuntiatum dere. Spiritu enim descendit, spiritu et virtute nobis adest; ita et ad inferos, id est mortuos, quondam descendit. Quocirca articulus ille fidei nostrae ${ }^{378}$ ex hoc Petri loco desumptus, alium sensum non habet, quam eum, quem hoc loco exponit Petrus; interim vero per eandem prosopopoeiam suffiguratus est. Caeterum, si quis omnino contendat etiam animam Christi ad patres descendisse sanctos, | non magnopere, ut et in 2 . Acto[rum] cap[ite] testabamur, ${ }^{379}$ reclamabimus. Interim vero istam sententiam, ut quae Petri verbis eruta videtur, expendendam propono lectoribus aequis, qui nescire non possunt, animam Christi tutelae patris creditam in coelos isto triduo fuisse receptam. Id enim gaudii pollicebatur latroni dicens: Lucae 23[,43].

$30 »$ Hodie mecum eris in paradiso«, utique in coelorum regia, ad quam simul omnes beatorum animae hostia in cruce consummata ilico evolarunt, cum et corpora Matth. 27[,52f.] quorundam sanctorum in sancta urbe resuscitata apparerent multis atque ea ipsa

Z. (18) capite] cap[ite] ZG - (19) nuntiatur] nunciatur $Z G$ - (26) reclamabimus] In ZG folgt zusätzlich Legatur d[ivum] Aur[elium] August[inum], epist[ola] 99. ad Evodium, qui sancte de hac re disputat [Aug. epist. 164 (CSEL XLIV 521-541)].

374 Dan 12,1-3.

375 1Petr 3,19.

376 Siehe oben S. 205, Anm. 147.

377 Siehe oben S. $244 \mathrm{f}$.
378 Symb. apost. (DH 30): »[...] descendit ad inferna $[\ldots]$. «

379 Bull. act. $29 \mathrm{v}$.
»Descendit ad inferna«. 
hora apparerent, qua Christus expiraverat, in apertum profecto argumentum, quod hac unica filii dei hostia mortui iam iam sint vivificati inque sedes beatas una

Resurrectio mortuorum et

iudicium.

mortalis. cum | Christo recepti. Et quia quaeri poterat, quomodo prodierint ex carcere beatorum animae, amicti corpore an pura spiritus substantia, iterum per occupationem dicit Petrus: »Iudicabitur quidem et eorum caro, qui Christo victore liberati sunt, tunc, cum omnis caro«, id est omnes homines, »iudicabuntur; interea vero animae eorum in deo per Christum vivunt et laetantur.« Quo simul et rei summam probavit, nempe Christum iudicaturum vivos et mortuos. Dixit enim beatorum carnem non resurrexisse; quod, si non resurrexit, consectaneum est, quod publico iudicanda sit iudicio, proinde sit futurum iudicium; et immortali- 10 tatem animarum et corporum resurrectionem asseruit. Locus est omnino egregius, qui summa religionis nostrae mysteria et consolationem fidelium maximam continet, quocirca diligenter notandum censeo. Certe multae hoc confutantur haereses. Confutantur et illi, qui animas corporibus exutas dormire somniant et qui resurrectionem corporum floccifaciunt. ${ }^{380}$

\section{Porro rerum omnium finis imminet.}

Ne obiicerent: »Nae tu, Petre, suavis es, qui ad iudicii diem terminum sane quam remotissimum reiicis omnia. Id plerique suscipient grato animo, dummodo in praesentiarum volupe liceat vivere.« Respondet: »Ut ut illi praesentibus afficiantur rebus, hoc tamen certum est omnium rerum ut vicissitudinem esse, ita finem 20 quoque $\mid$ imminere. Peritura igitur ea sunt, quae illi imprudenter sane mirantur; at aeterna sunt, quibus nituntur christiani.« Elegans huius generis extat Plutarchi

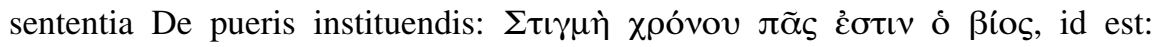
»Temporis punctum est omnis vita. $\ll^{381}$ Item alibi: »Cum exiguum vitae tempus datum sit hominibus, somnus velut foenerator dimidium eius aufert. $\ll^{382}$ Plura de 25 brevitate rerum omnium ipse Petrus dicet in 2. cap[ite] 3..$^{383}$

\section{Sitis igitur sobrii et vigilantes ad orandum.}

Vigilia et Occasione accepta a iudicio, sicut Christus alias saepe, ita Petrus quoque ad oratio. sobrietatem, vigiliam et orationem animat. Notissimus est locus Matthaei in 24. et apud Lucam in 21. de hac ipsa sobrietate, vigilia et precibus tam clare scriptus, ${ }^{384} 30$

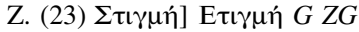

380 Vgl. Bull. adv. cat. $38 \mathrm{v}-44 \mathrm{v}$.

381 Plut. mor. 13A (Babbitt I 62). Zit. nach Erasm. adag. 1170 (ASD II/3 186,231f.).

382 Plut. mor. 958D (Babbitt XII 306): 'O $\mathrm{\lambda}$ íjov

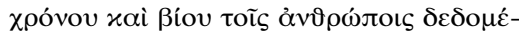

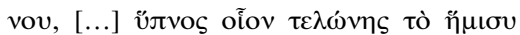

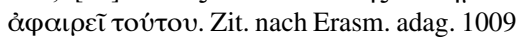
(ASD II/3 34,635f.).

383 2Petr 3,8f.

384 Mt 24,42-44; Lk 21,34-36. 
ut huius loci possit esse commentarius. Eras[mus] in Annotationibus monuit vท́ $\varphi \omega$ Graecis utrunque et »vigilare « et »sobrium esse « significare. ${ }^{385}$ Apostolos vero peculiariter ista »tria coniungere, sobrietatem, vigiliam et orationem, ut sobrietas opponatur luxui et crapulae, vigilia somnulentiae et inertiae «. ${ }^{386}$ Vigiliae

5 tractae sunt a re militari. Arma militiae nostrae spiritualia, adversarii carnalia sunt, Ephes. 6[,11-17]. Victoria nobis confertur coelitus, unde nobis indefessis precibus petendum auxilium, ne hostis potentissimi stratagematis delusi succumbamus. Expellenda e pectoris nostri vallo, quae ille ad expugnationem nostri arripere potest; ea sunt: crapula, ira, libido, cogitationes va|nae et noxiae et si 10 quid aliud est huius generis. Sic enim verum institueris ieiunium, veras vigilias et preces, non eas quidem, quas commenti sunt superstitiosuli harpygae aut quibus monachi et sacrifici hactenus Antichristo duce penu nostrum granaria et arcas expugnavere nummarias, sed gratuitas, dei et integritatis nomine susceptas, non hypocriticas, sed veras.

8 Ante omnia vero charitatem inter vos vehementem habetote. Nam charitas operiet multitudinem peccatorum. 9 Hospitales estote erga vos invicem sine murmurationibus.

Quia charitas vera innocentiae et omnium officiorum vita et spiritus est, in primis | commendat charitatem Petrus; charitatem vero non quamvis, sed intentam sive 20 vehementem ardentemve, quam alibi vocavit carentem fuco. ${ }^{387}$ Est enim et simulata charitas manifesta invidia pestilentior. Paulus ad Coloss[enses] 3. chari-

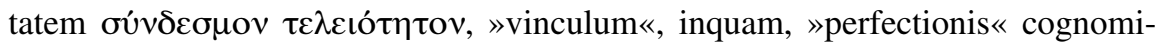
nat. ${ }^{388}$ Et Petrus vim et effectum eius non minori evidentia explicans: »Charitas «, ait, $» \varkappa \alpha \lambda u ́ \psi \varepsilon l \ll$, operiet sive obteget ${ }^{389}$ atque sopiet, »peccatorum multitudinem.«

25 Nam sensus est: »Si charitatem servaveritis inter vos mutuam, tum circa negotium totam evitaveritis scelerum turbam.« Nam ut $\varphi \iota \lambda \alpha v \tau i ́ \alpha$ omnium scelerum parens est ${ }^{390}$ et virtutum pestis, ita $\alpha \gamma \alpha \dot{\sigma} \pi \eta \mid$ omnium virtutum origo et vitiorum propulsatrix est. Paulus enim: »Dilectio«, ait, »proximo malum non operatur; consummatio itaque legis est dilectio« [Röm 13,10]. Alii hunc Petri locum detorserunt ad satisfactionem, quasi charitatis opera deleant peccata nostra; ${ }^{391}$ sed

\section{Z. (1) Eras[mus]] Erasmus ZG}

385 Erasm. 1Petr. (ASD VI/10 468,487f.).

386 Erasm. 1Petr. (ASD VI/10 468,489f.).

387 Petr 1,22

388 Kol 3,14.

389 Erasm. 1Petr. (ASD VI/10 472,524): »K $\alpha \lambda u ́-$ $\psi \varepsilon \iota$, id est >operiet< siue >teget< $[\ldots] . \ll$

390 Erasm. adag. 292 (ASD II/1 398,314f.): »Id vitii $[\varphi \iota \lambda \alpha v \tau i \alpha]$ Plato malorum omnium fon- tem autumat.« Vgl. Plat. leg. V 731e (Burnet V ebd.).

391 So Erasm. par. 1Petr. (ASD VII/6 208,645647): »Nam haec charitas ardens in proximum operit multitudinem peccatorum quibus obnoxii sumus Deo. Quod in illum deliquimus optime diluitur collocandis in proximum beneficiis.« Vgl. auch Fab. Stap. 1Petr. 31v: 
ea quidem expositio merito passionis dominicae multum derogat. Si enim ex nobis est satisfactio, iam Christus frustra passus est. ${ }^{392}$ Charitati affinis est hos-

Hospitalitas.

Metalepsis Nemo murmurat, nisi

quid faciat invitus.
Scopus omnium functionum. pitalitas, proinde hanc adiungit et in hac comprehendit omnia alia christianorum officia sive misericordiae opera. De quibus Christus apud Matth[aeum] in 25..$^{393}$ Illa porro omnia debent esse spontanea ac proficisci ex pectore non difficili, sed facili et benivolo. »Hilarem enim datorem requirit deus«, 2. Corinth. 9[,7]. Plura ad Hebraeos 13. ${ }^{394}$

10 Ut quisque accepit donum, ita alius in alium illud ministrantes ut boni dispensatores variae gratiae dei. 11 Si quis loquitur, loquatur ut eloquia dei; si quis ministrat, ministret tanquam ex virtute, quam suppeditat deus, ut in omnibus glorificetur deus per Iesum Christum, cui est gloria et imperium in saecula saeculorum. Amen.

Iam cum varia sint dona et in immensum se extendant charitatis officia, Petrus uno verbo omnia complectens generalem tradit regulam, qua singula digne administrentur: »Unusquisque«, ait, »donum sibi a deo datum velut dispensator 15 bonus ac fidelis in gloriam dei et utilitatem proximi distribuat.« Proin gloria dei et amor proximi scopus est omnium humanarum functionum. Multa in ecclesia oboriuntur dissidia ob donorum diversitatem atque abusum, dum alter alterum superare contendit, dum id sibi quisque cum fastu et aliorum contemptu arrogat, quod re vera dei est, ipsi vero in hunc usum a deo collatum erat, ut prodesset 20 plurimis. Petrus ergo donis excellentibus praeditos vocat dispensatores, non dominos. Donaque ipsa varia esse dicit, ne quis sibi displiceat, si minus videatur assequutus, vel nimium tribuat, si egregiis donis praecellat. Omnia enim dispensat dominus sapiens, ut ipsum agnoscamus et iis utamur ad aedificationem ecclesiae suae. Copiosiora his habes ad Roma[nos] 12., ${ }^{395}$ item 1. Corinth. 12[,7- 25 12]. et Ephes. 4[,11-13]. Porro omissis donis et functionibus reliquis, ne lectorem oneraret gravius, duas praecipue per distributionem perstringit, prophetiam et magistratum, quod plurimum momenti habeant, si hae rite administrentur. PaProphetia. raphrastes prius illud de prophetia membrum brevissime simul et appositissime sic exponit: »Si cui contigit doctrina sacra, si cui donum eruditae linguae, non 30 abutatur ad quaestum, ad fastum aut inanem gloriam, sed ad proximi salutem Christique gloriam. Sentiant auditores esse dei sermones, non homi|num, et eum, qui loquitur, nihil aliud esse quam organum divinae vocis. $«{ }^{396}$ Peccant igitur et multis nominibus execrandi sunt, qui titulo theologico gloriantur et doctores christiani videri volunt, sed humana interim commenta imprudentioribus obtru- 35

»Sicut ignis purgat omnia, quae illi apponuntur, sic charitas [...] ignis est purgans peccata.«

392 Gal 2,21.
393 Mt 25,35.43.

394 Hebr 13,1-13.

395 Röm 12,4-8.

396 Erasm. par. 1Petr. (ASD VII/6 209,661-665). 
dunt. Nihil in ecclesia aliud tradendum tractandumve erat quam verbum domini Ioan. 10[,4.16].

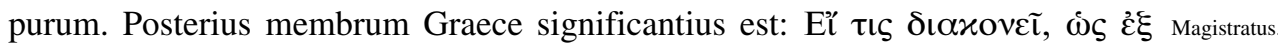

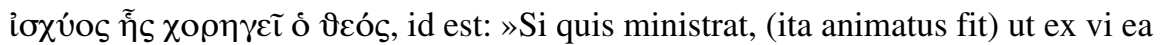
(praesit aut administret) quam suppeditat deus.« Id est: »Magistratus non suo 5 robore niti debet, id quod tyranni solent, sed meminisse debet, quod minister dei est, qui iustus est et iustitiam ac aequitatem amat; in his ergo constans et fortis sit, praesit, inquam, et imperiret volo, sed secundum voluntatem et robur dei, non secundum affectus humanos.« Non enim terrori esse debent principes bonis, sed malis. ${ }^{397}$ Nam ultores sunt ad iram iis, qui malefaciunt. ${ }^{398}$ Damnantur ergo hic a

10 Petro, qui vel sontes non plectunt vel innoxios non asserunt de nocentium tyrannide. Praefuerunt populo dei David, Ezechias, ${ }^{399}$ Iosias $^{400}$ et multi alii viri sancti, sed in $\mid$ virtute, quam deus suppeditat. Alii hunc locum exposuerunt de quibusvis functionibus, quas sic administrari velit Petrus, ut nemo sibi vindicet authoritatem, sed quisque deo transcribat, qui vim et robur suppeditet, ut efficaciter obeat, quod agit. ${ }^{401}$ Breviter: in $\mid$ omnibus officiis ut proximi salus ita dei gloria in primis est spectanda. Deo enim per Christum omnis debetur gloria semper.

12 Charissimi, ne miremini, dum per ignem exploramini, quae res ad experimentum nostri fit, perinde quasi novum aliquid vobis obtingat; 13 imo in hoc, quod consortes estis afflictionum Christi, gaudete, ut in revelatione quoque gloriae eiusdem gaudeatis exultantes. 14 Si probris afficimini in nomine Christi, beati estis, quoniam gloria et spiritus dei super vos requiescit. Iuxta ipsos quidem maledictis afficitur, iuxta vos autem glorificatur. ${ }^{402}$

Cyprianus hunc locum in epistola 4. libri sexta reddit ad hunc modum: »Charis- Patientia. simi, nolite mirari ardorem accidentem vobis, qui ad tentationem vestram fit, ne excidatis, tanquam novum vobis contingat, sed, quoties communicatis Christi passionibus, per omnia gaudete, ut et in revelatione facta claritatis eius gaudentes exultetis. Si improperatur vobis in nomine Christi, beati estis, quia maiestatis et virtutis domini nomen in vobis requiescit. ${ }^{403}$ Haec ex Cypriano non abs re annotavimus. Sunt enim in hac versione multa, quae ad expositionem faciunt versionis vulgatae. Iam vero transit ad patientiam, de qua per superiora saepius

397 Röm 13,3.

398 Röm 13,4

399 2Kön 18,1-20,21.

400 2Kön 22,1-23,29.

401 Erasm. par. 1Petr. (ASD VII/6 209,665-667): »Si quis magis valet functione quam doctrina, sic administret dotem suam vt non sibi vindi- cet autoritatem, sed Deo transcribat, qui vim et robur suppeditat vt efficaciter obeat quod agit.«

402 Zum letzten Satz in V. 14 vgl. die entsprechende Anmerkung in Erasm. 1Petr. transl. (ASD VI/4 425).

403 Cypr. epist. 58,2,2 (CCSL IIIC 322,45-51). 
dicere coe|perat, ${ }^{404}$ hic omni adhibito studio argumentis non contemnendis ad ipsam hortatur. Principio orationem figurat allegoria, dum nos auro, persequutionem sive afflictionem igni assimilat. De qua re dictum in cap[ite] $1 .{ }^{405}$ Deinde Roma. 1[,3-5]. argumentatur a caussa, dum affligi nos docet, non ut perdamur, sed ut probemur. Cruce enim probantur corda et fides sanctorum, sicut eodem cap[ite] 1. exposuimus. ${ }^{406}$ Porro ab exemplo et praemio post haec argumentans dicit: »Illud neque novum neque durum videri debet, quod in omnibus ab origine mundi sanctis videre est, quod in ipso nuper Christo domino praecessit, quod denique in tantam subvehit gloriam. Omnes enim prophetae sancti indigna ab impiis perpessi ipsum dominum Iesum, verum dei filium, in passionibus habuere consortem. Sed illud 10 hic peramoenum est, quod, qui hic cum Christo patiuntur, cum eodem et glorificantur.« Paulus enim: »Certus sermo est«, ait, »si commortui sumus, et convivemus; si sufferimus et conregnabimus « [2Tim 2,11f.]. Tantum ergo abest, ut propter afflictiones nobis dolendum aut metuendum, ut potius, si sapimus, exultandum sit. Maximum enim est consortem esse afflictionum filii dei. Maximum 15 est certum esse de vita beata, ad quam una cum Christo rapiaris, ubi cursum huius vitae brevem absolveris foeliciter. »At durum vicissim est«, ais, »convitiis proscindi, probris affici et aeterna commaculari ignominia etiam apud posteros, idque propter |Christum, dum scilicet mihi de iusta caussa bene conscius sum!« Atqui hoc nomine maxime beati estis, respondet Petrus, modo non ob malefacta, 20 sed ob nomen Christi affligamini. Nec enim est, quod timeamus iniuriam aut ignominiam vel in nobis haesuram vel in ignominiam Christi cessuram. Nam gloria et spiritus dei super nos requiescit. Id est: id quidem nobis in gloriam, deo vero in laudem cedit. Sequitur enim sententia, quae hanc ita exponit: tametsi enim et ipsa religio et nosipsi maledictis afficiamur, attamen et nobisipsis, utpote in 25 quibus est spiritus veritatis, et de religione ipsa nobis bene conscii sumus, ut nunc neque piis, neque pietati contumeliae aut calumniae impiorum quicquam officiant. Quibus interim peccant, non modo in nos, sed in ipsum deum, cui suo tempore commeritas dabunt poenas.

15 Ne vero quis vestrum affligatur ut homicida aut fur aut facinorosus, aut qui alienis inhiet. 16 Porro, si ut christianus affligitur aliquis, ne erubescat, imo glorificet deum in parte hac.

Affligi propter Commodum afflictionis caussas restringit, ne quis omnem protinus afflictionem scelera. crederet esse sanctam. Non omnis afflictio laudem meretur nec cruciatus quivis martyrem facit, | sed caussa iusta, aequa, vera et bona. »Nolim ergo vos«, ait, 3547 ZG »pati ob malefacta.« Qui enim ob furtum, caedem, seditionem, rapinam aut

404 Vgl. 1Petr 2,21; 3,8f.13f.

405 1Petr 1,7; siehe oben S. $189 \mathrm{f}$.
406 Siehe oben S. 189. 
dolum ma|lum, denique ob maleficium quodvis supplitio afficitur, nil habet, quod glorietur. Nam commeritas pendit poenas. Nemo tamen ei aditum ad aeternas sedes praecludit, modo patienter ferat, quod commeruit, et in vera in Christum fide excedat. Caeterum si quis, christianus cum sit, ob nomen Christi et iusta de caussa affligitur ab impiis, non est, quod pudeat supplitii, quin potius laudet deum, qui per hasce temporarias afflictiones ad aeterna ducit gaudia atque ita quoque in hisce terris conformem reddit imagini filii sui, ${ }^{407}$ qui et ipse per multas afflictiones ingressus est regnum patris. D[ivus] Aurelius Augustinus huic Petri loco maxime innixus Donatistarum martyrium miris viribus expugnat, cuius verba si ascripsero, non ingratam me lectori rem spero facturum. Ea vero contra Petiliani epistolam cap[ite] 17. ad hunc modum habent: »De persequutione autem vestra quaerela sedabitur, si cogitetis et intelligatis prius non omnem persequutionem esse culpabilem; alioqui non laudabiliter diceretur: >Detrahentem secreto proximo suo, hunc persequebar< [Ps 101,5]. Nam quotidie videmus et filium de 15 patre tanquam de persequutore suo conqueri et coniugem de marito et servum de domino et colonum de possessore et reum de iudice et militem vel provincialem de duce vel rege, cum illi plerunque ordinatissima potestate sibi homines subditos per terrorem leviarum poenarum a gravioribus $\mid$ malis prohibeant atque compescant, plerunque autem a bona vita et a bonis factis minando et saeviendo deter20 reant. Sed cum a malo et illicito prohibent, correctores et consultatores sunt; cum autem a bono et licito, persequutores et oppressores sunt. Culpantur etiam, qui prohibent a malo, si modum peccati modus coertionis excedat. Item iure culpandi sunt, qui turbide atque inordinate in eos coercendos insiliunt, qui nulla sibi lege subiecta sunt. $\ll^{408}$ Et paulo post: si iam vos »sine tumultu animi, sine turbulenta contentione, sine amaritudine odiorum consideretis diligenter ea, quae contra vos Haec legite vos, reges nostrae communionis constituunt, qua caussa patiamini, et si vos in ecclesia Christi esse inveneritis, >gaudete et exultate, quia merces vestra multa est in coelis< [Mt 5,12]. Vos enim tanquam martyres coronamini, illi autem tanquam persequutores martyrum iudicantur. Si autem vos contra ecclesiam Christi altare erexisse et a christiana unitate, quae toto orbe diffunditur, sacrilego schismate separatos esse et corpori Christi, quod est ecclesia toto orbe diffusa, et rebaptisando et blasphemando et, quantum potestis, oppugnando adversari sancta et canonica scriptura convincit, vos impii atque sacrilegi, illi autem, qui vos pro tanto scelere tam leviter damnorum admonitionibus vel locorum vel honorum vel Aug[ustinus] contra Donatistas. anabaptistae. pecuniae privatione deterrendos coercendosque decernunt, ut cogitantes, quare ista patiamini, sacrilegium vestrum cognitum fugiatis et ab aeterna damnatione

Z. (1) supplitio] supplicio $Z G$ - (5) supplitii] supplicii $Z G$ - (8) Marg. Aug[ustinus]] August[inus] ZG (12) quaerela] querela $Z G-(31-32)$ rebaptisando] rebaptizando $Z G$

407 Vgl. Röm 8,29.

408 Aug. un. eccl. 20,53 (CSEL LII 301,11-27). 
liberemini, et rectores diligentissimi et cultores piissimi deputantur. $\ll^{409}$ Hactenus

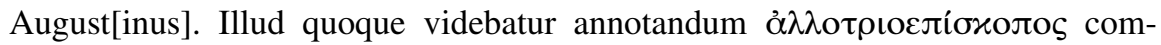
positam esse vocem et de verbo ad verbum significare »alienarum rerum inspectorem $\ll{ }^{410}$ Eras[mus] in Paraph[rasibus] exposuit »curiosum eorum, quae nihil ad nos pertineant $\ll{ }^{411}$ Cuiusmodi sunt seditiosi, malarum artium inventores, veteratores, rapaces et si quid aliud est huius generis. Certe in voce жахолоьós omnis generis facinorosos intellexit, quos iure divino et humano suppliciis afficere licet. Qui enim docent alienum a scripturis et voluntate dei esse homines

August[inus] De civitate dei lib[ro] 1 ., cap[ite] 21. noxios caedere, latronum, sicariorum et praedonum patroni sunt, indigni, quibus respondeatur pluribus. ${ }^{412}$ Satis clara sunt et haec Petri et apostoli Pauli verba ad 10 Roma[nos] $13 .^{413}$

17 Tempus enim adest, ut incipiat iudicium a domo dei. Quod si primum incipit a nobis, quis erit finis eorum, qui non credunt dei evangelio? $18 \mathrm{Et}$ si iustus vix salvus efficitur, impius et peccator ubi apparebit?

Iam consolatur afflictos a comparatis ${ }^{414}$ ducens argumenta, simul et ingenium dei describens, qui omnium hominum peccata visitans, in primis tamen populum 15 suum, affligit. Sic enim legimus apud Ieremiam in 25.: »Quod si renuerint gentes bibere calicem, dices ad eos: >Haec dicit dominus exercituum: omnino bibetis. Quoniam ecce, ego incipio affligere civitatem, | quae vocatur nomine meo, et vos impunes dimitterem? Non faciam, non eritis immunes « [Jer 25,28f.]. Ad hunc 20 ergo locum alludens Petrus per collationem: »Quemadmodum olim«, ait, »deus Hierosolymitas et populum suum sanctum primo afflixit, deinde vero reliquas gentes funditus excidit, ita hoc quoque nostro tempore, quod antiquis respondet, fit, ut fidelis ecclesia affligatur primum, deinde vero et impii puniantur.« Atque istis simul et pios consolatus est, ne de vindicta dei in impios exercenda aut de 25 foelicitate impiorum, infoelicitate vero et oppressione piorum sint solliciti. Quod autem deus impios aliquando perditurus sit, probat a comparatis: »Si tantis malis affliguntur viri boni, quid futurum credimus hominibus impiis, hoc est dei osoribus et responsatoribus, qui ut deum contemnunt, ita evangelium dei blasphemiis incessunt? « Si, inquam, per varia tormenta, per famem, exilia et diras proscrip- 30 tiones misere excarnificantur amici dei et evangelii eius officiosissimi professo-

Z. (2) August[inus]] Augustinus $Z G$ - (4) Eras[mus] ... Paraph[rasibus]] Erasmus in Paraphrasibus $Z G$ (9) Marg. lib[ro]] libro $Z G$ - (11) Roma[nos]] Romanos $Z G$ - (26) foelicitate] felicitate $Z G$ - (26) infoelicitate] infelicitate $Z G$

409 Aug. un. eccl. 20,55 (CSEL LII 303,4-21).

410 Erasm. 1Petr. (ASD VI/10 476,588f.).

411 Erasm. par. 1Petr. (ASD VII/6 210,693): »[...] curiositatem eorum, quae nihil ad vos perti-

413 Röm 13,4. nent.«

412 Vgl. Aug. civ. 1,21 (CCSL XLVII 23,1-21).

414 Zum »locus a comparatis« vgl. Agric. inv. 
res, quae poena putas illos manet, qui voluptatibus dediti, saginata carne omnem temperantiam irrident et sanctos dei homines suggillant, produnt, adeoque et interimunt? Addit et aliud eiusdem | generis ex Proverbiis testimonium, quod extat in cap[ite] 11.: »En, iustus in terra retributionem accipit, etiam certe impius 5 et peccator « [Spr 11,31]. Petrus sensum magis retulit: »Si iustus vix «, id est tanta difficultate et tantis exercitatus malis, »salvus efficitur, impius et peccator ubi conparebit? « Id est: quid, obsecro, is, qui alias omnium scelerum immunditium foetet, posthac sperare possit? His adde 51. cap[ut] Isaiae et probe expende singula. Nam gravia sunt haec et imis recondenda sensibus.

19 Proinde, qui affliguntur iuxta voluntatem dei, tanquam apud fidelem conditorem deponant animas suas benefaciendo.

Illatio est ad superiorem de patientia christianorum disputationem. Colligit enim Clausula. rem omnem in brevem summam et ait: »Proinde, qui non ob scelera, sed iuxta voluntatem dei«, id est propter nomen dei sanctum, »affligimini, omnem, oro, vindictam tradite iudici aeterno, vero, sancto, iusto et incorrupto, interim ipsi benefactis etiam hostes superare contendite, eventum vero rerum omnium divinae providentiae ac bonitati committite. In primis vero animas vestras ei deo concredite, qui, quae condidit, nimirum ut bonus conditor et pater clementissimus perire non sinit, maxime cum ipsius nomine effundamus atque efflemus animas nostras.«Christus enim in evangelio: »Si quis vult post me venire, ab|neget semetipsum et tollat crucem suam et sequatur me. Qui enim voluerit animam suam servare, perdet eam; rursus, qui perdiderit animam suam mea caussa, inveniet eam. «D[ivus] Aurelius Augustinus plurima ad hunc locum pertinentia disputat in lib[ro] De civitate dei, cap[ite] 8. et 9., disserens de commodis et incommodis, quae bonis et malis communia sunt, item de caussis correctionum, quibus simul et boni et mali flagellantur. ${ }^{415}$ In 30. cap[ite] eiusdem libri 1. et 20. cap[ite] 2. lib[ri] copiosissimis exponit, quam pudendis prosperitatibus velint affluere, qui de christianis paulo durioribus conqueruntur temporibus. ${ }^{416}$ Tractavit idem argumentum et d[ivus] Caecilius Cyprianus in Apologia adversus Demetrianum ${ }^{417}$ et in sermone De patientia, ${ }^{418}$ e quibus petat lector, quod in hisce nostris desiderarit. Inveniet in iis plurima, quae mirum in modum nostris quadrabunt temporibus, quibus plerique ex fortuna et infortunio metiuntur omnia,

\section{Z. (27) lib[ri]] libri $Z G$}

415 Aug. civ. 1,8f. (CCSL XLVII 7-10).

416 Aug. civ. 1,30 (CCSL XLVII 30f.); 2,20 (CCSL XLVII 51f.).

417 Zum Adressaten dieser Schrift Cyprians vgl. PRE IV/2 2764.
418 Vgl. Cypr. Demetr. 17f. (CCSL IIIA 44-46); Cypr. patient. 12-21 (CCSL IIIA 124-131).
Matth. 16[,24f.] Ioan. 12[,25]. 
adeo ut religionem Christi veram hoc potissimum nomine execrentur ac falsam credant, quod eius cultores affligantur et improsperiore semper fortuna utantur. Nihil enim nunc de iis dicam, qui evangelio acceptum ferunt, quicquid bellorum, turbarum, morborum et miseriarum calamitatumque miseros invaserit mortales. Non vident isti peccatis nostris maiora deberi. Experientur ergo propediem, quod mature satis moniti poenitentia sancta propellere noluerunt.

CAP. v. | 1 Presbyteros, qui inter vos sunt, obsecro, qui sum et ipse presbyter ac testis afflictionum Christi atque idem consors gloriae, quae revelabitur, 2 pascite, quantum in vobis est, gregem Christi, curam illius agentes non coacte, sed volentes, non turpiter affectantes lucrum, sed animo propenso, 3 neque ceu dominium exercentes in cleros, sed sic, ut sitis exemplaria gregis.

Episcopalis dignitas.

Redit ad officiorum institutionem ac excellentissimum prope officiorum brevi quidem, sed evidentissima praescriptione informat. Ab episcoporum, hoc est praeconum verbi, exemplo, doctrina et authoritate pendet totus populus. ${ }^{419}$ Mul- 15 tum ergo refert, qua sint eruditione, integritate vitae et constantia praediti presbyteri, hoc est seniores ac consules, ut sic dicam, populi christiani. Proinde maximam in his instituendis operam navat, suo primum exemplo proposito, ut ipsum imitantes, contemptis afflictionibus temporariis contendant per veritatis et integritatis professionem immarcessibilem capescere coronam; $;{ }^{420}$ sive se malo- 20 rum et officii socium presbyteris iungit, ut gratior illis sit institutio. Praescribit autem formulas quasdam presbyteris vivendi, quibus instructi foeliciter possint suo defungi officio. Plurima eius generis videre est et apud $\mid$ apostolum Paulum in 1. ad Timoth[eum] 3. ac 4., item ad Titum 1. et 2. cap[ite], ${ }^{421}$ qui loci cum hisce Petri verbis diligenter conferri debent; ut et prophetarum de hac eadem re non 25 minus clari. Ex his enim pleraque sua mutuavit Petrus, qui se in praesentiarum »presbyterum « appellitat, non principem apostolorum. ${ }^{422}$ Atqui Budaeus in

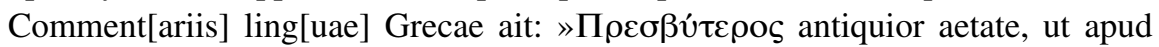

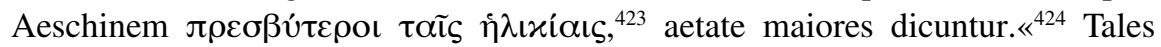
olim in senatum legebantur, utpote multarum rerum usu exerciti ac callidi. Trans- 30 umitur autem vocabulum in religionem christianam. In qua presbyteri dicuntur, qui in lege dei docti, multa quoque exercitatione in rebus divinis versati, veluti senatores et legisconsulti sunt populi christiani, apud quos velut legis divinae

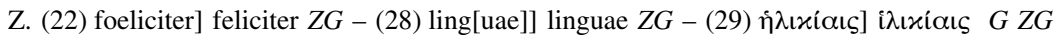

419 Erasm. par. 1Petr. (ASD VII/6 212,725f.): $\gg \mathrm{Ab}$ horum exemplo, $\mathrm{ab}$ horum doctrina, $\mathrm{ab}$ horum autoritate pendent reliquus grex.«

420 1Petr 5,4; vgl. 1Kor 9,25.

421 1Tim 3,1-13; 4,6-16; Tit 1,5-9; 2,6-8.

422 Vgl. Erasm. 1Petr. (ASD VI/10 480,638f.).

423 Aesc. fals. leg. 25 (Martin/Budé 117).

424 Bud. comm. 1001,39-42.
}

$49 Z G$ 


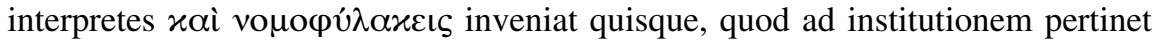
religionis. ${ }^{425}$ Sic enim legimus apud Malachiam in 2. cap[ite]: »Lex veritatis fuit in ore Levi et iniquitas non est inventa in labiis eius. In pace et in aequitate ambulavit mecum et multos avertit ab impietate. Quia labia sacerdotis custodient 5 scientiam et legem requirent ab ore eius, quia angelus domini exercituum est « [Mal 2,6f.]. Sed de functione et nomenclatura sacerdotis dictum est in 5. cap[ite] ad Hebrae[os]. ${ }^{426}$ Praeterea se testem esse ait afflictionum Christi, id quod non modo de praedicatione crucis et redemptionis Christi, sed $\mid$ afflictionibus quoque propter Christum perpessis potest intelligi. Sequitur enim: »Atque idem consors gloriae, quae revelabitur.« Innuit enim se spem habere, ut, cum illum dignum habuerit Christus, ut pro ipso pateretur aut denique ipsi compateretur, »eundem sit ad coelestis gloriae consortium admissurus $«{ }^{427}$ Quo simul et presbyteros, uti in initio huius cap[itis] monui, cohortatus est caeteros, ne quid metu poenarum dissimulent, sed libere Christum profiteantur, integritatem doceant et veritati, si 15 sic res postulet, immoriantur. Qui hodie vicarii Petri et apostolorum videri volunt successores, non presbyteri, sed principes et tyranni sunt, qui non tantum nihil patiuntur propter Christum aut veritatis doctrinam, sed etiam tormentis conficiunt Christi et evangelicae disciplinae studiosos. Iam sequitur: »Pascite, quantum in vobis est, gregem Christi.« Singula hic verba suum habent pondus. In genere presbyterorum describens officium ait: »Pascite gregem Christi.« Officium ergo Pascere est docere et reficere verbo episcoporum est pascere. Atqui figuram dicendi mutuavit Petrus ex prophetis. Hi enim allegoriis utentes ipsum Christum vocavere »pastorem «, ut Ieremias in 23. ${ }^{428}$ denique ipsos prophetas atque doctores »pastores «, sicut Ezechiel in 34. ${ }^{429}$ Ad quae simul ipse in evangelio dominus allusisse videtur, cum in 10. Ioann[is] 25 cap[ite] ait: »Ego sum pastor bonus « [Joh 10,11] et in 21. ad Petrum: »Simon Ioannis, diligis me plus his?« [Joh 21,15] »Pasce oves meas« [Joh 21,16.17]. Habent itaque $\mid$ ista omnia collationem. Quemadmodum enim pastor obambulat, vigilat, dispicit et curat, ne quid desit ovibus; quemadmodum pro ratione ovium victum sive pabulum parat, morbidas curat, separat, reficit omnesque diligentia summa pascit, ducit et reducit; ita aequum est, ut animarum pastor verbo vitae cibet, aqua sapientiae potet, morbidis medetur, firmas conservet et omnem diligentiam adhibeat, ne quid ex eo grege amittat, pro quo Christus mortuus est. Pari tropo Homerus imo spiritus sanctus in prophetis regem subinde appellavit $\pi 0$ -

\section{Z. (13) cap[itis]] capitis $Z G$ - (24) Ioann[is]] Ioannis $Z G$}

425 Vgl. Luth. 1Petr. 103r-v: »Hoc enim verbi, quo hic usus est d[ivus] Petrus, $\pi \rho \varepsilon \sigma \beta u ́ \tau \varepsilon \rho o s$, seniorem sgnificat eo significatu, quo et senatores appelati sunt, id est viri, qui aetate et prudentia polleant, nimirum multa experti. Ad hunc eundem modum Christus suos ministros suumque senatum, quorum interest spirituale imperium administrare, hoc est, praedicare et christianam ecclesiam curare, appellat seniores.«

426 Siehe oben S. 69-71.

427 Erasm. par. 1Petr. (ASD VII/6 212,732f.).

428 Jer 23,4

429 Ez 34,2-10. 
$\mu \varepsilon ́ v \alpha \lambda \alpha \tilde{\omega} v$, id est $»$ pastorem populorum « ${ }^{430}$ Plurima hic dici possent, sed remittimus lectorem ad prophetas. Breviter: »pascere« est docere, hortari et consolari, adeoque et verbo veritatis reficere..$^{431}$ Neque vero rei rusticae scriptoribus quaelibet probantur pabula, rivi quilibet. ${ }^{432}$ Ergo et hic noster nullum paret ovibus dei pabulum quam divini verbi cibum suavissimum animabusque fidelibus coelo Ioan. 10[4,4f.]. demissum. ${ }^{433}$ Oves enim solius pastoris vocem norunt, alienorum non norunt, at pastor coelestis est. Caeterum, cum haec professio durior ac periculosior sit, ne

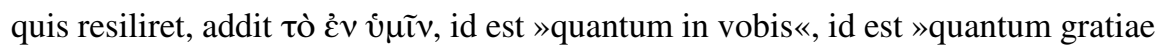
Matth. dederit dominus «. ${ }^{434}$ Varia enim sunt talenta quae in evangelio dividit paterfa25[,14-30]. milias: sed in singulis tamen probatur fidelitas, hoc est, illud requiritur, ut id, 10 quicquid tandem sit, fideliter dispensemus, quod divina bonitas benigne nobis contulit. Alii legunt: »Pascite, | qui in vobis est« aut »qui vobis subest, gregem 1. Corin. 3[,5]. Christi.« ${ }^{435}$ Significanter autem additur »gregem Christi«. Nos enim ministri Ioan. 3[229]. sumus, Christi est ecclesia. Baptista enim: »Qui«, ait, »sponsam habet, sponsus est. Amicus autem sponsi, qui stat et audit eum, gaudio gaudet propter vocem 15 sponsi.«Proinde illius sunt oves, non nostrae. Nemo nostri dominus est gregis, Lucae 22[,27]. sed ministri sumus omnes, dicente domino: »Uter maior est, qui accumbit, an qui ministrat? Nonne qui accumbit?« Accumbit autem ecclesia, ministramus nos; maior ergo ecclesia. At hodie videas servum super dominam exaltatum, miris modis fremere, minitari et conscindere, adeoque et indignis modis tractare ipsam. 20

In mores De episcopis, Romanensi in primis, et ecclesia Christi loquor. Illi enim, ut verbo nostrorum
episcoporum. veritatis miseras oves nunquam reficiunt, ita a belligerando et persequenda veritate nunquam cessant. Semper in procinctu Martis stant, ${ }^{436}$ semper novi aliquid comminiscuntur, semper nova foedera ambiunt, redimunt et artibus quibusdam pangunt, ut dominam opprimere et in imperio pessimis artibus parto, tyrannico et 25

Cura impio, securi agere possint. Sequitur iam expositio tropi superioris. Quod enim episcopalis.

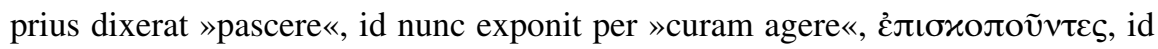

Z. (17) Marg. Lucae 22.] Lucae 12. G

430 Erasm. 1Petr. (ASD VI/10 478,612-614): »Idem verbum est in psalmo secundo, reges

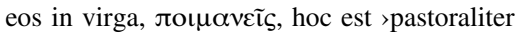
reges $<$ [...]. Et Homerus regem subinde vocat

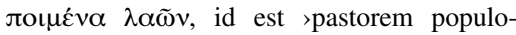
rum<.« Vgl. Ps 2,9 [LXx]; Hom. Il. 1,263 (Ludwich I 21); 2,243 (Ludwich I 65).

431 Luth. 1Petr. 104v: »Pascere aliud non est, quam praedicare evangeliov, und animae pascantur, pinguescant et foecundantur, ut ita evangelio oves nutriantur.«

432 Vgl. Colum. 1,5 (Boyd Ash I 58-64); Colum. 2,11 (Boyd Ash 180-186). Bullinger besaß eine Sammlung von »Libri de re rustica«, vgl. HBBibl III, Nr. 171.
433 Vgl. Joh 6,35.

434 Vgl. Erasm. 1Petr. (ASD VI/10 478,618f.): »Mihi tamen videtur esse sensus germanior, $>$ Pascite quantum in vobis est, gregem Christi $\ll$ «.

435 Vgl. Fab. Stap. 1Petr. 33r: »Pascite, qui in vobis est, gregem dei«; Luth. 1Petr. 104r: »Pascite eum, qui inter vos est, gregem Christi.«

436 Erasm. adag. 1642 (ASD II/4 114,619-622): »Martis campus. [...] In eos torquebatur, qui militari confidentia praediti viderentur quique rem vi, non iudicio gererent.«
$50 Z G$ 
est »intendentes « sive vigilum more inspicientes aut, si sic loqui liceat, »episcopantes ${ }^{4}{ }^{437}$ id quod multa in se continet, ut et haec loquutio nostratium: thůnd | ein ynsăhen vel versăhnd sy. Utcunque vero res habeat, hoc iam certum est, quod »pascentes « exposuit per »episcopantes «; unde consequens est, 5 quod pascere et inspicere sive curam agere et pastorem atque episcopum esse idem sit. Adduntur conditiones certae, sine quibus pastorale officium prorsus languet, nempe: ut volentes ac libenter hoc, quicquid est muneris, suscipiant; ne Officia boni privatum ex eo quaerant compendium; neve ambitiosi dominium, imo tyrannidem sibi usurpent in clerum. Ea nos sigillatim prosequemur paulo copiosius. Primum constat eos, qui metu aut necessitate quapiam impulsi provintiam aliquam subeunt, segnius administrare illam. Atqui socordia et negligentia in hac functione in primis pestilens est. Multa enim vigilia, alacritate et indefessa opus est diligentia. Petrus ergo: »Non coacte«, ait, »sed volentes.« Peccant igitur, qui prophetiae dono non vulgariter instructi, hoc uno nomine docendi provintiam detrectant, quod plurimum laboris habeat aut molestiae; aut qui ad hoc sanctissimum munus vocati, non strenue adeoque et summa cum voluptate negotium sacrosanctum alacriter peragunt. Tametsi non nesciam quosdam et indoctiores et obscuriores plus nimium promptos esse ad id muneris obeundum. ${ }^{438}$ Aiunt illi Paulum scribere: »Indubitatus sermo: si quis episcopi munus appetit, honestum opus desiderat.«Equidem; sed non est cuiusvis hominis adire Corin|thum. ${ }^{439}$ Sequitur enim: »Oportet autem episcopum irreprehensibilem esse, unius uxoris maritum, vigilantem, sobrium, aptum ad docendum « [1Tim 3,2] et quae sequuntur. Deinde praecipua pestis huius functionis est avaritia munerumque corruptela. Non damnatur lucrum honestum ex re honesta. Ipse quoque in evangelio dominus ordinavit teste Paulo, »ut, qui evangelium annuntiat, de evangelio quoque vivat $\ll$ [1Kor 9,14]. ${ }^{440}$ Et idem ad Timoth[eum] dixit: »Quod, si quis suis et maxime familiaribus non providet, fidem abnegavit et est infideli deterior « [1Tim 5,8]. Damnatur ergo avaritia et quod quidam faciunt, qui vel lucri gratia praedicant vel qui frusto panis conducti ${ }^{441}$ (ut apud Micheam ${ }^{442}$ est) quidvis dicere parati sunt. In 30 hos acerbissime invehuntur divini prophetae, Ieremias non uno loco, Ezech[iel] in

Z. (19-20) desiderat] desyderat $Z G$ - (25) annuntiat] annunciat $Z G$ - (26) Timoth[eum]] Timo[theum] $Z G$ - (30) Ezech[iel]] Ezechiel $Z G$

437 Erasm. 1Petr. (ASD VI/10 480,622f.): »'Eлt-

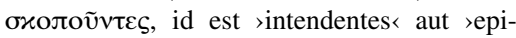
scopum agentes $<$.«

438 Vgl. Bull. adv. cat. 15r-21r.

439 Erasm. adag. 301 (ASD II/1 407,4-6): »>Non est datum cuiuis Corinthum appellere . Vetustum iuxta ac venustum adagium de rebus arduis et aditu periculosis quasque non sit cuiuslibet hominis affectare.«

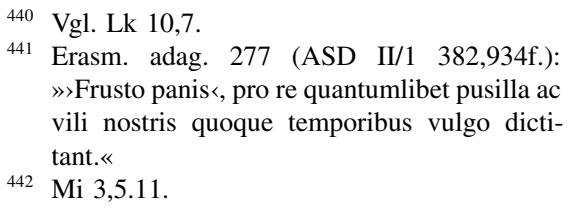
» Frusto panis $<$, pro re quantumlibet pusilla ac vili nostris quoque temporibus vulgo dictitant. $\ll$

442 Mi 3,5.11.

1. Timothei $3[, 1]$. 
13., Micheas in cap[ite] 3. et Isaias in $56 .{ }^{443}$ Christus istos mercenariorum nomine notat, ${ }^{444}$ Paulus in 1 . ad Timoth[eum] 6. cap[ite] eosdem gravissime increpat; ${ }^{445}$ at

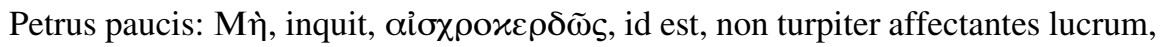
sed propenso animo sive prompte, ${ }^{446}$ synceriter et candide, non vestrum lucrum sectantes, sed ecclesiae commodum. Budaeus in Com[mentariis] ling[uae] Graecae scribit: „Фı $\lambda \circ \varkappa \varepsilon \rho \delta \varepsilon \tilde{\imath} \nu$ dicuntur homines lucripetae et quaestuarii. $\ll^{447}$

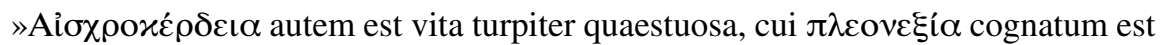

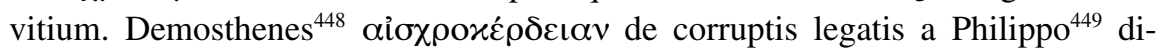
xit. ${ }^{450}$ Proinde non tam quaestuosa vita, ava|ritia, quam munerum corruptela hic damnatur. Male evenit omnibus in religionis negotio cauponantibus. Testes sunt 10 ex veteribus pseudoprophetae misere extincti, ${ }^{451}$ lepra quoque lesi, ${ }^{452}$ et maledictio Simonis Magi, Act. 8[,20-23]. Christus dominus ementes et vendentes magna

Omnia Ro[mani] pont[ifici]

venalia.

$$
\text { ve }
$$
venalia, adeo ut merito scribere prae foribus palacii potuerit: »Si nihil attuleris, ibis tu, Petre, foras. « ${ }^{44}$ Porro tertia huius functionis pestis est ambitio, tyrannis

aut dominandi libido, quae si pastoris incesserit animum, iam non pastor, sed
praedo, lupus et latro futurus sit. Proinde dominus in evangelio: »Reges«, dixit, "gentium dominantur et, qui praesunt, in hoc instituti sunt, ut benefaciant. Vos autem non sic (nempe instituti estis, ut dominemini), sed qui maior est inter vos,

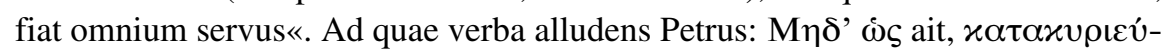

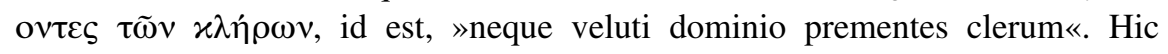
Erasmus: »Cleros autem vocat «, inquit, $» n o n$ diaconos aut presbyteros, sed gre- 25 gem, qui cuique forte contigit gubernandus. $\aleph^{455}$ Breviter: clerum dixit sanctum et delectum dei populum, qui deo veluti sorte obvenit, allusione facta $\mid$ ad divisionem terrae sanctae ${ }^{456}$ Nunc enim totus orbis est terra sancta. Nam per totum

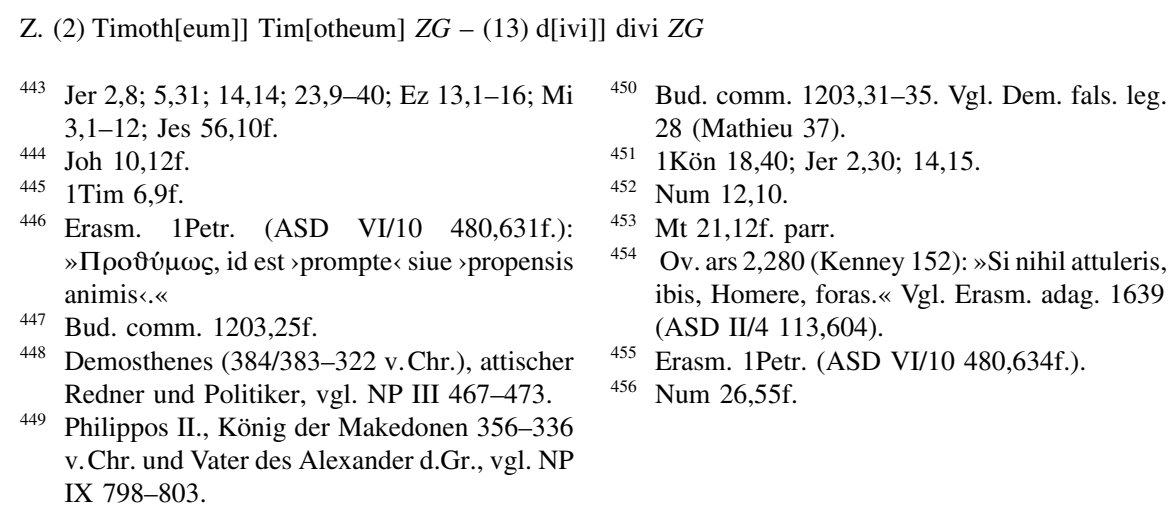

450 Bud. comm. 1203,31-35. Vgl. Dem. fals. leg. 28 (Mathieu 37).

451 1Kön 18,40; Jer 2,30; 14,15.

452 Num 12,10.

453 Mt 21,12f. parr.

454 Ov. ars 2,280 (Kenney 152): »Si nihil attuleris, ibis, Homere, foras.« Vgl. Erasm. adag. 1639 (ASD II/4 113,604).

455 Erasm. 1Petr. (ASD VI/10 480,634f.).

456 Num 26,55f. 
terrarum orbem est diffusa ecclesia Christi. Hic locus ex diametro pugnat cum constitutionibus papalibus, maxime cum ca[pitulo] »Constantinus $«,{ }^{457}$ distinct[ione] 96. ${ }^{458}$ In summa: Christus noluit apostolos esse reges, sed doctores, imo et exemplaria gregis. Nam et Paulus ait: »Super omnia temetipsum praebe Titum 2[,7f.].

5 formam bonorum operum, in doctrina, gravitate, integritate; doctrina sit sana et irreprehensibilis, ut is, qui repugnat, rubore suffundatur nil habens, quod de vobis male dicat.« Et dominus in evangelio: »Sic luceat lux vestra coram hominibus, ut Matth. 5[,16]. videant vestra bona opera glorificentque patrem vestrum, qui in coelis est. « Haec de officio christianorum episcoporum, quae in summam colligens Eras[mus] ita 10 scribit: »>Pascite gregem, non opprimite, non expilate, idque non coacte velut ex officio, sed syncero affectu tanquam patres, neque turpis lucri gratia<, quasi praesentientes ecclesiae pestem hinc orituram. Denique: >Non dominantes more regum, sed exemplo pascite, benefactis vincite $<. \ll{ }^{459}$ Tantum ille. Sed, o deus In ponti[fices] bone, quanta morum veteris et nostrae ecclesiae disparilitas? Illa habuit episcopos $\begin{aligned} & \text { Rom[anos] et } \\ & \text { praelatos. }\end{aligned}$ 15 sanctos, integros, doctos, constantes, impigros et ad omnia pericula pro nomine Christi et iustitiae subeunda fortissimos promptissimosque; illi pro veritate et Christo sanguinem quoque fuderunt ipsum, omne vero vitae tempus lectioni sacrae, precibus et praedicationi dediderunt, sed et praeclara conscripsere opera, | egregii, pii et docti animi monimenta. At nostri prorsus in alios mutati, veluti in 20 nova ecclesia, novam quoque functionem obierunt. Plerique enim indocti sunt, corrupti, impii, voluptatibus dediti sacrarumque rerum prorsus ignari, qui ut in venatione, aulica ambitione et pompa, in alea, palaestra, equestri et militari disciplina absolutissimi, ita sunt in orationibus, lectione biblica et praedicandi evangelii sanctissimo ministerio prorsus inexercitati. Neque vero tam foelices sunt, ut patrum sanctorum scripta legere possint. Consiliariorum ducuntur monitis, quibus velut oraculis credunt, cum satis constet ipsos et falli et fallere saepissime, quod unicam veritatis cynosuram, ${ }^{460}$ scripturam videlicet canonicam, in rebus omnibus non unice observent. An vero vel tu, Romane pontifex, vel tu, mytrata turba, istud negare potes? Quid, obsecro, clarius hisce d[ivi] Petri verbis, cuius vos videri vultis vicarii? Sed quae illa impudentia? Proferte vel ex his omnibus unum, quo Petri imitemini vel doctrinam vel exemplum. Quando ergo vos illius vestrae pigebit sortis? Certe vel ad praescriptum verborum Petri vobis vita vestra erit instituenda, vel silendum nomen Petri. Aut si omnino, o infoelix

Z. (9) Eras[mus]] Erasmus $Z G$ - (13) Marg. ponti[fices]] pont[ifices] $Z G$ - (24) foelices] felices $Z G$ (27) saepissime] sepissime $G$ - (29) d[ivi]] divi $Z G-(33)$ infoelix] infelix $Z G$

457 Konstantin der Große (um 275-337), römischer Kaiser 306-337, vgl. NP III 136-141.

458 Decr. Grat. D. 96 c. 13f. (Friedberg 342-345). Dabei handelt es sich um die »Konstantinische Schenkung«(Donatio Constantini), vgl. LMA V 1385-1387.
459 Erasm. 1Petr. (ASD VI/10 480,640-643).

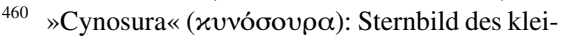
nen Bären, besonders wichtig als Orientierungsstern in der Schiffahrt, vgl. PRE XII/1 $37-41$. 
turba, pastoris nomine gloriari velis, ego non video quenquam prophetarum de isto pastore novo quicquam dixisse, nisi is forsan Zacharias sit, qui cap[ite] 11. pastoris cuiusdam meminit stulti, »qui derelicta non visitet, | dispersa non colligat neque contrita sanet, interim vero comedat carnes pinguium et ungulas fortium dissolvat « [Sach 11,16]. Unde et ipsi ceu stupido acclamans ait: »O pastor, o 5 idolum et derelinquens gregem « [Sach 11,17]. Non audiemus posthac minas vestras, qui hactenus authori|tate Petri et Pauli apostolorum miseros excommunicabatis. Didicimus enim istos a nostris stare partibus, unde et istorum verbis et doctrina freti, quoad vitam vestram non composueritis ad institutum apostolicum, continuis incursionibus impudentiam istam vestram oppugnabimus. Sed redimus 10 iam ad Petrum.

\section{Et cum apparuerit ille pastorum princeps, reportabitis immarcessibilem gloriae coronam.}

Praemium Pastorum princeps ipse est dominus Iesus, qui animam suam posuit pro ovibus pastorum. suis, ${ }^{461}$ non mytratus aliquis nedum Rom[anus] episcopus. Praemio autem pro- 15 posito laborantes in vinea domini ${ }^{462}$ confirmat et consolatur metaphora ducta a pugilibus et more coronandi, sed tropum exponit, cum addit »immarcessibilem «. Paulus enim clarius in 1. ad Cor[inthios] 9. cap[ite] ait: »Omnis autem, qui certat, per omnia temperans est; illi quidem igitur, ut perituram coronam accipiant, nos autem, ut aeternam « [1Kor 9,25]. Idem apostolus de hac ipsa in 2. ad Ti- 20 moth[eum] 4. cap[ite] disserens »iustitiae coronam« vocat, omnibus paratam a deo, qui bonum certamen certant, fidem servant, cursum $\mid$ consumant et adventum Christi diligunt. ${ }^{463}$

5 Similiter, iuniores, subditi estote senioribus sic, ut omnes alius alii vicissim subiiciamini.

Senioribus Nunc pro more apostolico sub finem quasdam paraeneses subiicit. In primis debetur honor. autem iuniores monet senioribus subditi sint. Seniorum est, ut morum integritate et exemplo sancto veluti patres multaque rerum experientia prudentiores gravioresque iuventuti praesint, et iuventus vicissim illos observet ac veneretur. Multum vero refert, quo pacto adolescentum ingenia erga seniores sint animata. Hinc 30 enim vel ingenium liberale et optimae spei aut corruptum et omnino pravum

Levit. 19[32]. facile aestimaveris. Neque enim frustra in lege sua praecepit dominus: »Coram cano capite consurge et honora personam senis et time deum tuum; ego domi-

Z. (15) Rom[anus]] Romanus $Z G$ - (22) consumant] consummant $Z G$

461 Joh 10,11 .

$4632 \operatorname{Tim} 4,7 f$.

462 Mt 21,41. 
nus.« Et Paulus in 2. cap[ite] ad Titum paulo copiosioribus senum officia describit. ${ }^{464}$ Fortassis ad senii laudem et cur illi praecipuum debeamus honorem, illa elegans Demeae ${ }^{465}$ Terentiani ${ }^{466}$ sententia pertinuerit: »Nunquam ita quisquam wytz kumpt bene subducta ratione ad vitam fuit, quin res, aetas, usus semper aliquid apportet novi, aliquid moneat, ut illa, quae credas scire, nescias, et quae tibi putaris prima, in experiundo repudies. ${ }^{467}$ His vero breviter praescriptis in genere subdit: »Omnes invicem estote subiecti.« Id quod Paulus ad Philip[penses] 2. copiosius persequitur. ${ }^{468}$

| 5 Humilitatem animi vobis infixam habete, propterea quod deus superbis resistit, humilibus autem dat gratiam. 6 Humiliemini igitur sub potenti manu dei, ut vos extollat, cum erit opportunum. 7 Omni cura vestra coniecta in illum, nam illi cura est de vobis.

Praecipua pestis mutui consensus et obedientiae mutuae est arrogans superbia. De humilitate Proinde, ut hanc ex pectoribus eiiceret fidelium, humilitatem, quae arrogantiae et $\begin{gathered}\text { contra } \\ \text { superbiam }\end{gathered}$

15 superbiae contraria est, commendat: »Humilitatem animi«, dicens, »vobis infixam habete «; animi, inquam, hoc est veram. Simulata enim humilitas ipsissima est superbia et hoc pestilentior, quo tectior. 'E $\gamma \varkappa 0 \mu \beta \omega ́ \sigma \alpha \sigma \tau \varepsilon$ autem dixit pro eo, quod est: »innodatam habete $«{ }^{469} \gg$ Sentit enim humilitatem arcte retinendam esse in animo veluti nodis illigatam $\ll,{ }^{470}$ ne uspiam excutiatur. Caussa sequitur, quae 20 permoveat: deus enim superbis resistit, humilibus dat gratiam. Id quod paraphrastes exposuit: humilibus »libenter impartit suas dotes $«{ }^{471}$ Hoc vero tam vulgare in scripturis est, ut multis non sit opus. Multa enim habes in historiis sacris exempla, quanta cum indignatione saepius convulserit superborum cris$\operatorname{tas}^{472}$ altissimus, quam benignus et clemens fuerit humilibus. Vide Proverb[io25 rum] 6., Isaiae 14., Ecclesiast[is] 10., Esther 5., 6., 7., Lucae 14. cap[ut]. ${ }^{473}$ Maria 81v $G \quad$ virgo cecinit: »Deposuit potentes $\mid$ de sede et exaltavit humiles« [Lk 1,52]. His omnibus veluti infert: »Cum ergo tanta sit humilitas, humiliemini sub potenti

\footnotetext{
Z. (24-25) Proverb[iorum]] Prover[biorum] ZG - (25) Lucae] Luce $G$

464 Tit 2,2 .

465 Demea ist der Name des strengen Vaters der beiden Brüder Ctesipho und Aeschinus in Ter. Ad. (Prete 351-398).

466 Terenz (Publius Terentius Afer, gest. 159/58 v.Chr.), römischer Komödiendichter, vgl. NP XII/1 149-154.

467 Ter. Ad. 855-858 (Prete 391). Vgl. Erasm. adag. 760 (ASD II/2 286,72-75).

468 Phil 2,2-4.

469 Erasm. 1Petr. (ASD VI/10 482,657): »[...]

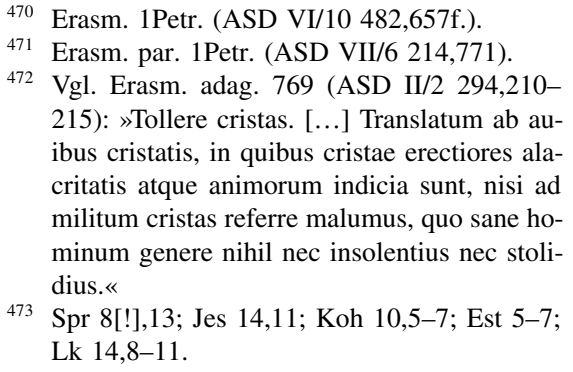
215): »Tollere cristas. [...] Translatum ab auibus cristatis, in quibus cristae erectiores alacritatis atque animorum indicia sunt, nisi ad militum cristas referre malumus, quo sane hominum genere nihil nec insolentius nec stolidius. $\ll$

473 Spr 8[!],13; Jes 14,11; Koh 10,5-7; Est 5-7; Lk 14,8-11. sinnodate<.《 
manu dei.« Quasi dicat: »Nemo obiiciat: >Cur me propudioso isti subderem homini? Qui enim se subiicit alii in timore domini, non homini, sed deo se subiicit.« Nec est, quod quisquam caussetur oppressionem, quasi humilitas nostra iniuriam provocet opprimentium aut occasio sit conculca|tionis. Qui enim se humiliant in timore dei, hi sese sub potenti manu dei humiliant. Proinde non est periculum, ne conculcentur perpetuo: ille, cuius nomine humiliamur, evehet in altum, ubi illi fuerit opportunum, ${ }^{474}$ qui sapientissime administrat omnia. Nobis itaque innocentiae studendum, deo vero permittendus rerum eventus. Novit ille, quando et quid quoque agendum sit tempore. Ab his vero occasionem accipit

Omnis cura coniicienda in deum. docendi, quod omnis cura nostra in deum sit reiicienda. Additur caussa: »Nam illi cura est de vobis.« Id quod copiosissime exponunt prophetae, Psalmi ${ }^{475}$ in primis adeoque ipse dominus noster Iesus Christus apud Matt[haeum] in $6 .{ }^{476}$

\section{Sobrii estote, vigilate, quoniam adversarius vester diabolus tanquam} leo rugiens obambulat quaerens, quem devoret; 9 cui resistite solidi fide scientes easdem afflictiones in mundo vestrae fraternitati consumari.

\section{5}

(1)

\section{0} adeogu

Sobrietas et vigilia adversus
diabolum.

Denuo commendat nobis temperantiam, integrita|tem et vigilantiam, quod haec in rebus christianis plurimum habeant momenti. Addit hic, quod diligentiam excitet. Quoniam adversarius noster non dormitat, sed leoni famelico similis obambulat undique captans occasionem perdendi vorandique. ${ }^{477}$ Imitatur Petrus diligentes duces, qui militum animos ad vigiliam et alacritatem per istud excitant, quod sibi negotium esse cum hoste strenuo docent. Proinde et adversarium nostrum leoni confert; nec cuilibet, sed rugienti et famelico (alias enim clementissimi ingenii est leo $)^{478}$ oberranti et quaerenti, quod devoret. Quae omnia suam habent emphasim. Leonibus comparavit Solomon tyrannos dicens: »Ceu leo rugiens et esuriens ursus est princeps impius pauperi populo«, Proverb. 28[,15]. Et Paulus de Ne- 25

2. Tim. 4[,17]. rone ${ }^{479}$ loquens: »Eripuit me dominus«, ait, »ex ore leonis.« Nec est, quod plura ex Plinio, Iul[io] Solino ${ }^{480}$ vel ipso Aristot[ele] scribamus de leonibus. ${ }^{481}$ Breviter

\section{Z. (15) consumari] consummari $Z G-(25)$ princeps] prniceps $G$}

474 Vgl. Erasm. par. 1Petr. (ASD VI/10 214,776f.): »Non est periculum ne conculcemini perpetuo; ille vos euehet in altum et attollet cum venerit dies ille praemiorum.«

475 Vgl. Ps 121,1-8; 146,5-9.

476 Mt 6,8.

477 Vgl. Erasm. par. 1Petr. (ASD VII/6 214,782784): »Non enim dormit ille vestrae salutis aduersarius sitiens hominum exitium, sed obambulat veluti leo famelicus ac rugiens, vndique captans quem deuoret.«

478 Vgl. Sol. 27,14 (Mommsen 119,6-8): »Nam clementiae [leonis] indicia multa sunt: prostratis parcunt: in viros potius quam in feminas saeviunt: infantes nonnisi in magna fame perimunt.«

479 Vgl. Theophyl. 2Tim. transl. 137r: »Et liberatus sum de ore leonis.] Hoc est Neronis. Leonem enim hunc nominat ob eius imperii robur et magnitudinem.

480 Solinus, Caius Iulius (3./4. Jh. n. Chr.), Grammatiker und Buntschriftsteller, Verfasser der »Collectanea rerum memorabilium«, vgl. NP XI $701 f$. 
ferotiam significare voluit Petrus, qua hostis generis humani crudeliter in nos insurgit, ut devoret, id est, perdat. »Sed vos«, inquit, »resistite illi«; modumque et resistendi vires adversus tantum hostem indicans addit: »Solidi fide «, id est: »Si solidi fueritis in fide citra negotium viceritis cruentam beluam.« Nam »erga 5 diffidentes robur habet, erga fidentes imbellis est $\ll .{ }^{482}$ Plura divus Paulus ad Ephesios sexto. ${ }^{483}$ Adiicit et aliud, quo animet et consoletur tentatos: »Neque vero illud novum est, quod tentat vos Sathanas, | neque novum, quod per membra sua vos persequitur; nec solos vos persequitur, sed toti gregi Christi, omnibus, inquam, deo dilectis fratribus vestris infestus est. Caeterum ista omnia temporaria sunt et finem suum habebunt.«Videtur autem ea consolatio esse ducta ab exemplo et brevitate malorum.

10 Sed deus omnis gratiae, qui vocavit nos ad aeternam suam gloriam per Christum Iesum, parumper afflictos, idem instauret vos, fulciat, roboret, stabiliat. 11 Ipsi gloria, imperium in saecula saeculorum. Amen.

15 Claudit epistolam sententia imprecatoria, qua simul maxima quaedam religionis Epilogus. nostrae sacramenta perstringit. Deum enim »deum omnis gratiae « vocat, hoc est eum, a quo omne donum et beneficium derivetur in nos. Ipse enim author et Iacobi 1[,17]. »fons« est »omnium bonorum «. ${ }^{484}$ Hic vocavit credentes ad aeternam suam gloriam, de qua scriptum est: »Quae oculus non vidit nec auris audivit nec in cor 1. Corinth. 2[,9].

20 hominis ascendit, ea praeparavit deus diligentibus se. ${ }^{485}$ Vocavit autem illos non per viam quamvis, sed per meritum et redemptionem passionis domini nostri Iesu Ioan. 14[,6]. Christi et sub hac conditione, ut hic illi commoriamur. ${ }^{486} \mathrm{Nec}$ illud cuiquam grave videri debet. Nam ad breve tempus hic affligimur. Atqui in afflictione persisten- 1. Pet. 1[,6]. dum. Iam ergo imprecatur coetui fide|lium Petrus, ut deus, qui fidelibus suis alias ad opitulandum promptissimus est, ipsos instauret, si uspiam coeperit per negligentiam carnis destrui institutum sanctum, fulciat, si nutare incipiat, roboret, si infirmetur, et stabiliat, ne subsidat sanctum dei aedificium, ut in petram firmis- Matth. 7[,24f.]. simam fundatum perstet adversus omnes tentationis procellas; ut in membris semper glorificetur Christus, qui laudandus est in saecula. Amen.

12 Per Sylvanum vobis, fidelem fratrem, ut arbitror, paucis scripsi adhortans ac testificans hanc esse veram gratiam dei, in qua statis.

Z. (1) ferotiam] ferociam $Z G$ - (7) Sathanas] Satanas $Z G$

481 Plin. nat. 8,46-58 (Ianus/Mayhoff II 93,898,58); Sol. 27,13-22 (Mommsen 118,2120,16); Arist. hist. an. 8,44 629b 8-630a 8 (Balme 382-386).

${ }^{482}$ Erasm. par. 1Petr. (ASD VII/6 214,788f.).

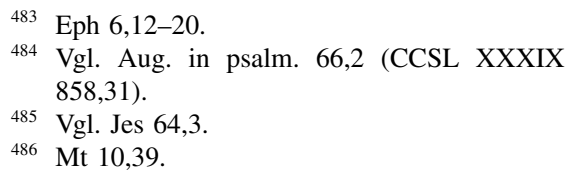


Alii putant d[ivum] Petrum de tertia quadam loquutum esse epistola, ${ }^{487}$ sed videtur de hac ipsa esse loquutus, quam vel Sylvano tradidit Asianis perferendam Scopus vel iisdem scribendam dictavit, pro more veteri. Certe paucis hisce verbis, quod epistolae. et in argumento epistolae adnotavimus, ${ }^{488}$ totum suum colligit institutum, nempe cur scripserit aut quid quibusve de rebus scripserit. Maximum porro id argumentum est tam adversus eos, qui putant non omnia ea, quae ad salutem necessaria sunt, scripta esse, quam adversus illos, qui nullam religionem veram, iustam et absolutam credunt, quam quae secundum patrum traditiones sit instituta. Petrus enim: »Hac«, ait, »epistola illud obtestare volui hanc, in qua nunc statis, esse veram gratiam, id est fidem et $\mid$ religionem veram.« Proinde constat iam omnes eos verae religionis esse cultores, quoquot apostolicam amplectuntur doctrinam, etsi patrum constitutiones, quae apostolicae doctrinae vel adversantur vel conformes non sunt, neglexerint prorsus.

13 Salutat vos ea, quae est in Babylone, vestrae consors electionis ecclesia et Marcus filius meus. 14 Salutate vos mutuo charitatis osculo. Pax vobis omnibus, qui estis in Christo Iesu. Amen.

Quemadmodum Paulus ad finem omnium epistolarum salutationes varias appendit, ita et Petrus facit. Contraversum autem est inter doctos, de qua Babylone hic loquutus sit. Sunt, qui Romam intellexisse putent, quod illa per omnia responderit Babyloni. ${ }^{489}$ Alii, quorum sententia veritati videtur esse proximior, de Babylone exponunt, quae dicitur Aegyptia et alio nomine Chayrum, ${ }^{490}$ quam tamen Strabo Arabiae magis quam Aegypto inscribit. ${ }^{491}$ Marcum vero, cuius hic fit mentio evangelistam illum esse volunt, quem filium quidem vocarit spiritualem, ${ }^{492}$ sicut et Paulus Timotheum. ${ }^{493}$ De osculo diximus in caput Rom[anorum] $16 .{ }^{494}$ Iam ut Paulus epistolas suas hac sententia claudit: »Gratia domini nostri Iesu Christi sit 25

Z. (19) loquutus] locutus $Z G$ - (20) Babyloni.] In ZG folgt zusätzlich Alii non male de Chaldaica Babylone exponunt. - (20) videtur ... proximior] nihil repugnat $Z G$

487 So Erasm. par. 1Petr. (ASD VII/6 214,801804): »In praesentia non agam vobiscum pluribus; nam hac ipsa de re vobis, opinor, nuper scripsi, licet paucis, per Syluanum, fratrem fidelem, qui non dubito quin epistolam bona fide reddiderit. In ea vos obsecrabam et obtestabar vt in eo quod coepistis perseveretis ne qua res dimoueat animum vestrum «; vgl. Erasm. praef. par. 1Petr. (ASD VII/6 182,58f.).

488 Siehe oben S. 180.

489 Erasm. 1Petr. (ASD VI/10 486,696f.): »Sunt qui Babylonem hic interpretentur Romam, quod mihi sane non vsquequaque probatur.«
490 Luth. 1Petr. 112r: »Duae alioqui Babyloniae sunt, una in Chaldaea, altera in Aegypto, quae modo Alcayr vocatur.« Vgl. auch Volat. comm. 136r: »Ptolemaeus hanc quoque Babyloniam vocat, hodie vero Cairum appellant.«

491 Strab. geog. 17,1,30 (Jones VIII 84-86).

492 Luth. 1Petr. 112v: $»[\ldots]$ de Marco evangelista loqui, quem filium appellet, quod spiritu eum, non carne, filium agnoscat.«

4931 Tim 1,18; 2 Tim 1,2; 2,1 .

494 Bull. Rom. 16,16 (Baschera 223,18-20). 
cum omnibus vobis «, ${ }^{495}$ ita Petrus suam hac concludit: »Pax vobis omnibus, qui estis in Christo Iesu.«Quae tam de externa quam interna $\mid$ pace intelligi potest, magis tamen de conscientiarum pace. De qua Paulus ad Philipp[enses] scripsit: »Et pax dei, quae superat omnem intellectum, custodiet corda vestra et sensus 5 vestros per Christum Iesum« [Phil 4,7].

Absolvimus his primam Petri epistolam, in qua explananda fidei filum sequutus sum, ne alicubi gravius impingerem. Nodos enim habet perplexissimos, quos si infoelicius pro ingenii nostri tenuitate dissolvi, nihil tamen adversus fidei canonem peccavi. Haec vero christiano lectori exactius expendenda offero, ut ea, 10 quae pietatis sunt, observet et teneat, a caeteris vero, si quae occurrant absurdiora et minus ad rem pertinentia, deficiat. Meminisse enim oportet verborum Pauli: »Omnia probate, quod bonum est, tenete« [1Thess 5,21].

Z. (8) infoelicius] infelicius $Z G$ - (12) tenete] In $Z G$ darunter Finis.

495 Vgl. 1Kor 16,23; 2Kor 13,13; Gal 6,18. 

KOMMENTAR ZUM ZWEITEN PETRUSBRIEF 

Eusebius Caesariensis, vir eruditionis rarae et lectionis variae, lib[ri] histori[ae] De authoritate eccl[esiasticae] 3. cap[ite] 2.: »Petrus apostolus «, ait, »praedicationis suae mo- ${ }^{\text {secundae }}$ epistolae Petri. 5 nimenta nobis perpauca dereliquit. Una etenim eius epistola est, de qua nullus omnino dubitavit. Nam de secunda multis incertum est, apud plurimos tamen ipsa etiam legenda suscipitur. ${ }^{1}$ Quibus tamen verbis nolim offendi quenquam aut permoveri tantundem, ut minus deferat sanctissimae simul et utilissimae huic epistolae. Nam iniquum est, ut cuiusquam hominis iudicium divinae praeiudicet veritati, quae, ut certa est, ita in certas quoque restricta regulas facile convincit, quid canonicum sit et quid minus. Suscipiendum enim a coetu ecclesiastico, quicquid consentit cum illis, repellendum, quod cum iis non congruit. Iam etsi fuerint, qui dubitarint, plures tamen, qui nihil dubitarunt. Nec illi ullas habent dubii caussas iustas. Certe hoc ne illiipsi quidem negarint, quod in hac prorsus extet nihil, quod novum dici aut a reliqua scriptura alienum videri possit. Proinde non est ulla istis caussa, propter quam secundam hanc epistolam canone ex|cludant aut certe de eius authoritate quicquam dubitent. Fateor sane non omne protinus scripti genus referendum esse inter canonica, quod a communibus regulis non discrepat veritatis; plurimum enim hic quoque facit et scribentis authoritas et scripti vetustas. Iam vero non desunt nobis vulgaria argumenta, quibus citra negotium ostendere possumus et vetustatem huius et authoritatem, nempe quod haec ab eodem sit apostolo Petro aedita, a quo et prior. Nam ut e multis istud duntaxat moneam: titulus sive inscriptio, ${ }^{2}$ sed et mentio Christi in monte glorificati $^{3}$ et compositionis genius satis convincunt, quod Petri sit. Quod enim alii characteris et stili caussantur dissimilitudinem, satis puerile est, sicut alibi monuimus. ${ }^{4}$ Nos isto contenti erimus, quod spiritus Petri, imo Christi, sese in hac unice exeruit, quod sibiipsi Petrus nullibi dissimilis est et quod maximi quique religionis nostrae antistites eius authoritate ut canonica et apostolica usi sunt, Origenem, ${ }^{5}$ Hieronymum, ${ }^{6}$ Augustinum, ${ }^{7}$ imo et ipsum Eusebium et multos alios 30 puto. In primis autem nostris temporibus haec congruit et utilis, imo et necessaria est, id quod suis in locis indicabimus. Breviter: plena est saluberrimae doctrinae

August[inus] de civit[ate] dei libro 20 ., capite 18.

Z. (3-4) histori[ae] eccl[esiasticae]] hist[oriae] ecclesiast[icae] $Z G$ - (4) cap[ite]] capite $Z G$ (29) Marg. civit[ate] ... capite] civitate ... cap[ite] $Z G$

1 Rufin. hist. 3,3,1 (GCS IX/1 189,15-191,1). Zit. auch in Erasm. 2Petr. (ASD VI/10 518,404-407).

2 Petr 1,1 .

3 2Petr 1,16-18. Vgl. Erasm. praef. par. 1Petr. (ASD VII/6 180,48f.); Erasm. 2Petr. (ASD VI/10 498,119-121).
Siehe oben S. 15.

Orig. in Jos. 7,1 (GCS XXX 328,2f.): »Petrus etiam duabus epistolarum suarum personat tubis.«

Hier. epist. 120,11,5 (CSEL LV 508,1-4). Aug. civ. 20,18 (CCSL XLVIII 729,1-22). 
et admonitionis, ut mihi persuaserim prorsus istud dubii, quodcunque apud quoscunque de hac epistola fuit, ex diaboli enatum esse versutia. Invidebat ille nimirum nobis tantum thesaurum obti|gisse. Dolebat, quod regnum suum tam distinctis et tam claris depictum esset coloribus. Timebat plurimas hac tam salubri admonitione animas periculum et laqueos antichristi evasuros vitaturosque. Proinde, cum totam abolere non posset, saltem vel asperginibus quibusdam hanc commaculare voluit. Nos, ut Petri esse credimus atque suscipimus, ita divino auxilio invocato ut spiritus sancti opus exponemus.

\section{Argument[um] epistolae.}

Ad eos secundam scribit epistolam, ad quos scripserat primam. Sic enim ipse fatetur in cap[ite] 3.: »Hasce iam alteras vobis, charissimi, scribo literas « [2Petr 3,1]. Caeterum monitoria est epistola, permultum habens adhortationis. Dum enim spiritu quodam divino persentisceret diem fatalem sibi astare prae foribus, amore paterno et apostolica cura adactus voluit prius Asianos adeoque et totam Christi ecclesiam munere aliquo egregio donare. Ostendit ergo iis, quod ea reli- 15 gio, in qua tunc agebant, vera et absoluta sit religio ${ }^{8}$ deinde vero adhortatur, ut in hac perstent, innocentiae verae studeant. ${ }^{9}$ Addit protinus et quaedam certa verae religionis testimonia, quibus suffulti firmius perstare queant. ${ }^{10}$ Hic iam pseudoprophetas quosdam venturos praedicit, quorum nomine hoc ardentius ad constantiam adhortetur. ${ }^{11}$ Hos enim viam veritatis blasphematuros habiturosque de- 20 mentiae suae complurimos sectatores. | Illos vero graphice per integrum caput secundum depingit, disserens de artibus infandis, peccatis, versutiis, demum et de interitu eorum. Quibus summa diligentia absolutis in 3. cap[ite] de impiis postremi saeculi moribus scribit, de contemptoribus divini iudicii adversus quorum impudentiam effrenem iudicium dei futurum asserit, docens fidelium esse, ut 25 contemptis impiis illis ipsi sese parent ad diem illam certissimam quidem, sed nemini tamen cognitam. Porro haec omnia argumentis agit pressis et densis, evidentibus atque clarissimis. Stilus enim gravis est, sed argumentum facile piis et quod singulis propemodum verbis maxima offerat mysteria.

Z. (9) Argument[um]] Argumentum $Z G-(21-22)$ caput secundum] cap[ut] 2. $Z G$

2 Petr $1,3 \mathrm{f}$.

2Petr $1,5-11$.
102 Petr $1,12-21$.

11 2Petr 2,1-22. 
Inscriptio.

\section{Symeon Petrus servus et apostolus Iesu Christi his, qui aeque pretiosam nobiscum sortiti sunt fidem in iustitia dei nostri et servatoris Iesu Christi: 2 gratia vobis et pax multiplicetur per agnitionem dei et Iesu domini 5 nostri.}

| Inscriptio haec exposita est. Continet scriptoris nomen et docet, quibus sit scripta; iis quoque foelicitatem pro more epistolari imprecatur. Scriptor est Sy-

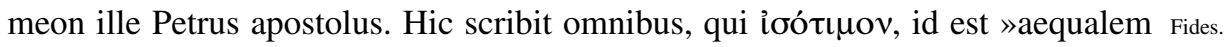
sive eiusdem pretii ${ }^{12}$ cum eo, fidem sortiti sunt, hoc est fidelibus in Christum omnibus, Asi|anis tamen praecipue. Caeterum non dicit omnibus aequalia obtigisse dona per fidem, sed monet a fide arceri neminem, sive is Iudaeus sit, sive gentilis, sed et omnes christianos in fidei dono aequari. Non praefert se aliis, sed omnes Christo fidentes alloquitur ut fratres. Fides vero illa innititur in iustitiam dei et servatoris Iesu Christi. Id quod bifariam exponi potest: vel quod fides innitatur iustitiae, hoc est veritati et promissioni dei ${ }^{13}$ vel quod fides sit iustitia propter Christum, ${ }^{14}$ »qui nobis a deo datus est sapientia, iustitia et sanctificatio« [1Kor 1,30]. Est et illud observandum, quod dixit pacem multiplicari per agnitionem dei et domini nostri Iesu Christi. Hic enim dixit: »Qui ederit me, non esuriet, et qui crediderit in me, non sitiet unquam« [vgl. Joh 6,35].

3 Ut eius divina virtus omnia nobis largita est, quae ad vitam ac pietatem pertinent, per agnitionem eius, qui vocavit nos per gloriam ac virtutem, 4 per quae pretiosa nobis ac maxima promissa donata sunt, ut per haec efficeremini divinae consortes naturae, si modo refugeritis a corruptione, quae est in mundo per concupiscentiam.

Confirmaturus fratres in fide Christi ipsosque ad vi|tae innocentiam hortaturus, Omnia nobis in commodum in capite negotii totam summam religionis in brevia verba restringit. Christo dedit Cumque paucis et citra expolitionem dicere potuisset: »Deus in Christo Iesu omnia ea nobis suppeditavit abundantissime, quae ad vitam et pietatem perti-

Z. (7) foelicitatem] felicitatem $Z G$ - (20) Caput I.] in marg. $Z G$

12 Erasm. 2Petr. (ASD VI/10 489,6f.).

13 Vgl. Erasm. par. 2Petr. (ASD VII/6 217,8-12): $»[\ldots]$ in euangelicae fidei professione, per quam nobis contigit vera iusticia $[\ldots]$ per bonitatem Dei nostri perque mortem Seruatoris nostri Iesu Christi, qui gratis condonauit nobis vetera peccata vt posthac sequamur iusticiam euangelicam.«

14 Vgl. Luth. 2Petr. 114r: »Per fidem enim coram deo solum iusti sumus, quare et fides iustitia dei vocatur.« 
nent «, maluit tamen istud efferre per admirationem: »Ut eius divina virtus « etc. $» \mathrm{Ut}$ « autem particula admirativa est quemadmodum et quam saepius. Notissimus est literatis ille versiculus poetae: »Ut vidi, ut perii, ut me malus abstulit error! $\ll^{15}$ Greace est $\hat{\omega} \varsigma$. Et grammatici hoc Homeri carmine eius significationem expo-

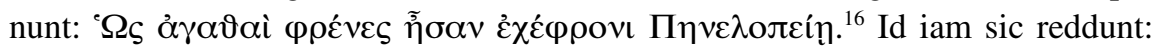
$\gg$ Dii boni, quam bonae mentes (bona indoles) erant prudenti Penelope! ${ }^{17} \mathrm{Li}$ cuisset itaque et interpreti nostro ${ }^{18}$ neglecta verborum obscuritate sensum copiosius et dilucidius reddere: »O quam abunde omnia nobis largita est divina virtus« etc. Ad hunc modum restituenda sunt etiam Germanica: o wie hatt unns die gòttlich krafft alles so volkommen gegăben, das zů dem 10 låben unnd go̊̀tichem wăsen dienet! Est praeterea amplificatio in eo, quod non dixit »deus«, sed »divina virtus«. Augustius enim est hoc, significans ineffabilem dei potentiam et virtutem, a qua ipsum sacra scriptura dominum »sabaoth«, id est »exercituum«, appellitat, pro quo LXX interpretes fere transtu-

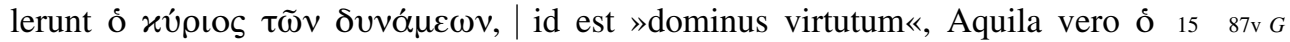

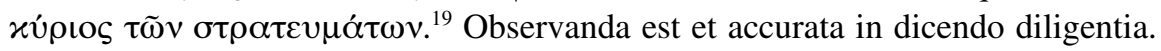
Cum enim dixisset: »Divina virtus omnia nobis largita est «, ne quis in dictione »omnia« luderet, per interpretationem subdit: »Omnia, inquam, dedit deus, quae ad vitam et vitae pietatem pertinent.« De reliquis enim, quae ad vitam et pietatem nihil pertinent, nihil anxius est christianus. Ita quidem et Ioannes apostolus 20 Ioan. 20[30f.]. scripsit multa quidem et alia extare signa salvatoris, quae non sint scripta in historia evangelica, ea vero, quae scripta sint, sufficere ad cognitionem Christi et vitam consequendam. Tota sane religio partim consistit in cognitione dei et spe immortalitatis, partim in pietate vera, in qua servus dei in hisce exerceatur terris, donec ipsi obtingant coelestia. Utraque dedit deus abundantissime. »Sed quando«, 25 dices, »aut qua in re?« Respondet Petrus: »Tum omnia nobis dedit deus, cum filium misit in mundum, id quod nobis tum primo revelatum est, cum per fidem sanctam illum agnovimus. « Christus enim dominus vocavit, id est asseruit, nos

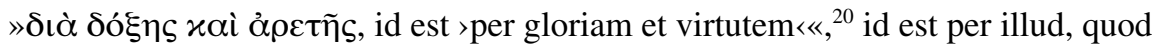
filius dei et homo virtutibus sacer, hoc est hostia pura, esset. Gloria e|nim et apud 30

Ioan. 1[,14]. Ioannem ponitur pro divinitate filii. Ad clariorem superiorum expositionem faciunt et sequentia. Hoc enim dicit: »Cum autem orbi donasset filium deus, tum sane pretiosa et maxima $\mid$ nobis promissa, olim per prophetas adumbrata, fidelibus exhibuit«; nimirum »ut per haec«, id est per agnitionem dei atque filii eius, »efficeremur divinae consortes naturae «, hoc est, ut in Christo haberemus im- 35

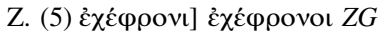

15 Verg. ecl. 8,41 (Mynors 21).

16 Hom. Od. 24,194 (Ludwich II 327): ' $\Omega \varsigma$

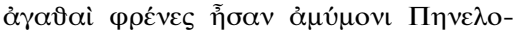
л⿻ín.

17 Vgl. Urb. inst. [B7]v.
18 Gemeint ist Erasmus von Rotterdam, der $\omega \varsigma$ durch »sicut« übersetzt, vgl. Erasm. 2Petr. transl. (ASD VI/4 434).

19 Vgl. Pagn. thes. 1999.

20 Erasm. 2Petr. (ASD VI/10 490,24f.). 
mortalitatem et vitam sempiternam. Deus enim natura incorruptus, immortalis et aeternus est, et eadem gloria donat cum Christo omnes eos, qui sibi credunt. Haec vero de eo breviter dicta sint, quod in Christo nobis omnia dedit pater. »Sed quid ista«, ais, »ad institutum Petri faciunt?« Permultum sane. Nam qui audit omnia, 5 quae ad vitam vitaeque pietatem pertinent, semel esse in uno aliquo tradita, nova et aliena nec audit nec expectat amplius, imo repudiatis facile reliquis omnibus, receptis semel adhaeret firmissime. In hoc autem instituit orationem suam Petrus, ut fidelibus persuadeat, in recepta religione perseverent, utpote quae absoluta et nullius rei indiga sit. Quod si priori saeculo persuasum fuisset scripturis sacris omnia, quae pietatis verique cultus sunt, comprehensa esse, non haberemus nunc Lapsus nostri tot decreta, decretales, summas, sententias et sententiarios; imo si vel icti saperemus et vel hodie crederemus scripturis canonicis omnia esse comprehensa, quae ad vitam pertinent, non ita pertinaciter digladiaremur pro constitutionibus humanis. Sed valeant stulti et, qui sordent, sordescant adhuc! Porro consequenti Innocentia. conditione aditum sibi parat ad adhortationem innocentiae. Pulchre autem | nectuntur omnia. Dixerat nos per Christum in eum evectos gradum, ut aliquando consortes divinae naturae futuri simus. Iam vero aequum est, ut incorruptionem et immortalitatem coelestem expectantes, a corruptione abstineant terrena. Unde Petrus ait: »Efficiemini divinae consortes naturae, sed si refugeritis a corrupti20 one. « A qua, obsecro? Quae in mundo est et quae in concupiscentia est. Corrumpit enim mundus, corrumpit et consupiscentia mala. De quo et Iacobus, Iacobi 1[,14f.]., et Ioannes, 1. Ioan. 2[,16f.]. Quod autem in Christo et scriptura canonica omnia ad vitam necessaria dederit et revelarit deus, non modo Petrus docuit, sed et Paulus disertis verbis ad Colossen[ses] 2. et 2. ad Timoth[eum] 3. capite. ${ }^{21}$

5 Toto itaque studio huc incumbite, ut in fide vestra subministretis virtutem, in virtute vero scientiam, 6 in scientia vero temperantiam, in temperantia vero patientiam, rursus in patientia pietatem, 7 in pietate autem fraternam charitatem, in fraterna vero charitate dilectionem. 8 Haec enim cum vobis adsint et exuberent, haud otiosos nec in irritum laborantes efficiunt ad domini nostri Iesu Christi cognitionem. 9 Nam cui non adsunt haec, is caecus est et manu viam ten|tans, oblitus sese a veteribus peccatis suis fuisse purgatum.

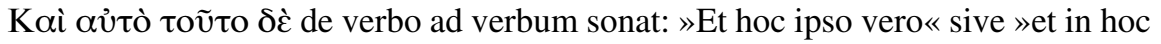
ipsum autem $\ll .{ }^{22}$ Loquutio est, pro qua nos reddidimus: »Toto itaque studio $\ll^{23}$ etc.

Z. (21) Iacobi] Iaco[bi] ZG - (24) Colossen[ses]] Coloss[enses] ZG

21 Kol 2,9f.; 2Tim 3,16f.

23 So auch Luth. 2Petr. 117r.

22 Vgl. Erasm. 2Petr. transl. (ASD VI/4 434);

Erasm. 2Petr. (ASD VI/10 492,40). 
Poterat et sic exponi: »Eius rei gratia date operam« etc. Iam palam invitat ad studium innocentiae. Erant enim tum quoque, sicut et nostro saeculo multi sunt, qui ore quidem Christum confitebantur, at vita Sardanapalum ${ }^{24}$ referebant. Hos in

Virtutum corona. festiva, qua prope virtutes omnium maximas veluti in sertum concinnavit pulcherrimum. Paraphrastes ista paucis quidem, sed aptissimis exposuit sensibus, cuius verba ascribere non piguit. Sunt autem haec: »Innocentiam semel largitus

Fides. est deus; eam non satis est tueri, sed omni studio adnitentes satagite, ut benefactis Virtus. locupletemini, ne fides sit otiosa, sed hanc comitetur probitas, ne quid agatur Scientia. dicaturve, nisi quod honestum est. Probitatem excipiat scientia, ut non solum sequamini, quae recta sunt, verum etiam perspiciatis, quid, quo loco, apud quos, quatenus et qua ratione sit agendum. Scientiam comitetur temperantia et animus invictus adversus omnes illecebras mundi sine deflexu constanter sequatur id, quod optimum esse iudicavit. Temperantiae iungatur patientia, ut, dum benefacitis, mala $\mid$ fortiter toleretis. Nam quos blandimenta mundi non emolliunt, hos aliquoties frangit impatientia malorum. Patientiae adsit pietas, ut, quicquid $\mid$ agitis aut patimini, ad dei gloriam referatis. Pietatem comitetur fraterna charitas, ut, quemadmodum deum amatis propter ipsum, ita illius gratia diligatis omnes, qui deum profitentur. Fraternam charitatem augeat cumuletque dilectio, quae bene mereri studeat de omnibus, non solum de piis et christianis, verumetiam de 20 impiis. Atque hi sunt fructus evangelicae fidei. ${ }^{25}$ Hactenus Eras[mus]. Sequenti vero sententia palam affirmat in his summam verae consistere pietatis, maxime si »exuberent«, id est, si incrementis indies assurgant usque ad plenam mensuram adulti Christi. ${ }^{26}$ Sensus autem est: »Si in istis fueritis toti, tum sane testabimini, quod non frustra agnoveritis Christum. « Quidam enim Christum frustra cogno- 25 scunt, qui videlicet verbis ipsum confitentur, factis autem negant. Subditur enim et a Petro contraria sententia: »Cui vero haec non adsunt, is caecus est manuque palpitans, oblitus sese a veteribus peccatis fuisse purgatum. «Qua nimirum allusit ad illam diram dei execrationem in lege: »Percutiet te dominus amentia et caecitate ac furore mentis, et palpes in meridie, sicut palpare solet caecus in 30 tenebris, et non diriges vias tuas. «Quibus non absimilia prodidit et Isaias in cap[ite] 59. ${ }^{27}$ Breviter: caecus iter quidem instituit, sed ubique impingit nec certam ra|tionem habet, palpitat itaque; ita et hypocritae fideique simulatores speciem sane habent pietatis, sed ubique impingunt, circumaguntur in voluptatibus mundanis et veram Christi viam non vident. Alias enim intelligerent se a 35

\section{Z. (17) comitetur] commitetur $G$ - (21) Eras[mus]] Erasmus $Z G$}

24 Sardanapal, legendärer assyrischer Herrscher, besonders bekannt für seinen ausschweifenden Lebenswandel, vgl. Cic. tusc. 5,35,101 (King 526).
25 Erasm. par. 2Petr. (ASD VII/6 218,38-52).

26 Vgl. Eph 4,13.

27 Jes $59,10$. 
Christo non in hoc liberatos esse a peccatis, ut in iisdem pergant acrius novaque accumulent identidem, sed ut semel peccatis mortui, reliquum vitae tempus Christo ac iustitiae in poenitentia vivant. Atque hoc illud ipsum argumentum est, quod et d[ivus] Iacobus in epistola sua copiosius tractavit. ${ }^{28}$ Quae omnia mire 5 quadrant in nostri seculi homines, qui et ipsi fidem iactantes fructibus fidei carent, omni modo sterilibus arboribus similes, quae proculdubio excindentur, ni veniam Ioan. 15[,6]. sibi poenitenti vita impetrent.

10 Quapropter, fratres, potius operam date, ut vocationem et electionem vestram firmam efficiatis. Haec enim si feceritis, non labemini unquam. 11 Siquidem ad hunc modum abunde subministrabitur vobis introitus in aeternum regnum domini nostri et servatoris Iesu Christi.

Illatio est. Planis enim verbis iam adhortatur, ut pietati insistant. Commodis Fideles autem utitur verbis, ut permoveat. »Annitimini«, ait, »ut vocationem et electio- $\begin{gathered}\text { electionem } \\ \text { efficiunt }\end{gathered}$ nem vestram firmam efficiatis. « Ampla et augusta haec est sententia, illorum firmam. refellens blasphemam vaesaniam, qui | aiunt: »Si electus sum, plane citra meam fidem et iustitiam servabor, nimirum per solam dei vocationem. Si vero electus non sum, non proderunt quicquam iustitiae opera.« Petrus enim multo commodius et syncerius iubet, ut nos electionem et vocationem nostram efficiamus firmam. Non quod infirma sit apud deum electio. Stat enim illa immobilis, ut in Romanis docuit apostolus, ${ }^{29}$ sed quod ordo sit in electione et vocatione, ut ostendimus in cap[ite] 1. epistolae prioris. ${ }^{30}$ Quos enim elegit, hos ad se trahit ac vocat praedicatione evangelica; quos autem vocavit, hos fide iustificat; quos vero fide iustificavit, hos in pietate et moribus sanctis conformes reddit imagini filii sui. ${ }^{31}$ De pietate ergo et moribus sanctis loquens Petrus rectissime: »Electionem «, inquit, »vestram firmam efficite. « Moribus enim sanctis perficitur electio. Nam vocationem dei sequitur vitae sanctimonia. Proinde, qui vitae impurioris sunt, produnt se alieniores esse a vocatione dei. Atque hoc fortassis nomine d[ivus] Augustinus non omnino male fertur dixisse: »Qui elegit te sine te, non salvabit te sine te. $\ll^{32}$ De ordine et dispensatione salutis loquimur, non nescii alias nihil 30 deberi viribus nostris, sed gratiae et merito Christi omnem deberi gloriam. Addit Petrus aliud argumentum, quo permoveat: »Haec si feceritis, oủ $\mu \grave{\eta} \pi \tau \alpha i ́ \sigma \eta \tau \varepsilon$ $\pi о \tau \varepsilon$, nequaquam labemini unquam «, id est: »non excidetis« aut »aberrabitis a via veritatis «. Aberrant enim a veritatis sco|po, qui contemptis literis sacris sectantur humanas traditiones. ${ }^{33}$ Ad expositionem huius sententiae pertinet et

Z. (11) aeternum] aeterum $\mathrm{G}$

32 Vgl. Aug. serm. 169,11 (PL XXXVIII 923): »Qui ergo fecit te sine te, non te iustificat sine te.«

33 Vgl. Kol 2,8. 
sequens: »Siquidem ad hunc modum $\pi \lambda o v \sigma i \omega s$, abunde, subministrabitur vobis introitus in regnum dei«, quasi dicat: »Non est quod novum aliquod doctrinae genus amplectamini. In hoc enim habetis, quod ad salutem consequendam sat est.« Proinde non immerito miretur quis, quae egerit pontificios insania, quod decreta quaedam et observationes traditionum | humanarum ad salutem credidere necessarias. Ruunt hic istorum omnia velut ociosa ac inania ad salutem. Divinis abunde subministratur nobis introitus in vitam aeternam. Perstemus itaque in traditione Christi et doctrina apostolorum.

12 Quapropter haud negligam vos semper commonere de his, tametsi sciatis et confirmati sitis in praesenti veritate. 13 Attamen iustum arbitror, quandiu sum in hoc tabernaculo, excitare vos per commonitionem, 14 cum sciam brevi futurum, ut deponam hoc tabernaculum meum, quemadmodum et dominus noster Iesus Christus significavit mihi. 15 Dabo igitur semper operam, ut vos post exitum meum horum mentionem facere possitis.

De monumentis et scriptis apostolorum.

Obiter inserit nunc, qua occasione quibusve de re|bus scribere hanc coeperit.

Orationem autem ipsam sic connectit: »Cum itaque certo constet, quod haec, quam tradidimus vobis, unica, vera et absoluta sit doctrina et religio sana, non potui non hac vos submonere epistola, ut in hac ipsa pergatis et perseveretis usque in finem. « Porro ne isti obiicerent: »Igitur de fide nostra dubitas?«, prae- 20 venit et ait: »Scio equidem et doctos et longo pietatis progressu confirmatos vos esse in illa ipsa veritate, ad quam nos hortamur; nihilominus non inutile vobis futurum credidimus, si subinde eandem vobis rem inculcaremus et calcaria adderemus currentibus. ${ }^{34}$ Hoc enim certo scio, quod brevi sim moriturus; unde prius memoraculum aliquod pium apud vos deponere volui, per quod aeternum apud 25 vos prodessem viveremque. Nam volventibus subinde vobis epistolas nostras, nostri, imo doctrinae nostrae meminisse licebit etiam post obitum, cum post fata loquentem audire non detur amplius. « Haec de sensu apostoli. Iam plurima hic occurrunt monenda. Primum, quod salubris est commonitio, tametsi in pietatis summa et doctrina christiana nihil aut parum nobis deesse videatur. Deinde, quod 30 mira proprietate et similitudine appositissima Petrus humanum corpus scenam sive tabernaculum vocavit. Ducta enim est metaphora a tentoriis, quae quod homini oberranti et nullas sedes fixas habenti sunt, id corpus homini. Extant

Z. (6) ociosa] otiosa $Z G$ - (31) appositissima] apositissima $G$

34 Erasm. adag. 147 (ASD II/1 264,185-192): »Calcar addere currentibus. [...] Translatione sumpta ab equitibus, qui nonnunquam etiam sponte currentibus equis, quo currant celerius, calcar addunt. Ita nobis calcar addit, qui extimulat languentes; addit currentibus, qui cupiditatem ac studium nostrum auget acuitque.« 
quaedam apud d[ivum] Paulum ad $\mid$ Hebrae[os] 11. et 2. Corinth. 5., ${ }^{35}$ quae hunc locum nonnihil explicant. Porro apud Ioannem in 21. exponitur copiosius, quod hoc loco Petrus paucis annotat. Dicit enim ad Petrum dominus: »Amen amen dico tibi, cum esses iunior cingebas te et ambulas, quo volebas; cum autem senueris, extendes manus tuas et alius te cinget et ducet, quo non vis « [Joh 21,18]. Postremo videmus, quo loco quove gradu literae sanctorum dei hominum sint habendae. Apostolos et apostolicos viros dederat nobis deus doctorum loco. Caeterum cum homines essent et proinde mortales, qui saltem uno alicui saeculo prodesse poterant docendo, visum est viris optimis et nostri studiosissimis totum

10 doctrinae suae genus summarie immortalibus credere literis atque ita se totos transmittere ad posteros. Quapropter ingenue fatemur veras apostolorum, pro- De veneratione phetarum et omnium sanctorum veterum olim in fide mortuorum reliquias et et reliquiis monimenta literas esse ab ipsis scriptas, non corpora sepulta. Habent sane corpora suam quoque spem, sed nos in sanctis dei non carnem, non sanguinem, non ossa, 15 non staturam et habitum corporis miramur, sed animum divinum, purum, syncerum, integrum. At libri testimonia et indices adeoque et specula quaedam formaeque animi expressissimae sunt. Verae itaque sanctorum reliquiae nobis venerandae ipsi sanctorum libri sunt, in quibus animum et spiritum illum suum plane nobis delinearunt et ceu testamento de|legarunt. Proinde praeposteri sunt, 20 qui craneum decalvatum exosculantur, at ipsum capitis sensum non magni pendunt. Qui vero divorum intercessionem ex hoc loco approbare voluerunt, inscitiam suam prodiderunt. Non enim dixit Petrus: »Efficiam, ut post obitum meum me invocetis«, sed: »In hoc scribo«, ait, »ut etiam me mortuo habeatis, quod doctrinae olim a me traditae admoneat.«

16 Non enim arte compositas fabulas sequuti notam vobis fecimus domini nostri Iesu Christi virtutem et adventum, sed qui oculis nostris aspeximus illius maiestatem. 17 Acceperat enim a deo patre honorem et $\mid$ gloriam, voce ad illum delata huiusmodi: ${ }^{36}$ hic est filius meus dilectus, in quo mihi complacitum est. 18 Et hanc vocem audivimus e coelo delatam, cum essemus una cum illo in monte sancto.

Redit, ut fidelibus approbet eam religionem, in qua tum agebant, certam, veram et absolutam esse, nimirum ut illos permoveret, in hac perstarent huicque immoAuthoritas fidei rerentur. Id porro exquisitis agit verbis et argumentis. Principio in genere dicit:

Z. (1) Hebrae[os]] Heb[raeos] $Z G$ - (2) Ioannem] Ioan[nem] $Z G$ - (25) sequuti] secuti $Z G$

35 Hebr 11,4; 2Kor 5,1-4.

36 Bullinger lässt in der Übersetzung den Teilsatz

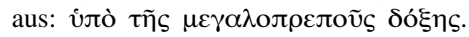


»Caeterum nos, qui orbi nuntiavimus Christi Iesu virtutem et adventum, non fabulas quasdam sequuti sumus, sed illud, quod oculis no|stris vidimus, annuntiavimus.«Deinde speciatim exponit, quid viderint. Atqui in illis verbis haec potissimum consideranda sunt nobis: quod totum Christi negotium in adventum et virtutem partitus est. Adventus habet praestituta illa a prophetis tempora et adventum illum in carnem et mundum. Virtus vero comprehendit divinam Christi vim, miracula, doctrinam, quod ipse fidelium vita, salus, hostia, iustitia et redemptio est. Hoc itaque dicit: »Quaecunque de Christo diximus, quomodo is in mundum venerit, quanta cum virtute salutis hoc negotium peregerit, non ex fabellarum protulimus arcanis, sed ex confessae veritatis consensu.« Opponit enim testimonio, ut sic dicam, oculato arte compositas fabulas. Quales erant olim philosophorum argutae magis quam salubres disputationes ${ }^{37}$ et poetarum figmenta quaedam, a vero quidem desumpta, sed propter vanitatem hominum mendaciis involuta. Nihil igitur fallaciae, nihil artis, nihil persuasionis, nihil conspirationis aut doli mali quisquam in doctrina nostra latitare credat. Quae enim docemus, 15 rustica prorsum simplicitate absque verborum fucis, phaleris et involucris, absque sophismatis et humanis argutiis auditori proponimus. Visa enim narramus et comperta. Iam quis nescit certiora esse, quae cernuntur, quam quae audiuntur? Horatius $^{38}$ certe fatetur,

Segnius irritant animos demissa per aurem,

Et Ioan[nes] apostolus non absimili fiducia orditur epistolam suam: »Quod erat ab initio, quod audivimus, quod vidimus oculis nostris « [1Joh 1,1] etc. Per maiestatem vero intellexit Petrus gloriam illam filii dei, quam viderunt in monte. 25 Nunc enim ex omnibus Christi cum dictis tum factis id solum producit, quod in monte sancto dominus coram discipulis transformatus legitur apud Matt[haeum] in 17. et Lucam in 9. cap[ite], ${ }^{40}$ nimirum quod in ea historia semel omnia Christi mysteria sint comprehensa. Ea nos paucis hoc loco perstringemus. Iesus ergo ostensurus discipulis suis, quod a deo patre missus sit in orbem redemptor et 30 doctor, cui consentiant lex et prophetae et in cuius manu sit vita et immortalitas, selectis ex omni turba tribus, Petro, Ioanne et Iacobo, ut absolutior esset testium numerus, subducit illos in montem vehementer excelsum, ipsa loci celsitudine

Z. (1) nuntiavimus] nunciavimus $Z G-(2-3)$ annuntiavimus] annunciavimus $Z G$

37 Vgl. Erasm. par. 2Petr. (ASD VII/6 220,8991): »Neque enim doctrina nostra talis fuit qualis philosophorum qui fabulis arte compositis et humanis argutiis persuadere conantur quod ipsi non intelligunt inter se quoque dissentientes.«
38 Horaz (Quintus Horatius Flaccus, 65-8 v.Chr.), einer der bedeutendsten römischen Dichter, Verfasser der »Satiren «, »Epoden«, »Oden« und »Episteln«, vgl. NP V 720-727.

39 Hor. ars 180-182 (Klingner 301).

40 Mt 17,1-13; Lk 9,28-36. 
declarans se nil humile, sed arduum et coeleste quippiam traditurum. Nam in montis cacumine protinus coram illis transfiguratus est, id est, eadem corporis manente substantia aliam induit formam et illustriorem quidem illam. Refulsit enim facies eius in morem solis et vestimenta eius albicarunt in morem nivis et 5 lucis. Sic enim gustum ipsis exhibebat aliquem divinitatis, imo immortalitatis et gloriae futurae. Simul autem comparuere Moses atque Helias et ipsi gloriosi. Hi colloquebantur cum ipso. Dicebant autem excessum eius, quem completurus erat Hierosolymis. Quaecunque enim Christus passus est, quaecunque egit, non secus egit nec aliter passus est, quam prophetae et ipsa lex praedixerant. In Christo ergo consentiunt lex et prophetae. Christo testimonium ferunt lex et prophetae, quod ipse sit vita credentium. Discipuli ubi tanta viderent ipsis praesentibus agi, propemodum exanimati sunt, adeoque ipse Petrus spectaculi maiestate totus sibiipsi raptus cupit eius loci sempiternus fieri inhabitator, oblitus omnium eorum, quae aliquando viderat in terris, in quibus somnia et umbras verius quam res ipsas 15 miramur atque complectimur. Magna quidem haec sunt, sed maiora sequuntur. Protinus ergo lucida nubes, quae nullibi non in sacris creatori suo officium praestat suum, obumbrat ipsos, Christum tamen in $\mid$ primis, cui pater coelestis maximum sane confert testimonium ilico. Nam vox e nube illa lucida, nimirum a magnifica gloria, id est a magnifico deo, qui ob maiestatem inedicibilem ipsa 20 dicitur gloria, audita est, quae dicebat: »Hic est filius meus dilectus, in quo placatus sum; ipsum audite « [Mt 17,5]. Hoc vero quid aliud est quam approbatio, quod Christus dominus verus sit Messias, naturalis filius dei, ${ }^{41}$ adeoque et patri aequalis et dilectus, in quo sibi complacuit universam inhabitare plenitudinem ${ }^{42}$ et per eum sibi reconciliare, quae in coelo et quae in $\mid$ terra, ${ }^{43}$ et quod hunc nobis dederit in doctorem, lucem et exemplum vitae, in quo habeamus omnia? Abeant ergo posthac ad Cynosarges, ${ }^{44}$ quicunque alios nobis doctores praecipiunt audiendos, quicunque alios intercessores aliave ad salutem media ostendunt. Unus Christus proponitur nobis doctor et redemptor, in hoc uno et solo omnia habet fidelis anima. Unum et solum celebravere omnium sanctorum prophetarum, apostolorum et apostolicorum virorum voces, vota et scripta, quae et summa cum animi laetitia et promptitudine propter Christum suscipimus, exosculamur et veneramur; caetera vero, quae iis non consentiunt, ut inutilia et impia execramur. Satis nobis est Christus summi dei unicus filius. Sed ad Petrum redimus, qui miro consilio ex omnibus Christi dictis et factis hoc longe sanctissimum et saluber35 rimum delegit, in quo patris coelestis de filio et doctrina eius et apostolorum habemus testimonium, ut posthac nisi volentes et malitiose de veritate religionis christianae dubitemus, quam hic audimus atque videmus tot tantisque approbatam

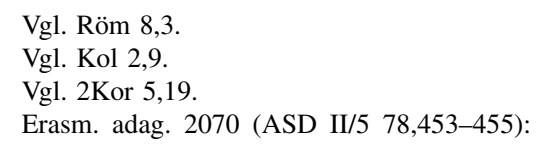

»Ad Cynosarges, prouerbiali conuicio dicebatur [...]. Erat autem Cynosarges locus in Attica quispiam, in quo nothi spuriique exercebantur.« 
esse testimoniis. Perstemus ergo, o fratres, in recepta veritate! Doctrina enim nostra veritatis doctrina est coelitus delapsa, quae vincet in aeternum.

19 Et habemus firmiorem sermonem propheticum, cui dum attenditis ceu lucernae apparenti in obscuro loco, recte faci|tis, donec dies illucescat et lucifer exoriatur in cordibus vestris.

Satis erat credentibus testimonium patris, sed nondum omnes credebant evangelicae historiae et praedicationi apostolicae, ergo propter istos: »Quod si «, inquit, »cuiquam infirmiora videantur, quae diximus, proferemus prophetarum testimonia, quibus isti fortassis plus credent. Quod autem nos de fide christiana docemus, idem ante nos docuerunt prophetae, cuius quidem rei argumenta quae- 10 dam ostendimus in cap[ite] 1.«Firmiorem ergo dixit propter infirmiores in fide, non quod firmiora testimonio patris crederet prophetarum testimonia, cum non ignoraret etiam prophetarum testimonia patris esse instinctum. Erant autem ex Iudaismo conversi multi vehementer intenti prophetarum testimoniis, quemadmodum et de Berrhoeensibus tradidit Lucas, ${ }^{45}$ quorum studium hic approbat 15 Petrus dicens: »Cui dum attenditis, recte facitis.« Est enim scriptura sacra veluti lucerna quaedam, ut ait David in Psal[mo] $118 .{ }^{46}$ Quemadmodum enim lucerna in obscurum locum posita oberrantibus viam aperit emergendi e tenebris, ita scriptura sancto proposito et mente fideli lecta educit ex erroribus in apertum veritatis campum. Qui vero mente obscura et curiosa ad sacra accedunt, plus dispendii quam compendii sibi comparant. ${ }^{47}$ Proinde Petrus significanter addit: »Donec dies illucescat et lucifer exoria|tur in cordibus vestris.« Habet autem allegoriam locutio. Diem praecedit lucifer diei nuntius, at ipsa dies per incrementa quaedam succedit illucescitque. Iam hisce additur quod tropum explicet: »Exoriatur in cordibus vestris. «Ecce »in cordibus « ait, non in coeli regia, »exoriatur «. Itaque 25 de augmento fidei et cognitionis Christi loquutus est, quam per luciferi stellae ac diei amoenas metaphoras significavit. In hunc ergo finem legendi sunt prophetarum libri, ut in Christum tandem credamus, ut ipsa lux evangelica ipseque lucifer Iesus Christus oboriatur in mentibus nostris.

20 Si illud prius noveritis, quod omnis prophetica scriptura non sit privatae interpretationis. 21 Non enim voluntate hominis allata est olim prophetia, sed a spiritu sancto impulsi loquuti sunt sancti dei homines.

Expositio sacrae Quod semel coeperat, clarius et copiosius hisce exponit, nempe in quem finem aut quomodo canonica scriptura sit legenda, imo exponenda. Illud (inquit) lectori

45 Apg 17,10-12.

46 Ps 119,105 (Vulg. 118,105).

47 Vgl. Erasm. cop. 1,76 (ASD I/6 138,772f.):
»Eruditio ad pietatem plus adfert dispendii quam compendii, et non tam promouet quam moratur.« 


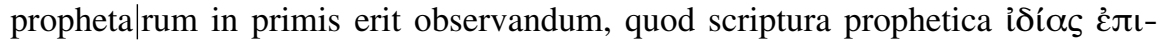

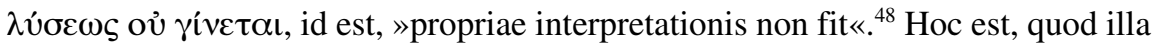
non sit exponenda secundum cuiusque arbitrium, sic, ut cuique fuerit visum, sed quemadmodum ipse spiritus flagitat, qui prophetas inspiravit. Sequitur enim caussa: |»Non enim voluntate hominis allata est prophetia«, id est: »Prophetae, qui vaticinia prodiderunt, non e suo sensu animique arbitrio ea prodiderunt, sed a spiritu sancto impulsi loquuti sunt dei homines.« Idcirco vaticinia eorum iuxta spiritus quoque instinctum aut ipsa scriptura per sese, obscuriora videlicet per clariora sunt exponenda. ${ }^{49}$ Insignis est hic locus, quo docemur illud in primis: quod tametsi homines fuerint prophetae, vaticinia tamen eorum non sint humana, sed sancti spiritus inspiratio. Deinde: quod ea demum scripturae expositio approbanda sit, quae ex scripturis petita nihil dissidet ab ingenio divini spiritus. De qua re disseruit et apostolus Paulus in 1. ad Corinth[ios] cap[ite] 2. ${ }^{50}$ Aberrant ergo, qui humano iudicio aestimant sensum scripturae. Cum enim de sensu 15 alicuius loci contravertitur, expositio vera vel circumstantiis vel per contextum vel per clariorem vel per contrarium locum erit ostendenda. Non enim valet hic locus ab authoritate, ut dicamus Thomas, Hugo, ${ }^{51}$ Lyranus $^{52}$ vel Gregorius eum locum ita exposuere, sed excutiendae rationes, cur sic exposuerint et an expositio consentiat cum ingenio spiritus divini et quam sit fidei et charitatis regulae 20 conformis; ${ }^{53}$ sed de his alias plura. ${ }^{54}$

Hactenus vero de eo, quod deus nobis in Christo omnia dedit, quae ad vitam et pietatem pertinent quodque fides sive religio christiana certa, vera et absoluta $\mid$ sit, approbata coelestis patris et prophetarum testimoniis. Quae omnia, si qui intelligunt rectius, ultro in recepta veritate perstant, cum videant nihil posse vel 25 excogitari vel dici melius. Omnia enim extra Christum et canonicam scripturam tenebrae sunt.

1 Fuerunt autem et pseudoprophetae in populo, quemadmodum et inter vos erunt falsi doctores, qui clam inducent sectas perniciosas, etiam dominum, qui illos mercatus est, abnegantes, accersentes sibiipsis celerem interitum; 2 et plerique sequentur illorum exitia, per quos via veri-

48 Erasm. 2Petr. (ASD VI/10 500,144f.).

49 Vgl. Bull. lect. (Baschera 5,19-21): »Ego enim libere confiteor scripturae sanctae interpretationem ex ipsa sola esse petendam, ut ipsa interpres sit sui charitatis fideique regula moderante. «

50 1Kor 2,14-16.

51 Hugo von Saint-Cher (ca. 1190-1263), Do- minikanermönch und Kardinal, Autor einer »Postilla in Bibliam«, vgl. LMA V 176f.

52 Nikolaus von Lyra (gest. 1349), besonders bekannt als Exeget durch seine »Postilla litteralis in totam Bibliam«, vgl. LMA VI 1185.

53 Vgl. Baschera 2012, LXIX.

54 Bull. proph. 10v-11r. 
tatis blasphemabitur, 3 et ex avaritia factitiis sermonibus de vobis negotiabuntur.

De falsis Aliam inducit rationem, per quam constantiam illis in fide commendet. Ducta est doctoribus. a contrario. Est enim sensus: »Quod autem tam anxie vos moneo deum in Christo nobis dedisse omnia, quod toties inculco perstandum esse in veritate recepta, hinc est, quod certo novi venturos pseudoprophetas, qui sint commentaturi nova quaedam adeoque et aliena et contraria traditis addituri. Hos autem caveri velim.« Caeterum nemo sibi cavebit, nisi prius persuasum habuerit omnia semel in sacris esse tradita, quae verae pietatis sunt. Hi enim vident nihil superesse, quod istis relinquatur, quasi de $\mid$ novo adiiciendum decernendumque. Sic videmus Paulum in 2. ad Timoth[eum] 4. cap[ite] ardentissimis verbis obtestari discipulum, imo quemlibet episcopum, ut in tradita disciplina incorrupta mente et constanter pergat, et caussam tandem subdere: »Nam erit tempus, cum sanam doctrinam non sustinebunt « [2Tim 4,3] etc. Iam ne vanam crederent esse Petri de venturis pseudoprophetis divinationem, addit, quod fidem faciat: »Fuerunt autem iam olim et pseudoprophetae in populo. $\mathrm{Ab}$ anteactis enim trahitur argumentum, ut sit sensus: »Nunquam defuere vel sanctissimo dei populo pseudoprophetae. Semhistorias et prophetas sanctos. per enim infoelix hoc lolium nimis quam foeliciter excrevit in agro dominico, proinde ne nunc quidem cessabunt in ecclesia Christi falsi doctores.« Falsos autem doctores vocavit vel eos, qui contemptis sacris literis figmenta praedicant 20 humana vel sacras scripturas ad animi sui affectum libidinemque detorquent. Sed ipse Petrus illos suis pingit coloribus. ${ }^{55}$ Certa enim attributa illis tribuit certasque notas et tanquam stigmata quaedam ostendit, ut per haec nemo non, nisi qui omnino nolit, sibi ab istis cavere possit. Ipso enim digito indicat, quos velit. Non secus, ac si quis ita moneat: »Si quis obviam prodeat, qui barba sit hispida et 25 subrusa, facie torva, oculis micantibus, veste stricta et viridi, caligis indutus scissis et varii coloris, tectus insuper pileo purpureo, hic ater est, hunc tu cave|re memento.«Ita enim Petrus: »Venient «, ait, »falsi doctores, qui clam inducent sectas perniciosas, qui dominum negabunt, viam quoque veritatis blasphemabunt et ex avaritia de fideli|bus sermonibus fictitiis negotiabuntur.« Descriptionem 30 ergo et veluti hypotyposim quandam pseudoprophetarum subiicit Petrus. Nos

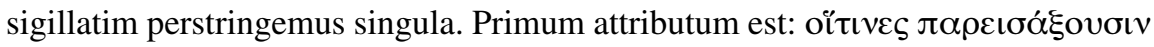

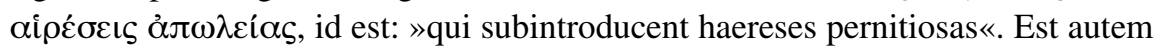
in singulis verbis, ut solet in omnibus vaticiniis, mira emphasis. Non ait »inducent « haereses, sed »subintroducent «, id quod Erasmus propriissime vertit: »clam 35

Z. (11) Timoth[eum]] Timo[theum] $Z G$ - (18) infoelix] infelix $Z G$ - (18) foeliciter] feliciter $Z G$

55 Erasm. adag. 306 (ASD II/1 414,168-170): »)Tuis te pingam coloribus<, id est talem te describam, qualis es. Translatum a pictoribus, qui nonnunquam faciem hominis ita vt est exprimunt ac repraesentant, nonnunquam alienis fucant coloribus.« 
inducent $\ll .{ }^{56}$ Non ergo palam negabunt scripturam sacram, non omnino negabunt deum, sed ista confitentes, aliquid de suo assuent ${ }^{57}$ atque hoc ipsum titulo pietatis ac veritatis contegent et imprudentibus ut verum proponent. Haereses autem dixit sectas, id est institutum quodvis novum humanum et a canonicis scripturis se5 paratum ac alienum; in primis tamen, quod perniciosum est, id est, quod perdit, dum a Christo et vero abducit aut dei, Christi et veritatis gloriam transfert. Sic enim Paulus ad Roma[nos] 16.: »Obsecro«, ait, »fratres, ut consideretis eos, qui dissidia et offendicula CONTRA DOCTRINAM, quam vos DIDICISTIS, gignunt, et declinetis ab illis « [Röm 16,17]. Petrus ergo: »Illi«, inquit, »nolent videri hostes

aliud interim agentes inducent dogmata et instituta quaedam aliena et separata a veritate canonica, ergo et perniciosa. Id quod factum vidimus et in priore illo et nostro saeculo. Venit enim Valentinus et simulabat se dei, veritatis et Christi gloriam quaerere, interim vero veris falsa et noxia dogmata adversus incarnationem Christi miscuit et ecclesiae corpus conscidit, rapiens multos in istud blasphemum vitae et doctrinae suae institutum. ${ }^{58}$ Successit Arrius presbyter quondam Alexandrinus et de religione christiana sanctissime disputans, subtexuit illud nephandum de inaequalitate patris et filii dogma, et totum pene Orientem in suas attraxit partes. ${ }^{59}$ In hoc numero recensendus videtur et Pelagius Britto noxius 20 haereticus, qui de operibus iustitiae quam officiosissime et admodum plausibiliter disserens, tandem in animis auditorum sui fidutiam gratiaeque contemptum pestiferum sane aculeum reliquit. ${ }^{60}$ Et nostro tempore inter evangelicae praedicationis hostes, professores legum humanarum, neminem non audias ingeminantem: »Quis negaret scripturas? Quis non crederet esse deum? Iamdudum audivimus de

25 Christo et redemptione eius. Semper illius nobis evangelium est praedicatum.« Sed si interim quis facta et dicta vitaeque instituta, opiniones, dogmata, ritus, ceremonias, regulas, decreta |idque genus alia norit, expendat et ad scriptam dei regulam examinet districtius: deus bone, quanta rerum dissimilitudo! Omnia enim istorum iuxta evangelion instituta sunt et a communi veritatis via abducunt et novum quodpiam vitae genus praescribunt, instituunt et defendunt. Nam ut e multis vel unam illam Hydram monasticam protraham: an non ista clam in ecclesiam Christi irrepsit? An non adversum traditionem canonicam privatum genus vivendi et vere perniciosa secta esse coepit? Non ergo est, ut multis inquiramus, quibus de loquutus sit Petrus, cum ipsa res et usus nostri saeculi

56 Erasm. 2Petr. transl. [2,1] (ASD VI/4 440).

57 Vgl. Tert. adv. Marc. 4,11,9 (CCSL I 567,19f.): »Ueteri, id est priori euangelio, pannum haereticae nouitatis adsuisti.«

58 Aug. haer. 11 (CCSL XLVI 295f.).

59 Aug. haer. 49 (CCSL XLVI 320f.).

60 Aug. haer. 88 (CCSL XLVI 340-342). Der aus
Britannien stammende Pelagius (4./5. Jh. n. Chr.) wurde 416 und 418 wegen seiner Leugnung der Ursündenlehre sowie aufgrund seiner als häretisch betrachteten Soteriologie verurteilt, vgl. NP IX 487f.; TRE XXVI 176185 . 
Abnegant vim redemptionis. subinde ista exponant clarissime. Sequundum attributum fere pertinet ad expositionem primi. In eo enim dixerat, quod sectas introducturi essent perniciosas. In hoc ostendit, quo potissimum nomine sint perniciosae; hoc potissimum, quod istis

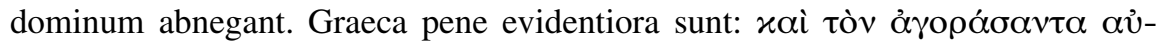

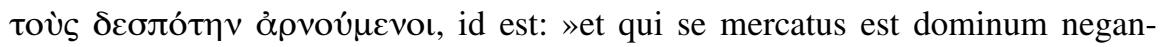
tes « ${ }^{61}$ Significat autem istos non omnino negaturos esse Christum, sed ea potissimum parte, qua salutaris est. Valentinus enim non omnino negavit Christum, sed ea parte, qua hostia salutaris est pro peccatis mundi: incarnationem enim negavit. Arrius vero divinitatem Christi posuit in dubium, secundum quam dominus noster panis est vitae. ${ }^{62}$ Iam et Pelagius ea dun|taxat parte Christum, qua nos liberavit, negavit. Si enim ex operibus est iustitia, Christus frustra mortuus est. ${ }^{63}$ Et monachica pontificiaque religio tantum non adorat nomen Christi, sed si ritus, decreta et commenta illorum expendas, dices nil unquam virtuti passionis dominicae magis fuisse adversum. Si enim unica hostia peccata nostra expiavit Christus, si semel oblatus, ${ }^{64}$ amplius non offertur. Si hoc illi credunt, quid Chris- 15 tum offerunt quotidie? Si solus ille mediator, satisfactio, salus, intercessor et vita est, quid isti tot fingunt intercessores satisfactionis et iustitiae modos? Sed hoc illud ipsum est, quod Petrus dixit: »Negabunt Christum«, sed ea maxime parte, qua redemit. Et redemptionis gloriam aliis tribuisse et non uni Christo est negasse Christum. Pudet me hoc loco recensere condonationum modos, bullarum sive 20 diplomatum artes et alias huius generis impostrices blasphemias. Petrus certum et celerem istis impostoribus minatur exitium, dicens: »Accersentes sibiipsis celerem interitum.«Quae sententia allusionem habet ad superiorem. Superius enim dixit: »Subintroducent sectas pernitiosas «; hic addit: »Sed his sibiipsis celerem accersent perniciem. « Arrius enim cacando expiravit. ${ }^{65}$ Misere et insperato in- 25 teriere et alia haereticorum monstra. Haud diu praefuit Machometus. ${ }^{66}$ Paucissimos annos imperitant in hunc usque diem pontifices Roma[ni]. Verum ego hanc Petri sententiam malim de vin|dicta domini exponere, quam illi in suum sibi caput consciscunt doctrina et vita impia. De poena seductorum ipse Petrus paulo post pluribus aget. ${ }^{67}$ His addit: »Et plerique sequentur illorum exitia.« Testantur enim 30 historiae, quam multos semper habuerint vaesaniae suae sectatores haeretici Valentinus, Martion, Arrius, Donatus, ${ }^{68}$ Pelagius. Testantur et nostra tempora, quot

\section{Z. (1) Sequundum] Secundum $Z G$ - (27) Roma[ni]] Romani $Z G$}

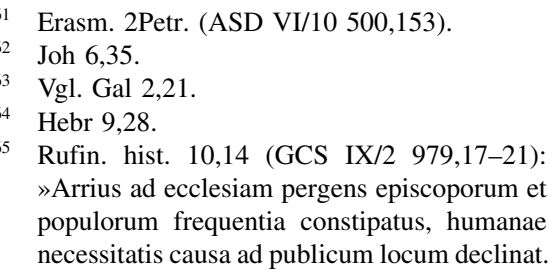
populorum frequentia constipatus, humanae necessitatis causa ad publicum locum declinat.

ubi cum sederet, intestina eius atque omnia viscera in secessus cuniculum defluxere; ita tali in loco dignam mortem blasfemae et foetidae mentis exsolvit.«

66 Mohammed (570-632), Stifter des Islams, vgl. NP VIII 337f.

67 2Petr 2,3-5.

68 Donatus (gest. 355), Bischof von Karthago; 
habeat cultores Machomet et papa. Caussam indicavit apud Ioannem Christus, dicens: »Si de mundo fuissetis, mundus, quod suum est, diligeret; sed ego selegi Ioan. 15[,19]. vos de mundo, propterea odit vos mundus.« Porro illud in primis observandum est, quod istorum religionem non vocavit fidem vel vitae institutum, sed »exiti5 um«. Nam istorum dogmatis haesisse aliud non est, quam se in interitum demersisse. Solus enim Christus est via, veritas et vita. ${ }^{69}$ Nemo autem miretur hodie, si videat maxima quaeque regna et magnam hominum partem repugnare evangelio. Id enim futurum praedixerunt prophetae. ${ }^{70}$ Tertium attributum est, quod veritatem viam veritatis blasphemabunt. Porro non est nisi unica veritatis via, illa nimirum, blasphemant. quam nobis in scriptis canonicis per Christum ad coelos ostendit coelestis pater, simplex quidem illa, exposita et in arctum compressa. Hanc illi incessunt convitiis, dicentes non omnia, quae ad salutem consequendam necessaria sunt, expressa esse canonicis literis. Apostolos enim nec omnia scisse $\mid$ nec omnia omnibus tradidisse. Scripturas sanctas esse obscuras et aliquibus in caussis steriles 15 satis, et proinde constitutiones quasdam esse necessarias (eas, quas ipsi condiderint), unde id protinus accusant haereseos, quod ipsis repugnarit, tametsi e sacris petitum sit literis. ${ }^{71}$ Istud vero est viam veritatis blasphemare. Quartum attributum ita sibi peculiare tenent pontificii, ut nullos hic patiantur corrivales. $»$ Ex avaritia «, ait, »factitiis « sive »confictis verbis de vobis negotiabuntur. $\ll^{72}$ Id Avaritia.

20 est: »Neglecta veritatis doctrina figmenta quaedam ex avaritia comminiscentur et haec docentes nihil aliud spectabunt, quam ut ex vobis sibi quam plurimum auferant lucri.«Quis vero negare ausit Romanis Chananeis, hoc est mercatoribus, hactenus omnia religionis fuisse venalia? Religio sane illis nil aliud quam quaestus haberi coepit. Non satis putabant esse, si vivos indulgentiis, votis, missis, donis, peregrinationibus, cultu divorum, confessionibus et id genus aliis nugis depraedarentur, nisi et a mortuis tributum exigerent. Sed nemo verbis queat assequi, quanta impudentia isti sacra et prophana avaritia sua inexplebili corruperint. Et cum tales sint, hunc Petri locum de nobis exponunt, qui tamen sola canonica scriptura contenti nullas insuper sectas subintroduximus et mysterium

30 incarnationis ita veneramur et colimus solum, ut caetera prae hoc omnia contem- Philip. 3[,8f.]. namus, unde et paucos $\mid$ habemus nostrae doctrinae sectatores synceros. Viam veritatis nullus nostrum blasphemat, humana duntaxat figmenta execramur. Quin et »victum et amictum habentes iis contenti sumus« [1Tim 6,8]. Pauperibus docemus offerendum esse, si quis deo gratum munus offerre velit. Neque ullas 35 profitemur deglubendi artes neque ulla didicimus verba fictitia, quibus simpli-

nach ihm wurde die ethisch radikale und als häretisch betrachtete Bewegung der »Donatisten « benannt, vgl. NP III 772-774; TRE I 640700 .

69 Joh 14,6.

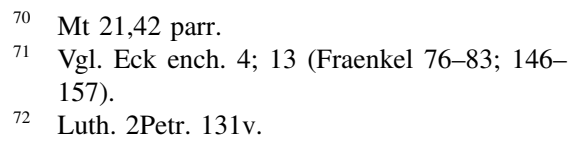

70 Mt 21,42 parr.

72 Luth. 2Petr. 131v. 
cioribus pecuniam extorqueamus. In nostrum ergo caput congerunt impudentes, cuius ipsi sese reos esse negare non possunt.

3 Quibus iudicium iam olim non tardat et perditio illorum non dormitat. 4 Nam si deus angelis, qui peccaverant, non pepercit, sed catenis noctis in tartarum praecipitatos tradidit servandos in iudicium, 5 et prisco mundo non pepercit, sed octavum iustitiae praeconem Noe servavit, diluvio in mundum impiorum inducto,

Male perdentur falsi doctores.
Iam disserit de iudicio et iusta poena pseudoprophetarum, qui felici rerum successu elati sanctos persequuntur et opprimunt, putantes in gloria et voluptatibus veram consistere beatitudinem neque unquam futurum, ut de ipsis com- 10 merita supplicia sumat deus. Sed Petrus: »Nemo«, ait, »credat istos perpetuo victuros impunes. Nemo seducatur a falsa ipsorum felicitate, quod hic ditescunt et suaviter vivunt. Haud | diu fruentur hac usura falsae felicitatis. « Haec si legerent et crederent multi, non audiremus quotidie tot blasphemas voces: »Nisi religio istorum esset vera, haud illis tot obtingerent bona." Obtingunt sane illis bona 15 temporaria multa, sed saginantur his ad mactationem et interitum. Certo enim iudicabit ipsos deus. Id ne cui esset dubium, exempla sive argumenta quaedam subiicit ex sacris, quibus astruat falsos istos doctores divino iudicio esse puniendos. Iudicium vero usurpamus ad morem Hebraicum pro poena et iusto supplicio. Primum argumentum ab exemplo sumptum per collationem a maiori ad 20 minus est aptatum: »Si angelis non pepercit, ne pseudoprophetis quidem parcet.« Defectiva enim ac truncata loquutio sic erit adiecto membro sarcienda. Hic vero amplificat horrendum supplicium, quod deus de angelis sumpsit, ut et pseudoprophetis incutiat terrorem. Atque hic locus est, propter quem nonnulli forsan de hac dubitarunt epistola, quod nullibi in sacris reperiatur expressum, quod hic 25 citatur de angelis. ${ }^{73}$ Caeterum videntur ipsa ex quarto capite Iob esse transcripta, ubi ad hunc modum legimus: »Nunquid homo dei comparatione iustificabitur? Aut factore suo purior erit vir? Ecce, qui serviunt ei, non sunt stabiles et in angelis suis reperit pravitatem. Quanto magis hi, qui habitant domos luteas, qui terre|num habent fundamentum, consumentur velut a tinea!« [Hiob 4,17-19] Plura nos de iudicio dei, quod sibi reservavit, curiosius disputare nolumus, eo contenti, quod disertis verbis scriptura daemones refert in tartarum praecipitatos aeternum expectare iudicium, quo una cum omnibus seductoribus et seductis aeternum doleant et excrucientur. Secundum argumentum a primo nihil differt. Sumptum est ex Gene[si], septimo cap[ite], ${ }^{74}$ habet autem hunc sensum: si veteri 35

\section{Z. (35) Gene[si]] Genesi ZG}

73 Vgl. Erasm. praef. par. 1Petr. (ASD VII/6 ${ }^{74}$ Gen 7,13-17. 180,38f.).
$65 Z G$

$101 \mathrm{r} G$ $101 \mathrm{v} G$ 
illi saeculo non pepercit, quod seductum esset et seductores haberet plurimos, certe nec impiis istis doctoribus et seductis per ipsos parcet. Iam et prius sae- Noe praeco culum satis mature monuerat per Noe iustitiae divinae praeconem, ut et nunc satis tempestive monet per apostolos et apostolicos viros, qui si contemnantur, supp5 licium certo sumetur de contemptoribus. Olim Noe octavus est servatus (quam locutionem probe reddidit Germanus interpres: selbachtet ${ }^{75}$ ); sic sanctorum numerus, tametsi semper sit exiguus futurus, servabitur a scabie haereticorum et supplicio, quod de seductoribus et seductis sumet deus.

6 et civitates Sodomorum et Gomorrhae in cinerem redactas subversione condemnavit eosque fecit exemplum iis, qui impie forent acturi, 7 et iustum Loth oppressum ab impudica conversatione abominandorum hominum liberavit 8 (is enim | oculis et auribus iustus, cum habitaret inter illos, quotidie animam iustam iniquis illorum factis excruciabat), 9 novit dominus pios e tentatione eripere, iniustos autem in diem iudicii puniendos servare.

Et hoc argumentum a superioribus nihil discrepat. Eodem enim refertur et eodem modo aptatur, quo et superiora, nisi quod in hoc quaedam sunt apertiora. PrinLiberantur a cipio enim excidium Sodomae ${ }^{76}$ publicum vocat exemplum et Sodomitas in exemplum omnium impiorum esse subversos, nimirum quod et ipsis non sit parsurus deus iustus, si in impietate perrexerint. Deinde copiosius et planius hic loquitur de liberatione piorum. Quae enim superius in exemplo Noe coeperat, inabsolutiora et tectiora fuerunt. Hic vero multis agit, quomodo Loth a nephariis oppressus, indies coactus sit videre, quae nollet. Quo ex loco illud quoque liquido colligere licet, istud quidem typo esse gestum. Nam hodie multi quoque viri boni in ecclesia audire et videre coguntur ab impostoribus ac seductoribus, quod doleat. Sed liberavit virum bonum dominus, poterit ergo vel hodie pios omnes liberare. Erasmus monuit hunc locum paulo esse obscuriorem. Eum de verbo ad verbum ita transtulit: »Aspectu enim et auditu iustus inhabitans inter illos cotidie animam iustam iniquis operibus excruciabat sive explorabat. ${ }^{77} \mid$ Significat autem Petrus »illum, cum oculos haberet sanctos et aures sanctas abhorrentes ab omni turpitudine, graviter discruciatum fuisse, quod vivens inter illos cogeretur quotidie videre et audire, quae nollet $\ll .{ }^{78}$ Idem in Paraphrasi: »Ex his satis declaratum est«, ait, »nunquam committere deum, ut cuiquam sua innocentia sit frustra aut ut cuiquam sua impietas sit impunita, etiamsi ad tempus leniter fert aliquos, ut

Z. (6) locutionem] loquutionem $Z G$ - (28) cotidie] quotidie $Z G$

75 Vgl. ZBib 1531, 2Petr 2,5: »[...] Noe den prediger der gerechtigkeit selbacht.«

76 Gen 19,23-25. 
aliquando resipiscant. Etiamsi patitur suos ad tempus aliquando tentari, tamen, cum tempus adest, novit pios eripere. ${ }^{79}$ Iam enim sequitur generalis sententia 1. Cor. 10[,13]. sive gnome quaepiam: »Novit dominus pios e tentatione eripere, iniustos autem in diem iudicii puniendos servare. « Atqui miram emphasim habet verbum »novit«. Cum enim sapiens iustus et bonus sit deus, novit, quid, quando et quomodo quidlibet sit faciendum. Ne ergo putemus, quod iustorum sit oblitus, si videamus regnare impios. Novit dominus iustus, quid cuique debeatur, quantum cuique concessum, quousque quisque progredi pervenireque debeat. Quocirca cum ad terminos ventum fuerit praescriptos, et illorum libidini et intolerandae superbiae, ambitioni, avaritiae et crudelitati imponetur modus et asserentur in libertatem filiorum dei omnes pii, quin et rerum vertentur vices. Nam impii aeternis suppliciis excruciabuntur, pii vero aeternis voluptatibus ad satietatem fruentur. ${ }^{80} \mathrm{Haec}$ expendite | diligentius, o fratres, qui nobiscum gemitis et corruptum adeoque deploratum illud saeculum nostrum lugetis. Videntur sane appetiisse dies Noe et Loth, de quibus etiam in evangelio dominus. ${ }^{81}$ Caveamus ergo, ne mundanis 15 delusi illecebris involvamur simul cum delusoribus et hypocritis, sed vigilemus potius solidi fide, ut possimus stare ante dominum.

10 Maxime vero illos, qui carnem sequentes in concupiscentia pollutionis ambulant ac dominationem contemnunt; audaces, praefracti, qui gloria praecellentes non verentur convitiis incessere, 11 cum ipsi angeli, qui sunt robore et virtute maiores, non ferunt adversus sese apud dominum maledicum iudicium.

Redit nunc ad descriptionem pseudoprophetarum. Deflectit autem oratione in criminationem. Miro enim fervore persequitur illos. Hic duo illis impingit: immundiciam sive scortationem et contemptum sancti magistratus. Caeterum ora- 25 tionem pulchre sibi nectit. Dixerat de Sodomitarum libidinosa et nepharia conversatione, quam tandem igne et sulphure exciderit dominus; ${ }^{82}$ commodum ergo nunc ingerit: »Puniet itaque et illos potissimum, qui nihil quam carnis voluptates sequentes in concupiscentia pollutionis ambulant«, hoc est: »qui sese foedis libidinibus oblectant, imo to|tos sese hoc coeno immergunt et conspurcant.« 30 103v $G$ Atque hic, nisi castis parcerem auribus, annotarem, quid nobis vota pepererint monastica et fictus ille sacerdotum coelibatus. Verum ipsa res clamitat ipsaque testantur saecula nostra, quod ab apostolicis istis, si diis placet, viris, totum illud fit, quod Petrus praedixerat futurum. Nam ab istis sacrosanctum damnatur matrimonium, scortatio vero et omnis generis libido et immunditia defenditur. Eos 35

Z. (24) immundiciam] immunditiam $Z G$ - (24-25) Marg. nephanda] nefanda $Z G$

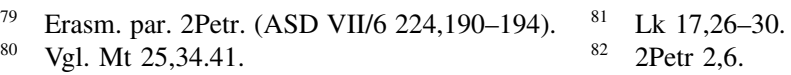


enim diris excruciant tormentis, qui, ne foedius urantur, coniugio se dedunt; at istos, qui, quod noverunt, praestare non possunt et impudentius quam canes per omnia libidinis, adulterii, stuprorum et scortationis genera grassantur, in deliciis fovent, honoribus augent et ex ecclesiasticis bonis lautissime nutriunt, ut nunc 5 hic, si uspiam, exclamare liceat: $\mathrm{O}$ tempora, o mores! ${ }^{83}$ Posterius, quod in illis accusat, est contemptus magistratus. »Isti «, ait, »non modo impuri sunt, sed etiam audaces et $\alpha \cup ̛ \vartheta o ́ \delta \delta \varepsilon ı \varsigma$, praefracti et intractabiles. ${ }^{84}$ Nam authoritate publica prae- Dominationem ditos non modo contemnunt, sed et convitiis incessunt. Id vitii iam per collaticontemnunt. onem amplificat. Angeli, qui hominibus multo fortiores et maiores sunt, cum nuntiorum vice funguntur, coram deo magistratui non impingunt maledicum iudicium, id est crimen audacius; at hi tantam sibi authoritatem, imo impudentiam sumunt, ut vel opti|mos principes execrentur, excommunicent di|risque devoveant. Sunt qui de malis exponant angelis. ${ }^{85}$ Iam vero quid cum optimis principibus egerint pontifices Roma[ni], testantur historiae; rursus quomodo asseclae istius sese sanctis principum edictis, legibus et ordinationi civili subduxerint, quomodo blasphement vel hodie totam magistratus institutionem, testantur decretales, bullae et quotidianae experientiae. ${ }^{86}$ Porro nihil peccant, qui principibus malis peccata, socordiam, venale iudicium, luxum, neglectum iustitiae et contemptum legum opprobrant; hoc enim factitarunt et prophetae, fecit hoc ipsum et Baptis20 ta. ${ }^{87}$ Sed peccant, qui vel magistratus functionem ut impiam damnant, id quod catabaptistae verissimi pseudoprophetae solent, ${ }^{88}$ et qui magistratus legibus aequis non obtemperant, iis sese eximunt easque contemnunt, id quod pontificii omnes pene faciunt.

12 At isti veluti bruta animantia, natura genita in capturam et in perniciem, in his, quae non intelligunt, maledicentes in perditione sua peribunt, 13 reportantes mercedem iniustitiae,

Alii referunt ad superiora, ut haec illa absolvant. Paraphrastes enim: »At isti spiritibus «, inquit, »impiis sceleratiores, ceu bruta pecora nata in hoc ipsum, ut capiantur et perdantur, cum non vereantur praefectis suis obtrectare ac maledicere, ignorantes interim il|lud ipsum, cuius gratia de illis maledicunt. Quemadmodum corruptis suis moribus accersunt sibi perniciem, ita pecudum ritu peri-

Z. (10) nuntiorum] nunciorum $Z G$ - (14) Roma[ni]] Romani $Z G$ - (15) edictis] aedictis $G$

83 Vgl. Cic. Catil. 1,1 (MacDonald 32).

84 Erasm. 2Petr. (ASD VI/10 504,211): »Agit enim Petrus de praefractis et intractabilibus.«

85 Erasm. par. 2Petr. (ASD VII/6 224,201f.): »Cum angeli longe praestantes viribus ac robore, licet alias impii [...].«
86 Vgl. Luth. 2Petr. 137r.

Mt 14,4 parr.

88 Vgl. Bull. adv. cat. 99v-100r. 
bunt, percipientes impiae vitae dignam mercedem. $\ll^{89}$ Caeterum videri poterat novi criminis nova esse accusatio, ut crudelitatem istorum, quam exercent in pios, notarit. Leonibus enim, pantheris et lupis natura ad rapiendum et saeviendum pronis illos comparavit. Nesciunt bruta, cur saeviant in prostratos, iram et appetitum sequuntur magistros. Nesciunt et tyranni nostri, cur nos persequantur. Nam quod doctrinam veritatis calumniantur et hanc in culpa esse aiunt, imprudenter agunt. Nam illam nunquam intellexerunt. Proinde et sanctos dei ita persequuntur, ut non habeant in eos ullam caussam. Verum istud quidem non facient impune. Nam ut pecudum ferarumque ritu saevierunt, ita more insanientium luporum occidentur; et ut iniustitiae studuerunt, ita iniustitiae mercedem, interi- 10 tum videlicet aeternum, recipient. Ita videmus Petrum ubique supplicia intentare prophanis.

13 pro voluptate ducentes, si in diem deliciis fruantur, labes ac maculae, qui convivantes in erroribus suis insultant vobis, 14 oculos habentes plenos adulterae.

Luxus vitae. Luxum vitae notat. »Isti«, inquit, »sibi videntur lumina esse ecclesiae, sed revera

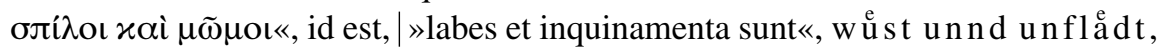
quorum merito puderet pigeretque ecclesia. Caussa: existimant suavem ac magnificam vereque beatam esse vitam, si prorsus exuto omni pudore foedis voluptatibus indies indulgeant. Erroribus autem et imposturis acquirunt ac lucrantur 20 hoc, quod tam turpiter absumunt. Petrus ergo: »Convivantes«, ait, »in erroribus suis.« Nec hoc solum, verum etiam summe alias miseris insultant petulantius velut insanis, qui praesentis vitae commodis non fruantur. Et cum nunquam non madeant vino et crapula distenti sint, libidine quoque foeda ardent. Quocirca Petrus subdit: »Oculos habentes plenos adulterae «, id quod multo vividius est, 25 quam si dixisset: »Libidinosi sunt «. Nunc enim comparavit illos adulterae mulieri procaci et lascivienti, proinde lascivos et prorsus impudentes illos fore significavit. ${ }^{90}$ Atque hisce quidem tam affabre et tam scite molliculam istam praelatorum nostrorum et procerum ecclesiasticorum turbam delineavit, ut non videatur vaticinium texuisse, sed rem gestam descripsisse. Isti enim ventrem pro deo 30 colunt, in deliciis agunt, hypocrisi et superstitione lucrantur, quod abliguriant, seductis insultant. Quis enim nescit, quod pecuniis per religionem falsam e nobis emunctis nos indies oppugnant? Quis denique nescit, quod Romanenses miseros Germanos ut beluas et stupidi inge|nii homines contemnunt? Dum enim aliquid sperant se accepturos, clamant: »German, bon christian!«; at ubi peram evacuaris, 35 grandis fies bestia. De libidine, stupris et adulteriis istorum satius est nihil dicere, 
quam | pias aures offendere. Breviter caret fere exemplo, quod istis hac in re videtur esse leviculum et parvi momenti.

14 Et qui a peccando cessare nesciant, inescantes animas instabiles, cor habentes exercitatum rapinis, execrabiles filii, 15 qui relicta recta via aberraverunt, sequuti viam Balaam filii Bosor, qui mercedem iniquitatis dilexit, 16 sed redargutus fuit de sua iniquitate. Animal subiugale mutum, humana voce loquens prohibuit prophetae dementiam.

In his primo accusat mentem in istis poenitere nesciam adeoque et in peccatis induratam. Deinde damnat in illis hoc potissimum, quod non satis habebant, quod 10 ipsi essent mali, nisi et alios, si qui essent paulo leviores, in consortium luxuriae pertraxissent. Id vero flagitii in sacris passim damnatur gravissime et nostris illis tam est peculiare, ut paucos habeant amicos, quos non ista ratione sibi astrin-

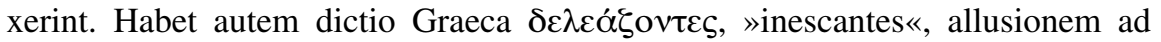
aucupes, qui illecebris quibusdam in rete pelliciunt aves. ${ }^{91}$ Sic enim isti conviviis, munusculis et $\mid$ compotationibus quorundam hominum fidem sibi astringunt. Hinc Fraus. avaritiam et rapinam istorum execratur. Non enim simpliciter dicit: »Avari ac rapaces sunt «, sed: »Cor habent exercitatum (durchriben) rapinis et imposturis.« Iam et illud accusat, quod quaestus gratia quidvis facturi sint et pro muneribus quidlibet dicturi. Id iterum auget adiecto e sacris exemplo Balaam, qui, ut extat Numeri vigesimosecundo capite, ob lucrum iis maledicebat, quos benedixerat deus. ${ }^{92}$ Id cum nostri quoque soleant, multo rectius se Balaam Iesi et Simonis Magi $^{93}$ successores iactarent quam apostolorum vicarios. Atque hic iterum miscet criminationi poenam pro more. Quemadmodum enim dementiam avari et corrupti prophetae olim corripuit asina, ${ }^{94}$ ita nunc plebei et prorsus contempti homines successorum Balaam protrahunt imposturam. Merito autem talis patella tali contegitur operculo. ${ }^{95}$ Proinde nemo posthac glorietur in errore. Deus enim vel de ipsis potest excitare lapidibus, ${ }^{96}$ qui errorem, impietatem et impudentiam vestram protrahant, convincant et conculcent! »Verbum domini manet in aeternum « [Jes 40,8; 1Petr 1,25].

Z. (28) domini] domni $G$

91 Erasm. 2Petr. (ASD VI/10 508,272): » $\Delta \varepsilon \lambda \varepsilon-$

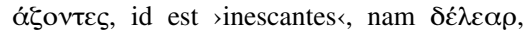
>еscar.«

92 Num 22,6f.

93 Apg 8,18-23.

94 Num 22,28-30.

95 Vgl. Hier. epist. 7,5 (CSEL LIV 29,22-30,2):
»Accessit huic patellae iuxta tritum populi sermone prouerbium dignum operculum, lupicinus sacerdos «; Erasm. adag. 972 (ASD II/2 468-470,104f.): »Significat autem episcopum ad improbos populi mores accomodatum.«

96 Vgl. Mt 3,9; Lk 3,8. 
17 Isti sunt fontes aqua carentes, nebulae, quae a procella feruntur, quibus caligo tenebrarum in aeternum servata est.

Vana doctrina. Recte comparantur falsi doctores fontibus caren|tibus aqua et nebulis huc atque 106v $G$ illuc vento impulsis. Nam ad fontes recreantur sitientes. Nebulae autem sitienti terrae pluvii spem faciunt. Ita doctores in hoc instituti sunt, ut anxias conscientias verbo veritatis consolentur et pluvia doctrinae salubris irrigent corda mortalium. Verum, cum hi doctores novi evangelica consolatione neglecta novos quosdam confinxerint condonationis modos, id apud eos invenient sitientes, quod apud fontem aqua carentem invenias, lutum et sordes. Dereliquerunt enim Christum fontem aquae vivae et foderunt sibi cisternas, quae aquas non retinent salutares; ${ }^{97} 10$ de quibus multa dominus disseruit in evangelio Ioannis. ${ }^{98}$ Spem quidem praebebunt condonationis, non secus atque nubes quaepiam ventorum procellis iactata solet spem facere futurae pluviae. Sed ut illa ne guttulam quidem distillat, ita hi, cum coelesti verbo destituti sint, sitientis peccantisque animam vana spe lactant. Nec interim impune. Nam quemadmodum veritatis lucem tenebris involverunt 15 humanis, sic vicissim aeterna caligo ipsos aliquando excipiet apud inferos.

18 Siquidem ubi vehementer fastuosa vanitatis verba sonuerint, inescant homines per concupiscentias carnis voluptatibus, eos, qui vere aufugerant, eos, qui in errore | conversantur, 19 dum illis libertatem pollicentur, cum ipsi servi sint corruptionis. Siquidem a quo quis superatus est, huic etiam in servitutem est addictus.

Hisce verbis exponit superiorem parabolam, quod impostores isti miseris multa polliceantur, nihil autem praestent, imo magnificis pollicitationibus ceu illecebris quibusdam in | peccata rapiant. »Pollicentur«, ait, »peccatoribus libertatem «, id est peccatorum condonationem, »quam interim ipsi non habent, cum fide in 25 Christum careant et servi sint corruptionis. « Hic appendit sententiam generalem: »A quo quis superatus est cuiusque arbitrio vivit, huic iure servus dicitur.« Eam forsan mutuavit ex octavo capite Ioannis. ${ }^{99}$ Breviter: »Caeci sunt «, inquit, »caecis ergo si viam ostendant, utrique cadunt in foveam. « ${ }^{100}$ Illud vero gravius est, quod pollicitationibus suis non modo vana spe illudunt miseris, sed et maioris mali occasio sunt. Eos enim, qui semel aufugerant scelerum turbam, pollicitationibus istis suis revocant, ut postea confidentius in flagitiosorum via ingrediantur freti indulgentiis illorum. Equidem nostrum illud saeculum non nescivit largitiones, bella, venale iudicium, usuram, adulterium, furtum, homicidia, invidiam, ambi-

Z. (28) octavo] 8. ZG

97 Jes 2,13.

98 Joh 4,14.
99 Joh 8,34-36.

100 Vgl. Mt 15,14. 
tionem, luxum | esse peccata mortifera nec illa posse nisi sancta poenitentia et sanguine Christi expiari. In hac si constanter perrexisset, aufugerat perditionem, sed voluptas et concupiscentia carnis remorabatur. Huic suppetias ferebant largae pontificum indulgentiae, quas cum miseri viderent tam esse largas, in eodem luto

5 et errore confidentius haerebant. Videbant parva pecunia iustos etiam condonationum acervos posse parari. Mirandum vero, qua fronte Romani pontifices sub nomine apostolorum Petri et Pauli istas indulgentiarum nundinas coeperint instituere, cum divus Petrus hac epistola nobis tam amice suaserit cavendum esse $\mathrm{ab}$ istis impudentibus mercatoribus. Quo simul et fidem suam liberavit. Nam si 10 quis posthac istorum credit confictis vaframentis, persuasus, quod Petri authoritate ista faciant, sua culpa sciens et volens perit.

20 Nam si, postquam refugerunt ab inquinamentis mundi per agnitionem domini et servatoris Iesu Christi, tamen his rursum involuti superantur, facta sunt illis postrema peiora primis. 21 Satius enim fuisset illis non cognovisse viam iustitiae, quam, ubi cognoverunt, converti ab eo, quod illis traditum fuit, sancto praecepto. 22 Verum accidit illis id, quod vero proverbio dici | solet: canis reversus ad suum ipsius vomitum, et: sus lota reversa ad volutabrum coeni.

Non negat hisce verbis poenitentiam lapsis, quod multis Novatianica tamen labe infectis visum fuit, ${ }^{101}$ sed principio hisce exponit superiora ostendens, quam graviter peccent seductores et seducti; deinde gravi oratione deterret a consuetudine peccandi et continuo scelerum studio. Huc enim orationis ductu delapsus est, ut ad studium puritatis adhortetur, occasione accepta ab iis, qui a seductoribus in peccata pristina revocati impudenter in iis pergunt. Primum argumentum sumpsit ex historia evangelica, Matth[aei] cap[ite] 12. et Lucae 11. Quibus locis pulcherrima parabola adumbratur, quam periculosum sit post veritatem agnitam pristinis indies sordibus commaculari adeoque ad semel abnegatam impietatem redire. ${ }^{102}$ Secundum argumentum collationem habet. »Praestiterat illis«, ait, »omnino non novisse doctrinam evangelii, quam post agnitam veritatem, quae docet 30 deum fide delectari et sanctimonia, in impuritate per omnia libidinis et intemperantiae genera grassari. ${ }^{103}$ Tertio loco subiungit duplicem sententiam sive paroemiam. Utranque sumpsit ab immundissimis animantibus cane et sue. Canes

\section{Z. (25) Matth[aei]] Matthaei $Z G$}

101 Siehe oben S. 10, Anm. 39.

102 Mt 12,43-45; Lk 11,24-26.

103 Vgl. Erasm. par. 2Petr. (ASD VII/6 226,254257): »Praestiterat illis omnino non nouisse

doctrinam euangelicam, quae docet innocentiam ac puritatem, quam post cognitam et acceptam desciscere a sancto praecepto quod illis semel traditum fuit.« 
resorbent, quod evomuerunt, id quod et Solomon citavit Proverb[iorum] 28. ${ }^{104}$ Sues ab amne protinus recurrunt ad $\mid$ coenum. Ita et illi solent, qui post sanctam evangelii doctrinam redeunt ad porcinam vitam. Plura de hoc diverbio Eras[mus] Chil[iadis] 3. cent[uriae] 5. adag[io] 13. ${ }^{105}$ Quod si cui videatur hic locus Petri de peccato in spiritum sanctum esse exponendus, non magnopere reclamarim, quod et argumenti genus hanc expositionem admittat et certae videantur verbis inesse notae, quae istum prope sensum indicent atque evincant. Certe multam inter se affinitatem habent pseudoprophetae et peccatum in spiritum sanctum. Sed de his iudicent lectores.

CAP. III.
1 Hasce iam alteras vobis, charissimi, scribo literas, quibus extimulo per commonitionem vestram synceram mentem, 2 ut memores sitis ver|borum, quae praedicta sunt a sanctis prophetis, et mandati nostri, qui sumus apostoli domini et servatoris; Iam vero canit receptui ${ }^{106}$ colligens, in quem finem haec de falsis doctoribus obiter, unde haec acceperit, quo plus fidei apud nos haberent. Ex prophetis enim et verbis Iesu salvatoris nostri pleraque decerpta sunt. Nam hi de venturis pseudoprophetis et temporibus extremis multa vaticinarunt. Petrus itaque: »Scio«, ait, »quam synceri et alieni sitis ab omni doctrina et fide falsa, sed volo interim, ut posthac memores sitis verborum domini Iesu, prophe|tarum et apostolorum, qui- 20 bus praemuniti in recepta veritate possitis perseverare, ne uspiam pseudoprophetarum (quos illi venturos, sed cavendos monuerunt) blandiloquentia animi vestri corrumpantur.« Hisce vero sibi commodum ad sequentia transitum struxit. Nunc enim de impiis postremi saeculi moribus scribit, ut monuimus in argumento epistolae. ${ }^{107}$ Habet enim haec caussa affinitatem cum ea, quam de pseudopro- 25 phetis tractavit. Caeterum hic non putavi necessarium esse copiosius ex propheticis et evangelistarum literis disserere aut ostendere, ex quibus prophetis quibusve e locis singula decerpserit Petrus. Nam commentarii nobis plus aequo excrescerent. Certe Daniel et Zacharias maxime in hoc argumento prae caeteris versati sunt. ${ }^{108}$ Nostrum fuerit eorum probe meminisse, quae isti nobis bona fide 30 tradiderunt et quorum summarium quodpiam in praesentiarum contexuit Petrus.

\footnotetext{
Z. (1) Proverb[iorum]] Proverbiorum $Z G$ - (3-4) Eras[mus] Chil[iadis]] Erasmus Chiliad[is] ZG

104 Spr 26[!],11.

105 Erasm. adag. 2413 (ASD II/5 302,352-362).

106 Erasm. adag. 2488 (ASD II/5 340,288): » Receptui canere $<$ pro finire. «
}

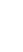


3 illud primum scientes, venturos in extremis diebus illusores, qui iuxta proprias concupiscentias ambulent 4 et dicant: ubi est pollicitatio adventus eius? Siquidem ex quo die patres dormierunt omnia, sic permanent, ut ab initio conditionis erant.

5 Diligenter describit, quales impii illi postremi saeculi futuri sint et qualia eorum consilia, quales ser|mones. Principio »illusores« vocat, non tam quod illis verbum domini merus videatur lusus, quam quod instructi sunt praestigiis et imposturis, quibus fallunt incautiores ${ }^{109}$ et non omni parte adhaerentes verbo domini. Hebraei eiusmodi genus hominum לצים appellant. ${ }^{110}$ Deinde »iuxta proprias«, ait, »concupiscentias ambulant «. Id quod ex priori enascitur. Quibus enim verbum domini et res divinae lusus sunt, iis et voluptas pro vita et libido pro ratione est. Ut enim pro animi sui turpissimi cupiditatibus turpiter vivunt, gulam sectantur et genio duntaxat indulgent, ita etiam pro libidine sua docent et dicunt, quod congruit prostitutae vitae et moribus turpissimis. ${ }^{111}$ Iam ergo, quid dicturi sint, per mimesim indicat: »Ubi«, inquiunt, »est pollicitatio adventus eius? « Nasum vero habet oratio omni parte audax et confidens. ${ }^{112}$ Abnegat enim et deum et iustitiam eius et mortuorum resurrectionem et divinum praemium, idque summo cum contemptu et risu. Qui enim iudicium abnegat, is et mortuorum resurrectionem et divinum praemium abnegat adeoque deum ipsum. Si enim deus est, iustus est. At iniustus esset, si non esset futurum iudicium et praemium tam piis quam impiis pro ratione operum, fidei et perfidiae cuilibet paratum. Additur et aliud per eandem mimesim, quo impie satis impiam prodant mentem: »Mortui«, inquiunt, »sunt patres nostri nec quisquam interim | illorum revixit aut rediit a mortuis, qui nuntiaret aliam praeter hanc superesse vitam, nec quicquam in orbe a constitu25 tione eius ad hunc usque diem innovatum est, eadem semper orbis facies, iidem semper nascentium et morientium vices; proinde, cum haec ita habeant, cur expectarem vel iudicium ullum vel ullam mortuorum resurrectionem? Age, vivamus hic, dum vivere conceditur! Istae quidem pfafforum ${ }^{113}$ minae sunt et terriculamenta, quibus nos vel decipere, vel tyrannidi suae nituntur subiugare.

30 Deus non curat nos, nec ullum nobis facessit negotium; >edamus ergo et bibamus, Ierem. 44[,17]. cras enim moriemur< [Jes 22,13; 1Kor 15,32].« Tales sunt et nostrorum quorun-

\section{Z. (24) nuntiaret] nunciaret $Z G$}

109 Erasm. par. 2Petr. (ASD VII/6 227,271f.): $»[\ldots]$ illusores instructos praestigiis et imposturis quibus fallant incautos.«

110 Vgl. Ps 1,1.

111 Erasm. par. 2Petr. (ASD VII/6 227,273f.): $»[\ldots]$ vt viuent pro cupiditatibus animi sui, ita etiam pro libidine sua docebunt quae tali vitae congruent.«
De illusoribus temporis. (

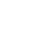

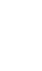


dam porcorum verius quam hominum blasphemae voces: »Quid nobis indies de fide, sanctimonia, iudicio, immortalitate inveteratam occinitis cantilenam? Iam olim istorum nos piguit: age, de voluptatibus, poculis et lepidis puellis disseramus. Quid enim | auspicati nobis invexit illa nupera religio? Olim, dum scortaremur, potaremus et principum sectaremur stipendia, ad votum succedebant omnia; at nunc, cum isti obstreperi graculi nobis quaedam de spernendo mundo, de amplectenda fide evangelica intonant, adversa habemus omnia. Praestat igitur novam istam doctrinam de evangelio contemnere et pristinum vitae institutum sectari et laetari.« Sed quid ad ista respondet Petrus?

5 Illud vero volentes nesciunt, quod coeli $\mid$ iam olim fuerint ac terra ex aqua et per aquam consistentes dei sermone, 6 per quae is, qui tum erat, mundus aqua inundatus periit. 7 At nunc qui sunt coeli et terra, eiusdem sermone repositi sunt et servantur igni in diem iudicii et perditionis impiorum hominum.

»Illi«, ait, »dicunt se nescire ullam rerum mutationem, res hominum eodem 15 semper loco eademque fortuna constitisse, sed illud interim nesciunt, imo nescire volunt, quod totus fatetur orbis: illud nempe, quod idem ille deus semel diluvio in orbem misso totum abolevit, maxime quod tum quoque impii essent, qui iudicium dei contemnerent et prorsus illud ipsum facerent, quod hic de illusoribus audivimus.« Ex eo autem facile licet colligere, quod divina iustitia non omnibus 20 dormierit semper, sed de omnium saeculorum impiis semper sumpserit supplicium. Huic iam pulchre nectit propositionem instituti sui: deum iudicaturum pios et impios ipsumque saeculum per ignem. Olim aqua immissa terram purgavit a sordibus. Coeli hactenus perseverarunt, sed et ipsi ad extremum diem purgabuntur igne, »cum per ignem perdentur impii, sicut olim perierunt per aquam «. ${ }^{114} 25$ Videntur autem haec sumpta esse ex Isaiae capite $66 .{ }^{115}$ Porro quod in priori membro terrae meminit, quod illa ex aqua et $\mid$ per aquam sermone dei sive virtute divina consistat, allusit ad 1. cap[ut] Gene[seos], ubi legimus, quod aquae terram ex parte nudarint, quam prius contexerant, magna simul aquarum vi in sublimi pendente. ${ }^{116}$

8 Unum autem hoc ne lateat vos, dilecti, quod unus dies apud dominum perinde est ut mille anni et mille anni ut dies unus. 9 Haud tardat dominus, qui promisit, quemadmodum nonnulli tarditatem existimant;

Z. (19) illusoribus] illusioribus $G$

114 Erasm. par. 2Petr. (ASD VII/6 228,292f.): 115 Jes 66,15f. $»[\ldots]$ per ignem perdentur impii quemadmo- ${ }^{116}$ Gen 1,9f. dum olim per aquam perierunt.« 
verum patiens est erga nos, dum non vult ullos perdere, sed omnes ad poenitentiam recipere.

Dicat iam aliquis: »Quando vero veniet?« Diu iam expectata est illa iudicii dies. De tempore Hunc et prophetae priores minati sunt peccatoribus. Respondet Petrus: cum semel vindictae. 5 constet diem illum certo venturum, non refert admodum, serius an maturius veniat. Rectissime enim loquitur paraphrastes: »Nobis pro animo nostro quaedam longa videntur, quaedam brevia. At deo nihil est neque breve neque longum. In suis promissis non sequitur cupiditatem nostram, sed suum aeternum et immutabile consilium. ${ }^{117}$ Utitur autem sententia Mosis, quae extat in Psalmo octuagesimonono, quae mire huc quadrat; est autem huiusmodi: »Tu, domine, redigis hominem in pulverem, et contra $\mid$ dicis: >Redite in integrum, filii hominum<. Quia mille ante te sunt, sicut dies hesterna, quae praeteriit, et excubiae nocturnae. Te illos dissipante somnus fiunt ac subito sicut foenum mutantur. Foenum mane floret et crescit, vespere incisum arescit. Sic te irato consumimur et in furore tuo deturbamur « [Ps 90,3-7] etc. Ex quibus verbis facile colligere licet, quod non tam in hoc produxerit istud testimonium Petrus, ut expectationem leniret et taedium morae discuteret piis, quam ut praesentissimam impiis poenam impendere ostenderet. Quod ergo iudicii diem procrastinat dominus, quod poenam differt diutius, nemo ita interpretetur (inquit Petrus) quasi ipse dominus nunquam sit vel iudicaturus orbem vel puniturus impios; sed propterea spacium praescribit longius, ut peccatores invitet ad poenitentiam. Unde et Paulus ad Roma[nos] 2.: »Cur divitias bonitatis et lenitatis dei contemnis ignorans, quod longanimitas dei te invitat ad poenitentiam?« [Röm 2,4] Haec, obsecro, expendamus diligentius, o fratres, ne uspiam per impatientiam murmuremus contra dominum aut impingamus. Si tardior videbitur|vindex nostri dominus, si benignior et lenior erga hostes nostros, meminerimus, quod deus non modo deus ultor, sed et deus longanimis sit, qui neminem temere opprimit, sed cuilibet spacium poenitendi concedit. Iam si ille hostis noster poeniteat, condonanda illi noxa ut alias et gaudendum nobis propter $\mid$ ovem restitutam. Porro si ille lenitate dei abutitur, certus sis, quod divina vindicta tarditatem supplicii gravitate compensabit. Certissimum enim illud Germanum proverbium: lang gbeittet ${ }^{118}$ ist nit $\mathrm{gschenckt}$.

Z. (7) deo] de $G Z G$ - (9-10) octuagesimonono] 89. ZG - (20) spacium] spatium $Z G$ - (21) Roma[nos]] Romanos $Z G$ - (27) spacium] spatium $Z G$ - (31) gbeittet] gebeittet $Z G$

117 Erasm. par. 2Petr. (ASD VII/6 228,296-298). $\quad 118$ »Beite ${ }^{\mathrm{n}} \lll=$ warten, vgl. SI IV 1846-1850. 
'PoıŁ̄óóv, sonore et magno cum impetu.

10 Veniet autem dies domini sicut fur in nocte, quo coeli procellae in morem $^{119}$ transibunt, elementa vero prae aestu solventur terraque et, quae in ea sunt, opera exurentur.

Planis iam, sed horrendis verbis describit futuram iudicii diem. »Inexpectatus «, ait, »aderit dies illa.«»Dum enim dixerint: >Pax et securitas<, repentinus illis incumbet interitus « [1Thess 5,3] nec aliter obrepet illa dies mortalibus, quam fur

Tale et illud: »Stellae de coelo cadent « [Mt 24,29] nocturnus obrepit dormientibus. Id quod et Christus praedixit futurum Matthaei vigesimoquarto ${ }^{120}$ et Paulus prima ad Thessalonicens[es], quinto. Iam, quae sequuntur, hypotyposis sunt futurae diei et declarant nobis hyperbola quadam adeoque et prosopopoeia, quanto terrore consternendi et quam diris suppliciis 10 impii sint afficiendi. Quod si quis simplicissime iuxta literam interpretetur, id quod magis mihi probatur, habet Augustinum virum in scripturis sacris maximum de hoc loco doctissime disputantem lib[ro] de civit[ate] dei 20., cap[ite] $18 .{ }^{121} \mathrm{Et}$ hactenus quidem probavit deum iudicaturum orbem et puniturum impios adversus impiam illusorum opinionem.

11 Cum igitur haec omnia solvantur, qua|les oportet esse vos in sanctis conversationibus et pietatibus, expectantes 12 et accelerantes ad adventum diei dei, per quem coeli incensi solventur et elementa aestuantia liquescent? 13 Sed coelos novos ac terram novam iuxta promissum illius expectamus, in quibus iustitia inhabitat.

Sanctimonia. Deflexu quodam defertur ad innocentiam, ad quam elegantibus argumentis hortatur, ut tandem in optatum feratur portum. Primum desumptum est ex re praesenti et aptatum per collationem. »Si«, inquit, »elementa per ignem expurganda sunt, quae tamen nihil peccarunt, quantopere nobis annitendum, ut puri vitaeque innocentia praeclari inveniamur in die illo? « ${ }^{122}$ Atque hoc quidem ipse beatorum 25 locus flagitat: novi enim coeli parantur iustis; iustitiae ergo studendum iis, qui novi coeli velint esse incolae. De coelo hoc novo et terra nova legere est apud Isaiam in 65. et Augustinum lib[ro] de civit[ate] 20., cap[ite] $16 .{ }^{123}$ Iustitiam per heterosim ${ }^{124}$ posuit pro iustis.

Z. (8) vigesimoquarto] 24. $Z G-(8)$ Thessalonicens[es], quinto] Thessalon[icenses] 5. ZG - (13) lib[ro] ... civit[ate]] libro de civitate $Z G$ - (28) lib[ro] ... civit[ate]] libro de civitate $Z G$

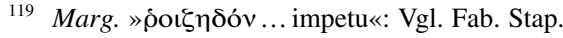

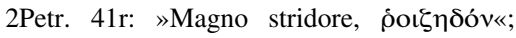
Erasm. par. 2Petr. (ASD VII/6 228,310): »[...] coeli magno impetu transituri sint $[\ldots] . \ll$

${ }_{120}$ Mt 24,43f.

121 Aug. civ. 20,18 (CCSL XLVIII 729f.).

122 Vgl. Erasm. par. 2Petr. (ASD VII/6 228,314316): »Quod si tunc oportet vsque adeo omnia esse pura vt haec etiam dissoluenda sint quae non peccant, quantopere vobis adnitendum est vt dies ille vos omni vitae sanctimonia, omnibus pietatis studiis integros ac purgatos reperiat?

123 Jes 65,17-25; Aug. civ. 20,16 (CCSL XLVIII 726f.). 
14 Quapropter, dilecti, haec expectantes, date operam, ut immaculati et incontaminati ab illo reperiamini in pace 15 dominique nostri patientiam salutem arbitremini, quemadmodum et dilectus frater noster Paulus iuxta sibi datam sapientiam scripsit vo|bis; 16 etiam in omnibus fere epistolis loquens de his, inter quae sunt nonnulla difficilia intellectu, quae indocti parumque firmi detorquent, sicut et caeteras scripturas, ad suam ipsorum perniciem.

Illatio est ad superiora. Est enim sensus: »Cum ergo rem expectetis tantam, praestat, ut iudicium hoc tam rigidum semper prae oculis habentes ita posthac 10 vivatis, ut veniens dominus inveniat vos paratos. Quod, si tardius venerit, nihil aliud cogitate, quam quod mora trahatur propter peccatores, quos salvare cupit dominus. ${ }^{125}$ Atque hic Pauli simul epistolas commendat fidelibus. Tametsi enim apostolis ex aequo collatus esset spiritus sanctus, non tamen quisquam eorum alterius monimenta contempsit. Daniel ille »desideriorum vir «, ${ }^{126}$ quo non fuit 15 sapientior alter, orationes prophetarum, Ieremiae in primis, legere solebat. ${ }^{127}$ Arrogantiae ergo et superbiae spiritu aguntur, qui optimorum virorum optimos libros lectione dedignantur nec quicquam approbant, nisi quod scripserint ipsi. | Colligimus hinc quoque, quod similis et constans adeoque et una omnibus fuerit apostolis ratio praedicandi evangelii. Interim vero monet, ut epistolas Pauli legamus animo fideli ac vigilanti. Esse enim in iis difficilia quaedam, sed iis, qui in fide indocti et in religione parum sunt exercitati et firmi. Nam hi non tantum Scripturae difficiles, scripta Pauli, sed omnes alias $\mid$ scripturas detorquent ad suam ipsorum pernitiem. Id enim his usuvenit, quod araneae dulcem succum floris sugenti. Quia etenim venenata est, omne, quod imbibit, protinus vertitur in venenum noxium. ${ }^{128} \mathrm{Sic}$, cum illi mente corrupti sint, omne etiam, quod legunt, pravis affectibus depravant. Rectissime ergo monuit Hilarius ${ }^{129}$ sensum scripturis non esse inferendum, sed e scripturis petendum. ${ }^{130}$

124 Vgl. Erasm. cop. 1,13 (ASD I/6 54,546548): »Ratio variandi per enallagen sive $\dot{\varepsilon} \tau \dot{\varepsilon} \rho \omega \sigma \iota v$ [...] est, cum eadem voce modice deflexa varietatis nonnihil conciliatur.«

125 Vgl. Erasm. par. 2Petr. (ASD VII/6 229f.,323329): »Quapropter, fratres charissimi, iudicium hoc tam rigidum semper prae oculis habentes, date operam vt Dominus adueniens vos reperiat puros et inculpatos [...]. Et si forte dies ille serius aduenerit, nolite sic interpretari quasi venturus non sit, sed hanc Domini lenitatem, qua facit omnibus spacium ad poenitentiam, existimate consulere saluti hominum.«

126 Dan 9,23; 10,19.
127 Dan 9,2

128 Vgl. Erasm. ench. (ASD V/8 248,376f.): »[...] aranearum instar tantum si quid inest veneni exugentes aut salutarem etiam succum nobis vertentes in venenum.

129 Hilarius (4. Jh.), Bischof von Poitiers, Autor exegetischer Werke sowie eines einflussreichen Traktats »De trinitate«, vgl. TRE XV 315-320; NP V 557-559.

130 Vgl. Hil. trin. 1,18 (CCSL LXII 18f.,17-20): »Optimus enim lector est, qui dictorum intellegentiam expectet ex dictis potius quam inponat et rettulerit magis quam adtulerit, neque cogat id uideri dictis contineri quod ante lectionem praesumpserit intellegendum.«
Epistolae $\mathrm{d}[$ ivi] Pauli commendatae a Petro. 
17 Vos igitur, dilecti, posteaquam praemoniti estis, cavete, ne simul cum aliis nephariorum errore abducti excidatis a propria stabilitate, 18 sed crescite in gratia et cognitione domini nostri et servatoris Iesu Christi. Ipsi gloria et nunc et in diem aeternitatis. Amen.

Conclusio. Hac clausula totam concludit epistolam et in hac mira brevitate omnia pene 5 constringit, quaecunque fusius in tota epistola tractavit. »Abunde«, inquit, »praemoniti estis, didicistis, quae vera sit religio, didicistis, quae falsa et quod ingenium seductorum et illusorum; restat ergo, ut firmiter in coepta veritate perseveretis et ab artibus impostorum vobis caveatis diligentissime, crescatis autem in gratia et cognitione domini Iesu, cui soli gloria in aeternum. Amen.«

$\mathrm{Si}$ vero nunc praestiti, quod in operis initio pollicitus sum, ${ }^{131}$ christiane lector, gaudeo; sin minus, ve|niam mereor, ut qui tibi prodesse volui. Dandum est etiam brevitati temporis nonnihil, qua oppressus vix relegere, non iam dicam revidere et expolire licebat, quod iamiam effuderam. Sed quid multis opus? Eloquentiae non studui, simplici quadam ratione tibi sensum Petri aperire volui. Tuum igitur erit opera nostra bene uti et, quod bene et pie dictum videris, bene et pie vivendo exprimere. Beati enim pronuntiantur a Christo domino, qui audiunt verbum dei et custodiunt illud. ${ }^{132}$

Z. (2) nephariorum] nefariorum $Z G$ - (17) pronuntiantur] pronunciantur $Z G$ - (18) illud] In ZG darunter Finis. 
KOMMENTAR ZUM ERSTEN JOHANNESBRIEF 

Qui vere cupis, lector, vera ac viva Christi philosophia imbui, huc accede. Sive enim spectes illud Plauti: ${ }^{1} \gg$ Pluris est oculatus testis unus quam auriti decem ${ }^{2}{ }^{2}$ sive hoc Socratis: »Pluris est auritus testis quam oculati decem ${ }^{3},{ }^{3}$ habes hic 5 testem fidei probatissimae, dilectum Iesu discipulum Ioannem, tonitrui filium, ${ }^{4}$ qui in coena illa mystica pectori dominico admotus ${ }^{5}$ divina mysteria exactissime et plenissime hausit. A quo nobis, ita disponente dei bonitate, erudita haec et sanctissima emanavit epistola, praecipuum novi testamenti decus, in qua brevitate mirifica et absolutissima, evidentius et perspicatius de pietate christiana disseruit quam omnes alias omnium sapientissimorum hominum copiosissimi commentarii. In hanc ergo paucula haec commentatus volui eruditiores provocare, ut ipsi proferant meliora; candidatos vero et rudiores iuvare, ut expeditius in sacris agant. Quod si ipse in locis difficilioribus aberro, veniam precor. Nihil enim temere adfero, sed ita prophetare volo, ut iudicium sit apud sedentes. Ideoque meliora 1. Cor. 4[,3f.]. doctus, lubens et volens cedam. Non contemno spiritum sanctum in apostolo dicentem: »Spiritus prophetarum prophetis subiiciuntur« [1Kor 14,32]. Caeterum si sensero praeexercitamenta haec nostra piis placere lectoribus, dabo et in epistolam Pauli ad Hebraeos expositionem. ${ }^{6}$ Tu interim orabis dominum pro me ac Tigurina nostra ecclesia.

Deliberativi generis ${ }^{7}$ est epistola. Nam hortatur credentes, ut puritate vitae et status. charitate fraterna Christum exprimant. Initio autem totum Christi negotium pau- 1.

Z. (1) Ad] In ZH darüber die Überschrift In epistolam Ioannis apostoli et evangelistae canonicam commentariolus - (1) lectorem] lectorem H[einryci] Bullingeri $Z H-(10)$ hominum] homium $H-$ (19) ecclesia] ecclesia. Mense Martio anno 1532. $\mathrm{ZH}$

1 Titus Maccius Plautus (3./2. Jh. v.Chr.), römischer Komödiendichter, NP IX 1118-1123.

2 Erasm. adag. 1554 (ASD II/4 60,993-997): »Pluris est oculatus testis vnus quam auriti decem, hoc est: longe maior est habenda fides referentibus ea, quae viderint oeulis, quam iis, qui narrant ab aliis audita.« Vgl. Plaut. Truc. 489 (Lindsay [Kk8]v).

3 Erasm. adag. 1554 (ASD II/4 61,12-17): »Adagii meminit et Apuleius libro primo Floridorum, narrans quemadmodum Socrates prouerbium inuerterit: >Pluris est auritus testis quam oculati decem. [...] Sensit itaque Socrates aurium iudicium certius esse quam ocu- lorum, quod oculis non nisi corporis formam contueamur, ex oratione mentis habitum deprehendamus.« Vgl. Apul. flor. 2,6 (Helm 2,5f.).

Mk 3,17.

Joh 13,23.

6 Bullingers Kommentar zum Brief an die Hebräer erschien im August 1532, vgl. HBBibl I, Nr. 38.

7 Zur deliberativen Redegattung und deren Unterschied von der judizialen und der demonstrativen vgl. Quint. inst. 2,21,23 sowie 3,4,14f. (Winterbottom I 128,6-9; 138,10-22); HLR $54 \mathrm{f}$. 
2. cis proponit. Deinde, ne quis ex redemptione Christi peccandi sibi (id quod plerique tum quoque solebant) arriperent licentiam, docet fidem in Christum congenitam sibi habere puritatem vitae, ad cuius amorem et studium vehementissime inflammat. Caeterum erant, qui currentes in via domini remorarentur haeretici et homines maligni; hos ergo fugiendos suadet ut Antichristos et an-

3. nunciatae veritati indivulse haerendum. Mox redit et iterum ad puritatem vitae animat. A qua deinde ad charitatem transit adhortans, ut hac fratribus syncere

4. serviamus et re ipsa, non verbis diligamus. Hic vero interserit quaedam de probandis spiritibus; redit ad charitatem et fidei vi fideliter excussa pulchre

5. claudit epistolam. Fidei enim in superioribus quatuor capitibus saepe meminerat, 10 unde pro more apostolico diligentius ea retractanda erat.

occasio. Hisce itaque oppugnavit et veluti ex obliquo subruit cum Hebionica ${ }^{8}$ et Cerinthiana ${ }^{9}$ phalange, pseudochristianos etiam omnes; quorum illi Christum pe|nitus abnegabant, hi vero verbis imo loquacitate futili Christum quidem referebant, vita autem cacodaemonem. Isti praeterea Ioanni ansam scribendi praebuisse videntur, 15 quanquam pia senis cura et christianae plebis amor piissimum apostoli animum proculdubio ad scribendum vel maxime impulerunt.

Usus. Epistola est nostris temporibus accommodatissima, quippe quae homines protulere, quorum alii divinitatem Christi in dubium ponunt, alii vero humanitatem ignorant et alii rursus sint, qui pietatem metiantur vel humanis commentis vel 20 ceremoniis vel suavibus et expolitis de christiana religione verbis. Isti autem omnes hac epistola discunt Christum Iesum verum esse deum et hominem; discunt Christum Iesum unicam et aeternam esse orbis salutem; discunt veram religionem consistere in fide, vitae puritate et charitate, non in loquentia, hostiis aut humanis inventis.

\section{| Argumentum capitis primi.}

Asseverat se certissima adeoque comperta proferre, nempe evangelium de Iesu Christo vero deo et homine, in quo discamus vitae innocentiam et in quo consequamur peccatorum remissam, si modo peccata confiteamur.

Z. (10) Fidei] Fdei $H$ - (14) referebant] confitebantur $Z H$ - (15) autem] autem referebant $Z H$

8 Aug. haer. 10 (CCSL XLVI 294,1f.): »Hebionitae Christum [...] tantummodo hominem dicunt."

9 Aug. haer. 8 (CCSL XLVI 294,1-5): »Cerin- thiani $[\ldots]$ dicentes $[\ldots]$ Iesum hominem tantummodo fuisse, nec resurrexisse. « Kerinthos (1./2. Jh.), judenchristlicher, in apostolischer Zeit auftretender Gnostiker, vgl. NP VI 441f. 


\section{Expositio.}

CAP[UT] I.

\section{Quod erat ab initio,}

Hic est mos Ioannis evangelistae, ut fere absque omni verborum ambage sua mox ab ipso auspicetur deo, ut qui sit omnium rerum initium, conservatio et finis. Magnam ista gratiam habent, sed et speciem quandam exordii. Nam veluti benevolentiam ambiens, dicit se nihil novi allaturum, sed id, quod fuerit ab initio, neque dubii quicquam, sed negocium longe compertissimum, laetum, inquam, evangelii nuncium. Idem porro agit in exordio huius epistolae, quod egit in sui evangelii principio. ${ }^{10}$ Nam ostendit Christum Iesum verum esse deum et totius orbis salutem unicam. Et Christum quidem dominum sine nomine insinuat, quod hominibus divina natura sit ineffabilis nomineque careat. Periphrasi autem usus

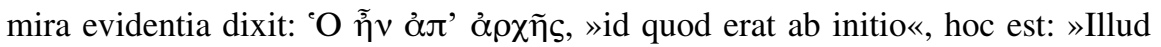
omnium rerum principium et aeternum illud bonum dei filium annun|ciamus 15 vobis.« Longo enim intervallo repetendus sensus, quem obscurum conturbat hyperbaton. ${ }^{11}$ Iam quod in evangelio suo »verbum « dixit, idem hoc loco »quod Ioan. 1[,1]. erat ab initio« nominavit. Et verbi quidem significatio augusta est apud Hebraeos. ${ }^{12} \mathrm{Hi}$ enim vocant דבר quodvis negocium, rem et caussam quamlibet et propemodum id, quod Germanus infinitam rem expositurus das ding adpellitat.

20 Ita hunc locum significantius fortassis redderet Germanus: den handel, radt, anschlag und das ding, das von anfang was. Initium vero sive principium longe alia ratione hic inducitur quam apud Mosen in primo. ${ }^{13}$ Ibi enim principium veluti ordinis est, quasi tu dicas: »Primo quidem creavit deus coelum et terram, deinde vero digessit singula.«Quem sane sensum vides spectare ad 25 sequentia sive relationem (ut aiunt) habere non ad superiorem aeternitatem, sed consequentem creationis ordinem. ${ }^{14}$ Id quod et Hebraica innuere videntur, quibus

Z. (1) Expositio] om. $Z H$ - (2) Cap[ut] I.] in marg. $Z H$ - (8) negocium] negotium $Z H$ - (9) porro] vero $\mathrm{ZH}-(15)$ repetendus] repetendus est $\mathrm{ZH}-(18)$ negocium] negotium $\mathrm{ZH}$

10 Joh $1,1$.

11 Das »Hyperbaton« ist die Trennung zweier syntaktisch eng zusammenhängender Wörter durch ein nicht an diese Stelle gehöriges Satzglied, vgl. Quint. inst. 8,6,62-67 (Winterbottom II 475,22-476,22).

12 Vgl. Zw. am. exeg. (Z V 593,1-3): »Est autem verbi significatio amplior ac splendidior apud Hebraeos, quam rei apud Latinos.«

13 Gen 1,1 .
14 Vgl. Zw. Gen. [1,1] (Z XIII 6,26-7,6): »Principium hic non capitur ut Ioannis primo, ubi euangelista divinam generationem explicaturus filium dei certa ratione $\lambda$ ó $\gamma o v$ adpellat,

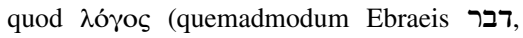
>dabar $<$ ) rem, verbum, sermonem, causam, rationem, supputationem, consilium, propositum significat, quae omnia in filium dei competunt. [...] Hic vero sin principio tantum valet, ac si diceret: ab initio, primum, principio.« 
ראש est principium, caput et cuiusvis rei exordium. ${ }^{15}$ Caeterum hic videmus principium notam esse periphrasticam infiniti et aeterni. Neque vero dissimulandum nobis, quod scripsit »erat« et non potius »fuit«, quo certe cavere voluit, ne quis putaret filium per incarnationem id esse desiisse, quod erat, priusquam Ioan. 8[,58]. nasceretur ex virgine. Unde ipse Christus significatissime in evangelio dixit:

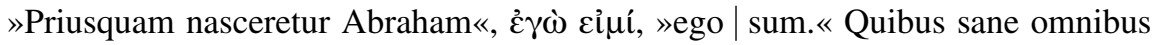

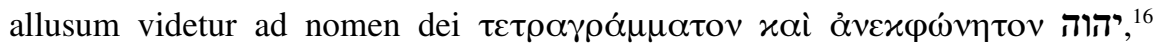
quod sacratissimum dei nomen illi non ab effectu inditum est ut »creator«, »dominus « et »omnipotens «, sed ab essentia. ${ }^{17}$ Est enim deus vita et esse omAct. 17[,28]. nium, quia »per ipsum vivimus, movemur et sumus «.

1 quod audivimus, quod vidimus oculis nostris, quod perspeximus, et manus nostrae contrectaverunt de sermone vitae;

Hisce iam notatur evangelii veritas et certitudo. Nam admiranda verborum vi ac turba auditores tenet et urget. Est enim in oratione mirum incrementum. Non satis erat, quod dixerat, »audivimus«; adiicit: »quod vidimus«; nec hoc contentus 15 subdit: »oculis nostris«, imo aliud gravius iungit: »quod perspeximus«. His denique omnibus superimponit: »et manus nostrae contrectaverunt «, quae loquutio postrema hyperbolem alias sapit, quanquam et ad resurrectionis veritatem poterat referri, quam discipulis comprobavit redivivo corpore ob oculos posito et Thomae contrectandum oblato. Porro nihil aliud istis omnibus dixit, quam quod in evangelio istis verbis expressit: »Et conspeximus gloriam eius. « Item Petrus: »Non enim arte compositas fabulas sequuti notam vobis fecimus domini nostri Iesu Christi virtutem et adventum, sed qui oculis nostris aspeximus illius maiestatem. «Sed quorsum pertinet, quod sequitur: |»de sermone vitae«? Hic demum absolvitur sententia, etsi planius paulo post claudatur, hic tamen aperitur, quod- 25 nam consilium, quae res et quod negocium fuerit ab initio; quid, inquam, viderint et audierint apostoli utique verbum vitae, hoc est Christum et salutem evangeliIoan. 1[,4]. cam, verbum et negocium $/$ vivificum. Est enim schema Hebraicum. ${ }^{18}$ In hoc enim, inquit in historia, »vita erat«. Et Paulus: Christus, inquit, »mortem quidem abolevit, vitam autem in lucem produxit et immortalitatem per evangelium«. Quin 30 audiamus ipsum sese exponentem autorem.

Z. (1) רוש [ראש $H Z$ - (18) hyperbolem] hyperbolen $Z H$ - (26) negocium] negotium $Z H$ - (28) negocium] negotium $Z H$

15 Vgl. Pagn. thes. 2251.

16 Vgl. Hier. epist. 25,3 (CSEL LIV 219,13f.): »Nonum [dei nomen] tetragrammum, quod óvยx

17 Vgl. Zw. Exod. [3,14] (Z XIII 306,35f.):
»Nam haec vox [יהוה] ab essendo deducta est.«

18 Oecol. 1Joh. 7v: »De sermone vitae, hoc est, iuxta tropum Hebraicum, [...] vere viva quaedam res.« 
2 et vita manifestata est et vidimus, ideo testamus et annunciamus vobis vitam aeternam, quae erat apud patrem et manifestata est nobis.

Epanaphora ${ }^{19}$ est iuncta ephexegesi. ${ }^{20}$ Redit enim ad sese, ut se de sermone vitae dilucidius expediat: »Vita«, inquit, »manifestata est «, hoc est, »verbum caro 5 factum est « [Joh 1,14] ipsumque evangelii mysterium orbi retectum est. »Vidimus « repetit ad maiorem evidentiam. »Etiam testamur«, xoí inferentis nota est: $»$ ideo testamur«. Sic Ioan[nis] 1.: $»$ In principio erat verbum et verbum erat apud deum et deus erat verbum« [Joh 1,1]. Nam postremum »et« concludentis est particula, non coniunctio copulativa. Servit enim duobus mediis unica illatio, ad

10 hunc modum: deus infinitus est, ab initio, id est ab aeterno, subsistens; ver|bum est a principio; ergo verbum deus. Huic servit posterius »et verbum erat apud

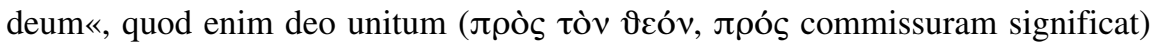
cum deo sempiternum sit oportet, adeoque deus ipse; sed verbum est apud deum; ergo verbum deus. Hoc exemplo vides »et« commode et vere poni pro illationis particula »ergo« aut simili quapiam. Sed quid, oro, testaris, apostole, qualis est ista tua contestatio? Respondit: »Annunciamus vobis vitam aeternam, id est, praedicamus vobis Christum Iesum, per quem orbi restituta est vita aeterna.« Siquidem in evangelio dixit: »Haec est autem vita aeterna, ut cognoscant te solum Ioan. 17[,3]. deum verum et, quem misisti, Iesum Christum.« Hic erat apud patrem, nam verbum erat apud deum; et manifestata est nobis, id est: »Verbum caro factum est et habitavit in nobis« [Joh 1,14]. De qua re pluribus disserit Paulus in Phil[ippensium] $2 .^{21}$

\section{Quod vidimus et audivimus, annunciamus vobis,}

Hactenus $^{22}$ quidem totus sermo suspensus fuit, nunc demum absolvitur senten- Longum 25 tia. $^{23}$ Quasi dicat: »Id, inquam, aeternum bonum, quod audivimus, vidimus et hyperbaton pervidimus, annunciamus vobis, nempe quod hominem deus induerit, quod nobiscum conversatus sit et quod vitam mortuo mundo restituerit.« Verum hoc paulo copiosius edisserit sequentibus.

5v H Hinc vero liquet, quanta sit christianae philosophiae $\mid$ authoritas, quanta mai- Christianae 30 estas, quanta rerum gestarum veritas. Nulla est scientia, nulla religio, professio ${ }_{\text {veritas. }}^{\text {religios. }}$

Z. (16) Respondit] Respondet $Z H-(21-22)$ Phil[ippensium]] Philip[pensium] $Z H$

19 Isid. orig. 1,36,9 (Lindsay I F1v): »Epanaphora est in uno versu per principia sensuum eiusdem verbi repetitio.«

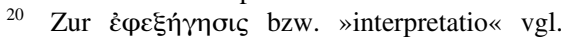
Quint. inst. 1,9,2 (Winterbottom I 58,5): »[...] mox mutatis uerbis interpretari«; HLR 530.

21 Phil 2,5-11.
22 Marg. »hyperbaton«: siehe oben S. 311, Anm. 11.

23 Erasm. 1Joh. (ASD VI/10 521,9-11): »Post hyperbaton redeat ad id quod instituerat dicere: >Quod vidimus, inquam, et audiuimus annunciamus vobis $<. »$ 
nulla, quae christianae aequari possit. Illae enim rebus nituntur dubiis, ratiocinationibus humanis, vanis stultorum et vanorum hominum testimoniis. Nostra autem undique sibi constant, quadrant et robore quodam compacta sunt, ut nemo nisi stultissimus quisque dubitarit.

Quomodo visum verbum

vitae.

Ioan. 1.

Ioan. $5[, 37]$.

Videbatur et hoc obiter monendum ista apostoli verba »quod vidimus et au- 5 divimus de verbo vitae « non pugnare cum istis locis: »Deum nemo vidit unquam« [Joh 1,18; 1Joh 4,12] et cum hoc: »Neque vocem eius unquam audistis neque speciem vidistis.« Discipuli enim non viderunt aliud quam humanitatem adsumptam, divinitatem non viderunt. Quia vero deus humanam induerat naturam, hinc dicunt se vitam vidisse, hoc est Christum incarnatum, qui iccirco vita sit fidelium, 10 quod deus. Est itaque in verbis alloeosis, ${ }^{24}$ qua consuetus ordo commutatur propter aliquam affinitatem et vicinitatem. Poterant et per hyperbolen excusari. Quid quod totus orationis status non tam ad ipsam Christi dei personam quam evangelii negocium poterat referri? Ut hic sit sensus: »Praedicamus vobis Iesum Christum dei filium, vitam et redemptorem mundi, et quaecunque de eo praedi- 15 camus, verissima scimus esse et probatissima. $\ll^{25}$

Redimus iam visuri, quis sit fructus aut quae sit ratio huius annunciationis. Sequitur itaque:

| 3 ut et vos societatem habeatis nobiscum et societas nostra sit cum patre et filio eius Iesu Christo.

Hic est fructus huius annunciationis et evangelii, quod ii, qui suscipiunt testimonium et credunt, unum sunt cum patre et filio, id est foedere deo iunguntur et consortes efficiuntur vitae aeternae. Sed age, introspiciamus singula penitius. Principio quidem »quod vidimus«, ait, »annunciamus vobis, ut et vos societatem habeatis nobiscum«. Quibus sane | verbis omnem a se purgat dominii et quaestus $77 \mathrm{ZH}$ suspicionem, quasi dicat: »Annunciamus vobis salutaria, non quod dominium cupiamus aut opes vestras ambiamus, ${ }^{26}$ sed ut vestrae consulatur saluti. Cupio enim vos esse collegas et cohaeredes illius aeterni boni.«Ut primo hoc membro nihil aliud voluerit Ioannes, quam quod in Cor[inthiis] Paul[us] istis verbis

2. Cor. 1[24]. insinuavit: »Non quod dominemur vobis nomine fidei, sed socii et adiutores 30

Z. (3) quodam] quodam divino $Z H-(26)$ suspicionem] suspitionem $Z H$

24 Unter »Alloiosis« versteht man die »Umbildung einer gebräuchlichen sprachlichen Struktur durch Einsetzung ähnlicher, aber von der syntaktischen oder semantischen Norm abweichender Formen und Ausdrücke « (HWR I 415-417).

25 Vgl. Erasm. par. 1Joh. (ASD VII/6 258,4648): »Nos autem ideo voluit esse spectatores ac testes omnium quae gessit in terris vt nostro praeconio cum fide diuulgarentur per vniuersum orbem terrarum.«

26 Vgl. Oecol. 1Joh. 8v: »Igitur non quaerimus aurum vestrum, non quaerimus vos redigere in servitutem, nolumus gravia onera vobis imponere: hoc enim non apostolorum est.« 
simus gaudii vestri.«Videntur autem metaphorae esse desumptae ab iis, qui in haereditatem aut functionem quampiam alios quoque admittunt, qua in re tantum abest, ut sua quaerant, ut magis sua aliis communicent. Et Graece est $\varkappa o เ v \omega v i ́ \alpha$, quae, etsi varia significet, hic tamen cogentibus circumstantiis aliud nihil est 5 quam communio, familiaritas, amicitia et societas. Sequitur: »Et societas nostra sit cum patre « etc. Nihil egregii dixisset superiori membro, si humanam | tantum intellexisset societatem, splendidius igitur subdit: »ut, inquam, societatem habeamus cum ipso deo. «Sic enim et alibi oravit: »Non pro eis autem rogo tantum, Ioan. 17. sed pro omnibus, qui credituri sunt per sermonem eorum in me, ut omnes unum 10 sint, sicut tu, pater, in me et ego in te, ut et ipsi in nobis unum sint « [Joh 17,20-22] et »ubi ego sum, ibi sint mecum et videant gloriam meam« [Joh 17,24] etc. Itaque societas hic quoque pro pace, concordia, consensu, amicitia et foedere sumitur, quo deo unimur non substantia, sed amicitia et participatione. De qua in Corinthiis ita scripsit apostolus: »Fidelis deus, per quem vocati estis in consor- 1. Cor. 1[,9]. tium filii ipsius Iesu Christi domini nostri.«

\section{Et haec scribimus vobis, ut gaudium vestrum sit plenum.}

Veluti clausula est ad superiora, quasi dicat: »Neque vero istis omnibus aliud specto, quam ut conquiescant conscientiae vestrae.« Fide autem paratur animi Ioan. 16[,33]. traquillitas et gaudium, externis non item. Consulatur Pauli locus ad Hebr[aeos] $9 .^{27}$

5 Et haec est annunciatio, quam audivimus ex ipso et annunciamus vobis,

Hactenus Christi negocium paucis, sed quantum instituto suo satis, perstrinxit, ostendens pro more apostolico vitam in Christo esse redditam. Nunc propius ad suum descendit institutum ac docet hac Christi vita non tra|di licentiam peccandi, 25 sed magis vitae puritatem: »Et haec«, inquit, »est annunciatio.« 'Eл $\alpha \gamma \gamma \varepsilon \lambda i ́ \alpha$ expositio est sive narratio et denunciatio, alii promissionem exposuere, ${ }^{28}$ atqui prior lectio huc magis quadrat. ${ }^{29} »$ Et haec «, ait, »est denunciatio«, das ist der antrag, die erforderung und anmůtung, quasi dicat: »Audistis qualem sese nobis deus exhibuerit, quomodo in filio restituerit peccato amissam vitam et

Z. (21) annunciatio] annuuciatio $H-(22)$ negocium] negotium $Z H$

27 Vgl. Hebr 10[!],34.

28 Oecol. 1Joh. 11v: »)Et ita est annunciatio<; malo legere >promissio<. Graece enim est $\dot{\varepsilon} \pi \alpha \gamma \gamma \varepsilon \lambda i \alpha^{\alpha}$, quod ubique interpretantur promissionem.«

29 Erasm. 1Joh. (ASD VI/10 522,32-38): »Gra- ecis est $\dot{\varepsilon} \pi \alpha \gamma \gamma \varepsilon \lambda i \alpha$, quod magis sonat >promissionem< $[\ldots]$. Mihi non displicet promissionis verbum, nisi quod parum apte cohaerent quae sequuntur, >quod Deus lux est, et tenebrae in eo non sunt vllae «.» 
quod vocarit nos in consortium dilecti sui filii, nunc ergo, quid is a nobis vicissim exigat, percipite, istud nimirum, quod et praedicamus«, nempe:

5 quod deus lux est et tenebrae in eo non sunt ullae.

Hisce iam tradit doctrinam de puritate vitae. Deus, inquit, sanctus est et purus; qui ergo deo cohabitare aut illi foedere adhaerere velit, purificetur oportet. Atqui istud nulla praestabit carnis impotentia, nulla hominis virtus. Proinde filium nasci oportuit, qui corruptum peccatis mundum sanaret et innocentem vitam orbi commendaret. Ideoque, quotquot istud dei negocium intellexerunt, innocentiae student, quippe qui senserunt deum esse sanctum et sanctimoniae amantem. Ita

Gene. 17[,1]. Levit. 20[,26]. Psal. 14. Psal. 23. scriptum est: »Ambula coram me et esto integer.« Et alibi: »Sancti estote, quia et ego sanctus sum.«Item: »Domine, quis habitabit in tabernaculo tuo? « [Ps 15,1 (Vulg. 14,1)] »Innocens manibus et mundo corde« [Ps 24,4 (Vulg. 23,4)] etc. Et iterum: »Quis po|terit habitare cum igne devorante?«, Isaiae 33[,14]. Ex quibus prophetarum locis haec Ioannis desumpta videntur. Porro deum appellavit lucem

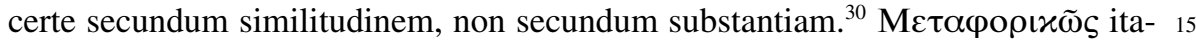
que lux est deus. Luce enim nihil pulchrius, amoenius, purius; ita deo nihil mundius aut praestantius. Tenebris contra nihil tristius, squalidius, impurius et foedius; et peccatis ac erroribus quid, oro, tetrius aut horribilius? Iam ergo annotatis istis certus et perspicuus erit allegoriae sensus. Allegorica enim sunt sequentia. Et allegoria est perpetua metaphora. ${ }^{31}$

6 Si dixerimus, quod societatem habemus cum eo, et in tenebris ambulamus, mentimur et veritatem non facimus.

Haec, inquam, adversus istos dicuntur, qui deum se nosce dicunt, factis autem negant. »Si«, inquit, »nomen et foedus christianum verbis magnificis ultro citroque iactaverimus, interim perseveraverimus in erroribus, flagitiis et carnalibus 25 desyderiis, hypocritae sumus, pessimi homines optimarum rerum simulatores.« 2. Cor. 66,14]. »Quod enim consortium «, inquit apostolus Paulus, »iusticiae cum iniusticia? Aut quae communio lucis et tenebrarum?« His consentiunt verba salvatoris in evanMath. 7. gelio dicentis: »Quid autem dicitis >domine, domine! et non facitis, quae dico?« [Lk 6,46] Veritatem autem facere est fidelitatem et id, quod audis aut profiteris, re 30 ipsa praestare.

Z. (8) negocium] negotium $Z H-(26)$ desyderiis] desideriis $Z H-(27)$ iusticiae] iustitiae $Z H-$ (27) iniusticia] iniustitia $Z H$

30 Vgl. Oecol. 1Joh. 13r: »Hic ne humiliter sapias et, sicut olim anthropomorphitae deo humana membra affinxerunt, ita tu lucem quandam similem huic conditae in deo imagineris.«
31 Quint. inst. 9,2,46 (Winterbottom II 498,25-

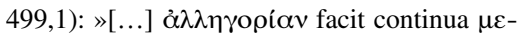

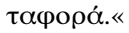


Peculiare est Ioanni per antitheses et membra contraria eandem efferre rem, certe ut res alioqui praeclaras clarius proponat auditoribus et infigat altius. Sic in 5 evangelica historia: »Qui credit«, inquit, »in eum, non condemnatur; qui vero non credit, iam condemnatus est, quia non credit in nomen unigeniti filii dei.« In hoc exemplo vides ter eandem rem ingeri, sed subinde clarius et evidentius. Pari elegantia et evidentia eadem res hic quoque repetitur. Caeterum ambulamus in luce, qui innocentiae studemus, Ioannis 3[,21]. Deus est in luce, id est, deus absolute purus est et sanctus. Nostro itaque modulo ita ambulamus in luce, sicut deus est in luce. Ille enim ipsa lux est et puritas. Nos ab ipso illuminamur et Ioan. [[,9]. illuminati nihilominus homines et peccatores sumus. Qui ergo »non ambulamus Rom. 8[,4]. secundum carnem, sed secundum spiritum«, societatem habemus inter nos mutuam. Proculdubio, ut cum deo sumus foedere nexi, ita inter nos ipsos quoque cohaeremus vinculo charitatis.

\section{7 et sanguis Iesu Christi filii eius emundat nos ab omni peccato.}

Digreditur ab instituto suo et disserit de peccato|rum remissione. Auspicatur autem ab antipophora, ${ }^{32}$ ut omnia probe cohaereant. Nam cum deus immaculatus sit et lux purissima, nos vero in peccatis geniti nihil nisi malorum lerna ${ }^{33}$ simus, videri poterat neminem mortalium cum deo tam sancto societate uniri nec quemquam pure vivere posse. Ei itaque obiectioni occurrit Ioannes et dicit: »Sanguis filii dei emundat nos ab omni peccato.«Ut sit sensus: si quis nostras spectet vires, alienissimi erimus ab amicitia dei neque quisquam invenietur non pollutus; aliud porro spectandum, gratia videlicet divina, qua salvi facti sumus per filium dei, per quem habemus aditum ad deum, per quem et abluti sumus (ut Paulus ait) et 1. Cor. 6[,11]. sanctificati et iustificati. Iam ut haec Paulina miram habent emphasim, sic haec Ioannis admirabiliorem. Sanguis enim Christi passio est, hostia et mors Christi. Ea fortassis contemni potuisset, nisi addidisset »filii eius«. At morte Christi filii dei nihil vidit orbis vel magnificentius vel admirabilius, denique nullum aliud malagma omnibus peccatorum vulneribus medendis praesentius. Hinc Baptista quoque: »Ecce«, inquit, »agnus dei, qui tollit peccata mundi.«Peccatum, inquam, Ioan. 1[,29]. dixit is numero singulari, $\tau \tilde{\eta} v$ $\alpha \mu \alpha \rho \tau i \alpha v$, non peccata, eoque plus quiddam

Z. (18) antipophora] antypophora $Z H-(20-21)$ quemquam] quenquam $Z H-(30)$ praesentius] praesentius est $Z H$

32 Unter »Anthypophora « versteht man eine Fragefigur, bei der der Redner eine von ihm gestellte Frage selbst beantwortet, vgl. Quint. inst. 9,3,87 (Winterbottom II 532); HWR I $685 f$.

33 Siehe oben S. 210, Anm. 171. 
expressit, quam si dixisset »peccata«. Per peccatum enim omne id intellexit, quod peccati nomine censeri potest, sive id capitale sit sive minus. |Genus itaque pro omnibus posuit speciebus synekdocha ${ }^{34}$ quadam. Iam si peccata dixisset numero plurativo, potuisset cogitari certa sive numerata duntaxat ablata esse, non omnia; ideo peccatum utrobique dixit et intellexit omnium peccatorum colluviem, non unius hominis aut aetatis, sed omnium et hominum et temporum. Cuius equidem rei certissimas notas utrobique etiam subdidit; hic: »emundat nos ab omni peccato«, in historia vero: »qui tollit peccatum mundi« [Joh 1,29]. Sed mundus ad omnes et ad omnium refertur aetates, non ad certum vel hominum vel peccatorum numerum. Plura in Roma[norum] cap[ite] 5. et 1. Pet[ri] 3. ${ }^{35}$ Blasphemias enim in 10 sacrosanctum dei filium eiaculantur, qui docent Christum vel pro originali peccato tantum, vel pro veterum delictis tantum, vel pro aliquibus peccatis tantum et non etiam pro omnibus omnium temporum peccatis perlitasse. ${ }^{36}$

8 | Si dixerimus peccatum non habemus, nos ipsos fallimus et veritas in nobis non est.

Alia est occupatio, quasi dicat: »Neque est, ut quisquam hic elabatur et suam iactitet munditiam aut ita se lustratum existimet, ut peccatum non habeat.« Nam Iob. 4[,17]. nemo est mortalium, qui mundatione Christi non egeat. Nemo est, qui vivat, Rom. 3[23]. inquit scriptura, et non peccet. ${ }^{37} »$ Omnes peccaverunt et destituuntur gloria dei «, ergo omnes | purificatione opus habemus. Haec adversus Novatianos ${ }^{38}$ et catab- 20 9v $H$ aptistas $^{39}$ fortissima et loetalia sunt iacula. Quod autem in 5. cap[ite] dicit: »Omnis, qui natus est ex deo, non peccat« [1Joh 5,18], expediemus, cum expositione eo pervenerimus. ${ }^{40} \gg$ Nos ipsos fallimus «: Mire elevat vanam istorum spem, qui se iustos esse credunt aut certe per Christum ita mundatos, ut nihil reliqui sit peccati. Et iterum mire deprimit istorum cristas, ${ }^{41}$ cum subdit: $\gg$ et 25 veritas in nobis non est«, hoc est, nihil verae religionis, nihil pietatis in nobis est, oủò̀v v̛̉ı́c, nihil solidi, nihil sani.

9 Si confiteamur peccata nostra, fidelis et iustus est, ut remittat nobis peccata nostra et emundet nos ab omni iniquitate.

Z. (4) duntaxat] dumptaxat $H$ - (10) Plura] Plura de his traduntur $Z H$

34 Tropus, bei dem eine quantitative Verschiebung zwischen dem gemeinten und dem tatsächlich ausgedrückten Begriff vorliegt, vgl. Quint. inst. 8,6,19-22 (Winterbottom II 465f.); HWR IX 356-366.

35 Röm 5,14-21; 1Petr 3,18f.
Siehe oben S. 247, Anm. 352.

Vgl. 1Kön 8,46.

Siehe oben S. 10, Anm. 39

Bull. adv. cat. 29v-30r.

Siehe unten S. 369.

Siehe oben S. 51, Anm. 301. 
Contrario membro (more suo) rem penitius animis fidelium figit et docet confitentibus conferri peccatorum remissionem. Caeterum peccata hic esse agnoscenda sive confitenda. Confitentur autem peccata sua, qui infirmitatem suam agnoscentes totos sese deo subiiciunt, de suis viribus desperant et ab unica dei

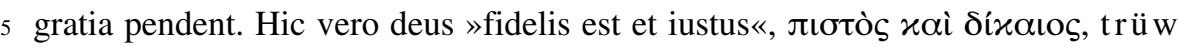
und ufrecht, qui, quae pollicebatur, praestet. Pollicitus est autem poenitentibus peccatorum remissam, Psal. 31. ${ }^{42}$ et Ezech. 18[,21-23]., Isaiae item 1[,26f.]. Iccirco fide indubitata praestabit. Iusticia itaque hoc loco non accipitur pro ea Iusticia. virtute, qua emunctim aequum discernimus ab iniquo, sed pro constantia et

veritate, Est enim fi|dei iuncta velut expositio, videlicet ne quis per imprudentiam intelligeret fiduciam, sed magis veritatem. Ita saepe videmus precari prophetam: Psal. 30 $»$ In iusticia tua libera me« [Ps 31,2 (Vulg. 30,2)]. Item: »Iudica me secundum iusticiam tuam« [Ps 35,24]. Alibi vero: »Ne intres in iudicium cum servo tuo, Psalm. 128. quia non iustificabitur in conspectu tuo omnis vivens « [Ps 143(!),2]. Iusticia 15 itaque dei in istis locis veritas dei est, qua pactis stat idque, quod dicit, facit. »Ab omni iniquitate «: Etsi indies peccaverimus, ipse tamen dei filius sempiterna est hostia. ${ }^{43}$ Vana itaque et impia est merx Romana indulgentiae, absolutiones, missae, confessiones et si quid aliud est eius generis.

\section{Si dixerimus: non peccavimus, mendacem facimus eum et sermo eius} non est in nobis.

Eandem rem tertio iam infert $\varkappa \alpha \tau^{\prime} \alpha \hat{\jmath} \xi \eta \sigma \iota v .{ }^{44}$ Nam inexpiabile scelus est, si peccatum tuum dissimules. Quae enim sanitatis spes apud eum fuerit, qui vulnus perito medico retegere nolit? Mendacem itaque facimus deum, non quod aeterna veritas mentiri possit, sed quod nos veritati dei non credentes, ipsa re testamur, quod deum non credimus vera dixisse. Si enim credimus deum veracem, qui fit, ut peccata nostra non agnoscamus? Is enim dixit: »Omnis homo mendax « [Ps 116,11 Psal. 115. (Vulg. 115,11)]. Iam si verum dixit deus, certe non est iustus, non est intelligens, non est requirens deum. Sermo itaque eius non est in $\mid$ nobis, qui infirmitatem non agnoscimus. $\Lambda$ ó $\gamma$ os, »verbum« vel »sermo«, ponitur pro religione, vi et veritate dei: sin forcht, erkantnus und krafft. In superiori enim membro dixerat: $»$ Et veritas in nobis non est « [1Joh 1,8$]$.

Z. (8) Iusticia] Iustitia $Z H$ - (8) Marg. Iusticia] Iustitia $Z H$ - (12) iusticia] iustitia $Z H$ - (13) iusticiam] iustitiam $Z H-(14)$ Iusticia] Iustitia $Z H-(28)$ non] uon $H$

42 Ps 32,1f. (Vulg. 31,1f.).

43 Hebr 10,14.

44 Erasm. cop. 1,27 (ASD I/6 73,993f.): »Ex au- xesi, hoc est amplificatione variatur oratio, cum amplificandae rei gratia verbum atrocius subiicimus loco proprii.« 


\section{Argumentum cap[itis] II.}

Hortatur nomine fidei ad vitae puritatem, charitatem mutuam et multam vigilantiam eo, quod antichristi multi sint, quorum artes evitare possint, si doctrinae spiritus sancti indivulse haeserint.

\section{CAP[UT] II.}

1 Filioli mei, haec scribo vobis, ne peccetis.

Initium capitis secundi pertinet ad finem capitis primi. In eo enim dixerat: $\gg \mathrm{Si}$ dixerimus: >Non peccavimus $<$, mendacem facimus eum « [1Joh 1,10]. Nunc igitur Rom. $3[, 8]$. diluit, quod obiici potuerat: si igitur veritas dei nostro commendatur mendacio atque $\mid$ peccato, peccemus itaque, ut veritas dei nostris grandescat peccatis. Re- $10 \quad 80 \mathrm{ZH}$ spondet ergo Ioannes et ait: »Ista vero non in hoc scripsi, ut ad peccandum incitarem, sed in hoc potius scripsi, ut a peccando retraherem.« Pluribus id negotii exponit Paulus in Roma[nis], cap[ite] 3. et $6 .{ }^{45}$ ex eo, si copiosiora velis, pete. »Filioli «: Specimen est apostolicae lenitatis et exordioli formula quaedam admodum blanda, quae paternum spirat amorem, longanimitate et benignitate 15 nobis imitanda.

1 Et si quis peccaverit, advocatum ha|bemus apud patrem, Iesum Christum iustum.

»Iam vero cum exigis, apostole, ne peccemus, rem profecto exigis homini impossibilem, utpote qui totus ex peccatis consutus, nihil nisi peccare possit. Si 20 igitur peccaverimus, an ne protinus desperabimus atque peribimus? « Hic Ioannes per occupationem: »Et si quis«, inquit, »peccaverit, advocatum habemus apud patrem.« Neminem (inquit) desperare volo. Neminem enim reiicit ad se redeuntem divina bonitas. Neminem a se pellit, modo sancte et solida fide accedat. Id

Luce 7[,47-50]. Luce 23[,42f.]. Luce 19[,8-10]. Matth. 9[,9]. Matth. 26[,75]. Matth. 9[,12].

Matth. 11[,28]. De paracleto. »Advocatum«, inquit, habemus apud patrem«; Graece: П $\alpha \rho \alpha ́ x \lambda \eta \tau o v ~ \varepsilon ้ \chi o \mu \varepsilon v$

Magdalene, de latrone in extremo supplicio ad gaudia paradisi vocato, de Zachaeo, Matthaeo et Petro. Huc pertinent et illae evangelicae sententiae: »Non veni vocare iustos, sed peccatores ad poenitentiam« [Lk 5,32]. »Qui sani sunt, medico opus non habent, sed qui male habent.« Item: »Venite ad me omnes, qui laboratis et onerati estis, et ego reficiam vos.« Sed age, excutiamus singula diligentius: 30

Z. (1) cap[itis]] capitis $Z H-(5)$ Cap[ut] II.] in marg. $Z H-(25)$ in primis] imprimis $H$

45 Röm 3,5-8; 6,15-23. 


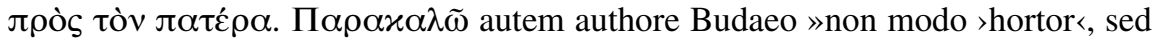
etiam >oro $<$ significat $\ll,{ }^{46}$ item $»$ pro alio precator intervenio ut advocatus et patronus $\ll{ }^{47}$ Unde $\pi \alpha \rho \alpha ́ x \lambda \eta \tau o \zeta$ dictus $»$ advocatus et fautor $\ll,{ }^{48}$ qui alicuius caussam agat apud iudicem, | non verbis tantum, sed qui seipsum interponat medi5 atorem et obsidem; apud Germanos: der vertrôstet und dem rechten wil gnůg thůn. Talem dicit Ioannes esse Christum, nimirum per metaphoram quandam aut ethopoeiam aut per prosopopoeiam. Est autem ethopoeia imitatio morum alienorum, ${ }^{49}$ prosopopoeia vero personarum fictio. ${ }^{50}$ Ioannes itaque de remissione peccatorum per Christum collata agens fori expressit morem, iudicum, patrono10 rum et reorum referens personam; quasi scilicet pater aut ipsum numen iudex sit, Christus vero advocatus vel patronus et peccatores sive hominum genus raei.

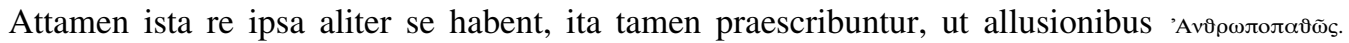
docti divina et spiritualia rectius et facilius intelligamus. Nam nullum est in coelo forum iudiciale, nullae sunt lites aut accusantium et defendentium altercationes. Quo magis mirandum est, quae istos agat dementia, qui divorum intercessionem probaturi similitudine patronorum coram iudice aut principe defendentium raeos abutuntur. Conducit equidem, non eo inficias, advocatus, sed non quilibet. »Habemus autem advocatum certum ac definitum a deo, qui intercedat; ipsum, inquam, dei filium Iesum Christum iustum.«»Talis enim decebat, ut esset nobis Hebr. 7[,26f.]

20 pontifex sanctus, innocens, impollutus, segregatus a peccatoribus et sublimior coelis factus, cui non sit quotidie necesse prius pro propriis, deinde pro populi peccatis offerre. Nam | id fecit semel, cum seipsum obtulit.« Manet autem in

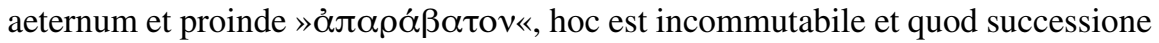
non transmigret ad alium, »habet sacerdotium, eo quod absolutissime servare possit omnes, qui per ipsum accedunt ad deum, semper vivens in hoc, ut interpellet pro illis« [Hebr 7,24f.]. Haec pene omnia ex Paulo huc transcripsimus. Ex quibus aestimare licet, cur tantopere divorum intercessionem impetamus, certe quod intercessionis beneficium et negotium solius sit Christi iusti et sacerdotis aeterni. tantum, sed etiam pro totius mundi.

46 Bud. comm. 1124,45-47.

47 Bud. comm. 1124,51f. Vgl. auch Bud. comm.

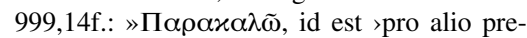
cator intercedo, deprecor $<. \ll$

48

49

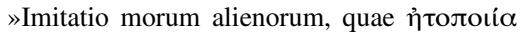
[...] dicitur.«

50 Quint. inst. 9,2,29 (Winterbottom II 494,22): $»[\ldots]$ fictiones personarum, quae $\pi \rho о \sigma \omega \pi о-$ лolía dicuntur.« 
Adiiciuntur haec a sanctissimo evangelista paucula quidem, sed sacrosancta, ad maiorem evidentiam et claritatem, ne quis putaret unum atque alterum peccatum sublatum, non omnia, et eius rei gratia existimaret Christum non esse semper et propter omnia peccata compellandum. »Sane Christus«, inquit, »semper nobis adeundus est, quippe cum $\mid$ sit propitiatio pro peccatis nostris nec pro nostris tantum, sed pro peccatis totius mundi.« Verum annotavimus huius generis et alia

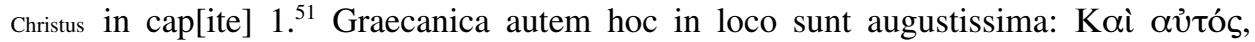

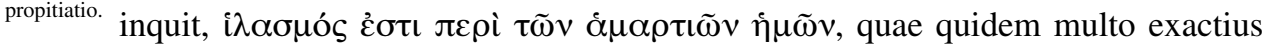
intelligemus, si nonnulla huc ex 3. ad Ro[manos] ca[pite] transcripserimus. Ea sunt: »Omnes | peccaverunt et destituuntur illa dei gloria. Iustificantur autem munere favoris eius gratuiti, idque beneficio redemptionis, quae contigit nobis per Iesum Christum, quem deus«, velut orbi unicum sydus, »proposuit i $\lambda \alpha \sigma-$

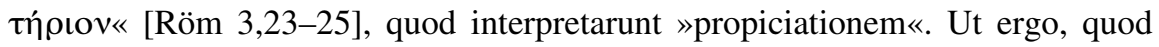

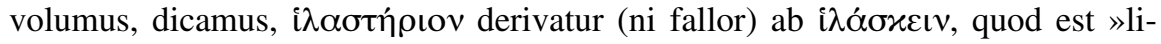
tare « sive »placare« et »deum benignum facere«. Hinc vero est i $\lambda \alpha \sigma \mu$ ó $\varsigma$ (quo 15 usus est hoc in loco Ioannes), quod perlitationem significat, sacrificium, satisfactionem, placationem et conciliationem. Est itaque Graecanicae voculae multo maior vis quam Latini exprimamus. Praeterea apparet Paulum apostolum hac voce allusisse ad Hebraeorum »propiciatorium«, quod illi vocant כפרת כ2 Nam כפר autem expiatio, redemptionis praecium et 20 sanctificatio. ${ }^{53}$ Christus ergo is est, in quo »patri complacitum est universam inhabitare plenitudinem et per eum reconciliare cuncta erga se, pacificatis per sanguinem crucis eius, per eundem, sive quae in terra sunt sive quae in coelis «, Act. 4[,12]. Coll. 1[,19f.]. Recte itaque et Petrus clamavit: »Non est in alio quoquam salus; nec aliud est sub coelo nomen datum hominibus, in quo oporteat nos salvos 25 fieri.« Haec autem subruite nobis, si potestis, o vos pontificii, qui neglecta hac unica et aeterna salute indulgentias, poenitentiales satisfactiones et missas impie impiissimi venditis! Nam vel | hisce locis convicti, blasphemia vos liberare non poteritis.

3 Et per hoc scimus, quod cognovimus eum, si iussa illius observamus. 4

Qui dicit novi eum et praecepta eius non servat, mendax est et in eo veritas non est.

Admodum docte ad sese redit apostolus et occupatione rhetorica consequentia nectit superioribus. Ab eo enim loco: »Et sanguis Iesu Christi filii eius emundat

Z. (5) cum] quum $Z H$ - (9) Ro[manos] ca[pite]] Romanos capite $Z H$ - (13) propiciationem] propitiationem $\mathrm{ZH}$ - (19) propiciatorium] propitiatorium $\mathrm{ZH}$

51 Siehe oben S. $317 \mathrm{f}$.

53 Vgl. Pagn. thes. 1061-1064.

52 Ex 25,16. 
nos ab omni peccato « [1Joh 1,7] digressus, obiter disseruit de peccatorum remissione, altera evangelii parte. Nunc vero redit et de puritate vitae, altera evangelii parte, exhortationem continuat. Occupatione autem (ut monuimus) orditur. Siquidem audivimus Christum Iesum sacrificium esse $\gg$ pro peccatis nostris, 5 nec pro nostris tantum, sed pro peccatis totius mundi « [1Joh 2,2]. Unde iterato impius colligere potuisset: »Impune ergo et libere peccabo, quando iam olim ea sint abolita peccata, quae ego nunc quidem facio aut in posterum patraturus sum.« Haec autem est omnium impiorum protrita obiectio, qui protinus atque discunt unico Christi sacrificio tolli peccata mundi suas illas blasphemias eiaculantur.

10 Sed apostolus: »Et per hoc scimus «, inquit, »quod cognovimus eum, si iussa illius observamus. « Hoc est: ea est christiani hominis nota certissima, si legi divinae Psal. 1[,1f.] noctes atque dies insumpserit, si innocentiae $\mid$ et sanctimoniae studuerit. Locus est a caussis. ${ }^{54}$ Est autem Christum cognoscere re ipsa christianum esse. Exemplo fiet res dilucidior: »Qui dicit«, ait Ioannes, »novi eum«, hoc est, si quis iactarit se christianum esse et se intelligere Christum totius orbis esse salutem, »interim verbum Christi contemnit, is in tenebris agit«; quod si impuram vitam vivit, profecto hypocrita est et nulla in eo veritas est, nihil solidi, imo nullus in eo deus est. Quam sententiam Germanus foelicius fortassis redderet ad hunc modum: und der hat kein rechte verrichtung mit Gott.

Idem est sensus huius membri, qui et prioris. Nemo tamen $\tau \alpha v \tau o \lambda o \gamma i \alpha v$, foedum orationis vitium, committi putaverit. Nam in 1. cap[ite] annotavimus, id quod per integram epistolam et omnia Ioannis scripta unice observari volumus, Ioannem creberrime uti adeoque delectari contrariis inter se membris componendis. ${ }^{55} \mathrm{Id}$ quod hic quoque fecit. Negativam praemisit, sed affirmativam hic subiungit.

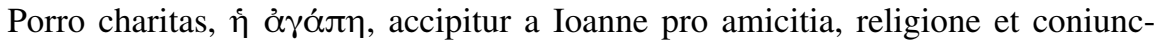
tione. Ut sit sensus: caeterum qui sermonem eius servat et innocentiae studet, hic vere pius est, hic vere deo foedere et amicitia iunctus est, | der ist mit Gott recht vereint. Sic audiemus in quarto charitatem dei sumi pro vera religione. ${ }^{56}$ 30 Sequitur:

| 5 Per hoc scimus, quod in ipso sumus.

Dubia est sententia. Nam referri potest non tam ad consequentia quam praecedentia. Quod si referas ad praecedentia, iam veluti epiphonema ${ }^{57}$ et clausula

Z. (11) Marg. Psal.] Spal. $H$

54 Vgl. Agric. inv. 1,14 (Mundt 86-92).

55 Siehe oben S. 317.
$56 \quad 1$ Joh $4,17$.

Vgl. Quint. inst. 8,5,11 (Winterbottom II 
quaedam rhetorica erit, ac si tu dicas: ex istis vero liquet, quod, qui christiani sunt, pie quoque vivunt. Atque ita poterat et epanalepsis ${ }^{58}$ videri, ad illud, inquam, respiciens, quod praecesserat: »Et per hoc scimus, quod cognovimus eum « [1Joh $2,3]$. Idem enim nunc repetit post probationem et dicit: »Per hoc scimus, quod in ipso sumus.«Et quod paulo ante dixit, »quod cognovimus eum« [1Joh 2,3], id hoc loco clarius effert: »quod in ipso sumus«, id est, quod ipsi vere adhaeremus, quod illi societate et amicitia iuncti sumus. Quod si referas ad consequentia, iam hic erit sensus: si vitam nostram ad Christi exemplum composuerimus, per hoc, inquam, sciemus, quod in ipso sumus. Sed quo interim referemus, quod protinus sequitur: »Qui dicit se in eo manere?« [1Joh 2,6] Magis itaque mihi probatur prior sensus, qui haec nectit superioribus. Iam enim sequitur separatum argumentum.

6 Qui dicit se in eo manere, debet, sicut ille ambulavit, et ipse ambulare.

Aut a connexis ${ }^{59}$ aut ab exemplo ducit argumentum. Cuius hic est sensus: quicumque christiano se nomine venditat, is et a Christi exemplo pendere debet. Qui enim Platonici dicuntur aut cynici magistrorum dogmata et exempla impense Christus sectantur. Si igitur christiani sumus, age: Christum quoque magistrum vita et exemplum. moribus imitemur! ${ }^{60}$ Est $\mid$ enim hic nobis a deo datus sapientia, vitae magister et vivum pietatis exemplum, ut eius conversatione instituti sanctam agamus vitam.

Ioan. 13[,15]. Hinc in evangelio dicit Christus: »Exemplum dedi vobis, ut, quemadmodum ego 20 feci, sic vos faciatis.« Hinc etiam veteres dicebant omnem Christi actionem Ioan. 2[,1-10]. nostram esse institutionem. ${ }^{61}$ Non quod aquam protinus vertas in vinum, aut Matt. 4[,2]. quadraginta dierum curriculum ieiunio et inedia superes. Nam ea, quibus divinitatem demonstrare voluit, sub hanc regulam non cadunt, sed ea, quibus fidem nobis commendavit, charitatem et innocentiam. Itaque pari etiam tropo expedi- 25 mus, quod alii hic intricatissime involvunt, fieri non posse, ut quisquam mortalium ita ambulet, sicut Christus ambulavit. Nam pro nostro modulo et iuxta vim gratiae nobis a deo datae, ita ambulamus, non utique filio dei aequalis, sed quantum a deo nobis conceditur. Neque vero et de hac re hic disputatur, sed

457,25f.): »Est enim epiphonema rei narratae uel probatae summa acclamatio.«

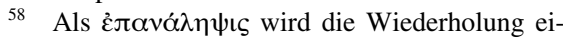
ner Wortgruppe bezeichnet, vgl. HLR 312f; Erasm. cop. 1,30 (ASD I/6 74,26f.).

59 Vgl. Agric. inv. 1,19 (Mundt 112,2-4): »Connexa dicimus, quae non circunstant quidem rem quemadmodum locus locus et tempus, sed extrinsecus tamen in ipsam incumbere videntur.«

60 Vgl. Erasm. paracl. (Holborn 140,19-25):
»Platonici, Pythagorici, Stoici, Cynici, Peripatetici, Epicurei suae quisque sectae dogmata tum penitus habent cognita, tum memoriter tenent, pro his digladiantur illi vel emorituri citius quam auctoris sui patrocinium deserant. At cur non multo magis tales animos praestamus auctori nostro principique Christo? « 61 Ps.-Aug. serm. 16,2 (Caillau/Saint-Yves 98): »Omnis enim Christi actio christianorum est instructio." 
docetur vitae integritas, quandoquidem Christus, qui christianorum sit archetypus, integritatem sua nobis vita commendarit; unde iam consequatur indecorum esse, si quis ex illius familia nomine quidem christiano decoretur, interim Christo vitae et moribus non respondeat. Observabis hic quoque ambulandi verbum ad morem

5 Hebraicum pro conversandi modo esse usurpatum. Item apostolum hisce verbis: »Qui dicit se in eo manere«, allusisse ad ista salvatoris verba: »Qui diligit | me, Ioan. 14[,23]. sermonem meum servabit, et pater meus diliget eum, et ad eum veniemus et mansionem apud eum faciemus.«

7 Charissimi, non praeceptum novum scribo vobis, sed praeceptum vetus, quod habuistis ab initio. Praeceptum vetus est sermo, quem audistis ab initio.

Hoc autem de puritate et integritate vitae praeceptum ipsa vetustate, argumento plausibili et a pronunciatis petito commendat. Denique purgat se generali illa suspicione, qua nonnulli apostolos reddebant invisos, quasi evangelica praedicatione rebus novis studerent. Ideoque dicit: »Cum ad innocentiam vitae hortor et sanctum filii dei exemplum propono, nihil novi propono, sed id prorsus, quod habuistis ab ipso statim religionis initio. Nempe: praeceptum vetus est sermo, quem audistis ab initio.«Sic enim ipse sese exponit. Sed verborum hic est ordo et sensus: sermo ille, id est illa praedicatio, quam audistis ab initio per legem et prophetas, hoc ipsum praeceptum est, quod iam nunc proferimus. ${ }^{62}$ Tota enim scriptura sacra fidem tradit, innocentiam et charitatem. Et Christus in evangelio: Matth $»$ Dilige «, inquit, »dominum deum tuum ex totis viribus tuis et proximum, sicut te ipsum. In his autem duobus mandatis pendent lex et prophetae.« Quod si (inquis) idem est $\mid$ praeceptum, eadem doctrina, priusquam | nasceretur Christus, et posteaquam natus est, eadem: quid ergo nascendo nobis contulit?

8 Rursum praeceptum novum scribo vobis, quod verum est in ipso, idem verum est et in vobis: quia tenebrae praeterierunt et verum lumen iam lucet.

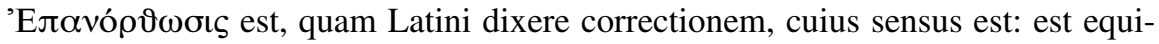
30 dem christiana praedicatio nova praedicatio. Sed qua parte aut quomodo dicetur nova? »Quod verum est in ipso«, inquit, »idem verum est et in vobis«, quae

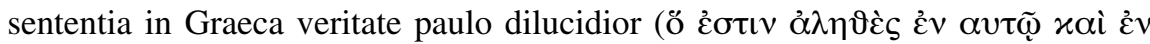
ט $\mu \tilde{\imath} v)$ et tamen propter brevitatem satis obscura est. Copiosius ergo ad hunc

Z. (1) archetypus] architypus $H$

62 Vgl. Erasm. par. 1Joh. (ASD VII/6 264,188f.): »Non est nouum hoc praeceptum de charitate quod scribo vobis, sed iam olim hoc prodidit et lex Mosaica [...].« 
modum reddenda: »Denique novum praeceptum scribo vobis; novum, inquam, ea parte, qua omnia in filio vera sunt et per hunc etiam in nobis veriora, quam hactenus, certiora et perfectiora.« Hoc enim profuit Christus, quod ipse omnibus

Coll. 2[,17]. Ioan. 14[,6]. Ioan. $1[, 17]$ satisfecit, umbras et typos antiquavit, corpus (ut scriptura ait) et veritas rerum omnium. »Lex«, inquit Ioannes, »per Mosen data est, gratia et veritas per Iesum Christum exorta est.« Veritatem autem et nos facimus, qui spiritu Christi imbuti praecepta dei diligimus. Huc pertinent sequens $\alpha i \tau \iota 0 \lambda o \gamma i \alpha$ : »Quia tenebrae praetereunt et verum lumen iam lucet.« Lumen istud Christus est, spiritus et fides in cordibus fidelium. Christus autem umbras legis discus sit. Fides item tenebras carnis et errorum propellit. Haec autem orbi contulit Christus; proinde praecep- 10 tum, hoc est mandatum, et praedicatio Christi nova dicitur.

9 Qui dicit se in luce esse et fratrem suum odit, in tenebris est usque adhuc. 10 Qui diligit fratrem suum, in lumine manet et offendiculum in eo non est. 11 Qui autem odit fratrem suum, in tenebris est et in tenebris ambulat et nescit, quo eat, quia tenebrae occaecaverunt oculos eius.

Rara eruditione et supra modum admirabili ratione totam inter se connectit orationem, qui hactenus harenam sine calce ${ }^{63}$ nonnullis recensuisse videbatur. Nunc enim occasione sumpta a lumine iterum a connexis ducit argumentum et charitatem, potissimam christianorum notam et alterum huius epistolae statum, ingerit, quem tamen in cap[ite] 3. et 4. latius persequitur. Hic enim obiter eam perstringit, 20

Charitas. docens christianam religionem ut puritate vitae, ita et mutuo amore constare. Utitur autem suo iterum idiotismo, qui peculiaris est autoris cuiusvis dicendi genius: nam pro ardore suo nimio eandem rem diversis et geminatis membris effert. »Qui«, inquit, »dicit se in luce esse«, hoc est: qui lucem evangelicam et Christum sibi illuxisse fatetur. Nam allusit ad illud Ioannis octavo: »Ego sum|lux 25 16v $H$ mundi; qui sequitur me, non ambulat in tenebris « [Joh 8,12]. »In tenebris est usque adhuc«, id est: etiamdum, etiamsi grandia iactitet. Schema est Germanico respondens: es ist nüt, und ob du noch einist so vil klappertist. »Et offendiculum in eo non est«: Quemadmodum is non impingit, qui in luce ambulat, sic is non impingit, qui ad lucem Christi vivit. Aut certe vita sua nemini est 30 offendiculo. »Et in tenebris ambulat«: incrementum est et similitudo. »Et tenebrae obcaecarunt oculos eius «: a corpore ad animum, per metaphoram, deflectit significationem. Per tenebras enim intellexit carnis caliginem, invidiam, iram et

Z. (2-3) quam ... perfectiora] certiora et perfectiora, quam hactenus $Z H-(4)$ veritas] veritas sit $Z H-$ (7) Quia] Qui $H$ - (9) discussit] duscussit $H$ - (13) fratrem] fartrem $H$ - (25) Ioannis octavo] Ioan[nis] 8. $\mathrm{ZH}$

63 Erasm. adag. 1257 (ASD II/3 276,356f.): »[...] Senecae orationem sine calce arenam sit $[\mathrm{Ca}-$ ligula Caesar] solitus appellare tanquam dissolutam ac neruis carentem et ordine.« 
odium. Haec occaecant homines, ut, quod rectum est, non videant. Simili allegoria usus est etiam Christus, Matth. 6[,22f.].

12 Scribo vobis, filioli, quod remittuntur vobis peccata propter nomen eius.

5 Epanaphora ${ }^{64}$ est. Quia enim dixerat se non studere rebus novis, iccirco eo redit et brevi quadam periocha colligit potissima evangelicae doctrinae capita omnibus cum hominibus tum aetatibus congrua, quasi dicat: »Quod olim docui, idem nunc repeto, ut, inquam, videatis me vobis antiqua et sancta et praecipua et divina, non humana aut nupera aut nova tradere.«Initio, quod peccata nobis remittuntur, non 10 propter iusticiam nostram, sed propter nomen, gratiam, bonitatem, misericordiam et virtutem Iesu Christi. Plura $\mid$ huius generis legas in Ephes[iorum] 2. cap[ite]. ${ }^{65}$

13 Scribo vobis, patres, quoniam cognovistis eum, qui ab initio est.

| Secundum et quod revera primum est et maximum: non praedicamus deum ignotum, sed eum, qui est ab initio, deum, inquam, verum, vivum et aeternum. Denuo enim allusit ad essentiam dei, de qua annotavimus in capite primo. ${ }^{66}$

Idem respondendum est nostri saeculi hominibus, qui et ipsi clamitant nos vetus religio. nova et inaudita quaedam producere dogmata, quum tamen nostra illa sint vetustissima et iam olim prophetarum et apostolorum testimoniis mundo praedicata, et per nos ab humanis sordibus et mendaciis, quae asperserant pontificii, duntaxat 20 repurgata et in lucem denuo prolata.

13 Scribo vobis, adolescentes, quoniam vicistis illum malum.

Proximum est in functione evangelica, ut carnis labefactentur cupiditates et ut Sathanas suo expellatur regno. Dixit enim Christus: spiritus sanctus »arguet Ioan. 16. mundum de iudicio« [Joh 16,8], quia »princeps mundi huius iam iudicatus est « 25 [Joh 16,11]. Nulli vero hominum aetati Sathanas aeque insidiatur atque iuvenili, quod ea aetas iis abundet, quibus vitia aluntur. Hinc »lubricam « dixere vetusti. ${ }^{67}$ Armanda ergo erat adversus Sathanae astus armatura dei; de qua paulo post

Z. (8) et] om. $Z H$ - (8) et] om. $Z H$ - (10) iusticiam] iustitiam $Z H-(15)$ capite primo] cap[ite] 1 . $Z H$ (19) duntaxat] dumptaxat $H-(20)$ denuo prolata] prolata denuo $Z H-(23)$ Sathanas] Satanas $Z H-$

(25) Sathanas] Satanas $Z H-(27)$ Sathanae] Satanae $Z H$

64 Siehe oben 313, Anm. 19.

65 Eph 2,1-10.

66 Siehe oben S. 312.

67 Vgl. Orig. in Exod. 4,8 (GCS XXIX 180,11f.): $»[\ldots]$ fluidam et lubricam iuventutis vitam [...]«; Erasm. cop. 2 (ASD I/6 262,611f.): »[...] prima illa et lubrica puerorum aetas.« 
plura ${ }^{68}$ et copiosissima $\mid$ apud Paulum in Ephes[iorum] 6. ${ }^{69}$ Daemonem autem

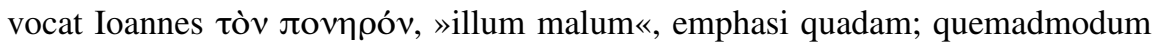

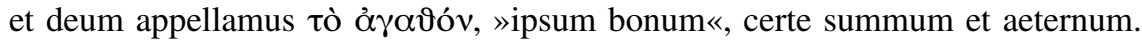

14 Scribo vobis, filioli, quoniam cognovistis patrem.

Deus non modo fortis est, iustus, omnipotens, terribilis, magnus dominus, iudex 5 et aeternus, sed etiam aequus, suavis, benignus, familiaris, bonus, misericors et pater, qui mundo per omnia id praestat, quod solent parentes adamatis praestare liberis. Producit enim, fovet, nutrit, conservat, protegit, condonat, regit et sanat. Atque haec omnia solus et semper facit deus, qui eius rei gratia apud Mosen et Psal. 103[,13]. per Isaiae scripta subinde se ingerit parentis nomine.$^{70}$ In Psalmis legimus: »Sicut 10 miseretur pater filiorum, ita misertus est dominus timentibus se.«

14 Scripsi vobis, patres, quoniam cognovistis eum, qui ab initio est.

Non caret mysterio, quod hanc sententiam secundo iam ingerit. Forsan propter donum divinae cognitionis, qua citra controversiam nihil est in orbe nobilius. Rem ergo repetit inaestimabilem, quod maiestatem ac bonitatem dei verbis, 15 quantumvis augustis, nemo satis exequi possit. Repetiit et propter praecedens membrum, quo deum appellavit patrem. Iam vero, ne humili hac appellatione vilesceret deus in humanis mentibus, an|tithesi occurrit ac dicit hunc patrem non terrenum esse patrem, sed coelestem, aeternam omnium rerum subsistentiam,

Ioan. 1. vitam et conservationem. Ita, cum dixisset in evangelio: »In mundo erat «, mox 20 subdit: »et mundus per eum factus est« [Joh 1,10]. Rursus: »Et habitavit in nobis«, sed, ne quis offenderetur humanitate, subiungit: »et vidimus gloriam eius « [Joh 1,14]. Hoc modo et hac ratione putamus etiam hoc loco eandem rem et idem membrum repetitum esse. Quo et illud pertinere videtur, quod dixit »scripsi« et non »scribo $\ll$.

14 Scripsi vobis, adolescentes, quoniam fortes estis et verbum dei manet in vobis et vicistis illum malum.

Sermonem iterum convertit ad adolescentes et proinde dicit »scripsi« et non »scribo«. Id enim, quod prius dixerat paulo brevius et obscurius, nunc clarius et copiosius repetit. Repetit, inquam, ut commodius ea subnecteret, quae de fugi- 30 endis concupiscentiis mundanis dicenda erant. Et superius quidem dixerat adolescentes vicisse illum malum; ${ }^{71}$ hic autem victoriae nervum et vim addit: forti-

68 Joh 2,24 .

69 Eph 6,14-17.
70 Dtn 32,6; Jes 63,16; 64,8.

71 1Joh 2,13. 
tudinem. Fortitudo autem haec non est temeraria mortalium audacia, sed animi Fortitudo. robur, virtus et gratia dei, quae per nos operatur, imo temperantia est et constantia christiana, qualis fuit in adolescente Ioseph. Porro haec enascitur ex verbo dei Gene. 39[7-10].

$18 \mathrm{v} H$

$$
5
$$
eodemque firmatur ac conservatur. At verbum dei non illud | est externum, ut vocant, verbum, sed virtus spiritus, operatio divina, institutio, fides, timor dei et religio eius. ${ }^{72}$ Istis enim armis superantur cacadaemonis artes. Hinc et ipse Ioannes subdit: »Et vicistis illum malum «, quasi dicat: »Sic, inquam, intelligatis volo, quod superius dixeram: >Scribo vobis, adolescentes, quoniam vicistis illum malum. Non enim vestris vi|ribus, sed divino robore vicistis. «»Vicistis « autem dixit pro »vincetis «. Qua enallage ${ }^{73}$ pulchre usus est Lucullus ${ }^{74}$ imperator, qui pugnaturus contra Mithridatis et Tygranis ${ }^{75}$ copias, priusquam pugnare coepisset, clamavit: »Vicimus, milites! ${ }^{76}$ Nondum enim vicerat, qui nondum pugnare coeperat; videbatur autem vicisse, qui vincendi occasionem nactus erat. Ita et adolescentes vicisse dicuntur, qui rationem vincendi habent. Et poeta: »Dimidium 15 facti «, inquit, »qui coepit, habet. « ${ }^{77}$

\section{Ne diligatis mundum neque ea, quae sunt in mundo.}

Hactenus ostendit se nullis studere rebus novis et doctrinam evangelicam de fide, innocentia et charitate praecipientem doctrinam esse vetustam et sacrosanctam. Nunc redit ad id, unde erat digressus, et innocentiam ac puritatem vitae commendat fidelibus, occasione nihilominus sumpta ab adolescentum pugna et victoria. Retegit autem hoc tandem loco illud malum, quo innocentia et puritas vitae proditur et labefa|ctatur. Poterant ea videri a caussis vel eventis esse petita. Initio autem in genere praecipit: »Ne diligatis mundum.« Nam in eorum vertimur

\section{Z. (4) eodemque] eodem $Z H$}

72 Vgl. Zw. am. exeg. (Z V 582,3-5): »Euangelii verbum, inquiunt, prędicamus ore, quod quidem est externum verbum. [...] Quod autem in corde creditur et in mente intelligitur, illud est internum verbum. « Zur Herkunft der Unterscheidung zwischen »verbum externum« und »internum« vgl. Schindler 1965, 104-114; zu deren Verwendung bei Martin Luther vgl. Beutel 1991, 372-406.

73 Vgl. Erasm. cop. 1,13 (ASD I/6 54,547f.): $»$ [Enallage] est, cum eadem voce modice deflexa varietatis nonnihil conciliatur.«

74 Lucius Licinius Lucullus (117-57/56 v. Chr.), römischer Senator, Konsul und Feldherr, Oberbefehlshaber im 3. Mithridatischen Krieg gegen den pontischen König Mithridates VI., vgl. NP VII 166-168.
75 Tigranes II. (geb. um 140 v.Chr.), König von Armenien, vgl. NP XII/1 567.

76 Erasm. apoph. 5,13, 268F-269A: »Quum Romani cataphractos praecipue formidarent, bono animo illos esse iussit [Lucullus] [...]. Quumque primus in collem ascendisset, speculatus hostium tumultus exclamavit: >Vicimus, commilitones! $<$ simulque impetu facto in hostes, quum nemo irruentis impetum sustineret, quinque tantum Romanos, qui ceciderant, amisit, hostium vero centum milia trucidavit.«

77 Hor. epist. 1,2,40 (Klingner 245). Vgl. Erasm. adag. 139 (ASD II/1 254,974f.): »>Principium dimidium totius. $<$ Hoc adagio significatum est maximam difficultatis partem in aggrediundo negocio sitam esse.« 
naturam, quorum familiaritatem nobis conciliavit arctior coniunctio et amicitia. ${ }^{78}$ Porro »mundus « aliquando homines significat mundanos vel peccatores, aliquando impios, aliquando vero totam universi machinam; hinc Ioannes subiungit: »Neque ea, quae in mundo sunt «, ut intelligeremus apostolum loquutum esse de concupiscentiis mundanis. De quibus paulo post.

15 Si quis diligit mundum, non est charitas patris in eo.

Charitas patris vera est religio et fides vera, qua discimus bonitatem et charitatem dei erga nos. Dicit ergo: »Si quis sectatur mundum et impura sese oblectat vita, is sane pius non est neque unquam amicum illud dei negocium sane intellexit, quod evangelica praedicatione ad nos defertur. Et mundus et charitas patris veluti 10 repugnantia inter se sunt.«

16 Quoniam omne, quod est in mundo, veluti concupiscentia carnis et concupiscentia oculorum et fastus vitae, non est ex patre, sed ex mundo.

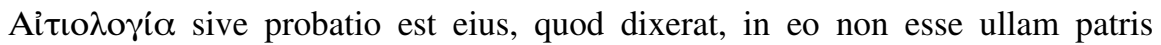
2. Cor. $6[14]$. charitatem, qui mundum sectaretur. ${ }^{79} \mathrm{Nam} \gg$ nulla«, inquit, »est conventio lucis et tenebrarum«. | Deus enim purus est, sanctus, mundus et integer. Et religio eius pura est. Mundus vero corruptus est, pollutus et omnigenis flagitiis dissolutissimus. Sed et studium mundi cum foedum est tum abominandum. Et hic sese aperit dilucidissime apostolus, quid in superioribus intellexerit per mundum et ea, quae sunt in mundo: concupiscentiam videlicet carnis, qua comprehendit omnia cordis impura et carnalia desyderia, sicut per concupiscentiam oculorum omnia flagitia, quae externis sensibus, visu, auditu, tactu, gustu et olfactu concipiuntur et fiunt,

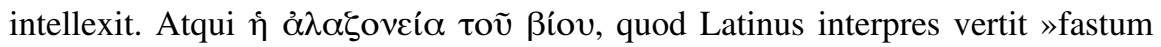
vitae ${ }^{80}{ }^{80}$ poterat etiam ad opum sive facultatum referri fastum et pompam. ${ }^{81} \mathrm{Id}$ vero hoc in loco in primis admirandum est, quod intra arctissimam hanc sectio- 25 nem omnia pene scelera colligere licet. Omne enim peccatum vel sub concupiscentiam carnis vel sub concupiscentiam oculorum vel sub fastum vitae et facultatum refertur.

Z. (4) loquutum] loqutum $H$ - (9) negocium] negotium $Z H-(21)$ desyderia] desideria $Z H-(25)$ in primis] imprimis $H$

78 Vgl. Sen. dial. 5,8,1 (Hermes 116,18f.): »Sumuntur a conversantibus mores. Siehe auch Erasm. adag. 974 (ASD II/2 472-474).

79 1Joh 2,15.

80 Erasm. 1Joh. transl. [2,16] (ASD VI/4 468).
81 Erasm. 1Joh. (ASD VI/10 528,112f.): »Bíos significat victum et omnes facultates ad vitae vsum pertinentes et vitae genus et ipsam vitam.« 
17 Et mundus transit et concupiscentia eius. Qui autem facit voluntatem dei, manet in aeternum.

Ab utili et inutili suadet puritatem vitae, dehortatur a carnalibus et mundanis desyderiis. »Mundus«, inquit, »transit et concupiscentia eius.« Nam Solomon 5 mirifice hoc argumentum tractat in Ecclesiaste docens nihil uspiam in orbe esse vel firmum vel satis tutum. ${ }^{82} \mid$ Idem docet et Moses Psal[mo] 89. ${ }^{83}$ Et quis est, qui nesciat toties iam maxima esse mutata, imo et funditus deleta foelicissimarum gentium augustissima regna, summos viros fastigio deiectos et opulentissimos ad extremam redactos esse pauperiem? Rectissime igitur et verissime dixit Iacobus apostolus: »Quae est autem vita vestra? Vapor utique, qui ad exiguum tempus Iacob. 4[,14]. apparet et mox evanescit.« Rectissime quoque et verissime dixerunt vetusti, qui hominem bullam esse perhibuerunt ${ }^{84}$ de qua re eruditissime scripsit Erasmus in suis illis Chiliadibus. ${ }^{85}$ Ioannes vero istis mox subiicit membrum contrarium: »Qui autem facit vo|luntatem dei, manet in aeternum. « Faciunt autem voluntatem dei, qui filio eius credunt (Ioan. 6[,40].) et qui puram vitam vivunt. Nam »haec est voluntas dei«, inquit apostolus, »sanctificatio vestra«, 1. Thes. 4[,3]. Qui ergo fecerit voluntatem dei, hic vivet in aeternum.

\section{Filioli, novissimum tempus est.}

Ad mundum pertinent errores et haereses, quae non raro solent simpliciores iusta 20 excutere via, ut contentionibus impliciti, qua eundum sit, prorsus ignorent. Digreditur itaque hinc apostolus et deterret a doctrina falsa, cohortans ad multam vigilantiam et ad constantem in doctrina spiritus perseverantiam. Caeterum id negocii auspicatur a tempore. Veluti cum apostolus dicit: »Nunc tempestivum est, Rom. 13[,11]. ut a somno expergiscamur «, | ita hic quoque Ioannes fideles excitans: »Filioli«, 25 inquit, »novissimum tempus est.« Id est: periculosa sunt tempora, utpote quae turbas, seditiones ac uberrimam pseudoprophetarum tristem sane frugem minitantur, unde nobis diligenter vigilandum est. Verum ipse sese exponit et ait:

18 Et sicut audistis, quod antichristus venturus sit, etiam nunc antichristi multi coeperunt esse; hinc vero scimus novissimum tempus esse.

Z. (4) desyderiis] desideriis $Z H$ - (6) Psal[mo]] Psalmo $Z H$ - (7) foelicissimarum] felicissimarum $Z H$ (23) negocii] negotii $Z H-(24)$ Ioannes] Ioannnes $H$

82 Koh 3,19-4,8.

83 Ps 90,6-9 (Vulg. 89,6-9).

84 Erasm. adag. 1248 (ASD II/3 256,887-889):

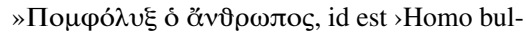
la<. Prouerbium hoc admonet humana vita ni- hil esse fragilius, nihil fugacius, nihil inanius. Est enim bulla tumor ille inanis, qui visitur in aquis momento temporis enascens simul et euanescens.«

85 Erasm. adag. 1248 (ASD II/3 256-264). 
Ioannes aperte distinguit inter antichristum et antichristos. Antichristus enim est insignis ille hostis Christi, illud ipsum abominandum regnum, quo virtus, gloria et maiestas Christi supra modum blasphematur, contemnitur et aboletur. Sicuti Dan. 11[,36-39]. fieri videmus in regno Turcico et pontificio. De quo et Daniel propheta et apostolus Paulus. Sed antichristi sunt omnes illi, qui impia doctrina simplici plebeculae imponunt. Cuiusmodi est haereticorum turba, in qua primas tenent Valentinus, Martion, Hebion, Cerinthus, Arrius, Pelagius, qui et ipsi non exigua Matth. 24[24]. portio sunt praecipui illius antichristici regni, magni videlicet antichristi praeambulones. Atque inde pulchre colligit Ioannes: hinc vero scimus novissimum tempus esse.

19 E nobis profecti sunt, sed non erant ex nobis.

Christiani olim fuerant, quos hic vocavit antichristos. Quod si tu chronica et priscae ecclesiae historias, Tertullianum ${ }^{86}$ quoque, Hirenaeum ${ }^{87}$ et Eusebium ${ }^{88}$ consulas, invenies Simonem Magum, ${ }^{89}$ Menandrum, ${ }^{90}$ Saturninum,,${ }^{91}$ Basilidem, ${ }^{92}$ Carpocratem, ${ }^{93}$ Cerinthum et Hebionem Ioannis floruisse temporibus. Et primos 15 quidem duos a sectatoribus suis dei loco adoratos, posteriores autem Christi vel divinam vel humanam negasse naturam. Caeterum cum christianorum nomine se venditarint haeretici, obiicere quis potuisset: »Cur igitur vocas antichristos? Cur ab illorum doctrina nos absterres, qui christiana religione imbuti aeque atque tu sacro sunt fonte lavati? « Respondet Ioannes: »Infitias non eo; christiani fuerunt, 20 sed e nobis exierunt «, id est, a fide et vera religione desciverunt. In caussa fuit, »quia nunquam fuerunt ex nobis«, hoc est, recensiti quidem sunt christianorum numero, nomine et titulo, sed revera nunquam crediderunt. Nam cum a pastoris voce nunc abhorreant, certe, quales aliquando fuerint, produnt. Verissime ergo

Rom. 9. dixit apostolus: »Non omnes, qui sunt ex lsrael, sunt Israel« [Röm 9,6] neque »ii 25 filii dei sunt, qui secundum carnem recensentur, sed qui secundum promissionem« [Röm 9,8].

\author{
Z. (13) Hirenaeum] Irenaeum $Z H$ \\ 86 Tert. praescr. 10,7f. (CCSL I 196,15-20); Tert. \\ anim. 23 (CCSL II 815); 50 (CCSL II 855f.). \\ 87 Iren. haer. 1,16-22 (Harvey I 190-213). \\ 88 Euseb. hist. eccl. 2,13 (GCS IX/1 132-136); \\ 3,26-28 (GCS IX/1 252-260); 4,7,1-9 (GCS \\ IX/1 308-312). \\ 89 Apg 8,9-24. \\ 90 Menandros (um 100 n.Chr.), Gnostiker aus \\ Samaria, vgl. NP VII 1221.
}


19 Nam si fuissent ex nobis, permansissent utique nobiscum.

21v $H \quad$ Genio et natura verae religionis probat, quod hae|retici nunquam fuerint in albo populi dei et verorum christianorum numero. Quia »si fuissent«, inquit, »de numero eorum, qui vere credunt, proculdubio non potuissent agnitam abiurasse 5 veritatem. « Nam »ad quem«, inquit Petrus, »ibimus domine? Verba vitae aeternae Ioan. 6[,68f.]. habes et nos credimus et cognovimus, quod tu es Christus, filius dei vivi.« Et Paulus in Ebraeis: »Fieri«, inquit, »non potest, ut, qui fuerint illuminati gusta- Hebrae. 6[,4]. verintque donum coeleste« etc.

19 Sed ut manifesti fierent, quod non sint omnes ex nobis.

10 Caussa est, cur isti exciderint; oportuit enim triticum cribrari et ventilari paleam. ${ }^{94}$ Nam et Paulus: »Oportet«, inquit, »haereses esse in vobis, quo, qui probati sunt, 1. Cor. 11[,19]. manifesti fiant inter vos. «Idem argumenti exquisitissime et copiosissime tractavit Paulus in 2. ad Timo[theum] $\mid$ 2. cap[ite $]^{95}$ et post eum Tertullianus in insigni illo suo de praescriptionibus haereticorum opusculo. ${ }^{96}$

Ostenso periculo iungit consolationem: maximum nobis ab haereticis imminet malum, sed tuti agemus, si doctrinae spiritus sancti indivulse haeserimus. Nam quaecunque ad salutem sunt necessaria, per istum nobis sunt prodita. Ad quem modum, posteaquam apostolus Paulus satis graphice pinxisset periculosa extremi | saeculi tempora, iisdem protinus subiecit: »At tu persistito in iis, quae didicisti et 2. Tim. 3[,14]. quae tibi concredita sunt« et quae sequuntur. Locus alias est longe elegantissimus et huic nostro instituto convenientissimus. Unctionis autem vocabulo allusit Ioannes ad $\chi \rho i ́ \sigma \mu \alpha$ veterum, typum sancti spiritus, quem hoc loco vocat tòv ö $\gamma \mathbf{l o v},{ }^{97}$ praeposito articulo specificativo, designans non quemvis spiritum aut unctionem quamlibet, sed illius promissi sancti et dei spiritus. Quod negotium mirum est, quam docte absolverit Dydimus ${ }^{98}$ in libris suis de spiritu sancto aeditis. ${ }^{99} \gg$ Omnia nostis « synekdocha ${ }^{100}$ est. Nam omnia norunt fideles, quae

Z. (7) Ebraeis] Hebraeis $Z H-(10)$ cur] quur $H$

94 Vgl. Lk 3,17; 22,31.

952 Tim 2,14-26.

96 Tert. praescr. 4,6 (CCSL I 190,16-19): »Et ideo haereses quoque oportebat esse ut probabiles quique manifestarentur, tam qui in persecutionibus steterint quam qui ad haereses non exorbitauerint.«

97 Anders interpretiert Oecol. 1Joh. 42v: »)Unc- tionem habetis a sancto<, id est Christo, per quem longe honestiores sacerdotes et reges sumus.«

98 Didymus »der Blinde« (313-398), Leiter der Katechetenschule in Alexandria und Autor zahlreicher Bibelkommentare sowie des hier erwähnten Traktats »De spiritu sancto«, vgl. NP III 554; Quasten III 85-100. 
Eccle. 3[,22]. nosse oportebat. Sunt enim et alia, quae ignorasse profuerit. Dicit enim propheta: $\gg$ Altiora te ne quaesieris et fortiora te ne scrutatus fueris, sed quae praecepit tibi deus, illa cogita semper et in multis operibus eius ne fueris curiosus.« Non est enim tibi necessarium ea, quae abscondita sunt, videre oculis tuis. Vide 1. Corinth[iorum] 2. capite et Roma[norum] $11 .{ }^{101}$

21 Non scripsi vobis quasi ignorantibus veritatem, sed tanquam scientibus eam

Quod »si omnia tradidit spiritus, si omnia«, ais, »didicimus, quid opus erat tua institutione?« Respondet Ioannes: »Non scripsi indoctis et istarum rerum imperitis, sed sane institutos volui hac mea institutione excitare et currenti (quod dici 10 solet) equo calcar addere. ${ }^{102}$

| 21 et quoniam omne mendacium ex veritate non est. 22 Quis est mendax, nisi qui negat Iesum esse Christum?

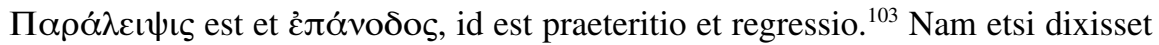
istos omnia videre, redit tamen et veluti non videntibus clarius ob oculos statuit 15 antichristos, istos, inquam, ut ut magna iactitent, nullatenus esse de coetu credentium. Idque probat hoc syllogismo: qui mendax est, is ex veritate non est (ductum a repugnantibus ${ }^{104}$ ); sed qui negat Iesum esse Christum, is est mendax; proinde qui negat Iesum esse Christum, is ex veritate non est. ${ }^{105}$ Hanc vero ratiocinationem dilucidissimam quidem, illam obscurant tropi et schemata. Nam 20 mendacium per enallagen ${ }^{106}$ ponitur pro mendace, res pro persona. Quanquam et vehementer flagitiosos soleamus ipsum vocare flagitium $x \alpha \tau^{\prime} \alpha \hat{v} \xi \eta \sigma \iota v .{ }^{107} \mathrm{Ve}-$ ritas autem sumitur pro vero, integro et solido, imo pro ipso vero dei populo, pro veris dei filiis, qui per veritatem sunt filii. Ut nunc »ex veritate non esse« dixerit pro eo, quod est $»$ non esse de consortio vere fidelium«. Porro ii negant Iesum 25

Z. (1) nosse] nosce $H-(5)$ capite] cap[ite] $H$

99 Didym. spir. 8; 73 (SC CCCLXXXVI 148150; 210-212).

100 Siehe oben S. 318, Anm. 34.

101 Röm 11,33f.; 1Kor 2,6-16.

102 Erasm. adag. 147 (ASD II/1 264,185-192): »Calcar addere currentibus. [...] Translatione sumpta ab equitibus, qui nonnunquam etiam sponte currentibus equis, quo currant celerius, calcar addunt. Ita nobis calcar addit, qui extimulat languentes; addit currentibus, qui cupiditatem ac studium nostrum auget acuitque.«

nachträgliche, verdeutlichende Wiederaufnahme der Glieder einer Aufzählung, während die

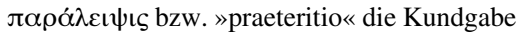
der Absicht ist, gewisse Dinge auszulassen, vgl. HLR 393; $436 f$.

104 Zum »locus de oppositis« bzw. »repugnantibus« vgl. Agric. inv. 1,26 (Mundt 164-170).

105 Der Syllogismus entspricht dem Modus »celarent «.

106 Siehe oben S. 329, Anm. 73.

103 'Eлóvoós bzw. »regressio« bezeichnet die

107 Siehe oben S. 319, Anm. 44. 
esse Christum, qui aut divinitatem aut humanitatem in Christo negant, aut qui non omnem in eo quaerunt plenitudinem, vitam et salutem. Sed de hac re copiosius disputabitur in cap[ite] $5 .^{108}$ filium, is ne patrem quidem habet. ${ }^{109}$

Palam nunc edicit, quid superioribus de antichristis disserens intellexit. Est itaque exegesis, quasi dicat: »Ex istis vero liquet istos esse antichristos, dei hostes«, nam antichristus componitur ab ỏvtí, adversativa particula, et $\chi \rho \iota \sigma \tau o ́ \varsigma, ~ » q u i$ filium aut contemnunt aut prophanant.«Deum enim, non hominem prophanant et aspernantur. Nam sicut pater suscitat mortuos et vivificat, ita etiam filius, quos vult, vivificat. Et quemadmodum pater praeter filium nihil agit, ita ne citra filium quidem iudicat (quo administrandi et regni functionem universam intelligimus) Pater non quenquam, quod et ipsum posuit pro quicquam. ${ }^{110}$ Est itaque omnis administratio filii, qui est expressa imago substantiae paternae, qui omnia moderatur verbo Hebrae. 1[,3].

15 potentiae suae in hoc, ut omnes honorent filium, sicut honorant patrem. Qui non honorat filium, non honorat patrem, qui misit illum. ${ }^{111}$ Haec transcripsimus | ex 5. Ioannis capite. Ea autem mirum in modum istorum detegunt impietatem, qui vafro dogmate Christi divinitatem negantes clamitant se isto modo divinae maiestati et gloriae consulere, ut, inquam, solus et unus adoretur deus. Sed ipsa veritas aliud statuit. Esse sane unum et solum deum verum adorandum, sed unum esse cum patre filium, ${ }^{112}$ ut qui nunc filium adorat, patrem non inhonestarit. |»Qui enim non habet filium «, inquit apostolus, »is ne patrem quidem habet.«Per filium enim agnoscitur pater. ${ }^{113}$

24 Vos igitur: quod audistis ab initio, in vobis permaneat. Si in vobis 25 permanserit, quod audistis ab initio, et vos in filio et patre manebitis. 25 Et haec est repromissio, quam ipse pollicitus est vobis: vitam aeternam.

Iam infert finalem conclusionem et id, quod piis persuasum cupit: ut, inquam, neglectis istorum novis dogmatis veritati spiritus indivulse haereant. Audierant autem ab initio sanctam apostolorum praedicationem, qua pure et simpliciter piis praedicarant ex scripturis Christum, fidem, vitae puritatem et charitatem. In his igitur vult permanere et exerceri credentes. Hic vero admiscet honesto utile. »Si«, inquit, »in vobis permanserit apostolica, quae et prophetica est, doctrina, et vos in patre et filio permanebitis.« Sed quid est in patre et filio permanere? Vitae

108 1Joh 5,1-13.

109 Zur Auslassung der zweiten Hälfte von V. 23 (»qui confitetur filium, et patrem habet«) vgl. Erasm. 1Joh. transl. (ASD VI/4 471).
110 Joh 5,22.

111 Joh 5,23.

112 Joh 10,30 .

113 Joh 14,7.9. 
aeternae consortem esse. Nam sequitur: »Et vita aeterna est illa promissio, quam promisit iis, qui perstiterint in traditione veritatis.«

26 Haec scripsi vobis de his, qui seducunt vos.

Subinde planius aperit institutum ac consilium suum, nempe, quod ista in hunc finem scripserit, ut imprudentiores a novis abstraheret haereticorum inventis, $\mid \begin{array}{ll}5 & 24 \mathrm{r} H\end{array}$ avitam autem amarent ac tenerent religionem utpote veram et firmam. Sequitur enim:

27 Et unctio, quam vos accepistis ab eo, manet in vobis. Hinc non necesse habetis, ut quisquam doceat vos, sed, sicut ipsa unctio docet vos de omnibus, ita verax est et nullum mendacium.

Sunt, qui hunc locum sic exponant: »Scio quidem nunc in vobis ut veris dei filiis unctionem manere; reliquum igitur est, detis operam, ut semper maneat. «114 Caeterum accomodatior forsan instituto apostoli fuerit hic sensus: »Non est, quod timeatis aut putetis spiritum sanctum alia nunc, alia vero olim docuisse. Nec est, quod vereamini spiritum aliquando cessaturum. Nam, sicut unicus et aeternus est 1 veritatis doctor, sic eius doctrina perpetuo sibi constat.« Si autem hic est apostoli sensus, iam primo eos confutavit, qui doctrinam suam, etiamsi a traditione apostolica esset alienissima, nihilominus spiritus sancti asserebant esse impulsum. Ioan. 14[,16f.]. Deinde vero allusit ad verba salvatoris in evangelio dicentis: »Et ego rogabo patrem et alium patronum dabit vobis, ut maneat vobiscum in aeternum, spiritum, 20 inquam, veritatis. «Huc faciunt sequentia, quibus superior haec sententia dilucidius exponitur. »Hinc non necesse habetis, ut quisquam vos doceat«, xai oủ

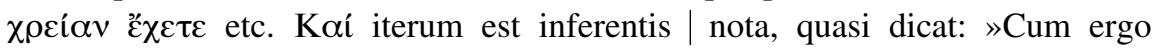
spiritum perpetuum habeatis praeceptorem, non est, quod alienos vobis asciscatis doctores. Sed spiritui obedientes istud pro certo vobis persuasum habetote, quod 25 vera et infallibilia sunt, quaecunque ille tradiderit. «Porro catabaptistae abutuntur hoc loco duplici nomine. Primo, quod per spiritum non intelligunt spiritum

2. Tim. 3[8f.]. sanctum, sed melancholiam suam, nescio quam, phanaticum scilicet spiritum, mentem attonitam et corruptissimi animi coruptissimas imo perplexissimas strophas; secundo, quod spiritum sanctum separant a scriptura sancta. ${ }^{115}$ Quasi vero 30 veritas dei a deo separari possit aut quisquam sit, qui nesciat ipsam etiam

Z. (22) necesse] neccesse $H$ - (31) separari] seperari $H$

114 Oecol. 1Joh. 46v: »Scio quidem, nunc in vobis ut germanis dei filiis manet unctio; reliquum

115 Vgl. Zw. elench. (Z VI/1 194,22-25): »Catabdate operam, ut semper maneat.« aptistę ubiubi lubet scripturam negant et spiritum suum iactant.« 
scripturam sanctam creberrime spiritum cognominari. ${ }^{116}$ Et quid, obsecro, est scriptura aliud quam instinctus spiritus sancti? Proinde noluit Ioannes istis verbis tollere praedicationem aut prophetiam, sed a sufficientia quadam haereticorum confutare dogmata. Non secus, ac si tu dicas: quaecunque ad salutem sunt ne5 cessaria, ea scripturis sunt prodita. Id si verum est, ut sane veritate comprobari potest, iam nihil opus est alienis vel doctrinis vel doctoribus. Nam si dogmata Haeretici. vestra scripturis repugnant, falsissima sunt. Quis vero audiat mendaces? Si vero ea scripturis consentiunt, qui fit, ut scripturis non omnem | tribuatis gloriam? Quid quasi de novis rebus gloriamini? Et Tertullianus author est hereti|cos ea retulisse 10 ad spiritum, successiones et apostolorum traditiones, quae scripturis firmare non potuissent: verum »confingant«, inquit, »tale aliquid haeretici. Quid enim illis Haeretici. post blasphemiam illicitum est? Sed etsi confinxerint, nihil promovebunt. Ipsa enim doctrina eorum cum apostolica comparata ex diversitate et contrarietate sua pronunciabit neque apostoli alicuius authoris esse neque apostolici. Quia sicut 15 apostoli non diversa inter se docuissent, ita et apostolici non contraria apostolis aedidissent nisi illi, qui ab apostolis desciverunt et aliter praedicaverunt. ${ }^{117} \mathrm{Haec}$ ex opusculo de praescriptionibus haereticorum. Cuius equidem libelli lectionem tam familiarem omnibus christianis cuperem, quam est usitatum et crebrum haeretici nomen.

Illatio est et rerum disputatarum conclusio, miro ardore per repetitionem illata. Hactenus enim per digressiunculam disseruit adversus novatores et haereticos de perpetua veritatis doctrina.

28 Et nunc, filioli, manete in eo, ut, cum apparuerit, habeamus fiduciam et non pudefiamus ab eo in adventu eius.

Qui capita apostolicarum epistolarum distinxit, is nullam rationem contextus Distinctio habuit; hinc factum, ut coniuncta saepius discerpserit, disiuncta vero commiserit. Huius rei argumentum vidisti in initio huius se|cundi capitis, eiusdem generis est etiam finis. Cohaeret enim cum materia capitis tertii. Nam redit apostolus et 30 horrore iudicii ceu a metu et poenis hortatur ad puritatem vitae. Quid enim aliud est manere in Christo, quam ita ambulare, sicut ipse ambulavit innocentissime? Et Christus ipse iudicii mentione hortabatur ad constantiam, cum diceret: »Quem- Mar. 8[,38]. cunque puduerit mei ac meorum sermonum in generatione hac adultera, pudebit illius et filium hominis, cum venerit iudicare.« Et per fiduciam (quae est $\pi \alpha \rho \rho \eta$ -

Z. (9) hereticos] haereticos $Z H$

116 Vgl. 2Tim 3,16.

117 Tert. praescr. 32,4f. (CCSL I 213,13-20). 
oía) non quamvis intellexit spem, sed liberam confidentiam. Nam pudori opponitur, quo fit, ut attoniti ne loqui quidem aut possimus aut sciamus.

29 Si scitis, quod iustus est, scitote, quod omnis, qui facit iusticiam, ex ipso natus est.

A coniugatis ${ }^{118}$ et natura rei duxit argumentum. Nam iustus et iusticia coniugata 5 sunt. Et ita rerum natura comparatum est, ut genuini filii parentum referant naturam. Iam vero si sumus ex deo per fidem renati et deus iustus est, certe fideles quoque iusticiae student et iusti sunt. Verba autem »scitis« et »scitote« miram habent cum gratiam tum vehementiam. Videtur enim apostolus eos perstrinxisse, qui de iusticia dei multa et magna commentabantur, imo garriebant, 10 sed impie interim vivebant. Germanus diceret: weist eins, so wüß ouch das ander.

\section{| Argumentum cap[itis] III.}

In eodem adhuc versatur argumento, adhortans ad morum vitaeque innocentiam, maxime vero ad charitatem fraternam.

\section{CAPUT III.}

1 Videte, qualem charitatem dedit nobis pater, ut filii dei nominemur. ${ }^{119}$

Amplificatione mira effert id, quod iam iam dixerat, nos esse natos ex deo, et commendat fidelibus beneficium et admirabilem charitatem dei. Sed $\gg$ charitatem dare « dixit Ioannes pro eo, quod est »beneficium exhibere« et dilectionem aliquo 20 praeclaro facinore commendare. Beneficio autem dei proposito non minus trahit ad innocentiam quam iusticia dei superius commemorata. Sic enim natura comparatum est, ut eos vicissim diligamus, qui nobis benefecerunt. Et nominari filium dei est iuxta proprietatem sermonis Hebraici esse filium dei. ${ }^{120}$

Z. (3) iusticiam] iustitiam $Z H-(5)$ iusticia] iustitia $Z H-(8)$ iusticiae] iustitiae $Z H$ - (10) iusticia] iustitia $Z H$ - (13) cap[itis]] capitis $Z H-(16)$ Caput III.] in marg. $Z H-(22)$ iusticia] iustitia $Z H$

118 Zum Locus »a coniugatis« vgl. Agric. inv. 1,10 (Mundt 64-68).

119 Zur Auslassung von »et simus« am Ende des Verses vgl. Erasm. 1Joh. transl. (ASD VI/4 472f.); Erasm. 1Joh. (ASD VI/10 530,140f.): » Et simus< apud Graecos non additur.«
120 Erasm. 1Joh. (ASD VI/10 530,143f.): »Hic loquitur de nomine quod a Deo tribuitur. Hic non est discrimen inter dici et esse.« 
1 Propter hoc mundus non novit vos, quia non novit eum.

Hic locus planior fiet, si adhibeas quartum caput prioris epistolae Petri, quo, Christiani exosi

$90 \mathrm{ZH}$ 26v $H$ postquam | ad innocentiam cohortatus esset, mox subiungit: »Atque id absurdum illis videtur, quod non accurratis una cum ipsis in eandem luxus refusionem, qui 5 de vobis male loquuntur; sed reddituri sunt rationem ei, qui paratus est iudicare vivos et mortuos « [1Petr 4,4f.]. Eandem absurditatem removet etiam hoc loco Ioannes. Nam hic est verborum sensus: »Scio equidem, quanto contemptu elevaturus sit mundus, si vos perrexeritis vitam filiis dei dignam vivere. Sed nolim quenquam eo offendi contemptu. Nam qui ex deo est, is ex mundo non est. Sed mundus sua tantum novit, ergo deum et divina non novit, et proinde mundus filios dei non potest non odisse. « Huc iam pertinent verba Christi, Ioan. 15. et 16. ${ }^{121}$ illud quoque Pauli: »Omnes, qui pie volunt vivere in Christo, persequu- 2. Tim. 3[,12]. tionem patiantur oportet«; iterum illud: »Si hominibus placerem, Christi servus Galat. 1[,10]. non essem«; illud quoque d[ivi] Iacobi: »Amicitia mundi inimicitia est cum deo. Iacob. 4[,4]. Quicunque ergo voluerit esse amicus mundi, inimicus dei constituitur.«

\section{Charissimi, nunc filii dei sumus et nondum apparuit, quod futuri sumus.}

Iterum extollit amplificatione per comparationem christianorum dignitatem, quo minus moveantur, si contemnantur a mundo. Comparatio autem in hoc consistit, quod nunc quidem filii dei dicimur, verum id quidem parvum esse, quantumvis per se magnum sit, si iis conferas, quae post hanc vitam paravit deus diligentibus 2. Tim. 2[,11f.] se. Huc fortassis quadrabit illud apostoli: »Siquidem sumus filii dei, certe cum eo Rom. 8[,17]. etiam patimur, ut et cum eo glorificemur.« Atqui adflictiones praesentis $\mid$ temporis impares sunt ad futuram gloriam collatae, quae revelabitur erga credentes. Sed quae, obsecro, est ista gloria? Quid, oro, futuri sumus? Respondet nunc et ait:

2 Scimus autem, quoniam, si apparuerit, similes illi erimus, quoniam videbimus eum, sicuti est.

Apparet autem nobis Christus, cum hinc per mortem nos ad coelestia traducit Ioan. 5[,25-29]. gaudia cumque orbem iudicaturus universum, omnem resuscitabit carnem, ut totus et integer homo aeternum cum deo vivat. Tunc similes ei erimus, liberati 30 adf adfectibus, morbis, variis corruptionibus, absoluti autem erimus et perennes. Tunc videbimus eum sicuti est, id est, ad sacietatem eo fruemur. ${ }^{122}$ Plura de hac re lege

Z. (12-13) persequutionem] persequtionem $H-(31)$ sacietatem] satietatem $Z H$

121 Joh 15,18f.; 16,20.

122 Vgl. Zw. fid. exp. (Z VI/5 130,4-131,3): »Visurum esse $[\ldots]$ numen ipsum in sua substan- tia [...] fruiturumque his omnibus non parce, sed ad satietatem.« 
in 1. Pauli ad Corint[hios] 15. cap[ite] et in epistola ad Philipp[enses] 3. et Coll[ossenses] 3. cap[ite]. ${ }^{123}$

3 Et omnis, qui habet hanc spem in eo, purificat se, sicut et ille purus est.

Ex praestructis colligit nunc omnes fideles puritatem colere vitae. Nam qui novit et credit vitam sempiternam eamque praestantiorem esse, is sese purificat, hoc Supra, est, abstinet a concupiscentiis carnis, propterea quod deus purus est et nemo illi cap[ite] 1[,6]. nisi purus cohabitare potest. Sed et indignum est, ut is, qui ad tantum destinatus est regnum quique tantarum opum haeres adoptatus est, sese omni polluat impuritate.

| 4 Omnis, qui committit peccatum, idem et iniquitatem committit, et 10 27v $H$ peccatum est iniquitas.

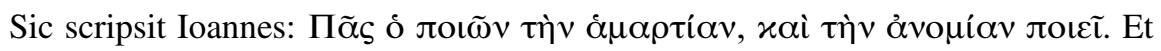
omnis difficultas in illis duabus consistit vocibus: $\alpha \mu \alpha \rho \tau i ́ \alpha$ et $\dot{\alpha} v o \mu i ́ \alpha$. Et prius quidem solet nonnunquam usurpari pro vitio et infirmitate; hic porro gravius quidpiam sonat, nempe scelus et flagitium, cum videlicet pecco non nescius, 15 quam foedam rem patrem. Posterius non multum abest a priori. Nam vó o $_{\text {o lex }}$ est, $\alpha$ $v o \mu i ́ \alpha$ autem transgressio et legis praevaricatio, summa videlicet iniquitas, cum sciens et volens pereo. Iam igitur haec erit apostoli sententia: »Qui autem christiana religione imbutus aeternam vitam credit et nihilominus perstat in immundicia, is sane infirmus dici non potest, sed contemptor verius est legum, 20 pietatis et innocentiae proditor.«Ut sit confutatio istorum, qui sceleribus suis blandientes et sese sanctimoniae titulo venditantes publica crimina solent infirmitates, errores et vitia quaedam nominare. Nam protinus subiecta sententia impuros istos arctissime urget: »Et peccatum est iniquitas «, hoc est: »Et quod in impuritate perstat, nemo $\mid$ illi pro errore imputare potest, sed summa est iniqui- $25 \quad 91 \mathrm{ZH}$ tas.« Germanice: und diß sin lasterhafft lăben, ist ein frăfel und můtwill.

| 5 Et scitis, quod ille apparuit, ut peccata nostra tolleret, et peccatum in 28r $H$ eo non est. 6 Omnis, qui in eo manet, non peccat; omnis, qui peccat, non vidit eum nec cognovit eum.

Z. (1) Corint[hios]] Corinth[ios] $Z H$ - (1) Philipp[enses]] Philip[penses] $Z H$ - (2) Coll[ossenses]] Coloss[enses] $Z H-(19-20)$ immundicia] immunditia $Z H-(26)$ frăfel] frăvel $Z H$

123 1Kor 15,50-58; Phil 3,20f.; Kol 3,1-4. 
A caussa incarnationis ducit argumentum, ut ad innocentiam trahat. Potissima (inquit) incarnationis caussa fuit, ut peccata nostra tolleret filius dei; tolleret, inquam, id est, hostia corporis sui expiaret. Deinde, ut pura doctrina et sancto vitae exemplo scelera aboleret, non equidem ut non agerent in hominum menti5 bus, sed ut sanctificati et fideles expurgarent se indies ab istis. Huc iam quadrant 15. cap[ut] Ioannis et 2. Pauli ad Titum. ${ }^{124}$ Porro ex genio credentium et exemplo Christi denuo colligit eos, qui vere pii sunt, non peccare, id est, non perstare in immundicia. Nam prius audivimus peccatum hoc loco non usurpari pro errore humano, sed pro iniquitate, quae est ex perfidia. Proinde sensus est: omnis, qui

10 fide adhaeret deo, is non perseverat in impuritate; ergo quicunque perseverat, deo non adhaeret, imo nunquam illum vel vidit vel cognovit, $\mu \varepsilon \tau \alpha \varphi о \rho\llcorner\tilde{\omega} \varsigma$ pro eo, quod est: »dei negotium nunquam intellexit.«

\section{Filioli mei, nemo vos seducat.}

Referuntur haec non tam ad praecedentia quam consequentia. Est enim exclamatio quaedam, veluti et illa:|»Qui aures habet ad audiendum, audiat!« Istis vero Matth. 13[,9]. excitantur auditorum animi, ut ea, quae dicuntur, diligentius perpendant. Et

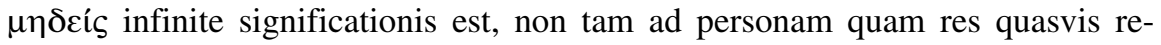
spectans: »Cavete, ne ulla res vos seducat.« Nam plurima sunt, quae innocentiae studentem remorantur. Hinc apostolus post istam Epicureorum sententiam: »Eda- 1. Cor. 15[,32]. mus et bibamus; cras enim morimur«, mox subiunxit: »Ne decipiamini. Corrum- 1. Cor. 15[,33]. punt mores bonos colloquia prava.«

\section{Qui exercet iusticiam, iustus est, sicut et ille iustus est.}

Iterum a coniugatis ${ }^{125}$ ducit argumentum, ad hunc sensum: »Qui operatur iusticiam, is certe iustus est, non is, qui multa garrit de iusticia. Hoc enim est, quod monui, ne quis sibi ipsi imponat vel ab aliis falsa specie seducatur. ${ }^{126}$ Fucum atque hypocrisim odit deus, veritatem exigit ac iusticiam, divinam quidem illam, hoc est, divinitus profectam et ad illius exemplar formatam, non ab homine vel per hominem inventam.«Ideoque additur hoc loco: »Sicut et ille iustus est.«Et in evangelio: »Nisi iusticia vestra plus abundarit quam scribarum et pharisaeorum « Matth. 5[,20]. etc.

Z. (5) istis] istis neque permittent imperium $Z H-(8)$ immundicia] immunditia $Z H-(22)$ iusticiam] iustitiam $Z H$ - (23-24) iusticiam] iustitiam $Z H$ - (24) iusticia] iustitia $Z H$ - (26) iusticiam] iustitiam $Z H-(29)$ iusticia] iustitia $Z H$

124 Joh 15,1-5; Tit 2,11-14.

126 1Joh 2,26; 3,7.

125 Siehe oben S. 338, Anm. 118. 
8 Qui committit peccatum, ex diabolo est, quoniam ab initio diabolus peccat.

Antithesis est, ab authore et factorum similitudine sumpta: quemadmodum ille iusticiam facit, qui ex iusto deo natus est, ita, qui peccat, ex diabolo natus est. Nam sicut deus sanctus est et iustus et sanctimoniae et iusticiae fons, ita diabolus 5 omnis iniquitatis author, Ioan. 8[,42-47].

8 Ad hoc apparuit filius dei, ut dissolvat opera diaboli.

Magno et gravi pondere repetitur caussa incarnationis dominicae. Et quod superius dixerat: »Apparuit, ut peccata nostra tolleret« [1Joh 3,5], id nunc paulo Rom. 5[,18f.]. planius dicit, ut dissolvat et aboleat opera diaboli. Huius autem opera mors, 10 peccatum et impietas in mundum subintroiit. Sed per Christum ea iterum elata sunt.

9 Omnis, qui natus est ex deo, peccatum non committit, quoniam semen ipsius in eo manet et non potest peccare, quod ex deo natus est.

Ex genio et natura rei argumentatur. Clarius item exponit, quod iam iam duobus 15 dixerat verbis: »Qui in eo manet, non peccat« [1Joh 3,6]. Nam hic subdit caussam: »Quoniam semen ipsius«, inquit, »in eo manet, ut non possit peccare, cum ex deo natus sit.« Alludit enim ad seminis naturam, quam ea referunt, quae ex eo nascuntur. Proinde cum deus sit purus, conse|quens est, ut et filii dei sint puri.

1. Pet. 1[,22f.]. Semen autem est verbum dei, virtus et veritas. Nam Petrus: »Diligite«, inquit, 20 »vos invicem impense et ex puro corde, renati non ex semine mortali, sed ex immortali, per sermonem viventis dei et manentis in aeternum.«

| 10 In hoc manifesti sunt filii dei et filii diaboli. Omnis, qui non facit iusticiam, non est ex deo, et qui non diligit fratrem suum.

Veluti epilogo superiora colligit et transitu quodam, mira arte ad charitatis neg- 25 otium transit. Hactenus enim de iusticia et puritate vitae disseruit. Horum summa est: quemadmodum filii diaboli impuritate, iniusticia et omni iniquitate patrem referunt, ita filii dei puritate, iusticia et omnigena sanctimonia referunt deum patrem. Proinde qui filii dei, id est veri christiani, sunt, pie quoque vivunt et semper innocentiae student. Hic autem alterum huius epistolae statum, charitatem 30 videlicet, annectit, ut unica sententia utraque complectatur capita. Fratres vero

Z. (4) iusticiam] iustitiam $Z H$ - (5) iusticiae] iustitiae $Z H$ - (24) iusticiam] iustitiam $Z H$ - (26) iusticia] iustitia $Z H$ - (27) iniusticia] iniustitia $Z H$ - (28) iusticia] iustitia $Z H$ 
vocavit ex more hebraico, quos nos vocamus proximos, sotios, contribules, cives christianos. Nam christiani initio et discipuli et fratres appellabantur. Antiochiae Ioan. 6[3.3.8.12]. coepere dici $»$ christiani $\ll .{ }^{127}$

11 Quoniam haec est annunciatio, quam audistis ab initio, ut diligatis vos invicem,

A capite doctrinae et religionis christianae ducit argumentum, ut ad charitatem incendat. Simul et superiorum caussam reddit. Quemadmodum vero unica et praecipua christianorum nota est puritas vitae, | ita et charitas. Nam ita dixit salvator in evangelio: »Praeceptum novum do vobis, ut diligatis invicem. Sicut Ioan. 13[,34f.]. dilexi vos, ut et vos diligatis invicem. In hoc cognoscent omnes, quod discipuli mei sitis, si charitatem habueritis inter vos mutuam.« Quibus verbis utrobique eodem filo ductis discimus Ioannem unice studuisse, ut quam propriissime imitaretur characterem et docendi modum Iesu Christi. Nam sicut ille in evangelio dixerat: »In hoc cognoscent« etc., ita Ioannes hoc loco dixit: »In hoc sunt manifesti filii dei.«Et sicut ille testabatur se novum praeceptum, id est praecipuum et praeclarum, in quo omnia essent comprehensa praecepta, orbi traditurum, ita Ioannes: »Haec est annunciatio«, inquit, »quam audistis ab initio« etc.

12 non sicut Cain, qui ex illo malo erat et occidit fratrem suum.

Proponit exemplum iusti et iniusti, filii dei et filii diaboli ex Geneseos cap[ite] 4. Exemplis autem nihil est in docendo nobilius, nihil apertius et quod magis Exempla. moveat. De qua re post Fabium elegantissima scripsit Erasmus in 2. Copiae. ${ }^{128}$

12 Et propter quid occidit eum? Quia opera eius mala erant, fratris autem eius iusta.

Caussam caedis obiter aperit et caedem ipsam amplificat. Opera autem posuit pro 30v $H \quad 25$ omnibus ad|fectibus et studiis. Equidem mala mens malus animus. Et sancti dei Hebr. nulla alia caussa caesi sunt semper quam iusticiae gratia, 1. Petri 4[,14].

13 Ne miremini, fratres, si odit vos mundus.

Z. (1) sotios] socios $Z H-(19)$ Geneseos] Genesis $H$ Gene[seos] $Z H-(24)$ aperit] apperit $H$ (25) adfectibus] affectibus $Z H-(26)$ iusticiae] iustitiae $Z H$

127 Apg 11,26.

128 Erasm. cop. 2 (ASD I/6 232,839-250,293); vgl. Quint. inst. 5,11 (Winterbottom I 279289). 
Ideoque cum ab ipso mox, inquit, mundi initio pium occiderit impius, minus mirandum est, si vel nostris temporibus pietas atque pii pariter exibilentur ab impiis omnibus. Nihil novi aut inusitati usu venit fidelibus, qui multis exemplis Acto. 14[,22]. praemuniti didicerunt, quod per multas adflictiones pateat via in regnum dei. Est autem species quaedam occupationis et epanaphorae. ${ }^{129}$ Nam huius rei meminit et 5 per initia cap[itis] $3 .{ }^{130}$

14 Nos scimus, quod translati sumus de morte ad vitam, quia diligimus fratres.

Consolationis loco subiiciuntur hoc sensu: »Iam etsi contemnat, adeo et occidat mundus, tamen nos de aeterna salute certi sumus. « Maximam enim et indubita- 10 tam certitudinem expressit verbo praeteriti temporis. Etenim non dixit »transferemur «, sed »translati sumus«. Sicut et Ioannis 5.: »Amen amen«, inquit Christus, »dico vobis: qui sermonem meum audit et credit ei«, sic enim exponit, quid per

Sic, inquam, aeterna erit, ut in iud[icium non veniat].

Ioan. 5[,27]. um«, hoc est poenam, »non veniet, sed transivit de morte ad vitam« [Joh 5,24]. 15 Addit conditionem apostolus: »Quia| diligimus fratres.«"O patur in scripturis quemadmodum et Hebraeorum כי ${ }^{131}$ Nam in hisce verbis Christi: »Et dedit ei potestatem iudicandi quoque, quia filius hominis est«, »quia« usurpatur pro »etsi«: licet sit filius hominis, homo verus, attamen divinam quoque usurpabit functionem, ut appareat, quod et deus verus sit. ${ }^{132}$ In praesentiarum 20 ponitur pro »dummodo«, ut sit sensus: »Translati sumus de morte ad vitam, modo diligamus fratres «, id est, »si modo vere credamus. « Nam signum verae fidei est 1. Tim. 1[,5]. »charitas ex puro corde et conscientia bona et fide non simulata«. Neque vero Galat. $5[, 6]$. temere usus est ista metalepsi, ${ }^{133}$ partim ut notaret se loqui de fide, quae per charitatem est efficax, partim ut continuaret disputationem de charitate. Nunc 25 enim sequitur:

14 Qui non diligit fratrem, manet in morte.

Z. (14) Marg. iud[icium non veniat]] iudicium non veniat $Z H$ - (20) sit.] In $Z H$ folgt zusätzlich Vel quia ille filius hominis est, quo de dixit Daniel in cap[ite] 7. [Dan 7,13f.]

129 Siehe oben S. 313, Anm. 19.

130 1Joh 3,1.

131 Vgl. Pagn. thes. 1019-1021.

132 Vgl. Aug. in euang. Ioh. 19,15 (CCSL XXXVI 198f.,20-24): »Hanc potestatem non haberet nisi acciperet, et esset homo sine potestate. Sed ipse est filius hominis, qui et Filius Dei.
Haerendo enim ad unitatem personae filius hominis Filio Dei, facta est una persona, eademque Filius Dei, quae et filius hominis.«

133 Vgl. Quint. inst. 8,6,37 (Winterbottom II 470): »[...] metalempsis, id est transumptio, quae ex alio tropo in alium uelut uiam praestat.« 
A poena et mulcta deterret ab odio et hortatur ad charitatem. Est enim veluti antithesis ei opposita sententiae: »Nos translati sumus de morte ad vitam.«Et Christus Ioannis 8.: »Nisi«, inquit, »credideritis, quod ego sum, moriemini in peccatis vestris « [Joh 8,24].

15 Omnis, qui odit fratrem suum, homicida est; et scitis, quod omnis homicida non habet vitam aeternam in se manentem.

Probat eum manere in morte, qui odiat proximum, probat autem syllogismo ex contrariis ducto ad hunc modum: omnis homicida non habet vitam aeternam $\mid$ in se manentem; omnis, qui fratrem odit, homicida est; proinde omnis, qui fratrem 10 odit, non habet vitam aeternam in se manentem. ${ }^{134}$ Per odium vero intellexit omnia, quae odium post se trahit et quae Ovidius ${ }^{135}$ probe annumeravit lib[ro] Metamorph[oseon] 2. invidiam describens. ${ }^{136}$ Huc refer omnia, quae adversus caedes, proditiones, invidiam et lites in scripturis dicuntur. Quod si miraris, qua ratione homicidam vocarit apostolus eum, qui odit fratrem, consule verba Christi

15 apud Matthaeum in 5.: »Audistis, quod dictum sit veteribus: >Non occides « $[\mathrm{Mt}$ 5,21] etc. Eodem loco dixit Christus: »Quicunque viderit uxorem proximi et concupiverit eam, iam moechatus est cum ea in corde suo « [Mt 5,28]. Item de Abraham volente filium mactare et tamen non mactante scribitur: »Quia fecisti Gene. 22[,16]. hanc rem et non pepercisti filio tuo. « Ex quibus omnibus colligimus et destinatam

20 voluntatem reputari a deo pro ipso opere. In qua sententia fuerunt et illi apud gentes, qui dixere: »In magnis et voluisse sat est. « ${ }^{137}$ Poterat et $\alpha \hat{\xi} \xi \eta \sigma \iota \varsigma^{138}$ videri. Nam hoc tropo dicimus »>occisum<, qui sit caesus«, »>exanimatum<, qui sit dolore adfectus «, et » revixisse $<$, qui spem receperit $\ll .{ }^{139}$ Porro in morte manet, qui agit vitam flagitiis undique scatentem, ex quibus existit mors. Proinde vitam Rom. aeternam in se manentem non habet, qui sceleribus palam declarat, quam nihil $6[, 16.21-23]$ fidei (quae vita est fidelium) gerat in pectore. Qui enim fratrem odit et caedit, is animum, qualis sit, prodit, prophanus scilicet et impius. Sic, inquam, con|stat homicidam non habere vitam aeternam in se manentem. Ideo vero hinc non 2. Regum

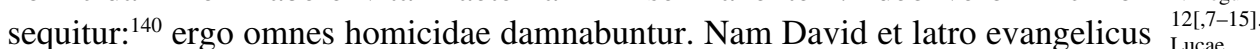
homicidae fuerunt. Et tum quidem non habuerunt vitam in se manentem, cum 23[,40-42].

Z. (3) Ioannis] Ioan[nis] $Z H-(11-12)$ Ovidius ... describens] Ovidius invidiam describens probe annumeravit libro Metamorph[oseon] 2. $Z H$ - (14) odit] odiat $H$

134 Der Syllogismus entspricht dem Modus »celarent $\ll$.

135 Publius Ovidius Naso (43 v.-17 n.Chr.), römischer Dichter, Verfasser u.a. der »Metamorphosen « und »Fasti «, vgl. NP IX 110-119.

136 Ov. met. 2,760-832 (Anderson 50-52).

137 Erasm. adag. 1755 (ASD II/4 184,759-761):
»Conuenit, vbi quis maiora viribus conatus, tametsi rei susceptae magnitudini non facit satis, tamen hoc ipso nomine laudem promeretur, quod rem pulcherrimam tentauerit.«

138 Siehe oben S. 319, Anm. 44.

139 Erasm. cop. 1,27 (ASD I/6 73,994-997).

140 Marg. »2. Regum«: Gemeint ist 2Sam. 
opera patrarent mortis. Vita enim hominis fides est, caedes ex perfidia est. Caeterum fideli poenitentia innocentia reparari potest.

16 Per hoc cognovimus charitatem, quoniam ille animam suam pro nobis posuit, unde etiam nos debemus pro fratribus animas ponere.

Occupatio est. Nam haec est apostoli mens: »Mirabitur forsan aliquis, quomodo 5 fratres sint diligendi; quis, inquam, sit modus et quae sit ratio charitatis christianae. Is ergo sciat Christum Iesum huius negotii esse absolutissimum exemplar. Hic vero pro nobis mortuus est; unde consequens est christianorum charitatem debere esse summam, utpote quae et vitam debeat fratribus, qua tamen nihil in orbe habemus nobilius aut charius.«»Quid enim«, inquit Christus, »dabit homo, 10 cuius permutatione redimat animam suam?« Allusit autem apostolus ad ista Ioan. 15[,12f.]. salvatoris verba in evangelio dicentis: »Hoc est praeceptum meum, ut diligatis vos invicem, sicut dilexi vos. Maiorem hac dilectionem nemo habet, ut quis animam suam ponat pro | amicis suis.« Animam vero usurpavit pro vita. Deinde animadvertendum et illud, quod »per hoc « dixit pro eo, quod est $»$ in hoc «, ${ }^{141}$ et 15 hac veluti certissima nota didicimus, quae sit charitatis ratio, quod ille suam nobis impendit vitam. Germanus ita redderet: darby habend wir erlernet der liebe aart.

17 Qui vero habuerit substantiam mundi et viderit fratrem suum egentem et clauserit viscera sua ab eo, quomodo charitas dei manet in eo?

Contrario exemplo sese clarius exponit et a comparatis arguit. » $\mathrm{Si} \ll$, inquit, »terrenas opes fratri non impartiris, quae interim instabiles temere et disperduntur et congregantur, quomodo vitam tuam tui nobilissimam portionem, quae semel amissa recuperari non potest, egenti impendas? Nulla itaque in te charitas dei, dei inquam, quae divinitus inspirata vel ad exemplum Christi filii dei formata sit.« 25 Verba autem apostoli plane sunt pathetica et quae ad misericordiam pium sollicitare possint animum. Paria, etsi non adeo elegantia et evidentia, legere est Iacobi $2 .{ }^{142}$ Sed longe comptiora apud Lucam in 16., ubi haec res divitis et Lazari Viscera. tragoedia ceu hypotyposi quadam oculis lectorum subiicitur. ${ }^{143}$ Viscera autem dicuntur omnia interiora hominis, ut sunt praecordia, cor, pulmo, iecur. Quia vero 30 in praecordiis, ut Platonici quoque volunt, | adfectuum sedes est, ${ }^{144}$ hinc usur- $\quad 33 \mathrm{r} H$

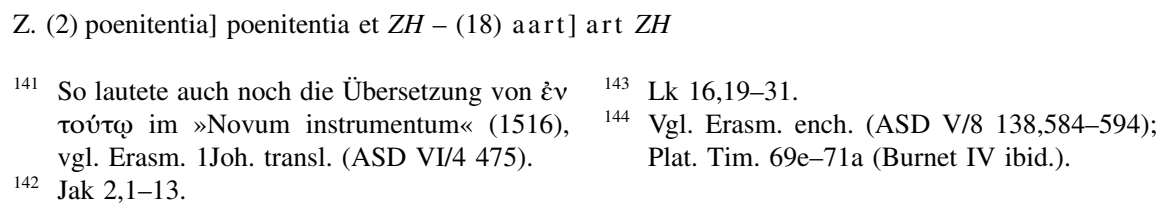


pantur viscera pro rebus ipsis, quas continent: concupiscentia, ira, dolore, gaudio, hoc sane loco pro misericordia. Est enim metonymia. ${ }^{145}$

18 Filioli mei, ne diligamus verbo neque lingua, sed opere et veritate.

Sententia est elegans, qua totum proponitur charitatis negotium. Et verbo quidem crisin et id asseverare vult, quod Iacobus apostolus istis voluit verbis: Quod si frater aut soror nudi fuerint et egentes quotidiano victu, dicat autem aliquis vestrum illis: >Abite cum pace, calescite et saturamini<, non tamen dederitis illis, quae sunt necessaria corpori, quae erit utilitas?«, Iacobi 2[,15f.]. Ad ornatum et gratiam dictionis pertinet et illud, quod sententia haec Ioannis et epiphonematis ${ }^{146}$ speciem habet et apostrophes figuram.

19 Per hoc cognoscimus, quod ex veritate sumus,

Ex veritate sunt, qui vere sunt filii dei. Nunc enim per enumerationem quandam exponit commoda christianae charitatis, id est, quid utilitatis ii percipiant, qui vere diligunt. Locus est ab honesto et utili. » $\mathrm{Si} \ll$, ait, »vere et ipso opere praestiterimus charitatis officia, hoc ipso ceu infallibili indicio comprobabimus, quod vere credimus.« Vide Matth. 25[,34-40].

| 19 et in conspectu eius suadebimus cordibus nostris.

Pertinet et illud ad praesens charitatis commodum, quod cum ad tribunal iudicis eundum fuerit, nobis nihil timendum sit eo, quod conscientiae nostrae sint pacatae, utpote de nulla sibi hypocrisi consciae. Et lectio Graecanica longe planior

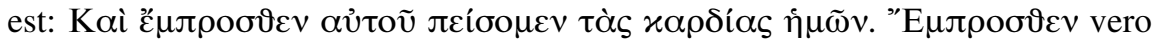
»coram« significat, veluti si quis ad conspectum statuatur iudicis. Пعí $\omega$ plura significat: »pareo «, »morem gero «, »suadeo « et »persuadeo $\ll,{ }^{147}$ item $»$ placo $\ll$, ut

25 Matt[haei] 28. Ibi enim dicunt principes Iudaeorum: »Dicite, quod discipuli eius nocte venerint et sustulerint eum, vobis dormientibus. Quod si haec res apud

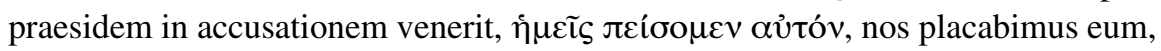

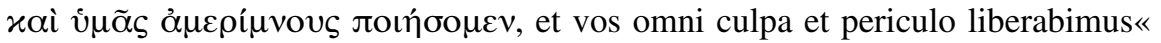
[Mt 28,13f.]. Ita hoc loco quadrantius fuerit: »Placati erimus in cordibus nostris.«

\section{Z. (25) Matt[haei]] Matthaei $Z H$}

145 Verwendung eines Wortes in der Bedeutung eines anderen, das semantisch mit dem verwendeten Wort in einer realen Beziehung steht, vgl. HLR 292.
146 Siehe oben S. 323, Anm. 57.

147 Erasm. Matt. (ASD VI/5 348,954f.): »П Graecis tria significat, $>$ pareo $<$ siue $>$ morem gero<, >suadeo $<$ et $>$ persuadeo<.« 
Cor autem affectuum sedes pro ipsis ponitur adfectuum motibus. Id quod in scripturis frequentissimum est. Fructus itaque verae charitatis et religionis est tranquilla mens, pacata et sibi bene conscia conscientia, qua nihil est in vita incundius. Quod multis alias sententiis inculcavit et Hebraeorum sapiens Solomon. ${ }^{148}$

20 Quoniam si condemnet nos cor nostrum, maior est deus corde nostro et novit omnia. 21 Charissimi, si cor nostrum non condemnet nos, fiduciam habemus erga deum,

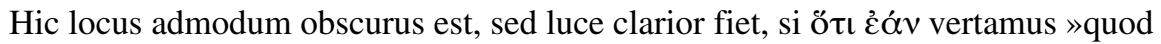
si«. Nec ignoro ö $\tau$ utrumque significare, et »quoniam« et »quod«. Caeterum 10 filum orationis | consulendum, quodnam ex multis deligendum sit. Equidem particula »quoniam« sive »quia« caussalis est, sed nulla caussalis huc quadrabit. »Quod « frequentius ordinat membra, proinde, cum duo hic iungantur membra, $»$ si condemnet« et »si non condemnet «, quadrantius erit »quod «. Deinde verisimile est orationi subesse aposiopesin ${ }^{149}$ sive, ut planius et magis proprie loquar, 15 eclipsin, hoc est defectum, qui sic possit sarciri: »Dixi de tranquilla mente et conscientia pacata. Quod si quis ista«, ut sit occupationis species, »ceu exigua et nullius momenti res contemnat credatque conscientiae motus supprimi atque dissimulari posse, is sciat deum «, id enim est deum corde nostro maiorem esse, »affectuum quoque deum esse, hoc est talem, qui abdita etiam cordis rimetur 20 adeoque norit omnia, ut hunc nihil secretorum lateat.« Huic loco duo alii ancillantur. Prior est apud Ioan[nem] in 10.: »Et pater, qui dedit mihi oves, maior omnibus est « [Joh 10,29], id est vere maximus, summus et super omnes est. Posterior apud prophetam est in Psal[mo] 93.: »Qui plantavit aurem, non audiet? Et qui finxit oculum, non considerat? « [Ps 94,9 (Vulg. 93,9)] Alii hunc locum sic 25 exponunt: »Quod si animus noster nos accuset ac damnet, fortior deus, | qui liberet et salvos faciat.«Sed quorsum referemus »et novit omnia«? Nunc enim non dicam, quod hoc sensu utraque membra coinciderent. Atqui priori sententiae multo concinnius addes nunc membrum posterius: »Charissimi, si cor nostrum « etc. Cuius sensus erit: »Caeterum si posito fuco et sublata hypocrisi in vera 30 charitate ambulaverimus, ut conscientia nostra nos non possit simulationis et mendacii convincere, iam libere cum deo agemus.« Id enim opponit iis, qui, quoniam hypocritae sunt, cum deo (qui omnia novit) libere agere non possunt.

Z. (1) adfectuum] affectuum $Z H-(11)$ orationis ... multis] orationit [sic] ostendit, utrum ex istis $Z H-$ (22) Ioan[nem]] Ioannem $Z H-$ (24) Psal[mo]] Psalmo $Z H$

148 Vgl. Spr 10; 15.

149 Unter óлобเஸ́лєøıৎ versteht man die Auslas- sung der Äußerung eines Gedankens, vgl. Quint. inst. 9,2,54 (Winterbottom II 500f.). 
22 et quicquid petierimus, accipimus ab eo.

Est et hic peculiaris verae charitatis fructus, quod, quaecunque petierimus, accipiemus ab eo. Allusit autem ad verba Christi, Matth. 6., 7. et Ioan. 15. et $16 .{ }^{150}$ At, ne quis offendatur, adhibeat et hanc Iacobi sententiam: »Petitis et non acci- Iacob. 4[,3]. 5 pitis eo, quod male petatis, ut in voluptatibus vestris insumatis.«

\section{Quoniam praecepta eius custodimus et ea, quae sunt placita coram eo, facimus.}

Caussa est, sed magis repetitum propositum, sicut et illud: »Hic erat in principio Ioan. 1[,2]. apud deum.« Nam oũ̃os exponentis est et repetentis probationem veluti conclusionis caussam. Veluti si dicam: omnis virtus est beata; veritas est virtus; ergo veritas est beata, quia virtus. Sic in evangelio: deus est ab initio; et verbum / est ab initio; ergo verbum deus, quia hoc erat ab initio. Ad hunc modum hic quoque colligit: qui vere diligunt, omnia, quae a deo petunt, accipiunt; nos diligimus; ergo omnia accipimus, quia diligimus. Nam idem est praecepta servare et diligere, Rom. 13[,10]. Sequitur:

\section{Et hoc est praeceptum eius, ut credamus nomini filii eius Iesu Christi et diligamus nos mutuo, sicut dedit praeceptum.}

Quia meminerat praeceptorum, ideo nunc omnem mandatorum summam in duo colligit capita, in fidem scilicet et charitatem. Fide agimus cum deo, sed charitate cum proximo. Porro charitatis nervus, vis et anima fides est. De nomine vero, quod pro maiestate, gloria et virtute dei accipitur, alii saepe monuerunt. ${ }^{151}$

\section{Et qui servat praecepta eius, in illo manet et ipse in eo; et per hoc} scimus, quod manet in nobis: e spiritu, quem nobis dedit.

Duplici nota et gemina sententia docet nos esse christianos: qui charitati student et innocentiae; qui huius epistolae capulus est. Prior sententia est: qui deo fidit et proximos diligit, is vere cum deo consentit verusque est christianus, sicut pluribus audisti in superioribus. Posterior vero sententia existit ex prio|re: nemo autem de consensu et amicitia dei nobiscum inita dubitare potest nisi is, qui nescit spiritum

\section{Z. (28) is] om. $\mathrm{ZH}$}

150 Mt 6,8; 7,7-11; Joh 15,7; 16,23f.

151 Vgl. Zw. Exod. [3,14f.] (Z XIII 306,29307,22): »Huc enim spectat deus hoc sermone, ut se illum esse ostendat, qui semper sit, nus- quam ac nunquam desit [...]. Nunc palam se et a potentia et a maiestate dominus adpellat, qui se paulo ante $a b$ essentia >qui sum < et >qui est adpellaverat.« 
Rom. 8[16]. sanctum in corda nostra missum, qui testetur nos esse filios dei. Ita nunc nemo 2. Cor. 1[,22]. propriis viribus servat mandata. Deinde qui Christi sunt, spiritum Christi habent; qui autem carent, ii non sunt eius.

| Argumentum cap[itis] IIII.

Interserit quaedam de probatione spirituum, deinde vero redit ad charitatem, ad 5 quam hortatur multis quidem argumentis.

\section{CAPUt IIII.}

1 Charissimi, ne cuivis spiritui credatis, sed probate spiritus, an ex deo sint, quoniam multi pseudoprophetae exierunt in mundum.

Digreditur apostolus. Nam suspenso charitatis negotio disserit de probatione 10 spirituum, occasione sumpta ex fine cap[itis] 3. Erant enim tum quoque plurimi, qui sua mendacia spiritus titulo venum exponebant. Adversus istorum impostu-

Spiritus. ram praemunit fideles et monet, ne cuivis credant spiritui. Spiritus autem significat revelationem sive dogma (metonomyce), non ipsum tantum dei spiritum. ${ }^{152}$

1. Cor. 144,32]. Est enim et spiritus malus ac mendax. Et Paulus: »Spiritus«, inquit, »prophetarum 15 prophetis subiiciuntur.« Posuit enim spiritum pro doctrina, sensu et mente enarratoris. Ea mens et is sensus prophetis subiicitur, ut, si cui vel melius vel appositius sit revelatum, ille protinus mentem in melius mutet. Et in 1. ad Thess[alonicenses] epist[ola], cap[ite] 5. | idem: »Spiritum«, inquit, »ne extinguatis « [1Thess 5,19]. Deinde sese exponit et subdit: »Prophetias ne asperne- 20 mini« [1Thess 5,20]. Quasi dixerit: »Per spiritum intellexi prophetias, hoc est dona spiritus, maxime vero scripturarum expositiones.« Ergone censes, Paule, omnia citra delectum a fidelibus esse suscipienda dogmata? Respondet: »Omnia probate et, quod bonum fuerit, tenete « [1Thess 5,21]. Ita Ioannes quoque: »Charissimi $\ll$, ait, »ne cuivis spiritui credatis, sed probate spiritus, an ex deo sint.« 25 Caussa: »Quoniam multi pseudoprophetae exierunt in mundum.« De quibus audisti in $2 .{ }^{153}$ et nonnulla audies paulo post. Recte porro monent grammatici $\psi \varepsilon \tilde{v} \delta$ o

Z. (4) cap[itis]] capitis $Z H$ - (7) Caput IIII.] in marg. $Z H$ - (11) 3.] 5. ZH - (19) Thess[alonicenses]] Thessal[onicenses] $Z H$

152 Vgl. Oecol. 1Joh. 63r; 64r: »Sunt et alii spiritus alio ducentes [...]. At non hic loquitur apostolus de spiritibus, qui in visibili forma nibus solicitant tam in doctrinis quam operibus eligendis.« apparent, sed de his, qui mentem inspiratio-

153 1Joh 2,18f 


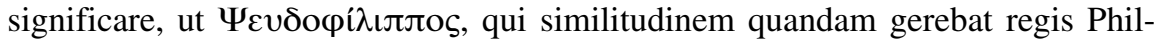
ippi. ${ }^{154}$ Vocavit igitur pseudoprophetas apostolus, qui, cum revera non sint prophetae, aliquam tamen propheticam prae se ferant speciem. Vide Iere[miam] in $23 .{ }^{155}$

\section{Per hoc cognoscite spiritum dei: omnis spiritus, qui confitetur Iesum} Christum in carne venisse, ex deo est; 3 et omnis spiritus, qui non confitetur Iesum Christum in carne venisse, ex deo non est.

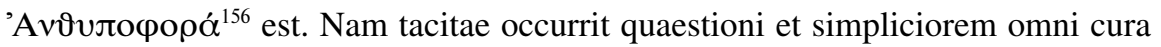
liberat, ne is per ignorantiam et imprudentiam ab argutulis istis seduceretur. | 10 Quod »si«, ait, »nescis, quae sit spirituum discretio aut quae nam dogmata vera sint, quae falsa, hanc tibi sumito regulam: omnis spiritus qui confitetur Iesum « etc. Ista autem verba apostoli plus habent in recessu, quam fronte promittant, ideoque diligentius excutiemus singula. Principio confitentur, qui vere et ex animo credunt. Confiteri enim alias laudare significat et gratias agere, ut in Confiteri.

15 Psalmis, ${ }^{157}$ et fateri, ut Iacobi 5.: »Confitemini alterutrum peccata et orate pro vobis invicem « [Jak 5,16]. Nam haec sententia refertur ad superiora, quasi dicat: »Quod si mutuae inter vos fuerint simultates, age, quisque suam culpam ingenue fateatur et condonet alteri offensam, et orate pro vobis invicem, ut salvi sitis.« Nam et invida mens et simultate exulcerata non conducit ad sanitatem corporum.

20 In praesentiarum »confiteri« est ex certa animi persuasione, imo ex perspectissima quadam $\pi \lambda \eta \rho о \varphi о \rho i ́ \alpha$ rei certissimae et indubitatae fidere, huic inniti eamque ut certissimam et verissimam palam et intrepide profiteri. Sic enim tradidit ista et ante nos divus apostolus Paulus in Ebraeis, cap[ite] 11. et in Roma[nis], cap[ite] 10.; denique ipse Christus Matth[aei] 10. ${ }^{158}$ Deinde »in carnem venire« suo more et schemate dixit pro eo, quod est »hominem induere« et »in humanis agere «. Nam idem in historia dixit: »In sua venit et sui eum non receperunt « [Joh 1,11], id est: semen Abrahae induit et inter fratres suos conversatus est, verum illi negabant $\mid$ illum esse istud semen promissum. »Porro Arrius et Hebion«, inquies, »aliaque haereticorum monstra confessi sunt Chris30 tum in carnem venisse; ergo ex deo nati sunt? « Respondeo: etsi humanam in

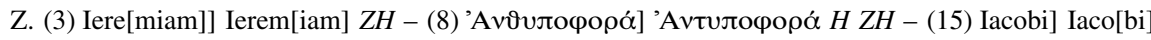

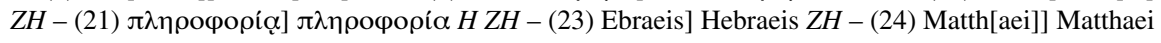
$\mathrm{ZH}$

154 Gemeint ist Andriskos von Adramyttion, genannt »Pseudophilippos«, weil er sich als Philippos, den zuvor verstorbenen Sohn des makedonischen Königs Perseus, ausgab. Andriskos war etwa ein Jahr lang (149-148 v.Chr.) König von Makedonien, mit Namen Philippos VI., vgl. NP I 688.
155 Jer 23,9-40.

156 Siehe oben S. 317, Anm. 32.

157 Vgl. Ps 97,12; 99,9; 100,4; 105,1.

158 Hebr 11,1; Röm 10,9-11; Mt 10,26-33. 
Christo naturam non negarint, tamen non crediderunt neque docuerunt Christum in carnem venisse. Nam duo sunt, quae hic significantur: alterum, quod fuerit ante carnem, et alterum ipsa caro. Aliud enim est, ad quod venitur, et aliud, quod venit. Itaque necessum est id fuisse aliquid, priusquam adve|nerit, quod in carnem venit; Christus itaque Iesus, id est persona in divinis filii, venit in carnem, id est, hominem induit, et venit in carne, id est, tanquam homo conversatus est. Id quod haeretici non confitentur. Ex quibus liquido liquet Ioannem, cum carnis meminit, non loquutum esse de humana tantum natura, ut videri poterat, sed de toto Christo vero deo et homine, sicut est una persona in duabus manens diversis substantiis. Nam notus est orthodoxorum consensus, iuxta quem ita confitemur: unus est 10 Christus »non conversione divinitatis in carnem, sed assumptione humanitatis in deum «; unus, inquam, »non confusione substantiae, sed unitate personae « ${ }^{159}$ Ita nunc commodissime intelligemus per carnem totum illud negotium, quod deus egit in assumpta carne. Tum sane hic erit apostoli sensus: »Omnis doctrina, quae huc unice spectat, ut doceat Iesum Christum dei $\mid$ filium hominis factum esse filium et in humana natura nobiscum fuisse conversatum, mortuum, resuscitatum et coelos assumptum; illum, inquam, ipsum illum esse sacerdotem et sacrificium mundi unicum, hoc est redemptionem, salutem et veritatem aeternam; ea doctrina proculdubio ex deo est. Quae autem contrarium agit, ea prorsus ex deo non est.« Et hac ratione neque Arrii neque Macedonii neque Photini ${ }^{160}$ neque Pelagii neque 20 pontificiorum doctrina omnis ex deo erit. Nam si nostris viribus et inventis paratur salus, iam Christus frustra passus est, Galat. 2[,21]. En, habes regulam, qua probes omnia omnium dogmata.

3 Et hic est ille spiritus antichristi, de quo audistis, quod venturus sit et nunc iam in mundo est.

Alludit ad ea, quae audivimus in cap[ite] 2., ${ }^{161}$ eaque dilucidius exponit. Unde nos discimus antichristi spiritum et vim coepisse apostolorum temporibus, sed nostris omnino absolutam esse. Nos enim vidimus Turcicam fidem ex Arrii et Nestorii haeresibus collectam extremis blasphemiis Christum proscidisse. ${ }^{162}$ Vidimus et hisce auribus audivimus pontificia religione, hoc est indulgentiis, satisfactionibus, 30 missis, divorum cultu, monasticis votis aliisque id genus humanis inventis Christum adeo obsolevisse, ut vix centesima humani cordis portio ei fuerit dicata

Z. (4) advenerit] venerit $Z H$ - (7) carnis] adventus in carnem $Z H$

159 Symb. Quic. (DH 76).

160 Photinos (gest. 376), Bischof von Sirmium, Schüler des Markellos von Ankyra (ca. 280374) und Vertreter einer adoptianischen Christologie, vgl. RGG ${ }^{4}$ VI 1322; LThK $^{3}$ VIII 267.

$97 \mathrm{ZH}$ 15. $37 \mathrm{v}$ 20

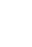


amplius. Quid ergo restat $\mid$ aliud, quam ut immani, truculenta et saevissima antichristi (quae certo imminet ac irruit) persequtione superata expectemus iustissimum venturum iudicem?

4 Vos ex deo estis, filioli, et vicistis eos,

5 Mitigatio est, species quaedam correctionis, qua consolatur in discrimine constitutos. Similis ei, quam habuimus in cap[ite] 2.: »Sed vos unctionem habetis« [1Joh 2,20] etc. Nam hic est verborum sensus: »Monitione hac forsan non erat opus apud vos, qui ex deo nati estis et spiritum dei arrabonem habetis, qui, cum sit spiritus veritatis et constantiae, non permittet, ut vos quovis vento doctrinarum Ephe. 4[,14]. 10 circumagamini. «Porro de enallage, ${ }^{163}$ quae subest verbo »vicistis «, annotavimus in cap[ite] 2. ${ }^{164} »$ Eos« refertur ad antichristos.

4 quoniam maior est, qui in vobis est, quam qui in mundo.

Caussa est: »Non vincetis vestris viribus neque vestro robore vicistis, si quid vicistis, sed dei auxilio, qui spiritu suo animat et confortat ecclesiam suam. «Dicit enim Christus in evangelio: »Spiritus veritatis ducet vos in omnem veritatem « Ioan. 14. [Joh 14,26]. »Non enim relinquam vos orphanos« [Joh 14,18], sed »alium consolatorem dabo vobis, illum veritatis spiritum « [Joh 14,16f.]. Item: »Non est, ut Lucae. anxie de defensione sitis solliciti; nam ipse dabo vobis os et sapientiam, cui non 21[,14f.]. poterunt contradicere neque resistere omnes, qui adversabuntur vobis.« Et apud dum. « Recte igitur et propriissime dixit apostolus: »Non est, quod astus et vires istorum timeatis; deus enim vobiscum est, qui solus fortis et omnipotens est.« Vide Isaiam in 51. et Paulum in Rom[anis], cap[ite] 8.; item Sapientiae 7. ${ }^{165}$

5 Ipsi e mundo sunt; ideo e mundo loquuntur et mundus eos audit. 6 Nos ex deo sumus. Qui novit deum, audit nos; qui non est ex deo, non audit nos.

| Iam vero, ne quis offenderetur multitudine et prosperitate errantium, pulchram subiicit antithesim, qua et causas utriusque religionis et doctrinae ostendit. Christiana ex deo est, sectatores eius coelestes; hinc in orbe paucissimos habet veros cultores. Nam mundus est terrenus, terrena ergo diligit. Sed hominum inventa et

Z. (2) persequtione] persequutione $Z H-(20)$ adflictionem] afflictionem $Z H-(20)$ sitis] sitis sitis $H$ (22) vobiscum] nobiscum $H-(28)$ causas] caussas $Z H$

163 Siehe oben S. 329, Anm. 73.

164 Siehe oben S. 329. 
haereticorum dogmata sunt terrena, impio, stulto et caeco homine orta; quo fit, ut impius, stultus et caecus mundus amplexetur, imo impensius sectetur mundana sive humana quam coelestia. Allusit autem ad verba Christi, quae extant in evangelio, cap[ite] 8 . et 15 . $^{166}$

6 Per hoc cognoscimus spiritum veritatis et spiritum erroris.

Clausula est. Veluti diceret: »Et hactenus quidem de probatione spirituum disseruimus.«

7 Charissimi, diligamus nos invicem, quia charitas ex deo est;

Absoluto negotio de probandis spiritibus redit ad institutum atque ad charitatem hortatur, inde enim digressus erat in fine cap[itis] $3{ }^{167}$ Nunc vero ducit argu- 10 mentum a caussis. »Diligamus «, inquit, »nos invicem, quia charitas ex deo est, res sancta et divina est, illud praecipuum dei mandatum est.«

7 et omnis, qui diligit, ex deo natus est et cognoscit deum. 8 Qui non diligit, non novit deum, quoniam deus charitas est.

Pertinent haec ad superiorem argumentationem. Idem enim clarius reddit anti- 15 thesi posita ob oculos. Et filii genium referunt parentum. Id quod supra ostendimus. ${ }^{168}$ Deus autem charitas est, $x \alpha \tau$ ' $\alpha \hat{\jmath} \xi \eta \sigma \iota v .{ }^{169}$ Nam hominem prostitutae impudentiae appellamus »impudentiam«, hominem impense clementem »clementiam«. Eodem modo et ratione eadem dixit Ioannes deum esse charitatem, qui et alias exemplar est charitatis. Iam enim sequitur:

9 In hoc apparuit charitas dei, quod filium suum unigenitum misit deus in mundum, ut vivamus per eum.

Dixerat deum esse charitatem, id vero nunc probat ex actis, ut nihilominus exemplum sit, quo credentes ad charitatem (ut postea audiemus) trahuntur. Porro singula verba pondere quodam et matura qua|dam gravitate mirifice urget lec- $25 \quad 39 \mathrm{v} H$ tores, mirifice item et supra, quam dici possit, proprie incomparabilem dei erga nos charitatem describit. »Verum hoc«, ait, »argumento probavit nobis deus charitatem suam, qua erga humanum genus adfectus est, quod filium suum

Z. (1) haereticorum] haereticoum $H$ - (4) evangelio] evangelio Ioan[nis] $Z H-(28)$ erga ... est] deperit in humanum genus $\mathrm{ZH}$

166 Joh $8,42-47 ; 15,18-25$.

167 Joh 3,23 .
168 1Joh 3,1f.

169 Siehe oben S. 319, Anm. 44. 
misit.« Nam ipse dominus Iesus in evangelio dicit: »Sic deus dilexit mundum, ut Ioan. 3[,16]. daret filium suum pro mundo.« En tibi, filium suum dedit nobis! Magnus ae- Gen. 22[,12]. stimatur et merito Abraham, qui filium suum deo dederit. Hic autem nihil offert creatura creatori, sed ipse creator deus summus, verus et aeternus filium suum, 5 suum, inquam, nobis impendit, et unigenitum quidem illum. En amplificationis incrementum. Impendit autem impio mundo. Sed quis est, qui pro amicis moriatur? Aut filium suum hosti impendat? Deus autem pro hostibus summum decus coeli suasque illas gratissimas delicias, dilectissimum filium in mortem dedit. ${ }^{170}$ Quae ergo posthac alia invenietur charitas ardentior?

10 In hoc est charitas, non quod nos dilexerimus deum, sed quod ipse dilexit nos et misit filium suum propitiationem pro peccatis nostris.

Etiam istis amplificat charitatem dei, ut hoc vehementius evidentissimis istis inferat: »Si sic deus dilexit nos « [1Joh 4,11] etc. Amplificare autem solent rhetores correctione quadam, ut Cicero in Verrem: ${ }^{171}{ }$ Non enim furem, | sed

15 raptorem; non sacrilegum, sed hostem sacrorum; non sicarium sed crudelissimum carnificem civium sociorumque in iudicium vestrum adduximus. ${ }^{172}$ Simili correctione subdidit et Ioannes: $\gg \mathrm{Nec}$ est, ut quisquam suis id tribuat viribus, quod filium suum misit deus. Non enim nos dileximus deum, sed ipse nos dilexit deus. « Non ipsi nobis salutem nostris paravimus meritis, quae revera nulla sunt, sed ille elegit nos ex gratia. Nam »elegit nos in ipso«, ut Paulinis utar verbis, »antequam iacerentur fundamenta mundi« [Eph 1,4], »ut adoptaret in filios per Iesum Christum« [Eph 1,5] etc., Ephe. 1. Hinc vero discimus, quanto contemptu et blasphemia divinae gratiae iactentur quorundam de meritis et libero arbitrio placita. Nam si salus est »ex gratia, iam non est ex operibus« etc., |Roma. 11[,6].

25 Quod autem superius extulerat: »Misit filium, ut per eum vivamus « [1Joh 4,9], id nunc sic effert: »Misit filium propitiationem pro peccatis nostris.«Vide, quae annotavimus in cap[ite] 2. ${ }^{173}$

\section{Charissimi, si sic deus dilexit nos, et nos debemus nos mutuo diligere.}

Adaptat nunc exemplum ad suum institutum. »Si«, inquit, »deus tanto nos amore 30 complexus est, ut ne filio quidem praedilecto nostri causa pepercerit, certe ius-

Z. (30) causa] caussa $Z H$

170 Vgl. Röm 5,7f.

171 Caius Verres (gest. 43 v.Chr.), römischer Senator und Statthalter der Provinz Sizilien, vgl. NP XII/2 78-81.

172 Cic. Verr. II 1,9 (Greenwood I 128): »Non enim furem sed ereptorem, non adulterum sed

expugnatorem pudicitiae, non sacrilegum sed hostem sacrorum religionumque, non sicarium sed crudelissimum carnificem civium sociorumque in vestrum iudicium adduximus.«

173 Siehe oben S. 322. 
tissimum et aequissimum est, ut etiam nos mutuo diligamus «, nec vulgariter quidem, sed impense, imo flagrantissime.

| 12 Deum nemo vidit unquam. Si diligamus nos invicem, deus in nobis manet et charitas eius est perfecta in nobis.

Tacitae obiectionis tacita responsio est. Quasi dicat: »Istis vero omnibus nolim 5 quisquam intelligat deum esse visibilem, quasi scilicet is, qui nobis in charitate imitandus praeponitur aut nobiscum consentire et foedere necti traditur, visibilis Exodi 33[20]. sit et corporeus. Stat enim scipturae sententia: >Deum nemo videbit et vivet $<$. Aliud autem volo, eo videlicet penetrare, ut intelligatis deum nobis charitate unitum esse, hoc est, eos cum deo esse nexos foedere, qui fratres diligant.« Qui 10 enim diligit, ex spiritu dei diligit. Proinde spiritus ille charitatis utrumque coniuxit: homini deum et deo hominem. Charitas itaque christiana certissimum signum est gratiae divinae, amicitiae et coniunctionis. Nam »charitas eius« ponitur pro ipso deo diligente, sicut Herculis robur et Caesaris maiestas pro ipso Hercule et Caesare usurpamus. Et Germanis usitatissimum est: uwer lieb, 15 fürstliche gnad. Annotandum et illud: $\vartheta \varepsilon o ́ v$ et hoc in loco et in historia evangelica legi citra articulum praepositivum, fortassis eius rei gratia, ut divinitatem magis intelligeremus quam deum. Nam vera est propositio: divinitas a nemine est visa. Quanquam et illa non sit falsa: deum nemo vidit unquam. Invenias tamen, qui non perinde capiant, si absolute dicas: | deum nemo vidit $20 \quad 41 \mathrm{r} H$ Rom. 9[5]. unquam. Apostoli enim viderunt Christum, qui (ut Paulus ait) »deus est super omnia benedictus «, quanquam Christi caro tantum visa sit, ut ostendimus cap[ite] 1. ${ }^{174}$ Quae omnia non in hoc monemus, ut deum et divinitatem separemus, sed ut doceamus, quanto studio quantave diligentia debeant tractari sacra. Quod si tu deum alibi legas a prophetis visum, id certe de assumpta intelliges forma vel 25 specie, qua sese voluit mortalium oculis ingerere. Huius generis plurima legas apud Tertullianum in opere illo incomparabili adversus Praxaean pro sacrosancta trinitate aedito. ${ }^{175}$ Item apud Ambrosium in lib[ro] de incarna[tionis] dom[inicae] sacra[mento]. ${ }^{176}$

13 Ex hoc cognoscimus, quod in eo manemus et ipse in nobis, quoniam de spiritu suo dedit nobis.

Clarius edisserit, quod iam iam de amicitia dei dixit. Spiritualiter (inquit) unum sumus cum deo; spiritu cohaeremus. Poterant autem haec omnia videri ab utilitate

Z. (15) uwer] üwer $Z H-(22)$ cap[ite]] capite $Z H$ - (28) incarna[tionis]] incarnatione $Z H$

174 Siehe oben S. 314.

175 Tert. adv. Prax. 14f. (CCSL II 1176-1180).
176 Ambr. incarn. 4,23-5,45 (CSEL LXXIX 235247). 
esse deducta hoc sensu: »Quod si fratres dilexerimus, unum cum deo futuri sumus.«Et in evangelio paria tribuit fidei. Dicit enim: »Qui edit meam carnem et Ioan. 6[,56]. bibit meum sanguinem, in me manet et ego in illo.« Iam ut fidelis non cupit ipsam Christi naturalem, hoc est humanam, carnem edere, sed spiritu contentus fide in Christum Iesum mortuum et resuscitatum satura|tur, ita omnes pii spiritu deum videre, spiritu deo cohaerere et, quoad in terris agunt, charitate uniri gaudent.

\section{Et nos vidimus et testamur, quod pater misit filium servatorem mundi. 15 Quisquis confessus fuerit, quod Iesus est filius dei, deus in eo manet et ipse in deo.}

10 Epanaphora ${ }^{177}$ redit ad id, quod dixerat: »Et misit filium suum propitiationem pro peccatis nostris « [1Joh 4,10]. Id vero poterat alicui videri infirmatum per subiectam sententiam: »Deum nemo vidit unquam« [1Joh 4,12], quasi Christus non sit deus. Mature itaque redit ac dicit: »Et nos vidimus et testamur «, quae apostolica est attestatio, rhetorica asseveratione et vehementior | et certior. Plura huius generis annotavimus in cap[ite] $1 .{ }^{178}$ Addit: »Ad religionem itaque pertinere, ut confiteamur «, id est, »credamus Iesum esse dei filium. Nisi enim sic credas et fatearis, profecto neque tu in deo eris neque deus in te manebit«, hoc est, neque propitium numen neque cum numine foedus habebis. Quod si hanc sententiam apostoli ei iunxeris, quam in initio 4 . cap[itis] de adsumpta carne tractavimus, ${ }^{179}$ 20 videbis Christum duabus (ut monuimus) constare naturis. Secundum naturam divinam salus est et vita; secundum humanam gratiae pignus et redemptionis praecium. Plura require ex tertio et sexto cap[itis]| Ioannis, item ex Paulo ad Romanos 3. et ad Hebraeos 1. ac 2. capite. ${ }^{180}$

16 Et cognovimus et credimus charitatem, quam habet deus in nobis. Deus charitas est, et qui manet in charitate, in deo manet et deus in eo.

Fidei certissimo negotio charitatis coniungit (ut in coepta pergat via) aeque certum negotium, eadem utens asseveratione. Hoc enim dicit: sicut visa et comperta docuimus de fide in dominum Iesum, ita certa quoque tradimus de charitate. Quod scilicet deus charitas sit ${ }^{181}$ (en, ut nunc colligat) et qui in charitate manet, 30 in deo etiam maneat et deus in eo. Nam cum deus videri ab hominibus non possit $^{182}$ nisi per spiritum et benefacta sua, recte ex actis vocavit deum charitatem:

Z. (18) foedus] foedus et communionem $Z H$ - (22) praecium] pretium $Z H$ - (23) Romanos] Rom[anos] $\mathrm{ZH}$ - (23) Hebraeos] Hebr[aeos] $\mathrm{ZH}-(23)$ capite] cap[ite] $\mathrm{ZH}$

177 Siehe oben S. 313, Anm. 19.

178 Siehe oben $312 \mathrm{f}$.

179 Joh 4,2f.

180 Joh 3,16; 6,51; Röm 3,25; Hebr 1,3; 2,5-8.

181 1Joh 4,8 .

182 Joh 4,12 . 
ein früntlich lieblich gůt. De quo nonnihil attigimus inter initia huius capitis. ${ }^{183}$

17 In hoc perfecta est charitas nobiscum, ut fiduciam habeamus in die iudicii, quod sicut ille est et nos sumus in mundo hoc.

Abrupta hortatione docere instituit, ut tamen non currat (quod dici solet) »extra oleas «. ${ }^{184}$ Nam notis quibusdam certis veram et absolutam charitatem designat. Ubi ego per charitatem non tantum dilectionem, sed etiam totam religionem intelligo, quae fide et charitate | absolvitur. Igitur duabus notis certo deprehendemus, an vera religione vere simus imbuti. Prima: si conscientiam habuerimus in die iudicii inconcussam; secunda: si in hoc mundo instituerimus vitam nostram ad 10 exemplum Christi, ut et nos in innocentia vitae et summa vivamus charitate, sicut et ipse vixit. Et de hac re satis disputatum est in cap[ite] $2 .{ }^{185}$ De fiducia vero in die iudicii habenda et de impavida conscientia, de qua saepius coeperat dicere apostolus nec unquam absolvere poterat, audiamus, quae sequuntur:

18 Timor non est in charitate, sed perfecta charitas foras eiicit timorem, quia timor cruciatum habet. Qui autem timet, non est perfectus in charitate.

Non est, quod multis agamus de timore servili et filiali neque de timore dei, qui est religio eius, cura et studium mandatorum eius et reverentia eius. De quo

Prover. 2. propheta dixit: »Initium sapientiae est timor domini « [Spr 1(!),7]. Nihil enim 20 horum hic agitur. Sed timor sumitur pro desperatione et conscientia consternata, quae angitur curis indefessis. Nam ipse Ioannes statim subiecit: »Timor cruciatum habet.« Vult ergo dicere apostolus: »Qui vere pii sunt vereque cognoverunt illud amabile, quod deus mundo per filium exhibuit, negotium, imo beneficium, ii desperare non possunt.« Nam religio, quae absoluta est, timorem expellit, hoc est, 25 Rom. 5[,1]. conscientiam | pacificat. Nam ex fide existit pax. Unde in evangelio legimus: Ioan. 4[,13f.]. »Qui bibit ex aqua hac, sitiet iterum; qui autem ex ea biberit, quam ego dabo, non Ioan. 6[,35]. sitiet in aeternum. «Item: »Ego sum panis vitae: qui venit ad me, non esuriet, et qui credit in me, non sitiet unquam.« Quod si quis timet, id est, si adhuc acerba ringitur conscientia, is in charitate non est perfectus, id est, nondum vere et 30 absolute, ut debebat, credidit, nondum sese totum dedidit amico dei negotio. Nam Esa. 57[,15f.]. qui fieri posset, ut eius pungeretur conscientia, cuius intellexisset animus deum

Z. (32) cuius ... animus] qui credidit $Z H$

183 1Joh 4,9.

184 Erasm. adag. 1110 (ASD II/3 136,186-188): »Extra oleas [...]. Vbi quis terminos prae-

scriptos transgreditur aut aliena nec ad rem pertinentia facit dicitue.«

185 Siehe oben S. 324-327. 
nihil posse negare fidelibus, quippe qui nec filio pepercerit, sed pro nobis om- Rom. 8[,32]. nibus tradiderit illum? Hinc vero coniicere licet pontificiam religionem omnium esse ut perversissimam, ita stultissimam quoque, utpote quae rebus nitatur, e quibus nullam expectes animi tranquillitatem.

19 Nos diligimus eum, quoniam ipse prior dilexit nos.

Videtur nunc epilogum contexere eorum, quibus hactenus inflammavit ad charitatem. Charitas oritur non ex homine, sed ex deo, quem ideo diligimus, quod ipse et amo|rem sui prior inspiraverit et beneficiis suis ad amandum se illexerit.

20 Si quis dixerit: diligo deum, et fratrem suum oderit, mendax est.

43v H 10 Colligit magnificis verbis non delectari deum, sed $\mid$ splendido charitatis opere. Qui enim fausta precatur fratri egenti, interim inopiam eius, cum possit, non iuvat, nihil praestitit. Proximus enim (ut in 2. cap[ite] audivimus) ${ }^{186}$ opere, non sermone diligendus est. Et dilectio dei et proximi ita cognata sunt, ut altera sine altera non subsistat. ${ }^{187}$ Hinc sequitur:

1520 Qui enim non diligit fratrem suum, quem vidit, deum, quem non vidit, quomodo potest diligere?

A comparatis colligit. Nam ea, quae coram contuemur, plus movent quam ea, quorum mentionem tantum audivimus. Si ergo habeas substantiam huius mundi, videas autem fratrem tuum egere et non communicaveris ei facultates tuas, iam 20 nulla est in te dei charitas. Ille enim ut invisibilis est, ita non potest nisi per spiritum suum habitare in pectoribus nostris. Sed spiritus dei comis est, benignus et misericors. Tu vero difficilis es, immitis et immisericors, haec itaque facta palam testantur, quod, ut spiritum dei non habes, ita neque ipsum deum diligas neque proximum.

21 Et hoc habemus praeceptum ab eo, ut, qui diligit deum, diligat et fratrem suum.

Summario legis concludit hoc negotium. Est autem haec summa legis et prophetarum: dilige dominum deum tuum ex toto corde et proximum tuum sicut $\mid$ te

Z. (4) tranquillitatem] traquillitatem, quae item doceat nescire hominem, odio an amore dignus sit $Z H-$ (22) immitis] imitis $H$

186 Joh 2,10f.

187 Vgl. Mt 22,37-40 parr. 
ipsum. ${ }^{188}$ Dicit ergo Ioannes: »Quid vero multis opus? Ipsa dei praecepta omnia in hoc sunt tota, ut diligamus deum et proximum. Proinde, qui vere deo inservire velint, qui re, non ipso tantum nomine christiani esse, quam nominari, malint, fratres diligant.«

\section{Argumentum cap[itis] V.}

Disserit de virtute fidei; fidei, inquam, quae est in Christum Iesum, qui sit verus dei filius et aeterna credentium salus, adeo ut extra eum non sit ulla salus.

\section{CAPUT V.}

1 Omnis, qui credit Iesum esse Christum, ex deo natus est.

Apostolicae functionis erat non modo opera iusticiae inculcare, sed et vim ip- 10 samque bonorum operum, innocentiae videlicet et charitatis, animam, quae fides est, accurate curare eamque potissimum exornare provinciam. Apostolus itaque cum fidei, redemptionis et sanguinis Christi in innocentiae et charitatis negotio saepius meminisset, nihil tamen solide et ex professo de iis scripsisset, nunc accingitur, ut solide et quantum satis esse possit de fide in dominum Iesum 15 scribat. Et initio quidem caput fidei proponit. Deinde vero ostendit, quod haec fides non sit otiosa quaedam (ut aiunt) qualitas in animis hominum, sed virtus et potentia dei, e qua $\mid$ illa duo maxima, de quibus hactenus egit, innocentia et charitas nascantur. Et haec duo in praesentiarum tractabimus. Caput itaque fidei hoc est, ut credamus Iesum esse Christum, id est, Iesum esse Messiam. Nam esse 20 Christum est esse Messiam. In idem recidit vox utraque, sed altera est altera

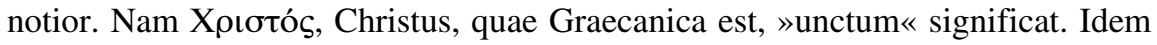
significat et משיח, Messias, quae Hebraica est. Est autem Messiam sive Christum esse regem et pontificem esse maximum, liberatorem, hostiam, redemptionem et salutem. Reges enim et pontifices inungebantur. Regum autem erat liberare et 25 servare. Pontificum hostiis atque donis iratum numen placare. Christus ergo Iesus, veri Israelitici populi rex et sacerdos verus, venit in orbem et ea mundo praestitit, quae boni et iusti principes suo populo solent et debent: sanctas tulit leges; impias et tyrannicas solvit; oppressam libertatem et ab impiis dirutam restituit; ementes et vendentes e templo (veluti sacer templi dei verus rex) 30 exturbavit ${ }^{189}$ pharisaicam et humanam doctrinam impiam iuxta ac inutilem la-

Z. (3) quam nominari] om. $Z H$ - (5) cap[itis]] capitis $Z H$ - (8) Caput V.] in marg. $Z H$ - (10) iusticiae] iustitiae $Z H-(31)$ pharisaicam] pharizaicam $H$

188 Vgl. Mt 22,37-40 parr.

189 Mt 21,12-17 parr. 
befactavit; ${ }^{190}$ dei gloriam asseruit. Sed et ipsum sese deo patri obtulit, certe ut a daemonis tyrannide et aeterna morte suos liberaret. Idem a mortuis resurrexit et tanquam aeterni regni rex et sacerdos aeternus coelos ascendit, ut ibi pro suis intercedat et in orbe regnet, ve|rus deus in saecula saeculorum. Haec vero omnia confitemur, cum confitemur Iesum esse Christum. Haec item omnia tradebat in synagogis Iudaeorum aposto|lus Paulus, cum ostenderet Iesum esse Christum. Act. 17[,2]. Haec confitebatur et apostolus Petrus, cum omnium apostolorum nomine interroganti Christo, quem se esse dicerent, responderet: »Tu es Christus, filius dei Matth. 16[,16]. vivi.« Quemadmodum vero Petrus post eam confessionem audiebat: »Caro et 10 sanguis non revelavit tibi, sed pater meus, qui in coelis est « [Mt 16,17], ita hoc in loco audimus: »Omnis, qui credit Iesum esse Christum, ex deo natus est.« Est enim ex deo natum esse a deo doctum esse adeoque et coelitus renatum esse. De Ioan. 6[,45]. qua nativitate pluribus egit Christus apud Ioannem in 3., ubi Nicodemum instituit et ait: »Nisi quis renatus fuerit e supernis, non poterit« [Joh 3,3] etc. Et haec in transcursu de capite fidei disseruimus. Videamus nunc, quomodo ostendat hanc fidem esse vivam et bonorum operum feracem. Sequitur:

1 Et omnis, qui diligit eum, qui genuit, diligit et eum, qui natus est ex eo.

Ex deo nascuntur credentes, sicut modo audivimus; proinde credentes sunt filii dei. Iam ergo docet similitudine humana, quod fides non possit non progignere a 20 se charitatem. Nam ita comparatum est in rebus humanis, ut, qui patrem diligat, filium quoque | patris nomine diligat. Quid quod unicum habent omnes credentes patrem? Unde consequens est omnes credentes esse fratres uno patre genitos. At immane fuerit flagitium, si fratrem quis uterinum oderit aut caeciderit.

2 In hoc cognoscimus, quod diligamus filios dei, cum deum diligimus et praecepta eius servamus.

Nota est, unde possit cognosci, quod vere diligamus. Si (inquit) ipsum diligamus deum, necessario diligimus etiam fratres. Deinde, si rationem habuerimus mandatorum eius, iam necessario diligimus. Dilectionem enim praecepit deus. A pronunciatis igitur denuo probavit, quod fides non sit sine charitate. Subiicit 30 evidentem caussam et assertionem:

3 Haec est enim charitas dei, ut praecepta eius servemus.

\footnotetext{
Z. (12) renatum esse] esse renatum $Z H-$ (13) Ioannem] Ioan[nem] $Z H$

190 Mt 15,1-20 par.
} 
Hoc est: ea est enim natura eorum, qui diligunt deum, ut praecepta eius servent; sed summa praeceptorum est charitas; ergo genio et instinctu quodam naturae, quae ex renascentia est, diligant.

3 Et praecepta eius gravia non sunt, 4 quoniam omne, quod natum est ex deo, vincit mundum; et haec est victoria, quae vicit mundum: fides vestra.

Interserit hoc, ne quis obiiciat praeceptorum dei $\mid$ difficultatem. Nam per contrariam sententiam dicit: »Et praecepta eius gravia non sunt.« Huius rei statim addidit: »Quoniam omne, quod natum est ex deo«, nascuntur autem ex deo, qui credunt, »vincit mundum. « At in 2. audivimus mundum aliud nihil esse quam malarum rerum concupiscentiam et studium. ${ }^{191}$ Fides igitur ea est victoria (vide ut 10 ipsum sese exponat), quae vicit mundum. Hinc fit, ut praecepta eius non sint Philip. 4[,13]. gravia. Quia ipsa fides, qua renascimur, facile potest omnia. »Omnia enim possum in eo«, inquit apostolus, »qui me confortat.« Atque hoc modo pulchre coniunxit charitati puritatem vitae, ut, quae hactenus per integram epistolam coniuncta tractavit, eadem ne hic quidem, ubi de fidei vi agitur, separet. Nam ex 15 fide enascitur non modo charitas fraterna, sed et sancta innocentia, temperantia et puritas. Ita simul et hoc probavit, quod vera fides non sit otiosa neque veri fideles sint impuritati dediti. Nam sanctam esse fidem et sanctimoniae genitricem. Huc refer integrum cap[ut] 11. ad Hebraeos de virtute fidei scriptum et videbis, quomodo fide vicerint mundum omnes a condito mundo servi dei. Huc pertinet et 20

Matth. 16[18]. illud Christi verbum: »Et portae infernales non praevalebunt adversus eam«, ecclesiam, quae per fidem Christo Iesu innititur. Illud quoque: »Omnia possibilia sunt credenti $\ll[$ Mk 9,23].

| 5 Quis est, qui vincit mundum, nisi qui credit, quod Iesus est filium dei?

Pulchre connectit omnia. Nam commode nunc transit ad id, quod instituerat 25 probare: Iesum esse dei filium, verum Messiam. Pertinent enim haec ad expositionem superioris sententiae: »Omnis, qui credit Iesum esse Christum, ex deo natus est « [1Joh 5,1]. Iam enim absoluta fidei vi et ostenso, quod fides non sit vana quaedam opinio, sed efficax virtus, accingitur, ut caput fidei, quod in initio summarie tantum proposuerat, firmis nunc fulciat argumentis. Hisce nimirum, 30 quae iam sequuntur.

Z. (7) causam causam] caussam $Z H-$ (19) Hebraeos] Heb[raeos] $Z H$

191 Joh 2,16. 
6 Hic est, qui venit per aquam et sanguinem, Iesus Christus;

$103 \mathrm{ZH}$
| Alii hunc locum varie exposuerunt. ${ }^{192}$ Ego, si quid mihi post alios coniicere licet, ista diligentius pensitanda piis propono lectoribus. Duobus potissimum argumentis probare vult, quod Iesus sit filius dei, verus salvator mundi. Iccirco enim

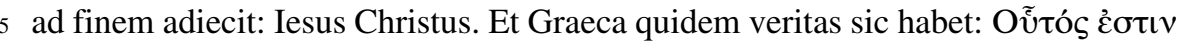

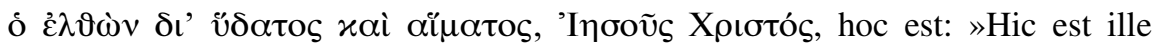
veniens « aut »qui venturus erat per aquam et sanguinem, Iesus Christus.«Quasi senserit divinum spiritum per scripturas praenunciasse aliquando venturum esse salvatorem, qui se orbi probaturus sit per aquam et sanguinem, quod sit salvator. |

10 Per aquam vero intelligimus coelestem doctrinam et sapientiam idque ob puritatem, et quod reficiat ac fluat. Nam $\rho v ́ \omega$ »fluo« est, unde et $\rho$ ó $\varsigma$, fluxus, oratio et verbum. Ex aqua fere omnia nascuntur, aqua omnia conservantur et vegetantur. Ita nunc metaphorice doctrinam Christi vocavit aquam. Sed et sanguinis nomine allusit ad veterum sacrificia. Et »sine sanguinis effusione«, ait apostolus, »non fit Heb. 9[,22]. remissio«. Ponit ergo sanguinem pro hostia, remissione et redemptione. Venit igitur Iesus doctor et lux mundi, ${ }^{193}$ hostia et redemptor aeternus. Nam docuit coelestem sapientiam et morte sua vivificavit nos et sanguine suo lavit. Quibus ceu infallibilibus argumentis mundo declaravit, quod ipse sit Christus, hoc est, quod Iesus verus sit Messias, verus dei filius.

6 non per aquam solum, sed per aquam et sanguinem.

Correctione rem amplificat. Nam Iesus Christus non modo venit per aquam, id est doctor aut legislator, veluti Moses aliquis, sed per aquam et sanguinem, id est redemptor et conciliatio mundi, cui aquam, id est, evangelicam iunxerat praedicationem. Ita vides aquam, id est doctrinam, non esse solam, sed sanguini iunctam. Hinc in evangelio dixit Ioannes: »Legem per Mosen esse latam, sed gratiam Ioan. 1[,17]. et veritatem per Iesum Christum esse exortam.«

6 Et spiritus est, qui testificatur,

\section{Z. (3-4) argumentis] argumenttis $H$}

192 Vgl. Oecol. 1Joh. 88v: »Duobus etenim sacramentis benignam suam erga nos voluntatem Christus indubitatam esse voluit, quorum symbola hic nominantur, nempe aqua et sanguis, quae ex latere Christi mortui effluxerunt non absque mysterio. [...] Aqua baptismus, sanguine synaxis, quae et ad martyrium cohortatur, nobis commendatur.« Erasm. par.
1Joh. (ASD VII/6 283,739-742): »Per aquam venit et sanguinem Jesus Christus - per aquam vt nos ablueret a peccatis, per sanguinem vt nobis vitam conferret immortalem. Baptizari voluit immunis ab omni peccato vt nobis largiretur innocentiam; mori voluit in cruce vt nobis aperiret viam ad immortalitatem.«

193 Joh 8,12. 
Est et spiritus peculiare argumentum, quod Iesus sit Christus verus dei filius. Per spiritum autem intellexit vel illud spiritus sancti testimonium, de quo legimus Ioan[nis] 1.: »Vidi spiritum descendentem de coelo specie columbae« [Joh 1,32] Rom. 1[,4]. etc.; vel illud, quod et Paulus allegat in Romanis: »Qui declaratus fuit filius dei cum potentia per spiritum sanctificationis« etc. De quo, qui copiosissima velit, 5 legat Isaiam in 11. cap[ite] et $61 .{ }^{194}$ Additur robur et aggravatio:

6 quoniam spiritus est veritas.

Spiritus testimonium verum, certum et divinum est testimonium, ut, si solum restaret, satis roboris caussa haberet.

7 Quoniam treis sunt, qui testimonium dant: 8 spiritus et aqua et sanguis, et hi treis unum sunt.

Veluti in foro res agatur, producit testes. Dixerat omnino verum esse, quod Iesus sit Christus. Id porro negabatur a multis. At Moses voluit, ut res dubiae discernerentur duorum aut trium contestatione. Nam $\gg$ in ore«, inquit, »duorum aut trium stabit omne verbum « [Dtn 19,15]. Probaturus ergo rem dubiam Ioannes et 15 in certum ordinem compositurus testimonia aquae, sanguinis et spiritus, tres producit testes; aquam, inquam, sangui|nem et spiritum, de iis loquens, tanquam personae sint, quae revera personae non erant. Subest itaque verbis prosopopoeia. ${ }^{195}$ Iam vero, si testes non consentiant, vanum est testimonium. Proinde non temere subiunxit: »Et hi treis unum sunt «, id est, omnium suffragia sive testi- 20 monia consentiunt et in idem recidunt. Germani exactius id schematis ita reddimus: die zügen sind ein $\beta$. Quidam multis hic agunt de unitate trinitatis, sed non in loco suo. Nihil enim hic agit de unitate trinitatis, quae alibi commodius et firmius inducitur et comprobatur. Nam illud membrum, quod quaedam insertum habent exemplaria (»quoniam tres sunt, qui testimonium dant in coelo: pater, 25 sermo et spiritus sanctus, et hi treis unum sunt ${ }^{196}$ ) e margine videtur irrepsisse. ${ }^{197}$ Annotavit forsan sciolus aliquis istud, qui non vidit aqua significari coelestem doctrinam, sanguine redemptionem et spiritu virtutem et administrationem divinam. Fecit itaque ex aqua patrem eo, quod ex aqua omnia generari dicantur, ex sanguine filium eo, quod sanguinem fuderit, sed ex spiritu personam spiritus 30

Z. (22) einß] eins $Z H-(27)$ Annotavit ... istud] Annotavit id forsan sciolus aliquis $Z H$

194 Jes 11,$2 ; 61,1$.

195 Siehe oben S. 321, Anm. 50.

196 Zit. nach Erasm. 1Joh. transl. [5,7] (ASD VI/4 482).

197 Erasm. 1Joh. (ASD VI/10 542,276f.): »In co-

dice qui mihi suppeditatus est e bibliotheca minoritarum Antuerpiensium, in margine scholium erat asscriptum de testimonio Patris, Verbi et Spiritus.« 
sancti. Verum plura huius generis annotata sunt et ab Erasmo in eruditissimis illis suis in novum testamentum Annotationibus. ${ }^{198}$

9 | Si testimonium hominum accipimus, testimonium dei maius est, quoniam $\mid$ hoc est testimonium dei, quo testificatus est de filio suo.

5 Confirmat sua fortius argumento ducto a comparatis, a minore ad maius, ut: si quis civi honorem putat deferendum, cur non magis consuli? Ita hoc loco: » $\mathrm{Si} \ll$, ait, »humano credimus testimonio, cur divino non crederemus? At divinum testimonium hoc palam asseverat, quod diximus de filio, nempe quod Christus sit vita et redemptio. Proinde certum est, quod Iesus sit Christus.« Similia lege in 10 historia, Ioan. 5[,36f.].

10 Qui credit in filium dei, habet testimonium in seipso. Qui non credit deo, mendacem fecit eum, quia non credit in testimonium, quod testificatus est deus de filio suo.

Prius est, ut Christum, quis et qualis sit, cognoscamus; posterius vero, ut cognito ita adhaereamus, sicut eum cognovimus. Iam vero cognovimus eum ut filium dei et unicum et aeternum salvatorem totius mundi; proinde aequum est, ut Iesu Christo toto corde fidamus et nitamur ut saluti. Et hic est finis praedicatae religionis christianae. Hinc et Ioannes idem pulchre ingerit, posteaquam, quis esset, docuisset. Iam itaque: »Qui«, inquit, »testimonio dei credit, quo testatus est Iesum esse vitam et salutem, is testimonium habet in se ipso«, id est: ipsam vitam et redemptionem habet in seipso | vereque assecutus est. Nam usurpavit testimonium pro ipsa re testata, pro ipso Christo aut salute. Et per antithesim pro suo more adiicit: »Qui autem hoc divinum testimonium non suscipit, is deum mendacii coarguit.« Caussa: »Quia non credit in testimonium« etc.

11 Et hoc est testimonium, quod vitam aeternam dedit nobis deus et haec vita in filio eius est. 12 Qui habet filium, habet vitam; qui non habet filium dei, vitam non habet.

Ne quid obscuritatis inesset rei nobilissimae et summae hanc subiungit exegesim, ut omnia ipso sole clariora fierent utque nullo alio indigeremus interprete. Et quid, oro, potuit clarius dici, quam quod dictum est? »Et hoc est testimonium,

Z. (7) cur] quur $H$ - (9) vita ... redemptio] doctor coelestis, vita orbis et redemptio $Z H$ - (15) ita] eo modo $Z H-(15)$ sicut] quo $Z H-(21)$ assecutus] assequtus $H-(29)$ interprete] iuterprete $H$

198 Erasm. 1Joh. (ASD VI/10 540-550). 
quod vitam aeternam dedit nobis deus.« Rursus ne quis nesciret, quomodo oblatam assequeretur aut susciperet vitam, addidit: »Et haec vita est in filio dei, ut, qui nunc filium dei per fidem possideat, is certo vitam aeternam habeat; qui vero huic non fidat, is vitam prorsus non habeat. En tibi, brevia, absoluta et clara habes. Quid vero dicent ad haec sacrosancta et luce clariora verba pontificii? Qui credit in filium (ait apostolus), habet vitam, adeo omnis in filio habitat plenitudo. ${ }^{199}$ Qui non credit in filium, vitam non habet, adeo extra hunc non est ulla alia salus. Ideoque qua fronte quave impudentia audetis vos vi|tam vestris tribuere inventis, qui auditis in unico Iesu Christo et in nulla alia re esse salutem? An non intelligitis? In nullo alio est salus. Nullum aliud est medium. Nemo venit ad deum, nisi per Christum. Vestris sane naeniis populum deo per Christum non adducitis, sed a deo quam longissime abducitis, ut, inquam, eam gloriam creaturis deferant, quae revera creatoris et mediatoris Christi erat. An ne pudebit vos aliquando vestrae impietatis? Quod si Christo (ut videri vultis) vere creditis, uni omnem date gloriam et cum apostolo ex animo clamate: »Absit, ut glorier, nisi in 15 cruce domini nostri Iesu Christi, per quem mihi mundus crucifixus est et ego mundo«, Gal. 6[,14]. Vide igitur, o ingratissimum saeculum, an haeresim doceamus, qui adversus impii antichristi regnum unici Christi unicam gloriam tam anxie adserimus!

13 Haec scripsi vobis, qui creditis in nomen filii dei, ut sciatis, quod vitam habetis aeternam, et credatis in nomen filii dei.

Pertinent etiam ista ad exegesim superiorem. Nam »haec «, inquit, »scripsi vobis de aeterna salute, non quod putem vos esse incredulos; sed credentes confirmare volui, ut hoc certiores sitis de vera salute«, observa emphasim, »neque quicquam dubitaretis de vita.«Et $» u t$ credatis «, id est »credere pergatis «. Nam iam nunc 25 audivimus eos credidisse et proinde haec de perseverantia sunt interpretanda. Credimus autem »in nomen filii dei«, $\mid$ id est, pro|pterea credimus in Christum, quod sit filius dei. Nam nulla creatura potest esse fidei obiectum. Ergo nos credimus in nomen filii dei, id est, innitimur divinae eius virtuti.

14 Et haec est fiducia, quam habemus apud eum, quod, si quid petierimus secundum voluntatem eius, audit nos. 15 Et si scimus, quod audit nos, quicquid petierimus, scimus, quod habemus petitiones, quas postulavimus ab eo.

Z. (4) habeat] haceat $H$ - (30) fiducia] fidutia $Z H$

199 Vgl. Kol 1,19. 
Faciunt ista ad robur fidei. Nam ei liberius et confidentius fidimus, qui et velit et possit praestare, quod cupias. Talem dicit hoc loco Ioannes esse deum, certe, ut huic per Christum citius et tutius adhaereret mundus. Fiduciam autem dixit nobilem aliquem thesaurum, qui nobis depositus sit apud deum. Nam thesauris 5 solemus fidere plurimum. Et quid, oro, augustius dici potest, quam quod omnipotens ille deus audit nos, id est, sese nobis et promptum et benignum impendit et prorsus talem, qualem se nobis foedere astrinxit? Nam, cum certum sit, quod audiat nos, est etiam hoc certum, quod, quaecunque petierimus, ab eo dabit nobis (est enim deus omnipotens et $»$ Schadai $\ll^{200}$ ), si modo petierimus secundum voluntatem eius, id est, si sancte sancta postulaverimus. Nam voluntas dei sancta est et bona. dabit ei vitam; peccantibus non ad mortem.

Quia coeperat de oratione disserere, hinc eandem rem clarius exequitur, ut doceat 15 nos solida fide etiam aliis prodesse posse; non equidem, quod alter pro altero credere possit, sed quod »multum valeat«, ut Iacobus dicit, »deprecatio iusti Iacobi 5[,16]. efficax«. Istis vero omnibus veluti foeturis, commoditatibus et concomitantiis extollit apostolus fidei praeconium. $» \mathrm{Si} \ll$, inquit, »videas fratrem tuum peccare peccatum non ad mortem «, hoc est, si videris fratrem tuum agere vitam non 20 usque adeo puram, sed lascivam et impudentem, ita tamen, ut interim veritatem evangelicam non contemnat aut veritati doctus et correptus reclamet, »iam ora pro homine et impetrabis ei vitam, nec huic uni tantum«, vide augmentum, »sed et omnibus mortiferum peccatum non peccantibus impetrabis vitam «, ut scilicet ii divina bonitate conversi vitam pristinam mutent in melius. »Verum quomodo«, dicis, »vitam dabit homo, qui vitam non habet?« Respondeo: schema est nobis quoque usitatissimum. Nam »dare « usurpamus pro »impetrare« idque, quod impetravimus, dedisse videmur. Dicis: »Quid ergo? Censes pro incredulis non esse orandum?« Istud porro non agit hoc loco Ioannes, sed istud potius vult ostendere, quod ea, quae a deo in fide petimus, accipiamus. Poterat autem aliquis pro|impio 30 aliquo contemptore dei orare deumque ipsum non exauditus arguere mendacii. Istud ut declinaret apostolus, notanter addidit: »Impetrabis quidem, si ille deum convertentem non contempserit.« Nam quid, oro, dares ei, qui offerentem convitiis peteret ac diceret: »Quid dabis? Quid istud? Quasi vero illud curaverim aut petierim unquam. Tibi servato. Ego vero istis neque egeo neque talia volo. Sic 35 enim impii: »Quid«, inquiunt, »evangelium affers? Quasi vero quis evangelio

Z. (3) Fiduciam] Fidutiam $\mathrm{ZH} \mathrm{-} \mathrm{(11)} \mathrm{bona]} \mathrm{In} \mathrm{ZH} \mathrm{folgt} \mathrm{zusätzlich} \mathrm{Cadunt} \mathrm{hic} \mathrm{impura} \mathrm{et} \mathrm{inutilia} \mathrm{omnia,}$ quae non largitur petentibus divina bonitas.

200 Gen $17,1$. 
caruerit unquam. Poenitentiam praedicas, sed quid illa opus? Christum praedicas, sed non omnia solus. Vivemus equidem, sed si meritis nostris vitam nobis ad coelos paraverimus.« Hi omnes cum morbum non agnoscant, neque ipsum medicum curant. Proinde frustra cucurrerit, qui medicum ad talem vocare tentaverit. 1. Tim. 2[,1]. Alias ex Paulo didicimus orandum esse pro omnibus hominibus, pro bonis et malis, nempe ut deus peccatores ad se convertat, impiis vero oculos aperiat etc.

16 Est peccatum ad mortem; non pro illo dico, ut roges. 17 Omnis iniquitas peccatum est;

Iterum exponit se, quid intellexerit per peccatum mortiferum et qui nam illi sint, quibus oratio fidelium nihil impetret. Primo: »Pro eo«, inquit, »qui ad mortem 10 peccat, rogari nolo.« Id est: »Nolo, quis expectet se quicquam consequuturum, si oret pro perfido et im|pio contemptore numinis.« Nam vides metaleptica ${ }^{201}$ quadam oratione postulationem pro ipsa poni venia, quae postulatur. Secundo: peccatum ad mortem aliud nullum est quam peccatum in spiritum sanctum, ${ }^{202}$ per-

Ioan. 8[,24]. fidia scilicet et incredulitas. ${ }^{203} \mathrm{Nam}$ in evangelio dicit Chri|stus: »Si non credi- 15 deritis, quod ego sum, moriemini in peccatis vestris.«Et hic per sententiam generalem subiicitur: »Omnis iniquitas peccatum est.« Ea vero sententia tantum Rom. 14[,23]. pollet, quantum illa Pauli: »Omne, quod non est ex fide, peccatum est.« Nam ódıxí $\alpha$ iniuria est; iniuria autem iniquitas est, cum aliquid fit praeter phas et ius, ein unbill. Quae vero maior est iniuria, quam praedilectum dei filium, aeter- 20 nam veritatem et salutem paratam, nolle agnoscere aut recipere, imo oblatam convitiis proscindere et summo cum ludibrio fastidire?

\section{7 est peccatum non ad mortem.}

Aliud vero est peccatum sive alia peccati species, cum credens in Christum carnis imbecillitate victus carni succumbo, sed mox per poenitentiam vitam in melius 25 muto. Haec vero facile condonabitur a deo. Pro hac orabunt sancti indesinenter. ${ }^{204}$

Psal. 18. Nam »delicta quis intelligit?« [Ps 19,13 (Vulg. 18,13)] Verum ista explicabuntur per sequentia.

Z. (5) Marg. 1. Tim. 2.] In ZH zusätzlich 2. Timoth. 2[,25f.]. - (11) consequuturum] consequturum $H-$ (19) phas] fas $Z H$

201 Siehe oben S. 344, Anm. 133.

202 Mt 12,31f

203 Vgl. Aug. de serm. dom. 1,22,75 (CCSL XXXV 84,1829-1832): »Hoc est fortasse peccare in spiritum sanctum, id est per malitiam et inuidiam fraternam obpugnare caritatem post acceptam gratiam spiritus sancti, quod

peccatum dominus neque hic neque in futuro saeculo dimitti dicit.«

204 Vgl. Erasm. 1Joh. (ASD VI/10 554,444f.): »Venialia delicta, sine quibus non viuitur, cotidiana precatione delentur: >remitte nobis debita nostra<.« 
18 Scimus, quod omnis, qui natus est ex deo, non peccat.

Quomodo itaque dixit in 1. cap[ite]: »Si dixerimus peccatum non habemus nos ipsos fallimus « [1Joh 1,8]? Quid, quod iam dixit | esse aliquod peccatum, quod non sit ad mortem? ?05 $^{20}$ Sequitur expositio:

18 Sed qui genitus est ex deo, servat seipsum et malus ille non tangit eum.

Peccant etiam pii, sed peccato, quod non est ad mortem. Fide enim purgantur filii dei. Fide custodiunt se ab illecebris et impuritate vitae. Fide, si labantur, resurgunt. Custodia igitur illa christiana dicitur innocentia, quam, etsi saepius labefactet Sathanas, evertere tamen non potest. Quam rem propriis sane verbis ex10

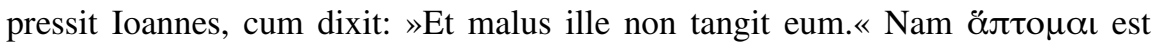
irretire, vincire et adglutinare, den klawen schlachen, ut nulla supersit evadendi spes. Tentarat quidem Sathanas Davidem, Adam et Petrum, sed capere

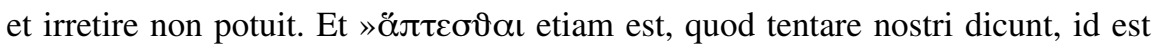
ledere $\ll^{206}$ et affligere.

19 Scimus, quod ex deo sumus et mundus totus in malo constitutus est.

»Et nos«, inquit, »qui credimus, ii sumus, quos malus ille non tangit; ${ }^{207}$ sed quia ex deo sumus, divina quoque et sancta diligimus, quemadmodum isti quoque terrena et prophana diligunt, qui ex Sathana sunt.« Totus autem mundus $\dot{\varepsilon} v \tau \widetilde{\omega}$

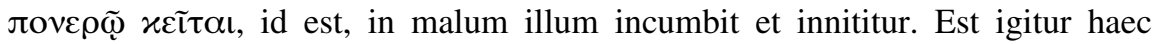
subiecta ex contrariis sententia. Quemadmodum vero deus ille $\mid$ bonus bonorum est acervus, ${ }^{208}$ ita Sathanas ille malus omnium malorum est lerna, ${ }^{209}$ id quod monuimus et cap[ite] $1 .^{210}$

20 Scimus autem, quod filius dei venit et dedit nobis mentem, ut cognoscamus illum, qui verus est, et sumus in vero, in filio eius Iesu Christo; hic est verus deus et vita aeterna.

Epilogus est eorum, quae disputata sunt de fide. Nemo autem verbis exequi queat, quanto ardore, quantis verbis et quam foelici brevitate omnia dixerit. »Venit«, inquit, »filius dei«, filius, inquam, dei carnem induit humanam et »dedit nobis

Z. (9) Sathanas] Satanas $Z H$ - (12) Sathanas] Satanas $Z H$ - (18) Sathana] Satana $Z H$ - (21) Sathanas] Satanas $Z H-(22)$ 1.] 2. $Z H-$ (27) foelici] felici $Z H$

205 Joh $5,17$.

206 Bud. comm. 790,49f.

207 Vgl. 1Joh 5,18.
208 Siehe oben S. 126, Anm. 660.

209 Siehe oben S. 210, Anm. 171.

210 Siehe oben S. 317. 


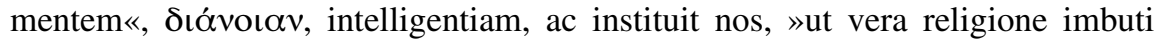
nunc verum deum cognoscamus et in vera religione vivamus; nam Christus est verus deus, per quem nobis contigit vita aeterna «. Huic fidere et illi sese dedicare est veram religionem tenere. Illi vero non credere vel saltem non soli credere est superstitionem colere:

21 Filioli, cavete vobis a simulachris.

Per simulachra omne id intellexit, quod ad simulachra pertinet: aras, aedes, tabulas, anathemata, ornamenta, sacrificia, pontifices, vota et si quid aliud est huius generis. Miro autem ingenio simulachra absoluto Christi negotio induxit. Nam idololatria enascitur ex ignorantia dei. Qui ergo deum vere cognoscit, $\mid$ is $10 \quad 53 \mathrm{r} H$ facile ab idololatria deficit. Cum enim videt neminem in toto orbe esse omnipotentem, verum, aeternum et bonum nisi unum deum, protinus ad hunc convertitur deum. Signa iis statuimus, quorum auxilium imploramus et quibus bene fidimus; at fidelis mens nemini praeterquam uni deo fidit; neminem itaque nisi unum deum colit et veneratur. Non utique rebus caducis, auro, ebore, $\mid$ argento, $15 \quad 107 \mathrm{ZH}$ gemmis et vestibus Damascenis, quibus didicit aeternum illud bonum non delectari, sed spiritu et veritate, fide, innocentia et charitate. Commode igitur ad finem appendit hanc commonitionem: »Filioli, cavete a simulachris.« Nam qui hac epistola iam didicerant unicum tantum esse deum, qui se orbi aperuerit per filium, in quo sit omnis plenitudo ${ }^{211}$ et vita aeterna, et qui docuerit verum dei cultum 20 consistere in fide, vitae puritate et charitate, ii facilime poterant idololatriam deserere.

$$
\text { | Epilogus. }
$$

Ita exhibuit nobis Ioannes hac epistola verum deum et veram religionem. Iesus Christus verus et unus est cum patre et spiritu sancto deus. Et christiana religio 25 vera et indubitata est religio. Sed ea uni deo per Christum omnem tribuit gloriam, salutem, vitam et redemptionem. Hunc confitetur verum esse deum et hominem eumque tradit sanctum esse, qui non possit coli rebus caducis, sed innocentia et charitate, ad quae ista quidem epistola cohortatus est.

Z. (24) exhibuit] tradidit $Z H-(29)$ est] In $Z H$ darunter Finis.

211 Vgl. Kol 1,19. 
KOMMENTAR ZUM JAKOBUSBRIEF 



\section{De autore epistolae.}

Nimis quidem procaciter epistolam hanc d[ivi] Iacobi quidam contempserunt tractaruntque scurriliter, ${ }^{1}$ cui pepercissent merito vel propter antiquitatem vel 5 propter salubria, quae in ipsa continentur, vitae praecepta. Fateor sane de hac non nihil dubitatum esse etiam apud veteres quosdam, sed hi absque petulantia et reverenter admodum summaque cum modestia addubitarunt. Nam, ut huius quaedam proferam testimonia, Eusebius Caesariensis, inter ecclesiasticos scriptores Iudicia veterum Graecos haud postremus, lib[ro] Ecclesiast[icae] histo[riae] 2., cap[ite] 23., vitam de hac epistola. et interitum d[ivi] Iacobi ex Egesippo referens ad finem ista appendit verba: »Et hactenus de Iacobo, cuius illa habetur epistola, quae prima scribitur inter eas, quae >catholicae< appellantur. Sciendum tamen est, quod a nonnullis non recipiatur nec facile quis antiquorum meminerit eius, sicut ne illius quidem, quae dicitur Iudae, quae et ipsa est una de septem. Nos tamen scimus etiam istas cum 15 caeteris ab omnibus pene ecclesiis recipi. $\ll^{2}$ Haec Eusebius. Ad quem modum et $\mathrm{d}$ [ivus] Hieronymus, inter scriptores Latinos praecipuus, in Catalogo ecclesiasticorum scriptorum: »Unam tantum«, ait, »Iacobus scripsit epistolam, quae de septem catholicis est, quae et ipsa ab alio quodam sub nomine eius aedita asseritur, licet paulatim tempore procedente obtinuerit authoritatem. $\ll^{3}$ Tantum Hie20 ronymus. D[ivus] Aurelius Augustinus ${ }^{4}$ et reliqui patres sancti testimoniis ex illa depromptis etiam in rebus seriis libenter usi sunt. Tametsi igitur de ipsa non nihil apud quosdam sit addubitatum, nemo tamen legitur illam explosisse exibilasseque penitus. Sua illi reverentia perpetuo habita est, suum locum in ecclesia nunquam non tenuit.

25 Iam qui decimumtertium fingunt apostolum Iacobum fratrem domini, alium ab eo, qui cognominatur Alphei, quales apud priscos fuisse, author est in 5. Commentariorum in Isaiam libro divus Hierony[mus], ${ }^{5}$ facile refutari possunt ex eiusdem d[ivi] Hieronymi scriptis contra Helvidium. Ibi enim ostendit eundem esse Iacobum, qui Alphei et »minor« et »frater domini« appellatur. ${ }^{6}$ Paulus certe

1 Vgl. die Infragestellung der Kanonizität des Jakobusbriefes durch Martin Luther: Luth. vorr. 384,7-18.

2 Euseb. hist. eccl. 2,23,24f. (GCS IX/1 174,1217); zit. nach Rufin. hist. 2,23,24f. (GCS IX/1 175,12-17).

3 Hier. vir. ill. 2 (PL XXIII 639B). Dieser Passus wird auch in Erasm. Iac. (ASD VI/10 428,458-460) zitiert.
Vgl. etwa Aug. in euang. Ioh. 57,3 (CCSL XXXVI 470,1f.); 73,1 (CCSL XXXVI 509,7-9); 101,2 (CCSL XXXVI 592,13-15). Hier. in Is. 5,17,5 (CCSL LXXIII 185,13-16): »Duas oliuas, et tres, et quattuor, et quinque, quattuordecim apostolos interpretantur, id est duodecim qui electi sunt, et etrtiumdecimum Iacobum, qui appellatur frater Domini.«

6 Hier. virg. Mar. 13 (PL XXIII 205B-C). 
in 1. cap[ite] epistolae ad Galatas: »Alium«, inquit, »apostolorum vidi neminem nisi Iacobum fratrem domini « [Gal 1,19].

Qui vero contendunt tertium quendam fuisse Iacobum, non apostolum quidem et illum e numero duodecim neque decimumtertium, »sed alium quendam cognomento Iustum, filium Mariae sororis matris domini et qui primus ab apostolis fuerit ordinatus Hierosolymorum episcopus ${ }^{7}{ }^{7}$ cuius haec sit epistola, ab ipso refutantur Egesippo, qui in 5. Commentariorum suorum libro, ut apud Eusebium est: »Suscepit«, ait, »ecclesiam cum apostolis frater domini Iacobus, qui ab omnibus cognominatus est $>$ Iustus $<$, ab ipsis domini temporibus perdurans usque ad nos. Et multi quidem Iacobi vocati sunt, sed hic ex utero matris suae sanctus fuit $~^{8}$ etc. Praeterea d[ivus] Hieronymus in libello contra Helvidium de sorore illa matris domini, de matre inquam Iacobi, disputationem concludens: »Restat «, inquit, »conclusio, ut Maria ista, quae Iacobi minoris scribitur mater, fuerit uxor Alphei et soror Mariae matris domini, quam >Mariam Cleophae< Ioannes evangelista cognominat ${ }^{9}$ sive a patre sive a gentilitate familiae aut quacunque alia 15 caussa ei nomen imponens. ${ }^{10}$ Sed et Beda ${ }^{11}$ in Annotatis suis in Acta apostolorum redarguit illos, qui tertium quendam configunt Iacobum aliumque a Iacobo Alphei putant Iacobum iustum et fratrem domini. Ostendit autem unum duntaxat fuisse eundemque esse Iacobum, qui et $\gg$ Alphei « et »Iudae« et »iustus « et »frater domini $\ll$ nuncupatus sit. ${ }^{12}$

Quae quidem non ideo recenseo, quod iudicio praefractiori hanc epistolam Iacobo vendicem filio Alphei, sed ut ostendam, quam nihili nitantur argumentis, qui epistolam adimunt apostolo, aliis vero veluti rerum suarum certi tribuunt, cum interim maiora supersint argumenta, quae illi hanc tribuant, magis quam adimant. Verum hac in re nolumus cum quoquam contentiosum ducere funem. Consultis- 25 sime enim iudicans sanctae memoriae d[ominus] Erasmus: »Supervacuum«, ait, »arbitror anxie de authore digladiari, rem potius amplectamur et spiritum sacrum authorem exosculemur. ${ }^{13}$ Huius ergo consilio obsequentes ipsam nunc aggredimur epistolam.

Scribit s[anctus] Iacobus conversis ad Christum dominum, ideoque nihil agit in hac epistola de primis fidei rudimentis et dogmatis nostrae religionis: de poeni-

7 Erasm. Iac. (ASD VI/10 388,10-12). Dies war offenbar die Meinung des Hieronymus, vgl. Hier. in Gal. 1,1,19 (CCSL LXXVIIA 38,3741).

8 Euseb. hist. eccl. 2,23,4 (GCS IX/1 166,9-12); zit. nach Rufin. hist. 2,23,4 (GCS IX/1 167,710).
Joh 19,25.

Hier. virg. Mar. 13 (PL XXIII 206A).

11 Beda Venerabilis (ca. 672-735), angelsächsischer Benediktinermönch, Theologe und Geschichtsschreiber, vgl. NP II 532-535.

12 Beda act. 1,13 (CCSL CXXI 10f.,133-158).

13 Erasm. Iac. (ASD VI/10 388,20f.). 
tentia, de abrogata lege, de fide sola iustificante, hoc est de salute per unicum Christum parta totique mundo oblata, aut de peccato et libertate christiana idque genus locis aliis, in quibus proculdubio satis erant instituti; sed corrigit quaedam, quae in populo dei exoriebantur peccata. Erant enim, qui iactarent se evangelio credidisse, interim vero mire impatientes, cum propter nomen Christi aliquid erat ferendum. Erant, qui impure loquebantur de sancta et iusta dei providentia omnem peccati culpam reiicientes in deum. Idem iactabant fidem, sed operibus fructibusque fidei carebant, homines vani et irreligiosi. Ambiebant alii munus docendi nulla expectata vocatione, ii et lingua erant promptissimi et ad contendendum semper armati. Quidam vero ad rem attentiores fraudabant proximos genioque indulgebant intemperantius. Hos aliosque his similes errores corrigit apostolica severitate, adhortans pios ad patientiam, mox etiam docens sancte et reverenter loquendum esse de dei providentia, cum certum sit homines non dei vitio, sed sua culpa fieri malos. Statim autem post illa hortatur, ut positis affec5 tibus carnalioribus vita religionem veram exprimant, non verbis, non iactabundis de fide vocibus. Fidem enim semper esse feracem bonorum operum, imo hanc non posse esse sine bonis operibus. Ibidem docet non temere ambiendam esse docendi functionem, docet item coercendam esse linguam a contentionibus, avaritia circumscribente a pauperum oppressione atque studio voluptatum omnino 20 esse temperandum. Addit ad finem et alia quaedam vitae praecepta et sancta et salubria. Recte igitur d[ominus] Erasmus censuit Iacobum in hac epistola versari in locis communibus. ${ }^{14}$ Nostro autem saeculo mire utilis est. Laborat enim iisdem morbis, quibus illud, propter quod d[ivus] Iacobus hanc aedidit. Stilus facilis est et expositus, ratio tractandi plana et pulchra. in dispersione, salutem.

Proditur hac inscriptione, quis author huius epistolae et quibus peculiariter scripta sit, additur et epistolaris salutatio. Author est Iacobus »servus dei ac domini nostri Iesu Christi«. Homines magnum existimant, si dicantur regum huius saeculi ministri. Iacobus ter maximum putavit servum esse Iesu Christi veri dei et domini: ${ }^{15} \gg d e i \ll$, inquam, id est essentiae vivae, aeternae et omnipotentis ac omniscientis; »domini« autem, id est assertoris et redemptoris. Diligenter sibi caverunt viri dei a titulis arrogantioribus. Hodie gaudet alius vocari »sanctissimus«, alius »evangelicae veritatis restaurator«, alius »lux mundi«, alius »haere-

14 Erasm. par. Iac. (ASD VII/6 117,12f.): »Iacobus fere versatur in locis communibus. «

15 Vgl. Didym. in Iac. (PG XXXIX 1749A): »Sicuti mortalem gloriam homines appetentes in suis conscriptionibus dignitates, quas putan- tur habere, praeponunt, ita sancti viri in epistolis, quas scribunt ad ecclesias, principaliter proferunt servos se esse domini nostri Jesu Christi, aestimantes hanc appellationem supra regna totius mundi consistere.« 
ticorum malleus «, etsi quid aliud est, quo sibi palpat humana stultitia. Inscribit hanc epistolam peculiariter duodecim tribubus in dispersione, id est Iudaeis per varia dispersis regna. Captivitas enim Assyriaca, ${ }^{16}$ deinde Babylonica, ${ }^{17}$ motus item Asiatici et Aegyptii, ${ }^{18}$ item intestina dissidia et Romanorum arma, ${ }^{19}$ denique et rabies pharisaica, cuius meminit Lucas in Actis, cap[ite] 8., ${ }^{20}$ Iudaicam gentem in varias disiecerant terras. ${ }^{21}$ Ut autem Petrus peculiaris fuit Iudaeorum apostolus, ita Iacobus quoque. ${ }^{22}$ Deinde scripta est haec epistola omnibus ex aequo dei filiis omnibusque palantibus. His omnibus imprecatur salutem non corporis tantum, sed animae potius. ${ }^{23}$ Apostoli enim animarum magis quam corporum medici erant.

\section{Pro summo gaudio ducite, fratres mei, quoties in tentationes incideritis varias, 3 illud scientes, quod exploratio fidei vestrae parit patentiam, 4 caeterum patientia opus perfectum habeat, ut sitis perfecti et integri nullaque in parte diminuti.}

Patientiam Verum verae religionis studium certissimam post se crucem trahit, vel ipso 15 Christo apud Ioannem in cap[ite] 15. et 16 . teste. ${ }^{24}$ Fieri autem non potest, ut animus humanus non expavescat ad persequutiones carni prorsus intolerabiles. Iam erant, quibus evangelium adlubescebat quidem, sed gravatim interim ferrent, si quid tolerandum erat propter dominum. Hi querebantur religionem christianam plus satis inauspicatam ac turbulentam esse et tantum non consternabantur animo 20 ex afflictionibus. Hos ergo compellans |d[ivus] Iacobus: »Tantum abest«, inquit, »ut tentationes «, ${ }^{25}$ id est affliciones, »ob Christum inflictae moerorem vobis incutere, ut magis debeant exhilerare. Si enim propius expenderitis, quid fructus enascatur ex illis, plus sentietis his inesse mellis quam fellis.« Statim autem per subiectam gradationem explicat laudem et fructus crucis. »Deus «, inquit, »author est afflictionum, quas immittit vobis, non ut perdat, sed ut provehat.« His enim explorat fidem, num solida sit et firma. Cedunt in tentationibus, qui non crediderunt vere nec senserunt, quid pararit dominus illis, qui mundum hunc propter aeterna relinquunt. Porro exploratio illa, cum habeat egregia documenta et experimenta multa, parit patientiam, ut fidelis in re sancta et propter praemia 30 summa sibi proposita volens et libens, quidlibet perpetiatur propter dominum.

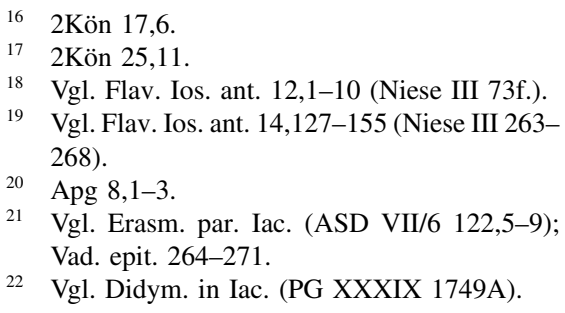

23 Erasm. par. Iac. (ASD VII/6 122,9-11): »Precans iis veram salutem, non hanc corporis tantum quam mundus optat, sed eam quam Christus suis, etiam in mediis exitiis ac mortibus, largitur.«

24 Joh 15,19-21; 16,1-4.

25 Vgl. Zw. Iac. (Z XXI 364,29): »Tantum abest, ut adflictiones vos consternent $[\ldots] . \ll$ 
»Patientia autem illa omne opus bonum et virtutes omnes perficiet, absolvet, expoliet, ut sitis undique perfecti et integri, nec quicquam desyderetur in vobis, quod pertinet ad perfectionem hominis christiani.« Quae quidem congeries et copia verborum est. D[ivus] Paulus ad Hebraeos, cap[ite] 10.: »Patientia«, inquit, 5 »vobis opus est, ut, ubi voluntatem dei peregeritis, reportetis promissionem « [Hebr 10,36]. Idem ad Roma[nos] 5. iisdem propemodum verbis de patientia loquens usus est, ${ }^{26}$ quibus hic utitur Iacobus. Et d[ivus] Cyprianus in serm[one] de bono patient[iae] 3. de hac ipsa disserens scribit, quod ad sententiam Iacobi intelligendam non parum facit. Sunt autem haec martyris verba: »Patientia est, quae nos deo commendat et servat. Ipsa est, quae iram temperat, quae linguam frenat, mentem gubernat, pacem custodit, disciplinam regit, libidinis impetum frangit, tumoris violentiam comprimit, incendium simultatis extinguit, coercet potentiam divitum, inopiam pauperum revovet, tuetur in virginibus beatam integritatem, in viduis laboriosam castitatem, in coniunctis et maritatis individuam 15 charitatem. Facit humiles in prosperis, in adversis fortes, contra iniurias et contumelias mites. Docet delinquentibus cito ignoscere; si ipse delinquas, diu et multum rogare. Tentationes expugnat, persequutiones tolerat, passiones et martyria consummat. Ipsa est, quae fidei nostrae fundamenta firmiter ponit, ipsa est, quae incrementa spei sublimiter provehit, ipsa actum dirigit, ut tenere possimus 20 viam Christi, dum per eius tolerantiam gradimur, ipsa efficit, ut perseveremus filii dei, dum patientiam patris imitamur. $\ll^{27}$ Hactenus Cyprianus.

5 Quod si cui vestrum deest sapientia, postulet ab eo, qui dat, nempe deo; qui dat, inquam, omnibus simpliciter nec exprobrat, ac dabitur ei, 6 sed postulet cum fidutia nihil haesitans. Nam qui haesitat, is similis est fluctui maris, qui ventis agitur et impetu rapitur. 7 Neque enim existimet homo ille se quicquam accepturum a domino. 8 Vir animo duplici inconstans est in omnibus viis suis.

At dicat aliquis: »Unde mihi ea sapientia, ut possim esse patiens? « Respondet: »Non e philosophia humana, non a divorum aut operum nostrorum meritis, sed ab 30 ipso deo, a quo indefessis postulanda est precibus. « Tria vero hic agit apostolus. Principio docet patientiam petere a deo. Deinde ostendit, qualis debeat esse oratio nostra, firma videlicet et fidelis, nihil prorsum vacillans. Hinc ubique inserit argumenta, quibus et invitat ad preces et abstrahit a diffidentia. Solus deus orandus est in rebus omnibus, maxime vero ut patientiam nobis conferat. Solus Orationibus petenda patientia. enim omniscius et omnipotens omnia tantasque dotes nobis dare potest. Abeant ergo, quo digni sunt, qui pro deo divos animis hominum inserunt. Horum enim impudentia fit, ut creatore praeterito supplices divis accidant homines simplici- 
ores. Deinde bonam cultus dei partem conferant a creatore in creaturam, imo hanc plus reveantur ac colant quam illum. Argumenta vero, quibus moveri possunt corda nostra, ut sponte petituri deum accedamus, duo sunt potissima. Primum petitum est ab ipsa dei promissione et veritate. Nam in evangelio dixit dominus: »Petite et accipietis. Quisquis enim petit, accipit« [Mt 7,7.8 par.]. Quo respiciens s[anctus] Iacobus: »Postulet«, inquit, »a deo, qui dat; et dabitur ei.« Secundum petitum est ab ipsa dei natura, quae facilis, exposita, munifica est: »Neminem«, inquit, »excludit.« Dat omnibus sapientibus et insipientibus, pauperibus et divitibus, omni sexui et aetati. Dat autem »simpliciter «, quod bifariam potest exponi: vel $\mid \gg$ dat abundanter et copiose«; vel »dat liberaliter nec spectat nostram grati- 10 am«, hoc est, ut beneficio suo maius eliciat a nobis beneficium. Sic enim alibi scriptum est: »Qui ministrat, in simplicitate ministret« [Röm 12,8], id est, ita benefaciat, ut purum sit beneficium, non vitiatum. Est autem vitiatum, cum non studio benefaciendi, sed maiora consequendi benefacio. Id quod avarorum est. Dat, inquam, simpliciter »nec exprobrat «, id est, non maligne dat nec solet facere, 15 quod faciunt sordidi quidam, qui, dum beneficium exprobrant, ex beneficio maleficium faciunt. Deus ut natura bonus est et munificus, ita dona sua nobis syncere, pure, simpliciter, sancte, copiose benigneque confert absque invidia, avaritia et malignitate. Deinde quod ad modum attinet orationis, qualis scilicet illa esse debeat, exponit hisce verbis: »Sed postulet cum fiducia.« Idque, quid sit, 20 iterum exponens subdit: »Nihil haesitans.« Ergo qui nihil haesitat, postulat cum fiducia. Haesitat autem, qui fluctuat nec toto pectore in promissa dei innititur, sed affectibus et perturbationibus animi abripitur, ut sese non committat divinae bonitati, interim pendet ab humanis praesidiis. Hocque ipsum denuo expolit et ob oculos statuit eleganti similitudine petita a fluctibus marinis, a quibus etiam 25 ductum est proverbium »maritimi mores $«$, in homines inconstantes. ${ }^{28}$ Huc pertinere videtur illud Ciceronis, quod pro Plancio ${ }^{29}$ hisce verbis exposuit: »Quod fretum, quem Euripum tot motus, tantas, tam varias creditis habere agitationes, commutationes, fluctus, quantas perturbationes et quantos aestus habet ratio comitiorum? $\ll^{30}$ Non potuisset ergo Iacobus animum haesitantem picturatioribus depinxisse coloribus, quam pinxit. Exaggerat et amplificat evidentiam, quod addidit: »Qui ventis agitur et impetu rapitur.« Mare enim per se fluit et refluit, at vento turbatum non insanit. Animorum autem venti affectiones sunt et varia obiecta, quae animum nunc metu, nunc spe, mox dolore conturbant. De hac

\section{Z. (27) Plancio] Plaucio $Z$}

28 Erasm. adag. 3529 (ASD II/8 34,368-378).

29 Gnaeus Plancius (Quaestor 58 v.Chr.), römischer Politiker und Unterstützer Ciceros, vgl. NP IX 1063f.

30 Cic. Mur. 35 (MacDonald 232). Bullinger ent- nimmt das Zitat wohl Erasm. adag. 862 (ASD II/2 384,235-237), der ebenfalls irrtümlicherweise »Cicero pro Plautio [!]« als Quelle angibt. 
haesitatione annotavi quaedam in 5. cap[ite] Pauli ad Rom[anos]. ${ }^{31}$ Addit: »Qui huiusmodi est, non putet se quicquam accepturum a domine.« Id quod miris modis abstrahit a diffidentia. Fide sola recipiuntur dei promissiones. Quae autem ad finem adiicitur $\gamma \vee \omega ́ \mu \eta: ~ » V i r$ duplici animo inconstans est in omnibus viis 5 suis«, hanc habet sententiam: »Cuius animus bifariam difissus est, hac parte deum respiciens, ista mundum, is inaequalis est et inconstans, non tantum in precibus suis, sed in omnibus etiam, quae agit, aliud habens in ore, aliud in pectore, proque tempore nunc hoc, nunc illo affectus modo. $\ll^{32}$ Solent autem esse tales, qui prae animi impatientia nihil ferre possunt propter Christum, sed pro flatu reflatuque fortunae animum, instituta et studium mutant. Nunc enim sunt evangelici, mox nubecula aliqua oborta non agnoscunt evangelicos. Hoc autem hominum genus longe est turpissimum vel diverbiis notatum gentilium. ${ }^{33}$

\section{Glorietur autem frater, qui est humilis, in sublimitate sua, 10 contra qui} dives est, in humiliatione sui, quoniam veluti flos herbae praeteribit. 11 Exortus est enim sol cum aestu, et exaruit herba et flos illius decidit et decor aspectus illius periit; sic et dives in abundantia sua marcescet.

Confutat nunc illa sopitque, quae excitant et alunt impatentiam: ea sunt pauperies, Removet, quae contemptus opumque direptio, exilium ac proscriptio. Dicit autem: »Si quis fimpatientiam frater «, hoc est christianus, »humilis«, id est spretus a mundo, »tenuis fortunae ac pauper est, non despondeat animum, imo hoc nomine gaudeat ac glorietur magis: quod apud mundum contemptus, apud deum non fit contemptus. $\ll^{34}$ Deus enim, quos diligit, sic subvehit ad gloriam. Nam in humiliatione consistit christianorum exaltatio. Sic enim et Christus caput nostrum humiliatum est, ut aliquando exaltaretur super omnes coelos ipsique subiicerentur omnia. ${ }^{35}$ Iam, quod attinet divites, solent nonnunquam vel bonos viros in exitium demergere divitiae impurae. Recte ergo d[ivus] Iacobus iubet divites sibi gratulari »ob humiliationem sui«, id est ob ereptas opes. Licet enim in mundo sint humiliati, apud deum interim sunt exaltati. Sublata est peccatorum multorum occasio. Praeterea non est, quod quisquam doleat ob surreptas opes. Sunt enim incertae et per omnia floribus similes, 30 quibus ut nihil quidem pulchrius in orbe est, ita nihil instabilius et diuturnum minus. Copiose autem posset haec tractari parabola, sed plana est, desumpta ex

Bull. Rom. 4[!],20f. (Baschera 97,25-98,10). Erasm. par. Iac. (ASD VII/6 124,83-87).

Vgl. Erasm. adag. 862 (ASD II/2 382,218f.): »Euripus homo. In inconstantes ac moribus inaequalibus homines dicetur«; 1792 (ASD II/4 208,262f.): »Transversum agere. Transversus agi dicitur qui vi et impetu quodam ab instituto deflectitur «; 2012 (ASD II/5 46,623f.): »Duplices viros, prouerbiali loco vocabant, qui essent lubrica et insyncera fide, quos nun vulgo etiam bilingues appellant.«

34 Vgl. Erasm. par. Iac. (ASD VII/6 124,89-91): »Quin potius Christianus humilis ac variis malorum molibus pressus erigat animum et hoc nomine glorietur, quod mundo contemptus non sit contemptus apud Deum.«

35 Vgl. Phil 2,8-10. 
prophetis, Isaia maxime ex $\mid$ cap[ite] $40 .{ }^{36}$ In Psalmis quoque huius generis invenias plura. ${ }^{37}$

12 Beatus vir, qui suffert tentationem, quoniam, cum probatus erit, accipiet coronam vitae, quam promisit dominus his, a quibus fuerit dilectus.

Concludit locum de patientia. Proponit autem praemium amplissimum, vitam 5 sempiternam, sub involucris et metaphoris petitis a pugilibus et coronis triumphalibus. Unde intelligimus neminem fore coronandum, nisi prius certaverit legitime fortiter, intrepide. Et Christus beatos pronunciat, qui persequutionem patiuntur propter iustitiam, quoniam illorum sit regnum coelorum. ${ }^{38}$ Ex divitiis autem, hoc est metallo, nulla est vera beatitudo. At si quis metalli in morem per 10 ignem tribulationis fuerit excoctus et solidus in fide inventus, is vere felix erit, 1. Petri 4[,12f.].

13 Ne quis, cum tentatur, dicat se a deo tentari. Nam deus, ut malis tentari non potest, ita nec ipse quenquam tentat. 14 Imo unusquisque tentatur,

Deo non est imputanda culpa peccati nostri. dum a propria concupiscentia abstrahitur et inescatur. 15 Deinde concupiscentia, posteaquam concepit, parit peccatum, peccatum vero perfectum progignit mortem.

Deflectit nunc ad alium locum. Dixit de tentatione hactenus, id est de afflictionibus, quibus deus tentat, id est, explorat fidem nostram probatque; iam contra eorum disputabit impudentiam, qui tentationem, id est lapsum in tentatione (est 20 enim metastasis in voce »tentatio«), deo impingunt, dicentes: »Lapsus sum, fateor, in afflictione sive persequutione, obmurmuravi, impatienter tuli adversa, negavi Christum, terrena magis quam coelestia sum sectatus, atqui dei potius quam mea culpa sic peccavi. Cur enim tentavit me deus? Aut si omnino tentare voluit, quare non contulit animi robur ac vires, quibus vincerem?« His respondet 25 Iacobus ad hunc modum: »Si quem molestia afflictionum a statu mentis recto et a pietate abducit, non est, quod imputet deo « $;^{39}$ qui non in hoc immittit afflictiones, ut perdat et in impatientiam coniiciat, sed ut $\gg$ pro sua bonitate materiam segetemque pietatis $\aleph^{40}$ suppeditet, id est, occasionem praebeat pulchris virtutibus, hoc est, fortitudini, constantiae, patientiae, fidei et spei. Pulcherrimae enim hae vir- 30 tutes exerunt et sese exercent maxime in tentationibus afflictionibusque. Caeterum, ut totum hoc negotium, quod videlicet deus omni careret peccati nostri culpa, fieret spectabilius et explicatum certumque magis, profert, quae sit ipsa dei natura. »Deus«, inquit, »natura bonus est, nullis malis sollicitari potest, ideoque
36 Jes 40,6f.

37 Vgl. Ps 37,2; 90,5; 103,15f.

38 Mt 5,10f.
39 Vgl. Erasm. par. Iac. (ASD VII/6 126,143145).

40 Erasm. par. Iac. (ASD VII/6 126,147f.). 
neminem sollicitat ad mala. «11 Quod ergo alibi scriptum est: »Tentavit deus Abraham « [Gen 22,1], hunc habet sensum: deus experimentum sumere voluit de fide Abrahae adeoque omnibus hominibus documentum praebere, quam fuerit Abraham obsequens et timens dei. Unde liquet »tentare « non usurpari perpetuo 5 pro »impellere «, ut in praesenti accipitur. Nam sensus verborum Iacobi hic est: quemadmodum deus in mala non labitur et propellitur, ita neminem in malum propellit. Iam dicat aliquis: »Cui ergo imputabimus mala aut a quo impellimur ad malum?« Respondet Iacobus: »Imo unusquisque tentatur, dum a propria concupiscentia abstrahitur et inescatur. «Quasi dicat: »In nobis est peccati seminarium 10 ipsa videlicet concupiscentia et ad vitia proclivitas insita nobis adeoque agnata ex primorum parentum vitio. ${ }^{42}$ Ideoque $\dot{\varepsilon} \mu \varphi \alpha \tau \iota x \tilde{\omega} \varsigma$ dicitur »a propria concupiscentia«. Malum ergo sive peccatum proprie nostrum est, quod suggestione daemonis primo quidem enatum est, nunc autem eadem illa fovetur et augetur indies apud corruptos homines. Ita enim et de Satana loquitur apud Ioannem dominus: 15 »Cum loquitur mendacium, ex propriis loquitur, quia mendax est et mendacii pater « [Joh 8,44]. In qua sententia observandum est, quod dicit »ex propriis loquitur« et »mendax est et mendacii pater«, nimirum fons, principium et origo. Interim vero hac disputatione nostra non ponimus duo rerum principia. Agnoscimus enim unum omnium rerum principium et deum quidem caussam esse 20 mali, sed talem, qualem et scholae vocarunt $»$ sine qua non $\ll{ }^{43}$ Praeterea dicitur et illud $\dot{\varepsilon} \mu \varphi \alpha \tau \iota x \tilde{\omega} \varsigma$ »abstrahitur et inescatur«. Deus | enim bonum condiderat hominem, ipse suo vitio in peccatum est prolapsus, adeoque abstractus. Abstrahitur autem, qui in diversum ab eo, in quo fuerat, abripitur. Abripitur autem in malum, ergo fuerat in bono. Item deus vel nunc pro ingenita bonitate sua hominis misertus inserit pectoribus nostris notiones veri, aequi et boni, at ab illis abstrahunt et in diversum rapiunt animos nostros cupiditates, quae per cupedias et obiecta sensibus varia illiciuntur in opera carnis foeda, ut scilicet id, quod concupivimus animo, sectemus avide opereque compleamus. Et sanctus Paulus sensit aliam legem in mente, aliam in membris suis rebellantem legi mentis et abstra30 hentem a sancto, vero, iusto et bono in id, quod non probabat. ${ }^{44}$ Lex autem illa in membris concupiscentia et proclivitas erat ad peccandum. Lex autem mentis ipse dei spiritus, ipsa fides, dei ac veri notiones erant animo insculptae a solo deo. Caeterum legem animi veluti deo propriam, legem autem membrorum ceu homini propriam tribuit. Idem prodidit et de conscientia accusante et excusante,

41 Vgl. Erasm. par. Iac. (ASD VII/6 126,153f.).

42 Vgl. Erasm. par. Iac. (ASD VII/6 126,158f.): »Ex primorum parentum vicio insita est animis nostris quaedam ad vicia procliuitas; ea ceu peccati seminarium est.«

43 Vgl. Biel sent. IV dist. 1 q. 1 E (Werbeck/Hofmann IV/1 15f.,45-71): »Quando ad esse unius >sequitur aliud ex sola voluntate alterius $<$ illud ad praesentiam eius producentis [...] dicitur causa sine qua non. [...] Unde Deus nihil facit per causam secundam, quin illud faciat per seipsum aeque principaliter et non minus quam si solus faceret.«

44 Röm 7,15.22f. 
item de lege naturae ad Romanos cap[ite] $2{ }^{45}$ Inscribit deus naturae legem in pectora hominum. Ex illa autem lege informantur conscientiae. Quod autem praevaricamus insculptam legem, non dei vitio id quidem fit, sed nostra culpa, qui lumen illud coeleste lutulenta caligine, hoc est ingenito malo, obscuramus. Unde Iacobus propriissime dixit homines per concupiscentiam abstrahi et illici ad res malas. Post quae allegoria et allusione pulcherrima describit peccati ortum, progressum et fructum. Concupiscentia ceu matrix concipit peccatum, oritur autem atque nascitur, cum opere atque consensu fit, perfectum occidit ac damnat. Intelligunt autem omnes metaphoram esse tractam a conceptione, partu et effectibus hominis. ${ }^{46}$ Et Paulus ad Romanos, cap[ite] 5., hoc ipsum argumentum 10 tractans peccatum, mortem et damnationem ab Adamo deducit, gratiam, vitam et salutem a Christo. ${ }^{47}$ Haec autem expendant, qui parum sobrie de iusta dei sanctaque providentia theologicantur.

16 Ne erretis, fratres mei dilecti. 17 Omnis donatio bona et omne donum perfectum e supernis est, descendens a patre luminum, apud quem non est transmutatio aut conversionis obumbratio. 18 Is destinata voluntate progenuit nos sermone veritatis, ut essemus primitiae quaedam suarum creaturarum.

Ut ab homine malum, sic omne bonum a solo deo est.

Bona non merita, sed dona vocat Iacobus.
Infert nunc ad hunc modum: »Cum autem haec ita habeant, hoc est, cum ex nobis oriatur malum, nemo imputet posthac peccati sui culpam deo. Procul absit a nobis error tantus!« Huic subiicit dogma christianum: »Omnis donatio bona, et omne donum perfectum e supernis est. «Quem locum enarrans paraphrastes: »Ut deus«, inquit, »suapte natura pure summeque bonus est, ita nihil ab ipso proficiscitur nisi bonum. Igitur si quid in nobis est vitiorum, non deo, sed nobisipsis feramus acceptum; si quid bonae rei, si quid verae lucis, si quid illibatae sapientiae, id 25 totum authori deo ascribamus. Si quid lucis habet hic orbis crassior, a coelestibus illis corporibus habet et potissimum a sole. Quicquid in nobis verae est cognitionis, quicquid puri syncerique affectus, id a nobis non oritur, qui alioqui nil aliud sumus quam peccatores et ignorantes, sed e sublimi proficiscitur; ab authore bonorum omnium venit, quicquid vere bonum est; a fonte totius perfectionis 30 obtingit, quicquid legitimum et perfectum est taleque, ut nos deo commendet; quicquid vere lucidum est, id nobis ex sese mittit ille pater et princeps omnis verae lucis. Haec non impartit meritis nostris, sed gratuito nobis largitur, ut est natura benignus. Dona sunt verius quam praemia, liberalitas est verius quam

Z. (27) in] a $Z$

45 Röm 2,14f.

47 Röm 5,12-18.

46 Erasm. Iac. (ASD VI/10 392,67): »Metaphora sumpta a grauidis.«

.


merces. Fas igitur non est, ut hinc quicquam nobis arrogemus; sed pro nostris malis dei misericordiam interpellemus, pro bonis non nostris illius liberalitati gratias agamus. $\ll^{48}$ Hactenus paraph[rastes]. Egregie itaque Iacobus ostendit a deo esse omne bonum idque nobis conferri gratuito, ab homine autem malum, qui in 5 peccatis concipitur ${ }^{49}$ et nascitur filius irae. ${ }^{50}$ Quicquid ergo boni et salutis est homine, id totum divinae bonitati acceptum feret, qui sapit et deo vult esse gratus. Quod quidem primarium est religionis nostrae dogma. Subiicit ad hanc rem pertinentem et aliam rationem a natura dei petitam: »Apud quem non est transmutatio aut conversionis obumbratio. « Quasi dicat: »Deus est aeternus, immu-

\section{fit frequens transmutio, ut, qui fuerat hactenus vir bonu et munificus, mox fiat} malus et sordidus. Deus semper sui similis est, semper benefacere cupit. Apud nos sunt diei et noctis vicissitudines. Exoritur sol, idem mox densis conditur tenebris, imo ipse sol crescit et decrescit, habet obumbrationes suas. In deum vero 15 aeternum et purissimum solem nihil obumbrationis cadit, semper lucidus, semper illustris et purissima lux est atque manet. At qui hanc rationem secum excutit, nunquam poterit deum fontem mali constituere. Porro in hisce loquutionibus omnibus nemo non agnoscit idiotismos Hebraicos: »pater luminum« pro summa et aeterna luce, a quo ceu fonte omnis lux emicat, ${ }^{51} \gg$ conversionis obumbratio pro obumbratione suas habente vices. Hic vero non possum satis mirari, quid $\mathrm{s}$ [ancto] Hiero[nymo] venerit in mentem, ut haec apostoli verba de umbris exposuerit legis. Verba sancti, si quis requirat, haec sunt in 1. contra Iovinianum libro: »Transeamus ad Iacobum«, inquit, »qui frater domini dicebatur, tantae sanctitatis tantaeque iustitiae et perpetuae virginitatis, ut Iosephus quoque historicus Iudaeorum propter huius necem Hierosolymam subversam referat. ${ }^{52} \mathrm{Hic}$ primus episcopus ex Iudaeis Hierosolymae credentis ecclesiae, ad quem Paulus cum Tito Barnabaque pergebat, loquitur in epistola sua: >Nolite errare, fratres mei dilecti. Omne datum bonum et omnis perfecta donatio de sursum est descendens a patre luminum, apud quem non est differentia aut conversionis obumbraculum [Jak 1,16f.].« ${ }^{53}$ Et paulo post: »Apud quem non est differentia Iudaei sive gentilis nec illa umbra, quae versabatur in lege, premit eos, qui de nationibus crediderunt $\aleph^{54}$ etc. Haec ille, quem qui sequuntur, me quidem non offendunt. Praeterea quod deus salutis et gratiae omnisque boni, non perditionis, peccati ac mali author sit, liquet vel ex aeterno dei consilio et mysterio evangelii, item ex fine vocationis nostrae. Dicit enim Iacobus: »Is destinata voluntate progenuit nos sermone ve-

Erasm. par. Iac. (ASD VII/6 128,178-192). Ps 51,7 .

Eph 2,3.

Vgl. Zw. Iac. (Z XXI 371,1f.): »Quum dicit >a patre luminum<, Hebraismus est pro authore lucis aut pro summa luce.»
52 Flavius Josephus berichtet zwar von der Steinigung des »Herrenbruders « Jakobus, erwähnt aber keine daraus entstandenen Unruhen, vgl. Flav. Ios. ant. 20,200f. (Niese IV 310).

53 Hier. adv. Iovin. 1,39 (PL XXIII 277D-278A).

54 Hier. adv. Iovin. 1,39 (PL XXIII 278A-B). 
ritatis, ut essemus primitiae quaedam suarum creaturarum.« Quae quidem hunc habent sensum: »Adam genuit nos morti. Seductus enim mendacibus serpentis pollicitationibus vitam amisit, peccatorumque tenebris obscuratus genuit nos tenebris obnoxios, ${ }^{55}$ adeo ut nunc coelestia fastidiamus, inhiemus autem terrenis. ${ }^{56}$ Deus vero nostrae misertus calamitatis, nullo nostro merito provocatus, sola sua bonitate regenuit nos, non iterum ex corrupto semine carnis, sed ex purissimo et verissimo semine sermonis aeterni. ${ }^{57}$ Hic autem coelestis sermo tam est efficax, ut prorsus mutet homines, qui iam execrantur, quod amarunt prius, amantes nunc, quae execrarunt antea. ${ }^{58}$ " Id vero est illud ipsum, quod evangelii mysterio traditur mundo. Hoc illud aeternum dei consilium est, quo statuit reparare mundum. Quis autem haec audiens temere posthac peccati culpam deo impegerit? Rursus, si spectemus vocationem nostram, ad quid simus vocati, ut videlicet essemus primitiae quaedam suarum creaturarum, ${ }^{59}$ non maculae et labes, sed opimum et praestantissimum dei sacrificium, ${ }^{60}$ quod prae omnibus creaturis deum amaret, deo gratum esset, veraque coleret iustitia, ${ }^{61}$ haec, inquam, qui spectat, non potest 15 ullam peccati culpam reiicere in deum. Haec de apostoli sententia et de eo, quod homines suo vitio mali sint, dei beneficio boni, quodque homines de sancta dei providentia reverenter debeant loqui. De spontanea et gratuita dei in nos voluntate, id est beneficentia, de electione et vocatione nostra copiosius disputatum est in epistolis Pauli, ${ }^{62}$ ut et de regeneratione Ioan[nis] 3. et 1 . Pet[ri] cap[ite] $1 .{ }^{63}$

19 Itaque, fratres mei dilecti, sit omnis homo velox ad audiendum, tardus ad loquendum, tardus ad iram. 20 Nam ira viri iustitiam dei non efficit.

Colligit vela et concludit locum de divina providentia, nonnihil adhuc respectans locum de patientia. Ira enim, quae impatientiae vis et fomes est, efficit, quo minus faciamus iustitiam dei, hoc est, quo minus simus malorum patientes perque 25 tolerantiam omnem dei iustitiam perficiamus. Petulantia vero linguae ex ignorantia est rerum divinarum. Haec autem oritur ex illa temeritate, qua prius magistri esse volumus, quam fuerimus discipuli, cum quilibet frena linguae laxat deque religione et operibus dei cornicatur ineptissime. ${ }^{64}$ Hinc enim sunt illae

55 Vgl. Erasm. par. Iac. (ASD VII/6 128,207f.): »Ille [sc. Adam] seductus fallacibus promissis serpentis genuit nos tenebris.«

56 Vgl. Erasm. par. Iac. (ASD VII/6 128,203f.): »Quod fastidiamus coelestia, quod inhiamus terrenis, illius ingenium referimus."

57 Vgl. Erasm. par. Iac. (ASD VII/6 128,208f.): $\gg$ Hic rursus nos genuit, non ex corrupto semine terreni patris sed ex purissimo semine sermonis aeterni ac veridici.«

58 Vgl. Erasm. par. Iac. (ASD VII/6 128,213215): »Tam efficax autem est sermo coelestis vt nos non mutarit solum, sed velut prorsus in alios homines transformarit execrantes iam quae prius adamabamus, adamantes quae prius execrabamur.«

59 Vgl. 2Thess 2,13.

60 Röm 12,1; Eph 5,27; Kol 1,22; 1Petr 2,5.

61 Mt 22,37-39 parr.

62 Vgl. Röm 9,14-29; Eph 1,3-14.

63 Joh 3,5-8; 1Petr 1,22-25.

64 Vgl. Zw. Iac. (Z XXI 374,3-5): »Huiusmodi enim homines, quum de fide ubique garriunt, fide vera interim carentes ferre haudquaquam 
voces impiae: »Deus potuit me potentia sua a lapsu praeservare, quia omnipotens est, qui etiam providentia sua praevidit, quid essem facturus, caeterum non praeservavit; ipsius ergo culpa, non meo vitio peccavi.«Ideoque d[ivus] Iacobus: »Itaque, fratres mei dilecti, sit omnis $\mid$ homo«, inquit, »ad audiendum«, id est ad discendum, »velox «, acer, diligens, impiger, »tardus ad loquendum «, id est prudens et circumspectus in sermonibus, ne scilicet lingua mentem praecurrat aut aliud loquatur de religione deique operibus, quam ipsa praescripserit pietatis doctrina, quam hic probe didicisse oportet. »Sitis item ad iram tardi«, hoc est animi potentes, patientes et longanimes. Causa additur: »Ira hominis iustitiam dei non efficit.« Nam hominem sibiipsi eripit, ut nullum locum habeat ullum pietatis officium. Nam, ut patientia animique lenitas totum virtutum chorum post se trahit, sic impatientia sive ira omnia scelera habet.

\section{Quapropter deposita omni immunditia et superfluitate malitiae cum} mansuetudine recipite insitum sermonem, qui potest salvas reddere animas vestras.

Connectit superioribus consequentia. Dixerat paulo ante deum nos ex mera beneficentia genuisse per sermonem veritatis. ${ }^{65}$ Nunc infert: »Ut ergo huic semini naturaeque respondeamus divinae, age, deponamus a nobis omnem immunditiam, quam omnes sibi homines a primo contraximus parente, ut scilicet ex nostris viribus nihil, quam peccare, possimus; deponamus praeterea superfluitatem malitiae, hoc est inutiles, superfluos, ineptos, imo impios de rebus divinis sermones, qui enascuntur ex malitia et ignorantia rerum divinarum; recipiamus autem insitum illum sermonem, id est, per regenerationem illam coelestem insitam pectoribus vim, aut quae insita debebat esse animis nostris, quandoquidem vere eramus regeniti; recipiamus hanc, inquam, cum mansuetudine, id est recte, cum patientia, modestia et iustitia, modeste et prudenter sentientes de operibus dei, sancte loquentes de his, iuste quoque viventes in hoc saeculo. Sic autem poterit animas nostras ille dei sermo salvas facere, qui interim salvas non facit, cum immodestius et sentimus et loquimur de operibus dei, cum irascimur et turbu30 lentiores animi sequimur motus, cum impatientissime ferimus manum domini, cum religionem verbum dei et fidem christianam iactamus ore, opere vero abnegamus.« Hac autem ratione magno spiritu persequutus est superiores duos locos conclusitque et viam stravit consequentibus, quibus docet vanos esse, qui sine fructu bonorum operum multa de fide et verbo dei garriunt. Regnum enim dei non in sermone, sed in virtute esse docuit etiam ipse apostolus Paulus. ${ }^{66}$

possunt, ut a caeteris erroris sui vel admoneantur; omnes docent, doceri a nemine volunt.«
65 Jak 1,18.

661 Kor $4,20$.
Fidem, quae est sine pietate, non iustificare. 
22 Sitis autem effectores sermonis et non auditores tantum, fallentes vosmetipsos. 23 Quoniam si quis audiat sermonem nec eum factis exprimat, hic similis est viro consyderanti faciem nativitatis suae in speculo. 24 Consyderavit enim seipsum et abiit et continuo oblitus est, qualis esset.

Qui, inquit, audiunt verbum dei, non autem faciunt et ideo se christianos putant, 5 quod audierunt, longe falluntur. »Philosophi quidem ediscunt bene vivendi rationes et id satis esse putant, longe fallentes semetipsos, cum non in lingua, sed in vita hominis felicitas sita sit. $\ll^{67}$ Christus autem in evangelio nobis dixit: »Beati, qui audiunt verbum dei et custodiunt illud « [Lk 11,28]. Item apud Matth[aeum]: »Omnis«, inquit, »qui audit ex me sermones hos et facit eos, assimilabo illum 10 viro prudenti, qui aedificavit domum suam super firmam petram « [Mt 7,24]. Proinde et d[ivus] Iacobus ex doctrina Christi hortatur suos, ut, quod didicerunt ex doctrina veritatis, opere compleant pietatis neque satis esse putent, si audierint tantum, didicerint et probarint pietatis doctrinam. Falli enim, qui in hoc summam pietatis collocent. Atque hic est scopus consequentium ad cap[ut] usque 3. Addit egregiam parabolam, qua explicet, quam vanum et inutile sit audisse quidem verbum dei, sed parum cogitasse de moribus ad illud corrigendis. »Vultis audire«, inquit, »quam nullum fructum referat, qui leviter et incogitanter evangelicum sermonem audit? ${ }^{68}$ Simillimus est homini contemplanti faciem nativitatis, id est nativam, in speculo, qui, cum »accessit, ut videret, qua forma esset, nec interim 20 cogitavit de mutandis formae vitiis $\ll,{ }^{69}$ idem ille non alius a speculo discedit, quam accesserat, imo »simulatque recedit a speculo, ne meminit quidem, qualem se conspexerit $\ll{ }^{70}$ Speculum certe purissimus est sermo evangelicus. Ad hunc sese contemplaturi accedunt, qui vel ad lectiones vel contiones veniunt sacras. Ex his discunt, quae deceant hominem christianum, quae minus. Si quae in vita 25 ipsorum ma|culae sunt, labes, scelera, protinus relucent illae in hoc sacro speculo repercutiunturque in faciem contuentium. Hic nisi quis cogitet de nevis abluendis repurgandisque vitiis, inutilis fuit spectator atque auditor; imo statim atque verba in auribus eius sonare cessaverint, cessavit simul et peccatorum memoria, sed et omnium, quae ille audierat, obliviscitur proque more solito vivit perdite.

25 At qui prospexerit in legem perfectam, quae est libertatis, et permanserit, hic, cum non sit auditor obliviosus, sed effector operis, beatus facto suo erit. 
bertatis «. Et verbum quidem dei constans, firmum sibique per omnia simile est, semper habens suam naturam, vim et efficaciam. Varietas ergo illi non ex sese tribuitur, sed ab auditorum diversitate. Accedit enim ad verbum dei vanus aliquis hypocrita, huic sane speculum est. Rursus accedit vir sanae mentis et qui ex 5 animo deum quaerit, ei verbum dei lex est perfectionis et libertatis. Iacobus ergo: »Qui«, inquit, »accedit non tantum ut audiat, non uti verbo dei tanquam speculo utatur, sed tanquam ad absolutam vitae regulam omniumque functionum directorium; qui, inquam, totus in hoc est, ut perficiatur et vere liberetur ab erroribus, ab iniquitatibus et ab omni corruptela, nec incipit tantum pio zelo, verum magis pergit et in sancto studio permanet; talis, inquam, cum non sit obliviosus verbi dei auditor, sed effector magis praecepti dei, vere beatus erit. Non quod audierit, sed quod praestiterit, id est, vere et ex animo crediderit fidemque expresserit factis.« Huc vero oratio Iacobi consiliumque non spectat, ut persuadeat nos iustificari per opera. Omnis enim doctrina et evangelica et apostolica in hoc tota est, ut doceat 15 nos non per opera ac merita nostra, sed per meram Christi gratiam in fide iustificari. Unde d[ivus] Iacobus hoc primarium religionis nostrae dogma non impugnat aut evertit, sed magis conatur approbare illam fidem, quam iactabant quidam, bonis operibus vacuam et nihil aliud quam inanem opinionem et gloriationem non prodesse, sed veram fidem prodesse, quae se bonis operibus prodit, 20 imo quae sine operibus bonis esse nequit. De qua re pluribus disputabitur in cap[ite] $2 .^{71}$

26 Si quis videtur religiosus esse inter vos, qui non frenat linguam suam, sed aberrare sinit cor suum, huius vana est religio.

Exemplo planius ostendit, contra quos disputet et qui auditores sermonis, non Qui habeant effectores sint, ${ }^{72}$ hoc est, qui vera careant fide, interim maxime religiosi volunt vanam fidem. videri: qui videlicet linguam suam non frenant, deinde qui corda sua sinunt aberrare, in quibus speciebus omnia alia complexus est vitia. In lingua enim et corde affectuum sede inhaerent peccata et omnia et maxima. ${ }^{73}$ Laxant frena linguae, qui irreverenter de deo, de operibus eius, de providentia dei, de fide iustificante et operibus fidei loquuntur et iudicant vel in ipsum deum mali culpam regerentes vel iustitiam ita elevantes, ut auditores existiment se in carnis libertatem esse assertos, satis denique esse, si quis dicat se credere, utcunque vivat, impure interim. Praeterea linguam suam non frenant, qui sibi non temperant a convitiis, obtrectationibus et turpiloquiis. ${ }^{74}$ Caeterum corda sua aberrare sinunt Ephes. $4[, 14]$. hypocritae et pravi homines deum et timorem eius expectorantes et sese totos affectibus et concupiscentiis tradentes. Ex vago autem et instabili corde nascitur

71 Siehe unten S. 395-404.

Jak 1,22 .

73 Vgl. Jak 3,5f.
74 Vgl. Erasm. par. Iac. (ASD VII/6 132,293f.): $»[\ldots]$ non refrenans linguam suam ab obtrectationibus, a conuitiis, a turpiloquiis.« 
linguae petulantia. ${ }^{75}$ Qui autem tales sunt, utcunque iactitent fidem iustificantem et evangelii praedicationem, indubie tamen vani sunt vanaque ipsorum est religio.

27 Religio pura et immaculata apud deum et patrem haec est: invisere orphanos et viduas in afflictione sua et immaculatum seipsum servare a mundo.

Vera religio ac fides quibus illustris.

Ad finem capitis pulcherrima exprimit sententia, in quo consistat vera apud deum religio: non in amplis verbis splendidisque de religione, non in multa sacrarum literarum lectione vel auscultatione etiam, neque vero et in iis, in quibus plerique sitam existimant, in delectu ciborum et dierum, in monachorum regulis, in missis, indulgentiis et horis canonicis, in prolixis precibus ac ceremoniis pompave tem- 10 plari, sed in misericordia et cha|ritate, in innocentia et custodia vitae. Significanter autem dixit »religio pura et immaculata «. Sunt enim religiones impurae et pollutae, hoc est superstitiones, quarum mentio fit ad Coloss[enses] 2. ${ }^{76}$ Addit notanter et hoc »apud patrem «, id est, quae locum habet apud patrem et quae deo placet. Est enim religio, qua sibi homines placent admodum, quae deo interim 15 supra modum displicet clamanti: »Quis requisivit haec a manibus vestris?« [Jes 1,12] Verae autem religionis duo ponit capita, misericordiam videlicet sive charitatem, et innocentiam sive custodiam vitae. Annumeravit species certas, at in his comprehendit alias similes, pares, affines. Per orphanos ergo et viduas omnes intelligit homines auxilio et consilio destitutos, quibus nos opera nostra prodesse possumus. ${ }^{77}$ Per mundum intellexit omnia, quae sunt in mundo, ut sunt concupiscentia carnis, oculorum etc., 1. Ioan. 2[,16]. Atque in his veram versari religionem convincunt post alios multos hi potissimum loci scripturae: Deute. 6[,17f.]., 10[,17-19].; Psal. 14. et 23. ${ }^{78}$ Isaias in 1[,16f.]. et 58[,6f.].; Ieremias in 7[,5-7]. et 22[,3f.].; Ezech[iel] in 18[,30-32]. et 22[,7f.].; Oseas in 6[,6].; Mi- 25 cheas in 6[,8].; Zach. in 7[,9f.]. et 8[,16f.]. Christus denique ipse, Matth. 25[,40.45]., Ioan. 13[14f.].; Paulus quoque ad Romanos 12[,9-21]. et 1. Thess. $4[, 3-8]$., ut interim infinita alia loca transeam. Porro nisi haec omnia ex fide fiant, nulla sunt. »Omne enim, quod non est ex fide, peccatum est« [Röm 14,23]. Rursus si illa non fiant, dicat aliquis interim se credere aut fidem habere, nullus 30 est. »Non enim in sermone, sed in virtute est regnum dei « [1Kor 4,20]. »Nihil«, item, »valet praeputium, nihil circumcisio, sed fides per charitatem efficax $\ll[\mathrm{Gal}$

75 Vgl. Zw. Iac. (Z XXI 382,6): »Linguae petulantia animum vanum et corruptum indicat.«

76 Kol 2,21-23.

77 Vgl. Zw. Iac. (Z XXI 382,27-29): »Per orphanos quoque et viduas omnes adflictos, opp- ressos, desolatos et pauperes intelligit, imbellem nempe turbam.«

78 Ps 15,2-5 (Vulg. 14,2-5); 24,2-5 (Vulg. $23,2-5)$.
$117 \mathrm{Z}$ 
5,6]. De qua re d[ivus] Augustinus egregie disputavit libro ad Bonifatium ${ }^{79}$ contra duas Pelagianorum epistolas 3., cap[ite] $5 .^{80}$

1 Fratres, ne cum respectu personarum habeatis fidem domini nostri Iesu

Christi ex opinione. 2 Nam si ingrediatur in coetum vestrum vir aureum gestans annulum, veste indutus splendida, ingrediatur autem et pauper in sordida veste, 3 et respexeritis ad illum, qui vestem gestat splendidam, et dixeritis illi: tu sede hic bene; et pauperi dicatis: tu sta illic aut sede hic subter scabellum meum; 4 an non diudicati estis in vobisipsis et facti estis iudices cogitationum malarum?

10

Audivimus religionem consistere in misericordia et charitate. Hinc vero occasionem capit suique saeculi redarguit vanitatem. Erant homines, qui fidem iactabant Christi, interim autem proximorum nullam habebant rationem, imo pauperes contemnebant penitus, quos tamen unice suis commendarat Christus, ${ }^{81}$ magni autem pendebant, quos opes, gloria et mundi huius fortuna magnos fecerat.

15 Contra hos ergo ex praedisputatis disserens Iacobus: » $\mathrm{Si} \ll$, inquit, »fidem habetis, ut vultis videri, certe estis religiosi. Fides enim vera est religio; religio docet charitatem et misericordiam; ergo si eam habetis fidem, quam et doctrina et exemplo vitae nobis commendavit Iesus Christus, certe non oportet ita, ut facitis, respicere personas, idque ex opinione«, id est vestra existimatione carnali, »qua non spectatis, quam pius, fidelis, virtuosus aliquis sit, sed quam dives, nobilis stemmatisque clarus.« Non quod nolit honorem exhiberi viris honorandis, sed quod improbet nimium harum rerum studium pauperumque contemptum. Caeterum subiecta hypotyposi exponit, quid et qualis sit illa receptio personarum, quam damnat: »Si«, inquit, »ingrediatur in coetum vestrum aliquis aureo insignis annulo aut torque splendidave veste conspicuus, simul autem ingrediatur et pauper aliquis, nec annulum gestans in digitis nec purpuram in corpore, sed veste vili sordidaque tectus, continuo assurgitis non ob aliud, quam quod miramini splendorem illum fortunae inglorium, defertis protinus immerito locum honoratiorem cum geniculatione dicentes: >Tu sede hic bene<; pauperi autem veluti contempto dicitis: >Tu sta illic aut sede illic subter scabellum meum $<$ nec ob aliud quam ob fortunam tenuiorem aut ob viliorem vestem. $\ll^{82}$ Habes, qualis fuerit receptio personarum; iam audi, quomodo profligetur duriter ab apostolo: »Cum autem sic facitis, quaeso, an non statim animus veste reclamat et condemnat in corde vestro factum hoc vestrum, qui honorem, qui debebatur virtuti, per adulationem tribuitis auro ac purpurae, contemnitis autem eum, quem commendavit Christus, quem

79 Bonifatius I., Papst 418-422, vgl. LThK $^{3}$ II 578; AugL I 655-658.

80 Aug. c. Pelag. 3,5,14 (CSEL LX 501-503).
81 Vgl. Lk 14,13f.

82 Vgl. Erasm. par. Iac. (ASD VII/7 133,357363).
Respectus personarum charitati adversus refutatur. 
item vera animi bona $\mid$ commendant, fidei synceritas, animi modestia, sobrietas, castitas caeteraeque dotes, quae vere splendidum reddunt hominem? « ${ }^{83} \mathrm{Haec}$ autem de sententia apostoli. Non potui autem mihi temperare, quin ascriberem verbotim pulcherrimum d[omini] Leonis Iudae ${ }^{84}$ praeceptoris et fratris nostri observandissimi charissimique locum, qui est in illa explanatione huius epist[olae] luculenta, quam ex ore clariss[imi] viri d[omini] Huld[rychi] Zuinglii exceptam triennio ab hinc aedidit. ${ }^{85}$ Haec autem sunt optimi et doctissimi viri

In saeculi nostri praeposterum iudicium circa divites. verba: »Personas accipere aut respicere loquutione Hebraica significat oculos et animum in externum hominis habitum defigere eumque ex hoc vel aestimare vel contemnere, ex hoc respectu ei deferre, eum metuere, in gratiam illius, quod phas non est, committere. Ab hoc nephando et pessimo vitio, quoniam longissime abest dei natura, per spiritum sanctum in scripturis avocat et absterret eos, quos sibi in peculium quoddam selegerat. Et quoniam humilibus gaudet ab omni fastu mundi abhorrens, huius rei vivum exemplar in Christo Iesu filio suo proposuit, qui >cum dives esset, pauper< [2Kor 8,9], et cum omnium rex atque dominus, ${ }^{86} 15$ servus pro nobis factus est, ${ }^{87}$ ut disceremus humiles esse et pauperes nec mirari aut amare, quae mundus miratur et amat. Sed nec prophetarum atroces minae nec Christi exemplum et doctrina mansuetissima nec apostolorum voces tantum apud nos valuerunt, quin grande hoc malum hodie passim in orbe regnet omniaque late occupet. Posteaquam ergo > vera rerum vocabula iam pridem $<$, ut Cato ${ }^{88}$ aiebat, 20 >amisimus, quod bona aliena largiri liberalitas, malarum rerum audacia fortitudo vocatur $<{ }^{89}$ difficile est (inexpertis maxime) in tam confuso et perturbato rerum omnium ordine virtutes, non dico amare, sed ne nosse quidem et a vitiis secernere, partim quod oculus hominis corruptus in externam rerum faciem tantum fertur, non in animum, actionum omnium fontem, penetrat, partim quod vitia 25 virtutum nomina induunt et earum veste sese venditant, adeo ut vix tandem vel a spiritualissimis deprehendi possint, dum scilicet vel longo rerum usu edocti id sentiunt, vel hypocrisis, quae perpetua esse non potest, suo se vitio prodit. Catilinae $^{90}$ largitionem tum demum liberalitatem non fuisse deprehensum est,

83 Vgl. Erasm. par. Iac. (ASD VII/7 134,363370).

84 Leo Jud (1482-1542), ab 1523 Pfarrer in der St. Peterskirche in Zürich, enger Mitarbeiter Zwinglis und Bullingers, aktiv als Bibelübersetzer, Verfasser von theologischen Schriften sowie als Herausgeber von Zwinglis Bibelkommentaren (BZD C 131; C 134; C 156; C 286; C 201; C 223), vgl. HBBW I 55.

85 Zwinglis »Brevis et luculenta in epistolam beati Iacobi expositio« erschien erstmals 1533, vgl. BZD C 223; Z XXI 359.

861 Tim 6,15.

87 Phil 2,7.
88 Marcus Porcius Cato (Uticensis, 95-46 v. Chr.), erbittetster Gegner Caesars in der Endphase der römischen Republik, vgl. NP X 158-161.

89 Sall. Catil. 52,11 (Kurfess 42,24f.).

90 Lucius Sergius Catilina (gest. 62 v.Chr.), römischer Politiker, vgl. NP II 1029f. Hier wird speziell auf jene durch Catilina geforderte Zinsenreduktion angespielt, welche, nachdem er die Führung des durch Caius Manlius initierten Aufstandes übernommen hatte, als Manöver zur Rechtfertigung der Rebellion gedeutet wurde. 
dum proditorio animo apertoque Marte in urbem et patriam suam conspirasset et arma movisset. ${ }^{91}$ Haec $\pi \rho \circ \sigma \omega \pi о \lambda \eta \psi i ́ \alpha$ omnium vitiorum nobis, omnium malorum denique causa est, dum et virtutes et virtutum nomina evanuerunt. Ex hac hydra tot nobis hypocritae, tot adulatores pullularunt. Nam dum virtuti nec locus

5 est nec honos nec praemium, regina vero pecunia regnat et quisque tantum fidei et existimationis, quantum in arca nummorum, habet, fit, ut nemo solidae virtuti, nemo verae gloriae studeat. $\ll^{92}$ Tantum ille.

5 Audite, fratres mei dilecti: nonne deus elegit pauperes huius mundi divites in fide et haeredes regni, quod promisit iis, a quibus dilectus fuerit? 6 Vos autem contemptui habuistis pauperem. Nonne divites tyrannidem exercent in vos? Et iidem trahunt vos ad tribunalia? 7 Et iidem male loquuntur de bono nomine, quod invocatum est super vos?

A persona pauperis et divitis trahit argumenta, quibus respectum personarum Pauperes dei dissuadeat. Et primo quidem de pauperibus loquens: »Pauperes«, inquit, »mundi amici. huius elegit deus«, hoc est: »Pauperes deo placent, pauperes hic amat, his dilectatur, hos magni facit.« Huic membro opponitur: »Vos autem contemptui habuistis pauperem «, quae sane magna est iniquitas adeoque magna dei iniuria, utpote quae non in hominen, sed in ipsum deum redundat. Nam »amicorum omnia communia « sunt. ${ }^{93}$ Oportet ergo et iniurias esse communes. Et pauperes dei amici sunt. Intelligis ergo, quantum scelus sit observasse personas. Iam ne quis abuteretur nomine »pauper«, significanter addit »mundi huius«, hoc est, quibus tenuis est fortuna in mundo. Et cum illi quoque nonnunquam magni sint nebulones, quos contemnat vir bonus merito, iterum addit »divites in fide« et »haeredes regni «. Hoc est, qui tametsi inopes sint et egeni, praedivites tamen sunt in fide et virtutibus adeoque haeredes aeternae gloriae. Illam vero, ne quis merito ascriberet humano, statim subdit: »Quod promisit iis, a quibus fuerit dilectus.« Promisit enim ex gratia, datur ergo vita ex gratia. Quod autem et dilectioni attribuitur, ne id quidem aliud est quam gratia. Di|ligit enim, qui credit. At fides merum dei donum est. Deinde loquens de divitibus exponit, de quibus loquatur: non omnibus; sunt enim quidam divites viri boni. Proinde Iacobus: »Divites«, Divites inquit, »exercent in vos tyrannidem, violentia videlicet, usuris et aliis artibus malis opprimentes vos. Illi pertrahunt vos ad tribunalia, id est, reos vos peragunt vel propter debita vel propter religionem. Iidem illi blasphemant religionem christianam, a qua vos nomen adepti estis, ut dicamini >christiani<.« Est enim 35 loquutio frequens in scripturis, quemadmodum et illa in Genesi: »Invocabitur nomen meum super illos« [Gen 48,16], id est: »Illi vocabuntur appellabunturque 
meo nomine et censebuntur mei filii.« Hodie certe videre est, ut illis geniculemur, quibus omne studium dirigitur ad internetionem verae religionis et ad instaurationem idololatriae. Atqui ea re, id est personarum receptione, prodimus, quam nulla in nobis sit fides vera.

8 Si legem quidem regiam perficitis iuxta scripturam: diliges proximum tuum sicut teipsum, benefacitis; 9 sin vero personam respicitis, peccatum committitis et redarguimini a lege veluti transgressores.

Christiani non personas respiciunt, sed regiam legem.

Absolvitur sententia ad hunc modum: »Hinc consequitur«, inquit, »benefacere vos ipsoque opere professioni vestrae vos respondere, cum legem perficitis regiam; rursus peccare et ab ipsa redargui lege, si respexeritis personas.« Regiam 10 vero legem vocavit praeceptum charitatis, quod charitas veluti corona adeoque omnium virtutum regina sit, omnium praeceptorum colophon et summarium. ${ }^{94}$ Docet igitur hoc loco Iacobus, quod ad Galatas tradidit Paulus, fidem, quae per charitatem efficax est, prodesse. ${ }^{95}$

10 Quisquis enim totam legem servarit, offenderit autem in uno, factus est omnium reus. 11 Nam qui dixit: ne moecheris, dixit etiam: ne occidas. Quod, si non fueris moechatus, occideris tamen, factus es transgressor legis.

Nemo excuset se leviculis peccatis et quod alii peccant gravius.
Dixit transgressores esse legis, qui recipiunt personas. Id vero videbatur quibusdam durum admodum. Dicebant enim: »Tametsi illa re aberraverimus nonnihil, 20 ideo tamen non sumus transgressores legis. Pauperi enim nihil incommodavimus, quod ei praetulimus opulentiorem.« Respondet Iacobus imo et probat, quod sint transgressores legis, idque hac ratiocinatione: »Qui offenderit in uno, violatae legis tenetur reus; offendistis autem vos in uno; estis ergo rei violatae legis.« $\mathrm{Si}$ enim fieri posset, ut aliquis totam servaret legem (quod quidam sibi falso tri- 25 buebant) aberraret autem in uno tantum, iam legis transgressor non minus factus est, quam si omnium esset reus factus, id est, non minus hoc ipso facto suo illegitimo in legem peccavit, quam si aliquod peccasset ex omnibus, quae lege prohibentur, ne fiant. Non dicit apostolus, quod omnia peccata fecerit, quae in lege prohibentur, qui unum aliquod peccatum designavit; sed non minus, inquit, 30 peccavit, quam si ex universitate illa peccatorum aliud quodpiam peccasset. Nam certissimum est eum non esse homicidam et adulterum, qui pauperem contempsit, divitem in honoratiorem locum collocavit. Caeterum non minus peccavit, quam
Vgl. Zw. Iac. (Z XXI 386,29-31): ») Regiam vero legem pręceptum de charitate vocat, quoniam summa est et praecipua et reliquas omnes leges in se complectitur.«

$95 \mathrm{Gal} 5,6$. 
qui homicidium commisit aut adulterium, licet alterum altero gravius sit. Illuc autem pertinet exemplum consequens: »Qui dixit: >Ne moecheris $<$, idem dixit etiam: >Ne occidas $<. «$ At ideo non sequitur, quod, qui adulterium commisit, idem et homicidium patrarit; illud autem sequitur, quod, qui adulterium designavit, non

$$
5 \mathrm{~min}
$$
minus peccarit, quam qui homicidium fecit, adeoque quod hoc nomine se non possit excusare et veluti innoxium iactare, qui tametsi in multis non offendit in certo tamen aliquo impegit. Ergo, ut ad institutum nostrum revertamur, apostolus: »U««, inquit, »demus in plerisque vos inculpabiles esse, id tamen negare non potestis a vobis recipi personas. Atqui constat ea re peccari a vobis contra regiam

10 legem, unde vos non poteritis a transgressione legis liberare.« Caussa: qui in unam aliquam legem peccavit, non minus tenetur violatae legis, quam qui in caeteras peccat. D[ivus] Aurel[ius] August[inus] epist[ola] ad d[ivum] Hierony[mum] 29. hunc locum de charitate exponit, cuius verba, si quis requirit, haec sunt: »Unde fiet omnium reus, si in uno offendat, qui totam legem servaverit? An forte quia >ple|nitudo legis charitas est< [Röm 13,10], qua deus proximusque diligitur, in quibus praeceptis charitatis >tota lex pendet et prophetae $<$ [Mt 22,40], merito fit reus omnium, qui contra illam facit, in qua pendent omnia? Nemo autem peccat nisi adversus illam faciendo. Quia >non adulterabis, non homicidium facies, non furaberis, non concupisces et si quod est aliud mandatum in hoc sermone, recapitulatur in eo, quod diligis proximum tuum sicut teipsum. Dilectio proximi malum non operatur; plenitudo autem legis charitas< [Röm 13,9f.]. Nemo autem diligit proximum nisi diligens deum et hoc, quantum potest, proximo impendat, quem diligit tanquam seipsum, ut et ille diligat deum, quem si ipse non diligit, nec se nec proximum diligit. Ac per hoc, qui totam legem servarit, si in uno offenderit, fit omnium reus, quia contra charitatem facit, unde tota lex pendet. Reus itaque fit omnium faciendo contra eam, in qua pendent omnia. Cur ergo non dicantur paria peccata? An forte quia magis facit contra charitatem, qui gravius peccat, minus, qui levius, et hoc ipso, quod admittit, fit quidem omnium reus, sed gravius peccans vel in pluribus peccans, magis reus, levius autem vel in paucioribus peccans minus reus; tanto maiore scilicet reatu, quanto amplius, tanto minore, quanto minus peccaverit, tamen, etiam si in uno offenderit, reus est, quia contra eam facit, in qua pendent omnia? ${ }^{96}$ Haec Augustini sunt.

12 Ita loquamini et ita faciatis, veluti per legem libertatis iudicandi. 13 Siquidem iudicium absque misericordia erit ei, qui non praestiterit misericordiam. Et gloriatur misericordia adversus iudicium. 
Ad normam charitatis dirigenda omnia.

Dogma istis subiungit, docens ad charitatis regulam seu normam omnia vel dicta vel facta esse exigenda. Appellat autem charitatem legem libertatis, quam prius vocavit »legem regiam « [Jak 2,8]. Liberat enim animos nostros legis odio, liberat peccatis. Ubi ergo charitas est, ibi libertas est conscientiarum. Unde s[anctus] Ioannes in Canonica sua: »Filioli mei«, inquit, »ne diligamus verbo neque lingua, 5 sed et opere et veritate. Per hoc cognoscimus, quod ex veritate sumus et in conspectu eius suadebimus cordibus nostris« [1Joh 3,18f.] etc. Quod vero dicit nos iudicandos per legem charitatis, sumpsit ex doctrina Christi, qui apud Matth[aeum] in cap[ite] 25. totam faciem iudicii adumbrans eos damnatione liberat absolvitque, qui opera praestiterunt charitatis, damnat autem, qui operibus caruere misericordiae. ${ }^{97}$ Unde Iacobus quoque in praesentiarum argumentans a poenis et praemiis, quo magis pertraheret animos nostros ad charitatis ardens studium: »Qui«, inquit, »nullam fratribus misericordiam praestiterit, ei nulla quoque a iudice deo praestabitur misericordia, sed hoc punietur acrius, quo maius a deo sensit beneficium. «Benefecit autem nobis deus, imo bonorum acervo nos 15 locupletavit, cum dedit filium, nihil a nobis stipulatus nisi misericordiam. »Estote«, inquit, »misericordes, quia pater vester misericors est« [Lk 6,36]; »date et dabitur vobis« et »qua mensura mensi fueritis, eadem remetietur vobis « [Lk 6,38]. Et ut vos remiseritis hominibus peccata sua, ita remittet vobis pater coelestis peccata vestra. ${ }^{98}$ Item: $\gg$ Beati misericordes, quoniam misericordiam con- 20 sequentur « [Mt 5,7]. Qua ergo fronte a iudice deo petet misericordiam, qui servus in conservum se praebuit immisericordem? Quo ore postulabit a deo diligi, qui proximum suum non diligit? Proinde qui vult, inquit Iacobus, iudicium nancisci dilutum misericordia, praebeat se erga proximum vel peccantem vel egentem misericordem. Adiungit his nunc et contrariam sententiam: »Et gloriatur mise- 25 ricordia adversus iudicium. «Usurpatur autem gloriari verbum pro fidenti pacatoque praeditum esse animo. Nam d[ivus] Paulus 2. Cor. 1[,12]. gloriationem ut alias saepe ponit pro fiducia..$^{99}$ Deinde enallage ${ }^{100}$ videtur esse in voce $\gg$ misericordia $\ll$. Misericordiam enim dixit et misericordem intellexit, rem pro persona. Et saepe sit, ut per $\alpha$ v้ $\xi \varepsilon \sigma v^{101}$ virtuosum hominem et pacificum ipsam virtutem et 30 pacem appellemus, ita misericordiam apprime misericordem. Porro iudicium ipsa est sententia et supplicium, quod per iudicem in iudicio pronunciatur in reum, hoc est damnatio. Iam ergo sententia apostoli erit: »Misericors securo et confidenti animo erit in iudicio.« Nam non est, quod damnationem metuat propter peccata. Deus enim misericordiam pollicitus est illis se praestiturum, qui misericordiam 35

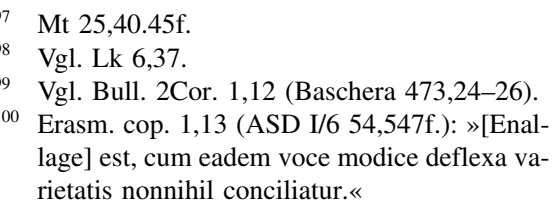

101 Zur rhetorischen Technik der »amplificatio «

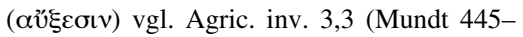
453); Erasm. cop. 1,27 (ASD I/6 73,9931002). 
exercuerint in proximos; ita vides hanc extremam apostoli sententiam proximae veluti per antithesim opponi. Proxima est: »Immisericors in iudicio nul lam assequitur misericordiam.« Opposita sententia est: »Misericors autem misericordiam consequitur.«

14 Qua utilitas, fratres mei, si fidem dicat aliquis habere se, facta vero non habeat? Num potest fides salvum facere illum? 15 Quod si frater aut soror nudi fuerint et egentes quotidiano victu, 16 dicat autem aliquis vestrum illis: abite cum pace, calescite et saturamini, non tamen dederitis illis, quae sunt necessaria corpori, quae erit utilitas? 17 Sic et fides, si facta non habuerit, mortua est per se.

Refutat nunc validius hypocritas et titulotenus christianos vividis argumentis docens, non satis esse verbis profiteri fidem, nisi et operibus misericordiae et charitatis praestemus eandem. Isti, quod et paulo ante monui, iactabant solam fidem iustificare, se autem credere, ergo et iustos esse, et recte quidem si per 15 fidem intellexissent coelestem, vivam et efficacem per charitatem vim, ${ }^{102}$ nunc autem iactabant vanam quandam de deo et religione opinionem, quam nulla sequebatur vitae morumque mutatio. Ea vero non est fides illa, cui scripturae tribuunt iustificationem. Appellatur tamen a Iacobo »fides « idque per mimesim; hypocritae enim de opinione sua ceu fide gloriabantur. ${ }^{103}$ Contra hos autem: 20 »Quae«, inquit, »utilitas, fratres mei, si dicat aliquis se habere fidem, facta vero non habeat? « Hoc est: »Nihil prodest homini, si tantum dicat: >Credo in Christum $<$, interim vero effectis caret fidei.«Efficit autem fides in pectoribus fidelium serenam conscientiam, tranquillum animum, securum minimeque de bonitate dei Effectus sive atque promissis, maxime de remissione peccatorum nihil ambigentem, sed inconcussa spe aeternam vitam expectantem. ${ }^{104}$ Efficit praeterea, ut rebus studeamus sanctis piisque, abnegemus indies mundanas concupiscentias et desyderia carnalia. Praestat item, ut deum diligamus atque proximos, iis inserviamus officiis pietatis, misericordia ac charitate. Haec, inquam, sunt facta sive fructus fidei. Iam ergo, qui his destituitur, nullum certe fructum ex eo sentit, quod dicit se 30 credere. Atque hoc est, quod dicit Iacobus: »Num potest fides salvum facere illum?«, iterum nominans fidem non vividam fidem, sed inanem de religione conceptam opinionem. Iactitat aliquis se habere vel herbam vel radicem, quae ex lacte hausta medeatur febribus. Haec quid, obsecro, prodest febricitanti, si hausta eam vim non habet, quam iste iactabat habere? Ad eundem modum quid proderit

102 Vgl. Gal 5,6.

103 Vgl. Zw. Iac. (Z XXI 393,2f.): »Per mimesim autem loquitur eos imitatus, qui de mortua fide, quae tamen fides non est, tanquam de viva et vera gloriabantur.«
104 Vgl. Zw. Iac. (Z XXI 380,19-21): »Qui enim vere credunt, [...] contemptis omnibus bonis huius mundi certa et inconcussa spe ad aterna anhelant.«
Defenditur fides vera, refutatur inanis. 
homini fidem iactasse et effectibus fidei caruisse? Iactitat aliquis fidem, sed fides iustificat et ad opera charitatis impellit; hic vero iniustus et immisericors est; quid ex his aliud colligas, quam istum fide carere? D[ivus] Iacobus huius rei evidentem producit parabolam: »Si quis«, inquit, »sorori aut fratri, cui vestis desit ac victus quotidianus, dicat blandis verbis: >Abite cum pace $<$ (Gott beradt üch) $>$ dominus provideat vobis victum et amictum<, atque haec loquutus nihil interim eorum dederit, quae vitae necessaria sunt sustentandae, verba quidem bona loquutus est, sed illa nihil prosunt egentibus, qui nihilominus algent et esuriunt.« Ioannes potius non sermone et lingua, sed in veritate et opere docet christianos diligere. ${ }^{105}$ Ad hunc autem modum habet et negotium praesens. Si quis dicat: 10 »Credo in Christum et habeo fidem evangelicam《, egregiam quidem professionem facit, at si nihilominus impurus est, avarus et immisericors, inutilis est illa professio. Id vero Iacobus sic enunciat: »Sic et fides, si facta non habuerit, mortua est per se«, hoc est sola; id est: inane fidei vocabulum inefficax est. Et mortuus homo speciem habet hominis, vim et opera hominis non habet. Inde autem tracta 15 est metaphora ad fidem vocabulo tantum, non etiam re fidem.

Iacobus non pugnat cum

Paulo.

At hic dixerit aliquis Iacobi sententiam pugnare cum dogmate s[ancti] Pauli, qui ad Rom[anos] 3.: »Colligimus igitur«, ait, »fide iustificari hominem absque operibus legis« [Röm 3,28]. Et ad Galat[as], cap[ite] 2.: »Scimus hominem non iustificari ex operibus legis nisi per fidem Iesu Christi« [Gal 2,16]. Item ad 20 Ephesios: »Gratia estis servati per fidem, idque non ex vobis; dei donum est, non ex operibus, ne quis glorietur« [Eph 2,8f.] etc. Caeterum hisce testimoniis non pugnat cum Iacobo Paulus. Siquidem Paulus loquitur de fide per charitatem efficaci, Iacobus autem hanc eandem $\mid$ commendat, reiicit vero inanem fidem, quae fides dicitur non ex ipsa re et vere, sed secundum imitationem. At hanc non 25 docet Paulus nec tanta inani tribuit vocabulo. Ipse enim ad Galat[as] dixit: »In Christo Iesu neque circumcisio quicquam valet neque praeputium, sed fides per dilectionem operans « [Gal 5,6]. Iam vero obiiciat adhuc mihi aliquis: »Si fides

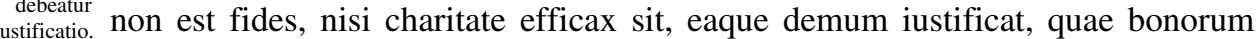
operum ferax est, quid vetat, quo minus dicamus ipsa quoque bona opera iusti- 30 ficare vel saltem fidei iustificationis partem deberi, operibus autem nostris partem alteram, ut scilicet gratiae alterum, nostris autem meritis alterum transcribatur?« Respondeo: prinicipio quidem certum est iustificari aliud non esse, quam a peccatis absolvi et purgari. Est et illud non minus certum et omnium cum prophetarum tum apostolorum testimoniis confirmatum traditumque peccata no- 35 stra nobis nullo operum nostrorum respectu, sed sola dei misericordia in sanguine Christi nobis condonari, cui quidem gratiae cum fides tribuat purgationem et reconciliationem nostram, dicitur sola iustificare, etiam sine operibus. Non enim propter nos et nostra bona opera, sed propter Christum ex misericordia salvos nos 
fecit. Caeterum qui fidei beneficio sic a patre coelesti purgati sunt, inseruntur viti Christo ceu palmites, ${ }^{106}$ ut fructum ferant bonorum operum, qui quidem fructus sequuntur, non praecedunt iustificationem. Iustus enim ex fide vivit ${ }^{107}$ et iustus facit opera iustitiae. Haec autem non faciunt fidem. Fides enim purum et merum 5 dei donum est. Habent tamen illi fructus iustificatorum per fidem nomen iustitiae eo, quod fiant a iustis. Omne enim, quod non fit ex fide, peccatum est. ${ }^{108}$ Ergo, quod iusta dicuntur, opera e fide habent. At fides gratiae est, unde et opera gratiae esse necesse est. Licet itaque illa dicantur nostra, non tamen ideo cessarunt esse dei dona. Quo fit, ut pietas non sinat iustificationem dividi, ut pars transcribatur deo ac fidei, pars autem nobis et operibus. Flagitat autem illa, ut in solidum omnia tribuamus gratiae. Neque enim alias et fidei tribuitur iustificatio ut nostro operi et conatui, sed ut mero dei dono et quod fides omnia tribuit deo, nobis nihil quam confusionem. Sathanica autem superbia est velle de dei donis quasi nostris rebus gloriari aut eam gloriam, quae soli deo debetur, in nos transferre. Solius 15 autem dei opus et gloria est iustificare impium, remittere peccata, conferre vitam retinereque in via iustitiae.

Haec vero cum ad hunc modum tradimus, insimulamur a multis hostes esse bonorum operum et novae cuiusdam doctrinae haereticae authores. Intelligunt autem, quibus vel ulla est ratio, quam indignis tractemur modis, et quod nihil in 20 hac re adferamus, quod non possimus communi totius sanctae ecclesiae assensu centumque scripturae locis evincere, imo ex antiquis etiam orthodoxisque scriptoribus demonstrare. Caeterum, cum aliquot locos in epistolas d[ivi] Pauli annotarim, ${ }^{109}$ libet hic subiungere plana aliquot s[ancti] Augustini, doctoris per omnia catholici, testimonia, e quibus appareat illam responsionem, quam iam nunc ad obiecta quorundam dedimus, omnino esse orthodoxam, non haereticam aut nuper domi nostrae natam.

Augustinus, De fide et operibus, cap[ite] 14.: »Cum ergo dicit apostolus arbitrari se iustificari hominem per fidem sine operibus legis, non hoc agit, ut percepta ac professa fide opera iustitiae contemnantur, sed ut sciat se quisque per 30 fidem posse iustificari, etiam si opera legis non praecesserint. SEQUUNTUR ENIM IUSTIFICATUM, non praecedunt iustificandum. Unde in praesenti opere non opus est latius disputare, praesertim quia modo de hac quaestione prolixum librum aedidi, qui inscribitur >De litera et spiritu<. Quoniam ergo haec opinio tum fuerat exorta, aliae apostolicae epistolae, Petri, Ioannis, Iacobi, Iudae, contra eam maxime dirigunt intentionem, ut vehementer astruant fidem sine operibus nihil prodesse; sicut etiam ipse Paulus non qualemlibet fidem, qua in deum creditur, sed eam salubrem planeque evangelicam definivit, cuius opera ex dilectione procedunt. >Et fides $<$, inquit, >quae per dilectionem operatur $<$ [Gal 5,6]. Unde

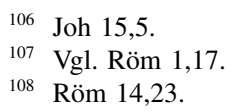

109 Vgl. Bull. Rom. 6,9-11 (Baschera 114,22-39); Bull. Gal. 5,6 (Baschera 102,5-15); Bull. Eph. 2,8-10 (Baschera 148-151). 
illam fidem, quae sufficere ad salutem quibusdam videtur, ita nihil prodesse asseverat, ut dicat: >Si habeam omnem fidem, ita ut montes transferam, charitatem autem non habeam, nihil sum< [1Kor 13,2]. Ubi autem haec fidelis charitas operatur, sine dubio bene vivitur; >plenitudo enim legis charitas< [Röm 13,10]. «110

De litera et spiritu ad Marcelli[num] ${ }^{111}$ cap[ite] 9. et 10.: »Hic forte dicat illa humana praesumptio «, $\mid$ ait, »ignorans dei iustitiam et suam volens constituere, merito dixisse apostolum: >Quia ex lege nemo iustificabitur< [Röm 3,20]. Ostendit enim tantummodo lex, quid faciendum quidve cavendum sit, ut, quod illa ostenderit, voluntas impleat ac sic homo iustificetur non per legis imperium, sed per liberum arbitrium. Sed, o homo, audi, quid in apostoli verbis sequitur: $>$ Nunc autem $<$, inquit, >sine lege iustitia dei manifestata est, testificata per legem et prophetas < [Röm 3,21]. Parumne insonat surdis? >Iustitia dei<, inquit, >manifestata est $<$. Hanc ignorant, qui suam volunt constituere et huic nolunt esse subiecti. $>$ Iustitia<, inquit, >dei manifestata est $<$, non dixit >iustitia hominis< vel >iustitia propriae voluntatis $<$, sed $>$ iustitia dei<, non qua deus iustus est, sed qua induit 15 hominem, cum iustificat impium. Haec testificatur per legem et prophetas. Huic quippe testimonium perhibent lex et prophetae. Lex quidem hoc ipso, quod iubendo et minando et neminem iustificando satis indicat dono dei iustificari hominem per adiutorium spiritus; prophetae autem, quia id, quod dixerunt, Christi implevit adventus. Nam hinc sequitur et adiungit dicens: >Iustitia autem dei per 20 fidem Iesu Christi< [Röm 3,22], hoc est per fidem, qua creditur in Christum. Sicut autem ista fides Christi dicta est, non qua credit Christus, sic illa iustitia dei, non qua iustus est deus. Utrunque enim nostrum est, sed ideo dei et Christi dicitur, quod eius nobis largitate donatur. Iustitia ergo dei sine lege non sine lege manifestata est. Quomodo enim per legem testificata, si sine lege manifestata? Sed 25 iustitia dei sine lege est, quam deus per spiritum gratiae credenti confert sine adiutorio legis, hoc est non adiutus a lege, quandoquidem per legem ostendit homini infirmitatem suam, ut ad eius misericordiam per fidem confugiens sanaretur. De sapientia quippe eius dictum est, quod legem et misericordiam in lingua portet; legem scilicet, qua reos faciat superbos, misericordiam autem, qua 30 iustificet humiliatos. >Iustitia< ergo >dei per fidem Iesu Christi in omnes, qui credunt. Non enim est distinctio. Omnes enim peccaverunt et egent gloria dei< [Röm 3,22f.], non gloria sua. Quid enim habent, quod non acceperunt? Si autem acceperunt, quid gloriantur, quasi non acceperint? Egent itaque gloria dei et vide, quid sequatur: >Iustificati per gratiam ipsius< [Röm 3,24]. Non itaque iustificati 35 per legem, non iustificati per propriam voluntatem, sed siustificati gratis per gratiam ipsius<. Non quod sine voluntate nostra fiat, sed voluntas ostenditur infirma per legem, ut sanet gratia voluntatem et sana voluntas impleat legem, non

110 Aug. fid. et op. 14,21 (CSEL XLI 61,2562,18).

111 Flavius Marcellinus (4./5. Jh.), christlicher
$123 \mathrm{Z}$ s 
constituta sub lege nec indigens lege. >Iusto< enim >lex non est posita< [1Tim 1,9], quae tamen >bona est, si quis ea legitime utatur $<$ [1Tim 1,8]. Haec duo apostolus velut inter se contraria connectens, monet movetque lectorem ad perscrutandam quaestionem atque solvendam. Quomodo enim bona est lex, >si quis ea legitime 5 utatur<, si etiam, quod sequitur, verum est: >Sciens hoc, quod iusto non est lex posita $<$ Nam quis legitime utitur lege, nisi iustus? At ei non est posita, sed iniusto. An et iniustus, ut iustificetur, id est, ut iustus fiat, legitime lege uti debet, qua tanquam paedagogo perducatur ad gratiam, per quam solAM, quod lex iubet, possit implere? Per ipsam quippe iustificatur gratis, id est nullis suorum operum 10 praecedentibus meritis, >alioqui gratia iam non est gratia< [Röm 11,6]. Quandoquidem ideo datur, non quia bona opera fecimus, sed ut ea facere valeamus, id est, non quia legem implevimus, sed ut legem implere possimus ${ }^{112}$ etc.

In eodem libro, cap[ite] 13., differentiam ostendens inter legem factorum et legem fidei: »Quid igitur intersit«, ait, »breviter dicam. Quod operum lex mi15 nando imperat, hoc fidei lex credendo impetrat. Illa dicit: >Non concupisces $<$ [Ex 20,17], ista dicit: >Cum scirem, quia nemo potest esse continens, nisi deus det, et hoc ipsum erat sapientiae, scire, cuius esset hoc donum, adii dominum et deprecatus sum $<$ [Weish 8,21]. Ipsa est illa sapientia, quae pietas vocatur, qua colitur pater luminum, a quo est omne datum optimum et omne donum perfectum.

20 Colitur autem sacrificio laudis et gratiarum actionis, ut cultor eius non in seipso, sed in illo glorietur. Ac per hoc lege operum dicit deus: >Fac, quod iubeo<, lege fidei dicitur deo: >Da, quod iubes $<$. Ideo enim iubet lex, ut admoneat, quid faciat fides. Id est, ut, cui iubetur, si nondum potest, sciat, quid petat; si autem continuo potest et obedienter facit, debet etiam scire, quo donante possit. >Non enim 25 spiritum huius mundi accepimus $<$, ait idem ipse constantissimus gratiae praedicator, >sed spiritum, qui ex deo est, ut sciamus, quae a deo donata sunt nobis [1Kor 2,12]. Quis est autem spiritus mundi huius, nisi superbiae spiritus, quo cor insipiens ob|scuratum est eorum, qui cognitum deum non ut deum gratias agendo glorificarunt? Nec alio spiritu decipiuntur etiam illi, qui >ignorantes dei iustitiam et suam iustitiam volentes constituere iustitiae dei non sunt subiecti< [Röm 10,3]. Unde mihi videtur magis esse fidei filius, qui novit, a quo speret, quod nondum habet, quam qui sibi tribuit hoc, quod habet. Quamvis utrique horum praeferendus sit, qui et habet et novit, a quo habeat, si tamen non se credat iam esse, quod nondum est, ne incidat in vitium illius pharisaei, qui, quamquam deo gratias 35 ageret ex his, quae habebat, nihil tamen petebat dari sibi, tanquam nihilo indigeret ad augendam perficiendamve iustitiam. ${ }^{113}$ His igitur consideratis pertractatisque pro viribus, quas dominus donare dignatur, colligimus non iustificari hominem

\footnotetext{
112 Aug. spir. et litt. 9,15-10,16 (CSEL LX ${ }^{113}$ Lk 18,11f. $166,23-168,23)$.
} 
praeceptis bonae vitae nisi per fidem Iesu Christi, hoc est non lege operum, sed lege fidei, non litera, sed spiritu, non factorum meritis, sed gratuita gratia. «114

In operis conclusione, cap[ite] 35.: » $\mathrm{Si}$ «, inquit, »propterea non est opus dei, quia per nos agitur vel quia illo donante nos agimus, nec illud est opus dei, ut mons transferatur in mare, quia per fidem hominum fieri posse dominus dixit et hoc ipsorum operi attribuit, dicens: >Si habueritis in vobis fidem tanquam granum sinapis, dicetis monti huic: tollere et mittere in mare, et fiet et nihil impossibile erit vobis $<$ [Mt 17,19 parr.]. Certe > vobis $<$ dixit, non $>$ mihi< aut >patri<; et tamen hoc nullo modo facit homo nisi illo donante et operante ${ }^{115}$ etc.

Fuerunt etiam olim maxime Augustini temporibus diversa de operibus et fide iudicia. Distinguebant inter opera, quae fidem praecedunt et quae sequuntur. Putabant fidem esse ex nobis, sequentia autem fidem opera ex deo. Rursus erant, qui existimarent fidei initium esse ex deo, id est ex gratia, sed, quae sequuntur, opera perseverantiae esse nostra. Imo Augustinus ipse fatetur se aliquando in ea fuisse sententia, ut crederet fidem »non esse donum dei, sed a nobis esse in nobis, 15 et per illam nos impetrare dei dona, quibus temperanter et iuste et pie vivamus in hoc saeculo ${ }^{116}$ Caeterum eam sententiam recantavit et post libros Retractationum $^{117}$ aeditos conscripsit adhuc duo egregia opuscula: alterum De praedestinatione sanctorum, alterum vero De bono perseverantiae, in quibus hoc negotium solide et fuse tractat, docens et initium fidei et progressum et perseverantiam esse 20 gratuitae dei gratiae, per quam solam salvemur, non per merita nostra, quod perinde est, ac si dixisset solam fidem, non opera, iustificare. Locos, si quis breves ex eo libro petat, hi sunt:

De praedestinatione sanctorum libro, cap[ite] 2.: sunt manifestissima testiillud: >Pax fratribus et charitas cum fide a deo patre et domino Iesu Christo< [Eph $6,23]$ et caetera talia. Nolens ergo his tam claris testimoniis repugnare et tamen volens a seipso sibi esse, quod credidit, homo, quasi componat cum deo, ut partem fidei sibi vendicet atque illi partem relinquat; et quod est elatius, primam 30 tollit sibi, sequentem dat illi; et in eo, quod dicit esse amborum, priorem se facit, posteriorem deum. Non sic pius atque humilis doctor ille sapiebat, Cyprianum beatissimum loquor, qui dixit: >In nullo gloriandum, quando nostrum nihil sit. ${ }^{118}$ Quod ut ostenderet, adhibuit apostolum testem dicentem: >Quid autem habes, quod non accepisti? Si autem accepisti, quid gloriaris, quasi non acceperis? $<35$

\section{Z. (10) diversa] diversae $Z$}

114 Aug. spir. et litt. 13,22 (CSEL LX 175,13176,17).

115 Aug. spir. et litt. 35,63 (CSEL LX 223,3-12).

116 Aug. praed. sanct. 3,7 (PL XLIV 964).

117 Aug. retract. (CCSL LVII).

118 Cypr. testim. 3,4 (CCSL III 92,1). 
[1Kor 4,7] Quo praecipue testimonio etiam convictus sum, cum similiter errarem putans fidem, qua in deum credimus, non esse donum dei, sed a nobis $\ll^{119}$ etc.

Et cap[ite] 7.: »Solet«, inquit, »dici: >Ideo credere meruit, quia vir bonus erat, et antequam crederet.< Quod de Cornelio dici potest, cuius acceptae sunt ele5 emosynae et exauditae orationes, antequam credidisset in Christum; ${ }^{120}$ nec tamen sine aliqua fide donabat et orabat. Nam quomodo invocabat, in quem non crediderat? ${ }^{121}$ Sed si posset sine fide Christi esse salvus, non ad eum aedificandum mitteretur architectus apostolus Petrus, quamvis, >nisi dominus aedificaverit domum, in vanum laboraverunt aedificantes eam< [Ps 127,1]. Et dicitur a vobis:

10 >Fides est a nobis, caetera a domino ad opera iustitiae pertinentia.< Quasi ad aedificandum non pertineat fides, quasi ad aedificium, inquam, non pertineat fundamentum. Quod si in primis et maxime pertineat, in vanum laborat praedicando aedificans fidem, | nisi eam dominus miserando intus aedificet. Quicquid igitur, et antequam in Christum crederet et cum crederet et cum credidisset, bene 15 operatus est Cornelius, totum deo dandum est, ne forte quis extollatur. ${ }^{122}$

Quemadmodum vero in libro De praedestinatione sanctorum in hoc totus est, Opera ut approbet initium salutis ipsamque fidem purum dei donum esse, ita in libro posteriore De bono perseverantiae multis probat omnia opera, quae fidem sequuntur et enascuntur ex fide, non nostra esse merita, sed et ipsa esse dei dona.

20 Nam in 13. cap[ite]: »Unde satis«, inquit, »dilucide ostenditur et inchoandi et usque in finem perseverandi gratiam dei non secundum merita nostra dari, sed donari secundum ipsius secretissimam eandemque iustissimam, beneficentissimam, sapientissimam voluntatem. Quoniam >quos praedestinavit, ipsos et vocavit< [Röm 8,30] vocatione illa, de qua dictum est: > Sine poenitentia sunt dona et vocatio dei< [Röm 11,29]. Ad quam vocationem pertinere nullus est homo ab hominibus certa asseveratione dicendus, nisi cum de hoc saeculo exierit, in hac autem vita humana, quae tentatio super terram, ${ }^{123}>$ qui videtur stare, videat, ne cadat< $\left[1\right.$ Kor 10,12]. Ideo quippe, sicut iam supra diximus, ${ }^{124}$ non perseveraturi perseveraturis providentissima dei voluntate miscentur, ut esse discamus non alta sapientes, sed humilibus consentientes ${ }^{125}$ et cum timore et tremore nostram ipsorum salutem operemur; deus est enim, qui operatur in nobis et velle et operari pro bona voluntate. ${ }^{126}$ Nos ergo volumus, sed deus operatur in nobis et velle; nos ergo operamur, sed deus in nobis operatur et operari pro bona voluntate. Hoc nobis expedit et credere et dicere: hoc est pium, hoc verum, ut sit humilis et submissa confessio et DETUR TOTUM DEO. Cogitantes credimus, cogitantes loquimur, cogitantes agimus, quicquid agimus. Quod autem attinet ad pietatis viam et verum dei cultum, non sumus idonei cogitare aliquid tanquam ex nobismetip-

119 Aug. praed. sanct. 2,6-3,7 (PL XLIV 963f.).

120 Apg 10,4.

121 Vgl. Röm 10,14.

122 Aug. praed. sanct. 7,12 (PL XLIV 969f.)
123 Hiob 7,1.

124 Siehe Aug. persev. 8,19 (PL XLV 1003).

125 Röm 12,16.

126 Phil 2,12f. 
sis, sed $>$ sufficientia nostra ex deo est< $[2$ Kor 3,5]. Non enim est in potestate nostra cor nostrum et nostrae cogitationes $\ll^{127}$ etc.

Evidentissimus August[ini]

locus.

Mira collatio scripturae.

2. Timoth. 4[,7].

In libro De gratia et libero arbitrio ad Valentinum, ${ }^{128}$ cap[ite] 6. evidentibus scripturae locis ostendit opera bona, hoc est, merita fidelium plane esse dona dei. ${ }^{129}$ In 7. autem ca[pite]: »Si ergo dei«, inquit, »dona sunt bona merita tua, non deus coronat merita tua tanquam merita tua, sed tanquam dona sua. Proinde consyderemus ipsa merita apostoli Pauli, quibus dixit coronam redditurum iudicem iustum, ${ }^{130}$ et videamus, utrum merita ipsius tanquam ipsius, id est ex ipso, ei comparata, an dona sint dei. >Bonum<, inquit, >certamen certavi, cursum consummavi, fidem servavi<. Primo ista bona opera, si non praecessissent ea cogi- 10 tationes bonae, nulla essent. Attendite igitur, quid de ipsis cogitationibus dicit.

2. Cor. 3[,5]. Ait enim scribens ad Corinthios: >Non quia idonei sumus cogitare aliquid a nobis tanquam a nobisipsis, sed sufficientia nostra ex deo est.< Deinde singula inspiciamus. >Bonum<, inquit, >certamen certavi<. Quaero, qua virtute certaverit, utrum quae illi ex semetipso fuerit, an quae desuper data sit. Sed absit, ut tantus doctor 15

Deut. 11. gentium ignoraverit legem dei, cuius vox est in Deuteronomio: $>\mathrm{Ne}$ dicas in corde tuo: fortitudo mea et potentia manus meae fecit mihi virtutem magnam hanc; sed memoraberis domini dei tui, quia ipse tibi dat fortitudinem facere virtutem < [Dtn 8(!),17f.]. Quid autem prodest bonum certamen, nisi sequatur victoria? Et quis 1. Cor. 15[,57]. dat victoriam nisi ille, de quo dicit ipse: >Gratias deo, qui dat nobis victoriam per 20 dominum nostrum Iesum Christum. $<$ Et alio loco, cum commemorasset testi-

Psal. 43. monium de Psalmo: >Quoniam propter te mortificamur tota die, deputati sumus ut Roma. 8[,37]. oves occisionis $<{ }^{131}$ subiecit atque ait: $>$ Sed in his omnibus supervincimus per eum, qui dilexit nos. $<$ Deinde dixit: >Cursum consummavi<, sed ille hoc dixit, qui

Roma. 9[,16]. alibi dicit: >Itaque non volentis neque currentis, sed miserentis est dei.< Quae 25 sententia nullo modo potest etiam sic converti, ut dicatur: non miserentis dei, sed volentis et currentis est hominis. Quisquis enim hoc ausus fuerit dicere, aperte se ostendit apostolo contradicere. Postremo dixit: >Fidem servavi<; sed ille hoc dixit, 1. Timot. 1. qui alibi ait: >Misericordiam consequutus sum, ${ }^{132}$ ut essem fidelis< [1Kor 7,25]. Non enim dixit: >Misericordiam consequutus sum, quia fidelis eram $<$, sed $>$ ut 30 fidelis essem<, hinc ostendens etiam ipsam fidem haberi nisi deo miserante non Ephes. 2[,8]. posse et esse donum dei. Quod apertissime docet dicens: >Gratia salvi facti estis per fidem et hoc non ex vobis, sed dei donum est.< Possent enim dicere: >Ideo accepimus gratiam, quia credimus $<$, tanquam sibi fidem tribuentes, gra|tiam deo. Propter hoc apostolus, cum dixisset >per fidem<, et hoc inquit: >Non ex vobis, sed 35

127 Aug. persev. 13,33 (PL XLV 1012f.).

128 Valentinus (4./5. Jh.), Abt eines Klosters in Hadrumetum um 427, in dem der Streit über die Gnadenlehre entstanden war, der Augustinus u.a. zur Verfassung von Aug. grat. veranlasste, vgl PRE XXXI/2 2278f.
129 Aug. grat. 6,13-15 (PL XLIV 889-891).

130 2Tim 4,8.

131 Ps 44,23 (Vulg. 43,22).

32 Vgl. 1Tim 1,13.16. 
dei donum est $<$. Rursus ne dicerent se suis operibus donum tale meruisse, continuo subiecit: >Non ex operibus, ne quis forte extollatur< [Eph 2,9]. Non quia negavit aut evacuavit opera bona, cum dicat deum unicuique reddere secundum Roma. 2[,6]. opera eius, sed quia opera sunt ex fide, non ex operibus fides; ac per hoc ab illo

5 sunt nobis opera iustitiae, a quo est ipsa fides, de qua dictum est: >Iustus ex fide Roma. 1[,17]. vivit.< Homines autem non intelligentes, quod ait ipse apostolus: >Arbitramur Roma. 3[,28] iustificari hominem per fidem sine operibus legis $<$, putaverunt eum dicere sufficere homini fidem, etiamsi male vivat et bona opera non habeat. Quod absit ut sentiret vas electionis, qui, cum dixisset quodam loco: >In Christo enim Iesu Galat. 5[,6]. neque circumcisio aliquid valet neque praeputium $<$, mox addidit: $>$ sed fides, quae per dilectionem operatur $<$. Ipsa est fides, quae fideles dei separat ab immundis daemonibus. Nam et ipsi, sicut dicit apostolus Iacobus, >credunt et contremis- Iacobi 2[,19]. cunt $<$, sed non bene operantur. Non ergo habent istam fidem, ex qua iustus vivit, id est, quae per dilectionem operatur, ut reddat ei deus vitam aeternam secundum 5 opera eius. Sed quia et ipsa bona opera nobis ex deo sunt, a quo nobis fides est et dilectio, propterea idem ille doctor gentium etiam ipsam vitam aeternam GRATIAM nuncupavit. Et nascitur inde non parva quaestio, quae domino donante Quomodo vita solvenda est: si enim vita aeterna bonis operibus redditur, sicut apertissime dicit scriptura, quoniam deus reddet unicuique secundum opera eius, ${ }^{133}$ quomodo gratribuatur
operibus simul tia est vita aeterna, cum gratia non operibus reddatur, sed gratis detur, ipso apostolo dicente: >Ei, qui operatur, merces non imputatur secundum gratiam, sed Roma. 4[,4]. secundum meritum $<$ ? Et iterum: $>$ Reliquiae $<$, inquit, $>$ per electionem gratiae sal- Roma 11[,5f.] vae factae sunt< et mox addidit: $>\mathrm{Si}$ autem gratia, iam non ex operibus, alioqui gratia iam non est gratia<; quomodo ergo est gratia vita aeterna, quae ex operibus sumitur? An forte vitam aeternam non dixit apostolus gratiam? Imo vero sic dixit, ut negari omnino non possit, nec intellectorem accutum, sed tantummodo intentum desiderat auditorem. Cum enim dixisset: >Stipendium peccati mors $<$, conti- Roma. 6[,23]. nuo subdidit: >Gratia autem dei vita aeterna in Christo Iesu domino nostro.< Ista ergo quaestio nullo modo videtur mihi dissolvi posse, nisi intelligamus et ipsa bona opera nostra, quibus aeterna redditur vita, ad dei gratiam pertinere propter illud, quod ait dominus Iesus: >Sine me nihil potestis facere $<.{ }^{134}$ Et quae sequun- Ioan. 15[,5]. tur. Sunt enim et alia huius generis in consequentibus pulcherrima eiusdem authoris, quae annotare nolui, quod haec videri poterunt quibusdam esse nimia. Certe satis clara sunt ista sanctissimi viri testimonia, quanquam non dubitem exorituros, qui haec nostra contemnant dicantque: »Expectabamus loca Augustini, quibus testaretur solam fidem, non opera iustificare; at tu nobis adducis nescio quos locos de gratia dei et nostris meritis!« Caeterum qui tales sunt, contentiosum funem ducere, quam veram simplicitatem discere malunt. Quod enim nos appellamus fidem, id Augustinus vocat gratiam, et quod nos per opera

133 Mt 16,27.

134 Aug. grat. 6,15-8,19 (PL XLIV 891f.). 
intelligimus, ille explicat per merita. Fides enim gratiae et misericordiae dei nititur, opera autem merita putantur. Proinde nemo nisi prodigiose superstitiosus, contentiosus et caecus non videt aequipollere has loqutiones: »Gratia, non meritis salvamur « et: »Fide beamur, non operibus«. Et utrasque has positiones invenire est in Augustino, id quod vel ex adductis colliquescit testimoniis. Nos redimus ad Iacobum nostrum, qui inventus est nihil adversari apostolo Paulo. Nam omnes apostoli unum atque eundem acceperunt spiritum. Verum diversae tractatuum occasiones diversique et temporum et personarum et locorum respectus efficiunt, ut pugnare sibi videantur, quae minime pugnant. Si semel institutum d[ivi] Iacobi tenuerimus, nihil erit in ipso nobis difficile, nihil videbitur aliis scripturis repug- 10 nans.

18 Sed dicet aliquis: tu fidem habes et ego facta habeo; ostende mihi fidem tuam ex factis tuis et ego ostendam tibi ex factis meis fidem meam. 19 Tu credis, quod deus unus est? Recte facis; et daemonia credunt et contremiscunt.

Redarguit Cohaerent haec cum superioribus hoc modo: dixit omni carere fructu, si quis dicat $\mid$ se fidem habere, virtutem interim fidei non habeat, fidem enim per se (id est inane vocabulum fidei) mortuam esse, itaque quemlibet talem fidem habentem evinci posse erroris ac vanitatis; id quidem docuit pulchra similitudine ducta $a b$ illis, qui bona imprecantur egentibus, quibus tamen nihil dant. ${ }^{135}$ Idem nunc 20 ostendit planius per prosopopoeiam. ${ }^{136}$ Inducit enim personam magistri alicuius vera fide praediti, qui evidenter hypocritas convincat erroris. Quasi dicat: »Vos quidem fidem vestram iactatis egregie, sed, si quis vera fide donatus serio vobiscum ageret atque conferret, intelligeretis, quam vana sit vestra fidei iactatio. Fingamus enim nunc aliquem efficaci fide et per charitatem operanti praeditum 25 adesse et ad hunc modum expostulare vobiscum: dicitis vos habere fidem. Cum autem constet fidem vivam esse vim et efficacem quandam coelestemque regenerationem adeoque semen divinum, consequens est, ut, ubicunque fides est, ibi et fructus fidei sint, argumenta et indicia naturae divinae, hoc est sanctitatis et iustitiae. Quaero ergo, an possitis ex talibus factis seu fructibus mihi fidem 30 vestram probare; poteritis autem, si modo fidem habueritis. Age ergo: si fidem habetis, ostendite mihi talibus argumentis fidem vestram. Quod me attinet, ego possum id, quod a vobis exigo, praestare et fructibus fide dignis ostendere, quod fidem habeam. An hic mihi id obiicietis argumenti, credere vos unum esse deum atque hoc modo separari vos a gentilibus ceu dei peculium? Recte sane creditis 35 unum tantum esse deum; verum an haec sit iusta fides iniustos iustificans, an vero

135 Jak 2,15f.

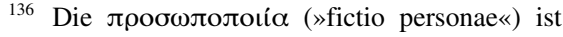
die Einführung nichtpersonhafter Dinge als sprechender und zu personhaftem Verhalten befähigter Personen, vgl. Quint. inst. 9,2,2937 (Winterbottom II 494-497); HLR 411-413. 
hac vestra responsione approbaveritis fidem vestram et an satis sit ad salutem, si dicamus nos credere unum esse deum, diligenter consyderandum est. Et occurrit nobis confestim exemplum, quo convincemini huiusmodi responsione vestra vos non satis demonstrasse fidem veram et salvificam. Daemonia enim credunt et hoc 5 ipsum pro se afferre possunt, quod iam respondistis vos. Nam confitentur Iesum esse Christum, procidunt ante eum, appellitant, imo fatentur hunc esse sanctum illum dei filium; perinde atque vos dicitis ac fatemini unum esse deum deique filium Iesum Christum. Lucae enim 4. sic legimus daemonium immundum voce magna clamasse: >Eia, quid tibi nobiscum est, Iesu Nazarene? Venisti ad perdendum nos? Scio te, quis sis: sanctus ille dei< [Lk 4,34]. Marci vero 3. legimus: $>$ Et spiritus immundi, cum illum vidissent, procidebant ei et clamabant dicentes: tu es filius dei< [Mk 3,11]. Hic autem quaero ex vobis, num propter hanc fidem suam verique confessionem salvati sint? Negabitis, opinor. Unde pari ratione dabitis mihi vos quoque minime esse salvandos, propterea quod dicitis: >Credo in deum. $<$ Vera et vivifica fides non consistit in verbis tantum et in hypocrisi, sed in virtute dei et veritate.« Est quidem in fide cognitio sive scientia, sed non sola. Qui enim vere agnoverunt deum, huic ut summo bono adhaerent, hunc ut amantissimum patrem amant, ad huius increpationem metuunt, at non desperant. ${ }^{137}$ Daemonia autem, impii et hypocritae confitentur quidem esse deum, sed huic non

20 fidunt, hoc est, sese et sua omnia uni non dedunt, hunc non ut patrem benignum amant, sed metuunt tantum ut iudicem atque tortorem. Metuunt sane et boni deum, sed cum fidei et spei, imo et charitatis perseverantia. Apud illos autem nihil aliud quam metus est et desperatio. ${ }^{138}$

20 Vis vero scire, o homo inanis, quod fides absque factis mortua sit? 21 Abraham pater noster nonne ex factis iustificatus est, cum obtulisset filium suum super altare? 22 Vides, quod fides adiumento fuerit factis illius et ex factis fides perfecta fuerit; 23 et impleta est scriptura, quae dicit: credidit Abraham deo et imputatum est illi ad iustitiam et amicus dei vocatus est. 24 Videtis igitur, quod ex factis iustificetur homo et non ex fide tantum?

137 Vgl. Zw. Iac. (Z XXI 394,29-395,1): »Cognitum deum ut patrem amant [pii], colunt, venerantur, tremunt ad sermones eius, metuunt, sed ne tantum benefactorem et patrem offendant, omnem fiduciam in eum collocant, ab ipso toti pendent, sese totos in hunc coniiciunt.«

138 Vgl. Zw. Iac. (Z XXI 394,22-27): »Haec cognitio in daemonibus et impiis hominibus quandoque fides adpellatur, ut quum simulacrum hominis hominem adpellamus, quum frigida quaedam confessio sit duntaxat formidinem et desperationem noxiam habens adiunctam. Agnitum enim deum non ut patrem amant, sed metuunt ut tyrannum, non delectantur nec fidunt eo. Timorem quidem habent, sed servilem, non filialem et castum.« 
Exemplis scripturae constringit hypocritas.
Pergit in eodem argumento. Et verba haec tribuuntur adhuc magistro illi, quem diximus per prosopopoeiam ${ }^{139}$ induci. Is enim contra hypocritas agens veramque fidem as|serens et falsam confutans: »Vis«, inquit, »scire, o homo inanis, quod fides absque operibus mortua sive inefficax est? Edocebo hoc duplici scripturae exemplo. «Subiungit enim bina Abrahae et Rachab exempla. Mira autem gratia appellavit hypocritas »homines inanes«. Quemadmodum enim vasa vacua hoc crepitant magis, quo sunt inaniora, ita fide vera iustitiaque vacui homines multa de deo et iustitia eius garriunt, imo longe vincunt loquacitate constantes et plenos omni bonitate et virtute viros. ${ }^{140}$ Primum exemplum petitum est ex Gene[seos] 22. cap[ite], ubi fidei vivae maximum Abrahae opus mira describitur energia. ${ }^{141}$ Fidei enim attribuit opus apostolus Paulus dicens ad Hebrae[os] 11.: »Per fidem obtulit Abraham Isaac, cum tentaretur, et unigenitum obtulit, in quo promissiones acceperat, ad quem dictum fuerat: >In Isaac vocabitur tibi semen $<$; cum illud secum perpendisset deum vel a mortuis excitare posse semen. Unde illum etiam in resurrectionis typum reduxit« [Hebr 11,17-19]. Proinde Iacobus, qui non potuit 15 diversum a doctore gentium tradere, per facta intellexit fidem factis efficacem ${ }^{142}$ et nequaquam, quod quidam doceri asserique putant, opera hominum satisfactoria. Facta enim sancta ex fide existunt et hanc veluti demonstrant. Id quod ipse Moses in hoc ipso Abrahae exemplo satis testatur. Angelus enim libranti manum Abrahae in puerum acclamat: $\gg \mathrm{Ne}$ mittas manum tuam in puerum, quia iam 20 cognovi, quod tu timeas deum, quia non pepercisti filio tuo unico propter me« [Gen 22,12]. Audis, opinor, in scripturis opus hoc Abrahae vocari argumentum fidei verae. »Per hoc«, inquit, »factum, quod unigenito et charissimo filio tuo non pepercisti, sed me illi praetulisti, plus obsequens praeceptis meis quam indulgens affectui paterno, per hoc, inquam, factum ceu ocularem demonstrationem didici 25 nihil in orbe tam adamatum habere te, quod non sis mihi, si petam impensurus; hoc est, quod revera et ex animo diligas me supra omnia, quae sunt in mundo, quae quidem verae fidei vis et natura est.«Pulchre ergo d[ivus] Iacobus sub-

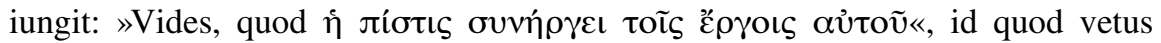
interpres vertit: ${ }^{143} \gg$ Vides, quod fides cooperabatur operibus illius «, sed signifi- 30 cantius videtur reddi posse: »Vides, quod fides vim suam exeruerit aut efficax fuerit operibus sive per opera illius.« Sic enim et ad Galat[as] 2. cap[ite] hoc

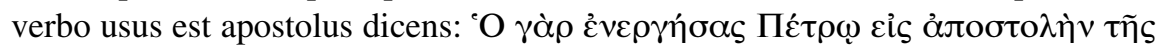

\section{Z. (28) Pulchre] Pulchrae $Z$}

139 Siehe oben 404, Anm. 136.

140 Vgl. Zw. Iac. (Z XXI 396,2-6): »[...] quidam tument multa de fide, de deo deque divinis rebus sonantes. Quemadmodum vasa quo sunt minus plena, hoc, dum volvuntur et quassantur, magis crepitant et sonum aedunt vehementiorem. Huiusmodi homines vanos ac fidei va5

$128 Z$ 


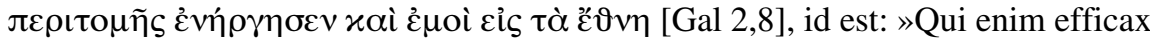
fuit «, id est, »vim suam exeruit in Petro ad apostolatum circumcisionis, efficax et in me fuit in gentes. ${ }^{144}$ Probe ergo et proprie dixit Iacobus: $\gg$ Vides «, inquit, »quod illa fides Abrahae non fuerit in labris tantum et nuda dei confessione, sed 5 quod vires et nativam suam vim exeruerit in operibus Abrahae. « Addit et aliam sententiam, quae hanc exponat: »Et ex factis sive operibus fides $\varepsilon \dot{\tau} \lambda \varepsilon \iota \omega ́ \tau \eta \ll$, id

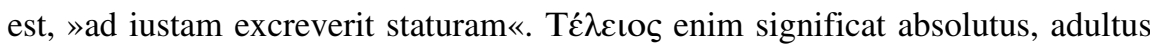
et qui est »iustae magnitudinis et aetatis «. ${ }^{145}$ Dicebantur enim apud Graecos $\tau \varepsilon \lambda \varepsilon i ́ \alpha$ i $\varepsilon \rho \alpha ́$, »eximia, iusta, largiora et luculenta sacra ${ }^{146}$ Proinde quod apos-

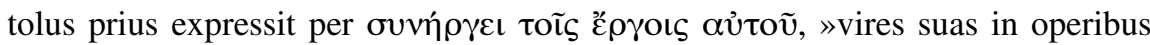

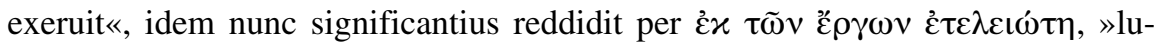
culenter et eximie exercuit per opera «. Nam luculentum et eximium opus Abrahae est, quod praedicat scriptura. Iam ergo quod quidam hinc colligunt initium iustificationis fidei, hoc est gratiae ac dei, esse, absolutionem autem iustificationis operum, id est meritorum nostrorum, ${ }^{147}$ nemo est, qui non videat, quam hoc sit alienum ab instituto apostoli, qui huc tantum spectat, non ut doceat viribus et An per opera nostra absolvatur iustificatio incepta per operibus nostris absolvi iustificationem, sed ut refutet illorum opinionem et securitatem, quibus perpetuo in ore erat fides, in vita autem et moribus ipsorum perfidia, lascivia, nequitia, avaritia, invidia. Imo blasphemia est diabolica asse20 rere dei esse initium iustificationis nostrae, sed perfectionem operum nostrorum. Hoc enim est adorare opera manuum nostrarum; hoc est gloriam creatoris creaturae tribuere et creaturam plus colere quam creatorem, ${ }^{148}$ imo huic initium tantum tribuere, nobis autem, quod perfectius est, absolutionem iustificationis. Satan cupit sibi impendi divinum honorem. Divinus honor est credere, quod solius dei opus sit iustificare impium. Qui itaque suis operibus tribuit iustificationis absolutionem, an non satanica impietate creatorem suum blasphemat? Veri dei filii credunt et confitentur, quod initium $\mid$ fidei ac iustificationis, absolutio autem iustificationis potissimum solius divinae gratiae sit, et quod ipsa vere bona opera fidem ipsam non praecedentia, sed consequentia a solo deo sint, gratuita videlicet dei dona. Unde cum propheta clamant: »Non nobis domine, non nobis, sed nomini tuo da gloriam« [Ps 115,1]. Sequitur in Iacobo: »Sic«, inquit, »scrip-

\section{Z. (21-22) creaturae] creatori $Z$}

144 Zw. Iac. (Z XXI 397,8f.): »Qui efficax fuit et vim suam ostendit in Petro, idem et in me vim suam exeret.《

145 Bud. comm. 872,39f. Vgl. Zw. Iac. (Z XXI 365,16f.)

146 Bud. comm. 873,29-31.

147 Vgl. Herb. ench. 4 (Schlager 27,23-27): »Quanquam enim Christus huius ianuam aperuerit [...], voluit tamen idem ipse Iesus Chris- tus et nos in bonis operibus, quibus fides ipsa primaque illa atque iustificans beatitudo perficitur, operam omnem navare. «In Herb. ench. 4 (Schlager 30,8-26) wird diese These unter Verweis auf Jak 2,20-24 bekräftigt. Siehe auch Biel sent. III d. 19 q.un. G 23-29 (Werbeck/Hofmann III 327).

148 Röm 1,25. 
turae locus intelligendus est, qui habet: >Credidit Abraham deo et id isti ad iustitiam imputatum est $<. \ll$ Non enim intelligendum est, quod illa confessio tantum, qua deum unum confitebatur, iustificarit ipsum, sed quod vivifica fides, quae postea sese exerebat per opera iustitiae, iustificarit ipsum. Ideo enim amicus dei vocatus est, quod secundum conditiones pacti foederis ambularet cum Deo. Qui enim secundum pravitatem cordis sui ambulant, nulla amicitia iunguntur Psal. 5[,5f.7]. Deo. Nam scriptum est: »Tu es deus, cui non placet impietas, cui non cohabitat malignus. Odio habes omnes, qui operantur scelus. « Proinde Iacobus appendit epiphonema: ${ }^{149} \gg V i d e t i s$ igitur, quod ex factis iustificetur homo et non ex fide tantum. «Ubi iterum abusione quadam, id est per catachresim, ${ }^{150} \gg$ facta « ponit pro 10 fide factis vel operibus efficaci, »fidem « pro inani fidei vocabulo. Nam significanter dicit: »Et non ex fide tantum. «Illud quoque videbatur annotandum esse in locum praesentem, quod d[ominus] Leo ${ }^{151}$ submonuit loquutionem esse, quod Abraham dicitur imolasse filium: »>Dimidium enim facti, qui bene coepit, habet $<{ }^{152}$ Et qui in opere coepto non cessat, facere aut perficere censetur. Etenim 15 quod ad voluntatem Abrahae attinet obtulerat filium suum, ni factum ipsum et librantem manum angelus intercepisset. ${ }^{153}$ Sic facere vel perficere voluntatem dei dicuntur pii, cum divinae voluntati ex corde assentiuntur et ad hanc perficiendam impigre accinguntur, licet carnem sentiant reclamantem legemque membrorum spiritui repugnantem utcumque voluntatem dei ad plenum perficiant nun- 20 quam. $\ll^{154}$

25 Similiter autem et Rachab meretrix an non ex factis iustificata est, cum excepisset nuncios et alia via emisisset? 26 Nam quemadmodum corpus absque spiritu mortuum est, ita et fides absque factis mortua est.

Alterum exemplum petitum est ex Iosuae cap[ite] $2 .{ }^{155}$ Simile est autem priori. 25 Eadem enim aptatio et ratio utriusque est, idem scopus idemque consilium. Sed et Paulus ad Hebrae[os], 11. cap[ite], ex fide produxit facta Rachab dicens: »Per fidem Rachab meretrix non periit una cum iis, qui non obedierant, cum excepisset hospitio exploratores pacifice« [Hebr 11,31]. Egregium sane opus est, quod fecit

\section{Z. (9) epiphonema] epiphomena $Z$}

149 Quint. inst. 8,5,11 (Winterbottom II 457,25f.): $\gg$ Est enim epiphonema rei narratae uel probatae summa acclamatio.«

150 Quint. inst. 8,6,34(Winterbottom II 469):»[...] catachresis, quam recte dicimus abusionem, quae non habentibus nomen suum accomodat quod in proximo est«; Erasm. cop. 1,19 (ASD I/6 66).

151 Siehe oben S. 390, Anm. 84.
152 Hor. epist. 1,2,40 (Klingner 245). Vgl. Erasm. adag. 139 (ASD II/1 254,974f.): »>Principium dimidium totius. $<$ Hoc adagio significatum est maximam difficultatis partem in aggrediundo negocio sitam esse.«

153 Gen 22,11f.

154 Zw. Iac. (Z XXI 396,27-34).

155 Jos 2,1-24. 
illa, neque simplex, sed multas habens partes. Vere enim et ex animo agnovit deum verum idque ex operibus factis in populo Israelis. Ideoque iungit se Israelitis et religioni ipsorum et secundum hanc fidem suam operatur. Nam Israelitas dei veri cultores recipit atque defendit, idque non citra exiguum capitis et om5 nium fortunarum discrimen. Actum enim fuisset de ipsa, si Ierechuntinus rex pacta inter exploratores Israeliticos et Rachab, huius item fidem et beneficia exploratoribus praestita rescivisset. At haec omnibus illis contemptis periculis impellentem fidem sequitur et ideo bene operatur. Porro si fictam habuisset fidem, dixisset: »Fateor sane deum vestrum deum esse verum, fateor opera illa 10 magnifica inter vos peracta divina esse opera deumque ipsum vestris favere partibus, adeoque ipsa egregie et vobis et religioni vestrae faveo; sed, quod praesens attinet negotium, periculosum ipsi esse intelligitis, o exploratores, si quis huic gravi caussae sese immisceat. Praeterea negotium dei parum fuerit promotum, si vestri gratia peream. Sed et mulier et meretrix sum, unde intelligitis 15 parum aut nihil in re tanta me posse. Et deus fortassis nolet agi negotium suum per meretricem, ipse quidem satis potens est, qui vos tueatur. Sed et ipsius est negotium, qui iam iam vobis aperuit Iordanem, idem vel obseratas portas citra operam meam aperiet. Huic ergo vestras res commendo, ego interim nihilominus vestra esse pergam.« Caeterum nihil tale praetexit. Veram enim ac efficacem 20 habuit fidem, quae tam non potest non bene operari, ubicumque est, quam non potest non ardere et calefacere ignis, ubicumque est. Ad finem appendit pulcherrimam sententiam eleganti comptam similitudine, talem videlicet: »Nam quemadmodum corpus absque spiritu mortuum est, ita et fides absque factis mortua est. «Corpus autem destitutum spiritu seu vita nullum facit officium, non movetur, nemini utile est; ita fides, nisi sese $\mid$ depromat in opera, nullum facit pietatis officium, non exerit vires, nemini utilis est, sed inane nomen iactatur. ${ }^{156}$ Et hactenus de fide et operibus contra hypocritas.

1 Nolite plures magistri fieri, fratres mei, scientes, quod maius iudicium CAP III. sumpturi simus. 2 In multis enim labimur omnes.

30 Transit ad locum alium. Deterret autem quosdam nimium propensos et tamen non iuste instructos a docendi functione. Quales et nostra saecula plurimos habent, praecipue autem anabaptistas, ut ambitiosissimos omnium mortalium, ita pariter omnium rerum plane ignaros. ${ }^{157}$ Primo proponit ipsam rem vel rei summam: $»$ Nolite plures magistri fieri, fratres mei.« »Plures«, inquam, id est omnes pro-

156 Vgl. Erasm. par. Iac. (ASD VII/6 140,545f.): »Etenim quemadmodum corpus anima destitutum mortuum est et inutile, ita fides, si desit charitas non ociosa, mortua est et inefficax."

157 Vgl. Zw. elench. (Z VI/1 194,14-16): »Catab- aptistę sumunt sibi omnes prędicandi officium atque de aliis, qui legitime a Christianis ecclesiis inautorati sunt, scissitantur: Quis te elegit? qum isti ne a sua quidem cacoecclesia mittantur«; Bull. adv. cat. 15r-16v. 
miscue et citra delectum ac vocationem. Addit iam incommodum et minas, quibus absterreat: »Scientes, quod maius iudicium sumpturi simus«, quasi dicat: »Qui praesunt plebi et quibus cura gregis dominici commissa est, duram sustinent conditionem et hoc nomine periculosam, quod ovium sanguis et interitus ab ipsorum manibus requiritur, si docuerint secus, quam oportet.« His adiungit argumentum tertium sumptum ab infirmitate hominis dicens: »In multis enim labimur omnes«, id est: »Ea est hominis infirmitas et proclivitas ad peccandum, ut nemo non saepe ac varie labatur in vita sua, ut iam nihil sit necessum aliunde peccata asciscere et in se transferre.«Aliunde enim in se peccata transferunt, qui ambiunt docendi munus, cui sunt impares.

2 Si quis in sermone non labitur, hic perfectus est vir, qui possit freno moderari totum etiam corpus. 3 Ecce, equis frena in ora immittimus, ut obediant nobis et totum corpus circumagimus. 4 Ecce, naves quoque cum tantae sint et a ventis saevis agantur, circumaguntur a minimo gubernaculo, quocunque impetus dirigentis voluerit. 5 Ita et lingua pusillum membrum est et magna iactat.

Quis Cohaerent cum superioribus ad hunc modum: »Ut autem multi et varii lapsus sunt praeficiendus
nuneri docendi. Nec quicquam est in vita mortalium difficilius, quam sic undique moderari linguam, ut nunquam labaris. Quod si quis coercere potest linguam suam et 20 lapsus omnes vitare, hic vir perfectus videri possit, qui totum etiam corpus veluti rationis freno moderetur. Hoc est, qui possit et alios doctrina moderari recte et res

Linguae vires. suas omnes apte componere. «Hinc autem descendit ad recensendas linguae vires, bona ac mala, quae in hoc proponit, ut doceat linguam homini christiano esse coercendam fidei et charitatis sanctae repagulis, quo spectant, quae sequuntur, 25 ferme omnia huius capitis. Scopus est linguam esse coercendam. Ratio additur: magna est vis linguae. Expolitur haec ratio per parabolas. Quod equo frenum est, quod temo sive clavus aut gubernaculum navi, hoc homini lingua. Frenum exiguum est ferrum et clavus minima quasi portio navis. Sed quis illa ideo contempserit et non magis observarit, quod videat tanta esse momenta in rebus 30 pusillis? Quid ferocius equo effuso in cursum? Quid saevius ventorum vi, quae maximas rates disiicit et tantum non coelum terrae miscet? Verum exiguum istud instrumentum et frenum et gubernaculum compescit utrunque. Ita et lingua humana minimum quidem est membrum in corpore, sed maximas habet vires tam ad bonum quam ad malum. »Magna iactat «, id est, res maximas adornat. Pusillum 35 enim cum sit, est tamen turgidum et iactabundum, late miscens exitium et ingentes excitans tumultus, totos populos et regna inter se commiscens, ni cohibeatur freno rationis et dirigatur temone charitatis. ${ }^{158}$ Huic iam infer summam causae, ergo lingua homini coercenda est. 
5 Ecce, exiguus ignis quantam materiam incendit. 6 Et lingua ignis est, mundus iniquitatis. Sic lingua constituitur in membris nostris, quae maculat totum corpus et inflammat rotam nativitatis et inflammatur a gehenna.

131 Z 5 | Alia parabola ostendit, quanta sit vis linguae, ut hinc colligamus, quanta nobis Lingua ignis est. adhibenda sit diligentia, quo cohibeatur. Exemplum vero est accommodatissimum. »Ecce«, inquit, »quantulus ignis, quam ingentem materiarum vim incendit. Unde saevum illud et latissime volitans incendium? Ex una natum est scintillula. ${ }^{159}$ Ita pusillum quidem membrum lingua est, sed ex ipsa est summa humani 10 generis pernities. Sequitur enim altera parabolae pars, quae explicat priorem: »Et lingua«, ait ille, de quo dixi, »ignis est.« Et sane naturae opifex deus ob hanc significationem voluit »linguam hominis et specie et colore ignis esse nec aliter volubilem ac rotatilem, quam est flamma ${ }^{160}$ Deinde per enumerationem amplificationis recenset mala linguae, ut scilicet appareat, quantus sit ignis, quantum 15 incendium lingua. Mundus, inquit, est iniquitatis, id est »congeries vitiorum omnium. Quemadmodum enim exigua scintilla veluti seminarium est totius incendii«, verbis utor paraphra[stis], »ita, quicquid est malorum in vita, ex mala lingua velut e mundo promitur. Et quemadmodum materiarum acervo miscetur paulum ignis, ut paulatim totam congeriem incendio misceat, ita lingua sic admixta est membris corporis, ut, ni coerceatur, inficiet et inquinet sua lue corpus universum totamque hominis vitam ab incunabulis ad extremam usque aetatem inflammet omni vitiorum incendio. ${ }^{161}$ Recte enim d[ominus] Leo: »Corpus«, inquit, »pro ipso homine aut pro tota contione et ecclesia, quae unum corpus est, aut pro tota actione et vita hominis accipit. Sic et sequentia videntur intelligi. Nam cum dicit: >Inflammat rotam nativitatis $<$, vocabulum $\tau \rho o \chi o ́ \varsigma$ accipit pro revolutione vitae humanae $a b$ incunabulis ad extremam usque aetatem. Fortassis scriptum est aliquando $\tau \rho$ ó $\chi 0 \varsigma$ penultima acuta, quod cursum significat. ${ }^{162} \mathrm{Et}$ cursum nativitatis dixit pro totius vitae cursu et revolutione. At dicat aliquis: »Unde vero linguae humanae tanta mali vis?« Respondet: »A gehenna«, quasi dicat: verum illam mali vim non illi indidit deus vel »natura, quae dentium vallo $^{163}$ et labiorum maceria admonuit oportere linguae usum circumspectum esse et moderatum, sed afflata est illi ex igne gehennae«, unde per impios spiritus animus concupiscens inflammatur »et animi lues per organum linguae prorumpit in maius et hominem e malo reddit pessimum $\ll .{ }^{164}$

158 Vgl. Erasm. par. Iac. (ASD VII/6 140,581584): »Pusillum est membrum, sed turgidum et iactabundum lateque miscens exitium et ingentes excitans tumultus ni freno animi cohibeatur. Haec totos populos, tota regna inter se committit.«

159 Erasm. par. Iac. (ASD VII/6 141,585-587).
160 Erasm. par. Iac. (ASD VII/6 141,592f.).

161 Erasm. par. Iac. (ASD VII/6 141f.,594-600).

162 Zw. Iac. (Z XXI 400,13-18).

163 Vgl. Gell. 1,15,3 (Rolfe I 72): »[...] petulantiaeque verborum coercendae vallum esse oppositum dentium luculente dixit [Homerus].«

164 Erasm. par. Iac. (ASD VII/6 142,601-604). 
7 Omnis enim natura et ferarum et volucrum serpentumque et marinorum domatur et domita est a natura humana. 8 Linguam autem nullus hominum domare potest; incoercibile malum, plena veneno mortifero. 9 Per ipsam benedicimus deo et patri et per eandem maledicimus hominibus, qui ad similitudinem dei conditi sunt. 10 Ex eodem ore procedit benedictio et maledictio.

Collationibus demonstrat linguam incoercibile esse malum. Idem ex actis sive effectis probat. »Quid«, inquit, »est usquam tam impotens, quod non aliqua ratione mansuefaciat humana cura? Nulla est fera tam fera, nulla est avis tam immanis, nullus serpens tam pestilens, nulla maris belua tam immitis, quin 10 hominum ingenio beneficiisque mansuescat. Cicurantur leones, mansuescunt tigrides ac dracones, serviunt etiam elephanti. Subiguntur et crocodili, mitescunt aspides, redduntur familiares aquilae et vultures, ad amicitiam alliciuntur delphini. « ${ }^{165}$ Sola lingua hominum malum est immedicabile, quae »gemino malo noxia est et feritate insuperabili et veneno letali $\ll .{ }^{166}$ Hoc autem exponit per 15 consequentia. »Lingua «, inquit, »laudamus deum et appellamus patrem nostrum, cum eadem proximum ad dei similitudinem conditum infamemus. Eodem ore canimus Deo hymnos et spurca ac amatoria carmina.«»Ex eodem ore calidum efflamus et frigidum. ${ }^{167}$

10 Non oportet, fratres mei, haec ita fieri. 11 Nunquid fons ex eodem foramine emittit dulcem et amaram aquam? 12 Nunquid potest, fratres mei, ficus oleas gignere aut vitis ficus? Sic nullus fons salsam ac dulcem potest aquam aedere.

Hactenus mirabili evidentia per hypotyposim delineavit, quanta sit vis linguae et quantum sit malum; nunc ipsum, quod voluit, infert: coercendam esse. Binas 25 autem ad hanc rem persuadendam adducit parabolas. Principio in genere dicit: »Non oportet ita fieri apud christianos. «Deinde parabolas profert, quibus ostendit vitium linguae, de quo egit, nunc cum ipsa etiam rerum natura pugnare. »Sunt «, inquit, »fontes, qui suffundant aquam dulcem ac potabilem; sunt rursus, qui praebeant aquam amaram salsamque. Id vero mirum non est, cum per diversas 30 fluant venas. Caeterum prodigii simile videtur, si ex eadem vena fontis amara et dulcis effunditur aqua. Pari ratione eadem arbor non potest proferre diversos

\section{Z. (10) immanis] imanis $Z$}

165 Erasm. par. Iac. (ASD VII/6 142,606-611).

166 Erasm. par. Iac. (ASD VII/6 142,617f.).

167 Erasm. adag. 730 (ASD II/2 251f.,403-405): » Eodem ex ore calidum ac frigidum proferre<.
Bilingues et qui eundem modo laudant modo vituperant, ex eodem ore calidum ac frigidum spirare dicuntur.« 
fructus. Diversae quidem diversos aedunt foetus. An non igitur absurdum est, imo et cum natura pugnat monstrique simile est >eundem hominem ex eodem corde et ore per eandem linguam pietatem et impietatem, veritatem et mendacium, salutem et exitium depromere? ${ }^{168}$ « Quid colligemus ex his omnibus? Summa cura ac diligentia linguam esse coercendam. Quod si quis hac de re plura petit, requirat ab Eras[mo] Rot[erodamo], qui de lingua aureum scripsit libellum. ${ }^{169}$

13 Quis sapiens et scientia praeditus inter vos? Ostendat ex bona conversatione opera sua cum mansuetudine sapientiae. 14 Quod si aemulationem amaram habetis et contentionem in corde vestro, nolite gloriari et mendaces esse adversus veritatem. 15 Non est enim ista sapientia e supernis descendens, sed terrena, animalis, daemoniaca. 16 Ubi enim aemulatio et contentio, ibi inconstantia et omne opus pravum.

Quidam, quod superius monui, ${ }^{170}$ ambiebant docendi officium, garriebant expedite de religione atque ita volebant videri sapientes, praeterea concertationibus contendebant frequentius contra illos, quibus displicebat ipsorum studium, ambitio, superbia, arrogantia et rixandi libido. Nec aberat zelus et invidia. Cuius quidem vivum exemplum hodie in sophistis illis scholasticis partim, ${ }^{171}$ partim autem in anabaptistis ${ }^{172}$ et indocte doctis habemus. Verum corripit hos d[ivus] Iacobus deque vera et falsa disserit sapientia. »Si quis«, inquit, »haberi vult vere Vera et falsa sapientia. sapiens, is ostendat suam sapientiam non in sophisticis tricis, in syllogismorum argutiis aut etiam in eloquentiae phaleris, non in pomposo superciliosove habitu, sed in synceritate vitae, in moribus purgatis et in mansuetudine sapientiae «, id est in mansueta, non turgida et aspera sive rixosa sapientia. Addit contrarium: »Quod si cui cordi est aemulatio et contentio, non est, quod ullam putet se assequutum esse sapientiam. At si nihilominus illam iactarit, certe contra veritatem mentitur evangelicam, quae tradit neminem vere sapientem esse, nisi qui se agnoverit et vicerit, praeterea deo et proximo sese dediderit totum. « Adiungitur his et alia sententia veluti superioris caussa, cur illi adversus veritatem glorientur. Talis enim sapientia non est e coelo, sed e terra, non repurgata syncere, sed animalis, id est affectibus corrupta, ${ }^{173}$ adeoque demoniaca, non dei bono spiritu, sed malo profecta. Hoc denuo alia exponit sententia: »Ubi aemulatio et contentio, ibi

168 Erasm. par. Iac. (ASD VII/6 144,668f.).

169 Erasm. ling. (ASD IV/1 233-370). Auf Jak 3,6-12 wird ebd. (ASD IV/1 331f.,375-404) eingegangen.

170 Siehe oben S. 409f.

$171 \mathrm{Zu}$ Bullingers Kritik an der Spitzfindigkeit mancher Ausformungen der mittelalterlichen Schultheologie vgl. Bull. script. 2,18 (Campi/Wälchli 222,13-15) sowie ebd. (Campi/Wälchli 223, Anm. 609).

172 Vgl. Bull. adv. cat. 13v-15r.

173 Vgl. Zw. Iac. (Z XXI 403,21). 
ỏx $\alpha \tau \alpha \sigma \tau \alpha \sigma i \alpha \ll$, id est inconstantia, motus, turbae, tumultus et seditio, ${ }^{174}$ imo omne opus pravum.

17 Quae autem e supernis est sapientia, primum quidem casta est, deinde pacifica, modesta, tractabilis, plena misericordia et fructibus bonis, absque diiudicatione, sine simulatione.

Quemadmodum descripsit sapientiam falsam, ita nunc pingit veram. Paraphrastes autem eleganter hunc locum totum exponens: »Sapientia«, inquit, »quae e supernis proficiscitur, a spiritu Christi, primum casta puraque est, nullis pravis affectibus inquinata; deinde pacifica et ab omni studio contentionis abhorrens; ad haec modesta minimeque torva; praeterea tractabilis et morigera neque gravate cedens ei, qui doceat meliora; clemens et misericors erga lapsos et errantes, quos magis studet servare, quam perdere, leniter tollerans et nihil non tentans, ut resipiscant; plena fructibus bonis, dum nunquam cessat de omnibus bene mereri, impios convertens ad pietatem, errantes revocans, indoctos docens, lapsos erigens, cessantes extimulans, afflictos consolans. $«{ }^{175}$ Haec paraph[rastes]. Simul 15

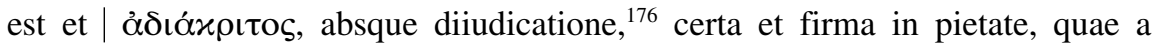
veritate ne tantillum quidem se abduci sinit ${ }^{177}$ neque veritatem obscuratam recipit, imo ne obscurare quidem ulli permittit. »Nihil enim fuci habet aut simulationis. « ${ }^{178}$ Ad hanc legem verae sapientiae si exigas philosophorum et theologorum omniumque mundi sapientum sapientiam, facile erit pronunciare, quid verum, 20 quid falsum sit.

\section{Fructus autem iustitiae in pace seminatur facientibus pacem.}

Claudit hunc locum pulcherrimo epiphonemate, ${ }^{179}$ cuius hic est sensus: ut autem plantetur iustitia in ecclesia Christi, ut illa ferat fructus in piis, non contentiosis opus est hominibus, sed qui paci student. ${ }^{180}$ Lis enim seritur ex lite, ${ }^{181}$ iustitia ex 25 pace. Iam relinquit illis aestimandum, quos potissimum ad munus subvehant docendi, qui scilicet tales sunt, quales descripsit hactenus; caveant ab illis, quibus diversa cordi sunt. Et haec de praeficiendis muneri docendi et linguae vitiis.

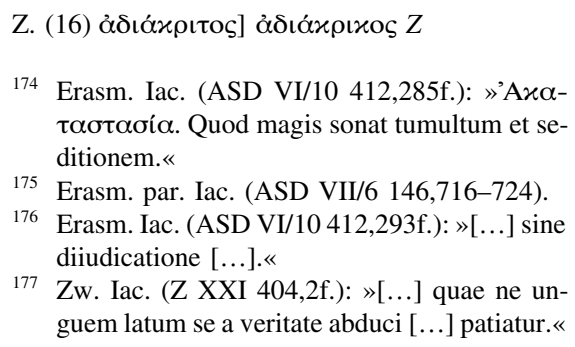

177 Zw. Iac. (Z XXI 404,2f.): »[...] quae ne unguem latum se a veritate abduci $[\ldots]$ patiatur.«

\footnotetext{
178 Erasm. par. Iac. (ASD VII/6 146,725).

179 Siehe oben S. 408, Anm. 149.

180 Zw. Iac. (Z XXI 404,4-6): »Egregia sententia, et quasi epiphonemate claudit dicens: [...] ut iustitia plantetur et promoveatur ac fructum ferat, opus est hominibus, qui paci student.«

181 Vgl. Erasm. adag. 1941 (ASD II/4 300,442): »Lis litem serit.«
} 
1 Unde bella et lites in vobis? Nonne hinc, nimirum ex voluptatibus vestris, quae militant in membris vestris? 2 Concupiscitis et non habetis, invidetis et aemulamini et non potestis adipisci. Pugnatis et bellatis, non habetis, propterea quod non postulatis. 3 Petitis et non accipitis eo, quod male petatis, ut in voluptatibus vestris insumatis.

Caput multorum scelerum est studium rei privatae immoderatius. Recte enim Contra studium apostolus dixit: »Radix omnium malorum est avaritia« [1Tim 6,10]. Hinc enim rei privatae. oritur invidia, aemulatio, contentio, fraus, mendacium, furtum, usura, oppressio, aliquando et caedes et latrocinium. Nec pauci tum erant, cum haec scriberet Iacobus, quemadmodum nunc quoque innumeri sunt, qui cum fidem crepabant et evangelium, ad rem tamen attentiores limites aequi, iusti et boni rei familiaris augendae gratia praevaricantur. Quos in praesenti severe corripit d[ivus] Iacobus revocatque a studio impio argumentis variis. Sed locum eum pulchre nectit superioribus, in quibus pacis meminit et iustitiae. ${ }^{182}$ Iam enim audistis, inquit, quid deceat christianos: iustitiam et pacem. At haec ubi inter vos? Audio enim bella et contentiones inter vos esse. Unde vero haec? Certe hinc, quod nulla est inter vos iustitia et sapientia vera, quod nulla linguae temperies, praecipue vero quod concupiscentiae frena permittitis. Putatis bellum, quod in baptismate cum Satana suscepistis, esse debellatum, cum dicitis: »Credo in deum, qui me redemit per filium suum. « Vera quidem et sancta est professio, Christus enim solus expiat peccata mundi. Interim vero in membris remanent reliquiae, quibuscum concertandum est ad finem usque vitae. Hic autem estis vos negligentiores et professioni vestrae non respondetis per omnia, quemadmodum decebat strenuos milites. Adhuc enim non tantum veteris vitae reliquiae deprehenduntur in vobis, sed imperium quoque obtinent, nulla est cum his pugna seria. Nam »alius concupiscit gloriam, alius inhiat lucro; hic studet regno, ille voluptatem venatur. Et dum non assequimini, quod quisque vehementer appetit, protruditis competitorem, invidetis assequuto, decertatis cum eo, qui videtur assequuturus. Animo discruciamini, variisque curarum tumultibus distrahimini, dum, quod impense petitis, non potestis adipisci. Ita nec unicuique secum pax est neque cum alio. Cupiditates tumultuantur in pectore; lingua, manus caeteraque membra pugnant ac belligerantur foris cum proximo. Atqui interim neque satis fit cupiditatibus vestris insatiabilibus et a veris bonis exciditis. ${ }^{183}$ Sed obiiciat hic mihi aliquis: »An vero pulchrum putas negligere familiam? An non viri boni est prospicere uxori et liberis?« Respondet: est utique. Verum christianus honestis rationibus sibi suisque prospicit. Non utitur malis artibus nec diffidit deo, imo hunc perpetuis solicitat precibus. Deinde nihil non facit, quod facere debet. At vos non petitis a

182 Jak 3,18.

183 Erasm. par. Iac. (ASD VII/6 146-148,745572). 
deo, quae videntur necessaria, sed a mundo, sequimini negotiationes pravas, his vultis prospicere rei familiari. Nec ignoro, inquit, quid etiam nunc possit obiici mihi: diu multumque vos petere prolixis etiam precibus ad deum effusis, sed nequicquam. Ad hoc autem respondeo: petitis, sed non hoc, »quod oportet neque quomodo oportet. Siquidem aut noxia petitis pro $\mid$ salubribus aut petitis diffidentes aut in usum impium petitis, nimirum ut, quod ex benignitate contigisset ad sublevandam vitae necessitatem aut egestatem proximi refocillandam, id explendis voluptatibus vestris insumatis. $\ll^{184}$

4 Adulteri et adulterae, nescitis, quod amicitia mundi inimicitia est cum deo? Quicunque ergo voluerit amicus esse mundi, inimicus dei constituitur.

Avaritia, Gravissime nunc increpat illos asperrimis utens verbis. Nam et apostolus Paulus avaros autem et deditos pecuniae adulteros et adulteras. »An nescitis«, inquit, »deum fide sibi animas vestras copulasse? Inviolatum autem erit hoc sacrosanc- 15 tum inter vos et deum connubium, si adametis solum et uni totos vos dedicetis. At si plus amaveritis opes huius mundi, si omnia studia vestra huc contuleritis, ut rem augeatis familiarem, periit inter vos fides et amor coniugalis. Plus enim mammonae defertis quam Christo.« Est autem illud praecipue observandum, quod postrema illa apostoli sententia non tantum refertur ad avaritiam, sed ad 20 omnia alia scelera. Est enim $\gamma v \omega ́ \mu \eta$ generalis, ${ }^{186}$ videlicet sententia. Nihil enim est commercii luci cum tenebris, Christo cum mammona, nihil deo cum Belial, iustitiae cum iniustitia. ${ }^{187}$ Mundum abneget necesse est, qui vult solida cum deo amicitia cohaerere.

5 An putatis, quod inaniter scriptura dicat: ad invidiam concupiscit spiritus, qui habitavit in vobis; 6 maiorem autem dat gratiam?

Deus est Spiritum sanctum dedit in corda nostra, id est semetipsum, coelestis ille sponsus zelotypus. veluti arrham arctissimae coniunctionis. ${ }^{188}$ Hic autem spiritus $»$ ad invidiam concupiscit «, videlicet amorem nostrum, id est, ut unum quam ardentissime amemus. Zelotypus enim est. ${ }^{189}$ Id quod passim in scripturis est proditum, maxime autem 30 in prophetis, quos quidem locos semel citavit omnes apostolus. Sensus ergo verborum hic est: »Dixi indignum esse, ut sponsa Christi sive mens fidelis

184 Erasm. par. Iac. (ASD VII/6 148,755-758).

185 Eph 5,5.

186 Zw. Iac. (Z XXI 405,26).

187 Vgl. Mt 6,24 par.; 2Kor 6,14f.
188 Vgl. Röm 5,5; Eph 1,17f.; 1Thess 4,8; 1Tim 1,14; Tit 3,5f.; 1Joh 4,13.

189 Vgl. Erasm. par. Iac. (ASD VII/6 148,787): »[...] zelotypus est et, vt ita loquar, inuidus.« 
praeterito sponso colludat et rem habeat cum mammona. ${ }^{190}$ Id autem vel ex illis maxime scripturae locis intelligi potest, qui testantur deum esse zelotypum. ${ }^{191} \mathrm{Si}$ enim id verum est, ut sane falsum esse nequit, quod prodidit spiritus veritatis, non feret deus cultorem, qui simul et mundum deperit et Christum se amare dicit, qui 5 mammonae servit, hoc est, lucro et rei familiari augendae inhiat, et fidem Christi profitetur.« Oportet omnino Christum sponsum solum et prae omnibus diligere, prae hoc omnia contemnere, quae sponso audimus esse adversa. Quod si quis mihi obiiciat: »Rem exigis maximam et quae non potest a quoquam praestari mortalium «, respondeo: »Exigit sane a nobis deus eximium quendam amorem, 10 sed idem confert nobis maiorem gratiam, id est multo uberrimam. ${ }^{192}$ Equidem »difficillimum est praestare, quod exigit, sed in hoc ipsum largitur vires, ut facile possimus $\ll .{ }^{193}$

7 Subditi ergo estote deo, resistite autem diabolo et fugiet a vobis. 8 Appropinquate deo et appropinquabit vobis.

15 Nunc infert summam caussae, quasi dicat: »Cum ergo deus sit zelotypus nec ferat adulterum et hominem mammonae dedicatum, vos subditi este deo, ut, quemadmodum sponsa marito obtemperat soli, ita vos quoque praebete uni deo per omnia morigeros. Diabolus conabitur vos ab illius amore studioque retrahere et vos sibi copulare; verum illi firma fide resistendum neque propter eius improbitatem desperandum est. Ubi enim senserit vos serio amare dominum, abhorrere illius lenocinia, metuet vos nec metuet modo, sed et fugiet a vobis.« Quae quidem maxima est consolatio decertantium nunc bellum periculosissimum contra Satanam. Et quia studium pecuniae sive rei privatae maxime seiungit a deo, ideo pulchram ingerens sententiam: »Appropinquate«, ait, »deo et appropinquabit vobis.« Nam quo magis mundum fugimus, quo longius a nobismetipsis et concupiscentiis nostris migraverimus, hoc propius accedimus ad deum.

8 Emundate manus, o peccatores, et purificate corda, duplices animo. 9 Affligimini et lugete et plorate, risus vester in luctum convertatur et gaudium in moerorem. 10 Submissi sitis in conspectu domini, et eriget vos.

| Significantius effert, quod hactenus proposuit veluti sub involucro; quasi dicat: »Vos autem appello, o peccatores, neque enim aliud nomen invenio, quo vos commode appellitem, vobiscum, inquam, mihi res est. Hoc autem est, quod peto a

190 Jak 4,4.

191 Vgl. Ex 20,5; 34,14; Dtn 4,24; 6,15; Ps 78,58; Ez 8,3.

192 Vgl. Erasm. par. Iac. (ASD VII/6 149,791f.):
»Sed vt exigit a nobis eximium quendam amorem longeque puriorem quam lex Mosaica, ita confert vberiorem gratiam.«

193 Erasm. par. Iac. (ASD VII/6 149,792f.). 
vobis, ut emundetis manus. «Qua quidem sententia allusit ad illud Isaiae: »Cum multiplicaveritis orationem, ego non exaudiam. Nam manus vestrae sanguinibus plenae sunt. Lavate igitur, mundamini et auferte malitiam conatuum vestrorum a conspectu oculorum meorum, cessate male facere, discite bene facere, quaerite iudicium, asserite oppressum « [Jes 1,15-17]. Et per manus quidem symbolum actionum nostrarum intellexit: fraudes, furta, circumscriptiones, denique omnes artes, quae committi solent in negotiationibus, a quibus vult abstinere cultores Christi. ${ }^{194}$ Huc pertinet, quod sequitur: »Purificate corda, duplices animo. « Haec enim sententia explicat superiorem. Nam quod ibi vocavit manus, hic corda appellat. Ex corde enim sunt actiones veluti ex fonte rivuli. Hypocritae autem sunt, qui emundant manus, corda vero non mundant. Iacobus ergo veram docens sanctimoniam, manibus adiunxit corda. »Duplices animo« dixit, quos iam vocavit »peccatores «. Volebant enim et deo servire et mammonae, quum ipse dominus dixerit in evangelio: »Nemo potest duobus dominis servire. Non potestis deo servire et mammonae« [Mt 6,24 par.]. Praeterea avari isti et locupletes, quibus 15 cum agit apostolus, effluebant vita luxuriosa, omnia illorum erant risus, iocus, gaudia, tripudia, epulae diesque festi, quae quidem solent plerunque opes consequi et ex opibus institui. Unde statim adiungit: »Affligimini et lugete et plorate « etc. Videtur autem ista sumpsisse ex 6. cap[ite] Lucae, ubi dominus dicit: $\gg$ Vae vobis, divitibus, quia habetis consolationem vestram. Vae vobis, qui saturi 20 estis, quia esurietis. Vae vobis, qui ridetis nunc, quia lugebitis et flebitis « [Lk 6,24f.]. Proinde Iacobus suadet nunc lugendum esse atque plorandum. Non quod sic damnet moderata honestaque gaudia, sed quod luxum, petulantiam et nimiam in risus et gaudia effusionem nolit esse in moribus christianorum. Iam cum opes quoque insolentes et superbos efficiant, hinc recte subiungit: »Humiliamini in 25 conspectu domini et eriget vos.« Nam in evangelio quoque dixit dominus: »Omnis, qui se humiliaverit, exaltabitur, et qui se exaltaverit, humiliabitur « [vgl. Mt 23,12 parr.].

11 Nolite detrahere vobis invicem, fratres. Qui detrahit fratri quique iudicat fratrem suum, detrahit legi et iudicat legem. Quod si iudicas legem, non es observator legis, sed iudex. 12 Unus est legislator, qui potest servare et perdere. Tu quis es, qui iudicas alium?

Detractio. Ex superbia et arrogantia sequitur livor, ex livore autem detractio; nunc ergo agit contra detractionem, pessimum vitium. Primo ponit praeceptionem: »Nolite, fratres«, inquit, »vobis invicem detrahere.«Caussam protinus appendit: »Quisquis 35 fratri detrahit, is detrahit legi quoque«, id est, »peccat contra legem«, quae vetat,

194 Vgl. Zw. Iac. (Z XXI 407,32-35): »Manus symbola sunt actionum. [...] Lavare manus, quum ab omni genere malefactorum praecipiunt abstinere, a fraude, vi, rapina, furto etc.« 
ne detrahamus. Rursus quisquis iudicat proximum, hic functionem sibi iudicis dei sumit. Caeterum debemus nos legi subdi et obedire, non dominari vel ista neglecta sequi pravos affectus. Est denique iudex unus, cui soli est in omnes vitae necisque potestas, qui pro iustitia sua novit, quos et quando sive perdat sive servet. Proinde huic committamus omne iudicium, subiiciamus nos legi et abstineamus a detractione. Emphasim vero evidentissimam habet, quod in fine ponit: »Tu quis es, qui iudicas alium?« Primo enim monet, ut quisque in se descendat et, qualis apud sese domi suae sit, expendat. ${ }^{195}$ Inveniet autem quisque in oculo proprio trabem, quam eruat sibi, priusquam festucam tollat ex oculo 10 fratris sui. ${ }^{196}$ Deinde turpe est sibi imperium usurpare in servum alterius iuri subditum. ${ }^{197}$ Quisquis igitur a summo iudice nolit iudicari, ne ipse quenquam iudicet temere. ${ }^{198}$

13 Age nunc, qui dicitis: hodie et cras eamus in hanc civitatem et faciamus ibi annum unum et mercemur et lucrum faciamus, 14 qui ignoratis, quid futurum sit postero die. Quae est enim vita vestra? Vapor enim erit, qui ad exiguum tempus apparet et deinde evanescit. 15 Pro eo, quod dicere debueritis: si dominus voluerit et si vixerimus, faciamus hoc aut illud. 16 Nunc autem exultatis in superbiis vestris. Omnis exultatio talis mala est. 17 Igitur qui noverit recte facere nec facit, hic peccato tenetur.

20 Iterum in avaros et studiosos pecuniae stringens calamum acclamatione commoda excitat mentes ipsorum et per mimesim graphice fastuosa ipsorum verba refert stultaque, pomposa et praesumptuosa ipsorum consilia recenset, quae quidem plana sunt, maxime si conferas cum mercatorum nostrorum consiliis et sermonibus amplificis. Hic enim nihil invenias exigui, numerati, mediocris; inexpensa, amplissima, gravissima sunt omnia. Nihil auditur ab his quam de lucrandi rationibus, de negotiationibus, de emporiis et mercibus; raro fit ulla dei, virtutum honestarumque rerum mentio. Caeterum ab hac vanitate, superbia, iactantia et cupiditate revocat per incertitudinem brevitatemque vitae humanae, dicens: »Quae tandem est ista vita vestra, cui uni prospicitis, cui uni laboratis ac 30 molimini? Nimirum vapor est ad breve tempus apparens ac mox evanescens. «199 Quod quid aliud est, quam quod proverbio dicitur: »Homo bulla est « ? $^{200}$ So- Brevitas vitae

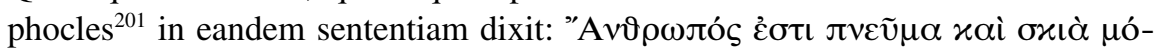

Contra fastuosa divitum verba et consilia.
195 Vgl. 1Tim 3,5.

196 Mt 7,3-5 par.

197 Röm 14,4. Vgl. Erasm. par. Iac. (ASD VII/6 152,863-865): »Postremo in seruum alienum ius tibi vindicas, haud citra contumeliam Domini communis. Relinque illum suo Domino, qui solus iuste iudicat.«

198 Mt 7,1f. par.
199 Erasm. par. Iac. (ASD VII/6 152,885-887).

200 Erasm. adag. 1248 (ASD II/3 256,887f.): »Homo bulla. Prouerbium hoc admonet humana vita nihil esse fragilius, nihil fugacius, nihil inanius.«

201 Sophokles (5. Jh. v.Chr.), attischer Tragiker, vgl. NP XI 726-735. 
vov. ${ }^{202} »$ Homo«, ait, »spiritus est et umbra tantum. « Pindarus ${ }^{203}$ vero de hominis

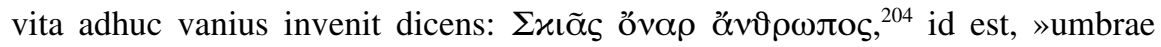
somnium homo. Nihil sane inanius est quam umbra, videtur enim esse, cum nihil sit. At hac quoque reperit quiddam vanius Pindarus, nimirum umbrae somnium. ${ }^{205}$ Scripsit et in 7. libro elegans caput Plinius de brevitate et miseria vitae humanae. ${ }^{206}$ Sed et ipse Christus dominus eadem ratione apud Lucam in 12. legitur usus, dissuadens studium divitiarum a brevitate vitae humanae, qui locus huc pulchre quadrabit. ${ }^{207}$ Verum dicat aliquis: »Igitur negotiari prohibes? « Respondet: »Nihil nunc de negotiationibus iustis et necessariis disputo, sed vestram culpo vanitatem, qua toti rebus addicti estis terrenis atque adeo, ut timor dei nullum apud vos locum habeat, virtutis studium nullum. Volo igitur, ut ante omnia quaeratis regnum dei, ${ }^{208}$ ut eius curae et sanctae providentiae omnia vestra commendetis utque inculpatae voluntati eius vosmet credatis totos. Atqui neg-

Sententia generalis ponitur contra omnem vanam gloriationem. lectis his studiis sanctis exultatis in superbiis vestris. Id quod malum est: nam omnis talis exultatio mala est. Igitur talem exultationem volo a vobis esse quam 15 alienissimam. «Hisce omnibus suppingit vividum quodpiam epiphonema: ${ }^{209} \gg$ Igitur qui noverit recte facere nec facit, hic peccato tenetur.« Volebant autem isti, quibus cum agit apostolus christiani, videri, qui docti essent evangelium Christi; unde: »Gravius«, inquit, »peccant, qui ex evangelica doctrina, quid agendum sit, norunt, interim pravos affectus sequi malunt, quam qui, quid faciendum sit, 20 nondum didicerunt et corruptos sequuntur affectus. $\ll^{210}$ Videtur autem Iacobus id sumpsisse ex illis domini verbis, quae leguntur apud Lucam in capite 12. ad hunc modum: »Ille autem servus, qui cognovit voluntatem domini sui et non se praeparavit nec fecit secundum voluntatem eius, plagis vapulabit multis. Qui autem non cognovit et fecit digna, plagis vapulabit paucis« [Lk 12,47f.]. Proinde, quod 25

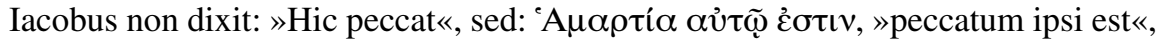
sive »peccato tenetur «, emphasim habet; quasi dicat: »Huic peccatum suum imputabitur pro scelere maximo et ideo maximum quoque de ipso sumetur supplicium.«

CAP. v. 1 Agite nunc, divites, plorate ululantes super miseriis vestris, quae advenient vobis. 2 Divitiae vestrae putrefactae sunt; vestimenta vestra tineis obnoxia facta sunt. 3 Aurum et argentum vestrum erugine vitiatum est, et

202 Erasm. adag. 1248 (ASD II/3 260,976). Vgl. Soph. frag. 13 (Radt 120).

203 Pindar (geb. 522/518 v.Chr.), griechischer chorlyrischer Dichter, vgl. NP IX 1031-1036.

204 Pind. Pyth. 8,95f. (Maehler 105).

205 Erasm. adag. 1248 (ASD II/3 260,962-965).

206 Plin. nat. 7,167f. (Ianus/Mayhoff II 58,6-21) Vgl. Erasm. adag. 1248 (ASD II/3 258,910919).
207 Lk 12,15-21.

208 Mt 6,33.

209 Siehe oben S. 408, Anm. 149.

210 Vgl. Erasm. par. Iac. (ASD VII/6 152f.,903905): »Porro grauius peccat qui, cum ex euangelica doctrina sciat quid sit agendum, tamen corruptus malis affectibus sequatur eadem quae sequuntur ii qui Christum ignorant.« 
erugo eorum in testimonium vobis erit et exedit carnes vestras sicut ignis.

Thesaurum congessistis in extremis diebus.

Gravius nunc invehitur in divitum vitia, iram dei malorumque glomos et ipsam securitas damnationem sempiternam ipsis interminans, si tales esse perrexerint, quales divitum.

5 multo cum dedecore se gesserint hactenus. Primo autem taxat illorum securitatem, insana gaudia et dissolutam vitam. »Securi«, inquit, »estis, confidentes opibus vestris, ideo exultatis, luditis et canitis, cum interim plorandum erat magis et ululandum, idque propter aeternas illas calamitates, quae statim imminebunt vobis. $\ll^{211}$ Vae enim, ait Christus, illis, qui hic habent $\mid$ consolationem suam, qui

10 hic rident, mox enim flebunt amare. ${ }^{212}$ Deinde aliud vitium taxat in divitibus: congerendi et thesaurizandi studium. Nihil enim ipsis satis est, hinc condunt, Thesauri defodiunt, exaggerant perpetuo. Partis vero his ipsi non utuntur nec aliis sinunt usufructum. Malunt sua perire situ, erugine aliisque vitiis, malunt tineis et blattis obiicere, quam indigentibus impartiri. Sed hic addit d[ivus] Iacobus: »Erugo illa testabitur vestram impietatem, qui malueritis facultates vestras situ perire, quam in usus egentium depromere. $\ll^{213}$ Dominus apud Matthaeum in 6. ab incertitudine opum argumentans, ostendit his nihil esse fidendum, dicens: »Ne reponatis vobis thesauros in terra, ubi erugo et tinea corrumpit, et ubi fures perfodiunt et furantur, sed recondite vobis thesauros in coelo, ubi neque erugo neque tinea corrumpit« [Mt 6,19f.]. Praeterea damnum divitiarum et animum divitum sese excruciantem notat in praesenti Iacobus et ait: »Et exedit carnes vestras. « Curae enim immoDivitiae aculei dicae, quae emergunt ex studio divitiarum, macerant, pungunt et tantum non enecant, unde et divitiae a Christo comparantur spinis. Iacobus addit similitudinem »sicut ignis«. Ardet enim et aestuat avari animus flammis perpetuis, ut nunc bis sint miseri, partim quod hic nihil nisi tormenta sentiunt ab opibus, partim quod post hanc vitam affligentur flammis sempiternis. Sequitur epiphonema: ${ }^{214}$ »Thesaurum congessistis in extremis diebus«, quasi dicat: »Egregie factum putatis, quod auri cumulos congessistis, quod frugum vobis supersint acervi ingentes; sed congessistis thesaurum quidem, at parum vobis profuturum. Congessistis enim vobis thesaurum divinae irae, congessistis vobis carbones super capita Roma. 2[,5-8]. vestra, ${ }^{215}$ deus enim iusta vos vindicta persequetur et perdet aeternum. « Habet ergo ironiam et antiphrasim ${ }^{216}$ oratio.

211 Vgl. Erasm. par. Iac. (ASD VII/6 153,909f.): »Si mentem habetis, plorate et vlulate reputantes aeternas illas calamitates quae mox imminent vobis.«

212 Vgl. Lk 6,24f.

213 Vgl. Erasm. par. Iac. (ASD VII/6 153,916f.): »Eaque aerugo testabitur vestram impietatem, qui malueritis situ perire quam in vsus egentium expromere.«
214 Siehe oben S. 408, Anm. 149.

215 Vgl. Spr 25,21; Röm 12,20.

216 Bei der Antiphrasis oder Litotes wird der superlativische Grad der Bedeutung durch die Negierung des Gegenteils umschrieben, vgl. HLR 304. 
4 Ecce, merces operariorum, qui messuerunt regiones vestras, quae fraude non reddita est, a vobis clamat et clamores eorum, qui messuerant, in aures domini sabaoth introierunt.

Fraus divitum. Furta, fraudes, rapinas et violentias divitum corripit. Maximum vero in his peccatum est mercedem debitam vel negare vel differre vel non iuste numerare. Nam Iacobus numerat inter peccata clamantia, ea videlicet, quae omnium gravissima semper in conspectu dei sunt et vindictam flagitant. Verba petiit apostolus ex Deut[eronomii] 24. cap[ite], ubi legis: »Non opprimes mercenarium, pauperem et inopem, sive sit de fratribus tuis sive peregrinis tuis, qui sunt in terra tua atque intra portas tuas. Die suo dabis ei mercedem suam nec occidet super eum sol, 10 quia pauper est et cum illo sustentat animam suam, ut non clamet contra te ad dominum et fiat tibi in peccatum « [Dtn 24,14f.]. Utinam vero tam illa placerent divitibus, quam placet, si nanciscantur industrios mercenarios. Porro dominum in praesenti appellat »dominum sabaoth «, id est »dominum exercituum«, haud sine caussa. Ita enim significat illos potentissimi ducis manum non subterfugituros.

5 In delitiis vixistis super terram et lascivistis, enutriistis corda vestra ut in die occisionis.

Luxus divitum. Aliud vitium, imo scelus divitum incusat: »Non tantum estis iniurii in tenues illos vestros mercenarios, sed opes illas male partas pessime collocatis. Toti enim estis in voluptatibus atque delitiis. Agitatis epulas et convivia frequentia, in his nullis 20 parcitis sumptibus, omnes inferuntur delitiae.« Lasciva hic quoque sunt omnia: loci, sales, risus, gaudia, cantiones, musica, choreae et petulantia dissolutissima quotidiana sunt. Eriguntur in altum aedificia regia, parantur horti et balnea nec quicquam intermittitur, quod carni volupe videtur. »Atqui ita alienus sudor vos alit, aliena fames vos saginat. Ringuntur mercenarii, algent alii, cum quibus vobis 25 negotium est, fame sitique enecantur pauperes, vos interim suaviter et in delitiis lascive pascitis cuticulam vestram, quotidiana agitantes convivia, non minus splendida quam alii solent festo die mactata victima. ${ }^{217}$ Quanquam hoc postremum videatur quibusdam sic posse intelligi: »Quod tamen non secus cedet vobis quam pecoribus accurata et diligens saginatio, quae ubi fuerit perfecta, rapiuntur 30 protinus in lanienam et mactantur.« Caeterum superior sententia melior est. His similia invenies apud Ieremiam in cap[ite] $22 .^{218}$

| 6 Condemnastis et occidistis iustum, et non resistit vobis. 
Pessimum nunc accusat in divitibus crimen crudelitatis et corrupti iudicii. Solent Tyrannis enim opulentiores, qui iudiciis praefecti sunt, invidiam suam et affectus pravos divitum. exercere in dicendis sententiis et tenuiores damnare, vel quod non solverunt, quantum illi poposcerant, vel quod liberius de illorum insolentia libidine et 5 tyrannide loquuti sunt, vel quod pro libitu obsequi noluerunt, vel quod exosam illis religionem sequuntur. Maius autem periculum imminet hic tenuioribus, quam qui clientelis et familiis instructi sunt ac resistere possunt. Illi enim cum neminem habeant, qui caussam ipsorum agat, neque ulla sit resistendi facultas, facile subvertuntur. Praecipue autem pertinent praesentia ad eos, qui religionis caussa persequutionem patiebantur. Sequitur enim:

7 Patientes igitur estote, fratres, usque ad adventum domini. Ecce, agricola expectat pretiosum fructum terrae, patienter expectans illum, donec accipiat pluviam tempestivam et serotinam. 8 Patientes igitur estote et vos et confirmate corda vestra, quoniam adventus domini appropinquat.

15 Iam consolatur oppressos sermone converso ad afflictos, simul autem interminatur iudicium divitibus illis oppressoribus. Sic enim et sensus absolvitur tandem. Patientiam Est enim haec iusta cohaesio: »Vos, divites, canitis, ridetis, securi estis, congeritis thesauros, fraudatis mercenarios, vivitis delicate, damnatis et occiditis egenos, persequimini religionem christianam, hanc vultis extinctam, caeterum dominus propediem aderit et scelera ista vestra nefanda ulciscetur iudicio suo iusto liberabitque oppressos vita sempiterna ipsis donata, vobis autem in aeternum ignem coniectis. «Quemadmodum et Christus depinxit parabola divitis et Lazari, Lucae 16. ${ }^{219}$ Nunc ergo consolatur oppressos, idque per adventum domini, in quo digna sint operibus suis recepturi tam oppressores quam oppressi. Adhibet his parabolam petitam a re rustica. Quemadmodum enim agricola aequo animo fert omnes labores, ut aliquando metat fructum, ita nobis quoque ferenda est iniuria, ut aliquando accipiamus coronam vitae. ${ }^{220}$ Et ut pluviam, quae sementi omnino necessaria est, non accipit agricola, cum vult, sed cum deus dat, unde illum patienter expectare necesse est; ita a dei pendet arbitrio, quando liberet nos dominus, quando puniat iniurios. Nostrum erit patienter illius gratiam expectare. Unde Iacobus infert: »Patientes igitur estote et vos et confirmate corda vestra.« Hisque iterum caput consolationis appendit: »Quia adventus domini appropinquat.« Qui quidem domini adventus non ultima modo dies, sed quaelibet visitationis dies est, qua dominus venit suos erepturus, adversarios autem punitu35 rus. $^{221}$

219 Lk 16,19-31.

221 Vgl. 1Kor 3,13; Bull. adv. cat. 41v.

220 Vgl. 2Tim 4,8; Jak 1,12. 
9 Nolite ingemiscere, fratres, alius adversus alium, ut ne condemnemini. Ecce iudex ante ianuam assistit. 10 Exemplum accipite, fratres mei, afflictionis ac patientiae prophetas, qui loquuti sunt in nomine domini. 11 Ecce, beatos dicimus eos, qui sustinent. Tolerantiam Iob audistis et finem domini novistis, quod valde misericors sit dominus ac commiserans.

Pertinent et haec ad superiorem scopum. Hoc autem est, quod dicit: »Proinde, fratres mei, ne quis sibi videatur infelicior, quod pluribus malis affligitur, neve quis invideat ei, qui mitius habet. $\ll^{222} » \mathrm{Ne}$ sit inter vos impius ille gemitus, index livoris et diffidentiae, ut ne condemnemini. $\ll^{223} \mathrm{Ut}$ autem id ipsis persuadeat, varia subiungit argumenta. 1. iudex assistit ante ianuam, ${ }^{224}$ daturus uniuscuiusque operi 10 condignam mercedem. ${ }^{225} 2$. producit afflictiones prophetarum et patientiam horum exemplo nos hortans ad tolerantiam. Illi, inquit, fuerunt legati dei; interim vero indignis modis tractabantur a regibus, a principibus, a divitibus et huius saeculi hominibus. Quid igitur mirum, si nos peccatores, quae nolimus, experiamur? $?^{226}$ 3. ducitur ab authoritate Christi, qui apud Matthaeum in quinto beatos pronunciavit, qui persequutionem patiantur propter iustitiam. ${ }^{227} 4$. petitur ab exemplo Iob, cuius quidem patientia decantatissima est. Commemorat et finem tenta|tionis Iob, quasi dicat: »Nec illud modo spectandum, quid passus sit Iob, sed etiam, quam felicem finem ista concertatio nacta sit. « Restitutus est enim sibiipsi, factusque est in omni substantia septuplo auctior, quam fuerat prius. ${ }^{228}$ Ubi 20 subtexit et quintum argumentum a natura et bonitate dei sumptum, quae non sinit nos supra id tentari, quod possumus. ${ }^{229}$

12 Ante omnia autem, fratres mei, nolite iurare neque per coelum neque per terram neque aliud quodcunque iusiurandum. Sit autem vestrum est est, non non, ut ne in simulationem incidatis. Impatientia et obmurmuratio habet diras imprecationes et iuramenta. Agit igitur hic quoque contra iuramenta. Sumpsit autem omnia ex quinto capite Matthaei e verbis domini. ${ }^{230}$ Breviter: christianus linguam suam ita debet moderari, ut in rebus suis neque nomine dei neque creaturarum per imprecationes sive deierationes abutatur. Deinde ne quid in omnibus sermonibus suis simulet aut dissi- 30 mulet, id est, mentiatur, idque in dei ignominiam et proximi detrimentum, sed

\footnotetext{
22 Erasm. par. Iac. (ASD VII/6 154,960f.).

223 Erasm. par. Iac. (ASD VII/6 155,964f.).

224 Vgl. Mk 13,29.

225 Vgl. Mt 16,27.

226 Vgl. Zw. Iac. (Z XXI 413,11f.): »Quid ergo mirum, si nos peccatores variis adflictionibus vexamur?«
} 
loquatur simpliciter, religiose, reverenter, candide et constanter. Et voce quidem »iusiurandum « haud proprie, sed per catachresim ${ }^{231}$ usus est. Non enim usurpavit illam pro sacramento, sed pro qualibet deieratione. Id quod alii ante nos ostenderunt contra anabaptistas ${ }^{232}$ et ipse quoque prolixius in libris contra ipsos ae5 ditis. $^{233}$

\section{Affligitur autem aliquis inter vos? Oret. Aequo animo est aliquis?} Psallat.

»Quid ergo faciam in afflictionibus meis?«, dicat aliquis. Respondet Iacobus: $\gg$ Ne diffidas deo, ne blasphemes et dira impreceris persequutoribus, ne desponQuid facias in prospera et deas animum, sed confuge ad auxilium domini et huius gratiam indefessis pete precibus.« Idem hoc faciat, quisquis est in tentationibus, quisquis sentit sibi aliquid imminere periculi. Huic statim addit contrarium: »Aeque animo est aliquis?«, id est: »Si quis prosperiore utitur fortuna, ne efferatur, sed timeat, sed psallat «, id est, deo agat gratias. Psalmus enim aliud non est quam laus et 15 praeconium dei. ${ }^{234}$

\section{Infirmatur quis inter vos? Accersat seniores ecclesiae et orent super eum ungentes eum oleo in nomine domini. 15 Et obsecratio fidei salvum reddet laborantem et eriget eum dominus; et si in peccatis fuerit, remit- tetur ei. 16 Confitemini invicem alius alii delicta et orate pro vobis invicem, ut salvi sitis.}

Afflictionis species est adversa corporis valetudo. Disputavit autem hactenus de afflictionibus patienter tolerandis, nunc vero instituit adversa valetudine correptos, quomodo et ipsi sese gerant et alii circa ipsos. Principio: »Si quem«, inquit, »affligit adversa valetudo, non accersat magos et incantationibus utentes aut exercentes praestigia, sed vocet ad se seniores christianae congregationis. « Sic

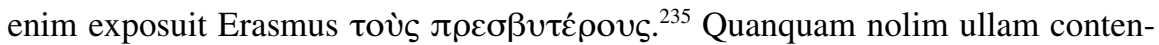
tionem cum eo suscipere, qui per presbyteros intelligit ministros ecclesiae, hoc est ministros verbi, quod si quis locum exponat de rasis et unctis tantum sacrificis, non habebit ullum in verbis Iacobi praesidium, quo suam firmet expositionem. Liberum enim est aegroto optimos quoque vel e plebe vel ministris accersere, illos consulere, ab his consolationem audire petereque pietatis officia. Ideo autem »seniores « dixit, id est prudentes et rerum divinarum gnaros, quod iuventus petulans raro sapit, sed nimis obsequens affectibus minus convenit aegrotis in-

231 Siehe oben S. 408, Anm. 150.

232 Vgl. Zw. Iac. (Z XXI 413,23-416,8); Zw. elench. (Z VI/1 144,2-154,15).

233 Bull. adv. cat. $115 \mathrm{v}-128 \mathrm{r}$.
234 Vgl. Erasm. Iac. (ASD VI/10 424,421f.): »[...] in rebus secundis gratias agamus Deo. Nam id vocat psallere.«

235 Erasm. par. Iac. (ASD VII/6 158,1005f.).
Quomodo se gerant aegrotantes 
stituendis consolandisque. Deinde exponit, quid agant, hoc est, quae sint officia visitantium infirmum. »Orent super eum «, inquit, »ungentes eum oleo in nomine domini.« Duo praecipit: ut orent et ut oleo inungant aegrotum. Orent autem super eum, id est pro eo. Certum enim est tantum domini apostolum nihil virium tribuere recitationi verbisque conceptis et super aegrotum pronunciatis. Omnis Unctio olei. enim virtus dei ac fidei est. Et de oratione mox dicet pluscula. Quod unctionem olei attinet, multus fuit olei usus in Palaestina et per | universum orientem, ${ }^{236}$ $140 Z$ praecipue autem adhibebatur ad cultum corporis, ut apud nos solent aquae odoriferae, et ad medicandum corpori. Id vero satis liquet cum ex aliis scripturae locis tum maxime ex Matth[aei] cap[ite] 6. et Lucae 7. Ibi enim iubet dominus ieiunantes inungere faciem suam oleo, ne videantur hominibus ieiunare. ${ }^{237}$ Hic autem effundit peccatrix alabastrum plenum oleo in pedes domini. ${ }^{238}$ Proinde cum d[ivus] apostolus iussit nos aegrotos ungere oleo, notatione usus per speciem notavit genus nec aliud praecepit, quam ut infirmorum corpora curemus, foveamus et ut medicamenta adhibeamus in nomine domini. ${ }^{239}$ Leguntur enim et 15 apostoli domini apud Marcum in 6. in curandis aegrotis adhibuisse oleum. ${ }^{240}$ Sed et dominus ipse aegrotos sanavit aliquando per contactum, ${ }^{241}$ aliquando sine contactu; ${ }^{242}$ aliquando aperuit oculos caecorum verbo, ${ }^{243}$ aliquando expuit in terram et maceratum lutum oculis illevit caeci et abluere iussit. ${ }^{244}$ Media itaque naturalia aegrotis non sunt aspernanda. Quod autem alii hic constituunt sacra- 20 mentum, produnt inscitiam suam et quam nihil intelligant scripturarum. ${ }^{245}$ Iacobus nihil tale somniavit unquam, quale isti tantum non asserunt ad salutem consequendam esse necessarium. Loquitur enim de cura corporis, de misericordia deque officiis pietatis aegroto praestandis, de medela seu fideli usu medicinae, adhibendae scilicet cum fide in nomen, id est potentiam, dei, quae nunc per media 25 nunc sine mediis aegrotos sibi restituit, quam tamen restitutionem sancti non oleo, hoc est curae et medicamentis mediisve, sed nomini domini acceptam ferunt. Porro ne quis preces, cui in hac re tribuit potissimas, crederet vanas inefficacioresque, quam quae tantopere commendentur et aegrotis et aegrotos invisentibus, Orationis vis. statim subdit: »Et obsecratio fidei«, id est fidelis oratio, ${ }^{246}$ quae scilicet proficis- 30 citur ex vera in deum fide, »salvum reddet «, id est, sanitati restituet laborantem, id est morbo obnoxium. Sequitur enim expositio in ipsis Iacobi verbis: »Et eriget eum dominus.«Observa autem verborum emphasim: dominus, inquit, eriget eum,

236 Vgl. Zw. Iac. (Z XXI 416,27f.): »Apud istas gentes mos fuit oleo corpus ungere.«

237 Mt 6,17f.

238 Lk 7,37f.

239 Vgl. Zw. Iac. (Z XXI 417,1-3): »Nos certe olei seu unctionis nomine omne officium charitatis intelligimus, quod infirmis impendi potest.«

240 Mk 6,13.
241 Vgl. Mt 8,3.

242 Vgl. Mt 8,13.

243 Vgl. Mk 10,52

244 Joh 9,6f.

245 Vgl. Eck ench. 12 (Fraenkel 143-145). Gemeint ist das Sakrament der »letzten Ölung «.

246 Zw. Iac. (Z XXI 417,5f.): »>Oratio fidei< Hebraismus est pro >fidelis oratio<.« 
non ulla vis aut ars humana. Et si in peccatis fuerit, remittentur ei, si videlicet et ipse non destituatur fide. Nam Ioannes quoque dixit: »Si quis viderit fratrem suum peccare peccatum non ad mortem, petet et dabit ei vitam, peccantibus non ad mortem« [1Joh 5,16]. Sed dicis: »Si propter nostras orationes remittit dominus 5 peccatum, inanis est crux Christi.«Respondeo: »Solius meriti Christi et gratiae divinae donum esse peccatorum remissionem. « Interim tamen vult dominus, ut oremus pro nobis invicem. Id quo fiat fervidius, magna pollicetur, quae quidem solus praestat propter se. Post haec iterum praescribens infirmis ait: »Confitemini Confessio. invicem alius alii peccata sive delicta ac lapsus ( $\pi \alpha \rho \alpha \pi \tau \omega \dot{\mu} \alpha \tau \alpha)$ vestros. «Haud enim parum morbos fovet et auget recrudescens subinde de illatis iniuriis dolor, invidia, ira, offensio. Nec aliud est, quod perinde officit animis. Iubet ergo Iacobus omnem affectum in alios gravius conceptum expectorare, dolorem, invidiam, iram, vindictam; iubet, ut nobis mutuo condonemus noxas, et, quilibet alteri libere fateatur peccasse se in alterum, iubet precari veniam: Das einer dem anderen sin val und übertrăttung fry bekenne und umb verzyhung bitte. Nihil enim aliud docet in praesenti Iacobus, quam quod de condonatione dominus apud Matthaeum in 6. cap[ite] et $18 .^{247}$ Quo et illud pertinere videtur quod addit: »Et orate pro vobis invicem.«Praecepit enim dominus idemque exemplo suo docet orare pro inimicis. ${ }^{248}$ Addit fructum: »Ut salvi 20 sitis. « Mente enim sana, tranquilla et repurgata citius restituitur corpus. Iterum vero produnt hoc loco suam inscitiam pontificii. Nam locum hunc, qui de condonatione mutua et quotidianis offensis scriptus est, praecipiens, ut alter alteri condonet noxam, confiteatur delictum et precetur veniam, illi detorquent ad auricularem istam suam confessionem, qua praecipiunt sacerdoti alicui sacrifico omnes peccatorum species recensere et ab illo absolutionem a peccatis expectare. ${ }^{249}$ Cum tamen nihil horum in mentem venerit Iacobo, qui quam simplicis-

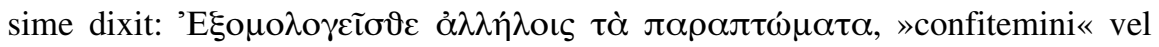
fateamini libere »invicem delicta . Sed ubi vel scriptum, dictum vel pictum est, quod $\alpha \lambda \lambda \hat{\eta} \lambda$ oıs, $\gg$ invicem«, sit rasus confessor et unctus sacrifex; quod confiteri 30 sit omnes peccatorum species recensere? ${ }^{250}$ Ita vero stultitiam suam produnt miseri, quoties sua scripturis firmare volunt. D[ivus] Eras[mus] Rot[erodamus] in Annotationibus suis: »Magis«, inquit, »est errata quam peccata, $\pi \alpha \rho \alpha \pi \tau \omega \dot{\mu} \alpha \tau \alpha$, quasi dicas >lapsus $<$. Sentit enim de quotidianis offensis christianorum | inter ipsos, quos continuo vult reconciliari. Alioqui si de confessione sensisset, quam dicimus partem sacramenti poenitentiae, non addidisset $\dot{\alpha} \lambda \lambda \dot{\eta} \lambda$ oı $\varsigma$, id est $>$ vobis invicem $<$, sed $>$ sacerdotibus $<$. Ab hac sententia non dissentit interpretatio Bedae.

247 Mt 6,14; 18,21f.

248 Mt 5,44 par.; Lk 23,34.

249 Vgl. Eck ench. 8 (Fraenkel 119).

250 Vgl. Petr. Lomb. sent. 4,21,7,1 (Grottaferrata
II 384,4f.): »Omnia criminalia semel saltem oportet in confessione exprimi, nisi a mente aliqua exciderint.« 
Et ita palam citat in commentariis, quod scripsit in 5. cap[ut] epistolae Ioannis. ${ }^{251}$ Haec Eras[mus].

16 Multum enim valet deprecatio iusti efficax. 17 Helias homo erat similiter obnoxius affectionibus ut nos et precatione precatus est, ne plueret, et non pluit super terram annos tres et menses sex. 18 Et rursum oravit et coelum dedit pluviam, et terra produxit fructum suum.

Orationis vis. Redit iterum ad preces et exemplo ex scripturis, nempe ex 3. lib[ri] Regum cap[ite] 17. et 18. adducto, ${ }^{252}$ demonstrat, quanta possit oratio, certe ut ad assiduum studium precum incitaret. Initio ponit sententiam hanc: »Multum potest

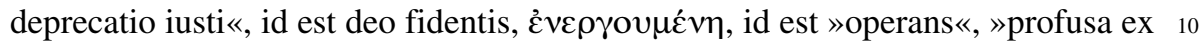
animo«, »assidua ${ }^{253}$ Quid enim impetraret cessans et tepida oratio? Huic sententiae adpendit exemplum, quo confirmet sua: »Non est quod quis«, inquit, »obiiciat se non esse sanctum et iustum, sed peccatorem et hominem. Videte mihi Heliam illum, qui et ipse erat homo iis quoque praeditus affectibus, quibus sumus praediti omnes; quia vero fidem habebat in deum, oravit nec vana fuit oratio eius. 15 Impetravit enim, quae videntur hominibus esse impossibilia. Nam non pluit super terram annis tribus et mensibus sex. Deinde vero iterum conversus ad preces pluviam terrae impetravit, docens nihil non posse a nobis impetrari per orationem simplicem, puram, assiduam, fidelem.«Videat igitur quisque, ut in precibus sit assiduus et fidelis.

19 Fratres, si quis inter vos erraverit a veritate et converterit quis eum, 20 sciat, quod, qui converti fecerit peccatorem ab errore vitae suae, salvam faciet animam a morte et operiet multitudinem peccatorum.

Transit a corporis infirmitatibus ad animi morbos, maxima illis pollicens praemia, qui correptos animi vitiis diligenter curarint. Paraphrastes ea perspicue exposuit 25 dicens: »Iam illud perpendite, fratres. Si pium est, si christianae charitatis est communibus precibus sublevare morbum corporis alieni, quanto magis par est, ut animi morbo laborantibus subveniamus? Neque enim magnum est hoc impetrare precibus, ut huic aut illi mors aliquanto serius accidat, omnino tamen aliquando ventura, sed magnum est vitasse mortem animi. Itaque si quis extiterit inter vos, 30 qui aberret ab evangelica veritate sive nimium adhuc adhaerens legi Mosaicae sive paganismi a maioribus traditi pertinax cultor, ne quis hunc existimet convitiis exagitandum, sed huc potius oportet omnibus studiis adniti, ut conversus

251 Erasm. Iac. (ASD VI/10 424-426,431-436). Vgl. Beda epist. can. [Jak 5,16-17] (CCSL CXXI 222,184-190); ebd. [1Joh 5,16] (CCSL CXXI 325,219-223).
252 1Kön 17,1; 18,1.42-45.

253 Erasm. Iac. (ASD VI/10 426,437f.). 
resipiscat ab errore suo. Quisquis enim hoc fecerit, magno sacrificio demerebitur deum, qui non optat mortem peccatoris, sed magis ut convertatur et vivat. ${ }^{254}$ Rem enim magnam praestat, qui servat animam a morte, fratrem liberans a peccatis, per quae morti tenebatur obnoxius. Nec interim is carebit suo praemio, siquidem

5 Christus vicissim huic sua peccata condonabit etiam, quamlibet multa. $\ll^{255} \mathrm{Hac}-$ tenus paraphrastes. Videtur Iacobus illa sumpsisse ex 18. cap[ite] Matth[aei]. ${ }^{256}$ Haec autem paucula habuimus in epistolam d[ivi] Iacobi, quam proculdubio scimus tibi iam esse multo gratissimam commendatissimamque. Curemus singuli, ut, quod ex hac didicimus, altius animis inhaereat nostris et ut malimus esse 10 evangelicae doctrinae factores quam auditores.

Finis.

255 Erasm. par. Iac. (ASD VII/6 158-160,10271039). 

KOMMENTAR ZUM ZWEITEN UND DRITTEN JOHANNESBRIEF SOWIE ZUM JUDASBRIEF 

| Commentarii in secundam et tertiam epistolam

Ioannis apostoli, et unam Iudae.

Argumentum II. epistolae.

Gratulatur fideli ecclesiae, quod receperit veritatem. In hac vero, ut perseveret et 5 sese mutuo diligat et a pseudoprophetis sibi caveat, hortatur.

1 Senior electae dominae et filiis eius, quos ego diligo in veritate (et non ego solus, sed et omnes, qui cognoverunt veritatem) 2 propter veritatem, quae permanet in nobis et nobiscum erit in aeternum. 3 Erit nobiscum gratia, misericordia, pax a deo patre et a domino Iesu Christo, filio patris, in veritate et charitate.

Inscriptio est epistolae, qua continetur authoris nomen, quibus illam inscripserit, et salutatio sive imprecatio apostolica. Nam in genere hoc dicit: »Senior Ioannes scribo hanc epistolam fideli ecclesiae huicque imprecor gratiam et pacem, et ut in veritate et charitate perseverent. «Quod autem se nominat »seniorem«, non »Ioannem «, ideo fortassis factum est, quod illud esset apud omnes usitatissimum et receptum, plenum authoritate et suavitate apostolica, non ob caniciem modo venerandam, sed ob vocationem et officium sanctum. ${ }^{1}$ Porro ecclesiam vocat »dominam «, quod sponsa sit domini Iesu; huius autem ecclesiae membra appellat »filios«, ita persistens in allusione. Imprecatio autem satis est nota vel ex aliis epistolis. ${ }^{2}$ Ioannes pro more suo appendit veritatem et charitatem optatque, ut in his sint et perseverent. At veritatem opponit hypocrisi, errori, mendacio, ut nil aliud sit quam ipsa fides vera. Charitas complectitur omnia pietatis officia. Praeterea inserit his, quae ipsi apud auditores conciliant benevolentiam, item quaedam de veritate, quibus confirmet et attentos efficiat animos auditorum. $25 »$ Quos«, inquit, »diligo in veritate«, id est vere, ex animo, syncere. Debet enim charitas christiana esse sine omni hypocrisi. »Diligo autem propter veritatem «, id est, »ideo diligo, quia cultores sunt veritatis «. »Nec ego solus diligo, sed omnes, qui cognoverunt veritatem $\ll,{ }^{3}$ quibus illorum animos erigit et ad amplius veritatis

1 Vgl. Fab. Stap. 2Joh. 66r: »Haec igitur nuncupatio, >senior<, maxime Ioanni apostolo consentanea est tum ratione aetatis tum apostolatus, tum divini mysterii «; Beda epist. can. [2Joh 1] (CCSL CXXI 329,9-12): »Seniorem autem se dicit Iohannes uel quia iam prouectus erat aetate quando has scripsit epistolas uel quia nomen senioris, id est presbiteri, etiam pontifici propter maturitatem sapientiae et grauitatis congruit. «

2 Röm 1,7; 1Kor 1,3; 2 Kor 1,2; Gal 1,3; Eph 1,2; Phil 1,2; Kol 1,2; 1Thess 1,1; 2Thess 1,2; 1Petr 1,2; 2 Petr 1,2.

3 Vgl. Erasm. par. 2Joh. (ASD VII/6 289,5): »Nec id facio solus, sed omnes mecum qui cognouerunt veritatem evangelicam.« 
studium prolicit. Quo et illud pertinet, quod dicit nobiscum permansuram veritatem in aeternum. Qua re nemo non potest non confirmari in pietate.

4 Gavisus sum valde, quod inveni de filiis tuis ambulantes in veritate, sicut praeceptum accepimus a patre.

Auspicatur nunc a gratulatione, gaudens repertos esse apud illos, qui desertis erroribus et relictis seductoribus veritatem sint amplexi; nec quamlibet (putant enim toto nonnunquam coelo aberrantes ${ }^{4}$ perspicuam se veritatem tenere), sed traditam a patre per doctrinam certe evangelicam. Neque enim alia veritas esse potest. Videmus ergo atque discimus, quas ob res gaudeamus. Videmus, quae sit regula divinae iustaeque veritatis.

5 Et nunc rogo te, domina; non tanquam mandatum novum scribo tibi, sed quod habuimus ab initio, ut diligamus nos mutuo. 6 Et haec est charitas, ut ambulemus secundum praeceptum eius.

Hortatur, ut in veritate evangelica pergant constanter et sese mutuo diligant. Id vero commendat illis ab authore et vetustate. »Non ego«, inquit, »praecipio, ut 15 pergatis in vero, sed ipse dominus, qui in evangelio dixit: >Qui perseverarit in finem usque, hic salvus erit< [Mt 10,22; 24,13]; neque novum aliquod praeceptum nuperque domi nostrae natum scribo vobis, sed illud vetustissimum in lege quoque ipsa praeceptum: >Dilige dominum deum et proximum tuum $<{ }^{5} \mid$ quod Christus restituit et quod ab initio verae religionis floruit; hoc, inquam, scribo vobis, ut scilicet diligamus nos mutuo. Videtis, quam haec non sint aspernanda.« Deinde per interpretationem addit: »Et haec est charitas, ut ambulemus secundum praeceptum eius.« Hic, inquit, est genius charitatis christianae, ut servet praecepta. Nam dominus in evangelio (unde haec videntur petita) dixit: »Qui habet praecepta mea et servat ea, ille est, qui diligit me « [Joh 14,21]. Item: »Manete in 25 dilectione mea. Si praecepta mea servaveritis, manebitis in dilectione mea [ [Joh 15,9f.]. »Hoc est praeceptum meum, ut diligatis invicem, sicut dilexi vos« [Joh $15,12]$. Nec est, quod quis haec salvatoris verba miretur. Nam omnia praecepta ad charitatem revocantur etiam ab apostolo Paulo, ad Roma[nos] $13 .{ }^{6}$

4 Erasm. adag. 49 (ASD II/1 166,507-516): »Toto coelo errare. [...] Metaphora ducta vel a Phaethontis aut Cereris fabula, vel a nauigantibus, qui coeli syderumque obseruatione cursum moderantur. Proinde naucleri, cum ve- hementer aberrant, in coeli parte longe diuersa Cynosuram imaginantur nonnunquam totoque aberrant cursu.«

Dtn 6,5; Lev 19,18; Mt 22,37.38 parr.

Röm 13,10. 
6 Hoc est praeceptum, quemadmodum audistis ab initio: ut in eo ambuletis. 7 Quoniam multi seductores ingressi sunt in mundum, qui non confitentur Iesum Christum venturum in carne; hic est seductor et antichristus.

5 Pro more suo ingeminat et inculcat charitatem. Addit caussam, cur hanc tantopere urgeat, quae quidem caussa et ecclesiam excitat ad vigilantiam et vehemens pietatis studium. »Ideo«, inquit, »tantopere urgeo dilectionem, ideo decet vos esse diligentes, quia multi seductores venerunt in mundum, qui conantur vos a via veritatis abducere in errorem. Ab his cavebitis vobis et in vera religione, veritate et dilectione pergetis.« Deinde certis notis pingit illos seductores. »Non confitentur«, inquit, »Iesum Christum illum esse Messiam verum deum et hominem, quem praedixerant prophetae venturum in hunc mundum. « His statim infert et profligens istos dicit: »Hic est seductor et antichristus.«Plura de his dixi in 2. cap[ite] et 4. prioris epistolae, unde haec brevia sarciri possunt. ${ }^{7}$

\section{Intuemini vosipsos, ne perdamus, quod operati sumus, sed ut mercedem} plenam recipiamus.

Argumentatur a damno. Videntur autem petita esse ex illis, quae apud Ezechielem sunt verbis: »Si iustus averterit se a iustitia sua et fecerit iniquitatem, num vivet? Omnes iustitiae, quas fecit, non venient in recordationem « [Ez 18,24]. Est

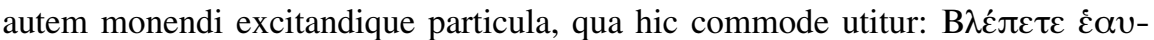

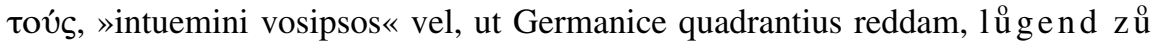
ü ch selbs. Hoc vero est, quod dicit: »Caveat sibi quisque, ne, si relinquat, quod bene coepit, perdat omnem fructum eorum, quae hactenus bene gessit; sed demus operam, ut«, praeteritis antichristi doctoribus, »plenam mercedem recipiamus, quae non contingit nisi perseverantibus usque in finem. $\ll^{8}$

9 Omnis, qui transgreditur et non manet in doctrina Christi, deum non habet; qui manet in doctrina Christi, hic et patrem et filium habet.

Graviora nunc subiungit. Multo enim maximum detrimentum est deo carere, neque patrem neque filium habere. Caeterum, qui non pergit in veritate et dilectione, is neque patrem neque filium habet. Omnibus ergo modis annitendum est nobis, ut in via veritatis pergamus. Eadem scribuntur in 2. cap[ite] epistolae prioris. ${ }^{9}$

8 Erasm. par. 2Joh. (ASD VII/6 290,24-27). 
10 Si quis venit ad vos et hanc doctrinam non adfert, ne recipiatis eum in domum nec ave ei dixeritis. 11 Qui enim dicit illi ave, communicat operibus eius malis.

Planioribus verbis praecipit consortium haereticorum fugere et doctrinae Christi constanter adhaerere. Haeretici sunt, qui suam, non Christi doctrinam adferunt vel adversam Christi doctrinae praedicationem tradunt et sequuntur. Doctrina autem Christi comprehensa est in prophetarum et apostolorum literis. Quisquis ergo scripturas non attulerit aut aliquid adversum scripturis docuerit, nequaquam recipiendus est in consortium tuum et tuorum neque in colloquium. »Inficiunt enim corrupta colloquia bonos mores « [1Kor 15,33]. Cohabitatio quoque subvertit vel 10 optimos quosque. Per »domum« ergo intellexit universam cohabitationem, per »ave« colloquia familiaria. Paraphrastes haec omnia pulchre hisce verbis exposuit: »Si quis venerit ad vos, qui diversam ab hac doctrinam afferat, ut vos abducat ab evangelica | veritate, huic adeo non debetis auscultare, ut nec in domum sit admittendus, si quaerat hospitium, nec ave dicto salutandus, si forte sit 1 obvius in via. Periculum est enim, ne familiam suo convictu inficiat et pro officio communicati tecti rependat maleficium atque e salutatione nascatur colloquium. $>$ Corrumpunt autem bonos mores colloquia prava $<.{ }^{10}$ Porro qui salutat et congreditur cum impostoribus huiusmodi, consors esse videtur malefactorum. Addit enim animum improbo, dum se videt esse alicuius pretii apud eos, quos nititur 20 subvertere; et aliis speciem mali praebet, quasi favere videatur illius malitiae, cuius non horret familiaritatem. ${ }^{11}$ Hisce finitimum est, quod legimus apud Ecclesiasticum, cap[ite] 13.: »Qui tetigerit picem, inquinabitur ab ea; et qui communicaverit superbo, induet superbiam « [Sir 13,1].

12 Cum multa haberem vobis scribenda, nolui per chartam et atramentum, sed spero me venturum ad vos et praesentem praesentibus loquuturum, ut gaudium nostrum sit completum. 13 Salutant te filii sororis tuae electae. Amen.

Concludit epistolam et pollicetur se venturum ad ipsos praesentemque praesentibus haec et alia his similia expositurum copiosius; idque in hunc finem, non ut 30 dolis capiat, artibus fallat, dominium exerceat aut pecuniam emungat, sed ut gaudium christianum sit completum. Completur autem, cum recte omnes fidei negotium intelligimus et illud per charitatem exercemus. Appendit ad finem salutationem eius ecclesiae, unde hanc scripsit. Facit autem ecclesias sorores unius Christi domini sponsas et membra, id est christianos, non sine gratia 35 appellitat »filios«. Habet et illud gratiam, quod doctrinam veritatis mavult illorum 
committere mentibus quam chartis. Et nobis quidem nihil profuerit vidisse, audisse et legisse doctrinam apostolorum atramento chartis inscriptam, nisi etiam menti inscribamus transferamusque in vitam et mores nostros. Resipit autem haec epistola per omnia genium Ioannis apostoli, utcunque alii contenderint hanc presbyteri cuiusdam Ioannis esse. Sed utcunque hominum varient iudicia, certe in hac nihil scribitur, quod non legatur et in prima, eundem ergo cum illa habet spiritum, ut nemo hanc nisi impius aspernari possit. ${ }^{12}$ Deo sit laus et gloria, qui voluntatem suam nobis aperit dilucidissime.

Finis.

Gratulatur Caio, quod in recepta ambulet veritate beneficentiamque exerceat in fratres. Perstringit Diotrephen et commendat Demetrium.

1 Senior Caio dilecto, quem ego diligo in veritate. 2 Dilecte, de omnibus opto, ut prospere agant et recte valeant, sicut prospere agit anima tua.

Inscriptio et salutatio plana est. Haec tamen paulo est diversior a receptis salutationibus apostolicis. Poterit autem et ad res et ad familiares Caii referri, ut sit sensus: »Cupio et opto, ut, quemadmodum anima tua prospere agit in omnibus ornata coelestibus dotibus, felix et beata, ita et omnes domestici vel familiares tui bene habeant « vel »ita et omnia tua bene fortunet sospitator dominus $\ll{ }^{13}$ Est autem summa felicitas $»$ mens sana in corpore sano $\ll .{ }^{14}$

12 Beda epist. can. [2Joh 1] (CCSL CXXI 329,2-9): »Quidam putant hanc et sequentem epistolam non esse Iohannis apostoli sed cuiusdam presbiteri Iohannis cuius sepulchrum usque hodie monstratur in Epheso, cuius etiam Papias auditor apostolorum et Hierapoli episcopus in opusculis suis saepe meminit. Sed nunc iam generalis ecclesiae consensus habet quod has quoque epistolas Iohannes apostolus scripserit, quia re uera multam uerborum et fidei similitudinem cum prima eius epistola ostendunt et simili zelo detestantur hereticos.«

13 Vgl. Erasm. par. 3Joh. (ASD VII/6 292,5-7): »Illud votis opto a Iesu Christo vt quemadmodum propsere agit anima tua perseuerans in euangelica doctrina, ita et in caeteris omnibus prospere agat bene fortunante Christo.«

14 Iuv. 10,356 (Clausen 133): »Orandum est ut sit mens sana in corpore sano.« Vgl. Erasm. adag. 2090 (ASD II/5 93f.). 
3 Gavisus sum enim valde venientibus fratribus et testimonium addentibus veritati tuae, sicut tu in veritate ambulas. 4 Maius his non habeo gaudium, quam ut audiam filios meos in veritate ambulare.

Gratulatur primo de recepta veritate et quod in hac maximo cum fratrum praeconio ambulet. Est autem in veritate ambulare vitam agere piam iuxta regulam veritatis absque fuco et simulatione. Nec satis est scisse veritatem, nisi in ipsa ambulemus, id est, ad hanc instituamus vitam nostram, omnia dicta et facta. Porro maximum sanctorum gaudium est, cum audiunt nos in veritate ambulare; nolunt ergo se superstitiosius coli. Dicuntur et angeli gaudere de peccatoribus conversis ad poenitentiam. ${ }^{15}$ Quae quidem nos animare debent, ut omni conatu propagemus 10 veritatem.

5 Charissime, fideliter facis, quicquid operaris in fratres et in hospites, 6 qui testimonium reddiderunt charitati tuae in conspectu ecclesiae; quos benefacies, si deduxeris digne deo. 7 Pro nomine enim eius profecti sunt, nihil accipientes a gentibus. 8 Nos ergo debemus recipere huiusmodi, ut cooperatores simus veritati.

Primum est, ut veritatem recipiamus et in fide simus integri; proximum vero, ut simus benefici. Post receptionem ergo veritatis congratulatur apostolus Caio de hospitalitate et beneficentia, quam praedicarant coram tota ecclesia, qui beneficia receperant. Qui sane locus gratitudinem docet et quod nemo iusta est fraudandus 20 laude. Ut autem omnibus debemus beneficentiam, ita praecipue ministris verbi dominici. Unde Ioannes hos Caio et in hoc omnibus fidelibus commendat fideliter, argumentis utens ab honesto et utili ductis. »Honestum est enim«, inquit, »si deduxeris digne deo«, id est, »si instruxeris eos viatico, benigne apud te foveas. Nosti vero, cui impendas: deo, qui dixit: >Qui vos recipit, me recipit< [Mt 10,40].« 25 Huc pertinet et consequens ratio: »Pro nomine Christi profecti sunt «, id est, »ut evangelium praedicent, circumeunt, non ut ditescant et res suas agant. Ideo enim nihil accipiunt stipendii a gentibus, quibus praedicant, certe ut eo plus Christo fructus afferant, quo apud gentes alieniores sunt a suspitione captati quaestus. Itaque nos, qui didicimus operarium mercede sua dignum esse, ${ }^{16}$ debemus hui- 30 usmodi viros bonos recipere et opibus nostris iuvare.« Appendit hic quoque ad finem praemium, »ut cooperatores simus veritati«, videlicet, ut propagemus et nos veritatem et, quandoquidem negatum est munus docendi, sarciamus id opibus nostris, iuvantes scilicet illos, qui vocati et muneribus docendi instructi sunt. Dixit autem in evangelio dominus: »Qui prophetam recipit in nomine prophetae, 35 mercedem accipit prophetae $\ll\left[\mathrm{Mt} \mathrm{10,41]} .{ }^{17} \gg\right.$ Et quicunque ad bibendum dederit 
uni ex pusillis his poculum aquae frigidae tantum nomine discipuli, amen dico vobis: non perditurus est mercedem suam« [Mt 10,42]. Apparet autem ex hoc loco plurimos tum temporis fuisse viros bo|nos, qui Pauli exemplum imitati gentibus praedicarunt evangelium gratis. Gloriam enim Christi domini tam cu5 piebant primaevae ecclesiae homines promotam, ut huius caussa nihil non facerent atque ferrent. Quibus vero datum non erat docendi munus, huc omnes suas facultates conferebant, ut nihil deesset rerum necessariarum iis, qui pollebant docendi gratia. Inter hos vero praecipuus erat Caius ille, opulentissimus, ut apparet, vir, quem etiam Paulus ad Romanos 16. et suum vocat hospitem et totius ecclesiae. ${ }^{18}$ Et mediae aetatis homines liberaliter iuverunt studia pietatis. Nos soli, in quos fines saeculorum devenerunt, stertimus ignavi. Quibus contigit a deo docendi gratia, nolunt se resque suas exponere periculo aut docendi munus non obeunt, nisi opimis regiisque stipendiis conducti. Verum paucissimis aut certe nullis talia dantur. Nam quibus ministrorum verbi cura commissa est, miseros 5 egere sinunt, adeoque nihil conferunt de suis facultatibus, ut ab aliis collata iam olim invideant praeripiantque. Ita vero et doctrina pietatis periclitatur et nominis Christi gloria. Dominus autem det nobis spiritum illum, quem videmus illorum insedisse pectoribus, quos in praesenti Ioannes commendat!

9 Scripsi ecclesiae, sed is, qui amat primatum gerere in eis, Diotrephes, non recipit nos. 10 Propter hoc, si venero, indicabo facta illius, quae facit, verbis malitiosis garriens in nos et, nec his contentus, non solum non recipit fratres, verumetiam volentes recipere prohibet et e congregatione eiicit.

Non satis liquet, de quo scripti genere loquutus sit Ioannes, apparet tamen hunc 25 scri scripsisse epistolam ad eam ecclesiam, in qua agebat Caius, qua adhortatus sit, ut id facere pergeret, quod videbat facere Caium. Verum obstabat sanctis his monitis Diotrephes quidam, quem in praesenti perstringit, accusans in ipso haeresim, calumnias seu linguae petulantiam et studium superbiae seu ambitionis; praeterea incusat et inhumanitatis, contemptus, crudelitatis, adeoque tyrannidis in fratres. Est ergo hic exemplum omnium haereticorum et improborum hominum, qui et ipsi obsistunt evangelio. Nihil autem nunc scribit in ipsum virulentius, sed reservat in adventum suum. Minatur enim se tum illi detracturum larvam. Id vero est fidelium pastorum nihil condonare aut parcere impostoribus. Quid putas autem dicturum Ioannem, si rediret hodie in eas ecclesias, quae videri volunt 35 apostolicae, inveniretque non unum aliquem Diotrephen primatum ambire, sed

17 Vgl. Erasm. par. 3Joh. (ASD VII/6 292,24f.): »Sic enim promisit Christus, qui prophetam acciperet vt prophetam, hunc habiturum prophetae mercedem.«

18 Röm 16,23. 
infinitos simul cardinales, patriarchas, episcopos et proceres ecclesiasticos? Ut nunc nihil dicam de eo, quod plerique istorum contra veritaris doctrinam, nescio quid, garriunt, quod puram apostolorum doctrinam non recipiunt quodque recipere volentes damnant atque diris devovent fulmine excommunicationis saevo inflicto. Tam scilicet periculosa sunt tempora nostra. Deus eripiat animas nostras 5 ex ore leonis! ${ }^{19}$

11 Dilecte, ne imiteris, quod malum est, sed quod bonum est. Qui bene facit, ex deo est, qui autem male facit, non videt deum.

Addit ista, ut ab offensione praeservet Caium, quasi dicat: »Nosti, quid conetur et agat Diotrephes, nolim autem te imitari mores hominum. « Hic autem ponit 10 generalem sententiam, id scilicet imitandum esse, quod bonum est, non illud, quod malum est. Quae quidem sententia opponi potest illis, qui pro se allegant longa tempora, patrum mores et consuetudines. Adiungit huic et aliam sententiam: »Qui bene facit, ex deo est, qui autem male facit, non intelligit dei negotium neque post hanc vitam deum videbit.« Proinde quod bonum est, quod deus iussit, 15 faciendum est, non quod praescribunt aliorum hominum exempla et consuetudines.

12 Demetrio testimonium redditur ab omnibus et ab ipsa veritate, sed et nos testimonium perhibemus et nostis, quod testimonium nostrum verum est.

Pravo exemplo iungit opponitque optimum optimi viri Demetrii, ne desit, quod Cai animum confirmet. Vehementer enim concutiuntur bonorum animi malorum exem|plis, unde videmus mederi huic morbo scripturas frequentissime. Mirae vero integritatis virum fuisse Demetrium necesse est, cui testimonium ferebant omnes boni, denique ipsa veritas; adde et Ioannes apostolus, homo sine fuco, qui 25 adulari nihil didicerat. Praeterito itaque Diotrephe imitemur potius Caium et Demetrium!

13 Multa habebam, quae scriberem, sed nolo per atramentum et calamum scribere tibi. 14 Spero autem protinus me visurum te et praesentes coram loquemur. 15 Pax tibi. Salutant te amici. Saluta amicos nominatim.

Quemadmodum posteriorem clausit epistolam, ${ }^{20}$ ita nunc concludit et postremam. Sunt tamen in his charitatis et amicitiae pulchra argumenta imitanda nobis potius quam disputanda. D[ivus] Hieronymus videtur et secundam et tertiam hanc epis- 
tolam tribuere cuidam Ioanni presbytero. ${ }^{21}$ Ego non video, quid in his Ioanne indignum contineatur. ${ }^{22}$ Est sane in brevitate illa mira gratia. Habet et brevitas sua mysteria. $^{23}$

Finis.

Iudas, quem Matthaeus nominat Lebbaeum, ${ }^{24}$ cognomento Thadaeum dicitur fuisse frater Iacobi Alphaei et Simonis Chananaei, ${ }^{25}$ vixit adhuc, si Eusebio Egesippum citanti credimus, temporibus Domitiani, ${ }^{26}$ aliquot annis post sublatos domini apostolos. ${ }^{27}$ Proinde quod in corruptissima incidisset tempora, sed et spiritu praevideret, quid porro futurum esset, hanc scripsit epistolam, in qua hortatur sanctos, ut et ipsi in pura religione perseverent et aliis quoque adiumento sint, quo possint perseverare, et ut veritatem evangelicam exprimant bonis operibus, caveant autem ab impostoribus, quos hic depingit graphice, exitium ipsis interminans. Pleraque vero mutuavit ex posteriori epistola Petri. ${ }^{28} \mathrm{Nec}$ id quidem cuiquam novum videri debet. Videmus enim et prophetas posteriores priorum legisse orationes et libros atque adeo usurpasse et multa illorum in sua retulisse

21 Hier. vir. ill. 9 (PL XXIII 655B): »Reliquae autem duae [epistulae] [...] Joannis presbyteri asseruntur.« Vgl. Erasm. 3Joh. (ASD VI/10 564,23-25): »Constat inter autores primam Ioannis epistolam eius esse Ioannis, quem Iesus dilexit plurimum. Caeterum duas posteriores Ioannes presbyter scripsit, non Ioannes apostolus.«

22 Siehe oben S. 437, Anm. 12.

23 Vgl. Erasm. adag. 3425 (ASD II/7 256,575582): »Grata brevitas. [...] Quaedam mole placent ac magnitudine. Sunt quae ob id ipsum grata sunt quod minuta, veluti gemmae quaedam ac sculpturae. Idem vsu venit in epistolis ac libris, qui non raro ipsa breuitate redduntur commendatiores, praesertim apud fastidiosos et occupatos.«

24 Die Variante $\Lambda \varepsilon \beta \beta \alpha$ ĩo bei Mt 10,3 ist zwar in einigen Handschriften des griechischen Textes bezeugt, wird jedoch in heutigen $\mathrm{Bi}$ belausgaben ebenfalls durch $\Theta \alpha \delta \delta \alpha i o s ~ e r-$ setzt.

25 Mk 3,18. Orig. Rom., praef. (Heither I 72,15-
24): »Mattheus in catalogo apostolorum dicit post multos: >Mattheus publicanus et Iacobus Alfei et Lebbeus et Simon Cananaeus< [Mt 10,3f.]. Marcus uero ita refert: >Mattheus publicanus et Thomas et Iacobus Alfei et Thaddeus< [Mk 3,18]. Hunc eundem quem Mattheus Lebbeum Marcus Taddeum posuit, Lucas uero ita ponit: >Mattheus, Thomas, Iacobus et Iudas Iacobi< [Lk 6,15f.]. Igitur eundem, quem Mattheus Lebbeum et Marcus Thaddeum dixit, Lucas Iudam Iacobi scripsit«; Isid. orig. 7,9,19 (Lindsay I [U4]v,26-29): »Iudas Iacobi, qui alibi appellatur Lebbaeus, [...] in alio evangelista Thaddaeus scribitur.«

26 Titus Flavius Domitianus (51-96 n. Chr.), römischer Kaiser 81-96, vgl. NP III 746-750.

27 Euseb. hist. eccl. 3,32,5f. (GCS IX/1 268,17270,6).

28 Vgl. Beda epist. can. [Jud 1] (CCSL CXXI 335,2-5): »Iudas apostolus quem in euangelio Matheus et Marcus Thaddeum appellant scribit contra eosdem fidei corruptores quos et Petrus et Iohannes in suis damnant epistolis.« 
scripta. Ergo, quae hic attinguntur parcius, paulo fusius tractantur in epistola Petri.

1 Iudas Iesu Christi servus, frater Iacobi, his, qui in deo patre sanctificati sunt quique Iesu Christo servati sunt, vocatis: 2 misericordia vobis et pax et charitas multiplicetur.

Quemadmodum Paulus ita Iudas se vocat servum Iesu Christi. Quia vero multi erant Iudae, ideo ad differentiam aliorum addit »Iacobi frater«. Nam Lucas in 6. Iudam Iacobi appellat, ${ }^{29}$ quem alii vocant Thadaeum. ${ }^{30}$ Erat enim quadrinominis: Iudas, Iudas Iacobi, Thadaeus et Lebbaeus. ${ }^{31}$ Habes authorem huius epistolae et subscriptionem. Sequitur, quibus hanc inscribat: omnibus vocatis, id est electis, 10 dei. Sed qui sunt vocati? Sanctificati a deo patre. Sed qui dicuntur sanctificati a patre? Eramus natura nostra impuri filii irae, ${ }^{32}$ servi Satanae. Deus autem nostri misertus filium suum misit in carnem. Hic effudit sanguinem suum pro peccatoribus et sanguine suo nos lavit sanctificavitque, asseruit e servitute Satanae et nos sibi consecravit in peculium. ${ }^{33}$ Ergo sanctificati sunt, qui redempti sunt per 15 mortem Christi et per ipsius purgati sanguinem. ${ }^{34}$ Habes in his totam evangelii summam, quam et Paulus praecipue immiscet inscriptionibus. ${ }^{35}$ Sequitur bona imprecatio, salutatio et benedictio apostolica: »Misericordia vobis« etc. Tria autem petit sanctis multiplicari et augeri: misericordiam, pacem et charitatem. Misericordia gratia dei est. Hanc auget nobis coelestis pater, cum nostri misertus 20 condonat nobis peccata et sese omniaque dona sua in diem liberalius in nos effundit, et sese nobis astringit subinde fortius. Pax animae est tranquillitas et concordiae studium cum omnibus hominibus. Charitas plenitudo legis est. ${ }^{36}$

3 Dilecti, tantum mihi studium fuit scribendi ad vos de communi salute, | ut non potuerim non scribere vobis, obsecrans, ut vestris laboribus adiumento sitis fidei, quae semel data est sanctis.

Caussam exponit, quae ipsum impulerit ad scribendum, ita captans benevolentiam, simul et scopum praefigit eorum, de quibus est dicturus. Recte vero monuit Erasmus hunc locum bifariam posse accipi. Prior sensus est: »Non solum mihi fuit summum studium scribendi ad vos de communi salute, verumetiam neces- 30 sitas scribendi fuit propter inimicos Christi.«Posterior sensus hic est: »Cum esset mihi mirum studium scribendi vobis de communi salute, non potui non scribere,

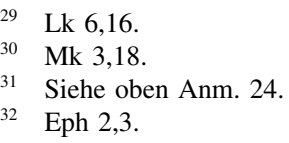

Lk 6,16.

Siehe oben Anm. 24.

Eph 2,3.

Vgl. 1Kor 6,11.

Vgl. Hebr 9,13f.; 10,10.

Vgl. Röm 1,7; 1 Kor 1,2; Gal 1,4.

Röm 13,10. 
hoc est, non potui non obsequi desiderio animi mei. « ${ }^{37}$ Iam vero epistolae scopus hic est: vult illos hortari, ut laboribus suis adiumento sint sanctis, ut in fide vera et semel a Christo apostolisque tradita perseverare et fraudes seductorum declinare possint. Vel hortari vult, ut operibus vere bonis exprimant eam fidem, quam 5 dominus sanctis, id est christianis, revelavit, neve seducantur ab impostoribus, qui fidem et christianam libertatem putant esse peccandi licentiam.

\section{Obiter enim subierunt quidam homines impii, qui prius descripti fuerant in hoc iudicium, qui dei nostri gratiam transferunt ad lasciviam ac deum, qui solus est herus, ac dominum nostrum Iesum Christum negant.}

$10 »$ Quod«, inquit, »hanc vobis scribo, quod inhortor, ut sanctis operibus fidem vestram exprimatis et ut aliis adiumento sitis, ne seducantur, hinc est, quod iam nunc irrepserunt quidam impostores, qui gratiam evangelicam vertunt in occasionem lasciviae ${ }^{38}$ ipsumque deum et dominum Iesum abnegant. « Habent autem singula verba suum pondus. П $\alpha \rho \varepsilon \iota \sigma \varepsilon ́ \delta v \sigma \alpha v$, ait, id est, »furtim et clanculum 5 ingressi sunt $\ll{ }^{39}$ Sic enim notat artes et impudentiam istorum, qui nolunt videri hostes veritatis pietatisque, imo specie pietatis se venditant. Petrus de iisdem: »Erunt inter vos«, inquit, »falsi doctores, qui clam inducent sectas pernitiosas « [2Petr 2,1]. »Hos «, inquit, »praevidit deus iam olim ab aeterno. « Non quod divina potentia hoc cogantur facere, quod faciunt, sed quia, quid facturi essent, praevidit, descripsit illos »in hoc iudicium«, id est, decrevit eis poenam. Alludit enim ad iudices et reges populorum, qui facinorosorum nomina et facinora in libellos seu nebulonum catalogum atro designant calculo, poenam adiicientes sceleri. Porro duo in istis accusat: et quod gratiam dei transferunt ad lasciviam carnis, et quod dominum nostrum Iesum Christum negant. Siquidem libertate per Christum parta et per evangelium annunciata abutebantur ad turpitudinem ac peccandi licentiam, putantes ob remissionem peccatorum annunciatam sibi licere quidlibet. Peccabant igitur impudentius et ultro recidebant in eam servitutem, unde ipsos Christus suo sanguine redemerat, qua quidem re deum et Christum eius abnegarunt. Verbis quidem confitebantur, factis vero negabant.

5 Volo autem vos commonefacere, cum sciatis semel illud, quod dominus, posteaquam populum ex Aegypto salvum eduxerat, rursus eo, qui non credebant, perdidit; 6 quodque angelos, qui non servaverant suam originem, sed reliquerant suum domicilium, ad iudicium magni illius diei

37 Erasm. Iud. (ASD VI/10 567,9-13).

38 Erasm. par. Iud. (ASD VII/6 232,28-30): »Gratuitam beneficentiam Dei nostri [...] vertunt in occasionem lasciviae $[\ldots] . \ll$
39 Vgl. Bud. comm. 212,41-48: »П $\alpha \rho \varepsilon \iota \sigma-$

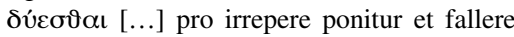
introeundo et sese insinuando.« 
vinculis aeternis sub caligine servarit. 7 Sicut Sodoma et Gomorrha et his finitimae civitates, quae ad consimilem modum cum illis stupris inquinatae fuerant ac sequutae fuerant carnem alienam, propositae sunt exemplo, ignis aeterni poenam sustinentes.

Exemplis aliquot coacervatis demonstrat non satis esse fateri liberatos nos esse et 5 profiteri libertatem evangelicam, nisi et vita accedat sancta. Quibus quidem omnibus confutat seductores illos et adhortatur sanctos, ut vita Christo digna fidem Christi exprimant aliisque adiumento sint, ne sequantur turpe istorum exemplum. Utitur autem praefatiuncula et ait: »Non est, quod vos doceam, cum satis esse putem, si vel in memoriam reducam exempla veterum. « Hic iam tria 10 producit. Primum sumptum est ex Exodo, ${ }^{40}$ est au|tem huiusmodi: quemadmodum deus olim Israelem ex dura Aegyptii regis servitute per alveum Erythrei maris et per desertum duxit in terram promissam, ita idem ille deus nos ex Satanae servitute per baptismi lavacrum, quo abluit nos a peccatis omnibus duce Christo domino ducit ad vitam aeternam. Verum ut illis non profuit liberatio, qui 15 obmurmurarunt deo in deserto, qui idololatria, epulis deorum, stupris et comessationibus se polluerunt, nam illorum aliquot millia ceciderunt in deserto; ${ }^{41}$ ita non proderit nobis redemptionis praedicatio, si perrexerimus in vita impia et impura. Secundum exemplum tractavit et apostolus Petrus in 2. episto[lae] 2. cap[ite]. ${ }^{42}$ Est autem tale: non profuit angelis, quod conditi adeoque divinae 20 naturae essent facti consortes. Ubi enim felicissimam suam naturam mutassent in pravitatem neque perstitissent in sua conditione, coelo deturbati sunt ad inferos, ubi detinentur in vinculis ad ultimum illud iudicium usque, in quo aeternae damnationis sententiam suscipient. Ita quidem nil proderit et nobis, quod optime condidit nos dominus, quod per filium redemit, nisi in statione nostra et officio 25 maneamus, facientes, quae decent dei filios. Tertium exemplum petitum est ex 19 . capite Geneseos. ${ }^{43}$ Multa quidem beneficia contulerat dominus in urbes illas fatales Sodomam, Gomorram et finitimas, at, cum illae abuterentur dei beneficiis, igne coelesti consumptae sunt, idque in exemplum omnibus illis, qui domini beneficiis abutuntur ad vitae turpitudinem. Non enim effugient iudicium dei. 30 Reliqua, quae hic erant dicenda, petantur ex decimonono capite Geneseos.

8 Similiter sane et hi delusi insomniis carnem quidem polluunt, dominos vero spernunt, in potestate praeditos maledicta congerunt. 9 At Michael archangelus, cum adversus diabolum certans disceptaret de corpore Mosi, non ausus est illi impingere notam maledicti, sed dixit: increpet te 
dominus. 10 At isti, quae non noverunt, ea maledictis insectantur; quae vero natura ceu animantia rationis expertia sciunt, in his corrumpuntur.

Describit nunc seductores in hunc finem, ut cognoscantur et devitentur, non ut bilem relevet. Sic autem cohaerent haec cum superioribus: quod fecerunt isti, 5 quos extinxit coelitus immissus ignis, hoc faciunt hi quoque seductores. Id iam expolit per enumerationem. Primo dicit illos esse somniatores, imo delusos insomniis, hoc est seductos, qui ex vanitate mentis amplexentur pro veris falsa, voluptates videlicet, quae miseros reddunt, non felices. Videntur enim sibi delitiis frui, qui habent insomnia, cum longe fallantur. Deinde »carnem «, inquit, »pol10 luunt«, id est, sese totos ingurgitant voluptatibus, libidini, stupris, adulterio, scortationi, ebrietati et conviviis. Neque polluunt se modo, verum etiam aspernantur praefectos suos sanctumque magistratum; nec spernunt modo, sed et maledicta in illum congerunt dirisque devovent. Id vero sceleris vehementer amplificans adhibet exemplum hoc modo: »Cum esset disceptatio inter angelos bonos et malos de corpore sive cadavere Mosis, tamen ipse archangelus Michael veritus est diabolo palam dicere convitium; sed, quum convitia illius ferre non posset, moderate dixit: >Increpet te deus $<.{ }^{44}$ Audimus hic angelum noluisse maledicere diabolo. Quis hinc non intelligit turpissimum esse, si homo sceleratus maledicere non veretur viris authoritate et dignitate praeminentibus? Caeterum

20 sequitur in Iuda: »At isti maledictis insectantur non modo nihil execratione meritos, sed quae non noverunt «, id est, »quae non intelligunt, et ubi nulla est maledicendi caussa. $\aleph^{45}$ Addit his aliud et novum scelus, quod etiam extollit amplificatione. »Adeo«, inquit, »luxu libidineque corrupti sunt, ut in his rebus, in quibus animantia rationis expertia probe moderateque degunt, veluti cibo, potu 25 coituque, in his perditissime se gerant. $\ll^{46}$ Plura petantur ex 2. cap[ite] 2. epist[olae] Petri, ubi eadem haec inveniuntur. ${ }^{47}$ Quae vero adduxit de disceptatione angelorum super cadavere Mosis, citavit ex apocryphis. ${ }^{48}$ Et verisimile est concertationem hinc esse ortam, quod Satan vellet servare cadaver Mosis tradereque Israelitis, ut hoc colentes impingerent et contra dominum peccarent. ${ }^{49}$

30 Semper enim Satan cupit ereptam creatori gloriam creaturae tribuere. ${ }^{50}$ Quod si

44 Vgl. Erasm. par. Iud. (ASD VII/6 234,69-72): »At Michael archangelus, cum illi esset disceptatio cum Diabolo de corpore Mosi, tamen veritus est illi, licet turpissimo daemoni, palam dicere conuitium. Sed cum illius impium sermonem ferre non posset, moderatus est maledictum hunc in modum: >Increpet $<$, inquiens, >te Dominus $<. \ll$

45 Vgl. Erasm. par. Iud. (ASD VII/6 234,74-76): $\gg$ At istorum tanta est peruersitas vt cum nullam habeant causam, tamen ea maledictis insectentur quae non intelligunt.«
46 Erasm. par. Iud. (ASD VII/6 234,76-78).

47 2Petr 2,10-12.

48 Erasm. Iud. (ASD VI/10 570,61): »Porro locus quem hic citat Iudas, sumptus est ex apocryphis Hebraeorum.«

49 Luth. Iud. 158r: »[...] contentionem, de qua hic Iudas meminit, exortam, cum diabolus vellet corpus Mosis mainfestari et populo idololatriae occasionem iniici.«

50 Vgl. Aug. in euang. Ioh. 52,6 (CCSL XXXVI 448,16-18): »Dominabatur [diabolus] in cordibus infidelium, ad creaturam colendam, de- 
vitio non ver|titur Paulo, quod citavit Menandri, ${ }^{51}$ Epimenidis $^{52}$ et Arati $^{53}$ testimonia, cur unus Iudas ab omnibus male audit, quod quaedam citavit ex apocryphis ${ }^{54}$ Solet vera pietas nihil aspernari, quantumvis sit obscurum et humile, sed cum iudicio ex stercoribus colligit aurum. Idem fecit et Iudas, hoc nomine laudandus magis quam vituperandus. Apocrypha fortassis maximam habebant apud illos authoritatem, ad quos hanc epistolam potissimum scripsit. Hactenus ergo inservivit illis et quavis ratione illos deo et puritati voluit lucrari.

11 Vae illis, quoniam viam Cain ingressi sunt et deceptione mercedis, qua deceptus fuit Balaam, effusi sunt et contradictione Chore perierunt.

$\mathrm{Ab}$ aliis sceleribus describit eosdem, nempe a parricidio et homicidiis, a corrup- 10 tione et avaritia, a proditionibus, turbis, ambitione et factionibus. Verum non potuit ista in ipsis vividius describere et increpare quam per adiuncta exempla. Sunt autem in istis sceleribus memorabiles nequam illi tres, quos producit: Cain, Balaam et Chore. Cain enim infamis est parricidio fratris, quem ex invidia et propter puriorem religionem occidit. ${ }^{55} \gg$ Et hi «, inquit Iudas, »viam Cain ingressi 15 sunt «, hoc est, sequuntur mores et studia latronis, ex invidia et avaritia persequentes syncerioris theologiae studiosos. Locus petitus est ex 4. cap[ite] Gene[seos]. Balaam vero, corruptus avaritia et quaestu, conatus est maledicere populo, cui dominus benedixerat. ${ }^{56}$ Ita hi, inquit, decepti mercede, quaestu et largitionibus iniquis effusi sunt, id est, in omne facinus prolapsi, ut iam non 20 abstineant ab ullo scelere. Quid enim non potest auri sacra fames ? $^{57}$ Eodem exemplo usus est et Petrus, 2. Petri 2. ${ }^{58}$ Petitum est ex Numeris Mosi, cap[ite] 22. At Chore superatus ambitione voluit ad se rapere sacerdotium ideoque maximam in castris Israelitis turbam commovit, ${ }^{59}$ verum non diu Mosi sese opposuit. Statim enim cum tota factione coniuratorum a terra dehiscente absorptus, vivus descen- 25 dit ad inferos, ${ }^{60}$ horrendo exemplo demonstrans omnibus mortalibus, quid expectent, qui arrogantiae et superbiae spiritu seducti contra veritatis ministros excitant

serto Creatore, deceptos captiuosque pertrahebat.«

51 1Kor 15,33. Menandros (ca. 342-290 v. Chr.), bedeutendster Dichter der Neuen Komödie in Athen, vgl. NP VII 1215-1219.

52 Tit 1,12. Epimenides (ca. 7.-5. Jh. v.Chr.), legendäre religiöse Figur aus Kreta. Epimenides wurde als »Sühnepriester « und »Seher « betrachtet und manchmal zu den »Sieben Weisen« gerechnet, vgl. NP III 1144; Diog. Laert. vit. 1,10 (Hicks I 114-120).

53 Apg 17,28.

54 Vgl. Hier. in Tit. 1,12-14 (CCSL LXXVIIC 31f.,685-709).
55 Gen 4,8 .

56 Num 22,6f.12. Vgl. Erasm. par. Iud. (ASD VII/6 234-236,81f.): »Balaam, qui corruptus quaestu conatus est maledicere populo cui benedixerat Deus.«

57 Vgl. Verg. Aen. 3,56f. (Mynors 154): »Quid non mortalia pectora cogis, / auri sacra fames! «

58 2Petr 2,15.

59 Num 16,1-3.

60 Num 16,31-33. 
turbas. Huic autem confert sui saeculi imo omnium saeculorum seductores, qui sibi functionem docendi vendicant repulsis doctoribus veritatis. Huc pertinent illae voces nostrorum: »Quis vero illis nebulonibus impuris aperuisset mentem scripturae? Nos ordinavit sancta sedes Romana, nos sumus doctores illuminati, 5 nostra est facultas docendi et determinandi!« Istis vero et principum quorundam et popularium mentes commovent in optimos viros testes veritatis, quos et affligunt, sed suum in detrimentum maximum. Sentient enim aliquando, quibus cum concertarint, ubi scilicet ad exemplum Choritarum meritas penderint poenas. ${ }^{61}$

12 Hi sunt inter charitates vestras maculae inter se convivantes absque ullius timore, suopte ductu arbitrioque viventes; nubes aquam non habentes, quae a ventis circumaguntur, arbores autumno marcescentes, infrugiferae, bis emortuae et eradicatae, 13 undae efferae maris, despumantes sua ipsorum dedecora, stellae erraticae, quibus caligo tenebrarum in aeternum servata est.

Hactenus quidem depinxit seductores exemplis, nunc eosdem pingit colore similitudinum evidentissimo vivacissimoque. Priusquam tamen producat parabolas,

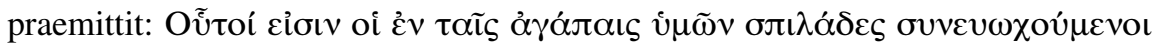

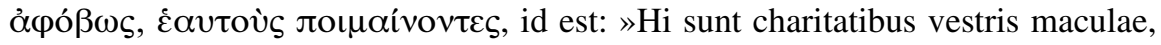
convivantes inter se intrepide, seipsos pascentes.«Pulchre autem monuit Erasmus

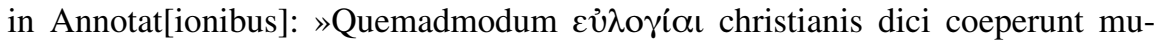
nuscula ex charitatis affectu missa, ita convivia, quae pauperibus refocillandis

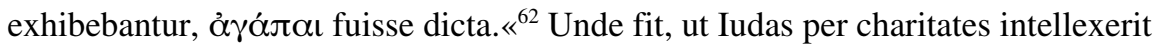
eleemosynas fidelium. »In his «, inquit, »isti sunt maculae, dedecorantes nimirum eleemosynam. « Sequitur enim: »luxuriosis conviviis inter sese certantes « ${ }^{63}$ idque ex bonis ecclesiasticis et absque ullius timore. Nam pascunt seipsos, id est, pastorum in modum seipsos agunt et ducunt et sibiipsis sunt pastores, nullius parent imperio, suo ductu et arbitratu vi|vunt; unde non est, quod quenquam metuant, sed secure, quod libet, agunt, ventri serviunt, se pascunt genioque indulgent. Hodie certe videmus episcopos et abbates ecclesiasticarum opum tanquam iustissimos possessores luxu interim dissipantes omnia, defendi a regibus et principibus. Nullus est, qui mutire contra istos vel verbulo audeat aut in medium proferre, quis sit verus ecclesiasticarum opum usus. Recte itaque dixit Iudas istos semetipsos pascere et suo arbitrio vivere. Quondam monachorum monasteria 35 fuerunt bonarum literarum scholae et pauperum xenodochia, nunc sunt equorum et venaticorum canum stabula, inertium quoque ventrium domicilia et spiritua-

61 Vgl. Luth. Iud. 159r.

62 Erasm. Iud. (ASD VI/10 572-574,77-79).

63 Vgl. Erasm. par. Iud. (ASD VII/6 236,86): $»[\ldots]$ luxuriosis comessationibus inter sese indulgentes.« 
lium praelatorum sive principum (ita enim salutari gaudent) aulae. Erudite vero et pie hunc Iudae locum cum Petri verbis contulit clarissimus vir d[ominus] Martinus Lutherus in illo suo libro nobili, quem ante annos XVI contra Ambrosium Catharinum $^{64}$ aedidit. Eius verba, si quis requirat, haec sunt: »>Labes et maculae< (sunt enim hi homines nihil nisi dedecora et labes in populo dei, cum prorsus inutiles suis tantum delitiis et vitiis in ecclesia saginati sibi serviant). >Delitiis affluentes, in conviviis suis luxuriantes vobiscum< [vgl. 2Petr 2,13]. Mihi hic locus corruptus videtur. Nam Iudas sic refert eundem: >Hi sunt inter charitates vestras maculae, inter sese convivantes absque ullo timore semetipsos pascentes [Jud 12]. Pontificum enim et sacerdotum monachorumque delicatam vitam de- 10 scribit, qui iis, quae pia charitate fidelium ad ecclesiam collata sunt et conferuntur indies, profusissimo luxu perdunt, nec dei nec hominum conspectum veriti, nec scandalis infirmorum, nec odiis bonorum quicquam commoti. Seipsos enim eximie curant et pascunt, nihil aliud quam maculae, labes, dedecus, onus ecclesiae facti, cuius debebant esse summa ornamenta et luminaria et columina. Nonne ista 15 iam dudum videmus? Unde Petri verbum >luxuriantes vobiscum< [2Petr 2,13], intelligi oportet >luxuriantes vestris opibus< seu, ut Iudas indicat, >vestris charitatibus< [Jud 12], quia et vestris et vobis abutuntur ad luxuriam et pompam suam, sine timore. Nam quod Graecus Petri textus habet $>$ in erroribus suis $<$ quod noster reddit >in conviviis suis $<$, puto factam errore librarii metathesim literarum, $\grave{\varepsilon} v 20$

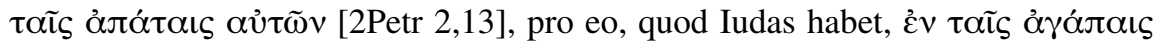
$\dot{v} \mu \tilde{\omega} v$, id est, >in charitatibus vestris seu beneficiis vel eleemosynis $<. \ll{ }^{65}$ Hactenus Lutherus. Nunc venimus ad similitudines, quibus hoc genus hominum pingit. Primo, quemadmodum et Petrus, ita et Iudas appellitat ipsos nubes aqua carentes et a vento circumactas. Habent enim speciem doctorum veritatis, pollicentur 25 docturos se doctrinam salvificam, sed veritate destituuntur et quovis circumaguntur doctrinae vento, Ephes[iorum] quarto. ${ }^{66}$ Secundo vocat arbores, »quae sub finem autumni proditis floribus mendacem fructus spem faciunt, cum mox emarcescant $\ll{ }^{67}$ Non solum autem infrugiferae, ait, sed bis sunt mortuae. Isti enim praeter hoc, quod vitam vivunt evangelicae doctrinae parum respondentem, etiam 30 alios secum cum perversa doctrina tum exemplo pravo trahunt in pernitiem. Imo eradicatae sunt arbores, haud secus, inquam, deplorati homines »quam arbores radicitus evulsae, quibus iam nulla spes superest revirescendi $\ll .{ }^{68}$ Tertio assimilat undis marinis saevientibus et in altum se extollentibus, ita notans istorum turbas, motus, clamores contra veritatem. Sed quemadmodum unda marina, quo saevius 35

64 Ambrosius Catharinus Politus (Lancellotto de' Politi, 1484-1553), Dominikanermönch und Kontroverstheologe, Autor u.a. der »Apologia pro veritate catholicae et apostolicae fidei ac doctrinae adversus impia ac valde pestifera Martini Lutheri dogmata« (1520), zu der
Luther in Luth. resp. Cath. Stellung bezog. Vgl. LThK $^{3}$ I 494f.

65 Luth. resp. Cath. (WA VII 755,24-756,5).

66 Eph 4,14.

67 Erasm. par. Iud. (ASD VII/6 236,92f.).

68 Erasm. par. Iud. (ASD VII/6 236,95f.). 
furit procellis, hoc magis despumat sordes, turbatur et sese efficit luculentam, ita isti suis clamoribus, seditionibus nihil aliud efficiunt, quam ut probra suaque dedecora omnibus exponant. Videtur haec parabola sumpta esse ex 57. capite Isaiae, ubi legimus: »Impii autem sunt sicut mare motum, quod quiescere non 5 potest, sed aquae eius eiiciunt lutum et coenum « [Jes 57,20]. Quarto nuncupat stellas erraticas. Sibi enim videntur stellae, illuminati videlicet doctores, lumina mundi, profundissimi professores, sed quia sibi non constant neque constantem sequuntur veritatem, sed magis obsequuntur affectibus, imprudentes coniiciunt in naufragium. ${ }^{69}$ Post haec omnia interminatur ipsis iudicium et ait: »Quibus caligo 10 tenebrarum in aeternum servata est «, quasi dicat: »Etsi nunc videantur regnare, iudicium tamen domini nequaquam effugient. « Servat enim hos deus aeternum cum Satana puniendos in caligine tartarea. ${ }^{70}$

14 Prius autem his vaticinatus est septimus ab Adam, Enoch, dicens: ec|ce, venit dominus in sanctis millibus suis, 15 ut faciat iudicium adversus omnes, et redarguat omnes ex eis, qui sunt impii, de factis omnibus, quae impie patrarunt, deque omnibus duris, quae loquuti sunt adversus eum peccatores impii.

Ex apocryphis profert testimonium, quo approbat seductores illos deo iudici daturos poenam. Nec est quicquam in hoc testimonio, quod non de verbo ad verbum reperias in scriptura canonica. Nullibi enim non obvium habes deum et dicta et facta nostra iudicaturum, praecipue autem puniturum, quod in ipsum et veritatem ipsius libere, imo temere dictum fuerit. ${ }^{71}$ Caeterum, cur Iudas tam frequenter utatur apocryphis, coniecturam meam paulo ante exposui. ${ }^{72}$

16 Hi sunt murmuratores, queruli, iuxta concupiscentias suas ambulantes et os illorum loquitur tumida, admirantes personas utilitatis gratia.

Iterum describit seductores a studiis suis. Hi (inquit) cum ambulent secundum concupiscentias suas, hoc est, cum toti in hoc sint, ut, quod carni volupe est, sectentur, obmurmurant, quoties aliquid incidit afflictionis, quod quidem vitium est maximum, severe admodum in Israelitis per desertum errantibus punitum. ${ }^{73}$ 30 Sunt praeterea queruli, dolentes de hominum miserabili conditione, quaerentes de

69 Vgl. Erasm. par. Iud. (ASD VII/6 236,99-102): »Similes stellis, quae cum lucis specie promittant se fore viae duces, tamen quoniam erraticae sunt neque constanter sequuntur quod rectum est sed affectibus suis nunc huc, nunc illuc abducuntur, simplices et incautos inducunt in naufragium.«
70 Vgl. Erasm. par. Iud. (ASD VII/6 236,102104): »Hae stellae [...] non effugient iudicem Deum etiam si in praesentia non punit illos, sed seruat eos aeternae tartari caligini.«

71 Vgl. Gal 5,19-21.

72 Siehe oben S. 446.

73 Num 14,29. 
morborum variis incommodis deque brevitate vitae; futuram etenim non norunt neque credunt, qui nihil quam praesentem curant. Interim tument superbia, crepitant nescio quae de virtutibus oracula, omnia tamen pectore ficto. Neque enim ex animo veritatem et virtutes amant. Nam quidlibet quaestus gratia obeunt, non loquentes ea, quae ipsa res poscebat et veritatis ratio, sed quae blanda et grata sunt, a quibus sperant aliquid compendii. »Palpones $\aleph^{74}$ ergo sunt ac adulatores turpissimi, admirantes personas, qua re nihil est caecum et improbum magis.

17 Vos autem, dilecti, memores estis verborum, quae ante hac dicta fuerunt ab apostolis domini nostri Iesu Christi, 18 quod dixerunt vobis in extremo tempore futuros illusores, qui iuxta suas impias cupiditates ambularent. 19 Hi sunt qui segregant, animales, spiritum non habentes.

Civilius nunc infert et hortatur, ut sibi caveant sancti ab impostoribus illis et impietate maxima, maneant autem in doctrina apostolorum, atque in hoc producit fideles apostolorum Christi commonitiones; quasi dicat: »Cavebitis scio ab illis. In memoria enim tenaci inhaerent sanctae apostolorum admonitiones. Priusquam 15 enim ex hoc mundo ad Christum concederent in coelos, ecclesiae dei cautum voluerunt et ideo praedixerunt venturos illusores« etc. Quod si loca et nomina apostolorum requiras, de quibus haec sint exponenda, proculdubio Petrum citavit eadem scribentem in posteriori epist[ola], cap[ite] 2. et 3.; item apostolum Paulum, qui huius generis multa scripsit in omnibus epistolis, praecipue autem in 2.20 ad Thess[alonicenses], cap[ite] 2. et in 1. ad Timoth[eum], cap[ite] 4. et in 2. epist[ola], cap[ite] $4 .^{75}$ Est autem diligenter observandum, quod tantum apostolum non puduit usurpare adeoque allegare coapostolorum scripta; at hodie invenias arrogantia ingenia, quae nolint aliorum bene dictis uti, imo nihil recte dictum aut factum putent, nisi quod fecerint ipsi. Denuo vero ad finem notis 25 quibusdam impostores notans ait: »Hi sunt qui segregant «, id est, qui movent »dissidia contra doctrinam, quam didicistis«, Roma. 16[,17]. Deinde animales sunt, vacui scilicet spiritu Christi, tantummodo inservientes voluptatibus, nihil spectantes nisi terrena et praesentia.

20 Vos autem, dilecti, sanctissimae vestrae fidei superstruentes vosipsos, per spiritum sanctum orantes, 21 vos invicem in charitate dei servate, expectantes misericordiam domini nostri Iesu Christi in vitam aeternam.

Idem dicit, quod nunc dixit, adhortans, ut perseverent in veritate et operam dent pietati. Iacta, inquit, sunt fundamenta fidei sanctae. Fundamentum aliud poni non

74 Erasm. par. Iud. (ASD VII/6 238,122).

75 2Petr 2,12-22; 3,3f.; 2Thess 2,3-12; 1Tim 4,1-3; 2 Tim 4,3-5. 
potest, quam quod positum est: Iesus Christus, lapis vivus. ${ }^{76}$ Super hunc vos »ceu vivi lapides coagmentemini ${ }^{77}$ in $\mid$ templum vivum dei. ${ }^{78}$ Et quia haec structura non potest viribus perfici humanis, ideo frequenter nobis orandus est deus, orandus autem »puris ac spiritualibus precibus $\ll .{ }^{79} \mathrm{Cum}$ item charitas illud glutinum 5 sit, quod compingit nos et conglutinat in unum corpus verumque deo placens templum, advigilandum est, ut charitate mutua cohaereamus et nos in concordia retineamus. Quod quo fiat facilius, spectandus est nobis finis omnibus propositus et, quod omnibus nobis imminet, iudicium, in quo consequemur misericordiam et vitam aeternam, si fuerimus inventi fideles et misericordes. Hunc ergo finem spectantes serviamus deo in fide vera et »charitate non ficta« [2Kor 6,6].

\section{Et hos quidem commiseremini, dum diiudicamini, 23 illos autem per timorem salvos facite, ex incendio rapientes, odio prosequentes et eam, quae ex carne est, maculatam tunicam.}

Pertinent haec ad charitatem et ad potissimum huius epistolae scopum. Diximus enim Iudam inhortari sanos, ut operam dent, ne imprudentiores seducantur. Cum ergo nunc meminisset charitatis, addit: »Eadem illa charitas cupit servare omnes, dolet enim de interitu miserabilium hominum. «Sensum enim verborum apostoli hic est: »Dum diiudicamini «, id est, »vosmetipsos separatis ab illorum consortio, quos videtis esse insanabiles, commiseramini eos et quodam cum dolore vices illorum deflete.«Videmus enim id fecisse maxima authoritate et sanctimonia praeditos viros, Samuelem in primis et Ieremiam; quorum hic excidium Hierosolymitanum acerbissime deflevit, ${ }^{80}$ ille vero maxima cum commiseratione fatum Saulis luxit. ${ }^{81}$ »Neque vero satis est«, inquit, »cum dolore deploratos istos devitasse, nisi etiam omni studio advigilemus, ut, quos videmus adhuc esse curabiles, quovis modo Christo lucrifaciamus, praecipue autem urgeamus illos metu et minis iudicii dei, si hos veluti ex incendio aliquo Sodomitico possimus eripere.« Quia vero sani et extra periculum constituti propter humanam imbecillitatem nonnunquam pereunt una cum illis, quibus ferunt suppetias, hoc est, quia meliores nonnunquam vincuntur a peioribus, ideo addit »odio prosequentes «; quasi dicat: »Nolo, ut nimium familiares vos efficiatis malis aut ut colludatis cum illis, sed ut odio habeatis malos, non ipsam quidem mali personam, sed quatenus mala est. « Huic enim addit »et eam, quae ex carne est, maculatam tunicam«; id est: »Volo, ut odio prosequamini non ipsos quidem homines, sed turpes affectus, qui existunt ex carne et hominem polluunt. ${ }^{82}$ Per tunicam enim maculatam aliud non intellexit quam exuvias veteris Adami, concupiscentias et opera carnis.

1Kor 3,11 ; 1 Petr 2,4 .

Erasm. par. Iud. (ASD VII/6 238,135).

1Petr 2,5.

Erasm. par. Iud. (ASD VII/6 238,138f.).
80 Vgl. Klgl 1-5.

81 1Sam 15,35.

82 Vgl. Erasm. par. Iud. (ASD VII/6 238,145147): $»[\ldots]$ odio habentes non homines ipsos 
Contrarium ei est, quod Paulus iubet, induere dominum Iesum, ${ }^{83}$ quod euangelion iubet, nos induere vestem nuptialem. ${ }^{84}$ Sunt autem hae loquutiones symbolicae.

24 Ei vero, qui potest illos servare a peccato immunes et statuere in conspectu gloriae suae incontaminatos cum exultatione, 25 soli sapienti deo servatori nostro: gloria et magnificentia et imperium et potestas nunc et in omnia saecula. Amen.

Iubilo quodam et gratulatione concludit epistolam. In hac autem conclusione ostendit, quis servet a peccato, unde sint vires perseverantiae et operum bonorum, unde sit vita aeterna: a deo videlicet, cui soli debeatur omnis gloria, non nostris conatibus et viribus. »Deus est«, inquit, »qui servat nos a peccato, hic nobis 10 fideliter adeundus et orandus est; idem est, qui efficit per Christum, ut cum gaudio appareamus in conspectu illius, cum vel ex hoc corpore exeundum est, vel in iudicium tremendum abeundum. Is idem ille est, qui confert nobis per misericordiam suam magnam coronam vitae. ${ }^{85}$ Huius ergo solius omnis gloria est. Huic sit laus, confessio et gratiarumactio in saecula saeculorum. Amen.«

Finis.

sed corpus hoc terrenis affectibus inquinatum, qua ceu tunica polluta grauatur et inquinatur humanus animus.«
83 Röm 13,14; Gal 3,27.

84 Mt 22,11f.

85 Jak 1,12 . 


\title{
BIBLIOGRAPHIE
}

\author{
1. Quellen
}

Aesc. fals. leg.

Aesop. fab.

Agric. inv.

AGZR

Ambr. incarn.

Ambr. spir. sanct.

Apul. flor.

Arist. cael.

Arist. cat.

Arist. hist. an

Arist. phys.

Arist. top.

Ps.-Athan. quaest.

Aug. c. Gaud.

Aug. c. Maximin.

Aug. c. Pelag.

Aug. c. Petil.

Aug. civ.

Aug. de serm. dom

Aug. epist.
Aeschines, De falsa legatione, in: Eschine, Discours, Bd. 1: Contre Timarque - Sur l'ambassade infidèle, hg. von Victor Martin und Guy de Budé, Paris 1973 (Collection des Universités de France), 109-169.

Aesopus, Fabulae [Corpus fabularum Aesopicarum], hg. von A. Hausrath, 2 Bde., Leipzig 1957/1959 (Bibliotheca scriptorum Graecorum et Romanorum Teubneriana).

Rudolf Agricola, De inventione dialectica libri tres (Drei Bücher über die Inventio dialectica), hg. von Lothar Mundt, Tübingen 1992 (Frühe Neuzeit $\mathrm{XI})$.

Actensammlung zur Geschichte der Zürcher Reformation in den Jahren 1519-1533, hg. von Emil Egli, Zürich 1879.

Ambrosius Mediolanensis, De incarnationis dominicae sacramento, hg. von Otto Faller, Wien 1964 (CSEL LXXIX 225-281).

Ambrosius Mediolanensis, De spiritu sancto libri tres, hg. von Otto Faller, Wien 1964 (CSEL LXXIX 7-222).

Apuleius Madaurensis, Florida, hg. von Rudolf Helm, Leipzig 1959 (Apulei Platonici Madaurensis opera quae supersunt II/2 - Bibliotheca scriptorum Graecorum et Romanorum Teubneriana).

Aristoteles, De caelo, hg. von W. K. C. Guthrie, London/Cambridge, MA 1960 (The Loeb Classical Library).

Aristoteles, Categoriae, in: Aristotelis Categoriae et Liber de interpretatione, hg. von L. Minio-Paluello, Oxford 1949 (Scriptorum classicorum bibliotheca Oxoniensis), 3-45.

Aristoteles, Historia animalium, hg. von A. L. Peck (Bde. 1-2) und D. M. Balme (Bd. 3), 3 Bde., London/Cambridge, MA 1965-1991 (The Loeb Classical Library).

Aristoteles, Physica, hg. von W. D. Ross, Oxford 1960.

Aristoteles, Topica, in: Aristotelis Topica et Sophistici Elenchi, hg. von W. D. Ross, Oxford 1958 (Scriptorum classicorum bibliotheca Oxoniensis), $1-189$.

Pseudo-Athanasius von Alexandria, Quaestiones ad Antiochum principem (PG XXVIII 597-700).

Aurelius Augustinus, Contra Gaudentium donatistarum episcopum, hg. von M. Petschenig, Wien/Leipzig 1910 (CSEL LIII 201-274).

Aurelius Augustinus, Contra Maximinum Arianorum episcopum (PL XLII 743-814).

Aurelius Augustinus, Contra duas epistolas Pelagianorum libri quattuor, hg. von Karl F. Urba und Joseph Zycha, Wien/Leipzig 1913 (CSEL LX 423570).

Aurelius Augustinus, Contra litteras Petiliani, hg. von M. Petschenig, Wien/Leipzig 1909 (CSEL LII 3-227).

Aurelius Augustinus, De civitate Dei, hg. von Bernhard Dombart und Alfons Kalb, Turnhout 1955 (CCSL XLVII-XLVIII)

Aurelius Augustinus, De sermone domini in monte libri duo, hg. von Almut Mutzenbecher, Turnhoult 1967 (CCSL XXXV).

Aurelius Augustinus, Epistulae, hg. von Alois Goldbacher, Wien 1895/1904/1911 (CSEL XXXIV, XLIV, LVII). 
Aug. fid. et op.

Aug. grat.

Aug. haer.

Aug. haer. app.

Aug. in euang. Ioh.

Aug. in psalm.

Aug. op.

Aug. persev.

Aug. praed. sanct.

Aug. quaest. hept.

Aug. retract.

Aug. rhet.

Aug. serm.

Aug. spir. et litt.

Aug. un. eccl.

Ps.-Aug. serm.

Beda act.

Beda epist. can.

Biel sent.

Brenz Ioh.

Brenz syngr.

Bud. comm.

Bug. Hebr.

Bull. 1Cor.

Bull. 2Cor.
Aurelius Augustinus, De fide et operibus, hg. von Joseph Zycha, Wien et al. 1900 (CSEL XLI 35-97).

Aurelius Augustinus, De gratia et libero arbitrio (PL XLIV 881-912).

Aurelius Augustinus, De haeresibus ad Quodvultdeum, hg. von R. vander Plaetse und C. Beukers, Turnhout 1969 (CCSL XLVI 283-345).

Appendix Augustini operis genuini de haeresibus, hg. von R. vander Plaetse und C. Beukers, Turnhout 1969 (CCSL XLVI 349-351).

Aurelius Augustinus, In Iohannis evangelium tractatus CXXIV, hg. von Radbodus Willems, Turnhout ${ }^{2} 1990$ (CCSL XXXVI).

Aurelius Augustinus, Enarrationes in Psalmos, hg. von Eligius Dekkers und Johannes Fraipont, Turnhout 1956 (CCSL XXXVIII/XXXIX)

Divi Aurelii Augustini omnia opera [...] summa vigilantia repurgata a mendis innumeris per Desiderium Erasmum Roterodamum, 10 Bde., Basel: Johannes Froben, 1528/29 (VD16 A 4148).

Aurelius Augustinus, De dono perseverantiae (PL XLV 993-1034).

Aurelius Augustinus, De praedestinatione sanctorum (PL XLIV 959-992).

Aurelius Augustinus, Quaestionum in heptateucum libri septem, hg. von I. Fraipont, Turnhout 1958 (CCSL XXXIII 1-377).

Aurelius Augustinus, Retractationum libri duo, hg. von Almut Mutzenbecher, Turnhout 1984 (CCSL LVII).

Aurelius Augustinus, De rhetorica (PL XXXII 1439-1448).

Aurelius Augustinus, Sermones (PL XXXVIII; XXXIX 1493-1718).

Aurelius Augustinus, De spiritu et littera, hg. von Karl Franz Urba und Joseph Zycha, Wien 1913 (CSEL LX 155-229).

Aurelius Augustinus, De unitate ecclesiae (Epistula ad catholicos de secta Donatistarum), hg. von M. Petschenig, Wien/Leipzig 1909 (CSEL LII 231322).

Pesudo-Augustinus (Belgicus), Sermones, hg. von D. A. B. Caillau und D.B. Saint-Yves, Paris 1836 (Sancti Aurelii Augustini operum supplementum I). Beda Venerabilis, Expositio actuum apostolorum, hg. von M. L. W. Laistner, Turnhout 1983 (CCSL CXXI 3-99).

Beda Venerabilis, In epistolas septem catholicas, hg. von David Hurst, Turnhout 1983 (CCSL CXXI 181-342).

Gabriel Biel, Collectorium circa quattuor libros sententiarum, hg. Wilfridus Werbeck und Udo Hofmann, 4 Bde., Tübingen 1973-1992.

Johannes Brenz, In d[ivi] Iohannis evangelion exegesis, Hagenau: Johann Setzer, 1529 (VD16 B 7708).

Johannes Brenz, Syngramma [...] super verbis coena dominicae [...] ad Iohannem Oecolampadion, in: Johannes Brenz, Frühschriften, Teil 1, hg. von Martin Brecht et al., Tübingen 1970 (Johannes Brenz Werke. Eine Studienausgabe), 234-278.

Guillaume Budé, Commentarius linguae Graecae, in: Omnia opera Gulielmi Budaei Parisiensis, Bd. 4, Basel: Nikolaus Episcopius d.J., 1557 (VD16 B 9075).

Johannes Bugenhagen, In epistolam ad Hebraeos annotationes, in: Annotationes Io[annis] Bugenhagii Pomerani in Epistolas Pauli ad Galatas, Ephesios, Philippenses, Colossenses, Thessalonicenses primam et secundam, Timotheum primam et secundam, Titum, Philemonem, Hebraeos, Basel: Adam Petri, 1525 (VD16 B 9237), 116v-139v.

Heinrich Bullinger, In priorem Pauli ad Corinthios epistolam commentarius, in: Heinrich Bullinger. Kommentare zu den neutestamentlichen Briefen (Röm - 1Kor - 2Kor), hg. von Luca Baschera, Zürich 2012 (HBTS VI 229-464).

Heinrich Bullinger, In posteriorem d[ivi] Pauli ad Corinthios epistolam, in: Heinrich Bullinger. Kommentare zu den neutestamentlichen Briefen (Röm 1Kor - 2Kor), hg. von Luca Baschera, Zürich 2012 (HBTS VI 467-591). 
Bull. act.

Bull. adv. cat.

Bull. Eph.

Bull. Gal.

Bull. hebd. Dan.

Bull. lect.

Bull. orig. div.

Bull. orig. euch.

Bull. proph.

Bull. Rom.

Bull. script.

Bull. stud. rat.

Bull. vorl. Hebr.

Cassiod. hist.

Chrys. 1Tim.

Chrys. 1Tim. transl.

Chrys. Hebr.

Chrys. Hebr. transl.

Chrys. laud.

Chrys. laud. transl.

Cic. Catil.
Heinrich Bullinger, In Acta apostolorum [...] commentariorum libri sex, Zürich: Christoph Froschauer d.Ä., 1533 (HBBibl I, Nr. 43).

Heinrich Bullinger, Adversus omnia catabaptistarum prava dogmata, Zürich: Christoph Froschauer d.Ä., 1535 (HBBibl I, Nr. 29).

Heinrich Bullinger, In Pauli epistolam ad Ephesios, in: Heinrich Bullinger. Kommentare zu den neutestamentlichen Briefen ( Gal - Eph - Phil - Kol), hg. von Luca Baschera, Zürich 2014 (HBTS VII 127-208).

Heinrich Bullinger, In Pauli epistolam ad Galatas, in: Heinrich Bullinger. Kommentare zu den neutestamentlichen Briefen (Gal - Eph - Phil - Kol), hg. von Luca Baschera, Zürich 2014 (HBTS VII 3-124).

Heinrich Bullinger, De hebdomadis, quae apud Danielem sunt, opusculum, Zürich: Christoph Froschauer d.Ä., 1530 (HBBibl I, Nr. 27).

Heinrich Bullinger, [Epistola ad lectorem], in: Heinrich Bullinger. Kommentare zu den neutestamentlichen Briefen (Röm - 1Kor - 2Kor), hg. von Luca Baschera, Zürich 2012 (HBTS VI 3-12).

Heinrich Bullinger, De origine erroris in divorum ac simulachrorum cultu, Zürich: Christoph Froschauer d.Ä., (HBBibl I, Nr. 11).

Heinrich Bullinger, De origine erroris in negocio eucharistiae ac missae, Zürich: Christoph Froschauer d.Ä., 1528 (HBBibl I, Nr. 10).

Heinrich Bullinger, De prophetae officio et quomodo digne administrari possit, Zürich: Christoph Froschauer d.Ä., 1532 (HBBibl I, Nr. 33).

Heinrich Bullinger, In sanctissimam Pauli ad Romanos epistolam, in: Heinrich Bullinger. Kommentare zu den neutestamentlichen Briefen (Röm 1 Kor - 2Kor), hg. von Luca Baschera, Zürich 2012 (HBTS VI 15-226).

Heinrich Bullinger, De scripturae sanctae authoritate deque episcoporum institutione et functione, bearb. von Emidio Campi unter Mitwirkung von Philipp Wälchli, Zürich 2009 (HBTS IV).

Heinrich Bullinger, Studiorum ratio, hg. von Peter Stotz, 2 Bde., Zürich 1987 (Heinrich Bullinger Werke, Sonderband: Studiorum ratio - Studienanleitung).

Heinrich Bullinger, Vorlesung über den Hebräerbrief (1526/27), hg. von Hans-Georg Berg und Susanne Hausammann, Zürich 1983 (HBTS I 135268).

Flavius Magnus Aurelius Cassiodorus, Historia eccelsiastica tripartita, hg. von Walter Jacob und Rudolph Hanslik, Wien 1952 (CSEL LXXI).

Johannes Chrysostomos, Homiliae XVIII in epistolam primam ad Timotheum (PG LXII 501-598).

Johannes Chrysostomos, Homiliae in primam epistolam Pauli ad Timotheum, in: Operum Ioannis Chrysostomi Constantinopolitani, Bd. 3, Basel: Andreas Cratander, 1522 (VD16 J 397), 173-230.

Johannes Chrysostomos, Enarratio in epistolam ad Hebraeos (PG LXIII 9-236).

Johannes Chrysostomos, Expositio in epistolam beati Pauli apostoli ad Hebraeos [...] Mutiano scholastico interprete, in: Operum Ioannis Chrysostomi Constantinopolitani, Bd. 3, Basel: Andreas Cratander, 1522 (VD16 J 397), 55-173.

Johannes Chrysostomos, De laudibus Pauli apostoli homiliae / Panégyriques de S. Paul, hg. von Auguste Piédagnel, Paris 1982 (SC CCC).

Johannes Chrysostomos, De laudibus Pauli apostoli homiliae, in: Operum Ioannis Chrysostomi Constantinopolitani, Bd. 3, Basel: Andreas Cratander, 1522 (VD16 J 397), 3-24.

Marcus Tullius Cicero, Orationes in Catilinam, in: Cicero, In Catilinam I-IV - Pro Murena - Pro Sulla - Pro Flacco, hg. von C. MacDonald, Cambridge, MA/London 1977 (The Loeb Classical Library), 32-164. 
Cic. inv.

Cic. Manil.

Cic. Mil.

Cic. Mur

Cic. off.

Cic. orat.

Cic. top.

Cic. tusc.

Cic. Verr.

Colum.

Cypr. Demetr.

Cypr. epist.

Cypr. op.

Cypr. patient.

Cypr. testim.

Cypr. unit. eccl.

Decr. Grat.

Dem. fals. leg.

Didym. in Iac.

Didym. spir.

Diog. Laert. vit.

Ps.-Dion. Ar. div. nom. Pseudo-Dionysius Areopagita, De divinis nominibus, hg. von Beate Regina

Suchla, Berlin/New York 1990 (Patristische Texte und Studien XXXIII).

Marcus Tullius Cicero, De inventione, in: Cicero, De inventione - De optimo genere oratorum, Topica, hg. von H. M. Hubbell, London/Cambridge, MA 1960 (The Loeb Classical Library), 2-344.

Marcus Tullius Cicero, Pro lege Manilia (De imperio C. Pompei), in: Cicero, The Speeches: Pro lege Manilia - Pro Caecina - Pro Cluentio - Pro Rabirio, hg. von H. Grose Hodge, London/Cambridge, MA: 1959 (The Loeb Classical Library), 14-82.

Marcus Tullius Cicero, Pro T. Annio Milone, in: Cicero, The Speeches: Pro T. Annio Milone - In L. Calpurnium Pisonem - Pro M. Aemilio Scauro Pro M. Fonteio - Pro C. Rabirio Postumo - Pro M. Marcello - Pro Q. Ligario - Pro rege Deiotaro, hg. von N. H. Watts, London/Cambridge, MA: 1958 (The Loeb Classical Library), 6-122.

Marcus Tullius Cicero, Pro Murena, in: Cicero, In Catilinam I-IV - Pro Murena - Pro Sulla - Pro Flacco, hg. von C. MacDonald, Cambridge, MA/London 1977 (The Loeb Classical Library), 186-298.

Marcus Tullius Cicero, De officiis, hg. von Walter Miller, London/ Cambridge, MA 1961 (The Loeb Classical Library).

Marcus Tullius Cicero, Orator, hg. von H. M. Hubbell, in: in: Cicero, Brutus - Orator, London/Cambridge, MA (The Loeb Classical Library), 306-508. Marcus Tullius Cicero, Topica, in: Cicero, De inventione - De optimo genere oratorum, Topica, hg. von H. M. Hubbell, London/Cambridge, MA 1960 (The Loeb Classical Library), 382-458.

Marcus Tullius Cicero, Tusculanae disputationes, hg. von J. E. King, London/Cambridge, MA 1960 (The Loeb Classical Library).

Marcus Tullius Cicero, In C. Verrem orationes sex, 2 Bde., hg. von L. H. G. Greenwood, London/Cambridge, MA 1959 (The Loeb Classical Library).

L. Iunius Moderatus Columella, Res rustica, hg. von Harrison Boyd Ash et al., 3 Bde., London/Cambridge 1960 (The Loeb Classical Library).

Cyprianus Carthaginensis, Ad Demetrianum, hg. von Manlio Simonetti, Turnhout 1976 (CCSL IIIA 33-51).

Cyprianus Carthaginensis, Epistulae, hg. von Gerardus Frederick Diercks, Turnhout 1994/1996 (CCSL IIIB-IIIC).

Opera divi Caecilii Cypriani episcopi Carthaginensis [...] nobis praestitit ingenti labore suo Erasmus Roterodamus, Basel: Johannes Froben, 1521 (VD16 C 6509).

Cyprianus Carthaginensis, De bono patientiae, hg. von C. Moreschini, Turnhout 1976 (CCSL IIIA 118-133).

Cyprianus Carthaginensis, Testimoniorum libri tres (Ad Quirinum), hg. von R. Weber, Turnhout 1972 (CCSL III 3-179).

Cyprianus Carthaginensis, De ecclesiae catholicae unitate, hg. von M. Bévenot, Turnhout 1972 (CCSL III 249-268).

Decretum Gratiani, in: Corpus Iuris Canonici, Bd. 1, hg. von Emil Friedberg, Leipzig 1879.

Demosthenes, De falsa legatione, in: Démosthène, Plaidoyers politiques, Tome III, hg. von Georges Mathieu, Paris 1972 (Collection des universités de France).

Didymus Caecus, In epistolam beati Iacobi apostoli brevis enarratio (PG XXXIX 1749-1754).

Didymus Caecus, De spiritu sancto, hg. von Louis Doutreleau, Paris 1992 (SC CCCLXXXVI).

Diogenes Laertius, Vitae philosophorum, hg. von R. D. Hicks, 2 Bde., Cambridge, MA/London 1980 (The Loeb Classical Library). 
Durant. rat.

Eck ench.

Eck sacr.

Epiph. haer.

Erasm. 1Joh.

Erasm. 1Joh. transl.

Erasm. 1Petr.

Erasm. 1Petr. transl.

Erasm. 2Petr.

Erasm. 2Petr. transl.

Erasm. 3Joh.

Erasm. adag.

Erasm. apoph.

Erasm. conscr.

Erasm. cop.

Erasm. ench.

Erasm. Eph.

Erasm. epist.

Erasm. Hebr.

Erasm. Hebr. transl.

Erasm. Iac.

Erasm. Iud.
Guillelmus Durantus, Rationale divinorum officiorum, hg. von A. Davril und T. M. Thibodeau, Turnhout 1995 (CCCM CXL, CXLA-B).

Johannes Eck, Enchiridion locorum communium adversus Lutherum et alios hostes ecclesiae (1525-1543), hg. von Pierre Fraenkel, Münster 1979 (Corpus Catholicorum XXXIV).

Johannes Eck, De sacrificio missae libri tres (1526), hg. von Erwin Iserloh et al., Münster i.W. 1982 (Corpus catholicorum XXXVI).

Epiphanius, Adversus haereses (PG XLI-XLII).

Desiderius Erasmus, In epistolam Ioannis apostoli primam annotationes, hg. von M. L. van Poll-van de Lisdonk, Leiden/Boston 2014 (ASD VI/10 521558).

Desiderius Erasmus, Epistola Ioanni apostoli prima, in: Novum testamentum ab Erasmo recognito, IV: Epistolae apostolicae (secunda pars) et Apocalypsis Iohannis, hg. von Andrew J. Brown, Amsterdam et al. 2013 (ASD VI/4 463-488).

Desiderius Erasmus, Annotationes in epistolam Petri apostoli priorem, hg. von M. L. van Poll-van de Lisdonk, Leiden/Boston 2014 (ASD VI/10 428488).

Desiderius Erasmus, Epistola beati Petri apostoli prima, in: Novum testamentum ab Erasmo recognito, IV: Epistolae apostolicae (secunda pars) et Apocalypsis Iohannis, hg. von Andrew J. Brown, Amsterdam et al. 2013 (ASD VI/4 386-432).

Desiderius Erasmus, Annotationes in epistolam Petri apostoli secundam, hg. von M. L. van Poll-van de Lisdonk, Leiden/Boston 2014 (ASD VI/10 489519).

Desiderius Erasmus, Epistola beati Petri apostoli secunda, in: Novum testamentum ab Erasmo recognito, IV: Epistolae apostolicae (secunda pars) et Apocalypsis Iohannis, hg. von Andrew J. Brown, Amsterdam et al. 2013 (ASD VI/4 433-462).

Desiderius Erasmus, In epistolam Ioannis tertiam annotationes, hg. von M. L. van Poll-van de Lisdonk, Leiden/Boston 2014 (ASD VI/10 563-565).

Desiderius Erasmus, Adagia, hg. von M. L. van Poll-van de Lisdonk et al., Amsterdam et al. 1981-2005 (ASD II/1-9).

Desiderius Erasmus, Apophthegmatum libri, in: Desiderii Erasmi Roterodami opera omnia, Bd. 4, Leiden 1703, 85-380.

Desiderius Erasmus, De conscribendis epistolis, hg. von Jean-Claude Margolin, Amsterdam 1971 (ASD I/2 205-579).

Desiderius Erasmus, De copia verborum et rerum, hg. von Betty I. Knott, Amsterdam 1988 (ASD I/6).

Desiderius Erasmus, Enchiridion militis christiani, hg. von J. Domanski und R. Marcel, Leiden/Boston 2016 (ASD V/8 59-303).

Desiderius Erasmus, In epistolam Pauli ad Ephesios annotationes, hg. von M. L. van Poll-van de Lisdonk, Leiden/Boston 2009 (ASD VI/9 162-272). Desiderius Erasmus, Opus epistolarum, 12 Bde., hg. von H. M. Allen [Bde. 1-3] und P. S. Allen [Bde. 4-12], Oxford 1906-1965.

Desiderius Erasmus, Annotationes in epistolam Pauli ad Hebraeos, hg. von M. L. van Poll-van de Lisdonk, Leiden/Boston 2014 (ASD VI/10 229-384). Desiderius Erasmus, Epistola Pauli apostoli ad Hebraeos, in: Novum testamentum ab Erasmo recognito, IV: Epistolae apostolicae (secunda pars) et Apocalypsis Iohannis, hg. von Andrew J. Brown, Amsterdam et al. 2013 (ASD VI/4 219-348).

Desiderius Erasmus, Annotationes in epistolam Iacobi, hg. von M. L. van Poll-van de Lisdonk, Leiden/Boston 2014 (ASD VI/10 387-428).

Desiderius Erasmus, In epistolam Iudae annotationes, hg. von M. L. van Poll-van de Lisdonk, Leiden/Boston 2014 (ASD VI/10 567-579). 
Erasm. Joh. transl.

Erasm. ling.

Erasm. matr. inst.

Erasm. Matt.

Erasm. par. 1Joh.

Erasm. par. 1Petr.

Erasm. par. 2Joh.

Erasm. par. 2Petr.

Erasm. par. 3Joh.

Erasm. par. Hebr.

Erasm. par. Iac.

Erasm. par. Iud.

Erasm. paracl.

Erasm. praef. par. 1Petr. Desiderius Erasmus, Praefatio in paraphrases in duas epistolas Petri, apostolorum principis, et in unam Iudae, hg. von John J. Bateman, Amsterdam et al. 1997 (ASD VII/6 179-182).

Erasm. Rom.

Erasm. Tit.

Euseb. chron. Euseb. hist. eccl.

Fab. Stap. 2Joh.

Fab. Stap. Hebr.

Flav. Ios. ant.

Flav. Ios. ant. transl.

Gell.

Desiderius Erasmus, Evangelium secundum Ioannem, in: Novum testamentum ab Erasmo recognito, II: Evangelium secundum Iohannem et Acta apostolorum, hg. von Andrew J. Brown, Amsterdam et al. 2001 (ASD VI/2 13-210).

Desiderius Erasmus, Lingua, hg. von F. Schalk, Amsterdam 1974 (ASD IV/1 233-370).

Desiderius Erasmus, Christiani matrimonii institutio, hg. von A. G. Weiler, Amsterdam et al. 2008 (ASD V/6 57-248)

Desiderius Erasmus, In Evangelium Matthaei annotationes, in: Annotationes in Novum Testamentum. Pars prima, hg. von P. F. Hovingh, Amsterdam et al. 2000 (ASD VI/5 65-348).

Desiderius Erasmus, In epistolam Ioannis primam paraphrasis, hg. von John J. Bateman, Amsterdam et al. 1997 (ASD VII/6 257-288).

Desiderius Erasmus, Paraphrasis in epistolam Petri apostoli priorem, hg. von John J. Bateman, Amsterdam et al. 1997 (ASD VII/6 184-215).

Desiderius Erasmus, In secundam Ioannis epistolam paraphrasis, hg. von John J. Bateman, Amsterdam et al. 1997 (ASD VII/6 289f.).

Desiderius Erasmus, Paraphrasis in epistolam Petri apostoli posteriorem, hg. von John J. Bateman, Amsterdam et al. 1997 (ASD VII/6 184-215).

Desiderius Erasmus, In tertiam Ioannis epistolam paraphrasis, hg. von John J. Bateman, Amsterdam et al. 1997 (ASD VII/6 292-294).

Desiderius Erasmus, Paraphrasis in epistolam ad Hebraeos, hg. von John J. Bateman, Amsterdam et al. 1997 (ASD VII/6 39-106).

Desiderius Erasmus, Paraphrasis in epistolam Iacobi episcopi Hierosolymitani, hg. von John J. Bateman, Amsterdam et al. 1997 (ASD VII/6 117-160). Desiderius Erasmus, Paraphrasis in epistolam Iudae apostoli, hg. von John J. Bateman, Amsterdam et al. 1997 (ASD VII/6 232-239).

Desiderius Erasmus, Paraclesis ad lectorem pium, in: Desiderius Erasmus Roterodamus, Ausgewählte Werke, hg. von Hajo Holborn, München 1933, 139-149.

Desiderius Erasmus, Annotationes in epistolam Pauli ad Romanos, hg. von P.F. Hovingh, Leiden/Boston 2012 (ASD VI/7).

Desiderius Erasmus, Annotationes in epistolam Pauli ad Titum, hg. von M. L. van Poll-van de Lisdonk, Leiden/Boston 2014 (ASD VI/10 173-216).

Eusebius von Cäsarea, Chronicorum libri duo (PL XXVII 11-508).

Eusebius von Cäsarea, Historia ecclesiastica, hg. von Eduard Schwartz und Theodor Mommsen, Berlin 1903-1908 (GCS IX/1-2).

Jacobus Faber Stapulensis (Jacques LeFèvre d'Étaples), Commentarius in secundam epistolam Ioannis, in: Id., Commentarii in epistolas catholicas, Basel: Andreas Cratander, 1527 (VD16 B 5208), 65v-68r.

Jacobus Faber Stapulensis (Jacques Lefèvre d'Étaples), Commentariorum in epistolas beati Pauli apostoli liber quartusdecimus, qui est in epistolam ad Hebraeos, in: Id., S. Pauli epistolae XIV ex Vulgata, adiecta intelligentia ex graeco cum commentariis, Paris: Henri Estienne, 1512, 230v-262r.

Flavius Iosephus, Antiquitatum Iudaicarum libri XX, in: Flavii Iosephi opera, Bde. 1-4, hg. von B. Niese, Berlin 1955.

Flavius Iosephus, Antiquitatum Iudaicarum libri XX, in: Flavii Iosephi [...] opera quaedam Ruffino presbytero interprete, Köln: Gottfried Hittorp 1524 (VD16 J 957), 1-592.

Aulus Gellius, Noctes Atticae, hg. von John C. Rolfe, 3 Bde., London/Cambridge, MA 1978-1984 (The Loeb Classical Library) 
Gennad. dogm.

Gennad. vir. ill.

Greg. M. epist.

Herb. ench.

Hier. adv. Iovin

Hier. epist.

Hier. in Eph.

Hier. in Ezech.

Hier. in Gal.

Hier. in Is.

Hier. in Tit.

Hier. op.

Hier. quaest. hebr. in Gen

Hier. vir. ill.

Hier. virg. Mar.

Hil. trin.

Hom. Il.

Hom. Od.

Hor. ars

Hor. epist.

Ioh. Dam. exp. fid.

Iren. haer.

Isid. orig.

Iuv.
Gennadius Massiliensis, Liber de ecclesiasticis dogmatibus (PL LVIII 9791000).

Gennadius Massiliensis, De viris illustribus, hg. von Ernest Cushing Richardson, Lepizig 1896 (Texte und Untersuchungen zur altchristlichen Literatur XIV/1 57-97).

Gregorius Magnus, Epistulae, hg. von Dag Norberg, Turnhout 1982 (CCSL CXL-CXLA).

Nicolaus Herborn, Locorum communium adversus huius temporis haereses enchiridion (1529), hg. von Patricius Schlager, Münster i.W. 1927 (Corpus Catholicorum XII).

Hieronymus Stridonensis, Adversus Iovinianum libri duo (PL XXIII 221352).

Hieronymus Stridonensis, Epistulae, hg. von Isidor Hilberg, Wien 1910 1918 (CSEL LIV-LVI/1).

Hieronymus Stridonensis, Commentariorum in epistolam ad Ephesios libri tres (PL XXVI 467-590).

Hieronymus Stridonensis, Commentariorum in Hiezechielem libri XIV, hg. von François Glorie, Turnhout 1964 (CCSL LXXV).

Hieronymus Stridonensis, Commentariorum in epistolam ad Galatas libri tres, hg. von Giacomo Raspanti, Turnhout 2006 (CCSL LXXVIIA).

Hieronymus Stridonensis, Commentariorum in Esaiam libri, hg. von Marc Adriaen, Turnhout 1963 (CCSL LXXIII-LXXIIIA).

Hieronymus Stridonensis, Commentarii in epistolam ad Titum (PL XXVI 589-636).

Omnium operum divi Eusebii Hieronymi Stridonensis [...] una cum argumenits et scholiis Des[iderii] Erasmi Roterodami, 10 Bde., Basel: Johannes Froben, 1516 (VD16 H 3482).

Hieronymus Stridonensis, Quaestiones Hebraicae in libro Geneseos, hg. von Paul de Lagarde, Turnhout 1959 (CCSL LXXII 1-56).

Hieronymus Stridonensis, De viribus illustris (de scriptoribus ecclesiasticis) (PL XXIII 631-760).

Hieronymus Stridonensis, De perpetua virginitate b[eatae] Mariae liber adversus Helvidium (PL XXIII 193-216)

Hilarius Pictaviensis, De trinitate, hg. von P. Smulders, Turnhout 1979-1980 (CCSL LXII-LXIIA).

Homer, Ilias, hg. von Arthur Ludwich, 2 Bde., Stuttgart et al. 1995 (Bibliotheca scriptorum Graecorum et Romanorum Teubneriana).

Homer, Odyssee, hg. von Arthur Ludwich, 2 Bde., Leipzig 1889/1891 (Homeri carmina II/1-2).

Horatius, De arte poetica, in: Q. Horatii Flacci opera, hg. von Friedrich Klingner, Leipzig 1959 (Bibliotheca scriptorum Graecorum et Romanorum Teubneriana), 294-311.

Horatius, Epistulae, in: Q. Horatii Flacci opera, hg. von Friedrich Klingner, Leipzig 1950 (Bibliotheca scriptorum Graecorum et Romanorum Teubneriana), 240-293.

Iohannes Damascenus, Expositio fidei, hg. von Bonifatius Kotter, Berlin/New York 1973 (PTS XII).

Irenaeus, Adversus haereses, hg. von W. Wigan Harvey, 2 Bde., Cambridge 1857.

Isidorus Hispalensis, Etymologiarum sive originum libri XX, 2 Bde., hg. von W. M. Lindsay, Oxford 1971 (Scriptorum classicorum bibliotheca Oxoniensis).

D. Iunius Iuvenalis, Saturae, in: A. Persi Flacci et D. Iunii Iuvenalis saturae, hg. von W. V. Clausen, Oxford 1992 (Scriptorum classicorum bibliotheca Oxoniensis), 37-175. 
Kim. Zech.

Kurtz. Ber.

Lact. inst.

Lit. Bas.

Lucr.

Luth. 1Petr.

Luth. 2Petr.

Luth. Iud.

Luth. resp. Cath.

Luth. vorr.

Luth. wort

Macr. Sat.

Macr. somn.

Mar. Victorin. rhet.

Mel. loc.

Mirab. pol.

Non.

Oecol. 1Joh.

Oecol. Rom.

Orig. in Exod.

Orig. in Jos.

Orig. Rom.
David Kimchi, Commentary upon the Prophecies of Zechariah, hg. von David Alexander McCaul, London 1837.

Kurtzer unnd warhaffter Bericht unnd Vergriff der unbillichen Gewalts unnd Schmaachhandlungen, so einer loblichen Statt Zürich und andern jren Mitverwandten der christenlichen Burgerstettenn der Eydtgnoschafft sidt jüngst uffgerichten Landtsfriden hăr und dem selben zůwider von jren Eydtgnossen der Fünff Orten Lucern, Ury, Schwytz, Underwalden unnd Zug zůgefügt, Zürich: Christoph Froschauer d.Ä., 1531 (BZD C 200).

L. Caelius Firmianus Lactantius, Divinae institutiones, hg. von Samuel Brandt, Wien 1890 (CSEL XIX/1-2).

Liturgia Basilii [9. Jh.], in: Liturgies Eastern and Western, hg. von F. E. Brightman, Bd. 1: Eastern Liturgies, Oxford 1896, 309-344.

Lucretius, De rerum natura, hg. von Cyril Bailey, Oxford 1997 (Scriptorum classicorum bibliotheca Oxoniensis).

Martin Luther, Enarratio in priorem d[ivi] Petri epistolam, in: ders., Enarrationes in epistolas d[ivi] Petri duas et Iudae unam, Straßburg: Johannes Herwagen d.Ä., 1524 (VD16 L 4599), [2]v-112v.

Martin Luther, Enarratio in priorem d[ivi] Petri epistolam, in: ders., Enarrationes in epistolas d[ivi] Petri duas et Iudae unam, Straßburg: Johannes Herwagen d.̈̈., 1524 (VD16 L 4599), 113r-150v.

Martin Luther, Enarratio in d[ivi] Iudae epistolam, in: ders., Enarrationes in epistolas d[ivi] Petri duas et Iudae unam, Straßburg: Johannes Herwagen d. Ä., 1524 (VD16 L 4599), 151r-164r.

Martin Luther, Ad librum eximii magistri nostri magistri Ambrosii Catharini, defensoris Silvestri Prieratis acerrimi, responsio, Weimar 1897 (WA VII 705-778).

Martin Luther, Vorrhede auff die Episteln Sanct Jacobi unnd Judas, in: D. Martin Luthers Werke. Die Deutsche Bibel, Bd. 7, Weimar 1931, 384.

Martin Luther, Das diese wort Christi (Das ist mein leib etce) noch fest stehen widder die Schwermgeister, Weimar 1901 (WA XXIII 65-283).

Ambrosius Theodosius Macrobius, Saturnalia, hg. von James Willis, Leipzig 1994 (Bibliotheca scriptorum Graecorum et Romanorum Teubneriana).

Ambrosius Theodosius Macrobius, Commentarii in Ciceronis somnium Scipionis, hg. von James Willis, Leipzig 1970 (Bibliotheca scriptorum Graecorum et Romanorum Teubneriana).

Marius Victorinus, Explanationes in Ciceronis Rhetoricam, hg. von Antonella Ippolito, Turnhout 2006 (CCSL CXXXII).

Philipp Melanchthon, Loci communes rerum theologicarum seu hypotyposes theologicae (1521), hg. von Hans Engelland und Robert Stupperich, in: Melanchthons Werke in Auswahl, Bd. II/1, Gütersloh 1978, 16-185.

Domenico Mirabelli, Polyanthea opus suavissimis floribus exornatum, Paris: Josse Bade und Jean Petit, 1512.

Nonius Marcellus, De compendiosa doctrina libri XX, 3 Bde., hg, von Wallace M. Lindsay, Leipzig 1903 (Bibliotheca scriptorum Graecorum et Romanorum Teubneriana).

Johannes Oecolampadius, In Ioannis apostoli catholicam primam demegoriae, Basel: Andreas Cratander, 1524 (VD16 O 345).

Johannes Oecolampadius, In epistolam Pauli ad Rhomanos adnotationes Basel: Andreas Cratander, 1525 (VD16 O 341).

Origenes, In Exodum homiliae, hg. von W. A. Baehrens, Leipzig 1920 (GCS XXIX 145-279).

Origenes, In librum Iesu Nave homiliae, hg. von W. A. Baehrens, Leipzig 1921 (GCS XXX 286-463).

Origenes, Commentarii in epistulam ad Romanos, hg. von Theresia Heither, 6 Bde., Freiburg i.Br. et al. 1990-1999 (Fontes christiani II/1-6). 
Ov. ars

Ov. met.

Pagn. thes.

Pasch. Radb. corp.

Pell. Gen.

Pell. chron.

Petr. Hisp. tract.

Petr. Lomb. in Hebr.

Petr. Lomb. sent.

Philostr. imag.

Pind. Pyth.

Plat. Charm.

Plat. leg.

Plat. Menex.

Plat. Tim.

Plaut. Truc.

Plin. nat.

Plut. mor.

Plut. vit. Lyc.

Ps.-Plut. placit.

Ps.-Plut. placit. transl.

Prop.

Prud. perist.
Publius Ovidius Naso, Ars amatoria, in: Publii Ovidii Nasonis Amores Medicamina faciei femineae - Ars amatoria - Remedia amoris, hg. von E. J. Kenney, Oxford 1961 (Sciptorum classicorum bibliotheca Oxoniensis), 113200.

Publius Ovidius Naso, Metamorphoses, hg. von William S. Anderson, Leipzig 1977 (Bibliotheca scriptorum Graecorum et Romanorum Teubneriana). Sante Pagnini, Thesaurus linguae sanctae, Lyon: Sebastian Gryphius, 1529. Paschasius Radbertus, De corpore et sanguine domini, hg. von Beda Paulus, Turnhout 1969 (CCCM XVI).

Konrad Pellikan, Commentarium [...] in librum Geneseos, in: Commentaria bibliorum [...] Chuonradi Pellicani, Bd. 1, Zürich: Christoph Froschauer d. Ä., 1532 (BZD C 217), 1-66.

Konrad Pellikan, Chronicon, hg. von Bernhard Riggenbach, Basel 1877.

Petrus Hispanus, Tractatus (Summulae logicales), hg. von Lambertus Maria De Rijk, Assen 1972 (Philosophical texts and studies, Universiteit Utrecht XXII).

Petrus Lombardus, Collectanea in epistolam ad Hebraeos (PL CXCII 399_ 520).

Petrus Lombardus, Sententiae in quattuor libris distinctae, hg. von Collegium S. Bonaventurae ad Claras Aquas, 2 Bde., Grottaferrata 1971/1981 (Spicilegium Bonaventurianum IV-V).

Philostratus d. Ä., Imagines, hg. von Arthur Fairbanks, London/Cambridge, MA 1969 (The Loeb Classical Library), 2-270.

Pindarus, Pythia, in: Pindari carmina cum fragmentis, hg. von Hervicus Maehler (post B. Snell), Teil 1, Leipzig 1984 (Bibliotheca scriptorum Graecorum et Romanorum Teubneriana), 59-121.

Platon, Charmides, in: Platonis opera, Bd. 3, hg. von John Burnet, Oxford 1903 (Scriptorum classicorum bibliotheca Oxoniensis).

Platon, Leges, in: Platonis opera, Bd. 5, hg. von John Burnet, Oxford 1907 (Scriptorum classicorum bibliotheca Oxoniensis).

Platon, Menexenos, in: Platonis opera, Bd. 3, hg. von John Burnet, Oxford 1903 (Scriptorum classicorum bibliotheca Oxoniensis).

Platon, Timaeus, in: Platonis opera, Bd. 4, hg. von John Burnet, Oxford 1902 (Scriptorum classicorum bibliotheca Oxoniensis).

Titus Maccius Plautus, Truculentus, in: T. Macci Plauti comoediae, Bd. 2, hg. von W. M. Lindsay, Oxford 1905 (Scriptorum classicorum bibliotheca Oxoniensis), [Ii2]r-[Mm6]r.

C. Plinius Secundus, Naturalis historia, hg. von Ludwig Ianus und Karl Mayhoff, 5 Bde., Leipzig 1892-1909 (Bibliotheca scriptorum Graecorum et Romanorum Teubneriana).

Plutarchus, Moralia, hg. von Frank Cole Babbitt et al., 15 Bde., Cambridge, MA/London 1959-1969 (The Loeb Classical Library).

Plutarchus, Vita Lycurgi, in: Plutarque, Vies, hg. von Robert Flacelière et al., Bd. 1, Paris 1964 (Collection des Universités de France. Série grecque), 120-166.

Pseudo-Plutarchus, Placita philosophorum (Moralia 874D-911B), in: Plutarque, Oeuvres morales, Bd. 12,2: Opinions des philosophes, hg. von Guy Lachenaud, Paris 1993.

Plutarchi Chaeronei de placitis decretisque philosophorum [...] Gulielmo Budaeo [...] interprete, in: Omnia opera Gulielmi Budaei Parisiensis, Bd. 1, Basel: Nikolaus Episcopius d. J., 1557 (VD16 B 9075), 511-539.

Sextus Propertius, Carmina, hg. von E. A. Barber, Oxford 1953 (Scriptorum classicorum bibliotheca Oxoniensis).

Aurelius Prudentius Clemens, Liber peristefanon, in: Aurelii Prudentii Clementis carmina, hg. von Maurice P. Cunningham, Turnhout 1966 (CCSL CXXVI 251-389). 
Quint. inst.

Reuch. quaest. Athan.

Rhod. lect.

Rufin. hist.

Rufin. symb.

Sall. Catil.

Sen. Ag.

Sen. dial.

Sen. epist.

Sol.

Soph. frag

Soz. hist.

Strab. geog.

Suet. Cal.

Suet. Tib

Symb. apost.

Symb. Const.

Symb. Nic.

Symb. Quic.

Ter. Ad.

Ter. Andr.

Tert. adv. Iud.

Tert. adv. Marc

Tert. adv. Prax.

Tert. apol.

Tert. carn.
Quintilianus, Institutio oratoria, hg. von M. Winterbottom, 2 Bde., Oxford 1970 (Scriptorum classicorum bibliotheca Oxoniensis).

Johannes Reuchlin, Liber S. Athanasii de variis quaestionibus nuper e Graeco in Latinum traductus [...]. Adhuc item annotationes Capnionae, Hagenau: Thomas Anshelm, 1519 (VD16 A 3996).

Ludovicus Coelius Rhodiginus, Lectionum antiquarum libri XVI, Basel: Johannes Froben, 1517 (VD16 R 2163)

Tyrannius Rufinus, Eusebii historia ecclesiastica translata et continuata, hg. Eduard Schwartz und Theodor Mommsen, Berlin 1903-1908 (GCS IX/1-2). Tyrannius Rufinus, Expositio symboli, hg. von Manlio Simonetti, Turnhout 1961 (CCSL XX 133-182).

C. Sallustius Crispus, Catilinae coniuratio, in: C. Sallusti Crispi Catilina, Iugurtha, Fragmenta ampliora, hg. von Alphons Kurfess, Stuttgart/Leipzig 1991 (Bibliotheca scriptorum Graecorum et Romanorum Teubneriana), 2-52. Lucius Anneus Seneca, Agamemno, in: Seneca, Tragedies II, hg. von Frank Justus Miller, London/Cambridge, MA 1968 (The Loeb Classical Library), 4-86.

Lucius Annaeus Seneca, Dialogorum libri XII, hg. von Emil Hermes, Leipzig 1923 (L. Annaei Senecae opera quae supersunt I/1).

Lucius Annaeus Seneca, Epistulae morales ad Lucilium, hg. von Otto Hense, Leipzig 1914 (L. Annaei Senecae opera quae supersunt III).

Caius Iulius Solinus, Collectanea rerum memorabilium, hg. von Theodor Mommsen, Berlin 1895.

Sophocles, Deperditarum fabularum fragmenta, in: Tragicorum Graecorum Fragmenta, Bd. 4: Sophocles, hg. von Stefan Radt, Göttingen ${ }^{2} 1999,99-656$. Sozomenos, Historia ecclesiastica, hg. von Joseph Bidez und Günther Christian Hansen, Berlin 1960 (GCS L).

Strabo, Geographica, hg. von Horace Leonard Jones, 8 Bde., Cambridge, MA/London 1960-1970 (The Loeb Classical Library).

C. Suetonius Tranquillus, Caius Caligula, in: C. Suetoni Tranquilli opera, Bd. 1: De vita Caesarum libri VIII, hg. von Maximilian Ihm, Leipzig/Berlin 1923 (Bibliotheca scriptorum Graecorum et Romanorum Teubneriana), 153189.

C. Suetonius Tranquillus, Tiberius, in: C. Suetoni Tranquilli opera, Bd. 1: De vita Caesarum libri VIII, hg. von Maximilian Ihm, Leipzig/Berlin 1923 (Bibliotheca scriptorum Graecorum et Romanorum Teubneriana), 118-161. Symbolum apostolicum (DH 30).

Symbolum Constantinopolitanum (DH 150)

Symbolum Nicaenum (DH 125f.).

Symbolum »Quicumque « pseudo-Athanasianum (DH 75-76)

Terentius, Adelphoe, in: P. Terenti Afri comoediae, hg. von Sextus Prete, Heidelberg 1954, 351-398.

Terentius, Andria, in: P. Terenti Afri comoediae, hg. von Sextus Prete, Heidelberg 1954, 55-110.

Quintus Septimius Florens Tertullianus, Adversus Iudaeos, hg. von Emil Kroymann, Turnhout 1954 (CCSL II 1339-1396).

Quintus Septimius Florens Tertullianus, Adversus Marcionem, hg. von Emil Kroymann, Turnhout 1954 (CCSL I 441-726).

Quintus Septimius Florens Tertullianus, Adversus Praxean, hg. von Emil Kroymann und Ernest Evans, Turnhout 1954 (CCSL II 1159-1205).

Quintus Septimius Florens Tertullianus, Apologeticum, hg. von E. Dekkers, Turnhout 1954 (CCSL I 85-171).

Quintus Septimius Florens Tertullianus, De carne Christi, hg. von Emil Kroymann, Turnhout 1954 (CCSL II 873-917). 
Tert. mart.

Tert. praescr.

Theod. Stud. coel. Theophyl. 2Tim. transl.

Theophyl. Hebr. transl.

Thom. Aqu. off. corp. Urb. inst.

Vad. epit.

Vel. Petr.

Verg. Aen.

Verg. ecl.

Ps.-Vigil. Thaps. trin Volat. comm.

ZBib 1531

Zw. act.

Zw. am. exeg.

Zw. antw. Luth

Zw. elench.

Zw. epich.

Zw. Exod.

Zw. fid. exp.

Zw. Gen.

Zw. Iac.

Zw. Ier.

Zw. Isa.
Quintus Septimius Florens Tertullianus, Ad martyras, hg. von E. Dekkers, Turnhout 1954 (CCSL I 3-8).

Quintus Septimius Florens Tertullianus, De praescriptione haereticorum, hg. von R. François Refoulé, Turnhout 1954 (CCSL I 187-224).

Theodoros Studites, In coelestium ordinum coetum (PG XCIX 729-748).

Theophylactus von Achrida, In secundam epistolam ad Timotheum enarratio, in: Theophylactus, In omnes d[ivi] Pauli epistolas enarrationes, diligenter recognitae Christophoro Persona Romano interprete, Köln: Peter Quentel, 1529 (VD16 B 4995), 131r-137v.

Theophylactus von Achrida, In epistolam ad Hebraeos enarratio, in: Theophylactus, In omnes d[ivi] Pauli epistolas enarrationes, diligenter recognitae Christophoro Persona Romano interprete, Köln: Peter Quentel, 1529 (VD16 B 4995), 142v-169v.

Thomas Aquinas, Officium de festo corporis Christi (STO VI 580f.).

Urbano Dalle Fosse (Bolzanio), Institutiones Graecae grammatices, Venedig: Aldo Manuzio, 1497.

Joachim Vadianus, Epitome trium terrae partium, Zürich: Christoph Froschauer d.Ä., 1534 (BZD C 233).

Ulrichus Velenus, In hoc libello gravissimis certissimisque et in sacra scriptura fundatis rationibus variis probatur apostolum Petrum Romam non venisse, Basel: Andreas Cratander, 1520 (VD16 V 505).

P. Vergilius Maro, Aeneis, in: Publii Vergilii Maronis opera, hg. von Roger Aubrey Baskerville Mynors, Oxford 1969, 103-422.

P. Vergilius Maro, Eclogae sive Bucolica, in: Publii Vergilii Maronis opera, hg. von Roger Aubrey Baskerville Mynors, Oxford 1969, 1-28.

Pseudo-Vigilius Thapsensis, De trinitate libri duodecim (PL LXII 237-334). Raphael Volaterranus [Raffaele Maffei], Commentariorum urbanorum libri XXXVIII, in: Id., Commentariorum urbanorum libri XXXVIII. Item Oeconomicus Xenophontis ab eodem Latio donatus, Basel: Johannes Froben, 1530 (VD16 M 114), 3r-459r.

Die gantze Bibel der ursprünglichen Ebraischen und Griechischen waarheyt nach auffs treüwlichest verteütschet, Zürich: Christoph Froschauer d.Ä., 1531 (VD16 B 2690).

Huldrych Zwingli, Action oder bruch des nachtmals, hg. von Georg Finsler, Leipzig 1927 (Z IV 13-24).

Huldrych Zwingli, Amica exegesis, id est expositio eucharistiae negocii, ad Martinum Lutherum, hg. von Oskar Farner, Leipzig 1934 (Z V 562-758).

Huldrych Zwingli, Uber D. Martin Luters bůch, bekentnuß genant, zwo antwurten, hg. von Joachim Staedtke, Zürich 1968 (Z VI/2 22-248).

Huldrych Zwingli, In catabaptistarum strophas elenchus, hg. von Walther Köhler, Zürich 1961 (Z VI/1 21-196).

Huldrych Zwingli, De canone missae epicheresis, hg. von Georg Finsler, Leipzig 1908 (Z II 556-608).

Huldrych Zwingli, In Exodum alia farraginis annotationum particula, hg. von Oskar Farner, Zürich 1963 (Z XIII 294-426).

Huldrych Zwingli, Christianae fidei brevis et clara expositio ad regem christianum, hg. von Fritz Büsser, Zürich 1991 (Z VI/5 50-162).

Huldrych Zwingli, Farrago annotationum in Genesin, hg. von Oskar Farner, Zürich 1963 (Z XIII 5-288).

Huldrych Zwingli, Brevis et luculenta in epistolam beati Iacobi expositio, hg. von Max Lienhard und Daniel Bolliger, Zürich 2013 (Z XXI 361-418). Huldrych Zwingli, Complanationis Ieremiae prophetae foetura prima, hg. von Oskar Farner, Zürich 1956 (Z XIV 417-679).

Huldrych Zwingli, Complanationis Isaiae prophetae foetura prima, hg. von Oskar Farner, Zürich 1956 (Z XIV 5-410). 
Zw. rel.

Zw. ußleg.
Huldrych Zwingli, De vera et falsa religione commentarius, hg. von Walther Köhler, Leipzig 1914 (Z III 628-911).

Huldrych Zwingli, Ußlegen und gründ der schlußreden oder articklen, hg. von Georg Finsler, Leipzig 1908 (Z II 14-457).

\section{Reihen, Quellensammlungen, Bibliographien, Lexika und weitere Nachschlagewerke}

\section{ASD \\ AtH \\ AugL \\ BBKL \\ BZD \\ CCCM \\ CCSL \\ CSEL \\ $\mathrm{CoE}$}

CR

DH

GCS

HBBibl I

HBBibl III

HBBW

HBTS

HLR

HLS

HISMA

HWR

LMA

LThK $^{3}$
Omnia opera Desiderii Erasmi Roterodami, Amsterdam et al. 1969ff.

Athanasius Handbuch, hg. von Peter Gemeinhardt, Tübingen 2011.

Augustinus-Lexikon, hg. von Cornelius Mayer et al., Basel 1994ff.

Biographisch-bibliographisches Kirchenlexikon, hg. von Friedrich Wilhelm Bautz et al., Hamm et al. 1975ff.

Bibliographie der Zürcher Druckschriften des 15. und 16. Jahrhunderts, hg. von Manfred Vischer, Baden-Baden 1991 (Bibliotheca bibliographica Aureliana CXXIV).

Corpus Christianorum. Continuatio mediaevalis, Turnhout 1959ff.

Corpus Christianorum. Series Latina, Turnhout 1953ff.

Corpus scriptorum ecclesiasticorum Latinorum, Wien 1866ff.

Contemporaries of Erasmus. A Biographical Register of the Renaissance and the Reformation, 3 Bde., hg. von Peter G. Bietenholz und Thomas B. Deutscher, Toronto et al. 1985/1987.

Corpus Reformatorum, hg. von Karl Gottlieb Bretschneider et al., Berlin et al. 1834-2012.

Enchiridion symbolorum definitionum et declarationum de rebus fidei et morum / Kompendium der Glaubensbekenntnisse und kirchlichen Lehrentscheidungen, hg. von Heinrich Denzinger und Peter Hünermann, Freiburg i. Br. et al. ${ }^{37} 1991$.

Die griechischen christlichen Schriftsteller der ersten Jahrhunderte, Leipzig et al. $1897 \mathrm{ff}$.

Heinrich Bullinger Bibliographie, Bd. 1: Beschreibendes Verzeichnis der gedruckten Werke von Heinrich Bullinger, bearb. von Joachim Staedtke, Zürich 1972 (Heinrich Bullinger Werke, Erste Abt., Bibliographie).

Heinrich Bullinger Bibliographie, Bd. 3. Heinrich Bullinger Privatbibliothek, bearb. von Urs B. Leu und Sandra Weidmann, Zürich 2004 (Heinrich Bullinger Werke, Erste Abt., Bibliographie).

Heinrich Bullinger Werke. Zweite Abteilung: Briefwechsel, hg. vom Zwingliverein Zürich, Zürich 1973ff.

Heinrich Bullinger Werke. Dritte Abteilung: Theologische Schriften, hg. vom Zwingliverein Zürich et al., Zürich 1983ff.

Heinrich Lausberg, Handbuch der literarischen Rhetorik. Eine Grundlegung der Literaturwissenschaft, München 1960.

Historisches Lexikon der Schweiz, Chefred. Marco Jorio, Basel $2002 \mathrm{ff}$.

Peter Stotz, Handbuch zur lateinischen Sprache des Mittelalters, 5 Bde., München 2002-2004 (Handbuch der Altertumswissenschaft II/5.1-5).

Historisches Wörterbuch der Rhetorik, hg. von Gerd Ueding et al., Tübingen 1992-2012.

Lexikon des Mittelalters, hg. von Norbert Angermann et al., 9 Bde., München 1980-1999.

Lexikon für Theologie und Kirche, hg. von Walter Kasper, 11 Bde., Freiburg i. Br. et al. ${ }^{3} 1993-2001$. 


\begin{abstract}
MBBW
NP

PG

PL

PRE

PTS

Quasten

RTAJ

$\mathrm{SC}$

SI

STO

TPMA

TRE

VD16

WA

Z

Martin Bucer Briefwechsel, hg. von Jean Rott et al., Leiden 1979ff. (Martini Buceri opera omnia III/1ff.).

Der Neue Pauly. Enzyklopädie der Antike, hg. von Hubert Candcik und Helmuth Schneider, 16 Bde., Stuttgart 1996-2003.

Patrologia Graeca, hg. von J[acques] P[aul] Migne, 162 Bde. und 1 Bd. Verzeichnisse, Paris 1857-1912.

Patrologia Latina, hg. von J[acques] P[aul] Migne, 217 Bde. und 4 Bde. Verzeichnisse, Paris 1878-1890.

Real-Encyclopädie der classischen Althertumswissenschaft in alphabetischer Ordnung, hg. von August Pauly und Georg Wissowa, 66 Halbbde., 15 Supplementbde., Register, Stuttgart 1894-1980.

Patristische Texte und Studien, Berlin et al. 1964ff.

Johannes Quasten, Patrology, 4 Bde., Notre Dame, IN 1986.

Deutsche Reichstagsakten. Jüngere Reihe, hg. durch die Historische Kommission bei der Bayerischen Akademie der Wissenschaften, Göttingen $1962 \mathrm{ff}$.

Sources chrétiennes, Paris $1942 \mathrm{ff}$.

Schweizerisches Idiotikon. Wörterbuch der schweizerdeutschen Sprache, Frauenfeld 1881ff.

S[ancti] Thomae Aquinatis opera omnia, hg. von Roberto Busa, 7 Bde., Stuttgart- Bad Cannstatt 1980.

Thesaurus proverbiorum medii aevi, begr. von Samuel Singer, hg. vom Kuratorium Singer der Schweizerischen Akademie der Geistes- und Sozialwissenschaften, 13 Bde. und Quellenverzeichnis, Berlin 1995-2002.

Theologische Realenzyklopädie, hg. von Gerhard Krause und Gerhard Müller, 36 Bde., Berlin/New York 1977-2004.

Verzeichnis der im deutschen Sprachbereich erschienenen Drucke des 16. Jahrhunderts: VD16, 22 Bde., Stuttgart 1983-1995.

D. Martin Luthers Werke. Kritische Gesamtausgabe (Weimarer Ausgabe), 67 Bde., Weimar 1883-1997.

Huldreich Zwinglis Sämtliche Werke, hg. von Emil Egli et al., Berlin et al., 1905-2012 (CR LXXXVIII-CVIII).
\end{abstract}

\section{Literatur}

Adalma 1965

Backus 2004

Baschera 2012

Baschera 2017

Beutel 1991

J. A. de Adalma, Repertorium Pseudochrysostomicum, Paris 1965 (Documents, études et répertoires publiés par l'Institut de Recherche et d'Histoire des Textes $\mathrm{X}$ ).

Irena Backus, Bullinger als Neutestamentler. Sein Kommentar zu den Paulusbriefen und den Evangelien, in: Heinrich Bullinger und seine Zeit. Eine Vorlesungsreihe, hg. von Emidio Campi, Zürich 2004 (Zwingliana XXXI), 105-131.

Luca Baschera, Einleitung, in: Heinrich Bullinger. Kommentare zu den neutestamentlichen Briefen (Röm - 1Kor - 2Kor), hg. von Luca Baschera, Zürich 2012 (HBTS VI LIX-LXXXIII).

Luca Baschera, Fehlverhalten oder Irrtum in der Lehre? Die Deutung des »Apostelstreites« (Gal 2,11-14) und dessen Ursache bei Heinrich Bullinger und Martin Luther, in: Auslegung und Hermeneutik der Bibel in der Reformationszeit, hg. von Christine Christ-von Wedel und Sven Grosse, Berlin 2017 (Historia Hermeneutica. Series Studia XIV), 243-263.

Albrecht Beutel, In dem Anfang war das Wort. Studien zu Luthers Sprachverständnis, Tübingen 1991 (Hermeneutische Untersuchungen zur Theologie XXVII). 
Bonorand 1962

Dobner 2004

Egli 1901

Heller 2005

Hengel 1976

Jahns 1976

Leemans 2005

Moser 2012

Mühling 2001

Posset 2015

Pratsch 1998

Schindler 1965

Sider 1998

Sloan 2010

Staehelin 1939

Steenbek 1996

Stählin 1955

Suchla 2008
Conradin Bonorand, Vadians Weg vom Humanismus zur Reformation und seine Vorträge über die Apostelgeschichte (1523), St. Gallen 1962 (VadianStudien. Untersuchungen und Texte VII).

Hubertus R. Dobner, Lehrbuch der Patrologie, Frankfurt a.M. et al. ${ }^{2} 2004$. Emil Egli, Biographien: Bibliander, Ceporin, Johannes Bullinger, Zürich 1901 (Analecta reformatoria II).

Marvin J. Heller, Earliest Printings of the Talmud, in: Printing the Talmud. From Bomberg to Schottenstein, hg. von Sharon Liberman Mintz und Gabriel M. Goldstein, New York 2005, 61-78.

Martin Hengel, Die Zeloten. Untersuchungen zur jüdischen Freiheitsbewegung in der Zeit von Herodes I. bis 70 n.Chr., Leiden 1976 (Arbeiten zur Geschichte des antiken Judentums und des Urchristentums I).

Sigrid Jahns, Frankfurt, Reformation und Schmalkaldischer Bund. Die Reformations-, Reichs- und Bündnispolitik der Reichsstadt Frankfurt am Main 1525-1536, Frankfurt a.M. 1976 (Studien zur Frankfurter Geschichte IX).

Johan Leemans, Christus Agonothetes. An Exploration of an Agonistic Image to Speak about God and Christ, in: Jesus Christ in the Theology of Gregory of Nyssa. Minutes of the Ninth Conference on St. Gregory of Nyssa (Athens, 7.-12. September 2000), hg. von Elias D. Moutsoulas, Athens 2005, 529-556.

Christian Moser, Die Druckgeschichte von Heinrich Bullingers Kommentaren zu den neutestamentlichen Briefen, in: Heinrich Bullinger. Kommentare zu den neutestamentlichen Briefen (Röm - 1Kor - 2Kor), hg. von Luca Baschera, Zürich 2012 (HBTS VI XI-LVIII).

Andreas Mühling, Heinrich Bullingers europäische Kirchenpolitik, Bern et al. 2001 (Zürcher Beiträge zur Reformationsgeschichte XIX).

Franz Posset, Johann Reuchlin (1455-1522). A Theological Biography, Berlin/Boston 2015 (Arbeiten zur Kirchengeschichte CXXIX).

Thomas Pratsch, Theodoros Studites (759-826) - zwischen Dogma und Pragma. Der Abt des Studiosklosters in Konstantinopel im Spannungsfeld von Patriarch, Kaiser und eigenem Anspruch, Frankfurt a.M. 1998 (Berliner Byzantinische Studien IV).

Alfred Schindler, Wort und Analogie in Augustins Trinitätslehre, Tübingen 1965 (Hermeneutische Untersuchungen zur Theologie IV).

Robert Sider, Erasmus and Ancient Christian Writers. The Search for Authenticity, in: Nova \& Vetera. Patristic Studies in Honor of Thomas Patrick Hamilton, hg. von John Petruccione, Washington, DC 1998, 235-254.

Michael C. Sloan, Aristotle's Nicomachean Ethics as the Original Locus for the Septem Circumstantiae, in: Classical Philology 105/3 (2010), 236-251. Ernst Staehelin, Das theologische Lebenswerk Johannes Oekolampads, Leipzig 1939 (Quellen und Forschungen zur Reformationsgeschichte XXI). Andrea W. Steenbek, Introduction, in: Apologia ad Iacobum Fabrum Stapulensem, hg. von Andrea W. Steenbek, Amsterdam et al. 1996 (ASD IX/3), $1-76$.

Rudolf Stählin, Die Geschichte des christlichen Gottesdienstes von der Urkirche bis zur Gegenwart, in: Leiturgia. Handbuch des evangelischen Gottesdienstes, hg. von Karl Ferdinand Müller und Walter Blankenburg, Bd. 1: Geschichte und Lehre des evangelischen Gottesdienstes, Kassel 1955, 1-80. Beate Regina Suchla, Dionysius Areopagita. Leben - Werk - Wirkung, Freiburg i.Br. et al. 2008. 


\section{BIBELSTELLENREGISTER}

Das Register verzeichnet die in den Editionsteilen angeführten Bibelstellen. Nicht berücksichtigt sind Verweise auf und Zitate aus Hebr, Jak, 1-2Petr, 1-3Joh und Jud in den entsprechenden Kommentaren. Die abweichende Psalmenzählung der Vulgata und der Septuaginta ist nur im Falle einer expliziten Verwendung dieser Zählung durch Bullinger angegeben.

\begin{tabular}{|c|c|c|c|}
\hline Genesis (Gen) & & 47,31 & 153 \\
\hline 1,1 & 311 & $48,8-16$ & 153 \\
\hline $1,9 \mathrm{f}$. & 302 & 48,16 & 391 \\
\hline 2,18 & 237 & 49,10 & $196 \mathrm{f}$. \\
\hline 2,24 & 166 & $50,24 \mathrm{f}$ & 153 \\
\hline 3,15 & 107,193 & & \\
\hline 3,17 & 55 & Exodus (Ex) & \\
\hline $4,1-8$ & 148 & 2,2 & 154 \\
\hline 4,8 & 446 & 3,8 & 107 \\
\hline $5,21-24$ & 148 & $12,3-14$ & 210 \\
\hline $6,5-22$ & 150 & $13,17-14,31$ & 444 \\
\hline $7,13-17$ & 292 & $16,32-34$ & 114 \\
\hline 8,21 & 43 & $18,13-27$ & 171 \\
\hline $12,1-4$ & 150 & 19,5 & 222 \\
\hline $12,1-28$ & 155 & $19,5 \mathrm{f}$. & 222 \\
\hline 12,3 & 239 & $19,16-19$ & 163 \\
\hline $13,17-14,31$ & 155 & 20,3 & 107 \\
\hline $14,18-20$ & 89,95 & 20,5 & 417 \\
\hline 14,20 & 92 & 20,14 & 167 \\
\hline 17,1 & 106f., 145, 193, 316, & 20,17 & 167,399 \\
\hline & 367 & 21,6 & 128 \\
\hline 17,7 & 106,193 & $22,10 f$. & 86 \\
\hline 17,10 & 107 & $24,3-8$ & 121 \\
\hline 17,13 & 108 & $25,8 \mathrm{f}$ & 65 \\
\hline $18,1-16$ & 166 & $25,10-22$ & 114 \\
\hline 18,12 & 236 & 25,16 & 322 \\
\hline $19,1-29$ & 166 & $25,23-28$ & 113 \\
\hline $19,4-25$ & 444 & 25,31 & 112 \\
\hline $19,23-25$ & 293 & $25,31-40$ & 112 \\
\hline $21,1-8$ & 151 & 25,37 & 112 \\
\hline 22,1 & 381 & 25,40 & 105 \\
\hline 22,2 & 152,406 & 26,33 & 111 \\
\hline $22,9-12$ & 406 & 26,36 & 112 \\
\hline $22,11 \mathrm{f}$ & 408 & 29,36 & 233 \\
\hline 22,12 & 355,406 & 30,1 & 114 \\
\hline 22,16 & 345 & 30,3 & 114 \\
\hline 22,18 & 94,107 & 30,6 & 114 \\
\hline $25,29-34$ & 162 & 32,19 & 114 \\
\hline 26,4 & 94 & 33,3 & 126 \\
\hline $27,27-29$ & 153 & 33,20 & 356 \\
\hline 27,37 & 162 & 34,14 & 417 \\
\hline $27,39 \mathrm{f}$ & 153 & $34,27 f$. & 114 \\
\hline 33,18 & 91 & & \\
\hline $39,7-10$ & 329 & & \\
\hline
\end{tabular}


Leviticus (Lev)

$$
8
$$

9,1-4

11

$14,4 \mathrm{f}$.

$16,5-10$

16,11

$16,12 \mathrm{f}$

16,15

16,17

19,2

19,18

19,32

20,26

24,5-9

25,8

Numeri (Num)

12,7

12,8

12,10

13,2-15

13,16

14

$14,6-10$

14,29

14,35

14,45

$16,1-3$

$16,8-35$

$16,31-33$

$16,31 \mathrm{f}$

16,35

17,14

17,23-25

$18,21-28$

19

$19,1-5$

$19,2-9$

19,6

19,9

20,23-29

$22,6 \mathrm{f}$.

22,12

22,22-35

22,28-30

24,24

25,9

$26,55 \mathrm{f}$.

28,3-8

Deuteronomium (Dtn)

$\begin{array}{ll}4,24 & 165,417 \\ 6,4 & 25 \\ 6,5 & 434\end{array}$

6,13

$6,15 \quad 417$

6,17f. $\quad 388$

$7,26 \quad 250$

8,17 f. $\quad 402$

$9,19 \quad 163$

$10,17-19 \quad 388$

$17,6 \quad 139$

$18,19 \quad 52$

$19,15 \quad 364$

24,14f. $\quad 422$

28,28 f. $\quad 280$

$32,6 \quad 328$

$32,35 \quad 232$

32,35 f. $\quad 140$

$32,39 \quad 25$

Josua (Jos)

1,5

2,1-21 155

2,1-24 408

$3 \quad 60$

5,13-15 36

6,1-16 155

$6,20 \quad 155$

$12 \quad 155$

Richter (Ri)

$\begin{array}{ll}3,31 & 156 \\ 4,14-16 & 155 \\ 7,15 & 155 \\ 11,29-40 & 155 \\ 14,5 \mathrm{f} . & 155 \\ 14,19 & 155 \\ 15,8 & 156\end{array}$

1. Samuel (1Sam)

$\begin{array}{ll}7,15 & 155 \\ 9,1-31,5 & 4 \\ 12 & 155 \\ 14,1-15 & 156 \\ 15,22 \mathrm{f} . & 57 \\ 15,35 & 451 \\ 17,34 \text { f. } & 155 \\ 17,37 & 155 \\ 22,16-19 & 156 \\ 24,15 \text { f. } & 155 \\ & \\ \text { Samuel (2Sam) } & \\ 7,11 & 107 \\ 7,14 & 31 \\ 8 & 155 \\ 12,7-15 & 345\end{array}$


1. Könige (1Kön)

$\begin{array}{ll}1,30 & 29 \\ 8,46 & 318 \\ 16,28-22,40 & 4 \\ 16,29-32 & 92 \\ 17,1 & 428 \\ 18,1 & 428 \\ 18,13 & 156 \\ 18,40 & 264 \\ 18,42-45 & 428 \\ 19,10 & 156 \\ 21,13 \mathrm{f} . & 156 \\ 22,26 \mathrm{f} . & 156 \\ 22,41-51 & 4\end{array}$

2. Könige (2Kön)

$$
4,34 \mathrm{f} \text {. }
$$

12,3

17,6

$18,1-20,21$

22,1-23,29

22,8

$22,19 \mathrm{f}$.

$23,2 \mathrm{f}$.

23,21-23

23,29

24,17-20

25,11

\section{6}

4

184,376

4, 255

4, 255

7

7

7

7

7

4

184, 376

1. Chronik (1Chr)

$\begin{array}{ll}11 & 156 \\ 20 & 155 \\ \text { Chronik (2Chr) } & \\ 5,10 & 114 \\ 14 & 156 \\ 20 & 156 \\ 24,20-22 & 4 \\ 24,20 \mathrm{f} . & 6,156 \\ 26,16-21 & 96 \\ 31,4-7 & 94\end{array}$

Nehemia (Neh)

$$
5,14
$$

200

Ester (Est)

$$
\text { 5-7 }
$$

\section{Hiob}

$\begin{array}{ll}4,17 & 318 \\ 4,17-19 & 292 \\ 7,1 & 157,248,401 \\ 42,10-15 & 424\end{array}$

\section{Psalmen (Ps)}

$\begin{array}{ll}1,1 & 301 \\ 1,1 \mathrm{f} . & 323 \\ 2,2 & 206 \\ 2,7 & 30,68,206\end{array}$

$2,9 \quad 262$

$6,5 \quad 156$

$6,10 \quad 156$

$8,6 \quad 40 f$.

$14,1 \quad 149$

15 (Vulg. 14), 1316

15 (Vulg. 14),1-5 209

15 (Vulg. 14),2-5 388

15 (Vulg. 14), 4

16 (Vulg. 15),2-6 206

18 (Vulg. 17),2f. 220

18 (Vulg. 17), $3 \quad 44$

19 (Vulg. 18), $13 \quad 368$

22,1-32 206

$22,9 \quad 232$

$22,22 \quad 440$

22,23 44

24 (Vulg. 23),2-5 388

24 (Vulg. 23), $4 \quad 316$

31 (Vulg. 30), $2 \quad 319$

32 (Vulg. 31), $1 \mathrm{f.} \quad 319$

34 (Vulg. 33),9 217

34 (Vulg. 33),13-17 239

34 (Vulg. 33),13f. 240

$34,15 \quad 240$

34,16f. $\quad 240$

$35,24 \quad 319$

37 (Vulg. 36),1-4 179

$37,2 \quad 380$

$37,37 \quad 107$

40 (Vulg. 39),7-9 128

44,22 179

44 (Vulg. 43),22 402

45 (Vulg. 44), 7 f. $\quad 32$

$45,8 \quad 32$

50 (Vulg. 49),12f. 194

50 (Vulg. 49), $14 \quad 170$

$50,17 \quad 223$

$51,7 \quad 383$

$55,5 \quad 167$

$55,10 \quad 167$

63 (Vulg. 62),12 87

66 (Vulg. 65),10-12 190

$78,58 \quad 417$

82 (Vulg. 81),3f. 228

90,3-7 303

$90,5 \quad 380$

90 (Vulg. 89),6-9 331

94 (Vulg. 93),9 348

$95,7 \quad 56$ 


\begin{tabular}{|c|c|c|c|}
\hline 95 (Vulg. 94),7-11 & 54 & Kohelet (Koh) & \\
\hline $95,7 \mathrm{f}$ & $59 \mathrm{f}$. & $3,19-4,8$ & 331 \\
\hline 95,11 & $59 \mathrm{f}$. & 3,22 & 334 \\
\hline 96,3 & 223 & $10,5-7$ & 267 \\
\hline 97,7 & 31 & & \\
\hline 97,12 & 351 & Jesaja (Jes) & \\
\hline 99,9 & 351 & 1,12 & 388 \\
\hline 100,4 & 351 & $1,15-17$ & 418 \\
\hline 101,5 & 257 & $1,16 \mathrm{f}$ & 388 \\
\hline 102 (Vulg. 101),26-28 & 33 & $2,1-5$ & 163 \\
\hline 103 (Vulg. 102),8f. & 186 & 2,13 & 298 \\
\hline 103,13 & 328 & $5,8-24$ & 249 \\
\hline $103,15 \mathrm{f}$ & 380 & $6,2 \mathrm{f}$ & 36 \\
\hline 104,4 & $34-36$ & $8,12 \mathrm{f}$. & 241 \\
\hline 104 (Vulg. 103),4 & 32 & 8,14 & 205 \\
\hline 105,1 & 351 & $8,14 \mathrm{f}$. & 221 \\
\hline 106,1 & 170 & 8,18 & 44,205 \\
\hline 110 & 24 & 9.5 & 25 \\
\hline 110 (Vulg. 109),1 & $27,34,41,199$ & 11,1 & 130 \\
\hline 110 (Vulg. 109),1-7 & 206 & $11,1-5$ & 32 \\
\hline 110 (Vulg. 109), 4 & $68,75,95-97,99$ & 11,2 & 364 \\
\hline 115,1 & 407 & 11,10 & 196 \\
\hline 116 (Vulg. 115),8 & 170 & 14,11 & 267 \\
\hline 116 (Vulg. 115),11 & 319 & 22,13 & 301 \\
\hline 118 (Vulg. 117), 6 & 167 & 28,1 & 33 \\
\hline 118,22 & 130 & 28,4 & 33 \\
\hline 118 (Vulg. 117),22f. & 198,221 & $28,14-16$ & 220 \\
\hline 118,23 & 224 & 28,16 & $130,198,205$ \\
\hline 119,105 & 112 & 29,13 & 98 \\
\hline 119 (Vulg. 118),105 & 286 & $29,15 f$ & 63 \\
\hline $121,1-8$ & 268 & $33,11 \mathrm{f}$. & 165 \\
\hline 127,1 & 401 & 33,14 & 165,316 \\
\hline 132,11 & 24 & 35,10 & 61 \\
\hline 141,2 & 114 & 38 & 156 \\
\hline 143,2 & 319 & $40,6-8$ & 214,225 \\
\hline $146,3-6$ & 4 & $40,6 \mathrm{f}$ & 380 \\
\hline $146,5-9$ & 268 & 40,8 & 297 \\
\hline \multirow[t]{2}{*}{$147,19 \mathrm{f}}$. & 20 & 42,1 & 130,205 \\
\hline & & 42,8 & 73 \\
\hline prüche (Spr) & & $43,10-13$ & 28 \\
\hline 1,7 & 358 & 43,11 & 25 \\
\hline $3,11 \mathrm{f}$. & 159 & 43,13 & 25 \\
\hline 3,21 & 37 & 43,21 & 223 \\
\hline 8,13 & 267 & 45,5 & 26 \\
\hline 10 & 348 & 45,18 & 26 \\
\hline 11,16 & 236 & 45,23 & 87 \\
\hline 11,22 & 236 & $49,1 \mathrm{f}$. & 63 \\
\hline 11,31 & 259 & $49,14-21$ & 241 \\
\hline 15 & 348 & 50,1 & 201 \\
\hline 25,21 & 421 & 51 & 259 \\
\hline 26,11 & 300 & $51,6-8$ & 353 \\
\hline 28,15 & 268 & $51,6-11$ & 241 \\
\hline \multirow[t]{3}{*}{31,30} & 236 & 51,11 & 61 \\
\hline & & 52,14 & 47 \\
\hline & & 53,1 & 223 \\
\hline
\end{tabular}




\begin{tabular}{|c|c|c|c|}
\hline 53,3 & 47,49 & 44,17 & 301 \\
\hline $53,4 \mathrm{f}$. & $232 \mathrm{f}$ & $52,1-11$ & 4 \\
\hline 53,5 & 130 & & \\
\hline 53,6 & $110,130,233,244$ & Klagelieder (Klgl) & \\
\hline 53,8 & 91 & $1-5$ & 451 \\
\hline 53,9 & 232 & & \\
\hline $56,10 \mathrm{f}$. & 264 & Ezechiel (Ez) & \\
\hline $57,15 f$ & 358 & $3,16-21$ & 171 \\
\hline 57,20 & 449 & 8,3 & 417 \\
\hline $58,5-7$ & 85 & 10 & 115 \\
\hline $58,6 \mathrm{f}$. & 388 & $13,1-16$ & 264 \\
\hline 59,10 & 280 & $16,10-13$ & 249 \\
\hline 60,1 & 223 & $18,5-9$ & 52 \\
\hline 61 & 32 & 18,23 & 429 \\
\hline 61,1 & 33,364 & 18,24 & 435 \\
\hline 63,16 & 101,328 & $18,30-32$ & 388 \\
\hline 64,3 & 269 & $22,7 \mathrm{f}$ & 388 \\
\hline 64,8 & 328 & $22,10 \mathrm{f}$. & 249 \\
\hline 65,16 & 87 & 34,1 & 71 \\
\hline $65,17-25$ & 304 & $34,2-10$ & 261 \\
\hline 66,2 & 218 & $34,11-16$ & 233 \\
\hline $66,3 \mathrm{f}$. & 217 & $36,24-32$ & 209 \\
\hline $66,10 \mathrm{f}$. & 216 & & \\
\hline $66,14-16$ & 81 & Daniel (Dan) & \\
\hline 66,15 & 139 & 2,34 & 198,205 \\
\hline $66,15 \mathrm{f}$ & 302 & $2,34 \mathrm{f}$. & 130 \\
\hline 66,19 & 223 & 2,44 & 198 \\
\hline \multirow[t]{2}{*}{66,21} & $217 \mathrm{f}$. & 2,45 & 205 \\
\hline & & 3,25 & 156 \\
\hline Jeremia (Jer) & & 6,23 & 155 \\
\hline 2,8 & 264 & 7,10 & 35 \\
\hline 2,30 & 264 & 7,13 & 203 \\
\hline 3,8 & 201 & $7,13 \mathrm{f}$ & $24,203,344$ \\
\hline 5,31 & 264 & 9,2 & 305 \\
\hline $7,5-7$ & 388 & 9,17 & 199 \\
\hline $7,21-23$ & 194 & $9,18 \mathrm{f}$ & 199 \\
\hline 14,14 & 264 & 9,23 & 305 \\
\hline 14,15 & 264 & 9,24 & $33,112,199$ \\
\hline $16,11 \mathrm{f}$. & 7 & $9,24-27$ & 199 \\
\hline 20,2 & 156 & 9,25 & $199 \mathrm{f}$. \\
\hline 22,3 & 422 & 9,26 & 201 \\
\hline $22,3 \mathrm{f}$. & 388 & 9,27 & $201 \mathrm{f}$. \\
\hline 22,30 & 196 & 10,11 & 196,199 \\
\hline 23,4 & 261 & 10,13 & 36 \\
\hline 23,5 & 130,198 & 10,19 & 305 \\
\hline $23,5 \mathrm{f}$. & 24 & 10,21 & 36 \\
\hline $23,9-4$ & 264 & $10 \mathrm{f}$. & 300 \\
\hline $23,9-40$ & 351 & $11,36-39$ & 332 \\
\hline $25,28 \mathrm{f}$ & 258 & 12,1 & 36 \\
\hline 26,3 & 245 & $12,1-3$ & 251 \\
\hline $31,31-34$ & 106,121 & 12,2 & 251 \\
\hline 31,33 & 194 & & \\
\hline $31,33 \mathrm{f}$. & 131 & Hosea (Hos) & \\
\hline 32,2 & 156 & 1,1 & 215 \\
\hline 37,15 & 156 & 1,6 & 224 \\
\hline
\end{tabular}




$\begin{array}{ll}6,6 & 84,170,388 \\ 14,2 & 223 \\ 14,3 & 170,223\end{array}$

Weisheit Salomos (Weish)

14,3

170,223

$7,22 \mathrm{f}$.

353

8,21

399

Amos (Am)

5,27

Jesus Sirach (Sir)

Micha (Mi)

3,1-12

3,5

3,11

$4,1-8$

5,1

6,8

7,3

Habakuk (Hab)

$1,1-4$

$2,3 \mathrm{f}$.

Haggai (Hag)

1,1

2,6

2,8

2,10

2,21

$2,21 \mathrm{f}$.

2,23

Sacharja (Sach)

$$
3,1
$$

3,2

3,3

3,4

3,5

3,8

$3,8 \mathrm{f}$.

3,9

4,6

$6,12 \mathrm{f}$.

6,13

$7,9 \mathrm{f}$.

$8,16 \mathrm{f}$.

9,11

$11,4-17$

11,16

11,17

12,3

13,7

13,7-9

Maleachi (Mal)

1,11

2,6 f.

2,7
108

264

263

179

143

263

163

91

170,388

8

13,1

436

Matthäus (Mt)

$\begin{array}{ll}1,12 & 197 \\ 1,18 & 101 \\ 1,18-23 & 45 \\ 3,2 & 78 \\ 3,9 & 29\end{array}$

$3,17 \quad 30,129$

4,1-11 204

$4,2 \quad 324$

$4,4 \quad 113$

$4,10 \quad 31$

$4,17 \quad 78$

$5,7 \quad 394$

$5,8 \quad 161$

$5,10 \quad 240,424$

$5,10 \mathrm{f} . \quad 380$

$5,11 \mathrm{f} . \quad 142$

$5,12 \quad 179,257$

$5,16 \quad 233,265$

$5,17 \quad 210$

$5,20 \quad 341$

$5,21 \quad 345$

$5,28 \quad 345$

5,33-37 424

$5,44 \quad 427$

$6,8 \quad 268,349$

$6,14 \quad 427$

$6,17 \mathrm{f} . \quad 426$

6,19-21 142

$6,19 \mathrm{f} . \quad 421$

$6,22 \mathrm{f} . \quad 327$

$6,24 \quad 416,418$

$6,32 \quad 167$

$6,33 \quad 420$

$7,1 \mathrm{f} . \quad 419$

$7,3-5 \quad 419$

$7,6 \quad 113,241$

$7,7 \quad 378$

$7,7-11 \quad 349$

$7,8 \quad 378$

$7,13 \quad 290$

$7,24 \quad 386$

7,24 f. $\quad 55,269$

$8,3 \quad 426$

$8,13 \quad 426$

$9,9 \quad 320$

$9,12 \quad 320$

$\begin{array}{ll}9,38 & 171\end{array}$ 


\begin{tabular}{|c|c|c|c|}
\hline 10,3 & 441 & 21,41 & 266 \\
\hline $10,3 \mathrm{f}$. & 441 & 21,42 & 198, 291 \\
\hline 10,10 & 438 & $21,42-44$ & 222 \\
\hline $10,17-22$ & 140 & 21,44 & 225 \\
\hline 10,22 & $85,158,434$ & $22,2-14$ & 224 \\
\hline $10,26-33$ & 351 & $22,11 \mathrm{f}$ & 452 \\
\hline 10,28 & 241 & 22,21 & 229 \\
\hline 10,39 & 269 & 22,30 & $35 \mathrm{f}$ \\
\hline 10,40 & 438 & 22,37 & 325,434 \\
\hline 10,41 & 438 & $22,37-39$ & 384 \\
\hline 10,42 & 439 & $22,37-40$ & $193,359 \mathrm{f}$. \\
\hline 11,5 & 39 & 22,38 & 434 \\
\hline 11,28 & $49,66,320$ & $22,39 \mathrm{f}$ & 325 \\
\hline $11,28-30$ & 8 & 22,40 & 393 \\
\hline 12,18 & 205 & $22,42-45$ & 27 \\
\hline 12,25 & 259 & $22,43-45$ & 199 \\
\hline $12,31 \mathrm{f}$ & 368 & 22,44 & 34 \\
\hline 12,41 & 150 & 23,12 & 418 \\
\hline $12,43-45$ & 299 & 24,13 & $52,85,158,434$ \\
\hline $13,3-23$ & 84 & 24,23 & 125 \\
\hline 13,9 & 341 & 24,24 & 332 \\
\hline 13,24 & 213 & $24,25-27$ & 125 \\
\hline $13,36-43$ & 251 & 24,29 & 304 \\
\hline 13,44 & 136 & $24,42-44$ & 252 \\
\hline 13,46 & 225 & $24,43 \mathrm{f}$ & 304 \\
\hline $14,3-10$ & 6 & $25,14-30$ & 262 \\
\hline 14,4 & 295 & $25,31 \mathrm{f}$ & 34 \\
\hline $15,1-20$ & 361 & $25,31-46$ & $81,84,150,251$ \\
\hline $15,7-11$ & 137 & 25,34 & 294 \\
\hline 15,9 & 98 & $25,34-40$ & 347 \\
\hline 15,14 & 298 & 25,35 & 254 \\
\hline $16,6-12$ & 113 & $25,35 \mathrm{f}$ & 166 \\
\hline 16,17 & 147,361 & 25,40 & $84,388,394$ \\
\hline 16,18 & 220,362 & 25,41 & 45,294 \\
\hline $16,18 \mathrm{f}$. & 181 & 25,43 & 254 \\
\hline 16,24 & 232 & 25,45 & 388 \\
\hline $16,24 \mathrm{f}$. & 259 & $25,45 \mathrm{f}$ & 394 \\
\hline 16,25 & 148 & 26,28 & $108,121,201$ \\
\hline 16,26 & 154,346 & $26,40-45$ & 206 \\
\hline 16,27 & 403,424 & 26,64 & 204 \\
\hline $17,1-13$ & 284 & $26,69-75$ & 206 \\
\hline 17,5 & 21,285 & 26,75 & 320 \\
\hline 17,19 & 400 & $27,42 \mathrm{f}$. & 232 \\
\hline 18,2 & 216 & 27,51 & 202 \\
\hline $18,10-14$ & 429 & $27,52 \mathrm{f}$. & 251 \\
\hline $18,12-14$ & 68 & $28,2 \mathrm{f}$ & 36 \\
\hline $18,21 \mathrm{f}$ & 427 & 28,6 & 48 \\
\hline $19,4-6$ & 166 & $28,13 \mathrm{f}$. & 347 \\
\hline 20,21 & 29 & 28,19 & 26 \\
\hline $20,27 f$ & 130 & & \\
\hline 20,28 & 130 & Markus (Mk) & \\
\hline 21,5 & 90 & 1,4 & 78 \\
\hline $21,12-17$ & 360 & $1,14 \mathrm{f}$ & 38 \\
\hline $21,12 \mathrm{f}$. & 264 & 1,15 & 78 \\
\hline $21,33-41$ & 224 & 2,7 & 27 \\
\hline
\end{tabular}




\begin{tabular}{|c|c|c|c|}
\hline 3,11 & 405 & $15,8-10$ & 244 \\
\hline 3,17 & 309 & 15,10 & 438 \\
\hline 3,18 & $441 \mathrm{f}$. & $15,11-32$ & 244 \\
\hline 4,28 & 55 & $16,19-31$ & 346,423 \\
\hline 6,13 & 426 & 16,22 & 245 \\
\hline 7,7 & 227 & 16,24 & 245 \\
\hline 8,35 & 142 & $17,26-30$ & 294 \\
\hline 8,38 & 337 & $18,11 \mathrm{f}$. & 399 \\
\hline 9,23 & 362 & $19,8-10$ & 320 \\
\hline $9,42-48$ & 81 & $21,14 \mathrm{f}$. & 353 \\
\hline $10,29 \mathrm{f}$. & 142 & 21,19 & 142 \\
\hline 10,52 & 426 & $21,34-36$ & 252 \\
\hline \multirow{2}{*}{13,29} & 424 & 22,19 & 132 \\
\hline & & 22,25 & 228 \\
\hline Lukas (Lk) & & $22,25 \mathrm{f}$ & 264 \\
\hline $1,11-20$ & 36 & 22,27 & 262 \\
\hline $1,26-38$ & 45 & 22,31 & 333 \\
\hline 1,35 & 119 & $22,31-34$ & 181 \\
\hline 1,36 & 151 & $22,56-62$ & 181 \\
\hline 1,52 & 267 & 23,34 & $72,232,427$ \\
\hline 2,12 & 39 & $23,40-42$ & 345 \\
\hline $2,13 \mathrm{f}$. & 36 & $23,42 \mathrm{f}$. & 320 \\
\hline $2,29-31$ & 207 & 23,43 & 117,251 \\
\hline 2,34 & 198,221 & 24,39 & 48 \\
\hline 3,3 & 78 & 24,49 & 28 \\
\hline 3,8 & 297 & 24,51 & 38,105 \\
\hline 3,17 & 333 & & \\
\hline $3,23-38$ & 43 & Johannes (Joh) & \\
\hline 4,34 & 405 & 1,1 & $203,214,311,313$ \\
\hline 5,32 & 320 & $1,1 \mathrm{f}$ & 25 \\
\hline $6,15 \mathrm{f}$ & 441 & 1,2 & 349 \\
\hline 6,16 & 442 & 1,3 & 20 \\
\hline $6,24 \mathrm{f}$. & 418,421 & 1,4 & $24,94,312$ \\
\hline 6,36 & 394 & 1,5 & 223 \\
\hline 6,37 & 394 & 1,9 & 223,317 \\
\hline 6,38 & 394 & 1,10 & 328 \\
\hline 6,46 & 316 & 1,11 & 351 \\
\hline $7,37 \mathrm{f}$ & 426 & 1,12 & 159 \\
\hline $7,47-50$ & 320 & 1,13 & 186 \\
\hline 9,23 & 232 & 1,14 & $25,46,214,278,312 \mathrm{f}$. \\
\hline $9,28-36$ & 284 & & 328 \\
\hline 9,55 & $193 \mathrm{f}$. & 1,17 & 326,363 \\
\hline 10,7 & 263 & 1,18 & 314 \\
\hline $10,23 \mathrm{f}$. & 207 & 1,29 & $110,131,210,233$ \\
\hline $11,24-26$ & 299 & & $317 \mathrm{f}$. \\
\hline 11,28 & 306,386 & 1,32 & 364 \\
\hline $12,15-21$ & 420 & $2,1-10$ & 166,324 \\
\hline 12,20 & 154 & 3,3 & 186,361 \\
\hline 12,35 & 208 & 3,5 & 213 \\
\hline $12,47 \mathrm{f}$. & 420 & $3,5-8$ & 384 \\
\hline $13,6-9$ & 84,281 & $3,5 \mathrm{f}$. & 186 \\
\hline $14,8-11$ & 267 & 3,8 & 213 \\
\hline $14,13 \mathrm{f}$. & 389 & 3,14 & 110 \\
\hline $15,3-7$ & 244 & 3,16 & $193,233,355,357$ \\
\hline $15,4-7$ & 233 & 3,18 & 317 \\
\hline
\end{tabular}




\begin{tabular}{|c|c|c|c|}
\hline 3,21 & 317 & 10,9 & 53 \\
\hline 3,23 & 91 & 10,11 & $205,261,266$ \\
\hline 3,29 & 262 & $10,11-16$ & 233 \\
\hline 3,34 & 33 & $10,12 \mathrm{f}$. & 264 \\
\hline 3,35 & 31 & 10,16 & 255 \\
\hline 3,36 & 74,221 & $10,17 \mathrm{f}$ & 102 \\
\hline $4,13 \mathrm{f}$. & 358 & $10,28-30$ & 25 \\
\hline 4,14 & 298 & 10,29 & 348 \\
\hline 4,24 & 160 & 10,30 & 22,335 \\
\hline 4,42 & 137 & $11,25 \mathrm{f}$ & 45 \\
\hline 5,17 & 20 & $12,24-26$ & 142 \\
\hline 5,20 & 156 & $12,24-28$ & 45 \\
\hline 5,21 & 21 & 12,25 & 148,259 \\
\hline $5,21-30$ & 81 & $12,25 \mathrm{f}$ & 232 \\
\hline 5,22 & 335 & 12,32 & 120 \\
\hline $5,22 \mathrm{f}$. & 204 & 12,34 & 120 \\
\hline 5,23 & 335 & 12,38 & 223 \\
\hline 5,24 & 148,344 & 12,44 & 146 \\
\hline $5,25-29$ & 339 & $13,1 \mathrm{ff}$. & 135 \\
\hline 5,27 & 21,344 & $13,14 \mathrm{f}$ & 388 \\
\hline 5,34 & 3 & 13,15 & 324 \\
\hline $5,36 \mathrm{f}$. & 365 & 13,23 & 309 \\
\hline 5,37 & 314 & $13,34 \mathrm{f}$ & 343 \\
\hline $5,45-47$ & 51 & 14,1 & 25 \\
\hline 6 & 134 & 14,6 & $88,98,137,269,291$, \\
\hline 6,3 & 343 & & 326,366 \\
\hline 6,8 & 343 & 14,7 & 335 \\
\hline 6,12 & 343 & 14,9 & 335 \\
\hline 6,33 & 185 & $14,9 \mathrm{f}$. & 23 \\
\hline 6,35 & $136,262,277,290$ & $14,16 \mathrm{f}$ & $207,336,353$ \\
\hline & 358 & 14,18 & 353 \\
\hline 6,40 & 331 & 14,21 & 434 \\
\hline 6,45 & 361 & 14,23 & 325 \\
\hline 6,47 & 25,49 & 14,26 & 213,353 \\
\hline 6,51 & 25,357 & 14,28 & 42 \\
\hline $6,53-63$ & 45 & $14,30 \mathrm{f}$ & 204 \\
\hline 6,56 & 357 & $15,1-5$ & 341 \\
\hline 6,63 & 168 & $15,1-8$ & 84 \\
\hline $6,68 \mathrm{f}$. & $139,221,333$ & 15,5 & $81,397,403$ \\
\hline 7,39 & 193,195 & 15,6 & 281 \\
\hline 8,12 & 326,363 & 15,7 & 349 \\
\hline $8,21-30$ & 45 & $15,9 \mathrm{f}$. & 434 \\
\hline 8,24 & 345,368 & 15,12 & 434 \\
\hline $8,34-36$ & 298 & $15,12 \mathrm{f}$. & 346 \\
\hline $8,39 \mathrm{f}$. & 54 & 15,13 & 239 \\
\hline $8,42-47$ & 342,354 & 15,16 & $73,84,220$ \\
\hline 8,44 & 381 & $15,18-25$ & 354 \\
\hline 8,46 & 144 & $15,18 \mathrm{f}$ & 339 \\
\hline 8,58 & 25,312 & 15,19 & 291 \\
\hline $9,6 \mathrm{f}$ & 426 & $15,19-21$ & 376 \\
\hline $9,28 \mathrm{f}$. & 17,51 & 15,20 & 6 \\
\hline $10,1-18$ & 172 & $16,1-4$ & 376 \\
\hline $10,2 \mathrm{f}$ & 332 & 16,2 & 6,179 \\
\hline 10,4 & 255 & 16,7 & 137 \\
\hline $10,4 \mathrm{f}$. & 262 & 16,8 & 144,327 \\
\hline
\end{tabular}




\begin{tabular}{|c|c|c|c|}
\hline 16,10 & 191 & 13,39 & 32 \\
\hline 16,11 & 327 & 14,22 & $6,191,344$ \\
\hline 16,13 & 207 & 15,8 & 63 \\
\hline 16,15 & 21 & 15,9 & 137 \\
\hline 16,20 & 339 & 15,29 & 168 \\
\hline $16,23 \mathrm{f}$ & 349 & 17,2 & 361 \\
\hline 16,33 & $142,315,353$ & $17,10-12$ & 286 \\
\hline 17,3 & 313 & 17,23 & 14 \\
\hline $17,9-23$ & 72 & 17,28 & $14,24,312,446$ \\
\hline $17,20-22$ & 315 & 17,30 & 78 \\
\hline 17,24 & 315 & 19,6 & 80 \\
\hline 18,38 & 202 & 20,28 & 69,71 \\
\hline 19,6 & 202 & $21,27-28,31$ & 141 \\
\hline 19,30 & 131,202 & 26,22 & 206 \\
\hline 19,34 & 130 & & \\
\hline 20,19 & 204 & Römerbrief (Röm) & \\
\hline 20,23 & 182 & $1,3-5$ & 256 \\
\hline $20,26 \mathrm{f}$ & 312 & 1,4 & 213,364 \\
\hline 20,28 & 25 & 1,7 & 433,442 \\
\hline $20,30 \mathrm{f}$. & 278 & 1,17 & 397,403 \\
\hline 21,15 & 261 & $1,19 \mathrm{f}$. & 146 \\
\hline 21,16 & 261 & 1,25 & 407 \\
\hline 21,17 & 181,261 & 2,4 & 303 \\
\hline 21,18 & 283 & 2,6 & 250,403 \\
\hline \multirow[t]{2}{*}{$21,18 \mathrm{f}$. } & 182 & $2,14 \mathrm{f}$. & 382 \\
\hline & & $3,5-8$ & 320 \\
\hline \multicolumn{2}{|c|}{ Apostelgeschichte (Apg) } & 3,20 & 97,398 \\
\hline 1,9 & 38,105 & 3,21 & 398 \\
\hline 1,24 & 63 & 3,22 & 32,398 \\
\hline $2,1-4$ & 207 & $3,22 \mathrm{f}$. & 398 \\
\hline 2,14 & 70 & 3,23 & 318 \\
\hline 2,38 & 78 & $3,23-25$ & 322 \\
\hline 3,17 & 84 & $3,23 \mathrm{f}$. & 211 \\
\hline 3,23 & 52 & 3,24 & 398 \\
\hline $3,24-26$ & 222 & 3,25 & 115,357 \\
\hline 3,25 & 94 & 3,26 & 90 \\
\hline 4,11 & 130 & 3,28 & 396,403 \\
\hline 4,12 & 322,366 & 4,1 & 116 \\
\hline 4,29 & 171 & 4,4 & 403 \\
\hline 7 & 144 & $4,13-17$ & 58 \\
\hline $7,39-43$ & 108 & $4,18-22$ & 151 \\
\hline 7,51 & 144 & 5,1 & 358 \\
\hline $8,1-3$ & 376 & 5,2 & 212 \\
\hline $8,9-24$ & 332 & 5,3 & 160,189 \\
\hline $8,18-23$ & 68,297 & $5,3 \mathrm{f}$. & 377 \\
\hline 8,22 & 78 & 5,5 & 416 \\
\hline 9,15 & 38 & 5,6 & 128 \\
\hline 10,4 & 401 & $5,6-10$ & 73 \\
\hline $10,34 \mathrm{f}$. & 209 & $5,6-11$ & 45 \\
\hline 10,44 & 117 & $5,7 \mathrm{f}$ & 355 \\
\hline 10,48 & 117 & $5,8-10$ & 48 \\
\hline 11,26 & 343 & 5,11 & 53 \\
\hline 13,17 & 14 & $5,12-18$ & 382 \\
\hline 13,26 & 343 & 5,14 & 66 \\
\hline 13,38 & 343 & $5,14-21$ & 318 \\
\hline
\end{tabular}




\begin{tabular}{|c|c|c|c|}
\hline 5,17 & 186 & 12,3 & 400 \\
\hline $5,18 \mathrm{f}$. & 342 & $12,4-8$ & 254 \\
\hline 6 & 125 & 12,8 & 378 \\
\hline $6,1-11$ & 45 & $12,9-21$ & 161,388 \\
\hline $6,1-18$ & 120 & 12,14 & 232 \\
\hline $6,3-23$ & 233 & 12,16 & 401 \\
\hline 6,9 & 125 & 12,19 & 232 \\
\hline 6,12 & 249 & 12,20 & 421 \\
\hline $6,15-23$ & 320 & 13,1 & 227 \\
\hline 6,16 & 345 & 13,2 & 228 \\
\hline $6,21-23$ & 345 & 13,3 & 255 \\
\hline 6,23 & $78,186,403$ & 13,4 & $228,255,258$ \\
\hline $7,5-13$ & 229 & 13,7 & 229 \\
\hline 7,7 & $78,97,249$ & 13,8 & 229 \\
\hline $7,7 \mathrm{f}$. & 226 & $13,9 \mathrm{f}$. & 393 \\
\hline $7,14-23$ & 226 & 13,10 & $166,253,349,393$ \\
\hline 7,15 & 381 & & $398,434,442$ \\
\hline $7,22 \mathrm{f}$. & 381 & 13,11 & 138,331 \\
\hline $8,2-4$ & 45 & $13,12-14$ & 120 \\
\hline 8,3 & 97,285 & 13,14 & 452 \\
\hline 8,4 & 317 & 14,4 & 419 \\
\hline $8,6-8$ & 226 & 14,23 & $148,368,388,397$ \\
\hline 8,16 & 350 & $15,1 \mathrm{f}$. & 58 \\
\hline 8,17 & 339 & 15,4 & 206 \\
\hline 8,23 & 256 & $15,8 \mathrm{f}$. & 50 \\
\hline 8,24 & 146 & $15,15 \mathrm{f}$ & 70 \\
\hline 8,29 & 185,257 & 15,16 & 218 \\
\hline $8,29 \mathrm{f}$. & 281 & 15,24 & 183 \\
\hline 8,30 & 401 & $16,3-15$ & 183 \\
\hline $8,31-39$ & 353 & 16,7 & 184 \\
\hline 8,32 & 359 & 16,17 & $216,289,450$ \\
\hline $8,33 \mathrm{f}$. & 49 & 16,22 & 15 \\
\hline 8,36 & 179 & 16,23 & 439 \\
\hline 8,37 & 402 & $16,25-27$ & 171 \\
\hline $8,37-39$ & 147 & $16,25 \mathrm{f}$ & 70 \\
\hline $9,4 \mathrm{f}$ & 25 & & \\
\hline 9,5 & 25,356 & 1. Korintherbrief (1Kor) & \\
\hline 9,6 & 332 & 1,2 & 442 \\
\hline 9,8 & 332 & 1,3 & 433 \\
\hline $9,11 \mathrm{f}$. & 281 & 1,9 & 315 \\
\hline $9,14-29$ & 384 & 1,10 & 238 \\
\hline 9,16 & 402 & 1,30 & $24,90,277$ \\
\hline $9,32 \mathrm{f}$. & 130 & $2,6-16$ & 334 \\
\hline 10,3 & 399 & 2,9 & 269 \\
\hline 10,4 & 50,98 & 2,12 & 399 \\
\hline $10,9-11$ & 351 & $2,14-16$ & 287 \\
\hline 10,14 & 401 & 3,1 & 76 \\
\hline $11,5 \mathrm{f}$. & 403 & $3,4 \mathrm{f}$. & 5 \\
\hline 11,6 & 355,399 & 3,5 & 262 \\
\hline 11,17 & 224 & 3,11 & 220,451 \\
\hline 11,29 & 401 & $3,16 \mathrm{f}$. & 217 \\
\hline $11,33 \mathrm{f}$ & 334 & 3,17 & 52 \\
\hline 11,36 & 24 & 4,1 & 70 \\
\hline 12,1 & $170,218,384$ & $4,1 \mathrm{f}$. & 51 \\
\hline 12,2 & 147,209 & $4,3 \mathrm{f}$. & 309 \\
\hline
\end{tabular}




\begin{tabular}{|c|c|c|c|}
\hline 4,7 & 73,401 & 1,24 & 314 \\
\hline 4,20 & 385,388 & 3,5 & 402 \\
\hline 5,7 & 210 & 3,6 & 194 \\
\hline 6,11 & $50,209,317,442$ & $4,6 \mathrm{f}$ & 75 \\
\hline $6,12-20$ & 167 & 4,7 & 248 \\
\hline 7,2 & 167 & 4,16 & 236 \\
\hline 7,12 & 234 & $5,1-4$ & 169,283 \\
\hline 7,13 & 234 & 5,16 & 137 \\
\hline 7,21 & 230 & 5,19 & 285 \\
\hline 7,22 & 230 & 6,6 & 451 \\
\hline 7,25 & 402 & 6,14 & 316,330 \\
\hline $7,27 \mathrm{f}$. & 166 & $6,14 \mathrm{f}$ & 416 \\
\hline $8,5 \mathrm{f}$ & 25 & 6,16 & 218 \\
\hline 9,14 & 263 & 8,9 & 390 \\
\hline $9,19-22$ & 14,113 & 9,7 & 254 \\
\hline 9,25 & $118,160,260,266$ & 11,29 & 166 \\
\hline $10,1-5$ & 58 & 13,13 & 271 \\
\hline 10,12 & 401 & & \\
\hline 10,13 & $189,294,424$ & Galaterbrief (Gal) & \\
\hline $10,16 \mathrm{f}$ & 194 & 1,3 & 433 \\
\hline 11 & 134 & 1,4 & 442 \\
\hline 11,19 & 333 & 1,10 & 6,339 \\
\hline 11,25 & 133 & 1,11 & 184 \\
\hline 11,26 & 133,223 & 1,12 & 11,16 \\
\hline $11,27-29$ & 114 & $1,15 \mathrm{f}$ & 38 \\
\hline $12,4-11$ & 39,80 & 1,18 & 183 \\
\hline $12,7-12$ & 254 & 1,19 & 374 \\
\hline $12,24-26$ & 166 & 2,1 & 183 \\
\hline $12,27-30$ & 69 & 2,8 & 407 \\
\hline 13 & 138 & 2,9 & 183 \\
\hline 13,2 & 398 & 2,16 & 396 \\
\hline 13,4 & 138 & 2,21 & $110,254,290,352$ \\
\hline 14,3 & 71 & 3,1 & 29,190 \\
\hline 14,20 & 216 & 3,22 & 50 \\
\hline $14,24 \mathrm{f}$ & 63 & 3,27 & 452 \\
\hline 14,32 & 309,350 & 4,29 & 194 \\
\hline $15,5 \mathrm{f}$ & 16 & 5,6 & $63,191,344,388,392$, \\
\hline 15,8 & 16 & & $395-397,403,406$ \\
\hline $15,12-58$ & 80 & 5,17 & 226 \\
\hline $15,20-28$ & 186 & $5,19-21$ & 449 \\
\hline 15,22 & 186 & 5,22 & 33 \\
\hline $15,23-26$ & 251 & 5,24 & 233 \\
\hline $15,24-28$ & 41 & 6,12 & 6 \\
\hline 15,28 & 20 & 6,14 & 366 \\
\hline 15,32 & $80,301,341$ & 6,18 & 271 \\
\hline 15,33 & $341,436,446$ & & \\
\hline $15,50-58$ & 340 & Epheserbrief (Eph) & \\
\hline 15,53 & 47,61 & 1,2 & 433 \\
\hline 15,57 & 402 & 1,3 & 94 \\
\hline \multirow[t]{2}{*}{16,23} & 271 & $1,3-12$ & 184 \\
\hline & & $1,3-14$ & 384 \\
\hline \multicolumn{2}{|c|}{ Korintherbrief (2Kor) } & 1,4 & 355 \\
\hline 1,2 & 433 & 1,5 & 355 \\
\hline 1,12 & 394 & $1,5-12$ & 211 \\
\hline 1,22 & 350 & 1,9 & 70 \\
\hline
\end{tabular}




\begin{tabular}{|c|c|c|c|}
\hline $1,17 \mathrm{f}$ & 416 & 3,21 & 190 \\
\hline $1,20-23$ & 29 & 4,7 & 271 \\
\hline $2,1-10$ & 327 & 4,13 & 362 \\
\hline 2,3 & $43,186,383,442$ & & \\
\hline 2,8 & 129,402 & \multicolumn{2}{|c|}{ Kolosserbrief (Kol) } \\
\hline $2,8 \mathrm{f}$. & 396 & 1,2 & 433 \\
\hline 2,9 & 403 & 1,15 & 203 \\
\hline $2,11-13$ & 224 & $1,16 \mathrm{f}$. & 20 \\
\hline 2,14 & $90,220 \mathrm{f}$. & 1,19 & $98,366,370$ \\
\hline 2,16 & 90 & $1,19 \mathrm{f}$. & 91,322 \\
\hline $2,19-22$ & 53 & 1,22 & 384 \\
\hline 3,13 & 141 & 2,3 & 248 \\
\hline 4,11 & 69 & 2,8 & $76,168,281$ \\
\hline $4,11-13$ & 69,254 & 2,9 & 285 \\
\hline 4,13 & 217,280 & $2,9 \mathrm{f}$. & 279 \\
\hline $4,13 \mathrm{f}$. & 76 & 2,17 & 326 \\
\hline 4,14 & $353,387,448$ & $2,21-23$ & 388 \\
\hline $4,14 \mathrm{f}$. & 168 & 2,23 & 209 \\
\hline 4,15 & 76 & $3,1-4$ & 340 \\
\hline 5,2 & 110 & 3,3 & 187 \\
\hline 5,5 & 416 & 3,14 & 253 \\
\hline 5,18 & 249 & & \\
\hline $5,21-33$ & 166 & \multicolumn{2}{|c|}{ 1. Thessalonicherbrief (1Thess) } \\
\hline 5,23 & 237 & 1,1 & 433 \\
\hline $5,25-27$ & 53 & 2,2 & 16 \\
\hline $5,25 \mathrm{f}$ & 137 & $2,14 \mathrm{f}$. & 142 \\
\hline 5,27 & 198,384 & 4,3 & 331 \\
\hline $6,5-8$ & 230 & $4,3-5$ & 249 \\
\hline $6,11-17$ & 253 & $4,3-8$ & 388 \\
\hline $6,12-20$ & 269 & 4,8 & 416 \\
\hline $6,14-17$ & 328 & $4,16 f$. & 251 \\
\hline $6,18 f$ & 171 & 5,3 & 304 \\
\hline \multirow[t]{2}{*}{6,23} & 400 & 5,19 & 350 \\
\hline & & 5,20 & 350 \\
\hline Philipperbrief (Phil) & & 5,21 & 271,350 \\
\hline 1,2 & 433 & & \\
\hline 1,6 & 3 & \multicolumn{2}{|c|}{ 2. Thessalonicherbrief (2Thess) } \\
\hline 1,7 & 16,141 & 1,2 & 433 \\
\hline $2,1-4$ & 238 & $1,5-10$ & 251 \\
\hline $2,2-4$ & 267 & $1,6 \mathrm{f}$ & 190 \\
\hline $2,5-11$ & 313 & $1,7-9$ & 139 \\
\hline 2,6 & 203 & $2,3-12$ & 332,450 \\
\hline $2,6-8$ & 73 & 2,13 & 384 \\
\hline 2,7 & $44,66,130,204,390$ & 3,17 & 172 \\
\hline 2,8 & 128 & & \\
\hline $2,8-10$ & 379 & \multicolumn{2}{|c|}{ 1. Timotheusbrief (1Tim) } \\
\hline 2,9 & 205 & 1,1 & 146 \\
\hline $2,9-11$ & 247 & 1,5 & 344 \\
\hline 2,10 & 34 & 1,8 & 399 \\
\hline $2,12 \mathrm{f}$. & 401 & 1,9 & 97,399 \\
\hline 2,13 & 81,171 & 1,13 & 402 \\
\hline $2,19-24$ & 172 & 1,14 & 416 \\
\hline $3,8 \mathrm{f}$. & 291 & 1,16 & 402 \\
\hline 3,20 & 169,226 & 1,18 & 270 \\
\hline $3,20 \mathrm{f}$. & 187,340 & 2,1 & 368 \\
\hline
\end{tabular}




\begin{tabular}{|c|c|c|c|}
\hline 2,2 & 228 & 1,9 & 144 \\
\hline 2,5 & 366 & 1,12 & 446 \\
\hline $2,9 \mathrm{f}$. & 236 & 2,2 & 267 \\
\hline $2,14 \mathrm{f}$. & 238 & $2,3-5$ & 237 \\
\hline 3,1 & 69,263 & $2,6-8$ & 260 \\
\hline $3,1-7$ & 71 & $2,7 \mathrm{f}$ & 265 \\
\hline $3,1-13$ & 260 & $2,11-14$ & 341 \\
\hline 3,2 & 69,263 & 2,13 & 25 \\
\hline 3,5 & 419 & 2,14 & 224 \\
\hline 3,15 & 53 & $3,5 \mathrm{f}$. & 416 \\
\hline $4,1-3$ & 167,450 & 3,7 & 137 \\
\hline $4,6-16$ & 260 & & \\
\hline 4,7 & 209 & Philemonbrief (Phlm) & \\
\hline 4,13 & 69 & 22 & 171 \\
\hline 4,14 & 80 & & \\
\hline 5,8 & 263 & Hebräerbrief (Hebr) & \\
\hline 5,10 & 237 & 1,2 & 211 \\
\hline 6,1 & $229 \mathrm{f}$. & 1,3 & $203,335,357$ \\
\hline 6,8 & 291 & $1,4-14$ & 247 \\
\hline $6,9 \mathrm{f}$. & 264 & $2,5-8$ & 357 \\
\hline 6,10 & 415 & 4,15 & 233 \\
\hline 6,15 & 390 & 5,4 & 218 \\
\hline \multirow[t]{2}{*}{6,20} & 241 & 6,4 & 333 \\
\hline & & $7,24 \mathrm{f}$. & 321 \\
\hline \multicolumn{2}{|c|}{ 2. Timotheusbrief (2Tim) } & $7,26 \mathrm{f}$. & 321 \\
\hline 1,2 & 270 & 7,27 & 243 \\
\hline 1,8 & 3 & $7-10$ & 211 \\
\hline 1,10 & 312 & $8,5 \mathrm{f}$. & 202 \\
\hline 1,12 & 141 & 9,10 & 210 \\
\hline 2,1 & 270 & $9,11-22$ & 201 \\
\hline 2,5 & 142 & $9,11-28$ & 185 \\
\hline 2,9 & 141 & 9,12 & 210,243 \\
\hline $2,11 \mathrm{f}$. & 256,339 & $9,13 \mathrm{f}$. & 442 \\
\hline $2,14-26$ & 333 & 9,22 & 243,363 \\
\hline 2,15 & 69 & $9,26-28$ & 243 \\
\hline $2,17 \mathrm{f}$. & 83 & 9,28 & $211,233,290$ \\
\hline 2,21 & 3 & 10,10 & 442 \\
\hline $3,1-5$ & 58 & 10,14 & $205,210,319$ \\
\hline $3,8 \mathrm{f}$ & 336 & 10,34 & 315 \\
\hline 3,12 & 154,339 & 10,36 & 377 \\
\hline $3,12 \mathrm{f}$. & 179 & 11 & 362 \\
\hline 3,14 & 333 & 11,1 & 190,351 \\
\hline 3,16 & 337 & 11,4 & 283 \\
\hline $3,16 \mathrm{f}$. & 279 & 11,6 & 217 \\
\hline 4,3 & 288 & 11,7 & 246 \\
\hline $4,3-5$ & 450 & 11,10 & 210 \\
\hline 4,7 & 402 & $11,17-19$ & 406 \\
\hline $4,7 \mathrm{f}$ & 266 & 11,31 & 408 \\
\hline 4,8 & 402,423 & $11,36-38$ & 343 \\
\hline 4,10 & 83 & $13,1-13$ & 254 \\
\hline \multirow[t]{2}{*}{4,17} & 268 & 13,3 & 238 \\
\hline & & 13,14 & 210 \\
\hline Titusbrief (Tit) & & 13,15 & 218 \\
\hline $1,5-9$ & 260 & & \\
\hline $1,7-9$ & 71 & & \\
\hline
\end{tabular}




\begin{tabular}{|c|c|c|c|}
\hline \multirow{2}{*}{\multicolumn{2}{|c|}{ Jakobusbrief (Jak) }} & \multirow[b]{2}{*}{2,1} & \multirow[b]{2}{*}{443} \\
\hline & & & \\
\hline 1,12 & 452 & 2,4 & 444 \\
\hline $1,14 \mathrm{f}$. & 279 & $2,10-12$ & 445 \\
\hline 1,17 & 269 & $2,12-22$ & 450 \\
\hline 1,22 & 58 & 2,13 & 448 \\
\hline $1,22-27$ & 281 & 2,15 & 446 \\
\hline $2,1-13$ & 346 & 2,22 & 83 \\
\hline $2,14-26$ & 281 & $3,3 \mathrm{f}$. & 450 \\
\hline $2,15 \mathrm{f}$ & 347 & $3,8 \mathrm{f}$. & 252 \\
\hline 2,17 & 148 & 3,13 & 33 \\
\hline 2,26 & 58 & & \\
\hline $3,1-12$ & 239 & \multicolumn{2}{|c|}{ 1. Johannesbrief (1Joh) } \\
\hline 3,14 & 162 & 1,1 & 284 \\
\hline 4,3 & 349 & 1,7 & 119 \\
\hline 4,4 & 339 & 1,9 & 67 \\
\hline 4,14 & 331 & $2,1 \mathrm{f}$ & 49,164 \\
\hline \multirow[t]{2}{*}{5,16} & 351,367 & $2,7-11$ & 138,213 \\
\hline & & 2,16 & 388 \\
\hline 1. Petrusbrief (1Petr) & & $2,16 \mathrm{f}$. & 279 \\
\hline 1,2 & 433 & 2,17 & 33 \\
\hline $1,6-9$ & 160 & 2,19 & 83 \\
\hline 1,19 & 28 & $2,22 \mathrm{f}$ & 435 \\
\hline $1,22-25$ & 384 & 3,2 & 190 \\
\hline $1,22 \mathrm{f}$ & 342 & 3,18 & 396 \\
\hline 1,25 & 297 & $3,18 \mathrm{f}$. & 394 \\
\hline 2,4 & 451 & 4,1 & 30 \\
\hline 2,5 & 384,451 & $4,7-21$ & 213 \\
\hline 2,22 & 101 & 4,13 & 416 \\
\hline 3,15 & 137 & 4,20 & 191 \\
\hline 3,18 & $119,131,137$ & 5,4 & 187 \\
\hline $3,18 \mathrm{f}$. & 318 & 5,16 & $427 \mathrm{f}$. \\
\hline 3,21 & 137 & $5,16 \mathrm{f}$. & 83 \\
\hline $4,4 \mathrm{f}$ & 339 & 5,20 & 25 \\
\hline 4,6 & 157 & & \\
\hline $4,12-19$ & 120 & \multicolumn{2}{|c|}{ 2. Johannesbrief (2Joh) } \\
\hline $4,12 \mathrm{f}$ & 380 & $12 \mathrm{f}$. & 440 \\
\hline 4,14 & 343 & & \\
\hline 4,15 & 159 & \multicolumn{2}{|c|}{ Offenbarung des Johannes (Offb) } \\
\hline $5,1-4$ & 71 & 13,8 & 124,211 \\
\hline & & 22,8 & 31 \\
\hline \multicolumn{4}{|l|}{ 2. Petrusbrief (2Petr) } \\
\hline 1,2 & 433 & & \\
\hline 1,16 & 312 & & \\
\hline
\end{tabular}





\section{QUELLENREGISTER}

Das Register verzeichnet die in den Editionsteilen angeführten Quellen. Die Quellensiglen sind in der Bibliographie aufgelöst.

\begin{tabular}{|c|c|c|c|}
\hline Aesc. fals. leg. & 260 & Brenz Ioh. & 47 \\
\hline Aesop. fab. & 237 & Brenz syngr. & 191 \\
\hline Agric. inv. & $\begin{array}{l}31,38,41,52,59,82, \\
93 \mathrm{f} ., 121,149,209, \\
258,323 \mathrm{f} ., 334,338 \\
394\end{array}$ & Bud. comm. & $\begin{array}{l}18,60,71,75 \text { f., } 86, \\
103,116,145,165, \\
230,249,260,264, \\
321,369,407,443\end{array}$ \\
\hline AGZR & 133 & Bug. Hebr. & $16,80,83,113 \mathrm{f}$ \\
\hline Ambr. incarn. & 356 & Bull. 1Cor. & 223 \\
\hline Ambr. spir. sanct. & 233 & Bull. 2Cor. & 394 \\
\hline Apul. flor. & 309 & Bull. act. & $183,195,206,211$, \\
\hline Arist. cael. & 147 & & $245,250 f$ \\
\hline Arist. cat. & $93 \mathrm{f}$. & Bull. adv. cat. & 87, 194f., 247, 252, \\
\hline Arist. hist. an. & 269 & & $263,295,318,409$ \\
\hline Arist. phys. & 145 & & 413,425 \\
\hline Arist. top. & 144 & Bull. Eph. & 397 \\
\hline Ps.-Athan. quaest. & 34 & Bull. Gal. & 397 \\
\hline Aug. c. Gaud. & 231 & Bull. hebd. Dan. & $199 f$. \\
\hline Aug. c. Maximin. & 26 & Bull. lect. & 62,287 \\
\hline Aug. c. Pelag. & 389 & Bull. orig. div. & 168,250 \\
\hline Aug. c. Petil. & 231 & Bull. orig. euch. & 71 \\
\hline \multirow[t]{2}{*}{ Aug. civ. } & $21,65,132,258$ f., 275 & Bull. proph. & 287 \\
\hline & 304 & Bull. Rom. & $183,185,218,228 \mathrm{f}$. \\
\hline Aug. de serm. dom. & 368 & & $250,270,379,397$ \\
\hline Aug. epist. & $48,132,205,251,393$ & Bull. script. & 413 \\
\hline Aug. fid. et op. & 398 & Bull. stud. rat. & 41 \\
\hline Aug. grat. & $402 \mathrm{f}$. & Bull. vorl. Hebr. & $10,15,19,28,38,80$ \\
\hline Aug. haer. & $92,192,289,310$ & & $90,92,95,104,112$ \\
\hline Aug. haer. app. & 46 & & 139 \\
\hline Aug. in euang. Ioh. & $\begin{array}{l}169,195,344,373, \\
445\end{array}$ & Cassiod. hist. & 23,46 \\
\hline Aug. in psalm. & 269 & Chrys. 1Tim. & 65 \\
\hline Aug. op. & 40 & Chrys. 1Tim. transl. & 65 \\
\hline Aug. persev. & $401 \mathrm{f}$. & Chrys. Hebr. & $37,56,59,67,77,91$, \\
\hline Aug. praed. sanct. & $400 \mathrm{f}$. & & 111 \\
\hline Aug. quaest. hept. & 99,117 & Chrys. Hebr. transl. & $59,67,77,91,93,100$, \\
\hline Aug. retract. & 400 & & 111, 119, 126f., 140, \\
\hline Aug. rhet. & 90 & & 145,153 \\
\hline Aug. serm. & 281 & Chrys. laud. & 10 \\
\hline Aug. spir. et litt. & $399 \mathrm{f}$. & Chrys. laud. transl. & 10 \\
\hline Aug. un. eccl. & $40,257 \mathrm{f}$ & Cic. Catil. & 295 \\
\hline \multirow[t]{2}{*}{ Ps.-Aug. serm. } & 324 & Cic. inv. & $15,39,77$ \\
\hline & & Cic. Manil. & 215 \\
\hline Beda act. & 374 & Cic. Mil. & 19 \\
\hline Beda epist. can. & $428,433,437,441$ & Cic. Mur. & 378 \\
\hline Biel sent. & $185,247,381,407$ & Cic. off. & 5 \\
\hline
\end{tabular}




\begin{tabular}{|c|c|c|c|}
\hline Cic. orat. & 161 & \multirow[t]{3}{*}{ Erasm. cop. } & $12,16,40,286,305$ \\
\hline Cic. top. & 149 & & $319,324,327,329$ \\
\hline Cic. tusc. & 164,280 & & $343,345,394,408$ \\
\hline Cic. Verr. & 355 & Erasm. ench. & 305,346 \\
\hline Colum. & 262 & Erasm. Eph. & 15 \\
\hline Cypr. Demetr. & 226,259 & Erasm. epist. & 28 \\
\hline Cypr. epist. & $12,72,132,255$ & Erasm. Hebr. & 11, 15f., 23f., 28, 30, \\
\hline Cypr. op. & 181 & & $37,42,50,56-59,63$, \\
\hline Cypr. patient. & 259,377 & & 65, 67f., 70, 73, 76-79, \\
\hline Cypr. testim. & 400 & & $82 \mathrm{f} ., 90,93,95,101$ \\
\hline Cypr. unit. eccl. & $181 \mathrm{f}$. & & $\begin{array}{l}103 \mathrm{f} ., 112,114,122 \\
126,128,137,144 \mathrm{f} .\end{array}$ \\
\hline Decr. Grat. & $69 f ., 167,265$ & & $153,157 \mathrm{f} ., 161,166$ \\
\hline Dem. fals. leg. & 264 & Erasm. Hebr. transl. & $59,79,83,91,93,100$, \\
\hline Didym. in Iac. & $375 \mathrm{f}$. & & $122,150,153$ \\
\hline Didym. spir. & 334 & Erasm. Iac. & $373 \mathrm{f} ., 382,414,425$, \\
\hline Diog. Laert. vit. & 228,446 & & 428 \\
\hline Ps.-Dion. Ar. div. nom. & 36 & Erasm. Iud. & $443,445,447$ \\
\hline Durant. rat. & 135 & Erasm. Joh. transl. & 144 \\
\hline & & Erasm. ling. & 413 \\
\hline Eck ench. & $49,70,105,169,181$, & Erasm. matr. inst. & 238 \\
\hline & $291,426 f$. & Erasm. Matt. & 347 \\
\hline Eck sacr. & 105,124 & Erasm. par. 1Joh. & $314,325,363$ \\
\hline Epiph. haer. & $35,70,167$ & Erasm. par. 1Petr. & $181,184,187-190$ \\
\hline Erasm. 1Joh. & $\begin{array}{l}313,315,330,338, \\
364 f ., 368\end{array}$ & & $\begin{array}{l}192,207,213,215, \\
218,220,226,228,\end{array}$ \\
\hline Erasm. 1Joh. transl. & $330,335,338,346$ & & $234,238,241,244-$ \\
\hline & 364 & & $246,248,250,253-$ \\
\hline Erasm. 1Petr. & $\begin{array}{l}183 \text { f., } 188,206,208, \\
212 \text { f., } 216 \text { f., 220, 224, }\end{array}$ & & $\begin{array}{l}255,258,260 f ., 267- \\
270\end{array}$ \\
\hline & $226,228,230,233$ & Erasm. par. 2Joh. & $433,435 \mathrm{f}$. \\
\hline & $235,238 \mathrm{f} ., 243 \mathrm{f}$. & Erasm. par. 2Petr. & $277,280,284,294-$ \\
\hline & 246f., 253, 258, 260, & & $296,299,301-305$ \\
\hline & $262-265,267,270$ & Erasm. par. 3Joh. & 437,439 \\
\hline Erasm. 1Petr. transl. & $208,246,249,255$ & Erasm. par. Hebr. & $16,42,100,124,153$ \\
\hline Erasm. 2Petr. & $\begin{array}{l}275,277-279,287, \\
290,293,295-297\end{array}$ & Erasm. par. Iac. & $\begin{array}{l}375 f ., 379-381,383 f ., \\
386 f ., 389 f ., 409,411-\end{array}$ \\
\hline Erasm. 2Petr. transl. & $278 f ., 289$ & & 417, 419-422, 424f., \\
\hline Erasm. 3Joh. & 441 & & 429 \\
\hline Erasm. adag. & $6,8,13,18,31,33,49$ & Erasm. par. Iud. & $443,445-451$ \\
\hline & $51,53,67,69,71,78$ & Erasm. paracl. & 242,324 \\
\hline & $81 \mathrm{f} ., 88,111,113,126$ & Erasm. praef. par. 1Petr. & $270,275,292$ \\
\hline & 132f., 189, 195f., 201, & Erasm. Rom. & 70 \\
\hline & $210,214,217,242$ & Erasm. Tit. & 224 \\
\hline & 252f., 262-264, 267, & Euseb. chron. & 182,200 \\
\hline & $282,285,288,297$, & Euseb. hist. eccl. & $13-15,46,71,182$, \\
\hline & $\begin{array}{l}\text { 300f., 309, 326, 329- } \\
331,334,345,358\end{array}$ & & $\begin{array}{l}195,226,332,373 f ., \\
441\end{array}$ \\
\hline & $378 \mathrm{f} ., 391,408,412$, & & \\
\hline & $\begin{array}{l}\text { 414, 419f., 434, 436f., } \\
441\end{array}$ & Fab. Stap. 1Petr. & $\begin{array}{l}184,186,212-214, \\
233,247,253,262\end{array}$ \\
\hline Erasm. apoph. & 329 & Fab. Stap. 2Joh. & 433 \\
\hline Erasm. conscr. & 100 & Fab. Stap. 2Petr. & 304 \\
\hline & & Fab. Stap. Hebr. & 42,61 \\
\hline
\end{tabular}


Flav. Ios. ant.

Flav. Ios. ant. transl.

Gell.

Gennad. dogm.

Gennad. vir. ill.

Greg. M. epist.

Herb. ench.

Hier. adv. Iovin.

Hier. epist.

Hier. in Eph.

Hier. in Ezech.

Hier. in Gal.

Hier. in Is.

Hier. in Tit.

Hier. op.

Hier. quaest. hebr. in Gen.

Hier. vir. ill.

Hier. virg. Mar.

Hil. trin.

Hom. Il.

Hom. Od.

Hor. ars

Hor. epist.

Hor. sat.

Ioh. Dam. exp. fid.

Iren. haer.

Isid. orig.

Iuv.

Kim. Zech.

Kurtz. Ber.

Lact. inst.

Lit. Bas.

Lucr.

Luth. 1Petr.

Luth. 2Petr.

Luth. Iud.

Luth. resp. Cath.

Luth. vorr.

Luth. wort

Macr. Sat.
90, 112, 197, 230, 376,

383

90, 115, 200, 202

18, 87, 166, 203, 230,

411

$27,45-47$

46

135

105,407

6,383

11, 14, 46, 89, $91 \mathrm{f}$., 106, 245, 275, 297 ,

312

115,220

12,115

374

6,373

35,446

89

153

$6,15,46,181-184$, 373,441

$31,373 \mathrm{f}$.

305

$32,214,262$

20, 32, 278

284

408

236

$35 \mathrm{f}$.

132, 182, 195, 332

11, 36, 44, 93, 221, $239,313,441$

437

205

6

54, 78, 170, 182, 195

123

20

184, 189, 212, $227 \mathrm{f}$. 234, 239f., 244, 248, $261 \mathrm{f} ., 270$

277, 279, 291, 295

445,447

448

11,373

47

56
Macr. somn.

Mar. Victorin. rhet. 77

Mel. loc. $\quad 144$

Mirab. pol. $\quad 39$

Non. $\quad 39,184$

Oecol. 1Joh.

Oecol. Rom.

Orig. in Exod.

Orig. in Jos.

Orig. Rom.

Ov. ars

Ov. met.

Pagn. thes.

Pasc. Radb. corp.

Pell. chron.

Pell. Gen.

Petr. Hisp. tract.

Petr. Lomb. in Hebr.

Petr. Lomb. sent.

Philostr. imag.

Pind. Pyth.

Plat. Charm.

Plat. leg.

Plat. Menex.

Plat. Tim.

Plaut. Truc.

Plin. nat.

Plut. mor.

Plut. vit. Lyc.

Ps.-Plut. placit.

Ps.-Plut. placit. transl.

Prop.

Prud. perist.

Quint. inst.

Reuch. quaest. Athan.

Rhod. lect.

Rufin. hist.

Rufin. symb.

Sall. Catil.
13

144
39

312, 314-316, 333,

$336,350,363$

229

114,327

275

441

264

88,345

113, 239, 278, 312,

322,344

125

201

196

144

117

146,427

250

420

78

78,253

5

346

309

$16,147,184,249,269$,

420

252

167

147, 149

149

236

170, 219

12, 18f., 33, 56f., 74, 79, 86, 92f., 103, 139, 144, 149, 160, 205, 220, 241, 249, 309, $311,313,316-318$, 321, 323, 343f., 348, 404, 408

34-36

$32,113,147,230$

81, 181, 196, 275, 290, $373 \mathrm{f}$.

28

167, $390 \mathrm{f}$. 


\begin{tabular}{|c|c|c|c|}
\hline Sen. Ag. & 39 & Urb. inst. & 278 \\
\hline Sen. dial. & 187,330 & & \\
\hline Sen. epist. & 188,235 & Vad. epit. & $183 \mathrm{f} ., 376$ \\
\hline Serv. rest. & 24 & Vel. Petr. & 182 \\
\hline Sol. & $268 \mathrm{f}$. & Verg. Aen. & $87,90,141,226,446$ \\
\hline Soph. frag. & 420 & Verg. ecl. & 149,278 \\
\hline Soz. hist. & 167 & Ps.-Vigil. Thaps. trin. & 21,31 \\
\hline Strab. geog. & 184,270 & Volat. comm. & 352 \\
\hline Suet. Cal. & 111 & & \\
\hline Suet. Tib. & 183 & ZBib 1531 & 293 \\
\hline Symb. apost. & $34,69,125,191,250 \mathrm{f}$ & Zw. act. & 133 \\
\hline Symb. Const. & $30,195,204,233$ & Zw. am. exeg. & 311,329 \\
\hline Symb. Nic. & $23,30 f ., 153,204$ & Zw. antw. Luth. & 47 \\
\hline Symb. Quic. & $27,42,352$ & Zw. elench. & $\begin{array}{l}87,107,192,224,336 \\
409\end{array}$ \\
\hline Ter. Ad. & 267 & Zw. epich. & 53 \\
\hline Ter. Andr. & 88 & Zw. Exod. & 312,349 \\
\hline Tert. adv. Iud. & $132,183,195$ & Zw. fid. exp. & $48,61,133,135,187$ \\
\hline \multirow[t]{2}{*}{ Tert. adv. Marc. } & $132,192,195,208$, & & 339 \\
\hline & 245,289 & Zw. Gen. & 311 \\
\hline Tert. adv. Prax. & $21,23,26,356$ & Zw. Iac. & $376,383 \mathrm{f} ., 388,391 \mathrm{f}$ \\
\hline Tert. anim. & 332 & & $395,405-408,411$ \\
\hline Tert. apol. & 73,226 & & $413 f ., 416,418,424$ \\
\hline Tert. carn. & $45,47,66$ & & 426 \\
\hline Tert. mart. & 4 & Zw. Ier. & 109 \\
\hline Tert. praescr. & 182, 332f., 337 & Zw. Isa. & 23,220 \\
\hline Theod. Stud. coel. & $35 \mathrm{f}$ & Zw. rel. & 247 \\
\hline Theophyl. 2Tim. transl. & 268 & Zw. ußleg. & 53 \\
\hline
\end{tabular}

Theophyl. Hebr. transl. 24, 64, 79f., 114, 172

Thom. Aqu. off. corp. 113, 133 


\section{PERSONENREGISTER}

Das Register verzeichnet die in den Editionsteilen vorkommenden Personennamen. Stellenangaben mit biographischen Informationen und/oder Literaturhinweisen zu den entsprechenden Personen sind mit einem Asterisk * versehen. Nicht indiziert sind »Bullinger, Heinrich« sowie »Paulus « im Kommentar zu Hebr, »Jakobus« im Kommentar zu Jak, »Petrus (Simon, Kefas)« im Kommentar zu 1-2Petr, »Johannes, Apostel« in den Kommentaren zu 1-3Joh und »Judas« im Kommentar zu Jud.

Aaron 17, 64, 67f., 92, 95, 99, 101, 103-105, 107, 110f., 114, 153, 155, 205, 218

Abel 148, $163 \mathrm{f}$.

Abiram 80

Abraham 17, 25, 45, 54, 85, 87, 89, 92-95, 101, 106f., 150-152, 159, 166, 193f., 235f., 245, $251,312,355,381,405-408$

Abram 89

Achab, König von Israel 4, 92

Achilleus 32

Adam 43, 55, 65f., 107, 186, 193, 198, 369, 384, 449,451

Aeneas 141

Aeschinus 267

Aetius 27*

Agamemnon 32

Aischines 249*, 260

Albertus Magnus 113

Alexander der Große, König der Makedonen 264

Alphäus 373f., 441

Ambrosius von Mailand 11*, 12, 233, 356

Amos 108

Andriskos von Adramyttion (»Pseudophilippos«) $351^{*}$

Andronikus 184

Anius 90

Annius Milo, Titus 19*

Antiochos IV. Epiphanes, König des Seleukidenreiches $8^{*}$

Antipatros 196*

Apollinarios von Laodikeia 46*, 47

Apollon (Phoebus) 90

Apollos 5

Apringius 398

Apuleius von Madaura 309

Aquila (Onqelos) 196*

Aratos aus Soloi 14*, 446

Aristoteles 75, 93, 147, 268

Arius 11*, 21, 23, 26f., 289f., 332, $351 \mathrm{f}$.

Arsames 200

Artaxerxes I., persischer König 200*

Artemon $46^{*}$
Asa 156

Athanasius von Alexandria 21*, 26f., 31, 42, 107

Augustinus von Hippo 14, 26f., 40, 48, 65, 92, $107,117,132,169,195,231,251,257-259$, $275,281,304,373,389,393,397,400,402-$ 404

Augustus, römischer Kaiser 200*

Baal 92

Barak 155

Barnabas 14, 383

Basileides 332*

Basilius von Cäsarea 28, 71, 123*

Beda Venerabilis 183, 374*, 427

Beliar 416

Beryllus 46*

Bibliander (Buchmann), Theodor 200*

Bileam 202, 297, 446

Bonifacius 132*

Bonifatius I., Papst 389*

Bosor 297

Briareos 24*

Bucer, Martin 3

Budé, Guillaume 60*, 71, 103, 249, 260, 264, 321

Caecilius Metellus Numidicus, Quintus 166*

Caesar, Caius Iulius 29*, 390

Caligula (Caius Iulius Caesar Augustus Germanicus), römischer Kaiser $111^{*}, 183$

Callixtus I., Papst 27

Cassiodorus, Flavius Magnus Aurelius 145

Catilina, Lucius Sergius 167*, 390

Ceres 434

Chiskijahu, König von Juda 4, 156, 255

Chrysippos 230*

Chrysostomos s. Johannes Chrysostomos

Cicero, Marcus Tullius 5, 19, 50, 77, 161, 164, $215,355,378$

Claudius, römischer Kaiser 182*, 183

Clemens von Rom 13*, $14 \mathrm{f}$.

Clemens, Titus Flavius von Alexandria 13*, 14f.

Clodius Pulcher, Publius 19 
Constantius II., römischer Kaiser 23

Cornelius 117, 209, 401

Cornelius Scipio Aemilianus Africanus, Publius $113^{*}$

Ctesipho 267

Cyprian von Karthago 12*, 28, 71, 132, 181, 226, $255,259,377,400$

Cyrillus Alexandrinus s. Kyrillos von Alexandria

Damascenus s. Johannes von Damaskos

Daniel 24, 33, 35, 112, 130, 153, 155f., 196-205, $251,300,305$

Dardanus, Claudius Postumus 14*, 48

Dareios I., persischer König 200*

Dareios II., persischer König 200*

Datan 80

David 4, 24, 27 f., 30, 42, 44, 59f., 96, 103, 107, 130, 155f., 189, 196, 198f., 255, 286, 345, 369

Demas 83

Demea 267*

Demetrianus 259

Demetrius 437, 440

Demosthenes 264*

Diagoras 149*

Didymus (»der Blinde «) von Alexandria 333*

Dionysios von Alexandria 26*

Dionysios von Korinth 182*

(Pseudo-)Dionysios Areopagites 35*, 36

Diotrephes 437, 439f.

Domitianus, Titus Flavius, römischer Kaiser 441*

Donatus 40, 290

Donatus, Aelius $75^{*}$

Ebion $46^{*}, 310,332,351$

Efraim 59

Elasar 68

Elija 156, 194, 285

Elisabet 151

Elischa 156

Epikuros 80*, 242, 324

Epimenides 446*

Epiphanios von Salamis 35*, 167

Erasmus von Rotterdam (paraphrastes, Latinus interpres) 15f., 23f., 28, 42, 58, 67, 76, 82f., $88,91,100,103 \mathrm{f} ., 114,124,144,150,153$, 181, 184, 186f., 189, 192, 206-208, 214, 218, 226, 228, 233, 235, 238, 241, 246, 253f., 258, 264f., 267, 278, 280, 288, 293, 295, 300, 303, 330f., 343, 365, 374f., 382f., 411, 413f., 425, 427-429, 436, 442, 447

Esau 153, 162

Euhemeros 149*

Eunomios von Kyzikos 26*, 27, 47
Eusebius von Cäsarea 12, 13*, 14f., 23, 26, 28, 71, 182, 195-197, 226, 275, 332, 373f., 441

Eusebius von Vercelli $21^{*}$

Eutyches 46*, 248

Evagrius von Antiochia 89*, $91 \mathrm{f}$.

Evodius 251

Ezechiel 209, 233, 261, 263, 388, 435

Fortunatus 27*

Franz I., französischer König 60

Fronto, Marcus Cornelius 203*

Gabriel, Erzengel 199

Gaius 437-440

Gaius, römischer Theologe 182*

Gaudentius 231*

Gellius, Aulus 87*, 166, 203

Geryoneus 24*

Gideon 155

Gregor I. der Große, Papst 135*, 287

Gregor von Nazianz 28

Habakuk 179

Hadrian I., Papst 135*

Haggai 165, 197f., 201

Hegesippos 71*, 373f., 441

Helvidius $31 *$, $373 \mathrm{f}$.

Henoch 148f., 193, 449

Herkules 24

Hermagoras 90

Herodes I., der Große 196*, 197f., 202

Hesiod 164*

Hieronymus Stridonensis $11 *, 12-15,31,35,75$, 89, $91 \mathrm{f} ., 106,182,275,373 \mathrm{f} ., 383,393,440$

Hilarius von Poitiers $305^{*}$

Hiob 157, 424

Hippolyt von Rom 46

Homer 20*, 32, 164, $261 \mathrm{f} ., 264,278,411$

Horaz (Quintus Horatius Flaccus) 284*

Hoschea (Josua, »Iesus Nave«) 59*

Hosea 170, 215, 222f., 388

Hugo von Saint-Cher (Carrensis) 287*

Hymenäus 83

Hystaspes 200*

Irenäus von Lyon 13*, 132, 182, 195, 332

Isaak 151-153, 159, 406

Isebel 92, 156

Iulius Agrippa II., Marcus 206*

Jakob (Israel) 4, 20, 106, 151, 153, 159, 196f., 199, 201

Jakobus 58, 107, 279, 281, 284, 347, 349, 367

Jakobus (Herrenbruder) 70f., 183, 374, $441 \mathrm{f}$. 
Jakobus (Sohn des Alphäus) 374

Jechonja 197

Jehojada 156

Jehoschafat, König von Juda 4

Jehoschua 130

Jephta 155

Jeremia 6f., 24, 89, 106, 114, 121, 130f., 153, 198f., 258, 261, 263, 305, 388, 422, 451

Jesaja 6, 25, 47, 49, 101, 110, 130, 156, 205, 214, 216-218, 220-223, 232f., 241, 259, 280, 328, $364,380,388,418,449$

Joasch, König von Juda 4

Johannes Chrysostomos 10*, 35-37, 59, 65, 67, 77, 91, 100, 111, 119, 126f., 140, 145, 153

Johannes der Täufer 6, 31, 78, 107, 110, 130, 262, 295,317

Johannes von Damaskos $35^{*}, 36$

Johannes, Apostel 67, 82, 119, 153, 183, 187, 213, 279, 284, 394, 396f., 441

Johannes, Evangelist 25, 130, 203, 205, 213f., 221, 233, 278, 291, 298, 374

Johannes, Verf. der Apokalypse 14, 124

Jonathan 156

Joschafat 156

Joschijahu, König von Juda 4, 7, 255

Joseph 31, 153, 159

Josephus, Flavius 89*, 91, 112, 197, 200, 383

Josua 60 f., 155

Jud, Leo 390*, 408, 411

Juda 96, 106

Judas 397

Judas der Galiläer 230*

Jugurtha 166

Junius 184

Kain 148, 343, 446

Kajafas 204

Kaleb 59

Karl der Große, römisch-fränkischer Kaiser 135

Karpokrates 332*

Kerberos 24*

Kerdon (Cerdo) 192*

Kerinthos 310*, 332

Kimchi, David 205*

Klopas 374

Konjahu, König von Juda $196 \mathrm{f}$.

Konstantin der Große, römischer Kaiser 265*

Korach 80, 446f.

Kyrillos von Alexandria 249*

Lactantius, Lucius Caelius Firmianus 54*, 170, 182,195

Lazarus 245, 346, 423

Lebbäus $441 \mathrm{f}$.

Lefèvre d'Étaples, Jacques 42
Levi 93, 95f., 197, 218, 261

Licinius Lucullus, Lucius 329*

Lorenzo Valla 16

Lot 166, $293 \mathrm{f}$.

Lukas, Evangelist 10, 13, 15, 39, 43, 45, 183, 194, $221,228,233,244,252,286,418,420,426$, $441 \mathrm{f}$.

Luther, Martin 11, 227, 329, 373, 448

Lykurgos $167 *$

Macrobius, Ambrosius Theodosius 56*, 112

Makedonios von Konstantinopel 27*, 352

Maleachi 132, 261

Manasse, König von Juda 6, 156

Mani 27*

Manlius, Caius 390

Marcellinus, Flavius 398*

Maria 31, 45f., 248, 267, 374

Maria von Magdala 320

Maria, Ehefrau des Alphäus 374

Maria, Ehefrau des Klopas 374

Markellos von Ankyra 46*, 352

Markion 27*, 46, 132, 192, 195, 208, 245, 290, 332

Markus 270

Markus, Evangelist 38, 55, 405, 426, 441

Mars 262

Matthäus, Evangelist 45, 130, 140, 205f., 213, $222,232,240,252,254,268,320,421,424$, 426f., 441

Matthäus, Zöllner 441

Melchisedek 17, 68, 74f., 86, 88-97, 99, $103 \mathrm{f}$.

Meletios von Antiochia 27*

Menandros, Dichter 446*

Menandros, Gnostiker 332*

Micha 263, 388

Michael, Erzengel 444f.

Michajehu 156

Mithridates VI. Eupator, pontischer König 215*, 329

Mohammed 290*, 291

Mose 17f., 20, 25, 51-55, 57, 59f., 64f., 67, 75, 80, 86, 91 f., 95f., 98, 102, 104, 107, 110, 115, 121f., 139, 141, 146, 148, 153f., 163f., $183 \mathrm{f}$., 193, 196, 201, 206, 210, 218, 222, 285, 303, 311, 325f., 328, 331, 363f., 406, 428, 444-446

Mucianus Scholasticus $145^{*}$

Müntzer, Thomas 230*

Musaios 164*

Myconius, Oswald 182

Nabot 156

Nebukadnezar (Nabû-kudurri-usur) II., neubabylonischer König 8*

Necho II., ägyptischer König 7* 
Nehemia 200

Nero, römischer Kaiser 6*, 182f., 268

Nestorius 248*, 352

Nikodemus 361

Nikolaus von Lyra 183, 287*

Noah 91, 107, 150, 193, 244f., 247, $293 \mathrm{f}$.

Nonius Marcellus 39*

Novatianus 10*, 11f., 81, 299, 318

Nun 59

Odysseus 20

Oekolampad, Johannes 4, 5*

Origenes $12^{*}, 13,15,27 \mathrm{f} ., 46,275$

Orpheus $164^{*}$

Ovid (Publius Ovidius Naso) 345*

Pammachius 106*

Paphnutios 167*

Papias, Bischof von Hierapolis 437

Paul von Samosata 35, 46

Paulus 179, 182-185, 187, 189-191, 194, 201, 203, 206, 209-212, 217f., 220, 223f., 226230, 232-234, 236-238, 241, 243, 246-248, $251,253,256,258,260,263-271,279,281$, 288f., 299, 303f., 309, 312, 314-316, 320f., 328, 333, 341, 351, 356f., 361, 364, 368, 373, 377, 379, 381-385, 388, 392, 394, 396f., 402, 404, 406, 408, 416, 439, 442, 450, 452

Pelagius 289*, 290, 332

Pellikan, Konrad 196*

Penelope 278

Perseus, makedonischer König 351

Petilianus 40*, 231, 257

Petrus (Simon, Kefas) 5, 16, 28, 70f., $83 \mathrm{f} ., 107$, 119f., 130f., 153, 159f., 312, 320, 322, 333, $339,342,361,369,376,397,401,407,441$, 444-446, 448, 450

Phaëthon 434

Philemon 171

Philetus 83

Philipp von Hessen $3 *$

Philippos II., König der Makedonen 264*

Philippos, Sohn des makedonischen Königs Perseus 351

Philippus 23

Photinos von Sirmium 352*

Pilatus s. Pontius Pilatus

Pindar 420*

Plancius, Gnaeus 378*

Platon 5, 78, 164, 228, 242, 324, 346

Plautus, Titus Maccius 309*

Plinius d. Ä. 16*, 147, 184, 249, 268, 420

Plutarch von Chaironeia 147*, 167, 252

Politus, Ambrosius Catharinus (Lancellotto de' Politi) $448^{*}$
Pontius Pilatus 11, 202

Porcius Cato (Uticensis), Marcus 390*

Porphyrios $75^{*}$

Praxeas $21 *, 22,26 f$.

Propertius, Sextus 236*

Prudentius Clemens, Aurelius 170*, 218

Ptolemaios, Klaudios 270

Pucci, Lorenzo 28

Pythagoras 242, 324

Quintilianus, Marcus Fabius 103*, 144, 343

Rahab 155, 406, 408f.

Raschi (Schlomo Jizchaki) 113*

Reuchlin, Johannes (Capnion) 34*, 35

Ricchieri, Ludovico (Coelius Rhodiginus) $32 *$, 113, 147, 229

Romanos 170*, 218

Rufinus, Tyrannius von Aquileia 28*

Sabellius 27*

Sacharja 130, 195, 197f., 201, 204, 225, 245, 266, 300

Sallustius Crispus, Caius 167*

Salomo 28, $31 \mathrm{f} .$, 37, 236, 268, 331, 348

Samson 155f.

Samuel 57, 107, 155, 451

Sanherib (Sin-ahhe-eriba), assyrischer König 8*

Sara 151, $235 \mathrm{f}$.

Sardanapal 280*

Satorneilos $332 *$

Saul 4, 57, 155 f., 451

Schamgar 156

Schealtiel 197

Scholasticus 135

Schunamitin 156

Secharja, Sohn des Jehojada 4, 6, 156

Sem 91

Seneca, Lucius Annaeus 111*, 187f.

Serubbabel 197f.

Servetus, Michael 24

Silvanos von Tarsus $27 *$

Silvanus 180f., 269f.

Simeon 195, 207

Simon Kananäus 441

Simon Magus 182, 264, 297, 332

Sokrates 164, 309

Sokrates Scholastikos $167^{*}$

Solinus, Caius Iulius 268*

Sophokles $419^{*}$

Spartacus 230*

Steiner, Werner $9 *$

Stephanus 107f., 144

Strabon $184^{*}, 270$

Sueton (Gaius Suetonius Tranquillus) 183* 
Telemachos 32

Terenz (Publius Terentius Afer) 267*

Tertius 15

Tertullian (Quintus Septimius Florens Tertullianus) $21 *, 22 \mathrm{f}$., 26f., 45, 73, 132, 182f., 192, 195, 208, 226, 245, 332f., 337, 356

Thaddäus $441 \mathrm{f}$.

Theodoros 149*

Theodoros Studites 35*

Thomas von Aquin 113*, 287

Thomas, Apostel 25, 153, 312, 441

Tiberius Caesar Augustus, römischer Kaiser 183*

Tigranes II., armenischer König 329*

Timotheos II. Ailuros 46*

Timotheus 3, 65, 71, 79, 141, 154, 167, 172, 236$238,260,266,270,288,450$

Titus 25, 71, 144, 224, 237, 260, 341, 383

Titus (Titus Vespasianus Augustus), römischer Kaiser 203*
Ussijahu, König von Juda 96

Utinger, Heinrich $9 *$

Vadian (von Watt), Joachim 3, 182*, 183

Valentinus 46* $182,195,289 \mathrm{f}$., 332, 402

Vergil (Publius Vergilius Maro) 90*, 141

Verres, Caius 355*

Vespasian (Titus Flavius Vespasianus), römischer Kaiser 201*

Vigilius von Thapsus 21*

Xerxes 200

Zachäus 320

Zacharias 6

Zebedäus 29

Zeus 24

Zidkijahu, König von Juda 4

Zwingli, Huldrych 3-6, 8f., 109, 390 



\section{ORTSREGISTER}

Adramyttion 351

Ägypten 7, 55, 60, 106, 108, 146, $153 \mathrm{f} ., 193 \mathrm{f}$., 270, 376, 443f.

Alexandria 11, 13-15, 21, 26f., 46, 249, 289, $332 \mathrm{f}$.

Algerien 231

Antiochia 14, 27, 89, 191, 332, 343

Antwerpen 364

Arabien 270

Armenien 329

Asia (römische Provinz) 181, 184, 270, 276f., 376

Askalon 198

Assyrien 184, 280, 376

Athen 14, 446

Attika 285

Babylon 181, 184, 197f., 214, 270, 376

Basel 5, 135

Beisan (Skythopolis) 91

Bern 135

Beröa 286

Beromünster 9

Biel 135

Bithynien 181, 184

Bosra 46

Cäsarea $12 \mathrm{f}$.

Chaldäa 270

Chalkedon 46, 248

Cirta 231

Damaskos 35, 108, 370

Delphi 78

Deutschland (Heiliges Römisches Reich Deutscher Nation, Germanien) 7, 142, 230

Eidgenossenschaft (Schweiz, Helvetien) 109, 133, 182

England (Britannien) 289

Ephesus 71, 248, 437

Eritrea 444

Galatien 181, 184, 190

Galiläa 196

Gallien (Frankreich) 13, 142

Gomorra 293, 444
Hadrumetum 402

Helvetien s. Eidgenossenschaft 109, 182

Hessen 3

Hierapolis 437

Ikonium 191

Israel 221

Italien 202

Jericho 155, 409

Jerusalem 8, 28, 70f., 91, 163f., 183, 199-202, $216,230,258,285,383,451$

Juda 196f., 221

Judäa 196, 202

Kairo 270

Kanaan 59f., 90, 130, 152, 224, 291

Kappadokien 181, 184

Kappel am Albis 5, 7

Karthago 12, 16, 290, 398

Kasdäa 152

Kilikien 14

Konstantinopel 10, 27, 46, 167, 248

Korinth 182, 263

Kreta 446

Kyzikos 26

Libyen 100

Luzern 9

Lyon 13

Lystra 191

Mailand 11

Makedonien 184, 197f., 264, 351

Mauretania 16

Melos 149

Milet 71

Mülhausen 135

Narbonne 205

Ninive 150

Nizäa 11, 27, 30, 46, 167

Nürnberg 3

Numidia 16

Palästina 8, 59, 426

Paris 113 
Persien 184, 197

Phönizien 8

Poitiers 305

Pontos 181, 184, 329

Regensburg 3

Rimini 23

Rom 10, 13, 15, 21, 182f., 192, 197f., 224, 265 , 270, 291, 299, 319, 447

Salamis 35

Salem 89-91

Samaria 196, 332

Schaffhausen 135

Schweinfurt 3

Schweiz s. Eidgenossenschaft 182

Sinai 163, 193

Sinope 196
Sion 199, 219f., 225

Sirmium 352

Sizilien 355

Sodom 293f., 444, 451

Soloi 14

Spanien 183

Sparta 81

St. Gallen 135, 183

Syrien 221

Tarsus 27

Thamugadi 231

Thebais 167

Tyros 75

Zion $163 \mathrm{f}$.

Zürich 6, 9, 29, 135, 200, 390

Zug 9 